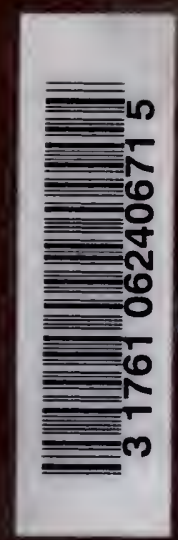

Ulinv of

IORONTO LBRARY 


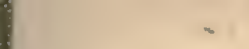


Digitized by the Internet Archive in 2007 with funding from Microsoft Corporation 



$$
-
$$





\section{A TEXTBOOK OF}

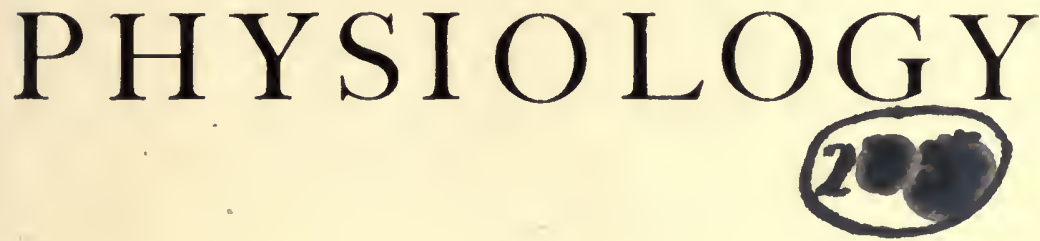

BY

\section{MARTIN FLACK \\ C.B.E., M.B., B.Cn.(Oxon.)}

RESEARCH STAFF, DEPARTMENT OF APPLIED PHYSIOLOGY, MTDICAL RESEARCH

COMMITTEe; late LECTURER IN PHYSIOlogy aND CHEMICAL PATHOLOGY

LONDON HOSPITAL MEDICAL COLLEGE;

\section{AND \\ LEONARD N HILL}

M.B., F.R.S.

DIRECTOR OF APPLIED PHYSIOLOGY DEPARTMENT MEDICAL RESEARCII COMMITTEE; LATE PROFESSOR IN PHYSIOLOGY (LONDON' UNIVERSITY) LONDON

\section{ILLUSTRATED}

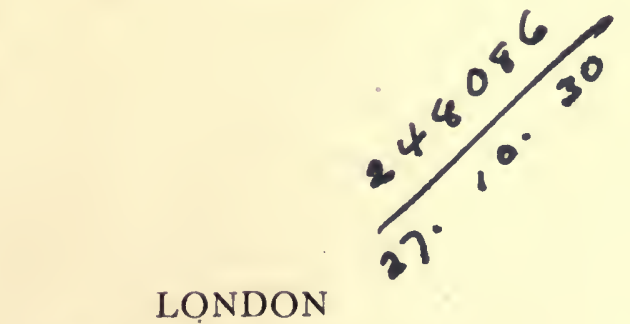

EDWARD ARNULD

1919

All rights reserved 



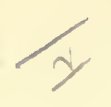

\section{PREFACE}

THE preparation of this textbook was begun before the war at a time when we were both actively engaged in teaching at the London Hospital Medical College, and when it was considered that we might with advantage put together and harmonize the physiology we were teaching. In order to secure uniformity of style, each section has been written in the first instance by the same hand, and then finished in its present form by careful collaboration between the two of us.

While physiological research has been confined in many directions, progress along certain lines has been especially remarkable since the outbreak of war. We have endeavoured to take these recent advances into consideration, before completing the work, in spite of the great difficulties under which we, in common with all physiologists, have laboured.

The book has been written with the primary object of giving to the student in an easily understandable form the fundamental facts and theories of physiology, bearing in mind the limitations necessary in a student's textbook. We have followed the example of Michael Foster, and have avoided burdening the students memory with the names of authorities. When ready to leave the narrow scope of a textbook for the wide realms of independent thought, those who wish to extend their physiological knowledge can easily find their way into the literature of research by means of the various archives and journals of physiology.

Although written primarily to meet the requirements of the medical student, it is hoped that, in view of the ever-increasing importance of the proper application of physiology to general medicine, the work may also prove of value to the general pracitioner.

For the use of illustrations we are indebted to Dr. J. Barcroft, F.R.S.; Professor W. M. Bayliss, F.R.S.; Professor W. B. Cannon; 
Professor J. M. Cowan; Professor V. Dahlgren; Professor W. E. Dixon, F.R.S.; Dr. Robert Hutchison; Professor A. Keith, F.R.S.; Professor J. N. Langley, F.R.S.; Dr. Thomas Lewis, F.R.S.; Dr. F. W. Mott, F.R.S.; Professor F. G. Parsons and Professor William Wright; Dr. M. S. Pembrey; Sir E. A. Sharpey Schäfer, F.R.S.; Professor C. S. Sherrington, F.R.S.; Sir J. Purves Stewart, K.C.M.G.s Professor Swale Vincent; and Dr. A. D. Waller, F.R.S. Also to the Editors of the Journal of Physiology, the Quarterly Journal of Experimental Physiology, and Brain; to the Secretary of the Royal Society: and to the following publishers for permission to use such illustrations: Messrs. Longmans, Green and C'o.; J. and A. Churchill; Constable and Co., Ltd.; Macmillan and Co., Ltd.; John Wright and Sons, Ltd.; the Delegates of the Clarendon Press; the Syndics of the Cambridge University Press; Yale University Press; Oxford Medical Publications; Shaw and Sons. 


\section{CON'TEN'TS}

BOOK I.-GENERAL PHYSIOLOGY

СНALTER

I. BIOLOAICAL INTRODUCTION

II. THE CELL

III. PHYSICO-CHEMICAL INTRODUCTIO

IV. THE CHEMIOAL COMPOSITION OF THE BODY

V. THE PROTERYS .

VI. FATS AND LIPOIDS

VII. THE OARBOHYDRATES

VII. ENZYMES OR FERMENTS

BOOK II.-THE BLOOD

IX. GENERAL ACCOUNT OF THE BLOOD

X. THE PLASMA

XI. THE CORPUSCLES OF THE BLOOD

XI. THE CLOTTINA OF BLOOD

XII. H ÆMOLYSIS AND IMMUNITY

XIV. THE TESTS FOR BLOOD

\section{BOOK III.-THE CIRCULATION OF* THE BODY FLUIDS}

XV. THE IECHANISM OF TRAYSPORT

XVI. THE PHYSIOLOGY OF THE HEART

XVII. THE COURSE OF THE CIRCULATION IN MAMMALS

XVIII. THE NUTRITION OF THE HEALT

XIX. THE CARDIAC NERVES

XX. THE PHYSICAL FACTORS OF THE CIRCULATION -

XXI. THE ARTERIAL PRESSURE

XXII. THE EFFECT OF POSTURE

XXIIT. THE VELOCITY OF BLOOD-FLOW

XXIV. THE PUISE

XXV. THE CAPILLARY CIRCULATION -

XXVI. THE PRESSURE AND VELOCITY OF THE BLOOD IN THE VEINS -

XXVIL. THE VASO-MOTOR NERVES

XXVIII. THE CIRCULATION IN SPECIAL PARTS -

XXIX. LYMPII -

\section{BOOK IV.-THE PHYSIOLOGY OF RESPIRATION}

XXX. GENERAL AOCOUNT OF RESPIRATIO XXXI. THE MECHANIS.M OF RESPIRATION

XXXII. THE MECHANICS OF BREATHISG

XXXIII. THE RELULATION OF BREATHIXG

XXXIV. THE EEFECTS OF EXCESS OF CARBOX DIOXIDE

XXXV. THE PRINCIPLES OF VENTILATION

XXXVI. METIODS OF DETERMINIYG RESPIRATORY EXCHANGE -

\section{BOOK V.-GENERAL METABOLISU AND DIETETICS}

XXXVII. GENERAL METABOLISM AND DIETETICS -

XXXVIII. METABOLISM DURING STARVATION

XXXIX. METABOLISM UNDER VARYING CONDITIONS

XL. GENERAL DIETETICS

XLI. THE CHIEF FOODSTUEFS

XLII. DIET UNDER VARIOUS CONDITIONS

¿XliI. SPECLAL DIETETIC METHODS, ETC. 
IHAPKL

BOOK VI.-THE PROCESSES OF 1IGESHIUN

XI.1 THE MECIHANISM OF SECRETION, ETC. -

XI.V. HIG ESTION IN THE MUUTH

XlVI. HIGESTION IN THE STOMACH

XLVII. DIGESTIOX IX THE SMALI INTHSTIXE -

ILII. THE JARGE INTESTINE

XLIX. THE MECIIANICAL FACTORS OF DIGESTION

\section{BOOK VII.-SPECIAL METABOLISMS}

L. TII METABOLISM OF PROTEIX - • - • • • - 421

LI. THE METABOLISM OF CARBOHYDRATE - . - . . - 426

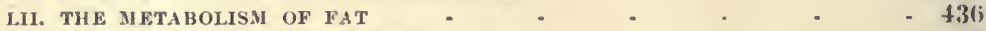

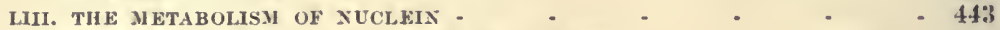

LIV. THE FUNCTIONS OF THE LIVER AND SPLEFY • . . $\quad \cdot 447$

\section{BOOK VIII.-THE FUNCTIONS OF 'THE KIDNEY}

LV. THE URINE

LVI. THE SECRETION OF URINE

BOOK IX.-THE FUNCTIONS OF THE SKIN AND THE BODY TEMPERATURE

WII. THE FUNCTIONS OF THE SKIX -

LVII. THE TEMPEIATURE UF TIIE BODY

BOOK $\mathrm{X}$.-THE FUNCTIONS OF THE DUCTLESS GLANDS

BOOK XI.-THE TISSUE OF MOTION

LX. THE MECHAXISM OF MOVEMENT

LXY. THE STRUCRURE AND PHYSICAL PROPERTIES OF MESCE

LXII. THE CONTRACTIOS OF MUSCIE

LXII. THE PRODUCTION OF HEAT AND TIE CHEMICAL CHAXENS IN MUSCLE TXIV. ANIMAI, EIECTIICITY

\section{BOOK XII.-THE NERVOUS SYSTIEM}

LXY. THE NEUROX

LXVI. THE PHYSIOLOGI OF THE NERVE-FIBRE

LXVII. TIIE RECEPTOR MECHANISUS-CUTAXEOUS SEXSATIONS

JXVIII. TASTE ANI SMBLI,

LXIX. VISIOX -

LXX. HEARING

LXXI. THE PROPIIO-CEPTIVE MECHAXISM

1.XXII. THE SPINAL CORD

LXXIIT. THE BRAIN

LXXIY. SLEEP

LXXV. SOUND PRODUCTION AND SPEECH

LXXYI. THE AUTONOMIC NERVOUS SYSTEN

\section{BOOK XIII.-REPROIOUCTION}

LXXYI. OROWTI AND REPRODUCTION 


\title{
A TEXTBOOK OF PHYSIOLOGY
}

\author{
BOOK I \\ GENERAL PHYSIOLOGY
}

CHA P T E R I

\section{BIOLOGICAL INTRODUCTION}

Living in the stagnant water of most ditches is the tiny animalcule known as the Amœba (Fig. 1). If a drop of water containing this little organism be placed on a slide beneath the lens of a microscope, exami-

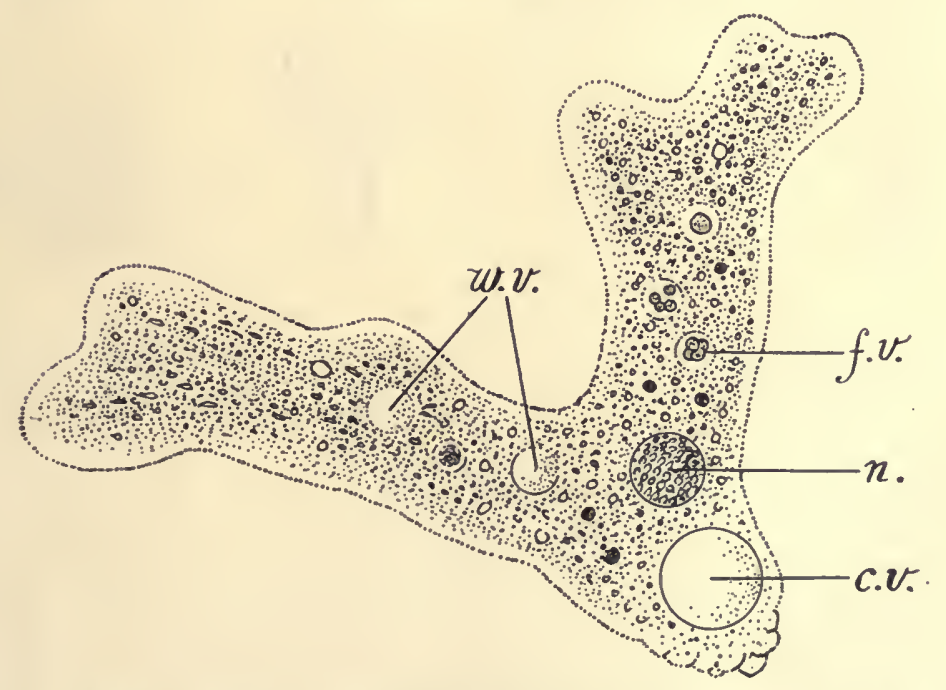

Fig. 1.-Amera Proteus, ax Organisir consistivg of a Single Naked Cell. $\times$ 280. (Redrawn after Sedgwick and Wilson.)

$N$, Nueleus; $w . v$. , water-vacuoles; c.v., contractile vacuolc; f.v., food vacnole.

nation shows that the tiny animal consists of a mass of scmi-fluid material known as protoplasm. Scattered in this semi-fluid mass are a number of granules; at one spot the:e is an empty spacc, the contractile vacuole; while in the centre is a round, more highly specialized 
structure, the nucleus. Observation shows that the amœba gradually moves about in the fluid-here thrusting out one little foot-like mass, or pseudopodium, there retracting another, and thus progressing. If it be touched in any way, the pseudopodia are withdrawn. The organism thus responds to a stimulus, and possesses what is termed irritability. Should there, perchance, be any food material present, such as algæ, it may be seen how, by means of the pseudopodia, the food is surrounded and gradually absorbed into the protoplasmic mass. This food is gradually broken down, digested, and assimilated, any indigestible or waste material bcing later extruded from the surface. From time to time the vacuole contracts, voiding by this process waste products of the animal's activity. Finally, under favourable circumstances, the little animal may be seen to grow, and eventually divide into two organisms, thereby rcproducing itself (Fig. 2).
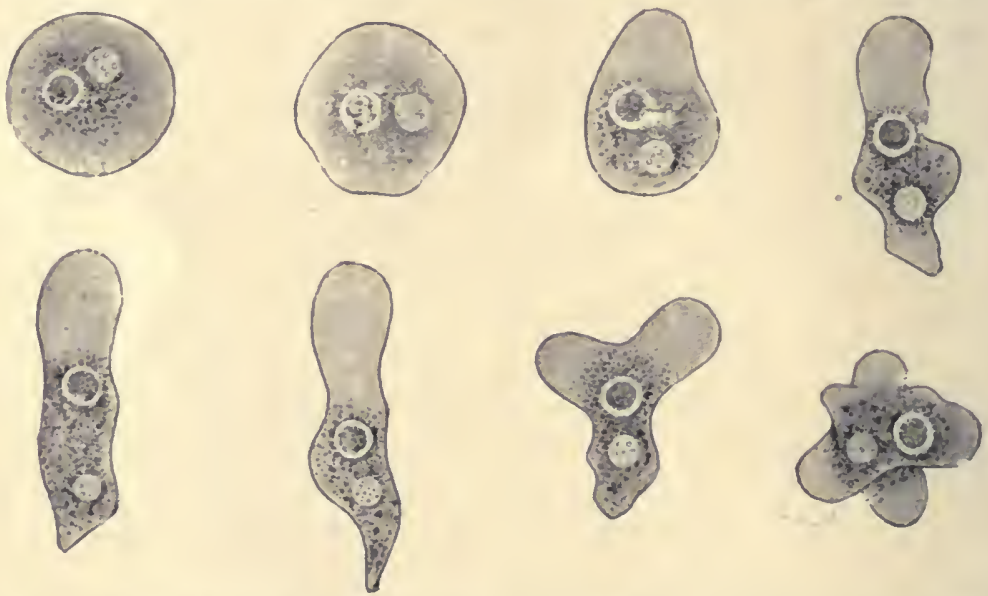

Fig. 2.-Successive Chixaes exhibited by AN Amaba. (Verworn from "Quain's Anatomy.")

The amoba is a type of what is known as a unicellular organism; it consists of but one unit or cell. That one cell performs all the life-processes. All organisms, however, are not so simple in structure; the higher forms of life consist of a great number of cells, and are therefore termed muiticellular. The multicellular organisms have been evolved from the simpler unicellular one-in some cases through an almost infinite number of stages. Past history, or phylogeny, as shown by fossil remains, indicates that, as the ages passed, animals gradually became more and more complex in structure. Some of the simpler forms have continued to exist, others have become lost. So, too, of the erolved multicellular forms-many continue with us, but some hare passed away. The ability of an organism to maintain its life depends upon its fower to adapt itself to existing conditions-uron its being efficient. The multicellular organism developed its efficiency over the unicellular organism along two lines: 
first, by forming a colony of individuals; secondly, by instituting a differentiation of cells, with a division of labour.

In the first method, the formation of a colony of similar cells, the cells, like the amœba, still carry out all the life-functions individually; each cell lives alone. The number of cells in such a colony is not limited; it is but a group of individuals, not one individual. Certain protozoa and protophyta exist as colonies. An example is Carchesium (Fig. 3).

In a little more advanced order of colonization the number of nembers of the colony is limited and kept constant, death of a member being followed by replacement. Such a colony is generally ensheathed by a wall, so that the cells have no independent movement. With these limitations, each cell of the colony performs its vital functions independently. An example of such a colony is Gonium (Fig. 4).

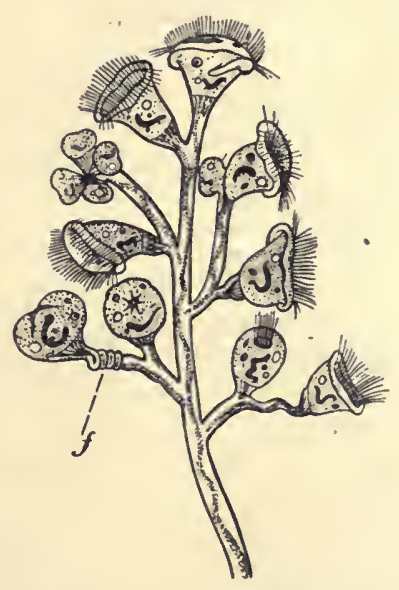

Fig. 3. - A Colony of Ixdividuls of Carchesium, attached by a Commox Branching Stalk, showiNg $f$, the Contractile Stalk of ONe Individual. (Remy, redrawn after Dahlgren and Kepner.)

In the second method a differentiation of cells, with a division of labour, takes place. Here the colony becomes the individual-not a group of individuals. The members of this group range from a simple multicellular organism to man. Volvox globator (Fig. 5) represents the beginning of this type of organization. In it certain cells become differentiated for the main function of life-reproduction - each of the other cells performing all the other functions.

In the higher organizations certain cells become segregated and form a tissue - that is, a group of cclls performing more or less one definite function. Later the differentiated tissucs become grouped into organs, each having some particular function. Nevertheless, each cell remains a separate living unit, having its own share of work to perform.

The developmental history - ontogeny - of the multiccllular organ- 


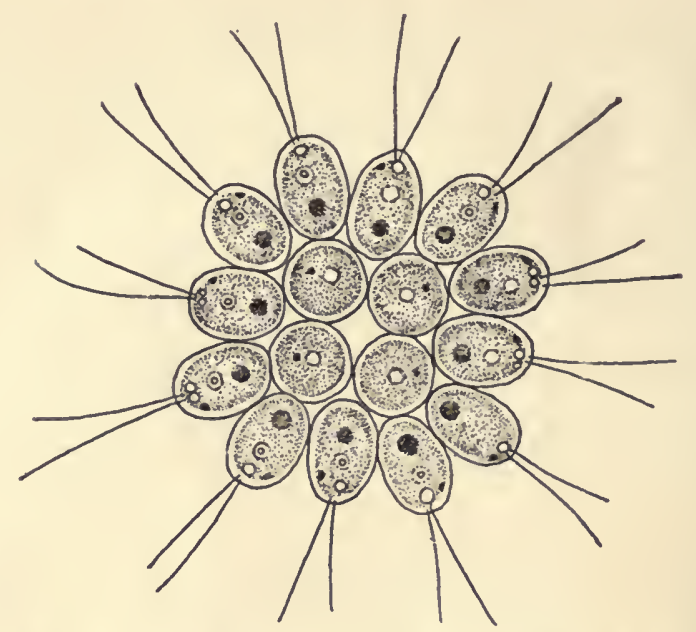

Fifi 4.-Goxilis Pectorale, showing the Ixpividuals. (From Labigren and Kepner, after Stern.)

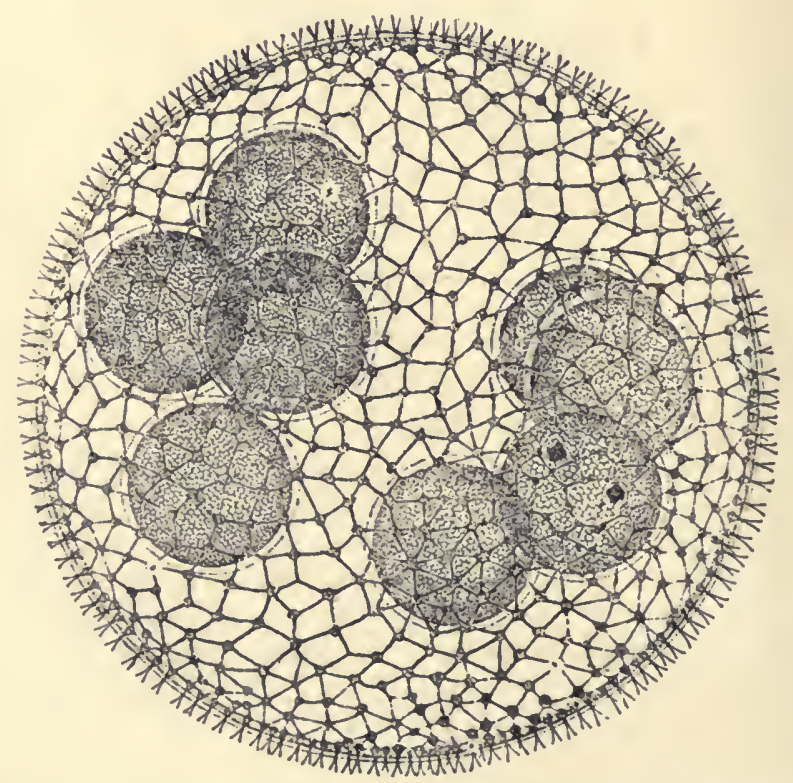

Fig. 5.-Volvox Globator, a Colony of Cells in which All the Cells are cunfined to the Surface of the Spilere, leavisg a Cavity Ixteriorly. (From Dahlgren and Kepner, after J. H. Fmerton.)

The cells are united by protoplasmic strands radiating from each ccll. The differentiated cells, or ova, are shaded dark. 
isms confirms the evidence of the past history, or phylogeny. Each multicellular organism develops from a single fertilized egg, or oə̈sperm.

The fertilized cell at first divides, and divides again to form many similar cells. These cells then become differentiated into various tissues, which eventually become grouped to form different organs (p. 773). In the course of development a three-layer blastoderm is formed.

From the outer layer-ectoderm-chiefly the epithelial protective and nervous tissues are developed; from the middle layer-mesoderm - the supporting and muscular tissues; from the inner-endodermthe respiratory and alimentary tissues.

By the name of epithelium is designated the tissue lining the outer and inner surfaces of the body. Occupying this position, its main function is that of transferring material from the surfaces to the tissues within. It also plays a part in protecting the underlying organs, and in receiving stimuli and transforming these into sensory nerve impulses. From it, also, the glandular structures of the body are developed-e.g., salivary glands, glands of stomach, intestine, etc.

The supporting and connective tissues are developed to give rigidity and tensile strength to protoplasm, and thus enable the multicellular organism to preserve a definite form. For these purposes fibres, plates; and such massive structures as the bones, are formed. The ligamentum nuchæ of the ox affords an excellent example of tensile strength, while the shells of molluses and eartilaginous and bony structures testify to the great rigidity which may be developed. Cells of like origin may also act as a storehouse of food materiale.g., fat.

The muscular tissue has become developed, not only to move the organism from place to place, but also to assist in the internal operations of the stationary organism-for example, the heart, cilia, etc. Its essential property is the power of contraction.

By a combination of tlies 3 three tissues, epithelial, connective, and muscular, the outer covering parts, or integument, of the body is formed. One of the chief functions of this integument is to protect the exposed outer parts of the body from dangers to which it is subjected, whether the animal live in the water or in the air. This it can do both mechanically and by the production of means of defence - e.g., poison. The integument possesses also lubricating and cleansing powers. Sometimes, too, it has the power to produce attractive or repulsive odours, to prepare adhesive material, or to spin.

Examples of mechanical protection are seen in the stiff fibres developed by many lower animals-e.g., the turbellarian worms, to protect against undue pressure; the cuticlc of the earthworm; the carapace of the lobster and the shell of the tortoise; the scalcs of fishes and of birds' legs; the feathers of birds and tlıe hair of animals; the outer covering of the human skin generally, and in particular the thickened areas of the palms of the hands and soles of the fect.

Various examples of offensive protection may also be given. Formed within the cell are the trichocyst of paramœcium, the rhabdites or 
stylets of the turbellarian worms, the stings of the nettle cells of hydra. Finit by cells arc the stings of bees and wasps, the poison hairs in the larva of some moths, the poison glands of some spiders, the stinging spine of the weaver-fish and of the whip-ray, the weak poison of the lectoral fin of the cat-fish, the spine of the porcupine, the claws of the higher animals, and the nail of man.

The integument may provide lubricating material either all over the body surface or only in special areas. The lubricant material may at the same time serve additional functions-for example, as a preservative from water, as a cleanser, or as a food-gatherer, and so forth. The lubricating material may be slimy (mucus), oily, or watery, in nature.

The mucus provided by certain of the clams serves the purpose of lubricating, and also of removing dust and aiding the collection of food. The slime produced by the earthworm serves the double purpose of lubricating the animal and of preparing its dwelling-place. The mucus of the salivary glands of the mammal and of the mucous cells lining the alimentary tract is both lubricant and protective.

The second form of lubricating material, that of an oily nature, is found in the higher animals (birds and mammals). It is a protection against both the drying of the skin and the wetting of the feathers, hair, or skin. Such a material is formed in the oil glands, by which birds oil their feathers, and in the sebaceous glands, by which the hairs and skin of mammals are kept greased. Sometimes these oils possess a distinctive scent, either repulsive or agreeable; such is the case, for example, in the musk rat, musk ox, and the skunk.

The watery (serous) form of secretion is comparatively rarc. Possibly the lachrymal glands moistening the eyes of mammals, and the sweat glands moistening the skin, may be grouped here, as well as the secretion which lubricates surfaces of joints, the synovial fluid. By the evaporation of sweat the body is cooled.

Among the lower animals an extremely adhesive fluid is sometimes produced, which enables them with the aid of a sucker or pad to stick to surfaces-e.g., that of the head of the leech and the legs of beetles. In other cases the adhesive fluid hardens into a thread; thus the cocoons are formed by the spinning glands of the larvæ of moths (silkworm).

Many of the lower animals also possess odour-producing glands -e.g., the skunk; a wcll known example also is the so-called stink-pot turtle. Other reptiles-for example, the American toad (Bufo) produce an extremely offensive fluid. The secretion of Bufo is partly mucous, partly serous, and it is said to be poisonous. But it is among the invertcbrates that this power of producing offensive and attractive odours, as judged by man, has been reduced to a fine art. Various butterflies produce distinctly pleasant odours. Such odoriferous glands are situated in various parts of the body or wings.

But besides rendering themselves efficient in this direction, the multicellular organisms have developed other systems of tissues, "well adapted to meet the conditions under which the animals live. With 
the division of labour there is elaborated $(a)$ an alimentary system, by which the necessary foodstuffs are taken into the organism and reduced to a proper state for absorption; (b) a respiratory system, by which the oxygen necessary for the cell processes is introduced, and the carbon dioxide produced by these processes eliminated; (c) a transport and circulatory system, by which these necessaries are conveyed to all the body cells to supply their needs, and the products of cell activity conveyed away for excretion either by the respiratory mechanism or by $(d)$ a specially developed excretory system.

Finally there remain two special systems-the nervous and the reproductive. The nervous system serves to put the organism into communication and correlation with outer chemical, physical, and mechanical conditions. It does this by its receptor, conductor, and effector functions. It is irritable, and receives a stimulus cither directly or indirectly, conducts the stimulus as a nerve impulse, discharges it on some other cell or cells, and the e produces its effect. The system is primarily intended for communication between parts of the body more or less widely separated; in the higher animals it becomes an extremely complicated system, and according to its degree of complexity and the manifold functions it performs, so is the organism classed by man in the ladder of life. Man, placed by himself at the top of the ladder, has the most complicated and most highly developed nervous system. To the reproductive system is assigned the highly important function of maintaining the particular species of the organism. In the multicellular organism, the cells other than the reproductive cells perish after a longer or shorter period of existence. But the reproductive cells, under appropriate conditions, give rise to fresh individuals, thereby perpetuating an unbroken chain of living cells.

Physiology is the science which treats of the normal functions of these various systems. 


\section{CHAPTER II}

\section{THE CELL}

During the latter part of the seventeenth century the simplo microscopes of the day demonstrated that plants were composed of small box-like spaces surrounded with a distinct wall, and filled with liquid. The name of cell was given to these. In 1839 Schwann put forward the theory that the animal body was built of cells. The identity of protoplasm in all forms of life, plant and animal, was established, and the cell defined as a nucleated mass of protoplasm. The cell may be regarded as a working unit of protoplasm.

The body of a cell consists of a substance called protoplasm or cytoplasm (Fig. 6). In the young living egg cell (such as echinoderm ova), the structure appears homogeneous, like egg white; while in older cells it appears alveolar or reticular. To bring structures into view, and to enable thin sections of organs to be cut, fixing and staining reagents are used. The reagents which are used to fix and harden tissues for microscopical examination, such as alcohol, a saturated solution of mercuric chloride, etc., coagulate protoplasm and produce thread-like and granular precipitates in cells - artefacts - which often produce appearances of structure not existing in the living cells. Such granules and fibres appear in homogeneous solutions of egg white or peptone when treated with hardening reagents. We must not draw conclusions as to cell structure without comparing the fixed with the living cell. The same method of hardening-i.e., the same chemical process-can, however, be justly used to compare the structure of normal with that of abnormal organs. Reagents can also be used to investigate the ehemistry of the cells; to identify in them by different staining reactions fat, glycogen, iron, potassium, etc. This is a valuable method of microscopical study. The essential structurs of a living cell appears to be a homogeneous fluid material studded with a large number of minute granules (Fig. 7). Between these two phases, granule and fluid, physico-chemical changes take place which manifest themselves in the life of the cell. The foam structure of protoplasm can be closely imitated by rubbing up oil with potash or sugar into a very finely divided paste. A drop of this is put into a drop of wat 3 r on a microscopic shide. The water is attracted by the osmotic pressurz of the potash or sugar and produces the foam. Radium bromide powder dropped into a gelatin and broth medium produces cell-like structures which increase in size and divide, multiplying, apparently, like a living organism. The radium gives off an emanation, the product of its 
atomic energy, and this is accompanied by heat. The emanation coagulates the protein and decomposes water into oxygen and hydrogen producing the "cells," really bubbles of gas surrounded by a coagulum. As the gaseous emanation continues to form, "cells" grow-i.e., the bubbles bulge out, burst, and form new bubbles. There is no production of life in these phenomena. They are of interest as showing ways in which an alveolar structure may be formed in colloidal solutions. The atomic energy made evident to us by radium may

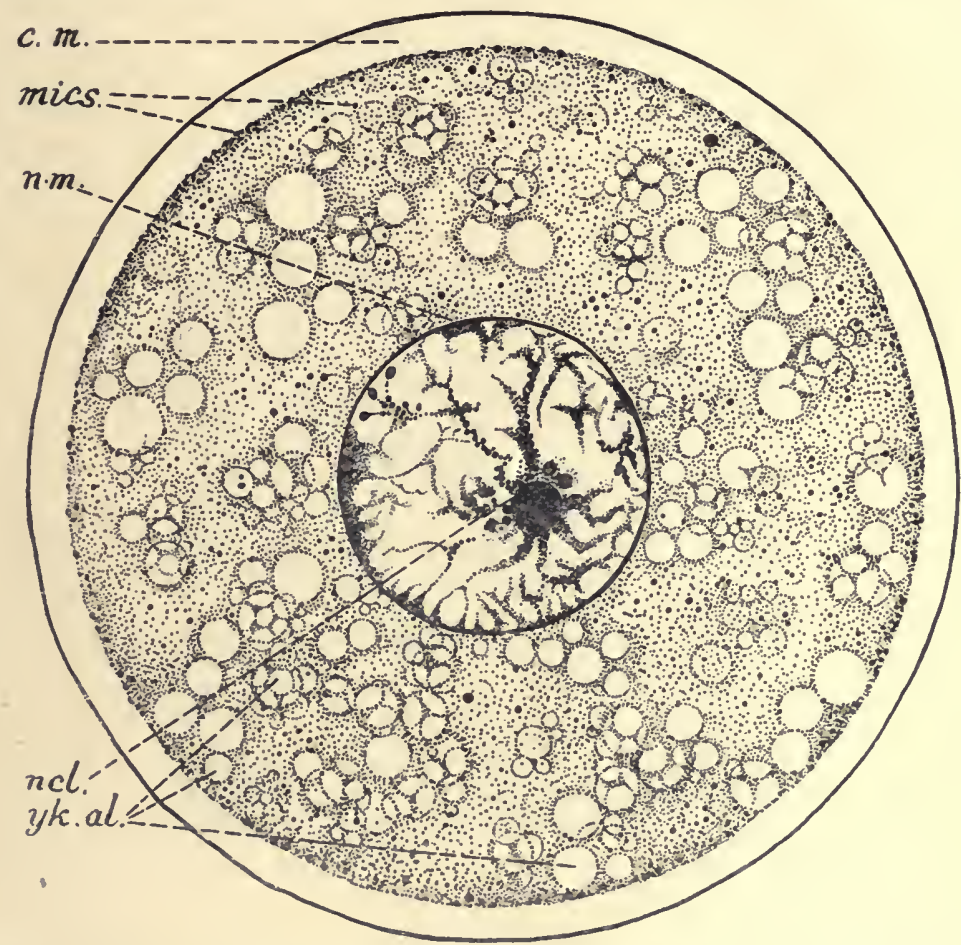

Fig. 6.-Ovom of a Cat Just Before Maturity. (Redrawn from Dahlgren and Kepner.)

C.m., Cell membrane; n.m., nuelear membrane; ncl.; nucleolus; mics., mierosomes; $y k, a l .$, yolk alreoli.

possibly be a form of energy of fundamental importance in living matter, although the elements into which living matter is decomposed are, as far as we can sce, stable. If an unstable mixture be madc of two sterile colloidal solutions of opposite electrical sign, such as ferric hydrate (+ve) and silicic acid (-ve), and be left standing, growth-like structures appear, simulating in outward appearance simple living protoplasmic forms.

The granules so frequently lodged in the ccll may be fat, pigment, glycogen, or protein. The last may stain either with a dye possessing 
an active acid radicle-e.g., prtassium chromale-or one with an actire basic radicle-e.g., rosanilin acetate. The granules with affinity for acid radicles are basic, those for basic are acidic in nature: still other granules are neutral and stain with both radieles: the names given for these are respectivcly oxyphil, basophil, and neutrophil granules. The first and last are most common. A constant element of the eell is the nucleus. It consists of nuclear plasma and nuclear network. The form of the nucleus varics, but corresponds in general to the shape of the cell-large and round in nerve eells, long and oval in involuntary muscle fibres, irregular necklace-shaped in leucocytes. Especially large nuclei are found in young ova and nerve cells. The nuclcar reticulum consists of granules of nuclein, which stain deeply with basic dyes, and is thus called chromatin by histologists. Tho basic affinity of nuclein is due to the

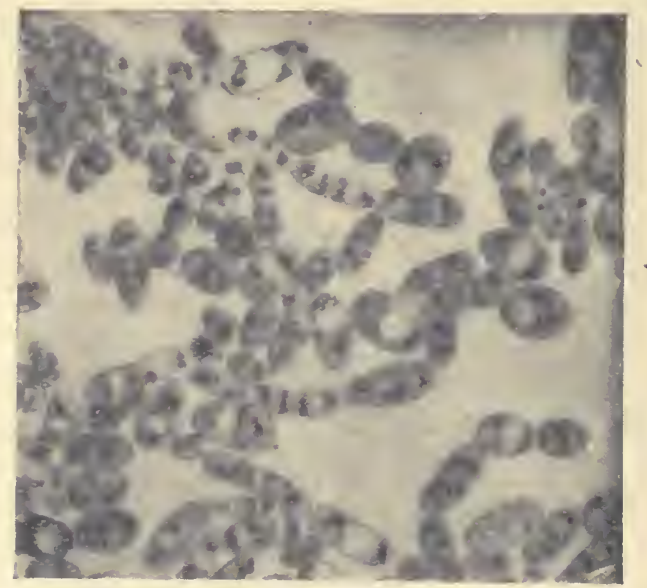

Fig. 7.- Yeast Cells photographed by Uitrafiolet Light throvgh Quaktz LEXSES. (Barnard.)

nucleic acid it contains. This substance is rich in phosphorus, as may be shown by special staining methods. The nuclein granules are embedded in a less stainable network-the linin. Embedded in the nucleoplasm are one or two larger granules which do not behare to chemical reagents in the same way as the nuclein; these are called nucleoli. Surrounding the resting nucleus is a perforated nuclear membranc, through which cell protoplasm and nucleoplasm are in continuity.

The nucleus seems to be the mainspring of the cell's activity. Wherever in a cell growth is active, there seemingly is placed the nucleus (Fig. 8). It controls the cell metabolism and its reproduction.

In the case of the protozoa, when the nucleus is separated off with one part of the cell, that part grows; the remainder ceases to grow, and dies. 
The complicated structure of protoplasm, and the fact that it is constantly in a state of flux and change, prevent its existence in large masses. It must be intimately bathed with the fluids that feed and eleanse it. Hence the cellular structure, and the evolution of circulatory mechanisms in the higher multicellujar animals. Protoplasm, in order to live, must protect itself from extremes of temperature, and from other active physical or chemical changes which split up its

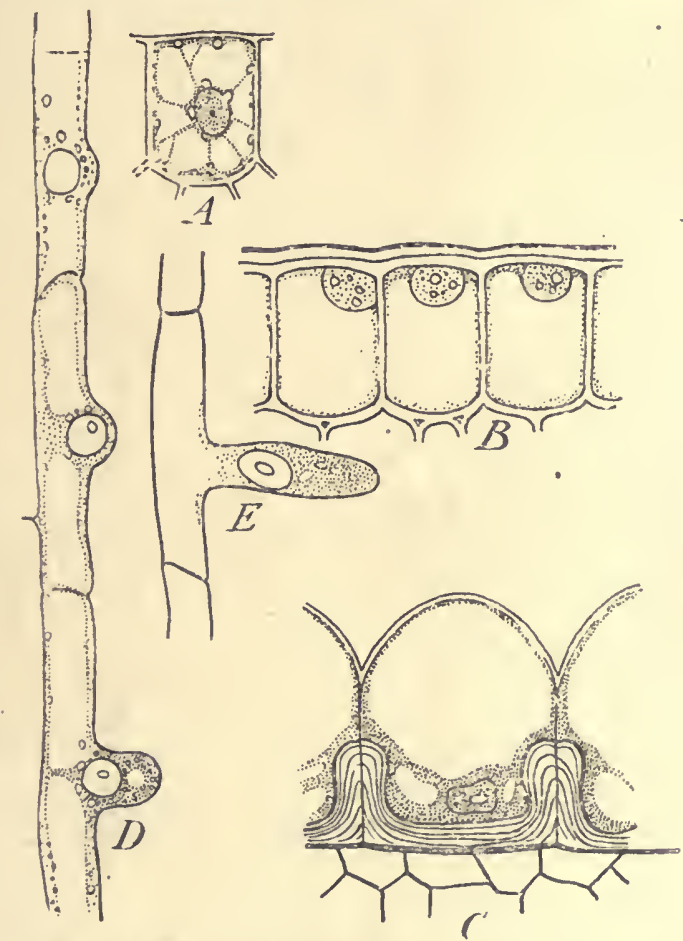

Fig. 8. - To show the Migration of the Nucleus to the Point of Girowth in Phants. (Redrawn after Haberlandt, from Wilson's "The Cell," etc.)

$A$, Young epidermal cell of Luzula, with central nueleus before thickening of the membrane; $B$, three epidermal cells of Monstera during thickening of outer wall; $C$, eell from seed coat of Scopulina during thickening of the inner wall; $D, E$, position of the nuelei during the formation of branches in the root-hairs of the pea.

molecules into simpler (dead) compounds. It must have the food necessary to keep up its cycle of change served to it in proper form. Protoplasm, therefore, moves, not only to find food, but to avoid injurious influences. Protoplasm moves by effecting a redistribution of its substance, and certain parts are especially sct apart, so situated as to produce definite changes in the shape of the living organism, and so differentiated in structure as to perform rapid movements-cilia, muscles. It is well to remember that movement in response to ex- 
citation is by no mcans confined to the living world. Heat and magnctism cause movements in inanimate matter, and the response of living matter to certain forms of excitation appcars to be as inevitable as the lengthening of an iron bar when heated. The uniccllular animals move either by flowing out in one or other direction, a part forming a pseudopodium, and the rest following, or by means of vibratile lashes, the cilia, which arc sct round the circumference of the cell body or at one or other pole. A pseudopodium may be imitated by a capillary tube filled with mastic varnish. This will extend a pseudopodiun towards and eventually engulf a glass fibre wet with alcohol. A glass fibrc covered with shellac is taken up by a chloroform drop (Figs. 9A and 9B).

Movement is excited by the various chemical and physical forms of energy, and may be toward the source of energy or against it-positive or negative. The slime fungus, Myxomycetes plasmodium,
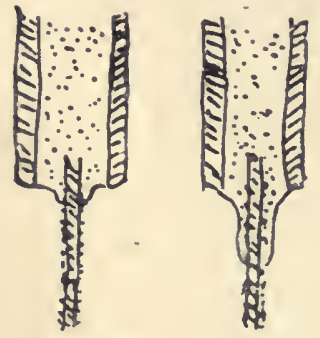

Fig, 9..-A Grass Fibre Wer with Alcohol being Exgulfed BI a Pseudopodium of Uastic Varish. (After Rhumbler.)

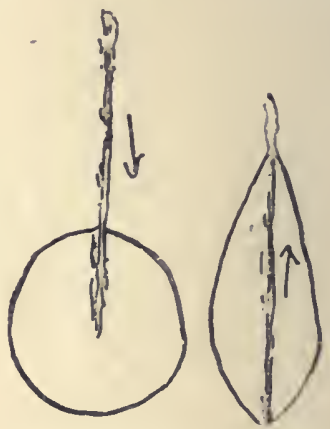

Fig. 9B.-A Grass Fibre Coated WITH SHELLAC, TAKEX UI BY A DROP OF ChLORO. FORM. (After Rhumbler.)

forms, by the union of many amœba-like cclls, a sheet of protoplasm which spreads for many inches, over rotten woods. The plasmodium shows marrcllous veins in which granular protoplasm strcams, with extraordinary rhythm, first in one and then in the reverse direction. The plasmodium flows towards and over its suitable food, digesting and absorbing as it gocs. It is attracted by certain chemical substances-positive chemiotaxis. It is repelled by others, e.g., a trace of quinine, or too concentrated a solution of salts, etc.-negative chemiotaxis. Similarly, paramocia or opalinæ gather round a drop of dilute acid, and are repclled by dilute alkali. $\mathrm{H}$ - ions exert a positive and $\mathrm{HO}+$ ions a negative chemiotaxis. Paramœcia exhibit positive galvanotaxis to the negative pole of a constant current. They gather round this pole when the current is passed through the diop of water containing them. Tadpoles turn their hoads toward the anode. They aroid one end of a trough if this be heated to $25^{\circ}-30^{\circ} \mathrm{C}$., and seek the cooler cud-negative thermotaxis. They seek red light and a void the bluc--phototaxis. Worms, earwigs, ctc., placed in a box with a 
cover half blue and half red, and exposed to sunlight, are disturbed by blue light, and actively move till they finally come to rest under the red. This exciting effect of blue light acts on the skin and produces its effect even in blind animals. It is the most refrangible rays of the spectrum, the so-called ultra-violet rays, which have the marked effect on living matter. These rays produce in us sunburn, followed by a protective pigmentation of the skin. They act as a bactericide, e.g., the tubercle bacillus is killed by light and the powerful are light (the Finsen light) is employed to cure lupus. The exclusion of all but red and yellow rays from the sick-room is said to prevent the suppuration of the eruption in small-pox. The black man is protected from the ultra-violet rays by his pigment. Similar but more powerful effects are produced by mercury vapour lamps enclosed in quartz. The light from these lamps is particularly rich in ultra-violet rays, since the spestrum of mercury vapour contains many bright lines in the ultra-violet region of the spectrum, and quartz, unlike glass,' is easily transparent to the rays (Fig. 10).

As a rule cells are small in size, some few thousandths of a millimetre in diameter. Occasionally-for example, the egg of a bird-the cell is macroscopic in size, owing to the large amount of vegetative or nutritive cytoplasm present.

The shape varies more than the size. In the various tissues it becomes modified to almost any shape-flat discs, cubes, hexagons, rods, or branching forms.

There is an individuality of the cells of the multicellular organism. Their power to survive removal from the body is very great; thus, the sperm of the drone is received by the queen bee in her nuptial flight, and remains active for the rest of her life in the receptaculum seminis. In the cloacal sac of the female salamander the sperm is retained active for two ycars after copulation. The bat is wed in autumn, and be-

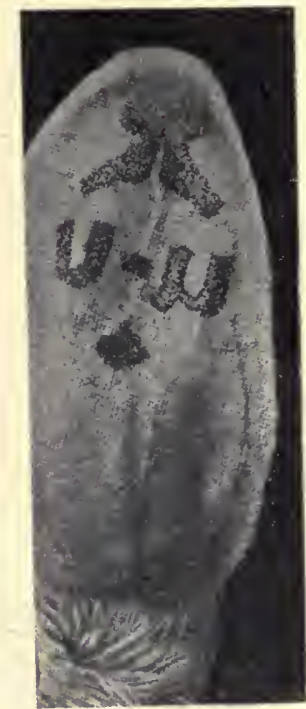

Fig. 10.-LEsioxs PRODUCED BY THE ULTRA - VIOLET RAYS ACTING UPON THE RABBIT'S EAR SCREENED BY A Piecr: OF BLack CARDBOARD, FROM WHICH THE DESIGN AXD LETTERS WERE Cut Out. (After V. Henri.) comes pregnant after her winter sleep. Living spermatozoa have been found cleven days after excision in the excised testicles of guineapigs kept at $0^{\circ} \mathrm{C}$. Living human spermatozoa have been found in the uterus eight and a half days after cohabitation. The leucocytes of the frog showed amœeboid movements after being kept thrce weeks in a moist chamber. Dog's blood kept ten days on ice has been successfully transferred into a dog. Movement of ciliated cells has been observed in a tumour eighteen days after its removal from the nose. Pieces of the mucous membrane of the frog's mouth put in the dorsal 
lymph sac of the same animal showed active cilia after five months Pieces of human skin kept in ascitic fluid for at least one week have grown on transplantation. The cornea of a hare kept at $0^{\circ} \mathrm{C}$. has survived nine to twelve days, and becn successfully transplanted. The excised heart of a three-months-old child has been made to beat twenty hours after death. In the last few years the survival of tissuo

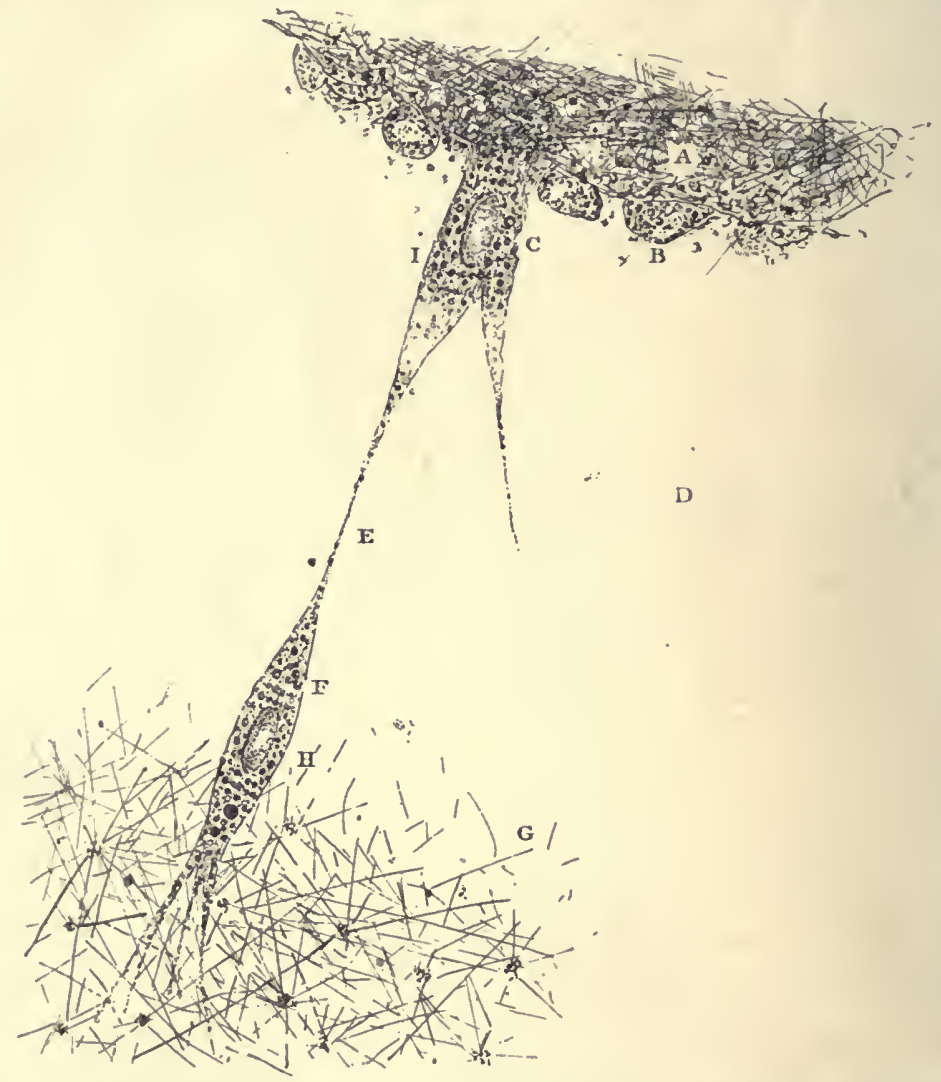

Fig. 11.-Camera Lucida Drawixg of Celles from the Heart of Rabits's Embryo (Seven to Eight Days Old) growing in Curture Medium. (N. C. Lake, from Journal of Physiology.)

$A$, Nain mass of tissuc; $B$, degenerate cells; $C$, inner columnar cell; $D$, liqucfied medium; $E$, protoplasmic thread; $F$, outer spindle cell; $G$, fibrin network with blocd platelets at nodes; $H$, nucleus showing chromatin; $I$, tendency to striation.

cells has been cxtensively studied, and the question arises as to whether true cultures are obtained. The growth of nerve cells has been studied in pieces of the frog cmbryo placed in clotted frog's lymph. By repeatedly alternating the life of the tissue, first putting it in a culture medium and warmth and then in Ringer's solution and cold, pulsating pieces of heart muscle have baen kept for three months. Cell move- 
ment in explanted tissue has been kinematographically studied. Such cells use the threads of fibrin of the plasma medium as guides in their wanderings. While the cells of explanted tissues live and multiply, it is doubtful how far they show the characteristics of the particular tissue. It is said the new-formed cells take on an indifferent character, and never show the characteristic formation of the mother organ. If true cultures of the cells' organs could be obtained, the method would lend itself admirably to the study of histogenesis, metabolic processes, age and death phenomena of cells. It has, however, been claimed recently that contractile cells which must be considered muscular have been obtained by culture of the cells of the heart of the embryo rabbit (Fig. Il).

The phenomena of movement, irritability, the digestion and absorption of food, its assimilation and dissimilation, the excretion of waste materials, growth and reproduction, are essentially those of living matter. Physiology is the study of such life processes.

These processes in part conform to the laws of physics and chemistry which have been found to govern matter generally. Of much, however, at present the explanation is not clear, and to expess the reactions of living matter terms such as "biological force," "vital force," and " biotic energy," are often employed. The use of such terms does not, or should not, indicate that there is any deep and unfathomable mystery about life phenomena other than that hitherto insoluble mystery which enwraps the universe, and conceals from us the ultimate origin and the nature of what we choose to term matter and energy; rather, it means that the physico-chemical laws governing matter have not yot been sufficiently found out to render clear the interpretation of living processes. With each fresh advance in natural science the phenomena of life are being correlated with phenomena of non-living matter, and there can be no doubt that with a fuller knowledge of chemical and physical laws many of the processes now labelled "vital" will be capable of being grouped under these laws. To say this does not lessen the dignity of the conception of life; rather, it exalts, by unifying, our general conception of the universe. A certain arrangcment of matter acts as a transformer through which the phenomena of life become manifest. The universal source of energy, whatever it may be, becomes transformed into the various manifestations of energy which we call life, including the workings of Mind. In dead matter the transformations of energy are otherwise in character; but the play of energy is no less ceaseless in character, no less keyond final explanation, no less worthy of veneration. Nothing is common or simple to him who has really probed into the secrets of Nature.

The following has been put forward as a tentative spcculation on the origin of life :

The whole world of living plants and animals depends for its present continuance upon the synthesis of organic compounds from inorganic by the green colouring matter of the plant acting as a transformer of light energy into chemical energy. This present state of affairs musthave been evolved from something more simple existing at the com. 
mencement. For chlorophyll, which now acts as the transformer, is itself one of the most complex of known organic substanees, and eould not have been the first organic substanee to be evolved from inorganic matter. In considering the origin of life, therefore, the start must be made in a purcly inorganic world without a traee of organic matter, either plant or animal.

Recently it has been shown that, when dilute solutions of eolloidal ferric hydroxide, or the eorresponding uranium compound, are exposed to strong sunlight, or to the ultra-violet rays of a quartz mercury are, there are synthesized the same organic compounds which are at present formed as the first stage in the process of organic synthesis by the green plant-namely, formaldehyde and formic acid. Taking the riew that the earth arose from a gaseous nebula, it may be assumed that at first, as the planet cooled down, only elements were present, at a lower temperature binary compounds formed, next simple crystalloidal salts arose. Then, by the union of single moletules into groups of fifty or sixty, large molecular colloidal aggregates appeared. As these nondiffusible or colloidal aggregates increased in complexity, they also became more delicately balanced in structure and labile-that is to say, they were easily destroyed by sudden changes in environment, but, within certain limits, were peeuliarly sensitive to energy changes, and could take up energy in one form and transform it into another. These labile colloids took up water and carbon dioxide, and, activated by the sunlight, produced the simplest organic structures. Next these simpler organic structures, reacting with themselves, and with nitrogenous inorganic matter, continued the process, and built up more and more complex, and also more labile, organic eolloids, until finally these acquired the property of transforming light energy into chemieal energy. By the continued action of this "law of molecular complexity" life originated. Such an origin of life was no fortuitous aceident, and the same processes are still guiding life onwards to higher evolution in a progressive creation. 


\section{CHAPTER III}

\section{PHYSICO-CHEMICAL INTRODUCTION}

THE cells of the body are bathed in solutions containing both colloids and crystalloids. The phenomena exhibited by substances in solutions are closely related to those exhibited by gases, conccrning which the basic facts are better known. The fundamental gas laws, proven by experiment, may be grouped, two as physical, and one as chemical, in nature.

The first law is that the volume occupied by a given mass of gas varies inversely as the pressure to which it is subjected, provided the temperature is kept constant (Boyle's law). Experimental work has shown that for ordinary gases under ordinary conditions Boyle's law may be taken as accurate.

The second law is that the volume occupied by a given mass of gas, kept under constant pressure, increases as its temperature is raised, and the relative expansion is approximately the same for all gases (GayLussac's law). It is found that the volume of a gas increases by of the volume it occupies at $0^{\circ} \mathrm{C}$. for a rise of $1^{\circ} \mathrm{C}$., always provided the pressure remains the same.

From these two laws it can bc shown that the pressure excrted by a given mass of gas kept at constant volume increases with rising tenperature in the same proportion as the volume increases at constant pressure.

The third law is also associated with the name of Gay-Lussac. It is the law of volumes. It states that, when two gases combine with each other to form a third gas, the volumes of the reacting gases are in simple ratios to one another and $t \mathrm{~s}$ the volume of the gaseous product, all being measured at the same temperature and pressure-for example, one volume of hydrogen combines with one volume of chlorine to form two volumes of hydrochloric acid. On one hypothesis (Avogadro's) regarding the nature of gases, it is supposed that equal volumes of different gases measured at the same temperature and pressure contain the same number of molecules or ultimate particlcs. The molecules are rot the same thing as the atoms of an element; a molecule may contain one, two, or more atoms, and the element is univalent, divalent, trivalent, according to the number of atoms its molccule contains.

Diffusion.-A characteristic fexture of a gas is its ability to occupy with great rapidity any space afforded it. If two vesscls containing different gases at the same pressure be put in communication with exch other, the gases gradually mingle, each moving from places of high concentration to places of low concentration until the partial pressure 
of each gas is the same througlout and equilibrium is attained. This is termed the process of diffusion of gases; it is a molecular process, and takes place independently of any movement of gas as a whole by stirring. Diffusion is a relatively slow process, and the mixture of gases is very greatly accelerated by stirring-e.g., in the lungs. Experimentally it was found by Graham that the velocity of "effusion," as he termed it, of a given volume of any gas is inversely proportional to the square root of its density. His experiments consisted in determining the timcs taken for a given volume of various gases, kept

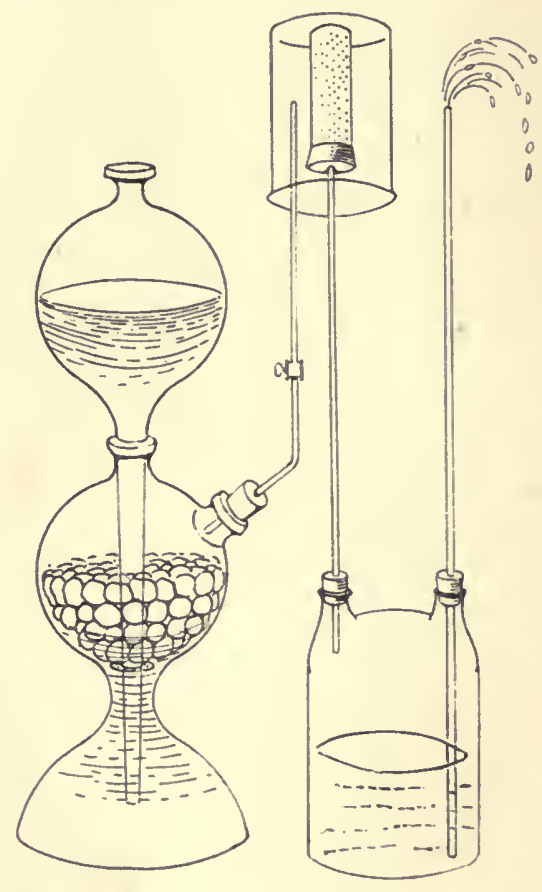

Fig. 12.- Hivergen Generated from a Kipp's AfParates is liberated in the Neighbourhood of the Porods Pot. The Hydrogen Diffuses into the

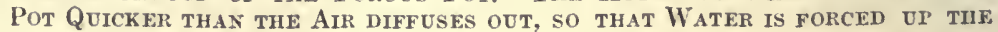
TUBE OUT OF THE WOULFFE'S BotTle.

at constant pressure, to pass through a minute hole in a metal plate into a receiver, which he kept constantly evacuated. This law, governing the rate of diffusion of gases, is well shown by the experiment illustrated in Fig. 12.

Experiments have kecn made in whieh the diffusion of a gas is observed through a tuke, when the concentration of the gas at one end is kept at zero or at a constant low value. For example, when caustic potash is kept at the lottom of a tall eylinder full of earton dioxide, there is a constant flow of carbon dioxide to the rotash at the rottom of the cylinder; the flow is inversely proportional to the 
length of the diffusion column. The same holds good for the diffusion of water vapour into strong sulphuric acid. If a diaphragm be placed at the free end of the diffusion column, it is found that the amount of gas which diffuses is proportional to the diameter of the aperture, and not to its area. Another remarkable fact is that, if in the diffusion tube a diaphragm be placed containing many minute perforations, the diffusion flow is checked but little or nil, each aperturc in a multiperforate diaphragm acting independently of the others.

It has been found that the assimilation of $\mathrm{CO}_{2}$ by the leaf of a plant is due to a similar process of diffusion. If the stomata or pores of the leaf be blocked, no assimilation of $\mathrm{CO}_{2}$ takes place. The amount of $\mathrm{CO}_{2}$ entering the leaf depends on the concentration of $\mathrm{CO}_{2}$ inside the leaf and the linear dimensions of the stomata. It is found experimentally with leaves of Helianthus that the amount of $\mathrm{CO}_{2}$ taken in is but a fraction of the amount calculated for the leaf as a multiperforate septum. This is because the gas, having entered the stomata, has to pass into solution in the leaf fluid--a relatively slow process as compared with gaseous diffusion.

This brings us to the next point-the passage of gases into solution in water. The power of water to dissolve a gas varies markedly with the nature of the gas; the solubility of the same gas in the water also varies with the temperature and the pressure at which the absorption is taking place, and with the concentration of other substances in solution in the water. In regard to temperature, the solubility diminishes as the temperature rises. The solution of the gases of the atmosphere in fat, on the other hand, is independent of the temperature. In regard to pressure, it is found that the quantity of gas dissolved, either by weight or volume, at normal temperature and pressure (N.T.P.) in a given volume of water at a given temperature is directly proportional to the pressure; thus, by doubling the pressure twice as much gas passes into solution (Henry's law).

The definite relationship between the gas and the absorbing fluid is sometimes termed the "absorption cocfficient "- that is, the volume of gas reduced to N.T.P. which is taken up by that volume of the fluid under the normal pressure of one atmosphere. In the following table the absorption cocfficients are given for oxygen, nitrogen, and $\mathrm{CO}_{2}$, in water.

$\begin{array}{cccc}\text { Temp. } & \text { Oxygen. } & \text { Nitrogen. } & \text { Carbon Dioxide. } \\ 0^{\circ} & 0.0489 & 0.0239 & 1.713 \\ 10^{\circ} & 0.0380 & 0.0196 & 1.194 \\ 20^{\circ} & 0.0310 & 0.0164 & 0.878 \\ 30^{\circ} & 0.0262 & 0.0138 & 0.665 \\ 40^{\circ} & 0.0231 & 0.0118 & 0.520\end{array}$

The table shows that the absorption coefficient of nitrogen in water at $30^{\circ}$ is 00138 - that is to say, one c.c. of water at $30^{\circ} \mathrm{C}$. absorbs at atmosphcric pressure 0.0138 c.c. of nitrogen mcasured at N.T.P. It also shows that oxygen is more soluble than nitrogen, and $\mathrm{CO}_{2}$ more soluble than either. Fat dissolves between five and six times as much of these gases as water. 
Diffusion of Gas through a Liquid Film.--The solubility of a gas is important in detcrmining the passage of a gas through a watery film. It is found that the velocity of its diffusion is directly proportional to the absorption coefficient of a gas in water. It is also found that, other things being equal, the amount of gas passing from the place of high pressure through a watery film to the place of low pressurc is proportional to the difference in pressurc of the gas on the two sidcs of the film. The importance of the first factor may be demonstrated as follows: A piece of pig's bladder is tied over onc end of a short wide tube. The other end of the tube is closed by a rubbe: cork through which is passed a narrow glass tube, which passes to a manometer containing coloured water or to some other mechanism for recording change in pressure. The membrane is now impregnated with water; it is important to note that membranes dried in air are almost if not quite impermeable to such gases as carbon dioxide and oxygen. A beaker containing a gas is then inverted over the tube carrying the membrane. If the gas be hydrogen, no movement of fluid is recorded by the manometer. On the other hand, with a very soluble gas such as ammonia, a rise of pressure is shown in a short time.

The exchange of oxygen and carbon dioxide in aquatic plants depends upon the power of the water to dissolve these gases, and on the diffusion of the dissolved gases through the membrane of the plant, which is impregnated with water. If the medium in which the plant lives be freed from air, the plant dies. The process of the diffusion through the walls of submerged plants has been shown to follow the laws cited above; the gaseous interchange is therefore a slow process. On this account the oxygen and carbon dioxide liberated in the assimilatory and respiratory processes of the plant are stored in intercellular spaces and kept for future use. This is particularly the case in the parts of aquatic plants which arc embedded in the mud at the bottom of the water. Further, since oxygen and carbon dioxide are more soluble in water at low temperatures, the facilitics for gaseous interchange are greater at these temperatures, and it is known that marine plants such as alga flourish more abundantly in the Aretic than in warmer waters.

In dealing with the gaseous interchange in the process of respiration, we shall have to discuss whether this takes place according to the principles regulating the diffusion of gases across a liquid film.

Solubility of Gases in Salt Solutions.-In general, the more concentrated a salt solution, the less soluble a gas in it. Thus, while 1 c.c. of pure wator at $25^{\circ} \mathrm{C}$. dissolves 00308 c.c. of oxygen, l c.c. of a $\frac{x}{2}$ solution of $\mathrm{NaCl}$ dissolves but 0.0262 c.c. of this gas, a $\mathrm{N}$ solution* 0.0223 c.c., a $2 \mathrm{~N}$ solution 0.0158 c.c. We shall see that the absorption of oxygen by the blood, which contains salts in solution, is not a physical process; for, instead of taking

* A normal solution ( $N$ solutiun) is made by dissolving the molecular weight in grammes of $\mathrm{NaCl}$ in 1 litre of water. ${ }_{2}^{\mathrm{N}}$ denotes a half normal solution, $2 \mathrm{~N}$ a twicc normal solution, and so on. 
up a lessened amount of oxygen compared with water, it is capable of taking up far more, the absorption of oxygen of blood as a whole not being a purely physical, but mainly a chemical, process. Besides salts, acids, bases, and soluble substances like cane-sugar, have a similar effect in lowering the solubility of gases. Recont study has demonstrated the fact that the relative effect on the solubility of gases of different salts is nearly independent of the gas employed. Therefore the diminisled solvent power of a salt solution as compared to water is mainly determined, not by the nature of the gas, but by some factor in the relationship of the water to the salt. It has also been suggested that the lowered solvent power is due to hydration of the dissolved salt, and thus some of the water is no longer free to absorb the gas.

The process of diffusion is not confined to gases. Solutions exhibit the phenomenon of diffusion. If water be carefully added to a strong blue solution of copper sulphate with as little mixing as possible, a process of diffusion begins which does not cease until the salt concentration is the same throughout the liquid, and the whole liquid coloured blue. Naturally the process takes time, the rate of movement being much less than in the case of gaseous diffusion. By plaeing a graduated tube on top of the vessel the rate of diffusion may be roughly measured (Fig. 13). Just as with a gas, the movement may be regarded as due to the pressure of the dissolved substance; the molecules are said to be driven from a place of high concentration to one of low coneentration under the influence of osmotic pressure.

To measure such pressure it is necessary to have a membrane which will allow free passage to the solvent, but not to the substance; it must be "semi-perme. able," $\mathrm{s}$ it is termed. Then with pure watar on one side of the membrane, and a watery solntion of a substance-e.g., sugar-oll the other, since diffusion of the dissolved substance is barred, the system seeks to get into equilibrium, as far as possible, by water passing through the membrane to the solution. Such a membrane nay be formed by filling a porous vessel of unglazed porcelain, which has been well soaked

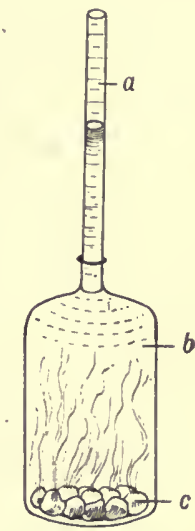

FIG. 13. - To Demonstrate DIFFUSION IN Lieuids.

The flask $b$ and the superimposed greduated tube $a$ are filled with water. Somo erystals of eopper sulphate are introduced. The diffusion of the blue salt ean be seen and the rate measured in the eali. brated tubs. in water, with a solution of copper sulphate ( $2 \cdot 5$ grains yer litre), and introducing it into a solution of potassium ferrosyanide $(2 \cdot 1$ grains per litre). The salts diffuse into the porcelain, and, meeting in the interior, form a filmy deposit of copper ferrocyanide. After standing a considerable time, the rot is taken ont, thoroughly washed, and soaked in water. Or a similar membrane may be formed by taking a glass tube akout 1 centimetre in diameter, one end of which has been dipfer in gelatin to whieh a little potassium dichro- 


\section{A TEXTBOOK OF PHYSIOLOGY}

mate has been added. The gelatin forms a film over the end of the tube, which is allowed to dry in the light. It is then soaked in water to remove the dichromate. Copper sulphate is now placed in the tube, which is then immersed in potassium ferrocyanide. By this means a brown film of copper ferrocyanide becomes deposited in the almost colourless gelatin, and a membrane is obtained which is good for demonstration purposes. The membrane of copper ferrocyanide has becn found to be impermeable to substances such as cane-sugar and dextrose, but permeable to water. It is therefore semi-permeable in regard to water and such substances in soluticn. This can be demonstrated by filling the ressel bearing the membrane with cane-sugar solution, and cementing into it a rubber cork carrying a long glass tube. On immersing the pot in a vessel of water, liquid is seen to rise in the glass tube, and it attains a considerable height if the membrane be sufficiently well made and strong. Eventually the height of the column balances the pressure, which is tending to force the water in, thereby giving a measure of the driving force, which, although opposite to it in direction, is equivalent to the osmotic pressure of the substance in solution.

In the animal and plant world we meet with many such semipermeable membranes. Such a one is that covering peas, beans, or barley grains. If the last be placed in an aqueous solution of sulphuric acid, the water penetrates the grain, which swells in consequence and increases 76 per cent. of its weight. Sulphuric acid does not penetrate, as is shown by the fact that the blue pigment in the aleurone granules inside the grain is not changed red, as it would be if the acid penetrated the grain. When the covering of the grain is broken, the change of colour at once takes placc.

Instead of the acid, a salt such as sodium chloride might be used. The amount of water absorbed by the seeds will then depend upon the concentration of the salt in the water, since there is now competition between the seed and the salt for the water. Thus, the increase of weight of the seeds with a 2 per cent. solution of sodium chloride is about 40 per cent.; with a saturated solution it is but 14 per cent. The phenomenon is, however, not one of osmosis only, the process known as imbibition also comes into play. This comparative impermeability of the outer coat of seeds is recognized by agriculturists; otherwise such poisons as copper sulphate could not be used to destroy fungus spores upon the seeds without killing the seeds themselves.

Much study has been devoted to the phenomena of osmosis. It has already been stated that, if the force of attraction between solvent and solution be measured, the osmotic pressure of the solution is measured at the same time. The exact nature of this force is not yet completely understood, but it has been shown that it is governed by certain fundamental laws closely allied to those already given for gases. Thus, it is found that the osmotic pressure exerted by a given quantity of the dissolved substance is inversely proportional to the volume of the solution (e.g., Boyle's law). In other words, the osmotic pressurc of a solution is proportional to the concentration of the dissolved sub- 
stance. In regard to temperature, it appears to be true, allowing for experimental difficulties, that the osmotic pressure of $a$ solution is proportional to the absolute temperature (e.g., Gay-Lussac's law for gases). Also it is true for dilute solutions (e.g., of surar) that the osmotic pressure is equal to the pressure which the molicular concentration of the substance would exert if it were in the gaseous state at the same temperature, and occupied the same volume as the solution.

If two solutions of different osmotic pressure be separated by a semi-permeable membrane, osmotic exchanga of water will take płace until the pressures are equal on the two sides of the membrane, the water passing from the solution with the smaller osmotic pressure to that with the greater. This can be well shown by the following pretty experiment, the success of which depends upon choosing the right strengths of solution: A little potassium ferrocyanide (nearly saturated) is slowly run from a narrow glass tube the end of which dips below a solution of copper sulphate (a gramme-molecular solution)* contained in a tall glass jar. As the ferrocyanide runs ont, a filmy bag of copper ferrocyanide is formed at the end of the tube. When the bag is about 1 to $2 \mathrm{~cm}$. in diameter, a slight jerk will disengage it, and it will sink slowly to the bottom of the vessel. Its content having a greater osmotic pressure, water will enter the bag and gradually distend it. The density of the bag is this gradually diminished, and eventually becomes less than that of the surrounding copper sulphate solution, when the bag rises spontaneously to the top of the jar. The experiment may be varied by fitting the top of the narrow glass tube, containing the ferrocyanide solution, with a piece of rubber tubing, and pushing a drop of ferrocyanide out by closing this tubing with a clip. When the glass tube is now lowered into the copper sulphate, a hanging membrane is formed at its bottom. Water passes into the ferrocyanide, and the copper sulphate, concentrating in the immediate neighbourhood of the membrane, becomes denser than the rest of the solution and sinks. This can be easily seen by the naked eye, owing to the difference in refractive power of the denser solution. If the experiment be reversed, and dilute ferrosyanide, in a tube with an upturned end, be placed in strong copper sulphate solution, the copper sulphate in the neighbourhood of the membrane is diluted, and a steady ascending stream of the diluted liquid can be seen.

Intcresting experiments on osmosis have been done with plants. For example, in the epidermis of the leaf of the plant Tradcscantia discolor the fluid coloured contents of the cells are normally in close contact with the rigid cell wall, which behaves as a semi-permeablo membrane (Fig. 14, A). If it be immersed in a solution containing 0.22 of a gramme-molecule of cane-sugar per litre, the colourcd contents detach thcmsclves from the wall at one or more places. "Plasmolysis," es it is termed, has taken place (Fig. 14, B). Owing to the withdrawal of water, therc has been a decrease in the bulk of the ccll

* The moleeular weight in grammes dissolved in 1 litre. 
contents. The solution of cane-sugar has therefore a greater osmotic prossure than the cell sap; it is termed a hypertonic solution. If, instead of sugar, another substance, such $\approx s$ potassium nitrate (1 gramme-molecule per litre), be used, the solution formed is so strongly hypertonic that the plasmolysis is very marked (Fig. 14,C).

Plasmolysis may also be readily demonstrated by taking shavings from a beetroot, carefully washing those and immorsing them for a time in 5 per cont. sodium chloridc. The aproarance under the microscope before and after is very characteristic. The red corpuscles of the blood behave in a similar manner. The delicate membrane surrounding the corpuscle is permeable to water, but impermeable to many dissolved substances. In this case, however, there is no rigid coll wall formirg the outer membranc. If, therefore, water passes into such a cell, it will first swell up, and then burst, thus allowing the contained red pigment to escape, a process known as the laking of
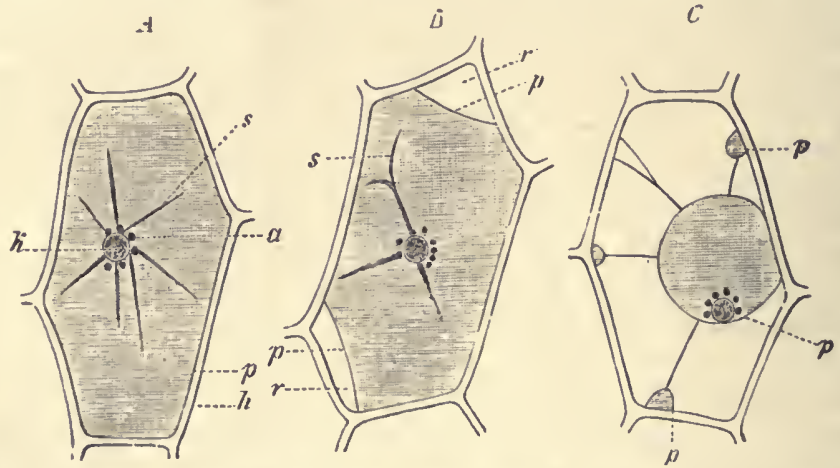

jia. 14.-To show tile Effect of Plasmolysis ix Tradescantia Discolor. (After De Vries.)

$h$, Cell wall; $k$, nucleus; $a$, plastids; $s$, stream lines in protoplasm; $p$, protoplast.

blood, or hremolysis. A solution from which water passes into the corpuscles is known as hypotonic. A solution from which water passes in and out of the corpuscle in equal amounts is known as isotonic. The concentration of sodium chloride required to form a solution isotonic with nearly all mammalian bloods is 0.9 for cent.; a solution of this "concentration is termed "physiological saline" or "physiological salt" solution.

Hypertonic solutions diminish the volume of the corpuscle owing to water passing out of then. It is suggested that this passing out of fluid from living cells as the result of the action of hypertonic solu. tions may affect the activity of such cells. Thus, it is rossible that in many plant cells the formation of starch from sugar only takes. place when the sugar concentration reackes a certain limit. Indeed, it is found that with cells having a sugar concentration short of this limit the formation of starch can be induced by producing plasmolysis with a solution of potassium nitrate; this by withdrawing 
watcr raises the concentration in the cell to the minimum neccssary for starch production.

It has also becn shown that unfertilized eggs of the sea-urchin (Strongylocentrotus purpuratus) may be made to derelop parthenogenetically by the use of hypertonic solutions. The unferti.ized egg of the frog develops if its membrane is pricked with a needle, and its osmotic relation to the surrounding water thus disturbed.

The Mode of Action of a Semi-Permeable Membrane. Since osmosis plays an important part in tho maintenance of cquilibrium between plant and animal cells and their surroundings, it is highly important to know how semi-permeable membranes act. From the study of precipitation membranes, it appears to ke the size of the molecular interstices which enables such a membrane "to differentiate between various substances. It was at first thought to act merely like a sieve, but that is not the sole factor. For oxample, if a glass tubs with a length of rubber tubing and a clemp at the end be filled with carbon dioxide, the rubber then clamped, and the glass tube quickly placed in a vertical position in a beaker of water, the carbon dioxide will gradually diffuse out through the rubber and the water rise in the glass tube (Fig. 15). Rubber is permeable to carbon dioxide but not to oxygen and nitrogen. Further, when methyl alcohol and ether aro separated by a membranc of pig's bladder, th re is an osmotic flow from the alcohol to the ether. If, however, the two fluids be separeted by vulcanized rubber, osmosis takes place in the opposite direction. This is because the pig's bladder absorbs ten times as much alcohol as ether, whereas rubber absorbs one hundred times as much ether as alcohol. Therefore the comparstive permeability or imperm:ability to different substances of a non-living semi-permeable membrene depends, also, on its power to dissolve

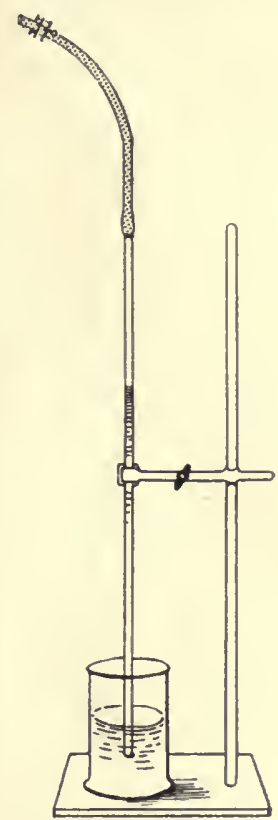

Fia. 15.-To show the Prisciple of The SeMi-PermeABLe MeMbrane.

As earbon dioxide diffuses out through the rubber tube at the top, water rises from the beaker, owing to the inability of air to diffuse in through the rubber. or absorb them. Expcriments on living membranes, made chiefly on plants, tend to skow that it is a selective absorption on the part of the membrane which determines the ability or inability of a substance to enter the cell. The permeable sukstances have keen found by experiment to be generally soluble in fatty oils; the plasmatic membrane of the cells, tlerefore, probably consists of some such substance; indeed, it is claimed that cell walls are rich in lecithin and cholestcrin-toth bodies of a lipoid nature. As evidence of this it is found that the basic aniline dyes, which readily permeate 
the eell, are dissolved by solutions of eholesterin and of lecithin, whereas sulphone dyes, to whieh the cells are impermeable, are but sparingly soluble in these media. This hypothesis of the lipoid nature of cell membranes is widely aeeepted at the present day, but it is not altogether satisfactory, and has been subjected to adverse criticism. It fails, for instance, to explain reasonably why eells are so readily permeable to water. It is also stated that there are dyes readily soluble in these lipoids whieh are quite incapable of penetrating into the living eell; while there are also dyes insoluble in cholesterin whieh readily pass through the plasmatic membrane of the cell. Moreover, certain inorganie salts insoluble in fat penetrate into the cell. The sap in the plant, for instance, supplies salts by some means to the cells.

From a physiological point of view, then, a purely physical theory of permeability is not altogether adequate. The red eorpuscle is rieh in potassium and phosphate, yet the medium (plasma) in whieh it floats is poor in these substanees, but rich in sodium and ehloride, in whieh the corpuscle is poor. Yet, as the cell reeeives its nutriment from the plasma, the membrane of the corpuscle cannot be wholly impermeable to potassium salts. If this be so, their retention in the cell is opposed to osmotie foree. Apparently there is some specific intervention of the membrane or some special affinity of the cell substanee for potassium salts. So, too, in the case of the bodily secretions. We shall see that it is difficult to understand, for instanee, how urea can be passed by purely osmotic agency from the blood, in which it is in weak eoncentration, to the urine, where its concentration is mueh greater. There appears, therefore, to be a physiologieal as well as a physieal permeability of the cell. This is further shown by the following interesting experiments: If tadpoles be immersed in a 5 to 6 per eent. solution of eane-sugar they are unaffected. If they be transferred to an 8 per cent. solution, they shrink, owing to loss of water. But immersion in a solution less than 6 per cent. (hypotonie) is not followed by an intake of water and swelling of the tadpoles, as might be expeeted. Therefore the epithelial membranes of the tadpole are apparently permeable to water in one direetion only. A bag made of toad's lung, if plaeed in efferveseing soda water, rapidly fills with gas and floats. If, however, the lung be turned inside out, it does not fill with gas. The experiment suereeds no less if the lung in each ease is filled with water. Eaeh cell must be regarded as the seat of aetive ehemieal action, where concentrations of dissolied substances are constantly altering. Other phenomena, e.g., jubibition, play an important part.

The direet determination of the osmotic pressure of a solution is a matter of diffieulty. Therefore it is usual to ascertain it by some indireet method-by other properties of solutions quantitatively related to osmosie pressure-such as the lowering of the vapour pressure of the solvent when the dissolved substanee is non-volatile, or the raising of the boiling-point of the solvent. The method, however, most generally employed for physiological solutions is the lowering 
of the freezing-point of the solvent. The extent to which the freezingpoint of a solution is lower than that of the solvent is proportional to the concentration of the dissolved substance.

Determination of the Lowering of the Freezing-Point.--The apparatus generally employed for this purpose is known as Beckmann's (Fig. 16). It consists of a tube, $A$, placed in a jacket, $B$, provided with a special thermometer, $D$, and a platinum or nickel wire stirrer. The jacket $B$ fits into a metal plate which covers a thick glass jar, $C$, also provided with a stirrer. When the experiment is to be made, this jar is filled with a freezing mixture, which will give a temperature about $2 \cdot 3^{\circ}$ below the F.P. of the solvent. A known weight (10-20 c.c.) of the solvent is placed in $A$, and its cork carrying the thermometer and stirrer inserted. The temperature of $A$ is first lowered by placing it in the freezing mixturc; but as the freezing-point is approached it is fitted into the jacket $B$ and stirred regularly, so that a steady fall of temperature is assured. The thermometer is carefully watched; after a time the mercury ceases to fall, then suddenly rises and remains stationary for a moment before starting to fall again. The point risen to gives the F.P. of the solvent for pure water, $0^{\circ} \mathrm{C}$. A known weight (1-2 gms.) of the solute (the body to be dissolved) is now introduced through the side-tube, and after it has dissolved the F.P. is again determined in a similar manner. It is well not to cool too rapidly or too much; the thermometer should not rise more than $0.4^{\circ}$ to $0.5^{\circ} \mathrm{C}$. to its final position, otherwise the operation must be repeated. Excessive supercooling causes the separation of a considerable quantity of the solid solvent when freezing occurs, and this makes an appreciable increase in the concentration of the solution. The freezing-point method has been extensively used in studying the osmotic pressure of the blood in different

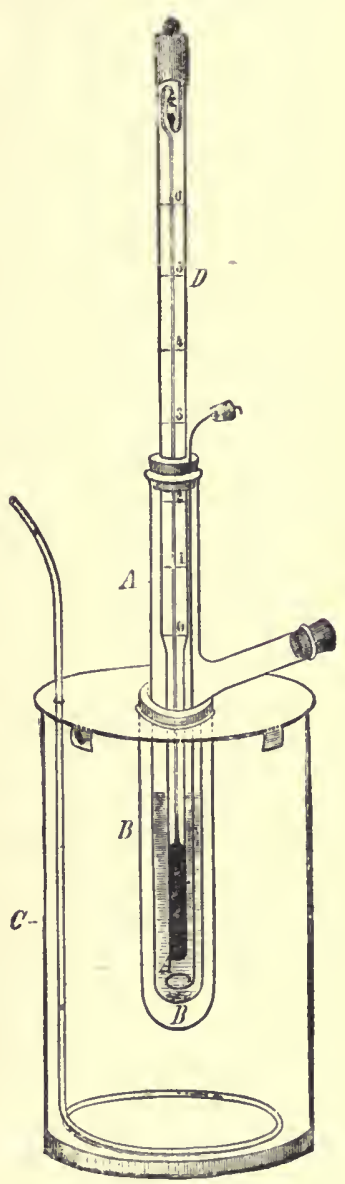

Fig. 16.-BECKMANY's APPARATUS FOR DETERMIN. ING THE DEPRESSION OF Freezing-Point. animals, and also the urine in pathological conditions in man. It has been shown that the F.P. of the body fluids of invertebrate marine animals is the same as that of the water in which they livs; they are incapable of preserving any difference of osmotic pressure; if the osmotic pressure of the water be varied, that of the body fluids varies also. But in the 
ease of many aquatie vertebrates this is not the case, the blood under ordinary conditions has a different osmotie pressure to the medium in which the animal lives, and is but slightly altered by variations in the nredium. This is true, for instanee, of the tcleostean fishes; the blood of the elasmobranehs, on the other hand, varies in osmotic pressure with that of the surrounding sea-water.

It was stated above that the lowering of the osmotie pressure of a solution is proportional to the eoneentration of the dissolved substanee. Although this is true, it is found that there are very many substanees, such as sodium ehloride, for example, which yield, by the method of the lowering of the F.P., a moleeular weight quite ineonsistent with the formulæ aceepted for them. The osmotic activity of these bodies points to an abnormally large number of dissolved units in their solutions. This is explained by the vicw that acids, bases, and salts, in aqueous solution beeome dissoeiated to a greater or less extent into positively and negatively eharged partieles or ions. These ions inerease the number of units present in the solution, and endow it with an enhanced osmotie aetivity. Sodium chloride, for example, when dissolved in water splits to a large extent into positively eharged sodium ions, $\stackrel{\mathrm{Na}}{\mathrm{a}}$, and into negatively eharged ehlorine ions, $\overline{\mathrm{Cl}}$. Hydroehlorie acid splits into $\stackrel{+}{\mathrm{H}}$ and $\overline{\mathrm{C}}$, eaustie potash into $\hat{\mathrm{K}}^{+}$ and $\overline{\mathrm{OH}}$, potassium nitrate into $\stackrel{+}{\mathrm{K}}$ and $\overline{\mathrm{NO}}_{3}$. One molecule, it will be seen, produces but two ions. The "ionie" hypothesis furnishes an adequate explanation of the abnormal osmotie influenee exerted by sueh bodies in aqueous soution. It also explains intelligibly the behaviour of various solutions to the passage of an electric eurrent. It is known that the solutions of the lodies which give an abnormal effeet in lowering the F.P. of water also eonduct an electrie eurrent: they are electrolytes. When two electrodes, one charged positively and the other negatively, are placed in sueh solutions, aecording to this hypothesis an attraetive force is exerted upon the ions of opposite signs. Thus, the positively eharged ions move towards the negative eleetrode, and the negatively eharged to the positive eleetrode; the undiscoeiated ncutral molecules, remaining unaffeeted and cxhibiting no tendeney to move in either dircetion, play no part in the transport of electricity through the solution. The effieieney, therefore, of a given quantity of a salt to eonduet an electrie eurrent depends upon the extent of discociation of that salt. It is found by experiment that the amount of dissoeiation, and therefore the conduetivity, increases as the solutions of the salts become less eoneentrated.

In the body fluids there are some substences in soluticn which are electrolytes, and will thcrefore eonduet elcctrieity; others which are non-eleetrolytes, and will not conduet eleetrieity. The fluids eonduet according to the amount of the electrolytes present. Thus, bloodserum has a eonduetivity of about the same as that of a 0.8 per eent. sodium cliloride solution. When the non-condueting corpuseles 
of the blood are present, as in whipped blood, the conductivity is reduced to about half.

We shall see how various ions are supposed to play important parts in the body functions. For example, the excised muscles rcmain contractilc and the heart beats when bathed with a solution containing a certain concentration of sodium, potassium, and calcium ions. The hydrogen (H) and the hydroxyl $(\mathrm{OH})$ ions also are important. These when combined yield a moleeule of water. The free $\mathrm{H}$ ion in aqueous solution possesses the property of endowing a substance with aeidity-e.g., $\mathrm{HCl}(\stackrel{+}{\mathrm{H}}$ and $\overline{\mathrm{Cl}})$; the $\mathrm{OH}$ ion, on the other hand, gives alkalinitye.g., caustie potash $(\overline{\mathrm{K}}$ and $\overline{\mathrm{OH}})$. Various reactions will only take plaee when a free $\mathrm{H}$ ion is present-for example, the splitting of cane-sugar into dextrose and levulose-and it is found that the rate of this change depends upon the eoncentration of the $\mathrm{H}$ ions. So, too, it is suggested that the free $\mathrm{H}$ ion in the blood plays a part in exeiting the respiratory centre and determining inspiration. The immunizing properties of the blood are closely connected with the eoneentration of $\mathrm{H}$ ions.

Crystalloids and Colloids.-Thus far attention has been paid only to sueh characteristics as the osmotie activity and the conduction of the electric current by various bodies. Another distinetion between substances may now be pointed outthat is, the readiness with whieh they erystallize from water; and those which crystallize readily - e.g., sodium ehloride, sugar-also diff use readily through animal nembranes, and are known as erystalloids. Those which crystallize with difficulty, or not at all, are characterized by low diffusive power or absolute inability to pass

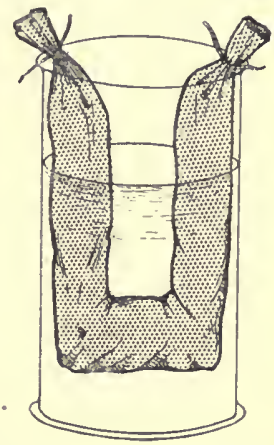

Fict. 17. - To show Dialysis of a CrysTALLOID, BUT NOT uf a Colloid.

The hæmoglobin in the parchment tube does not diffuse out, the chloride does. through animal or vegetable membranes. Sueh bodies are termed colloids, from the gummy nature of many bodies belonging to the group-e.g., gums, starches, etc.

This differenee may be demonstrated by placing a mixture of a colloid and erystalloid in a tube of parehment, and plaeing the tube in distilled water-e.g., a solution containing the red pigment of blood (hremoglobin) and sodium ehloride. The hæmoglobin does not pass through the membrane, and the water outside remains uncoloured. But a test for ehloride shows the presence of this in the water after a short time (Fig. 17).

Some erystalloids arc eleetrolytes and ionize; others are noncleetrolytes and do not ionize: All, however, form true solutions in water. In eontradistinction to the last property of these bodics, we have a group of substances which are quite insoluble in water when in bulk, but whieh, if finely divided by meehanieal means, can be 
suspended in water in such a manner as to be evenly distributed throughout the fluid with but little tendency to settle out or aggrcgate together. Such substances form suspensions or emulsions. They are non-diffusible, refract light, cxert no osmotic pressure, do not conduct electricity, and contain particles visible under the microscope. Between these two extremes comes the group of bodies classed at the present time as colloids, some approaching more nearly the crystalloids, some more nearly the suspensions. But for the most part colloids possess characteristics which clearly differentiate them from crystalloids. These characteristics may be enumerated as follows:

They are generally amorphous in form; some, however, can be made to crystallize under appropriate conditions. Although giving a homogeneous solution when seen beneath the microscope with ordinary illumination, yet if a beam of light be passed through the solution particles become visible, or, rather, halos surrounding these, owing to the dispersion of light waves from the surfaces of the particles suspended in the solution, just the same as a ray of light becomes visible on passing into a dusty room. This is known as "Tyndall's phenomenon." The particles are too small, but the halos surrounding them are large enough, to be seen under the microscope. Since colloids are not far removed from suspensions, relatively slight changes suffice to aggregate the particles and throw them out of solution. If the colloid, thus thrown out, can again be dissolved in the solvent, it is said to be precipitated; often, however, it cannot be redissolved, and it is then said to be coagulated. Agencies which produce aggregation or agglutination are a rise of temperature, and the adding of large quantities of neutral salts, a process known as "salting out."

The suspension of the colloid particles in the solvent depends on the particles carrying an electrical charge and their mutual repulsion. Any factor which reduces this charge tends to aggregate the particles. Colloidal suspensions, like those of colloidal gold, are at once thrown out by the electrical discharge of the particles-labile colloids. In the case of colloidal emulsions there is a relation between the molecules and the solvent, and the particles are less easily thrown out-stabile colloids.

In colloidal solutions the size of the particles, roughly, is between the limits of microscopical vision $(0 \cdot 1 \mu)$ and ultra-microscopical vision $(0.001 \mu)$. Above the limit we have suspensions, and below it we approach the true molecular solutions. The surface of the particles plays a great part in the chemistry of the colloids. The minute subdivision causes an enormous increasc in surface. Supfose a cubic centimetre of gold be subdivided into particles with a side of $0.001 \mu$ the little cubes ( $10^{19}$ in number) would have a total surface of 600 square metres, roughly equal to a surface measuring 25 yards by 25 yards. All surfaces have the power of adsorption-e.g., charcoal adsorbs gases, colouring matters; fire-clay adsorbs coal-gas in such a way that intense incandescence with very perfect combustion is brought about in the surface of the brick when coal-gas is forced through it and lighted; platinum black adsorbs and brings about the 
union of hydrogen and oxygen. The adsorptive power of colloids is very great owing to their fine particulate condition and enormous surface, and this plays a great part in the chemistry and physics of living cells.

Most colloids are held back by very fine filters. Thus, the colloids of blood-plasina can be separated by the use of a porcelain filter candle which has been soaked in a solution of gelatin. The water and salts can be pressed through such a filter. Colloids are indiffusible through animal or vegetable membranes. The membranes themselves are colloids, and, since colloids do not readily dissolve in colloids, it is clear they will diffuse but little through each other. Crystalloids, on the other hand, as we have seen, diffuse readily; they are generally soluble in colloids. This difference in property can be well demonstrated by placing a stick of agar jelly (colloid) in some ammoniated copper sulphate solution (crystalloid), and another in some Prussian blue solution (colloid). It will be found that the blue copper solution penetrates readily, the Prussian blue not at all. Colloids also appear to influence physico-chemical processes but little. Crystalloids will diffuse almost as readily from colloids as from water. So, too, chemical processes take place in colloidal solution almost as if colloids were absent. Advantage is taken of these properties in the body. A crystalloid, when not linked or adsorbed to a colloid, will wander freely and diffuse away from a cell; a colloid will remain where it is formed. Thus, we find that the crystalloid dextrose is converted in the liver into the colloid glycogen for storage purposes, but to escape from the liver cell the glycogen is converted again to the crystalloid dextrose. The osmotic pressure exerted by colloids is very small or nil. It is believed that when absolutely pure and free from traces of crystalloids colloids exert no osmotic pressure. Also they depress the freezing-point of a solution but little. Increasing the amount of egg albumin in water from 14 to 44 per cent. causes but an alteration of freezing-point from $0.02^{\circ}$ to $0.06^{\circ} \mathrm{C}$. Since, also, colloids ionize but little, they conduct electricity but little. On the passage of an electric current through a colloidal solution, however, the particles of most colloidal solutions tend to move in the electric field; cataphoresis, as the phenomenon is termed. This probably depends upon the existence of a high surface tension in colloids. Surface tension may be described as the force with which a fluid strives to reduce its free surface to a minimum. When, therefore, we speak of the lowering of the surface tension of a fluid, we mean that the force tending to reduce its free surface is weakened, so that the frec surface increases. The formation of emulsions is due to such a lowering of the surface tension. Water and oil will not mix, the oil floating on the surface of the water, owing to the high surface tension of the oil. If, however, some soap be added to the water, the big oil drop is seen to break down gradually into a number of smaller.

Imbibition.-Most of the organic colloids exhibit the property of taking up fluid without chemical change. This is the phenomenon of imbibition. For example, dry gelatin brought in contact with 
water swells greatly and becomes a jelly. Imbibition plays a great part in the vital phenomena of cells. Each eell has a normal water content, which, however, may vary within eertain limits according to the tissue. Withdrawal of water below the normal limits impairs the cell processes, which are either suspended for the time being, as in the case of the spores of baeteria, or altogether destroyed. Withdrawal of 15 per cent. of water rapidly from a frog, or of 33 per eent. slowly, stops all its cell aetivities. If, however, the amount of water in a cell rises above its normal upper limit, its activities are also impaired; it becomes water-laden and boggy, or, to use the scientific term, " œdematous." The power of a eell to regulate its water content is largely due to the phenomenon of "imbibition." In this phenomenon, perhaps the electrical charge, and repulsion of the particles, of the colloids of the eells are chiefly concerned, and exert the pull which draws the water into the eell. The process is different from osmosis, since the addition of eertain salts to the colloid, instead of aiding the passage of water, tends to hinder it. Electrolytes, which favour the aggregation of a eolloid, oppose the imbibition of water by it, and vice versa. The eells-e.g., secreting eells of glandsare confined by more or less rigid membranes, and the force of imbibition may be used to do work such as secretion. When a tissue becomes odematous, the normal imbibition power of the tissues is altered; for example, owing to an alteration of the reaction of the tissues in an acid direction, the proteins of the eell exert increased imbibitory power, and thus beeome " odematous" or "water-logged." Thus, the dead eye of an ox placed in faintly acid water becomes tensely swollen. Such swelling is hindered by the addition of sodium eitrate. So, too, if the hind-leg of a frog be ligatured so that the blood-supply is cut off, and the animal plaeed in water, the ligatured hind-limb swells up to three or four times the normal size. If placed in a dry vessel, the limb deereases in size, almost drying up If removed from the body and placed in water, it swells up again to a great size.

The muscles of a frog swell when exposed to a pressure of water over 350 atmospheres, and lose their eontraetile power. This may return if the excess of water is at once dried off. Exposure to sueh pressures kills all terrestrial and shallow-water life, except that of spore-bearing bacteria, by a kind of water coagulation. The baeteria are proteeted by their tough membrane. The deep sea fishes which live at depths of two miles or more must be immune to such waterpressures. 


\section{CHAPTER IV}

\section{THE CHEMICAL COMPOSITION OF THE BODY}

A CONSIDERABLE number of the elements have been detected on analysis of the dead bodies of the various forms of life found on the carth, but the number composing the bodily structure of the higher animals is strikingly few. The chicf of these are carbon $(\mathrm{C})$, hydrogen $(\mathrm{H})$, nitrogen $(\mathrm{N})$, oxygen $(\mathrm{O})$, phosphorus $(\mathrm{P})$, sulphur $(\mathrm{S})$, chlorine $(\mathrm{Cl})$ so sium $(\mathrm{Na})$, potassium $(\mathrm{K})$, calcium $(\mathrm{Ca})$, magnesium $(\mathrm{Mg})$, and iron $(\mathrm{Fe})$. Others, such as iodine, boron, and fluorine, are found in minute traces. The clements contained in the above list occur chiefly in combination; some, however, such as nitrogen and oxygen, are dissolved in the body fluids.

The chief chemical compounds which are obtained on dissociation of the body may be groupcd as (1) water, (2) inorganic compounds, (3) organic compounds.

Water is a constitucnt part of all tissues of the animal body, the water content varying according to the nature and function of the tissue from 50 to 90 per cent. The chief exceptions are the enamel and cement of the teeth, which contain $0 \cdot 2$ per ccnt. and 10 per cent. respectively. Adipose tissue contains 29 to 30 per cent. watcr, the brain 90 per cent., skin 72 per cent., muscles 76 per cent., lungs 79 per cent., heart 79.5 per cent., and the lens of the eye 98.7 per cent. The percentage in the body fluids ranges from 79 per cent. in blood to 99.5 per cent. in sweat and saliva.

Inorganic Compounds.-These are chlorides, phosphates, carbonatcs, and sulphates. The chlorides are found chiefly as sodium chloride. This salt may be extracted from all tissues and fluids. IIore rarely found are the chlorides of potassium and «mmonium.

The phosphates are also widely distributed, calcium and magnesium phosphatc oscurring particularly in bone, of which the ash contains respectively 85 to 90 of the former and 1.5 to .1 .9 per cent. of the latter sal $:$. Soluble phosphates are also found in nearly all the tissues and body fluids.

The soluble carbonates and bicarbonates of the alkalies, sodium and potassium, occur chiefly in the body fluids, helping to confer upon these a slightly alkaline reaction to litmus. Insoluble carbonates occur in bone. 
The sulphates do not occur in any large quantity, but the alkaline sulphates are regular constituents of the chief body fluids.

A littlc fluorine occurs combined as calcium fluoride in the teeth and bones.

Among the inorganic bodies must also be classed hydrochloric acid, which occurs in the secretion of the stomach, and carbon dioxide, present in the blood and body fluids as well as in the expired air.

Organic Compounds. - These are compounds of carbon with hydrogen, oxygen, and in some cases nitrogen. Phosphorus, sulphur, iron, chlorine, iodine, may also enter into the composition of the various organic compounds, of which there are three chief groups, proteins, fats and lipoids, and carbohydrates. In addition there are the products of the breaking down of these hodies within the organism.

The carbon atom is tetravalent-that is to say, it can combine with four atoms of another element (for example, hydrogen) to form such a body as $\mathrm{CH}_{4}$, which is methane, or marsh-gas. Another fundamental property of the carbon atom is that it can unite with other carbon atoms to form a chain or a ring, thus giving rise to the possibility of a large number of very complicated bodics, the molecules of which are united together through the carbon atoms contained in them. There are also rings composed of carbon and litrogen.

1. Starting from methane, $\mathrm{CH}_{4}$, by the addition of one atom of oxygell,

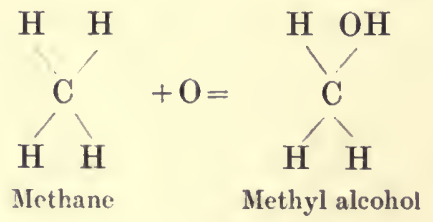

we obtain an alcohol, methyl alcohol, $\mathrm{HCH}_{2} \mathrm{OH}$, which, as it contains the group $\mathrm{CH}_{2} \mathrm{OH}$, is termed a primary alcohol. If we start from propane, $\mathrm{CH}_{3} \mathrm{CH}_{2} \mathrm{CH}_{3}$, the compound two above methane in the chain,
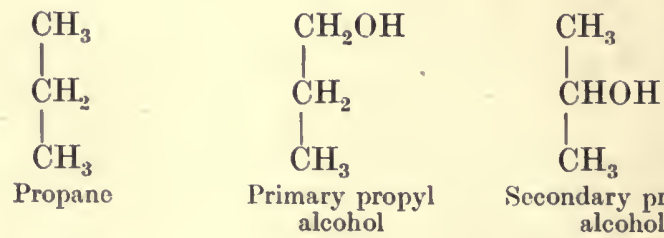

Secondary propyl
alcohol

the formula show that it is possible to obtain two monatomic alcohols (alcohols containing onc $\mathrm{OH}$ group): one the primary alcohol (primary propyl alcohol, as it is termed), containing the group $\mathrm{CH}_{2} \mathrm{OH}$; the other with the group $\mathrm{CHOH}$ characteristic of a so-called secondary alcohol-secondary propyl alcohol. 
But it is possible to obtain (if the carbon chain be long enough) diatomic, triatomic, hexatomic alcohols. For example, from propane:

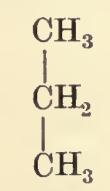

Propane

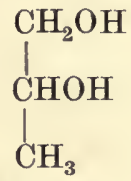

A diatomic alcohol
$\mathrm{CH}_{2} \mathrm{OH}$<smiles>CC(O)O</smiles><smiles>CCO</smiles>

Triatomic alcohol

(glycerine!

2. If, instead of one atom of oxygen, two atoms are linked on to methane,
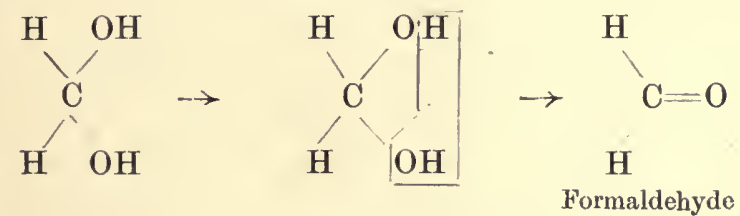

water splits off, leaving a body containing the group $=\mathrm{CO}$ which is designated as the carbonyl group.

Thus, from propane it is possible to obtain by oxidation:

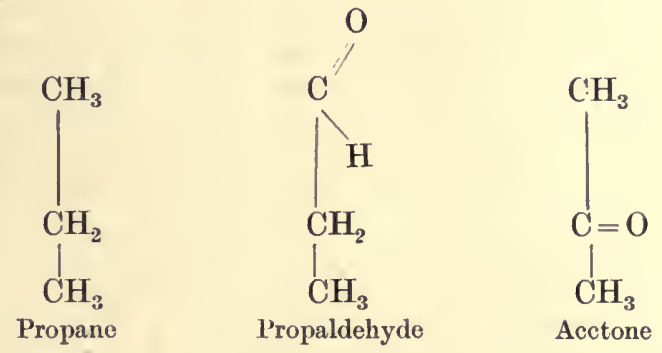

Bodies containing the characteristic grouping $\mathrm{CHO}$ are known as aldehydes; those with the grouping $\mathrm{C}=\mathrm{O}$ are termed ketones. Generally aldehydes and ketones are obtained by oxidation of alcohols, primary alcohols yielding aldehydes, secondary alcohols yiclding ketones.

Thus:

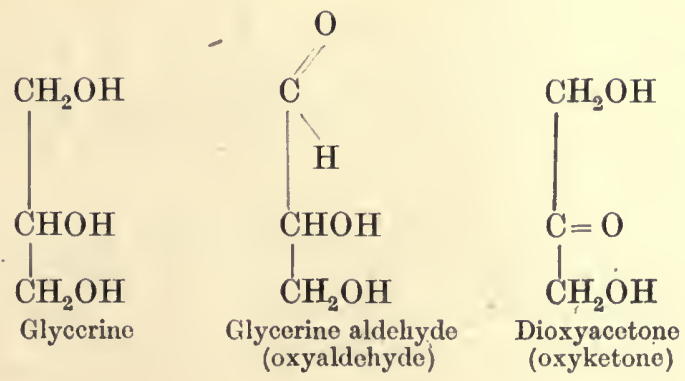


3. If three moleeules of oxygen be introdueed into methane, water again splits off:<smiles>O=C(O)C(O)C(O)CO</smiles>

or H.COOH

Formic acid

A body containing the characteristic group $\mathrm{COOH}$ is obtained. This is called the carboxyl group; its possession confers aeid properties upon the bodies containing it. From ethane, ${\underset{\mathrm{CH}}{3}}_{3}^{\mathrm{CH}_{3}}$ it is possible to obtain either one or two carboxyl groups by oxidation:<smiles>CCCC</smiles>

Ethane<smiles>CC(=O)O</smiles>

Acctic acid (a monocarboxylic acid)<smiles>O=C(O)C(=O)O</smiles>

Oxalic acid (a dicarboxylic acid)

A body containing one $\mathrm{COOH}$, such as acetic acid above, is known as a monocarboxylic aeid; a body eontaining two sueh groups, like oxalie acid, is known as a dicarboxylic aeid. In general acids are obtained by the oxidation of alcohols, aldehydes, ketones:

$$
\begin{aligned}
& \mathrm{CH}_{3} \cdot \mathrm{CH}_{2} \cdot \mathrm{OH}+\mathrm{O}_{2}=\mathrm{CH}_{3} \cdot \mathrm{COOH}+\mathrm{H}_{2} \mathrm{O} \\
& \text { Ethyl alcohol Acetic acid } \\
& 2 \mathrm{CH}_{3} \cdot \mathrm{CH}_{2} \cdot \mathrm{CHO}+\mathrm{O}_{2}=2 \mathrm{CH}_{3} \cdot \mathrm{CH}_{2} \cdot \mathrm{COOH} \\
& \text { Propaldchyde .. Propionic acid } \\
& \mathrm{CH}_{3} \cdot \mathrm{CO} \cdot \mathrm{CH}_{3}+2 \mathrm{O}_{2}=\mathrm{CH}_{3} \mathrm{COOH}+\mathrm{CO}_{2}+\mathrm{H}_{2} \mathrm{O} \\
& \text { Acctone }
\end{aligned}
$$

In the group of bodies known as amino-acids, one of the valcncics of the carbon atom is satisficd by the amino group $\mathrm{NH}_{2}$, instearl of with hydrogen:

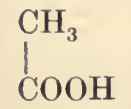

Acctic acid

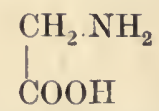

Monamino-acetic acid (glycin)

Just as there exist many acids of whieh acetic aeid is the first of the chain, so there exist many amino-acids of which glyein is the simplest. By introdueing two amino groups into the aeid molceule, bodies known as diamino-aeids are obtained.

4. If four moleeules of oxygen be introdueed into methane, two 
molecules of water split off, leaving carbon dioxide, $\mathrm{CO}_{2}$, the end product of oxidation of carbon compounds in the body.

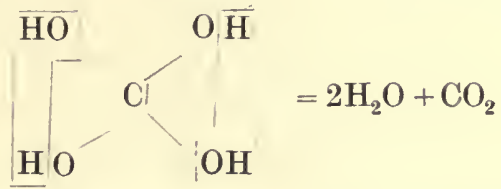

The tendency of the carbon molecule to form rings has been mentioned; the chief of these is the so-called benzene or carbocyclic ring, which is represented as six carbon atoms linked together thus:
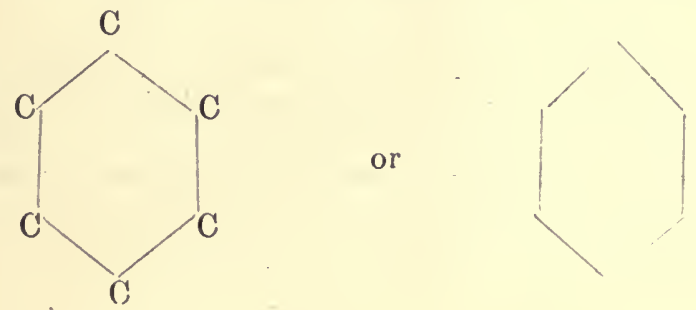

Benzene itself is $\mathrm{C}_{6} \mathrm{H}_{6}$, an atom of hydrogen being linked on to each carbon atom. Starting from benzene, it is possible to obtain a large number of compounds, so-called aromatic compounds, a few of which, such as phenylalanin and tyrosin, enter into the construction of some of the body compounds.

Or carbon may be linked with nitrogen to form a ring thus:

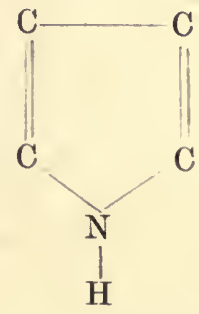

or

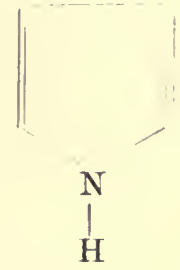

Four carbon atoms linked to $a n=\mathrm{NH}$ or imino group give the pyrrhol ring.

In other bodies the benzene and pyrrhol rings are found combined together, yielding a compound ring found in such bodies as tryptophan, indol, and skatol. The ring may be represented thus:

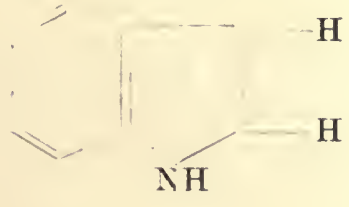


A combination of four carbon atoms with two nitrogen atoms yields a ring known as the pyrimidin ring:<smiles>[H][Y]1=[14CH][14CH]=[14CH][V][CH]1</smiles>

Another ring which occurs is-<smiles>[Hg]O[C+]1C=CN1</smiles>

known as the iminazol ring. This is found in the body histidin.

A combination of the pyrimidin with the iminazol ring yields the important nuclcus or ring known as the purin ring. The different positions in this nucleus have been numbered, and it may be represented thus:

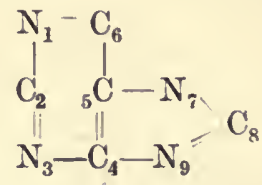

Each of these rings will be referred to when dealing with comrounds or groups of bodies containing them. 


\section{CHAPTER V}

\section{THE PROTEINS}

\section{SECTION I.}

THE protcins form a group which is to be regarded as the most important of all organic compounds. They are obtained from all dead eells, and are intimately connected with the life of the cell, for without them as foodstuffs the cells cannot live. They arc bodies of biological origin; so far no effort to make them in the laboratory has been successful. Most of the members of this group are amorphous bodies of high molecular weight. The protein molecule is made up of the elements carboin, hydrogen, nitrogen, oxygen, and sulphur. The amounts of these elements vary considerably in different proteins, as ean be seen from the following table:

$$
\begin{array}{llllll}
\text { Pro'ein. } & \text { C. } & \text { H. } & \text { N. } & \text { O. } & S .
\end{array}
$$

\begin{tabular}{|c|c|c|c|c|c|c|c|c|}
\hline ogen & $52 \cdot 93$ & . & $6 \cdot 90$ & .. & $16 \cdot 66$ & .. & $22 \cdot 06$ & \\
\hline Jum & & & & & & & & \\
\hline Serum globulin & $52 \cdot 71$ & . & $7 \cdot 0$ & & $15 \cdot 85$ & • & 23 & \\
\hline Keratin .. & $50 \cdot 65$ & . & $6 \cdot$ & & $17 \cdot 14$ & & $20 \cdot 85$ & \\
\hline $\begin{array}{l}\text { Elastin } \\
\text { Gelatin }\end{array}$ & $54 \cdot 32$ & & $6 \cdot 9$ & & $16 \cdot 75$ & .. & $21 \cdot 94$ & \\
\hline
\end{tabular}

The nitrogen and the sulphur are usually combined in two waysloosely and firmly. The loosely combined portions of nitrogen can be split off from the molecule, as ammonia, by heating with caustic alkali. The loosely combined sulphur may be demonstrated by heating with basic lead acetate and alkali when the black coloration due to formation of lead sulphide occurs. All proteins when heated give a smell of burnt feathers, due to the evolution of ammonia, pyridine, and other bodics.

\section{The Constitution of Protein.}

The constitution of protcin is exceedingly complex. The calculated formulæ for some protcins are as follows:

$\begin{array}{lllllllllll}\text { Egg albumin } & \ldots & \mathbf{C}_{239} & \ldots & \mathrm{H}_{386} & \ldots & \mathbf{N}_{58} & \ldots & \mathrm{O}_{78} & \ldots & \mathbf{S}_{2} \\ \text { Serum albumin } & \ldots & \mathrm{C}_{450} & \ldots & \mathbf{H}_{720} & \ldots & \mathbf{N}_{116} & \ldots & \mathrm{O}_{140} & \ldots & \mathbf{S}_{2} \\ \text { Hæmoglobin (horse) } & \mathrm{C}_{380} & \ldots & \mathbf{H}_{1098} & \ldots & \mathbf{N}_{210} & \ldots & \mathrm{O}_{241} & \ldots & \mathbf{S}_{2} \\ \text { Hæmoglohin (dog) } & \mathbf{C}_{725} & \ldots & \mathbf{H}_{1171} & \ldots & \mathbf{N}_{191} & \ldots & \mathbf{O}_{214} & \ldots & \mathbf{S}_{2}\end{array}$

This complex constitution has been recently studied in two ways: (1) by working out the products of the breaking down (the hydrolysis) of different proteins; (2) by cndcavouring to link together simple cleavage products, and thereby produce some form of protein. 
In the process of hydrolysis, water at first enters into the molecule, which then brcaks into smaller molecules. The first products are known as proteoses, the noxt as peptones, both of which groups retain many protein characters. The peptones arc further split into groups of amino-acids known as polypeptides, and finally these groups are broken down into the individual amino-acids-organic acids in which an atom of hydrogen has been replaced by an $\mathrm{NH}_{2}$ group.

The chicf products formed as the result of protein hydrolysis may be grouped as follows:

Grovp I.-Monamino-acids (containing onc $\mathrm{NH}_{2}$ group):

(a) Monocarboxylic (containing one $\mathrm{COOH}$ group), the chief of these being glycin, alanin, scrin, valin, leucin.

(b) Dicarboxylic (containing two $\mathrm{COOH}$ groups), the chief being aspartic acid and glutaminic acid.

Group II.- " Ringed " amino-acids, containing-

(a) The benzene ring, such as phenyl alanin, tyrosin.

(b) Heterocyclic rings, such as proline, oxyprolinc, tryp,tophan, and histidin.

Grour III.-Diamino-acids (containing two $\mathrm{NH}_{2}$ groups).

In this group are contained the two "hexone bases." lysin, arginin.

With these eystin, a sulphurized diamino-acid, may be classed. Other constituents arc:

(a) Pyrimidin bases, cytosin, thymin, and uracil.

(b) Purin bases, adenin and guanin.

The chief of these bodies will now bc considered in a little more detail.

Glycin is a monamino-acetic acid, $\mathrm{CH}_{2} \mathrm{NH}_{2} \mathrm{COOH}$. Hippuric acid is its benzoyl compound $\mathrm{C}_{6} \mathrm{H}_{5} \mathrm{CO} \cdot \mathrm{NH}^{2} \mathrm{CH}_{2}{ }_{2} \mathrm{COOH}$. Glycin is also compounded with cholalic acid, and forms sodium glycocholate, one of the salts of the bile.

Alanin is the amino-acid of the next acid atove acctic, namcly, propionic, $\mathrm{C}_{2} \mathrm{H}_{5} \mathrm{COOH}$. Its formula, therefore, is $\mathrm{C}_{2 .} \mathrm{H}_{4} \mathrm{NH}_{2} \cdot \mathrm{COOH}$ ( $\delta$-amino-propionic acid).

Serin is oxy-alanin (oxy-amino-propionic acid), $\mathrm{CH}_{2} \mathrm{OH} . \mathrm{CH}$. $\mathrm{NHCOOH}$.

Valin is amino-valerianic acid,

$$
\mathrm{CH}_{3}>\mathrm{CH}_{2} \mathrm{CH} . \mathrm{NH}_{2} \mathrm{COOH} \text {. }
$$

Ieucin, $\mathrm{C}_{5} \mathrm{H}_{10} \mathrm{NH}_{2} \cdot \mathrm{COOH}$, is the a-amino-acid of caproic acid, $\mathrm{C}_{5} \mathrm{H}_{11} \mathrm{COOH}$. It crystallizes readily as spherulcs, is widespread, and present normally in the pancreas, thymus, thyroid, spleen, brain, liver, kidneys, and salivary glands. 
Aspartic acid, $\mathrm{C}_{2} \mathrm{H}_{3} \mathrm{NH}_{2}(\mathrm{COOH})_{2}$, is amino-succinic acid:

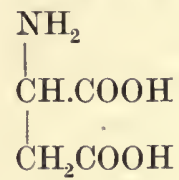

It is not present in large amounts among the protein produtets of decomposition. Asparagin, the amide of..this aeid, however, is very widely distributed in the vegetable kingdom.

Glutaminic acid, $\mathrm{C}_{3} \mathrm{H}_{5} \mathrm{NH}_{2}(\mathrm{COOH})_{2}$, is amino-glutaminic acid:

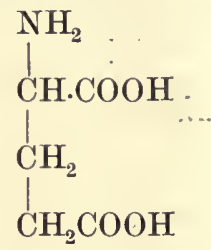

is especially abundant in the proteins of seeds, although it occurs in all the proteins yet examined, with the exeeption of protamines.

Phenyl alanin is alanin in which a further atom of hydrogen has been replaeed by the phenyl group $\left(\mathrm{C}_{6} \mathrm{H}_{5}\right)$. Its formula, therefore, is $\mathrm{C}_{2} \mathrm{H}_{3} \cdot \mathrm{CH} \cdot \mathrm{NH}_{2} \cdot \mathrm{COOH}$ (phenyl-a-amino-propionic acid), or more graphically:

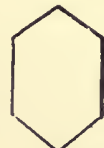

$\mathrm{CH}_{2} \mathrm{CH} . \mathrm{NH}_{2} \mathrm{COOH}$

Tyrosin eontains instead of the phenyl group the oxyphenyl group $\mathrm{C}_{6} \mathrm{H}_{4} \mathrm{OH}$. 'It is $p$-oxyphenyl-a-amino-propionic acid. $\mathrm{C}_{2} \mathrm{H}_{3}\left(\mathrm{C}_{6} \mathrm{H}_{1} \mathrm{OH}\right) \mathrm{NH}_{2} \mathrm{COOO}$, or graphieally:

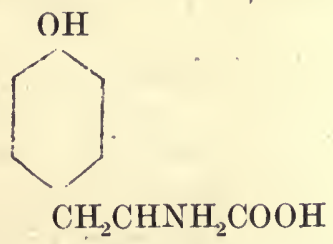

It ${ }^{*}$ crystallizes easily in fine needles, and with leucin was the first product of protein hydrolysis isolated. Millon's reaction is due to its presence.

Adrenalin, the active substanee of the suprarenal gland, has the formula

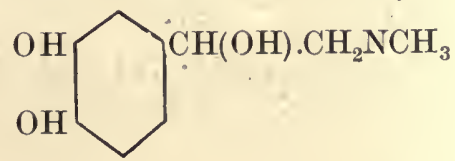


and is supposed to have its origin from tyrosin. Animal pigments such as melanin are formed from tyrosin by the action of a ferment, tyrosinase. Kresol and phenol are formed out of phenyl alanin and tyrosin in the eolon by bactcrial decomposition, and are excreted as "ethereal sulphates" in the urine.

Tryptophan, $\mathrm{C}_{11} \mathrm{H}_{12} \mathrm{~N}_{2} \mathrm{O}_{2}$, is $l$-indol-amino-propionic acid; it con tains a heterocyelie ring formed of the fusion of the benzene and pyrrhol rings. Its formula is--

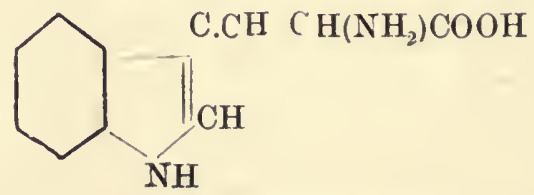

It is the mother-substance of indol and skatol. It is responsible for the glyoxylie reaction (see later).

Prolin is $l$-a-pyrrolidin earboxylic acid, $\mathrm{C}_{5} \mathrm{H}_{9} \mathrm{NO}_{2}$, or graphically:

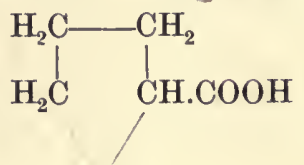

NH

It has been found in both animal and vegetable protcins.

oxyproline is oxy-pyrrolidin carboxylic acid, and was first obtained by the hydrolysis of easein and gelatin.

Arginin, lysin, and histidin, each eontain six molecules of earbon, and being of a basie nature, were formerly elassified together as the "hexone bases."

Lysin is a-diamino-eaproic acid; leuein is monamino-eaproie acid.

$$
\text { The formula of lysin is } \mathrm{CH}_{2}\left(\mathrm{NH}_{2}\right) \cdot\left(\mathrm{CH}_{2}\right)_{3} \mathrm{CH}<\underset{\mathrm{COOH}}{\mathrm{NH}}
$$

By putrefaction of lysin pentamethylendiamin (cadaverin) is produced, while tetramethylendianin (putrescin) is formed from ornithin.

Arginin is a guanidine derivative of ornithin, which is $a-\delta$-diamino-valerianic aeid, $\mathrm{C}_{4} \mathrm{H}_{7}\left(\mathrm{NH}_{2}\right)_{2} \mathrm{COOH}$. It has basic propertics, and reacts strongly to litmus. Its formula is-

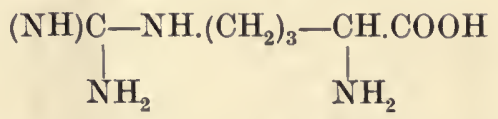

Histidin is not a true diamino-acid; it is a diazine derivative. It is amino-imidazol-propionic acid, and has the formula 


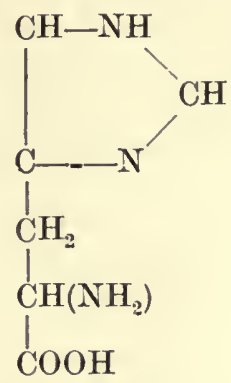

From the fact that these three bodies (especially arg nin) occur largely in the simplest proteins known (protamines), and appear to be among the very last bodies split off by hydrolysis from more complcx proteins, it has been thought that they form the central nucleus of protein.

Cystin is notable for the amount of sulphur which it contains. It is di-amino-di-thio-lactylic acid:

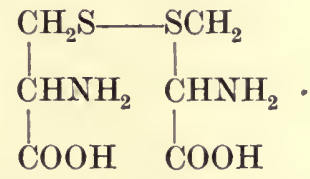

It is found largely in the keratin of hair, horn, nails, and hoofs. It crystallizes in colourless hexagonal plates.

The pyrimidin and purin bases are obtained chiefly from the group of protcins known as nucleoproteins, and are more fully discussed later

When protein is subjected to hydrolysis by the digestive juices, it is partly converted by the action of the acid or alkali present into a derivative of protein known as metaprotein. A considerable amount of ammonia is also split off. The hydrolysis of protcin may be represented as follows:

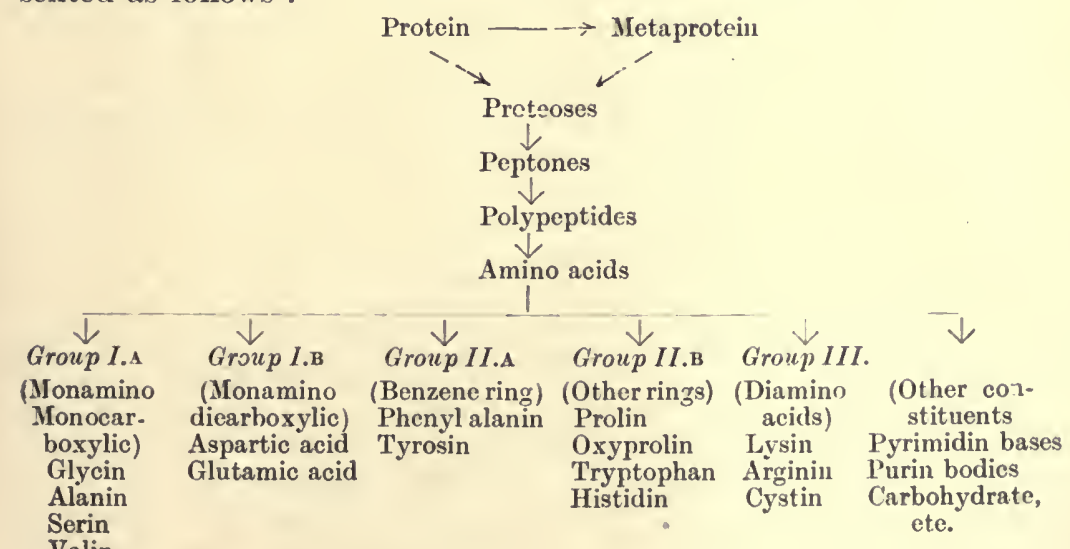

Valin

Lsuein 
In the following table will be seen the varying yields of the different a mino acids obtained from 100 parts of various protcins, after complete hydrolysis with hydrochloric or sulphuric acid. Tyrosin and cystin are separated by crystallization, after neutralizing and concentrating the liquid. The diamino acids-arginin, lysin, and the allied body histidin-are separated from the rest of the products by being precipitated by phosphotungstic acid in acid solution. Tryptophan is separated by precipitation by mercuric sulphate in the presence of 5 per cent. sulphuric acid after tryptic digestion. The other amino acids are separatcd after hydrolysis of protein by hydrochloric acid by fiactional distillation of their ethereal salts under greatly reduced pressure. It will be noticed that the figures given do not by any means add up to 100 per cent. This is due to the occurrence of some incvitable loss in the method of separation, and to the fact that, doubtless, all the components of protein have not yet been isolated.

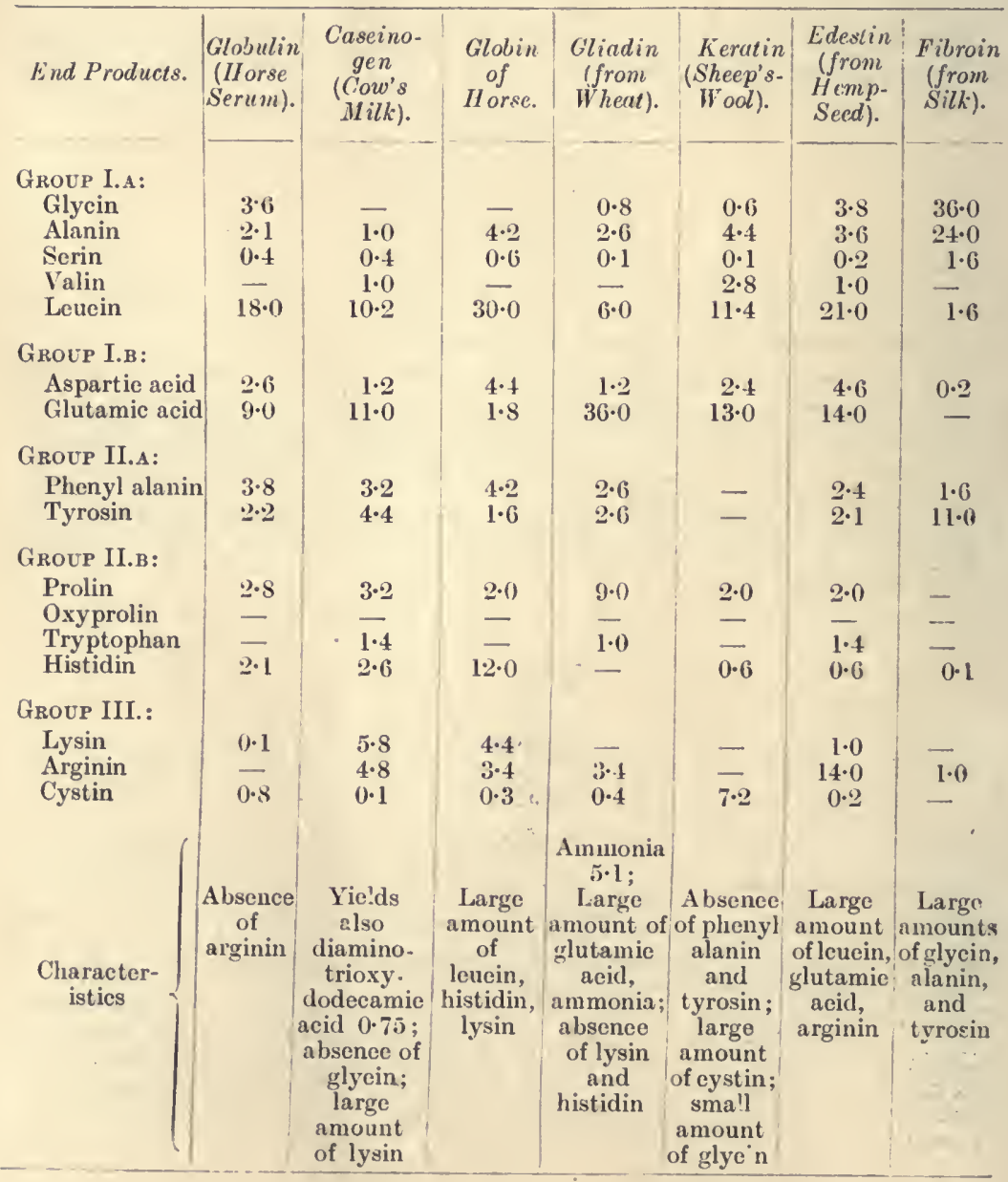


As a result of this hydrolytic method of procedure, we now know that the proteins differ greatly in composition; for example, the protein of the spleen is different from that of the thymus or of the pancreas. Further, the protein of the same tissue differs in animals of different species-e.g., the serum albumin of the blood of one animal has a different constitution to the serum albumin of an animal of another species; the same is true of the chief protein (caseinogen) of milk. We can understand, therefore, why it is that the proteins of the food have to be broken down into such numerous end products in the digestive tract; of these end products those are selected which are of value in building up the animal's own particular forms of protein, forms which differ in various parts of the body and differ from the protein ingested. It is only by a very complete hydrolysis that the particular valuable end products can be obtained free from products of lesser value (see also under Digestion).

The results of the second procedure, the synthetic, have becn highly interesting. Starting with a simple end product such as glycin, two of its molecules have been combined together, forming a dipeptide, glycyl-glycin, with the elimination of water, thus:

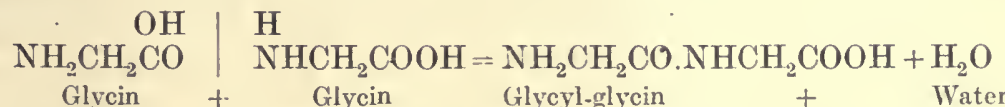

The addition of another molecule forms a tripeptide, and so on until polypeptides are formed. Penta-glycl-glycin, for example, is-

\section{$\mathrm{NH}_{2} \mathrm{CH}_{2} \mathrm{CO}\left(\mathrm{NHCH}_{2} \mathrm{CO}\right)_{4} \mathrm{NHCH}_{2} \mathrm{COOH}$}

Not only has glycin been combined with glycin; other end products, such as alanin, leucin, tyrosin, have been combined together. An example of such is the polypeptide (do-dekapeptide) lcucyl-dekaglycyl-glyein :

$$
\begin{array}{c|c|c}
\mathrm{C}_{4} \mathrm{H}_{9} \mathrm{CH}\left(\mathrm{NH}_{2}\right) \mathrm{CO} \\
\text { Leucyl }
\end{array}\left|\begin{array}{c}
\left(\mathrm{NHCH}_{2} \mathrm{CO}\right)_{10} \\
\text { Glycyl }
\end{array}\right| \begin{gathered}
\mathrm{NHCH}_{2} \mathrm{COOH} \\
\text { Glycin }
\end{gathered}
$$

By many such operations polypeptides have been obtained, which, if not actually having the same composition, have many resemblances to peptones.

\section{Section II.}

\section{The Physical and Chemical Properties of Proteins.}

The proteins possess certain wcll-marked physical and chemical properties.

1. All proteins, with the exception of a few vegetablc proteins, arc insoluble in alcohol and ether. They vary as to their solubility in water, the more common proteins (albumins and globulins) being either soluble in water (albumins) or soluble in weak saline solutions (globulins). 
2. The solution given by them, however, is colloidal, and therefore will not diffuse through animal membranes or parchment paper. In this they are unlike crystalloids, such as inorganic salts, which readily diffuse through snch membranes.

3. Most of the so-called native proteins (albumins and globulins) coagulate when their solutions are heated, different proteins coagulating at different temperatures, varying usually from $56^{\circ} \mathrm{C}$. to $78^{\circ} \mathrm{C}$. A faint degrec of acidity and the presence of much neutral salt aids this process.

Heat coagulation is probably brought about first by the interaction of protcin and water : a hydrolytic product, metaprotein, is produced (denaturation); secondly by aggiutination and separation. A certain increase of acidity or alkalinity favours denaturation, but opposes agglutination. The rcverse is true for neutral salts.

Protein does not form a true solution: its particles are suspended in the solvent, and carry an elcctrical charge. Any factor which reduces this charge tends to bring about agglutination, either precipitation, which is reversible on dialyzing away the reagent, or coagulation. The particles are no longer electrically repelled, and run together under the influence of gravity. In the case of proteins, which have amphoteric properties, the charge of the particle is positive when the fluid is acid, and negative when the fluid is alkaline. When a neutral salt is added, the agglutinating ion is that which carries a charge opposite in sign to that of the particle. The agglutinating power increases with the valency. Thus an acid solution of protein is precipitated by negative ions, for the particles of protein have positive charges; the potassium salt of citrie acid (trivalent) is much more effective than the potassium salt of sulphuric acid (divalent), and this more than the potassium salt of hydrochloric acid (univalent). An alkaline solution of protein is agglutinated by positive ions; ccrium chloride (trivalent) is more efficient than barium chloride (divalent), and this more than sodium chloride (monovalent).

4. Most proteins are uncrystallizable. Some proteins, however, can be fairly easily crystallized, especially certain vegetable proteins, such as those of hemp-seed (edestin) or of the Brazil nut (cxcelsin).

5. Almost all proteins turn polarized light to the left. Hæmoglobin is an exception.

6. Certain well-marked colour reactions are given by the majority of proteins, all of which give valuable information as to the constitution of the protein molecule. One such reaction-namely, tr.e biuret-is characteristic; a body that does not give this is not classed as a protein. The most important of these reactions are-

(a) The biuret. A violet or rose-pink colour with copper sulphate and caustic potash denotes the presence of two or more $\mathrm{CO}-\mathrm{NH}-$ linkages. All proteins give this reaction.

(b) The xanthoproteic. With nitric acid a white eurd turning yellow on heating, and orange on addition of ammonia, denotes the presence of the benzenc ring in the protein molecule. Proteins yielding the ringed amino-acids give this reaction.

(c) Millon's-with a mixture of mercuric and mercurous nitrates, a white precipitate turning brick red on heating - signifies the presence of a benzene ring with an hydroxyl group attached-in other words, the phenolic group. Proteins containing tyrosin give this test.

(d) Hopkins's modification of Adamkicwicz's reaction.

The reaction signifies the presence of tryptophan in the protein moleculc. Acetic acid, containing glyoxylic acid as an impurity, is 
added to protein, and then a little strong sulphuric acid carefully; a violet ring is developed at the junction of the fluids.

(e) Proteins containing a carbohydrate moiety yield Molisch's test. A purple colour over green is developed when $a$-naphthol and sulphuric acid are added to the protein.

(f) Proteins containing loosely combined sulphur yield with lead acetate and caustic alkali a black precipitate of lead sulphide.

(g) Many protcins are precipitated ("salted out ") from solution by the addition of neutral salts, such as ammonium sulphate, magnesium sulphate, sodium chloride, in varying concentrations. Such precipitates are again soluble in the original solvents.

(h) Proteins are coagulated-that is, thrown down as a precipitate no longer soluble in the original solvent-by mechanical agitation, addition of the salts of heavy metals, mineral acids and many other acids, such as tannic, picric, etc.

All proteins do not necessarily give all the above reactions. It is perhaps somewhat difficult to definc a protein. Most of them may be defined as bodies of biological origin insoluble in alcohol and giving the biuret test. (All these properties should be studied in connection with the experiments given in Practical Physiology).

\section{Section III.}

\section{The Classification of Proteins.}

The following classification has been adopted; it is based partly upon the results of chemical investigation, and partly upon such physical properties as solubility, salting out, etc. It cannot be regarded as complete.

1. Protamines.

2. Histones.

3. Albumins.

4. Globulins.

5. Phosphoproteins.

6. Scleroproteins.

7. Compound proteins.

The protamines are held to be the simplest proteins known. They occur combincd with nucleic acid in the spermatozoa of certain fishes such as the salmon, sturgeon, mackerel, and herring. Sturin, from the sturgeon, has the formula $\mathrm{C}_{36} \mathrm{H}_{69} \mathrm{~N}_{19} \mathrm{O}_{7}$; salmill (salmon) and clupein (hcrring) have the formula $\mathrm{C}_{30} \mathrm{H}_{57} \mathrm{~N}_{17} \mathrm{O}_{6}$. They are difficult to obtain in a state of purity. Upon hydrolysis they yield large amounts of the hexone bascs, arginin, lysin, and histidin, especially arginin.

The histones occur mainly in combination. They are more complex than the protamines, and are coagulable by heat, soluble in dilute acid, and precipitated from watery solution by ammonia. The best known is globin split off from the hæmoglobin of the blood. 
The albumins, of which scrum albumin, lactalbumin, and cgg albumin, arc examples, are soluble in distilled water and in saline, but not in saturated solutions of ammonium sulphats and anhydrous sodium sulphate.

The globulins, on the other hand, are insoluble in distilled water and in saturated solutions of all neutral salts. Furthermore, they arc insoluble in half-saturated solutions of ammonium sulphate and anhydrous sodium sulphate. They arc soluble in weak saline solutions. The most important are serum globulins, egg globulin, the myosinogen of muscle, and the fibrinogen of blood.

The phosphoproteins derive their name from the large amount of phosphorus which they contain. Phosphorus is easily split off by prolonged treatment with 1 per cent. caustic soda at $37^{\circ} \mathrm{C}$, a fact which distinguishes the phosphoproteins from nucleoprotcins. They differ, too, from the latter in containing no purin bodies. They resemble the globulins in many of their properties, but they are not coagulable by heat. The chief members of the groups arc the caseinogen of milk and the vitellin of egg yolk.

The scleroproteins comprisc a heterogeneous group of proteins formerly known as the albuminoids. They are obtained mainly from the " hard" or supporting structures of the body. Among, the better known are collagen, from white fibrous tissue, and its hydride gelatin. Gelatin is remarkable in yielding little or no aromatic bodies on dccomposition. Keratin, charactoriz d by containing a large amount of sulphur, occurs in the skin and its appendages, such as hair and horn. Elastin is found in elastic tissuc, ossein in bone.

The compound proteins consist of proteins to which-groups other than protein are united to form a complex molecule. The groups usually classified are-(1) chromoproteins, (2) glucoproteins, (3) nucleoproteins. Some authorities add lecitho-proteins - that is, compounds of lecithin and protein (sec Lecithin).

The chromoproteins, as their name signifies, are the coloured proteins, the chicf member being hæmoglobin, a compound of a globin, and an iron-containing portion, hæmatin.

The glucoprotains contain a carbohydrate nucleus attached to the protein. Sevcral proteins not contained in this class, such as egg albumin and nucleoprotein, contain carbohydrate, but not in such largc amounts. The chief members of this class arc the mucins. The carbohydrate in them is usually glucosamine, of which there is often as much as 30 per ccnt. When glucoprotein is treated with dilute mineral acid, a sugar is split off which gives the " reducing" tests for sugar, but will not ferment with yeast.

The nucleoproteins form the chicf constituent of the nuclei of cells. Thcy consist of protein in combination with nuclein, itself a compound of protein with nucleic acid. There are scveral nucleic acids. The simplest (so-called guanylic acid), found in the pancreas, yields, on decomposition, phosphoric acid, guanin, and a pentose; nucleic acid proper yields the purin bodics, guanin and adenin, a hexose, and 
pyrimidin bases, especially cytosin. The following scheme shows the relationship of nuclein:

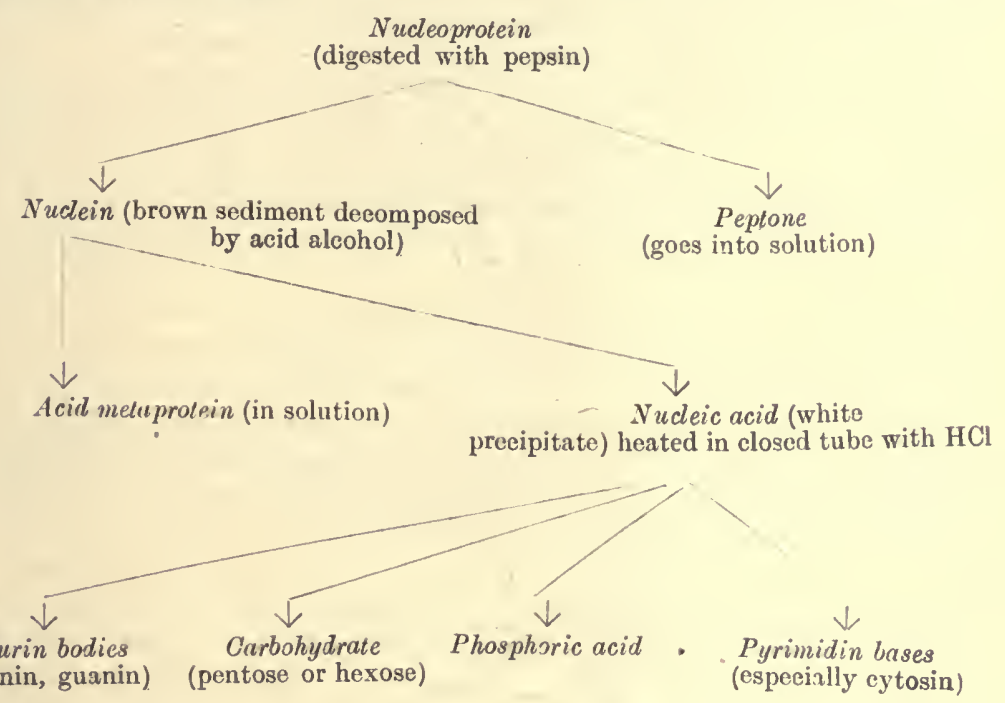

The chief of the pyrimidin bases is cytosin-amino-oxypyrimidin, $\mathrm{C}_{4} \mathrm{H}_{5} \mathrm{~N}_{3} \mathrm{O}$, graphically expressed:<smiles>C1N=NON1</smiles>

Uracil is dioxypyrimidin, $\mathrm{C}_{4} \mathrm{H}_{4} \mathrm{~N}_{2} \mathrm{O}_{2}$,<smiles>O=C1COCN1</smiles>

Thymin is methyl uracil, $\mathrm{C}_{5} \mathrm{H}_{6} \mathrm{~N}_{2} \mathrm{O}_{2}$,<smiles></smiles>

The Purin Bases are perhaps the most important clcarago products of nucleoprotein, distinguishing it from phosphoprotein, which does not contain them. They are all compounds of the hypothetical purin ring (see p. $3 \varepsilon$ ).

- The two immediate products of hydrolysis are adenin and guanin. These are in close relationship with the bases hypoxanthin and xanthin and with uric acid. 
Adenin is 6-amino-purin, $\mathrm{C}_{5} \mathrm{H}_{3} \mathrm{~N}_{4} \mathrm{NH}_{2}$, the amino grouping being in the 6 position of the purin ring. Grephically expressed it is<smiles></smiles>

Guanin, $\mathrm{C}_{5} \mathrm{H}_{3} \mathrm{~N}_{4} \mathrm{O}_{2}$, is 2-amino-6-oxypurin, or<smiles>O=C1NCCNC1NO</smiles>

Besides being found as a product of hydrolysis of nucleoprotein, it is found in small quantity in muscles and also in the scales of fishes

Hypoxanthin, $\mathrm{C}_{5} \mathrm{H}_{4} \mathrm{~N}_{4} \mathrm{O}$, is 6-oxypurin, or<smiles>C=Nc1nnc[nH]c1=O</smiles>

It is obtained from adenin by "deaminization," the replacement of the $\mathrm{NH}_{2}$ group by an atom of oxygen. This takes place in the body as the result of the action of an enzyme known as adenase:

$$
\mathrm{C}_{5} \mathrm{H}_{3} \mathrm{~N}_{4} \mathrm{NH}_{2}+\mathrm{H}_{2} \mathrm{O}=\mathrm{C}_{5} \mathrm{H}_{4} \mathrm{~N}_{4} \mathrm{O}+\mathrm{NH}_{3} \text {. }
$$

Hypoxanthin is also found in the muscles. It is abundant in the sperm of ccrtain fishes, such as the salmon and the carp. It also occurs in small quantitics in bone marrow, in milk, and in urine.

Xanthin, $\mathrm{C}_{5} \mathrm{H}_{4} \mathrm{~N}_{4} \mathrm{O}_{2}$, is 2, 6, dioxypurin, or<smiles></smiles>

It bears the same relationship to guanin as hypoxanthin does to adenin. In the body the enzyme guanase converts guanin into xanthin. Oxidizing enzymes also possess the power of converting hypoxanthin to xanthin by adding on an atom of oxygen.

Uric acid is trioxypurin; its chemical relationships are discussed fụlly later (see p. 458).

Derived Proteins: Acid and Alkali Metaprotein may be prepared by treating a solution of egg white with a little dilute acid $(10$ per cent. $\mathrm{HCl})$ or dilute alkali at body temperature for five minutes, and then heating up to the boiling-point. The metaprotein thus formed differs from the original cgg albumin in not being coagulated by heat while in the acid or alkaline solution, and in being precipitated (salted out) by half-saturation with ammonium sulphate (see table 
below). Acid metaprotein may be changed into alkali metaprotein, but the reverse change cannot take place, since the alkali splits off some of the loosely combined nitrogen and sulphur. If alkali metaprotcin be prepared by the action of strong alkali on egg white, a substance known as "Lieberkuhn's jelly" is formed. Acid metaprotein is formed in peptic, alkali metaprotein in tryptic, digestion.

Proteoses and Peptones.-These occur in the first stages of protein cleavage (see table tclow), and arc more fully dealt with under Digestion (p. 386).

The proteoses are usually divided into primary and secondary. They are not coagulated by heat, are very slightly diffusible, give a pink colour with the biuret test, and a white precipitate with salicyl-sulphonic acid, which disappears on heating and reappears on cooling. Primary proteoses (except a form known as heteroproteose) are salted out by half-saturation with ammonium sulphate, secondary proteoses by full saturation (see table bel $3 w$, also p. 3E6).

Peptones are characterizcd by their ready diffusibility through parchment membranes. They also give a characteristic pink colour with the biuret test. They are not coagulated by heat, and are not precipitated by nitric or salicyl-sulphonic acid. They are precipitated by alcohol and picric acid.

\begin{tabular}{|c|c|c|c|c|c|c|c|c|}
\hline Protein. & $\begin{array}{l}\text { Solu- } \\
\text { bility. }\end{array}$ & $\begin{array}{l}\text { Diffusi- } \\
\text { bility. }\end{array}$ & $\begin{array}{c}\text { Action } \\
\text { of } \\
\text { Heat. }\end{array}$ & $\begin{array}{l}\text { Biuret } \\
\text { Test. }\end{array}$ & 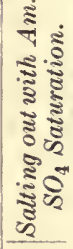 & 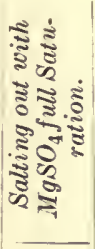 & $\begin{array}{l}\text { Nitric or } \\
\text { Salicyl } \\
\text { Sulphs. } \\
\text { nic } \\
\text { Acids. }\end{array}$ & $\begin{array}{l}\text { Action of } \\
\text { Alcohol. }\end{array}$ \\
\hline Globulin & Saline & Nil & $\begin{array}{l}\text { Coagu- } \\
\text { lated }\end{array}$ & Violet & Half & + & $\begin{array}{l}\text { Pp. insol. } \\
\text { on } \\
\text { heating }\end{array}$ & Ppt'd, then \\
\hline Albumin & Water & Nil & $\begin{array}{l}\text { Coagu- } \\
\text { lated }\end{array}$ & Violet & Full & - & Pp. insol. & Ppt'd, then \\
\hline $\begin{array}{l}\text { Primary } \\
\text { proteoses }\end{array}$ & Water & Slight & $\begin{array}{l}\text { Not } \\
\text { coagu- } \\
\text { lated }\end{array}$ & Pink & Half & + & $\begin{array}{l}\text { Pp. sol. } \\
\text { on } \\
\text { heating }\end{array}$ & Ppt'd \\
\hline $\begin{array}{l}\text { Secondary } \\
\text { proteoses }\end{array}$ & Water & Slight & $\begin{array}{l}\text { Not } \\
\text { coagu- } \\
\text { lated }\end{array}$ & Pink & Full & - & $\begin{array}{l}\text { Pp. sol. } \\
\text { on } \\
\text { heating }\end{array}$ & Ppt'd \\
\hline Peptoncs & Water & $\begin{array}{l}\text { Consider- } \\
\text { able }\end{array}$ & $\begin{array}{l}\text { Not } \\
\text { coagu- } \\
\text { lated }\end{array}$ & Pink & Not & - & No pp. & Not ppt'd \\
\hline $\begin{array}{c}\text { Acid } \\
\text { metaprotein }\end{array}$ & Acid & . & $\begin{array}{c}\text { Not } \\
\text { coagu- } \\
\text { lated }\end{array}$ & . & Half & + & . & - \\
\hline $\begin{array}{c}\text { Alkali } \\
\text { metaprotein }\end{array}$ & Alkali & - & Not & .. & Half & + & $\cdots$ & •. \\
\hline Caseinogen & $\begin{array}{l}\text { Weak } \\
\text { a kali }\end{array}$ & Nil & $\begin{array}{l}\text { Not } \\
\text { coagu- } \\
\text { lated }\end{array}$ & Violet & Half & + & .. & Ppi'd \\
\hline
\end{tabular}


Colour Tests for Proteins.

\begin{tabular}{|c|c|c|c|}
\hline Name. & Procedure. & Result. & Significance. \\
\hline $\begin{array}{l}\text { Biuret (Rose's } \\
\text { or Piotrowski's } \\
\text { test). }\end{array}$ & $\mathrm{KOH}$ and $\mathrm{CuSO}_{4}$ & $\begin{array}{l}\text { Violct or } \\
\text { pink colour }\end{array}$ & $\begin{array}{l}\text { Two CONH groups linked } \\
\text { together }\end{array}$ \\
\hline Xanthoprotcic & Add $\mathrm{HNO}_{3}$ & $\begin{array}{l}\text { White pp., } \\
\text { yellow on } \\
\text { heating, } \\
\text { orange with } \\
\text { ammonia }\end{array}$ & Prosence of benzene ring \\
\hline Millon's & $\begin{array}{l}\text { Add mixture of } \\
\text { mercuric and } \\
\text { mercurous } \\
\text { nitrates }\end{array}$ & $\begin{array}{l}\text { White pp., } \\
\text { brick red } \\
\text { on heating }\end{array}$ & $\begin{array}{c}\text { Presence of hydroxybenzene } \\
\text { ring }\end{array}$ \\
\hline $\begin{array}{l}\text { Adamkiewiez's } \\
\text { or Hopkins's } \\
\text { (glyoxylic) }\end{array}$ & $\begin{array}{l}\text { Glacial acetic and } \\
\mathrm{H}_{2} \mathrm{SO}_{4}\end{array}$ & Violet ring & Presence of tryptophan \\
\hline $\begin{array}{l}\text { Lead sulphide } \\
\text { test }\end{array}$ & $\begin{array}{l}\text { Lead acetate } \\
+\mathrm{KOH}\end{array}$ & $\begin{array}{l}\text { Black colour } \\
\text { on heating, } \\
\text { due to } \\
\text { formation of } \\
\text { lead sulphide }\end{array}$ & Presence of sulphur \\
\hline Molisch's test & $\begin{array}{c}a-\mathrm{Naphthol} \text { and } \\
\mathrm{H}_{2} \mathrm{SO}_{4}\end{array}$ & Purple ring & $\begin{array}{l}\text { Presence of carbohydrate } \\
\text { group attached to protein }\end{array}$ \\
\hline
\end{tabular}




\section{CHAPTER VI}

\section{FATS AND LIPOIDS}

\section{Section I.}

Neutral Fats and Fatty Acids.-Fats occur widely distributed in the plant and animal kingdom. In the former they occur in seeds, roots, and fruits; in the latter in varying quantities in all tissues, but particularly in the adipose tissue, bone marrow, and milk. Neutral fats are compounds of the fatty acids with the triatomic alcohol, glycerine. They are generally yellowish in colour or colourless, and when pure have neither odour nor smell. They have the general formula :<smiles>[R]OC(=O)OCC(COC([R])=O)OC(=O)O[R]</smiles>

-where $R$, the fatty acid radical, usually stands for palmitic, stearic, or oleic acid. Of these, palmitic and stearic are saturated acids, and have the general formula $\mathrm{CnH}_{2 n+1} \mathrm{COOH}, n$ being 17 in stearic acid, $\mathrm{C}_{17} \mathrm{H}_{35} \mathrm{COOH}$, and 15 in palmit:c acid, $\mathrm{C}_{15} \mathrm{H}_{33} \mathrm{COOH}$. Oleic acid, $\mathrm{C}_{17} \mathrm{H}_{33} \mathrm{COOH}$, is unsaturated, and therefore possesses the power of decolorizing dilute bromine-water and of combining with iodine. This latter property is used to determine the amount of olein present in the ordinary fats, which are mixtures of varying proportions of olein, stcarin, and palmitin. The melting-point of fat also varies according to the relative amounts of these fats present. Olein is fluid at ordinary temperature, melting at $-5^{\circ} \mathrm{C}$; whereas palmitin melts at $45^{\circ} \mathrm{C}$., and stearin at about $56^{\circ} \mathrm{C}$. The fluid nature of fat at body temperature is therefore due to the amount of olein which it contains. Butyrin occurs in the fat of milk.

When a liquid fat is shaken with soap, mucilage, or egg albumin, it becomes finely divided, or "emulsified." Rancid fat emulsifies on addition of alkali far more easily than neutral fat, because soap is formed from the alkali, free fatty acid being present, and the soap renders emulsification easier. Hence the fact that fat is rendered faintly rancid in the stomach is of importance. Emulsification is a physical change; the minute subdivision hastens the chemical change of fat.

By hydrolysis of fat, glycerine and fatty acid are produced. This process is known as saponification, and can be brought about by such agencies as superheated steam, boiling with alkali, long-continued 
contact with air (oxygen is taken up and rancid oil produced), the action of fat-splitting enzymes or lipases.

The rcaction can be represented thus:

$$
\underset{\text { Palmitin }}{\mathrm{C}_{3} \mathrm{H}_{5}\left(\mathrm{OC}_{15} \mathrm{H}_{31} \mathrm{CO}\right)_{3}}+\underset{\text { Glycerine }}{3 \mathrm{H}_{2} \mathrm{O}}=\underset{\text { - Palmitic acid }}{\mathrm{C}_{3} \mathrm{H}_{5}(\mathrm{OH})_{3}}+\underset{\mathrm{C}_{15} \mathrm{H}_{31} \mathrm{COOH}}{2}
$$

In true saponification the fatty acid formed combines with the alkali present to form a soap:

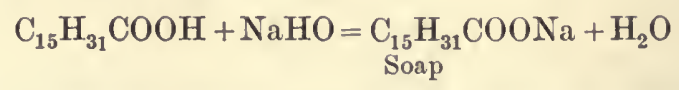

Fats from different species of animals vary in composition, and fats from differcnt parts of the same animal have varying composition depending upon the combination of individual fats which form the mixed fat of any part. From the liver, for example, fatty acids, more unsaturated than oleic and belonging to the linolic and linolenic series, have been isolated. Milk fat is characterized by its yield of butyric, caproic, caprylic, and other volatile fatty acids. From kidney fat an acid known as carnaubic acid has been isolated.

$$
\text { Stearin, } \begin{array}{r}
\mathrm{CH}_{2} \mathrm{OC}_{18} \mathrm{H}_{35} \mathrm{O} \\
\mathrm{CHOC}_{18} \mathrm{H}_{35} \mathrm{O} \\
\mathrm{CH}_{2} \mathrm{OC}_{18} \mathrm{H}_{35} \mathrm{O}
\end{array}
$$

occurs generally in animal fat, but is found also in certain vegetable fats. It is the hardest and most insoluble of the three common fats. Its melting-point when purc is $55^{\circ} \mathrm{C}$., but as obtained from the tissues about $63^{\circ} \mathrm{C}$.

Stearic acid, the acid of stearin, crystallizes in long rhombic plates, and crystals of it may sometimes be seen in a melted rancid fat after it has solidified.

$$
\text { Palmitin, } \begin{array}{r}
\mathrm{CH}_{2} \mathrm{OC}_{16} \mathrm{H}_{31} \mathrm{O} \\
\mathrm{CHOC}_{16} \mathrm{H}_{31} \mathrm{O} \\
\mathrm{CH}_{2} \mathrm{OC}_{16} \mathrm{H}_{31} \mathrm{O}
\end{array}
$$

occurs largely in human fat. Its mclting-point is about $50^{\circ} \mathrm{C}$. Palmitic acid crystallizes as finc needles.

$$
\text { Olein, } \begin{aligned}
\mathrm{CH}_{2} \mathrm{OC}_{18} \mathrm{H}_{33} \mathrm{O} \\
\mathrm{CHOC}_{18} \mathrm{H}_{33} \mathrm{O} \\
\mathrm{CH}_{2} \mathrm{OC}_{18} \mathrm{H}_{33} \mathrm{O}
\end{aligned}
$$

is very widespread, being found in most animal and regetable fats. At ordinary temperature it is liquid, solidifying at $-6^{\circ} \mathrm{C}$, and acts as a solvent for the stearin and palmitin of ordinary fat. The me.ting-point of a fat, its iodine valuc, and staining properties with osmic acid, depend upon the amount of oleic acid present.

The fatty acids may be obtained from neutral fats by trcating with dilute mineral acid, when the fatty acid will coilcet as an oily 
scum upon the top of the fluid. Fatty acids in appearance closely resemble neutral fats, being generally almost colourless.

Fatty acids may be distinguished from neutral fats-

1. By their reaction. This is usually tested as follows: Some alcoholic phenolphthalein solution is added to alcohol, and one drop of weak alkali (1 per cent. sodium carbonate) added. The addition of neutral fats will not discharge the red colour thus produced, fatty acids will.

2. Fatty acids dissolve in cold sodium carbonate to form a soap; ncutral fat is insoluble in cold sodium carbonate.

3. The acrolein test. The acrolein is derived from glycerine. Neutral fats therefore give this test, fatty acids do not. To perform the test, the substance is mixed with acid potassium sulphate $\left(\mathrm{KHSO}_{4}\right)$ by grinding in a mortar. Upon heating the mixture acrolein is evolved, if the test is positive, and may be recognized by its acrid sinell and by the fact that it blackens a piece of paper dipped in an ammoniacal solution of silver nitrate.

It is important to be able to distinguish different forms of fat. The chief chemical methods employed are--

1. Melting-point. This varies with different animals. Mutton fat, $44^{\circ}$ to $51^{\circ} \mathrm{C}$., is generally higher than pig fat, $36^{\circ}$ to $46^{\circ} \mathrm{C}$.

2. Specific gravity. Some melted fats will float in alcohol at room temperature; others will not. For example, margarine, which often contains light vegetable oils, will float, pure butter will sink.

3. Acid value. The amount of free fatty acid contained in the fat.

4. Iodine value. The percentage amount of iodine absorbed by a weighed quantity of fat. This depends upon the amount of unsaturated fatty acids present, such as olein.

5. The amount of volatile fatty acids present (Reichert-Mcissl value). Obtained by saponifying the melted fat with alccholic potash. and treating the soap thus obtained with sulphuric acid. Volatile fatty acids will distil off. These are collected in standard $\frac{\mathrm{N}}{10}$ alkali, and their amount determined by titration. Pure butter has a much higher value in volatile acids than has margarine.

Soaps are the compounds of fatty acici and a base. When the base is sodium, ordinary washing soap is obtained; when it is potassittm, "soft" soap is produced. Thozo are soluble in water, fo:ming a "soapy" colloidal solution. They are "salted out" by full saturation with ammonium sulphatc. With solutions of calcium or magnesium salts they yield a dense white precipitate; this accounts for the difficulty, familiar to everyone, of washing with a " hard "water.

When boiled with a mineral acid (20 per cent. sulphuric), the fatty acid is displaced from combination, and collects at the top as a white scum or oily fluid.

If lead acetate be added to a soap solution, a white precipitate of lead soap (lead plaster) is obtained. 


\section{SECTION II.}

Lipoids.--Under this name are grouped a number of fat-like (lipoid) bodies, resembling fat mainly in their common solubility in certain solvents.- They occur in the protoplasm of all cells, and are probably bodies of wide biological significance. They are particularly abundant in nervous tissue. They may be classified as follows:

I. The Phosphatides-bodies containing carbon, hydrogen, oxygen, nitrogen, and phosphorus.

II. The Galactosides-bodies containing carbon, hydrogen, oxygen and nitrogen.

III. The Cholesterols-bodies containing carbon, hydrogen, and oxygen.

I. The Pohsphatides are all compounds of the triatomic alcohol glycerine, to which a fatty acid, phosphoric acid, and a nitrogenous base are attached. The chief members of this group are the lecithins. The members may be classified according to the proportion of nitrogen to phosphorus in their molecule:

Monamino-monophosphatides: lecithins, cephalin. IN IP

Monamino-diphosphatides: cuorin.

$1 \mathrm{~N} \quad 2 \mathrm{P}$

Diamino-monophosphatides: sphingomyelin, jecorin. $2 \mathrm{~N}$ $1 \mathrm{P}$

Diamino-diphosphatides, etc.
$2 \mathrm{~N}$
$2 \mathrm{P}$, etc.

Triamino-monophosphatides: carnaubin, obtained from kidncy fat, belongs to this group, but yields no phosphoric acid.

The action of narcotics and of chloroform and ether has keen attributed to the solubility of these substances in the phosphatides of the nerve cells. In the reactions of specific cell poisons, toxins such as snake poison, and hæmolysins, lecithin may take an active part. So, too, in the action of ferments. Cholesterol, on the other hand, may act as an antibody, precipitating ferments, and ncutralizing the action of snake venom.

The Lecithins. The lecithins are the most important members of this group of phosphatides, and also, perhaps, the most important of lipoids. They are present in all the cells of the body, and are particularly plentiful in the envelope of red blood-corpuscles, in nervous tissue, bone marrow, liver, and bile.

The lecithins probably play an important part in the metabolism of the cells, forming easily dissociable compounds with sugars, proteins, etc., and helping in the transport of these substances in the body fluids. The fact that each tissue has its specific lipoid helps to endow that tissue with its specific function. In the nervous tissues these substances are of paramount importance, and on extensive degenerat:u:n of nervous tissue the body becomes poorer in lecithins. 
Lecithins differ from fats in containing nitrogen and phosphorus. Two of the hydroxyl groups of the glycerine radical are combined with fatty acids, the remaining one being linked to phosphoric acid in conjunction with an ammonium base, cholin. The structural formula of lecithin is, therefore-

$$
\begin{aligned}
& \text { Glycerine }\left\{\begin{array}{l}
\mathrm{CH}_{2} \mathrm{OC}_{17} \mathrm{H}_{35} \mathrm{CO} \\
! \\
\mathrm{CHOC}_{17} \mathrm{H}_{35} \mathrm{CO} \\
! \\
\mathrm{CH}_{2}-\mathrm{O}-\mathrm{O}-\mathrm{OH}
\end{array}\right. \text { Stearic acid }
\end{aligned}
$$

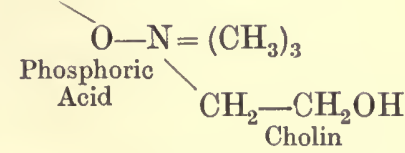

Pure lecithin has a waxy appearance; it is soluble in alcohol and chloroform, less soluble in ether. When mixed with water and viewed under the mieroscope, it gives out peculiar processes which remind one of the pseudopodia of an amœba. There are various lecithins, which differ according to the fatty acid combined with the molecule.

Like the fats, the lecithins can be hydrolyzed. When saponified they yield fatty acid, glycerophosphoric acid, and cholin:

$$
\begin{aligned}
& \mathrm{C}_{41} \mathrm{H}_{90} \mathrm{NPO}_{9}+3 \mathrm{H}_{2} \mathrm{O}=2\left(\mathrm{C}_{18} \mathrm{H}_{36} \mathrm{O}_{2}\right)+\mathrm{C}_{3} \mathrm{H}_{9} \mathrm{PO}_{6}+\mathrm{C}_{5} \mathrm{H}_{15} \mathrm{NO}_{2} \\
& \text { Lecithin Stearic Glycero- Cholin } \\
& \text { acid phosphoric }
\end{aligned}
$$

Lecithin is split up by cell ferments, and phosphatides may be rebuilt in the laboratory of the cell.

Cholin-trimethyloxyethylammonium hydrate-

$$
\left(\mathrm{CH}_{3}\right)_{3} \mathrm{~N}-\mathrm{CH}_{2} \cdot \mathrm{CH}_{2} \mathrm{OH}
$$

-is closely related to the alkaloid muscarin. Methylamines are among the products of bacterial decomposition of lecithins. Neur:n, which contains one molecule of water less than cholin, is a very poisonous product, and may be the cause of "ptomain" poisoning. Cholin produces a marked fall of blood-pressure when injected into the blood. It is said that cholin occurs in the blood and spinal fluid when nervous tissue is undergoing degeneration, and can be isolated as yellow octahedral crystals by adding platinum chloride to an alcoholic extract of the fluids. These crystals differ from similar ones obtained by the interaction of potassium chloride (also present in b!ood) with platinum ehloride, in that they become changed when treated with a strong solution of potassium iodide to dark brown plates. The claim that cholin can be demonstrated in these fluids has not met with general acceptance.

II. The Galactoside 5.- These bodies occur largely in the body known as protagon, obtained from the brain tissuc. They are so 
ealled because upon hydrolysis they yield the reducing sugar galactose. In addition they also yield a base known as sphingosin, and an acid of a fatty acid nature. The two chief members of this group are cerebrin, or phrenosin, and kerasin.

III. The Cholesterols. - Cholesterol, $\mathrm{C}_{27} \mathrm{H}_{45} \mathrm{OH}$, ehemically speaking belongs to quite a different scries of bodies. It contains neither nitrogen nor phosphorus, and is probably a monatomic alcohol of the terpene series. Bodies of this scries are common in plants, examples being camphor and turpentine. The following formula has been suggested:

$$
\begin{gathered}
\left(\mathrm{CH}_{3}\right)_{2}=\mathrm{CH}-\mathrm{CH}_{2}-\mathrm{CH}_{2}-\mathrm{C}_{17} \mathrm{H}_{26}-\mathrm{CH}=\mathrm{CH}_{2} \\
\mathrm{CH}_{2} \quad \underset{\mathrm{CH}}{\mathrm{CH}_{2}} \\
\mathrm{CHH})
\end{gathered}
$$

It occurs in all the cells and fluids of the body in small quantities, but particularly in nervous tissue and in the envelope of the red bloodcorpuscles. It is also present in the bile, from which in catarrhal states of the bile-ducts it may sometimes separate, forming biliary calculi.

Cholesterol is probably not merely a waste product as it was once deemed to bc. As stated above, it hinders the action of ferments and also that of certain poisons, such as snake venom and saponin, upon the red blood-corpuscles.

It is sometimes found as an ester in the liver and plasma in combination with a fatty acid such as oleic, palmitic, or stearic. It occurs also in the suprarenal capsules in this form.

Cholesterol is soluble in ether, chloroform, and warm alcohol. Its solutions are dextrorotatory. From these it crystallizes in characteristic colourless transparent plates, each with a small piece knocked out of the corner. It is insoluble in water, dilute acids, or alkalies. The most general tests for cholesterol are-

1. A red colour results when concentrated sulphuric acid is added to a chloroform solution of cholesterol. (Salkowski's test.)

2. A play of colours, red, blue, green, is obtained when the same acid is added to a solution of cholesterol in acetic anhydride. (Liebermann's test.)

Isocholesterol, a body similar to cholestcrol in most respects, is found in sebum. It differs from cholesterol in not giving Salkowski's test, and in being levorotatory in solution.

Phytocholesterol is the special name applied to the cholesterols of plants, from which animal cholcsterols are probably derived.

Cephalin is found largely in both the white and grey matter of nervous tissues. It is soluble in ether and chloroform, but not in alcohol.

Sphingomyelin is found in protagon, and also in the suprarenal capsules.

Jecorin is found in the liver. It is probably a combination of a phosphatide and a sugar. 


\section{CHAPTER VII}

\section{THE CARBOHYDRATES}

These important foodstuffs occur abundantly in the vegetable kingdom, and are also found in small quantities in the animal kingdom, either in the free state or combined with proteins. As a group the carbohydrates form one of the chief energy-producers or foods.

As their name implies, they are composed of carbon, hydrogen, and oxygen, the latter elements being present in the proportion found in water $(2: 1)$. Their general formula is $\mathrm{C}_{m} \mathrm{H}_{2 n} \mathrm{O}_{n}$. It was at one time thought that carbohydrates were bodies containing six atoms of carbon or some multiple thereof. This is now known not to be the case; indeed, the most recent classification of the simplest members of the group is according to the number of carbon atoms contained in the molecule; those, for example, containing three atoms being termed trioses, those with five atoms pentoses, those with six atoms hexoses, and so on. It must not be thought that all bodies containing $\mathrm{C}, \mathrm{H}, \mathrm{O}$, with the hydrogen and oxygen in the proportion of water, are contained in the group of carbohydrates; for example, $\mathrm{C}_{2} \mathrm{H}_{4} \mathrm{O}_{2}$ is the empirical formula for acetic acid, $\mathrm{C}_{3} \mathrm{H}_{6} \mathrm{O}_{3}$ that of lactic acid.

Nevertheless, the definition holds for the mest part, and the bestknown members of the series do contain six molecules of carbon or some multiple of six. Thesc are generally grouped as follows:

1. The monosaccharides $-\mathrm{C}_{6} \mathrm{H}_{12} \mathrm{O}_{6}$

2. The disaccharides $-\mathrm{C}_{12} \mathrm{H}_{22} \mathrm{O}_{11}$

3. The polysaccharide $-\left(\mathrm{C}_{6} \mathrm{H}_{10} \mathrm{O}_{5}\right)_{\mathrm{N}}$

\section{SECTION I}

The Monosaccharides. - The chief monosaccharides of physiological importance are the hexoses, dextrose, levulose, and galactose. Each has the cmpirical formula $\mathrm{C}_{6} \mathrm{H}_{12} \mathrm{O}_{6}$. Dextrose is the aldehyde of the hexatomic alcohol sorbite; levulose is the ketonc of the hexatomic alcohol mannite; galactose is the aldchyde of another hexatomic alcohol, dulcite. Each alcohol has the formula $\mathrm{C}_{6} \mathrm{H}_{8}(\mathrm{OH})_{6}$. The structural formulæ of these sugars may be represented as given on 1). 60 .

Levulose differs from the other two in being a ketone; dextrose and galactose differ from each other and from thcir many isomers in the position of the so-called asymmetric carbon atoms. All bodies 
like the above, which rotate the plane of polarized light, eontain one or more asymmetrie atoms.

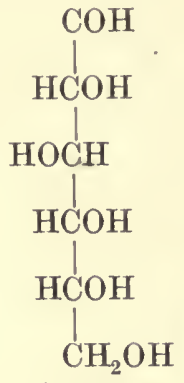

Dextrose
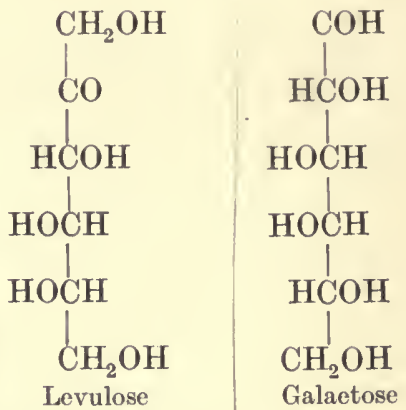

The waves of light, moving onwards, vibrate in every plane. When they pass through a quartz plate they are plane polarized, and vibrate only in one plane. A stretehed string ean be plueked and made to vibrate from side to side, or from above down, or in any other plane. If the string pass $3 s$ through a vertieal slit, it can only be made to vibrate in the above-down direetion; it is, so to speak, plane polarized. The quartz plate has a similar cffeet on light. If two quartz plates are arranged so tliat the light must pass through both, then the light polarized by the first plate ean pass through the seeond if this be placed with its optical axis in the same relation as that of the first plate. If the seeond plate is turned at right angles to the first plate, the light polarized by the first platc eannot pass the sccond. If a solution which rotates polarized light is plaeed in a tube between the two quariz plates, its effeet on the rotation of the seeond quartz plate ean be determined. Speeial instruments ealled polarimc "ers are eontrived for measuring the effeet of solutions on the rotation of polarized light, and so arriving at the strength of the solutions, e.g., of sugar.

The various groups may be arranged in a figure round an asymmetrie earbon atom so that one arrangement corresponds to dextrorotation, another to levorotation. The two figures eannot be superimposed so that the same two groups eoineide. In this respeet it is interesting to note that Pasteur found that racemie acid, which has holohedral erystals, and is neutral in its action to polarized light, eould be decomposed into dextrorotatory and levorotatory tartarie aeids with hemihedral erystals. Of these erystals, those which were right-sided gave dextrorotation, those which were leftsided gave levorotation. By growing Penicillium glaucum upon racemie acid, the dextrorotatory portion of ordinary tartarie aeid is destroyed and the levorotatory acid is left.

The monosaceharides are colourless erystalline bodies (with a sweetish taste) readily soluble in water, with diffieulty soluble in aleohol, and insoluble in ether. They possess the property of depositing metallie silver from ammoniaeal silver solutions, euprous oxide from alkaline eopper solutions, and bismuth suboxide from alkaline bismuth solutions. This property is of especial value as a test. The chief tests are the following:

1. Moore's test. Upon heating with one quarter of its volume of strong eaustie potash or soda, the solution beeomes yellow, then brown, 
due to the formation of caramel and levulinic acid; a faint odour of caramel is also produced.

2. Trommer's test. A mixture of weak copper sulphate and potassium hydrate yields, on heating with the sugar solution, a red precipitate of cuprous oxide. At first cupric hydrate is formed by the interaction of the alkali and the copper sulphate; this hydrate is then reduced to cuprous hydrate, with the formation of acid. The cuprous hydrate on further heating loses water, forming cuprous oxide.

$$
\begin{aligned}
& \text { 1. } \mathrm{CuSO}_{4}+2 \mathrm{KOH}=\mathrm{Cu}(\mathrm{OH})_{2}+\mathrm{K}_{2} \mathrm{SO}_{4} \\
& \text { Copper } \\
& \text { sulphate }
\end{aligned}
$$

2. $2 \mathrm{Cu}(\mathrm{OH})_{2}+\mathrm{RCHO}=\mathrm{Cu}_{2}(\mathrm{OH})_{2}+\mathrm{R} \cdot \mathrm{COOH}+\mathrm{H}_{2} \mathrm{O}$

$\begin{array}{ccc}\begin{array}{c}\text { Cupric } \\ \text { hydrate }\end{array} & \text { Aldehyde } & \begin{array}{c}\text { Cuprous } \\ \text { hydrate }\end{array}\end{array}$

3. $\mathrm{Cu}_{2}(\mathrm{OH})+\mathrm{H}_{2} \mathrm{O}=\mathrm{Cu}_{2} \mathrm{O}$

The above only takes place when the amount of copper solution is neither too little nor too much. Excess of copper salt leads to the formation of brown cupric hydrate, which spoils the test.

3. Fehling's test. For this reason the excess of copper salt is generally held in solution by the addition of Rochelle salt (sodium potassium tartrate) in definite proportion to the alkali and copper salt. This is known as Fehling's solution.* When freshly prepared it is unaltered by boiling. It is reduced by all the sugars except cane-sugar. Unfortunately, it is also reduced by other bodies, such as uric acid, creatinin, glycuronic acid, etc.

4. Nylander's test. This disadvantage does not pertain so much to the salts of bismuth. The solution most generally employed is Nylander's solution. $\dagger$ Upon boiling for a few minutes with a sugar, the solution goes yellowish-brown to black, and finally deposits a precipitate of metallic bismuth. Glycuronic acid gives this test; uric acid and creatinin do not.

5. Barfoed's test. An acid solution of cupric acetate gives a red precipitate with the monosaccharides.

6. Phenylhydrazine test. This test consists in heating about 10 c.c. of the sugar solution in a test-tube on a water-bath with phenylhydrazine hydrochloride and sodium acetate-as much as will cover a threepenny-piece of the former, and a sixpenny-piece of the latter. After about thirty minutes a yellow crystalline precipitate scttles out which looks like yellow sheaves under the microscope.

The osazones yielded by dextrose and levulose are the same; that of galactose is the same in appearance, but differs in melting-point (see table, p. 64).

Of the disaccharides, cane-sugar does not yield an osazone; until

* Fehling's solution=Copper sulphate $34 \cdot 36$ grammes, $\mathrm{NaOH} 50-60$, Rochclle salt 173 grammes, per litre of water.

$\dagger$ Nylander's solution=Bismuth subnitrate 20 grammes, Rochellc salt 40 grammes, lissolved in 1,000 c.e. of 8 per cent. $\mathrm{NaOH}$. 
it becomes inverted; lactose yiclds distinctive crystalline roscttes, which are better obtained if a little free acetic acid be also added to the sugar solution; maltose yields an osazone, so soluble that it does not appear until the solution is cooled.

7. Molisch's test. All carbohydrates yield with a-naphthol and sulphuric acid a purple colour. The grcenish colour which is also present forms no part of the test. The test is very sensitive; carbohydrates linked to proteins yield it.

8. The Fermentation test. This is a very useful test for aiding in distinguishing the different sugars. The sugar solution is introduced with a small picce of brewer's yeast into a Southall's urometer (see p: 458), and placed in an incubator at $37^{\circ} \mathrm{C}$. The production of carbon dioxide gas indicates fermentation. A control tube of yeast and water should yicld no gas.

9. The Polarimetric test. This consists in detcrmining the rotation power of a solution of lnown strength of the sugar. In the case of disaccharides the rotatory power is determined before and after inversion with acid. Each disaccharide behaves differently on hydrolysis (see table, p. 64).

Dextrose (also termed glucose and grape-sugar) occurs abundantly as such in the grape, in other sweet fruits, seeds and roots, and honey; it is more often found in conjunction with levulose. It is formed by boiling starches and dextrins with dilute sulphuric acid, the syrupy sugar thus formed being largely employed in beer, jam, and sweet - making. Occasionally arsenical impurities in the common sulphuric acid (oil of vitriol) used in this process have led to cases of arsenical poisoning. It is also produced from starch by hydrolytic changes in the alimentary tract. Dextrose is the sugar found in the blood and muscles ( 1 per 1,000 parts), being an important source of energy to the latter. Under normal conditions only the merest trace occurs in the urine. In the body it is converted into and stored as animal starch or glycogen. The specific power of rotation of glucose is $+5 \mathbf{2} \cdot 6$.

Levulose (fructosc) occurs widely in conjunction with dextrose in fruits, and also in honey. It is gencrally obtained as the result of the splitting up of cane-sugar. It may occur in the urine. It is readily soluble in water, but not in cold alcohol. Its levorotatory power is about $\mathbf{- 9 3}$. It gives the usual reducing tests, and ferments readily with yeast. Its osazono is similar to that of dextrose, the melting-point being $204^{\circ} \mathrm{C}$. The characteristic test for levulose is known as Seliwanoff's test. When one part of $\mathrm{HCl}$ in two parts of water, in which a few crystals of resorcin have becn dissolved, is added to levulose, a deep cherry-red colour results.

Galactose is obtained by the splitting of lactose (milk-sugar). It is also obtained when certain lipoids (galactosides) are split by weak mineral acids. It is less soluble in water than dextrosc. It gives the reducing tests. Its osazone melts at $196^{\circ}$ to $197^{\circ} \mathrm{C}$. It turns the plane of polarized light to the right, its rotatory power being +81 . With yeast it ferments but slowly. Upon oxidation with nitric acid 
it yields first galactonic and then mucic acid; the lattcr, being insoluble, scparates out as crystals.

The Pentoses, $\mathrm{C}_{6} \mathrm{H}_{10} \mathrm{O}_{5}$, occur as the complex carbohydrates of the vegetable world, known as pentosans. They also occur in the constitution of certain nucleoproteins of the animal kingdom (see p. 49). They are of interest as occurring in human urine in the rare anomaly of metabolism known as pentosuria.

Glycuronic acid, $\mathrm{C}_{6} \mathrm{H}_{10} \mathrm{O}_{7}$,

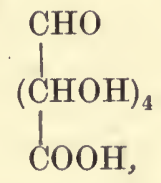

is a derivative of dextrose. It is found as a combined acid in the blood, bile, and urine. It gives the same reduction tests as dextrose, and also the special pentose reactions $(q . v$.$) . The osazone, which$ resembles glucosazone, is difficult to obtain. With bromphenylhydrazine hydrochloride a glycuronate is formed characterized by its insolubility in alcohol. Glycuronic acid itself is dextro: tatory, but its compounds are levorotatory.

Glucosa mine, $\mathrm{C}_{6} \mathrm{H}_{13} \mathrm{NO}_{5}$,

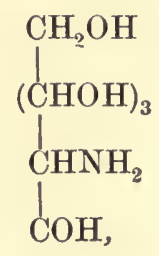

also called chitosamine, is most readily preparcd from chitin (e.g., decalcified lobster shells) by the action of strong hydrochloric acid. It is an amino sugar, and has been obtained from glucoproteins (mucins) and other proteins. Glucosamine has reducing properties similar to dextrose, yields the same osazone, but is not fermentable.

\section{SECTION II.}

The Disaccharides $\left(\mathrm{C}_{12} \mathrm{H}_{22} \mathrm{O}_{11}\right)$. 一 The disaccharides cane-sugar, maltose, and lactose, are to be regarded as the combination of two molecules of monosaccharides with the climination of a molecule of water.

$$
\begin{aligned}
\mathrm{C}_{12} \mathrm{H}_{22} \mathrm{O}_{11}+\mathrm{H}_{2} \mathrm{O} & =\mathrm{C}_{6} \mathrm{H}_{12} \mathrm{O}_{6}+\mathrm{C}_{6} \mathrm{H}_{12} \mathrm{O}_{6} \\
\text { Cane-sugar + water } & =\text { dextrose + levulose } \\
\text { Maltose + water } & =\text { dextrose+ dextrose } \\
\text { Lactose + water } & =\text { dextrose + galactose }
\end{aligned}
$$

Each disaccharide is readily split by boiling with weak minera! acid into its component monosaccharides. Cane-sugar may also be 
split by weak organic acids such as citric and tartaric. This process, one of hydrolysis, is sometimes termed inversion owing to the faet that cane-sugar before hydrolysis is dextrorotatory, but after hydrolysis is levorotatory. In the case of maltoso and lactose the tcrm is also employed, but no inversion of polarized light takes place on hydrolysis; maltose gives a considerable fall, lactose a slight rise, in rotating power after "inversion."

Nonc of the disaccharides yields Barfoed's test.

Cane-sugar, or saccharose, oceurs widely in the plant world, very abundantly in the sugar-eane and the sugar-beet. It possesses a distinetly sweet taste, is easily soluble in water, but with difficulty in alcohol. Its rotatory power is 66.5 before, and -20 after, inversion. In other respeets it gives few positive tests. It does not give Moore's test nor the ordinary reducing tests. It gives no osazone. It docs not ferment with yeast until inverted.

The Reactions of Monosaccharides and Disaccharides.

\begin{tabular}{|c|c|c|c|c|c|c|}
\hline & Dextrose. & Levulose. & Galactose. & Maltose. & Lactose. & $\begin{array}{l}\text { Cane- } \\
\text { Sugar. }\end{array}$ \\
\hline $\begin{array}{l}\text { Moore's test } \\
(\mathrm{KOH})\end{array}$ & + & + & + & + & + & - \\
\hline $\begin{array}{l}\text { Trommer's test } \\
\left(\mathrm{CuSO}_{4}+\mathrm{KOH}\right)\end{array}$ & + & + & + & $\begin{array}{c}\text { +ve } \\
33 \% \\
\text { weaker } \\
\text { than D. }\end{array}$ & $\begin{array}{l}+ \text { ve } \\
26.5 \% \\
\text { weaker } \\
\text { than D. }\end{array}$ & - \\
\hline $\begin{array}{c}\text { Fchling's test } \\
\left(\text { CuSO }_{4}+\mathrm{KOH}+\right. \\
\text { Rochclle salt })\end{array}$ & + & + & + & + & + & - \\
\hline $\begin{array}{l}\text { Nylander's test } \\
\text { (Bismuth sub- } \\
\text { nitrate+ KOH+ } \\
\text { Rochelle salt) }\end{array}$ & + & + & + & + & + & - \\
\hline $\begin{array}{c}\text { Barfoed's test (aeid } \\
\text { euprie acetate) }\end{array}$ & + & + & + & - & - & - \\
\hline $\begin{array}{l}\text { Phenylhydrazine } \\
\text { test (Osazone } \\
\text { erystals formed) }\end{array}$ & $\begin{array}{l}\text { Long thin } \\
\text { needles } \\
\text { M.P. } 204\end{array}$ & $\begin{array}{l}\text { Long thin } \\
\text { needles } \\
\text { M.P. } 204\end{array}$ & $\begin{array}{l}\text { Long thin } \\
\text { needles } \\
\text { M.P. } 186\end{array}$ & $\begin{array}{c}\text { Short } \\
\text { thiek } \\
\text { needles } \\
\text { M.P. } 206\end{array}$ & $\begin{array}{l}\text { Yellow } \\
\text { rosettes } \\
\text { M.P. } 201\end{array}$ & - \\
\hline $\begin{array}{c}\text { Rotary power on } \\
\text { polarized light }\end{array}$ & $+52 \cdot 7$ & -93 & +81 & +137 & +52.5 & +66.5 \\
\hline $\begin{array}{c}\text { Effect of liydro. } \\
\text { lysis on rotary } \\
\text { power }\end{array}$ & - & - & - & $\begin{array}{c}\text { Marked } \\
\text { fall }\end{array}$ & $\begin{array}{l}\text { Slight } \\
\text { rise }\end{array}$ & $\begin{array}{c}\text { Inverted } \\
\text { to } 20 \\
\text { to the left }\end{array}$ \\
\hline $\begin{array}{l}\text { Yeast fermentation } \\
\text { test }\end{array}$ & Marked & Marked & $\begin{array}{l}\text { Very } \\
\text { littlo }\end{array}$ & Marked & Nil & $\begin{array}{l}\text { Marked } \\
\text { after } \\
\text { inversion }\end{array}$ \\
\hline $\begin{array}{l}\text { Solubility in alco- } \\
\text { hol; cane-sugar=1 }\end{array}$ & - & + & . & : - & Insol. & 1 \\
\hline
\end{tabular}


Maltose is produced as the result of hydrolytic changes either by the action of acids or of enzymes upon starch. It is readily soluble in water, and fairly soluble in alcohol. Its solutions are dextrorotatory: $[a]_{\mathrm{D}}=137-139$. It ferments readily with yeast. It gives the same reduction tests as dextrose, with the exception of Barfoed's. The osazone is difficult to prepare, requiring warming for as long as one and a half hours. The crystals are characteristic in shape, being coarser than those of dextrososazone. Their melting-point is $205^{\circ}$.

Lactose is the characteristic animal sugar, being found only in milk, and occasionally in the urine of pregnant women. It dissolves fairly readily in water, has a faint sweetish taste, and is insoluble in alcohol. Its solutions are dextrorotatory, and $[a]_{\mathrm{D}}=52.5$. With the exception of Barfoed's it gives all the reduction tests. Its osazone forms characteristic rosettes, and has a melting-point of $201^{\circ} \mathrm{C}$. With nitric acid it yields mucic acid crystals. It is not fermentable with pure yeast, but it undergoes alcoholic fermentation with the "kephir" fungus. With this fungus an alcoholic drink is prepared chiefly from mare's and camel's milk.

\section{SeCtion III.}

The Polysaccharides.-This group includes the more complex carbohydrates, such as the dextrins and vegetable gums, starches and celluloses. They are characterized by the large size of their molecule, being therefore colloidal in nature.

The Celluloses $\left(\mathrm{C}_{6} \mathrm{H}_{10} \mathrm{O}_{5}\right)$ n.-Plant cellulose is in reality a mixture of celluloses. These bodies are insoluble in hot or cold water, alcohol, ether, and dilute acids or alkalies. They are soluble, however, in ammoniacal copper oxide solution (Schweitzer's reagent), from which they are precipitated by acids. When acted upon with strong sulphuric acid, cellulose yields a substance known as amyloid, which gives a blue colour with iodine solution; by prolonged treatment dextrose is produced. By the action of strong nitric acid, explosives (nitro-celluloses) such as gun-cotton are produced.

In the intestinal tract, particularly of herbivora, the enzyme known as cytase partially decomposes cellulose.

The Starches $\left(\mathrm{C}_{6} \mathrm{H}_{10} \mathrm{O}_{5}\right) n$ are a reserve food of wide distri bution in the vegetable kingdom, being stored as grains shaped in various forms in seeds (the cereals), tubers (potatoes), etc. As a commercial product starch is a white amorphous powder without taste or smell, insoluble in cold water, but yielding an emulsion with hot water. A starch emulsion is best made by mixing starch to a paste in the cold, and gradually stirring this into boiling water, a wellknown domestic process. By the action of the boiling water the starch grains are made to swell up and break, and the starch is converted 
from the variety known as insoluble starch into soluble starch. The solution yields a characteristic blue colour with iodine solution, which, if sufficient starch bc present, disappears on heating, and reappears on cooling. $2 \cdot 5$ to 4.6 per ccnt. solutions exhibit a rotatory power of about +202 . Starch gives ncither Moore's nor Trommer's test, and none of the other reduction tests. 'It does not ferment with yeast. Upon boiling with dilutc acid, or under the action of the group of enzymes known as diastases, it is split first into dextrins and then into sugars, maltosc being formed as the result of enzymc action, dextrose by the action of the acids. Starches arc "salted out" by half-saturation with ammonium sulphate. They are also precipitated - from their solutions by 50 to 55 per cent. alcohol. In some plants, such as the tubcrs of the dahlia, a special variety of starch known as inulin occurs. It forms an amorphous white powder, differing. from ordinary starch in giving a yellow colour with iodine solution, and yielding levulose on hydrolysis with acid. Diastatic enzymes have littlc or no effect on this body.

Glycogen, or animal starch, found chiefly in the liver of animals, is obtained as a white amorphous powder soluble to an opalescent solution in water. It gives a mahogany brown colour with iodine, is precipitated from solution by 60 per cent. alcohol and basic lead acetate.

Characteristic Reactions of Polysaccharides.

\begin{tabular}{|c|c|c|c|c|}
\hline & Starch. & Glycogen. & Erythrodextrïn. & Achroodextrin. \\
\hline Moore's test & - & - & - & - \\
\hline $\begin{array}{l}\text { Reduction tests: } \\
\text { Trommer,.etc. }\end{array}$ & - & - & - & - \\
\hline $\begin{array}{l}\text { Ditto after } \\
\text { hydrolysis }\end{array}$ & + & + & $\therefore+$ & + \\
\hline $\begin{array}{l}\text { Solubility in } \\
\text { water }\end{array}$ & $\begin{array}{l}\text { Opalescent: } \\
\text { sol. in } \\
\text { hot water }\end{array}$ & $\begin{array}{l}\text { Opalescent } \\
\text { solution in } \\
\text { cold }\end{array}$ & $\begin{array}{l}\text { Clear solution } \\
\text { in cold }\end{array}$ & $\begin{array}{l}\text { Clear solution } \\
\text { in cold }\end{array}$ \\
\hline $\begin{array}{l}\text { Solubility in } \\
\text { alcohol }\end{array}$ & Insol. & $\begin{array}{l}\text { Precipitated } \\
\text { by } 60 \%\end{array}$ & $\begin{array}{l}\text { Prccipitated by } \\
80 \%-85 \%\end{array}$ & $\begin{array}{c}\text { Precipitated by } \\
90 \%\end{array}$ \\
\hline Iodine solution & Blue & $\begin{array}{l}\text { Mahogany } \\
\text { brown }\end{array}$ & Red & No colour \\
\hline $\begin{array}{l}\text { Salting out with } \\
\mathrm{Am}_{2} \mathrm{SO}_{4}\end{array}$ & $\begin{array}{l}\text { Half- } \\
\text { saturation }\end{array}$ & Full & Full & $\begin{array}{l}\text { Not salted } \\
\text { out }\end{array}$ \\
\hline $\begin{array}{l}\text { Basic lead } \\
\text { acctatc }\end{array}$ & Precipitated & Prccipitated & Not prccipitated & Not precipitated \\
\hline
\end{tabular}

Dextrins $\left(\mathrm{C}_{6} \mathrm{H}_{10} \mathrm{O}_{5}\right) n$.- These are the first products of the hydrolysis of starches produced by the action of weak acids or of starch- 
splitting enzymes. Commercial dextrin is a swectish, sticky amorphous powder. It probably consists of many dextrins, of which two may be mentioned-erythrodextrin and achroodextrin. It often contains some reducing sugar.

Erythrodextrin, or "red dextrin," as its name implies, is so called because it yields a port-wine colour with iodine solution. It is regarded as the first product of the hydrolysis of soluble starch. It is distinguished from glycogen by giving a clear solution in hot water, and requiring 80 to 85 per cent. alcohol to precipitate it from solution. It is also not precipitated by basic lead acetate solutions. It requires full saturation with ammonium sulphate to salt it out (see table, p. 66).

Achroodextrin, or "colourless" dextrin, gets its name because it gives no colour with iodine solution. It occurs at a later stage in the hydrolysis of starch; being of smaller molecular weight, 90 per cent. alcohol is required to precipitatc it from solution. The dextrins when pure do not give Moore's test, Trommer's, or other reduction tests; these are only given after hydrolysis to sugars has taken place. 


\section{CHAPTER VIII \\ ENZYMES OR FERMENTS}

THE chemist recognizes a class of bodies of far-reaching action called catalysts. A catalyst is a substance which by its presence hastens a chemical reaction. A catalyst cannot start a reaction. Chemical equilibrium depends on the laws of chemical dynamics, on the naturc of the reacting substances, their active mass or concentration, and external conditions such as temperature, pressure, etc. A catalyst cannot alter the equilibrium of forces, or the final transformation of energy due to a reaction. It can only, so to speak, oil the wheels of the machine. When dry hydrogen and oxygen gas are mixed, they combine to form water, but with such slowness that the reaction $2 \mathrm{H}_{2}+\mathrm{O}_{2} \rightleftarrows 2 \mathrm{H}_{2} \mathrm{O}$ escapes observation. Finely divided platinum acts as a catalyst, and enormously accelerates this reaction. The catalysts may accelerate a reversible reaction in either direction. Thus, in the common type of reaction,

\section{Acid and alcohol $\leftrightarrows$ ester and water,}

the acid ester in the presence of a great excess of water can almost wholly be split into acid and alcohol, while in strong concentration most of the acid and alcohol goes to form the ester. The same catalyst can accelerate this reaction in either direction according to the conditions.

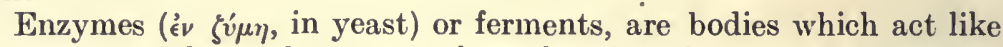
catalysts, and have the power of accelerating the rate of hydrolysis of certain substances or substrates. Probably all the reactions which takc place within living cells, or are produced in digests by the secretions of the cells, are accelerated by enzymes. It is the acceleration of any reaction which makes it manifest and effectual, for the transformation of energy produced by the reaction is concentrated in a short space of time. It was from the action of yeast that the term "fermentation" arose. The yeast sets the must in a ferment; it froths and bubbles. When the action of digestive juices came to be studied, it was seen to be of the same ferment nature, and a distinction came to be made bctween "organized" and "unorganized" fcrments. An organized ferment was the living cell, such as yeast, which brought about fermentation by the metabolism involved in its growth and multiplication. The unorganized ferment was contained in the juice secreted from a cell, and acted on a substrate at a distance from that cell-e.g., saliva acting on starch in the mouth and stomach. 
It was thought that only the living yeast organism could bring about this characteristic fermentation; after many attempts, however, a juice was expressed from the yeast cell which fermented no less well than the living organism; thus the distinction between the two kinds of ferments disappeared, and the term " organized ferment" became unnecessary.

When the action of enzymes, like those of yeast, is normally effected within the cell, the enzymes are grouped as "intracellular" enzymes, or endoenzymes; those which act when discharged from the cell are classed as "extracellular" enzymes, or exoenzymes. Under this latter group are placed the enzymes concerned in the processes of digestion. There are granules of a precursor, or zymogen, stored within the cells of the secreting glands of the stomach, pancreas, etc., and these are discharged in response to certain definite stimuli. The precursors when discharged require to be "activated "-i.e., turned into the active enzyme by the presence of some other body. Probably all enzymes require the presence of a "co-enzyme" before they manifest their full activity. Thus yeast juice can be squeezed through a porcelain filter candle impregnated with gelatin by a pressure of 300 atmospheres; the expressed juice is found to have no enzymic action until mixed with phosphates, and some other substance that is diffusible and not destroyed by boiling, which is left behind in the cell residues on the filter. These act as co-enzyme to the expressed juice. The "intracellular" enzymes are concerned intimately with processes of metabolism. If a piece of liver be kept under aseptic conditions, it will be found that the longer it is kept the less nitrogen it contains in the form of protein, the more in the form of products of protein disintegration. Thus, of the nitrogenous substances in some fresh liver, 90.4 per cent. were found to bc insoluble and 9.6 per cent. soluble in water. After keeping under aseptic conditions for twenty days, 39.4 per cent. of the nitrogenous compounds were found to be insoluble, and $60 \cdot 6$ soluble. Similar results have been obtained on keeping other organs, such as the spleen, thymus, kidney. The products of this sclf-digestion, or "autolysis," appear to be the same as those of ordinary intestinal digestion, but the different stages have not yet been worked out. Autolysis takes place in any part of the living organism when the blood-supply is shut off from it. Thus, if an artery be blocked by a thrombus, and the blood-supply cut off from part of the brain, it is found that the central part softens and undergoes autolysis. The same occurs in a part of the liver if the circulation be cut off from it. The chief circumstance favouring this change appears to be the increased acidity of the cell juice produced by want of oxygen. The peripheral parts do not undergo the same degree of autolysis, owing to the diffusion into them of oxygen and alkaline fluid from the neighbouring cells. Such changes take place anywhere in the body as the result of thrombosis or infarction. Autolysis also occurs in the living organism in acute yellow atrophy of the liver, in phosphorus-poisoning, and in certain acute fevers. The products of this digestion can in 
such cases be detceted in the urinc. It is supposed that therc are intracellular enzymes normally contained within the tissues; these enzymes, under the varying conditions of life, build up and break down the tissues according to the need of that tissue and of the body as a wholc. Under adverse circumstances, such as the shutting off of the blood-supply or the presence of toxins and poisons, the action may proceed mainly in the direction of disintegration.

Besides the enzyme concerned with the cell proteins, we have evidence of enzymes acting upon carbohydrates and fats. A striking example is the enzyme glycogenase, which forms glycogen from the dextrose brought to the liver cells, and as occasion needs reconverts this glycogen into dextrose. There are intracellular enzymes concerned in the formation of urea, uric acid, etc. From the liver alone at least fifteen enzymes have been isolated, which shows the great importance of the intracellular enzymes in the metabolic processes of the body.

Whether enzymes be extracellular or intracellular, they have the following well-marked properties:

1. Enzymes perform their action best at an optimum temperature. For the enzymes of our body this is $37^{\circ} \mathrm{C}$., the body temperature. Cold inihibits their action, but does not kill them, even when they are subjected (as has been the case with some unicellular organisms) to the great cold produced by evaporation of liquid air. Warming above the temperature of the body tends to inhibit, while temperatures varying from $55^{\circ} \mathrm{C}$. to $70^{\circ} \mathrm{C}$. destroy their action altogether.

2. They have an optimum medium in which they act. This is usually faintly alkaline (to litmus), and corresponds in the case of intraccllular enzymes to the reaction of the body tissue fluids. The pepsin contained in gastric juice acts best in an acid medium; others apparently work best in a ncutral medium. The enzymes of some micro-organisms work best in the absence of free oxygen, and are termed "anaërobic," in contradistinction to the cnzymes requiring free oxygen for their activity, which are called "aërobic."

3 . They are specific in action. Enzymes are classified according to the substratc upon which they act. There are, for example, proteolytic (protein-splitting), lipolytic (fat-splitting), amylolytic (starchsplitting), sucrolytic (sugar-splitting) enzymes, as well as several others. It is found that the proteolytic act only on protein, the starch-splitting only upon starch, and so forth.

Nevertheless, the active powers of some enzymes, which are secreted together, correspond so closely (for example, pepsin and rennin) that the double action may be manifestations of one parent substance. We may regard the parent substance as having different groups of "sidechains " attached to it, one group of side-chains acting as pepsin, the other as rennin. This idea is even more applicable where the sphere of action of some of them appcars to be so limited that it is difficult to conceive of the existence of a separate enzyme for each action.

Proteolytic (Protein-splitting) are pepsin, trypsin, and erepsin. Pepsin is the active proteolytic cnzyme of the stomach, trypsin 
of the pancreas. Erepsin occurs in the succus entericus, in the intestinal mucous membrane, and in the tissues generally. The main action of these enzymes (explained more fully later) may be synopsized thus:
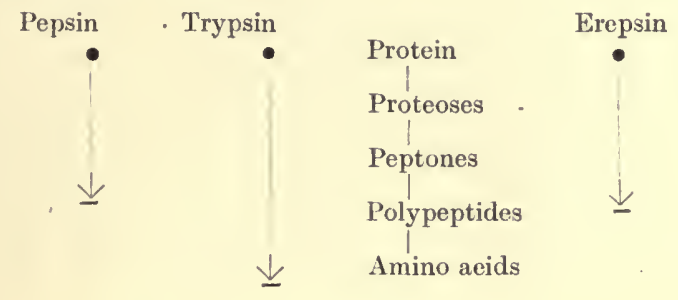

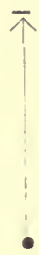

Erepsin (?)

Lipolytic (Fat-splitting) lipase or steapsin occur particularly in the gastric juice, pancreatic juice, and the blood:

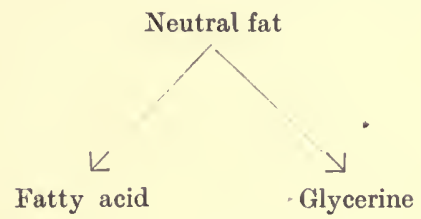

Amylolytic (Starch-splitting)-sometimes known as the diastases. "The chicf are the ptyalin of the saliva, which acts on boiled or soluble starch, and amylopsin of the pancreatic juice, which can act on unboiled starch.
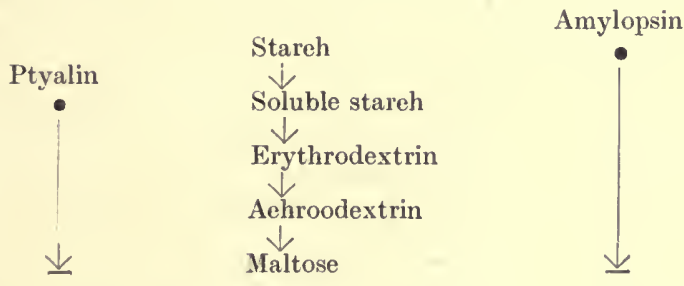

The glycogenase of the liver may perhaps be included in this group; it converts glycogen through similar stages to maltose.

Sucrolytic (Sugar-splitting).-These enzymes split the disaccharide sugar into monosaccharides. They occur chiefly in the succus entericus; their action may be expressed graphically as follows:
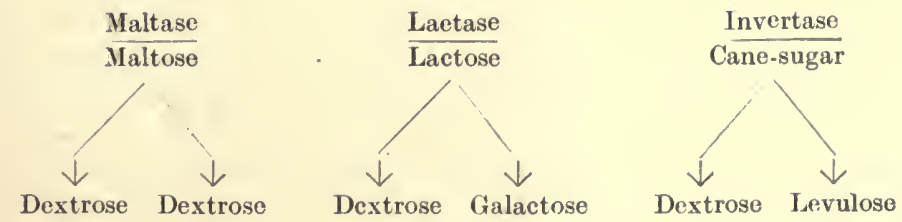
De-aminizing.-A group of enzymes which remove the $\mathrm{NH}_{2}$ groupfrom bodies, substituting therefor an $\mathrm{OH}$ group and forming ammonia. $-e . g$. :

$$
\begin{aligned}
& \mathrm{CH}_{3} \mathrm{CH} \cdot \mathrm{NH}_{2} \cdot \mathrm{COOH}+\mathrm{H}_{2} \mathrm{O}=\mathrm{CH}_{3} \mathrm{CHOH} . \mathrm{COOH}+\mathrm{NH}_{3} \\
& \text { Alanin Water Lactic acid Ammonia } \\
& \mathrm{C}_{5} \mathrm{H}_{3} \mathrm{~N}_{4} \cdot \mathrm{NH}_{2}+\mathrm{H}_{2} \mathrm{O}=\mathrm{C}_{5} \mathrm{H}_{4} \mathrm{~N}_{4} \mathrm{O}+\mathrm{NH}_{3} \\
& \text { Adenin Hypoxanthin Ammonia }
\end{aligned}
$$

Coagulative.-In this group are included "rennin," which helps. to bring about the clotting of milk, and "thrombin," which is believed to play a part in the coagulation of the blood. These actions are by no means identical; for whereas the product of the rennin action is still soluble, that of the thrombin action is insoluble:
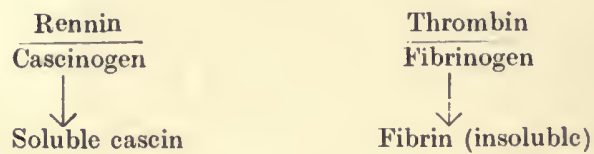

4. The action of cnzymes is inhibited by the accumulation of the products of activity. This is best seen in test-tube experiments. In the body such products are constantly being removed by absorption.

5. They are reversible in action. This has been shown to be true for a great number of enzymes, not yet for all. Reversible action was first shown with the sugar-splitting enzyme maltase. This enzyme usually splits maltose into two molecules of dextrose. In a test-tube experiment only a certain amount of maltose is converted into dextrose, the accumulating dextrose tending to stop the action. A point of equilibrium is therefore reached when there is present as the result of the enzymic action a certain amount of maltose and a certain amount of dextrose. If more maltose be added, the action goes on until the same proportion is reached. If dextrose be added, the enzyme reconverts some of the dextrose to maltose until the same point of equilibrium is again reached.

Another example is the enzyme (lipase) which, according to the conditions, breaks ethyl butyrate down into ethyl alcohol and butyric acid, or builds up ethyl butyrate from these bodies.

$$
\underset{\text { Ethyl butyrate }}{\mathrm{C}_{3} \mathrm{H}_{7} \mathrm{COOC}_{2} \mathrm{H}_{5}}=\underset{\text { Butyric acid }}{\mathrm{C}_{3} \mathrm{H}_{7} \mathrm{COOH}}+\underset{2}{\mathrm{C}_{2} \mathrm{H}_{5} \mathrm{OH}}
$$

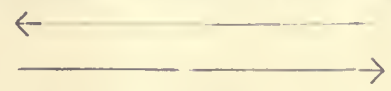

This reversible action is particularly important in the case of intracellular enzymes; with varying conditions of the blood and tissue. fluids the cells of the body may at one time act in a building-up. (anabolic), and at another time act in a breaking-down (katabolic), direction. 
6. They are inhibited by the action of antiseptics and disinfectants and kindred bodies. This statement is true for the enzymes found in the body, but not for all enzymes.

7. They are carried down from solution by flocculent precipitates. For this reason it is difficult to say whether enzymes are protein in nature or only carried down by the precipitated protein. Most enzymes are apparently closely associated with protein, although it is clained that some have been prepared which do not give the protein tests. They are colloidal in nature and indiffusible, and readily taken up by finely divided substances, such as kaolin, alumin, etc. In general they are soluble in dilute glycerine, sodium chloride solution, and dilute alcohol and water.

8. (a) They are precipitated from solution by alcohol and ammonium sulphate.

(b) The precipitate on redissolving in water again manifests enzymic characteristics. These facts $(6,7,8)$ show the intimate relationship that enzymes bear to other products of cell activity--e.g., bacterial toxins, hæmolysins, and such bodies.

9. By the presence of an enzyme a chemical action is accelerated without the enzyme itself being used up in the final reaction. One part of invertase can hydrolyze 100,000 parts of cane-sugar; one part of rennin acts on 200,000 parts of caseinogen. It is not possible to say whether an enzyme combines in any intermediate stage of the reaction. This is sometimes the case in other forms of catalytic action.

10. It was originally believed that the rate of action of enzymic activity was proportional to the square root of the amount of enzyme present. Recent investigations with more delicate methods tend to show that for most enzymes the intensity of action is almost directly proportional to the concentration of enzyme present.

11. The action of an enzyme may be hindered or stopped by the presence of a body known as an anti-enzyme. The exact manner in which these work is not sufficiently well known. Anti-rennin may be produced in the blood by the injection of rennin. The alimentary tract is believed to contain anti-enzymes which prevent the digestive enzyme from attacking it. Intestinal worms also contain antienzymes for the usual ferments of the digestive tract. Administration of an enzyme for which the worms (e.g., tape-worms) have no anti-enzyme (e.g., papain) brings about, their partial digestion, so that their removal from the body by a purge then becomes easy.

All the above-mentioned enzymes belong to a class the mode of action of which is hydrolytic. Besides these therc exists in the body a group of enzymes, "the oxidases," which plays a great part in the oxidative processes of the body. These are generally divided into two groups: the primary, or direct oxidases, which can transfer oxygen directly to other bodies; the indirect, or peroxidases, which transfer oxygen only in the presence of a peroxide, from which they set the 
oxygen free and then transfer it to the body to be oxidized. An example of oxidizing action occurring in the body is the following:

$$
\underset{\text { Hypoxanthin }}{\mathrm{C}_{5} \mathrm{H}_{4} \mathrm{~N}_{4} \mathrm{O}}+\underset{\text { Xanthin }}{\mathrm{C}_{5} \mathrm{H}_{4} \mathrm{~N}_{4} \mathrm{O}_{2}}+\underset{\text { Uric acid }}{\mathrm{O}}=\underset{\mathrm{C}_{5}}{\mathrm{H}_{4} \mathrm{~N}_{4} \mathrm{O}_{3}}
$$

The oxidases give a blue colour with tincture of guaiacum alone, the peroxidases with tincture of guaiacum in the presence of peroxides.

According to recent investigations, it is claimed that oxidases are in reality a mixture of oxygenases, bodies containing iron and manganese, and peroxidases. The oxygenase in the process of oxidation is believed to take up molecular oxygen and become converted into peroxide. This peroxide is then activated by the peroxidases, and has a great oxidizing power.

It is possible that certain of the reductions taking place in the body may be ascribed to the presence of enzymes known as "reductases." More light is required on this subject; some of the eductions in the body are apparently not of an enzymic nature. 


\section{BOOK II}

\section{CHAPTER IX}

\section{THE BLOOD}

ALL the cells of a multicellular organism are engaged in building-up (anabolic) and breaking-down (katabolic) processes. In the unicellular these processes are performed by a direct interchange between the single cell and the surrounding medium, but in the higher organizations special fluid tissues - the blood and the lymph-have been evolved, which circulate in order to supply the requisite conditions for these metabolic processes. The functions of the blood may be summarized as follows:

1. To act as the medium of absorption and exchange between the alimentary canal, the lungs, and the tissues, and to supply the sources of energy (food, oxygen) to the tissues for metabolic purposes.

2. To supply to the tissues a medium consisting of water, colloids and electrolytes (inorganic salts) of a concentration and osmotic pressure kept constant within narrow limits, in which they are able to carry out their vital processes.

3. To convey from one organ to another the internal sccretions and the hormones (chemical messengers), which regulate the activity of the organs.

4. To convey the products of katabolism from the tissues to the organs of excretion, the lungs and kidneys.

5. To endow the body with a mechanism protective against harmful micro-organisms.

6. In the higher animals to distribute and help to regulate the heat of the body.

7. By its power of elotting to seal up wounds and prevent serious loss of blood or tissue lymph.

The blood is a thick, viscous liquid, with a saltish taste and a peculiar faint odour. When viewed under the microscope it is seen to consist of a transparent liquid, the blood-plasma, in which float a number of formed bodies, the red and pale corpuscles of the blood. According to some authorities, there is a third solid component-the blood-platelets. 
The Colour of vertebrate blood varies from a bright red in the blood of the arteries to a deep purple-red in the veins. It is due to a pigment-hæmoglobin-whieh is eontained within the red corpuscles of the blood and aets as the earrier of oxygen. The blood of invertebrates and eordates may be either eolourless or possess one of a variety of colours. Hæmoglobin oeeurs in solution in the plasma of many of the worms and lower erustaeea. The eehinoderms also possess a red pigment in their blood (echinoehrom). Some erustacea have a blue pigment-hæmocyanin-which eontains eopper and is in solution in the blood. It is blue in the arterial blood, when combined with oxygen, and colourless in venous blood-i.e., when deoxygenated. Its combining power for oxygen is only about one-fourth that of hæmoglobin. Some worms eontain a green pigment (chloroeruorin); others a red pigment (hæmoerythrin). Certain molluses and tunicates possess eolourless blood and yet have substanees in it capable of eombining with oxygen and transporting it to the tissues (aehroglobin).

The Specific Gravity of the blood of man varies between 1055 and 1060. The red corpuscles have a specific gravity of 1080 and the plasma one of 1030. The speeific gravity is usually obtained by the following method. By means of a pipette a drop of blood is placed in the middle of a mixture of benzol (sp. gr. 0.88) and chloroform (sp. gr. 1.485). The mixture has a speeific gravity approaehing that of blood. If the blood-drop falls, more ehloroform is added; if it rises, more benzol-until a condition is obtained when the corpuselc remains suspended in the mixture. The specific gravity of the mixture is now taken with the hydrometer. The operation must be quickly performed ( 1 to 2 minutes), otherwise the specifie gravity of the blood alters owing to diffusion taking plaee between the blood and the liquids. The specific gravity is influenced by the number of eorpuscles and the amount of hæmoglobin. It is high in the new-born (1066). It sinks in starvation, after hæmorrhage, in anæmias, and in diseases of the kidney, ete.

\begin{tabular}{|c|c|c|c|c|c|c|c|}
\hline \multicolumn{8}{|c|}{ Specific Gravity of Blood. } \\
\hline an & . & . & .. 1056-1061 & Rabbit & & $\cdots$ & $10+2-1062$ \\
\hline Woman & • & .. & $1053-1061$ & Of serum & .. & .. & $1030-1042$ \\
\hline Dog ... & .. & .. & .. 1060 & Of red corpuscles & .. & .. & $1080-1085$ \\
\hline
\end{tabular}

The specific gravity varies with the age and sex; it is diminished after eating and inereased by exereise. It gradually falls during the day and rises during the night.

Reaction.-The reaetion of a fluid depends upon the number of free hydrogen $(\mathrm{H})$ ions in it, which give an aeid reaetion relative to the number of free hydroxyl $(\mathrm{OH})$ ions, whieh give a basie or alkaline reaction.

Blood is almost neutral in reaetion as determined by the electrical method. Its reaction to litmus is slightly alkalinc. This is because litmus aets as a weak aeid, and, displacing carbonie acid gas from its combination in the blood (carbonate), combincs with the base and turns 
blue-the alkaline reaction. To phenolphthalein blood is neutral, for this reagent cannot decompose the carbonates. Blood can take up a certain amount of acid before it begins to react acid. This is because it contains carbonates ("buffer salts") and proteins which combine with the acid. It is for this reason that it is difficult to ascertain the reaction of the blood by chemical means. Titrating with acid, the amount of neutralizable alkalinity is obtained, alkali being liberated in the process from the proteins and by dissociation of the carbonates $\left(\mathrm{Na}_{2} \mathrm{CO}_{3}, \mathrm{NaHCO}_{3}\right)$ and the phosphates $\left(\mathrm{Na}_{2} \mathrm{HPO}_{4}\right)$. This neutralizable alkali usually equals 350 to 400 milligrammes $\mathrm{NaHO}$ per 100 c.c. But the real alkalinity, as measured by the electrical method, is due to free $\mathrm{OH}$ ions, and these are usually present in a concentration little greater than in water. $\mathrm{Na}_{2} \mathrm{CO}_{3}$ in aqueous solution is dissociated, more or less, into the ions $2 \stackrel{+}{\mathrm{Na}}$ and $\mathrm{C \overline {O }}_{3}$. Some of the $\overline{\mathrm{CO}}_{3}$ ions combine with $\stackrel{+}{\mathrm{H}}$ ions of the dissociated water, forming $\mathrm{HCO}_{3}$, and $\overline{\mathrm{H}} \mathrm{O}$ ions are thus set free to produce the alkaline reaction. On adding acid

these $\overrightarrow{\mathrm{H} O}$ ions are removed, and, the equilibrium bcing disturbed, more $\mathrm{Na}_{2} \mathrm{CO}_{3}$ is dissociated, and this goes on until all the $\mathrm{Na}_{2} \mathrm{CO}_{3}$ is dissociated. The alkali existing as salts, carbonates, and phosphates, is known as diffusible alkali; that combined with protein is termed non-diffusible alkali. As the corpuscles are richer in diffusible alkali than the plasma, the number of corpuscles modifies the amount of neutralizable alkali.

On passing carbon dioxide gas through blood, the loose combination between alkali and protein of both the plasma and corpuscles is split up, and sodium carbonate partly formed. $\mathrm{CO}_{3}$ ions pass from the corpuscles into the plasma, and $\mathrm{Cl}$ ions from the plasma into the corpuscles, and as the sodium carbonate in the plasma is increased, so is the neutralizable alkalinity.

It is very difficult to affect the reaction of the blood by swallowing acids. Two drachms of official hydrochloric acid taken with food have no effect upon the reaction of the blood, because the acid combines with the proteins of the food, etc.; two drachms of tartaric acid, on the other hand, may diminish the neutralizable alkalinity. These acids combine with the bases and form salts which are little dissociated.

Acids entering the blood are neutralized by combination with ammonia, a product of protein katabolism, or by union with bases of the carbonates, carbonic acid being expired. Alkalies are neutralized by the carbonic acid produced in the body. The blood is thus kept neutral while the amount of acid or alkali passing into it varies considerably. Muscular exertion diminishes the titration alkalinity owing to the production of lactic acid. The concentration of the $\mathrm{H}$ ions in the blood regulates the activity of the respiratory centre; lactic acid and carbonic acid are both produced on exertion, and their cumulative effect produces dyspnœe. The "buffer salts" help to regulate this. 
The Amount of Blood.- This varies according to the method by which it is determined and for different animals. The following table gives some of the results which have becn obtained:

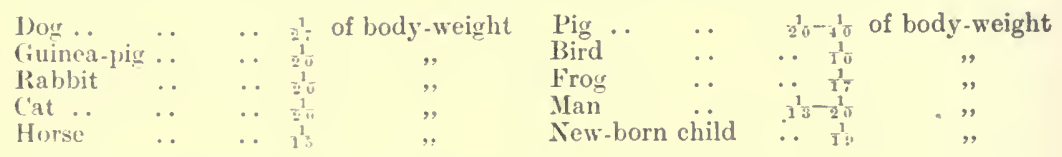

It is stated in man to rary from $3 \frac{1}{2}$ to 4 litres.

The old method (that of Wclcker) of obtaining the amount of blood of an animal was (1) to bleed the animal into a weighed flask, (2) remove all traces of blood by perfusing the vessels thoroughly with water, (3) chopping up the body with the exception of the intestines and washing the choppings in water. The washings are measured and the amount of blood in them gauged by determining the amount of hemoglobin-by finding how much the blood must be diluted to conrespond in depth of tint to that of the washings. This method is not verv exact. sinee during the death from hæmorrhage the tissue fluids pass into the blood, giving too high a result.

In man the amount has been ascertained by, the carbon monoxide method. In this method the subject breathes, through a tin of soda lime to absorb exhaled $\mathrm{CO}_{2}$. in and out of a bag containing a known volume of earbon monoxide mixed with a sufficiency of oxygen. Carbon monoxide has a strong affinity for hæmoglobin, and combine; with this. displacing oxygen. After sufficient time for the whole of the ('O to be absorbed a sample of the. subject's blood is taken and the percentage saturation of the blood with carbon monoxide determined. The carbon monoxide gives the blood, suitably diluted, a pink eolour, and the determination is effected by comparing the tint of (1) the sample, with (2) a sample of the subject's normal blood, (3) a sample of the subject's blood saturated with $\mathrm{CO}$, all threc samples being diluted 1 in 200 . A standard carmine solution is added to (1) and (2) till the tint of each equals that of (3). Suppose twice as much carmine has to be added to (2) as to (1), then (1) is half saturated with $\mathrm{CO}$. The amount of $\mathrm{O}_{2}$ or $\mathrm{CO}$ which can combine with 100 c.c. of the subject's blood is found by the use of the Haldane-Gowers hemoglobinometcr. The amount of $\mathrm{CO}$ absorbed is known, and thus, if it be found that blood is 25 per cent. saturated and the person has absorbed 150 c.c. of $\mathrm{CO}$, it is obvious that all the blood will require 600 c.c. of $\mathrm{CO}$ to saturate it. If it is found that 100 c.c. of the blood are saturated by 20 c.c. of carbon monoxide or oxygen, the total rolume of the blood is $\frac{600 \times 100}{20}=3,000$ c.c., etc.

By this method the amount of blood in man is reckoned to be about $: \frac{1}{\pi}$ of the body weight $\left(\frac{1}{30}\right.$ for fat men). Generally speaking, this method gives a lower value than the other, and there has been a considerable amount of discussion recently as to the accuracy of the ('O method. CO is taken up by the hæmoglobin in the muscles; the 
amount of this seems to inerease with age, even equalling 5 or 6 per eent. of the whole $\mathrm{Hb}$ content of the body. This is a source of error. The more muscular animals with darker flesh have more $\mathrm{Hb}$ in their muscles-e.g., hare more than rabbit, duck than fowl. It is claimed by 'authorities who have made careful experiments by the bleeding method that this is really the more exact, and that the quantity of blood in an animal bears a definite relationship to the amount of the body surface. These observers used oxygenated Loeke's fluid to wash out the circulatory system, and so avoided the transferenee of tissue fluid into the blood. $\mathrm{B}=\mathrm{W}^{n} / k$-where $\mathrm{B}$ is the blood-volume in eubic eentimetres, $\mathrm{W}$ the weight of the body in grammes, $n 0.70-0.72$, and $k$ a eonstant (calculated from experiments) determined for eaeh speeies of animal. The body surface is usually calculated from the body weight by the formula $\mathrm{S}=k . \mathrm{W} \frac{2}{3}(0 \cdot 70-0.72$ is more aecurate

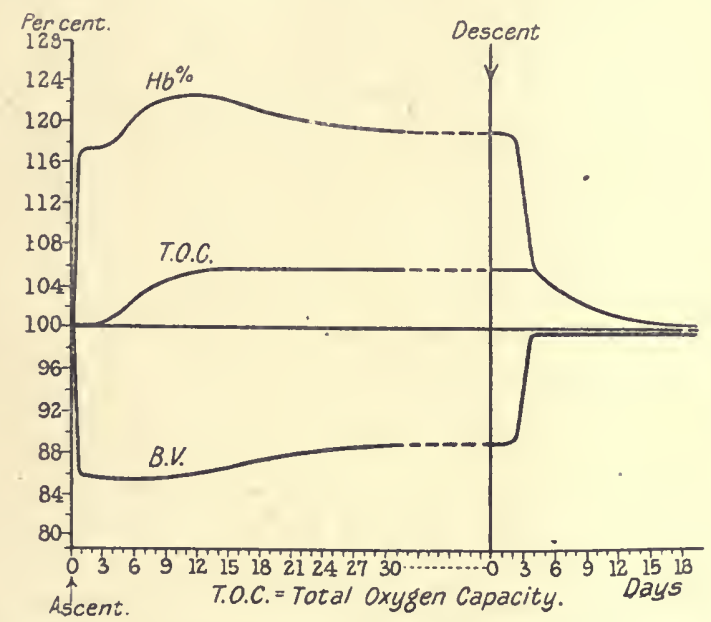

Fig. 18.-Effect of High Altitude on Blood. (Dreyer and Wal ker.)

than $\left.\frac{2}{3}\right)$. The smaller and lighter animals, which have a relatively greater body surface than the heavier ones, have also a relatively greater blood-volume. This agrees with their relative rates of body heat loss and metabolism, and also with the sectional arcas of their tracheæ and aortæ and weight of heart musele. A wild-rabbit eontains 25 per eent. less blood and 25 per cent. more hrmoglobin in its blood than a tame rabbit of the same weight. A wild-hare contains double the blood-volume, 30 per cent. more hæmoglobin, and three times more heart muscle than a wild-rabbit of the same wcight. No doubt the same kind of difference exists between an athlete and sedentary worker.

In travellers to high altitudes the blood becomes eoncentrated and the oxygen eapaeity inereased (Fig. 18). The eoncentration happens in the first day or two, and is due to withdrawal of plasma. After some wceks the number of eorpuscles and the total amount of 
hæmoglobin are found increased by the new formation of corpuscles in the red marrow. In rabbits taken from Basle (740 millimetres barometric pressure) to St. Moritz (620 millimetres) the total hæmoglobin increased 12 per cent. and the blood-volume decreased 11 per cent. The increase in the percentage of hæmoglobin was 12 per cent. Thus the body compensated for the attenuation of the air and lowered partial pressure of oxygen.

Cooling or bandaging a limb concentrates the blood therein. The breathing of an excess of $\mathrm{CO}_{2}$ and the taking of amyl nitrite dilutes, of chloral hydrate concentrates, the blood.

The Osmotic Pressure.-The osmotic pressure of the whole blood is measured by the depression of the freezing-point. Generally $\Delta=-0.56^{\circ} \mathrm{C}$. for human blood, but varies from $-0.51^{\circ} \mathrm{C}$. to $-0.62^{\circ} \mathrm{C}$. with the diet and amount of fluid ingested. If the products of metabolism increase in the blood, owing to the fact that they are not properly eliminated by the kidneys, $\triangle$ may be increased. According to some observers, if $\Delta$ constantly equals or exceeds $-0.58^{\circ} \mathrm{C}$. it is a sign that both kidneys are diseased.

The Electrical Conductivity of the Blood.-As the blood-plasma contains inorganic salts (electrolytes) in solution, it has the property of conducting an electric current. Defibrinated blood is generally employed for this measurement. The conductivity varies with the relative proportion of corpuscles and serum-being low with many corpuscles and less serum, high with relatively few corpuscles and much serum. In cases of anæmia the conductivity is greatly increased. The corpuscles, owing to their colloid nature, lessen the conductivity.

Viscosity.-Blood compared to water is relatively a viscous fluid. Its viscosity may be determined by allowing blood to flow under a definite pressure through a capillary tube of known dimensions, and measuring the outflow in a given time Taking the viscosity of water as 1 , that of the blood of man is $5 \cdot 1$; that of $\operatorname{dog}, 4 \cdot 7$; that of the cat, $4 \cdot 2$. Viscosity generally varies in the same direction as the specific gravity. Sweating increases it; increased temperature, on the other hand, diminishes it.

In the condition known as polycythæmia the viscosity may become 9 or 10 times that of water. In this condition the red bloodcorpuscles are greatly increased in number in proportion to the plasma, reaching as many as $11,000,000$ per c. $\mathrm{mm}$. On the other hand, in the form of anæmia known as chlorosis or "green sickness," because of the greenish look of the patient, the plasma is greatly increased in amount, so that the corpuscles are relatively diminished, and the viscosity of the blood is also much diminished, often to just over 2. The flow of the blood is so controlled by the vaso-motor system that slight alterations in viscosity are of little if any account.

Analysis.-The most accurate analyses of the blood have been done upon that of animals; the following table shows the quantitative composition of the blood in the ox, horse, and man: 


\begin{tabular}{|c|c|c|c|c|c|c|c|}
\hline & \multirow[t]{2}{*}{ - } & \multicolumn{2}{|c|}{ Ox Blood. } & \multicolumn{2}{|c|}{ Horse Blood. } & \multicolumn{2}{|c|}{ Human (Man). } \\
\hline & & $\begin{array}{l}\text { Cor- } \\
\text { puscles } \\
325 \cdot 5 .\end{array}$ & $\begin{array}{c}\text { Serum } \\
674 \cdot 5\end{array}$ & $\begin{array}{c}\text { Cor- } \\
\text { puscles } \\
397 \cdot 7 .\end{array}$ & $\begin{array}{c}\text { Serum } \\
602 \cdot 3 .\end{array}$ & $\begin{array}{c}\text { Cor- } \\
\text { puscles } \\
513 \cdot 02 \text {. }\end{array}$ & $\begin{array}{l}\text { Serum } \\
486.98 .\end{array}$ \\
\hline \multirow{5}{*}{$\begin{array}{l}\text { Water } \\
\text { Solids }\end{array}$} & .. & $192 \cdot 65$ & $616 \cdot 25$ & $245 \cdot 87$ & $551 \cdot 14$ & $349 \cdot 69$ & $439 \cdot 02$ \\
\hline & $\ddot{\ddot{r}} \quad \because$ & $132 \cdot 85$ & $58 \cdot 25$ & $153 \cdot 84$ & $51.15^{\circ}$ & $163 \cdot 33$ & $47 \cdot 96$ \\
\hline & / Hæmoglobin & $103 \cdot 10$ & - & $125 \cdot 8$ & - & 一 & 一 \\
\hline & Protein & $20 \cdot 89$ & $48 \cdot 90$ & $20 \cdot 05$ & $42 \cdot 65$ & - & 一 \\
\hline & $\begin{array}{l}\text { Sugar } \\
\text { Cholestcrin }\end{array}$ & $\overrightarrow{1 \cdot 10}$ & $\begin{array}{l}0 \cdot 708 \\
0 \cdot 835\end{array}$ & $\overline{0 \cdot 2}$ & $\begin{array}{l}0 \cdot 90 \\
0 \cdot 31\end{array}$ & 二 & 二 \\
\hline \multirow{6}{*}{$\begin{array}{l}\text { Organic } \\
\text { substánces }\end{array}$} & $\begin{array}{l}\text { Cholestcrin } \\
\text { Lecithin }\end{array}$ & $1 \cdot 22$ & $\begin{array}{l}0.833 \\
1 \cdot 129\end{array}$ & 1.93 & 1.05 & $159 \cdot 59$ & $43 \cdot 82$ \\
\hline & Fat . & - & $0 \cdot 625$ & - & $0 \cdot 50$ & E & 一 \\
\hline & Fatty acid & $\overrightarrow{0 .}$ & $\overrightarrow{0}$ & $0 \cdot 02$ & $0 \cdot 36$ & $=$ & $\overrightarrow{14}$ \\
\hline & $\begin{array}{c}\text { Phosphoric acid } \\
\text { as nuclein }\end{array}$ & 0.017 & $0 \cdot 0089$ & 0.05 & 0.01 & $3 \cdot 74$ & $4 \cdot 14$ \\
\hline & Soda & $0 \cdot 726$ & $2 \cdot 908$ & 一 & $2 \cdot 62$ & $0 \cdot 24$ & $1 \cdot 66$ \\
\hline & Potash & $0 \cdot 235$ & $0 \cdot 17$ & $1 \cdot 32$ & $0 \cdot 1$ & $1 \cdot 59$ & $0 \cdot 15$ \\
\hline & Iron oxide & $0 \cdot 54$ & & $0 \cdot 59$ & - & - & 一 \\
\hline \multirow{4}{*}{$\begin{array}{l}\text { Inorganic } \\
\text { substances }\end{array}$} & Magnesia & $0 \cdot 005$ & 0.03 & $\overline{0 \cdot 04}$ & $0 \cdot 03$ & 二 & 二 \\
\hline & Chlorine & $0 \cdot 59$ & $2 \cdot 48$ & $0 \cdot 18$ & $2 \cdot 20$ & $0 \cdot 90$ & $1 \cdot 72$ \\
\hline & Phosphoric acid & $0 \cdot 239$ & $0 \cdot 16$ & 0.9 & $0 \cdot 15$ & 一 & 一 \\
\hline & (Inorganic $\mathrm{P}_{2} \mathrm{O}_{5}$ & $0 \cdot 114$ & 0.057 & $0 \cdot 76$ & $0 \cdot 05$ & - & 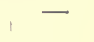 \\
\hline
\end{tabular}




\section{CHAPTER X}

\section{THE PLAS MA}

THE plasma in which the blood-corpuscles float is like the middleman, and barters between the tissues. Its composition summarizes the building-up and breaking-down processes of the body. It carries the necessary nutriment from the alimentary tract to the tissues, and foodstuffs to and from the food depots of the body. It carries also the necessary water and salts to the tissues, thereby surrounding them with a medium in which they can carry out their activities. Protoplasm yields 70 to 90 per cent. of water, and this proportion has to be maintained, or damage, and cventually death, ensue.

The electrolytes in solution are of the greatest importance, as demonstrated by the fact that a frog's heart beats for days in a solution containing potassium, sodium, and calcium salts in the proportion contained in blood. If, however, there be too much soluble calcium salts present, the heart ceases to beat, stopping tightly contracted in the state known as systole. If too much soluble potassium salt be present, the heart stops beating in a flabby, relaxed condition known as diastole. The nummalian heart may beat for days in the same solution if it is warmed to body temperature and oxygenated by bubbling oxygen gas through it.

The unfertilized eggs of sea-urchins and other animals can be made to develop into larvæ by altering the concentration of certain electrolytes in the sea-water. It is possible that some of the conditions of ill-health and disease may be due to an altered relationship of the salts of the plasma, disturbing the vital processes. At present it is not possible for us to investigate this proportion of salts; it is apt to be little considered or even overlooked altogether. Salts are constantly leaving the body in the urine, and unless they are replaced in the proper amount salt starvation occurs. An animal deprived of salts dies just as soon as an animal cut off from food. Besides the waste products formed in the different organs as a result of their activity, the plasma may receive from certain tissues special substances which have been elaborated by them. Such bodies are the so-called internal secretions. They play a great part in regulating the various functions of the body. Sometimes, too, a special messenger, or "hormone," is added to the p'asma. For example, blood leaving the upper part of the small intestine during digestion takes away in the plasma a messenger, or hormone, named secretin. The sccretin on reaching the pancreas in the course of the 
circulation, delivers, so to speak, a message that more pancreatic juice is required; the pancreas is thrown into a state of activity and secretes the necessary juice. Another example is furnished by the - ovary. When the mother becomes pregnant, the corpus luteum in the ovary elaborates a hormone which, passing into the maternal circulation, causes the large development of mammary tissue which takes place previous to the birth of the young. It has also been suggested that the embryo elaborates a hormone which, passing into the maternal blood, further stimulates the growth of the mammary gland. After birth this hormone no longer circulates, since its source is removed; the breast tissue is no longer built up, but, on the contrary, the lack of hormone leads to a breaking down of this proliferated tissue with the formation of the first milk necessary to the young which have been born.

It is questionable whether the plasma contains enzymes. It has no sugar-destroying ferment, but probably contains a lipase, which plays a part in the fat metabolism of the body.

The plasma is greatly concerned with the defences of the body against poisonous substances or living intruders. . It provides a medium in which the white corpuscles live, and one of their functions is to migrate to the scene of attack and, if possible, repel or kill invading bacteria. But besides the leucocytes there are in the blood defensive substances known as antitoxins, immune bodies. These enable the body either actively to neutralize, or in other ways to render ineffective, the harmful substances which may effect an entrance.

- Plasma may be most readily obtained by receiving horse's blood into a cooled vessel and allowing it to stand. The corpuscles sink and the plasma comes to the top. Blood which has been kept from clotting by the addition of neutral salts may be centrifuged; "salted" plasma is thus obtained. Sodium citrate or potassium oxalate may be employed to decalcify the blood and prevent clotting.

The plasma must be regarded as a living tissue. It is always to be borne in mind that the substances, considered below, obtained by submitting to analysis living tissues, are dead products. The constitution of the living protoplasm is a complex the nature of which is only surmised.

The Proteins.- On analysis 7 to 8 per cent. of proteins are obtained; these can be separated into three by the method of salting outfibrinogen, serum globulin, and serum albumin. The amount of fibrinogen is very small, 0.2 to 0.7 per cent. Present in blood-plasma, but not in the serum, it is this protein which is concerned in the process of clotting.

Serum globulin is precipitated by half-saturation with ammonium sulphate or full saturation with magnesium sulphate. Scrum albumin requires full saturation with ammonium sulphate. Fibrinogen is thrown down by half-saturation with sodium chloride.

Serum globulin is soluble in dilute saline solutions, but not in distilled water. It is therefore precipitated from solution when the 
salt is removed by dialysis, or by great dilution with water. It coagulates at $69^{\circ} \mathrm{C}$. to $75^{\circ} \mathrm{C}$, and has a levorotatory power of $-47 \cdot 8^{\circ}$. It is possible that it is not one single body, sinee by differenees in solubility and preeipitability two bodies have been obtained-euglobulin, easily preeipitated by 28 to 36 per eent. of ammonium sulphate; and pseudo-globulin, requiring 36 to 44 volumes per cent. of this salt.

Aeeording to some observers, after coagulation has taken place there is found in the serum a fibrin globulin whieh is formed as a product when fibrinogen is converted into fibrin. It is apparently almost identieal with fibrinogen.

Fibrinogen is a body of the globulin type, coagulated by heat at about $56^{\circ} \mathrm{C}$. It is precipitated from solution by half-saturation with sodium chloride. The precipitate may be redissolved in dilute saline, and the solut:on thus obtained clotted at $37^{\circ} \mathrm{C}$. by the addition of a trace of blood-serum. This experiment is important to the theory of the clotting of blood.

Serum albumin is a body soluble in water and not preeipitated from solution by magnesium sulphate. Its eoagulation temperature varies aecording to the amount of salt present in the solution. Dissolved in distilled water it coagulated at about $50^{\circ} \mathrm{C}$.; with salts present in the solution the temperature of eoagulation is higher. When a solution of serum albumin almost saturated with ammonium sulphate is allowed to coneentrate by standing, crystals of a eompound of albumin with the salt fall out.

The source of the proteins yielded by plasma is not known. The yield of fibrinogen is said to depend on the liver. Blood, the circulation of which is confined to the heart and lungs, loses its property of eoagulability, whereas blood eirculated through the liver has an inereased coagulative power. According to one theory of protein metabolism $(q . v$.$) , the blood-proteins are formed out of the protein$ products of digestion at the time of the passage of these through the intestinal wall into the blood.

The amount of protein yielded by the plasma is said to vary in certain diseased eonditions. In cases of infeetion, such as pneumonia, it is inereased, particularly the fibrinogen moiety. Globulins are said to be inereased relatively to the albumin (the so-called "protein (quotient") in parenchymatous nephritis. The normal proportion is $-4 \frac{1}{2}: 3$ in man. It varies in different animals. The plasma of coldblooded animals chiefly yields globulins. In the regeneration of the plasma after hæmorrhage the albumin is formed first, and afterwards the globulin. Closely allied to the globulin portion of the blood are the protective substanees, such as antitoxins, hæmolysins, bacteriolysins, precipitins, ete. Some observers state that proteoses, peptones, and amino-acids, are to be found in the blood. This, however, is strenuously contested by others.

Lipoids.-Fat in a very finely emulsified form and soaps are found in the blood. The amount in normal human blood raries aceording to the diet, being increased by the taking of milk or other fat. It 
varies normally from 1.8 to 0.85 per cent. In the pregnant animal the fat content of the plasma is much increased.

The lipoids lecithin and cholesterin are also present in the plasma, and probably play a consideable part in the protective mechanisms of the body, as well as furnishing a supply of these bodies to the other tissues.

Carbohydrate.-Dextrose is normally present; the percentage found varies from 0.06 to $0 . \mathrm{l}$. If the content is raised above the latter figure, the excess is excreted in the urine. It is a question whether the dextrose is free in solution or loosely combined with the proteins; a small amount of it is combined with lecithin to form a substance known as jecorin. The presence of glycuronic acid has been demonstrated in the serum. It is usually combincd as compound glycuronates. It has been recently shown that the red corpuscles contain sugar.

The salts obtained from plasma form 1 to 2 per cent. of its weight, and are chiefly sodium chloride, with traces of calcium, potassium, and magnesium chloride and phosphate.

The straw-yellow colouring matter of the plasma can be extracted with amyl al:ohol, and is called lipochrome.

The gases of the plasma will be dealt with later.

The plasma contains various antienzymes, immune bodies, complcment, etc., the presence of which is detected by biological tests.

The chief products of katabolism of the various foodstuffs, presence of which has been demonstrated in the plasma, are urea $(0.02$ to $0 \cdot 1$ per cent.), uric acid, creatin, creatinin, and traces of ammonia. While it is questioned whether amino-acids are normal constituents of plasma, they are undoubtedly present when any organ or tissue is digesting itself (autolysis), as in phosphorus poisoning, acute yellow atrophy of the liver, etc. They then make their appearance in the urine.

The plasma under diverse conditions is found to have a most striking consistency in composition. Thus, after the intravenous injection of water or salt solution the blood is rapidly brought to the normal composition. The tissues give or take from the blood, the glands secrete and kidneys excrete for this purpose. Even during starvation its composition is maintained. 


\section{CHAPTER XI}

\section{THE CORPUSCLES OF THE BLOOD}

The Red Blood-Corpuscles.-The red blood-corpuscles, or erythro. cytes, are the clements to which is due the red colour of the blood of all the vertebrate animals except Amphioxus, which has colourless blood. They were first scen in human blood by Leuwenhoek in 1673 . They had been previously seen in frog's blood by Swammerdam in 1658 .

Human red blood-corpuscles are non-nucleated biconcave discs having a diameter of about 7 to $8 \mu$. Two views are held as to their structure. According to one view they are to be regarded as capsules containing the red pigment, hæmoglobin $(\mathrm{Hb})$ - probably in a special colloidal state. The amount of the pigment is so great that it could not bc in solution. A red corpuscle contains 32.05 per cent. $\mathrm{Hb}$, and only 63.21 per cent. water, and so strong a solution of $\mathrm{Hb}$ cannot be made. The other view regards them as consisting of a stroma or network in which the pigment is enmeshed. In either case the outer surrounding structure is protein in nature, richly impregnated with lecithin and cholesterin. It has been suggested, but not proven, that these lipoid bodies stand guard over the corpuscles, and determine what substances may pass into the corpuscles and what may not.

The form of the red corpuscle varies in different species. Man and the other mammalia, with the exception of the camelidæ (camel, llama, etc.), have non-nucleated biconcave discs. Camels have long non-nucleated elliptical corpuscles. Birds, reptiles, fish, have elliptical nucleated corpuscles. The number to each cubic millimetre varies in general with the size-the larger the corpuscle, the smaller the number per cubic millimetre. The following table shows the size and number per cubic centimetre in various animals:

\begin{tabular}{|c|c|c|c|c|c|c|}
\hline & Length. & Breadth. & \multirow{2}{*}{$\begin{array}{c}\text { No. per c. } m \text { m. } \\
36,000\end{array}$} \\
\hline Proteus an & inus & $\ldots$ & & $62.5 \mu$ & $34.5 \mu$ & \\
\hline Frog. & .. & .. & .. & $25, \mu$ & $14.5 \mu$ & 404,000 \\
\hline Chaffinch & . & .. & . & $12 \cdot+\mu$ & $7.5 \mu$ & $3,600,000$ \\
\hline Man .. & .. & .. & .. & $7.9 \mu$ & - & $5,000,000$ \\
\hline Goat .. & .. & .. & .. & $5 \cdot 5 \mu$ & - & $9,500,000$ \\
\hline Llama .. & . & .. & .. & $8 \cdot 0 \mu$ & $4 \mu$ & $14,000,000$ \\
\hline
\end{tabular}

The corpuscles are endowed with elasticity, and alter their shape in passing through the capillaries. The red corpuscles represent 
35 to 40 per cent. of the weight of the blood. This can be ascertained by centrifuging blood in a fine graduated capillary tube known as a hæmatocrit. If done with a very rapid centrifuge, fresh blood may be used; otherwise oxalated or citrated blood is employed. The number of corpuscles is greatly reduced in anæmia. Normally there are 5,000,000 to 5,500,000 per cubic millimetre in man's blood, $4,500,000$ to $5,000,000$ in woman's blood ( 15 to 25 billions in the whole blood of a man with a surface of 1,000 to 1,700 square metres). The number por c.mm. varies from time to time; it is stated to be diminished after drinking much fluid and during pregnancy, increased after profuse sweating, after exercise, after hot and cold baths, in the blood of the new-born, and in venous stasis.

At high altitudes the number of the corpuscles and the $\mathrm{Hb}$ content of the body is inereased (see Fig. 18).

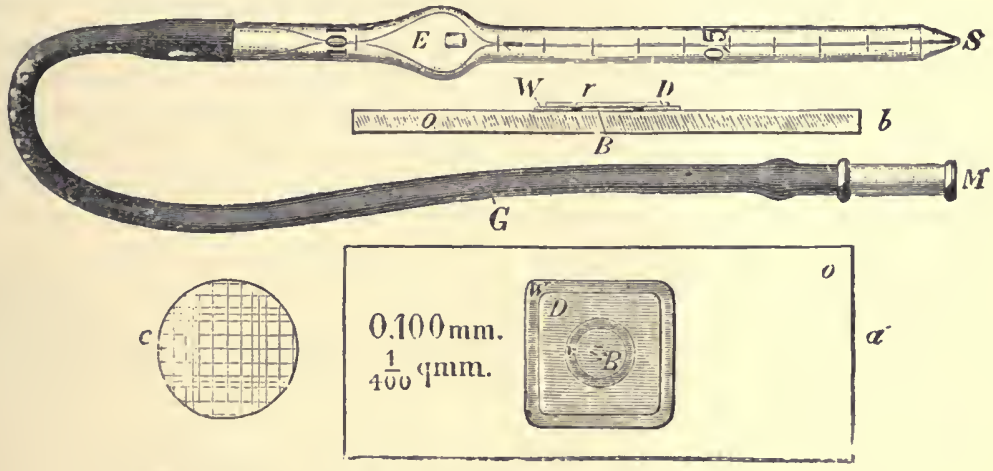

Fig. 19.-The Thoma-Zeiss Hamacytoneter.

The red corpuscles undergo various changes in shape when submitted to the action of different substances. Distilled watcr causes them to swell and burst ( $c f$. Hæinolysis); strong salt solution (hypertonic) causes them to shrink and crinkle, or crenate; tannic acid causes the hæmoglobin to leave the envelope and appear as a dot outside. When blood is shed, the red corpuscles show a tendency to run together into rolls like piles of coins.

Enumeration of Red Corpuscles.-This is done by an apparatus known as a hæmacytometer. The form generally employed is that shown in Fig. 19. The apparatus consists of (1) two graduated mixing pipettes, labelled 101 and 11 respectively; (2) a specially constructed counting chamber. A small disc of glass (B) and a thicker plate of glass (D) are affixed to a glass slide so as to form a platform (B) surroundedd by a well. When a cover-glass is placed over this platform, a fine film-like space of known thickness is left between the platform and the cover-glass. The platform is ruled in squares, each $\frac{1}{400}$ of a square millimetre (C in Fig.).

For counting red corpuscles the pipette labelled 101 is employed. Blood is sucked up to the mark $\mathbf{1}$, and then quickly diluting fluid up 
to the mark 101, and the mixture well shaken. For diluting normal saline 3 per cent. sodium chloride, or Hayem's solution,* may be used. For counting both forms of corpuscles, Sherrington's or Toison's $\dagger$ fluid may be employed. These contain a dye (methylene blue or methyl violet) which stains the pale eells and enables them to be counted more readily.

After a thorough shaking the first few drops of fluid are rejected, and then a drop of the mixture is placed upon the platform and mounted with a cover-glass. Any excess of fluid runs into the surrounding well. Care is taken that there is not sufficient fluid to fill the well, otherwise the film beneath the cover-glass is altered in thickness and the result vitiated. The scale on the platform is focussed, and the eells in a square and those lying on two of its adjoining sides are eounted. Usually 40 to 100 squares are eounted. Each square is $\frac{1}{400}$ of a square millimetre in area, and the depth of the cell is $0 \cdot 1$ millimetre. Over each square, therefore, lies $\frac{1}{4000}$ cubie millimetre of the diluted blood. On multiplying by 4,000 the average number of corpuscles found in each square, and again by 100 , because of the dilution, the number in 1 cubic millimetre of undiluted blood is obtained. For example, $12 \times 4,000 \times 100=4,800,000$, about the average number in man's blood.

The Origin of the Red Corpuscle.-The origin of the red eorpuscle varies with the stage of existence.

1. In early fotal life the nucleated red corpuscles are first formed from the mesoderm where-ever the formation of capillary vessels is taking place (Fig. 20).

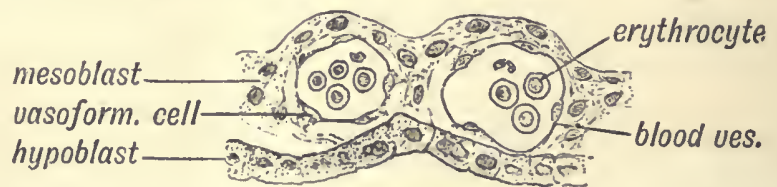

Fig. 20. - Sectiox across Yolk Sac Showixg Bloodvessels axd Nuct.ated Red Blood-Corpuscles formixg Ix Its Mesoblastic Layer. (Keith, after Selenka.)

The cells (angioblasts) in the region where a capillary is to be formed unite together to form a syncytium (a fusion of eells). Their nuclei divide at some places faster than others, so that an accumulation of colourless eells (primitive hæmoblasts) is formed at certain points. These cells become coloured by the formation of hæmoglobin within them, and form the primitive coloured cclls of the blood-the so-called primitive erythroblasts. A hollowing-ont process now takes place at the cnlargements, and the newly formed corpuscles float in a clear fluid in the cavities thus made, the whole forming so-called

* Hayem's solution eonsists of: Mereuric chloride, 0.5 gramme; sodium sulphate, 5 grammes; sodium chloride, 1 gramme; distilled water, 200 c.c.

† Toison's solution is: Methyl violet, 0.025 gramme; sodium ehloride, 1 gramme; sodium sulphate, 8 grammes; glycerine, 30 e.c.; distilled water, 160 e.c.

Sherrington's fluid is: Methylene blue, $0 \cdot 1$ gramme; sodium ehloride, $1 \cdot 2$ grammes; ncutral potassium oxalate, $1 \cdot 2$ grammes; distilled water, 300 e.c. 
blood-islands. The spaces between the blood-islands is next excavated, some of the angioblasts becoming converted into blood-corpuscles, others forming the cells of the capillary wall. This process goes on until the circulation is established and capillary formation is complete. The blood-cells thus formed multiply within the vessels. Later on, when the circulation is established, large blood-cells (megaloblasts), derived from the primitive hæinoblasts, also make their appearance in the blood. From the megaloblasts are derived smaller normoblasts, which lose their nuclei and become converted into the erythrocytes similar to those of the adult.

By some authorities it is held that hæmoblast cells also give rise to lymphoblasts, from which lymphocytes are developed, and possibly leucocytes; also to myeloblasts, from which myelocytes and leucocytes are developed. All the first blood-corpuscles according to this scheme have a common mesoblastic parent cell, the hæmoblast.

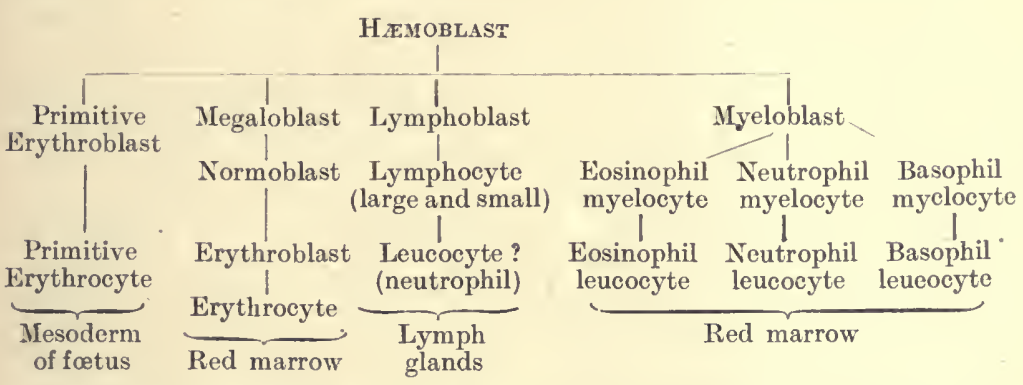

The red corpuscles are formed in mid-foetal life to a certain extent, and in late foetal life to a large extent, in the liver, spleen, connective tissue, and red bone marrow; but in the last few weeks of fœtal life the red bone marrow becomes almost the sole source. The cells arising from the bone marrow are non-nucleated.

In the human embryo at the fourth wcek only nucleated cells are present; in the fourth month they form about 25 per cent. of the whole, while at full time but few nucleated corpuscles are found.

2. After birth the red bone marrow is the sole source of the red blood-corpuscles. Here nucleated erythroblasts are always to be found, derived from mega'oblasts and normoblasts. When extensive destruction of the corpuscles is taking place, this crythroblastic tissue shows signs of grcat activity, and in times of great necd the nucleated red cells of the marrow may pass into the blood.

Generally, however, the erythroblasts multiply by cell division; these cells then exclude or absorb their nucleus, and pass into the circulation as non-nucleated erythrocytes.

Function.-The great function of the red corpuscles is to carry oxygen to the tissues. This it does by virtue of the hæmatin portion of its hæmoglobin. This function is destroyed on taking blood from an animal, defibrinating it, and heating it to $56^{\circ} \mathrm{C}$. On injecting into the animal the blood which has been thus warmed, the corpuscles 
are immediately dissolved. On the other hand, blood kept at $0^{\circ}$ for several days (threc to four) can be reinjected into an animal and still functionate. Hæmoglobin plays a considerable part in the transport of carbon dioxide from the tissues to the lungs. It has a specific capacity for absorbing carbon dioxide.

The Fate of the Red Blood-Corpuscles.-It is not possible to say how long the red corpuscle circulates before it is destroyed, possibly three to four weeks. Aftcr some such time the corpuscle is probably destroyed in the spleen, the liberated hæmoglobin passing to the liver to be disintegrated there. From it the iron-free bile-pigments bilirubin and biliverdin are formed, the iron being stored in the liver.

This iron can be stained blue by treating sections of the liver with potassium ferrocyanide and hydrochloric acid, or black by a pure solution of hæmatoxylin.

The iron in the liver is greatly increased in conditions in which a large destruction of red corpuscles takes place. It has been suggested that the splecn regulates the iron metabolism of the body; and it is possible that some of the destruction of red corpuscles takes place there, accompanied by the formation of pigment and the storage of iron in the splenic cells. It is supposed that the stored iron is again used to form hæmoglobin.

Chemistry of the Red Corpuscle.-The framework, or stroma, consists of protein and lipoids, within which are the salts, notably salts of potassium, and the hæmoglobin (sec table, p. 81).

The pigment hæmoglobin forms 90 per cent. of the corpuscle. It is one of the compound proteins, a chromoprotein consisting of an iron-containing portion (hæmatin) and a protein portion (globin); the latter is a histone.

Hæmoglobin, as other protcins, varies in composition in different animals.

\begin{tabular}{|c|c|c|c|c|c|c|c|c|}
\hline & & & $C$ & $H$. & $N$. & $S$. & $F e$ & O. \\
\hline$O x$ & .. & .. & $54 \cdot 66$ & $7 \cdot 25$ & $17 \cdot 70$ & 0.447 & $0 \cdot 400$ & $19 \cdot 54$ \\
\hline Horse & 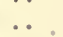 & . & $51 \cdot 15$ & $6 \cdot 76$ & $17 \cdot 94$ & $0 \cdot 390$ & 0.335 & $23 \cdot 43$ \\
\hline Dog & .. & .. & $54 \cdot 57$ & $7 \cdot 22$ & $16 \cdot 38$ & $0 \cdot 568$ & $0 \cdot 336$ & $20 \cdot 93$ \\
\hline Pig & . & .. & $54 \cdot 71$ & $7 \cdot 38$ & $17 \cdot 43$ & 0.479 & $0 \cdot 399$ & $19 \cdot 60$ \\
\hline
\end{tabular}

Its percentage composition is approximatelyC $54 \cdot 71$; H 7.38; N 17.43; S 0.79; Fe 0.399; O 19.602.

Hæmoglobin is readily soluble in water; coagulated by heat to a brown coagulum; dextrorotatory to polarized light. It can bc obtained in crystalline form, but more readily from some bloods than others. It is easily obtained from the blood of the rat after the addition of distilled water. In the guinea-pig's blood hæmolysis is first produced by the addition of chloroform or ether. Upon 
evaporation the chloroform or ether extract depozits crystals of oxyhæmoglobin.

Crystals are readily obtained from the blood of the squirrel, rabbit, and also from the inouse and rodents gcnerally; less readily from man, horse, cat, birds, and fishes. It is a morc difficult matter to obtain crystals from the blood of the sheep, ox, and pig.

The crystals vary in size and shape according to the animal from which they are prepared (Fig. 21). Those from the rat are needleshaped, resembling those from human blood; from the guinea-pig they are quadrilateral prisms; from the squirrel, hexagonal plates.

The rosy colour and plump look of health is due to a plentiful supply of well-oxygenated blood in the face. The great function of the red corpuscle is to carry oxygen, and the most characteristic property of the pigment hæmoglobin is its power to form a loose chemical combination with oxygen. The body thus formed is termed
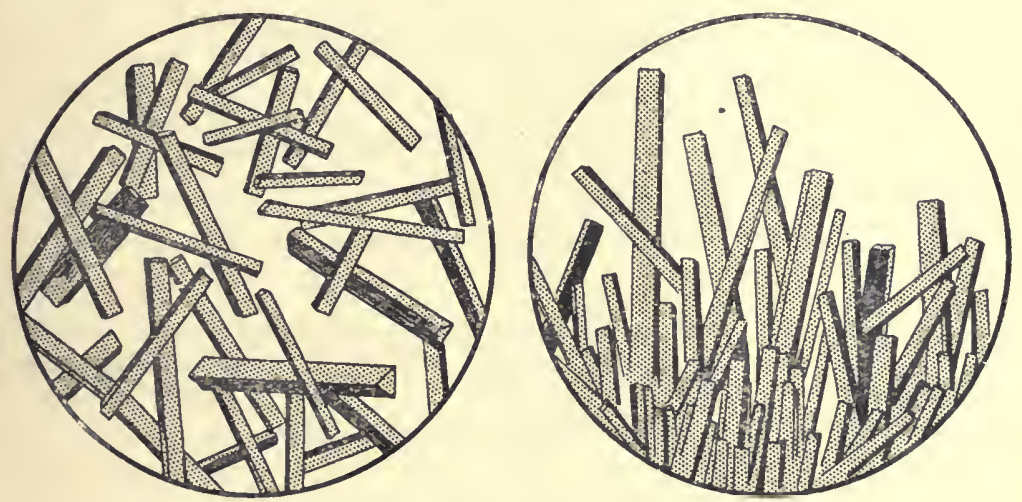

Fig. 21.-Crystals os Oxyhamoglobiy from Horse's Blood.

oxyhæmoglobin, and it is to this body that the bright red colour of arterial blood is due. If arterial blood, diluted, let us say, with water to 1 in 500, is examined with the spectroscope, two absorption bands are scen in the yellow and the green between the lines D and E (Fig. 22). The addition of a reducing substance, such as ammonium sulphide, to this solution displaces the oxygen from the oxyhæmoglobin. . The solution, now changed to a purplish colour, gives the spectrum of hæmoglobin; one broad but less dark band is seen between D and E (Fig. 22).

Carboxyhæmoglobin.-Blood exposed to coal-gas or carbon monoxidc gives a spectrum rescmbling $\mathrm{OHb}$, but the solution of $\mathrm{COHb}$ is markcdly pinker in colour, and is not reduced by the addition of ammonium sulphide. This serves to distinguish the two. When a solution of carboxyhæmoglobin is greatly diluted, it remains pink, while that of oxyhæmoglobin diluted to the same cxtent becomes yellowish-green. 
The presence of $\mathrm{CO}$ in eoal-gas and in after-damp in mines is a frequent eause of death. CO has about 150 times as great an affinity for $\mathrm{Hb}$ as $\mathrm{O}_{2}$, and thus it eomes about that, if a man breathes long enough an atmosphere containing $0 \cdot 1$ per cent. $\mathrm{CO}$, half the oxygen will be displaeed from his blood. The hæmoglobin of the blood becomes eombined to form $\mathrm{COHb}$, insufficient oxygen is now carried to the tissues, and death from oxygen want ensues. It is therefore dangerous to breathe an atmosphere containing more than 0.05 per cent. $\mathrm{CO}$ is without colour or smell, and its presence eannot be sensed. The want of oxygen gives little warning, and a man breathing $\mathrm{CO}$ may lose consciousness unwitting of his danger. A small vertebrate, such as a bird or mouse, is affected much sooner than a man, and it is a wise preeaution to send a cage bird with an exploring party into a mine where "after-damp" exists. Ordinary illuminating gas contains about 5 per cent. of carbon monoxide, and water-gas, used in some towns, as much as 30 to 40 per cent. CO poisoning in such towns has aceounted for even 1 per cent. of all the deaths. - Seventy-five per eent. saturation of the hæmoglobin with $\mathrm{CO}$ causes dizziness and palpitation on exertion; the heart fails to keep up the extra eireulation required then. Brain-power is greatly diminisherl although the subjeets do not know it. 'In deaths from house on fire the people are as a rule rendered unconscious by $\mathrm{CO}$ poisoning before they are burnt. The bodies of men killed by $\mathrm{CO}$ poisoning have a pink colour, due to the $\mathrm{COHb}$ formed.

Nitroxyhæmoglobin $(\mathrm{NOHb})$ also has a spectrum resembling the above, but the two bands, although in approximately the same position, are not by any means so clear-cut; the shading appears "woolly." $\mathrm{NOHb}$ is not reduced by ammonium sulphide. It is prepared by adding a solution of ammonia to the blood, and then passing nitric oxide gas through the solution. It is formed in the blood by the action of the nitrites-e.g., amyl nitrite or such bodies as nitro-benzol. Methæmoglobin is first formed, and afterwards nitroxyhæmoglobin.

For cases of partial poisoning by earton monoxide or nitrites the correct treatment is to place the patient in an atmosphere of oxygen, preferably under pressure, so that the $\mathrm{Hb}$ whieh is uncombined may have an ample supply of oxygen to draw upon, and more oxygen may become dissolved in the plasma of the blood owing to its increased partial pressure. At a pressure of oxygen of two atmospheres about 2.5 per eent. of oxygen is dissolved in the plasma, and this is enough to maintain life in the presence of any percentage of $\mathrm{CO}$. A mousepoisoned by $\mathrm{CO}$, and rendered moribund, revives in two atmospheres, of oxygen, and tumbles over again when the pressure is lowered to atmospheric pressure. The resuscitation and swooning of the mouse may be repeated.

$\mathrm{NOHb}$ is even more stable than $\mathrm{COHb}$. It can be distinguished from $\mathrm{COHb}$ by giving a bright red eoagulum on boiling, whereas $\mathrm{COHb}$ gives a brownish one. The difference in eolour is approximately that between the outer red ring of salt beef and the inner brown zone. In this case the hæmoglobin in the musele has formed $\mathrm{NOHb}$ owing 
to bacterial decomposition in the presence of the saltpetre used in the process of preservation.

Methæmoglobin (MctHb).-Oxyhæmoglobin is frequently represented by the formula $\mathrm{Hb}<\mathrm{O}$; methæmoglobin by the formula $\mathrm{Hb} / \mathrm{O}$, although the correctnoss of the latter has becin questioned. It is formed in the stale blood, and may be prepared by adding to a solution of $\mathrm{Hb}$ a few drops of a fresh-made solution of potassium

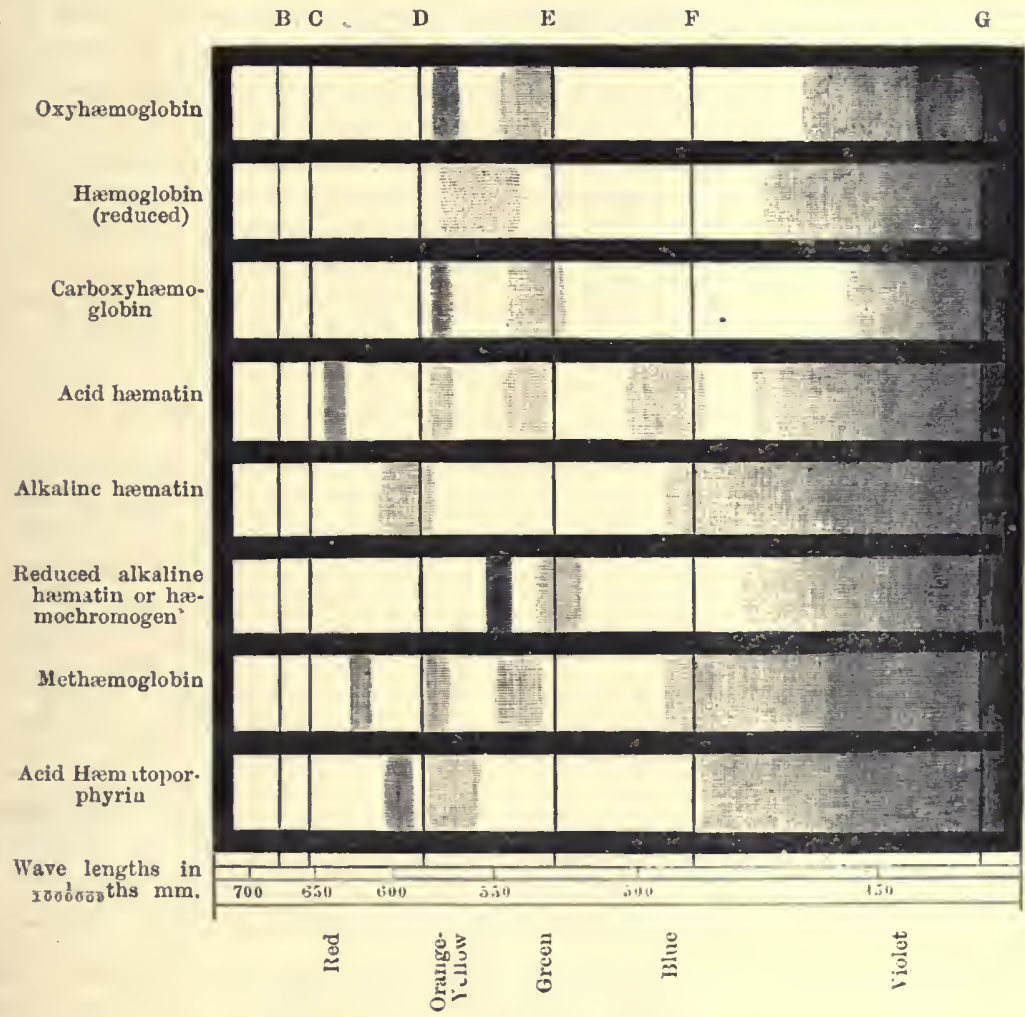

Fig, 22.-F lood Spectra. (Waller.)

ferricyanide. The looscly combined oxygen of the $\mathrm{OHb}$ is turned out, and the $\mathrm{Hb}$ then combines in a more stable form with an equal amount of oxygen taken up from the decomposition of bicarbonates in the blood, a chemical reaction taking place in which the ferricyanide is reduced to ferrosyanide.

$$
\begin{aligned}
& \mathrm{Hb}-{ }_{\mathrm{O}}^{\mathrm{O}}+4 \mathrm{Na}_{3}\left(\mathrm{FeCy}_{43}\right)+4 \mathrm{NaHCO}_{3}=\mathrm{O}_{2}+\mathrm{Hb}=\mathrm{O} \\
& +4 \mathrm{Na}_{4}\left(\mathrm{FeCy}_{6}\right)+4 \mathrm{CO}_{2}+2 \mathrm{H}_{2} \mathrm{O}
\end{aligned}
$$


On this rcaction depends the chemical method of determining the amount of loosely combined oxgyen in the blood.

The solution of $\mathrm{MetHb}$ is greenish-brown in colour. The spectrum of this solution suitably diluted shows, in addition to the two bands characteristic of $\mathrm{OHb}$, another band in the red near the line $\mathrm{C}$. These three bands are well marked and of almost equal intensity. The $\mathrm{O}_{2}$ in methæmoglobin is not yielded to the vacuum pump, and is not availablc for respiratory purposes. By treatment, however, with ammonium sulphide MetHb can be easily reduced to $\mathrm{Hb}$, which in turn can be converted again to $\mathrm{OHb}$ by shaking well in air. MetHb is sometimes passed in the urine after the administration of excessive doses of potassium chlorate, and antipyretics such as phenacetin, antifibrin, etc. It is formed when the red corpuscles are hæmolyzed and a considerable amount of $\mathrm{Hb}$ is set free in the blood-stream. The condition is known as methæmoglobinuria. The deep brown colour gives the urine a peculiar look. The spectroscopic test serves to identify it.

Hæmoglobin is split into globin and hæmatin by the action of heat, acids and alkalies, etc., and there are a number of derivatives of hæmatin which give characteristic spectra.

Chief of these are acid hæmatin, alkaline hæmatin, reduced alkaline hæmatin (hæmochromogen), and hæmatoporphyrin (iron-free hæmatin).

Acid Hæmatin is readily prepared by shaking up a small amount of defibrinated blood with a few drops of 20 per cent. acetic acid, and then suitably diluting the mixture with 60 per cent. alcohol. It forms a brownish solution, giving a well-marked absorption band in the red near the line $\mathrm{C}$, nearer than the similar band of MetHb. Sometimes two bands are seen between $\mathrm{D}$ and $\mathrm{E}$, but they are feeble, and not of the same intensity as the band in the red. Acid hrmatin cannot be reduced to $\mathrm{Hb}$ by the action of ammonium sulphidc. This serves to distinguish acid hæmatin from methæmoglobin.

Alkaline Hæmatin is prepared similarly by shaking up a small amount of defibrinated blood with 20 per cent. potash and diluting with weak alcohol. It gives one broad absorption band between $\mathrm{C}$ and $\mathrm{D}$, which is in contrast to the band of $\mathrm{Hb}$ between $\mathrm{D}$ and $\mathrm{E}$.

Reduced Alkaline Hæmatin (Hæmochromogen).-This gives an extremely characteristic spectrum in suitable dilutions; one very dark band between $\mathrm{D}$ and $\mathrm{E}$ and another less dark band between $\mathrm{E}$ and $b$. It is only the spectrum which has a band in this postion. Hæmochromogen is prepared by adding potash to the solution of blood, or dissolving an old dried blood-stain in potash, and reducing it by ammonium sulphide. As it can be prepared from old blood-stains, it affords us a test for blood of great medico-legal value. A solution of hæmochromogen and globin, if mixed and allowed to stand, will rcunitc and form hæmoglobin.

Acid Hæmatoporphyrin. - By the addition of acid to hæmochromogen the iron is split off from the compound with the production 
of acid hæmatoporphyrin. It can be prepared by treating a drop of defibrinated blood with a small amount of strong sulphuric acid, shaking well, and diluting the resultant mixture with more concentrated acid until the mixture is sufficiently diluted to be viewed through the spectroscopc. The spectrum presents two bands: one narrow, just to the red side of the line $\mathrm{D}$; another broader, between $\mathrm{D}$ and $\mathrm{E}$.

The sulphuric acid splits hæmoglobin into its constituents hæmatin and globin; the hæmatin is then deprived of its iron with the formation of hæmatoporphyrin.

Alkaline hæmatoporphyrin is produced in a similar manner to the acid, but very strong alkali is used. Alkaline hæmatin is first formed, but this is subsequently broken down to iron-free alkaline hæmatin or alkaline hæmatoporphyrin. The spectrum of this body presents four bands-a narrow band between $C$ and $D$, two between $\mathrm{D}$ and $\mathrm{E}$, and a broad band between $\mathrm{E}$ and $\mathrm{F}$.

Hæmatoporphyrin may occur in the urine after such drugs as sulphonal have been taken, and is usually of the alkaline variety. The formula for hæmatoporphyrin is $\mathrm{C}_{16} \mathrm{H}_{18} \mathrm{~N}_{2} \mathrm{O}_{3}$, It is closely related to the pigment bilirubin of the bile, which has the same empirical formula.

If a solution of a copper salt in ammonia be added to hæmatoporphyrin, turacin is formed-a pigment found in the red feathers of certain birds (plantain-eaters). The important pigment of plants, chlorophyll, is a near ally. . If treated with caustic potash at $190^{\circ} \mathrm{C}$., it yields a body phylloporphyrin, $\mathrm{C}_{16} \mathrm{H}_{18} \mathrm{~N}_{2} \mathrm{O}$. Both hæmatoporphyrin and phylloporphyrin yield on reduction a body called hæmopyrrol. It has been suggested that hæmoglobin is synthesized out of the chlorophyll eaten in the food.

From hæmatin, by the action of acids, hæmatoporphyrin and a body termed mesoporphyrin are obtained. By reduction of hæma toporphyrin, hæmopyrrol $\left(\mathrm{C}_{8} \mathrm{H}_{13} \mathrm{~N}\right)$ is obtained, and by oxidation ard treatment with caustic potash methylethylmaleic acid anhydric'e $\left(\mathrm{C}_{8} \mathrm{H}_{8} \mathrm{O}_{5}\right)$. Both these bodies can also be obtained by the splittirg of chlorophyll.

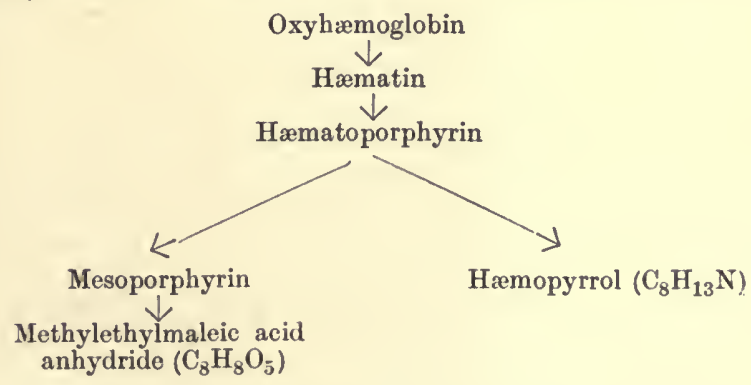

The pigments of the bile (bilirubin and biliverdin), the pigments of the frees (stercobilin), one of the pigments of the urine (urobilin), are derivatives of hæmatin, and, like hæmatoporphyrin, contain no iron. 
In old blood-elots, flat, lozenge-shaped crystals, of a bright red colour, are often found. This is an iron-free derivative of hæmoglobin, isomcrie with bilirubin, and called hæmatoidin.

Besides the derivatives which have been studied with the spectroscope, there is another derivative of hæmatin-hæmin, which is identified by the rhombie form and brown eolour of its erystals. Hæmin is the hydroehloride of hæmatin, and is prepared by heating blood with glaeial aeetie acid.

The Estimation of Hæmoglobin.-By estimating the hæmoglobin in the blood we. ean measure the oxygen-earrying power, and make comparative tests of the blood in cases of anæmia, ete. The measurement is made by the use of an instrument known as the hæmoglobinometer. In this country, apparatus shown in Fig. 23 is chiefly employed. This eontains a sealed tube $(D)$ eontaining coal-gas and

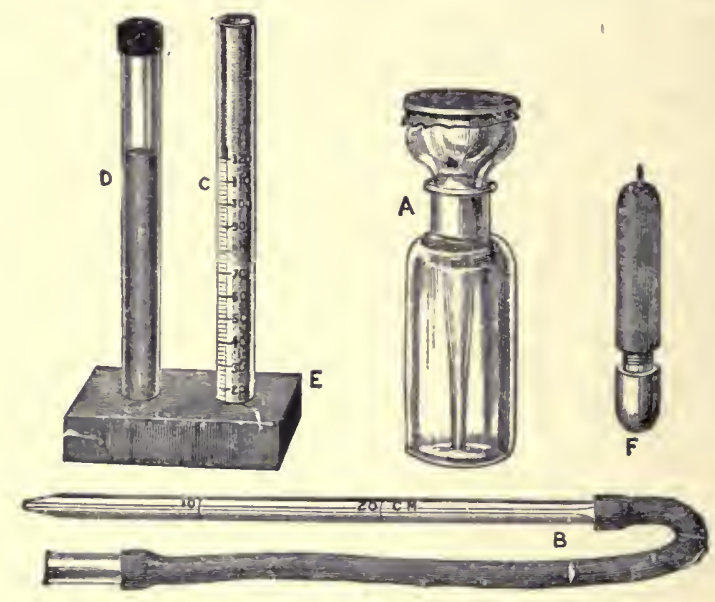

Fig. 23.-Haldaxe-Gowers' H.zmoglobixometer.

a standard solution of human blood ( 1 in 200); the hæmoglobin, being combined with $\mathrm{CO}$, makes the solution a stable one. A small quantity (up to mark 20 or so) of distilled water (earried in a bottle $(A)$ furnished with a pipette stopper) is placed in the graduated tube $C$. Blood is taken from the patient, either from the finger-tip or the lobe of the car, and sueked up into the pipette $B$ to the mark 20 , and then carcfully added to the watcr in the graduated tube. The distilled water lakes the blood, and a solution of oxyhæmoglobin is formed. This is converted into $\mathrm{COHb}$ by passing coal-gas into the tube and shaking it with the solution. Or the distilled water in the bottle $A$ may be previously saturated with $\mathrm{CO}$ by bubbling coal-gas through it. All that now remains is to dilute earefully the solution of $\mathrm{COHb}$ with water until it is of the same tint as the standard tube when eompared agairist a white background. The percentage of $\mathrm{Hb}$ is registered by the graduations in the tubc. - The standard is 
made from ox-blood which had the power to eombine with 18 i volumes of oxygen when shaken with air. Blood of the same strength as this can combine with the same amount of oxygen.

Taking the percentage of hæmoglobin in man as 100, woman normally has 90 per eent., children 85 per cent. The new-born infant has a high pereentage, $\mathbf{1 4 0}$ per eent., which quickly decreases in the first few months of life to just bolow normal. The effect of altitude has been mentioned.

The Pale Corpuscles.-The pale eorpuscles of the blood have bcen variously elassified. At present the best classification appears to be that based upon their supposed origin and their staining properties. Aceording to the origin, the pale corpuseles may be divided into leucocytes (amœeoid eells), arising in the kone marrow and passing primarily into the blood-essentially, therefore, blood-eorpuscles; lymphocytes, probably non-amœboid or but faintly amœboid eells, arising in lymphoid tissue and passing primarily into the lymph-essentially lymph-eorpuscles.

By staining reactions the leucoeytes are classified under three headings :

\author{
Neutrophil. \\ Eosinophil, or acidophil. \\ Basophil.
}

The lymphocytes are divided into two groups-the large and the small. The various staining properties can be seen in a wcll-made blood-film, which ean be prepared as follows:

Two clean slides are taken with well-cut edges. The slide upon which the film is to be made is gently rubbed with fino emery-paper to give it a very slightly roughened surface. The edge of the other slide is applied to a small drop of blood obtained by pricking the finger; this edge is applied to the roughened slide at an angle of $\mathbf{4 5}$ degrecs, and by a sweeping movement the blood is lightly and evenly spread over the roughened surfaee. To this film Leishman's stain is added; it consists of equimolecular wcights of methylene blue and eosin dissolved in methyl alcohol, and is a fixing agent by virtue of the methyl alcohol. After fixing for thirty seeonds the stain is diluted with water, $1: 2$, when it assumes a pinkish tint and acts as a stain. The film is stained for about five minutes, and is then washed with distilled water. It is finally dried with blotting-paper. The methylene blue acts as a basic dye because the base in this salt is the active group, and it reaets with nueleie aeid in the nucleo-protein of the eell. Eosin is an acid dye because the aeid in this salt is the active group, and it reaets with the basic substanees of the cell.

Stained in this way the neutrophil eorpuscles appear two and a half times as wide as a red eorpuscle, with a fragmented nueleus stained blue and the fragments joined together with faintly stained piees of chromatin. For this reason it is ealled polymorphonuelear. With the magnification of a $\frac{1}{6}$ objective small pinkish granules may be just visible; these are well seen with an oil-immersion $\left(\frac{1}{12}\right)$ lens. 
The eosinophil corpuscles are also polymorphonuclcar, but their big red granules are easily scen under the $\frac{1}{6}$ objective.

The rare basophil cell (sometimes called a mast cell) has large blue granules.

In numbers the pale corpuscles vary from 5,000 to 8,000 per cubic millimetre. If they are much above this number, the condition of leucocytosis is said to exist; below that, of leucopenia.

A differential blood-count of the pale corpuscles (i.e., the relative percentagc of each corpuscle) of a film shows that there is in normal blood usually 75 per cent. leucocytes and 25 per cent. lymphocytes. The leucocytes are divided as follows: Neutrophils 71 to 73 per cent., eosinophils 2 to 4 per cent., basophils 0.5 per cent. or less. Morbid conditions which cause large numbers of basophils to appear in the blood are extremely serious, and for this reason they have been termed "the harbingers of death." Of the 25 per cent. of lymphocytes, normally 23 per cent. are small, 2 per cent. large; these numbers vary slightly, but any large variation is regarded as pathological.

In the horse the number of leucocytes per cubie millimetre of blood is 8,000 to 11,000 ; in the ox, 7,000 to 9,000 ; goat, 9,000 to 12,000 ; sheep, 9,000; pig, 16,000 .

The proportion of leucocytes to lymphocytes also differs, lymphocytes forming 30 per cent. of the total in the pig, 30 to 40 per cent. in the horse, 25 to 35 per cent. in the ox.

The Origin of the Pale Corpuscles.-Altkough, as stated above, it is generally held that the leucocytes and lymphocytes have a separatc origin, especially in adult life, the leucocytes arising from myelocytes in the bone marrow, and the lymphocytes from lymphatic tissue, there are some authorities who believe that in fotal life the hæinoblast affords an origin for all the other forms of corpuscles (see table, p. 89).

The Functions of the Pale Corpuscles.-The leucocytes by virtue of their amœboid or pseudopodial movements can surround particles of foreign material and take them into their substance. For this reason they are termed phagocytcs. By virtue of their phagocytic action the lcucocytes play a great part in defending the body from the onslaught of invading microbes, emigrating from the vessels for the purpose (Fig. 24). They also probably play a part in forming the protective substances of the plasma, such as antigen, complcment, and opsonin (see p. 109). When blood is shed, these corpuscles help to produce the clotting of blood.

The lymphocytcs play a part in the absorption of fat, and possibly in uric acid metabolism.

Enumeration of White Corpuscles.-The pale corpuscles may be counted by the Thoma-Zeiss instrument. In this case the pipette giving the smaller dilution 1 in 10 (labclled 11) is used. The usual diluting fluid contains $0 \cdot 3 \mathrm{per}$ cent. acetie acid tinted with methyl green. The weak acid destroys the red corpusclcs, and the methyl 
green tints the nuclei of the pale corpuscles, rendering counting casier. The process of effecting the required dilution and placing it on the slide is the same as that described for the red corpuscle.

The pale may be counted at the same time as the red corpuscles if Toison's or Sherrington's fluid is used.

Leucocytosis.-An increase in the number of pale corpuscles occurs physiologically during digestion, especially after meals rich in proteins and fat; after muscular exercise; in pregnant and parturient women; and in the new-born child. The neutrophil cells are increased in a number of pathological conditions, in acute infections such as supparation, pneumonia, diphtheria, erysipelas, etc. In the condition known as leukæmia, either the leucocytes or the lymphocytes may be grcatly increased, according as the marrow or lymph glands arc the seat of disease. Sometimes, although the total number is not much increased,

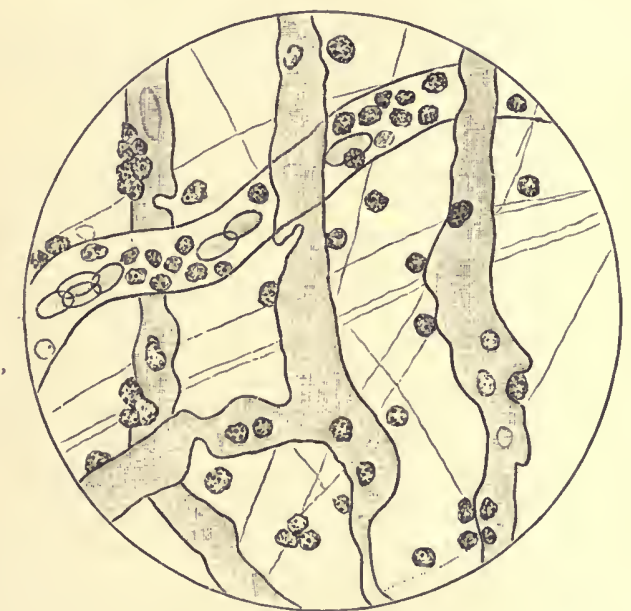

Frg. 2.t.-Emigration of Leccocrites. (From Waller's "Human Physiology.")

Vessols of the inferior surface of the frog's tongue as they appear after the escapo of the corpuscles, filled with stationary blood, deformed and indented at the points of escape, near which the corpuscles are generally found. (After Waller, Phil. Mag., 1846, "Microscopic Obscrvations on the Perforation of the Capillaries by the Corpuscles of the Blood.")

the proportion of eosinophil corpuseles is inercased. 'This occurs in cases infected with the parasites trichina or anchylostomum, in asthma, and eertain skin diseases.

Leucopenia oecurs after cxposure to $\mathrm{X}$ rays and injections of cholin. In ccrtain infections such as typhoid the pale corpuscles are said to be diminished.

Blood-Platelets.-The so-called blood-platelets, or thrombocytes, are bodies of doubtful origin. Opinions vary as to thcir character and nature. According to one group of obscrvers they are to be 


\section{A TEXTBOOK OF PHYSIOLOGY}

looked upon as a third kind of blood-corpuscle; according to the others they are but artefacts. A great diversity of opinion exists among the supportcrs of the view that they are a true corpuscle. They are variously stated to be amœboid and non-amœboid; nucleated and non-nucleated. Their diameter is $2-3 \mu$. They are best seen if a drop of blood is received on to a block of paraffin wax and placed in a moist chamber. The blood does not coagulate when thus received on wax. At the end of twenty minutes most of the red corpuscles have sunk to the bottom of the drop. The platelets, being lightest, remain at the top of the drop, and, if this be gently removed, large numbers of platelets will be seen.

Platelets increase in number after the blood is shed. In a wellmade blood-film few or no platelets are seen. If, howcver, the blood is allowed to stay on the slide some time before being drawn into a film, it will be found that many bodies which might be termed bloodplatelets are visible.

It seems probable that they are to be looked upon as artefacts, and may be grouped into four categories:

1. Platelcts containing hæmoglobin.

2. Platelets containing no hæmoglobin.

3. Platelets with an inner body.

4. Platelets without an inner body.

In normal blood there exist few, if any, platelets, and such as exist are generally clumped together. They separate from the plasma owing to contact with foreign bodies, and in part owing to the lowering of temperature. The addition of so-called fixing and indifferent fluids may producc enormous numbers of them, the number varying for different fluids. On adding a metaphosphate solution to blocd the platelets appear suddenly, and belong to the amœboid type; when a solution of potassium oxalate is used, they are at first of this type, but afterwards appear as pin-like and tailed bodies; subsequently sinall bodies arc extruded from the red corpuscles. These bodics stain differently, and resemble bodies which form in coagulating blood after the administration of certain poisons. It is possible that a few platelets of this type may exist in normal blood. The exact source of origin is not known; they may arisc from the fragmentation of red corpuscles, possibly the fraginentation of pale corpuscles, but generally are regarded as finc deposits of the blood-proteins. When first discovered they were regarded as young red corpuscles, afterwards they were thought to be young white corpuscles; both views are now known to be wrong.

Recently a compromise between the divergent views has been suggested, and the platelets grouped into "platelets"- true corpuscles, which are believed to play some part in the coagulation of the blood, and "blood-dust" protein granules of about $1 \mu$, known as hæmoconea. "Blood-dust" is insoluble in alcohol or ether, and is not blackened by osmic acid. Some regard it as formed of the extruded granules of the pale corpuscles. 


\section{CHAPTER XII}

\section{THE CLOTTING OF BLOOD}

If the blood be allowed to flow freely from a wound, the flow gradually lessens as the blood becomes more viscid, and at length ceases, a clot, or coagulum, being formed at the site of injury.

As a rule the blood coming from clean-cut wounds clots less readily than that from jagged wounds. Washing and cleaning a wound prolongs the bleeding; on the other hand, contact of the wound with a foreign body such as a piece of rag or of cotton-wool quickens its arrest.

The clot serves a double purpose-it plugs the bleeding-points, and so prevents the loss of precious blood, and it forms a protection against the entry of harmful organisms into the blood-stream. If the blood be received as it is shed into a perfectly clean vessel and put aside to clot in a quiet place, it will be found that the jelly-like coagulum is at first so solid that the vessel can be turned upside down, and considerable force is required to disengage the clot from the vessel. The clot gradually shrinks in size and squeezes out drops of a clear, almost colourless, fluid known as the serum. The shrinkage slowly continues until at last there remains a shrunken dark red clot at the bottom of the vessel and a quantity of clear straw-coloured serum above it. If the blood be horse's or cat's blood, an upper yellowish layer is also formed, known as the "buffy coat." This consists of the pale corpuscles which are lighter and romain on top, the heavier red corpuscles quickly settling down to the bottom in the blood of these animals.

Coagulation of the blood may be retarded in various ways. The best-known methods are the following:

(i.) Cold, by receiving blood into a vessel placed on ice.

(ii.) Contact with the wall of the bloodvessel. If a large veinfor cxample, the jugular vein of the horse-be ligatured in two places, and the tube of blood thus formed be excised and hung up, the corpuscles will sink to the bottom, leaving the unclotted plasma above.

(iii.) Receiving the blood into a smooth vessel smeared with oil.

(iv.) Addition to the blood of neutral salts such as magnesium or sodium sulphate.

(v.) Addition to the blood of a soluble oxalate, citrate, or fluoride.

(vi.) Addition of a body (hirudin) obtained by extracting the heads of leeches. Certain snake poisons and bacterial toxins also stop coagulation. 
(vii.) By injecting into an animal before killing it certain substances such as commercial peptone, soap solution, or, very slowly, a weak alkaline solution of nucleoprotein.

(viii.) The addition of acids, alkalies, ammonia sugar solution, glycerine, or much water.

Clotting may be facilitated, on the other hand-

(i.) By keeping the temperature that of the body.

(ii.) By injuring the wall of the containing bloodvessel.

(iii.) By receiving on to a rough surface to which the blood adheres; by beating it with twigs or shaking it with glass beads. The addition of finely powdered carbon or platinum black also quickens coagulation.

(iv.) By adding serum or blood-clot.

(v.) By adding saline extract of lymphatic glands and other tissucs.

(vi.) Possibly by the addition of soluble calcium salts.

The explanation of all the above facts in regard to the clotting of blood is a mattcr of great difficulty. Opinions strongly at variance are hcld in regard to the exact processes which take place.

The following seem to be the certain facts about the clotting of blood, whatever may be the interpretation of the same:

(i.) When blood clots the protein of the plasma known as fibrinogen is involved and becomes converted either partially or wholly into a solid body known as fibrin. This is shown by the experiment that fibrinogen may be precipitated from plasma, redissolved in saline, and clotted at $37^{\circ} \mathrm{C}$., by the addition of a trace of blood-serum or a watery extract of serum proteins coagulated by alcohol.

(ii.) Calcium ions are necessary for the process. Thus, the addition to blood, as it is shed, of a soluble oxalate or fluoride which precipitates the calcium ions, or of a soluble citrate which prevents their dissociation, stops the coagulation of the blood.

(iii.) Calcium jons tako part in an intermediate and not in the final process, since a calcium-free solution of fibrinogen may be clotted by the addition of calcium-frce blood-serum-i.e., blood which has already clotted.

(iv.) Tissue juice has the property of greatly accelerating the process of clotting. Bird's blood straight from the vessel does not clot; if tissue extract be added, the blood clots almost at once. The addition of lymph from a blister accelerates the clotting of human blood.

(v.) Adhesion between the blood and a foreign substance gives an impulse towards coagulation, while lack of such adhesion prevents the blood from clotting.

The explanation given of the above facts is that blood, flowing from a wound, bccomes mixed with the tissue fluids in the cut, and the blood with the tissue fluid in the presence of calcium ions forms an enzyme known as thrombin from a forerunner present in the blood, known as thrombogen or prothrombin, which is probably derived from the white corpuscles and blood-platelets. It is only when tissue juices and calcium ions are present that this enzyme formation takes Ilace. This cxplains why a jagged wound clots more readily than 
a clean eut, and why, when ealeium ions are withdrawn from the blood by the addition of a soluble oxalate or citrate, the blood will not elot. The cnzyme thrombin thus formed then aets upon the fibrinogen of the plasma and transforms it into so.id fibrin, whieh entangles the red eorpuscles and forms the blood-c'ot.

The process may be represented as follows:

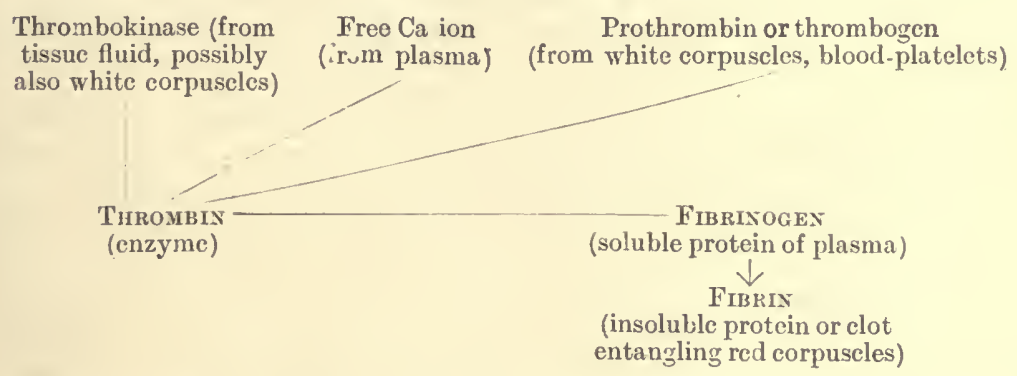

In aecordance with the above view of enzymic action it is supposed that oxalate, fluoride, and eitrate, prevent the formation of the enzyme by withdrawing ealcium jons, and that fluoride also destroys thrombokinase. Hirudin is bclieved to be an antithrombin. Cobra poison is held somehow to interfere with the aetion of thrombokinase. Roughened surfaces, ete., break down white corpuscles and provide points d'appui from which the enzyme can act. Cold inhibits enzymic activity; on the other hand body temperature hastens it. Oil and smooth surfaees deprive the enzyme of points for action.

Coagulation Trme, tested in a Glass Vessel at Roci Temperiture.

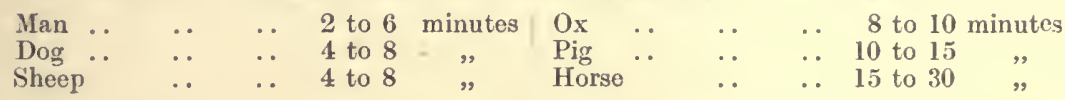

Aceording to the above view the tissue extract has only an indirect aetion on clotting; other authorities believe that the tissue juices have a direet elotting aetion. Reeently it has been suggested that thrombin results from the interaction of two substanees, cytozyme and serozyme. The former is said to be present in tissue cells and blood-platelets, and is not destroyed by heating to $100^{\circ} \mathrm{C}$., while the latter is present in serum and is destroyed by heat at $56^{\circ} \mathrm{C}$. Vury little serozyme is scid to be in plasma, and its origin is unknown.

According to another view of clotting, thrombin and its antibody, antithrombin, are present in the blood. When blood is shed the tissue fluid eombines with the anti-thrombin, leaving the thrombin free to convert fibrinogen into fibrin.

Aceording to still another view, thrombin docs not bring alout elotting, but is a body produced as the result of clotting. Upon this view the bodies whieh take part in the elotting are fibrinogen, thrombogen, thrombokinase (sometimes called thrombozyme), and ealcium salts. When blood is shed the three colloids-fibrinogen, 
thrombogen and thrombokinase-become in a state of unstablc equilibrium, and unite together to form fibrin and thrombin. The prescnce of calcium ions is necessary for this to take place. The proportion of fibrin produced, compared to thrombin, varies according to the proportion of the thrce colloids taking part in the process. The exciting cause of this unstable equilibrium may be any of the physical or chemical agents known to facilitate clotting, such as contact with the walls of a glass vessel, tissue extracts, and so forth.

Hæmophilia.-This is a disease charactcrized by the great tendency to severe bleedings in those afflicted with it; hence these are known as "bleeders." The characteristic bleedings are into joints, and subcutaneous hæmorrhages following slight injuries or strains. It is an hereditary disease, confined to the male sex; women transmit the disease, but never suffer from it. The cause of the condition is not known; it has been wrongly attributed to abnormal thinness or brittleness of the vessel wall. The most generally accepted view is that some agent (thrombokinase) is missing from the tissue fluids, so that these do not cause the blood to clot. This view accords with the fact that certain tissues of a bleeder may bleed, and not others; and that tissues may bleed at certain times, and not at other times. The condition is very rare. Genealogical trees, showing male bleeders and trancmission through females, have been constructed from records going beck to many generations. 


\section{CHAPTER XIII}

\section{HAMOLYSIS AND IMMUNITY}

Hæmolysis.--If small amounts of blood be taken in two testtubes and diluted with physiological saline $(0.8$ per cent. $\mathrm{NaCl}$ solution) and with distilled water respectively, it will be seen that there is a marked difference between the red fluid contained in the two tubes. The blood diluted with physiological saline is red and opaque; that distilled with distilled water is red and clear. The blood has become "laked," or hæmolyzed, by the water. By means of the change to a clear red solution it is easy to say when hæmolysis has taken place. Very slight traces of hæmolysis may be detected in the upper layers of the tube when the corpuscles have sunk to the bottom. By hæmolysis is understood the process in which a red corpuscle is damaged so that the hæmoglobin contained within passes into the surrounding fluid. Hæmolysis or laking is always due to injury of the stroma or envelope of the red corpuscle, and may be induced by a number of means:

(a) Physical.

(b) Chemical.

(c) Foreign sera.

(d) Bacterial toxins.

(e) Vegctable poisons.

(f) Animal poisons such as snake venoms.

Physical.--The addition of physiological saline to blood does not causc laking because it contains salt $(\mathrm{NaCl})$ in about the same concentration as that of the salts in the plasma. There is therefore no great interchange of water between the added fluid and the red corpuscles. The addition of distilled water causes laking because it contains no salts in solution. The red corpuscles of the blood contain inorganic salts in the ionized state. When the distilled water is added to the blood, water passes into the red corpuseles, until there is produced an equal concentration of ions on either side of the corpuscular envelopc. The water passing in greatly distends the corpuscle and eventually ruptures the envelope. The pigment contained in the corpuscle then passes into the surrounding medium, and, becoming dissolved in it, forms the clear red solution characteristic of hæmolysis. The membrane of the corpusclc forms a semi-permeable membrane which is easily permeated by the water but does not allow the salts to pass out. Alternate freezing and thawing also damage the envelope 
owing to water being scparated as ice in the process of freezing. Electrical currents of high potcntial may also disintegrate the corpuseles.

Chemical.-Many chemical bodics, sueh as arseniuretted hydrogen, nitro-benzol, nitro-glycerine, nitrites, guaiacol, saponin, pyrogallol, acetanilide, and ammonium salts, produce laking. Others, such as sugar and sodium chloride, do not; these cannot permeate the corpuscular envelope. Whilo urca and ammonium chloride permeatc the corpuscles readily, a solution of urca in isotonic solution of sodium chloride does not lake the corpuscles, although ammonium chloride docs. A solution of ether in distilled water produces laking. It is suggested that the pcrmcability of the corpuscles is controlled by the cholesterin and lecithin in the stroma as solvents of lecithin and cholesterin producc laking-for example, chloroform, cther, bile salts, and amyl alcohol; but the majority of hæmolytic agents, both inorganic and organic, are not solvents of these lipoids.

Hæmolysis by Foreign Sera.-If a few drops of the blood of a man be mixed with the serum of a rabbit in a test-tubc, it will be found that the solution, red and opaque to begin with, becomes after a time transparcnt, showing that hæmolysis has taken place. This property is increased by immunizing the rabbit against the foreign red corpuscles. The injection of a very small dosc of foreign corpuscles is sufficient to raise the hæmolytic power of the serum. For example, $0 \cdot 125$ grammc of ox blood, injected intravenously in the rabbit, produces a hæmolysin which specifically acts on ox corpuscles, so that rapid laking takes place when the rabbit's serum is mixed with ox corpuscles but not when mixed with any other animal's corpuseles.

The explanation given for this phenomenon is the same as for baeteriolysis (see p. 109). Sera; and espeeially imunized sera, have po, ier to destroy baeteria. There are eoneerned two substanees in the serum: (1) an amboeeptor, whieh is increased by immunization, and (2) a complement, whieh is present in fresh normal serum and is destroyed by heating to $55^{\circ} \mathrm{C}$. Very little is known as to the ehemieal properties or mode of aetion of these bodies. The action takes plaee quiekest at a little above body temperature. If the ox corpuseles and rabbit's serum are mixed at $0^{\circ} \mathrm{C}$., there is no hæmolytic aetion, beeause the complcment eannot aet at this temperature, but the amboceptor combines with the eorpuseles and ean be removed with these from the serum. After separation by the eentrifuge the corpuseles can be washed in isotonic salt solution, to remove all traees of the rabbit's serum, separated by the centrifuge again, and then mixed with normal serum and warmed to body temperature. Laking then takes place bccause the eomplement alone is wanted to eomplete the reaetion, and this is present in any fresh normal serum.

Hæmagglutinins, similar to the agglutinins which are produced to antagonize bacteria, can also be obtained by the injection of foreign blood into an animal. These eause the red eorpuseles to run together, or agglutinate. Some sera eontain no hæmolysins, only agglutinins; others contain hæinolysins and no agglutinins. The two bodies, however, usually exist side by side, sometimes the action of one being more marked, sometimes the action of the other. In agglutination the surfaee tension is altered; the lecithin and eholesterin eonstituents of the stroma are supposed to take a part.

The hæmolytie aetion of eel's serum is exeeptional. If as little as 0.1 e.c. of eel's serum per kilo of body wcight is injected into a rabbit, it dies in two or three minutes. This serum differs from other sera insomueh as heating to $54^{\circ} \mathrm{C}$. destroys its action, whieh is not restored by the addition of eomplement. 
Bacterial Hæmolysins.-Certain pathogenic bacteria-e.g., Bacillus pyocyaneus and staphylococcus (the organism of boils) - produee agglutinins for human corpuseles. Sometimes these play a part in the formation of emboli. The eorpuseles may b3 elumped together, mixed with the infecting baeteria, and carried by the eireulation to another part and so spread the misehief. Hæmolysis oeeurs in the blood during an attack of blood-poisoning (septieæmia). The best-known baeterial hænolysins are those produeed by the bacteria of tetanus (loekjaw) and of typhoid, and the staphy. loeoceus and streptococeus. They are known as tetano-lysin, typho-lysin, etc. Their action is due to direct eombination with the eell without the aid of an intermediary (amboceptor). They are therefore comparable to toxins, whieh unite direetly with the red corpuscles and destroy them.

Hæmolysis produced by Vegetable Poisons.-Some vegetable poisons, erotin (eroton-oil seed) and phalein (Phallus impudicus, a fungus), have a very marked hæmolytie aetion, and others, riein (eastor-oil bean) and abrin (jequirity bean), agglntinate, but produce little hæmolysis. Immunity ean be established against these bodies and antibodies produced. Against another group of vegetable poisons 110 antibodies are produeed. In this are ineluded saponin, eyelanin from eyelamen, solanin from the green potato, helvellie aeid from a speeies of mushroom (Helvella esculenta). Saponin produees hæmolysis in $1: 100,000$. These poisons differ altogether from baeterial toxins, being resistant to heat, and having no resemblanee to proteins. They are related to glueosides. The aetion of saponin is prevented by the presenee of an exeess of eholesterin in the blood; hæmolysis is probably eaused by the eholesterin portion of the stroma linking the poison to the corpuseles. The toxieity of these substances is not in any way proportional to their hæmolytie powers, their ehief effeet being paralysis of the heart and injury to the eentral nervous system.

Hæmolysis by Snake Venoms. - The salivary seeretion of eertain snakes-cobra, rattlesnake, eopperhead-eauses agglutination of the red eorpuseles, and in some eases also induces hæmolysis. The snakes seerete in their saliva an amboeeptor, and the person bitten provides the eomplement. An animal ean be immunized against snake venom so that it eomes to withstand many times the lethal dosc. An "antivenin" is produeed which, by linking on to the amboeeptor in the snake venom, prevents its union with the red eorpusele.

The hæmolysins ean be dried at a eool tenıperature without losing poteney, are destroyed by aeids and alkalies, and inhibited in their aetion by salts. Introdueed by the stomaeh they have no aetion. In health but little hæmolysis takes plaee apart from the destruetion of effetc corpuscles. In fevers hæmolysis may be produeed by bacterial toxins. It is suggested that eertain anæmias may be due to hæmolysins formed by parasitic inhabitants of the alimentary tract. If more than a small amount of hæmoglobin is set free in solution in the plasma, it eseapes in the urine, giving rise to the condition known as hæmoglobinuria. In some rare eases hæmoglobinuria follows exposure to cold-e.g., it oecurs in some persons after putting the hands in ieed water.

Immunity.-Besides the substances which can be isolated by chemical means, weighed, and analyzed, there are many and subtle properties possessed by the plasma, such as its immunizing powers, which can only be detected by the newly-discovered biological tests. These tests dcpend on the reaction of living substances, and are of the most extraordinary delicacy. On these propertics of the plasma depend the immunity of the organism against infective discases and ccrtain toxins of animal or vegctable origin. The immunizing substances are quite specific for cach bactcrium or toxin. It is known that man is immune to certain infective diseases which affect other animals. For example, he is immune to swine fever. This is termed natural immunity. It is also known that a second attack of whoopingcough, measles, smallpox, etc., is rarc. He who has suffered once has an acquired immunity. Such acquired immunity may be estab- 
lished against various forms of poisons, vegetable or animal, but in particular against baeteria and the poisons they claborate, which are known as toxins. Two forms of immunity, then, may be aequiredonc, which is the better understood, deals with the toxins, the sceond deals with the bacteria themselves. In dealing with toxins the body has the power to claborate a group of substances which are known as antitoxins. If at appropriate intervals and in appropriate doses an animal's body be injected cithcr (1) with one of the poisons or toxins, p:odueed in nutrient media by the growth of such bacteria as the baeilli of diphtheria, tetanus (lockjaw), or (2) with regetable proteins of a poisonous nature, such as abrin (jequirity bean) and riein (eastoroil bcan), or (3) with an animal poison, such as the venoms of different forms of snakes, scorpions, bees, wasps, and spiders, a specific antitoxin negativing the action of each of these poisons is produced in the blood.

It $h$ ss been postulated that the living protoplasm eonsists of a eentral living nucleus and numerous side ehains, or recep.ors, whieh are attached to this. To each of these one or other funetion is allotted-above all, the absorption of nourishment. The side chains, or reeptors, form eomplexes of atoms in the moleeules of the protoplasm whieh, owing to their ehemieal strueture, are able to eombine or link up with other substances-for example, nutritive material, or toxirs. The reeptors eombine with eertain groups of atoms of these substanees whieh, owing to their eombining powers, are termed haptophorie groups, or hıp'ophors. The eombination between these haptophors of the nutritive material, or of the toxins with the reeptors of the eells, whieh have an affinity for then, is neeessary before either the nutriment or the toxin ean have its effect on the ccll. If when a toxin gains entranee within the organism it finds no reecptors of a structural substanee to link with it, it ean exert no poisonous effeet, and the organism is naturally immune to that toxin. Besides the haptophorie group the toxin possesses a group whieh has the poisonous effeet. This is the toxiphorie group, or tjxophor. We may suppose that a nutritive group linking itself to the central ehemieal nueleus of the eel] helps to maintain the lability of the moleeular eomplex whieh manifests the phenomena of life, while a toxie group either arrests the lability or shatters the molecular strueture of this nueleus.

The toxophor is harmless unless anehored on to the eell by the haptophor. Just as a loek eannot be opened unless the person, the aetive agent, has the key. Evidence has been obtained which makes it likely that these two groups do exist, and that the toxin may lose its poisonous properties without losing its power of uniting to the eells; thus, in the ease of tetanus toxin it has boen shown that treatment witl earbon disulphide destroys the poisonous property of the toxin, but not its power to evoke the production of antitoxin. The haptophorie group remains linked with the body tissue eells, and produee 3 antitoxins by stimulating the production of reeeptors. Sueh a modified toxin is ealled a toxoid. Antitoxin; are eell-reeeptors whieh eombine with the haptophorous group of the toxin and render it harmless. These eell-reeeptors are produeed in great numbers, and set free in the blood by the aetion of a toxoid, or by repeated small and non-lethal injections of a toxin. The union of the haptophorie groups with the eell-receptors stimulates an inereased pro. duction of these eell-reeeptors whieh are scereted into the blood. Anti oxie sera are thus produeed by the injection of toxoids or non-lethal doses of toxins. It is suggested that the linkage of a ehemieal group with a partieular side ehain of a eell evokes the produetion of other side ehains of a similar eonfiguration, and the produetion of these may be stimulated to sueh an extent that they eseape from the eell into the blood and endow this with antitoxie power. The reeeptors (antitoxin) liberated by any mammal immunized against a given toxin are apparently the same; thus, the antidiphtheritie toxie serum of horse, sheep, or goat will, if injeeted, neutralize the diphtheria toxin in another animal-as, for example, the guinea-pig or man. But each antitoxin is speeifie and will neutralize the toxin whieh produees it and no other; antidiphtheritie serum, for example, would be of no use if cmployed as the eurative agent for the toxin of tetanus. Every loek, so to speak, must have its own key, and if the man has not the right key he eannot open the door. In this comparison the man 
is the toxin, the key the haptophor, the loek the reeptor. If the man happener to have left his key fitted in a loose loek he would not be able to open his door on reaching home. So the toxins meeting the loose reeeptors in the blood (antitoxi1ı) become bound to these and cannot attack the eells. The ncutralization of the toxin by the antitoxin ean be demonstrated in vitro. It is stated to be a ehemical proeess taking plaee in definite proportions with the liberation of a small amount of leat. Neither toxin nor antitoxin is destroyed in the process; they are simply linked together, and in some cases, at any rate, ean be separated again by appropriate means. The reaetion is aeeelerated by warmth, slowed by eold, and oeeurs more rapidly in strong than in weak solutions.

The ehemieal nature of the antitoxin is unknown. It is elosely related to serum globulin, being carried down when this is preeipitated, but is not neeessarily protein, although its general properties are those of a eolloid. Unlike an enzyme, it is not carried down by an indifferent preeipitats. A toxin seems to be a simpler body than an antitoxin, for in the ease of the hæmolysis produeed by the Megatheriun bacillus, the toxin can be pressed through a poreelain filter impregnated with gelatin, while the antitoxin eannot pass it. Toxie effects are sometimes produeed by the injection of antitoxic sera. These effeets must not be aseribed to the antitoxins, but to other bodies contained in the foreign serum which is injeeted.

There are niany bacteria which do not liberate soluble toxins into the plasma, but have endotoxins which aeeumulate within them, and only beeome liberated when the bacteria are disintegrated. The body elaborates no antitoxins for such as these. Under this elass come eholera and typhoid baeilli. If an animal be injected with appropriate doses of typhoid baeilli, alive or dead (the bacterial vaceines prepared for man are sterilized by heat), the blood aequires baetericidal properties which are speeifie for the typhoid baeillus. It is then found to contain an agglutinin which eauses the bacilli to stiek together or agglutinate, and, if motile, to become motionless. This is seen to take plaee when a drop of serum is mixed with a drop of eulture fluid containing living typhoid bacilli. Further, it eontains an opsonin which renders the baeilli more "tasty," so that they are eaten or destroyed by the white leueoeytes, known as phagoeytes. In some eases the plasma also aequires anti-enzymes whieh counteraet the action of the enzymes eontained in the baeteria. The plasma naturally eontains anti-enzymes which neutralize the enzymes in the body, sueh as thrombin, pepsin, etc. Lastly, by virtue of preeipitins it obtains the power of preeipitating the baeterial proteins. All these reactions are speeifie against the bacteria injected, and are quite distinet from each other.

The mode of action of bactericidal serum is different to that of antitoxie serum. If a baeterieidal serum-for example, a serum taken from an animal whieh has reeeived repeated injeetions of non-lethal doses of eholera vibrios-be heated to $55^{\circ} \mathrm{C}$. for fiftcen minutes, it is found to have lost its power of destroying these baeteria. Yet if now inaetive normal serum be added to this inaetivated heated serum, it again becomes bacterieidal. By tho proeess of immunization the blood has obtained some new substanee not destroyed by heating to $55^{\circ} \mathrm{C}$., which is unable by itself to kill bacteria, but is able to do so when associated with another body, which is eontained in normal serum and is destroyed by heating to $55^{\circ} \mathrm{C}$. Just as is the ease with hæmolytie sera, there are two bodies coneerned in this proeesz of baeterial immunitythe one devaloped during immunization and not destroyed by $55^{\circ} \mathrm{C}$., the immune body, or ambocsp:or ; the other present in normal serum and suseeptible to heatthe complemsut. Any protein whielı provokes the produetion of an hæmolysin, antitoxin, antivenin, preeipitin, immune body, ete., is ealled an ant $\mathrm{g}$ z⿰. 'The aetion of the immune body and eomplenent is explained on the supposition that the immune body is a haptophor which unites the baeteria to the eomplement. The eomplement takes on the rôle of toxin (toxie to the baeteria). The immune body differs from antitoxin in having two affinities-one for the baeteria and one for the eomplement; for this reason the inmune body is termed a $\mathrm{mb}$ eeptor. There are some sera whieh naturally possess amboeeptors apart from any proeess of immunization. The term inmune body is reserved for amboeeptors produced by immunization.

The Immune Body. - The immune body is apparently formed in all the tissues of the body, particularly the eonnective tissues. It is not destroyed by temperatures whieh are fatal to the complement. Thus, twenty hours' heating at $60^{\circ} \mathrm{C}$. seareely injures it, but at $100^{\circ} \mathrm{C}$. it is destroyed almost at onee. It is resistant to putrefaetion, and has been kept for as long as eight years. It seems to be elosely associated with, or absorbed to, the serum globulins, and on this account is not dialyzable. 
The Complement is believed to be the actual destroying agent. It is not increased in the blood during the process of immunization, and thus it comes about in sonie cases that there is not sufficient complement for all the immune substances whose action it is sought to demonstrate. A sufficiency can be provided by the addition of normal serum. The origin of the complement is not known. The lcucocytes and the tissues may each play a part in providing it. The complement is easily destroyed by heating to $56^{\circ} \mathrm{C}$. While its chemical nature is quite unknown, it is worth noting that in the case of snake venom the phosphorized fat, lecithin, plays the part of, or is associated with, the complement.

The Deviation of the Complement.-When serum containing a specific immune body is inactivated (has its complement destroyed) by heat and mixed with the antigen used in its production, a combination takes place between the two, and the antigen is then said to be sensitized. However, no visible effect is apparent until complcment contained in fresh serum, usually that of a guinea-pig, is added. The complcment combines with the sensitized antigen, and may produce a visible effect (e.g., hæmolysis). It should bc noted that an antigen can only be sensitized by its specific immune body, and that complement can only combine with the antigen when linked to the specific inmune body; thus, the combination, or fixation, of the complement can be made a test for the presence of a specific immune body. The test is very delicate and of great diagnostic value, and is carried out in the following way:

A rabbit is immunized against sheep's blood-corpuscles. Its serum is obtained, heated to $56^{\circ} \mathrm{C}$, and kept in sealed capsules. This serum will hæinolyze sheep's corpuscles if a certain minimal amount of normal serum of a guinca-pig is added. The minimal amount is dctermined by experiment. All is now ready for testing the blood, say, of a man suspected to be infected witl typhoid bacilli. Serum is obtained from this man and heated to $56^{\circ} \mathrm{C}$. to destroy the complement in it. It is then mixed with typhoid bacilli and the minimal amount of normal guinea-pig serum added. The mixture is kept at body teinperature, and time enongh allowed for the specific immune body (if present) to fix the complement and antigen (the typhoid bacilli). It is then added to a mixturc of sheep's corpuscles and the heated rabbit's serum. Hæmolysis will not take place if the complement has been fixed in the first stage of the test, since none will be left to combine with the sensitized sheep's corpuscles; and in such a casc it is clear that the suspected serum did in fact contain typhoid immune bodies. If hæmolysis does take place, the complement could not have been fixed in the first stage, and thus the suspected serum was not from a case of typhoid.

Opsonins.-These are spccific substances in the serum which act on bacteria in such a way as to make the phagocytes ingest them. Their presence is demonstrated thus: Blood is collected and allowed to clot. The white corpuscles are separated from the serum by mcans of the centrifuge. The serum is pipctted off, and the corpuscles mixed with physiological salt solution, and again separated by the centrifuge. This procedure washes the corpuscles free from serum. Bacteria are mixed with the washcd corpuscles and the mixture kept at body temperature for ten minutes. A film is then made, stained, and the average number of bacteria ingested by the phagocytes cointed. A similar experiment is pcrformed, only in this case the serum is allowed to act on the bacteria. The phagocytes ingest many bacteria which have been first acted on by the scrum, and very fow of those which have not been so treated. Thus, the serum contains opsonin which prepares the dish for the leucocytes to ingest. Opsonins exist in the normal blood of many animals, and are increased in amount by the process of immunization-by vaccination with dead bacteria. The opsonins in the serum of one animal are able to act on the bacteria, so that they are ingested by the phagocytes taken from another animal. Their chemical nature is not known. They are of the utmost importance in furthering the defence of the body by the phagocytes.

Agglutinins.-These are bodies possessing the property of clumping bacteria. The bacteria themselves are not greatly damaged by the process, but it tends to prevent the disscmination of the organisms, and it may in some way favour phagocytosis. The nature of the change thus brought about in the bacteria is not well known, but their colloidal nature is probably altered by changes in surface tension. Agglutinins can be prepared against almost all bactoria. Their place of formation is not known. They have been demonstrated in the blood and to a less extcnt in the milk. Attached in some way to the globulin in the plasma, they cannot be separated from it. They are destroyed by heat; the temperature of destruction varies for differcnt agglutinins. As in all processes of a like nature the concentration of the electrolytes in solution affects their action. 
Precipitins.-These bodies are present in the blood of an immunized animal, and produce a precipitation of the soluble bacterial proteins if added to a filtrate of the culture used for immunizing the animal. Their action is specific. Precipitins ean be produeed by the injection of any protein, provided that the protein is foreign. It is useless to try and immunize a rabbit against rabbit's serum, and it is better not to employ elosely related species, such as rabbit and guinea-pig. As the result of the injection of horse's serum into a rabbit a preeipitin is obtained in the rabbit's serum which precipitates the proteins in the serum of the horse and of no other animal. Similarly, as the result of the injection of cow's milk a precipitin is obtained which precipitates only the proteins of cow's milk and not those of the milk of any other animal. The specific action of precipitins shows us that the strueture of the homologous proteins varies in different animals. Only by the injection of forcign proteins can precipitins be produced, and the power of the proteins to produce precipitins is lost when they become split up into peptones. Fats and carbohydrates cannot produce precipitins. The precipitation test can only be made outside the body. If serum containing precipitins be injected intravenously, it does not cause precipitation, but provokes an increase in the number of leucocytcs. The material obtained from a mummy five thousand years old gave the precipitin reaction for man.

The action of precipitins is modified by the concentration of electrolytes. A precipitin has two linkages: one the haptophor, whieh links on to the protein, and another linkage (destroyed by heating to $60^{\circ} \mathrm{C}$.), which induces the change bringing abont the precipitation of the protein.

The precipitin appears in the blood about six days after the first injection of protein has been made. Following each subsequent injection it disappears for a time, and then appears again. When the injeetions are finished, the precipitin quickly disappears from the blood, its fate is not known, and it cannot be detected in the urine. The source of preeipitins is not known. As an increased number of leucocytes (leucocytosis) follows each injection, it has been thought that these produce the precipitins.

The precipitins are attached to the globulins in the plasma and cannot be separated from them.

Cytotoxins.-By the injection of animals' cells, bodies called cytotoxins are produeed in the blood. These are capable of destroying the foreign cells injected. Red corpuscles, leucocytes, spermatozoa, kidney substance, stomach, thyroid, and nervous tissues, have all yielded spccific cytotoxins, and so-called erythrolytic, nephrolytic, and other "lytic" sera have been produced. Small gastric ulcers have bcen caused by injecting the blood of one animal immunized against the injeetions of the mucous membrane of the stomach of another species of animal. The red corpuscles afford the best material for studying this phenomenon ( $c f$. Hæmolysis, p. 105).

Hypersusceptibility, Anaphylaxis.-Some people are extraordinarily sensitive to the ingestion of certain nutritive material such as crab flesh, strawberries, egg white. They are inade sick by eating one or other of these things, or suffer from the eruption of a nettle-rash, the result of a disturbance of the equilibrium between the osmotic pressure of the tissues and tissue lymph, which in its turn is due to the toxic effect which the ingested material has on the tissue metabolism. Similarily, sensitivity may be produed by injection of a small dose of a foreign protein-e.g., of horse serum; tho scnsitivity is so increased that a second dose of the same serum, containing perhays little more than a millionth of a gramme of protein, may produce the severest symptoms of intoxication and even death. The hypersusceptibility or hypersensitivity thus induced is termed anaphylaxis. The initial cause of the symptoms seems to be constrietion of the bronchial tubes and obstruction of the airway and a great fall in the blood-pressure, accompanied by congestion and even hromorrhages in the mucous membranes of the bowels. Convulsions, follow the eonseqtient anæmia of the brain. If the animal recover, it is immune to further injeetions of this serum. The sensitivity lasts a very long time. Anaphylaxis has been the cause of alarming symptoms in man in certain cases whero a seeond dose of antitoxic serum has been given after an interval of time. (In some 10 per cent. of norınal individuals a single injection of antitoxic serum is followed by similar though less severe symptoms.) Anaphylaxis may be regarded as the opposite to immunity. 


\section{CHAFTER XIV}

\section{THE TESTS FOR BLOOD}

Frow what has gone before we may now group the chief tests for blood. These may be divided into (1) microscopical, (2) spectroscopieal, (3) chemical, (4) biological.

-Microscopical.-By the use of the microscope the size and shape of the corpuscles can be asccrtained (see p. 86). Reptilian, birds', or camcl's blood can be distinguished from that of the domestic animals or man. The method is of no service in distnguishing betwcen the commoner mammals.

Spectroscopical. - The preparation of spcctra of hæmochromogen, hæmatoporphyrin, and acid hæmatin, are uscful in indicating the presence of blood (see p. 84). In old blood-stains the hæmoglobin is broken down to hæmatin.

Chemical.- Under this heading we may include $(a)$ the preparation of hæmin crystals, $(b)$ the guaiacum test for blood.

Preparaticn of Homin Crystals.- Some of the suspected deposit is taken and placed upon a slide with a crystal of common salt or sodium iodidc. Acetic acid is added sufficiently to float the cover-slip. Warmth is then applied until bubbles begin to riso beneath the coverslip. The slidc is then removed from the flame to cool, and the process is repcated three or four times. Great heat must not be used. Upon examination beneath the microscope, chocolate rbombic crystals of hæmin (hæmatin chloride or hæmatin iodide) will be scen (Fig. 25).

The Guaiacum Test for Blood is usually employed in testing for blood in urine, stomach contents, and other body fluids. If to the boiled suspected solution a drop of tincture of guaiacum be added, then a few drops of ozonic ether, and the reddish guaiacum turns to a blue colour, it signifies blood. The rezct:on depends on the iron combined in the hæmoglobin. The enzymes known as oxidases give the test, and therefore a positive result is sometimes obtained with such body fluids as milk and saliva, and with the juices of vegetables, apple, pincapple, potato, which sometimes lcave a brown stain resembling. stale blood. As the oxidases are destroyed by heat a solution suspected to contain blood should be boiled before it is tested. If this condition is complied with, a positive reaction may be taken to indicate blood. If the test is negative, blood is certainly absent. Instead of ozonic ether, hydrogen peroxide or old oil of turpentine can be used. Various tests have been devised using bodies other than guaiacum resin. Such bodics are-aloin, benzidin, and the leuco 
base of malachite green and of phenolphthalein. The last-named body is stated to be extremely sensitive.

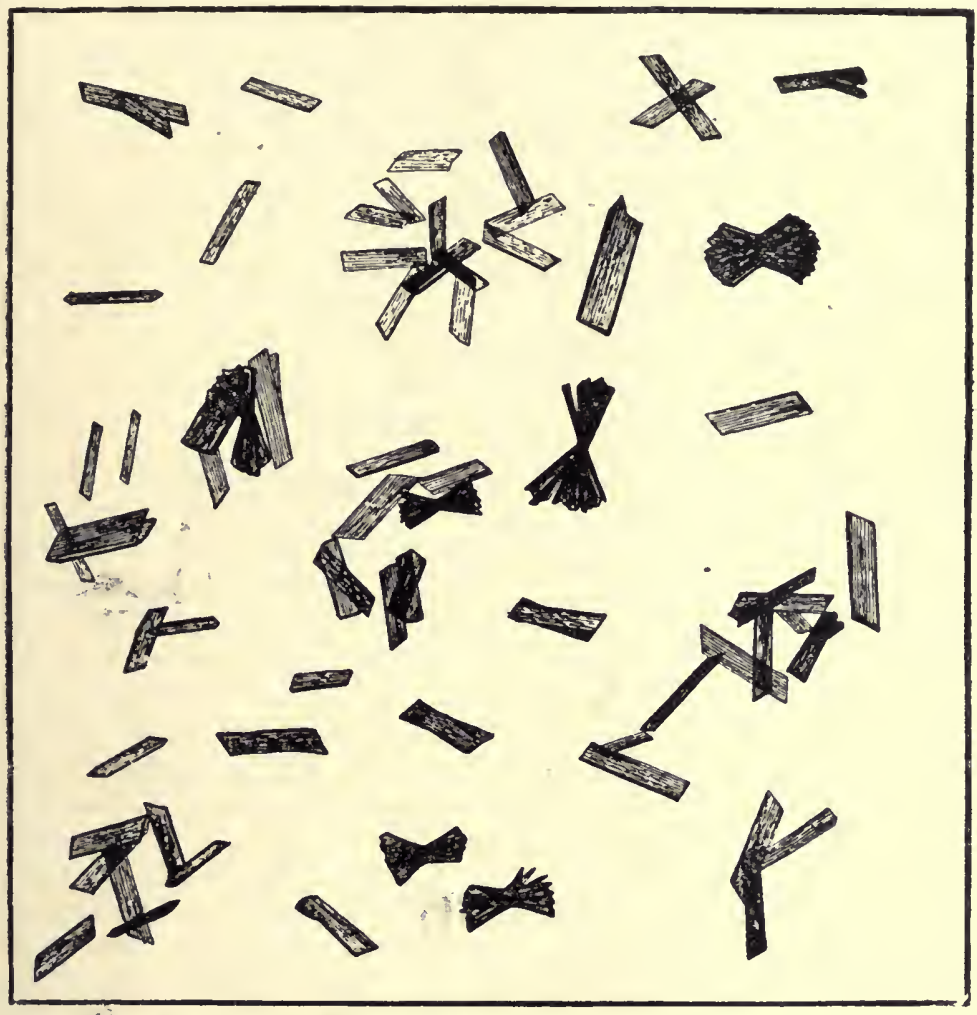

Fig. 25.-Hzin Crystals. $\times 1,500$.

Biological.-The biological test depends upon the fact that the serum of an animal injected with foreign corpuseles develops the power of precipitating, agglutinating, and dissolving corpuscles similar to those injected, but not those of other species of animals. A rabbit is injeeted with 2 to 3 c.c. of human serum at intervals during four days, until 10 to 15 c.c. have been injected. After one to two weeks the animal is bled, the serum collected and placed in sterile tubes, and used as needed. This serum is mixed with the suspected blood, which is dissolved or suspended in isotonic salt solution in the proportion of 1 : 100 ; the mixture is placed at $37^{\circ} \mathrm{C}$. If the blood be human, a turbidity is produced, changing within three hours to a flocculent preeipitate. The blood of closely allied speeies, such as the other Primates-e.g., ehimpanzee-may give a slight precipitate. The test has been used to detect human blood in medico-legal eases, and to confirm the supposed eonsanguinity of different species of animals. It shows the near relation of man to the gorilla, the ourang, and the ehimpanzee. 



\section{BOOK III}

\section{THE CIRCULA'TION OF THE BODY FLUIDS}

\section{CHAPTER XV}

\section{THE MECHANISM OF TRANSPORT}

THE unicellular organism floating in a nutritive watery fluid lives by exchange between its body and the surrounding medium. In the multicellular organism the deeper parts become too far removed from the surface for a rapid exchange of material to take place, and devices such as infolding are evolved, which lead the medium into the inner recesses of the body.

With the higher organization brought about by evolution, a limit soon became set to such infolding, which interfered with the differentiation of structure and division of labour necessary to render the organism efficient in the struggle for existence. Hence, there came about the development of a body cavity, or cœlom, filled with an internal medium, which, as blood or lymph, was at first made to circulate by the general movements of the body. Later was cvolved a special pump - the heart, or several hearts-and a system of vascular tubes, at first partly and then completely closed. By the aid of these the internal medium could be driven with greater swiftness and ins ure the better nourishment of every part. The internal tissue of a Turbellarian worm, for example, is a loose aggregate of cells, differentiated to a slight extent in structure and no doubt in function, connected by strands of protoplasm. Between the cells are intercellular clefts, which are connected with larger channels which extend through the body, and act as circulatory channels. These clefts and channels are filled with a fluid which carries the food and oxygen supply to, and the waste products from the internal tissues, and in every way acts as a simple blood. A to-and-fro movement takes place as a result of the movements of the animal. The mesodermal cells in contact with the primitive channels become differentiated in part into tissues, which form walls to these spaces. The primary circulation spaces become specialized into continuous channels which run the length of the body. The blood is driven to and fro in this body cavity, or cœlom, by the movements of the muscles of the body, and, so propelled, bathes the respiratory tissues, the wall of the gut, the ncphridia and other structures. 
In the mollusca we find definite blood-channels, the larger of which, in the cephalopods, have well-developed muscular walls, and act as pumps driving by wave-like contractions the contained fluid before them.

In the lobster there is developed a heart. It is endowed with a rhythmic activity of its own, and forces the blood through a system of larger vessels-the arteries-to smaller frailer vessels-the capillaries-and thence to open spaces between the masses of connective tissue-the lacunæ. From these lacunæ the blood is returned to the heart by another system of channels-the veins.

In insects the circulatory mechanism is simple. A dorsal pumpthe heart-forces the blood through a vessel which runs in the median line from one end of the body to the other into large sinuses and spaces; from these it is returned to the heart. In the limbs are placed accessory hearts, which force the blood to their extremities.

In the vertebrates the evolution of the circulatory system is carried to the highest point. Blood is pumped from a well-differentiated strong muscular heart, by means of an arterial system with wellmarked muscular and elastic walls, into a capillary system the walls of which are formed by a single layer of endothelium. The lacunar system still persists in part, for in certain organs, such as the spleen, the capillaries are not closed vessels, but open into the tissue spaces. From the capillaries the blood is returned by larger channels-the veins-to the heart.

In Amphioxus the blood vascular system is still of the primitive lacunar type This lowest vertebrate possesses two hearts-a dorsal heart, driving arterial blood to the system, and a ventral one, which is termed the " respiratory heart," sending blood to the gills. In fishes the heart is single, and essentially respiratory in function, propelling blood to the gills, thence to the aorta and to the system generally, and back again to the heart.

In the amphibia there are two auricles and one ventricle; in reptiles two auricles and a partial separation of the ventricle into two. It is only in the birds and mammalia that the two systems become quite distinct- two auricles" and two ventricles-the right auricle and ventricle forming the respiratory system, the left auricle and ventricle the systemic. This evolution has, however, been carried out on quite a different plan in the two hearts, the bird's heart differing in many points from the mammalian.

In man the heart is about equal in size to a closed fist, measuring about 5 inches long, $3 \frac{1}{2}$ inches wide, and weighing in the adult about 300 grammes, or $0 \cdot 46$ per cent. of the body weight. In the new-born baby it weighs about 24 grammes, 0.76 per cent. of the body weight. The average weight of the male and female heart is almost the same. The volume is estimated by filling the cavities with wax, to be 100 to 130 c.c. for each auricle, and 150 to 200 c.c. for each ventricle.

The auricles have much thinner walls than the ventricles. The muscle of the auricles consists of a circular layer common to both, 
and a deeper layer separate for each chamber. The auriculo-ventricular ring consists of connective tissue separating the muscle of the auricles from that of ventricles except at one spot on the septum (see p. 121, the A.-V. bundle), and possibly at the right lateral external margin.

The right auricle is more or less quadrilateral in shape, being prolonged in the upper corner to an ear-like process-the right a uricular appendix. Into it the superior and inferior venæ cavæ open. At the junction of the superior vena cava and auricle is situated a small mass of tissue known as the "sinu-auricular node."

The right ventriele forms the chief part of the anterior surface of the heart. It communicates with the right auricle and with the pulmonary artery. At the entrance from auricle to ventricle are

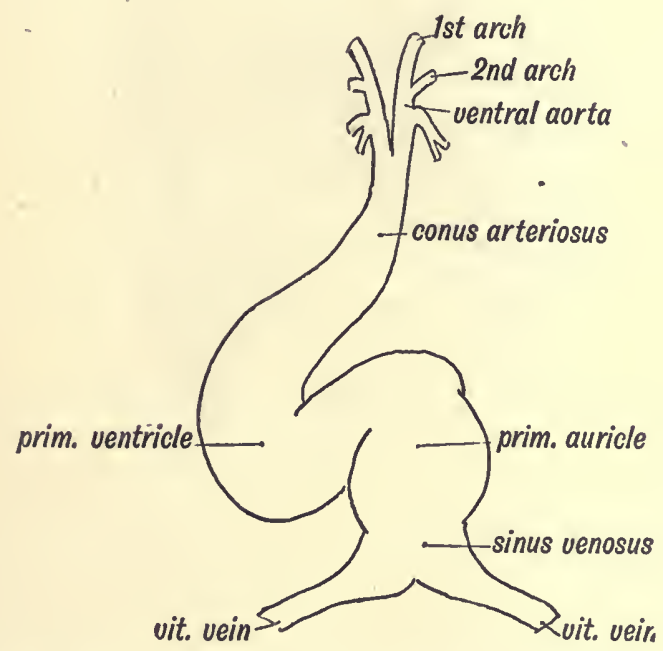

Fig. 26. - The Primitre Divisions of the Embryonic Heart. (Keith.)

situated the tricuspid valves, while the entrance to the pulmonary artery is guarded by thin watch-pocket-like valves-the semilunar valves.

The left auricle is situated posteriorly. It likewise possesses an appendix. Into it the four pulmonary veins open. The left auricle communieates with the left ventricle, the orifice being guarded by the two flapped bicuspid or mitral valves.

The left ventricle forms the chief part of the posterior surfaee, and also the apex of the heart. It forms the chief muscular mass of the hcart, the wall being in places $\frac{1}{2}$ inch in thickness. It communicates with the left auricle and with the aorta. At the orifice of the aorta are situated delicate semilunar or watch-pocket valves. Opposite the cusps are bulgings of the aortic wall-the sinuses of Valsalva. From the anterior one arises the right coronary artery, 
and from the left posterior the left coronary artery. These vessels supply the heart muscle.

Various accounts are given of the arrangement of the musculature of the ventricles. Internally, the muscular fibres are thrown into columns-the columnæ carnæ and the papillary muscles. The superficial fibres take origin from the auriculo-ventricular ring, and wind spirally about the heart, to end in the papillary muscles, or pass up in the septum to the ring again on the inner surface of the heart. The middle layers, which form the bulk of the tissue, consist of bundles of fibres running more or less circularly round the ventricles.

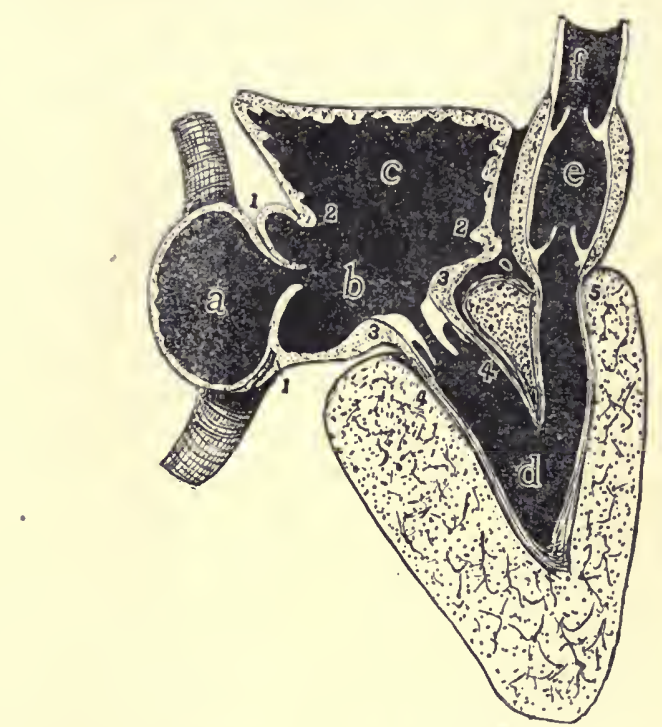

Fig. 27.-Generalized Type of Vertebrate Heart. (Keith.)

$a$, Sinus venosus and veins; $b$, auricular canal ; $c$, auricle; $d$, ventricle; $e$, bulbus cordis; $f$, aorta; I-I, sinu-auricular junction and venous valves; $2-2$, canalo-auricular junction; $3-3$, auricular part of auricle; 4-4, invaginated part of auricle ; 5 , bulbo-ventricular junction.

By the study of the primitive type of vertebrate heart a clear concept has been gained not only of anatomical arrangement, but of the function of certain parts in the more highly developed mam. malian heart.

The heart devclops as a tube (Fig. 26), and the auricle is regarded as a dorsal expansion of this tube, and the ventricle as a ventral expansion.

The diagram (Fig. 27) represents the general type of a primitive vertebrate heart. The cardiac tube begins at $(a)$ and ends at $(f)$. Dorsally is placed the expansion $(c)$, the auricle, while $(d)$ represents the ventricular outgrowth. Such a heart may be said to consist of five chambers. At the venous end $(a)$ the sinus venosus is formed by 
the junction of the two great veins. The blood enters the heart, and the wave of contraction begins here.

Chamber $(b)$ represents the original cardiac tube from which the auricle has grown out dorsally. It is known as the "auricular canal," and may be subdivided into three parts: $(A)$ the part of the cardiac tube antecedent to, and opposite, the outgrowth of the auricle (2-2) generally termed the "basal part"; $(B)$ the part which .comes after the outgrowth of the auricle and before the downgrowth of the ventricle (3-3)-the " auricular ring "; $(C)$ a part (4-4) which has become invaginated into the ventricle. The ventricle is represented by $(d)$, while $(e)$ at the arterial end of the cardiac tubə represents the chamber known as the "bulbus cordis."

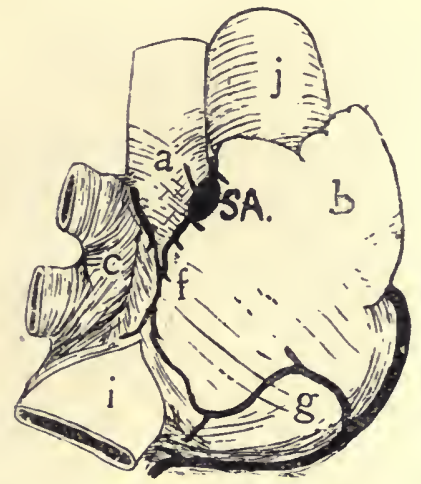

Fig. 28. - Right Auricle Sefin from the Side. (Keith and Flaek.)

$a$, Superior vena eava; $b$, appendix; S.-A., sinu-aurienlar node; $c$, vestibule of left auriele; $f$, union in sulcus terminalis of two braneh arteries arising from right eoronary artery; $g$, another anastomosing branch from right eoronary artery; $i$, inferior vena eava; $j$, aorta.

In such a heart the flow through the organ is directed by four sets of valves: (1) Placed between the sinus and auricular canal (the venous valves); $(2)$ at the auricular ring at the entrance to the ventricle; (3) and (4) at either end of the bulbus cordis.

The two auricles of the mammalian heart are formed by a fusion of the musculature of three parts of the primitive vertebrate heartthe sinus, the auricular canal, and the primitive auricle.

The two ventricles are developed side by side from the ventral wall of the primitive tube, an infolding of the walls fusing to form the interventricular septum.

The bulbus cordis comes to be represented by the infundibular part of the right ventricle.

In the mammalian heart the sinus venosus, with the venous valves, has almost disappeared. Its most important remnant is a small mass of tissue at the junction of the superior vena cava and the auricle (Fig. 28) - the sinu-auricular node.

In the human heart the sinu-auricular node is about the size of 
a grain of wheat. It has a special blood-supply, and here the nerves of the heart form an intimate contact with the musculature. Microscopically, it consists of pale cardiac muscle fitres, with which the nerve fibres appear to bccome actually continuous. This tissue, apparently intermediate in nature between muscle and nerve, is eharacteristic of the sinu-auricular and auriculo-ventricular nodes, and is termed "nodal tissuc." The nodal tissue bccomes less in amount and more eoncentrated in position as one passes from the lower to the higher type of heart. With the increasing specialization of the organ the extra-cardiac nerves enter into a more direct relationship with the cardiac musculature; the heart to a certain extent loses its independence, and becomes more a part of the gencral organization.

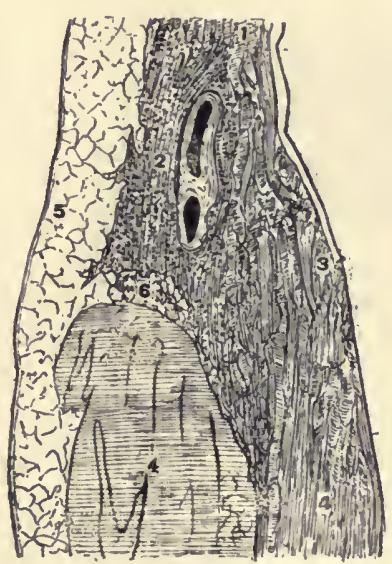

A

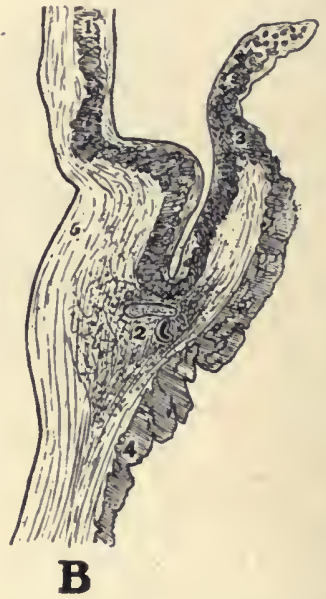

B

Fig. 29. - $A$, Stnu-Auricular Juxction ix Humax Heart; $B$, Sixu-Auricular. Junctiox in Turtle's Heart. The Figures represent Correspondnat Parts in the Two Hearts. (Kcith and Flack.)

1, Musculature of supcrior vena cava or sinus in $A$, of sinus venosus in $B$; 2 , artery and surrounding nodal tissuc at sinu-auricular junction; 3 , position of venous valve in $A$. In $B, 3$ indicates junction of musculature of sinus and auricle in the venous valve; 4 , auricular muscle, differs from sinus musculature in both $A$ and $B$ in having a very slight endocardial covering; 5 , subcpicardial tissue; 6 , connective tissue between sinus and auricle.

The aurieular canal has also become profoundly modified, owing to the development of two auricles instead of one. The basal part is represented chiefly by the interauricular septr $m$.

Similarly, the development of two ventricles by the downgrowth of an interventricular septum has brought about a rearrangement of the auricular ring and the invaginated portion of the auricular canal. Most of the auricular ring has become indistingnishable from the rest. of the auricular tissue, but at the base of the interauricular scpt::m there is found a mass of "nodal" tissue, known as the auriculoventricular or A.-V. node (3, Fig. 30). 
The invaginated portion has become greatly reduced in amount, and instead of extending into the ventricles all round the A.-V. groove, as it was in the primitive type of heart, it is represented by a small muscular band of fibres arising from the A.-V. node, and passing into the ventricles - the auriculo-ventricular bundle.

It consists essentially of four portions: The A.-V. node, the -main bundle, the septal divisions, the terminal ramifications.

These parts can be made out more easily in some hearts than other. In the hearts of the sheep and ox it is easy, owing to the paleness of its fibres, to disscet out the whole bundle. In these hearts, the fibres constituting the bundle present a greater contrast to the musculature of the heart.

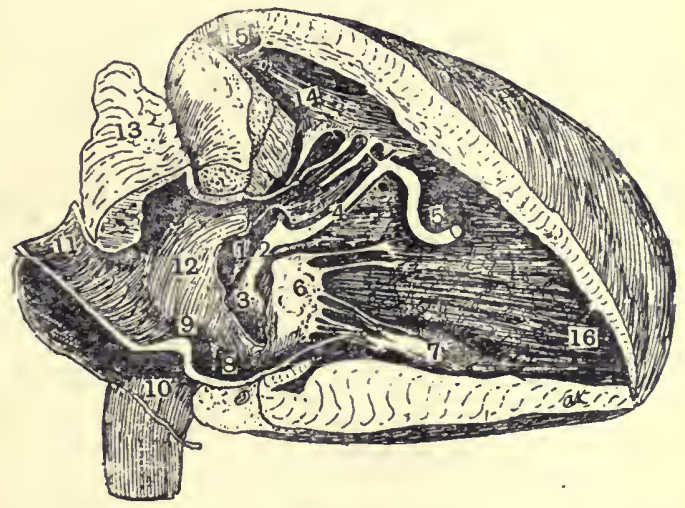

Fig. 30.-Right Auricle and Vextricle of Calf. (Keith and Flack.)

1, Central cartilage; 2, main A.-V. banłle; 3, A.-V. node; 4, right septal division of A. $-V$. bundle; 5 , moderator band; 8 , orifice of coronary sinus.

The auriculo-ventricular node lies at the base of the interauricular septum on the right side, below and to the right of the coronary sinus. It is in close muscular connection with the interauricular septum, and thus indirectly with the sinu-auricular node.

The main bundle, arising from the A.-V. node (Fig. 30), rides along the top of the interventricular septum below the pars membranacca septi -a spot easily found in the human heart by holding the organ up to the light aftor oponing the chamber. It then divides into the right and left septal divisions for the right and left ventricle respectively. The right band is cord-likc, and is somewhat embedded in the septum, becoming supcrficial as it approaches the septal group of the musculi papillares. The left bundle is subendocardial throughout its course to the septal musculi papillares, and has the form of a delicate ribbon of fibres.

The terminal ramifications may be said to arise from these groups of septal musculi papillares. Starting from these, they run in the "moderator band" on the right side, and in several small bands on the left side, passing as delicate trabcculæ to fuse with the ventricular musculature. 
On microscopic examination there may be seen (1) the branched network of cells in the A.V. node, (2) the large pale cells of the main bundle, (3) the peculiar Purkinje cells constituting the septal divisions and the terminal ramifications. In the human heart the different portions of the bundle are not so easily rcognized, but with practice it can be identified both macroscopically and microscopically. It is interesting to note that the invaginated portion of the auricular canal (the A.-V. bundle) has persisted in the part of the primitive cardiac tube which has been least disturbed by the development of the two ventricles.

There possibly exists another muscular connection between right auricle and right ventricle in the right lateral external part of the A.-V. groove.

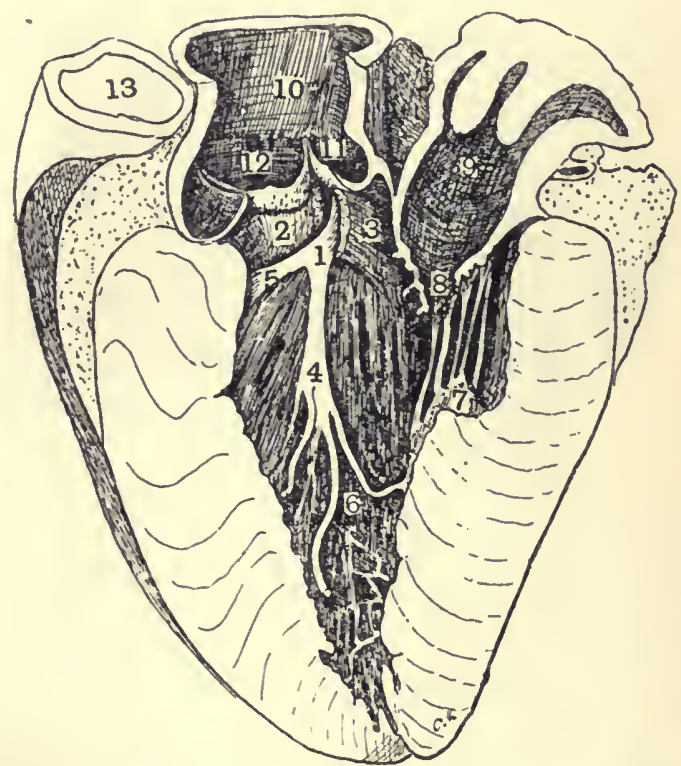

Fig. 31.-Left Ventricle of Calf. (Keith and Flack.)

1, Left septal division of A.-V. bundle; 2-3, subaortic musculature divided to show passage of bundle from right side of heart; 4-5, branches of left septal division passing to 6, moderator bands eontaining prolongations of bundle to fuse with musculature of heart wall; 9 , left auricle; 10, aorta; 11, 12, aortic valves; 13, pulmonary artery.

In the heart of the bird, which contains no sinu-auricular node and no muscular bundle in the position of the A.-V. bundle, a similar muscular connection has been found in the posterior aspect of the A.- V. groove in the region of the left superior vena cava.

Microscopic Anatomy. - The vertebrate heart-muscle consists of fibres, which in their turn are composed of fibrils, or sarcostyles and sarcoplasm. Nuclei are situated at regular intervals in the fibres, and are surrounded by a small mass of granular protoplasm-the sarcoplasm. Running out from the ecntral sarcoplasm to the periphery between the fibrils there is a very delicate protoplasmic membrane-. 
the sarcolemma-often richly impregnated with fine granules. The sarcoplasm and nuclei represent the remains of the primitive cells (myoblasts) from which the heart is developed; the fusion of these forms a syncytium in which the fibrils develop. These are the true contractile elements of the muscle fibres. They are somewhat prismatic in shape, and lie in bundles at the periphery of the fibre, the centre being occupied by the nucleus and sarcoplasm. The sarcostyles exhibit a longitudinal striation due to the fibrils, and sometimes a transverse striation due to the presence of singly and doubly refractile substances alternately placed within the fibrils (Fig. 32).

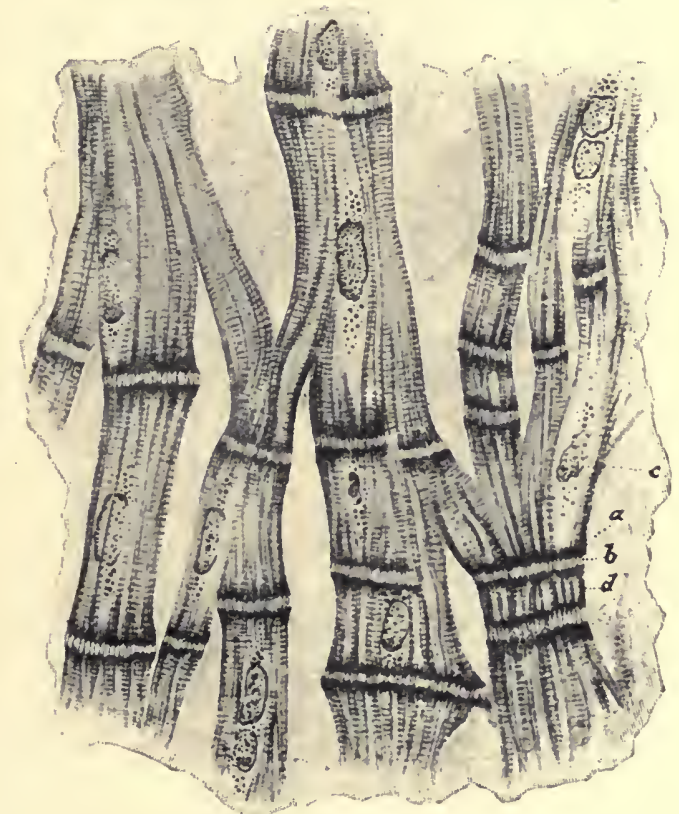

Fig. 32.-Muscular Network of Normal Heart of Adult Mas. (Przewoski.) $a$, Septum; $b$, fibrils passing through thickenings in fibre; $c$, nuclei of cells; $d$, short segment without nucleus. (From "Quain's Anatomy.")

There is an intimate fusion betwcen neighbouring fibres; a number of fibrils from one fibre pass into a neighbouring fibre.

At intervals transverse lines appear in the fibres. Some think these are caused by a local thickening of the fibre produced by the process of death; others believe they have some special function in regulating the growth of the fibres. They are not to be regarded as a cement substance separating different heart cells.

The Nervous Elements of the Vertebrate Heart.-The vertebrate heart is very rich in nervous elements-ganglion cells, nerve fibres, and nerve endings. There is a very rich supply of ganglion cclls in the auricle. In the frog's heart they are grouped at the sinu-auricular 
junction (G. 1, Fig. 33), upon the interauricular septum (G. 2, Fig. 33), at the auriculo-ventricular junction (G. 3, Fig. 33).

In regard to the distribution of ganglion cells in the ventricles, it is generally conceded that they exist in the upper third of the ventricle, the lower two-thirds being regarded as ganglion-free.

The nerve endings in the heart are both receptor and effector. As regards the sensory nerve endings (the depressor nerve), some observers hold that they do not supply the heart, but only the aorta; others believe they end as tree-like expansions very like those found in fascia and tendon in both the outer covering of the heart (epicardium) and the lining membrane (endocardium).

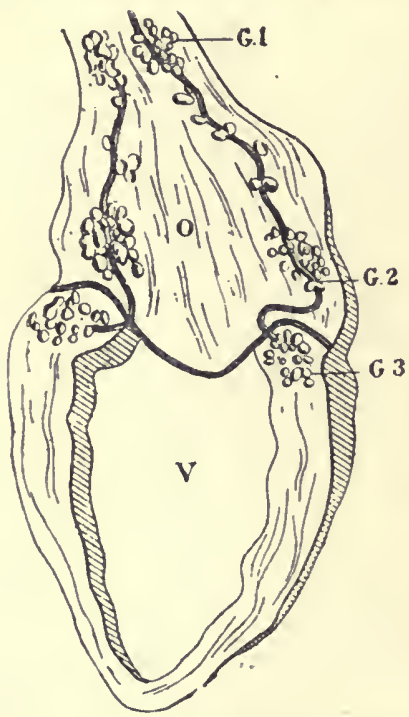

Fig. 33.-INter-Auricolar Septum and Ventricle showing the Vagus Nerves and Gavglia. (Hedon.)

$G$. 1, Sinu-auricular or Remak's; G. 2, septal, or v. Bezold's; G. 3, auriculo-ventricular, or Bidder's.

The effector nerve endings come from both the vagus and sympathetic nerves, and it is stated that each heart fibre is surrounded by a nervous network right down to the apex.

Structure of the Bloodvessels. - The whole vascular system is lined within by a layer of flattened cells-the endothelium. Each cell is exceedingly thin, and cemented to its fellows by a wavy border of an interstitial ccment (protoplasm) substance. The endothclium affords a smooth surface, along which the blood can flow with ease. It rests on a soft, thin film of connective tissue, the two together forming the internal coat, or intima. Outside it there exists in the arteries and vcins a middle and an cxternal coat. The middle coat, or media, varies greatly in thickness, and contains most of the nonstriated muscle-cells, which in the smaller arteries and arterioles form 
a particularly well-developed band. In the larger arteries a great deal of yellow elastic tissue, together with some white, fibrous tissue, pervades the middle coat. At the inner and outer border of this coat the elastic fibres fuse, to form an internal and external fencstrated membrane-a marked feature of an artery. This coat endows the arteries with lability (extensibility and elasticity) and contractility. The outside coat consists mostly of white fibrous tissue, and not only protects the arteries, but by its rigidity prevents overdistension. The connective tissue, like the leather case of a football, allows extension of the elastic layers up to a certain point, and then becomes taut. In the veins where the middle coat is somewhat thinner and contains less elastic tissue, the outer coat consists largely of muscle-fibres. There is more white connective tissue in the walls of the veins. The valves of the veins are formed of fibrous and elastic tissue covered with endothelium. The walls of the larger bloodvessels are supplied with blood through the vasa vasorum. As the arterioles branch into capilaries the muscular and elastic clements become less and less, until in the capillaries themselves there is left only the layer of endothelium, supported by some stellate connective-tissue cells. There is some evidence that the cells lining the capillaries can alter their shape, and so contract the lumen of these vessels. A phagocytic action is also ascribed to these cellse.g., in the liver. In early embryonic life these cells give origin to red corpuscles (see p. 88). The capillaries form networks, which accommodate themselves to the structure of the organs-e.g., longitudinal networks in muscle, loops in the papillæ of the skin, closemeshed networks round the alveoli of glands, cells of liver, etc. In the liver the blood penetrates into the substance of the liver cells, the capillaries forming sinusoids. In the spleen the capillaries open into the pulp. The lumen of the capillaries can be widened or narrowed by varying contractility. As the capillaries join together to form the venules, muscle fibres again appear and coat the wall of the latter. The bloodvessels arc supplied with vaso-motor nerves, which regulate thcir calibre and the supply of blood according to the needs of the body. The "nerves end in a plexus of fibrils among the muscle fibres. Ganglion cells occupy the larger nodes of the nerve plexus. The ends of a torn artery retract, coil up within the external coat, and so prevent hæmorrhage. The excised arteries-e.g., of an ox or sheep-contract when mechanically irritated, and remain capable of contraction for some days after excision. They may be relaxed by freezing, or by poisoning with a solution of fluoride of sodium.

The elastic tissues of the arteries successfully withstand the strain of the pulse some seventy times a minute throughout the years of a long life.

The elastic co-efficients of the several layers of the coat of an artery increase from within out, and thus great strength is obtained with the use of a small amount of material. The elasticity of a healthy artery is almost perfect, while the breaking strain both of arteries and veins is very great, and far above that exerted by the blood-pressure 
- e.g., they may withstand an internal pressure up to abolit 10 atmospheres. It has proved possible to stitch divided arteries and veins together so perfectly that the circulation can continue through them. The kidneys have thus been successfully transplanted from one cat to another, and have continued to functionate for some days. A piece of artery, killed by immersion in formol solution, has been intercalated in the aorta of an animal, and the circulation has continued unimpaired. It forms a scaffold for repair.

The heart is enclosed in a tough inextensile bag-the pericardium - the functions of which are to give the heart a smooth bag to work in, moistened with pericardial fluid; to prevent misplacement and check over-dilatation of the heart, in particular during great muscular efforts. The pericardium restrains the over-stretching of the heart in just the same way as the leather cover of a football stops over-distension of the indiarubber bladder within it.

The abdominal organs and bloodvessels, encompassed by the muscular wall of the abdomen, may be regarded as enclosed in a sphere of muscle. Above is the dome of the diaphragm, below the basin-like levator ani, closing the outlet of the pelvis; in front are the recti muscles, behind the quadrati lumborum and the spine; while the oblique and transverse muscles complete the wall at either side. The brain is enclosed in a rigid and unyielding box of bone-the cranium; the limbs are encompassed by the extensile and, in health, taut and elastic skin; while the organs, such as the salivary glands and kidneys, posscss a capsule which confines them and limits their expansion.

The bloodvessels are thus confined by the walls and membranes of the body and influenced by every muscular movement.

The heart's energy is spent in maintaining a pressure of blood in the elastic arteries, and owing to the difference of pressure in the arteries and veins, the blood is kcpt flowing through the capillarics into the veins. The movements of the body, particularly those of respiration, help to return the blood from the capillaries and vcins to the heart. In the veins, especially those of the limbs, valves are placed to direct the blood heartwards. The blood is propelled by the heart, which varies both in rate and energy of beat, through muscular and labile arteries, delicate capillaries, and muscular veins-a systcm which varies in capacity and may alter in lability. This system is supported by the tissues which, by their contractility, elasticity, and secretory force modify their support of the vascular system most profoundly. The width of bed through which the blood flows varies grcatly at different parts of the circuit. The resistance offered to the moving blood is very much greater in the capillary-sized vessels than in the large arteries and veins.

The problems of the circulation are thus far from simple. They resolve themselves mainly into a consideration of (1) the physiology of the heart; (2) the physical characters of the circulation; (3) the control of the heart and ressels by the nervous system. 


\section{CHAPTER XVI}

\section{THE PHYSIOLOGY OF THE HEART}

The Heart as a Muscle.-The properties of the cardiac muscle may be studied either on the beating or on the still heart. The excised heart continues to beat for some time outside the body, and has the power of rhythmic automaticity. The still heart is obtained in the mammal when the heart is cut out from the body and kept in physiological saline until it ceases to beat.

The contraction of the heart is usually recorded by means of a lever which writes on a smoked surface (Fig. 34). By this means a

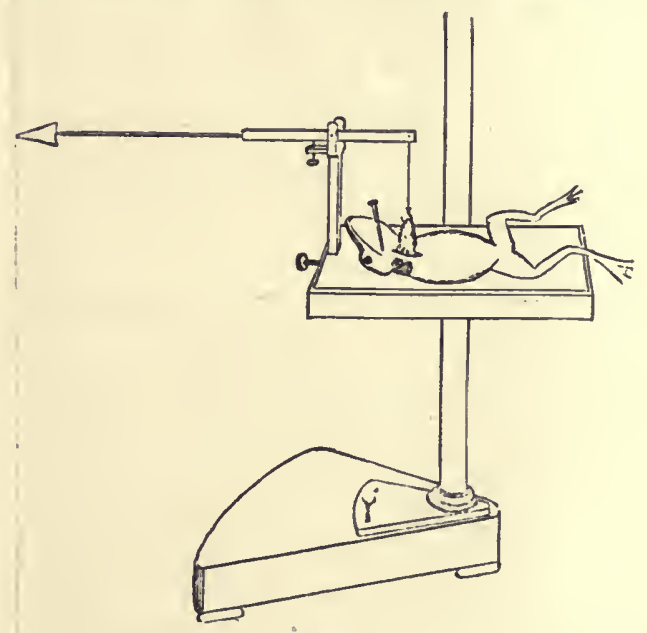

Fig. 34.-Lever for Recording the Frog's Heart. (Pembrey and Phillips.)

record such as Fig. 35 is obtained. If an arrangement of two levers be used, the contractions of the auricle and ventricle can be separately recorded (Fig. 36) if the heart be clamped at the auriculo-ventricular groove.

The excised heart of the frog will beat for days in a moist chamber. The auricles and ventricles stop beating when a ligature is tied around the sinu-a uricular junction (the first Stannius' ligature) (Fig. 35). Such a stilled frog-heart responds to a single stimulus-mechanical, thermal, chemical, or electrical-by a single beat. The electrical stimulus is generally chosen, but it is important to note that heart-muscle responds 


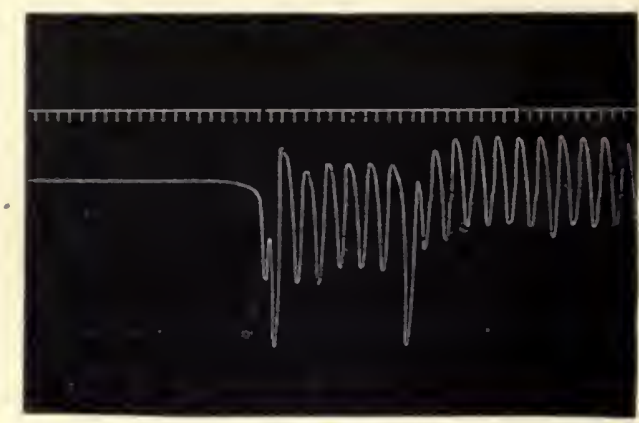

Fig. 35.-Contraction of the Frog's Heart Recorded by the Suspexsion Method. (L. H.)

The effect of tightening the first Stannius ligature at first gently and then firmly. The curve should be read from right to lett. The time is marked in seconds.

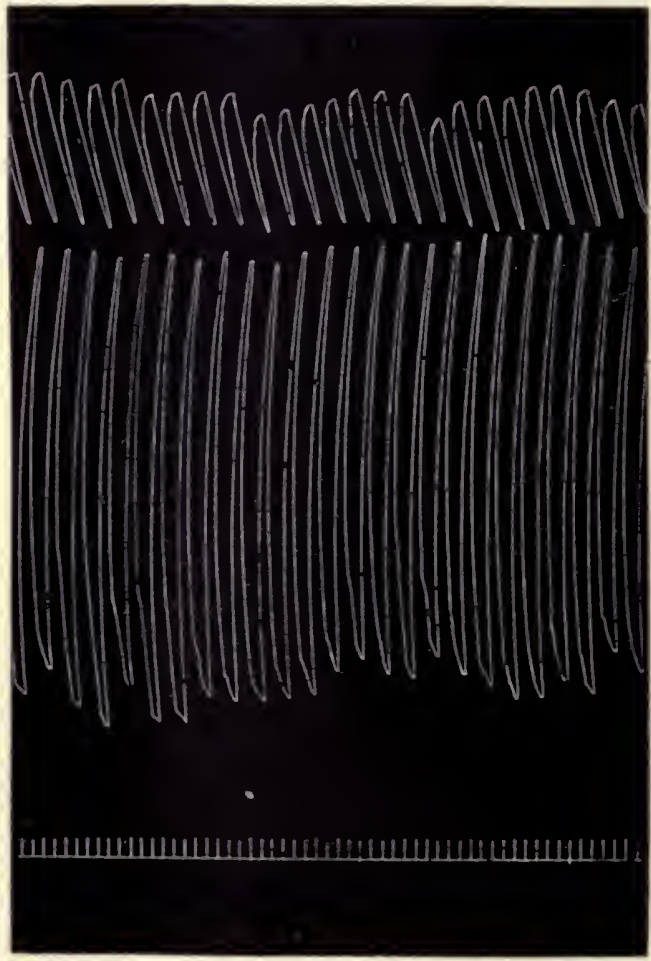

Fy. 36. -Record of the Contractios of Auricle and Ventricli (Toad) b5 the Use of Clamp aNd LEVRRs. (L. H.)

The upper tracing is the auricle, and here the contraction is represented by the downstroke. The time is marked in seconds. 
to the stimuli characteristic for muscle (ammonia, dilute mineral acids), and not to those for nerve (glycerine). We see, then, that the heart possesses the properties of excitability and contractility, and that excitability (the power to respond to a stimulus from without) continues longer than the property of rhythmic automaticity (the power of responding to the stimulus given from within).

Thus the heart of the embryo chick at three days possesses great rhythmic automatic power, but little excitability to artificial stimuli; later, the rhythmic automaticity, especially that of the ventricles, decreases, while the excitability increases. The auricle becomes more automatic than the ventricle, the ventricle more excitable than the auricle.

The power of contractility varies in different hearts and in different parts of the heart. It is most marked in the ventricular musculature. The difference between automaticity and excitability

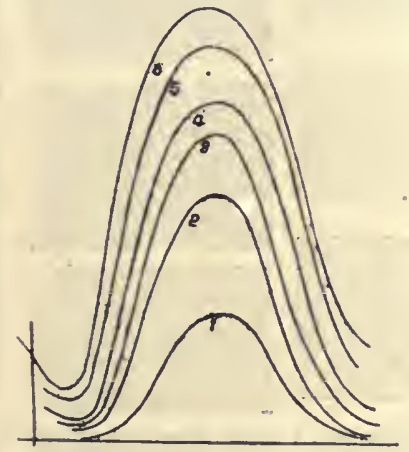

Fia. 37.-Effect of increasing Diastolic Presseres-that is, increasing the Load-oN the Isometric CURve of the Frog's Heart. (O. Frank.)

is more apparent than real, automaticity depending on the site of application and the kind of stimulus.

The contraction obtained by stimulating cardiac muscle resembles that obtained by stimulating ordinary muscle (see Fig. 275). Just as a striped muscle works better with increasing load up to a certain point, so, tco, the heart-muscle contracts more powerfully as the load is increased up to a certain point, but after that weakens and stretches (Fig. 37). In severc muscular exercise the work of the heart is grcatly increased: contracting more often, it rests less. The heart responds to such strains 'by growing larger and stronger.

Cardiac muscle presents certain fundamental characteristics which are different from those of striped muscle. Thus, cardiac muscle responds to any efficient stimulus with a maximal contraction, sometimes called the "all-or-nothing law." Striped muscle responds-to increasing stimuli by contractions rising from minimal to maximal. "The difference is more apparent than real, for probably only a few of the fibres of a muscle are stimulated by a minimal stimulus, while in the syncytium of the heart-muscle the stimulus spreads everywhere. 

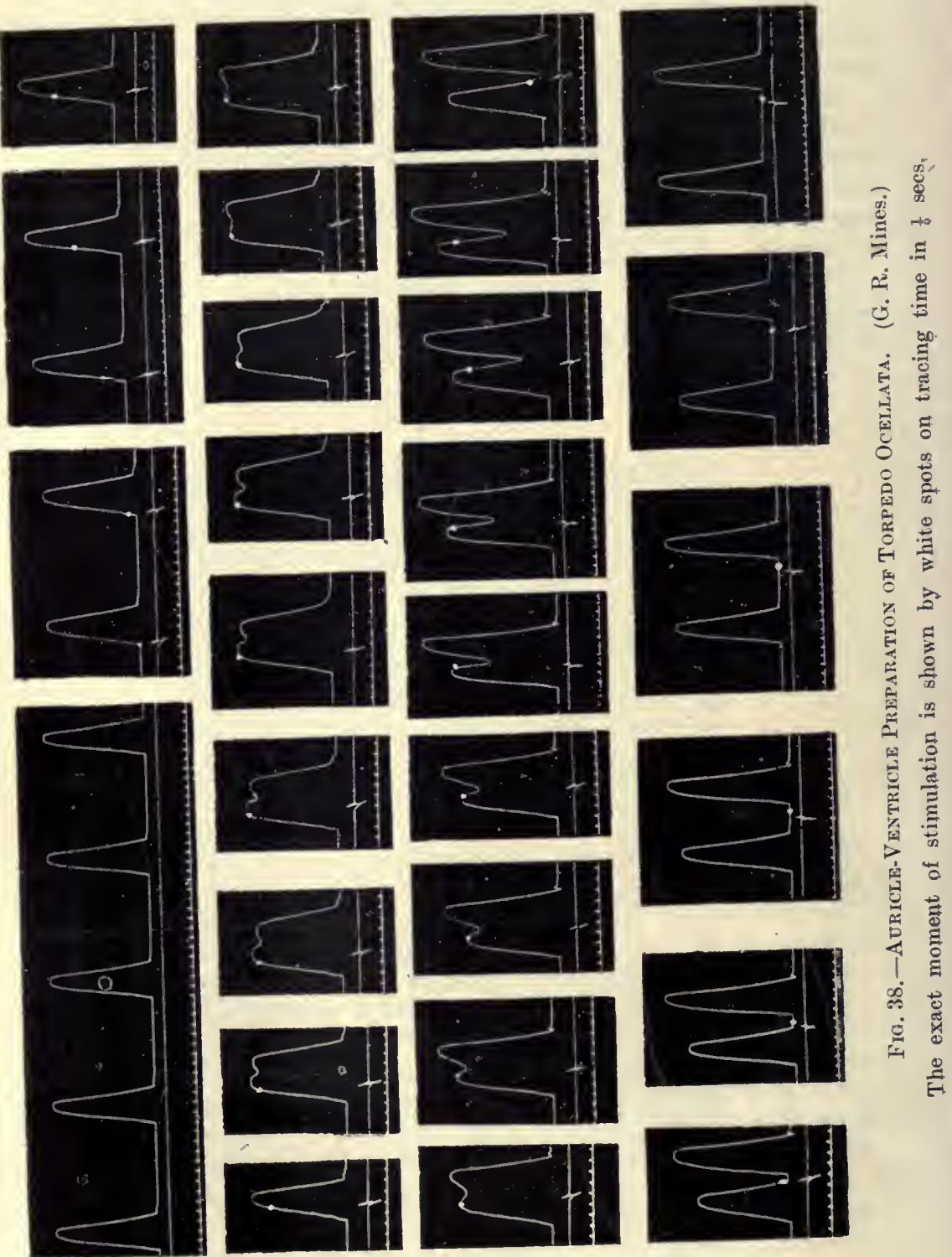
If an external stimulus be applied to the ventricle during the period of contraction or systole of the heart, it has no effect for a considerable period of the systole (Fig. 38). The heart-muscle is said, therefore, to possess a refractory period. The varying excita-

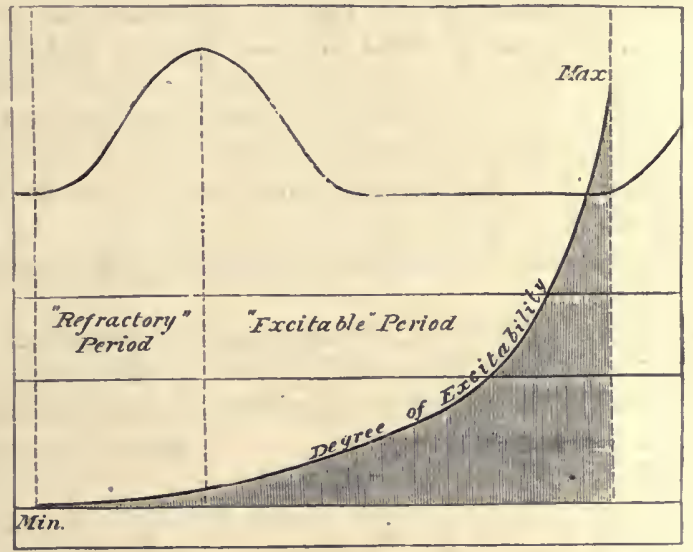

Fig. 39. - To illustrate the Varying Excitability of a Frog's Heart at Different Periods of Systole and of Diastole. (Waller.)

The excitability is lowest during the first half of systole, greatest during the second half of diastole.

bility of the heart at different periods of systole and diastole is represented in Fig. 39. If, however, the external stimulus be applied towards the end of systole and during the period of relaxation of the heart-the diastole - it responds with a contraction-an extra systole.

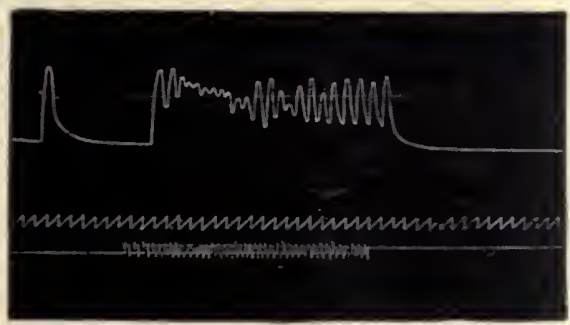

Fig. 40,-Effect of Tetayizivg the Stanniused Heart. (L. H.)

The curve should be read from left to right. The time is marked in seconds. The third line shows the period of stimulation.

Such extra systoles are followed by a longer pause than normalthe compensatory pause. It is nearly equal in length to the normal pause plus the amount cut off from the previous pause by the induction of the extra systole. The heart therefore continues to 
make the same number of beats as usual in a given time, in spite of the induction of extra systoles. The length of the compensatory pause is due to the refraetory period; the impulse causing the normal contraction reaches the ventricle at a time when it is in a state of systolc induced by the artificial stimulus. It is therefore refractory, and the normal impulsc has no effect. The ventricle is not stimulated again until the next normal impulse arrives, and thus the pause is produced.

In the case of the frog's heart, a compensatory pause does not follow extra contractions induced by stimulations of the sinus. Extra systoles, followed by the compensatory pause, are produced by a stimulus applied to some other part of the heart-e.g., auricle or ventricle. It is assumed, therefore, that the normal stimulus actually arises in the sinus.

This is also true for the mammalian heart. Electrical stimulation of the sinu-auricular node does not induce an irregularity of rhythm, but either a slowing or a weakening of the whole heart, according to the intensity of the stimulus.

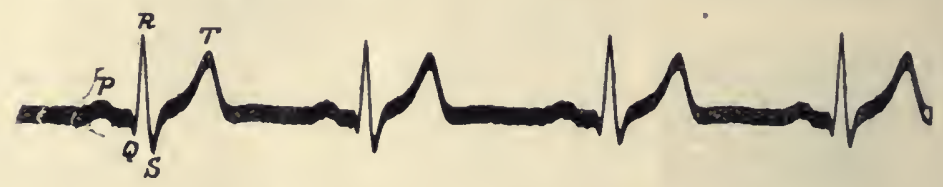

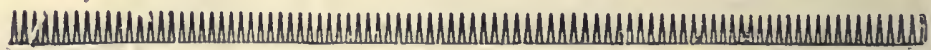

Fig. 41.-Normal Electro-Cardiogram. (W. T. Ritchie, from Cowan's "Diseases of the Heart.")

Normal cardiac muscle cannot be tetanized (Fig. 40 ), as it is impossible to bring about a true summation of stimuli in the normal hcart. In Fig. 38 it is scen that a second stimulus applicd towards the end of systole can only produce a small amount of summation, bccause it does not act sufficiently soon after the first stimulus owing to the refractory period.

The cardiac muscles of certain invertebrates-for example, of the horseshoe crab, Limulus-do not possess the characteristic properties of the vertebrate heart-tissue. It possesses no refractory period, gives submaximal contractions, and can be tetanized.

Like other forms of muscle, the heart-muscle possesses the property of tonicity. The heart may be tonically contracted or dilated, and by its systole expel the blood from a larger or a smaller cavity. The mammalian heart can be placed in an instrument called the "cardiometer". (Fig. G8), and its volume recorded and the alterations of tonicity measurcd. The tonicity is influenced by the cardiae nerves.

If the frog's ventricle be placed in a weak solution of caustic soda ( 1 in 20,000 of normal saline), it relaxes less and less between the beats, 
and eventually stands still in systole; in lactic acid ( 1 in 10,000 normaI saline) the contractions become less and less, and finally the ventricle stops in a state of complete relaxation. The drugs digitalis and veratrine yield results similar to alkalies, muscarin similar to that of acids. Chloroform lessens, and adrenalin increases, the tonicity of the heart. After death from chloroform, the heart is dilated and the muscle flabby.

The heart possesses the properties of rhythmic automaticity, of starting a stimulus. It also possesses the property of conduction

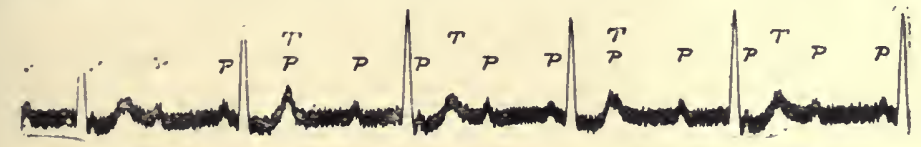

Fig. 42.-Electro-Cardiogram from a Case of Complete Heartblock. (W. T. Ritchie, from Cowan's "Diseases of the Heart.")

The auricular rate is 97 , the ventricular rate 38 , per minute.

of an impulse. It is a vexed question whether these properties reside in the heart-muscle itself, or in the nervous tissue abounding. there, or in the intermediate nodal tissue. The electrolytes in solution in the tissue lymph are essential factors in the maintenance both of rhythmic automaticity and tonicity.

The Electrical Change of the Heart.-The contraction of the heart, like that of other muscle, is accompanied by an electrical change. The part in contraction is at different potential to the part at rest.

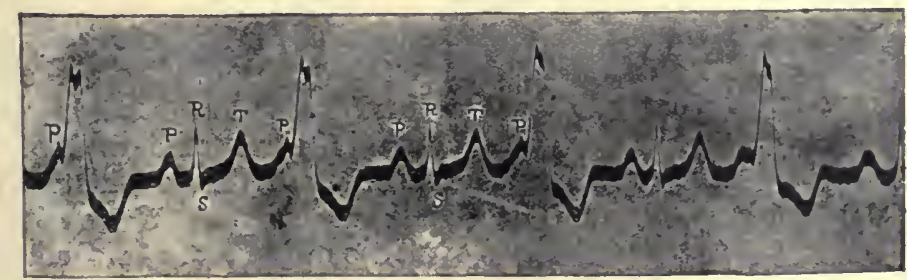

Fig. 43.-Electro-Cardiogram showing Regularly Recurring Ventricutar Extra Systoles. (W. T. Ritchie, from Cowan's "Discases of the Heart.")

i'hus, an electrical wave accompanies the wave of contraction. This is studied by means of either the capillary electrometer or the string galvanometer. The principle of the string galvanometer is that a movable conductor, a very fine silvered glass thread or a quartz fibre, suspended between the poles of a powerful electro-magnet at right angles to the lines of force of the magnetic field, tends to be deflected to one or other side according to the direction of the current. The degree of deflection is directly proportional to the intensity of the current and to the strength of the magnetic field, and inversely proportional to the weight and tension of the fibre. The changes of 
potential attending the contraction of the heart cause the fibre to oscillate; these oscillations arc reccrded on a moving photograplic plate. The photographic records (electro-cardiograms) obtained with these instruments afiord a most bcautiful method of recording the rhythm of normal and abnormal hearts in man; they can be obtained by connecting right and left hands, the right hand and left foot. or the left hand and left foot, of a patient with the instrument by means of baths of salt solution into which the wires dip. The second variation or " derivation" (right hand and left foot) is most commonly employed. The heart is placed obliquely across the body, and the wave of contraction and accompanying electrical wave begins in the base, passes to the apex, and thence to the base again. The right hand or mouth is favotrably placed as a lead for indicating the electrical condition of the base, and the left hand or either foot for that of the apex. By recording the electrical variation, and using in turn different leads, favourable and unfavourable-e.g., mouth and left hand, and mouth and right hand-the axis of the electrical current, and so of the heart in the body, can be determined. By making use of the telephone-wires, there have been recorded the electrical changes of the hearts of patients comfortably seated or in bed in a hospital a mile away.

The normal clcctro-cardiogram is seen in Fig. 41. $P$ is the deflcction due to auricular systole; $Q R S T$ are deflections of rentricular origin, $R$ representing ventricular systole. Fig. 42 represents thc condition of heartblock; the ventricles arc seen to bc beating at a slowcr rate than the auricles, and quite independent of them. Fig. 43 is an clectrocardiogram showing in the big upward deflection tho occurrence at rcgular intervals of a ventricular extra systole.

Tissue of Origin and Mode of Conduction of the Excitatory Wave.A long colltroversy has raged around the question as to the actual tissue in which the excitatory wave of the heart arises and by which it is conducted. It is to be borne in mind that the two questions are rcally distinct. They are frequently confused. Experiments which bear on the site of origin-i.e., the tissue in which the excitatory wave arises-have been quoted as cvidence of the mode of conduction of this wave, and vice versa. It must be granted that, if the excitatory wave be found to arise in one form of tissue, it is highly probable that it will also be conducted by that tissue, but it is not necessarily the case. It is quite conceivable that the excitatory wave may arise in nerve and be conducted by muscle, or arise in muscle and be conducted by nerve, or, arising how it may, the excitatory wave may be conducted both by muscle and by nerve in order that the proper sequence of contraction may be assured. The structure of the nodal tissues suggests that nerve structure there fuses into that of muscle. It is only recently that the claims of the nodal tissuc have been advanced as the site of origin of the excitatory wave. For several years a controversy has waged between those who uphold the neurogenic and myogenic theorics. According to the neurogenic theory, nerve is thought to be the supreme tissue, and it is supposed that the 
excitatory wave of the heart arises in nervous tissue within the heart, and is conducted by that tissue. Those holding the myogenic doctrine state that the wave has its origin in heart muscle-itself, and is propagated by muscle. In the end, it scems likely to be shown that the pacemaker of the heart is a kind of tissue half nerve, half muscle.

Of the two views, the neurogenic is the older. As the heart beats in the body after all the nerves passing to the heart are cut, or outside the body when properly fed, it was clear to the older observers that the nervous centre originating the heart impulse could not be in the brain, and therefore it was supposed to be in the ganglion cells of the heart. The fact that a ligature tied tightly round the sinu-auricular groove brings the auricles and ventricles of the frog's heart to a standstill was thought to indicate that the chief group of ganglion cells concerned in the origin of the excitatory wave was situated in that region. A second ligature applied to the A.-V. groove (the second Stannius' ligature) causes the ventricle to beat again, and the neurogenist ascribed this to the fact that the ganglia in this region are stimulated by such a ligature. Why one ligature should destroy the action of ganglion cells and a second similar ligature excite their action is not apparent; but it is said that, if the A.-V. ganglia be extirpated, this second ligature is ineffective in starting the ventricle. Other evidence cited as supporting the neurogenic theory is the experiment of thrusting a needle into the interventricular septum of the mammalian heart. It is said that, if the needle be inserted on the left side of the lower end of the upper third of the septum, it produces, instead of a beat of the ventricles, a condition known as "fibrillation."

Recent experiments upon the heart of the horseshos crab, L:mulus, afford clear evidence of the neurogenic origin of the excitatory wave in this invertebrate heart. The heart consists of a tube 10 to 15 centimetres long, divided into segments by the successive origin of the arteries. When the heart beats, all the segments appear to contract simultaneously, although probably a rapid wave of contraction passes. There are three nervous strands-one median and two lateral-which run along the outer surface of the heart and anastomose freely. The median strand contains ganglion cells, and one especially large ganglion. It is easy to separate this strand from the heart without injury to the muscle. Its entire removal causes cessation of the whole heart-beat, while removal of a portion causes stoppage in the corresponding segment of the heart.

As regards the nervous conduction of the excitatory wave; the chief points advocated in its favour are these:

1. It has been asserted that a different rhythm in auricles and ventricles (allorhythmia) can be set up by cutting a nerve running from auricle to ventricle. This is unconfirmed.

2. For a long time no muscular connection was known to exist between auricles and ventricles in the mammalian heart. This piece of evidenee is negatived by the discovery of the A.-V. bundle, but 
it cannot be denied that this connection contains nerve fibres-a point insistcd upon by the upholders of the neurogenic theory.

3. If in the heart of the Limclus a section of the median nervous strand be made, it immediatcly abolishes the synchronism of the different segments. The parts on either side of the section continue to beat, but no longer with the same rhythm. If a section be made of the muscle of this heart, it produces no effect.

In estimating the value of the experiments on Limules it must be remembcred that it is an invertebrate evolved in the epochs of geological time, and that the muscle of its heart seems more akin to mammalian smooth muscle.

The myogenic theory is based upon the following points:

1. The different chambers of the heart beat with a different rhythm when separated from each other. There is no differentiation of any nervous tissue of origin and conduction in these chambers, so far as is known, while there is a marked difference in the histological appearance of the muscle of the different heart chambers.

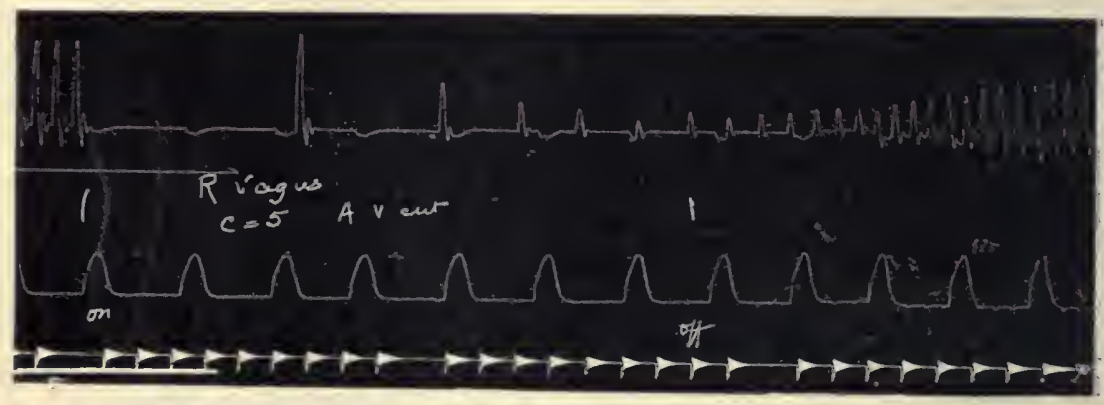

Fig. 44.-Rabbit's Heart, A.-V. Bundere Cut, showing Effect of Stimulation of Right Vagus Nerve. (W. Cullis and E. M. Tribe.)

The inderendent rhythm of auricles and ventricles is secn at the beginning, but particularly well at the end of the tracing. The nerve acts upon the auricles but not uron the ventricles.

2. The experiment in regard to the $A,-V$. ganglia is incorrect. Excitation of the ganglion cells of this group causes no contraction. It is the excitation of the musculature of the auricular ring which evokes contraction.

3. Isolated parts of the grcat veins of cold-blooded hearts containing no ganglion cells beat automatically. Thus, a piece of the sinus of the frog beats for four days, and no less than 17,000 contractions werc recorded.

4. The apex of the mammalian heart, said to have no nerve ganglia, when suitably fed exhibits slow rhythmic contractions.

5. The embryonic heart pulses before muscle and nerve have become differentiated in it.

6. It is possible to cause hearts to beat again several hours after death. The heart of a boy, dead of pneumonia, was resuscitated. 


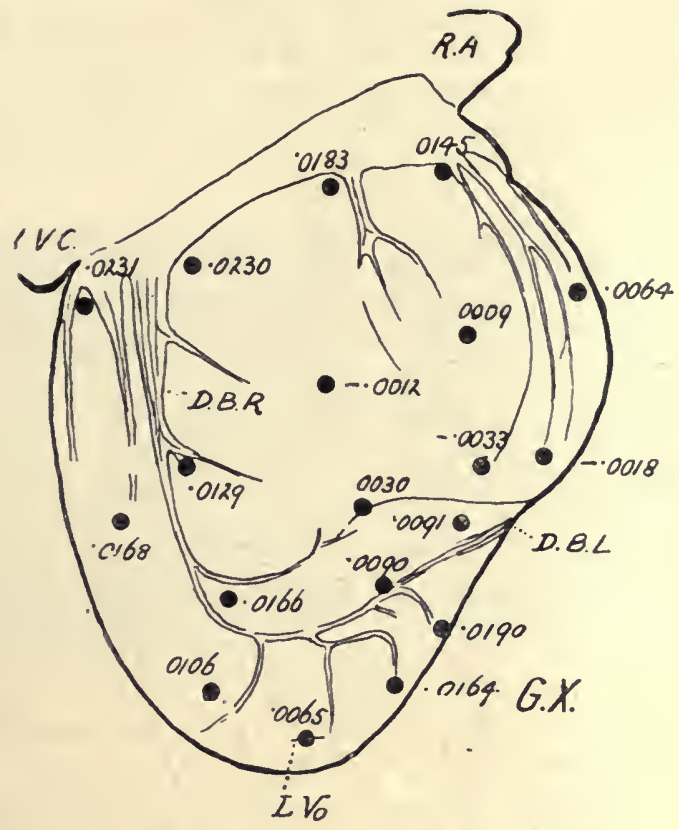

Fig. A.

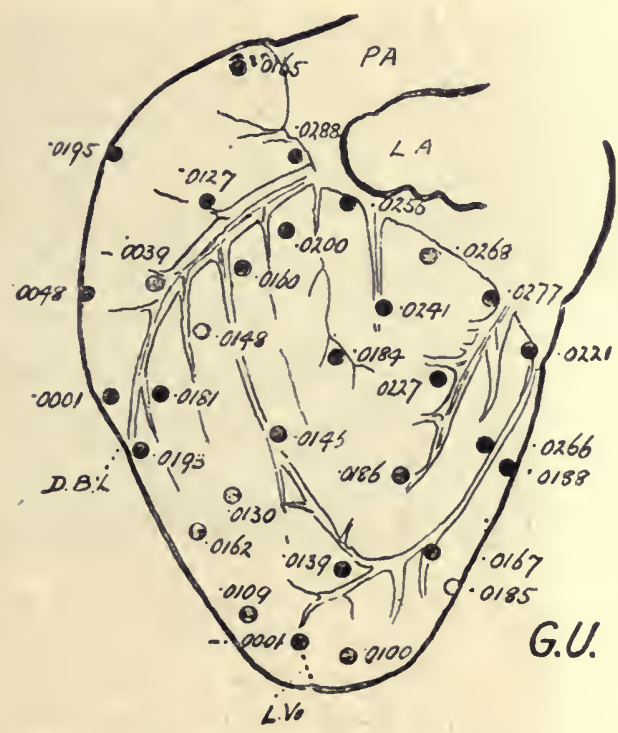

Fig. B.

Figs. 45a and 45B.-A, Odthine (Three-quarters Natural Size) to Scale of the Right Surface of a Dog's Heart, giving TIme-Readings of INTrinsio Deflections of the String Galvanometer taken at a Number of Points. $B$, Ditto OF_Left Surface. (Lewis and Rothschild.) 
twenty-eight hours after death, the heart of a cat after frcezing and thawing. Nervous tissue dies quickly.

7. Certain molluses, arthropods, and tunicates, have automatic hearts containing no ganglion cells.

For muscular conduction of the excitatory wave there is also a considerable array of evidence:

1. With the discovery of the A.-V. bundle there is now no histological reason against it; in fact, experiments upon this bundle show that its destruction by cutting, ligaturing, or clamping, produce allorhythmia-a different rhythm in auricles and ventricles, the

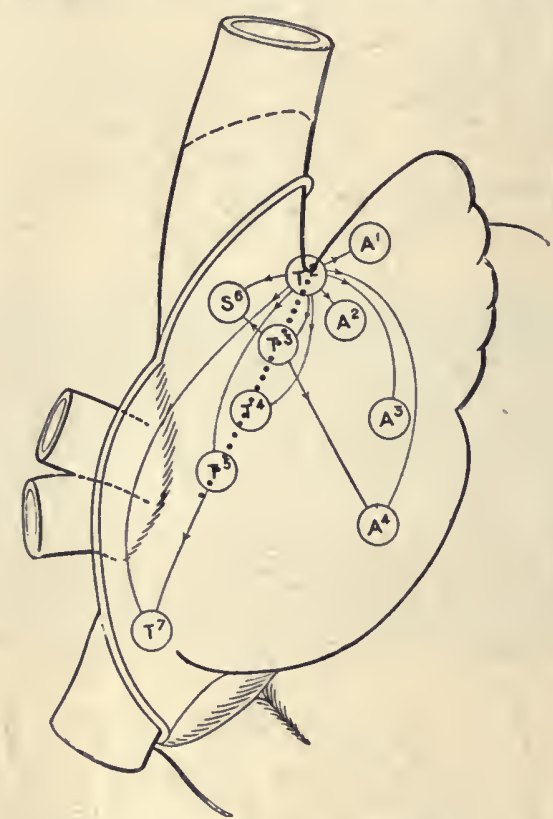

Fig. 46.-Figure showing $T^{2}$, the Point of Primary Negativity, as studied by the Strixg Galyarometer, to Various Leads from Other Parts of the Heart. The Excitatory. Wave therefore starts from $T^{2}$. $T$ are Leads From Texia, $S$ from Sivus, $A$ From AURICle. (T. Lewis.)

auricles beating considerably quicker than the ventricles (Fig. 44). By gradual compression of the bundle, varying degrecs of arhythmia can be produced before this allorhythmia is brought about. Recent work with the string galvanometer has shown that the excitatory wave follows the course of the A.-V. bundle. The impulse reaches the inside of the ventricular wall where the A.-V. bundle arborizes before it reaches the outer surface. It also reaches the outer surface in the neighbourhood of the molerator band before it reaches parts of the ventricular wall nearer the A.-V. groove (Fig. 45).

Clinically, disease of the A.-V. bundle leads to an allorhythmiaStokes-Adams' disease or heartblock (Fig. 42). Whether allorhythmia induecd by absolute destruction of the A.-V. bundle ever 
passes off, and the ventricles again come to follow the lead of the auricles, is a point requiring further investigation.

2. The auricular and ventricular muscle can be cut in zigzag fashion, and yet the muscular impulse still passes, provided the muscular bridges are of sufficient breadth.
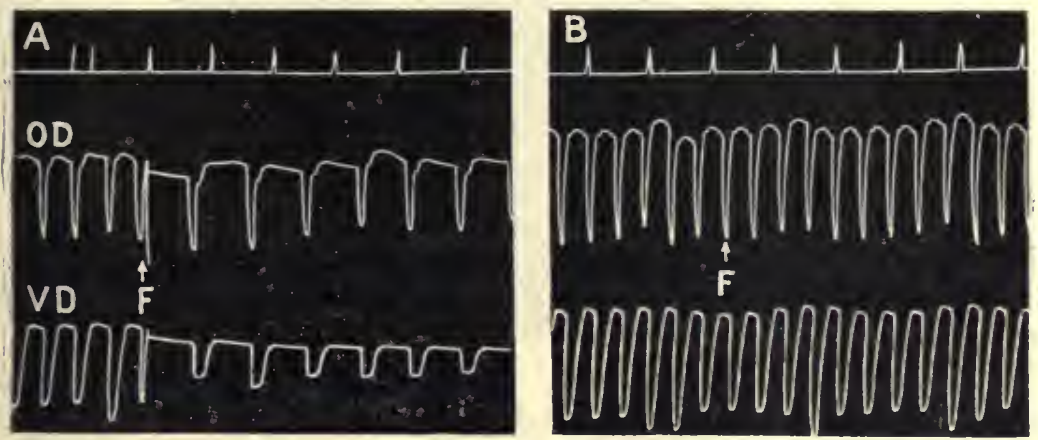

Fig. 47.-Showing $(A)$ Effect of Cold on the Dog's Sixu-Auricular Node (COLd applied at $F$ ) aNd $(B)$ on the AuRicle. (M. F.)

3. No disturbance of rhythm is brought about by cutting or stimulating the nerves connecting auricle and ventricle.

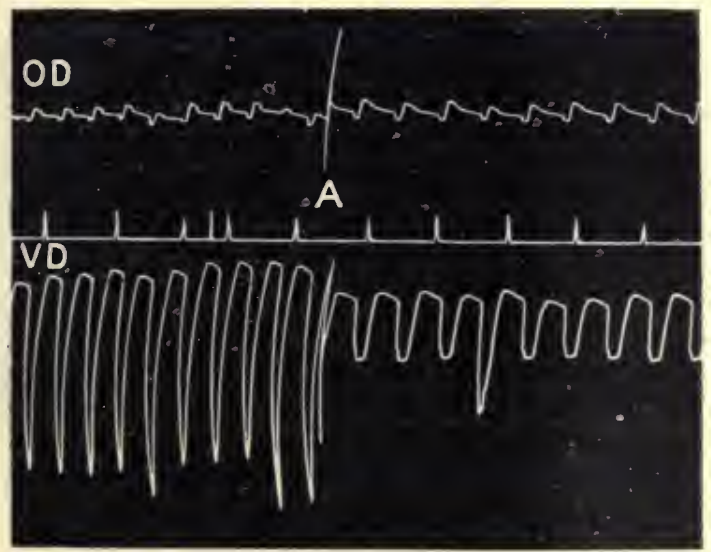

Fig. 48. - Showixg Effect of Clampina Sive-Auricular Node at $A$ in Dog's Heakt. No Stoppage, but Slight Slowixg of Rhythy. (M. F.)

Time in seconds.

4. In perfused hearts, conduction may occur when the nervous elcments arc presumably degenerated.

5. The conduction of the excitatory wave ean pass in all directions. Reverse conduction from ventricle to auricle can also occur. Thus, 
with a quick stimulation of the ventricles, these may beat first, followed by the auricles. The rate of conduction of the excitatory wave is said to be in favour of muscular conduction.

It is certain that the excitatory wave arises in the region of the

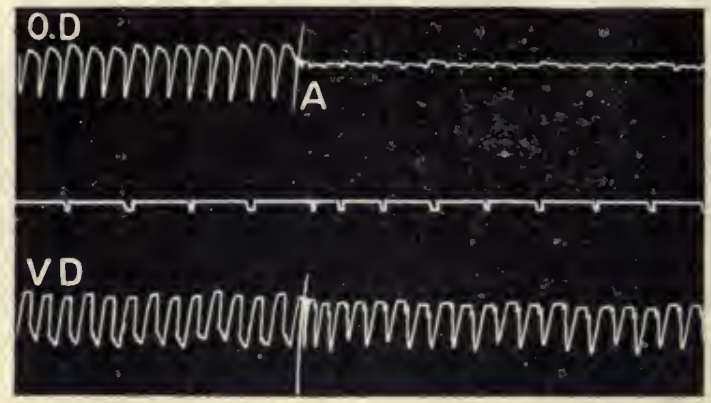

Fig. 49. - Showing Effect of Excision of Sind.Auricular Node and Part of the Superior Vena Cava and Right aúricle it $A$ in Rabit's Heart. No Stoppage of Heart, (M. F.)

great veins, and under normal conditions passes through the auricles and thence to the ventricles. With the discovery of the sinu-auricular node at the junction of the superior vena cava with the auricle there was a tendency to regard this nodal tissue as the automatic tissuc of the heart. Experimental evidence has shown that the nodal tissue
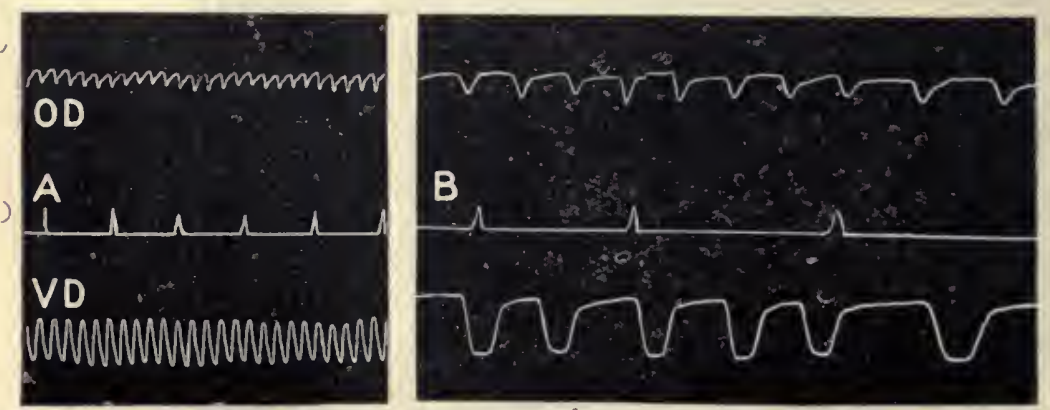

Fig. 50.-Showing the EFfect $(B)$ of Ligature of the Muscular Connection between Auricles and Ventricles in the Heart of the Chicken. HeartBLOCK IS INDUCED. (M. F.)

$$
A=\text { Normal rhythm before ligature. Time in seconds. }
$$

possesses a high degree of automaticity. The string galvanometer shows that it is in the sinu-auricular node that the normal excitatory wave of the heart arises (Fig. 46). Here alone can the normal rhythm of the mammalian heart be modificd-e.g., by cold, which lessens the frequency of the heart (Fig. 47), or by mechanical or electrical stimulation.

But clamping or excision of the sinu-auricular node docs not stop 
the normally beating heart (Figs. 48, 49). In the dog it causes a slight slowing, in the rabbit it has no effect. Under these circumstances, the electro-cardiogram shows that the excitatory wave now arises in the $\mathrm{A} . \mathrm{V}$. node.

But excision of the A.-V. node in the well-nourished normal heart, beating in situ, does not stop either auricles or ventricles. The auricles beat as before, and the ventricles with a slow independent rhythm of their own.

The nodal tissue, therefore, cannot be regarded as the sole repository of the automaticity of the heart. It is apparently longer lived than the other parts; so that under conditions of malnutrition the excision of the tissue may cause cessation of the heart-beat. It is in the areas of the nodes that the dying heart beats last, and beats first when restored by perfusion.

Further, the bird's heart, which possesses a very high degree of automaticity, possesses no nodal tissue.

In the bird's heart, heartblock may be induced by the ligature of the inuscular connection between auricles and ventricles (Fig. 50). This connection does not run in the position of the A.-V. bundle, but posteriorly in the outer wall of the right side of the heart. It is possible that there is also a connection between auricles and ventricles in the mammalian heart in this region, but if there be, it is not the path of the normal excitatory wave of the heart.

To sum up, it appears that the evidence at present available supports the view that the excitatory wave of the mammalian heart arises normally in the sinu-auricular node, and spreads over the auricular muscle, and thence to the ventricles by the musculature of the A.-V. bundle. The retardation which takes place in the A.-V. bundle causes the ventricle to beat at the proper period afier the auricle. The A.-V. bundle normally conducts the excitatory wave to the different parts of the ventricles, so that these parts contract co-ordinately, and wring the blood out of the heart.

Although the property of rhythmic automaticity is highly developed in the nodal tissue, this tissue is not to be regarded as the only tissuc of the heart possessing automaticity: The ordinary musculature of the auricles is also cndowed wivis this property, and that of the ventricles to a less degree. 


\section{CHAPTER XVII}

\section{THE COURSE OF THE CIRCULATION IN MAMMALS}

THE heart is to be regarded as a double organ, each half consisting of an auricle and a ventricle. The right half contains dark venous blood which has been returned from the body, and is sent to the lungs; the left heart contains the bright oxygenated blood which has been rcturned from the lungs, and is distributed to the body. There are thus two circulations - the one, the pulmonary, from the right side

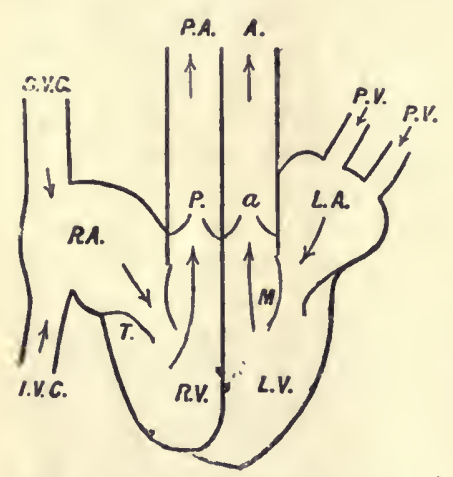

Fig. 51.-Diagram of Heart to SHOW the Course of the BLoOd. (M. S. Pembrey.)

S.V.C., Superior vena eava; I.V.C., inferior vena eava; R.A., right auricle; T., tricuspid valves; $R$.V., right ventricle; $P$., pulmonary valves; $P . A_{\text {., }}$. pulmonary artery; $P . V$. , pulmonary vein; $L . A$., left auricle; $M$., mitral valves; $L . V$. , lcft ventricle; $u$, aortic valves; $A$., sorta. auricle (L.A.), and so through the left auriculo-ventricular orifice, guarded by the mitral valve, into the left ventricle (L.V.). By the left ventricle the blood is driven through the aortic orifice, guarded by the semilunar valves, and is distributed to the systemic arteries, and so to the capillaries of the various organs and back to the veins. The muscular wall of the auricles, and that of the right ventricle, to the capillaries of the lungs, and back to the left heart by the pulmonary veins; the other, the systemic, from the left side of the heart by the aorta to the arteries and capillaries of the body tissues and organs, whence the blood returns by the veins to the right side of the heart.

A schematic represcntation is given of the circulatory system in the accompanying diagram (Fig. 51).

The venous blood flows into the right auricle (R.A.) from the superior and inferior velı cavæ, and from the right auricle into the right ventricle through the right auriculo-ventricular orifice. The right ventricle (R.V.) drives through the pulmonary artery the blood received from the right a uricle. The right auriculo-ventricular valve, or tricuspid, and the pulmonary semilunar valve, are represented directing flow of blood in this direction. From the pulmonary capillaries pulmonary veins (P.V.) into the left of the heart by the pulmonary artery 
are much thinner than that of the left ventricle. This is so because the energy required of the left ventricle must exceed that of the right ventricle, inasmuch as the resistance in the systemic system exceeds that in the pulmonary circuit.

The Cardiac Cycle. - The changes in form of the heart can be studied in an animal the heart of which has been exposed by opening the thorax under an anæsthetic, artificial respiration being meanwhile maintained, the movements being recorded by levers writing on the kymograph; or the mammalian heart may be removed and fed with warm oxygenated nutritive fluid (see p. 159); or the circulation may be short-circuited by what is known as the heart-lung preparation, the blood still being sent through the lungs of the animal to keep it oxygenated (see p. 163).

When the heart is watched beating in full vigour and rapidity, it is an impossible task to unravel by the eye alone the sequence of events.

Harvey, the discoverer of the circulation of the blood, felt and described this difficulty in his writings:

"When first I gave my attention to vivisections, as a means of discovering the movements and uses of the heart, and sought to discover these from actual inspection, and not from the writings of others, I found the task so truly arduous, so full of difficulties, that I was almost tempted to think (with Fracastorius) that the movement of the heart was only to be comprehended by God; for I could neither rightly perceive at first when the systole and when the diastole took place, nor when and where dilatation occurred, by reason of the rapidity of the movements, which in many animals is accomplished in the twinkling of the eye, coming and going like a flash of lightning; so that the systole presented itself to me, now from this point, now from that, the diastole the same; and then everything was reversed, the movements occurring, as it seemed, variously and confusedly together.

"When the heart begins to flag, to move more slowly, and, as it were, to die, the movements then become slower and rarer, the pauses longer, by which it is made much more easy to perceive and unravel what the movements really are, and how they are performed.

"In the pause," Harvey says, "as in death, the heart is soft, flaccid, exhausted, lying, as it were, at rest. In the movement and interval in which this is accomplished, three principal circumstances are to be noted:

" 1 . That the heart is excited, and rises upward, so that at this time it strikes against the breast, and the pulse is felt externally.

" 2 . That it is everywhere contracted, but more especially towards the sides, so that it looks narrower, relatively longer, and more drawn together.

"3. The heart, being grasped in the hand, is felt to become harder during its action. Now this hardness proceeds from tension, preciscly as, when the forearm is grasped, its tendons are perceived to become tense, and resilient when the fingers are moved. 
"4. It may further be observed in fishes and the coldcr-blooded animals, such as frogs, scrpents, etc., that the heart, when it moves, becomes of a paler colour; when quiescent, of a deeper red colour.

"There is also to be noticed in the heart a certain obscure undulation and lateral inclination in the direction of the axis of the right ventricle, as if twisting itself slightly in performing its work."

Analyzing the movements of the chambers of the heart, Harvey determined that:

"First of all the auricle contracts, and in the coursc of its contraction forces the blood (which it contains in ample quantity as the head of the veins, the storehouse, and cistern of the blood) into the ventricle, which being filled, the heart raises itself straightway, makes all its

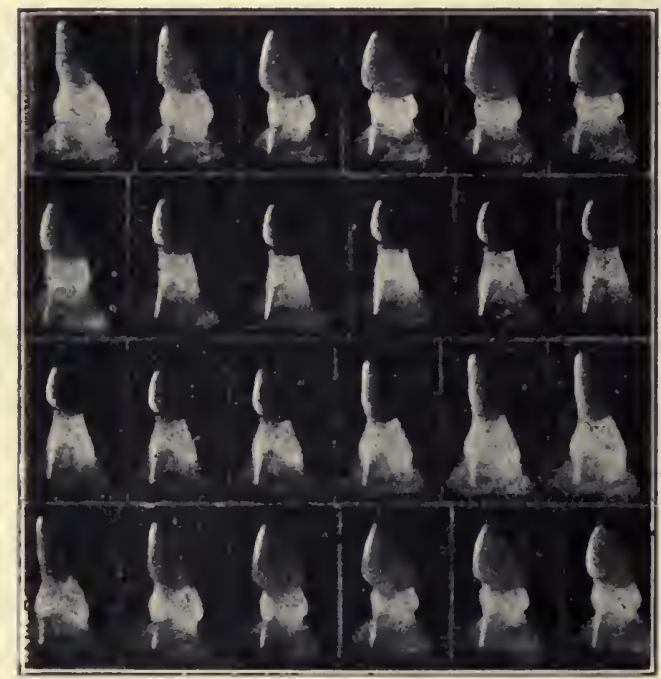

Fig. 52.-Serial Photographs of the Perfused Heart of the Frog, frum a Cinematograpil Fin; Fifteex Images Per Second, (G. R. Mines.)

fibres tense, contracts the ventricles, and performs a beat, by which beat it immediately sends the blood supplied to it by the auricle into the arteries."

A cinematograph record of the movements of a frog's heart is scen in Fig. 52 .

Movements of the Heart.-The movements of the heart consist of a period of contraction, which is called the systole, and a period of relaxation, the diastole. The two auricles contract at the same time, fellowed by the synchronous contraction of the ventricles. Finally, there is a period when the whole heart is in a state of relaxation. This sequence of events is known as the cardiac cycle. Taking scventy-five as the avcrage number of heart-beats per minutc, each cardiac cycle will occupy 0.8 second. 
By some it is believed that the right auricle contracts very shortly before the left auricle, and the left ventricle before the right ventricle. Of this period of $0 \cdot 8$ second-

Auricular systole occupies about $0 \cdot 1$ second.

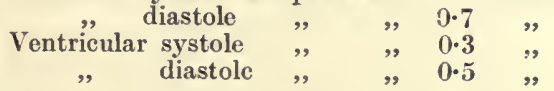

The sequence and duration of the events happening in the heart, and the pressure inside the heart-the endocardiac pressure-are studied by means of an instrument termed the "cardiac sound." The sound-a two-way tube-is pushed down the jugular vein until

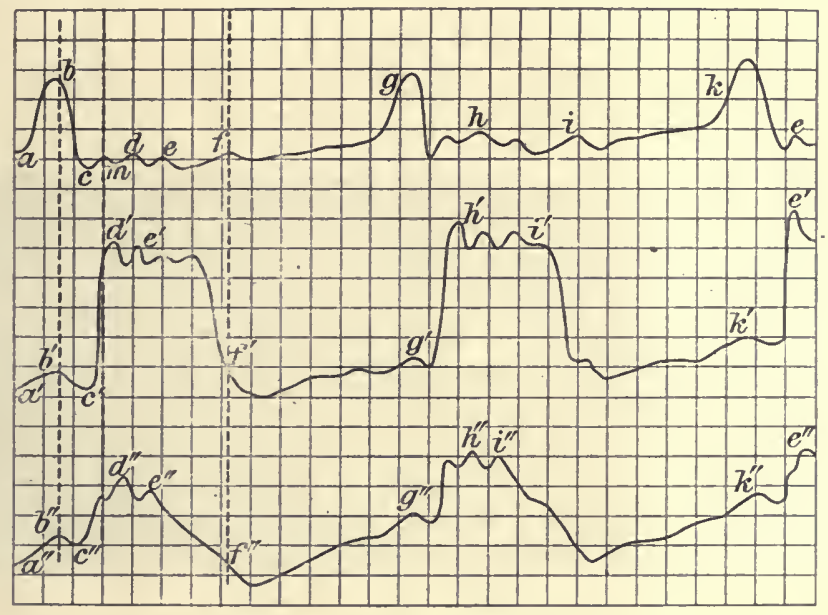

Fig. 53.-Traches from the Heart of a Horse, by Chauveau axd Marey.

The upper tracing is from the right auricle, the middle from the right ventricle, and the lowcst from the apex of the heart. The horizontal lines represent time, and the vertical amount of pressure. The vertical dotted lines mark coincident points in the thrce movements. The breadth of one of the small squares represents one-tenth of a second. The auricular contraction is less sudden than the ventricular, and lasts only a very short time, as indicated by the line $a b$. The ventricle, on the other hand, contracts suddenly and forcibly and remains contracted a considerable time, as shown by the linc $c^{\prime} d^{\prime}$ and by the flat top to the curve which succeeds $d^{\prime}$.

the orifice of one tube lies in the right ventricle, and of the other in the right auricle. The cardiac orifices of the tubes are covered with rubber membranc, beneath which are wire springs set to resist compression. The tubes are connected with recording tainbours, which write on a moving drum covered with smoked paper. Another tambour may be used to record the cardiac impulsc. The aortie pulse curve may also be recorded in other expcriments sinultaneously with the left intraventricular pressure. This is effected by pushing the sound down the carotid, so that one tube opened into the aorta and the other into the left ventricle. The tracings so obtained 
(Fig. 52) teach us the following facts: (1) The auricular contraction is less sudden than the ventricular, and lasts only a very short time, The ventricle, on the other hand, contracts suddenly and forcibly. and remains contracted a considerable time, as shown respectively by the ascent of the curve and the flat top of the curve which succeeds. (2) The auricular movement precedes the ventricular, and the latter coincides with the impulse of the apex against the wall of the chest. (3) The contraction of the auricle influences the pressure in the rentricle, as shown by the small rise $a^{\prime} b^{\prime}$, and that of the ventricle influences the pressure in the auricle somewhat, as shown by the wave $c^{\prime} d^{\prime}$.

A tracing of aortic and intraventricular pressure curves is given in Fig. 54. The beginning of the aortic pulse curve (1) obviously marks the opening of the scmilunar valves, the dicrotic notch (4) follows their closure. The moment of closurc (3) can be ascertained by listening to the sccond sound of the heart, which occurs immediately after the closure, and is produced by the sudden tension of the closed valves. It

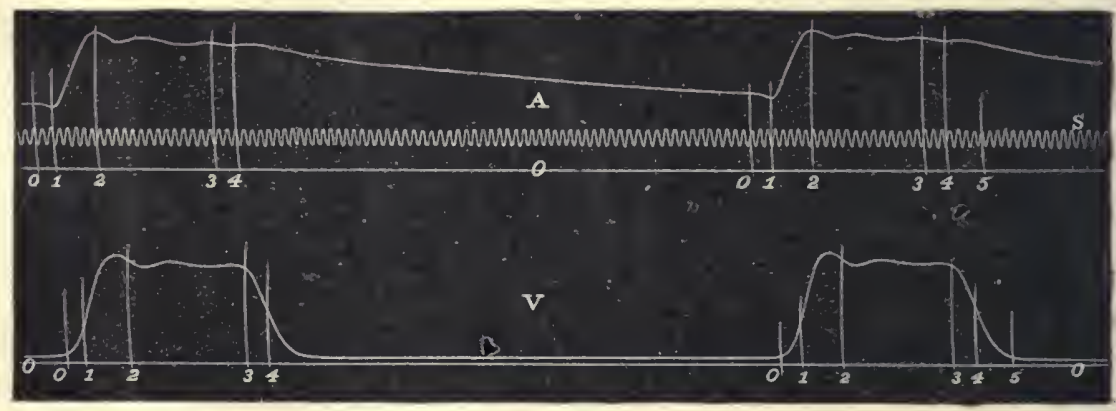

Fig. 5u.-Aortic axd Ixtrayextricular Pressure Curves. (Hürthle.)

Time trace $=\frac{1}{10} \overline{0}$ sec.; $0 \cdot 1$, period of rising tension; $1-4$, period of output; 4 , dicrotic notch.

can also be determined by connecting the two-way sound to a differential manometer, and recording the difference of pressure in the ventricle and aorta. The valves open at the moment when the ventricular pressure exceeds the aortic, and close when the aortic exceeds the ventricular pressure. If the differential manometer be used, with one sound opening in the right auricle and the other in the right ventricle, the tracing indicates the moment when the auriculo-ventricular valves close and open.

The absence of a mechanism for preventing regurgitation of blood from the auricles of birds and mammals is remarkable, for in fishes, amphibia, and reptiles, this is effected by valves guarding the sinuauricular junction (Fig. $2{ }_{\text {B }}$ ). In the warm-blooded vertebrates, with the appearance of the diaphragm and the fusion of the sinus venosus with the right auricle, the venous cistern formed by the superior and inferior venæ cavæ, the innominate, iliac, hepatic, and renal veins takes the place of the sinus. Six pairs of valves prevent regurgitation from this. 
cistern-viz., those placed in the common femoral, the subclavian, and jugular veins (Fig. 55). The cistern, when filled, may hold some 400 c.c. of blood. In the liver there may bc some 500 c.c. of blood. This can be expressed into the cistern by abdominal pressure. In the portal venous system, when distended, may be held another

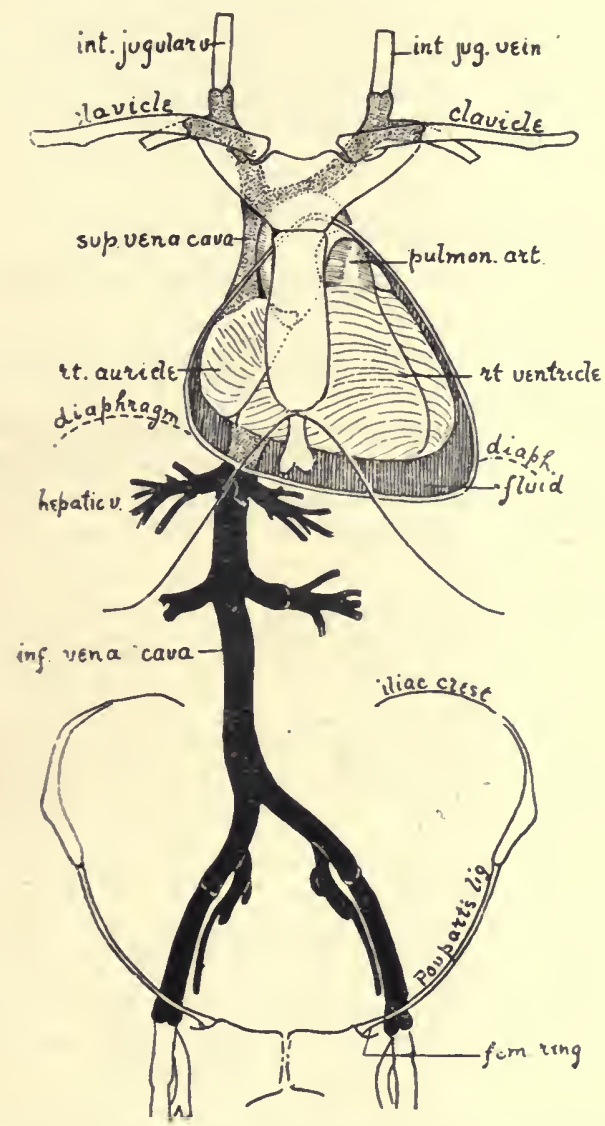

Fig. 55.-Diagras of the Venous Cisters from which the Heart is Filled. (Keith.)

The abdominal or infra-diaphragmatic part of the cistern is indicated in black; the thoracic or supra-diaphragmatic is stippled. The heart is compressed upwards and backwards against its attachments.

500 c.c., which can be expressed through the portal veins and the liver into the cistern. There is thus a large volume of blood for the heart to draw upon during diastole, and this may be of particular value during the performance of a great muscular effort. Respiration by the aspirating action of the thorax sucks this blood into the heart, while the inspiratory descent of the diaphragm squeczes the abdominal 
contents and forces blood from the liver and cistern into the heart. These forces take the place of the sinus venosus, and are far more efficient. The intra-abdominal pressure may be raised considerably on bending or straining. Under such conditions, the pericardium protects the right side of the heart from being over-distended with venous blood.

With these facts in view, we can now describe the complete course of a cardiac cycle (Fig. 56). We will start at the moment when both chambers of the heart are in diastole. The blood pours from the vena cava and pulmonary veins into the two a uricles. These are relaxed, and their cavities open into the ventricles by the funnel-shaped apertures formed by the dependent segments of the tricuspid and mitral valves. The blood passes freely through these apertures into the ventricles. The small positive pressure which is always present in the venous cistern (aided by the respiratory forces) is at this time filling both chambers of the right heart, while the positive pressure in the pulmonary veins is filling those of the left heart. The auricular systole now takes place. Their circular muscle bands compress the blood ont of the auricles into the ventricles, while the longitudinal bands aid in this, and also pull up the base of the ventricles to meet the load of blood (Fig. 58). As the contraction starts from the mouths of the vena cava, and sweeps towards the ventricles, little or no regurgitation of blood occurs into the venous cistern under normal conditions, but the cessation of flow into the auricle during its systole does produce a slight rise of pressure in the cistern, which is shown by the wave $a$ in tracings taken from the jugular pulse (see Fig. 116). The function of the auricles is to rapidly complete the filling of the ventricles, and thereby slightly distend its walls. Within normal limits, the greater the distension the more forcible the contraction.

The auriculo-ventricular valves are floated up and brought into apposition by eddies set up in the blood which streams into the ventricles, and close without noise or jar at the moment when the intraventricular pressure in the least exceeds that in the auricles. The thin, moist, film-like edges of the tricuspid and mitral valves of the heart come into perfect apposition, and prevent all lcakage, while the fibrous parts give strength and support. Then follows ventricular systole $(A$, Fig. 56). The contraction of the ventricular musculature around these orifices limits the size of the auriculo-ventricular orifices, and maintains the competency of the valves. By contracting synchronously with the muscular wall of the ventricles, the papillary muscles, with the aid of the chordæ tendineæ, pull down the diaphragm formed by the closed auriculo-ventricular valves. As these form the floor of the auricles, their cavities are thereby expanded. At the same time, the papillary muscles shorten the longitudinal diameter of the ventricles, and enable the valvular and muscular parts of the ventricles to approach together and squecze out the blood from the ventricles. By the attachment of the chordæ tendineæ to the auriculo-ventricular valves, and the action of the papillary muscles, the membranous diaphragm formed by the valves is made to act as part of the muscular wall of 
eaeh ventriele, and thus the eavity of eaeh comes to be equivalent to a sphere surrounded by musele.

When the intraventrieular pressure rises the least bit above that in the pulmonary artery and aorta respeetively, the semilunar valves

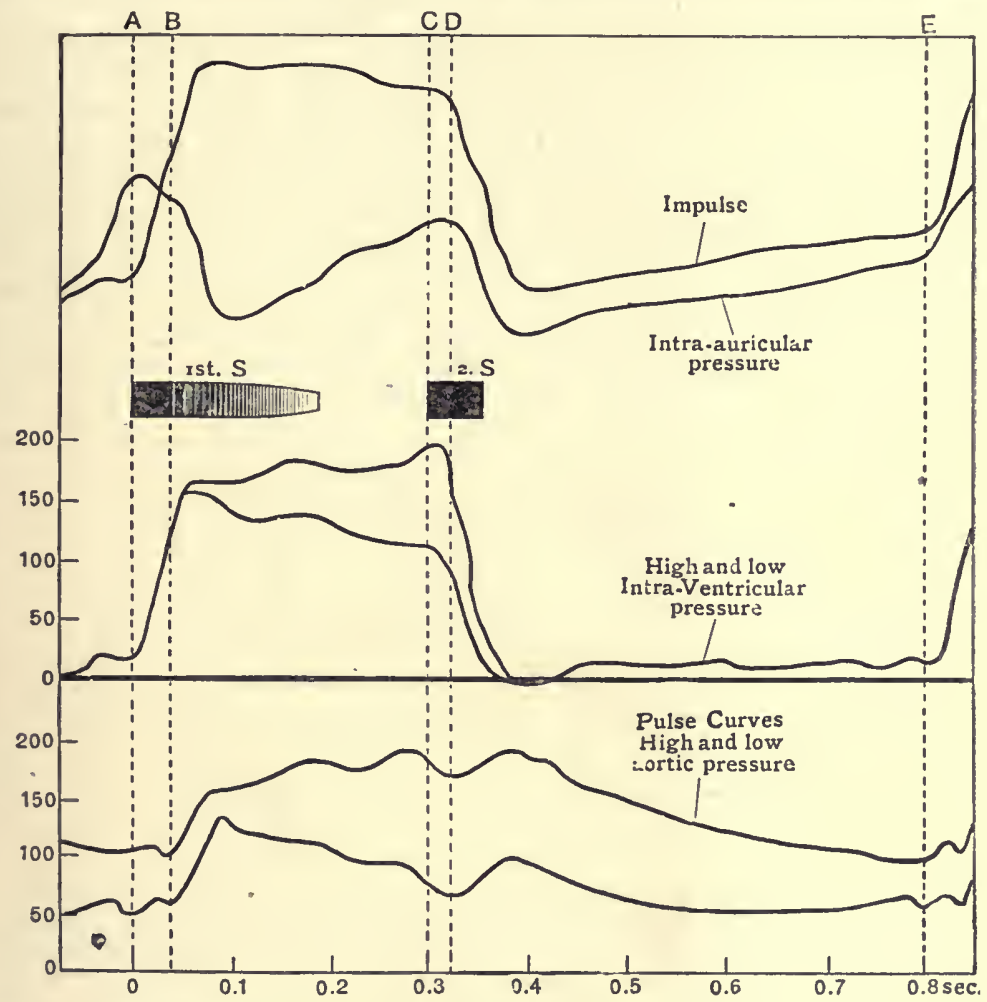

Fig. 56.-The Time Relations of the Impulse, Intra-Auricular and Ventricular, and Arterial Pressure Curves. (Modified from Hürthle; L.H., from Allchin's "Manual of Medicine.")

$A$, The beginning of ventricular systole; $B$, the opening of the semilunar valves; $A-B$, period of rising tension; $C$, the closure of the semilunar valves; $A-C$, period of output (systole); $D$, the beginning of the dicrotic wave on the pulse curve; $C-E$, period of diastole; $E$, the beginning of the next cardiac cycle. The duration of tho first and second sound of the heart is marked below the intra-auric. ular pressure curvo. The pressures aro given in $\mathrm{mm}$. Hg. The waves on the plateau of the ventricular curve are due to elastic vibrations and are partly instrumental; the first fall in the curve of auricular pressure is produced by the systolic output of blood; the sccond auricular fall is due to ventricular diastole. The high-pressure pulso is anacrotic.

quietly open ( $B$, Fig. 56) and the blood is expelled. The elastie vessels are in their turn expanded by the expulsive foree of the heart, so as to reeeive the blood.

The outflow of blood from the ventricles is rapid at first. It beeomes slower as the arteries beeome distended and the pressure of 
blood rises within them, and eeases when the arterial pressure beeomes equal to that in the ventricles. As the outflow diminishes, the semilunar poekets are filled by eddies of blood, and their thin, delicate edges are brought nearer and nearer, until finally they come into apposition. This closurc, which effectually prevents regurgitation, is effeeted without jar or noise at the moment when the outflow ceases and the ventricles begin to expand. The heart, as a good pump should, works with the least possible jar. During the contraction of the ventricles, blood has been pouring from the veins into the aurieles; and directly the ventricular systole ceases, the auriculoventrieular valies open, and the blood begins to fill the expanding ventrieular cavities. For a brief moment the ventricles remain dilated and at rest, then the auricles contract again, and the cycle of ehanges once more is repeated. During the first period of ventricular systole -the period of rising tension ( $A-B$, Fig. 56), or "presphygmic

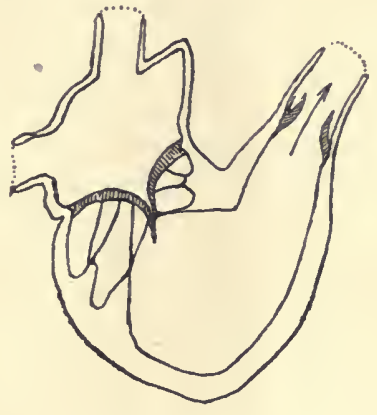

A

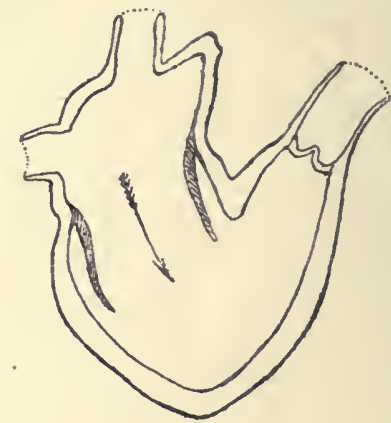

$\mathrm{B}$

Fig. 57.-Diagrail of Right Side of Heart, showixg A, Systole-Auriculo. Ventricular Valves Shut, Chorde Texdinez drawn Taut, Semilunak Valves of Pulmonary Artery Opex. $B$, Diastole-Auriculo-Ventricular Valves Open, Blood extering from Auricle to Ventricle, Semi. lunar Valves of Pulmoyary Artery Shut.

interval," as it is ealled-all the valves are elosed, and the ventricle is getting up pressure. This period has been measured, and has been found to oeeupy about 0.02 to 0.04 seeond. The second period is that of the systolie output $(B-C$, Fig. 56), and lasts about $0 \cdot 2$ seeond-that is, from the moment when the semilunar valves open to the moment when they close. These periods ean be measured on man by taking simultaneous records of the pulse in the carotid artery and of the eardiae impulse and sounds. The upstroke of the pulse-eurve reeorded from the carotid artery can be taken as marking the moment when the semilunar valves open, while the dicrotie notch on the pulse-eurve marks their closure. The seeond sound of the heart oeeurs immediately after their elosure, and, by listening to it, one ean note the time of this event on the impulse-eurve, the upstroke of which marks the beginning of ventricular systole. Thus, the presphygmic interval extends from the 
beginning of the upstroke of the impulse-eurve to the beginning of the upstroke of the carotid pulse-curve. The first sound of the heart is synchronous with the upstroke of the impulse-curve. A small correction must be made for the delay in the transmission of the pulss to the carotid artery. The period of systolic output extends from the beginning of the upstroke of the pulse-curve to the dierotic noteh, and the diastalie period from this noteh to the beginning of the next upstroke. The relation of the aurieular systole to the ventricular cain be determined by simultaneously reeording the pulse in the jugular vein and earotid artery. The $c$ wave in the jugular pulse is synchronous with the upstroke in the earotid pulse, and the $a$ wave, which preeedes the $c$ wave, marks the aurieular systole (see Fig. 116).

The intraventrieular pressure rises or falls during the output period according to the state of the pcripheral resistanee. The maximal systolie pressure exerted by the heart varies with the internal tension-that is, with the degree of diastolie filling and obstruction

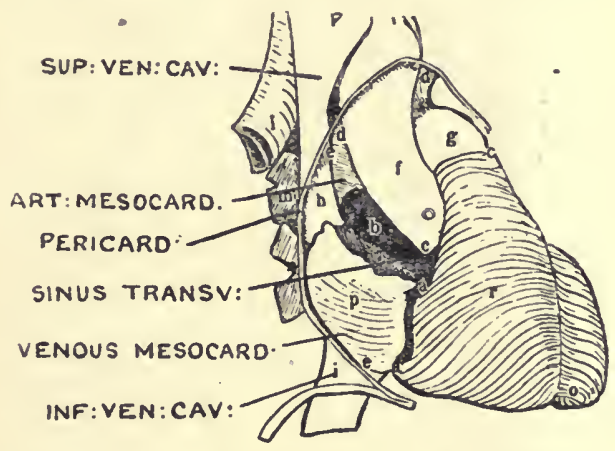

Fia. 58.-Heart pulled Forwards to show its Atrachment by Arterial (dd) and Vexous (ce) Mesccirdi. (Keith.)

to outflow. The heart-musele responds to inereased tension by a greater output of energy, and this it does with little loss in rapidity of action. By its reserve power the heart may throw out during hard exercise ten times the volume of the normal output per minute, and may maintain its output when the aortic pressure is even twice its normal value.

The Movements of the Heart in Situ.-The normal fulera for the movements of the heart in the elosed thorax are afforded through the perieardium (Fig. 58). The pericardium is reflected on to the wall of the heart at the point where the vena eava and aorta leave the pericardial sac. This part of the perieardium gives a fixation point to the aurieles, being attaehed to the roots of the lungs, and thereby to the tho:aeie wall, to the diaphragm, and to the structures at the root of the neck. On opening the ehest, the normal fulera for the movements of the auricles are lost, and this renders it difficult to record the exact movements of the heart. The longitudinal and eireular muselc fibres of 
the ventricles are antagonists. The circular fibres, by their contraction, tend to lengthen the apex-base diameter. The longitudinal fibres resist this, and the two together wring the blood out of the heart. The apex is maintained as a fixed point by this antagonistic action, and thus the longitudinal fibres are enabled to expand the auricles by pulling down the floor of these chambers. This action is important, as it contributes to the filling of the auricles simultaneously with the emptying of the ventricles. Tracings of the jugular pulse give evidence of such action.

In the case of the auricles, the longitudinal musculi pectinati not only help the circular fibres to expel the blood, but draw up the base of the ventricle to meet its load of blood. Thus, the A.-V. groove is

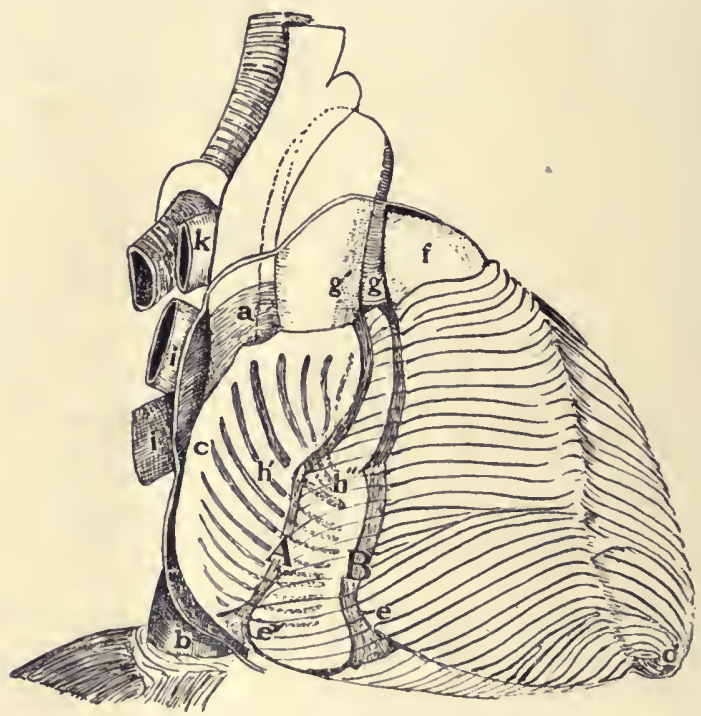

Fig. 59.-To show the Axtagonistic Action of the Musculatures of the Right AURicle AND VeNTricle. (Keith.)

$A$, position of A.-V. groove at end of auricular systole; $B$, at end of ventricular systole.

pulled up during auricular systole, and down during ventricular systole $(A, B$, Fig. 59). The postcrior and upper borders of the left auricle lie against the unyielding structures of the posterior mediastinum, the pulmonary artery, and bronchi, the floor and anterior part being in contact with the base of the rentricle and asecnding aorta respectively. The latter parts alone are free to move during systole. Thus, the left ventricular base is drawn up and the aorta back on auricular systolc.

Modes of Examining the Living Heart.- The physiologist or physician has many means at his disposal of examining the heart's action. Its efficiency may be tested by noting how much its 
rate of beat is increased by taking exercise and also how quickly the normal rate of beat is resumed after such exercise. By palpation, with the hand over the region of the heart, its stroke, the cardiac impulse, can be felt; by percussion, the anatomical limits of the organ can be defined; by auscultation with the ear directly, or with use of the stethoscope, the sounds of the heart can be heard. The cardiac impulse can be recorded by the tambour method of registration; the heart-sounds by means of the microphone and string galvanometer; while the volume and movements of the hcart. can be studied with the help of the Röntgen rays.

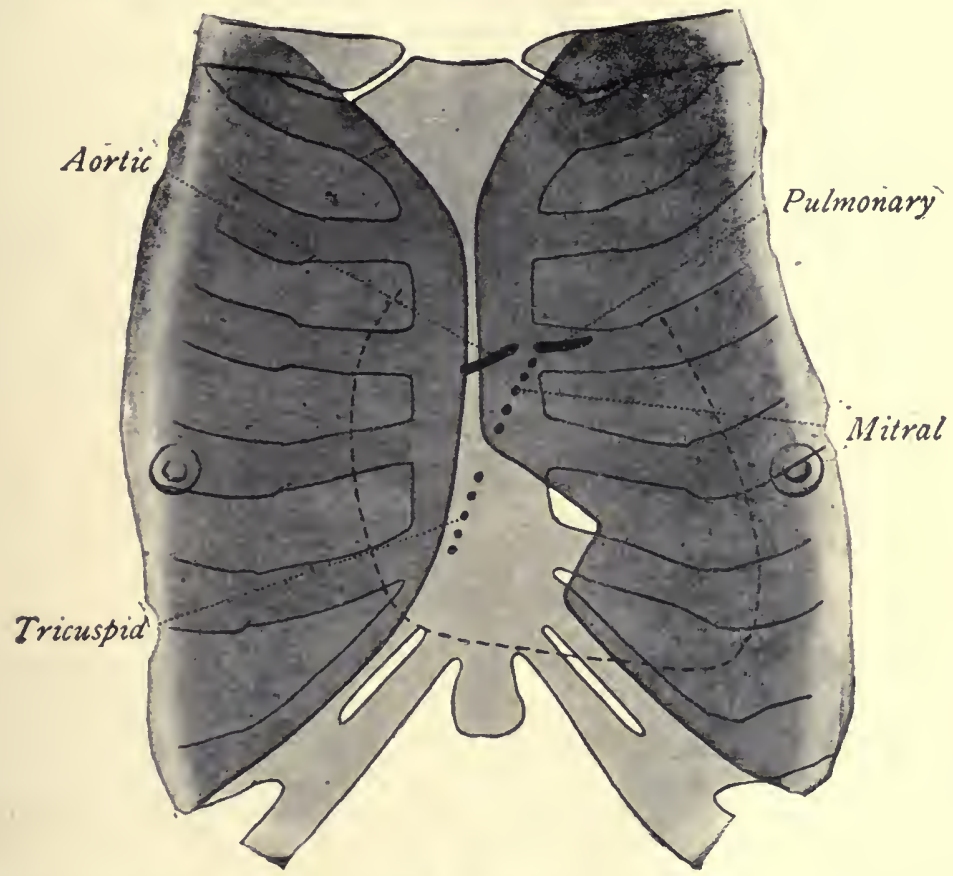

Fig. 60.-Diagray showing Surface Relations of Lungs, Heart, axd Cardiac Valves. (Cowan.)

The Cardiac Impulse.-The impulse is caused by the sudden hardening of the muscular mass of the ventricles against the chest wall. It coincides with the beginning of systole. The position at which the impulse is felt varies with the position of the body. Normally, with the body in the supine position, the impulse is visible in the fourth or fifth intercostal space 2 inches below the nipple and $3 \frac{1}{2}$ inches from the midsternal line (Fig. 60). In rising to the standing posture, the impulse shifts its position downwards and to the left for $\frac{1}{4}$ to 1 inch. When a man rolls over on to his right side, the impulse may shift from 3 to 4 inches to the right, and disappear beneath the sternum. Similarly, on rolling on to the left side, the impulse shifts to the left of the nipple line. 
The shifting is due to the effect of gravity on the heart. In cach position a different part of the heart is brought in close contact with the chest wall. The chest wall is driven out by the systole only where the heart-muscle touches it; at other places it is slightly drawn in. This indrawing is believed to be due to the expulsion of the blood from the thorax by the left ventricle. The thorax being a closed cavity, negative pressure is produced by each systole when the blood passes out by the arteries of the head, limbs, and abdomen. This vacuum is filled by (1) the drawing of air into the lungs; hence the cardio-pneumatic morcment, which may be detected by connecting a water manometer with one nostril, and closing the other nostril; (2) the drawing of venous blood into the great veins and right auricle; (3) the slight indrawing of the chest wall. The impulse may be recorded by placing a small cup or receiving tambour over the spot where it is most cvident, and connecting the inside of the cup by a tube to the recording tambour. The cup need not be closed by a rubber dam, for an air-tight junction can be effected by pressing it upon the skin. The stroke of the heart is transmitted as a wave of compression to the air within the system of tambours. The recording tambour writes on a drum moved by clockwork, and covered with a smoked paper. From the record so obtained we can obtain information as to the time-relations of the heart-beat, but no accurate information as to its energy or amount of contraction.

The Sounds of the Heart.- When the ear is applied over the cardiac region of the chest, or a stethoscope is employed, two sounds are heard. The first, heard most intensely ncar the apex, is a duller and longer sound than the second, which is shorter and sharper, and is heard best over the base of the heart. The syllables lïb, diupp, express fairly well the characters of the two sounds, and the accent is on lub when the stethescope is over the apex-thus, libb-dupp, lib-dupp, lib-dupp-and on the second sound when over the basc-thus, lubdiipp, lub-disp , lub-d üpp.

The first sound is caused by the sudden tension (1) of the cardiac muscle; (2) of the diaphragms formed by the closed auriculo-ventricular valves; (3) of the papillary muscles and chordæ tendineæ. This sound is heard in an excised mammalian heart empty of blood; therefore it is largely muscular in origin. It is not heard in a turtle's heart, because this contracts too slowly.

When the sounds and the contraction are recorded together, the record shows that the first sound begins about 0.01 second before the cardiogram marks the beginning of the systole, and for the first 0.06 second of its durat:on this sound is heard only over the apex (Fig. 61). Over the base of the heart the first sound is heard just at the time when the semilunar valves open and the output begins. The first sound ccases before the ventricular contraction is over, for it is the sudden tension, not the continuance, of contraction that causes it. The beginning of the second sound marks the sudden tension of the semilumar valves, which immediately follows their closure.

For clinical purposes it is important to bear in mind what is 
happening in the heart whilst one listens to its sounds. During the first sound we have (1) contraction of the ventricles, closure of the auriculo-ventricular valves, and impulse of the apex against the

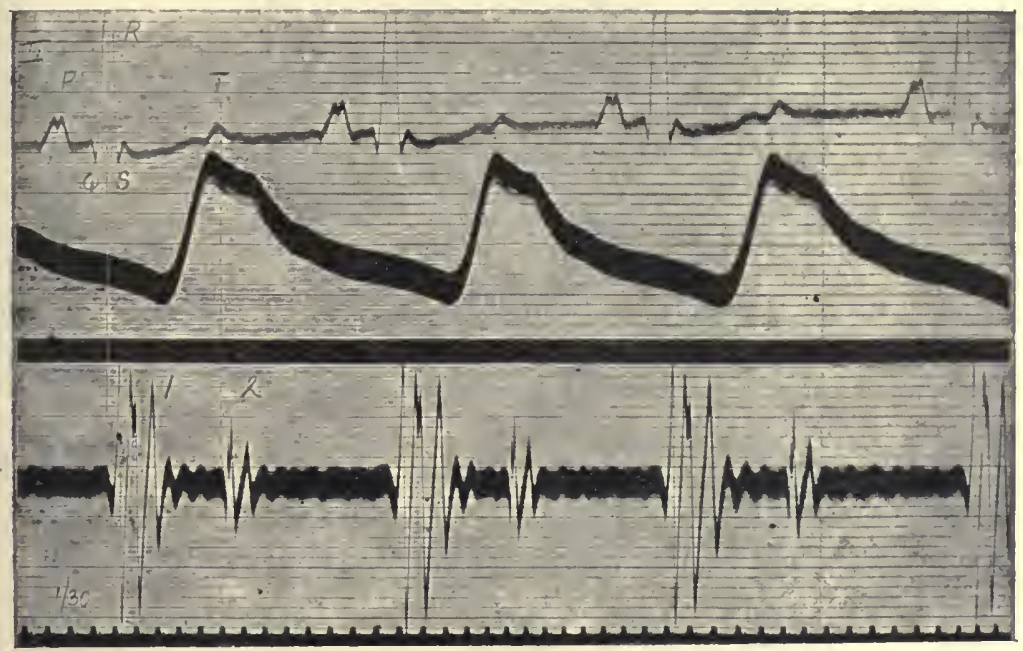

Fig. (il.--Electro-dardioßran, Carotid Pulse Curve, and Heart Sounds of A Dog. (T. Lیwis.)

The sounds are recorded by a microphone fitted to a stethoscope connected with a second string galvanometer.

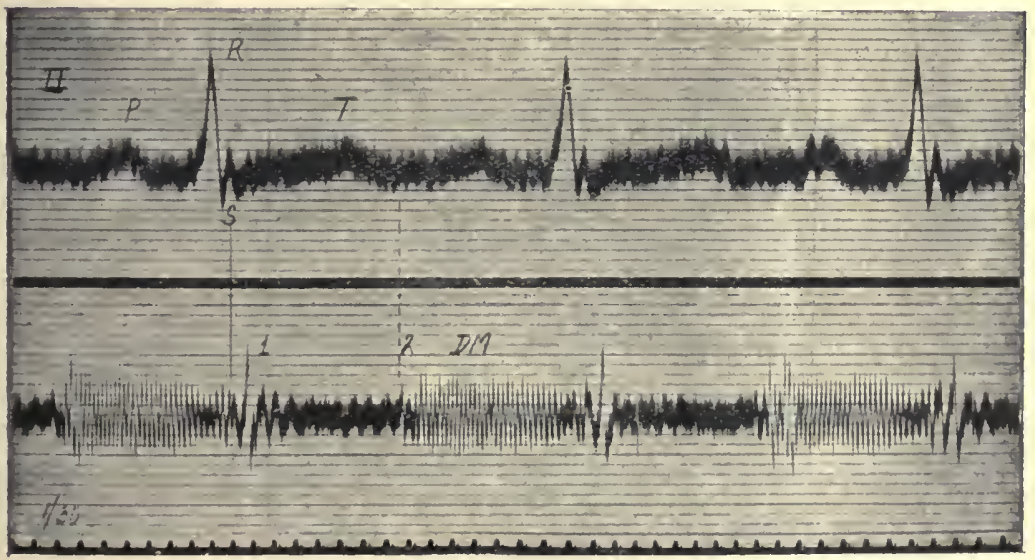

Fig. 62.-Electro-Cardiogram axd Rough Aortic Murnuz ix Max. (T. Lewis.)

chest; (2) rushing of the blood into the aortic and pulmonary artery, and filling of the auricles. With the second sound we have closure of the semilunar valves from the elastic recoil of the aorta and pul- 
monary artery, relaxation of the ventricular walls, opening of the auriculo-ventricular valves so as to allow the passage of blood from

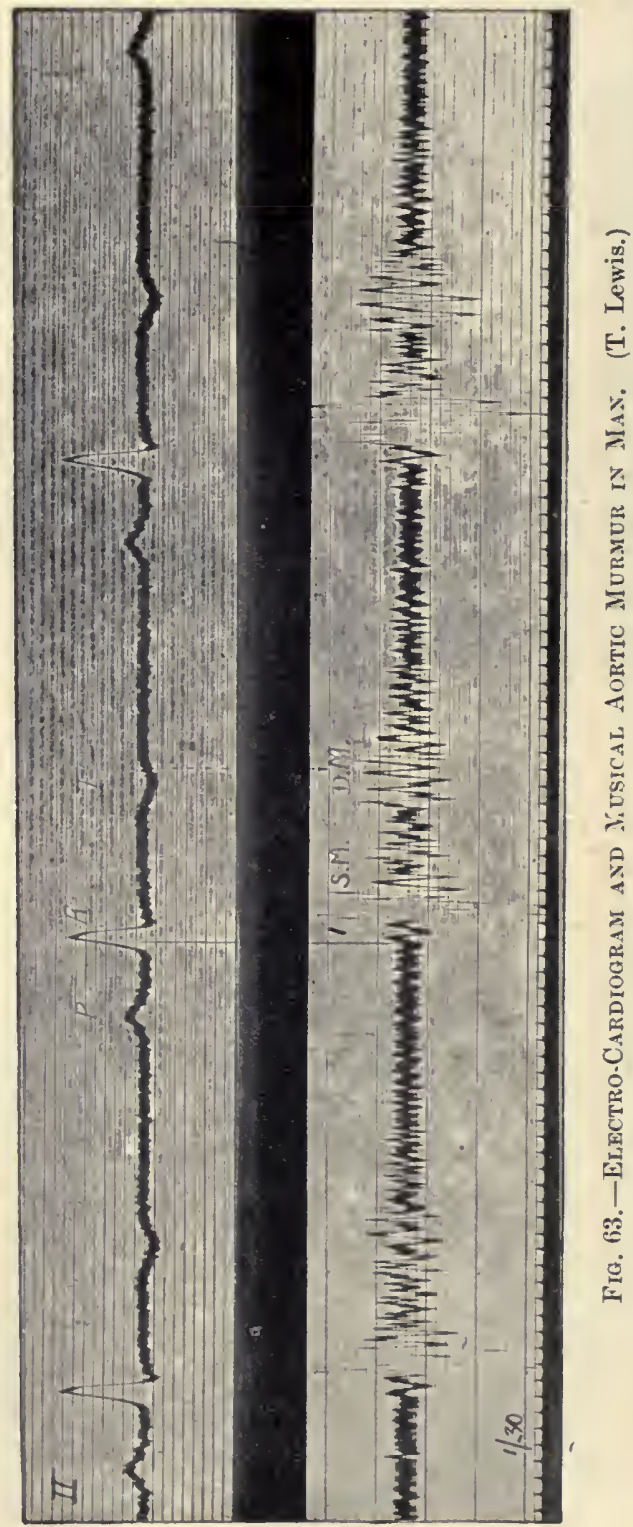

auricle to ventriele, and diminished pressure of apex against ehest wall. During the long pause there are taking plaee (1) gradual refilling of the ventriele from the auriele; (2) contraetion of the auriele 
so as to entirely fill the ventricle. The sound of the tricuspid valve is heard loudest at the junction of the fourth right costal cartilage with the sternum, that of the mitral over the apex beat, that of the aortic semilunar valves in the direction of the aorta, where it comes nearest to the surface at the second right costal cartilage- the pulmonary - to the left and external to the margin of the sternum. The sounds are changed in character by valvular lesion (Figs. 62 and 63) or muscular weakness of the heart, and afford important signs to the physician.

Murmurs are produced by eddies setting some part of the membranous walls or valve flaps in vibration. Thus, if a fine instrument provided with a hook be passed down the carotid into the aorta, and the aortic valves are torn and rendered incompetent, a murmur results. Inflammation, shrinkage, and incompetence of the valves results from rheumatic and other infections.

If a stethoscope be placed over a large artery, a murmur will be heard, caused by the blood rushing through the vessel narrowed by the pressure of the instrument. The fluid escapes into a wider portion of the vessel beyond the point of pressure, and the. sound is caused by the eddies set up there throwing the membranous wall of the vessel into vibration. Such a sound is heard over an aneurism. The placental bruit heard during pregnancy is a sound of this kind, arising from pressure on the uterine arteries. In cases of insufficient aortic valves a double blowing murmur may be heard, the first being due to the rush of blood into the vessel, and the second by the regurgitation of the blood back into the ventricle. These murmurs are produced by eddies of blood setting the membranous parts into vibration.

Occasionally a murmur seems to be produced by the displacement of air in the bronchial vessels by the beat of the heart, and may simulate the murmur of aortic incompetence. By placing a stethoscope over the jugular vein on the right side, and above the collar-bone, a murmur is heard - the bruit de diable - particularly if the subject turn his head to the left. This is held to be due to the vibration of the blood in the jugular vein rushing from the dilated to the contracted part. It is more marked during auricular diastole and during inspiration. 


\section{CHAPTER XVIII}

\section{THE NUTRITION OF THE HEART}

In the lower vertcbrates, such as the frog, the heart is directly nourished by the blood which fills the cavities in its sponge-like structure. In the warm-blooded vertebrates, there is a special arrangement of coronary vessels. The two coronary arteries (right and left) originatc at the root of the aorta from bulgings of the aortic wallsthe sinuses of Valsalva. The sinuses are three in number, corresponding to the number of cusps of the semilunar valves. The right coronary artery arises from the anterior sinus, the left coronary artery from the left posterior sinus. Their branches penetrate the muscular substance, and end in a rich plexus of capillaries. From these arise the radicles of the coronary veins, which open into the right auricle by the coronary sinus and other small vcins. These openings are valved by remnants of the primitive sinus venosus. The heart, in contracting, exerts a greater pressure than that of the coronary arteries, and so arrests the flow in these during the height of systole, and squeezes the blood within the coronary capillaries and veins on into the right auricle. On diastole, the coronary system fills again. Sudden occlusion-e.g., by the injection of paraffin-of any large part of the coronary arteries produces irregular and incoordinate contractions-" fibrillation," as it is called-followed by death of the heart. Degeneration of the coronary arteries in advanecd life is associated with a distressing form of cardiac illness known as "angina pectoris." The great anatomist John Hunter, who died "after a heated debatc, was found by Jenner to have calcified coronary arteries:

It has long been known that the heart of the frog or tortoise can be kept beating normally for hours after removal from the body, particularly if it is provided with a suitable solution of salts. Ringer worked out the necessary ingredients of this solution to be: sodium chloride, 0.7 per cent.; potassium chloride, 0.03 per cent.; calcium chloride, 0.025 per cent.

The cxcised mammalian heart can be kept beating in the same way, provided the nutritive fluid is oxygenated and the hcart kept at body tcmperature. A solution containing one-third defibrinated blood and two-thirds Ringer's salt solution is especially suitable. The beat of the heart of a child was restored thereby twenty hours after death from pncumonia; the excised heart of a cat was kept heating for four days; the heart of a monkey was restored after 
freezing the animal. The nerves of the exeised heart retain their aetion for some time if the nutritive fluid is immediately eirculated through the eoronary arteries. Thus, the heart's action can be conreniently studied when taken from the body of a mammal.

By using defibrinated blood mixed with the perfusion fluid food material is brought to the heart. By some it is considered that the serum albumin is the essential substanee. In Locke's fluid* dextrose is added to the above salts, and this forms an admirable perfusion fluid. But the heart will beat when supplied with oxygenated Ringer's solution only; neither the serum albumin nor the dextrose appear to be neeessary. The important faetors are the free ions of sodium, potassium, and calcium, and certain conecntrations of these appear to be absolutely necessary for the rhythmic automatieity and effieient working of the heart. With inerease of the eontents of the caleium ions the heart contraets more powerfully (Fig. 64). If the amount of calcium be large the heart relaxes less and less eompletely, and eventually stops in a state of tonic contraction.

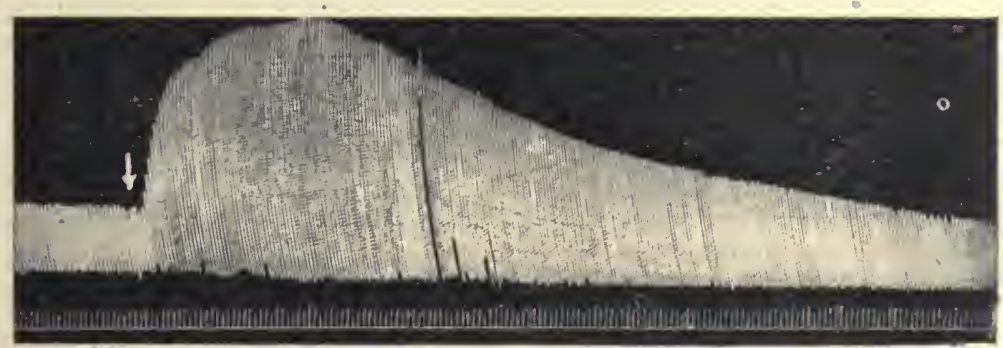

Fig. 64.-Isolated Rabbit's Heart Perfused with Locke's Solution. (Dixon.) At the arrow $5 \mathrm{mgrm}$. of calcium chloride were given. Time in seconds.

Exeess of the potassium ions has an opposite effeet (Fig. 65). The beat of the heart bceomes more and more feeble, and it eeases to beat in a state of eomplete relaxation (diastole). Exeess of the sodium ion causes the beat of the heart to become weaker and weaker, and eventually fail altogether (also in diastolc). There is therefore an antagonism between the caleium ions and those of sodium and potassium.

The origin of the excitatory wave is intimately dependent upon interaetion between these ions and the colloids of the heart musele, those of caleium playing a prominent part in the eontraetion of the heart, those of potassium in its relaxation.

If the heart is treated with lactie acid until it is brought to a standstill in diastole, it ean be partly restored by inereasing the concentration of caleium in the Ringer's solution, and eompletely restored

* Locke's fluid is distilled water, 100 c.c.; sodium chloride, 0.9 gramme; potassium chloride, $0 \cdot 042$ gramme; calcium chloride, $0 \cdot 045$ gramme; sodium bicarbonate, $0 \cdot 02$ gramme; dextrose, $0 \cdot 2$ gramme. 
by then perfusing with a high concentration of potassium salts, subsequently washed out by physiological saline.

Potassium itself may restore the heart from a lactic acid diastole, but not so completely as the combination of calcium and potassium. The fact that the heart can be restored from diastolc induced by lactic acid by a high concentration of potassium, which is poisonous
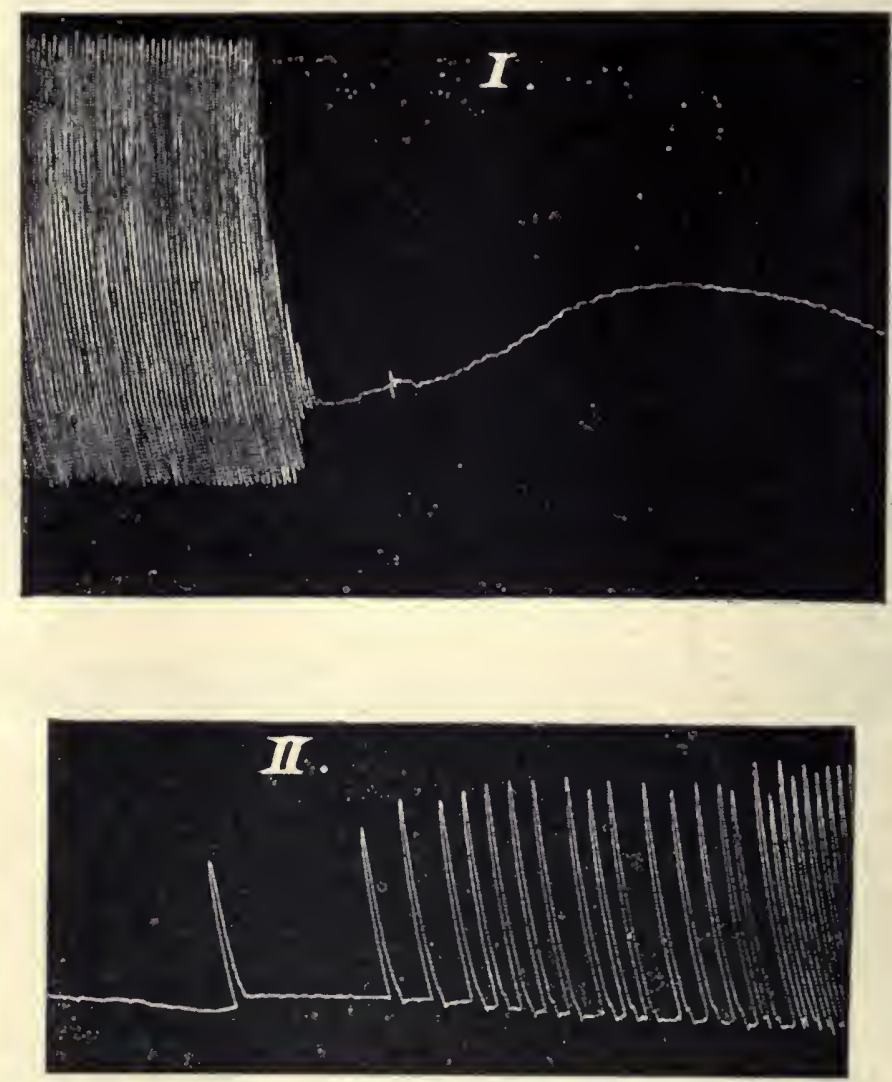

Fig. 65.-Isolated Rabit's Heart perfused with Ringer's Solution. (Dixon.) In $1,0.2$ per cent. potassium chloride added to the fluid. II. shows gradual recovery when $\mathrm{KCl}$ withdrawn.

to, and induces complete relaxation in, the normal heart, shows how far we are from understanding the true part played by these ions in relation to the automaticity of the heart.

The Diastolic Filling of the Heart.-In the excised heart no cvidence of any suction power has been observed; indeed, the heart will only fill when supplied with blood under a positive pressure. 
Similarly, when the thorax is opened, the heart cannot fill itself unless aided by a positive pressure in the veins.

If the pressure in the venæ cavæ were not positive, then negative pressure occurring in the heart cavities would lead to a collapse of the thin-walled venæ cavæ, and not to suction of blood from the veins. In hydraulic engineering, the efforts of engineers are directed towards making the water enter the system without shock. If the negative pressure had any sudden and decided action, there would be shock and consequent loss of energy.

The driving force of the heart is sufficient by itself to maintain, if any rate for a time, and in the horizontal position of the animal, a circulation when the thorax is opened, artificial respiration established, and the inuscles paralyzed by injection of curari. Under these conditions, the circulation may fail altogether in the vertical posture when gravity oppo зез the return (see later, the effect of posture, p. 194).

Normally, the filling of the heart is largely under the control of the respiratory pump. In the closed thorax, the pressure is less than that of the atmosphere by that amount which is required to overcome the pulmonary elasticity and expand the lungs to the size of the thoracic cavity. In ordinary inspiration, this pressure is equivalent to $9 \mathrm{~mm}$. $\mathrm{Hg}$; in the position of the deepest inspiration, it may sink to $30 \mathrm{~mm}$. $\mathrm{Hg}$. On the one hand, the extrathoracic veins are under a pressure made positive by the compressive action of the skeletal muscles, contraction of muscular walls of viscera, and the respiratory pump; on the other hand, the intrathoracic veins and the heart are under a slight negative pressure, which in inspiration may become 9 to $30 \mathrm{~mm}$. Hg. The venous blood is thus pressed and aspirated into the heart from the venous cistern. Each descent of the diaphragm compresses the abdominal organs, and if in sequence to, or synchronously with, the inspiratory movements of the thorax the abdominal inuscles be thrown into contraction, then the respiratory muscles act powerfully on the venous cistern, not only as a suction but also as a force pump. To prevent overdistension of the right heart, the breath is always held when the abdominal muscles are forcibly contracted-e.g., on straining at stool, or when the abdomen is compressed. The pericardium, too, supports the heart and limits its distension. The venous cistern in its turn is filled by the force of the heart-beat (the vis a tergo), but in particular by the muscular movements of the limbs and viscera aided by the valvular action of the veins. During any violent exercise, such as running, the skeletal muscles alternately contract and expand, and a full tide of blood flows through the locomotor organs. The stroke of the heart is then both more energetic and more frequent, and the blood circulates with increased velosity. Under these conditions, the filling of the heart is maintained by the pumping action of the skeletal and respiratory muscles. The abdominal wall is contracted, and the reserve of blood is driven from the splanchnic vessels to fill the dilated vessels of the lozomotor organs. At each respiration the pressure within the thoracic cavity becomes less than that of the atmosphere, and the blood is 
aspirated from the veins into the right side of the heart and lungs; conversely, at each expiration the thoracic pressure increases, and the blood is expressed from the lungs into the left side of the heart. While the respiratory pump at all times renders important aid to the circulation of the blood, its action becomes of supremc importance during such an excrcise as running. The runner pants for breath, and this not only increases the intake of oxygen, but maintains the diastolic filling of the heart. It is of importance to grasp the fact that the circulation of the blood depends not only on the heart, but on the vigour of the respiration and the activity of the skeletal muscles. Muscular exercise is for this reason a sine qua non for the maintenance of vigorous mental and bodily health.

An experiment which throws light on the filling of the heart is the following: A pressure-bottle filled with oil is connected by a T-piece with (1) an oil manometer, (2) a tube tied into the pcricardial sac. So soon as the pressure of the oil is raised to 60 to $70 \mathrm{~mm}$. oil, the arterial pressure falls by 20 to $30 \mathrm{~mm}$. $\mathrm{Hg}$, while the vena cava pressure rises to about $5 \mathrm{~mm}$. Hg. By a pressure of at most 240 to $300 \mathrm{~mm}$. oil, the arterial pressure is brought to zero. By no possible means in the anrsthetized animal can the vena cava pressure rise beyond this pressure, and thus the heart is unable to fill. The quantity of blood thrown into the aorta by each contraction of the left ventricle must correspond to that entering the right ventricle during diastole, otherwisc the blood will become congested in the veins, and the circulation quickly come to an end.

In the dog, either the vena cava superior, or the vena cava inferior below the liver may be completely occluded, and yet no change of pressure in arterial pressure is indicated by the arterial manometer. If on the other hand the vena cava inferior between the liver and the heart be compressed, there occurs an immediate and marked descent of the arterial pressure. Thus a rabbit, in which the portal vein has been ligatured, perishes within a few minutes, owing to the rapid accumulation of the blood in the portal tributaries. The capacity of these is so great that they are sufficient to hold all the blood; the plasma, too, rapidly leaks out of the capillaries when the circulation is thus arrested. The filling of the heart is thus cnormously diminished while the aorta continues to empty itself by its elastic reaction into these veins.

On occluding the pulmonary artery of an animal the left heart empties, and the arterial pressure falls towards zero. The pressure in the venæ cavæ rises, but only by a very few millimetres of $\mathrm{Hg}$. If one vena cava be half occluded, the venous pressure rises distal to the obstruction, but only by a few millimetres of $\mathrm{Hg}$, and for a short while. A fow hours after the pressure in the veins is found to be normal. It is important to note that the œedema, or dropsy, which follows such obstruction, or occurs in heart disease, is not caused by transudation due to a rise of venous pressure, but by nutritive changes in the tissues which follow the obstructed flow.

If the thorax of a dog or cat be compressed, the arterial pressure 
falls towards zero, owing to the increased intrathoracic pressure obstructing the filling of the heart, while the vena cava pressure rises a few millimetres of $\mathrm{Hg}$ (Fig. 66). The extent of the effect depends greatly on the rigidity of the thorax and resisting-power of the animal. In man, compression of the chest produces the same result; loss of consciousness may be induced and convulsive spasms owing to the production of acute cerebral anæmia.

In the fatal crushes of panic-stricken crowds, death is produced by compression of the thorax and circulatory failure. The women and children with collapsible chests are the first to die, while the men with most rigid chests escape. When a person is strangled, or the larynx is blocked by some hard, impacted mass of food too hastily swallowed, death is hastened by the violent expiratory spasms, which drive the blood out of the abdominal veins into the heart and engorge the face with venous blood.

To sum up, the heart is filled in diastole by-

1. The contraction of the heart producing a positive pressure in the veins (the vis a tergo).

2. The action of the respiratory pump creating a negative pressure in the thorax and a positive pressure in the abdomen.

3. The contraction of the muscles of the body generally impelling the blood onward toward the heart.

4. Change of posture and the action of gravity.

\section{The Systolic Output and the Work of the} Heart.-To estimate the work of the heart, it is necessary to know the mean pressure $(\mathrm{H})$, the velocity. of blood in the aorta (V), and the volume of systolic output $(\mathrm{Q})$.

The velocity of blood in the aorta may be obtained by one of the methods given (From Schäfer's "Physiology.") later (p. 203).

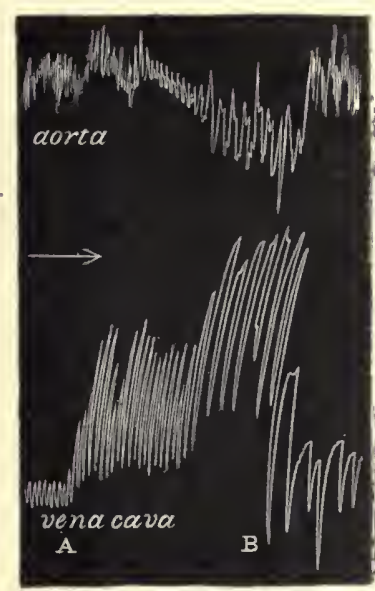

Fig. 66. - COMPRESSION OF THE THORAX $(A-B)$. (Hill and Barnard.)

Compensitory effect of powerful inspirations, alternating with forced expiratory efforts (glottis closed). Aorta $\mathrm{mm}$. $\mathrm{Hg}$, vena cava $\mathrm{mm}$. water.

Having obtained the velocity (V), the output can be reckoned if the sectional area of the aorta (A) and the time of the cardiac cycle (T) be known. To calculate half the diameter of the aorte, thus getting the radius $(r)$. The sectional area $(\mathrm{A})=\pi r^{2}\left(\pi=\frac{22}{7}\right)$; divided by the number of heart-beats per minute gives $T$ in seconds. Then $\mathrm{Q}=\mathrm{AVT}$.

The output of the heart may be determined by means of the heartlung preparation (Fig. 67). Under an anæsthetic, and after injection of hirudin to prevent the clotting of the blood, artificial respiration is established, and the common carotid artery, the descending aorta and 
the interior vena cava are ligatured. A cannula, connected with a manometer, M, is placed in the innominate artery. From this the blood is led past the air cushion B, which represents the elasticity of the arteries, to a rubber tube, $R$, in a tube, $T$. This can be compressed by the pump $\mathrm{S}$ and pressure bottle $\mathrm{A}$, and corresponds to the peripheral resistance. Thence the blood passes to a vessel, N, where it is aerated and thence siphoned to one where it is warmed, and from there to the supcrior vena cava through a cannula containing a thermometcr.

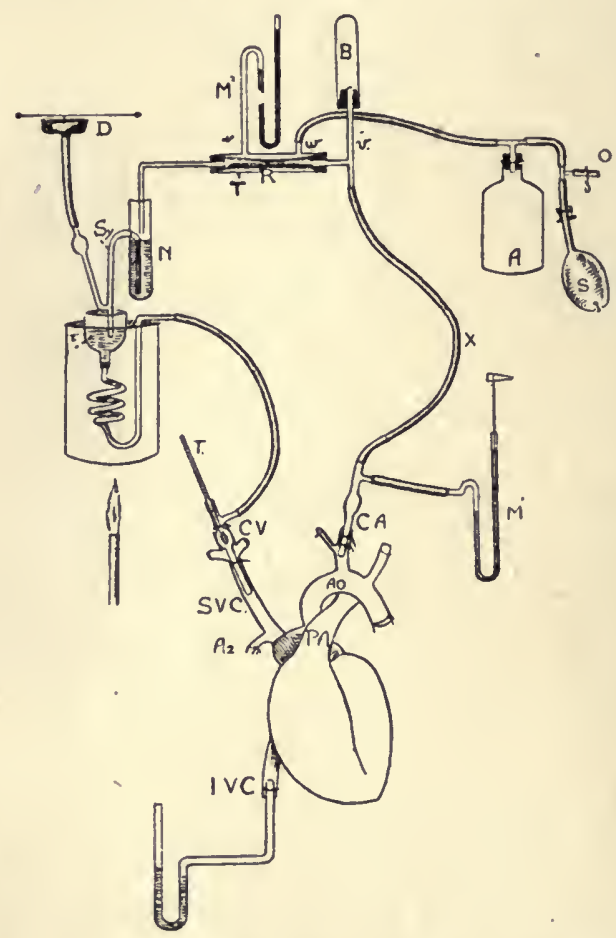

Fig. 67.-Diagram of Apparatus (Described in Text) used in the Heart-Lung Preparation. (Knowlton and Starling.)

The output of the ventricle for a given time may be cstimated by measuring the flow from the bypass to the vessel $\mathrm{N}$. If the rate of beat be known, the output per beat is easily calculated.

The volume of output may be estimated indirectly by determining (1) how much oxygen is absorbed from the inspired air per minute; (2) the difference in the oxygen content of the arterial and venous blood; (3) the number of heart-beats. If 1,000 c.c. of oxygen are absorbed from the air breathed in a minute, and the arterial blood contains 10 per cent. more oxygen than the venous, and the heart bcats 100 times per minute, then, since 10 c.c. of oxygen are carried away by each 100 c.c. of 
blood, the amount of blood necessary to carry away 1,000 c.c. is $1000 \times 100$

$\frac{10}{10}=10,000$. If this be divided by the beats per minute $(100)$, then the output for each beat would be 100 c.c. In man, the output volume can be determined by breathing in a deep breath of air mixed with nitrous oxide-a very soluble gas - holding the breath and finding how much of this gas is carried away by the blood during a given time, about thirty seconds. A sample of the alveolar air is taken at the beginning and at the end of holding the breath, and the amount of air in the lungs at the beginning and at the end of this period is determined. From the amounts of nitro:s oxide in the samples the amount of nitrous oxide present in the lungs at the beginning and at the end of the experiment is known. This gives the amount absorbed from the lung in the time. Then, knowing the solubility of the gas (1 c.c. of blood absorbs 0.43 c.c. of the gas), the amount of blood necessary to absorb the known amount from the mean percentage of gas present can be calculated. This divided by the length of time of the experiment and the heart-beats per minute gives the output for each beat. The output for man is calculated to be 60 to 100 c.c. It is ten times as great or more during hard exercise.

The work of the heart may be calculated from the following formula :

$$
\mathrm{W}=\mathrm{QH}+\frac{\mathrm{M} v^{2}}{2 g},
$$

where $\mathrm{M}=$ the weight of the mass of blood moved, and $g=$ the accelerating force due to gravity, this $=9 \cdot 8 . \quad \mathbf{Q} \times \mathbf{H}$ represents the work of each heart-beat in overcoming the peripheral resistance. $\frac{\mathrm{M} v^{2}}{2 g}=$ the energy of the velocity of the blood ejected. These two must be added together.

We may take the output of the left ventricle as 100 grammes; the mean pressure of the aorta as $110 \mathrm{~mm}$. $\mathrm{Hg}$. Since mercury is about 13.5 times heavier than blood, this

$$
\begin{gathered}
=110 \text { millimetres } \times 13 \cdot 5, \text { or } \\
0 \cdot 110 \text { metre } \times 13 \cdot 5 .
\end{gathered}
$$

We have thercfore in gramme-metres of work:

$$
\begin{aligned}
W & =100 \times 0 \cdot 110 \times 13.5+\frac{100 \times 0 \cdot 5^{2}}{2 \times 9 \cdot 8} \\
& =148 \cdot 5+1.26 j \\
& =149 \cdot 765,
\end{aligned}
$$

or, approximately, 150 gramme-metres of work for each contraction of the left ventriclc. It is clcar that almost all the work of the heart is spent in overcoming resistance, and it suffices, for roughly calculating the work, to multiply the output by the arterial pressure.

We can say that the work of the left ventricle is equivalent to 
throwing up a 5-ounce ball a yard high scventy times a minute. The right ventricle, since it contracts against considerably less pressure, has less work to do. It is generally considered as doing about onethird the work of the left.

Taking into consideration the variations in pressure and output, the human heart is estimated to perform about 12,000 to 20,000 kilogramme-metres of work per day - that is to say, it performs suffieient work to raise the body weight through 200 to 300 metres above sealevel-say up a hill of 1,000 feet.

Twenty thousand kilogramme-metres would be equivalent to 50 calories out of the total 3,000 calories whieh a man takes in as food. A labourer does about 150,000 kilogramme-metres of external work a day. The work of the heart is increased two or three times by museular labour, and even ten times by great exertion. When the heart does work it also produces heat, and probably five times as mueh heat as work. It has been estimated that the heart requires per diem, to

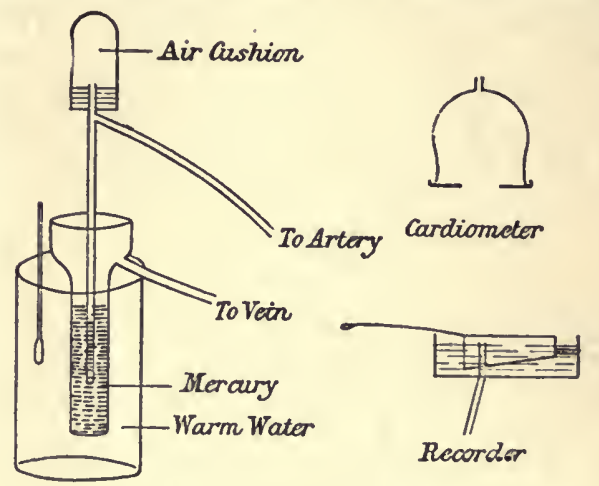

Fig. 68.-The Cardioneter.

maintain its energy, an amount of solid food (water-free) equal to the weight of solids in the heart itself-i.e., about 60 grammes of sugar or protein. A relatively high proportion of blood must be circulated per minute through the coronary arteries to maintain the vigour of the heart, and its use of oxygen per gramme of weight per minute is high. Thus, for the whole body of the dog there was used 0.017 c.c. per gramme of tissue per minute; for the heart, 0.045 to 0.083 ; and for the active secretory glands, 0.07 to $1 \cdot 0$.

The volume of the output of the heart may be recorded by means of the cardiometer.

Various forms have been devised. The most convenient consists of a large thistle funnel covered with a rubber membrane in which a round hole of appropriate size has been made with a heated solderingiron (Fig. 68). After the establishment of artificial respiration, the thorax of the animal is opened and its heart inserted through the rubber membrane so that this fits snugly to the base of the. ventricles. The tube of the funnel is connected with a piston recorder. A cannula 
is placed in the carotid artery, and connected to a mercury valve, whereby the blood-pressure can be regulated by raising or sinking a tube in mercury, and in which the blood is also kept warm until it is returned to the animal by the jugular vein. The circulation is confined to the heart and lungs, and the effect of various conditions on the output studied. Fig. 69 shows a tracing obtained by this mcans.

Experiments on the output of the heart show-

1. That within certain limits the systolic output is independent of the resistance.

2. That under favourable conditions a rise of resistance may increase the systolic output.

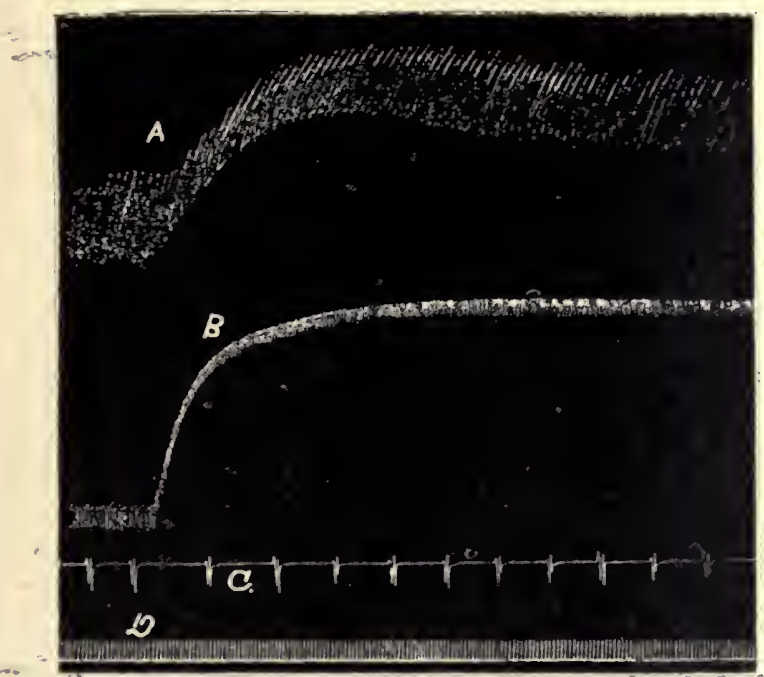

Fig. 69. - Tracing showing Voldme of OUtput of Heart. (Knowlton and Starling.) $A$, Volume of ventricle; $B$, arterial pressure; $C$, output of left ventricle measured; $D$, time in seconds.

3. That with increasing peripheral resistance the systolic output as a rule decreases.

4. That as the arterial pressure generally increases in spite of the diminished systolic output, the diminution in output per second must be proportionately smaller than the increase in resistance.

The diminution of the output per second is usually shown most strikingly during the rise of arterial pressure which is oecasioned by asphyxia. In the asphyxial condition the heart muscle rapidly fails, and passes into paralytic dilatation; while the output from the ventricles is opposed, the venous input is increased by the action of the respiratory spasms.

In the first stage of asphyxia a large vascular area of arterioles, 


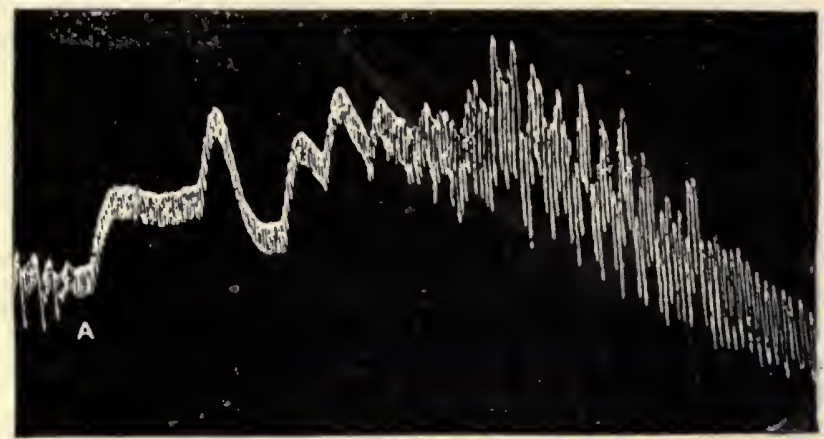

Fig. 70.-Arterial Pressure; Effict of Aspiyxia. Animal Anestultized and Curarized. (L. H.)

At $A$ the artificial respiration was stopped. The large oseillations are TraubeHering eurves.

Duration in hự redths of a second

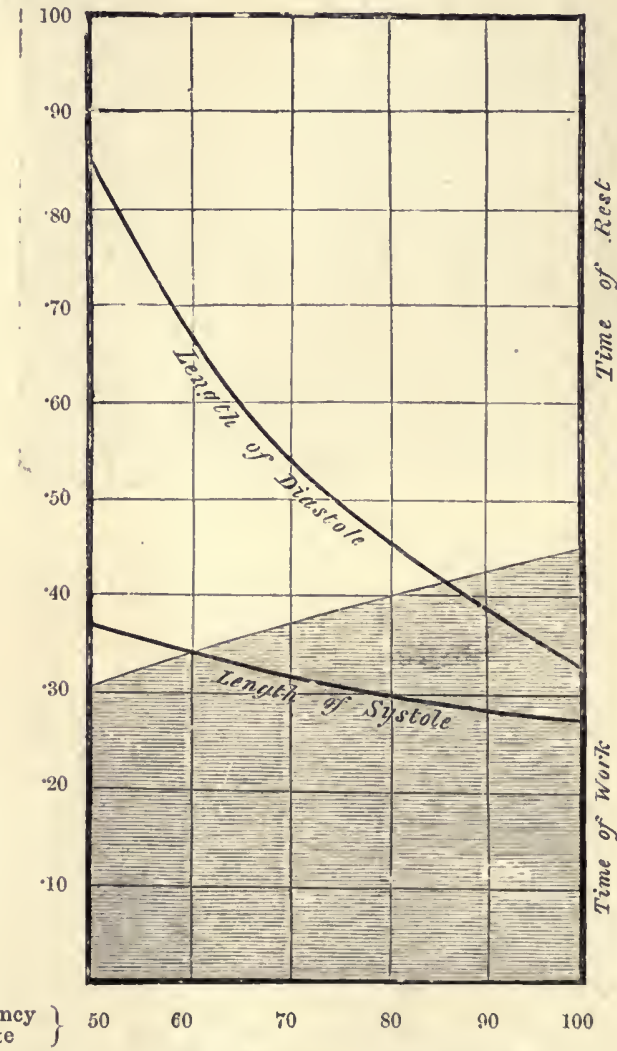

Fra. 71.-Duration of Systole and of Diastole with Different PulseFrequexctes. (Waller.) 
such as the splanchnic, is thrown into constriction, and the blood is propelled from the constricting vessels into the veins, and thus the diastolic filling of the heart is increased; at the same time, the velocity of flow through the locomotor organs is accelerated, owing to a compen-

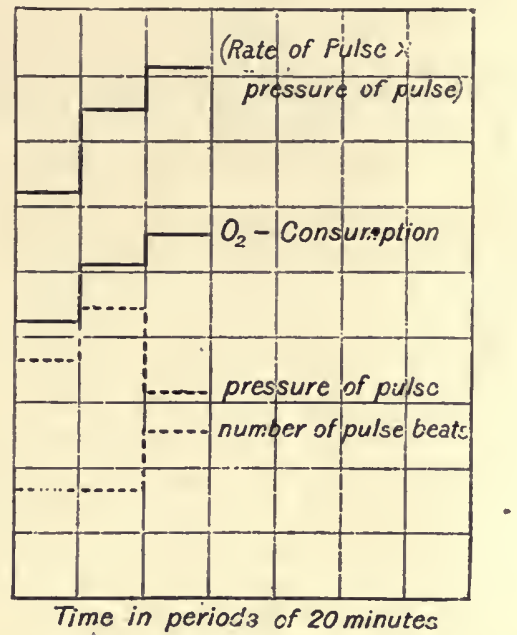

Fig. 72.-Diagram showing the Relationship of Oxygen Consumption to the Rate of the Pulse and the Arterial Pressure. (Bareroft.)

satory dilatation of the vessels in these organs. The heart accelerates, the systolic output increases, and the arterial pressure rises (Fig. 70). In the second stage the vagal centre of the spinal bulb is excited by the high arterial pressure, the heart frequency is lessened, and the

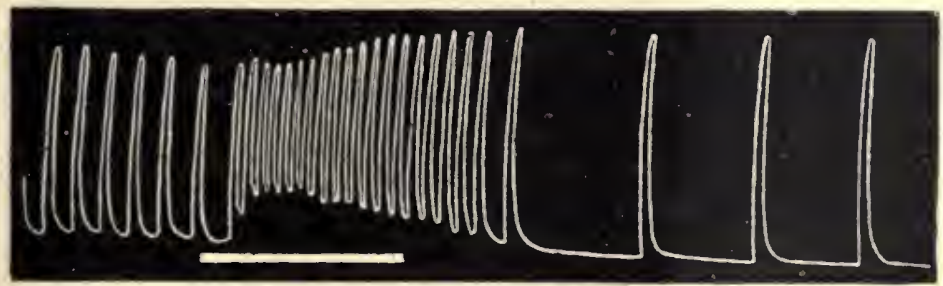

Fig. 73.-Contraction of Frog's Heart, showing Accelerator Effect of Weak Stimulation of Vago-Sympathetic. (Pembrey and Phillips.)

There is inereased tone in the after-effeet.

output diminished. Further, so soon as the arterial pressurc reaches a certain point, the heart becomes unequal to the strain of emptying itself against the resistance; the output then becomes imperfect, the rcsidual blood increases, the left auricular pressure rises, and the blood is congested in the lungs and within the venous system. 
The amount of work done by the heart varies with the pulse frequeney per minute (Fig. 71).

Table showixg Deration of Systole to Diastole, fic., with Different Pulse-Frequencies.

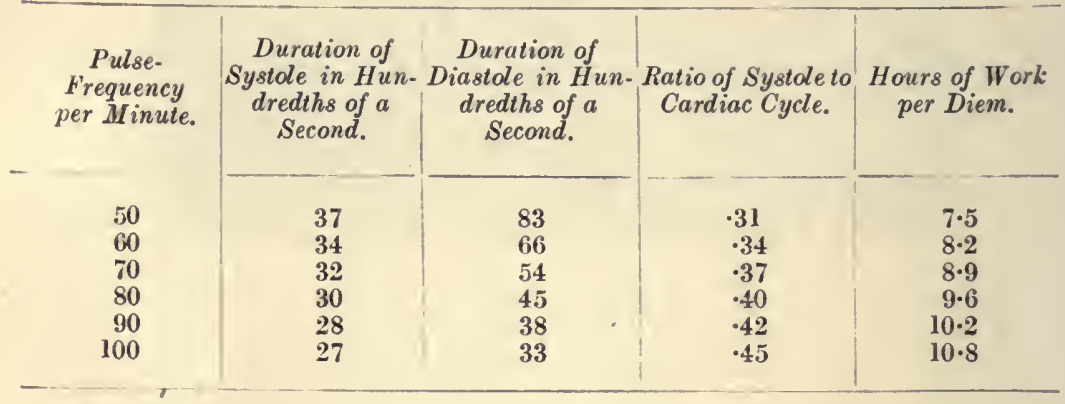

In Fig. 71 pulse-frequencies per minute are indicated along the abseissa. Durations of systole and of diastole are given in hundredths of a second. Their respective curves show that the systole shortens by about $\frac{-2}{100}$ second for each increase of ten beats per minute, and that the diastole shortens by about $\frac{10}{100}$ second.

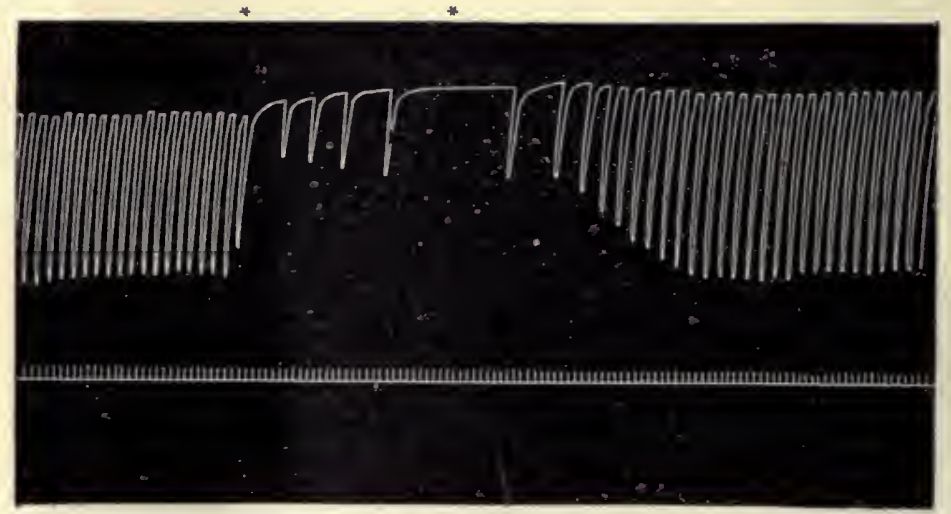

Fig. 74.-Excitation of Vago-Sympathetic. (L. H.)

Note the after-effeet: a stairease augmentation of the heart-beat. The stars indicate the'beginning and end of stimulation. The downstroke represents contraction. The time is marked in seeonds.

The shaded and unshaded portions represent respective time of work and time of rest at various pulse-frequencies.

The rate of beat and the arterial pressure also influence the amount of oxygen consumption by the heart musele. This is well seen in the diagram (Fig. 72). 


\section{CHAPTER XIX \\ THE CARDIAC NERVES}

THE vagus nerve, when excited, slows or even arrests the action of the heart (Fig. 44). The cardio-inhibitory nerves, as they are called, have been found in all classes vertebrates and in many invertebrates. The existence of nerve fibres which, when excited, augment and accelerate the beat of the heart has also been demonstrated. These belong to the sympathetic nervous system. In the frog, the two nerves run in one trunk - the vago-sympathetic nerve-a variable response to stimulation is therefore obtained (Figs. 73, 74). In the

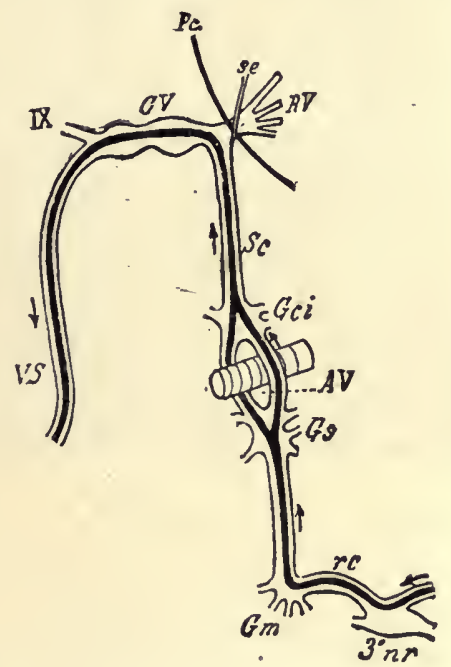

Fig. 75.-Cardiac Nerves of Frog.

frog, the sympathetic fibres come off the ganglion of the third spinal nerve (first post-brachial), and pass along the sympathetic trunk to join the vagus nerve where its ganglion lies at the base of the skull (Fig. 75). In mammals, the accelerator nerves arise from the first to the fifth thoracic anterior spinal nerve roots, the preganglionic fibres having their "cell stations" in the first thoracic and inferior cervical gangiia, whence they pass to the heart partly in company with the cardiac branches of the vagus, and partly as separate twigs (Fig. 76). The vagus cardiac fibres belong to the cercbral 
autonomic system. They arise from a centre in the medulla oblongata by the middle of the lowermost group of vagus roots, and the preganglionic fibres have thcir cell-stations in the ganglion cells of the heart. These ganglion cells lic chiefly in the subpericardial tissue, in the posterior wall of the auricles between and around the orifices of the venæ cavæ and pulmonary veins, and between the aorta and pulmonary artery. The right nerve goes particularly to the ganglion cells in the neighbourhood of the sinu-auricular node, through

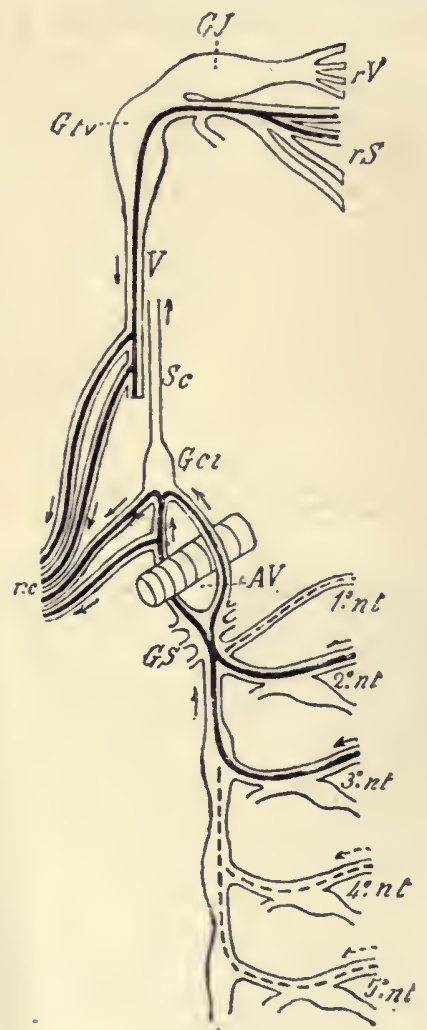

Fig. 76.-Cardiac Nerves of Dog. (Fostcr.)

which certain of the post-ganglionic fibres act. The inhibitory fibres run chiefly in this nerve. The centre is in tonic action, and ccastantly bridles the heart's action, and this when the vagi are divided, the frequency of the heart increases and the blood-pressure rises. During stimulation of the peripheral end of the vagus the arterial pressure falls and the vena cava pressure rises (Fig. 77). The vagus centre is reflexly excited by the inhalation of chloroform, ammonia, or other vapour irritant to the air-passages; also by the want of oxygen in the blood, as in asphyxia. It may be 
excited reflexly by irritation of the abdominal nerves-e.g., a blow in the abdomen-and by increased pressure in the cerebral vessels. The accelerator and augmenting fibres likewise have their centre in the spinal bulb, and this is in tonic action, antagonizing more or less the action of the vagal centre. The vagus nerve, by its action, produces changes which result in a depression of the excitability, the conductivity, the force, and the frequency of the heart. By some authorities these are believed to be separate influences, so that the vagus nerves are said to contain bathmotropic, dromotropic, inotropic,

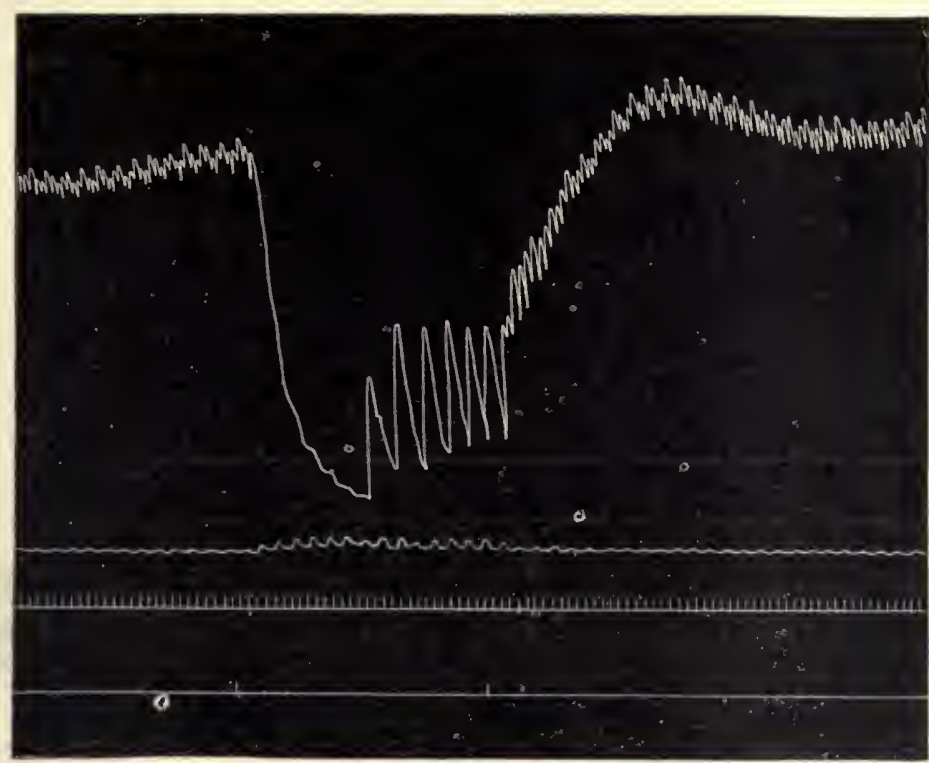

Fig. 77. - The Effect of Excitation of the Peripheral End of the Vagus Nerve upon the Blood-Pressure in the Aorta (Top Curve) and the Vena Cava (Second Curve) in m. Hg of a Curarized Animal with Artificial. Respiration. (L. H.)

Note the inhibition of the heart; the great fall of aortic and the insignificant rise of vena cava pressure; the escape of the heart from the vagus action and the aftereffect on the aortic pressurc. The time is marked in seconds, and the signal line shows the duration of vagus stimulation.

and chronotropic fibres, influencing through their ncrve endings the above-mentioned properties in the order named. Possibly, also, the tonicity of the heart muscle is affected. The chronotropic action, slowing the frequency of the beat, is the most characteristic action. The heart becomes dilated and engorged with blood, stopping in diastole. The right vagus, in which chronotropic fibres chicfly run, probably manifests its action upon the auricles through the sinuauricular node. The left vagus is held by those authorities who believe in the different kinds of fibre to contain chiefly fibres other 


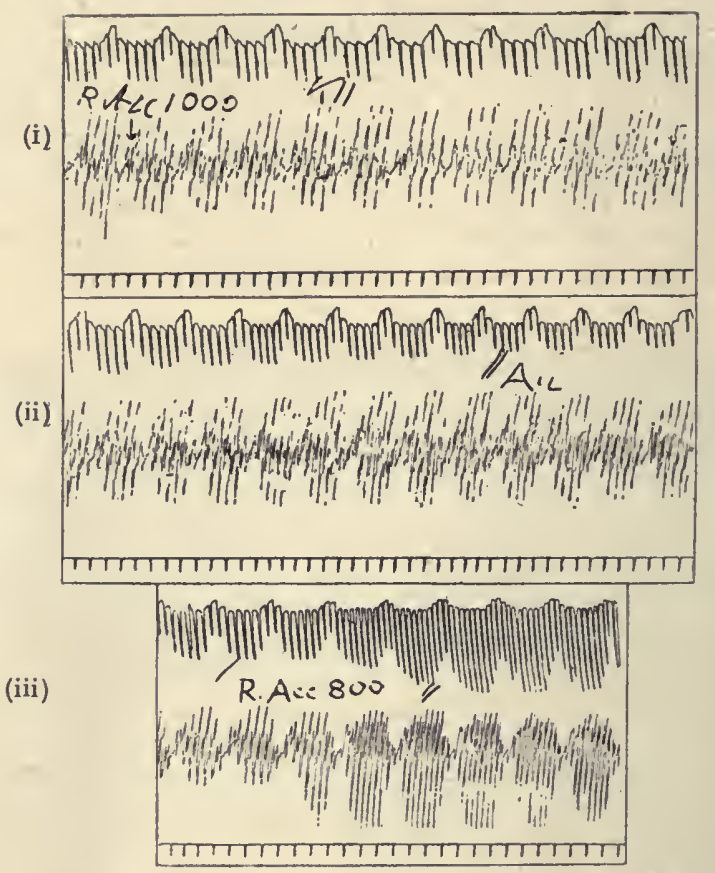

Fig. 78. -Tracings (i.) to show and (ii.) the Abolition of Effect of Right Accelerator in the Dog, freezing the S.-A. Node. The Accelerator Nerve was stimulated between the Strokes, (iii.) The Actiox of Right Nerve beforehand-The ACtion also returNed after the EFFects 'OF THE COLd HAD PASSED OFF. (M. F.)

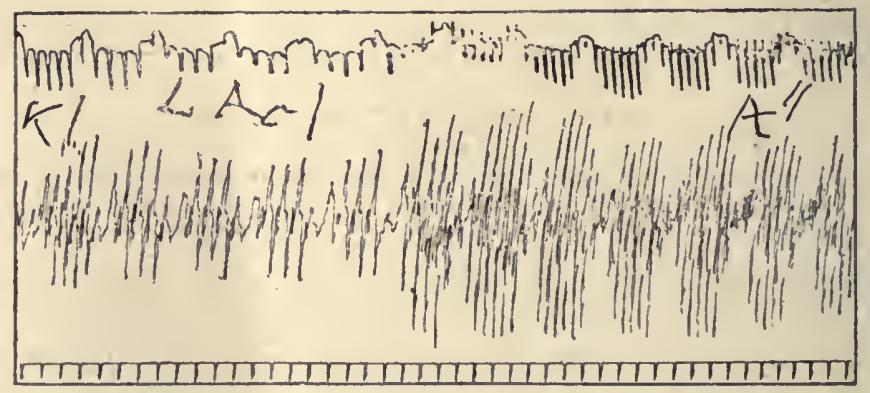

Fig. 79. - To show the Action of the Left Accelerator in the Dog even after FREEZING OF S.-A. NODE. (M. F.)

The nerve stimulated from $A^{\prime}-A^{\prime \prime}$; freezing started at $K^{\prime}$ and continued all the time. 


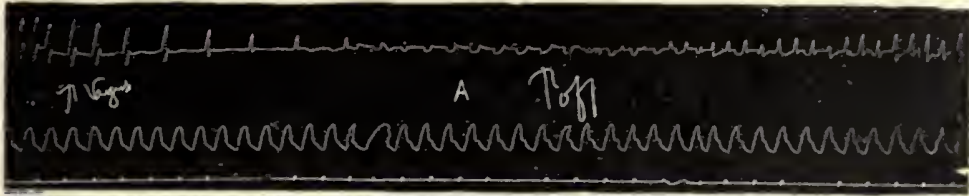

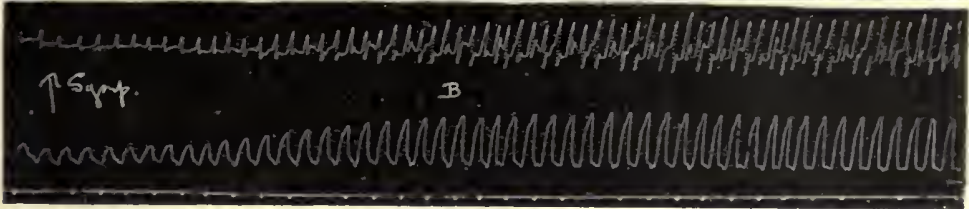

Fig. 80.-Shows Effect of Stimulation of Vagus $(A)$ and of Accelerator Nerves (B) in Cat's Heart with A.-V: Bundle Cot. (W. Cullis and E. M. Tribe.)

The vagus effeet is abolished, but the aetion of the aeeelerators persists, espeeially the augmentor effeet.

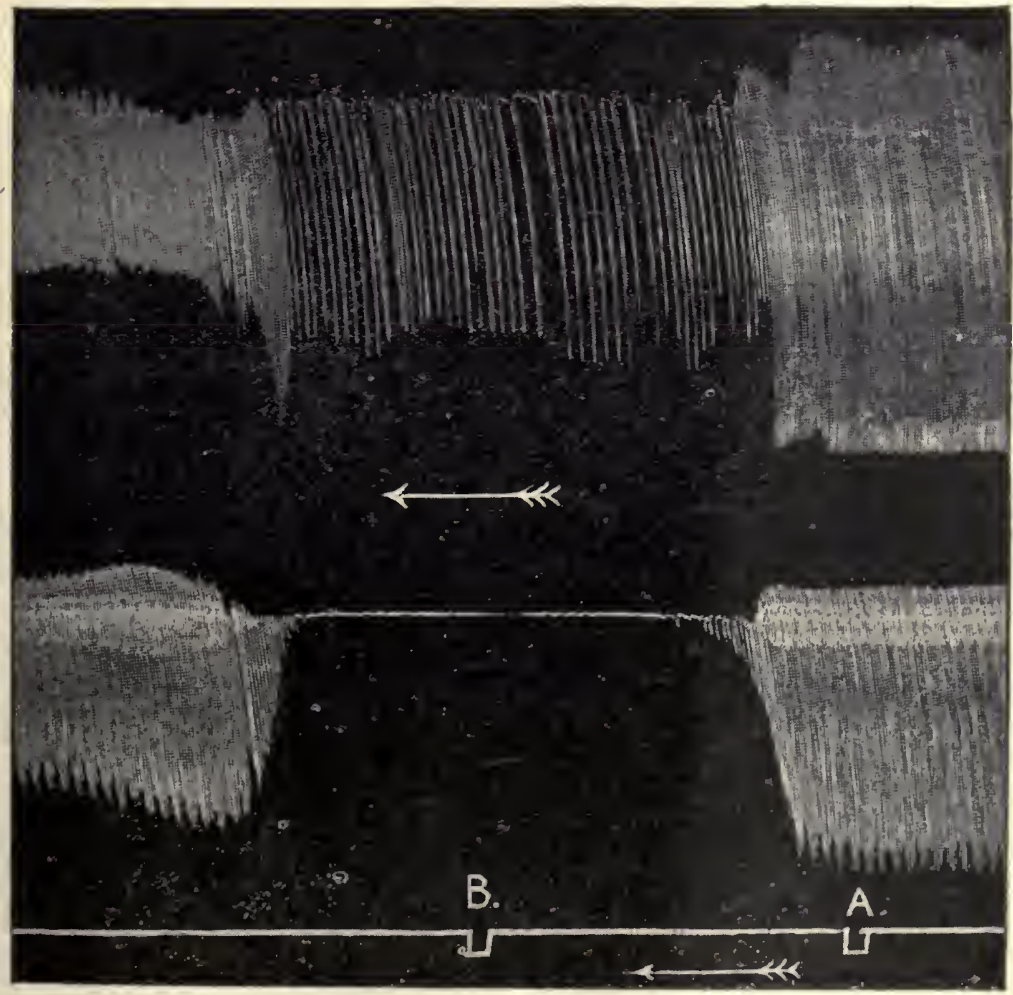

Fia. 81. - Shows the Effect of a Shall Injection of Muscartne upon the Dog's Heart (Vextricle Uprar, Auricle Lower Tracisg). (Dixon.)

The auriclo was eompletely inhibited in diastole. At $B$ atropine was injeeted into a rein, and the inhibitory effeets passed off. 
than chronotropic. Its chronotropic fibres generally do not pass to the sinu-auricular node; perhaps they may pass to the A.-V. node. The left nerve has been said to act directly on the ventricles; it is probable, however, that the vagus nerves only manifest their action indirectly through action upon the auricle (Figs. 44 and 80). We need not suppose different kinds of nerve endings; it is probable that the different results are obtained through varying intensity of stimulation action upon the same endings. After vagal arrest, the heart beats more forcibly, owing, perhaps, to the greater accumulation of contractile material during the period of rest.

The converse of all these effects occurs on stimulation of the accelerator nerves (Figs. 78 and 79). During stimulation of these

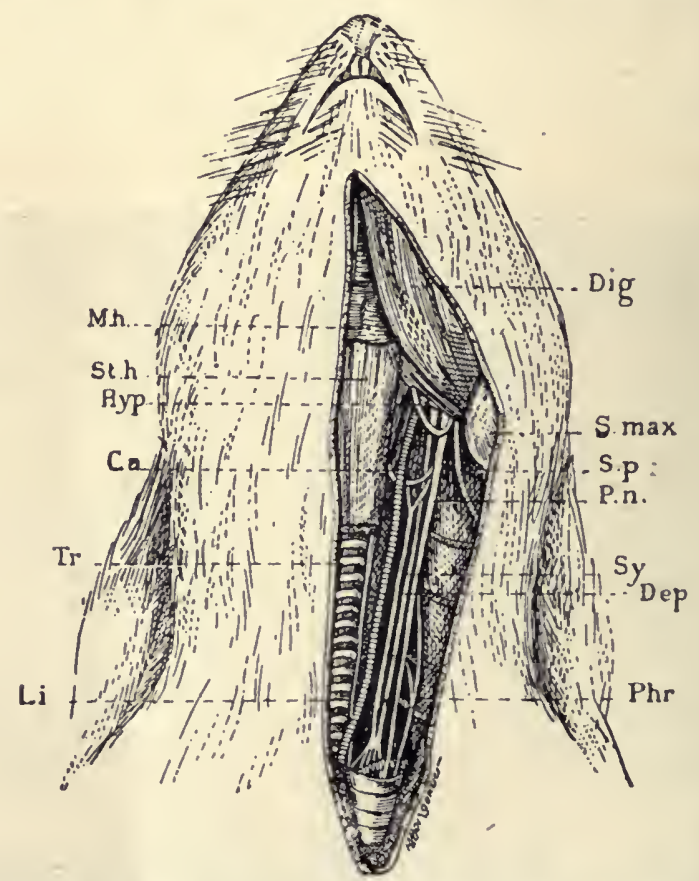

Fig. 82.-Dissection of the Vagus, the Depressor, and Cervical Srmpathetic Nerves in the Rabitt. (Cyon.)

nerves the heart beats more quickly and forcibly, excitability and conductivity being also increased. Excitation of these nerves may excite to renewed efforts an excised heart which has just ceased to beat owing to a withdrawal of the supply of nutritive solution; hence it is thought by some that the accelerator nerves tonically exert a sustaining influence on the heart. The accelerator nerves act directly upon both auricl s and ventricles (Figs. 79 and 80 ).

The alkaloid atropine paralyzes the vagal nerve endings in the heart, while nicotine paralyzes the endings of the preganglionic fibres in the 
ganglion cells. In a frog, these differences can be easily shown. Stimulation of the sinu-auricular groove will produce an action both before and after the application of nicotine, but not after atropine. Both drugs prevent the effect of stimulating the vagus. In mammals, a local application of the drugs to the sinu-auricular node abolishes the inhibitory action of the vagus. Muscarin, obtained from poisonous fungi, slows and finally arrests the heart probably by acting upon the vagus nerve endings; atropine antagonizes this action (Fig. 81).

A great many of the cardiac vagal fibres convey impulses to the spinal bulb (centripetal), and reflexly influence the heart-frequency, the breathing, and the tonus of the bloodvessels. In particular, certain fibres, termed depressor, cause dilatation of the arterioles, and a fall of arterial pressure, by inhibiting the tonic action of the vasomotor centre in the spinal bulb. The depressor fibres arise from the root of the aorta, and overdistension of this part excites them, as

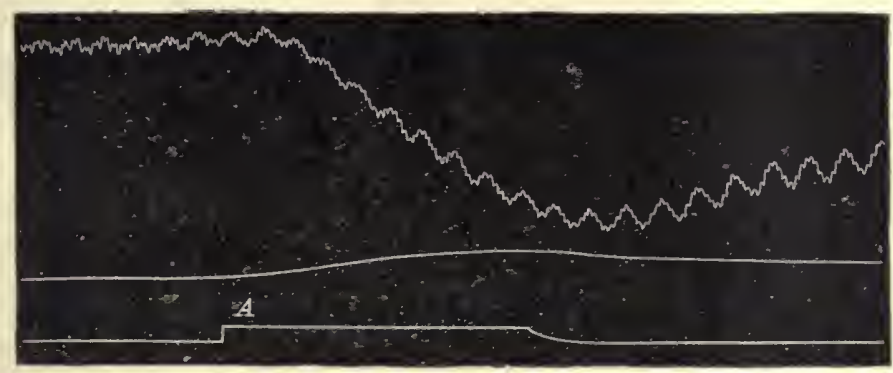

Fig. 83.-Aortic Pressure. Excitation of Depressor. (Bayliss.)

The drum was stopped in the middle of the eurve, and the excitation maintained for seventeen minutes.

evidenced not only by the above effect, but also by the electrical variation (action current) which has been observed passing up the depressor nerve. In some animals, such as the rabbit, it is found in the neck as a slender nerve running close to the sympathetic. It can be recognized in the rabbit by the fact that it joins the vagus and its superior laryngeal branch, dividing into two shortly before its junction with these (sce Fig. 82). Stimulation of its peripheral end has no effect.

The fall of blood-pressure (Fig. 83) induced by excitation of the depressor results chiefly from vaso-dilatation in the splanchnic area. After section of the splanchnics, this fall of blood-pressure naturally is not marked. Its action is increased by the secretion of the thyroid gland, induced by stimulation of the superior laryngeal nerves, or by the injection of thyroid extract.

In the vagus nerve there are also sensory fibres which when excited cause reflexly through the vasomotor centre a rise of pressure (Fig. 84). 
Sensory impressions originating in the heart do not as a rule enter into consciousness. Carried by the cardiac nerves to the sympathetic. ganglia, and thence to the upper thoracic region of the spinal cord, they come into rclation there with the sensory nerves from the pectoral region, upper limb, shoulder, neck, and head. The impressions are not felt in the heart, but referred to these sensory cutaneous nerves (Fig. 38i). Thus, cardiac pain is felt in the chest wall and upper limbs, and particularly on the left side. The function of the cardiac nerves is to

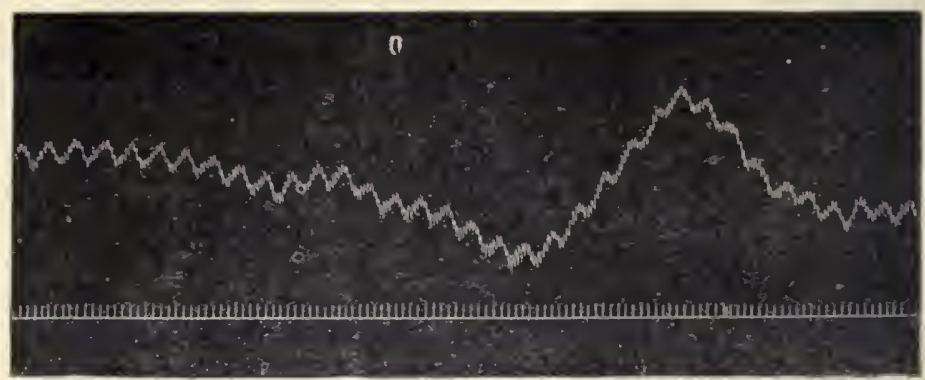

Fig. 84.-Aortic Blood-Pressure. (L. H.)

$A$, Effect of exciting the central end of vagus. The effect was depressor. $B$, On shifting up the electrodes to a fresh unexposed part of the nerve the effect changed to pressor. The time is marked in seconds.

co-ordinate the beat of the heart with the needs of the body, and to co-ordinatc the functions of other organs with the needs of the heart. For example, an undue rise of arterial pressure, induced, let us say, by compression of the abdomen, excites the centre of the vagus, and produces slowing of the heart and a consequent lowering of arterial pressure. The heart of a mammal continues to functionate after a section of all the branches of the cardiac plexus has been made, so that the nervous control and co-ordination of the heart are not absolutely esscntial to the continuance of life. 


\section{CHAPTER XX}

\section{THE PHYSICAL FACTORS OF THE CIRCULATION}

Sove of the physical laws which govern the circulation may be illustrated by means of schemata made of rigid cylindrical tubes.

Flow of Fluid in Cylindrical Tubes. - In a cylindrical tube, the fluid particles, flowing under constant pressure, move parallel with the axis, but with varying velocity. In the axial layer the velocity is at its greatest; at the wall it is almost nil. The wall is wet with the fluid, and there is friction between the moving particłes of fluid. The fluid may be considered as consisting of an infinite number of concentric cylindrical surfaces, which glide over one another, and move the more rapidly the smaller their radius. The velocity, which is reckoned from the outflow per second per sectional area of the tube, yields us the mean velocity of all these cylinders of fluid. Poiseuille has laid down the law that the mean velocity is directly proportional to the sectional area of the tube and pressure gradient. We can find the mean velocity by the product of three factors-sectional area, pressure gradient, and a constant coefficient, which depends on the viscosity or physico-ehemical nature of the fluid in the conditions of experiment. This coefficient can be defined as that mean velocity which a current would have with a unit pressure gradient in a tube of unit sectional area.

The coefficient at one and the same temperature varies for different fluids, and is found to be smaller in proportion to the viscosity of the fluid.

The viscosity of blood is found to be thrce and a half to five times that of distilled water. A mixture of blood and water is less viscous than blood. Thus, the velocity of the circulation is increased by the injection of Ringer's solution. The viscosity of the blood is increased when there is great loss of water-e.g., in cholera. Alterations in viscosity can be compensated for by the vaso-motor system, which regulates the peripheral resistance, and are therefore of minor importance.

By experiments upon the flow of distilled water in capillary glass tubes, 0.65 to 0.15 millimetre in diameter, Poiseuille reached the following conclusions:

1. That the amount of outflow is proportional to the head of pressure.

2. That the time spent in the outflow of a ccrtain volume of fluid 
at a constant pressure, if the diameter be constant, is directly proportional to the length of the tube.

3. That with the same head of pressure the time spent in the outflow of a certain volume of fluid through equally long tubes is inversely proportional to the fourth power of the diameter.

The Flow in a Tube of Varying Diameter.-Since fluid is incompressible, an equal amount must flow in the unit of time through every section of the tubc, and thus the velocity in any part of a tube which varies in diameter stands in inverse proportion to the sectional area. In such a tube the pressure gradient is steepest in the narrowest section, for there the velocity and the friction is greatest. In two sections of equal diameter the pressure gradient is the same. Where a wide section follows upon a narrower, the lateral pressure may either

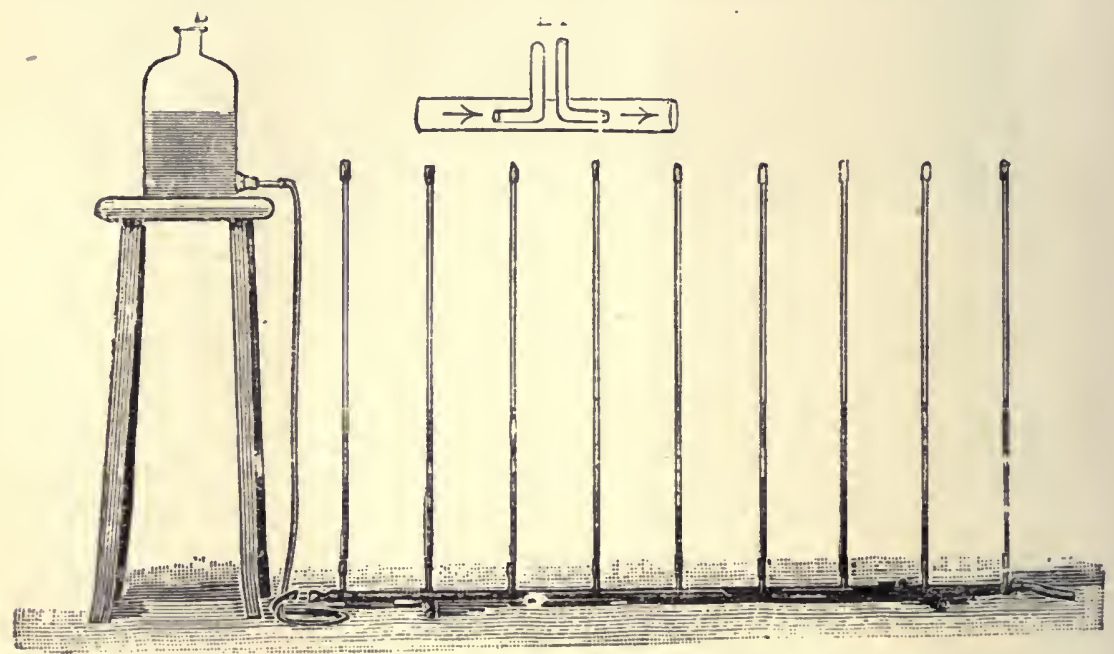

Fia. 85. - Schema to show the Velocity and Resistance Heads.

$B$, Pressure bottle; $A$, tube with piezometers; $E F$, Pitot tubes.

sink, remain unaltered, or even risc. How this can be so is seen by the following considerations: At any point of the tube the wholc pressure head $(\mathrm{H})$ equals the sum of the velocity head $\left(h^{1}\right)$ and the resistance head $\left(h^{2}\right)$. Now $H$ decreases uniformly along the tube, and since, where the tube widens, the velocity becomes less, and $\mathrm{H}^{1}$ suddenly diminishes, it follows that $h^{2}$ increases, and it is conceivable that $h^{1}$ in the wide section may become higher than $h^{2}$ in the narrow section. In other words, since more of $\mathrm{H}$ is spent in maintaining the velocity in the narrow section, the lateral pressure may be lower here than in the succeeding wide section.

The Flow in Branching Tubes.-When a tube branches into a number of smaller branches, and these connect again into one tube, we have two opposing factors to consider: 
1. The inerease of sectional area. The veloeity is inversely proportional to the whole seetional area of the branehes.

2. The inerease of resistanee, due to the great extent of surfaee contaet between the moving fluid and the fluid that wets the walls of the tubes. The resistanee is proportional to the surfaee area, nearly proportional to the square of the velocity, and inversely proportional to the seetional area. The formula used by engineers for what they eall "skin fraetion" is $\mathrm{R}=k \mathrm{~S} v^{2}$, where $\mathrm{R}=$ resistance; $k$, a eonstant; $\mathrm{S}$, surfaee area; $v$, veloeity.

If water flows from a head of pressure through a tube on whieh stand a number of vertieal side tubes, it is found that, aeeording to

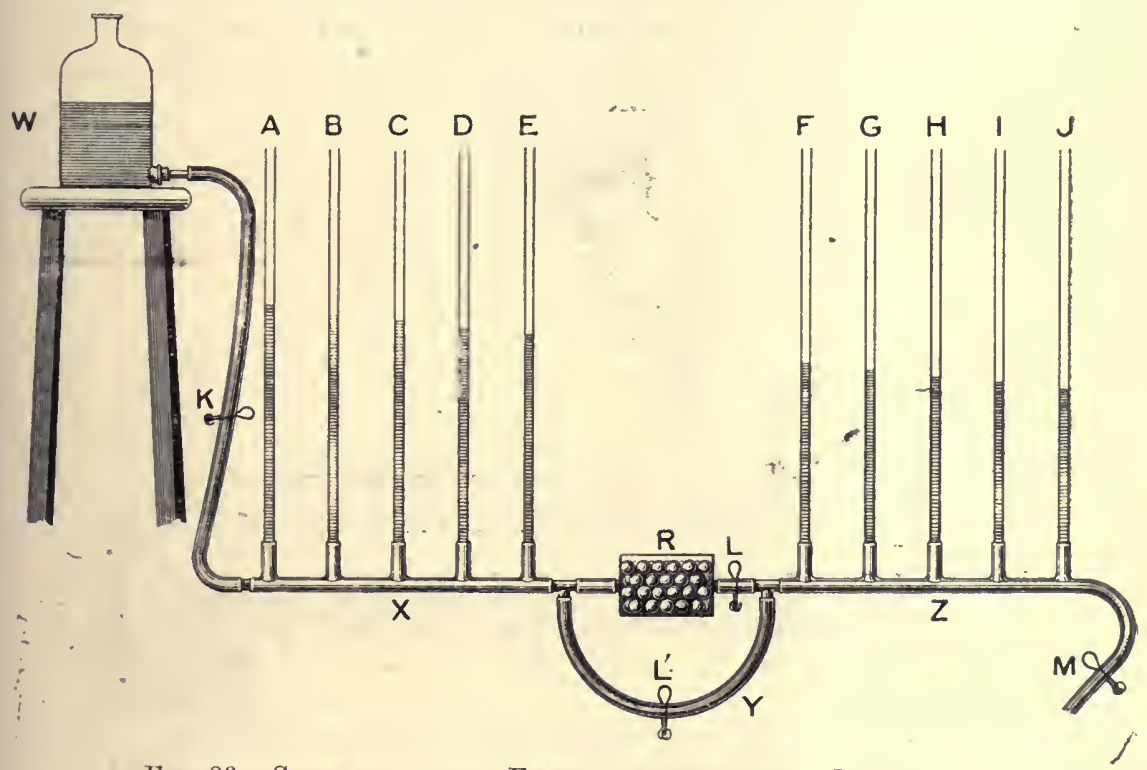

Fig. 86.-Schema to show Effect of introducing Resistance.

the degree that the outflow from the tube is obstructed, so will the water rise in the side tubes; the nearer the side tube to the head of pressure, the higher the fluid rises in it (Fig. 86).

This is beeause water flowing through a tube from a constant head of pressure eneounters a resistanee oecasioned by the friction of the moving water particles against each other and against the stationary layer that wets the wall of the tube. Part of the potential energy of the head of pressure is spent in endowing the fluid with kinetie energy, part in overeoming this resistanee. The latter and greater part is rubbed down into heat. The narrower the tube is made, the grcater the frietion, until finally the flow ecases, the total energy being then insuffieient to overeome the resistanee.

This is well exemplified by the modificd sehema (Fig. 86). $W$ is a bottle containing eoloured water eonneeted to the rigid tube $X$, on whieh 
stand the vertical side tubes $A$ to $E . \quad R$ is a resistance introduced by means of a wide tube filled with small glass marbles. $Y$ is a rubber tube of equal calibre to $X$ leading to the rigid tube $Z$, similar to $X$. The amount of fluid flowing to the tube can be regulated by the clamp $K$. Further, the fluid can flow from the tube $X$ to the tube $Z$ either by $Y$ when the clamp $L$ is shut and clamp $L^{1}$ open, or by the tube $R$ when the clamp $L^{1}$ is shut and clamp $L$ is open.

When there is a free flow from $W$ ( $K$ open), and free communication by $Y$ from $X$ to $Z$ ( $L$ closed, $L^{1}$ open), it will be seen, according to the resistance introduced by clamp $M$, the coloured fluid rises in all the side tubes to a nearly equal extent; gradually decreasing from $A$ to $J$. When the clamp $L^{1}$ is slightly closed, the fluid rises higher in tubes $A$ to $E$ than before, and falls in tubes $F$ to $J$. The same thing is seen if the fluid, instead of passing by $Y$, is sent through $R$, which better exemplifies the circulation.

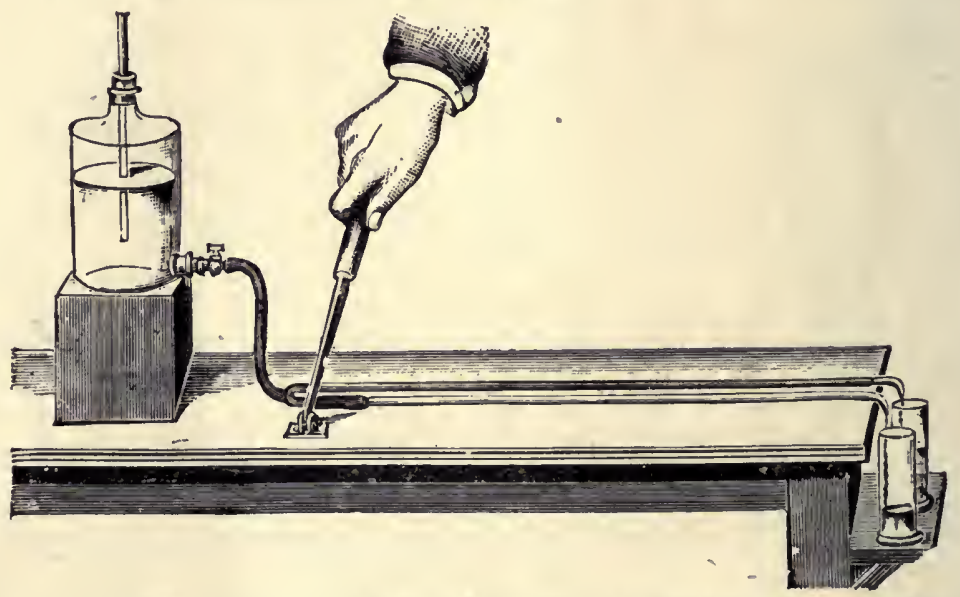

Fig: 87.-Schema to show the Flow in Rigid and Elastic Tubes. (Marey.)

The compressor should compress the single tube not the double tube, as figured.

In this schema the flow has been through rigid tubes. The same laws which have been discussed in connection with rigid tubes obtain in elastic tubes if the flow of fluid be continuous.

If the inflow be intermittent, in the case of the rigid tube, the whole column of fluid is driven on, step by step, by each stroke of the pump, and the outflow is intermittent. In an elastic tube, on the other hand, if the resistance to the output has been made great, as by constricting the orifice, the elastic wall of the tube is extended by the input of the pump, and the elasticity of the wall comes into play, and continues the output after the stroke of the pump has ceased, so that the flow becomes continuous.

This is shown by the schema (Fig. 87). Here the coloured water flows from a head of pressure through two tubes 1 metre long, and of the same bore; but one tube is rigid, the other elastic. The outflow orifices are also of the same size. 
On rhythmically shutting and opening the compressor, it will be found that the outflow from the elastic tube is continuous, from the rigid it is intermittent. The increased and continuous flow is due to the potential cnergy stored up in the stretched wall of the elastic tube. "The elastis tube also delivers more fluid per minute than the former.

In the circulatory system we are concerned with a system of elastic tubes. The conditions appertaining in the circulation can best be represented, therefore, by a schema having elastic tubes, such as Fig. 88.

Here $H$, the bulb of a Higginson syringe, represents the head of pressure-the heart. .Two valves, representing the mitral and aortic valves, regulate the flow in one direction only. Coming away from the syringe is a rubber tube (about $\frac{1}{4}$ inch diameter), which divides into two channels the arteries, leading (1) to two lamp glasses filled

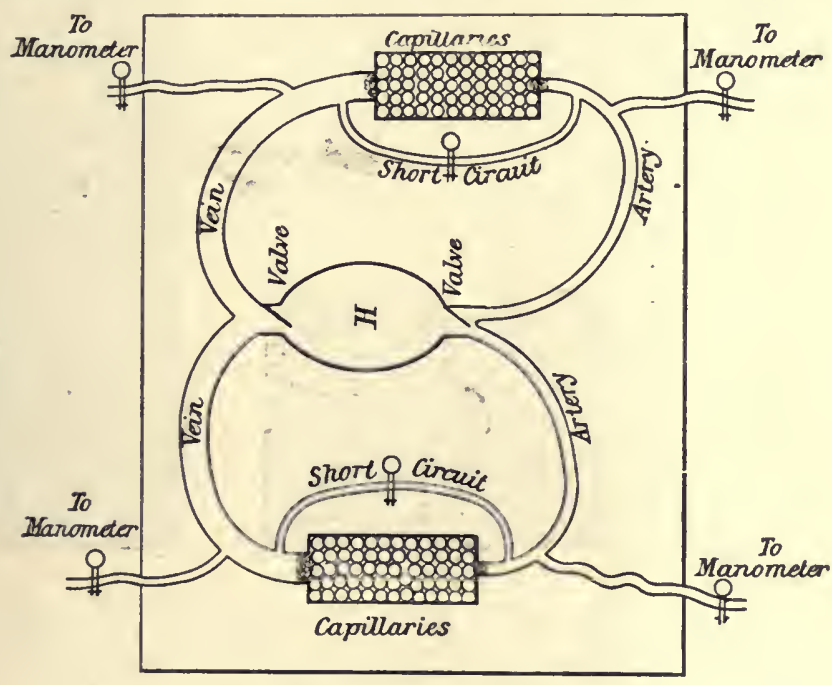

Fig. 88.-Artificial Schena.

with chopped rubber sponge (the capillaries), and (2) to a rubber tube shut with a clamp (the short circuit). This clamp represents the muscle wall of the arterioles. These are connected with the inner tube of a bicycle tyre, representing the capacious venous system, and this in turn to the Higginson syringe again.

Inserted in the eircuit are manometers eonneeted by $T$-pieces to the artery and to the vein. The whole system is filled with water, air being removed by tilting the board to which the schema is fixed and working the pump, but only so far that the vein is not distended, and there is no positive pressure in the system when at rest. When the screw clip (the arterioles) is widely open, there is little resistance to flow. The outflow from the artery into the vein then ceases during diastole, the conditions being the same as if the artery were a rigid tube. "The variations of pressure are great both in artery and veins, and both 
manometcrs are affeeted to almost a like extent. On serewing up the elip (inereasing the resistanee in the arterioles), the flow beeomes. less and less intermittent as the resistanee inereases, and eventually beeomes eontinuous. The pressure rises in the arteries, the systolic and diastolie variations in pressure beeoming greatly redueed. The variations in pressure disappear from the veins. This represents what takes place in the vaseular system.

The E'asticity of Arteries. - An artery possesses great lability, that is, it is easily distended; it has great elastieity, reeovering its shape after the distending foree is removed. The eurves of extensibility and elastieity may be worked out on excised arteries either by weighing and unweighing a strip of vessel wall, or by reeording the expansion of a short length of artery when submitted to a pressure of water. Sueh eurres vary aeeording as the artery is relaxed or eontraeted. The musele in its well alters the lability by its eontraetion or relaxation (Figs. 89, 80).

The breaking strain of a healthy artery is very great. In some experiments the earot'd of a goat sreecssfully withstood a pressure of 2,250 $\mathrm{mm}$. $\mathrm{Hg}$-that ir, about fourteen Fig. 89.-Eiongation of Contimes the normal tracted ARTERY, With Rise blood-pressure. It of Internal Pressure 0 to takes an internal 300 MM. HG). LE Г (T H pressure of 3,000

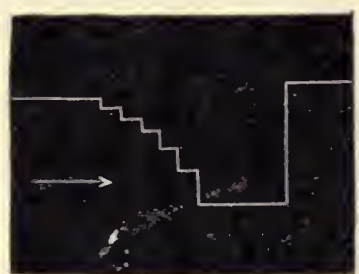
$=16$.Mr. (MacWilliam.)

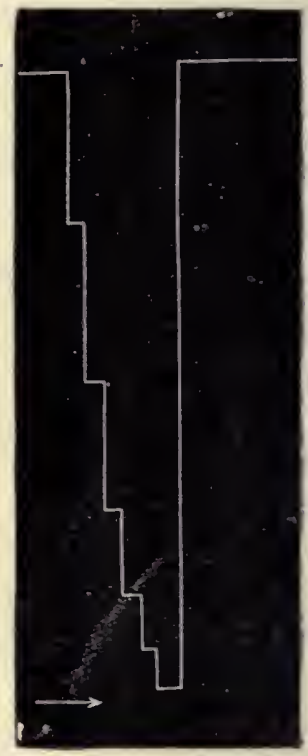

Fig. 90.-Elongation OF RELAXED ARTERY, WITH RISE OF INTERNAL. PRESSURE. LENGTH 21 Mr. (MacWilliam.) to $8,500 \mathrm{~mm}$. $\mathrm{Hg}$ to rupture the earotid artery of a dog. In the ease of the human earotid the sinallest rupturing pressure was found to be $1,290 \mathrm{~mm}$. Hg. The larger arteries rupture more easily than the smaller, and thus the aorta. breaks asunder at a lower tension than the radial.

In the vaseular system; an area of vessels of eapillary size is plaeed between the large arteries and veins. This area opposes a great resistance to flow. The effeet of the peripheral resistanee, as it is called, is to raise the pressure on the arterial side and lower it on the venous. The resistanee to flow is situated ehiefly, not in the eapillaries, but in the small arteries, where the veloeity is high. "Skin friction"-that is, the frietion of the moving eoneentrie layers of blood against one another and against the layer whieh wets the wall of these bloodvessels - is proportional to the surfaee area and to the viscosity of the blood; is nearly proportional to the square of the 
veloeity of flow; and is inversely proportional to the seetional area of the vessels. Owing to the resistanee to the eapillary outflow, the large arteries are expanded by each systolie output of the heart, and the elastieity of their walls eomes into play, causing the outflow to continue during the sueeeeding diastole of the heart. The eonditions are sueh that the intermittent flow from the heart is eonverted into a continuous flow through the eapillaries. If the arteries were rigid tubes, it would be necessary for the heart to foree on the whole eolumn of blood at one and the same time; but, owing to the elasticity of these vesscls, the heart is saved from sueh a prolonged and jarring strain, and ean pass into diastolie rest, leaving the elastieity of the distended arteries to maintain the flow. Besides the saving of heart-strain, there is the advantage of a greater outflow through elastie than through rigid tubes. As a result of disease, the elastie tissue may degenerate and the arteries beeome more rigid.

The four ehief factors which eo-operate in produeing the eonditions of pressure and veloeity in the vascular system are-

(1) The heart-beat;

(2) The peripheral resistanee;

(3) The elasticity of the arteries;

(4) The quantity of blood in the system.

Suppose the body to be in a horizontal position, and the vaseular system to be brought to rest by, say, arrest of the heart. A suffieieney of blood to distend it eolleets within the venous eistern. The arterial system, owing to its elastieity and eontraetility, empties. If the heart now begin to beat, blood is taken from the venous system, and is driven into the arterial system. The arteries reeeive more blood than escapes through the eapillary vessels, and the arterial side of the system beeomes filled until equilibrium is reaehed, when as mueh blood escapes from the arterial into the venous side per unit of time as is delivered into it by the heart. The flow in the eapillaries and veins now becomes a constant one, and if the side-pressure be measured, it will be found to fall from the arteries to the capillaries, and from the eapillaries to the venæ eavæ. In the large arteries. there is a large side-pressure whieh rises and falls with the pulses of the heart. The pulse-waves spread out over a wider and wider area as the arteries braneh. They finally die away in the arterioles. An inerease or deerease in the energy of the heart-beat will inerease or deerease respeetively the velocity of flow and pressure of the blood. An increase or deerease in the total width of the arterioles. respectively will lessen or raise the resistanee, inerease or decrease the veloeity, lower or raise the blood-pressure. A loss of blood, other eonditions remaining the same, would eause a deerease in pressure and veloeity. As a matter of fact, even a eonsiderable loss is compensated for by the adjustability of the vaseular system. Tissue lymph passes from the tissues into the blood, and the bloodvessels of the limbs and abdomen constriet, and thus the pressure is kept up, and an effieient eireulation maintained through the brain, lungs, and eoronary vessels of the heart. 


\section{CHAPTER XXI}

\section{THE ARTERIAL PRESSURE}

THE term "blood-pressure" is somewhat loosely used. Gencrally, it signifies the arterial pressure, but it can be equally well applied to the pressure of blood in the capillaries or in the veins. For the sake of accuracy, it is better to speak of the arterial blood-pressure or arterial pressure, the capillary pressure, and the venous pressure.

The Blood-Pressure.-It has long been known that the blood is under different pressure in the various parts of the system. From a divided artery the blood flows out in forcible spurts, from a vein it flows out continuously and with little force. It takes very little pressure of the fingers to blanch the capillaries of the skin or nail-bed, to stop the blood-flow in the superficial veins, but an appreciable amount of pressurc to obliterate the radial artery.

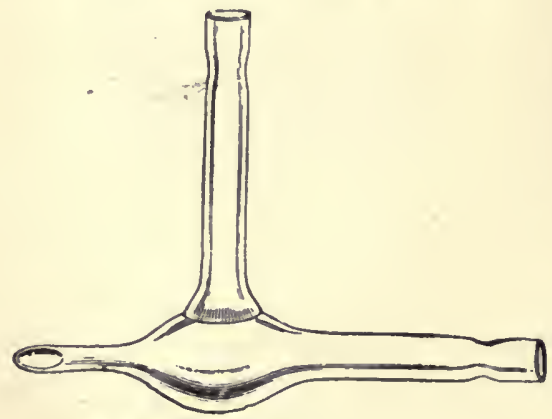

Fig. 91.-Arterial Cannula.

Measurement of Arterial Pressure.-Stephen Hales (1733) was the first to measure the blood-pressure. He fastened a long glass tube held vertically to the femoral artery of a horse, using a brass cannula and a goose's trachea as a flexible tube for making connection. $\mathrm{He}$ saw the arterial blood rise some 6 feet high in the tube, and oscillate there- with each pulse-beat and respiration.

Later the mercurial manometer was adapted to the same purpose. This consists of a $\mathrm{U}$-shaped tube containing mercury, which, being 13.5 times heavier than blood, allows the inanometer to be brought to a convenient height. On the top of the mersury rides a float provided with a writing style (see Fig. 92). The 
introduction of rubber tubing for the connections made the method of inquiry comparatively simple.

The method of procedure now usually employed is as follows:

The artery of an anæsthetized animal is exposed and ligatured. A clamp is pla:ed upon the artery nearer the heart, and the specialshaped cannula (Fig. 91) introduced between the ligaturc and the clamp. The cannula and tubing are filled with a suitable fluid,* to prevent coagulation, from a rescrvoir ( $R$, Fig. 92), raised to a height sufficient to introduce a pressure about equal to the anticipated arterial pressure of the animal. This prevents more than a trace of blood entering the connections.

The clamp is now removed from the artery, and the pressure is transmitted to the manometer, the style of which can be brought to

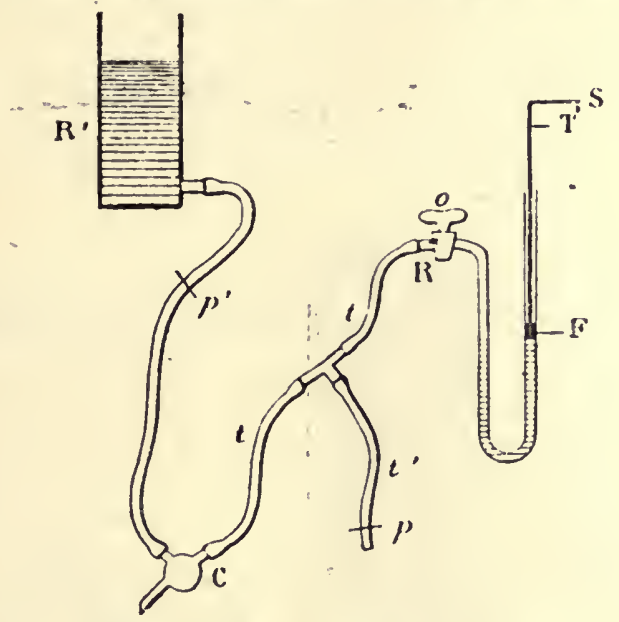

Fig. 92.-Arrangement of Cannula, Pressure Bottle, and 11 ercurial Manometer, for Recording Blood-Pressure.

$C$, Cannula; $p, p^{1}$, clips; $F$, float; $S$, writing style.

write on a drum covered with smo zed paper, and driven slowly round by clockwork or electric motor. By this means tracings of the arterial blood-pressure are obtained, and the influence upon the blood-pressure of various agents recorded and studied. For the veins, a manometer filled with salt solution is used, as mercury is too heavy a fluid to record the far slighter changes of venous pressure. The manometer may be connected with a recording tambour.

The arterial blood-pressure record obtained with the mercurial manometer exhibits cardiac and respiratory oscillations. The method gives us a fairly accurate record of the mean pressure, but the mass of the mercury causes such inertia that the instrument is quite

* Saturated magnesium sulphate may be employed for the dog and rabbit, but not for the cat. For this animal, saturated sodium sulphate should be used. A 10 per eent. sodium eitrate or 0.4 per cent. potassium oxalate solution may also be employed for all animals. 
unable to record faithfully the actual systolic and diastolic variations of pressure. To effect this record, delicate spring manometers of rapid action and small inertia have been invented (Fig. 93). The sphygmoscope consists of the finger of a rubber glove drawn loosely

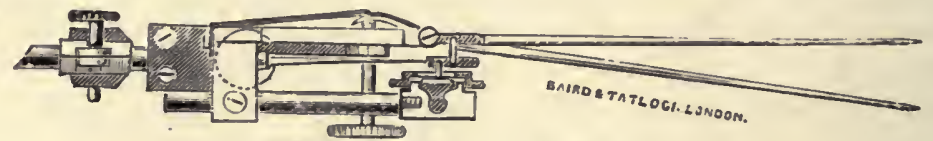

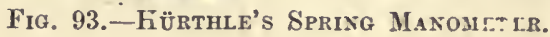

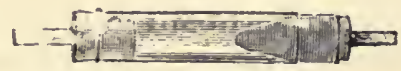

Fig. 84.-SPHygmoscope.

so as to leave an air-space over the end of a rubber cork and enclosed in a glass tube. The finger stall acts as a spring and the tube is connected with a recording tambour (Fig. 94). A mercury manometer

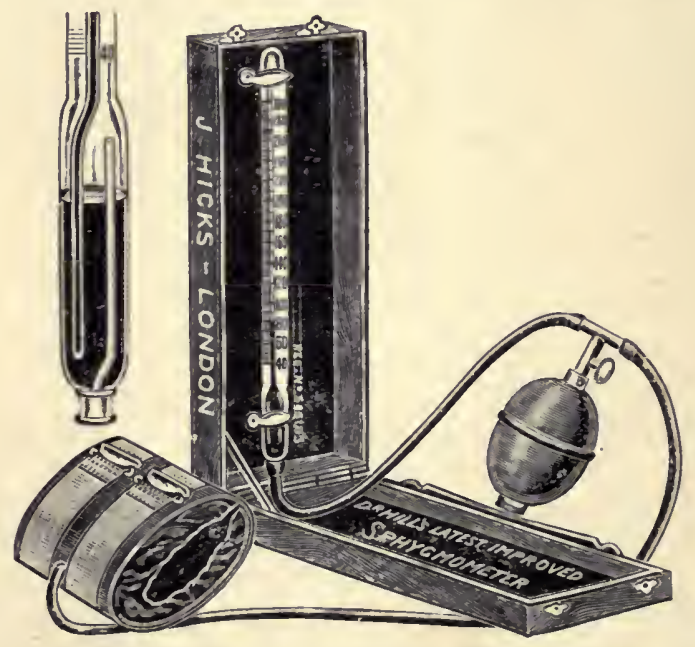

Fig. 95.-The Armlet Sphygmometer. (Leonard Hill.)

The arm is slipped through the armlet, and the latter fixed round the upper arm by drawing the straps tight. The armlet should be placed at the same level as the heart. The syringe bulb is then rhythmically compressed, while the radial pulse is felt. The height of the mercurial column is noted at which the pulse just fails to meet the wrist. The serew valve attached to the syringe bulb is opened, and the pressure allowed to fall gradually, a reading being taken at the moment when the pulsé again reaches the wrist.

provided with maximum and minimum valves has also been cmployed to indicate the maximal systolic and minimal diastolic pressure.

For determining the arterial pressure in man, the apparatus used is known as a "sphygmometer," or "sphygmomanometer." This con- 
sists of an armlet, a rubber bag eneased in soft leather, eonneeted by tubing and $\mathrm{T}$-pieee to a syringe bulb for raising the pressure, and a mereury manometer or spring gauge for registering the same (Fig. 95).

After the armlet is buekled on, the pressure is gradually raised in the armlet by means of the syringe. A reading is taken when the pulse in the artery is obliterated below the armlet (the systolic pressure). The disappearanee and reappearanee of the pulse may be felt with the fingers, or heard by plaeing a stethoseope over the artery at the elbow. When, as the pressure is relaxed, the pulse eomes through under the armlet, a loud sound is heard synehronous with eaeh systolie wave. As the pressure is further relaxed, the sound undergoes variation in tone, but at a eertain point suddenly diminishes or disappears. If the pressure be read at this point, it denotes the diastolie pressure. It has been proved by experiments on animals that the systolie and diastolie pressures, so measured, agree with measurements made direetly by eonneeting the artery with a spring manometer.

The poeket sphygmometer shown in Fig. 96 eonsists of a rubber

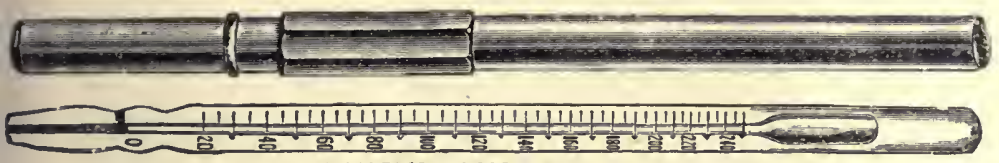

J.J.HICKS SOLE MAKER LONDON. PATENT.

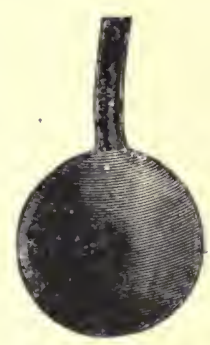

Fig. 96.-Leoxard Hill Pocket Sphygmometer.

bag eovered with silk, which is filled with air, and eonneeted by a short length of tube to a manometer. This manometer eonsists of a graduated glass tube open at one end. A small hole is in the side of the tube near this end. A meniseus of coloured \& lkaline water is introduced up, to the side hole-the zero mark on the seale-by plaeing the open end of the tube in water. The bag is now eonneeted to the gauge, so that the side kole is elosed by the rub!or tube. To take the arterial pressure the rubber bag is eovored with the hand, and pressed on the radial artery until the pulse (felt beyond) is obliterated, the height to which the meniseus rises in the manometer being read. This gives the systolie pressure in the artery. The air above the meniseus aets as a spring, eonverting the instrument into a spring manometer. It is graduated empirieally in millimetres of mereury.*

The systolie pressure of young men, taken in the radial artery with the arm at the same level as the heart, may be taken to be about 100 to $110 \mathrm{~mm}$. of $\mathrm{Hg}$. In men of forty to sixty years the systolic pressure is often about 140 millimetres, but in some robust men it is no higher than in youth.

It is very neeessary to remember that the blood-pressures, taken

* The graduation is at sea-level. A correction would be necessary for high altitudes. 
in different vessels and postures, vary with the hydrostatie pressure of the eolumn of blood which lies above the point of measurement. In the horizontal posture the pressure is praetieally the same in all the big arteries. In the standing position the arterial pressure in the
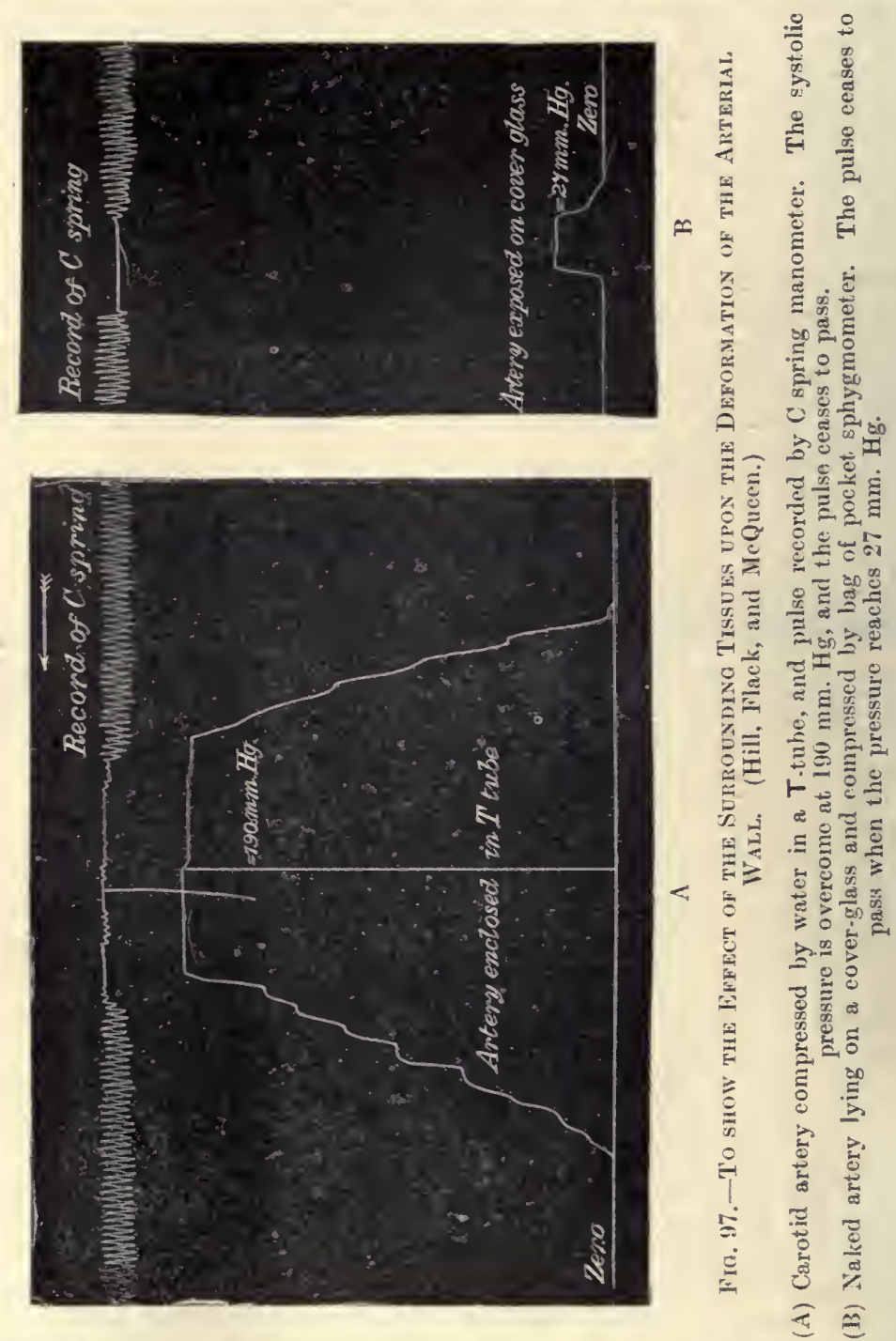

arterics of the leg is higher than in the arm by the hoight of the column of blood separating the two points of measurcment (see p. 200).

A difference between arm and leg pressurcs in the horizontal position can be brought about in the normal person by violent exercisc, for this increases the height of the systolic wave. The leg arteries, 
under the above conditions, are less labile, and conduct the big crest of the wave better than the arm arteries. There are other possible factors at work which cannot be discussed here. In cases of aortic regurgitation there is present a well marked and diagnostic difference of pressure between arm and leg in the horizontal position.

When the bag of the sphygmometer is applied to an artery (such as the dorsalis pedis) which lies upon bone unsupported by tissues, a far lower pressure $(30-35 \mathrm{~mm} . \mathrm{Hg})$ than that in the artery suffices to obliterate the pulse. Under these conditions, the artery is easily deformed from the round to the oval shape. This change in shape occasions an increased resistance to the passage of the pulse-wave, and the force of
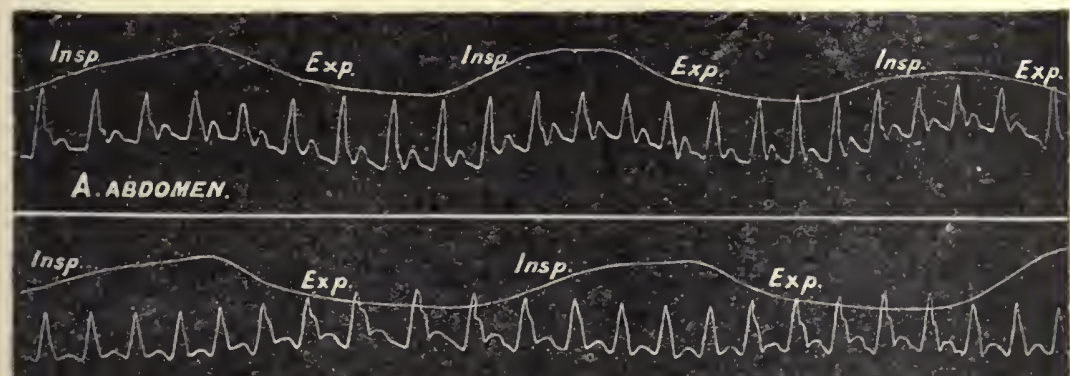

B. CHEST.

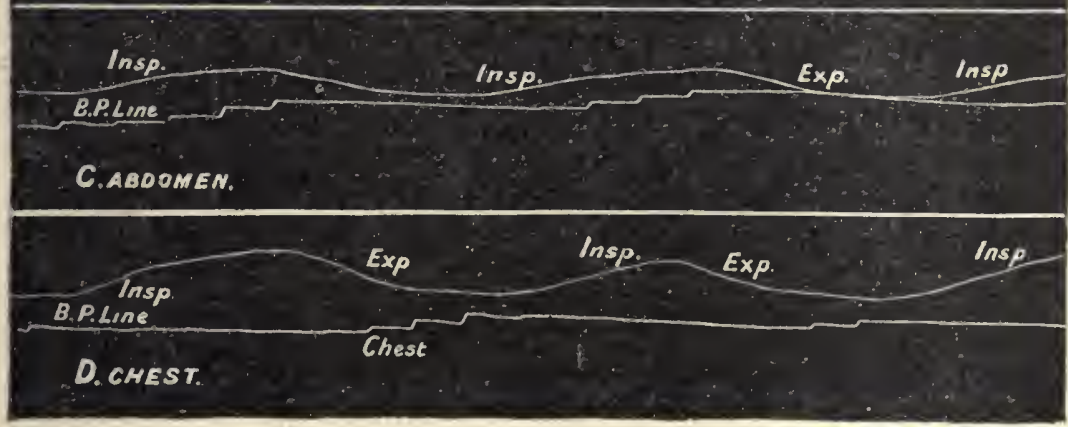

Fig. 98.-Influexce of Cilest and Abdonixal Breathixg on the Pulse. (Lewis.)

the pulse.in consequence becomes spent in the labile arterial system above the point of deformation. Where the artery is surrounded by tissues full of circulating blood, it cannot become deformed until the blood-pressure in the vessels of the surrounding tissues is overcome. The pressure of the bag first obliterates the veins; the pressure then rises in the capillaries and approximates to the arterial pressure as the compression is increased. Finally, the arterial pressure is overtopped, and then the compression comes to act upon the main artery, and this being deformed, the pulse ceases to come through. This is $c x-$ emplificd in Fig. 97. In A, with the artery lying in a tube surrounded by fluid, corrcsponding to the tissues, the prcssure required to demp 
down the pulse just overtopped the arterial pressure. When exposed on a watchglass, as in $\mathrm{B}$, the lumen became deformed and the pulse damped at a much lower pressure.

If the armlet be placed upon the arm, and kept at a pressure a little below that of the arterial supply to the arm, the limb gradually becomes congested and the superficial veins engorged with blood. Measurement of the pressure in these superficial veins reveals a pressure approximately equal to that registered by the manometer measuring the arterial pressure. The capillaries of the arm, under these conditions, become more and more congested; those that were previously empty gradually fill. An aching feeling comes on, which terminates the experiment. The experiment shows how many capillaries arc empty under normal conditions. In active life we are continually moving our position, so as to prevent continuous pressure on any part and further the circulation.

Circumstances affecting the Arterial Pressure.-The arterial pressure is raised during exertion by the more forcible beat of the hearte.g., pressures of 140 to $190 \mathrm{~mm}$. Hg have been observed immediately after running upstairs. It rapidly sinks to a lower level than usual after the exertion is over-e.g., $90 \mathrm{~mm}$. $\mathrm{Hg}$-owing to the quieter action of the heart and the persistence of the cutaneous dilatation of the bloodvessels which is evoked by the rise of body temperature. In athletes, after a long race, rectal temperatures of $102^{\circ}$ to $105^{\circ} \mathrm{F}$. have been observed. Mental occupation and excitement raises the arterial pressure. People engaged in brain work have in general a higher pressure than people engaged in purely manual labour working in the same atmospheric conditions. After meals there is a rise in pressure.

The ordinary statement that inspiration raises and expiration lowers the blood-pressure is only true for an animal under experimental conditions. The effect of respiration on the blood-pressure is very complex. A deep intercostal breath, if not too prolonged, yields a fall, a deep diaphragmatic inspiration, a rise, of pressure. Forced breathing causes a fall, while Valsalva's experiment, a deej, expiration with the mouth and nose shut, causes a marked rise in the arterial pressure. The effeets on the pressure of different types of breathing in a trained subjeet were as follows:

\begin{tabular}{|c|c|c|c|c|}
\hline Type of Ereathing. & Inspiration. & $\begin{array}{l}\text { Suspended } \\
\text { Inspiration. }\end{array}$ & Expiration. & $\begin{array}{l}\text { Suspended } \\
\text { Expiration. }\end{array}$ \\
\hline $\begin{array}{l}\text { Thoracic } \\
\text { Abdominal }\end{array}$ & $\bar{t}$ & \pm & \pm & $\overrightarrow{+}$ \\
\hline
\end{tabular}

Records of the pulse obtained by the suspension inethod (p. 211) show these results (Fig. 98). In such records a rise in the tracing indicates a rise of pressure, a fall in the tracing, a fall of pressure.

Increase in the amount of fluid by transfusion cannot raise the 
pressure above what can be obtained with a normal amount of blood. Similarly, bleeding to the extent of 2 to 3 per cent. of the body weight causes little or no fall of arterial pressure.

The taking of alcohol lowers the arterial pressure. During chloroform anæsthesia the pressure falls (Fig. 104). During deep sleep the pressure is lower, but not lower than in the waking state when the body is recumbent and at rest. Immersion in a hot bath lowers, in a cold bath raises, the pressure.

The arterial pressure is considerably higher in warm than in cold blooded animals - at least three times greater. The pressure is independent of the size of the animal, and thus may be as great in the cat as in the horse.

It will thus be seen that the maintenance of a mean arterial pressure of constant height is the function of the circulatory mechanism. On the one hand, we are convinced that this object is attained during life; on the other hand, we know that countless and ceaseless variations are occurring in all parts of the circulatory system. The whole system is, therefore, so craftily built and so delicately balanced that every variation in one part is compensated by a simultaneous and contrary variation in another part, and thus, throughout the wear and tcar of life, the aortic pressure is kept at a constant mean hcight. 


\section{CHAPTER XXII}

\section{THE EFFECT OF CHANGE OF POSTURE ON THE CIRCULATION}

THE eireulation is so eontrived that it remains eonstant and effieient, not only in the horizontal position, but also when the living animal is eeaselessly shifting the position of his body. The hydrostatie influenee of gravity must have had a most important bearing on the evolution of the meehanisms which eontrol the eireulation.

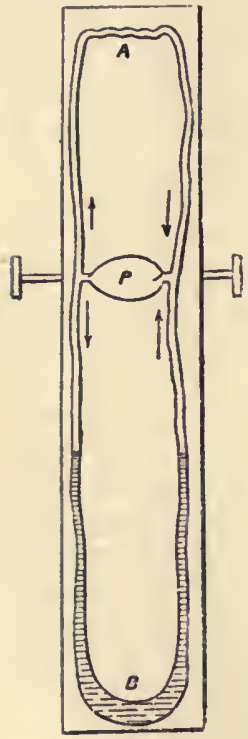

Fig. 99. - ARtifi. Cial Schema to SHOW EFFECT OF Gravity ox the Circulation.

This is well demonstrated by the following model :

Suppose a elosed and rigid tube filled with water and fixed to a board. When the board is placed in the horizontal position, the pressure in all parts of the tube will be the same. If the board be turned into the vertical position, then the pressure at the top end will beeome higher than the pressure at the bottom end by the height of the eolumn of fluid. The fluid will still equally pervade the tube in all its parts. This must be so, beeause the fluid is ineompressible, and the tube is rigid and unyielding in strueture.

If the rigid tube be now replaced by an elastie tube, and this at the points $A$ and $B$ be made to expand into thin-walled elastie bags, then the eonditions beeome markedly different (Fig. 99). On placing such a model in the vertieal position, the bag $(B)$ expands under atmospherie pressure plus the pressure of the eolumn of fluid $(A, B)$; and while the water flows into $B, A$ empties and shrinks under the atmospherie pressure.

If a pump, $P$, which ean work with uniformity and maintain a eonstant eireulation, be plaeed in sueh a model; if the outflow tubes or arteries be made of small eapaeity, and labile-that is, possessing considerable extensibility, and elastieity-and the inflow tubes or veins be valved, and be made of eonsiderable eapaeity and slight extensibility and elastieity; and if a sponge be inserted as a resistanee in the bags $(A$ and $B)$, then many of the eonditions of the systemie cireulation are closely represented in the model. $A$ is now equivalent to the eapillary area of the head, $B$ to the splanehnie area of eapillar.es.

When the model is placed in the vertieal position with the pump 
at work, owing to the great distensibility of the splanchnic capillaries and veins $(B)$, the fluid will collect in $B$, and $A$ will empty. But if $B$ is compressed by the hand so as to raise the fluid in the vcin up to the pump, then the circulation will recommence.

The blood, owing to its weight, continually presses downwards, and under the influence of gravity would sink if the veins and capillaries of the lower parts were sufficiently extensile to contain it. Such is actually the case in the snake or eel, for the heart empties so soon as one of these animals is immobilized in the vertical posture. This does not occur in an eel or snake immersed in water, for the hydrostatic pressure of the column of water outside balances that of the blood within. During the evolution of man there have been developed special mechanisms by which the determination of the blood to the lower parts is prevented, and the assumption of the erect posture rendered possible. The pericardium, by its attachments, prevents displacement of the heart as a whole, and also supports the right heart when the weight of a long column of venous blood suddenly bears upon it-as, for example, when a man stands on his head. The abdominal viscera are slung upwards to the spine; below they are supported by the pelvic basin and the wall of the abdomen, the muscles of which are arranged so as to act as a natural waistband. If tame hutch rabbits, with large patulous abdomens, be suspended and immobilized in the erect posture, death may result in from fifteen to thirty minutes, for the circulation through the brain ceases and the heart soon becomes emptied of blood. If, however, the capacious veins of the abdomen be confined by an abdominal bandage, no such result occurs.

In a nan 6 feet high the hydrostatic pressure of a column of blood reaching from the vertex of the head to the sole of the foot is equal to $140 \mathrm{~mm}$. Hg. But man is naturally provided with an efficient abdominal belt, although this is often weakencd by neglect of exercise and by gross indolent living. The splanchnic arterioles are maintained in tonic contraction by the vaso-motor centre, and thus the flow of blood to the abdominal viscera is confined within due limits. The veins of the limbs are broken into short segments by valves, and these support the weight of the blood in the erect posture. The brain is confined within the rig:d wall of the skull, and by this wall are the cerebral vessels supported and confined when the pressure is increased by the head-down posture. Every contraction of the skeletal muscles compresses the veins of the body and limbs, for these are confined beneath the taut and elastic skin. The pressure of the body against external objects has a like result. Guided by the valves of the veins, the blood is by such means continually driven upwards into the venæ cavæ. If the reader hangs one arm motionless until the veins at the back of the hand become congested, and then either elcvates the limb or forcibly clenches the fist, he will recognize the enormous influence which muscular exercise and continual change of posture has on the return of blood to the heart. It becomes wearisome and soon impossible for a man to stand motionless. When a 
man is crucified - that is to say, immobilized in the erect posturethe blood slowly sinks to the most dependent parts, œedema and thirst result, and finally death from cerebral anæmia ensues. In man, standing crect, the heart is situated above its chief reservoir-the abdominal veins. The blood is raised by the action of the respiratory movements, which act both as a suction and as a force pump; for the blood is not only aspirated into the right ventricle by the expansion
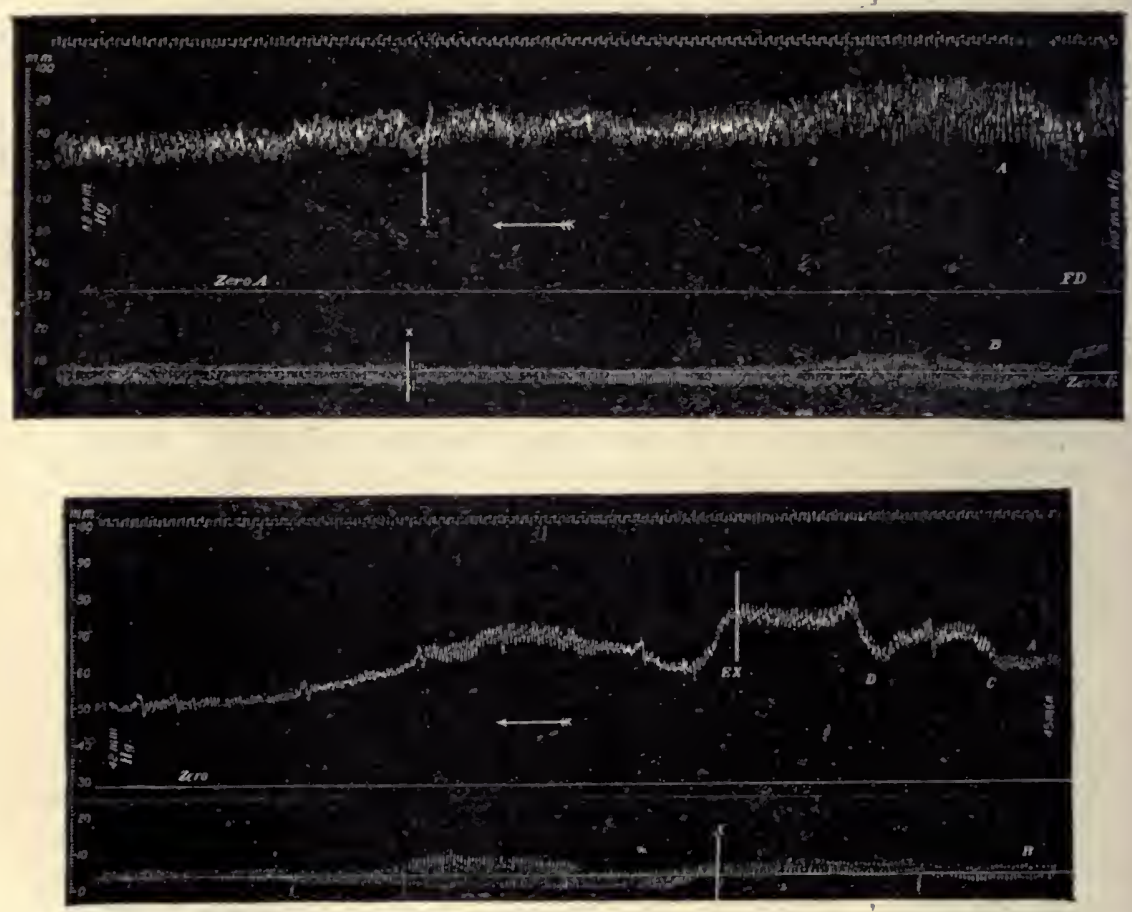

Fig. 100,-To show Effect of Gravity upon the Circulation: Carotid and Superior Vexa Cava Pressures of Dog. (I. H.)

$F D$, Animal turned into feet-down position with eannula in axis of rotation. The arterial pressure fell in fifty minutes from $110 \mathrm{~mm}$. $\mathrm{Hg}$ to $42 \mathrm{~mm}$. $\mathrm{Hg}$. From $C$ to $E X$ animal was immersed in a bath which was deepened to ehin at $D$. Noto increased effeet of respiration on venous pressure after $F D$, and again after bath. Note also fall of pressures at $F D$, and eompensatory rise of arterial pressure, which gradually weakens.

of the thoracic cavity, but is expressed from the abdomen by the descent of the diaphragm. When a man faints from fear, his nuscular system is relaxed and respiration inhibited. The blood, in conscquence, sinks into the abdomen, the face blanches, and the heart fails to fill. He is resuscitated either by compression of the abdomen or by being placed in a head-down posture. To prevent faintness and drive the blood-stream to his brain and museles, a soldier tightens 
his belt before entering into action. Similarly, men and women with lax abdominal wall and toneless muscles take refuge in the wearing of abdominal belts. To maintain a vigorous circulation and digestion, it is necessary to exercise the muscles daily, particularly those of the abdomen.

The question may be studied experimentally by passing cannulæe down the external jugular vein and earotid artery into respectively the superior vena cava and aorta of a dog, anæsthetized, and placed upon a specially constructed animal table, which is made to turn round an axis passing through the body at the level of the cannulæ. Upon turning the table, any alteration in the level of fluid in the manometer tubing is thus avoided. The effect of changes of posture are then truly recorded. On placing the animal in the feet-down posture, the arterial and venous pressures immediately fall. The venous pressure remains down until the horizontal posture is once more assumed. The arterial pressure rapidly rises again to normal

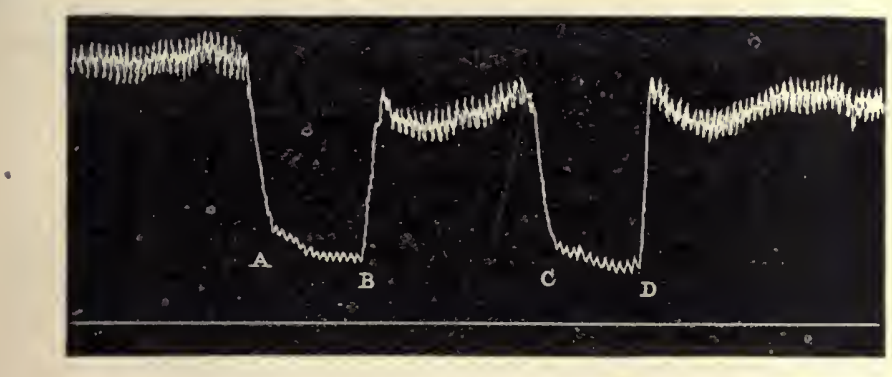

Fig. 101.-Aortic Pressure. (L. H.)

$A$, Vertical feet-down position ; $B, C$, effect of abdominal comrression; $D$, horizontal position.

$(F D$, Fig. 100), and often it may be found to rise above normal. "The respiratory undulations are frequently intensified while the animal is in the feet-down posture. If left long in the feet-down position, tho compensatory mechanism gradually fails and the arterial pressure falls (Fig. 100).

If the spinal cord be divided at the level of the first dorsal vertebra, the influence of the bulbar centres on the parts below the section is removed. Abdominal and intercostal respiration is paralyzed, and the breathing becomes purely diaphragmatic. The tone of the great splanchnic area of arterioles is lost, the tone of the abdominal wall is abolished, and thus the capacity of the abdominal vessels is greatly increased. The total effect on the animal, when lying in the horizontal posture, is a considcrable fall of arterial pressure, and a marked diminution of the respiratory undulations of pressure. If the animal be now dropperl into the vertical feet-down posture, the arterial pressure falls rapidly, and may reach zero; the circnlation is then at an end. This is so because the great abdominal veins sag ont under the hydrostatic pressure. In them the whole of the blood 
collects, for it can pass rapidly through the dilated arterioles; thereis no mechanism left for filling the heart. Thus the heart, cmpty of blood, continces to beat to no purpose. If the abdominal wall be compressed with the hand $(B, C$, Fig. 101), the capacity of theveins and splanchnic area is reduced, the right heart is once more filled with blood, the arterial pressure rises, and the circulation is renewed. On taking off the hand, the heart once more empties, the artcrial pressure falls, and the circulation ceases. When the animal is returned to the horizontal position, the influence of gravity is abolished, and the circulation inmediately becomes re-established. The effect of compression of the abdomen in the horizontal position is also evident $(B, C$, Fig. 102) but slight. In the feet-up position the aortic pressure rises under the influence of gravity, returning to normal if compensation takes place or when the horizontal position is resumed (Fig. 102). Such experiments prove that in thcanæsthetized animal there are two chief compensatory mechanisms by which the hydrostatic effect of gravity is overcome-namely, the vaso-motor mechanism of the arterioles and the respiratory rump.

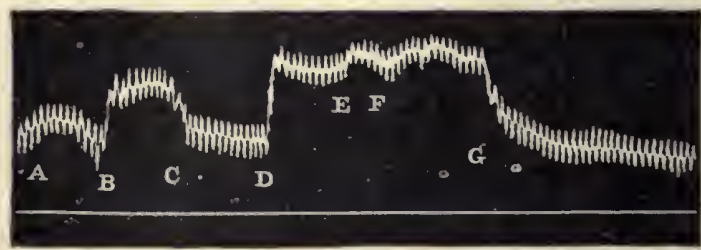

Fig. 102.-Aortio Pressure. (L. H.)

$A$, Horizontal position; $B, C$, abdomen compressed; $D$, rertical feet-up position ;

$E, F$, abdomen compressed; $G$, horizontal.

It is necessary to examine these scparatcly, and cstimate the relative power of each.

The vaso-motor tone of the great splanchnic area can be casily abolished, without affection of the respiratory mechanism, by section of the splanchnic nerves-that is to say, if these nerves are. reached by a lumbar incision, and all interference with the thorax or abdominal wall is avoided.

As the result of section of the splanchnic nerves in the vertical fectdown posture, the arterial pressure falls very considerably; but, neverthcless, the circulation may remain efficient, on account of the action of the respiratory pump. A form of respiration may be evoked which consists of thoracic inspiratory aspirations, combined with powerful abdominal compressions. Thercby the diastolic filling of the heart is maintained, and the relocity of flow through the splanchnic capillaries checked. On dividing, the abdominal wall by a crucial incision, the support of the abdominal muscles is withdrawn, the splanchnic ressels dilate, and the pressure falls to a further extent. Finally, on suddenly opening the thorax, the pressure falls to zero, 
and the circulation ceases (Fig. 103). By compression of the abdomen, or by a return to the horizontal posture, the circulation can be onse more renewed.

This experiment shows that the respiratory pump can compensate for the influence of gravity when the vaso-motor mechanism is paralyzed. The respiratory pump can be paralyzed by itself and without damage to the vaso-motor mechan sm by the inject:on of curari. The power of the heart mxy then be sufficient by itself to maintain the circulation in the feet-down position, so long as the capacity of the abdominal vessels is kept under control by the vasomotor nerves.

The effect on the circulation of rendering the intrathoracic pressure

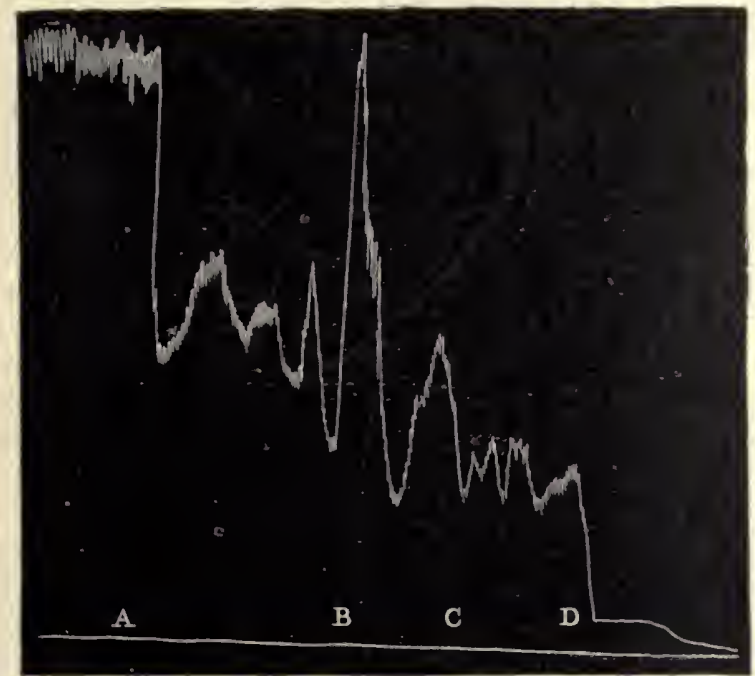

Fig. 103.-Aortic Pressure: Morphinized Dog. (I. H.)

$A$, Vertical feet-down position, splanchnic nerves divided; $B$, effect of compressing abdomen; $C$, abdominal wall divided; $D$, thorax opened.

positive-e.g., by compression of the thorax-is that the blood stagnates in the abdomen, and the circulation ceases, whenever, by any means, the thoracic pressure is rendered sufficiently positive to overcome the venous pressure produced by the driving power of the heart and the compressive action of the abdominal wall. Owing to the influence of gravity, this state of affairs is brought about more easily in the vertical feet-down position than in the horizontal posture. Compensation for the positive intrathoracic pressure is supplied by firm compression of the abdomen; the heart then fills, and the artcrial pressure regains its normal level.

Measurements of artcrial pressure likewise reveal the effect of gravity upon the circulation in man. In a normal man standing up- 
right the pressure in the post-tibial artery in the leg is higher than the pressure in the brachial artery by the height of the column of blood which reaches from one artery to the other, about $70 \mathrm{~mm}$. $\mathrm{Hg}$.

In the horizontal posture the pressures are the same. With the body in an $L$-shaped position, or in the head-down posture, there is also a difference in pressure between arm and lcg. These differences are well exemplified in the following figures. It will be noticed that it is the leg pressure which alters, not the brachial to any great extent:

\begin{tabular}{|c|c|c|c|c|c|c|}
\hline Posture. & & $\begin{array}{c}\text { Brachial } \\
\text { Artery, } \\
\text { Pressure in } \\
\text { Mm. IIg. }\end{array}$ & $\begin{array}{l}\text { Posterior } \\
\text { Tibial } \\
\text { Artery, } \\
\text { Pressure in } \\
\text { Mm. Hg. }\end{array}$ & $\begin{array}{c}\text { Difference } \\
\text { in } M m . H g .\end{array}$ & $\begin{array}{l}\text { Difference } \\
\text { calculated } \\
\text { fromHeight } \\
\text { of Column } \\
\text { in . Vm. Hg. }\end{array}$ & $\begin{array}{l}\text { Height of } \\
\text { Column } \\
\text { separating } \\
\text { Armlets, } \\
\text { in Cm. }\end{array}$ \\
\hline $\begin{array}{l}\text { Horizontal } \\
\text { Standing } \quad \text {. } \\
\text { L-posture, legs up } \\
\text { Vertical, head down }\end{array}$ & $\begin{array}{l}\ldots \\
\cdots \\
\cdots\end{array}$ & $\begin{array}{l}106 \\
110 \\
115 \\
115\end{array}$ & $\begin{array}{r}106 \\
165 \\
85 \\
50\end{array}$ & $\begin{array}{r}0 \\
55 \\
30 \\
65\end{array}$ & $\begin{array}{r}0 \\
58 \\
33 \\
63\end{array}$ & $\begin{array}{l}0 \\
75 \cdot 4 \\
44 \\
82\end{array}$ \\
\hline
\end{tabular}

In changes of posture, then, the pressure in the brachial arterythat is, in the root of the aorta-is maintained at practically a constant height by the tone of the splanchnie arterioles and action of the respiratory pump. If the splanchnic arterioles are in an efficient state of tone, and if the abdominal veins are supported by the tone of the abdominal wall, then the splanchnic vessels will not dilate unde: the hydrostatic stress of gravity. The nervous mechanism involved is probably of the simplest nature, for if the arterial pressure suddenly rise or fall at the moment of change in posture, the bulbar centres are thereby either directly or reflexly excited to increased or decreased activity. A sudden fall of arterial pressure. provokes acceleration of the heart, amplified respiration, and increased vasoconstriction. A sudden rise of pressure, on the other hand, provokes a slow heart, shallow respiration, and vaso-dilatation.

When the compensatory mechanism is abolished by destruction, exhaustion, or inhibition of the bulbar centres, the circulation fails, and becomes inadequate to maintain life in the vertical feet-down posture. The blood passes into the capacious reservoirs of the tone- less abdominal veins, the heart empties, and the cerebral circulation ceases. There can be no doubt that the control of this compensatory mechanism is one of the most important and necessary functions of the group of bulbar centres-a function which must have been evolved to its highest point as man in his evolution assumed the erect posture.

During the course of each day the compensatory mechanism becomes exhausted; especially is this so after severe muscular exertion. By sleep the compensatory power is restored. In conditions of neurasthenia; weakness and exhaustion after disease, shock after severe injury or hæmorrhage, this power may be almost entirely lost. In this connection we must bear in mind the supply of ad- 


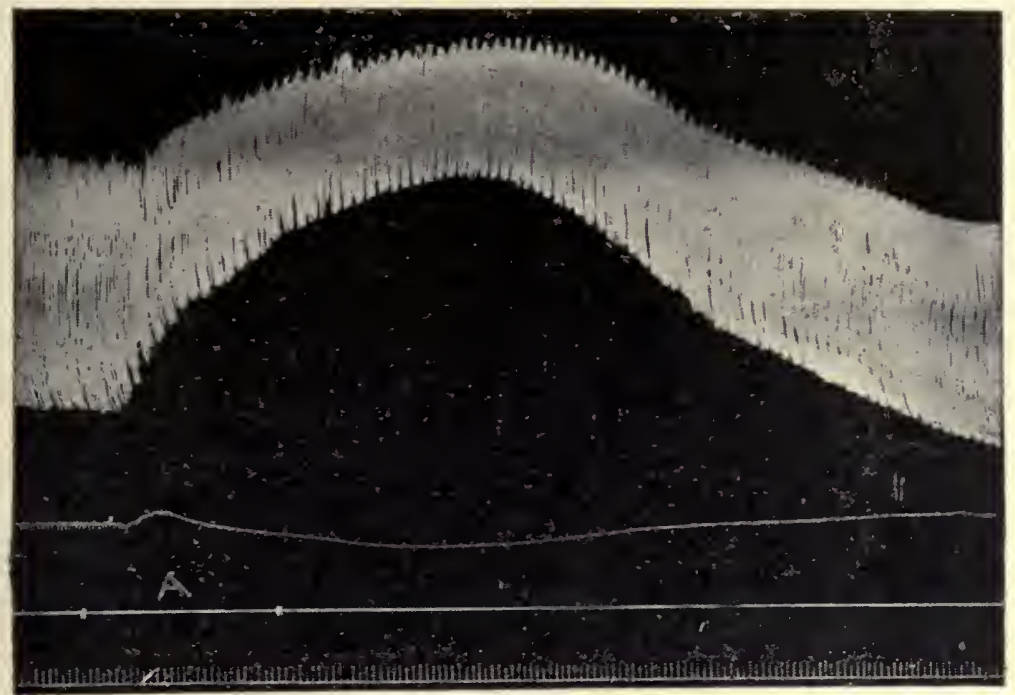

Fig. 104. -The Effect of Admisistration of Chloroform vpon the Heart Volume (Cardiometer) and Arterial Pressure of a Decerebrate Dog: True in Seconds. (Dixon.)

3 to 4 per cent. Chloroform administcred during period $A$. Systole (downstroke) becomes progressively weaker and cardiac tonus is diminished, so that the heart becomes distended with blood, only a small proportion of which is expelled during systole. The fall in blood-pressure is due to this effect; as the eardiac systole improves the blood-pressure rises.

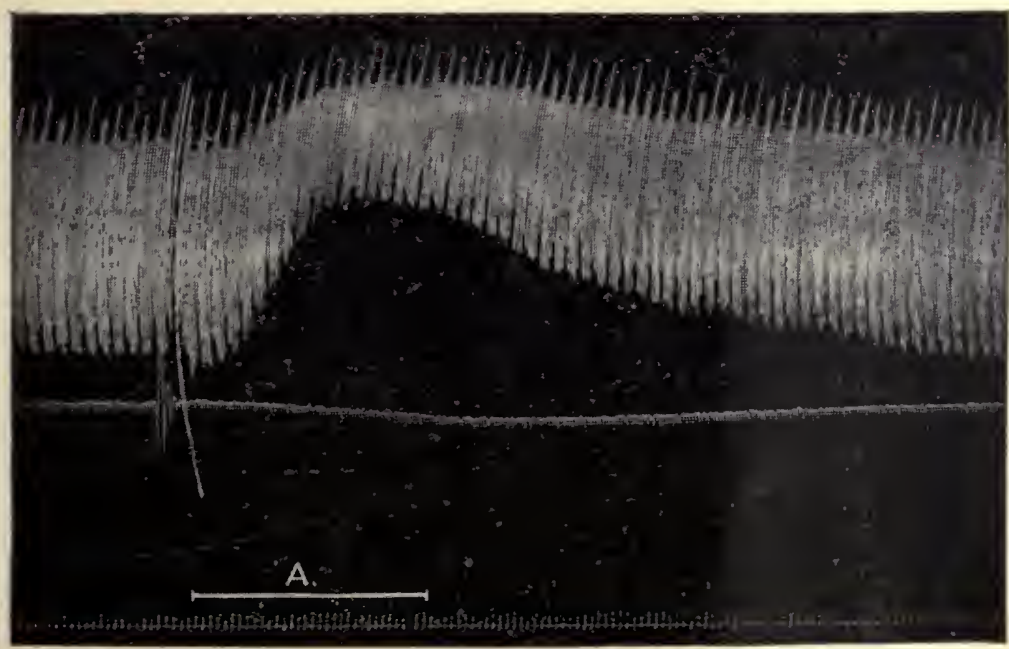

Fig. 105.- Same as Fig. 104, bur xearly Pure Ether admixistered. (Dixon.

Tlie systolic contractions are weakened, bet the effect is less serious than with chloroform, and the fall in blood-pressure less. 
renalin furnished by the adrenal glands. Adrenalin maintains the tone of the sympathetic system.

By sudden fright in the standing posture the respiration is often arrested, the vaso-motor tone inhibited, and syncope induced by the blood sinking into the abdomen. Recovery from syneope is brought about by the assumption of the horizontal position or compression of the belly. When the compensatory mechanism is entirely lost, the circulation is only possible in the recumbent position, and life is at its lowest ebb. Among the anæsthetics in common use, chloroform stands prepotent as a drug which has the power to abolish the compensatory mechanism. Chloroform causes cardiac dilatation (Fig. 104), weakens the respiration, and makes flaccid the abdominal muscles. The effects of ether are not so serious (Fig. 105).

A useful clinical guide to the condition of the compensatory mechanism in man is afforded not only by the pressure in the brachicl artery, but by the rate of the pulse on change of posture. If the hoart greatly accelerates on rising from the horizontal to the rertical position, the mechanism is deficient. 


\section{CHAPTER XXIII}

\section{THE VELOCITY OF BLOOD-FLOW}

THE velocity of the blood at any point in a vessel may be defined as the length of the column of blood flowing by that point in a second. In the case of a tube supplied by a constant head of pressure, we can divide the tube and measure the outflow per second; knowing the volume of this, and the cross area of the artery, we can detcrmine the length of the column. This kind of experiment cannot be done on the living animal, because the opening of the vessel alters the resistance to flow, and the loss of blood also changes the physiological conditions. To determine the velocity, other means must be devised. One form of instrument is called the "stromuhr" (stream-clock), (Fig. 106) consisting of two bulbs mounted on a rotating platform pierced with two holes. One bulb is filled with oil, the other with blood. The bulbs are connected together by a tube at their upper end, and the lower end of the one full of oil is brought over one hole in the rotating platform. The central end of the artery is connected to the same hole and the peripheral end to the other, over which stands the bulb full of blood. The blood, being allowed to flow, displaces the oil out of the one bulb into the other. Directly this happens, the bulbs are rotated, and the one full of oil is again brought over the central end

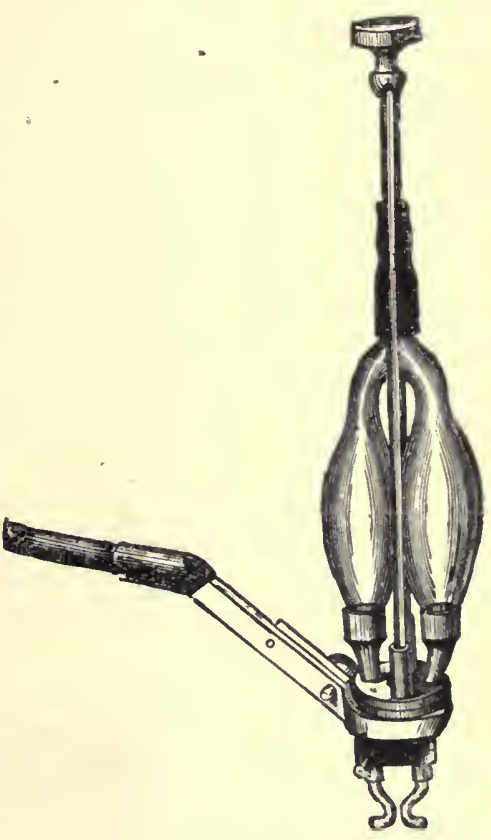

Fig. 106. - The Stronun.

of the artery. The number of rotations per minute is counted, and the volume of the bulb being known, we obtain the volume of blood that passes through the instrument per minutc.

An improved form of the instrument is seen in Fig. 107.

In using this instrument, the tube $\left(y_{1}\right)$ is placed in connection with the central end, and the tubc $\left(y_{2}\right)$ in connection with the 
peripheral end of the artery whieh is under investigation. The whole instrument is washed out with oil to prevent elotting, and filled with defibrinated blood. So soon as the blood is allowed to flow from the artery, the metal ball $(b)$ is driven over by the current till it reaehes the end of the eylinder $(a)$. The instrument is then rapidly rotated

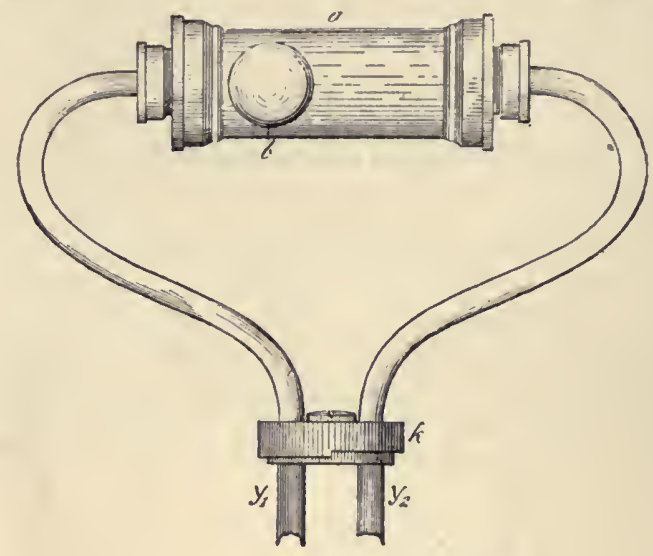

Fia. 107.-Stronuhr. (Tigerstedt.)

on the drum $(k)$, so that the position of the entering and exit tubes is reversed. The metal ball is now onee more driven by the current to the opposite end of the eylinder. This proeedure is repeated several times, and the number of revolutions during the period of observation is noted. The eapacity of the eylinder

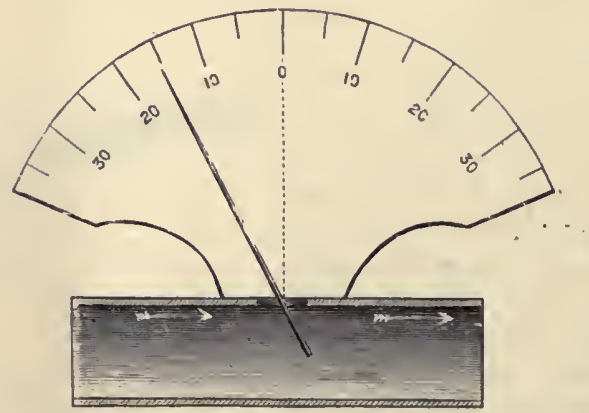

Fig. 108.-Chauveau's Hæmodromometer.

(a), minus the volume of the ball $(b)$, multiplied by the number of revolutions, gives the volume of blood whieh has passed during the period of observation; and this volume, divided by the time and the seetional area of the artery, gives the mean veloeity per seeond. In using the stromuhr, the mean veloeity in an artery is found to vary greatly. This, for the most part, is owing to the variations of resist- 
ance in the peripheral arterioles. During the operative procedure, the blood-flow must for a time be cut off, and this causes a temporary paralysis of the arterioles, which, passing off as the circulation is restored, causes variations in resistance.

In another instrument, the hæmodromometer (Fig. 108), a T-tube is inserted into the artery, in which hangs a small pendulum, the stem of the pendulum pasing through a rubber dam, which closes the vertical limb of the tube. The pendulum is deflected by the flow, and the greater the velocity, the greater the deflection. The deflection can be recorded by connecting the free end of the pendulum to a tambour arrangement. By this instrument the variations of velocity during systole and diastole of the heart can be recorded and measured, but it can only be used in the vessels of large animals.

If in a schema similar to that given in Fig. 85 two IIshaped tubes, $a$ and $b$ (Pitot's tubes), be inserted, one with the elbow opposing the stream, the other with the elbow in the direction of the stream, the fluid will rise higher in $a$ than in an ordinary side tube, and lower than this in $b$. This is because the flowing stream exerts a push on $a$ and a pull on $b$. The amount of this push and pull varies with the velocity of the stream, so that from the difference in the height of the two tubes the velocity can be calculated. In an instrument known as the photohæmatochometer (Fig. 109) the difference in height is recorded by photography.

The velocity may also be calculated by the elcctrical method, estimating the time taken for the blood to pass between two points of an artery when salt solution is injected into the circulation (see Circulation-time, p. 209).

In man, the quantity of blood which passes through the hand or foot has been measured by plethysmographic means (Fig. 110) and also deduced from the quantity of heat which the part gives off to a water calorimcter in which it is immersed. The flow in grammes

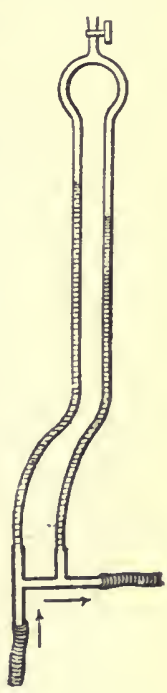

Frg. 109. CyBulski's Phot о наMAT O C H OMETER.

per minute is obtained from the formula, $\mathrm{Q}=\frac{\mathrm{H}}{m\left(\mathrm{~T}-\mathrm{T}^{1}\right)} \cdot \frac{1}{s}$, where $\mathrm{Q}$ is the quantity of blood, $\mathrm{H}$ the number of small calories given off in $m$ minutes, $\mathrm{T}$ the temperature of the blood entering the hand, $\mathrm{T}^{\perp}$ that of the blood leaving the hand, and $s$ the specific heat of the blood $\left(0.9^{\circ}\right)$. T may be taken as $0.5^{\circ}$ lower than the rectal tempcrature, and $\mathrm{T}^{1}$ the same as that of the tepid water in the calorimeter.

The general relations of the velocity of the blood in the arteries, capillaries, and veins, is expressed by the curve shown in Fig. 111 . The velocity in the large arteries may reach 500 millimetres per second in systole, and fall to 150 millimetres in diastole. The smaller the artery the less is this difference, and the more uniform the rate of flow.

The velocity and pressure of the blood in the aorta are dependent 
upon the encrgy of the heart and upon the peripheral resistance. In the living animal these factors are varying constantly.

1. With the energy of the heart constant, $(a)$ the peripheral resistance may increase, so that the pressure in the aorta beeomes greater

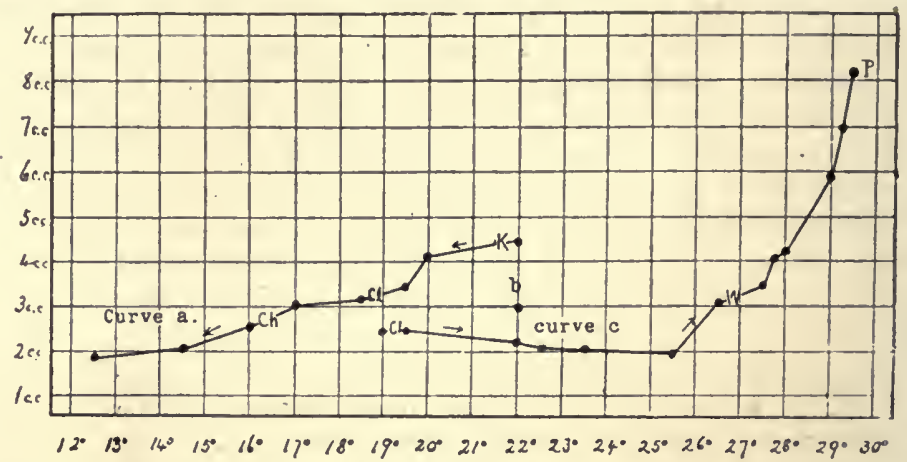

Fig. 110.-Velocity of Flow by Plethysmographic Method. (Hewlett.)

Observations on a single individual: $a$, Passing from comfort to marked chilliness; $b$, comfort; $c$, passing from coolness to beginning perspiration.

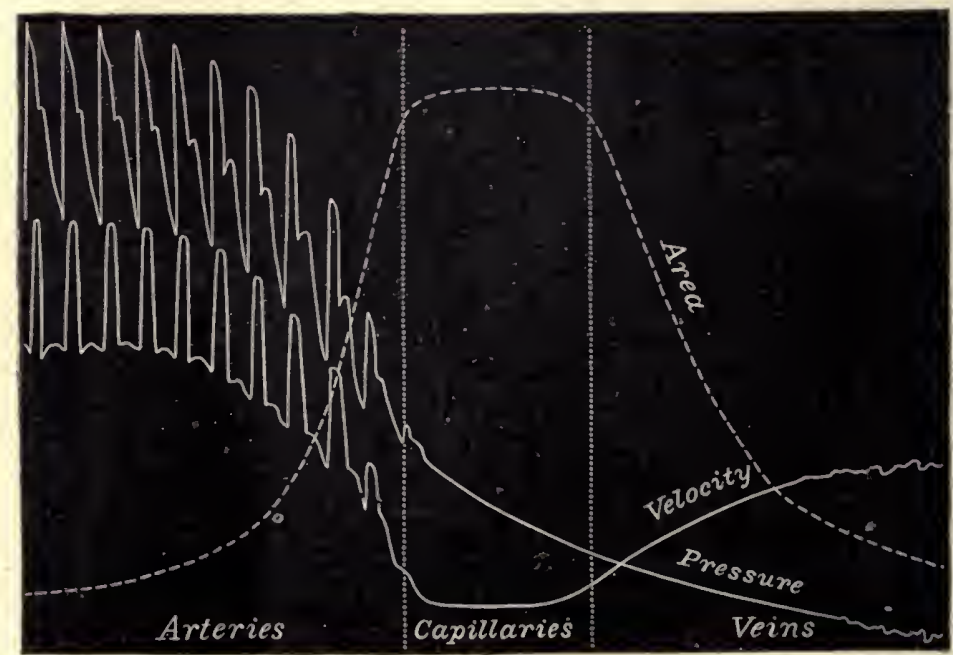

7ig. 111.-Diagram showing General Relations of the Velocityo f the Blood in the Arteries, Capillaries, and Veiss. (Fredericq.) L:

and the velocity less; $(b)$ the peripheral resistanee may decrease, the velocity becoming greater and the pressure less.

2. With the resistance eonstant, the energy of the heart may inerease or decrease, thereby inereasing or deereasing both velocity and pressure. 
3. If both the energy of the heart and the peripheral resistance increase proportionately, the pressurc will rise, but the velocity remain constant.

4. With an increase in the energy of the heart-beat, and a decrease in resistannce proportional to the increase of cardiac energy, the pressure will remain constant and the relocity become greater.

5. If the energy of the heart decreases, but the peripheral resistance increases in proportion, again the pressure remains constant, but the velocity becomes less.

6. With a decrease in heart-beat, and a proportional decrease in resistance, the pressure falls, but the velocity remains constant.

7. By virtue of the vaso-motor mechanism (see p. 229), the peripheral resistance may at the same time be increased in one section

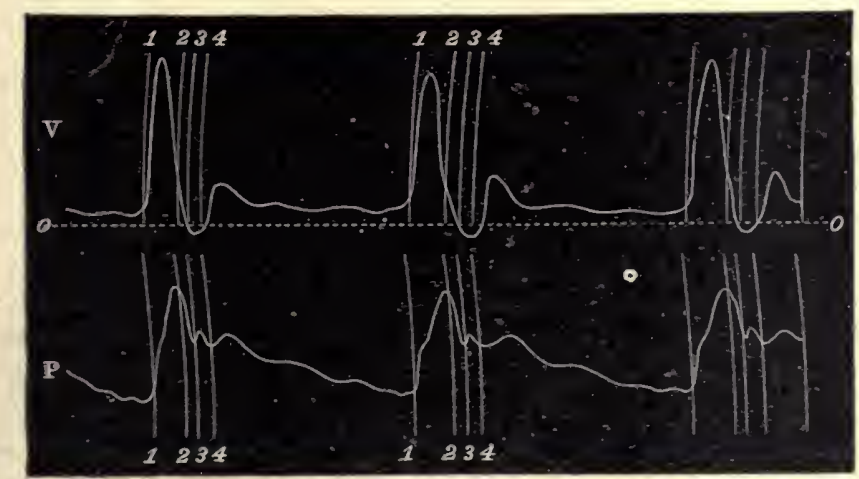

Fig. 112,-Carotid Artery: Velocity of Pressure Curves. (Chauveau and Lortet.)

of the arterial system and decreased in another, so that it is possible for the pressure and velocity in the aorta to remain constant, while the velocity is varying in opposite directions in different parts of the vascular system. The velocity in one particular artery, therefore, is no guide to the general condition pertaining in the system, and such velocity bears no absolute relation to the rate of heart-beat or general artcrial pressure.

In the tracing (Fig. 112) are shown the synchronous records of velocity $(V)$ and of pressure $(P)$ obtained in the carotid of the horse. It will be seen that the curve of velocity reaches its maximum before the curve of pressure. This is so because, as the arteries become overfilled, the heart cannot maintain the initial velocity of output. By experiment it was found that the velocity in the carotid artery of the horse reached 520 millimetres per second during systole, while at the time of the dicrotic wave the velocity sank to 220 millimetres per second, and in diastole to 150 millimetres per sccond. Continuous records of the velocity curve afford a valuable means of arriving at the volume of blood flowing through the vascular arca supplied by the artery in 
question. Thus the effeet on the blood-flow of vaso-motorial excitement or funetional aetivity ean be investigated.

By means of the dromograph it has been shown that, during systole, the blood is eheeked by the eompressive aetion of the eardiac musele in its flow from the aorta towards the eoronary arteries; that the veloeity of flow in the earotid is five or six times greater when a horse is actively mastieating than when at rest. The normal veloeity in the earotid artery during systole was found to be 540 millimetres per seeond. After seetion of the eervieal sympathetic, however, in consequenee of the peripheral dilatation, the veloeity beeomes equal to 750 millimetres per seeond. After seetion of the spinal cord in the upper dorsal region, the reloeity in the arterial system beeones greatly aecelerated during systole, and greatly diminished during diastole. Owing to the lowering of the peripheral resistance from the loss of raseular tone, the heart is able to diseharge the blood with greater rapidity into the venous system, and in eonsequence, during diastole, the arterial system is emptied of blood to a great extent. If this eondition be pushed to an extreme, and the frequeney of the heart be small, the blood beeomes diseharged into the veins intermittently.

Comparative reeords have been obtained of the veloeity of flow in the carotid and faeial arteries. At the end of the diastole the veloeity is small in the earotid, and relatively great in the faeial artery. In the beginning of the systole the primary wave of velocity rises rapidly in the earotid, and is proportionately small in the faeial artery. The seeondary inerease of veloeity, whieh is produeed by the dierotic wave, is far more evident on the earotid than on the facial eurve. These results show how the intermittent energy of the heart is stored up by the elastieity of the large arteries, and expended in maintaining a eontinuous flow through the small arteries.

The flow in the large veins is approximately equal to that in the large arteries. In the jugular vein of a dog the mean veloeity was found to be 225 millimetres, and in the earotid 260 millimetres, per seeond. The veloeity in the eapillaries has been measured by direet observation with the mieroseope. It is very small-e.g., 0.5 to 1 millimetre per seeond. This variation of veloeity in different parts of the vascular system is explained by the difference in the width of bed through whieh the stream flows. The vaseular system may be eompared to a streain whieh, on entering a field, is led into a multitude of irrigation ehannels, the sum of the eross-sections of all the channels being far greater than that of the stream. The ehannels gradually unite together again, and leave the field as one stream. If the flow proceeds uniformly for any given unit of time, the same volume must How through any eross-section of the system. Thus the greatest velocity is where the total bed is narrowest, and slowest where the bed widens to the dimensions of a lake.

Any general ehange in velocity at any seetion of this eircuit tells both baekwards and forwards on the veloeity in all other seetions, for the arerage veloeity in the arteries, reins, and eapillaries, these vessels being taken respeetively as a whole, depends always on the relative areas of their total cross-seetions. 
The Time Necessary for a Complete Circulation.-The blood, in deaving the heart, may take a short circuit through the coronary system of the heart, and so back to the right heart, or it may take a long and devious course to the toes and back, or through the intestinal capillaries, portal system, and hepatic capillaries. It is obvious, then, that the time any two particles of blood take to complete the circuit may be different. Experiments have been made to determine how rapidly any substance like a poison, which enters the blood, may be distributed over the body. A salt, such as potassium ferrocyanide, is injected into the jugular vein, and the blood collected in successive samples at seconds of time from the opposite jugular vein. These samples are tested for the presence of the salt by the addition of ferric chloride. A strong solution of methylene blue may be injected into the jugular vein of a rabbit, and the moment determined by a stopwatch when the blue colour appears in the carotid artery.

By this means the following times were obtained in different animals :

\begin{tabular}{|c|c|c|c|c|c|c|c|c|}
\hline & & & Seconds. & & & & & Seconds. \\
\hline Squirrel & 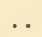 & $\cdots$ & $4 \cdot 39$ & Horse & $\cdots$ & $\cdots$ & .. & $31 \cdot 50$ \\
\hline & .. & .. & .. $6 \cdot 69$ & Cock & $\ldots$ & . & .. & $5 \cdot 17$ \\
\hline Hedgehog & .. & $\ldots$ & . $7 \cdot 61$ & Duck & .. & .. & .. & $10 \cdot 64$ \\
\hline Rabbit & .. & $\ldots$ & .. $7 \cdot 79$ & Goose & $\ldots$ & .. & .. & $10 \cdot 86$ \\
\hline Dog & .. & $\ldots$ & .. $16 \cdot 70$ & & & & & \\
\hline
\end{tabular}

The length of the circuit is found to make little difference in the animal lying horizontal. This is so because the time is chiefly spent in the passage of the blood, not through the arteries and veins, but through the capillaries. Thus, the following are mean results in four double determinations:

$$
\begin{array}{llllll}
\text { Tugular to jugular }(\mathrm{dog}) & \ldots & \ldots & \ldots & \ldots & 16 \cdot 32 \text { seconds. } \\
\text { Jugular to crural }(\mathrm{dog}) & \ldots & \ldots & \ldots & \ldots & 18.08
\end{array}
$$

If the respiratory movement of a man be recorded, and he take a breath from a bag containing, say, $5 \cdot 0$ per cent. of $\mathrm{CO}_{2}$, his breathing will be augmented when the blood charged with excess of $\mathrm{CO}$, in the lungs reaches the respiratory centre (half the circuit). This time can be measured, and it approximately indicates the time spent in the blood travelling from the lungs to the centre.

The circulation time of various organs may be determined by injecting salt solution into a vein, and observing with the aid of a Wheatstone's bridge arrangement and galvanometer the change in electrical resistance which occurs in the corresponding artery when the salt solution reaches it. The moment of injection and that of the altcration in resistance are observed with a stop-watch.

It has been determined that the fastest travelling blood can complete the circuit in about the time occupied by twenty-five to thirty heart-beats-say in twenty to thirty seconds. This result shows how rapidly methods must be taken to prevent the absorption of poisons-for example, snake-poison. The fastest travelling blood in the pulmonary circuit occupics only about one-fifth of the time spent by that in the systemic circuit. In animals of the same species 
the circulation time increases rather in proportion with the surface than the weight. That some of the blood takes a very long time to return to the heart is shown by the long time it takes to wash the vascular system free of blood by the injection of salt solution. The circulation-time is shortest for the heart and the retina.

The circulation-time for the stomach is relatively short-equal generally to about that of the lungs. It is relatively long in the kidney, spleen, and liver, being much more variable in these organs. than it is in the lungs, more easily affected by changes of external temperaturc-diminished by warmth, increased by cold.

\section{Circclatiox Tines.}

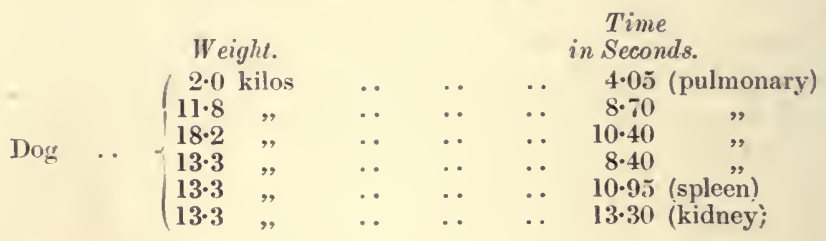




\section{CHAPTER XXIV}

\section{THE PULSE}

By the expulsion of the blood at each systule the walls of tho aorta are suddenly distended. From the aorta a wave of distension passes down the walls of the arteries. This wave of distension is ealled the "pulse." As the pulse is distributed over an ever-widening field its energy is expended in dilating the elastie arteries, and disappears finally in the arterioles. From a wounded artery the blood spurts in pulses, from a wounded vein it flows eontinuously. By

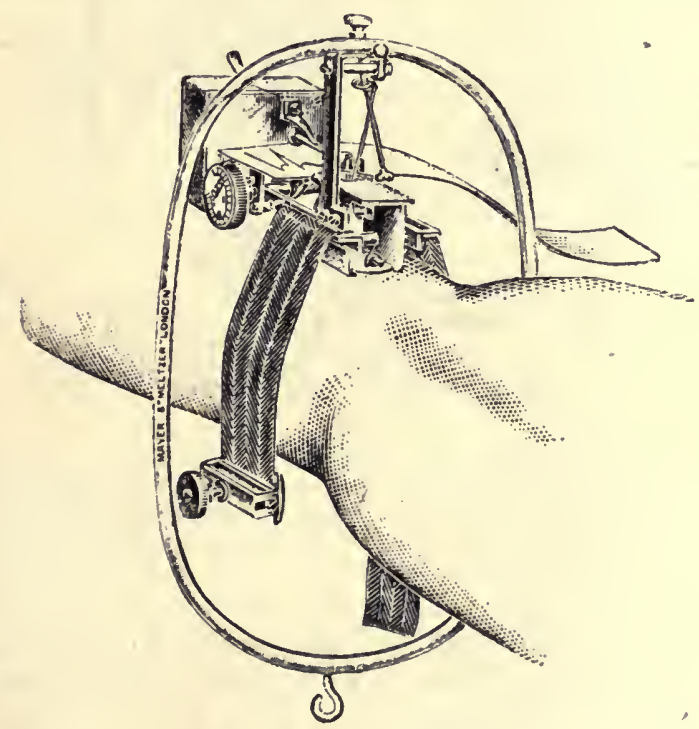

Fig. 113.-The Suspexsion Method of using the Dudgeon Spilgmograph. (Lewis.)

feeling two pulses, or, better, by plaeing tambours on, say, tne earotid and radial arteries, and reeording the two pulses synehronously, it has been found that the pulse oceurs later the farther the seat of observation is away from the heart. The veloeity with which the pulse-wave travels down the arteries has been determined thus. It is about 7 to 8 metres per seeond-twenty to thirty times as fast as the blood flow. The wave-length of the pulse is obtained by inultiplying the duration of the inflow of blood into the aorta by the veloeity of the pulse-wave. It is about 3 metres. 
The examination of the pulse is of great importance to the physician. It yields him information as to the state of the heart, the state of the arteries, the amount and variations of the arterial pressure.

The pulse may be investigated either direetly by the finger or by the aid of instruments known as sphygmographs (Fig. 113). The pulse is generally felt in the radial at the wrist, preferably on both sides. With the finger the points noted may be grouped into $(a)$ those which give information eoneerning the heart-e.g., the frequency, generally seventy to seventy-five per minute in man, regularity or irregularity, equality or inequality of the beats; $(b)$ those which yield knowledge

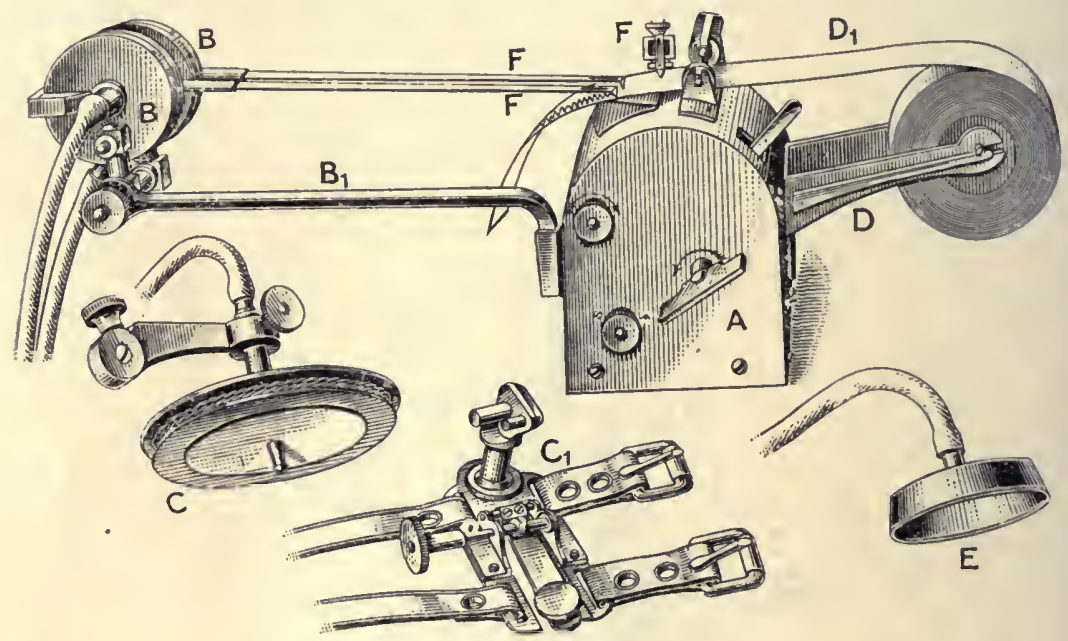

Fig. 114.-MACkExzIE'S PoLygral'H.

The parts of the polygraph may be deseribed as follows: The body $A$, eontaining the paper-rolling and time-marker movements; the writing tambours $B B$, with supporting bar, $B 1$; wrist tambour, $C$, with attaehment, $C 1$, for strapping on to wrist; paper roll bracliet, $D$; paper roll, $D 1$; eup receiver, $E$; pens, $F^{\prime} F F$.

about the vessel-e.g., its size and the eondition of its wall; $(c)$ those which yield eombined information of the two-the volume, foree, and tension of the pulse.

By volume is meant the amount of movement in the pulse during the passage of the pulse-wave; by foree is understood the maximum pressure as felt by the finger in the ressel during the beat; by tension the pressure between the beats.

These last data ean only be aceurately measured by means of the sphygmometers already deseribed, for the finger begins to flatten the artery and stop the passage of the pulse-wave when exerting a pressure much less than that within the artery.

In a normal healthy pulse the beats are regular and of equal strength. The vessel is soft and pliant, not tortuous, rigid, or thickened. The force and tension are moderate-that is, they are best felt when a moderate degree of pressure is applied. 
For recording the pulse, an instrument such as that shown in Fig. 113 may be used. The disadvantages are that the tracings are but of short length and that in the ordinary form, which is strapped round the wrist, the pulse tracing is modified by the effect of pressure upon the venæ comites of the army. For this reason it is better to cmploy the suspension method illustrated in the figure, in which the pressure of the lever is exerted directly over the radial artery.

Of greater service is the instrument known as the polygraph (Fig. 114). With this instrument it is possible to take two tracings at the same time, and that of a time-marker. The usual combination is a tracing of the radial and venous pulses.

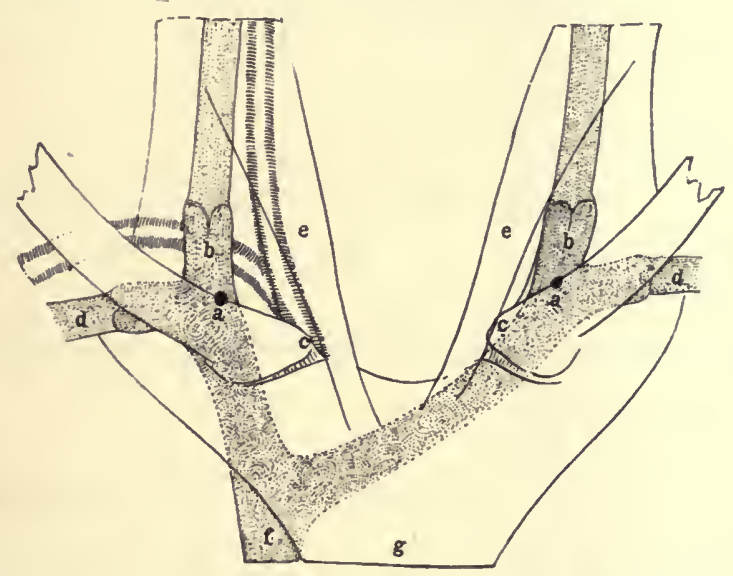

Fig. 115.-Diagram showing the Average Position of the Jugular Bulb. (Keith.)

$a$, The jugular point, $25 \mathrm{~mm}$. from the sternal end of the clavicle $(c) ; b$, jugular bulb, behind sternal head of sterno-mastoid and in front of first stage of subclavian artery; $d$, subclavian vcin; $e$, sternal head of sterno-mastoid; $f$, superior vena cava; $g$, manubrium sterni.

Such simultaneous graphic curves are valuable, since they record information of the time relations and the nature of the contraction of the separate heart chambers.

The Venous Pulse in man is best recorded by applying a small metal receiver ( 3.4 centimetres diameter, 1 centimetre deep) between the two heads of origin of the relaxed sterno-mastoid muscle (Fig. 115), and transmitting the pulsations by air to a delicate recording tambour. By this means a tracing of the jugular bulb is obtained, where it lies a little above, and about 25 millimetres external to, the inner end of the clavicle. The bulb is so called because in the internal jugular vein at this point is a pair of valves, and here a bulging of the vessel takes place in cases of impeded flow to, or of regurgitation from, the auricles.

The venous pulse shows three main elevations $(a, c, v)$. The exact interpretation of some of these factors is still a matter of doubt. 
The $a$ wave is due to the contraction of the right auricle. It disappears when this chamber is not beating, and is sometimes replaced by a series of oscillations when the auricle is fibrillating. Its exact mode of origin and propagation is not known, but it is certainly synchronous with, and an indication of, auricular contraction. Comparison of the records in Fig. 116 shows that $p$ precedes $a$. Allowanec must be made for time of propagation.

The $c$ wave owes its origin to the ventricular systole, since it disappears when the ventricle ceases to beat. It has been supposed to be due to the pulsation of the neighbouring artery, and in many instances this is undoubtedly the case; but it occurs also in curves taken when the arterial influence has been removed, and also in the curves of interauricular pressurc. It is possibly due to the bulging

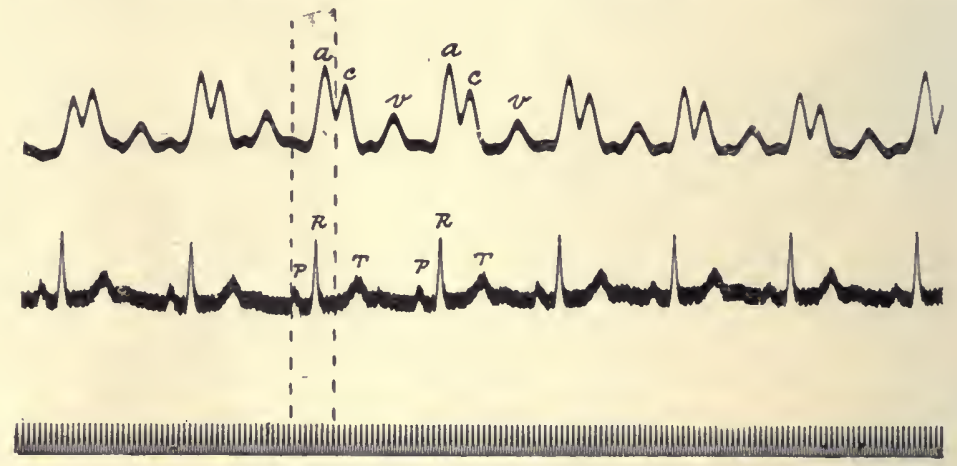

Fig. 116.-Sinultaxeots Records showing the Time Relations of Waves of Jugular Pulse and Electrocakijogram. (W. T. Ritchie, from Cowan's "Diseases of the Heart.")

P' Preeedes $a, R$ preedes $c$.

into the auricle of the closed tricuspid valve at the onset of ventricular systolc. The mode of origin is under discussion-both factors may contribute--while for clinical purposes it may be reckoned as synchronous with the primary wave of the arterial pulse in the neck. In Fig. 116 it is seen that the wave $R$ of the elcctrocardiogram precedes the warc $c$.

Various divergent views are held about the origin of the $v$ wave. The two views generally held are-(1) that it is due to the filling of the auricles during ventricular systole; $(2)$ that it is due to the norcment of the auriculo-ventricular groove at the beginning of diastole (Fig. . 39): Probably both factors contribute.

The depressions on either side of the $c$ wave, sometimes called $x$ and $x^{\prime}$, are really one depression broken by the $c$ wave. They are probably due to (1) the auricular relaxation dependent upon the inspiratory diminution of intrapleural pressure; (2) the expansion of the auricular walls which results from ventricular systole, by the depression of the diaphragm formed at the floor of the auricle by the closed auriculo-ventricular valves. The first factor is active only during inspiration. 
The depression after $v$, sometimes termed the $y$ depression, is usually attributed to the opening of the A.-V. valves, and the passage of blood from auricles to ventricles at the beginning of common diastole.

The Arterial Pulse Curve.-In the arterial record, or sphygmograph, the upstroke corresponds to the systolic oatput of the left ventricle, marking the opening of the aortic valves and the pouring of the blood into the arteries.

The downstroke represents the time during which the valves are shut and the blood is flowing out of the arteries into the capillaries. There arc subsidiary waves on the downstroke. The chief of these is called the "dicrotic wave," the notch preceding which marks the closure of the semilunar valves (c, Fig. 117). The dicrotic notch is caused by the swing back of the blood towards the heart when the outflow ceases, and the elastic rebound of the blood from the closed semilunar valves and root of the aorta causes the dicrotic wave. If the aortic valves move back $l$ centimetre and the diameter of the orifice of the aorta is $\mathbf{2 . 6}$ centimetres, then $1 \cdot 8$ centimetres of blood move back towards the heart. It is most manifest when the systole is short and sharp, and the output of blood from the arterioles rapid; in other words, when the heartbeat is strong, the systolic pressure high, and the diastolic pressure low. Its central origin is proved by the fact that it appears in the carotid or brachial at the same interval of time after the primary wave as in the radial artery. A smaller wave, predicrotic, preceding this occurs during the period of output, and sometimes is placed on the ascending limb of the pulse-curve. This occurs when the peripheral resistance is great, and the pulse is then termed anacrotic.

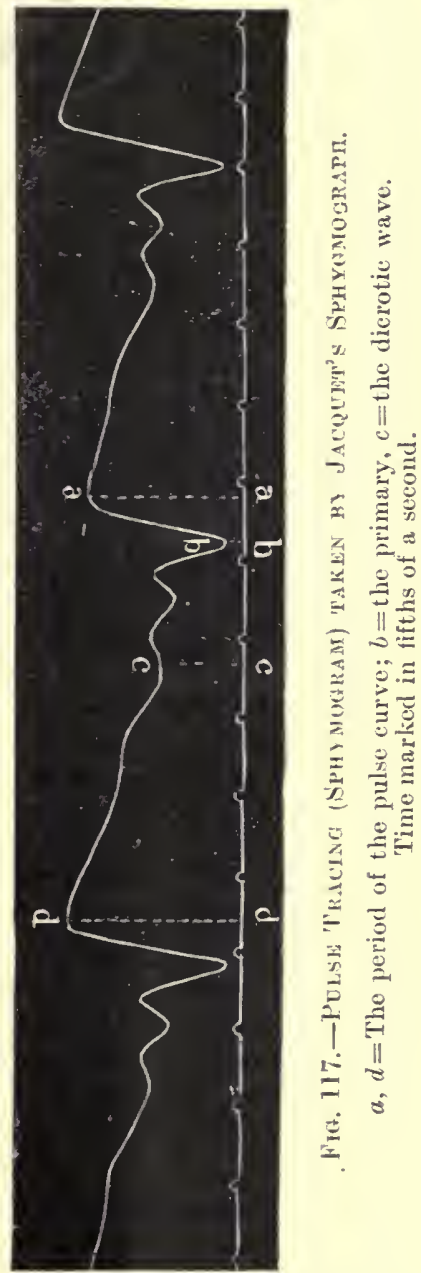
It usually occurs when the outflow from the heart is impeded-as, for example, by stenosis of the aortic valves. By compression of the abdominal aorta the carotid pulse can easily be made to exhibit an anacrotic wave.

The post-dicrotic waves are due to secondary elastic swings of the big arterics following the dicrotic swing. The form of these waves 
is modified by the pressure of applieation of the sphygmograph and by instrumental errors. The pulse may be reeorded by allowing an artery to spurt upon a moving paper (Fig. 118).

As already said, the pulse wave oeeurs later, the farther the place of observation is from the heart. This is well seen in Fig. 119.

We have no seale by whieh we ean measure the blood-pressure in sphygmograph traeings.

When the arterioles are dilated, or when the eapillaries are only filled at eaeh systole, the pulse may pass through the arterioles and

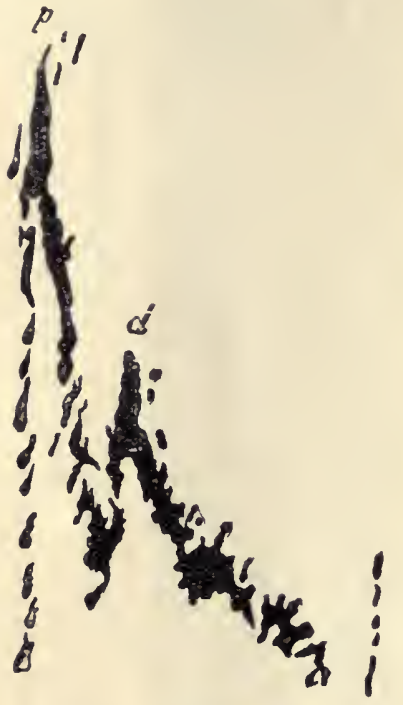

Fig. 118.-Hemautogran.

(Landois and Stirling.) reaeh the eapillaries, as may be seen in the pink of the nail when the arm is held above the head in eases of aortie regurgitation.

The normal average pulse-rate is 72 per minute, in woman about 80 . Tall men usually have a slower rate than short men. Individual variations from 40 to 100 have been observed eonsistent with health. Napoleon, a short man, had a pulse-rate of 40 . In the new-born, the pulse beats on the average 130 to 140 times a minute; in a one-year-old ehild, 120 to 130 ; three years, 110 ; ten years, 90 ; fifteen years, 80 to 85 . Aetive museular exereise may inerease the pulserate to 130 . Nervous exeitement, extreme debility, and rise of body temperature, also inerease it markedly. The pulse is more frequent when one stands than when one sits or lies down. In 100 young men of twenty-seven years the average was : 78.9 standing, $70 \cdot 1$ sitting, 66.6 lying. In states of debility this differenee between horizontal and ereet postures may inerease to 30 to 50 per minute. The taking of food, especially hot food, inereases the frequeney; so does smoking cigarettes.

The average pulse-rates for different ages is given in the following. table:

\begin{tabular}{|c|c|c|c|c|c|c|c|}
\hline \multirow{2}{*}{$\begin{array}{c}\text { Age, } \\
\text { in Years. } \\
\text { Foetus }\end{array}$} & & & & & & & $\begin{array}{l}\text { Pulse-Rate, } \\
\text { per Minute }\end{array}$ \\
\hline & .. & .. & . & .. & .. & .. & $135-140$ \\
\hline $0-1$ & .. & . & . & $\ldots$ & .. & .. & 134 \\
\hline $1-2$ & .. & . & .. & .. & .. & .. & 117 \\
\hline 3-4 & .. & .. & . & . & .. & .. & 108 \\
\hline $5-9$ & .. & .. & . & .. & .. & .. & 98 \\
\hline $9-10$ & .. & .. & .. & .. & .. & $\ldots$ & 91 \\
\hline $12-13$ & . & . & . & . & .. & .. & 88 \\
\hline $16-17$ & $\therefore$ & .. & .. & .. & .. & .. & 80) \\
\hline $19-20$ & Men & . & . & .. & .. & $\because$ & 72 \\
\hline & Women & & . & . & .. & .. & 80 \\
\hline
\end{tabular}


At the third month the infant's pulse may be faster than at birt owing to the increase of muscular activity.

Large animals have a slower rate than small. The elephant has a frequency of 25 to 30 , the ox 36 to 40 , the sheep 60 to 80 , the dog

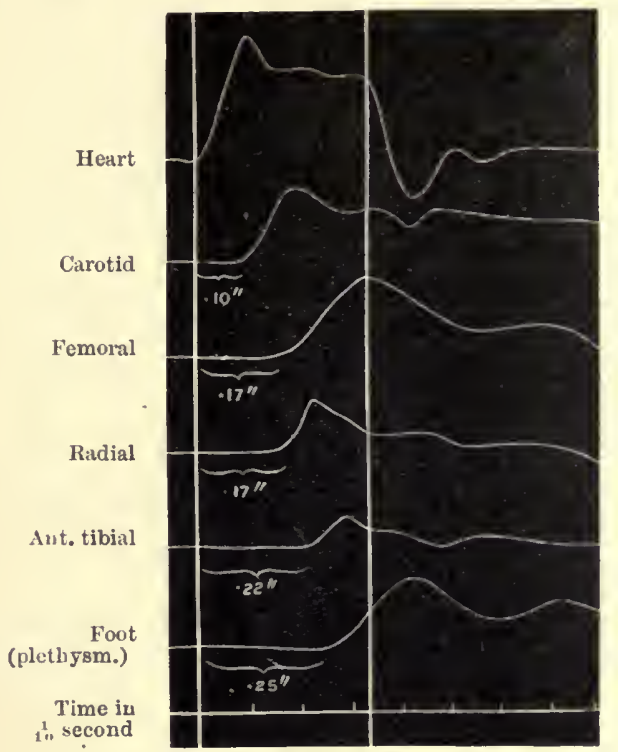

Frg. 119.-The Pulse Wave in the Arterlal Systel. (Wallor.)

100 to 120 , the rabbit about 150 , small birds and mice over 600 . In the last the rate is recorded by means of the electrical variation of the heart. 


\section{CHAPTER XXY \\ THE CAPILLARY CIRCULATION}

THE blood is brought into eontaet with the tissues through the endothelial wall of the eapillaries; this is therefore of the greatest tenuity. Here takes plaee that exehange of material which maintains the eombustion of the body - the fire of life. The aim of the eirenlation is attained when the arterialized blood laden with food material and oxygen is driven into the eapillaries of the body.

In size, the eapillaries vary in different organs. In the brain the length has been estimated to be 0.709 millimetre (pons) and 0.42 millimetre (optie thalamus); in the mueosa of the stomaeh 0.6 millimetre; and in the liver 0.5 to 1.1 millimetres. The diameter of the eapillaries varies from 0.007 to 0.013 millimetre.

Malpighi (1661) first observed the eapillary eireulation under the mieroseope. He examined the lung, the mesentery, and bladder of the frog. It has sinee been seen in many other transparent or translueent parts of animals.

The Microscopical Examination of the Circulation.-By using a low power it is possible to examine simultaneously arteries, eapillaries, and veins in the same field. The first thing whieh strikes the observer is the different direetion of the stream in the arteries and in the veins. On aeeount of the retieular arrangement of the eapillaries, the direetion of the stream through them is by no means eonstant. There may be a eomplete eessation of the flow for a period in a eapillary channel, or the direction of the eurrent may even be reversed for a longer or shorter time. The flow through the arteries is by far the most rapid. In the veins, also, the stream is so rapid that it is diffieult to eateh the eontour of the eorpuseles. The stream is slower in the small veins, and in the eapillaries the movement is, as a rule, so tardy that the individual eorpuseles ean be determined without any diffieulty. The ineonstaney of the eapillary stream is generally apparent. If a group of eapillaries be kept for some time under observation, the blood is oeeasionally seen to hurry suddenly through a number of these with inereased rapidity. This eontinues for a while, and then the stream beeomes again slower and slower, till after an interval it resumes the quiet rate of flow which has been maintained without interruption in the neighbouring eapillaries. These variations depend on alterations in the lumen of the afferent arteries.

The arterial stream is pulsative, and eaeh systole may be reeognized even in very small arteries by the rhythmical aeeeleration and re- 
tardation of the blood-stream. Such a rhythmical movement is absent from the eapillaries and veins in a normal eondition; the stream is continuous in both. In the arteries the eore of red corpuscles does not completely fill the lumen, but moves along the axis of the stream. To the outside there lies a clear layer of plasma, in which, when the stream moves slowly, white corpuseles roll. In the veins there is also a similar peripheral plasmatie layer, in which the white corpuscles roll slowly along, stieking now and again to the wall of the vessels in their eourse. In the smallest eapillaries the plasma layer cannot be distinguished, the red corpuscles mareh in single file, and often become distorted and bent as they pass. These eapillaries are invisible to the eye so socn as corpuscles eease to pass through them. Thus, in the course of an observation, eapillaries may be seen to appear and vanish from view. In tho angles of the eapillary network, red corpuseles may be seen to stick and hang in the balance, bent round the angle, half in one branel and half in another, until finally swept on into the rush and hurry of the stream.

The white eorpuseles progress with a slow rolling motion in the plasmatic layer. The axial stream travels with the greatest velocity, and thus the side of the lcueoeyte whieh lies at any moment nearer the axis is driven on with the greater speed; hence the rolling movement. The white eorpuseles travel in the peripheral layer, the red in the axial layer, for the latter are the heavier. It is not, as has been supposed, that the white are lighter and the red eorpuscles heavier than the plasma. Both forms are of a higher density than the plasma.

If partieles of graphite and earmine be eireulated through glass eapillaries, the lighter earmine partieles travel in the peripheral layer. When resin is substituted for graphite, the carmine travels in the axis. If pus eorpuseles and milk globules are eirculated, the corpuscles occupy the axial stream.

If the resistance in the arterioles be lowered to a certain point, the capillary , eirculation remains no longer pulseless. Tnus, when the chorda tympani nerve is stimulated, the blood may issue in pulses from the vein of the submaxillary gland. By plunging the hand in very hot water, the pulse may be seen to reaeh even the turgid veins on the back of the hand. In cases of aortie insuffieieney, a eapillary pulse is readily obtained in any area of eongestion whieh is produced by seratching the skin.

The effeet of vaso-dilatation ean be observed under the mieroscope - e.g., in the tongue of a eurarized frog. On brushing the tongue an appearanee of intense redness shows that arterial congestion has set in. All the vessels, arteries, capillaries, and reins, are wide and strongly distended with blood. Innumerable eapillaries are pereeptible at a glance, where previously a few red-coloured threads were toilsomely sought for ; and in all these vessels, small and large, the blood rushes on with the greatest rapidity - so rapidly that even in the capillaries the eye in vain strives to catch the outline of a single eorpuscle. 
By the application of a piece of ice to the tongue of a frog, vasodilatation can be converted into eonstriction. The arteries become narrow, the tongue pale. The eye has difficulty in finding any except the larger vessels. Few eapillaries appear to contain blood, and where a considerable quantity of blood is still present, as in the arteries and veins, the flow is tardy, and even in the arteries the individual corpuscles can now generally be reeognized.

In a warm-blooded animal, the results of exposure to an irritant are much more rapidly established. After exposure of a rabbit's ear to water at $55^{\circ} \mathrm{C}$., the blood is altogether unable to penetrate the arteries. A change has taken place in the relations between the blood and the vessel wall as regards friction and adhesiveness, and thus eomplete stasis of the cireulation arises. If the change be less intense, the porosity of the ressel is affected, and a quantitative and qualitative change in the transudation from the eapillaries ensues. The rabbit's ear may be entirely separated from the body, with exception of the central artery and vein. After section of all the vasomotor nerves by this means, vascular dilatation is greatly increased by rubbing the ear, and all the phenomena of inflammation occur after the application of an irritant. We have here to deal, not with a nervous mechanism, but with a change of the vessel wall. The circulation through the capillaries is possible only so long as the vessel wall is in the normal physico-chemical condition which characterizes the living state.

The corpuscles eontinue to move through the capillaries for some seconds, or even minutes in a few of the eapillaries, after the bulbus arteriosus has been ligated; they run faster on pressing or moving the leg. Observations of this kind show how immeasurably slight a differenee of pressure is required to produce a flow in the capillaries. On clenching the fist the eapillaries of the hand blanch. By the ceaseless museular morements and changes of posture of the living mobile animal the capillary pressure is kept in the skin approximately the same as the atmosphere, for whenever the blood is thus pressed out of them into the veins the pressure does not beeome positive in the capillaries till they fill again.

In the intestinal wall the blood is similarly expressed by the muscular contractions of the gut. In encapsulated organs, such as the glands, on the other hand, the capillary pressure may rise with the secretory pressure up towards the arterial pressure. This is the case in the salivary gland when the seeretion is made to take place against pressure. Secreting cells are confined by liniting membranes, membranæ propriæ, tough and homogeneous, but of great tenuity. These membranes, while allowing the protoplasm of gland eells or muscle plasma to imbibe fluid from the capillaries, limit the expansion produced by intracellular forces. Thus the salivary glands may secrete saliva at a pressure greater than arterial pressure, and the blood continue to flow through the gland. The expansion of the alveoli is limited, so that it narrows and does not shut up the reins (see Fig. 119). The result is 
a rapid flow of blood through dilated arteries, and almost rigid vessels, arteries, capillaries, and veins, all at the full or nearly full arterial pressure. Similarly, in an inflamed area, by the inbibition of fluid in the damaged tissue cells which arc confined by connective tissue, the veins arc compressed and narrowed, and the arteries being dilated, the capillary pressure rises, and the whole part throbs with the pulse and receives a rapid flow of blood. If the swclling is too great, strangulation of the circulation occurs, and the surgeon's knife is required to relieve tensicn and promote flow.

Rate of Flow. - The velocity of a blood-corpuscle in the capillarics of a frog's muscle has been reckoned to be $0.28 \mathrm{~mm}$. per second. The method most conveniently used is to employ an ocular micrometer, and follow the course of a corpuscle during a period of time given by a clock bcating one-fifth seconds. The velocity has thus been found by various observers to be 0.25 to 0.57 millimetre per second in coldblooded animals.

By the entoptic method the velocity in the retinal capillarics has bean calculated to be 0.75 millimetre per second. With suitable illumination of the eye the corpuscles are seen by the subject on a ground-glass screen held 11 to 16 centimetres from the eye. A corpuscle can be followed 20 to 30 millimetres on the screcn. Knowing the distance of the screen from the anterior nodal point of the eye (A), the distance of the retina from the posterior nodal point (B), and the distance travelled by the corpuscle on the screen $(C)$, the real distance $x$ travelled in a given time can be calculated.

$$
x=\frac{\mathrm{BC}}{\mathrm{A}} \text {. }
$$

As the red corpuscles travel in the axial part of the stream, and as the mean velocity in any tubs equals one-half the axial velocity, the true mean velocity of flow is less than the above. It can be taken to be about 15 to 39 millimstres per minute, and in the smallest capillaries, where the flow is often obstructed, it is still less. Since the velocity stands in inverse proportion to the sectional area at any point in a system of tubes, the proportional relationship of the total sectional area of the capillaries to that of the arta can be reckoned if we know the mean velocity in the capillaries and in the aorta. Thus, if the mean velosity be taken as 500 millimetres per second in the aorta, and 0.5 millimetre por second in the capillaries, the relution is $1=1,000$. In man the sectional area of the aorta is $4 \cdot 4$ square centimetres. The total sectional area of the capillaries filled with blood at the time is thus equal to 4,400 square centimetres. This result is, of course, only approximate.

The Capillary Blood-Pressure.-The measurement of the capillary pressure has been attempted by placing a glass plate 2.5 to 5 square millimetres in size on the skin in a suitable place, such as on the last joint of the finger. From this glass plate hangs a small scale-pan. 
On.this weights arc plaeed until the pressure is reached at whieh the skin is blancherl and the capillaries eompressed.

In arother method a small rubber bag with a hole in the eentre is placed on the skin. Both bag and skin are moistened with glycerine, and the whole is covered with a glass plate so held as to make an airtight junetion. By means of a side tube air is then blown into the bag until the skin blanehes, the pressurc being indicated on a manometer. These methods are inaeeurate, for the horny layer of the skin resists the compression.

The web or mesentery of a frog, being laid on a glass plate, can be eompressed, while under the mieroseope, by a thin transparent membrane, which forms the base of a glass capsule. The latter is filled with water, and connected with a pressure-bottle and manometer. $\mathrm{By}$ this means it was found that pressure of 100 to $150 \mathrm{~mm}$. $\mathrm{H}_{\mathrm{s}} \mathrm{O}$ is suffieient to stop the eireulation in the capillaries and veins of tice frog:s web; in the arteries 200 to $250 \mathrm{~mm}$. $\mathrm{H}_{2} \mathrm{O}$. In periods of a few minutes the pressure may vary 20 to $30 \mathrm{~mm}$. $\mathrm{H}_{2} \mathrm{O}$. On produeing vagus inhibition of the heart by striking the abdomen, the pressure sank to 0 , and then rose again in the veins to 70 to $100 \mathrm{~mm} . \mathrm{H}_{2} \mathrm{O}$, owing to venous congestion. Temporary anæmia of the web eaused dilatation of the vessels, and this produeed in its turn a higher capillary pressure.

Sueh methorls necessitate the fixation of the part, and cannot be quickly performed. They obstruct the flow and therefore do not give the capillary pressure under nornal conditions.

If the upper arm be constricted, so as to block the venous exits, the pressure in the cutaneous veins of the arms rises fairly rapidly to the static arterial pressure. It takes a long time for the capillaries to all become distended with blood. The veins fill through the wider channels. If we squeeze the fist under these eonditions, the capillaries are emptied into the veins and momentarily blanched, and we see that it is possible to have then a high pressure in loth arteries and veins, and a low pressure in the eapillaries. The distension of the eapillaries vessels eauses aching pain, and this diseomfort prevents our keeping our limbs motionless in a dependent posture, and causes us to move the parts of the body, to fidget, and so relieve congestion.

In the brain, the capillary venous pressure ean be estimated by finding the tension which is sufficient to just eompress the brain as it bulges into the trephine hole. This pressure in the horizontal position of the animal is usually about $10 \mathrm{~mm}$. $\mathrm{Hg}$. The eapillary pressure varies widely with ehanges in the general venous and arterial pressures, and with the position of the animal. Thus, in the brain, the pressure may fall below zero in the vertical feet-down position (the fontanelle of an infant suffering from diarrhœe may become depressed), and rise to almost $50 \mathrm{~mm}$. Hg during the height of strychnine eonvulsions. The intraeranial pressure (eerebro-spinal fluid pressure), and the eerebral venous pressure, are one and the same. So, too, in the eyeball the intra-oeular pressure (aqueous fluid pressure), and the pressure of the veins within the eyeball, are the 


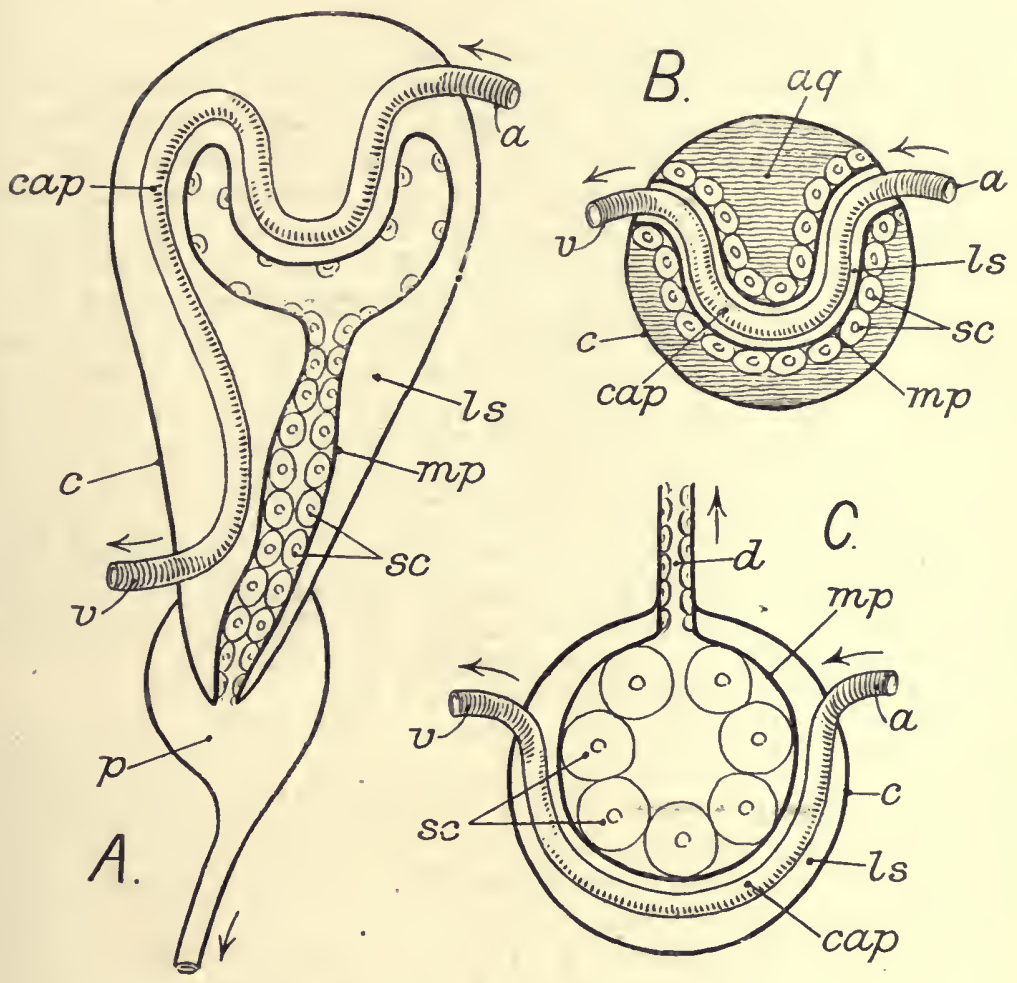

Fig. 119A. - Schema of Kidney.

The renal capsule $(c)$ eneloses the whole, ineluding ar:eries $(a)$, eapillaries (cap), 'and veins $(v)$, with surrounding lymph space $(l \cdot s)$. The membrana propria $(m p)$, eonfines the seereting eells $(s c)$. The pelvis $(p)$ and ureter, membrana propria and eapsule, are inextensile beyond a certain degree.

Fig. 119b.-Schema of EyebatL.

The rigid eoat $(c)$ eonfines the whole. The secreting cells $(s c)$ are set on a membrana propria $(m p)$, and seerete the aqueous $(a q)$. There is adjustment of eapillaryvenous to seereting pressure by latter aeting on venous outlet $(v)$. The flow of blood throngh capillaries (cap) stops when aqueous pressure is raised just about arterial pressure in $(a)$.

\section{Fic. 119c. - Schema of Salivary Glaxd.}

The alveolus, with seereting cells $(s c)$ and duet, are sur rounded by a menbrana propria $(m p)$, inextensile beyond a eertain degree. The eapsule of the gland $(c)$ is also inextensile beyond a eertain degree. The secretory eells $(s c)$ raise the pressure of saliva, and the membrana propria $(m p)$ prevent strangulation of the cireulation through eapillaries $(c a p)$ by limiting the expansion of the alveolus. A certain amount of expansion is permitted, which, aeting on the voin $(v)$ just before its exit through eapsule, raises the eapillary-venous pressure. The eapillaries and vein then beeome a more rigid system of tubes, and the flow of blood from $a$ to $v$ is aecelerated. 
same. Tissuc fluid pressure and capillary pressure constantly balance each other.

The capillary pressure stands in far closer relationship to the venous pressure than to the arterial pressure. Between an artery and its capillaries lies the unknown and varying resistance of the arterioles; between the capillaries and veins there is no such resistance.

Although often put forward, the view is erroneous, that fluid filters through the capillary wall under the influence of the capillary blood-pressure. No measurable difference in pressure normally exists between the capillary pressure and that of the tissue fluids, such as the aqueous or cerebro-spinal fluid. The wet films of the protoplasm which form the walls of capillaries cannot act as rigid sieve-like structures. The tissue cells are by their colloidal structure endowed with the power of linking up or setting free the crystalloids brought to them in solution. They are the seat of play of complex physical forces, such as imbibition and osmosis, as well as of chemical reaction, selective in character, and dependent on the enzymic contents of the cclls. The cells control the passage of fluid in one of the other directions in just the same way as do the unicellular organisms, in which, as regards the secretory processes, there can be no question of filtration. This view is illustrated in Figs. 119A, 119B, 119c.

Apart from other experiments which tell against the filtration hypothesis, and quoted in their respective sections, there rcmains the outstanding fact that in the brain and eye, where measurements have been made, the capillary-venous pressure and the tissuefluid pressure are not measurably different. Moreover, the membranæ propriæ are arranged to allow the tissue cells to produce osmotic and secretory pressures, not to support the capillaries as rigid filtering membranes. Leakage occurs when the skin, or capsule fan organ, is wounded. because capillary pressure is then no longer balanced by tissue fluid pressure.

The organs rhythmically pulse full with systole and shrink with diastole, and the pulse furthers the flow of tissuc lymph as well as the circulation. Every muscular movement, by compressive action and the action of valves in veins and lymphatics, aids the circulation. The membranæ propriæ, by limiting expansion, allow sccretory cclls to raise the pressure of the tissue fluid and produce, for example, the intra-ocular pressure. The capillary-venous pressure within the eyeball adjusts itself to this secretory pressure, for the pressure must just exceed the intra-ocular pressure for the circulation to continue. 


\section{CHAPTER XXVI}

\section{THE PRESSURE AND VELOCITY OF THE BLOOD IN THE VEINS}

The most striking difference between the structure of an artery and its venæ comites is a decrease of elastic tissue in the veins, together with an increasc of white connective tissue. The veins are tubes with muscular walls, which not only fall together, but contract when empty, and under slight pressure expand to their full capaeity. Beyond this point, the walls, on account of the quantity of connective tissuc entering into their structure can extend but little.

The resistance to a breaking-strain on the part of the veins is very great. It requires a higher pressure to rupture a vein than the corresponding artery.

If by external compression the various outlets be blocked, the pressure rises in the vein to the full pressure in the artery. For this reason the veins must be strong enough to bear any such increased strain. There is; however, another need for strength of veins, and that is that they may be ablc to bear the strain which may arise from external violence. The superficial veins are endowed with more muscular and elastic tissue than those deeper, while those veins which run in the muscles and in the bones, and are protected from violence and supported by firm structures, possess no muscular elements. When exposed, a superficial vein contracts on mechanical stimulation and on cooling, while it may be made to dilate on applying warmth.

Pressure in the Venous System.--In the active animal the venous pressure varies according to the hydrostatic pressure of the column of blood above the point of measurement and with the action of the muscles which express the blood onwards towards the heart. In the horizontal position, when these factors are almost eliminated, the pressure in the large vcins is found to be cqual to a few centimetres of blood, or about $5 \mathrm{~mm}$. $\mathrm{Hg}$. When a cannula is pushed down the jugular vein past the valve till its opening lies in the vena cava superior, the lateral pressure of this vein is obtained. It may become negative during inspiration. The negative pressurc which occurs in the right auricle on each cardiac oscillation is estimated at -2 to $-3 \mathrm{~mm}$. $\mathrm{Hg}$, and may become -5 to $-8 \mathrm{~mm}$. $\mathrm{Hg}$ during inspiration.

In the sheep, with the animal in the horizontal posture and im- 
mobile, during normal quiet respiration the following venous pressures have been found:

\begin{tabular}{|c|c|c|c|c|c|}
\hline & & $\mathrm{Mm} . \mathrm{Hg}$. & & & $\mathrm{Mm} . \mathrm{Hg}$ \\
\hline Left innominat & .. & $-0 \cdot 1$ & External facial & . & $3 \cdot 0$ \\
\hline Right juçular & .. & $0 \cdot 2$ & Brachial .. & .. & $4 \cdot 1$ \\
\hline Right subclavian & .. & -0.1 & Branch of the brachial & .. & $9 \cdot 0$ \\
\hline Left jugular & .. & $0 \cdot 1$ & Crural & .. & $+11 \cdot 4$ \\
\hline Left subclavian & .. & 0.6 & & & \\
\hline
\end{tabular}

It must be clearly understood that these venous pressures are only true for the animal in the horizontal posture. They vary greatly with the posture and movement of the body.

The negative pressure in the eentral veins is due to the aetion of the heart and the suetion of the thoraeie eavity produced by the elastie pull of the lungs. Owing to this negative pressure, when a large vein is opened in the neighbourhood of the thorax, air may be sueked into the eireulation. Air that has thus obtained an entry has been observed to pass right through the pulmonary eireulation and to enter the arteries. The danger of air thus entering during surgieal operations has been reeognized. A large amount of air ean be slowly injeeted into a vein without killing an animal. A rapid injeetion, such as would be eaused by blowing air into the venous eannula, kills by eausing frothing in the heart and embolism in the lungs and coronary arteries. The danger of embolism from the entry of air is mueh greater in a small than in a large animal, for the smaller the heart the less the amount of air required to hinder its aetion by frothing.

In man, the venous pressure has been measured by finding the pressure just required to prevent a eutaneous vein refilling after it has been emptied beyond a valve. The armlet, or bag, of the sphygmometer is pressed upon a suitable vein, with the limb placed at the heart level, and the vein emptied by stroking the blood on past the next valve. The pressure of the armlet, or bag, is then relaxed till the vein just refills, and the pressure read. On immobilizing the part to take sueh a measurement, the venous pressure rises; how quiekly depends on the state of dilatation of the arterioles in the limb. It is not possible thus to measure the pressure in the normal eonditions.

Rate of Flow in the Veins.-Turning to the question of the veloeity of the venous flow, it is obvious that the average input of the heart must equal the average output per seeond in order that the eireulation may eontinue. If the veins that enter the heart were of the same seetional area as the arteries that leave it, then the veloeity would be the same in these veins as in the arteries. When the venx cava are filled with blood, the total seetional area is found to be eonsiderably greater than that of the aorta. But, as normally these veins are not filled to their eapaeity, it is probable that the veloeity of the flow in them is approximately equal to that of the aorta. The veloeities in the earotid artery and the jugular vein, or in the umbilieal artery and the vein of sheep's embryo, have been measured with the stromuhr, and have been found to be almost the same. 
The valves in the veins allow the blood to be forced only towards the heart. The pumping action of walking can be observed on the veins of the back of the foot. After standing still for a time, the veins become prominent. The pressure is considerable, as can be gauged from the feel. After taking a few steps, they are emptied, squeezed between the skin and muscle.

Numerous anastomoses exist between the veins, so that, if the flow of blood be obstructed in one direction, it readily finds a passage in another.

The venous circulation is impeded by (1) a lesscning of the heart power; (2) cardiac valvular effects, such as incompetence or narrowing of the valvular orifices; (3) obstruction to the filling of the heart, as in cases of pericardial effusion; (4) obstruction of the pulmonary circulation, as by coughing and by pleuritic effusion. The results of venous congestion are less efficient circulation, a dusky appearance of the skin, a fall of cutaneous temperature, and an effusion of the fluid into the tissue spaces, producing edema or dropsy. This last effect is not due, as has been supposed, to increased capillary pressure producing increased transudation, for no such increase in venous and capillary pressure is found under the conditions. It is due to the altered nutrition of the tissues, which results from the deficient circulation. The products of katabolism which collect within them increase the osmotic properties of the tissues.

If for any reason the left ventricle fail to maintain its full systolic output, it ceases to receive the full auricular input, and in consequence the pulmonary vessels congest. This tells back on the right heart, and the right ventricle is unable to empty itself into the congested pulmonary vesscls, and this in its turn leads to venous congestion. The final result of any obstruction thus is a pooling of the blood in the venous cistcrn. Dyspnoa results from cardiac insufficiency. It is excited by the increased venosity of the blood acting on the respiratory centre. Both the excess of carbon dioxide and deficiency of oxygen increase the ac:dity of the blood, and this excites the centre. The increased respiratory movements aid the circulation.

The vascular system is so constructed that considerable changes of pressure may be brought about on the arterial side without any (or scarcely any) altcration of the pressures in the venous or pulmonary scctions of the circulatory system. A high-pressure main (the arteries) runs to all the organs, and this is supplied with taps; for by means of the vaso-motor nerves, which control the diameter of the arterioles, the straam can be turned on here or there and any part flushed with the blood, while the supply to the remaining parts is kept under control. Normally, the sum of the resistances which at any moment oppose the outflow through the capillaries is maintained at the same value, for the vascular system is so co-ordinated by the nervous system that the dilatation of the arterioles in any one organ is compcnsated for by constriction in another. Thus the arterial pressure rcmains constant, cxcept at times of grcat muscular activity.

The great splanchnic system of arterioles acts as "t'ic resisłance 
box" of the arterial system. By the constriction of thesc arteriolesduring mental or muscular activity, the blood-current through the abdominal organs is diminished, and increased through the brain and muscles; while by dilatation during rest and digestion the contrary effect is produced. The constriction of the splanchnic vessels does not scnsibly diminish the capacity of the total vascular system, for the veins relax. Thus big variations of arterial pressure, brought about by constriction or dilatation of the arterial system, produce little or no effect on the pressure in the great veins or pulmonary circuit. On the other hand, the contraction of the abdominal muscles, as we have seen, influences the diastolic or filling pressure of the heart.

Hæmorrhage and Transfusion.-The circulation may be aided by the transfusion of salt solution $(0.8$ per cent.) or blood after severe hæmorrhage, or in states of surgical shock. Only the blood of man must be used. The direct giving of blood by connecting the radial artery of a relation to the median vein of a patient has been used as a means of effecting restoration. Blood may be withdrawn from the system slowly to the cxtent of 4 per cent., rapidly to the extent of 2 per cent., of the body weight without lowering the arterial pressure, owing to the compensatory contraction of the arrerioles and the rapid absorption from the tissues into the blood. The beneficial effects of the old treatment by bleeding were probably due to this latter effect. 'The immune properties of the blood may be increased by the passage of tissue juices into it. The withdrawal of the tissue lymph excites extreme thirst and a great need for water after severc hæmorrhage. About 75 per cent. by weight of the tissucs, excluding fat and bone, consists of water. The volume of tissue lymph is unknown, but it must be considerable-perhaps greater than that of the blood. The lymphatics drain off the excess of fluid which transudes from the capillaries, and finally return it to the vascular system. The interchange between tissue, blood, and lymph, depends upon the forces of the living cells, which are as yet far from complete elucidation.

The vascular system confines the red corpuscles to its channels, but cannot be regarded as a closed system; for the fluid of the bloodplasma transudes through the capillary wall into the tissue spaces, and enters the lymphatics. Thus, if large quantitics of Ringer's solution be transfused into the circulatory system, it not only collects in the capacious reservoirs of the veins and capillaries, especially in the lungs, liver, and abdominal organs, but in the tissue spaces. Hence the pressure in the vascular system cannot be raised by the injection of enormous quantities of fluid. If the fluid part of blood be increased, capillary transudation becomes grcater, and the excess of fluid is excreted from the kidneys and glands of the alimentary canal. If the fluid part of the blood diminish, then fluid passes from the tissue spaces into the blood, and the sensation of thirst arises, and more drink is taken. 


\section{CHAPTER XXVII}

\section{THE VASO-MOTOR NERVES}

ThE bloodvessels are supplied with constrictor and dilator nerve fibres which regulate the size of the vascular bed and the distribution of the blood to the various organs. The arteries may be compared to a high-pressure main supplying a town. By means of the vasomotor nerves the arterioles (the house taps) can be opened or closed, and the current turned on to or off any organ according to its functional needs. If all the arterioles be dilated at one and the same time, the aortic pressure falls, and the blood, taking the pathways of least resistance, gravitates to the most dependent parts of the vascular system; just as, if all the taps in the town were opened at once, the pressure in the main would fail, and only the taps in the lower parts of the town would receive a supply. The discovery of the vaso-motor nerves is due to Claude Bernard (1851). He discovered that by section of the cervical sympathetic nerve he could make the ear of a rabbit flush, while by stimulation of this nerve he could make it blanch. He almost made the further discovery that stimulation of certain nerves, such as the chorda tympani supplying the salivary gland, produces an active dilatation of the bloodvessels. The vaso-constrictor fibres issuc in the anterior spinal roots (the white rami), from the second thoracic to the second lumbar root, and pass to the sympathetic chain of ganglia. The fibres are of small diameter, and probably arise from cells situated in the lateral horn of the grey matter of the spinal cord. They each have a cell station in one or other ganglion, and proceed as post-ganglionic fibres to the cervical sympathetic, to the mesenteric nerves, and back as the grey rami to join the nerves of the limbs (Fig. 457).

Nicotine paralyzes ganglion cell synapses, and by applying this test to the various ganglia the cell stations of the vaso-constrictor fibres supplying each organ have becn mapped out. The vaso-dilator fibres have not so restricted an origin, for they issue in the efferrent roots in all parts of the neural axis. The two kinds of nerves, although antagonistic in action, end in the same terminal plexus which surrounds the ressels. The presence of vaso-dilator fibres in the common nerve trunks is masked, on excitation, by the overpowering action of the vaso-constrictor nerves. The latter are, however, more rapidly fatigued than the former, and by this and other means the presence of vaso-dilator fibres, can be demonstrated in almost all parts of the body. The nervi erigentes to the penis and the chorda tympani supplying the salivary glands are the most striking examples of vaso-dilator nerves. 
The vaso-dilator nerves for the limbs issue in the posterior spinal roots. The posterior roots contain the afferent nerres (touch, pain, etc.). The same fibres serve as vaso-dilator fibres. The impulses

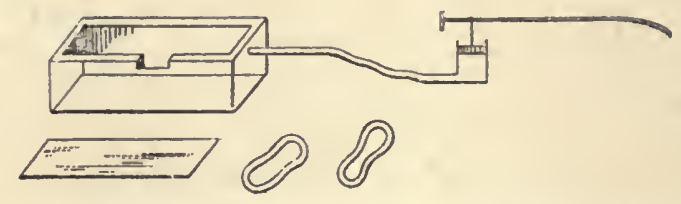

Fig. 120.-Diagray of a Plethysmograph axd Pistox Recorder.

The rubber bands fasten the glass lid in position.

which produce vaso-dilatation are termed "antidromic" (against. the stream). We know that nerre fibres conduct impulses indifferently in either direction, and that the synapsis and nerve endings control the result of such impulses.

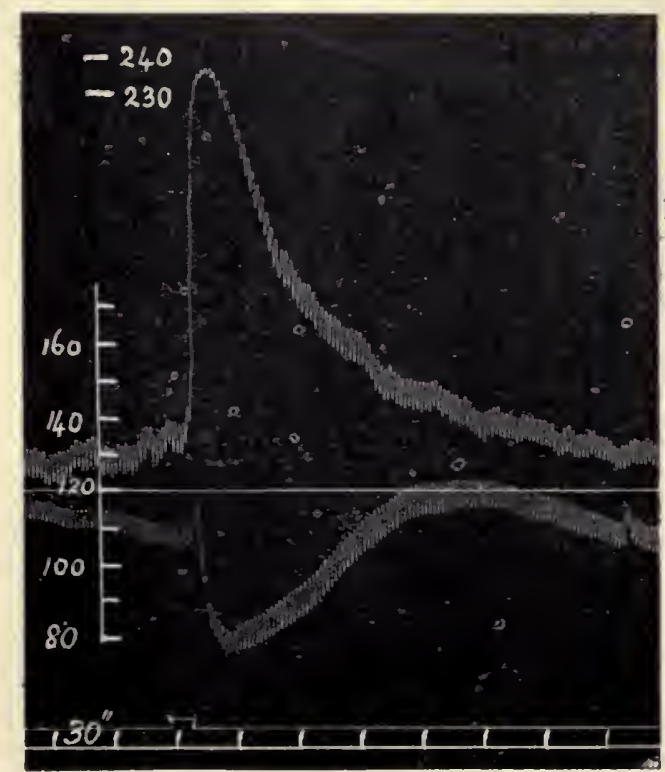

Fig. 121.-Pithed Cat : Carotid Blood-Presecte. (H. II. Lalc.)

Upper curve shows effect of 0.025 milligramme of adrenalin te'ore, lower curve of 0.1 milligramme of adrenalin after, 10 milligrammes of crgutoxir.c.

Excitation of these posterior roots causes reflexly a risc of bloodpressure, and directly a vaso-dilatation in the part the nerves supply. Thus it is assured that the irritated or injured part receives immedilately a greater supply of blood. 
The vaso-motor centre exerts a tonic influence over the calibre both of the arterial and portal systems.

Much work has been done to determine the origin and exact distribution of the vaso-motor nerves to the various organs, and the reflex conditions under which they come normally into action, and our knowledge, the fruits of these inquiries, has come to a condition of considerable exactness. This knowledge is of great practical importance to the physician, and it has been obtained entircly by experiment on living anæsthetized animals. No dissections of the dead animal could have informed us of the vaso-motor nerves. Vaso-

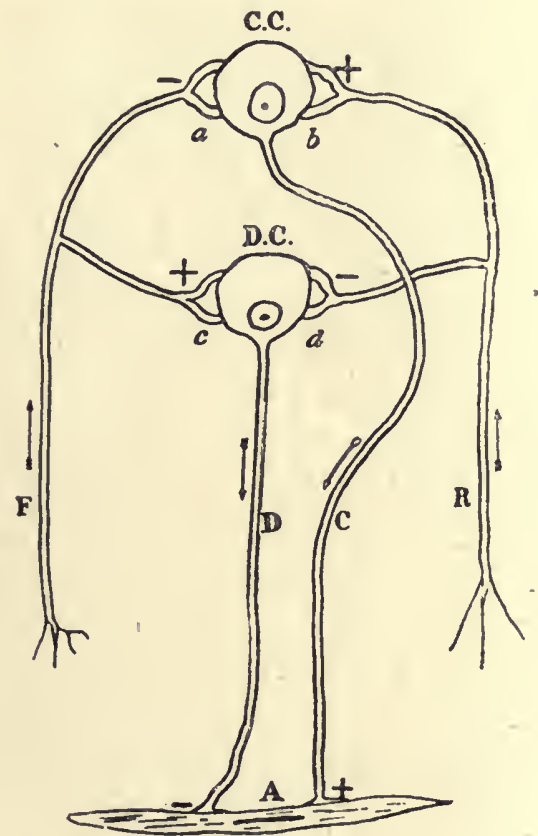

Fig. 122.

$F$, Depressor; $R$, pressor afferent impulses affeeting the arteriole musele through $C C$, vaso-eonstrictor centre, and through $D C$, vaso-dilator eentre. Effect shown by + and - signs. (Bayliss.)

motor cffects can be studied by (1) obscrving the flushing or blanching of an organ; (2) measuring the temperature of a part or organ; (3) measuring the venous outflow; (4) recording the pressure in the artery going to and the vein lcaving the organ; (5) observations on the volume of an organ. To make thesc last observations, the organ is enclosed in a suitable air-tight box, or plethysmograph, an opening being contrived for the vesscls of the organ to pass through so that the circulation may continue. The box is filled with air or water, and is connected with a recording tambour (Fig. 120).

The chief effects of vaso-constriction are an increased resistance 
and lessened flow through an organ, diminished volume and tension of the organ; the venous blood issues from it very slowly and is darker in eolour, and the temperature of the organ sinks. If a large area

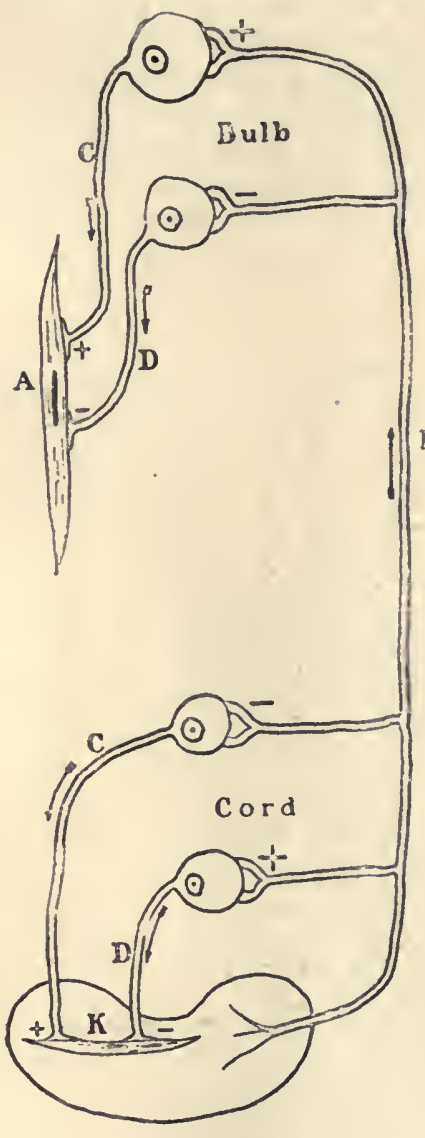

FIG. 123. be constricted, the general arterial pressure rises.

The vaso-motor centre is situated in the spinal bulb beneath the middle of the floor of the fourth ventriele. The tone of the vaseular system is not disturbed when the great brain and mid-brain is destroyed as far as the region of the pons, but as soon as the spinal bulb is injured or destroyed the arterial pressure falls very greatly, and the animal passes into a condition of surgical shoek if kept alive by artificial respiration. Painting the floor of the fourth ventricle with a loeal anæsthctic -e.g., cocaine-has the same lowering effeet on the blood-pressure. Division of the cervical spinal cord or of the splanehnie nerves lowers the bloodpressure greatly. The one lesion cuts off the whole body, the other the abdominal organs, from the tonic influenee of the eentre. The fall of pressure is due almost entirely to the pooling of the blood in the portal veins and vena cava inferior. On the other hand, eleetrical excitation of the lower end of the divided eord or splanchnic nerves raises the pressure by restoring the vascular tone. If an animal be kept alive after division of the spinal cord in the lower ccrvical region, whieh is possible, sinee the phrenies, the chief motor nerves of respiration, eome off above this region, it is found that the vaseular tone after a time becomes restored and the eondition of .shoek passes away. By no seeond seetion of the spinal eord can the general condition of shoek be reproduced, but a total destruetion of the eord onee more causes a general loss of the vascular tone. From the experimental result so obtained, it is argued that subsidiary vaso-motor centres exist in the spinal eord, and there is cvidenee to show that these eentres may be exeited reflexly. After the lumbar eord has been destroyed, the tone of the 
vessels of the lower limbs is reeovered in the course of a few days. In this ease the recovery is attributed to the ganglionie and nervous struetures which are interealated between the spinal eord and the muscular walls of the bloodvessels. There are thus three mechanisms of control: the bulbar eentre, influeneed pārtieularly by the visual, auditory, and vestibular nerves; the spinal eentres; and the peripheral ganglionie struetures.

The vaso-motor centre is reflexly excited by the afferent nerves, and its ever-varying tonic action is made up of the balance of the

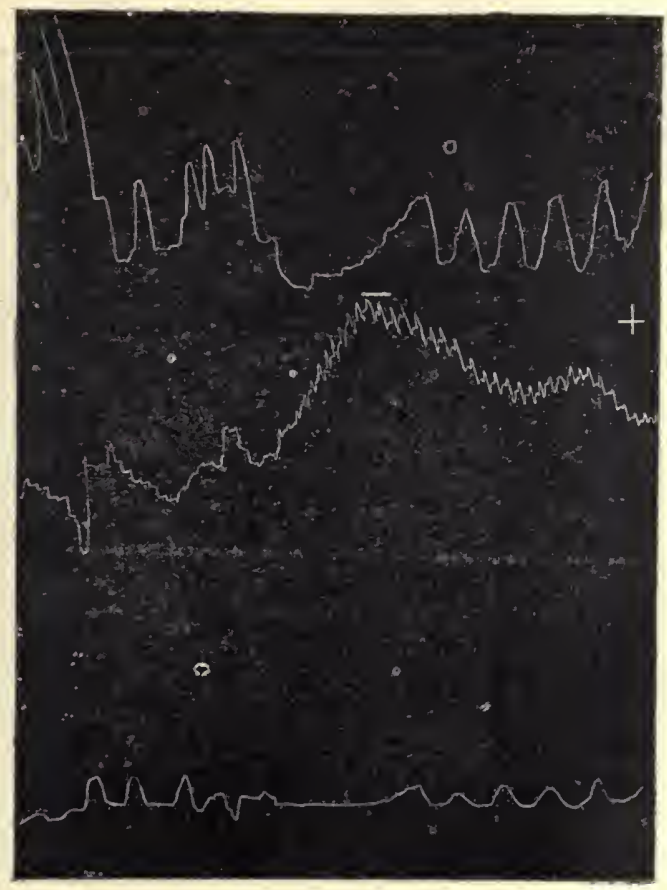

Fig. 124.-Showing the Effect of a Pleasant Taste (+) and of ax Uxpleasaxt Taste (-) Upox (1) the Volume of the Abdominal Orgaxs, (2) the Volume of the ARM, (3) the Respiration.

pressor and depressor influences which thus reach it, and from the quality of the blood which circulates through it. Pressor effeets-i.e., those causing increased constriction and rise of arterial pressure-may be produced by stimulating the eentral end of almost any afferent nerve, and especially that of a cutaneous nerve (see Fig. 84). Depressor effects are always obtained by stimulating the depressor nerve (Fig. 83), and may be obtained by stimulating the afferent ncrves under speeial conditions. There seems to be good evidenee that, after division of the vaso-constrietor nerves, dilatation of a limb can be brought about reflexly by stimulating the depressor nerve, and 
in this ease the effeet must be brought about by aetive excitation of the vaso-dilator nerves. It is probable that there are vaso-dilator fibres in sympathetic nerves. Thus adrenalin, which normally causes a rise of arterial pressure, after a dose of ergotoxine causes a fall (Fig. 121). The best explanation of this result is that vaso-dilator fibres are now stimulated. It scems probable that with depressor reflexes there is, along with the inhibition of tone in the vaso-constrietor centre, an exeitation of the vaso-dilator centre; and with pressor reflexes an excitation of the vaso-constrictor centre and an inhibition of the vaso-dilator centre (Fig. 122). When an afferent nerve from

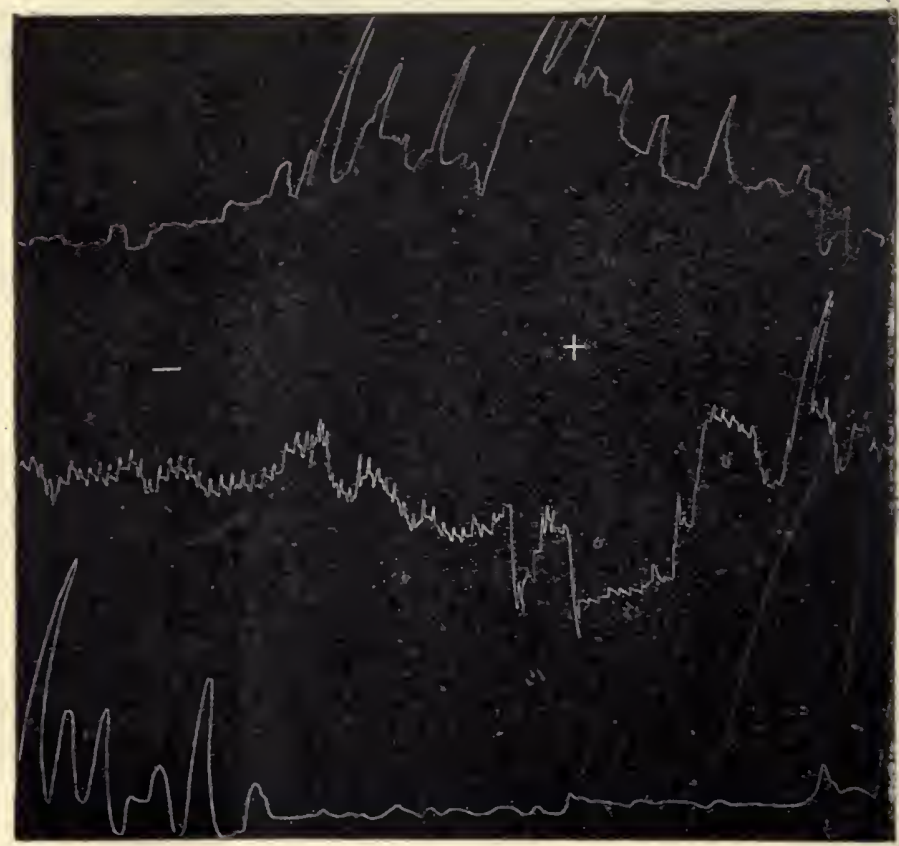

Fig. 125. - The Effect of the Suggestion to a Hypyotized Subject of his Execution ( - to + ) upox (1) the Volume of the Abdominal Organs, (2) the Volume of the Arm, (3) the Respiration.

any partieular organ-e.g., the kidney (Fig. 123) - excites the usual pressor reflex on the general blood-pressure, a vaso-dilatation is produced through spinal eentres in the organ itself, thus ensuring a maximal blood supply to the active organ. In these loeal reflexes there is excitation of eonstrictors and inhibition of vaso-dilators (Fig. 123). That these reflex vaso-motor effeets frequently oecur is shown by the blush of shame, the blanching of the face by fear, the blanehing of the skin by cold, and the, flushing which is produced by heat. The rabbit's ear blanches if its feet are put into cold water. In Fig. 124 are shown the cffects of pleasant ond-nupleasant tastes 
upon the volume of the abdominal organs, the volume of the arm, and the respiration. In like manner the effects of the suggestion of his execution to a hypnotized subject are recorded in Fig. 125. The vaso-motor mechanism is one of the most important of those mechanisms which control the body heat. Stimulation of the nasal mucous membrane causes flushing of the vessels of the head, constriction elsewhere, and a rise of arterial pressure. Food in the mouth, or even the sight or smell of food, causes dilatation of the vessels of the salivary gland. The mucous membrane of the air-passages flush and secrete more actively when a draught of cold air strikes the skin. Ice placed on the abdomen constricts not only the ressels in the skin, but those in the kidney. Many other examples might be given of the control which the vaso-motor system exerts, but the above are sufficient to suggest the influence which the physician can bring to bear on the blood-supply of the various organs. 


\section{CHAPTER XXVIII}

\section{CIRCULATION IN SPECIAL PARTS}

The Pulmonary Circulation.-The pulmonary artery, carrying venous blood, divides and subdivides, and the smallest branches end in a plexus of capillaries on the walls of the air cells of the lung. From this plexus the blood is drained by the radicles of the four pulmonary veins which open into the left auricle. The pressure in the pulmonary artery has been found to be 12 to $30 \mathrm{~mm}$. $\mathrm{Hg}$-that is, from one-third to one-sixth of the aortic pressure; the blood also takes only one-third of the time to complcte the pulmonary circuit that it takes to make the systemic. The four chief factors which influence the pulmonary circulation are--(1) the force and output of the right ventricle; (2) the diastolic filling action of the left auricle and ventricle; (3) the diameter of the pulmonary capillaries, which varies with the respiratory expansion of the lungs; $(4)$ the intrathoracic pressure.

In inspiration, the lungs are distended in consequence of the greater positive pressure on the inner surfaces being greater than the negative pressurc on their outer pleural surfaces. The negative pressure in the intrathoracic cavity results from the enlargement of the thorax by the inspiratory muscles. When the elastic lungs are distended by a full inspiration, they exert an elastic traction amounting to about $15 \mathrm{~mm}$. Hg. The heart and vessels within the thorax are submitted to this traction-that is, to the pressure of the atmosphere.minus $15 \mathrm{~mm} . \mathrm{Hg}$ - while the vascular system of the rest of the body bears the full atmospheric pressure. The thin-walled auricles and veins yield more to this elastic traction than the thick-walled ventricles and arteries. Thus, inspiration exerts a suction action which furthers the filling of the veins and auricles. This action is assisted by the positive pressure exerted by the descending diaphragm on the contents of the abdomen. Blood is thus both pushed and sucked into the heart in increased amount during inspiration.

Experiment has shown that the bloodvessels of the lungs when distended are wider than those of collapsed lungs. Suppose an elastic bag having minute tubes in its walls be dilated by blowing into it, the lumina of the tubes will be lessened, and the same occurs in the lungs if they are artificially inflated with air; but if the bag be placed in a glass bottle, and the pressure on its outer surface be diminished by removing air from the space between the bag and the side of the bottle, the bag will distend and the lumina of the tubes be increased. 'Thus, it seems that inspiration, by increasing the calibre of the pulmonary vessels, draws blood into the lungs, and the movements of the lungs become an effective force in carrying on the pulmonary 
circulation. It has been estimated that there is about one-twelfth of the whole blood quantum in the lungs during inspiration, and onefifteenth during expiration. The great degree of distensibility of the pulmonary vesscls allows of frequent adjustments being made, so that within wide limits as much blood in a given time will pass through the pulmonary as through the systemic system. The limits of their adjustment may, however, be exceeded during violent muscular exertion. The compressive action of the skeletal muscles returns the blood to the venous cistern, and if more arrives than can be transmitted through the lungs and oxygenated in a given time, the right heart becomes engorged, breathlessness occurs, and signs of venous congestion appear in the flushed face and turgid veins. The weaker the musculature of the heart, the more likely is this to occur, hence the breathlessness on exertion which characterizes cardiac affections. Any œdema of the lung resulting from its congestion also impedes the passage in of oxygen. Hence the benefit of oxygen inhalation in strenuous excrcise. The training of an athlete consists largely in developing and adjusting his heart to meet this strain. Similarly, the weak heart may be trained and improved by carefully adjusted exercise.

Rhythmic compression of the thorax is the method of resuscitation from suffocation, for this not only aerates the lungs, but produces a circulation of blood. By compressing the abdomen to fill the heart, and then compressing the thorax to empty it, the valves meanwhile directing the flow, a pressure of blood can be maintained in the aorta even when the heart has ceased to beat, and this if patiently continued may lead to renewal of the heart-beat.

As regards the effect of breathing upon the arterial blood-pressure, the results are complex. It is generally stated that inspiration at first causcs a fall and then a rise of blood-pressure, and that expiration causes first a rise and then a fall. The rate of the heart-beat is also affected during these times, being, when the vagi are intact, slower in expiration and quickened by inspiration.

In animals under decp anæsthesia the inspiratory rise is due to lessened pressure in the pericardium, and the consequent increased filling of the heart. It is abolished by allowing free access of air to the pericardial sac.

In man sphygmographic tracings, taken by the suspension method (Fig. 98), show that the cffect on the artcrial pressure varies with. the type of breathing (see p. 191).

A deep breath generally produces a fall, often accompanied by the so-called pulsus paradoxus, an alteration in rhythm often considered to have a pathological import, but normal in sleeping dogs, and of occasional occurrence in boys at the time of adolescence.

The pulmonary circuit may be shut off to a large cxtent in animals under artificial respiration, with little or no effect upon the arteriat blood-pressure. Ligation of the vesscls of the left lung produced in eighteen cases no noticeable cffect on the output of the heart per sccond. Of the other thirteen, in elcven the pressure was decreased 
6 to 10 per cent., in two 18 to 20 per cent. The lungs and their circulation in men are arranged to meet a demand ten times that of the resting condition. A rise of arterial blood-pressure is obtained in Valsalva's experiment-a deep expiration with the nose shut-and is due to the greatly increased abdominal pressure. In this condition and in coughing this pressure as measured per rectum may rise as high as $94 \mathrm{~mm}$. $\mathrm{Hg}$. In deep abdominal breathing it may rise to $30 \mathrm{~mm}$. $\mathrm{Hg}$, showing a respiratory variation of $20 \mathrm{~mm}$. Hg.

The evidence that the pulmonary arteries are controlled by vasomotor nerves is conflicting. In the intact animal it is difficult to determine whether a rise of pressurc in the pulmonary artery is produced really by constriction of the pulmonary system or by changes in the output of the heart; hence different observers have reached conflicting conclusions. When the lungs have been supplied with an artificial circulation and a constant head of pressure, to eliminatc the action of the heart, no diminution in outflow has bcen observed on exciting the branches of the vagus or sympathetic nerves which supply the lungs.

The use of adrenalin, which causes vaso-constriction when perfused through organs possessing vaso-constrictor nerves, has given conflicting results. This is apparently due to the fact that different preparations and compounds of adrenalin have been used. With adrenalin itself there is evidence of vaso-constriction; with adrenalin chloride there is no evidence of such. The vaso-constriction when produced is, however, not of a very marked character. Weighing the evidence, it would appear that the pulmonary vessels may possess vaso-constrictor nerves, but that the action of these is far less marked than that of the nerves to other organs.

The Coronary Circulation.- The heart is supplied with blood from the two coronary arteries, which arise from the aorta just above the semilunar valves. The arteries supply both auricles and ventricles, and their terminal ramifications run deep into the muscle. The heart becomes flushed and supplied with blood during each diastole; with each systole the heart pales and the blood is expressed into the right auricle through the coronary sinus. To determine the existence of coronary vaso-constrictor and of vaso-dilator fibres is a complex matter, since stimulation of the effector nerves, the ragus and the sympathetic, also affect the heart muscle. During stimulation of the vagus with the heart in situ, it is claimed that a marked vaso-dilatation of the smaller arterics can be secn with the aid of a hand lens. On the isolated perfused heart, stimulation of the vagus, according to some observers, yields a diminished outflow from the coronary reins, evidence of raso-constriction; stimulation of the sympathetic, an increased outflow, evidence of vaso-dilatation. In perhaps the most trustworthy of those experiments performed on the perfused heart, neither vagus nor sympathetic gave evidence of any effect whatsoever on the calibre of the coronary arteries. This is confirmed by the fact that adrenalin is also without apparent effect when perfused through the coronary vessels. 
The Cerebral Circulation.-The circulation of the brain is somewhat peculiar, since this organ is cnclosed in a rigid bony covering. The limbs, glands, and viscera, are enclosed in connective-tissue sheaths, but can expand when the blood-pressure rises; the expansion of the brain, on the other hand, is confined. The circulation in the marrow of bones resembles that in the brain and spinal cord.

In 1783, Alexander Monro the younger put forward the view that the quantity of blood within the cranium is almost invariable. "For being enclosed in a casc of bone," he writes, "the blood must be continually flowing out of the veins, that room may be given to the blood which is entering by the arteries. For as the substance of the brain, like that of the other solids of our body, is nearly incompressible, the quantity of blood within the head must be the same at all times, whether in health or disease, in life or after death, those cases only excepted in which water or other matter is effused or secretcd from the bloodvessels; for in these a quantity of blood equal in bulk to the effused matter will be pressed out of the cranium."

These facts are confirmed by experiment. If a glass plate be serewed into a trephine holc, on compressing the innominate and subclavian arteries, the pial arteries can be seen to become less in size. The brain, however, does not collapse or retreat from the glass window. If the arteries empty, the veins fill. If, on the other hand, the glass window be faultily placed, and allow leakage into the cranial cavity, air passes within; and the brain collapses under atmospheric pressure. This experiment proves that the brain in the closed cranium can by no means completely empty itself of blood, even though the arterial pressure should fall to zero.

Similarly, if an animal be placed in the vertical feet-down position, and the skull be trephined, then, on opening the dura mater, the brain, which before was in close apposition with that membrane, can be seen collapsing, as it is emptied of blood by atmospheric pressure. The quantity of cerebro-spinal fluid which moistens the surface of the brain is not large, and the blood-content of the brain can vary suddenly only to a slight degree by displacement of the cerebro-spinal fluid.

No sure evidence of the condition of the cerebral circulation can be drawn from examination of the brain after death, for in many different ways the relative volume of blood and the serous fluid within the cranium may be altored by post-mortem changes. By slow changes there can come about more blood and less tissue fluid and brain substance in the skull, or less blood and more brain substance and fluid. In inflammatory states brain substance may undergo lysis, and be carried away by the blood-strcam, and the bloodvessels dilate and hold more blood. The balance between volume of brain substance and blood must continually vary with the metabolism of this organ.

The conditions affecting the cerebral circulation may be studied by simultaneously recording (1) the aortic pressure, (2) the vena: cava pressure, (3) the intracranial pressure, (4) the cerebral venous pressure - the cranium being, as in the normal condition, a closed cavity. 
To effect this the intracranial pressure is measured by mcans of a brain-pressure gauge (Fig. 126), while the cerebral venous pressure is obtained by screwing a cannula into the torcular Herophili, a bony cavity within the occiput of the dog. The pressure of the cerebrospinal fluid can be measured by trcphining the atlas, opening the dura mater, screwing a tube into the trephine hole, and connecting this tube with a water manometer.

By these means the following principles of the cerebral circulation have been determined:

When the aortic pressure rises, the expansion of cerebral volume can take place only to a certain limited amount; for as soon as all the cerebro-spinal fluid has been driven out of the cranium, the brain is everywhere in contact with the rigid wall of the skull. Any further expansion of the arteries can only take place by an equivalent compression of veins, for the semi-fluid brain matter is incompressible. The reservoirs of blood in the veins will, therefore, be so far constricted, until the cerebral vcnous pressure rises to the prassure of the brain against these veins. Thus, as the arterial pressure 1 ises, the whole circulatory system of the brain will assimilate itself more and

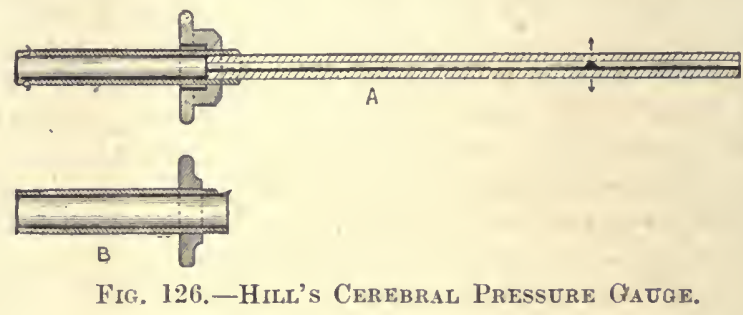

more to a scheme of rigid tubes. Thus the velocity of the blood-flow will be increased, and the relative distribution of the blood in the arteries, capillaries, and veins, will bc changed.

The intracranial pressure is in all physiological conditions the same as the cerebral venous pressure. The intracranial pressure, or pressure of brain against skull wall, is, in fact, that pressure which remains after the force of the heart has been expended in driving the blood through the cerebral arterioles. It is therefore an ever-varying quantity.

In the normal conditions, with the animal in the horizontal position, the intracranial pressure may approximate to about $100 \mathrm{~mm} . \mathrm{H}_{2} \mathrm{O}$.

In the spasms of strychnine-poisoning the intracranial tension may rise to 40 to $50 \mathrm{~mm}$. $\mathrm{Hg}$. Th's is dce, not only to the rise of arterial pressure, but to the rise of vena cava pressure produced by general muscular spasm.

The intracranial or cerebral venous pressure varies directly with changes in rena cara pressure, but only proportionately with those in aortic pressure. If the torcular Herophili be opened in a freshly killed animal, and the abdominal vcins be compressed, venous blood can be driven out of the torcular in a continuous stream. Between 
the rena cava and the torcular there lies no appreciable resistance; between the aorta and the cerebral capillaries or veins therc lics the resistance of the arterioles.

Every change in the position of an animal, owing to the influence of gravity on the vascular system, affects the cerebral circulation. Every variation in respiration and every muscular movement is followed by passive changes in the circulation of the brain. Compression of the jugular veins or the abdomen causes a marked rise in cerebral venous pressure. The movements of the muscles on the neck by pressing on the jugular vein are sufficient to affect the cerebral circulation.

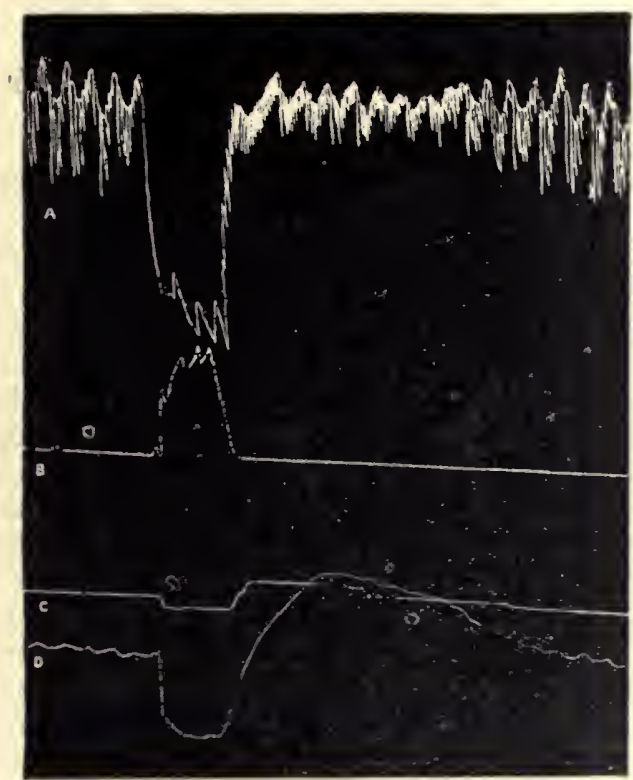

Fig. 127.-To show Effect of Stimulatixg Peripheral Exd of the Vagus on the Cerebral Pressure.

$A$, Carotid pressure; $B$, right auricle; $C$, intracranial pressure; $D$, torcular pressure.

Every stimulus that enters the organism and affects the general vaso-motor centre produces a passive cffect on the cerebral circulation. It is by means of the great splanchnic area that the blood-supply to the brain is controlled. An anæmia of the spinal bulb excites the vaso-motor centre; the splanchnic vessels constrict, the blood-pressure rises, and more blood is driven through the brain. At the same time the respiratory centre is excited, and by the increased action of the respiratory pump more blood is driven to the right heart, and thence to the brain. We have in the vaso-motor centre a protective mechanism by which blood can bc drawn at need from the abdomen and supplied to the brain. At the moment that excitation from the 
outside world demands cerebral response, the splanehnic abea constricts, and more blood is driven through the brain.

The arterial supply to the brain is in the lower animals so superabundant that in the dog four of the arteries-two common carotids and two vertebrals - which supply the brain can be ticd in the course of ten minutes, and yet the animal either at once, or after a temporary period of idioey and paralysis, completely recovers. In the monkey, on the other hand, ligation in one operation of the two carotids and one vertebral artery produces either death in twenty-four hours or softening of the great brain, aceompanied by idiocy and paralysis of movement and sensation. The efficiency of anastomosis through the circle of Willis varies in different individuals. Sudden compression of one common carotid artery in some men produces epileptic spasm, and ligation of this artery has been followed in some by more or less temporary paralysis on the opposite side of the body; in others the effect is nil.

Whether the cerebral arteries are supplied with vaso-motor nerves is very doubtful. The usual methods of investigation give no evidence of these in the brain of the intact animal. After establishing an artificial circulation of the brain, the addition of adrenalin to the nutritive fluid is stated to reduce the outflow; and it is supposed that adrenalin acts by stimulating the ends of the vasomotor nerves, rather than by stimulating the muscular coats of the arteries. The veins of the pia and dura mater have no middle muscular coats and no valres. The venous blood emerges from the skull in man mainly through the opening of the lateral sinuses into the internal jugular vein; there are communications between the eavernous sinuses and the ophthalmic veins of the facial system, and with the venous plexuses of the spinal cord. The points of emergence of the reins are well protected from closure by compression. The brain can regulate its own blood-supply by means of the cardiac and vaso-motor centres. Deficient supply to these eentres excites increased frequency of the heart and constriction of the arteries, especially those of the great splanchnic area. Cerebral excitement has the same effect, so that the aetive brain is assured of a greater blood-supply. As the brain in the processes of ideation, etc., acts as a whole, vaso-motor nerves for locally controlling the cerebral eirculation seem unneeessary.

The Circulation in the Head.-The vaso-constrietor fibres for the head issue from the spinal cord by the upper thoracic anterior roots ( 1 to 5 in the dog), and pass into the cervical sympathetie nerve.

The vaso-dilator supply to the face and mouth also issues from the upper thoracic roots, and passes up the cervical sympathetie nerve to the Gasserian ganglion, and thence to the fifth nerve. Some of the dilator fibres issue directly from the cranial origin of the fifth nerve, for stimulation of this nerve between the pons and the Gasscrian ganglion flushes the face. Excitation of the lingual and glossopharyngeal nerves dilates the vessels of the tonguc, while stimulation of the hypoglossal nerve constricts that organ. These constrictor fibres come from the superior cervical sympathetic ganglion. 
The circulation in the mucous membranc of the mouth has been examined by direct observation, while the volume of the torigue can be investigated with a suitable plethysmograph. By observing the effects of section or excitation of the cervical and thoracic sympathetie nerves during ophthalmoscopic examination of the eye in the curarized rabbit, both vaso-constrictor and vaso-dilator nerves have beén ascribed to this organ, but the evidence in support of such nerves is far from strong.

The Salivary Glands.-The vaso-constrictor fibres to the submaxillary gland issue from the first to the second or the second to the third thoracic anterior roots, and pass up the cervical sympathetie nerve. The cell stations for these fibres lic in the supcrior cervical ganglion.

The vaso-dilator fibres to the submaxillary gland pass by way of the chorda tympani from the facial nerve, and have their cell stations in contiguity with the gland. The vaso-dilator fibres to the parotid gland issue from the glosso-pharyngeal nerve, and pass to the gland by way of the auriculo-temporal nerve. The circulation in these glands has been studied by placing a cannula in an efferent vein and observing the outflow, or by exposing the gland and directly inspecting its colour.

The Circulation through the Limbs.-By far the greater quantity of the blood, 50 to 70 per cent., lies within the roomy reservoirs of the abdominal and thoracic organs. From thence, by means of the vaso-motor mechanism, the blood is distributed to the locomotor organs at need in times of activity.

In the organs of locomotion, the quantity of blood during rest has been roughly estimated to be 36 per cent., and during activity 66 per cent., of the whole blood quantum.

The blood-flow from the deep femoral vein of the dog during an epileptic fit (excited by essential oil of absinthe) is three to five times as great as during rest. The contraction of the muscles expresses the blood which is within them on into the veins.

Similarly, massage greatly increases the flow of blood through the muscles. Massage of a considerable muscular area produces a fall of general arterial pressure, in conscquence of the deviation of blood into the dilated muscular vessels. This fall may amount to one-fifth of the initial pressure. Warmth also greatly increases the blood-flow.

In the curarized animal the outflow from the muscular veins of the lower limb is increased on excitation of the motor nerves. Vasodilator fibres must run, therefore, in these nerves. On the other hand, evidence of a diminished outflow on stimulation of the peripheral end of the abdominal sympathetic has becn obtained in the curarized dog. We must therefore admit the existence of vaso-constrictor fibres. They are, however, but poorly developed in the inuscles.

At times of great muscular effort a man closes his glottis, and holds compressed his thorax and abdomen. By this means the intrathoracie and intra-abdominal pressures are raised, the outlet from the veins 
of the face and limbs impeded. Hence the veins stand out "knotted" in a straining man, and the pressure rises within them towards arterial pressure.

During a run the rhythmic movements help to pump the blood through the muscles and back to the heart. The control of the bloodsupply to the limbs has been studied by the thermometric or plethysmographic method. The temperature in the upper limb is raised by

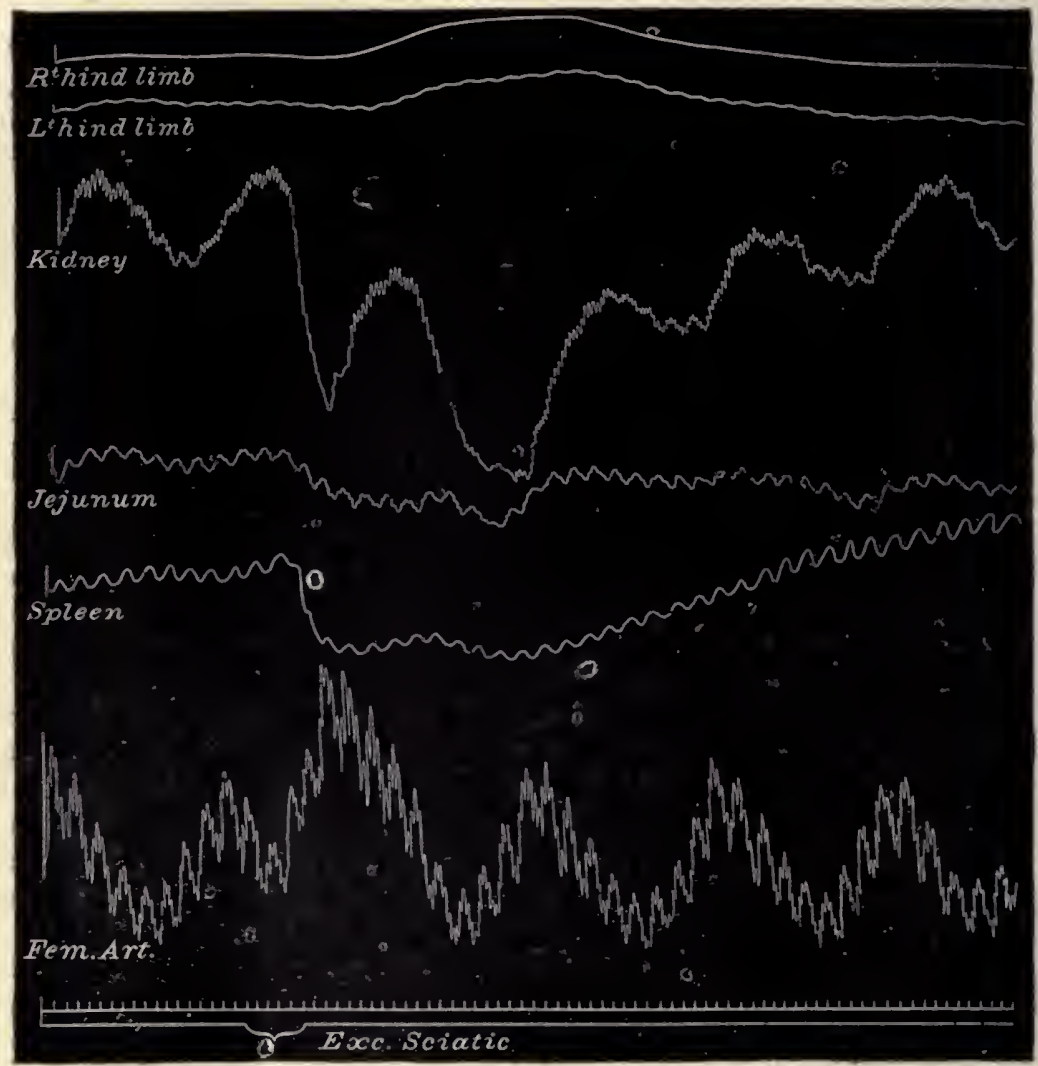

Fig. 128. - To show Effect of Excitation of the Superficial Branch of Crural. Nerve on tie Arterial Pressure and on the Volume of tue Splees, JejUNUM, KidNey, ANd Feet. (Hallion and François-Frank.)

destruction of the first thoracic ganglion, by section of the brachial plexus or mid-thoracic roots. In the hind-limb a rise of tcmperaturc occurs after dividing the sciatic nerve. The vaso-motor fibres have been traced to the lower thoracic roots. They pass down the sympathetic chain in the lower lumbar region. On excitation of thesc vasomotor nerves, the greatest change of temperature is found in the fcet. 'This is so kecause the pad of an animal's foot is frec from a furry coat, 
and thus forms one of the more important places for the regulation of the temperature of the body.

With the aid of the plethysmograph, the vaso-motor nerves of the limbs have been minutely studied. The vaso-constrictor fibres which supply the fore-limb leave by the anterior roots from the third to the cleventh thoracic nerves. The hind-limb is supplied by fibres. from the eleventh thoracic to the third lumbar nerve.

By each root the volume of the whole limb is effected.

The chief outflow of constrictor fibres occurs from the sixth dorsal to the first lumbar nerve. Thus the limbs and the abdominal viscera get their supply approximately from the same part of the spinal cord. The vaso-motor mechanism of the limbs is not powerfully developed.

By stimulation of a sensory nerve of a limb the vessels of that limb expand, and elsewhere the vessels constrict. Usually, the other limbs expand owing to the passive dilatation produced by rise of aortic pressure which follows the reflex constriction of the splanchnic vessels. The reflex constriction of these limbs can be obtained after section of the splanchnic nerves.

The sympathetic cell station for the fibres of the upper limb is the stellate ganglion; of the hind-limb, the sixth, seventh lumbar, and first sacral ganglia. The vaso-motor fibres to the trunk follow the same distribution as the pilomotor fibres.

The general changes which take place on exciting the central end of an afferent nerve are shown exceedingly well in Fig. 128. In this there is shown a simultaneous record of-

1. The pressure in the femoral artery

2. The volume of the spleen.

3. The volume of the jejunum.

4. The volume of the kidney.

5. The volume of the left hind-limb.

6. The volume of the right hind-limb (innervated).

On exciting the central end of the left sciatic nerve, the arterial pressure rises, and the spleen, jejunum, and kidney, constrict. The right foot is passively expanded by the rise of arterial pressure. There next occurs a compensatory slowing of the heart, accompanied by active dilatation of the left limb. The arterial pressure then falls to a lower height.

The volume of the limbs depends both upon the arterial and the vena cava pressure. If the artcrial pressure and the venous pressure rise, as on performing a Valsalva experiment, then the volume of the limb increases'greatly. Here the venous pressurc rises towards the mean arterial pressure, for the outlct of the veins is blocked by the rise of intrathoracic pressure. If the vena cava pressure rises while the arterial pressure falls, the two effects may balance each other, and the volume of the limb remain constant.

The tracing of the limb volume shows all the respiratory and cardiac oscillations. The limb may expand most either with expiration or 
with inspiration, according as the expiratory rise of vena cava pressure or the inspiratory rise of arterial pressurc has the greater effect.

During Traube-Hering oscillations of arterial pressure, the volume of a limb follows the rise and fall of aortic pressure.

It has been said that an antagonism exists between the vaso-motor mechanisms of the splanchnic and locomotor organs. Thus, while during asphyxia the splanchnic vascular area constricts, the vesscls of the skin and muscles dilate. The dilatation of the latter, however, is in all probability not occasioned by active dilatation, but is due to the overmastering power of the splanchnic constrictors. By the rise of aortic pressure the vessels in the remaining parts of the body are passively dilated, and the blood-flow is thus increased through the skin and muscles. That this is so is suggested by the fact that after the circulation has, by ligation of the thoracic aorta and vena cava inferior, been limited to the fore part of the body, either asphyxia or excitation of the vaso-motor centre produces a slight rise of arterial pressure, owing to the constriction of the vascular areas of the facc and fore-limbs. Previous to the double ligation the same excitation produces splanchnic constriction, a great rise of aortic pressure, and dilatation in the face and fore-limbs. Plethysmographic evidence of constriction of the leg has been obtained during asphyxia.

Whether the dilatation of the locomotor organs be active or passive is of no particular importance. The fact remains that the splanchnic area forms the chief seat of varying resistance, and when the splanchnic vessels are constricted the blood is driven with increased velocity through the locomotor organs, and is determined froin the decp to the superficial parts of the body.

The Portal Circulation.- - The portal circulation is peculiar in that the blood passes through two -sets of capillaries. Arterial blood is conveyed to the capillary networks of the stomach, spleen, pancreas, and intestines, by branches of the abdcminal aorta. The portal vein is formed by the confluence of the mesenteric veins with the splenic vein, which together drain these capillaries. The portal blood breaks up into a second plexus of capillaries within the substance of the liver. The hepatic veins carry the blood from this plexus into the inferior vena cava. Ligation of the portal vein causes intense congestion of the abdominal vessels, and so distensile are these that they can hold nearly all the blood in the body; thus, the arterial pressure quickly falls, and the animal dies just as if it had been bled to death. The fortal circulation is largely maintained by the action of the respiratory pump, the peristaltic movements of the intestinc, and the rhythmic contractions of the spleen; these agencies help to drive the blood through the second set of capillaries in the liver. The systole of the heart may tell back on the liver and cause it to swell, for there are no valves between it and the inferior vena cava, when there is obstruction in the right heart or pulmonary circulation. The increased respiration which results from muscular exercisc greatly furthers the hepatic circulation, increasing at the samc time the consumption of food material. Thus exercise relieves the overfed man. 
The liver is so vaseular and distensile that it may hold one-quar.cr of the blood in the body.

The hepatic branches of the portal vein are supplied by vasoconstrictor fibres issuing by the anterior roots from the third to the eleventh thoracic nerves.

Vaso-constrictor nerves run to the mesenteric arteries in the splanchnic nerves from the fifth downwards. They have cell stations in the semilunar ganglia. The upper roots go to the duodenum and jejunum, the lower to the ileum and colon. The splanchnics also contain vaso-dilator fibres. They issue especially in the eleventh to the thirteenth thoracic roots. Stimulation of these nerves gives a

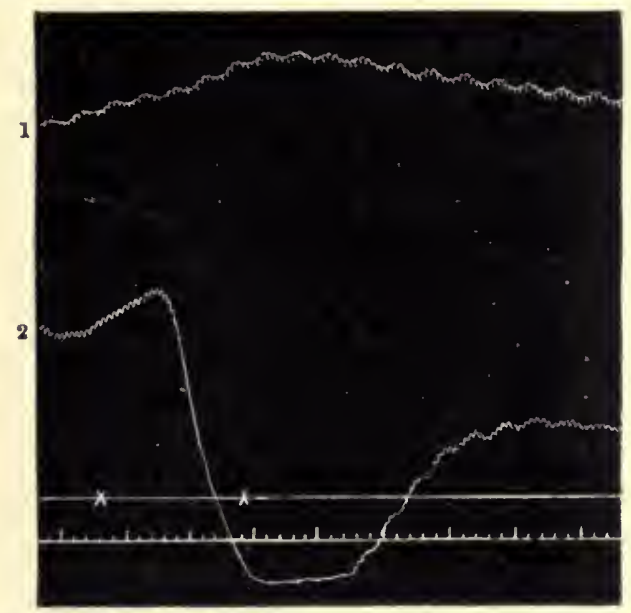

Fig. 129.-Arterial Pressure (1) axd Oxcometer Tracixg (2) of Kidney VoudMe. (Bradford.)

Between the points starred the tenth dorsal root was excited. The time is marked in seconds.

prcliminary constriction, followed by a dilatation. The usual effect, therefore, on the arterial pressure, of stimulating the peripheral end of the splanchnic, is a big rise followed by a fall of pressure.

The spleen is supplied through the splanchnic nerves with constrictor and inhibitory fibres. The existence of such has been demonstrated by oncometry. During digestion this organ shows rhythmic phases of expansion and contraction occurring at the rate of onc per minute. In addition, as digestion procceds, it gradually expands for several hours, and then returns slowly to its original size. The spleen therefore acts as a blood-reservoir in the portal circulation.

The Renal Circulation.-The circulation in the kidney is studied with great ease by the plcthysmographic method. A metal oncometer was first used for this purpose. A suitable box can be moulded with- 
out difficulty out of gutta-percha (Fig. 120). The kidney, having been: exposed by a lumbar incision, is drawn out of the wound and placed in the box. The pedicle of the kidncy passes out through a groovein one side of the chamber. The box is closed by a glass cover, and this is madc air-tight by a free application of thick vaseline. The alterations in the volume of the kidney are recorded by means of a tambour. The tracing of renal volume follows exactly the curve of arterial pressure, and exhibits both the cardiac and respiratory oscillations.

Excitation of the splanchnic nerves produces constriction of the kidney. The renal vaso-motor fibres to the anterior roots arise from the sixth to the thirteenth thoracic nerves. Most of the renal vasomotor fibres are found in the eleventh, twclfth, and thirteenth nerves.

By reflex excitation it is more common to obtain contraction than cxpansion of the kidney, but expansion is frequently witnessed when the central ends of the eleventh, twelfth, and thirteenth posteriorthoracic roots are stimulated. Vaso-dilator fibres in the anterior roots are evidenced by employing a slow rate of excitation (onc per second).

Injections of normal saline, or of a 2 to 3 per cent. solution of caffeine of soda, double the velocity of blood-flow in the renal artery, as measured by the stromuhr. This occurs after scction of the renal ncrves. Hence the diuretic action of these drugs. If urea be injected, it produces local dilatation of the kidney, while it excites the vaso-motor centre and causes general vaso-constriction.

The Circulation in the Generative Organs.-Excitation of the first. and second sacral nerves in the dog produces erection of the penis. The existence has been demonstrated of a centre in the lumbar region of the cord, by means of which erection can be reflexly excited. In the rabbit, monkey, and cat, the vaso-dilators run in the second and third anterior sacral roots.

The outflow from the vena pudenda communis is increased as much as eight times on excitation of the nervi erigentes. The vaso-constrictor fibres issue from the third, fourth, and fifth lumbar anterior roots.

The internal generative organs are supplied with vaso-constrictornerves from the lumbar anterior roots.

All the vaso-constrictor fibres to the generative organs pass through cells stationed in the inferior mesenteric and sacral ganglia of the sympathetic. The raso-dilator nerves pass through cell stations in scattered ganglia situated near these organs.

The Fœtal Circulation.-In the mature fœtus, the fluid brought from the placenta by the fotal umbilical vein is partly conveyed at once to the vena cava ascendens by means of the ductus venosus, and partly flows through two trunks that unite with the portal vein, returning the blood from the intestines into the substance of the liver, thence to be carried back to the vena cava by the hepatic vein. Having thus been transmitted through the placenta and the liver, the blood. 
that enters the vena cava is purely arterial in character; but, being mixed in the vessels with the venous blood returned from the trunk and lower extremities, it loses this character in some degree by the time it reaches the heart. In the right auricle, which it then enters, it would also be mixed with the venous blood brought down from the head and upper extremities by the descending vena cava, were it not. that a provision exists to impede (if it does not entirely prevent) any further admixture. This consists in the arrangement of the Eustachian valve, which directs the arterial current (that flows upwards through the ascending vena cava) into the left side of the heart, through the foramen ovale-an opening in the septum between the auricleswhilst it directs the venous current (that is being returned by the superior vena cava) into the right ventricle. When the ventricles contract, the arterial blood contained in the left is propelled into the ascending aorta, and supplies the branches that proceed to the head and upper extremities before it undergoes any further admixture; while the venous blood contained in the right ventricle is forced into the pulmonary artery, and thus through the ductus arteriosusbranching off from the pulmonary artery before it passes to the two lungs-into the descending aorta, mingling with the arterial currents which that vessel previously conveyed, and thus supplying the trunk and lower extremities with a mixed fluid. A portion of this is conveyed by the umbilical arteries to the placenta, in which it undergoes the renovating influence of the maternal blood, and from which it is returned in a state of purity. In consequence of this arrangement the head and upper extremities are supplied with pure blood returning from the placenta, whilst the rest of the body receives blood that is partly venous. This is probably the explanation of the fact that the head and upper extremities are most developed, and from their weight occupy the inferior position in the uterus. At birth the course of the circulation undergoes changes. As soon as the lungs are distended by the first inspiration, a portion of the blood of the pulmonary artery is diverted into them and undergoes aeration; and, as this. portion increases with the full activity of the lungs, the ductus arteriosus gradually shrinks, and its cavity finally becomes obliterated. At the same time the foramen ovale is closed by a valvular fold, and thus the direct communication between the two auricles is cut off. When these changes have been accomplished, the circulation, which was before carried on upon the plan of that of the higher reptiles, becomes that of the complete warm-blooded animal, all the blood which has been returned in a venous state to the right side of the heart being transmitted through the lungs before it can reach the left side or be propelled from its arterial trunks.

After birth the umbilical artcries shrink and close up, and become the lateral ligaments of the bladder, while their upper parts remain as the superior vesical arteries. The umbilical vein becomes the ligamentum teres. The ductus venosus also shrinks, and finally is closcd. The foramen ovale is closed, and the ductus arteriosus shrivels. and becomes the ligamentum arteriosum. 


\section{CHAPTER XXIX}

\section{LYMPH}

By means of the circulatory system the blood is taken to the great network of capillaries which ramify in their myriads amid the various tissucs of the body. Since, however, this blood capillary system is a closed one, blood itself does not come into actual contact with the tissue cells themselves.* These cells are bathed in a fluid-the tissue fluid, or lymph - and it is this fluid which finally takes to the tissues the substances necessary for their proper nutrition and adequate working, and takes from them the products of their activity.

The lymphatic system is a most extensive one. It consists of the interstitial or lacunar spaces which exist in almost all parts of the body; the delicate lymphatic capillaries; the larger lymphatic vessels, which ultimately unite to form the thoracic duct or the right lymphatic duct; the lymphatic tissues of the body, such as the lymphatic glands; and the lymphatic tissue incorporated in the spleen, thymus, etc. The large serous spaces, such as the peritoneum, pericardium, may. also be included in this system.

For many years past the exact relationship between the interstitial spaces and the lymphatic vessels has been the subject of considerable discussion. One view, formerly accorded almost gencral acceptation, is that the interstitial spaces, or lacunæ, communicate directly with the delicate lymph capillaries, which in turn unite to form larger channels or lymphatics, and ultimately open into the venous system by the thoracic duct or the right lymphatic duct.

According to this view, the tissue fluids bathing the cells and the lymph flowing from a lymphatic duct are one and the same fluid, since there is absolute continuity between the duct lumen and the tissue spaces. Another view, which has recently gained much support, is that the interstitial tissue spaces do not directly communicate with the lymph capillaries. The lymphatic system, according to this view, is, as regards the tissue spaccs, a closed system. It probably communicates by stomata with large serous spaces, such as the peritoneal space, and possibly also with the spaces of certain mucosæ-e.g., the bronchial and nasal.

On this hypothesis, the tissue fluid of the interstitial spaces is distinct from the lymph of the lymphatic system. Little or nothing is known as to the exact composition of such tissue fluid; it is assumed to be of much the same composition as the lymph. This bathes the

* Except in the spleen and liver. Blood-eapillaries, too, run into the giant ganglion cells whieh feed the electrie organ in Malapterurus. 
tissues with a suitable medium for their activities, and carries to them the food material necessary for such activities and for repair; carrying also bodies such as hormones or co-enzymes, which stimulate or aid tissue activity. From the tissues it carries away the products of their activity - either synthetic, such as internal secretions and hormoies, or the katabolic or waste products resulting from such activity.

In regard to the digestive tract, the tissue fluid acts as a transport fluid for the absorbed products of digestion. Some of these, such as those of protein and carbohydrate digestion, pass into the blood of the portal vein. The products of fat digestion, on the other hand, pass into the closed lymphatic vessel, or lacteal. They give to the lymph a milky appearance, from which the name of these particular, lymph channels is derived.

In other parts of the body, also, there is the same quick transference of some bodies from the tissue fluid to the blood, and of others to the lymph. In discussing the processes of lymph formation (see later), this point must be borne in mind. For example, when a salivary gland is secreting, we must inquire what processes detcrmine the bodies which pass (1) from the gland to the saliva, (2) into the tissue fluid, (3) from the tissue fluid to the venous blood, (4) from the tissue fluid into the lymph leaving the gland.

The properties of lymph are generally studied by collecting the fluid as it flows from the thoracic duct of a small mammal, or from the main lymphatic channel of each of the various organs of the larger domestic animals. For demonstration purposes, a cannula is usually placed in the thoracic duct of a fair-sized fasting dog, and a good flow of lymph insured by the intravenous injection of commercial peptone solution. Such lymph is a viscid, opalescent fluid, faintly alkaline in reaction, specific gravity 1010 to 1020 . The first lymph which flows coagulates spontaneously, although less quickly than blood. After a time, however, owing to the effect of the peptonc, it becomcs incoagulable. Chemically, it contains the same constituents as bloodplasma, the differences being quantitative. It is poorer in proteins, and richer in water and salts.

The lymph from different parts varies in quantitative composition. For example, that from the liver contains more solids than that from the limbs. The lymph flowing from the same organ also varies quantitatively in composition according to the degree of activity of the organ. As a result of various analyses, the composition of lymph may be given somewhat as follows:

\begin{tabular}{|c|c|c|c|c|c|c|c|}
\hline Water & .. & $\ldots$ & & $\cdots$ & & $\ldots$ & $\begin{array}{l}\text { Per Cent. } \\
93 \cdot 5-9.5 \cdot S\end{array}$ \\
\hline Solids & 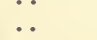 & $\because$ & 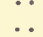 & $\because$ & $\because$ & $\cdots$ & $4 \cdot 2-(i \cdot 5)$ \\
\hline Proteins & .. & .. & .. & .. & .. & .. & $3 \cdot 5-4 \cdot 3$ \\
\hline $\begin{array}{l}\text { Fats } \\
\text { Soaps }\end{array}$ & & & & - & & & \\
\hline $\begin{array}{l}\text { Soaps } \\
\text { Lipoids } \\
\text { Dextrose }\end{array}$ & $\cdots$ & $\cdots$ & .. & $\cdots$ & . & -. & $0 \cdot 4-0 \cdot 9$ \\
\hline Salts (chief) & $\mathrm{Ay} \mathrm{NaCl}$ & & .. & $\cdots$ & .. & .. & $0.7-0 \cdot 8$ \\
\hline $\begin{array}{ll}\mathrm{O}_{2} & \ldots \\
\mathrm{CO}_{2} & \cdots\end{array}$ & .. & . & $\cdots$ & $\cdots$ & .. & . & traces \\
\hline & .. & •. & - & .. & - & $\cdots$ & \\
\hline
\end{tabular}


Lymph also contains white corpuscles similar to those in the blood, lymphocytes particularly predominating.

The amount of lymph flowing from the thoracic duct in twentyfour hours has been found in human patients to vary from 1,200 to 2,280 c.c. per day. In a dog of 10 kilos, the amount was 640 c.c. We cannot take this as indicative of the normal flow, for the escape of lymph through a wound is unrestrained by the conditions which pertain in the closed body.

The Processes concerned in the Formation of Lymph.-Considerable divergence of opinion is manifested as to these; a vast amount of evidence has accumulated which is held to support the various views entertained by different authorities. From such experimental data one great fact emerges-namely, that lymph flow is the concomitant of tissue activity. For example-

1. When the liver is active, either as the result of an injection of peptone or during the processes of digestion, there is an increased flow of lymph from the liver.

2 . When the salivary gland is made to secrete by stimulation of the chorda tympani nerve (see p. 374), there is a marked increase of lymph flow from the gland.

3 . When the pancreas is made to sccrete as the result of an injection of secretin (see p. 397), there is similarly an increased flow of lymph from that organ.

4. From the resting limbs there is practically no flow of lymph; activity gives rise to a well-marked flow.

The two chief views held in regard to lymph formation are the mechanical and the secretory. The mechanical view holds that lymph transudes from the blood-capillaries as the result of the processes of filtration and osmosis. A higher pressure is supposed to pertain in the capillaries and cause filtration. According to the secretory view, lymph is formed as the result of cell activity. The cells actively draw water, etc., from the blood-capillaries into the tissue spaces according to their functional nceds.

The experimental evidence in regard to filtration consists chiefly of experiments in which a r.se of capillary pressure is induced as the result of partial or total blocking of the venous circulation. This does not occur under normal conditions. The result, also, is an increased flow of lymph, which differs considerably in composition from that flowing under normal circumstances.

Such an experiment is the ligation of the veins of a limb, which causes an increased flow of lymph poorer in solids than normal and red-coloured, owing to the presence of red corpuscles. Ligation of the portal vein ra:ses the pressure in the capillaries of the intestinal area, and causes a marked increase of lymph. Occlusion of the inferior vena cava above the diaphragm causes an increased flow of lymph from the liver, due, according to this view, to the rise in pressure in the liver capillaries. Similarly, occlusion of the aorta causes an increased flow of lymph from the liver, the pressure in these circumstances in the inferior cava being slightly raised or remaining unaltered. 
It has never been shown that a rise in capillary pressure with a normal venous circulation produces an increased flow of lymph. On the contrary, experiments show that such a rise of capillary pressure may take place without an increased flow of lymph necessarily resulting. Reference, for example, has already been made to the fact that stimulation of the chorda tympani causes a great flow of saliva accompanied by a marked flow of lymph from the gland. When the endings of this secretory nerve are paralyzed by atropine, stimulation still produces a marked rise of capillary pressure, but no salivary secretion or increased lymph flow results. So, too, if the motor nerves to a limb be cut, and the blood-pressure raised by causing a general vaso-constriction of the rest of the body, the quantity of lymph flowing. from the limb while performing passive rhythmical movements is not increased, but diminished.

Differences in the constitution of lymph coming from different parts, or from the same part at different times, are attributed upon the filtration view to an altered permeability of the vessel wall. The exact reason for such alterations appears to be due rather to the different forms of activity in the various parts, and in the same parts at different times. Reasons for a disbelief in the possibility of a filtration mechanism within the body are adduced in dealing with the capillary pressure (see p. 223).

Furthermore, it has been shown recently that venous stasis causes lymph formation, not by virtue of filtration, but by changes in the tissues themselves, due primarily to lack of oxygen, causing the formation of acid. With such acid formation, water passes by imbibition into the tissues, leading, if long continued, to œedema. Such a condition is pathological, not physiological.

In regard to the part played by osmosis, it may quite well be that the interchange between blood and tissues is largely regulated by this process. For example, the lymph formation attending tissue activity may possibly be explained by the supposition that the products of cell activity, being relatively of small molecular weight, cause by incrcased osmotic pressure a flow of fluid from the blood into the tissue spaces.

The numerous experiments which have been made of injecting such crystalloid bodies as sodium chloride, dextrose, urea, so-called lymphagogues, tend to support the view that osmosis plays a part in the formation of lymph. Certain recent experiments, however, show that the chloride content of the lymph may rise above that of the blood-serum. If this be the case, then osmosis cannot be the whole story.

It has also been pointed out that each tissue or organ obtains its own special products from the lymph, often in large quantitics. The most-quoted example is the calcium content of milk. A cow may yield daily 25 litres of milk containing 42.5 grammes of Ca. As the lymph of the thoracie duct contains but 0.18 per cent., 236 litres of lymph would be necded to supply this calcium to the milk, assuming that all the calcium comes from the lymph. This is held greatly to support 
the secretory view, that lymph and milk are formed by the special activity of the gland cells. The cells of each organ draw what they need from the blood.

The fact that some bodies appear to be quickly transferred from the tissue fluid to the venous blood, while others appear to be passed on into the lymphatics, has led to the view that the bodies passed into the lymphatics are toxic, and are taken to the lymphatic glands to have this toxicity destroyed. It has been shown experimentally that lymph injected into the arterial system causcs marked effects upon the arterial pressure and rate of heart-beat.

The Movement of Lymph.-To what factors is due the flow of lymph? In the amphibia and fishes there are special lymph hearts, but these are lacking in mammals. The lymphatics have valves to direct the flow, and these valves have special muscle fibres arranged about them which, it has been suggested, act as a pumping mechanism. Such a claim has not bcen substantiated. The vessels, however, appear to be innervated with constrictor and dilator nerves, and it is conceivable, although not proven, that alterations in the lumen may aid the flow.

According to the mechanical view, the flow of lymph is maintained by the filtration pressure transmitted from the vis a tergo, the heart. This point has already been debated. The heart-beat plays an important factor in pulsing organs full of blood, with each heart-beat. This systolic filling squeezes on the lymph in the lymphatics.

The chief factors in causing a flow of lymph are the activities of the tissues, muscular movement, and the respiratory pump.

The various serous membranes of the body are moistened by fluids which more or less rescmble lymph in composition. The amount of protein in these different fluids varies considerably, although under normal circumstances the quantity of such fluids is in some cases so small that accurate analyses have not been made. The composition of the fluids is altered when therc is increased formation due to inflammatory disease, and it is such fluids which for the most part have been analyzed.

The pericardial fluid is a somewhat sticky, lemon-coloured fluid, which contains about 96.1 per cent. of water and 3.9 per cent. of solids. The chief solids are proteins (2.8 per cent.) and salts, mostly sodium chloride $(0.7$ per cent.). Traces of fat, lecithin, and cholesterin, are also present.

Pleural fluid is normally present in such small amounts that analys:s of the healthy fluid has not bcen made. The same is true of normal peritoneal fluid.

The cerebro-spinal fluid is a thin, clear fluid, characterized by its low specific gravity (1007 or 1008) and its low protein content. The protein is of a globulin nature. A small amount of copper-reducing substance is also present, which is probably sugar. In disease, the constitution of the fluid may be altered in various ways. The state- 
ment that choline is present in certain nervous diseases has not met with general acceptation. The fluid is secreted by the cells of the choroidal fringes of the brain, and absorbed into the cerebral veins, probably by way of the Pacchionian bodies.

The aqueous humour of the eyeball is a clear fluid, alkaline in reaction, of low specific gravity (1005 to 1008), and containing normally but a trace of protein. It is secreted by the ciliary processes of the eyeball, and absorbed by the veins of the iris and those in the angle of the eye. 



\section{BOOK IV}

\section{CHAPTER XXX}

\section{R ES PIR A T I ON}

ONE of the most remarkable properties of living substance is its dependence on a supply of oxygen. The vital processes in the cell substance by which energy is set free and food obtained depend on this, and carbon dioxide, the chief end product of these processes, must be got rid of, as well as a sufficiency of oxygen obtained. Many kinds of bacteria-e.g., tetanus bacilli-and parasitic worms, which live in the intestine, are what are termed "obligate anaerobes." They secure their oxygen by decomposition of foodstuffs, and are poisoned by free oxygen. All other bacteria, the higher plants, and animals, arc aerobes, and take up free oxygen from the atmosphere by a respiratory process. Plants both excrete carbon dioxide and assimilate it.

By the aid of chlorophyll energized by sunlight, plants synthesize water and carbon dioxide into formic aldehyde, which by molecular condensation is converted into an aldose; hence arise sugar and starch. At the same time as this remarkable synthesis goas on, the plant protoplasm uses up oxygen and produces carbon dioxide. From the nitrates and other salts absorbed by the rootlets and the aldose synthasized in the leaves the plant proteins are built. Sunlight forwards this synthesis, converting nitrates in watery solution into nitrites, an end 3 th $ə$ rmic reaction; the sugars and starch may also be converted into fat. The source of the energy of all these syntheses in the plant is the sun's rays. The chlorophyll absorbs the light.rays, and transforms them into energy which is stored as potential energy in the proteins, carbohydrates, and fats, built by the plant. These form the foodstuffs of bacteria, moulds, and animals, by which they are broken down again into water, carbon dioxide, salts, and simp.e compounds of nitrogen - - the materials for fresh plant synthesis. So the cycle of life proceeds (Fig. 130). The bacteria form the final link in the chain; some decompose dead animal and plant matter (denitrifying bacteria), while other symbiotic bacteria help the rootlets of ccrtain plants (legumes) to secure atmospheric nitrogen (nitrifying bacteria). If it were not for bacteria, the world would quickly become cumbered up as a charnel house. The circulation of nitrogen in nature is shown in Fig. 131.

It has recently been found that when carbon dioxide gas is passed 
through very dilute solutions of inorganic colloids (uranic or ferric oxide) in the presence of sunlight, the synthesis of formic aldehyde and acid is obtained. It has been suggested that we have in this a possible first stage in the evolution of organic material and life processes from inorganie matter.

t. 1

The exchange of gases between the respiratory tissue and the outer medium is known as "external respiration." The process whereby the exehange of these gases takes place between the blood and the different parts of the body is known as "internal," or "tissue respiration." Cold-blooded animals can live for some hours in an atmosphere of nitrogen, and hibernating cold-blooded animals-e.g.,

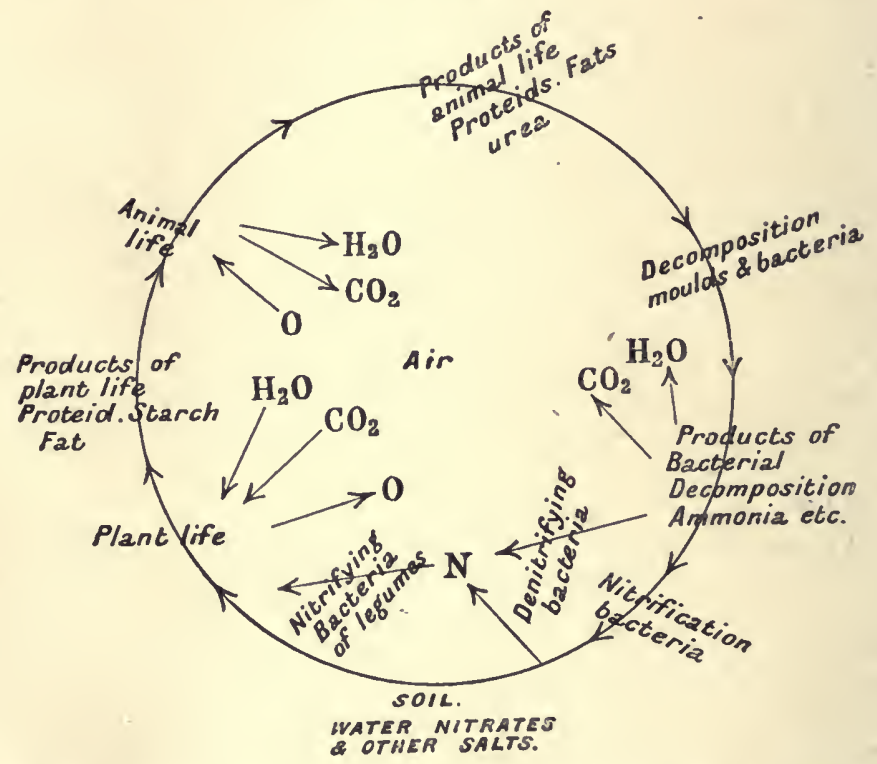

Fig. 130.-To illustrate the Crcle of Plant, Animal and Bacterial life.

The arrows indicate the materials which each take up and give out to the world.

snails which shut themsclves up for the winter-retain their existence for months without respiration. On the other hand, a very active respiration and rapid exchange of gases arc necessary in the warmblooded animal, because the rate of metabolism is very great, and within the body there is no means afforded for laying in a store of oxygen sufficicnt to last more than a minute. The carbon dioxide, too, which in normal concentrations plays an important part in regulating body processes, when present within the body in excess, has a narcotic poisonous effect upon the organism.

The blood is exposed to the air in the lungs over a very extensive surface-perhaps as much as 100 square metres - in a film one corpuscle thick, and the whole blood circulates through the lungs about once a 
minute when resting, and as often as ten times a minute during hard mascular work. According to the simplest hypothesis, and the one generally accepted, the venous blood, which enters the pulmonary capillaries, has a lower oxygen and higher carbon dioxide concentration or pressure than that in the pulmonary air. An exchange takes place between the blood and the pulmonary tissue lymph, and then between this fluid and the pulmonary air, this exchange being in accordance with the physical laws which govern the solution and diffusion of gases.

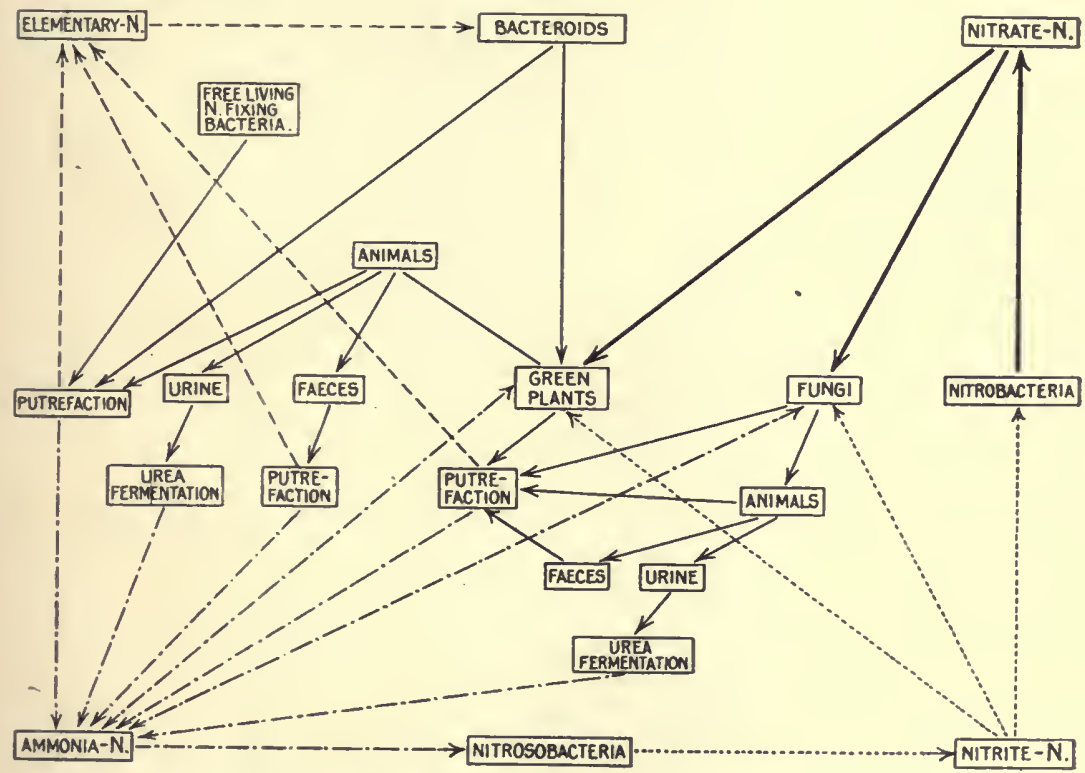

Fig. 131.-To illustrate the Circulation of Nitrogen in Nature.

The Blood Gases.-The presence of gases in the blood was first demonstrated when Robert Boyle (1636) placed blood under his vacuum pump and made it boil. The gas content of the blood is obtained-(I) by exposing the blood to a vacuum and pumping off the gases; (2) by chemical means, whereby the different gases are displaced chemically from the blood.

Extraction of Blood Gases by Means of Pump.-The gencral principle of the pump, of which many forms have been devised for the extraction of blood gases, is that the blood is exposed to a barometric vacuum. A simple form of pump is shown in Fig. 132. The pump consists of a mercury reservoir $(A)$, which is connected with a second reservoir $(B)$ by means of pressure tubing. The upper end of $B$ is closed by a three-way tap. By means of this tap $B$ can be put in connection with either the tube $E$ leading to the bloodreceiver $F$, or with the tube $C$ leading to the eudiometer $H$. The 
blood-receiver $F$ is constructed of three bulbs, so as to prevent the blood frothing over into $B$ during the extraction of the gases. To either end of $F$ is fixed a piece of thick, small-bored pressure tubing provided with a clip.

In using the pump, the blood-receiver $F$ is placed in the position indieated by the dotted line. $A$ is raised, and $B$ is put in conneetion with $F$, and $F$ is filled with mercury. The serew clip on the rubber

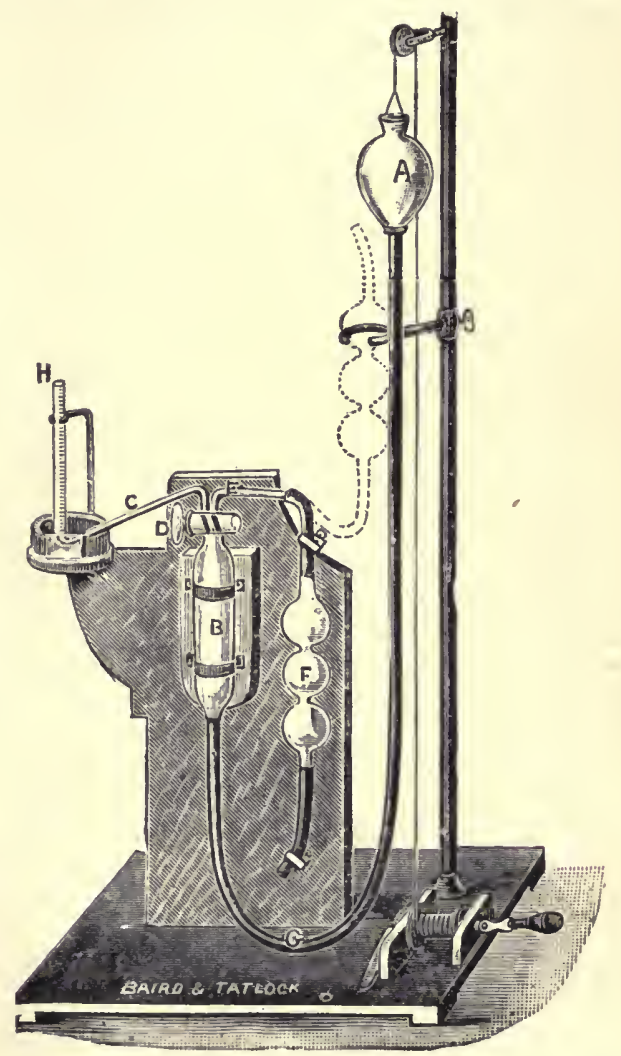

Fig. 132.-Hill's Blood-Gas Pump.

tube at the upper end of $F$ is then elosed, and $A$ lowered until $F$ is exhausted, except for 2 or 3 e.e. of mereury which are purposely left within. 'The screw clip on the lower end of $F$ is next elosed, and $F$ is then detaehed from the pump and weighed. Blood is eolleeted in this evaeuated reeeiver, which is then eonnected to the apparatus, and the gases pumped off into the eudiometer $H$, where they are analyzed. The amount of $\mathrm{CO}_{2}$ is determined by introdueing 20 per cent. $\mathrm{KOH}$, the oxygen by introdueing a solution of pyrogallic acid. The relative proportions of the gases are shown in Fig. 133. The remainder is nitrogen. 
For very accurate work a tapless modification of the Töpler pump, is best employed (Fig. 134). The general arrangement of the parts is shown in the figure, which is drawn to scale onetenth of the actual size. The pump $(P)$, together with the drying apparatus $(D)$ and condenser $(E)$, possesses neither taps, nor mercury, nor rubber joints, the various parts being glass and sealed together with a blowpipe. The blood is introduced into the froth-chamber, which is made up of a cylindrical bulb $(C)$ and two double-walled condenser bulbs $(A)$, the lower of which terminates in a barometer tube 85 centimetres long dipping below mercury. This part of the apparatus is sealed on to the condenser at $X$. The apparatus is evacuated in the usual way, and the height of the mercury in the vessel $B$ adjusted so that the barometric column just reaches the entrance of the lower froth-bubble $(A)$. In order to prevent the

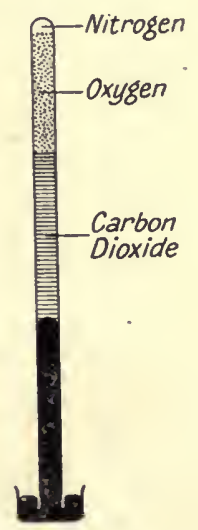

FIG. 133.

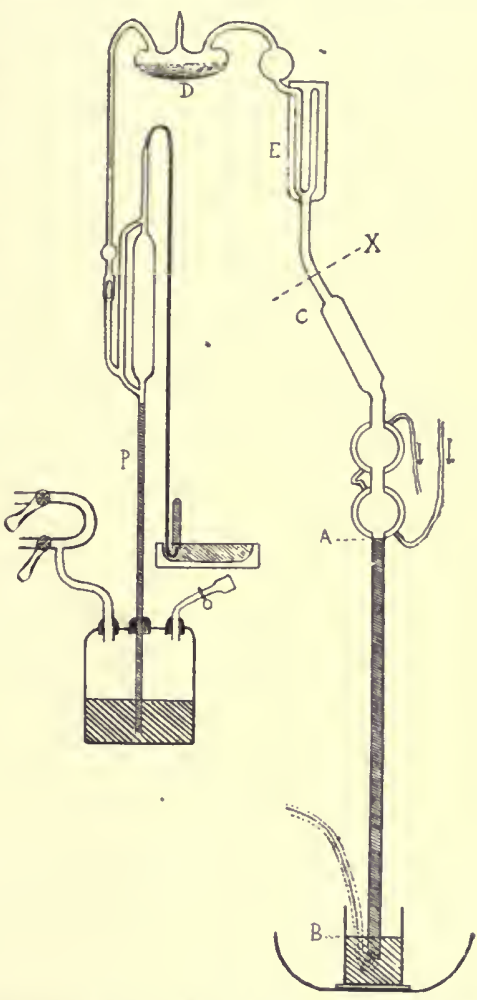

Fig. 134. - Modification of the Töpler Tapless Pump for Accurate Blood-Gas Analysis. (Buckmaster and Gardner.)

occlusion of air in the mercury, or between the mercury and the glass, after a high vacuum has been produced, the tube $A B$, and also $P$, is heated with a Bunsen burner almost to the boiling-point of mercury. The evacuation is then completed. It is now advisable to allow the pump to stand for a day or two, with occasional pumping before use. A very high vacuum can in this way be obtained. The condenser must be large, and as efficient as possible. The drying vessel, filled with pure sulphuric acid, is provided with a tube, the end of which can be easily broken, so that it is easy to refill with sulphuric acid. 
After using the pump, air is introduced up the barometer tube $A B$, and the froth-chambers cut from the condenser $X$. The detached part can then be readily cleaned, sterilized, and resealed on the condenser.

The chemical method employed is one in which oxygen is displaced from the blood by the use of potassium ferricyanide, and the $\mathrm{CO}_{2}$ is displaced by the action of tartaric acid. The most convenient form of apparatus for this purpose is that shown in Fig. 135. The oxygen is liberated from the hæmoglobin in one of the two bottles. The pressures in thesc become unequal, and the difference in pressure is indicated by the movement of fluid (clove-oil) in the manometer. The difference in the level of the fluid surface on either side is read, and by this means the amount of oxygen liberated is determined,

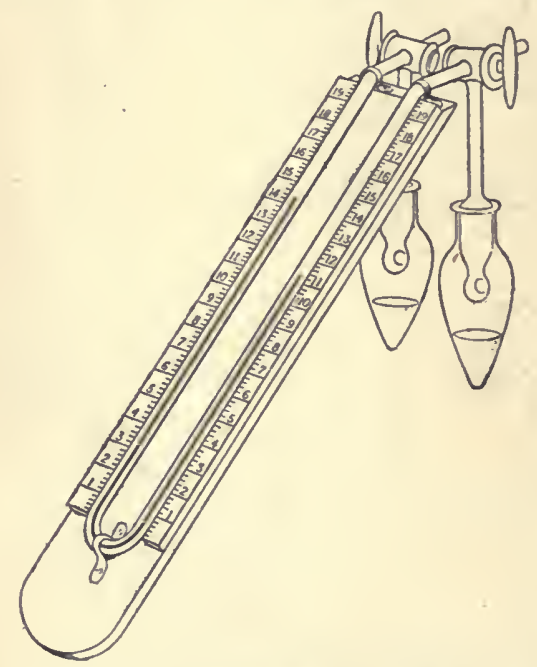

Fig. 135.-Barcroft's Differextial Blood-Gas Apparatus.

since a special calibration of the instrument has been made, and the amount of oxygen corresponding to a difference in level is known. By such means it is found that arterial blood has a gas content somewhere about 18 c.c. $\mathrm{O}_{2}, 44$ c.c. $\mathrm{CO}_{2}, 1$ c.c. $\mathrm{N}_{2}$; and venous 12 c.c. $\mathrm{O}_{2}$, 50 c.c. $\mathrm{CO}_{2}, 1$ c.c. $\mathrm{N}_{2}$. The blood from the veins varies widcly in its gas content according to the activity of the part from which it comes. Simultaneous analyses of the blood going to and coming from a part give, when the amount of blood circulating through the part is known, a knowledge of the internal respiration of that part (see later, p. 320).

The gases in the blood are in part dissolved according to the physical laws of absorption, but by far the larger amount is in socalled weak chemical combination. Water dissolves gases according to the pressure, temperature, and nature of the gas, and the solubility is lessened by the presence of salts, etc., in solution in the water. 
Table showing the Absorption Coefficients for Blood of Oxygen, Nitrogen and Carbon Dioxide.

\begin{tabular}{|c|c|c|c|c|c|c|c|c|c|}
\hline & & & & \multicolumn{2}{|c|}{ Oxygen. } & \multicolumn{2}{|c|}{ Nitrogen. } & \multicolumn{2}{|c|}{$\mathrm{CO}_{2}$} \\
\hline & & & & $15^{\circ}$ & $38^{\circ}$ & $15^{\circ}$ & $38^{\circ}$ & $15^{\circ}$ & $38^{\circ}$ \\
\hline $\begin{array}{l}\text { Water } \\
\text { Plasma } \\
\text { Blood } \\
\text { Corpuscles }\end{array}$ & $\begin{array}{l}\cdots \\
\cdots\end{array}$ & $\begin{array}{l}\cdots \\
\cdots \\
\cdots\end{array}$ & $\begin{array}{l}. . \\
\ldots \\
\ldots\end{array}$ & $\begin{array}{l}0 \cdot 0342 \\
0 \cdot 033 \\
0 \cdot 031 \\
0 \cdot 028\end{array}$ & $\begin{array}{l}0 \cdot 0237 \\
0 \cdot 023 \\
0 \cdot 022 \\
0 \cdot 019\end{array}$ & $\begin{array}{l}0 \cdot 0179 \\
0 \cdot 017 \\
0 \cdot 016 \\
0 \cdot 014\end{array}$ & $\begin{array}{l}0 \cdot 0122 \\
0 \cdot 012 \\
0 \cdot 011 \\
0 \cdot 010\end{array}$ & $\begin{array}{l}1 \cdot 019 \\
0 \cdot 994 \\
0 \cdot 937 \\
0 \cdot 825\end{array}$ & $\begin{array}{l}0 \cdot 555 \\
0 \cdot 541 \\
0 \cdot 511 \\
0 \cdot 450\end{array}$ \\
\hline
\end{tabular}

By the help of the absorption coefficients we can calculate the quantities of oxygen, nitrogen, and carbon dioxide which would be dissolved in 100 c.c. of blood shaken with air at room temperature $\left(15^{\circ} \mathrm{C}\right.$.) and 760 millimetres pressure. From a pressure of 760 millimetres that of the (average) water vapour at $15^{\circ} \mathrm{C}$. must be subtracted-12.7 millimetres-giving as total pressure for the air minus water vapour: $760-12 \cdot 7=747 \cdot 3$ millimetres. For oxygen, the partial pressure is $\frac{20.92}{100}$ of this pressure, 20.92 being the percentage of this gas in the atmosphere measurcd under dry conditions.

$$
\frac{20 \cdot 92}{100} \times 747 \cdot 3=156 \cdot 6 \text { millimetres. }
$$

With this partial pressure the amount of oxygen dissolved in 100 c.c. of blood will be

$$
\frac{0 \cdot 031 \times 100 \times 156 \cdot 6}{760}=0 \cdot 639 \text { c.c., }
$$

where 0.031 is the coefficient of absorption for blood at $15^{\circ} \mathrm{C}$.

But in the lung alveoli the conditions are different. The temperature is $38^{\circ} \mathrm{C}$.; therefore a different coefficient of absorption is required. The air is saturated with vapour, and the amount of water vapour is much increased, giving a partial pressure of 49.3 millimetres; and, lastly, the chemical composition of the air, measured under dry conditions, is different from that of the atmospheric air. Here the composition is, approximately: Oxygen, 14 to 15 per cent.; nitrogen, 80 to $80 \cdot 2$ per cent.; and carbon dioxide 4.8 to 5 per cent. Under these conditions, the amount absorbed by 100 c.c. of blood is-

$$
\begin{aligned}
& \text { Oxygen } \frac{\begin{array}{c}
\text { (Co- } \\
\text { efficient) } \\
0 \cdot 022 \times\left(100 \times \frac{15}{100}\right) \times(760-49 \cdot 3)
\end{array}}{760}=0.309 \text { c.c. } \\
& \text { Nitrogen } \quad \ldots \frac{0.011 \times 80 \cdot 2 \times(760-49 \cdot 3)}{760}=0.825 \text { c.c. } \\
& \text { Carbon dioxide } \frac{0051 \times 4.8 \times(760-49 \cdot 3}{760}=2 \cdot 29 \text { c.c. }
\end{aligned}
$$


When these values are compared with the amounts of the gascs obtained from the blood, it is found that only nitrogen is in true physical solution. Of the carbon dioxide and oxygen the greater part is in chemical combination; yet, inasmuch as considerable quantities of these gases can be pumped from the blood, this chemical combination is of an easily dissociable (weak) form. When the blood is submitted to the vacuum pump, the gases do not come off in proportion as the pressure is reduced-indeed, with the first reduction of pressure little gas comes off-but when the pressure is considerably lowered, and the blood warmed, the gases come off with a rush, and the blood "boils" and froths in a very striking way.

The oxygen is combined with the red corpuscles, as is shown by the fact that, when the corpuscles are removed from the plasma, the latter only takes up that amount of oxygen which is dissolved in accordance with the coefficient of absorption. It is to the hæmoglobin of the corpuscles that the oxygen is loosely attached, and
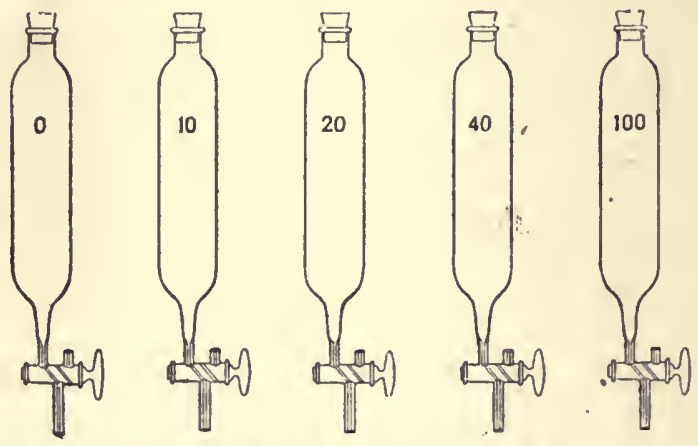

Fig. 136.-A Series of Toxometers indicatixg the Pressure of Oxyaen to WHICH THE BLOOD IS EXPOSED. (Barcroft.)

the amount of oxygen taken up by the blood over and above that which can be absorbed by purely physical means depends upon the amount of hæmoglobin present.

Many experiments have been made to ascertain the specific oxygen capacity of the blood. The earliest observations were made correctly on the blood itself; then it was thought better to separate the hæmoglobin and, purifying this, determine its combining powers. From the results so obtained it was. concluded that a given amount of hæmoglobin always combined with a definite amount of oxygen (1 grm. of $\mathrm{Hb}$ with 1.34 c.c. of $\mathrm{O}_{2}$ ); 100 c.c. of human blood contains about 12 to 15 grms. $\mathrm{Hb} .1 \cdot 34 \times 14=19$, which is about the percentage of oxygen found in arterial blood. Recent research, however, has shown that the exact amount of oxygen depends upon a number of factorse.g., the temperature, concentration of salts, and of carbon dioxide in the blood. The blood is exposed to an atmosphere containing a known concentration (pressurc) of oxygen, and thoroughly shaken with this (Fig. 136). It is then withdrawn without contact with the 
air, and the percentage of oxygen in it determined by the vacuum pump or the differential blood gas apparatus. Charts are thus prepared in which the amounts of oxygen combined at different pressures

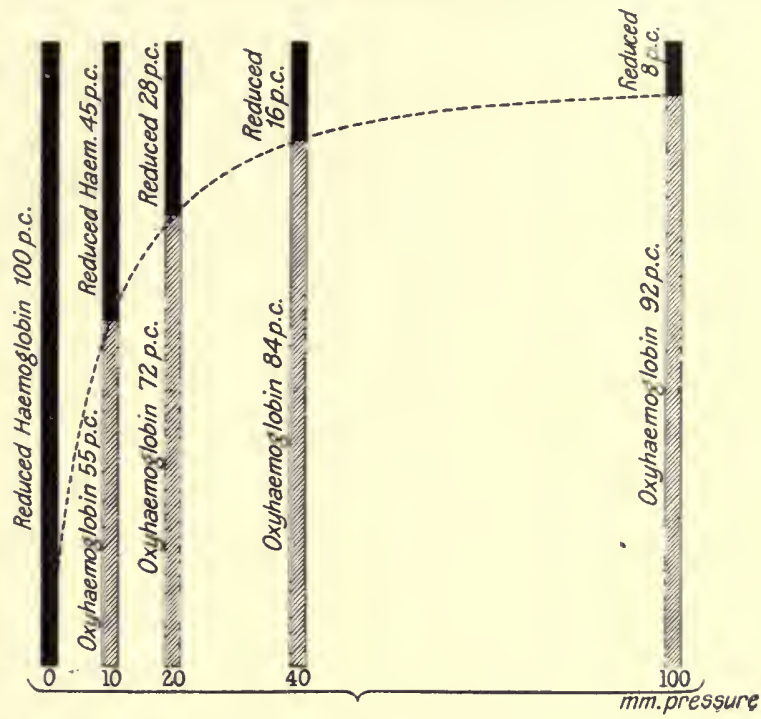

Fig. 137. - Cylinders Spaced Apart at Distances Proportioxal to the Pressures of OXYgen dissolved is Solution. (A. $t$; Bareroft.)

are plotted in the form of a curve (Fig. 137). There has to be subtracted from the total volume of gas found the amount which is calculated to be simply dissolved. The following table gives examples of the results obtained for horse's blood at $38^{\circ} \mathrm{C}$.:

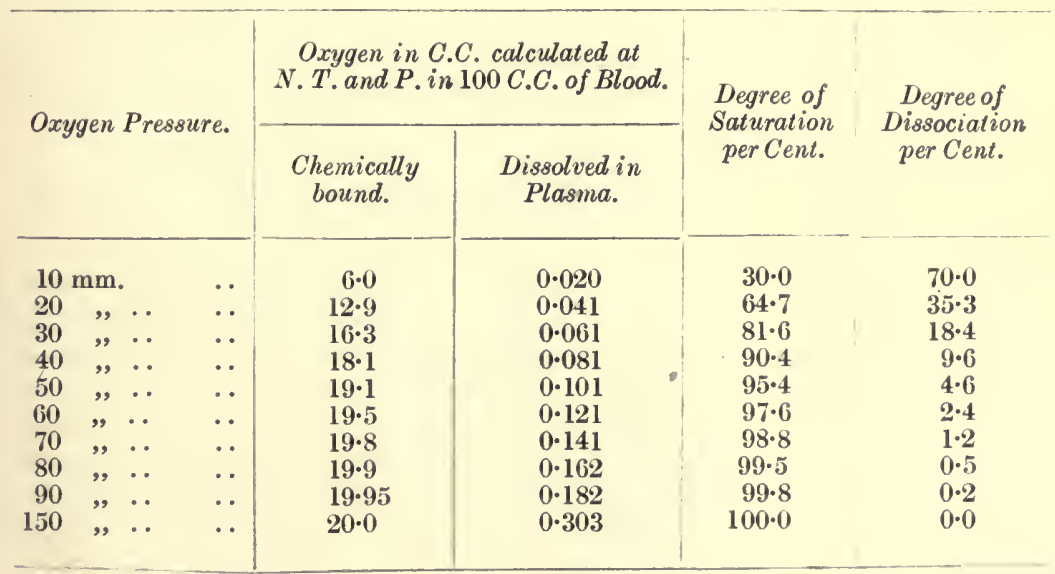

It is found that above a tension of oxygen of 150 millimetres, corresponding to an atmospheric pressure of 760 millimetres, the amount- 
of oxygen chemically combined increases inappreciably. Therefore, when blood is shaken with air at ordinary atmospheric pressure, it becomes practically saturated with oxygen, and the degree of saturation in the above table is obtained by comparing the amount of oxygen combined with the blood at a given pressure of oxygen with the amount combined when shaken with air at atmospheric pressure. By taking the amount of oxygen combined to 100 c.c. of blood as ordinates, and the oxygen tensions as abscissæ, the curve of dissociation of oxyhrmoglobin is obtained. Thus, by joining the points between the shaded portions of Fig. 137 a curve is obtained which shows the percentage of oxyhæmoglobin of the total hæmoglobin to the concentrations of oxygen dissolved in the fluid at all pressures up to 100 millimetres.

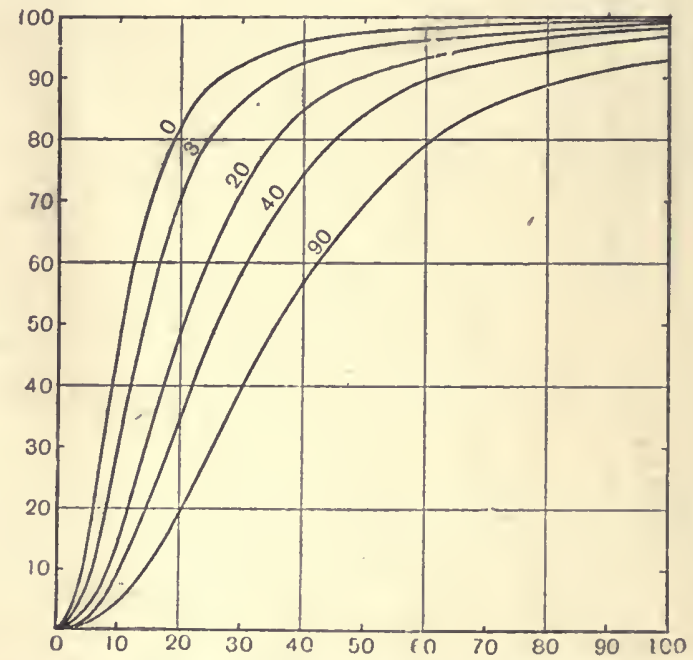

Fig. 138.-Oxygex Dissociation Curves of Humax Blood exposed to 0, 3, 20, 40, AND 90 Millimetres $\mathrm{CO}_{2}$. (Barcroft.)

Ordinate $=$ percentage saturation; abscissa $=$ oxygen pressure.

Various factors are found to modify this dissociation curve. Such factors are-

1. The $\mathrm{H}$ ion concentration present in the blood. The greater the $\mathrm{H}$ ion concentration, the less the amount of oxygen which combines with the blood. This is well seen in conditions when there is increased concentration of carbon dioxide and of lactic acid (Fig. 138).

2. Solutions of hæmoglobin give quite different values to those of hæmoglobin undischarged from the corpuscles. The hæmoglobin forms 90 per cent. of the dried weight of the corpuscles, and much more is present than can be in solution. It must be held in some peculiar colloidal state.

3. The proportion of salts present in the blood (Fig. 139).

4. The temperature (Fig. 140). 
The manner in which carbon dioxide exists in the blood is more difficult of explanation. Besides being dissolved in the watery plasma and corpuscles, it is believed that the carbon dioxide is in part loosely combined in the blood-plasma as a weak acid, attached to the alkali present and to the protcins, and also to the red corpuscles, particularly

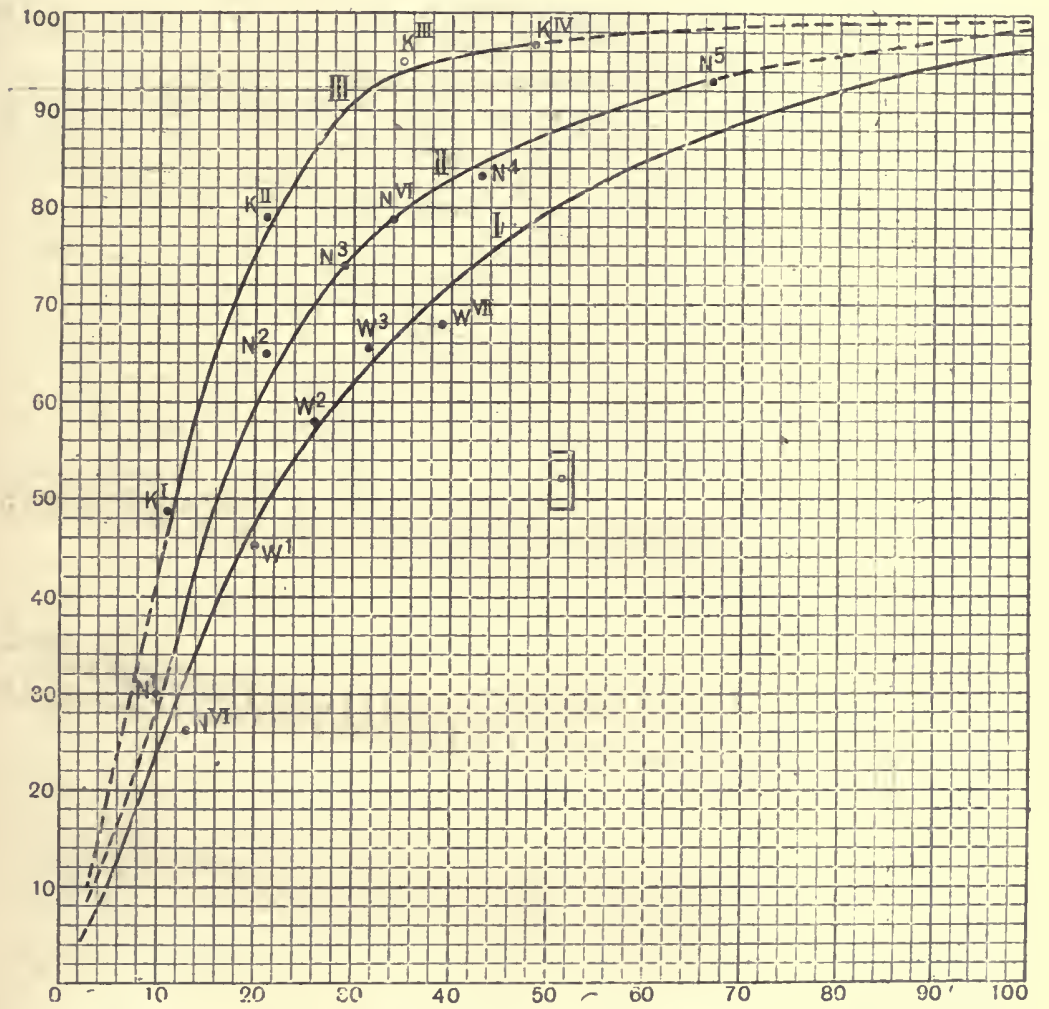

Fig. 139.-EfFect of Hayoglobin Solution and of Salts ox Oxygex Dissociation CuRve. (Barcroft.)

I. Dissociation curve of hæmoglobin dissolved in water. II. III.

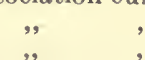
", $\quad, \quad \cdot 7 \% \mathrm{NaCl}$

Ordinate $=$ percentage saturation of hæmoglobin; abscissa $=$ tension of oxygen in millimetres of mercury. Rectangle surrounding point $=$ magnitude of experimental error. Temperature $37^{\circ}-38^{\circ} \mathrm{C}$.

the protcin portion (the globin) of the hæmoglobin. Hæmoglobin consists of 95 per cent. globin and 5 per cent. hæmatin; the oxygen is attached to the latter, which contains the iron. Two interesting facts have been shown in regard to the chemical combination of $\mathrm{CO}_{2}$ in the blood: first, that in spite of the presence of free alkali, blood-but not plasma-gives up almost all its $\mathrm{CO}_{2}$ to the 
vacuum pump; and, secondly, that blood added to a soda solution sets free $\mathrm{CO}_{2}$ from it. The probable cxplanation is that the bloodproteins, especially the hæmoglobin and the serum globulin, by virtue of their amphoteric reaction, can act as both acids and alkalies. The building-stones of proteins, the amino-acids, contain both $\mathrm{NH}_{2}$ and $\mathrm{COOH}$ groups. When the partial pressure of $\mathrm{CO}_{2}$ is low, as in the lungs, these proteins act as weak acids, and turn out $\mathrm{CO}_{2}$. On the other

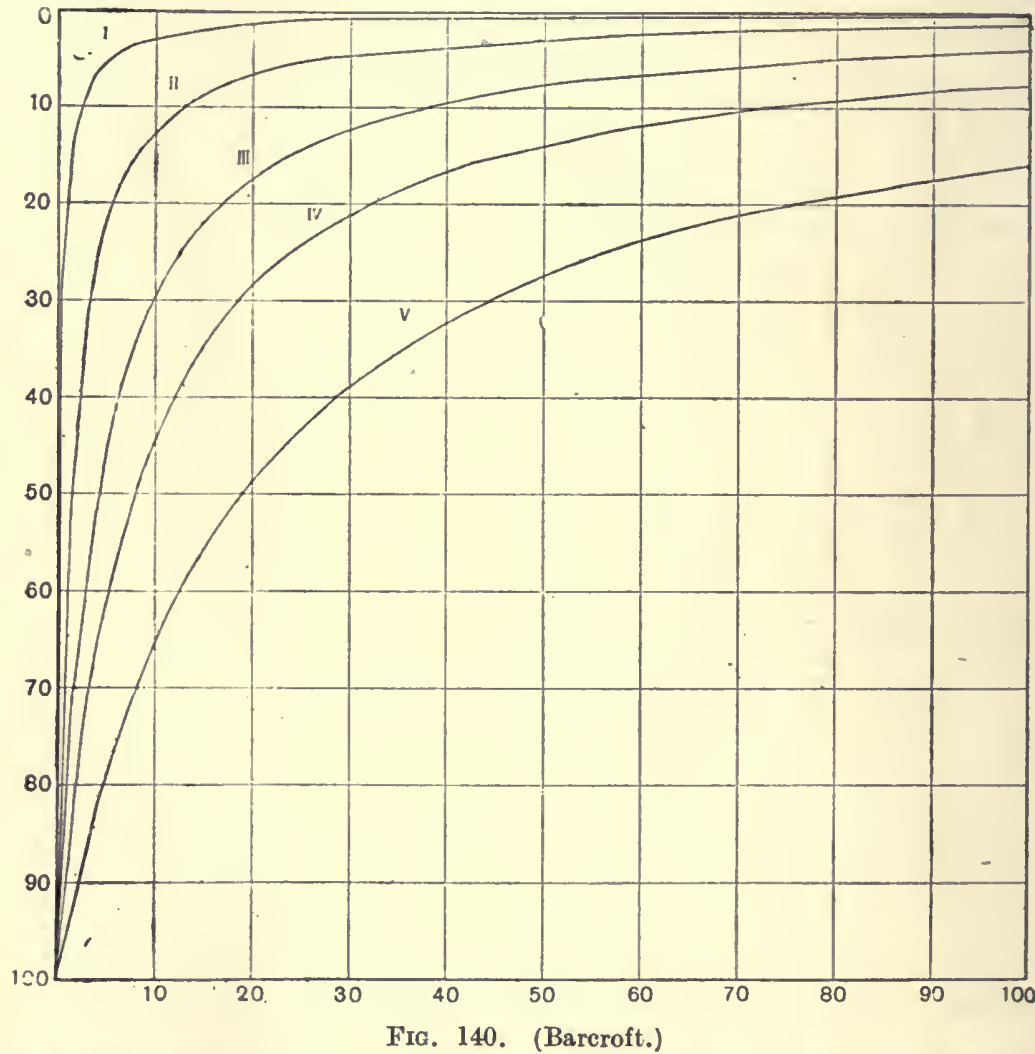

Dissociation curves I., IJ., III., IV., and V. correspond to $16^{\circ}, 25^{\circ}, 32^{\circ}, 38^{\circ}$, and $49^{\circ} \mathrm{C}$. respectively. Oxygen pressure plotted horizontally, percentage of reduccd hæmoglobin vertically downwards

hand, when the $\mathrm{CO}_{2}$ pressurc is high, as in the tissues, it seems probable that these proteins act as alkalies, and actually combine with the $\mathrm{CO}_{2}$ and aid in its transport away from the tissues.

That the corpuscles help to expel the $\mathrm{CO}_{2}$ is shown by the fact that acid must be added to plasma in order to obtain all the $\mathrm{CO}_{2}$ combined with it, exposure to a vacuum not being sufficient by itself wholly to decompose the $\mathrm{CO}_{2}$ compounds in the plasma. 
The following was estimated to be the distribution of $\mathrm{CO}_{2}$ in 100 c.c. of arterial blood, the pressure of $\mathrm{CO}_{2}$ being equal to $30 \mathrm{~mm}$. Hg: Physically absorbed, 1.9 c.c. $(0 \cdot 7$ c.c. in corpuscles $)$; as bicarbonate, 12 c.c.; as organic compounds in plasma, $11 \cdot 8$ c.c.; in hæmoglobin, about 7.5 c.c.; as bicarbonate in corpuscles, about 6.8 c.c. - total, 40 c.c.

\section{The Pressure of the Gases in the Alveolar Air, Blood, and Tissues.-} In order that we may discuss the processes by which the interchange of gases takes place between the alveolar air and the blood in the lungs, and between the blood in the capillaries and the tissue fluids, it is necessary that we know the pressure of the gases in these various parts. It is possible that such an interchange is a physical process fo'lowing well-known physical laws; on the other hand, it is possible that, owing to the incessant demand of the tissues for oxygen, and the need of freeing them from excess of $\mathrm{CO}_{2}$, that secretory processes, unexplainable by known physical laws, may play a part in this gaseous interchange. Such a process would be the passage of a gas from a region of lower concentration, through a layer of.cells wet with tissue lymph, to a region of higher concentration. If this took place, it would be fair to assume that the intervening cclls and the blood were in some way aiding the process by virtue of their own special vital metabolism. It might be said that the cells were actually secreting the gas into the region of higher concentration, just as the kidney secretes urea from the blood, where it may be 1 per 1,000 , into the urine, where it may be 20 per 1,000 .

Both views have been advocated, and are still advocated, in regard to the processes of respiration. One school of thought belicves that all the processes may be explained by known physical laws; another school holds that, under some circumstances at any rate, the processes of gaseous interchange are aided by active intervention on the part of the body cells, particularly those of the alveoli. To ascertain the merits of these conflicting views, it is necessary to know the partial pressure of the gases concerned in this interchange in the various parts of the body, and also to study the accuracy of the methods by which these pressures are calculated.

Partial Pressure of Gases in the Blood.-Many experiments have been made by various researchers to determine exactly the partial pressure of the gases in both arterial and venous blood. In general, the method employed has been to bring the circulating blood into contact with a gas mixture of known composition, and by analysis at the end of the experiment to ascertain the composition of this mixture. The blood, thoroughly shaken with the mixture, gets into equilibrium with it, and the blood gases then have the same partial pressure as those found in the mixture. The instruments cmployed for this purpose are known as "aerotonometers." The microtonometcr is the apparatus now most generally employed. In this apparatus (Fig. 141), a bubble of air (2) of 2 millimetres diametcr is brought into contact with the blood coming from an artery or vein. The blood cnters by a fine point (1), and keeps the bubble in constant movement, 
so that the exchange between the air in the bubble and the gases of the blood is a rapid one. The bubble (2) can be drawn into the fine calibrated tube (3) by means of the screw piston (4), and measured therein. The wide part of this tube (1) is first filled with Ringer's solution, and the bubble introduced into it by means of a pipette. It is then drawn into (3), measured, and again returned to (1). The blood is now allowed to flow through (1) for a few minutes by way of (5) and (6). The bubble is once more measured in (3), and then (5) is filled with potash solution, the bubble returned to (5), then to (3), and again measured. Finally, (1) is filled with sodium pyrogallate solution, and the manœurre repeated. Thus the percentage of $\mathrm{CO}_{2}$ and $\mathrm{O}_{2}$ is obtained, for the potash absorbs the $\mathrm{CO}_{2}$ and the pyrogallate $\mathrm{O}_{2}$. From the percentage measured at atmospheric pressure the partial pressures are calculated.
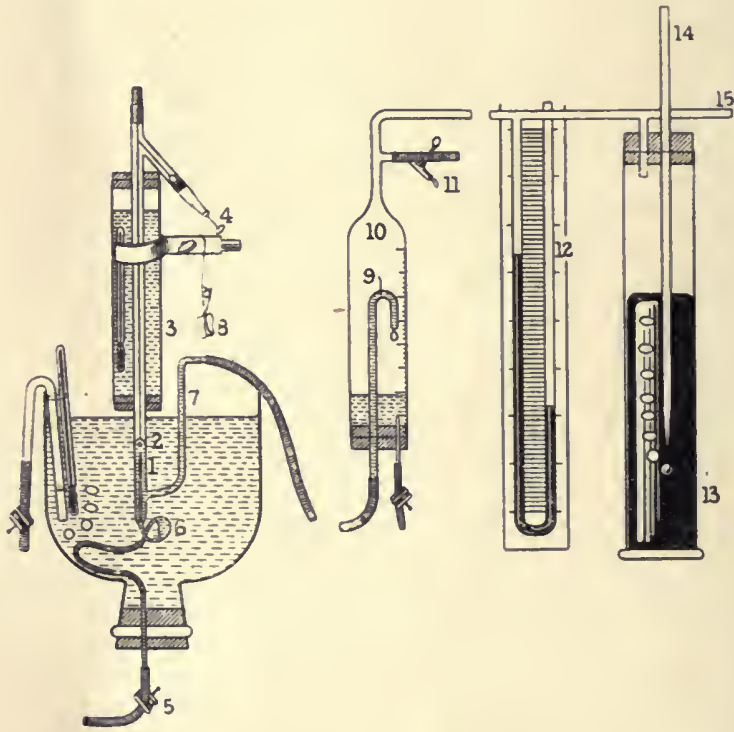

Fia. 141.-Schematic Representation of Krogh's Microtonometer.

Description in text.

The invasion coefficient is the amount of gas which cnters 1 square centimetre of the surface in one minute at atmospheric pressure. This has been measured in the case of a bubble of air by means of the microaerotonometer. The film covering this bubble is comparable in tenuity to that of the pulmonary endothelium.

A very rough calculation of the invasion coefficient suggests that it demands a difference of pressure on the two sides of the lung surface of $1 \mathrm{~mm}$. Hg for every 100 c.c. of oxygen absorbed by the lung per minute. 
The results obtained by the microtonometer support the view that the exchange of gases in the lungs is brought about by the process of diffusion, and not by active secretion. The oxygen passes from the alveolar air, where its pressure is higher, into the arterial blood, where its pressure is lower. The carbon dioxide passes from the venous blood, where its pressure is higher, into the alveolar air, where its pressure is lower; and the pressure of carbon dioxide in the arterial blood leaving the alveolus is higher, or at any rate not lower, than that in the alveolar air.

There is nothing inherently improbable in the conccption of the lung as a gas-secreting organ. Gas is secreted by several aquatic organ-

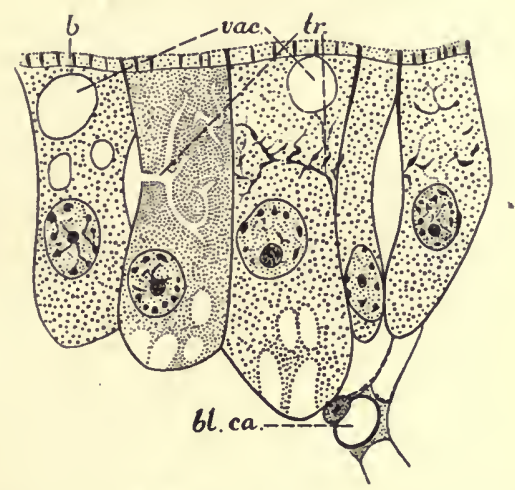

Fig. 142.-Five Gas-Secreting Cells from the Gas Gland iñthe Swim-Bladder? of the Paradise Fish Macropodus Viridi-auratus. (Redrawn after Peis and Nusbaum from Dahlgren and Kepner.)

$b$, Thiekened distal border of eells on the lumen; vac., gas-vaeuoles; $t r_{\text {. }}$, trophosfongia, the organs eoneerned in the elaboration of gas from the materials of the cell; $b l$. ca., blood eapillary.

isms for the purpose of flotation (Fig. 142). The swim-bladder "of the fish is an organ developed, like the lung, as an outgrowth from the gut. Gas is secreted in it, so as to render the specific gravity of the fish equal to that of the surrounding water. In fish at great depths, the gas is compressed by -even hundreds of atmospheres of pressure, due to the superincumbent water. The fish secrete oxygen gas against this enormous pressure, and the swim-bladder is immune to oxygenpoisoning. If the swim-bladder in a codfish is punctured, and the gas drawn off, the bladder fills again; but this does not take place if the vagus nerves be divided. Thus the secretion of the gas is controlled by these nerves. Some authorities have sought evidence that the gaseous exchange in the lungs is not only a process of secretion, but one controlled by the vagus nerves. The function of the swimbladder is manifested by taking two goldfish, and fastening a piece of cork to the dorsal fin of one, and a piece of lead to the ventral fin of the other. Both are returned to a tall jar of water, and the one 
is drawn by the cork to the surface, and the other by the lead to the bottom. Next day they have adjusted their specific gravity by means of their swim-bladders, and are swimming about easily. On removing the lead, that fish irresistibly floats to the surface; on removing the cork, the other one sinks to the bottom. They have again to adjust their swim-bladders. If goldfish in water are placed in a pressure chamber, and suddenly compressed, they sink to the bottom, owing to the shrinkage of the gas in the bladder. If a fish is hooked in deep

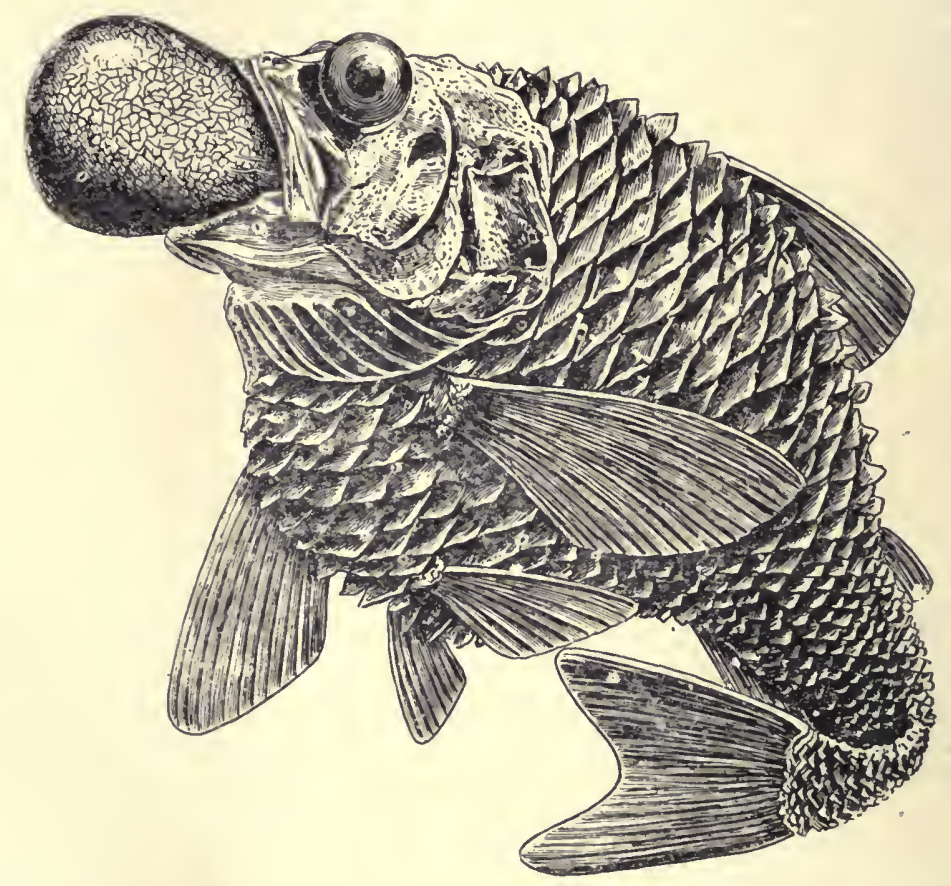

Fra. 143.-Fish brodaht op from a Considerable Depri with Swollen SwimBladder projecting from Mouth. (After Regnard.)

water, and started on the way up, the gas in the bladder expands, and the fish floats to the surface, and the bladder often bursts (Fig. 143). There is a glandular mechanism in the swim-bladder for secreting gas, and another mechanism for absorbing it.

Against the theory of pulmonary secretion is the fact that the pulmonary endothelial cell is a flattened structure entirely unlike the granular secreting cells typical of glands.

Evidence in favour of pulmonary secretion has been sought by a method quite different to that of the aerotonometer. If blood is shaken with air containing, say, 0.05 per cent. of carbon monoxide, the hæmoglobin is shared between the oxygen and carbon monoxide 
in proportions depending on their relative pressures and chemical affinity. Carbon monoxide has an affinity about 150 times as great as oxygen. Blood saturatę with carbon monoxide, and diluted 1 in 200 times, has a pink colour; the extent of saturation with carbon monoxide can be estimated by a method depending on the depth of this colour. If three samples of blood (diluted 1 in 200) are taken, and one is saturated with carbon monoxide (shaken with coal-gas), the second partly saturated, and the third not at all, the colours of the samples are obviously different. The normal sample is strawcoloured. A standard solution of carmine can be run in from a pipette, and the amounts found which will make Sample 2 and Sample 3 equal in pinkness to Sample 1. From the relative amounts of carmine used the degree of saturation of Sample 2 is discovered.

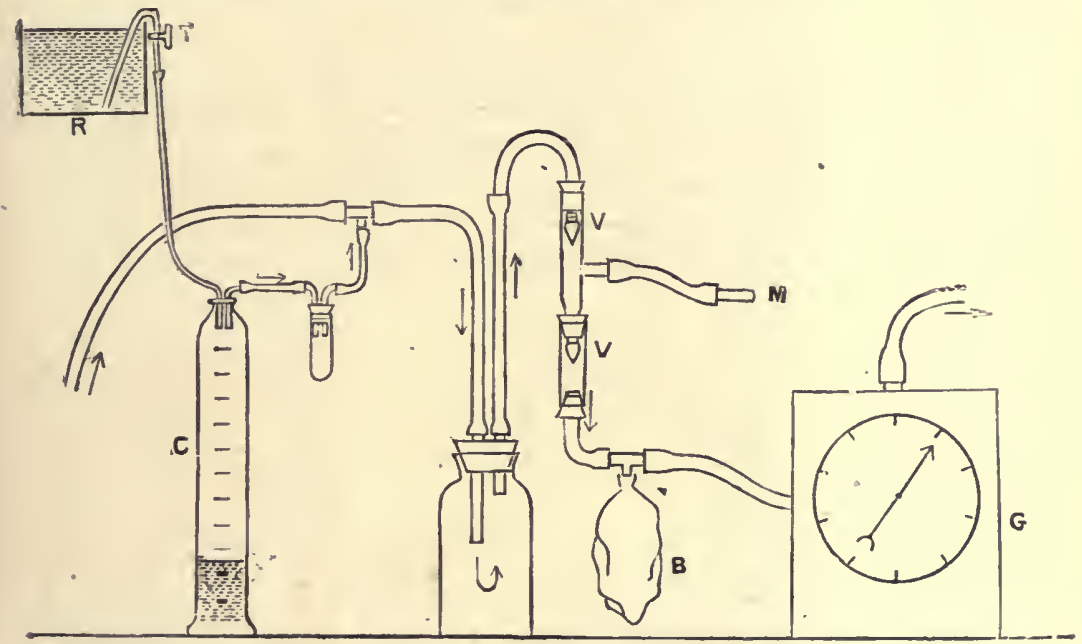

Fig. 144.-Haldane's Apparates for determinisg $\mathrm{O}_{2}$ Texsiox ix Human BLOOD.

$R, T, C$, Apparatus for bro athing air containing $\mathrm{CO}$ at measured concentration; $M$, mouthpiece; $V$, valves made of pieces of intestine; $B$, air-bag for controlling pressure during expiration; $G$, meter.

Now, when air containing 0.05 per cent. carbon monoxide is breathed for a sufficient period to allow the whole blood to get into equilibrium, the saturation with carbon monoxide is found to be less than that when the blood is shaken with the same mixture outside the body; particularly is this the case under conditions of oxygen want-e.g., at high altitudes, partial asphyxia-when it is suggested there would be secretion of oxygen into the blood by the lung. The oxygen pressure in the arterial blood raised by secretion is supposed to antagonize the union of carbon monoxide with the hæmoglobin. However, other explanations have been given of this result. The technique of the method is as follows: 
The subject inspires through the mouthpiece $M$, and cxpires through the meter (Fig. 144). Water is allowed to run from $R$ into $C$, which contains pure $\mathrm{CO}$, and displaces this gas at such a rate as to give a known concentration of $\mathrm{CO}$ in the volume of air, indicated by the meter, which is being breathed. The breathing is continued long enough for the blood to come into equilibrium with the partial pressure of $\mathrm{CO}$ and $\mathrm{O}_{2}$ which is being breathed (the partial pressure of $\mathrm{O}$ is that of the air). The finger is then pricked, and samples of blood taken, and the saturation determined by the carmine method given

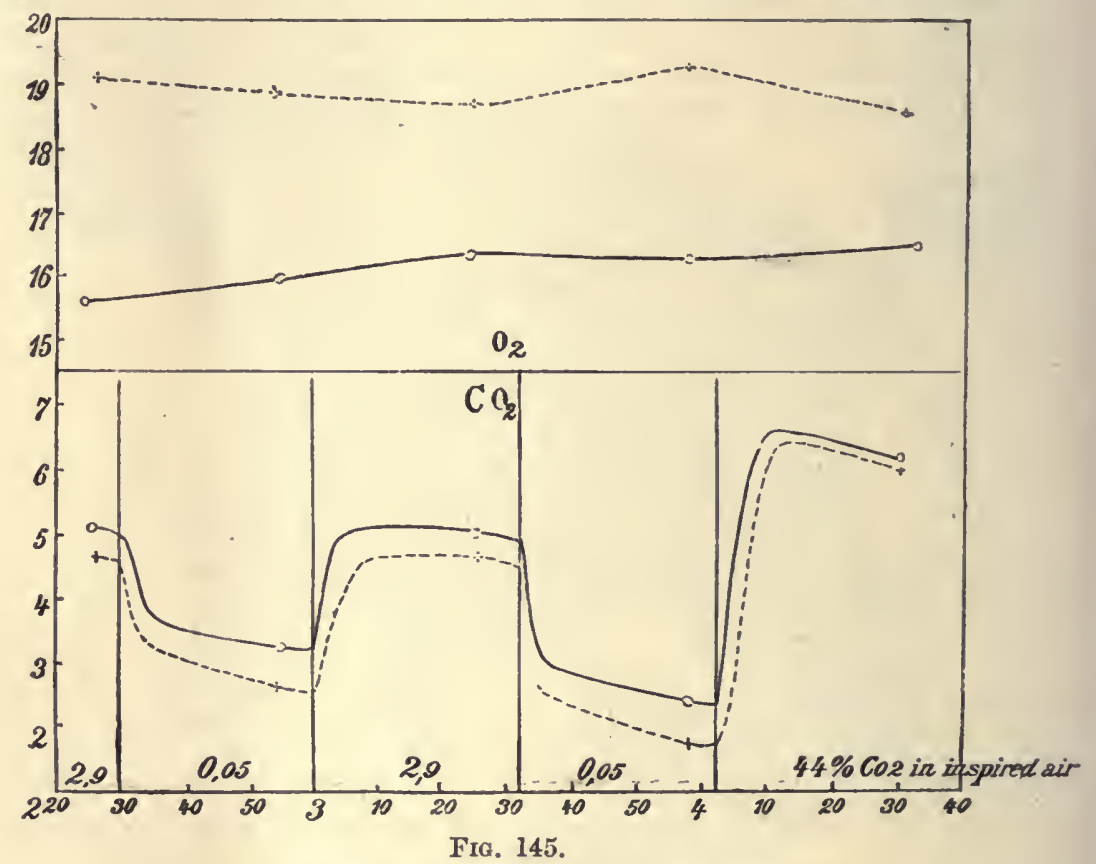

Dotted line $=$ pressure in the air at bifurcation of trachea.

Solid line = pressure in the blood.

In the upper part of the figure are shown the pressures of oxygen, in the lower part the pressures of carbon dioxide. Ordinate pressure of oxygen expressed in percentages of an atmosphere. Abseissa=time. (Krogh.)

above: A sample is shaken with the air (containing the known percentage of $\mathrm{CO}$ ), which was breathed. If this sample is found to be more saturated with $\mathrm{CO}$ than that drawn from the finger during the breathing; the conclusion is drawn that the partial pressure of oxygen in the blood in the pulmonary veins is higher than that in the air.

The colorimetric method is liable to error; moreover, a part of the carbon monoxide actually absorbed may leave the blood and combine with hæmoglobin in the muscles. There is no evidence in favour of any of the carbon monoxide being destroyed in the body,-error does not seem to arise from that cause. 
To sum up, the differences of pressure of carbon dioxide and of oxygen found by the microtonometer in the blood and at the bifurcation of the trachea support the view of diffusion (Fig. 145). It is estimated also that the process of diffusion can carry oxygen in amounts sufficient for hard work through the pulmonary endothelium. The rate of diffusion in the lung is probably accelerated by the chemical affinity of hæmoglobin with oxygen: we need not therefore ascribe a secreting power to the pulmonary endothelium.

But it is still a question whether diffusion can cover the oxygen needs at great altitudes-e.g., 24,000 feet, to which a few climbers have attained.

Carbon dioxide is about twenty-five times as soluble in water as oxygen is, hence it passes through the alveolar wall far more easily than oxygen with a given difference of partial pressure. A comparatively slight increase in breathing, by ventilating the lungs, enormously increases the small difference in diffusion pressure on which the passage of $\mathrm{CO}_{2}$ depends, but only produces a slight propoltional increase in the diffusion pressure which drives oxygen inwards. Hence, under certain conditions, greyness of the face, faintness, and danger from heart failure, the signs of oxygen-want, may arise when-hyperpnoa and venous congestion, the signs of $\mathrm{CO}_{2}$ excess, are absent. 


\section{CHAP'TER XXXI}

\section{THE MECHANISM OF RESPIRATION}

Is the uniccllular organism, oxygen is taken in from the surrounding medium, and the $\mathrm{CO}_{2}$ given out through the cell surface. In the mole complex organisms, a special respiratory apparatus becomes evolved, and two kinds of respiration are distinguished: external respiration, by which oxygen is taken from the surrounding medium into the circulating transport fluid-the blood-and the $\mathrm{CO}_{2}$ given off from this fluid to the medium; internal respiration, by which a gaseous interchange takes place between the body fluids and the various body cells, oxygen being taken to the cells, and $\mathrm{CO}_{2}$ removed from them. Internal respiration is probably the same process in all forms of animals. External respiration differs with the stage of developinent, and also with the habitat of the animal. The lower forms of invertebrates usually breathe through the skin; the higher forms, when living in the water, by a specially developed system of gills; when land dwellers, by a special system of branching tubcs known as "trachex," which carry the air direct to the blood-spaces surrounding the individual cells.

In low temperatures, the frog can breathe by its skin alone. In man, 1.5 per cent. of the respiratory exchange is reckoned to take place through the skin, and somewhat more on sweating. A small amount of respiratory exchange takes place through air which is swallowed: certain fishes breathe by this method.

Among the vertebrates, fishes have a special system of gills, by which the gaseous interchange between the surrounding water and the blood is effected.

Amphibians in the larral stage--e.g., the tadpole-also possess gills; but in the adult animal these are replaced by lungs. In the higher vertebrates, after birth, external respiration is always effected by means of specially developed lungs. During development, however-as, for example, in the human fotus-traces of the remains of the gill apparatus can still be seen.

In the higher organisms, the circulatory mechanism suffices for the transport of the gases to and from the tissues, and various devices have been adopted to facilitate the interchange between the outer medium and the respiratory apparatus. In fishes, the water is taken in through the mouth, passed over the gills, and out by the gill-slits; in many amphibia, the air is swallowed into the lungs. In birds, during rest, the movements of the ribs suffice to draw air through the lungs and in and out of the five large air-sacs. The lungs are not 
expanded with air, but the blood is pumped in and out of them by the movement of the ribs. During flight, the wing movement insures adequate respiration. The air-sacs play a great part in flight and extend the leverage with which the muscles act, at the same.time keeping the body light. Opening the air-sacs in the resting bird causes no upset of breathing. In the flying bird, an immediate dyspnoea is induced, and flight becomes impossible. It has also been shown that for proper heat regulation of the body the air-sacs are necessary.

In mammals, the gaseous interchange is effected.by the movements of the sternum, ribs, and abdomen, drawing air into and expelling it from the air-tight chest, or thorax (see later, p. 281).

In man, the respiratory tract may be said to consist of the following parts:

1. The Nose.-The respiratory portion of the nose consists of the inferior meatus and the lower portion of the superior meatus. These parts are covered by a very vascular ciliated mucous membrane, which provides a mucous secretion. Thick hairs, or vibrissæ, project into the respiratory airway, and guard the entrance against insects. Air taken in through the nose is warmed and moistened, and, more important still, injurious particles of dust and bacteria are, removed from it. The mucous membranc is extremely sensitive to changes in the atmosphere. When the air playing round the head is cool and relatively dry, the mucous membrane is firm and moist, and a good airway is insured; when the air is stagnant, warm, and humid, the mucous membrane becomes engorged, wet with secretion, and boggy. It is not the cold outside atmosphere of winter, but the warm infected air of crowded rooms, which causes the epidemics of "cold in the head." The nose also acts as an accessory resonating chamber in speech, as the term talking "through the nose " testifies. To produce this the airway through the nose is greatly diminished.

2. The Pharynx.-Air is conducted through the upper part of the pharynx inte the larynx. Its shape and movement play a large part in determining the quality of the voice. Here and in the tonsils there is much lymphoid tissue which possibly guards from infection by inhaled bacteria.

3. The Larynx.-This specialized part of the respiratory tract in which the voice is produced is dealt with later (sec p. 739).

4. The Trachea, or windpipe, which divides into the two as bronchi ; these divide into smaller divisions, known as bronchial tubes, which in their turn divide into bronchiales, ultimately opening into the essential distensible elements of the lungs, the funnel-shaped infundibuli, and the alveoli.

The trachea is provided with ciliated epithelium, and is wet with micus secreted by the glands of its mucous membrane. In this mucus any entering dust or bacteria are caught, to be carricd upwards by the cilia and away from the lungs. The walls of the larger of these passages (the trachea and bronchi) are provided with cartilage.

The bronchial tubes are supplied with smooth muscle innervated 
by the vagus and sympathetic nerves. During hard exercise the eapacity of the bronchial tubes is said by some to increase in order to lessen resistance and facilitate the rapid and great ventilation of the lungs. By means of this muscle the airway ean certainly be increased or decreased so that air may more or less readily be taken into the lungs (Fig. 146). Drugs also affect this mechanism (Figs. 147, 148). The muscle can control the entry of air into one or
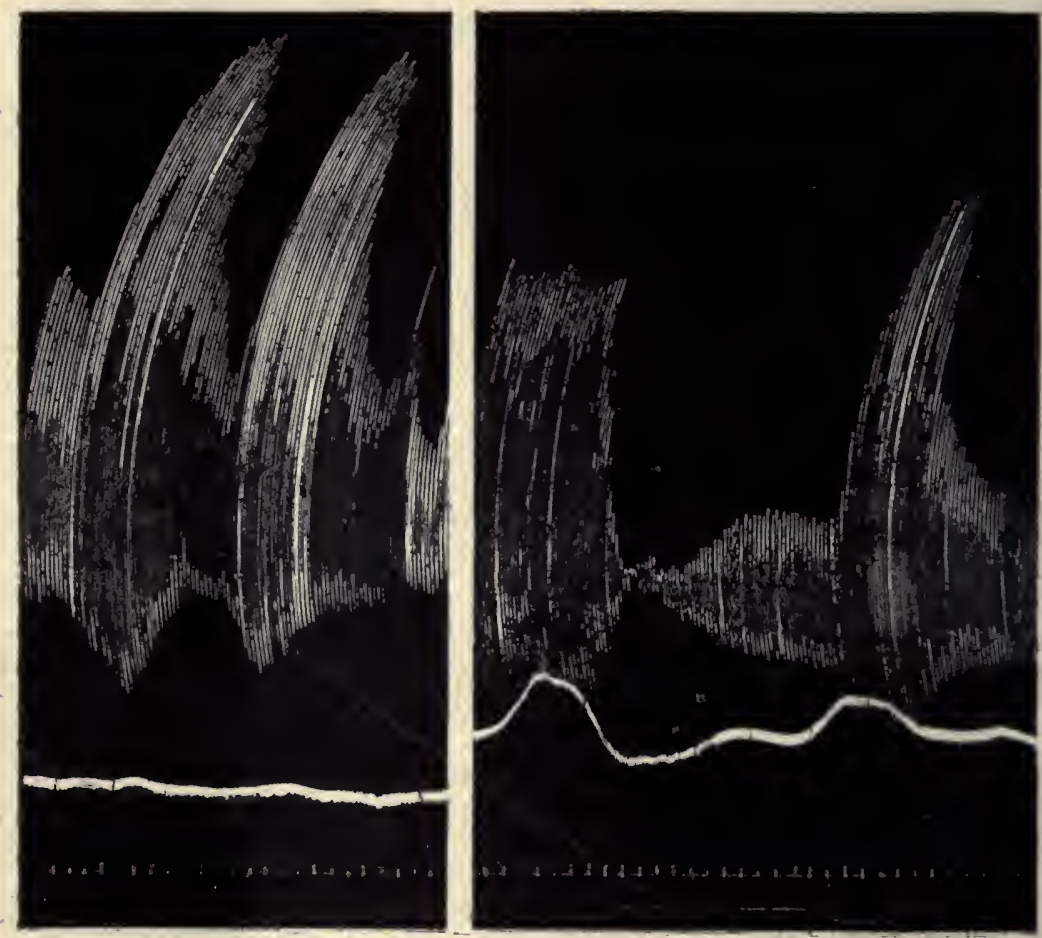

Fig. 146.-Decerebrate Animal: Lung Volume and Blood-Pressure. To show Effect of Excitation of Peripheral Vagus and of Right Cervical SyMPathetic. (Dixon and Ransom.)

other part of the lung. There is some evidence that all parts of the lung are not in action during quiet breathing. The muscle supports the tubes in expiratory effort.

The infundibular sacs of the lung are lined with flattened cubical cells, supported by a framework of elastic fibres and richly supplied by bloodvessels. The alveoli are smaller terminal expansions set in the funnel-shaped infundibula.

Air Volume.--In dealing with respiration, certain terms are used which require defining. The volume of air breathed by a person at each quiet respiration is termed the tidal air. This averages, in a 


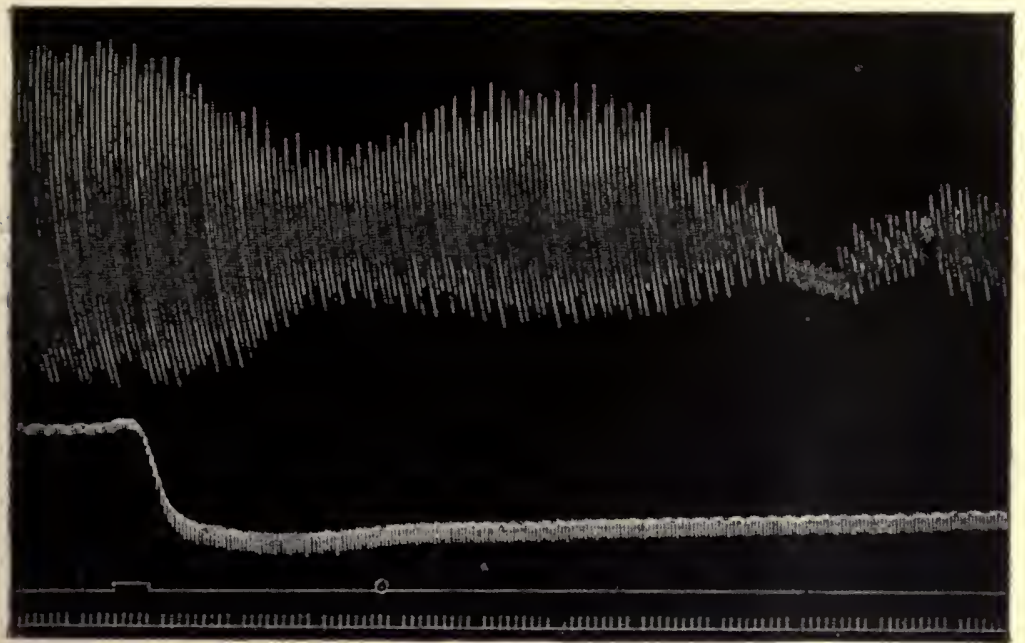

FIG. 147.

Upper curve shows lung volume, lower arterial pressure of eat with right ragus cut. At indication mark 0.0075 gramme of pilocarpine nitrate injected. There is constriction of the bronchial muscles, which diminishes the amount of air entering and leaving the lungs. The blood-pressure falls. Both effects are due to stimulation of the vagus nerve-endings. (Brodie and Dixon.)

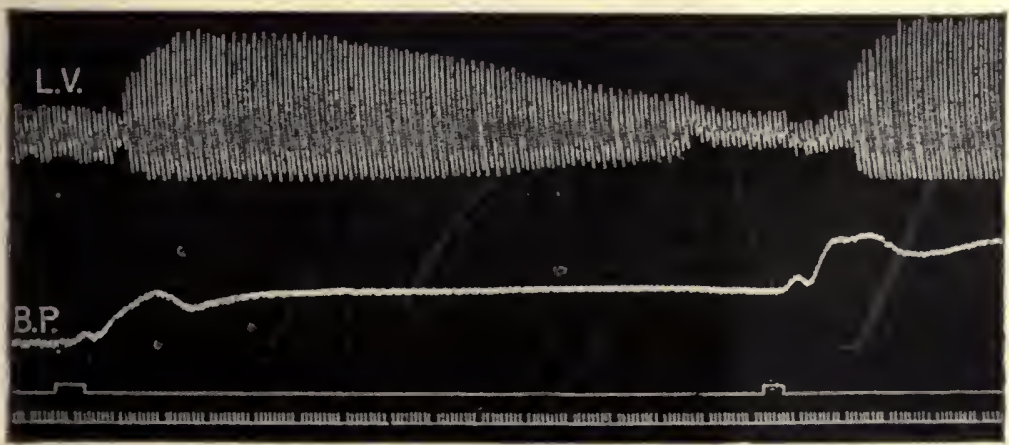

FIG. 148.

Upper curve represents the volume of small lobe of lung, amount of air entering and leaving lung shown respcctively by up-and-down strokes. Iower eurre, bloodpressure. At indicated marks two small doses of lobelia injected into a vein. There is almost immediate dilatation of the bronchioles; the rise in blood-pressure is a vaso-motor effect. (Brodie and Dixon.)

resting man, 300 to 500 c.c. The amount of air which can be taken into the lungs by forced inspiration after a normal quiet inspiration is the complemental air, averaging 1,500 to 2,000 c.c.; that which can by forced effort be expelled from the lung after a quiet expiration 
is the supplemental air, also 1,500 to 2,000 c.c. in volume. These three together give the vital capacity of an individual.

\begin{tabular}{|c|c|c|c|c|c|}
\hline Tidal air .. & & & .. & $\because$ & $300-500$ c.c. \\
\hline Complcmental air & & - & .. & & $1,500-2,000$ c.c. \\
\hline Supplemental air & & . & .. & .. & 1,500-2,000 c.c. \\
\hline Vital capacity & & . & ${ }^{\circ}$ & • & $3,300-4,500$ c.c. \\
\hline
\end{tabular}

The vital capacity can be measured by expiring to the greatest extent after the fullest possible inspiration into a spiroincter (Fig. 149) -a form of gasometer. The vital capacity of an individual can be

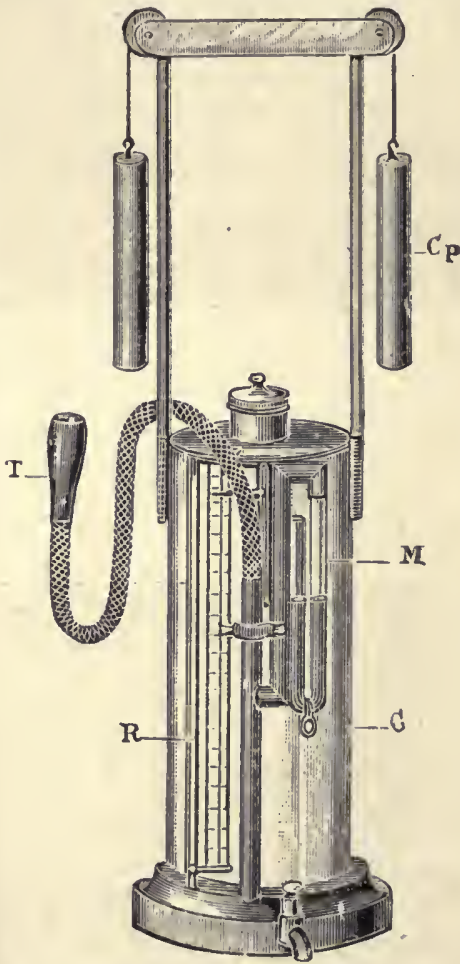

Fig. 149.-SPronetel.

$T$, Mouth-picc; $M$, mancmeter; $C p$, counterpoisc; $R$, scale.

greaty increased by practice. Some athletes (swimmers) have a. capacity of 61 litres. The amount breathed out depends largely upon proper muscular co-ordination. It also varies with posture, being greatest when standing, and least when lying down.

The amount of air left in the lungs after the greatest expiration possible has been taken is termed the residual air, and measures 1,500 to 2,000 c.c. The cxpired tidal air comes from the trachea, bronchi, and alveoli. It is calculated, of 500 c.c. expired, 140 to 160 c.c. comes from the trachea and bronchi, forming the "dead- 
space" air, and the remainder from the aveoli-true alveolar air. The dead-space air does not undergo a respiratory exchange. In the resting man, 350 c.c. of the total tidal air mixes with 3,000 to. 4,000 c.c. in the lungs (supplemental and residual air), so that only about one-tenth of the air is changed at each breath; much less in shallow breathing. In deep breathing, the complemental air is added to the tidal, and 1,660 to 2,360 c.c. mixes with the air in the lungabout one-half is changed.

A sample of alveolar air may be obtained by expiring deeply through a piece of rubber tubing of about 1 inch bore and 4 feet length (Fig. 150). The "dead-space" air is blown out of the tube, and the tube is filled with alveolar air. The end of the tube is closed with the tongue or with forceps, and through the $\mathrm{T}$-piece a sample is drawn off into a suitable sampling tube, which has been previously evacuated.

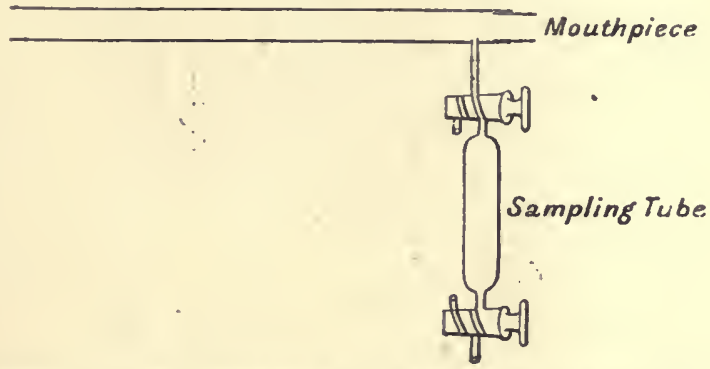

Fig. 150.-Apparatus for Collection of Sample of Alveolar Air. (Haldane and Priestley.)

by means of a reservoir fitted with a rubber tube. The sample may bo taken at the end of a normal expiration following an inspiration, or preferably two samples may be secured, the second immediately after expiration following normal inspiration. The mean of the analyses gives the normal alveolar air.

Alveolar air contains 4.5 to 6 per cent. $\mathrm{CO}_{2}, 13.5$ to 15 per cent. $\mathrm{O}_{2}$, 79 to 80 per cent. $\mathrm{N}_{2}$. The $\mathrm{CO}_{2}$ percentage in men (5 to 6 per cent.) is generally a little higher than in women and children ( 4 to 5 per cent.).

The composition of ordinary inspired air at normal temperature and pressure $-0^{\circ} \mathrm{C}$, and 760 millimetres-may be given as follows:

\begin{tabular}{|c|c|c|c|c|c|c|}
\hline Oxygen & & & & \multicolumn{3}{|c|}{$20 \cdot 92$ volumes per cent. } \\
\hline Carbon dioxide & $\therefore$ & .. & .. & $0 \cdot 03-0 \cdot 04$ & , & ", \\
\hline Nitrogen * & $\therefore$ & .. & .. & $79 \cdot 03$ & , & \\
\hline our & .. & .. & .. & .. & .. & Variable \\
\hline Temperature & .. & .. & .. & .. & .. & Variable \\
\hline
\end{tabular}

Expired air:

\begin{tabular}{|c|c|c|c|c|c|c|}
\hline Oxygen & & & .. & . & .. & 16.00 per cent. \\
\hline Carbon dioxide & .. & .. & .. & . & .. & $4 \cdot 00$ \\
\hline Nitrogen * $\ldots$ & $\ldots$ & .. & $\ldots$ & .. & .. & $80 \cdot 00$ \\
\hline Water vapour & .. & .. & .. & .. & .. & .. Saturated \\
\hline Temperature & $\ldots$ & $\ldots$ & .. & .. & .. & $37^{\circ} \mathrm{C}$ \\
\hline
\end{tabular}

* Including 0.94 per c sat. argoz. 
Expired air is diminished about one-fiftieth in volume as compared with the inspired air. This is due to the oxygen combined with products of tissue oxidation which passes out of the body in the urine. To obtain expired air for analysis, the subject breathes

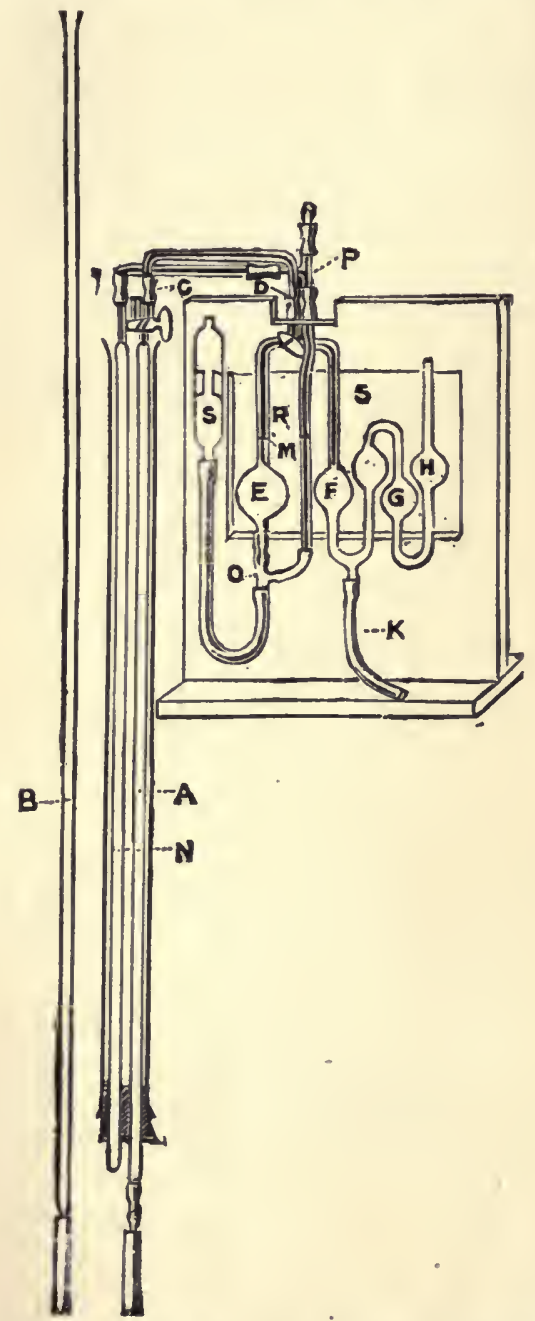

Fig. 151.-Haldane's Gas Axalysis Apparatus.

through a mouth-picce, provided with inlet and outlet valves, into a large rubber-lined canvas bag. The contents of the bag are squeezed through a meter, and thus the volume of expired air measured; while a sample is secured for analysis by means of a $T$-piece into an evacuated sampling tube. If the subject breathe for, say, 
ten minutes, and the number of respirations be counted, the tidal air can be calculated; from the analysis the respiratory exchange can be estimated as well as the composition of the expired air (see later, p. 317).

One of the best forms of apparatus for the estimation of the gases in inspired and expired air is shown in Fig. 151.

The gas is measured in the graduated gas-burctte $A$, provided with a three-way tap. Surrounding the gas-burette is a water-jacket. The whole is supported by a clamp and retort stand. The gas-burette is connected by pressure tubing to the levelling tube $B$, which is held by a spring clamp attached to the retort stand. $A$ and $B$ contain mercury, and by raising or lowering $B$ gas can be expelled from or drawn into $A$. One of the connections of the three-way tap is used for taking in the sample, the other connects the burette with an absorption apparatus arranged as in the figure.

The bulb $E$, filled with 20 per cent. caustic potash, absorbs $\mathrm{CO}_{2}$. The bulb $F$, filled with alkaline pyrogallic acid solution, absorbs $\mathrm{O}_{2}$. Alkali in $G$ and $H$ protects the pyro solution from the air. $F$ is emptied and refilled through $K$. The tap on the absorption pipette places either $E$ or $F$ in connection with the gas-burette. There is a control tube by which alterations in temperature or barometric pressure during the analysis can be compensated for.

The sample of gas is taken into the burette from the sampling tube (Fig. 150), mercury being sucked into the tube to take the place of the gas entering the burette. After measuring the amount of the sample it is passed into $E$ to absorb $\mathrm{CO}_{2}$. When a constant reading is obtained, it is passed into $F$ until all the oxygen is absorbed. To take an example: Suppose the amount of gas taken in was 20.12 c.c. After absorption of carbon dioxide in $E$ the burette reading was 19.06; after absorption of oxygen in $F$ it was 16.01 .

Then in $20 \cdot 12$ parts of the sample there is $20 \cdot 12-19 \cdot 06=1.06$ of $\mathrm{CO}_{2}$, in 100 parts therefore there are-

$$
\frac{1 \cdot 06 \times 100}{20 \cdot 12}=5 \cdot 22 \text { approx. }
$$

Also in 20.12 parts of the sample there are $19 \cdot 06-16.01=3.05$ parts of $\mathrm{O}_{2}$.

In 100 parts therefore there arc-

$$
\frac{3 \cdot 05 \times 100}{20 \cdot 12}=15 \cdot 11 \text { approx. }
$$

The percentage of sample, therefore, is $5 \cdot 22 \mathrm{CO}_{2} ; 15.11 \mathrm{O}_{2}$. 


\section{CHAPTER XXXII}

\section{THE MECHANICS OF BREATHING}

To facilitate gascous interchange, the process of breathing or ventilation of the lungs takes place. In the act of inspiration in mammals the chest is expanded, air is drawn into the lungs; in the act of expiration the chest and lung capacity is diminished, and air forced out from the lungs.

Anatomical Considerations.-To understand properly the movements concerned in the processes of inspiration and expiration, ccrtain anatomical details in regard to the bony framework and the musculature of the thorax have to be considered. The varying extensibility of different parts of the lung has also to be borne in mind.

In the inspiratory movement, the thorax is expanded in three dimensions. In regard to the exact manner in which these movements take place therc is still some uncertainty. The chicf movements, however, may be grouped as-

1. The movements of the diaphragm.

2. The movements of the ribs and rib cartilages.

Breathing of the abdominal type, such as occurs in man, is chiefly diaphragmatic; breathing of the thoracic typc, such as takes place in corsetted women, is mainly costal. Normally, breathing is a combination of the two types-sometimes one, sometimes the other prevails.

The Action and Movements of the Diaphragm.-Separating the thorax from the abdomen, the diaphragm, in its resting position, reaches up to about the fifth intercostal space. The fleshy part of the muscle lies close to the ribs, the central dome-like part being mainly of a tendinous nature. There has been considerable speculation as to the exact nature of the movements performed by the diaphragm. The vicw commonly expressed is that the muscle, by its contraction, in association with muscles which fix the throax, opens up the angle which it forms with the thoracic wall, thereby enabling the lung to expand in a downward direction.. In such a movement the ccntral tendinous portion is supposed not to participate. After contraction, it is assumed that the diaphragm passively returns to the position of rest.

Recent study of the diaphragmatic movement by means of the $\mathrm{X}$ rays has shown, however, that there is a forward downward move- 
ment of the whole diaphragm, accompanied by a definite movement of the abdominal viscera.

The diaphragm may be regarded as consisting of two parts: (1) The spinal, or crural, from the spinal column and arcuate ligaments to the back portion of the central tendon; (2) the costo-sternal, or anterior, attached to the front and sides of the central tendon, and arising by several digitations from the ribs. The arch of the diaphragm rests upon, and is supported equably by, the abdominal viscera, and is at the same time kept constantly applied at the circumference to the inner wall of the thorax by the negative intrathoracis pressure. Thus, when its two parts contract, it acts like a true piston, moving in a forward and downward direction. In quiet, normal breathing the amount of movement of the right dome is about $\frac{1}{2}$ inch, that of the left dome and of the central tendon somewhat less.

The Movement of the Ribs.-In general, two movements of the ribs are recognized as taking place in inspiration: (1) Round an axis corresponding to the spinal articulation, increasing the back-to-front diameter of the thorax; $(2)$ round one corresponding to the spinosternal articulation, increasing the diameter from side to side. Owing to the variation in size, shape, inclination, and articulation of the ribs, such an explanation, while essentially true in a general sense, is imperfect. It is better to divide the ribs into two sets: (1) The upper, the second rib to the fifth; (2) the lower,' the sixth rib to the tenth. These two sets differ in their musculature, in the nature of their articulation and ligaments, in their shape and arrangement, and in their movements.

It is better not to regard the first rib as one of the costal series, but to associate it with the manubrium sterni, with which it performs a special movement of its own. The lowest two ribs, inasmuch as they are unattached in front-" floating "- -are essentially parts of the abdominal wall. Concerned in the respiratory movements, therefore, are-

1. The first rib and manubrium sterni.

2. The upper costal series (2-5).

3 . The lower costal series $(6-10)$.

4. The floating ribs $(11,12)$.

The First Rib and Manubrium Sterni.-The first pair of ribs and the manubrium sterni are intimately bound together, and form, with the manubrium, a lid or operculum to the thorax. Behind this lid is articulated with the spinal column, in front with the body of the sternum, the manubrio-sternal joint (Fig. 152). During inspiration there is a slight upward movement of the lid, allowed by the manubriostcrnal joint, which causes an expansion of the anterior part of tho apex of the lungs. This movement is particularly marked in the thoracic type of breathing. To demonstratc the movement at the manubrio-sternal joint small mirrors are fixed above and below this joint, and the movements of the reflected spots of light observed on a. screen. During inspiration the spots diverge, during expiration 
they come together. In people with ill-developed chests there is but little movement here. The posterior part of the apex of the lung is but little affected by the movement of the operculum, its expansion being secured by diaphragmatic breathing.

The Movement of the Upper Ribs.-It is on these that most of the obserrations upon rib movements and the action of the intercostal muscles have been made. During inspiration, both sets of intercostal muscles act together, and draw up the upper ribs towards the operculum, which acts as a fulcrum. During expiration, the lower set of ribs are fixed, and act as fulcrum, and the upper set are drawn down toward them by the intercostal muscles. This view of the action of the intercostals is not accepted by everyone. There is some experimental evidence to show that the external intercostal muscles act during inspiration. The fibres slant from above downwards and for-

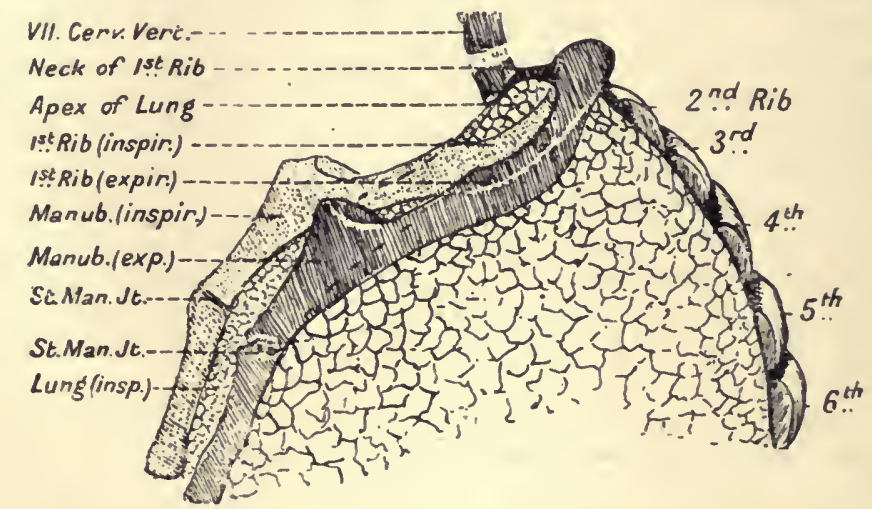

Fre. 152.-Uiagray to show Respiratori Movemexts of the First Pair of Ribs aNd Masobrity Stersi and the EFfect of these Movenents on the ExpanSION OF THE APEX OF THE LUNG. (Keith.)

wards, and. shortening, raise the ribs. The fibres of the internal intercostals. on the other hand, slant from above downwards and backwards, and, shortening, lower the ribs. The two, acting together, make rigid the thoracic wall. The intercartilaginous fibres act with the extemal intercostals.

The Movement of the Lower Ribs. - The purpose of the movement of the lower ribs is to expand the lower lobe of the lung. The diaphragm is the chief muscle concerned, aided by the ilio-costalis, and the external intercostals, and the interchondral muscles. The antagonistic muscles are the external oblique, the internal oblique, and the transversalis. During inspiration, owing to the mode of articulation of the ribs, the lateral and anterior part of each moves outwards more than the one above. At the same time, the lower ribs are raised. together with the sternum, so that the net result of the lower rih movement is to increase the transverse and back-to-front 
diameter of the lower thorax, and, with the diaphragm moving downwards, the vertical diameter of the whole cavity.

Inspiration is therefore a very complex act, and it is owing to the complicated nature of the movements concerned that the lungs are divided into lobes. The upper ribs are chiefly concerned in the

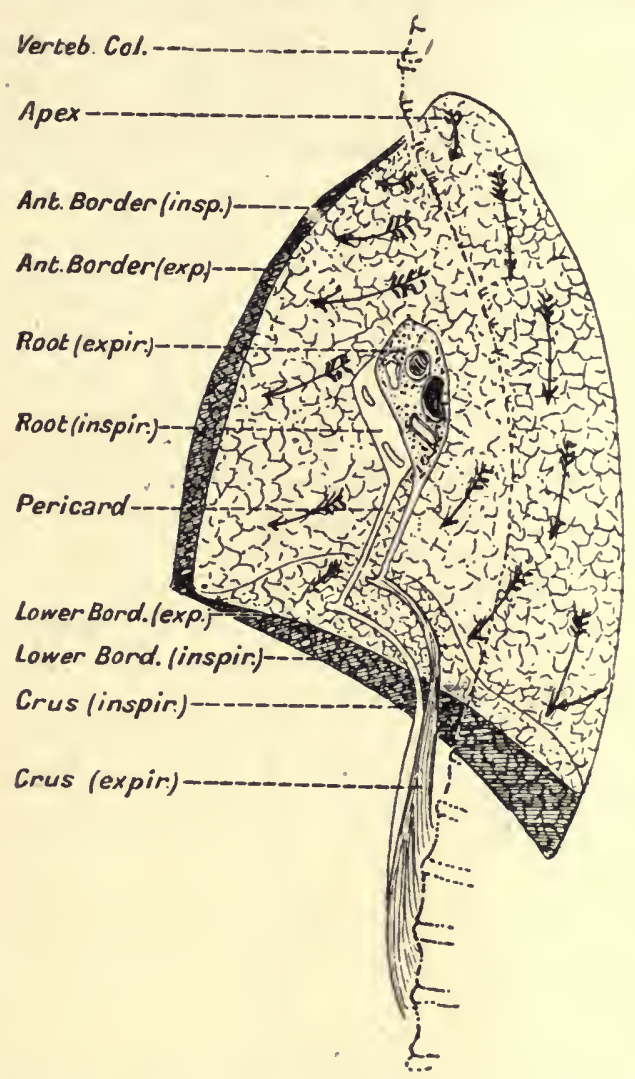

Fig, 153.-Mediastinal Aspect of Right Lung to show Respiratory Movement OF THE ROOT. (Keith.)

The crus of the diaphragm is also indicated, and its attachment to the root of the lung through the pericardium. Arrows indicate direction of inspiratory move. ment of various parts of the lung.

expansion of the upper lobes, the lower ribs in the expansion of the lower lobes, the diaphragm promoting the expansion of the whole lung.

In the act of inspiration it is also to be noted that, owing to the varying degree of extensibility of the different structures of the lung, the organ expands more in the manner of a Japanes 3 fan-least in the neighbourhood of the great vessels and bronchi (the root of the lung), most in the outermost zone just beneath the pleuræ (subpleural zone). 
The infundibula also vary in size in these different zones of the lung, being largest in the subpleural zone, and smallest at the root of the lung (Fig. 153).

The two surfaces which are most expanded are the diaphragmatic and the sterno-costal, or ventro-lateral. In general, the apical surfaces remain almost stationary. It is only when the lungs are well ventilated that the parts most remote from these surfaces of direct expansion are brought properly into action. In people of sedentary habits, therefore, such parts of the lung fall into a condition of disuse, and receive a poor supply of blood, with its immunizing properties. This explains why phthisis so frequently attacks the apex of the lungs first.

When inspiration becomes forced, accessory muscles, such as the scaleni, sterno-mastoid, trapezius, pectoral, rhomboid, and serratus anticus muscles are brought into play. The arms are fixed, so that the muscles passing from the thorax to the arms can come into play on the thorax. A patient suffering from dyspnœa sits up, and grasps the arms of a chair.

In regard to expiration, it is often stated that quiet expiration is brought about by a passive collapse of the expanded lung, the thorax following this recoil by virtue of its weight. It seems probable that such a process is aided and made to work smoothly, even in quiet expiration, by the contraction of the muscles antagonist ic to those concerned in inspiration. Such muscles are those of the abdominal wall, and possibly the internal intercostals.

In forced expiration many muscles are called into play, such as the serratus posticus inferior and the rectus, obliquus, and transversus muscles of the abdominal wall. 


\section{CHAPTER XXXIII \\ THE REGULATION OF BREATHING}

THE movements of respiration are regulated by a centre which has been localized in the medulla oblongata. This localization has been made by watching the effects upon respiration of removal of the brain from above downwards and from below upwards. By this means it is found that, when an area of grey matter in the floor of the fourth ventricle is damaged, all signs of respiratory movement completely cease. To this centre run afferent nervous paths from various parts of the body, and also from the higher nervous centres; from it pass

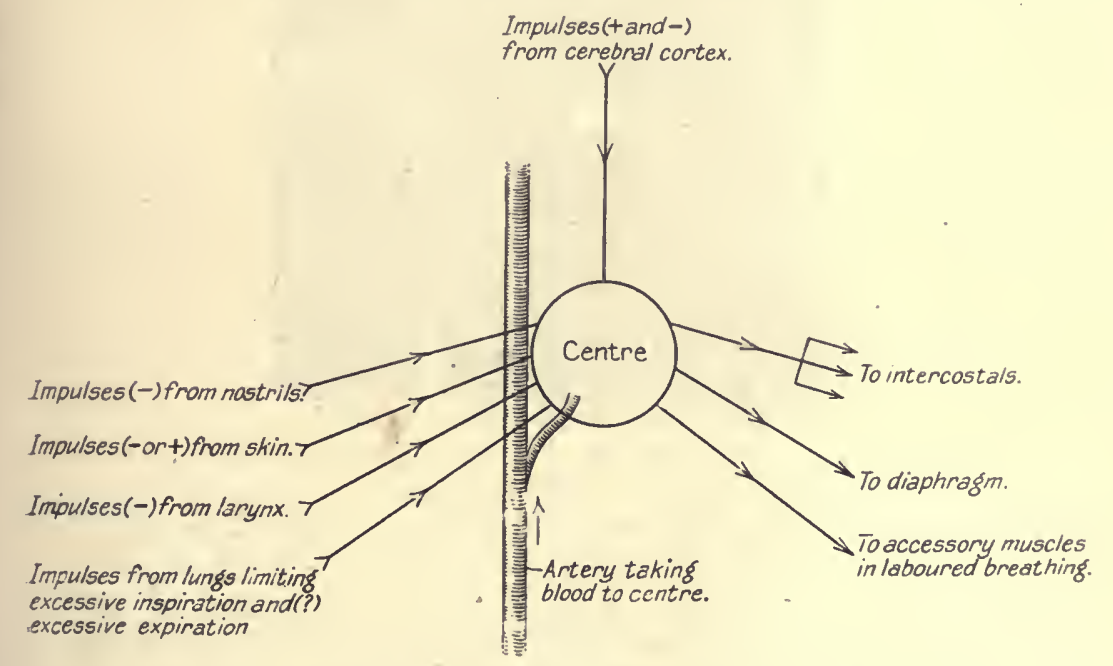

Fiv. 15t.-Diagrali ingstrativg Regulation of Respiratiox.

(+) signifies increased breathing; ( - ) diminished or inhibited breathing.

efferent channels to the muscles concerned in breathing. Such fibres do not pass directly from the centre to these muscles, but form a synapse with the anterior horn cells in the spinal cord, from which the effector nerves to the muscles of respiration arise. Thus the diaphragm is supplied by the phrenic nerve, which arises from the third, fourth, and fifth cervical nerves; the intercostal muscles from corresponding branches of the intercostal nerves.

Since the movements of breathing persist after all the afferent 
nervous connections have bcen eut, and cease when the circulation is stopped, it is clear that the centre is dependent, in the first place, for its activity upon the blood circulating through the centre. The respiratory centre may be diagrammatically represented as follows (Fig. 154):

The question next arises as to what is the condition in the arterial blood which calls the respiratory centre into action. Experimentally it can be shown that blood which has been shaken up with some carbon dioxide gas causes, when injected into the peripheral end of the vertebral or ca.otid artery - that is, towards the brain-an inmediate increase in the depth of the respiratory movements (Fig. 155). If injected into the jugular vein, there may be no effect upon the respiration; or if there be an effect, this will be delayed, and not by

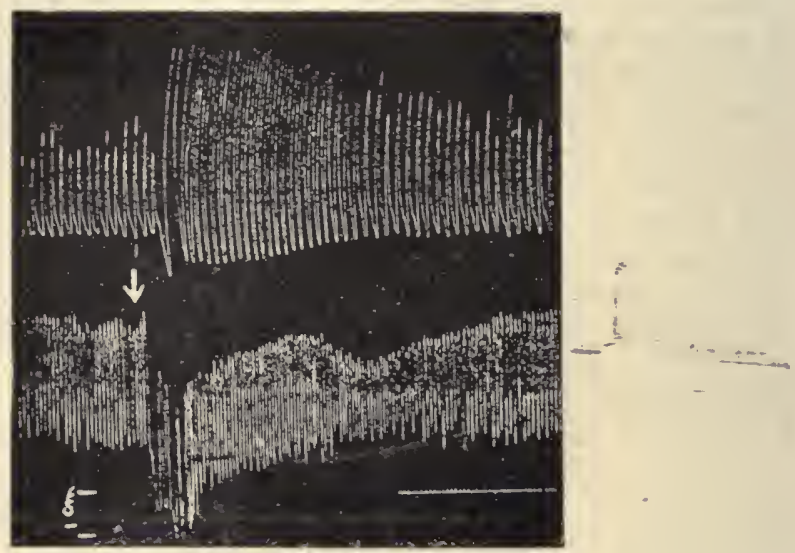

Fig. 155.-Andesthetized DGg.

Upper tracing, respiration; lower tracing, blood-pressure. The Errow marks the injection of 20 e.c. of $\mathrm{CO}_{2}$ and $\mathrm{O}_{2}$ saturated blood into peripheral carotid.

any means marked. When injected in this manner, the cxcess of $\mathrm{CO}_{2}$ may all be eliminated from the blood during its passage through the lungs. If not all eliminated, it will, after fourtecn or fifteen scconds (the time of the lesser circulation), causc an effect upon respiration-an effect which, as shown by the time of delay, is central in origin (Fig. 156). The carbon dioxide of the blood, therefore, in some way affects the respiratory movements centrally and not peripherally.

Again, if blood to which a little acid, such as lactic or butyric, has been added be injected towards the brain, the respiratory movements are likewise deepened. Thus, any increased acidity of the blood affects the centre. It will be remembered that blood, as tested by physical methods, is neutral. The $\mathrm{H}$ and $\mathrm{HO}$ ions balance onc another. Any excess of $\mathrm{H}$ ions at once stimulates the respiratory ecntre. 
Analyses of the alveolar air of the lungs reveal the faet that an individual normally so regulates his respiration that the pressure or eoneentration of $\mathrm{CO}_{2}$ in the alveolar air is kept eonstant, varying in different individuals from about 4.5 to 6 per eent., measured at normal barometrie pressure. If the barometrie pressure be inereased-as, for example, by going into eompressed air or down a mine-the pereentage of $\mathrm{CO}_{2}$ in the lung falls inversely in proportion to the inerease of barometrie pressure; if it be deereased, by going up a mountain, the pereentage of $\mathrm{CO}_{2}$ rises inversely in a similar proportion. The partial pressure of $\mathrm{CO}_{2}$ remains the same in the lung in eaeh ease. At great altitudes, where oxygen-want eomes into play, this no longer holds good, for the balanee of aeid and base in the blood is then altered by the exeretory aetivity of the kidney. The $\mathrm{CO}_{2}$ is redueed proportionately by inereased pulmonary ventilation, so that the total eoneentration of aeid in the blood remains the same. It is elear, then, that

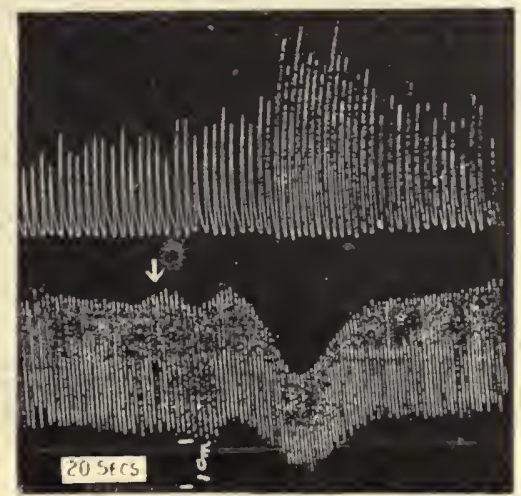

Fig, 156.-Axesthetized Dog.

Upper trwing, respiration; lower tracing, blood-pressure. The arrow marks the injection of 30 c.e. of $\mathrm{CO}_{2}$ and $\mathrm{O}_{2}$ saturated blood into the jugular vein.

the partial pressure of earbon dioxide in the alveolar air and in the arterial blood going to the respiratory eentre normally plays an important part in bringing about respiration. The addition of $\mathrm{CO}_{2}$ to the air breathed immediately inereases the deptl of breathinguneonseiously when the amount is small ( 1 to 2 per eent.); eonseiously, with marked hyperpnoea, when the amount is larger (3 to 5 per eent.). If, on the other hand, the tension of $\mathrm{CO}_{2}$ in the blood be redueed-as, for example, by foreed deep breathing - this is followed by a period of apnoa (eessation of breathing), until the $\mathrm{CO}_{2}$ again rises to a partial pressure suffieient to stimulate the eentre again.

Normally, the breathing movements of the body are so regulated that the partial pressure of $\mathrm{CO}_{2}$ in the blood is kept almost eonstant. When mueh $\mathrm{CO}_{2}$ is produced - as, for example, in hard museular work - the ventilation of the lungs is greatly increased. This inereased 
rentilation is then due in part to the lactic acid formed within the muscles. This increase in ventilation is seen from the following table:

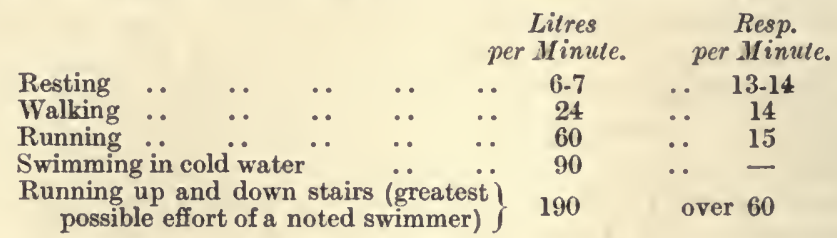

It will be seen that, with moderate exercise, the greater ventilation is brought about by increased depth rather than increased frequency. The frequency of respiration, even the sensation of depth of respiration, is no guide to the actual amount of ventilation. Thus, when

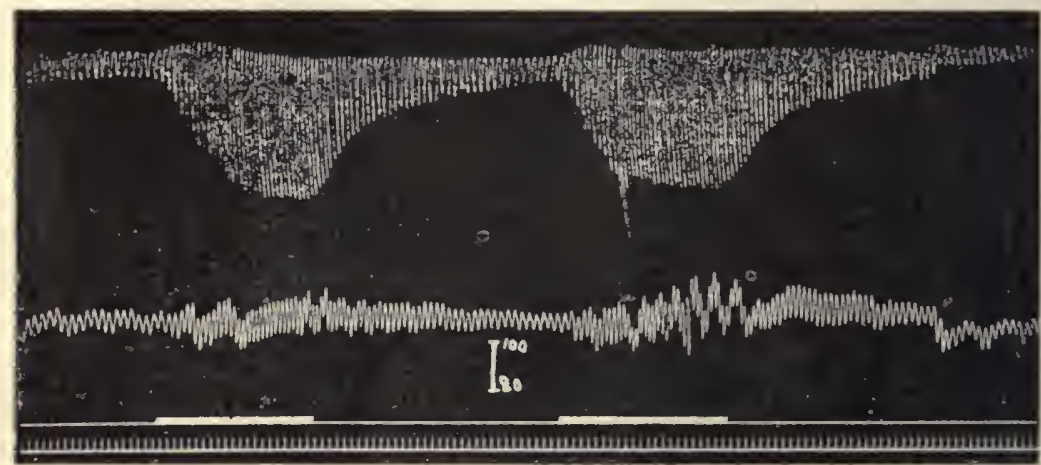

Fig. 157.

Upper tracing, respiration by diaphragm slip; lower tracing blood-pressurc. During first period $9 \cdot 6$ per cent. $\mathrm{CO}_{2}$ in air; during second period 10 per cent. $\mathrm{CO}_{2}$ with 33 per cent. $\mathrm{O}_{2}$. Time every two seconds. (F. H. Scott.)

reclining on a couch after a sea-bathe, one has the sensation of deep prolonged breaths, and imagines a great ventilation of the lungs is taking place. When measured, such ventilation may amount to but 4 to 6 litres per minute. Frequent shallow breathing may, in reality, put but little air into the lungs. Such breathing takes the air in and out of the mouth and trachea rather than into the lung alveoli.

It is, then, the hydrogen ion concentration of the arterial blood to which the respiratory centre responds. During normal life and health the centre reacts sharply to the slightest differences in the hydrogen ion concentration-differences so slight that they cannot be demonstrated by the present methods of blood gas analysis; special elcctrical methods are required to show them. The regulation of the hydrogen ion concentration seems to depend chiefly upon the kidney. The hydrogen ion concentration of the urine alters enor- 
mously under various conditions-25,000 times as great as the limit within which that of the arterial blood varies during rest. Since an increase of 2 millimetres of $\mathrm{CO}_{2}$ pressure in the blood increases the resting ventilation of the lungs by over 100 per cent., and yet causes a scarcely measurable alteration in the hydrogen ion concentration of the blood, it is obvious that the sensitivity of the respiratory centre is extremely great.

Any increase in the percentage of oxygen breathed, and of the pressure of oxygen in the blood, does not diminish the excitability of the centre to $\mathrm{CO}_{2}$ when the breathing is normal. The breath, however, can be held longer, and more work can be done while it is held, when the lungs are previously filled with oxygen than with air. Athletes may run a quarter or half mile more easily and quickly if they breathe oxygen before, and start with the lungs full of oxygen. Breathing oxygen before and after the race prevents stiffness. The explanation is that the greater oxygen supply lessens the formation of lactic

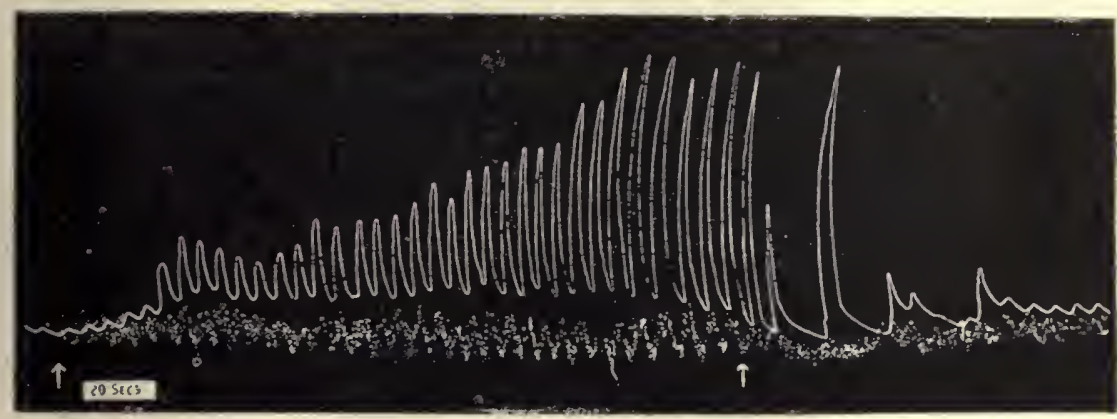

Fig. 158.-Axesthetized Dos..

Upper tracing, respiration; lower tracing, blood-pressure; white space $=20$ seconds. Between the arrows $4.52 \mathrm{O}_{2}$ was breathed.

acil in the muscles. This is proved by the fact that lactic acid appears in the urine which an untrained man passes in the next hour after a hard run; but if he wear a breathing apparatus (such as is used for rescue work in mines, etc.), and breathe oxygen during the run, little or no lactic acid appears in the urine. The increase of acid concentration tells particularly against the efficiency of the heart and skeletal muscles. Forced breathing can be carried on much longer and to a greater extent when oxygen is used instead of air, probably because the forced breathing interferes with the circulation in the brain.

When a very low percentage of oxygen is breathed, there results marked hyperpnœea (Fig. 158), but of less sudden onset than that produced by $\mathrm{CO}_{2}$. The same is true in animals when blood deficient in oxygen is injected into the peripheral carotid (Fig. 159). The effect of oxygen-want is not noticed until the $\mathrm{O}_{2}$ perccntage falls below 14. On grcater reductions-e.g., to 5 per cent.- 
eonsciousness may be lost before the hyperpnoea develops. For this reason the effects of want of oxygen are partieularly insidious. Henee the great danger of entering deoxygenated air which eollects in wells, sewers, and unventilated parts of eoal-mines-men are overeome without warning. Thus a man exploring a cavity in the roof of a mine breathed the deoxygenated air therein, and fcll uneonscious off a short ladder. Breathing the purer air on the floor, he quickly reeovered, and, jumping up, knocked down the man who held the ladder "for making him tumble off the ladder !"

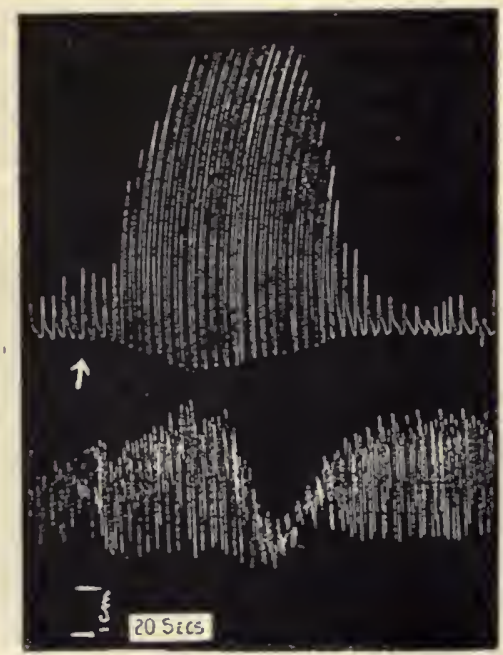

Fig. 159.-Ax.esthetized Dog.

Injection of 15 c.c. $\mathrm{CO}$ blood into peripheral carotid. Upper tracing, respiration; lower tracing, blood-pressure. Time in seconds.

To effect reseues from deoxygenated air, a suitable breathing apparatus must be worn. The presenee of such air ean be tested by the use of a eage-bird. Owing to its rapid metabolism, the bird is affected mueh more rapidly than a man.

In animals, it has been shown that the respiratory centre responds to ehanges in the temperature of blood going to the eentre. Warming the blood in the carotics eauses increased breathing; eooling it tends to diminish breathing. This meehanism probably plays a great part in those animals who regulate their heat loss niainly by respiration, and not by the skin. The short, sharp panting of the dog is characteristic. Sueh respiration is very frequent and shallow.

The respiratory centre is co-ordinated by impulses which reach it through afferent nervous channels, but eonsiderable divergence of opinion exists as to the amount these play in the regulation of respiration in man. Special aets are.undoubtedly due to nervous 
stimulation. Thus, the stimulation of the upper part of the larynx by a crumb "going the wrong way" induces through the superior laryngeal nerve inhibition of inspiration, followed by a fit of coughing, by which the crumb is expelled. During swallowing, respiration is inhibited; it is impossible to breathe and swallow at the same time. This is owing to a reflex excited through the glosso-pharyngeal nerve. Stimulation of the mucous membrane of the trachea and bronchi also induces coughing, excited reflexiy through the vagus nerve. Stimulation of the mucous membrane of the nose with a mechanical irritant induces sneezing, while a chemical irritant, such as an irrespirable gas-e.g., a high percentage of $\mathrm{CO}_{2}$, ammonía vapour, chlorine, sulphur dioxide-excites spasm of the glottis.

Stimulation of the walls of the external auditory meatus' with a foreign body or by a plug of wax may induce coughing - a reflex excited through a twig of the vagus nerve (the alderman's or Arnold's nerve). A powerful light may excite sneezing. The "stomach cough" is due to reflex irritation of the vagus nerve supply to the stomach. "Hiccough," caused by a spasmodic contraction of the diaphragm, is probably due to reflex stimulation of the centre, cxcited, perhaps, by overdistension of the stomach. Persistent hiccough may occur in case of severe illness-e.g., carcinoma of the stomach, large hæmorrhage from the intestines, etc.

The "winding" following a blow in the pit of the stomach has been attributed to stimulation of the respiratory centre through the splanchnic nerves. The "knock-out blow" on the chin is said to jan the medulla oblongata. A powerful electrical current passed through the head may temporarily arrest the respiration, while, if it pass through the heart, it may throw this into fibrillar contraction, and so produce death.

The nerve-supply of the larynx comes from the superior and from the inferior (recurrent) laryngeal branches of the vagus. The superior laryngeal is the sensory nerve to its mucous membrane, and furnishes the effector supply to the crico-thyroid muscle. The recurrent laryngeal branch of the vagus supplies the motor fibres to the other muscles. If this nerve be compressed or cut on one side, the voice is lost, because the corrcsponding vocal cord cannot be adducted. Breathing is also somewhat laboured, because it cannot be abducted, so that, when laryngoscopic examination is made, the cord does not move as it should to the middle line on phonation, nor away from it on inspiration. When the ncrve is gradually affected, the abductor muscle, the posterior crico-arytenoid, fails first; in deep ether anæsthesia the adductor, the lateral crico-arytenoid, is most affected. Paralysis of the superior laryngeal nerve, besides leading to loss of scnsation, causes hoarseness, due to deficient tension of the vocal cords as the result of paralysis of a crico-thyroid muscle.

Any sudden and forcible stimulation of the skin modifics the respiratory act-e.g., the first plunge into a cold bath. It is customary to flick with wet towels an infant which does not breathe after birth, or to smack it. 
Exposure to a cold wind induces a man to breathe more to keep himself warm.

A yawn is a long, dcep inspiration through the widely-opened mouth, and at the same time the body may be stretched in a characteristic way. This furthers the circulation, and increases the oxygen sulpply.

A sigh is a long-drawn inspiration, followed by a deep expiration.

The Influence of the Vagi.-The division of one vagus alone has little effect upon the respiratory movements. After section of both vagi, the breathing in animals, such as the dog, cat, or rabbit, becomes slower and decper; inspiration, normally the shorter, becomes longer than expiration (Fig. 160). The same effect is obtained if the two

Normal respiration Alter section of ons
vagus the frequeney
of respiration is somi.
what diminished

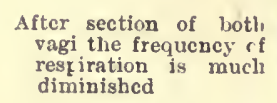

Excitation of centual cnd of left vagus accelcrates rcspiration

Time in seconds

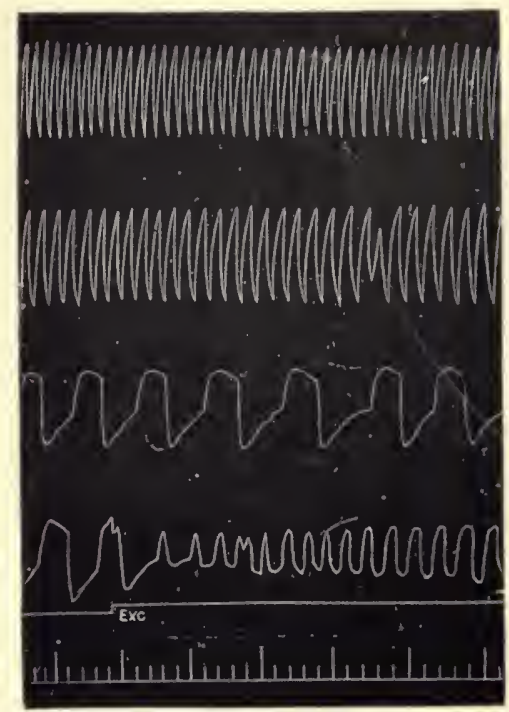

Fia. 160.-Ixfluexce of the Vages upox Respiratory Movemeats. (Waller.)

vagi be cooled to $3^{\circ} \mathrm{C}$, a process which eliminates any irritative effect of a current of injury such as might be established by dropping a cut nerve into a wound.

Who non-polarizable electrodes are placed upon the vagus nerve, and connected with a string galvanometer, it may be observed that inflation of the lungs induces a marked current of action, deflation a less marked one. In the animal breathing normally an clectrical variation in the vagus nerve has bcen rccorded synchronously with each inspiration, indicating the passage of a nerve impulse (Fig. 163). A forcible collapse of the lung also excites a negative variation in the vagus. It has been shown that positive inflation (blowing up) of the lungs causes the diaphragm to comc to a standstill in the expiratory position; negative ventilation (sucking air out of the lungs), induces inspiratory 
standstill of the diaphragm. These effects are abolished when the vagi are cut. These results are interpreted as showing that the vagus nerve terminates in two sets of nerve endings, one set stimulated by stretching of the lung during inspiration-inspiration-inhibiting-the other stimulated by collapse of the lung-inspiration-inducing.

Co-ordinating the action of all the skeletal muscles are "prop-ioceptive fibres," through which extension inhibits flexors, and flexion inhibits extensors (see Fig. 409, p. 683). It is most probable that each respiratory act should consist of the action of one set of

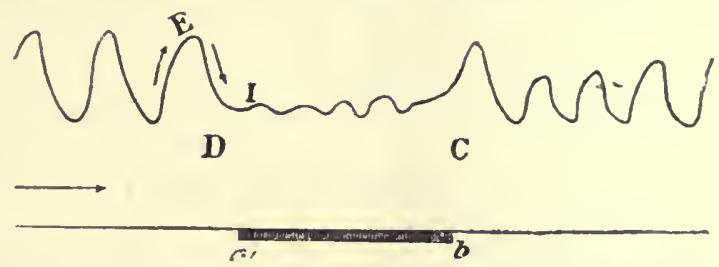

Fig. 161.-Inspiratory Spasm of the Diaphragi produced. by Excitation of tha. Vagus during the Period shown by the Signal $a, b$. (Fredericq and Nuel.)

The down-stroke represents inspiration; the up-stroke expiration.

muscles, and inhibition of the antagonists, co-ordinated by afferent fibres. The vagus nerve endings in the lungs would then correspond to nerve endings in joints. The phrenic nerves contain afferent fibres from, as well as motor fibres to, the diaphragm. The evidence so far is positive for the action of only one set of nerve endings -inhibiting inspiration-and these only when the inspiration is large-beyond the normal tidal capacity-but it may well be that the string galvanometer is not a delicate enough instrument to indicate normal gentle nerre impulses. We may conclude that while the

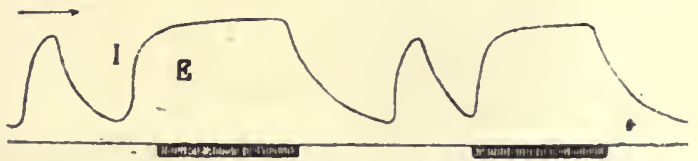

Fig. 162.-Expiration Spasm of the Diaphraga produced by Weak Stimulatiox of the Vagus. (Fredericq and Nuel.)

The down-stroke represents inspiration; the up-stroke expiration. The signal line shows the duration of stimulation.

chemical stimulus of acid in the blood is alway's present to induce a new inspiration, the afferent fibres to the centre reflexly makc. the muscles work smoothly and with perfect co-ordination.

Stimulation of the central end of the vagus nerve below the origin of the superior laryngeal branch with moderate induction shocks quickens respiration; strong excitation causes inspiratory spasm and may bring about cessation of breathing in inspiration (Fig. 161). Very wcak induction shocks and chemical stimuli-e.g., strong $\mathrm{KCl}$ solution-bring about slowing of respiration or standstill in the expiratory phase (Fig. 162). 
To sum up-

1. The respiratory centre is normally rhythmically stimulated by the hydrogen ion concentration of the blood. This ion concentration is kept constant both by the expiration of carbon dioxide and by the action of the kidneys. The regulation is such that the pressure of carbon dioxide in the alveolar air is kept remarkably constant. Any alteration markedly affects the breathing. An increase of $0 \cdot 22$ per cent. ( 2 to 3 per cent. in inspired air) doubles the ventilation of the resting man; a diminution by that amount causes a temporary cessation of breathing (apnœa).

2. The response of the respiratory centre is not modified under normal conditions by the amount of oxygen in the alveolar air. When the breath is held, or when hard muscular work is being performed, lactic acid is produced in the muscles owing to lack of oxygen. The breathing of oxygen lessens this acid production and its effect on the respiratory centre.

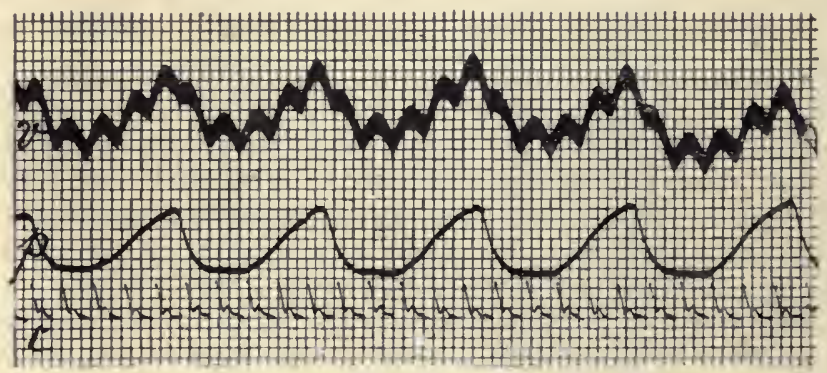

Fig. 163.-Figure showing the Electrical Changes in the Vagus Nerve which aCconpayy the Respiratory and Heart Movenexts. (Einthoven.)

$V$, Electrovagogram; $p$, respiration record (up, inspiration ; down, expiration); $c$, pulse record.

3. In certain animals, such as dogs, which depend upon breathing for the regulation of heat loss, the temperature of the blood affects the action of the respiratory centre. Similarly, in a man immersed in a very hot bath, the breathing becomes rapid.

4. Afferent fibres run to the respiratory centre from the lungs in the vagus nerve. The function of these fibres is to co-ordinate the action of the respiratory centre with the degree of distension or collapse of the lungs. Of the two sets of fibres, those which normally inhibit inspiration are the most generally active. By the action of these fibres, waste of time and muscular effort is saved in breathing. 'They play no part in exciting the normal rhythmic activity of the respiratory centrc.

5. The respiratory centre is also affected by nervous impulses from othe: parts of the body, which induce modifications of the respiratory act. 
Hyperpnœa, Dyspnœa. - By hyperpnoa, increased volume of breathing is designated; dyspnœa, on the other hand, applies to distressful breathing. Both may be induced by the agencies which excite the respiratory centre to increased action, such as excess of carbon dioxide, want of oxygen, diminished alkalinity of the blood, due to acid formation, and rise in the temperature of the blood (heat dyspnœa). The cardiac dyspnœa of heart disease is chiefly due to want of oxygen.

Apnœa.-The condition of "no breathing" is due to a lack of chemical stimulation of the respiratory centres. It occurs after forced breathing which washes out carbon dioxide from the blood (Fig. 164). It is claimed that there exists also a "vagus " a pnœa, produced in animals by repeated rapid distension of the lungs by artificial means. By this means the inspiration-inhibiting fibres of the vagus are so stimulated that apnoea ensues. This apnca may be due to washing carbon dioxide out of the blood, but it is more difficult to obtain when the vagi are cut; it is stated that if the ventilation of the lungs be made with an indifferent gas, such as hydrogen, it is possible to obtain apnoea, but not after the vagi are cut (Figs 165, 166). It is very doubtful if vagus apnœa occurs in man, for it has been shown that apnœa cannot be produced if the alveolar air percentage of $\mathrm{CO}_{2}$ is not reduced below the normal $\mathrm{CO}_{2}$ percentage.

Periodic, Grouped, or CheyneStokes Breathing.-Group breathing is natural in young children when aslecp, and in hibernating

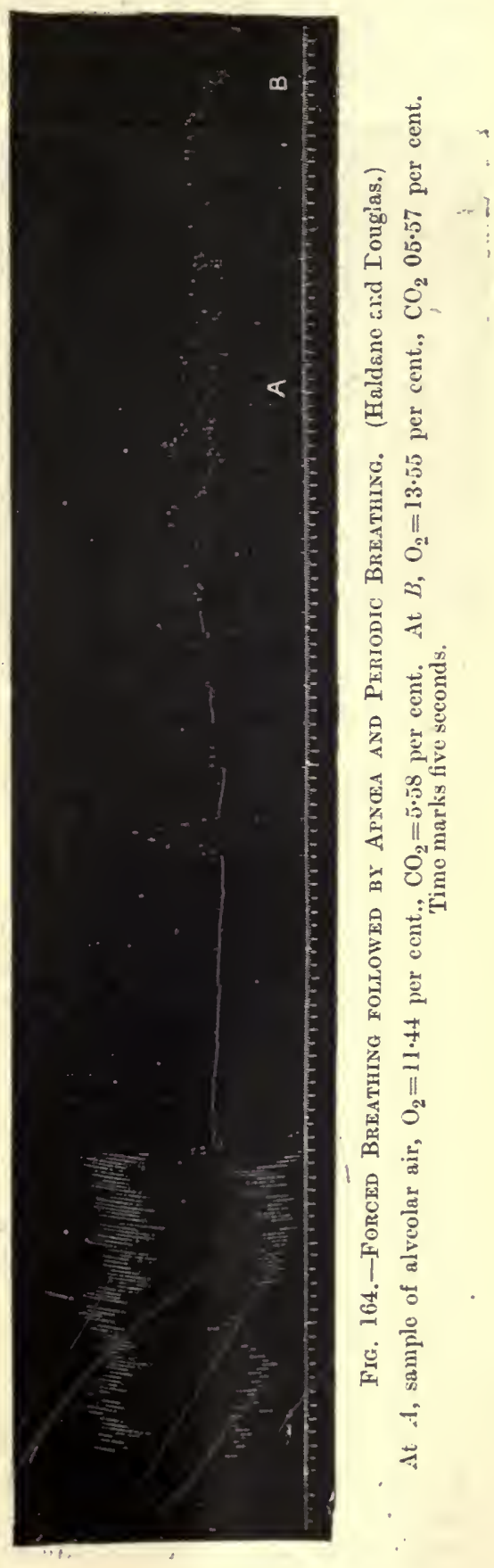


animals. Cheyne-Stokes breathing is a type of breathing characterized by a waxing and waning of the depth of the respiratory movements (Fig. 167). Starting from a state of apnoea, the respirations gradually

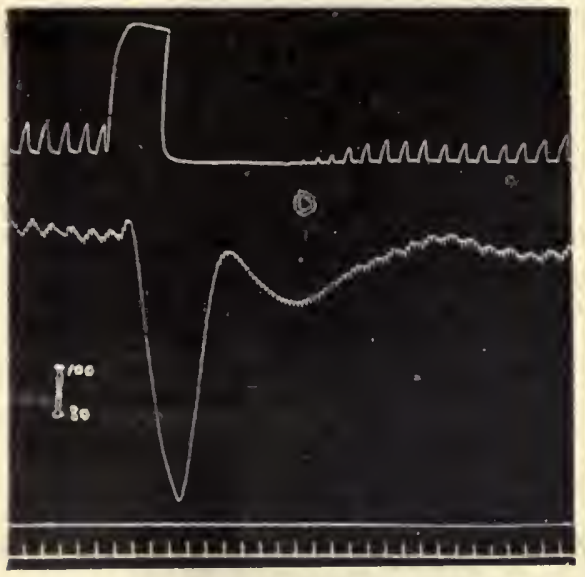

Fig. 165.-Cat, Vagi Intact. (F. H. Scott.)

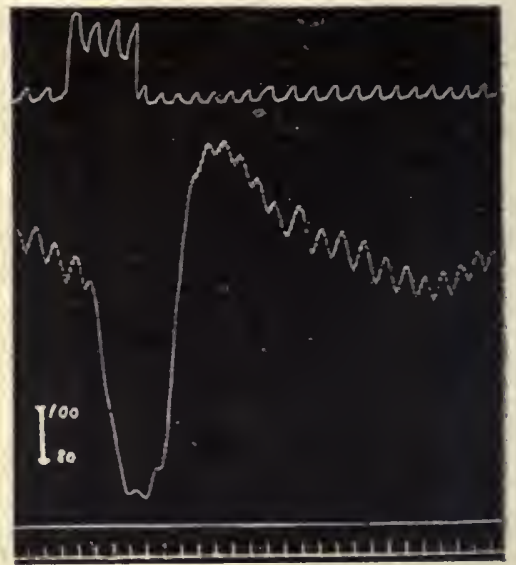

Fig. 166.-SAme Cat as Fig. 165. VAGI DIVIDED. (F. H. Scott.)

Upper tracing, thoracic respiration recorded by means of tambours; lower tracing, carotid blood-pressure. Period of insufflation of lungs shown by rise in line of respiratory tracing.

become more and more marked, reaching a maximum where the depth is considerably deeper than normal, and then gradually decline again, and cease, to be followed by another period of activity. This type of breathing occurs clinically in cases with defective circulation, renal

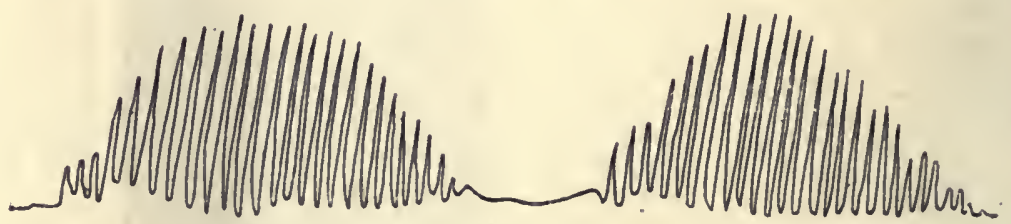

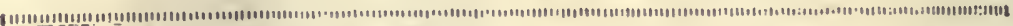

- Fig. 167.-CheyserStokes Respiration.

disease, etc., and is due to oxygen-want in the respiratory centre, which causes it to act in a periodic manner. Oxygen-want causes a hyperpnœa which reduces the alveolar percentage of $\mathrm{CO}_{2}$. Apnœa then results 
until oxygen want again stimulates the centre. Group breathing may be abolished by the giving of oxygen, or breathing 2 to 3 per cent. $\mathrm{CO}_{2}$. It frequently occurs at high altitudes, owing to the diminished partial pressure of oxygen in the rarefied atmosphere. It can be produced experimentally in most people by forced breathing for two to three minutes. After the subsequent apnoa, breathing returns for the first few minutes in a periodic fashion. If, however, the lungs are filled with oxygen instead of air at the end of the forced breathing, the apnœa is of much longer duration, and breathing returns in a perfectly regular manner.

Under these circumstances, in addition to the ordinary respiratory oscillations, rhythmic variations of pressure frequently appear in the tracings of arterial pressure. These variations are known as TraubeHering curves. They can be evoked by the injection of a little magnesium sulphate solution into the circulation of the dog (Fig. 168). During the asphyxial rise of arterial pressure in the curarized dog,

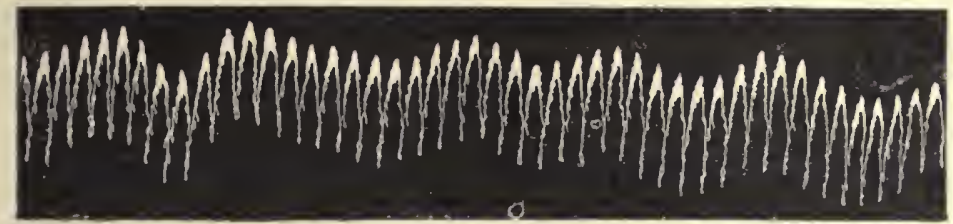

Fis. 163. - Traube-Hering Curves after Injection of Magnesium Sulphate.

these curves occur, and also after injection of a large dose of morphia. In conditions of anæmia of the bulbar centres, produced either by tying the cerebral arteries, or compression of the brain, and after injection of chloroform into the cerebral arteries, Traube curves frequently become apparent.

In periodic respiration of cerebral origin, the waxing and waning . of the blood-pressure seems to be due to the effect of the venous blood on the vaso-motor centre, rather than on the heart. Oxygen-want stimulates the respiratory and vaso-motor centres at the same time.

In the case of morphia, the respiratory centre injured by morphine does not react to the acid ions in the blood until these reach a concentration which injures the hcart. The periodic fall of pressure in this case is due to an asphyxia of the heart. When the breathing starts, the heart recovers, and the blood-pressure rises. The breathing ceases once more so soon as some of the carbon dioxide in the blool has been exhaled. 


\section{CHAPTER XXXIV}

\section{THE EFFECTS OF EXCESS OF CARBON DIOXIDE}

BREATHED in very high percentages, 30 per cent. and upwards, $\mathrm{CO}_{2}$ acts as an anresthetic and narcotic. There is first induced a spasm of respiration. then consciousness is lost, the respiration becomes quiet, the heart-beat enfeebled, and death ensues owing to the direct action of $\mathrm{CO}_{2}$ upon the heart-muscle. In smaller percentages $\mathrm{CO}_{2}$ has an excitatory $\in$ ffect-at first upon the respiration, then upon the circulation also. A small increase of $\mathrm{CO}_{2}$ in the air breathed in causes a marked increase in pulmonary ventilation. With an increase of 3 per cent. this lccomes noticeable to the person breathing; with 5 per cent. the hyperpnoea is very marked, the respirations are quickened, the pulse becomes quicker and fuller; with 6 per cent. there begins to be a retent: on of $\mathrm{CO}_{2}$ within the body, breathing is distressful, headache develops, profuse sweating breaks out. The blood-pressure is greatly raised, and the pulse may be felt drumming in the ears. Later, the mind becomes confused, and loss of consciousness ensues. It is possible for a man, having filled his lungs with oxygen, and then holding his breath, to run himself into a state of unconsciousness. In such cascs, as much as 11 per cent. of $\mathrm{CO}_{2}$ is found in the aiveclar air. Athletes who run themselves out are overcome by the excess of acid in the bloo:l.

Most deaths atiributed to excess of carbon dioxide are in reality due to oxygen-want. High percentages of $\mathrm{CO}_{2}$ sufficient to cause death cause spasm of the glottis and choking. Divers have often been overcome by an excess owing to defective supply of air in deep water. At a pressure of, say, 4 atmospheres (100 feet) there is four times the volume of air in the helmet, and to ventilate it four times as much air must be pumped through it as at 1 atmosphere. It has not been recognized until recently that the deeper the diver goes, the more air must bc given him.

Effects of Deficiency of Carbon Dioxide.--If carbon dioxide be washed out of the body by forced breathing, the desire to breathe disappears for a time, and a condition of apnoa ensues, which may last as long as two to three minutes, and even longer (Fig. 164). If oxygen lie forcibly breathed, the apnoa may last five to seven minutes, and cven nine minutes. Forced breathing produces a curious condition of spasm of the hand, sensations of "pins and nccdles" in the hands and feet, with coldness and pallor, and a sensation of tight- 
ness round the head. The forced breathing of oxygen is unaccompanied by such feelings.

Probably a certain tension of $\mathrm{CO}_{2}$ is required in the body fluids for the proper carrying out of many bodily processes. If this be lessened, such processes are impaired.

Effects of Excess of Oxygen.-Breathing an excess of oxygen under normal conditions does not cause increased oxidation of the body. The body cannot be fanned like a fire into rapid combustion. The nervous system sets the rate of activity of the tissues. When, however, hard

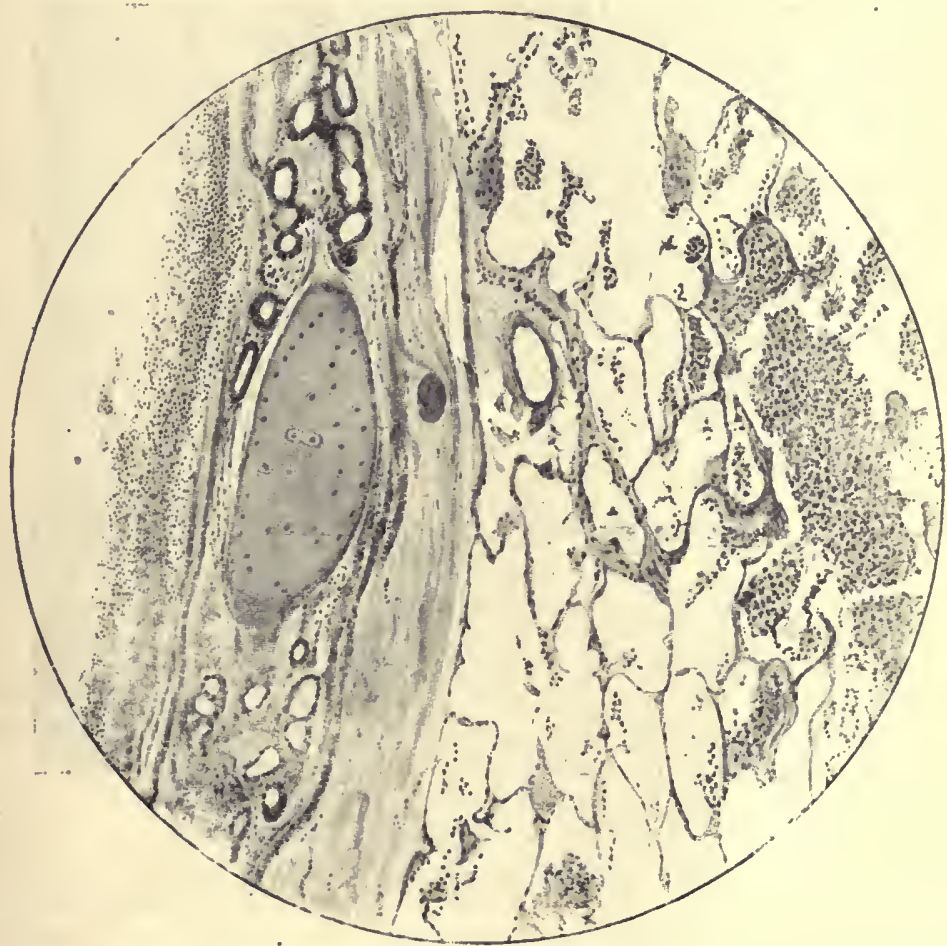

Fig, 169. - Section of Lung showing Exudation in Bronchial Tube and Alveola of Lung produced by Three Atmospheres of Oxyeen. (Bulloch and Hill.)

muscular work is being performed, an excess of oxygen in the alveolar air enables more work to bc done. This is because it prevents the formation of lactic acid in the muscles, and thus lessens the hyperpnoea, which renders work inefficient, and maintains the force of the heart.

High percentages of $\mathrm{O}_{2}-$ e.g., 3 atmospheres-act as an irritant to the lungs, induce pneumonia (Fig. 169), lower the metabolism, and cause convulsions. Breathing of pure oxygen for several hours at ordinary atmospheric pressure does not have any harmful effect, but it causes pneumonia if breathed continuously for a day or 
two. An atmosphere containing under 70 per eent. of oxygen ean be breathed with impunity for any length of time.

The Effects of Want of Oxygen.-The symptoms produed vary greatly according to the rate at which such want is produced. When immediate, as on breathing into the lungs marsh-gas, nitrogen, or hydrogen, there is rapid loss of conseiousness, followed by convulsions (Fig. 170), with a slight rise of blood-pressure, followed by cessation of respiration, broken only by occasional inspiratory gasps, fall of blood-pressure, due to vagus inhibition, and death.

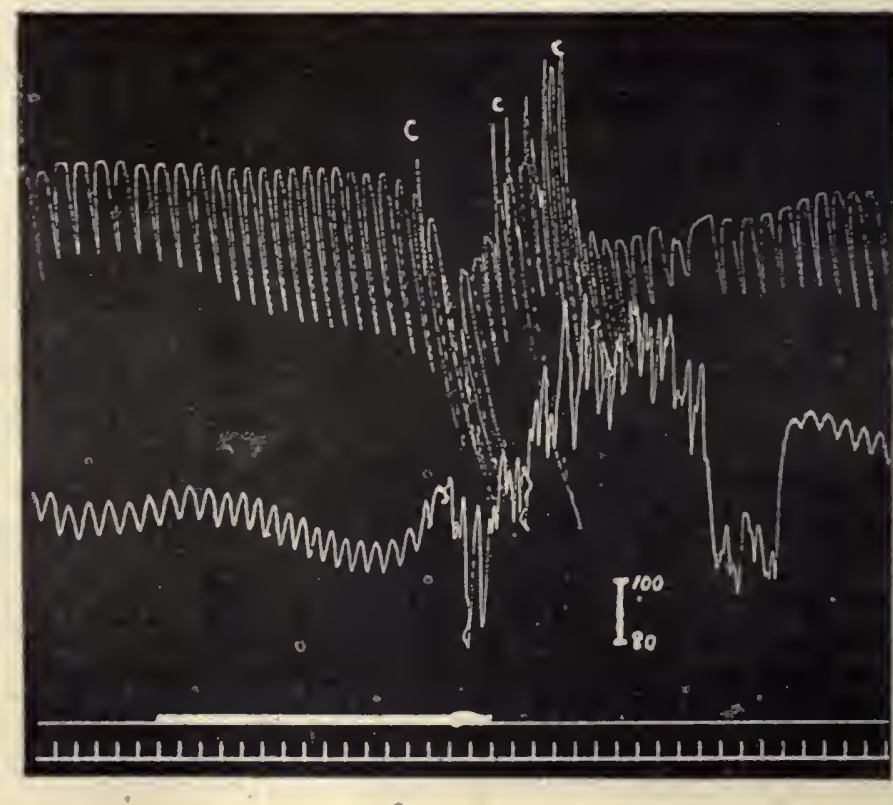

Fig. 170.

Upper traeing, respiration recordcd by diaphragm slip; lower traeing, earotid bloodpressure. Time =two seconds. During reriod indieated 5 per eent. oxygen in nitrogen was inhaled. (F. H. Seott.)

A match or eandle will not burn when there is less than 17 per cent. of oxygen in the atmosphere, but a man feels no inconvenience until the oxygen perecntage falls below 14 per eent. Then there supervenes a hyperpnœa of gradual onset, with a slight rise of bloodpressure, increased pulse-rate, and marked eyanosis; and when about 6 per cent. is reached, loзs of consciousness quickly takes place. At first, on breathing 14 to 10 per ecnt. $\mathrm{O}_{2}$, there is a slight exaltation. The person has the greatest confidence in himself, and is quite confident that he is "all there," whereas, in reality, his mental capacity is greatly affected. The breathing is deepened, but no dyspnoea is present. Then, at about 8 per cent., without warning, or possibly 
with slight dyspnœa or air-hunger, consciousness may be lost, followed by paralysis, or in some cases the paralysis of the muscles, particularly those of the limbs, may precede the loss of consciousness. Thus, in a balloon ascent, at 29,000 feet, Coxwell, although suddenly finding himself paralyzed in his limbs, was able to pull with his teeth the safety-valve rope of the balloon, and to save himself and Glaisher. In the case of the ascent of Crocé-Spinelli, Sivel, and Tissandier, the aeronauts were all paralyzed suddenly before they could breathe from the oxygen bags with which they had provided themselves. Similar symptoms follow gradual poisoning by carbon monoxide or coal-gas. Miners display the same lack of judgment when affected by carbon monoxide.

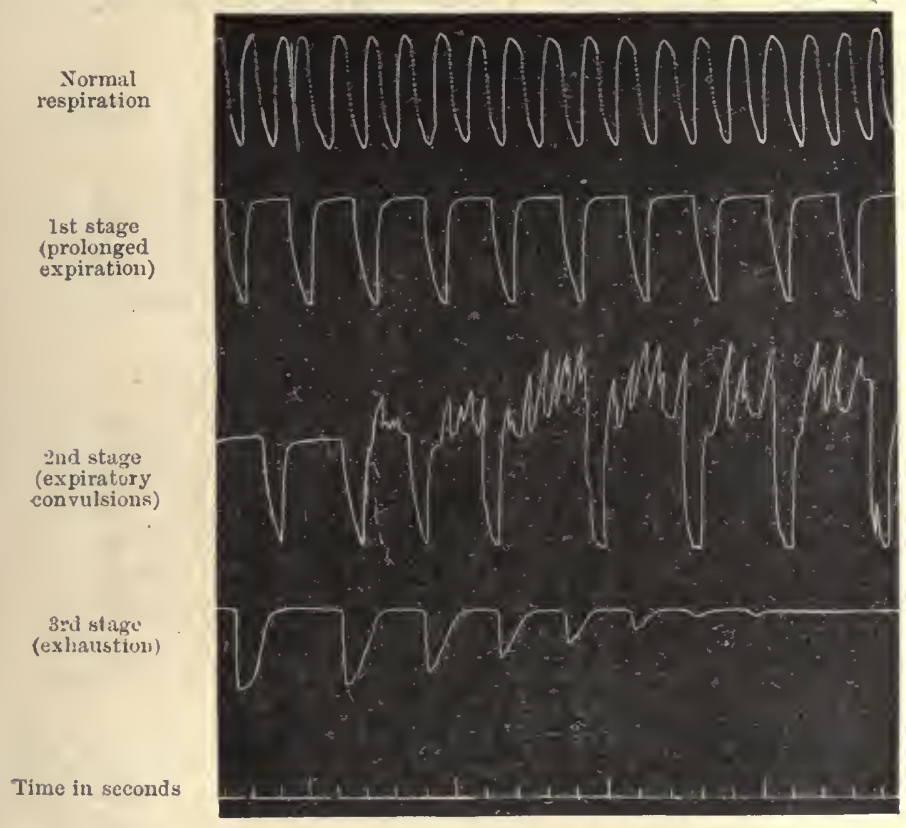

Fig. 171.-Asphyxia Tracing: Rabit. (Waller.)

The line falls with inspiration, rices with expiration.

In carbon monoxide poisoning, the lack of oxygen is brought about by the decreased oxygen-carrying capacity of the blood, due to the formation of $\mathrm{COHb}$. The symptoms begin to show themselves when the blood is one-fourth saturated. With 50 per cent. saturation, the niental symptoms become marked, and the slightest exertion is dangerous, since it may bring on convulsions and death. It is dangerous to breathe air containing as little as 0.05 per cent. $\mathrm{CO}$, for the affinity of $\mathrm{CO}$ for $\mathrm{Hb}$ is about 150 times that of $\mathrm{O}_{2}$. There is 5 to 6 per cent. $\mathrm{CO}$ in coal-gas, as much as 30 per cent. in water-gas, 3 per cent. or more in after-damp after explosions in mines. $\mathrm{CO}$ oscurs in con- 
fined plaees where there is fuel burning with defieient oxygen-supply. To relieve CO poisoning, oxygen should be administered, and artificial respiration performed.

The whole of the body is rery susecptible to a defieieney of oxygen; it leads to acid formation and lessened alkalinity of the tissues. Edema, eloudy swelling, and fatty degeneration, according to recent researeh, are associated with such diminished alkalinity. Lack of oxygen greatly affeets the working eapaeity of the museles, especially of the keart-musele. Irritant gas poisons, by prcdueing œdema of the lungs, eause oxygen-want. Recovery is very slow or may not occur after prolonged oxygen-want. Symptoms of oxygen-want may also be indueed by poisons which form methrmoglobin. Such poisons are the chlorates of sodium and potassium, nitrites, and dinitrobenzene.
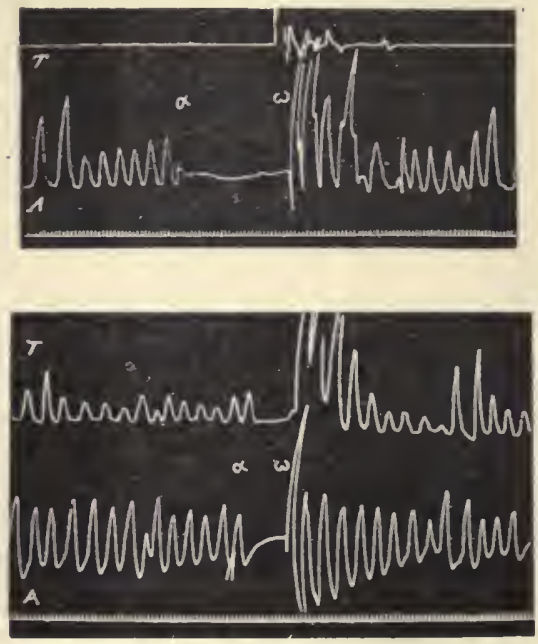

FIG. 172.

$T$, Tracing of theracic movements; $A$, tracing of abdominal movements. In top tracing is shown the respiratory movements and time $(\alpha-\omega)$ during which breath could be held in Turin. In lower tracing the same at Monte Rosa (15 00J feet above sea-level). The inereased depth of respiration and inability to hold the breath long is well seen. (Mosso.)

Asphyxia is eaused by interferenee with the ventilation of the lungs. It may be produced by breathing an irrespirable gas, as already deseribed, but it may also be produeed by such means as oeelusion of the trachea or opening the ehest eavity. When studied experimentally-as, for example, by elamping the trachea-asphyxia is divided into three stages (Fig. 171):

1. The stage of inereasing dyspnœa.

2. The eonvulsive stage.

3. The stage of exhaustion.

When the trachea is elamped, the first stage lasts about a minute. The breathing is markedly inereased in depth, expiration being pro- 
Jonged; the heart-beat is increased in force and frequency; the bloodpressure rises; the tongue in the case of an animal, the lips and face also in the case of man, darken to a purplish hue.

In the second stage, the respiration becomes violent and convulsive; the blood-pressure rcmains high, due to the vaso-constriction produced; the heart-beats show the sign of vagus inhibition; the duskiness of the mucous membranes increases.

In the third stage, the brcathing and convulsions practically cease; the heart beats fecbly and irregularly; the blood-pressure gradually falls, and the tracing shows marked undulations of pressure, known as the Traube-Hering waves (Fig. 168). The pupils become
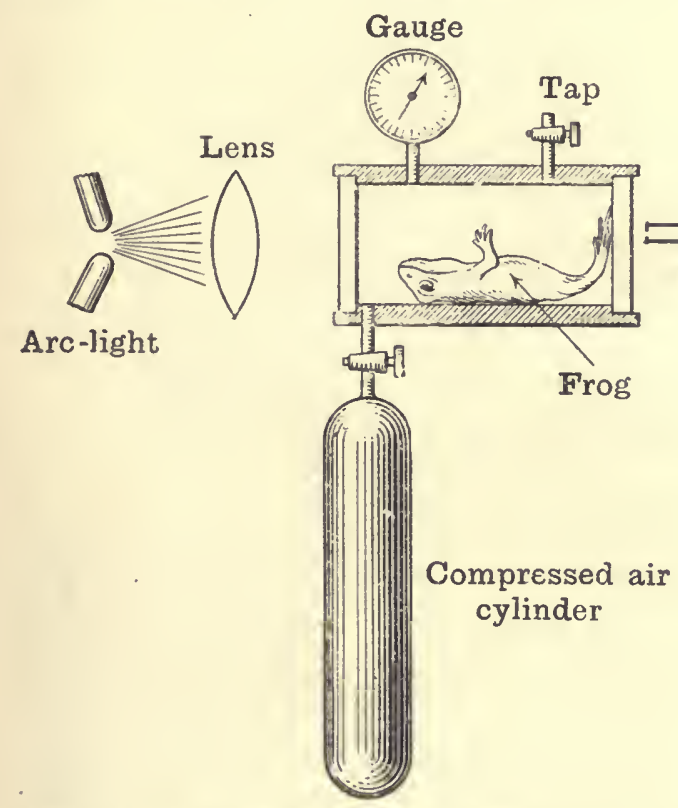

Fig. 173.-Diagram of Apparatus by which EFfict of Compression and Decompression is stjdied upox Capillaries of Frog's Web.

dilated, the mucous membranes bccome pale and anæmic, fæces and urine may be voided. Post mortem, the right side of the heart is found distended with blood, the left side contracted and cmpty. The great veins and the lungs arc also engorged with blood.

Effects of Diminished Atmospheric Pressure.-Another train of symptoms due to oxygen-want is that known as "mountain or altitude sickness." It effects aeronauts as well as mountain-climbers. In their case, the oxygen-want results from the dimin shed atmospheric pressure, and consequent reduction in the partial pressure of the oxygen in the blood. The symptoms are headache, nausca, distress in breathing, especially upon exertion. Mountain sickness frequently begins at altitudes of 6,000 to 10,000 fect, particularly 
if the ascent has been fairly rapid by railway, so that no adaptation takes place during the journey. It is suggested that the oxygenwant leads the kidney to excrete more base than acid from the blood, and thus increasing the breathing, lessens the concentration of carbon dioxide in the blood and alveolar air. By lessening the concentration of $\mathrm{CO}_{2}$ in the alveolar air, that of oxygen is increased.

The effect of oxygen-want is well seen in the inability voluntarily to hold the breath for any length of time (Fig. 172). Acclimatization takes place in about eight to ten days. This is due, in the first

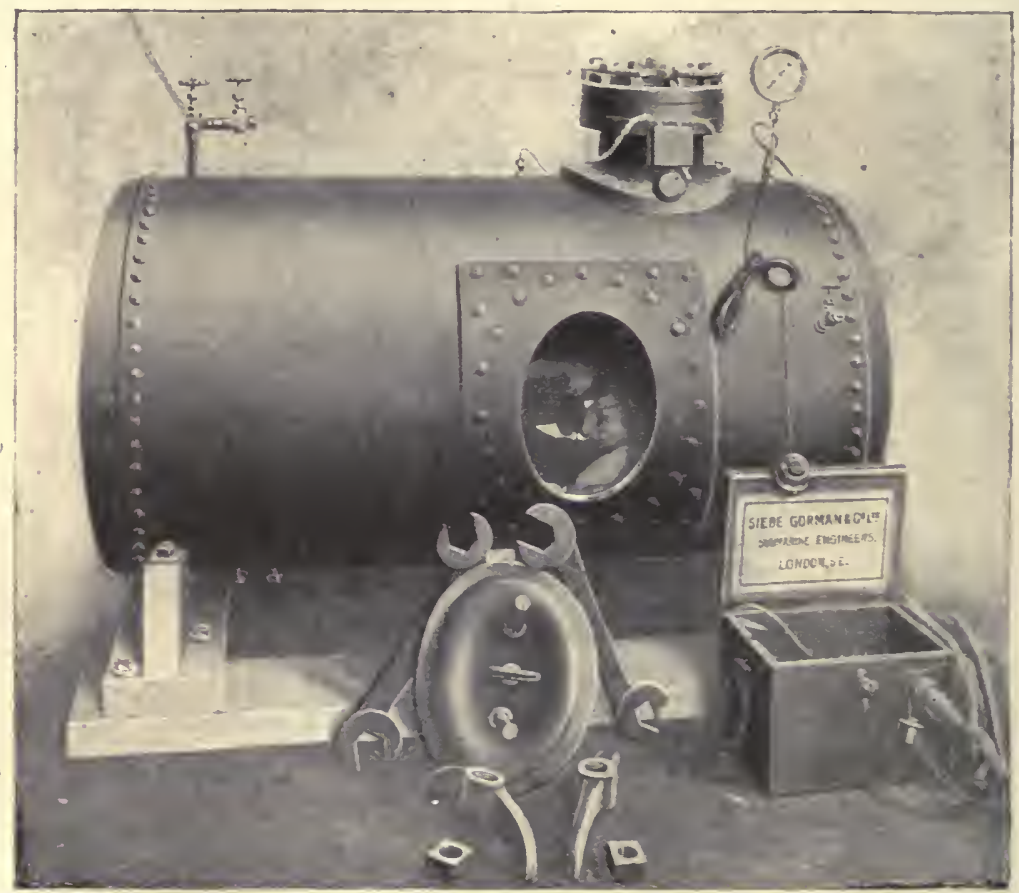

Fig. 174. - View of Chanibr used for Study of EFfects of Compression axd Decompression on MaN : Workuan Ixside. (Hill and Greenwood.)

The chamber is fitted with eleetrie belt, electric light, telephone, observation window, compression pipe from gas-engine, dccompression tap.

place, to a concentration of the blood-plasma, followed by an increased formation of blood-corpuscles and hæmoglobin (Fig. 18). Hence the oxygen-carrying power of the blood is increased; an alteration in the acid concentration of the plasma compensates for the diminished partial pressure of carbon dioxide.

On the strength of determinations of the partial pressure of oxygen in the blood, by the CO method (p. 273), it is asserted that compensation is brought about by secretory activity of the lung epithelium, since the oxygen-pressure of the arterial blood has been 


\section{THE EFFECTS OF EXCESS OF CARBON DIOXIDE :09}

found to be $3 \tilde{5}$ millimetres above the oxygen-pressure in the alvcolar air. But there are doubts as to the validity of this method.

Airmen usually suffer at altitudes from 15,000 to 20,000 feet. In their case there is no evidence of acclimatization to the effects of high altitudes. Administration of oxygen mitigates these ill effects.

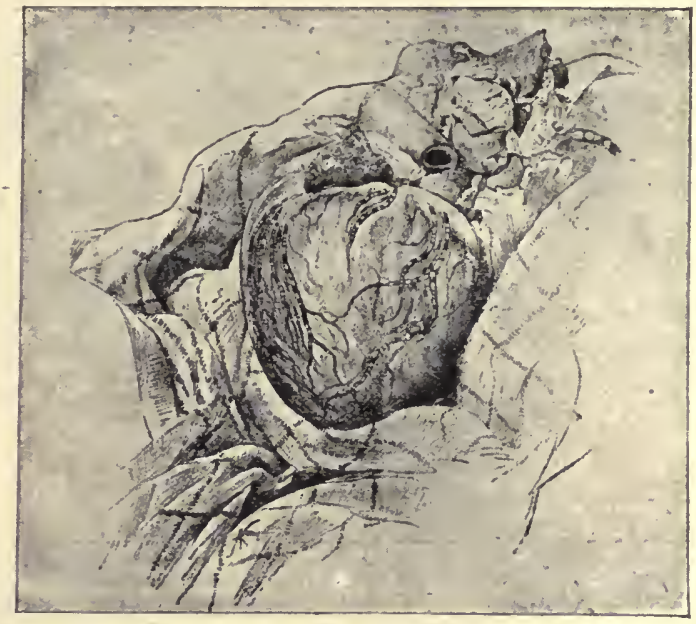

Fig. 175.-Air Bubbles Set Free in Vessels of Heart after Ray'id Decompression. (v. Schrötter.)

Increased Atmospheric Pressure-Caisson Disease.-In contradistinction to the effects of diminished barometric pressure, increased barometric pressurc in itself produces no untoward symptoms. "Caisson

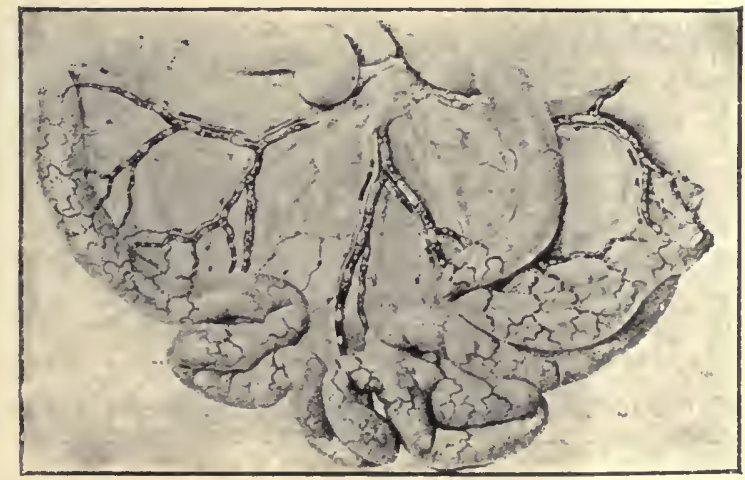

Fr:. 176. -To show Gas Bubbles ix Arteries axd Veins of Intestives after Rapid Decompressiox. (v. Schrötter.)

disease " and "diver's palsy" result from the effects of decompression from a high atmospheric pressure, not from the compression. Caissons 
are steel ehambers filled with compressed air, and provided with airloeks, used for exeavating tumnels and foundations of bridges under water. Divers are encased in a dress into which air is umped at a pressure just greater than that of the superincumbent water.

A
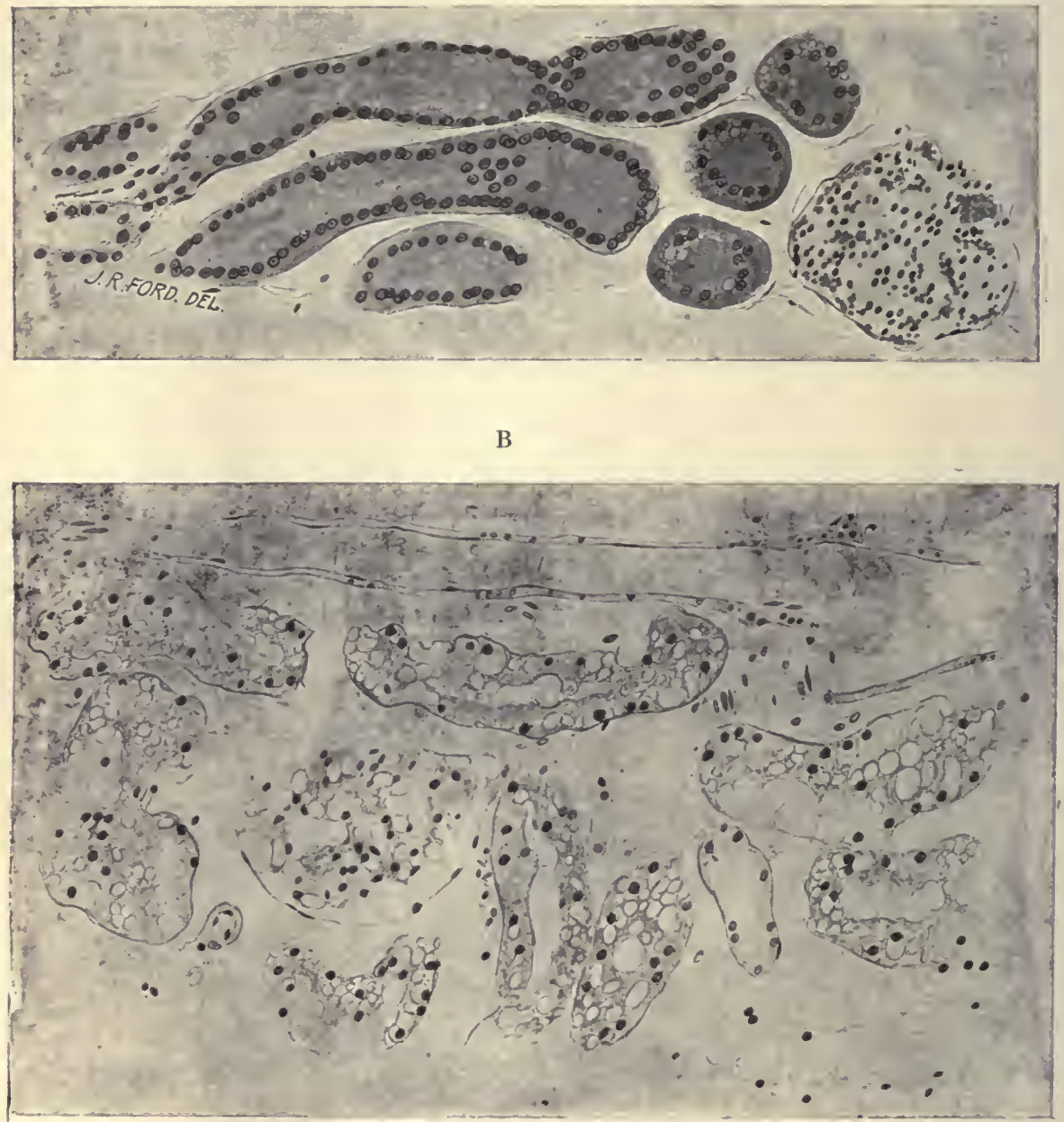

Fig. 177. - A, Normal Kidsey of Cat; B, Kidxey of Cat Decompressed Rapidey from Eight Atmospheres prepared bi SaMe Method.

At a pressure of 2 to 3 atmospheres it becomes impossible to whistle or whisper, owing to the density of the air. There are no sensations, beyond this disability, to indicate the abnormal pressurc. The pressure in the middle ear has to be equalized by opening the Eustachian tube during the rise of atmospheric pressure. This ean be effeeted 
by swallowing, or by an expiratory effort made with the mouth and nose shut.

The symptoms of sickness range from small pains in the joints and muscles, known as "bends," to sudden paralyses or death. The subject has been thoroughly studied experimentally (Figs. 173, 174) and the cause of the trouble is now clearly understood. At high pressures the blood and fat take up large quantities of nitrogen in simple physical soution. When the pressure is reduced rapidly, the nitrogen becomes freed in the circulation, and, becoming lodged as bubbles of gas in various parts of the body, produces symptoms of varying severity according to the degree of damage and the site of injury (see Figs. 175-178). Rapid decompression is therefore the danger. The rate of decompression must be regulated according to the pressure and period of saturation of the body. A diver who has been for a short time at

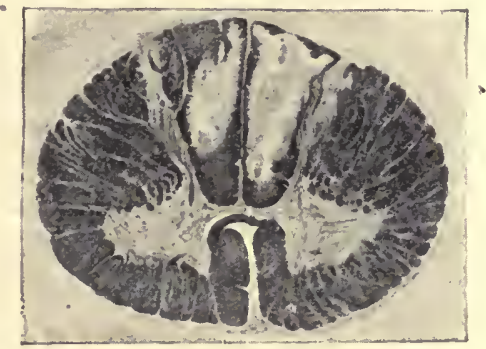

Fia. 178.-Necrotic Areas (Pale) in Posterior Columps of Spixal Cord, from a Fatal Case of Compressed Air Illuess. (v. Schrötter.)

a great depth may be relatively more quickly decompressed than a man who has been working several hours in a less pressure. The decompression is carried out in stages, for it is safe to allow a certain amount of supersaturation, as bubbles do not easily form in the blood - e.g., the diver ascends rapidly from a depth of 100 fect $(4$ atmospheres) to 33 feet ( 2 atmospheres), and pauses there for some time, meanwhile excrcising his muscles to accelerate the circulation and ventilation of the lungs, and so wash the excess of dissolved nitrogen out of his body. He then returns to the surface. For each atmosphere of air the water of the body dissolves about 0.8 per cent. of nitrogen. As fat dissolves five to six times as much nitrogen as water, there is particular danger of bubbles forming in the nervous tissues. All fat men are excluded from work in deep water.

The solution of nitrogen in the body fluids during collpression and the giving out of the excess of dissolved nitrogen during dccollpression has been studied on subjects who drank a quart or so of water just before entering the chamber, and collected samiples of their urine at various stages of compression and decompession. The nirrogen dissolved in these samples was pumped out by means of the mercury gas pump and estimated. 


\section{CHAPTER XXXV}

\section{THE PRINCIPLES OF VENTILATION}

OUR comfort or discomfort in crowded rooms and shut-up places depends on the chemical purity of the air only in so far as it affects the olfactory sense, but, to a rast degree, on the influence of the temperature, relative humidity, and the variations of these qualities of the air, which act on the great field of cutaneous sensibility. When it is stated that the chemical purity is of little account, the proviso is made that the air is only altered by the presence of healthy human beings, and is neither rendered poisonous by the escape of coal-gas, or other noxious trade product, nor deoxygenated by the oxidative processes of the soil, as it is in mines, reference being made only to the discomfort and ill-health caused by the deficient rentilation of, or bad methods of heating, dwelling-houses, schools, factories, theatres, chapels, etc.

The chemical purity of the air has to be considered from three points of view - the concentration of carbon dicxide, the concentration of oxygen, the supposed presence of organic poison exhaled in the breath.

It is commonly supposed that any excess of $\mathrm{CO}_{2}$ acts as a poison. The truth of the matter is quite otherwise; for, whatever the percentage of $\mathrm{CO}_{2}$ in the atmosphere may be, that in the pulmonary air is kept constant, as we have seen, at about 5 per cent. of an atmosphere by the action of the respiratory centre. It is therefore impossible that any excess of $\mathrm{CO}_{2}$ should enter into our bodies when we breathe the air of the worst-rentilated room, in which the percentage of $\mathrm{CO}_{2}$ assuredly does not rise abore 0.5 per cent., or at the outside 1 per cent. The only result from breathing such an excess of $\mathrm{CO}_{2}$ is a slight and unnoticeable increase in the rentilation of the lungs. The increased ventilation is exactly adjusted so as to keep the concentration of $\mathrm{CO}_{2}$ in the lungs at the normal 5 per cent. of an atmosphere.

At each breath we rebreathe into our lungs the air in the nose and large air-tubes (the dead-space air), and about one-third of the air which is inhaled into the lungs is "dead-space" air. Thus, no man breathes pure outside air into his lungs, but air contaminated perhaps by one-third or (on deep breathing) by onctenth with expired air. When a child goes to sleep with its head partly buried under the bedclothes, or in a cradle with the air confined by curtains, he rebreathes the expired air to a still greater 
extent, as do all animals that snuggle together for warmth's sakc. Not only the newborn babe sleeping against its mother's breast, but pigs in a stye, young rabbits, rats and mice clustered together in their nests, young chicks under the brooding hen, all alike may breathe a higher percentage than that legally allowed in spinning mills or weaving sheds. To rebreathe one's own breath is a natural and inevitable performance; to breathe some of the air exhaled by another is the common lot of men who, like animals, have to crowd together and husband their heat in fighting the inclemency of the temperate and Arctic zones. By a series of observations made on rats confined in cages with small ill-rentilated sleeping chambers, it has been shown that the temperature and humidity of the air-not the carbonic acid and oxygen concentration of the air-determines whether the animals stay inside the sleeping-room or come outside. When the air is cold, they like to stay inside, even when the carbonic acid rises to 4 per cent. or 5 per cent. of an atmosphere; when the sleeping chamber is made too hot and moist, they come outside.

In breweries, the men who tend the fermentation vats work for long hours in concentrations of $\mathrm{CO}_{2}$ of 0.5 to 1.5 per cent. Such men are no less healthy and long-lived than those engaged in other processes of the brewing trade.

The oxygen in the worst-ventilated schoolroom, chapel, or theatre, is never lessened by more than 1 per cent. of an atmosphere. The ventilation through chink and cranny, chimney, door, and window, and the porous brick wall, suffices to prevent a greater diminution of the oxygen concentration. In all the noted health resorts of the Swiss mountains, such as St. Moritz, the concentration of oxygen is lesscned considerably more than this. On the high plateaux of the Andes there are great cities: Potosi, with 100,000 inhabitants, is at 4,165 metres (barometric pressure about $440 \mathrm{~mm}$. Hg). Railways and mines have bcen built even at altitudes of 14,000 to 15,000 feet. Owing to the nature of the chemical combination of oxygen with hæmoglobin, man can adjust himself to very great variations in oxygen concentration. At Potosi, gir's dance half the night, and toreadors display their skill in the bull-ring. All the evidence goes to show that it is only when oxygen is lowered below a pressure of. 14 per cent. to 15 per cent. of an atmosphere that signs of oxygenwant arise. A diminution of 1 per cent. of an atmosphere has not the slightest effect on our health or comfort.

A commonly accepted hypothesis is that organic chemical poisons are exhaled in the breath, and that the percentage of $\mathrm{CO}_{2}$ is a raluable guide as to the concentration of these. It is believed necessary to keep the $\mathrm{CO}_{2}$ below $0 \cdot 1$ per thousand, so that the organic peisons may not collect to a harmful extent. The evil smell of crowded rooms is accepted by most as unequivocal evidence of the cxistence of organic chemical poison in the exhaled breath. This smell, however, is only sensed by, and excites disgust in, one who comes to it from the outside air. He who is inside, and helps to make the "fugg," is wholly unaware of the same, and unaffected 
by it. While we naturally avoid any smell that excites disgust and puts us off our appetite, yet the offensive quality of the smell does not prove its poisonous nature. On descending into a sewer, after the first ten minutes the nose ceases to smell the stench; the air therein is usually found to be far frecr from bacteria than the air in a schoolroom or tenement.

If we turn to foodstuffs, we recognize that the smell of alcohol and of Stilton or Camembert cheese is horrible to a child or dog, while the smell of putrid fish-the meal of the Siberian native-excites no less disgust in an epicure, who welcomes the cheese. Among the hardiest and healthiest of men are the North Sea fishermen, who sleep in the cabins of trawlers recking with fish and oil, and for the sake of warmth shnt themselves up until the lamp may go out from want of oxygen. The stench of such surroundings may effectually put the sensitive, untrained brain-worker off his appetite, but the robust health of the fisherman proves that this effect is nervous in origin, and not due to a chemical organic poison in the air.

The supposed existence of organic chemical poison in the cxpired air is based upon experiments in which either the condensation water obtained from the breath, or water which was used several timcs over to wash out the trachca of dogs, was injected into guinea-pigs and rabbits. The water was injected subcutaneously and in large amounts, and produced signs of illness, collapse, and death.

Such experiments have been repeated by many others, and with negative results by those whose methods of work demand most respect. A few confirmatory results have been obtained by methods of cxperiment which are truly absurd in their conception: 1 to 2 c.c. of condensation water (obtained by breathing for many hours through a cooled flask) have been injected into a mouse weighing 13 grammes or so. This is equivalent to injecting 5 litres of water into a man wcighing 65 kilos. Who would not be made ill by the injection of about 9 pints of cold water beneath his skin? It has been shown that injections of pure water alone in doses of orer 1 c.e. may make a mouse ill.

In the washings of a dog's trachea, or the condensation fluid obtained from the breath, there is bound to be present traces of the proteins of the saliva. A second injection of such into the "same animal might produce "anaphyläctic shock" (see p. 111). Experiments have been published which seem to show that guinea-pigs can be sensitized by the injection of the condensation water of human breath, so that anaphylaxis is produced in these pigs by a subsequent injection of a trace of human serum. Owing to the method employed, it secms certain that saliva must have contaminated the condensation water. The guineapigs therefore became sensitized to human protein by the injection of the condensation water containing traces of salivary protein. Such results, it is claimed, afford evidence in favour of the cxlialation of a volatile protein-an organic chemical poison. If there were anything in these claims, we should expect to find rats, which dwell in the same confined cage and breathe each other's breath, sensitive to 
the injection of a trace of each other's protein. According to those who study the phenomena of anaphylaxis, no such sensitivity can be shown. If rats and guinea-pigs be confined together for one or two months under the worst possible conditions of ventilation, the guineapigs subsequently show no signs of anaphylactic symptoms when injected with a small dose of rat's serum.

It has been claimed that if rabbits be arranged in a series of chambers, with the air led from one chamber to another; so that each succeeding chamber received the vitiated air from the one before it, the animals in the end cage died; but if the air received into this cage were passed through sulphuric acid the rabbits remained alive.

These experiments also have been repeated with the greatest care by several workers. It has been proved conclusively that no harm results so long as a sufficient air-current is maintained to keep the carbonic acid below a poisonous amount. The animal in the last eage dies when the $\mathrm{CO}_{2}$ reaches 10 to 12 per cent. If the $\mathrm{CO}_{2}$ is kept down, the animal in the last cage puts on weight and thrives as well as the animal in the first cage. Of course, it is necessary in such experiments to clcan the chambers daily, and supply the animals with suitable food and bedding.

A man can live many days in a closed chamber in comfort without damage to his health, having not the slightest cognizance of any defect in ventilation, when the ventilation is so reduced that the carbonic acid accumulates in the chamber up to 1 per cent.-that is to say, so long as the air in the chamber is kept cool and dry. Eight students were enclosed in a small chamber holding about 3 cubic metres of air, and kept therein until the $\mathrm{CO}_{2}$ has reached 3 to 4 per cent., and the oxygen has fallen to 17 or 16 per cent. Unaware that the oxygen was insufficient to support combustion they were puzzled to find they could not light a cigarette. The wet-bulb tcmperature rose meanwhile to about $85^{\circ} \mathrm{F}$., the dry-bulb a degree or two higher. Their discomfort became great, but this was relieved to an astonishing extent by putting on electric fans placed in the roof, whirling the air in the chamber, and so cooling their bodies.

In a crowded room, the air confined between the bodies and clothes of the people is almost warmed up to body temperature and saturated with moisture, so that cooling of the body by radiation, convection by evaporation, becomes almost impossible. This leads to sweating, wetness, and flushing of the skin, and a rise of skin temperature. The blood is sent to the skin, and stagnates there instead of passing in ample volume through the brain and viscera. Hence arise the feclings of discomfort and fatigue. The fans in the experiment mentioned above whirled away the blanket of stationary wet air round their bodies, and brought to the students the somewhat cooler and drier air in the rest of the chamber, and so relieved the heat stagnation from which they suffered. The relief became far greater when cold water was circulated through a radiator placed in the chamber, and so cooled the air of the chamber about $10^{\circ} \mathrm{F}$. 
The experiments showed that breathing increased percentages of $\mathrm{CO}_{2}$, and diminished oxygen percentages of 2 to 3 per cent., had littleeffect in modifying the frequency of the pulse, while the increased temperature and humidity of the air had a profound effect. If the percentage of $\mathrm{CO}_{2}$ in the chamber were suddenly raised up to 2 per cent., the subjects inside were quite unaware of this. If the air in the chamber were breathed through a tube by a man standing outside, none of the discomfort, experienced by those shut up inside, was felt. Similarly, if one of those in the chamber breathed through a tuhe the pure air outside, he was not relieved. The cause of the discomfort was thus proved to be heat stagnation due to the exccssive heat and humidity, and absence of movement of the air. The wet and dry bulb thermometers do not indicate the degree of this heat stagnation; this may be measured by the katathermometer described later (see p. 500).

The cooling power of the atmosphere exerted on the skin depends far more on its movement than on its temperature; the air in ordinaly rooms with the windows closed is so still that the cooling pcwer approximates to that in the tropics out of doors. The good effects of open-air life depend very largely on the wind and its cooling power stimulating the metabolism of the body. It has been shown that the will to perform either mental or physical tasks is diminished by hot, moist atmospheres, the pulse in increased in frequency, the arterial blood-pressure lowered and the appetite diminished by such. 


\section{CHAPTER XXXVI}

\section{METHODS FOR THE DETERMINATION OF THE RESPIRATORY EXCHANGE}

THE respiratory exchange can be measured by collecting the expired air in canvas-rubber bags. The bags are large so that the air expired by a resting man for periods of half an hour may quitc conveniently be collected. When it is required to determine

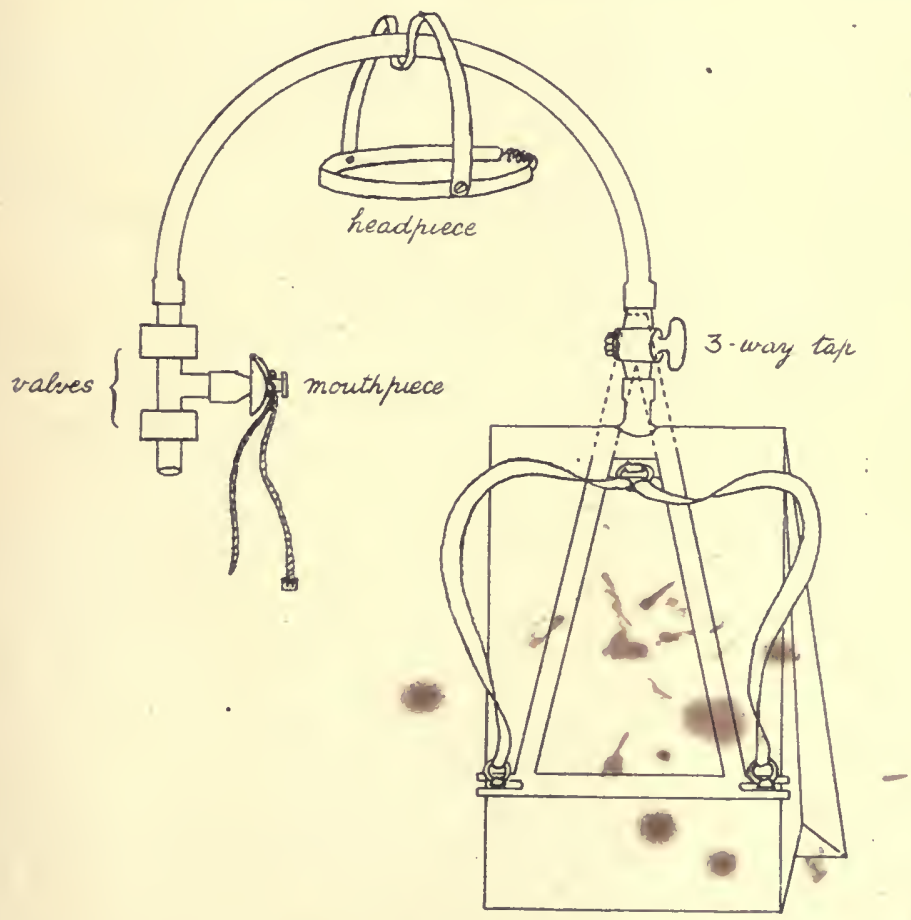

Fig. 179.-Apparatus used for Deternining the Total Respiratory Change in Max. (C. G. Douglas.)

the exchange during cxercise, such as walking, running, swimming, etc., smaller bags may be used, and the air of one or two minutes' breathing collected. The subject of the experiment wears a mouthpiece fitted with inspiratory and expiratory valves. The nose is closed by a clip. By means of the valves; the outside 
air is inspired, and the expircd air directed into the collecting bag (Fig. 179).

The respiratory exchange is calculated by squeczing the contents of the bag through a meter, and thus measuring the volume of the air expired in the given time, and by determining the composition of samples of the cxpired air. For example, if it be found that a man at rest has breathed out on an average 7 litres per minute, and that the expired air contains, say, 4 per cent. of $\mathrm{CO}_{2}$ and $15 \cdot 80$ per cent. of $\mathrm{O}_{2}$, then, taking the percentage of $\mathrm{O}_{2}$ in the inspired air under the conditions of the observation* as $20 \cdot 80$, the percentage absorbed is $5(20 \cdot 80-15 \cdot 80)$, the amount of $\mathrm{O}_{2}$ absorbed is $\frac{5 \times 7000}{100}=350$ c.c. per minute. Likewise, the amount of $\mathrm{CO}_{2}$ given out is $\frac{4 \times 7000}{100}=280$ c.c. per minute.

In the case of small animals, another method of procedure is adopted. The volume of $\mathrm{CO}_{2}$ expired is estimated from the weight of $\mathrm{CO}_{2}$ given out by the animal, while the oxygen used is arrived at by subtracting

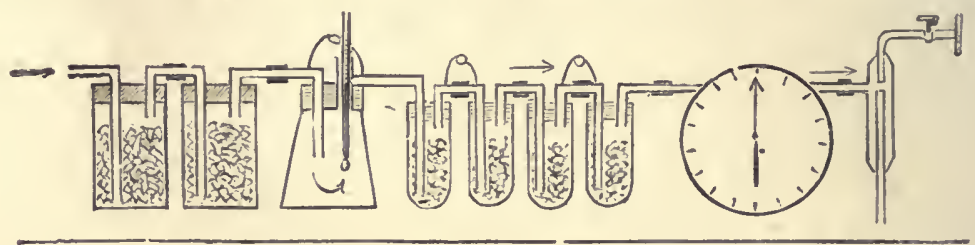

M N

A B C D

Fig. 180.-The Haldane-Penbrey Respiration Apparatus.

the loss in weight of the animal in a given time from the combined weights of $\mathrm{CO}_{2}$ and water given off by it. The apparatus suitable for a mouse or rat is illustrated in Fig. 180. A beaker serves as animal chamber; this is closed by acork and pierced by inlet and outlet tubes and a thermometer. The cork is soaked in melted paraffin before insertion to secure air-tight closure. The beaker is generally placed in a waterbath regulated to the desired temperature. Air is drawn into the chamber through a meter by means of an aspirator or filter pump. The incoming air is freed from $\mathrm{CO}_{2}$ and water by being drawn through a bottle $(M)$ containing soda lime, and another $(N)$ containing pumice and sulphuric acid. The issuing air is led through a pair of tubes $(A, B)$ containing sulphuric acid and pumice to remove the water, and another pair, $C$ containing soda lime, $D$ containing sulphuric acid and pumice. Tube $C$ removes the $\mathrm{CO}_{2}$, and $D$ catches the water liberated from the soda lime. In actual practice, tubes $C$ and $D$ are duplicated, as a control. The duplicates should not change in weight during an experiment. From the increase in weight of tubes $A, B$ during a given time the weight of water given off is obtained;

* For accurate work these volumes must be reduced to $0^{\circ} \mathrm{C}$. and $760 \mathrm{~mm}$. 
the increase of weight in $C$ and $D$ gives the weight of $\mathrm{CO}_{2}$. The loss of weight in the animal is obtained by weighing the animal in the beaker before and after experiment. Then since the molecular weight of a gas in grammes measures 22.4 litres under normal condition of temperature and pressure, the $\mathrm{CO}_{2}$ in grammes $\times{ }_{22 \cdot 4}^{44}=$ volume of $\mathrm{CO}_{2}$ given out; similarly, the loss of weight of $\mathrm{CO}_{2}$ and water vapour deducted from the loss of weight of the animal gives the weight of oxygen taken in; this in grammes $\times \frac{32}{22 \cdot 4}=$ volume of oxygen taken in.

Such a method is not convenient for larger animals and for man. The respiratory exchange in such has been investigated by placing the animal in a closed chamber which contains a known quantity of air. This air is circulated, the $\mathrm{CO}_{2}$ given off being absorbed by caustic alkali, and oxygen gradually added to replace that used up and keep the pressure constant. The oxygen used is known from the amount which has entered the chamber; the amount of $\mathrm{CO}_{2}$ absorbed is estimated by titrating the alkali. In some laboratories, large rooms have been fitted up for the special study of the respiratory exchange in man under varying conditions.

The respiratory exchange is greatly increased by muscular work, as the following table shows:

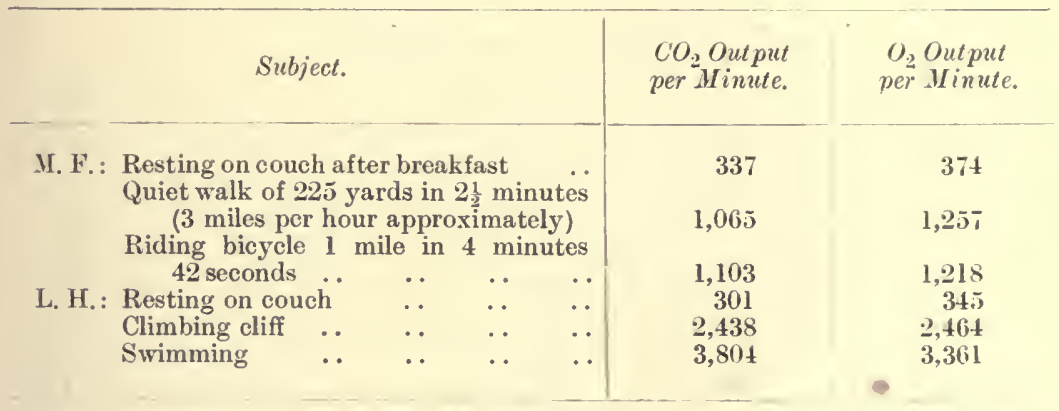

Exposure to a cold wind may double the respirator y exchange of the resting man; by stimulating him to muscular activity it ray do much more than this.

The Respiratory Quotient.-The volume of $\mathrm{CO}_{2}$ given out divided by the volume of $\mathrm{O}_{2}$ taken in gives the respiratory quotient:

$$
\mathrm{R} \cdot \mathrm{Q} .=\frac{\mathrm{CO}_{2} \text { by volume }}{\mathrm{O}_{2} \text { by volume }}
$$

Thus, in the expcriment on man, 280 c.c. of $\mathrm{CO}_{2}$ was gircn out, 350 c.c. of $\mathrm{O}_{2}$ taken in.

$$
\text { The R.Q. } \therefore=\frac{280}{350}=0 \cdot 8 \text {. }
$$

The respiratory quotient varies according to the nature of the food being oxidized in the body. On a mixed diet it is found to be about 0.85 . 
With carbohydrate the quotient is 1 . The following formula summarizes its decomposition:

$$
\begin{aligned}
\mathrm{C}_{6} \mathrm{H}_{12} \mathrm{O}_{6}+6 \mathrm{O}_{2} & =6 \mathrm{CO}_{2}+6 \mathrm{H}_{2} \mathrm{O} . \\
\frac{6 \mathrm{CO}_{2}}{6 \mathrm{O}_{2}} & =1 .
\end{aligned}
$$

In the case of carbohydrate there is sufficient oxygen in the molecule for the formation of water; oxygen is only required for the formation of carbon dioxide. In the case of protein and fat part of the oxygen taken in combines with hydrogen to form water; the R.Q. is therefore less than 1. With protein it is about 0.82. The following formula has been suggested as summarizing its decomposition:

$$
\begin{gathered}
\mathrm{C}_{72} \mathrm{H}_{112} \mathrm{~N}_{18} \mathrm{O}_{22} \mathrm{~S}+77 \mathrm{O}_{2}=63 \mathrm{CO}_{2}+38 \mathrm{H}_{2} \mathrm{O}+\underset{\text { Urea }}{9 \mathrm{CO}\left(\mathrm{NH}_{2}\right)_{2}}+\mathrm{SO}_{3} . \\
\mathrm{CO}_{2}=\frac{63}{\overline{\mathrm{O}}_{2}}=\frac{7}{77}=0.82 .
\end{gathered}
$$

For fats undergoing direct katabolism in the body it is found to be about $0 \cdot 7$. The following formula summarizes the katabolism of olein:

$$
\begin{aligned}
\mathrm{C}_{3} \mathrm{H}_{5}\left(\mathrm{C}_{18} \mathrm{H}_{33} \mathrm{O}_{2}\right)_{3}+80 \mathrm{O}_{22} & =57 \mathrm{CO}_{2}+52 \mathrm{H}_{2} \mathrm{O} . \\
\mathrm{CO}_{2} & =\frac{57}{\mathrm{~S} 0}=0.71 . \\
\mathrm{O}_{2} & =0 .
\end{aligned}
$$

Muscular work, although greatly increasing the respiratory exchange, may not affect the respiratory quotient. The respiratory quotient of animals previous to and during hibernation and during starvation is referred to under Fat Metabolism (pp. 439, 440).

Internal or Tissue Respiration denotes gaseous interchange between the blood and tissue fluids on the one hand, and the body cells on the others. A frog placed in nitrogen continues to produce $\mathrm{CO}_{2}$ for some hours, so does a frog whose blood is replaced by physiological saline. Excised "surviving" organs, artificially circulated, continue to use $\mathrm{O}_{2}$ and produce $\mathrm{CO}_{2}$. The glow organ of a glow-worm glows only in the presence of oxygen. These are proofs of tissue respiration. That the living tissues have a marked aftinity for oxygen can be shown by injecting a solution of methylene blue intravenously. On killing the animal, it is found that, although the blood be blue, the tissues, such as the muscles, are uncoloured. Upon exposing the muscles to oxygen, they become blue, showing that the muscles have reduced the methylene blue, and thus decolorized it. Since methylene blue is a fairly stable compound, the great affinity of the tissues is well shown by the experiment. They store up but little combined oxygen, and the oxidative changes which occur in them are supposed to be due to enzymes known as "oxidases" and "peroxidases" (see p. 73). When a tissue is active, much more oxygen is taken from the circulating blood and mo:e $\mathrm{CO}_{2}$ is given up to the bloot. This gaseous interchange can be calculated by estimating the amount of $\mathrm{CO}_{2}$ and $\mathrm{O}_{2}$ in the blood going to and leaving the organ, and by 
measuring the blood-flow through the organ in a given time. Such experiments have been made upon the heart, muscles, kidneys, salivary glands, and other tissues:

In the following table some of the results obtained are given. The gaseous interchange may be expressed either in c.c. per minute or in c.c. per gramme of tissue substance per minute.

Table showisg Effect of Activity dpox the Ixtersal Respiratory EXChAXge.

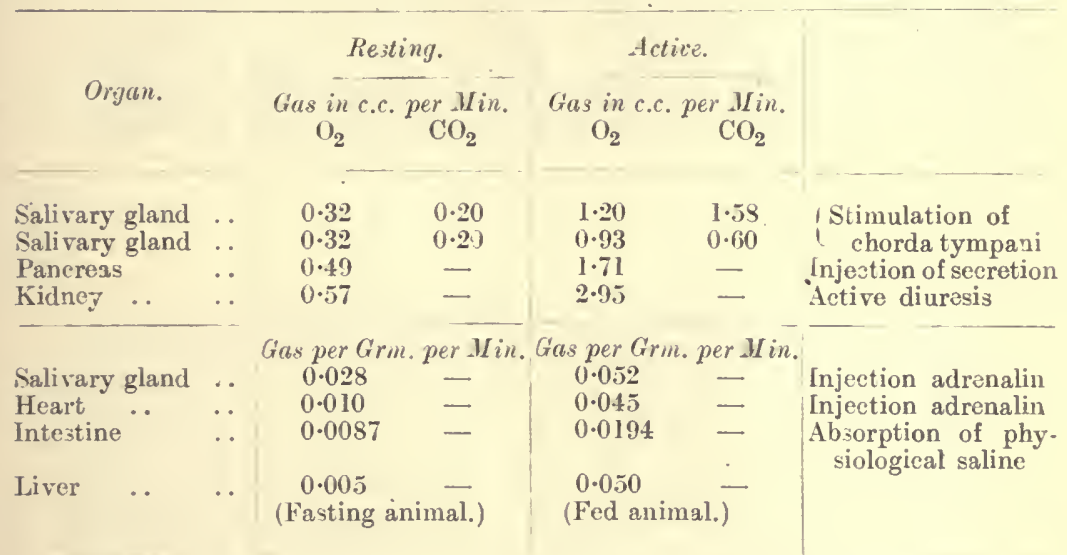

The oxygen use of the heart is reduced during vagal stimulation and increases after its cessation. The use of oxygen by the heart is also greatly reduced by the injection of chloroform water into the blood.

When the nerve of a muscle is divided, its metabolism is markedly decreased; the respiratory quotient is practically unaltered by the complete rest so induced. The oxygen use per minute per kilogramme of substance has been estimated as follows: Muscle, 4 c.c; salivary gland, 25 c.c.; pancreas, 40 c.c.; intestine, 23 c.c.; kidney, 26 c.c.; liver, 30 c.c.

Energy displayed by a contracting muscle or a secreting gland is not in itself a manifestation of oxidation in the sense that the work of an internal combustion engine is a direct manifestation of the oxidative cxplosion in the cylinder; they are more to be compared to the running-down of an alarm clock. The cloak is wound, and at a given moment the potential energy of the spring is released. It must then be rewound. It is during the period of "rewinding " that oxidation is increased and an ample supply of blood is required. There is some evidence that the pressure of oxygen in the tissue-juices of glands approximates to that in the venous blood, while in muscle it is almost nil. The latter, therefore, on any diminution of blood-flow suffers from oxygen-want.

The blool which leaves an organ is warmer, more acid, and altered in saline content. Each of these factors may ail the dis- 


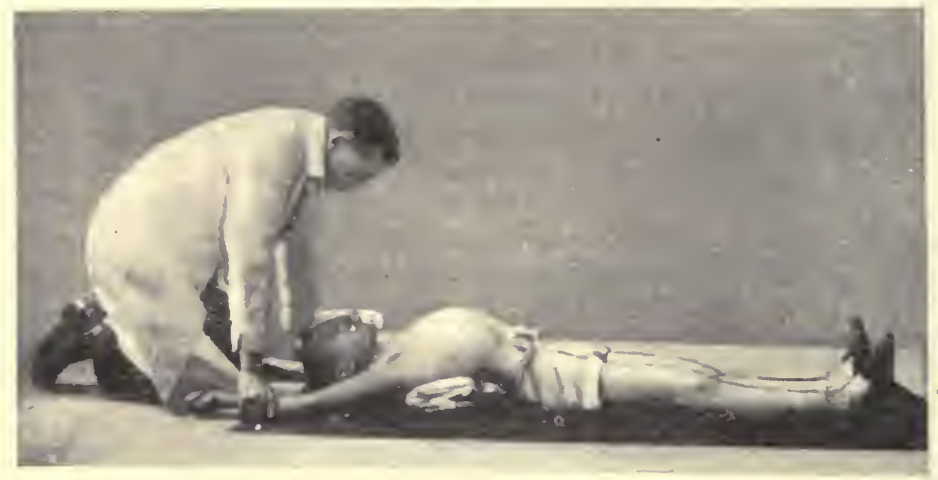

Fig. 181.-Sylvester's Method: Means of producing Inspiration.

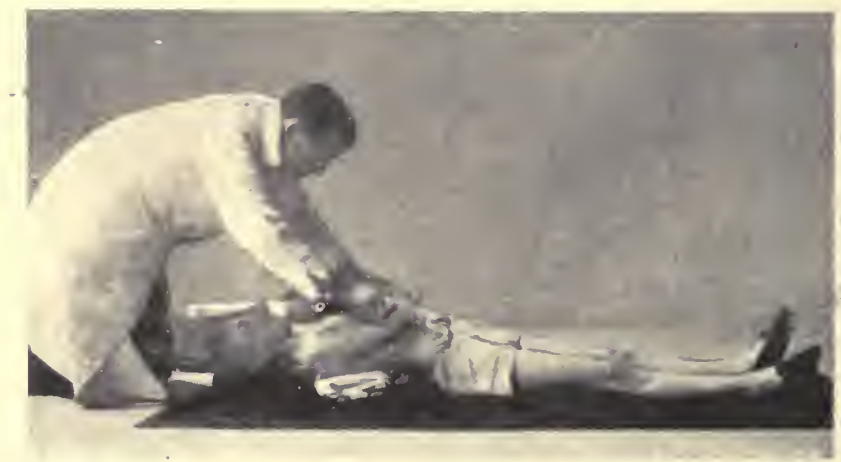

Fig. 181a.-Sylvester's Method: Means of producing Exiration.

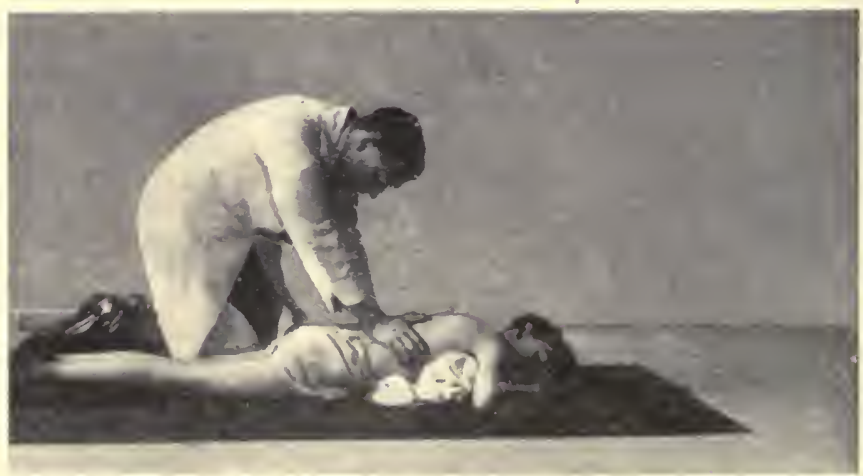

Fig, 182,-Schäfer's Method of Artificlal Respiratiox. (From Rowland's "Hygiene for Teachers.") 
sociation of oxyhæmoglobin. In partieular, by locally inereasing the acid in the blood within the eapillaries, the hard-working tissues dissociate oxygen from the oxyhæmoglobin and make the red corpuscle diseharge its cargo of oxygen with rapidity. At the same time, by increasing the general acidity of the blood, the tissues provoke the respiratory centre to inereased aetivity. The inereased aeidity of the blood not only modifies the dissociation eurve of oxyhæmoglobin, but is accompanied by a lower pereentage of $\mathrm{CO}_{2}$ in the alveolar air, a lower respiratory quotient, and diminished power of the hæmogiobin to eombine with oxygen in the lungs.

Artificial Respiration.- In this country two methods are in vogue. In the older method-Sylvester's - the subjeet is placed on his baek, with a pillow or folded garment beneath the shoulders. The tongue is pulled well forward, the mouth kept open. Inspiration is indueed by grasping the arms below the elbow, and gradually raising them above the head (Fig. 181). Expiration is produced by bending the arms,

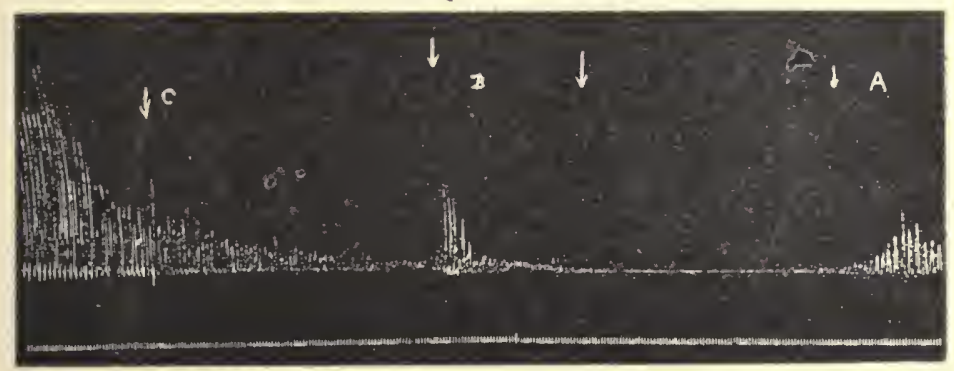

Fig. 183.-Cat: Record of Respiration.

$A$, Chloroform on between the arrows; $B, \mathrm{CO}_{2}$ on between the arrows; $C, \mathrm{CO}_{2}$ on again. Time in seconds.

and pressing them foreibly against the chest wall (Fig. 181 A). These operations should be performed about twenty times a minute. The method has the disadvantage of being fatiguing to the operator.

The more recent method - Sehäfer's - has largely overeome this defect. In it the subject is placed faee downwards, with the upper part of the chest raised by a pillow or some similar support. The operator stands at the side of the subject faeing his head; then, plaeing his hands on the lowest ribs on either side, he slowly brings the weight of his body to bear upon his own arms, and thus presses upon the thorax of the subject, and forees air out of the lungs. Then he gradually relaxes the pressure by bringing his own body up again to a more erect position without moving the hands (Fig. 182).

The rhythmic pressure on the thorax helps to squeeze blood through the heart and lungs, and it is as important to effect this as it is to introduce air. The excitatory effeet of $\mathrm{CO}_{2}$ upon the respiration might be made use of in eases of poisoning due to oxygen-want (carbonie 
oxide and nitrite, etc.) and in cases of drowning, suffocation and chloroform syncope (Fig. 182). To carry out the method most effectively there would be required an anæsthetic mouth-piece and rubber bag filled with oxygen in and out of which the operator has respired several times. This is then given the patient to breathe while artificial respiration is donc. To respirate children artificially it is best to put mouth to mouth (interposing a handkerchief) and rhythmically blow up the lungs. A hand placed on the belly prevents the stomach

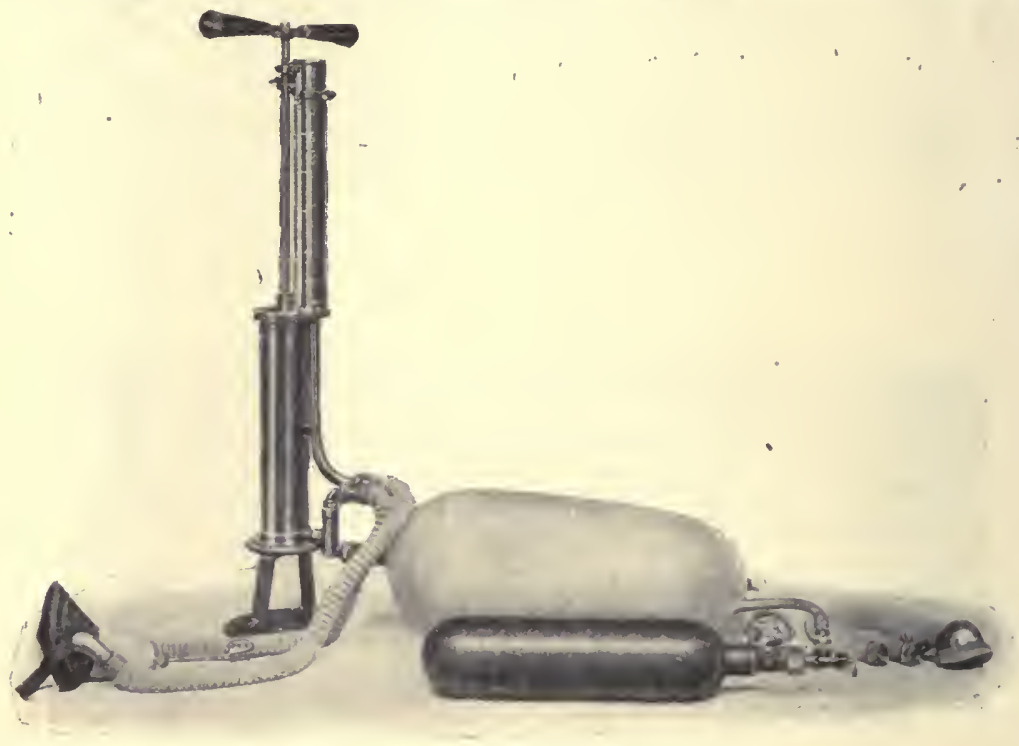

Hig. 184.-1He livator Apparatus for artificial Respiration.

(Siebe, Gorman and Co.)

The apparatus eonsists of a special pump, which, on the downstroke, delivers oxygen from a bag (connected to an oxygen eylinder) into the inspiratory tube of a mask, whieh is fastened or held tightly over the patient's nose and mouth. Having eompleted the downstroke and so foreed oxygen into the patient's lungs, the pump on its return or upstroke not only sueks in a fresh supply of oxygen to be delivered on the next downstroke, but also opens a valve, which is connected with the expiratory tube of the mask, thus allowing the expiratory recoil of the expanded ehest and lungs of the patient free play. The valvo remains open during the upstroke and automatically eloses when the stroke is eompleted. The piston of the pump then descends and delivers another supply of oxygen, and so on.

being blown up, or the gullet can be closed by pressing the larynx backwards. A pump has been contrived for this purpose, fitted with a face mask (Fig. 184). The stroke of the piston is arranged to open a valve at the end of the infiation so as to allow deflation of the lungs by the elastic rccoil of the thorax. Such a pump cannot be used to suck air out of the lungs, for suction causes the walls of the small bronchial tubes to come together, and docs not empty the alvcoli. 


\section{BOOK $r$}

\section{CHAPTER XXXVII}

\section{GENERAL METABOLISM AND DIETETICS}

Metafolism and reproduction are the chicf characteristics of living matter. We know that complex bodies such as proteins, fats, and earbohydrates, are constantly taken into the "body, and that eaeh undergoes its own special metabolism. As the result of these reaetions ehemical energy is transformed into heat and meehanical work; waste products, such as carbon dioxide and urea are formed, and exereted from the body.

The study of general metabolism coneerns the intake and output of energy by, and the processes of building up and breaking down whieh occur in, the body as a whole; while the study of the speeial metabolisms deals with the exact ehemical changes undergone by the various foodstuffs, and with the localization of such changes in the body.

General Metabolism: Methods.-The general metabolism of a man or animal may be investigated by two means: (1) Direetly, by ascertaining the heat value of the foodstuffs taken in, and then measuring the heat given off, either as such or as work, the work performed being subsequently caleulated as hcat. (2) Indirectly, by drawing up a balance-sheet between the intake (the amount of food and amount of oxygen taken in) and the output (the amount of the various bodies excreted in the breath, urine, fæces, and sweat), and from these ealculating the energy cxchange. Of these, the seeond method demands a less difficult technique and is more generally employed. For very exact work a eombination of the methods is used.

The body is to be looked upon as a maehine capable of performing work and liberating heat. In the living as in the inanimate world, there is no sueh thing as a loss of energy. All such apparent losses are merely transformations of encrgy, the chief transformation in the body being that of the chemieal energy of the foodstuffs into work and heat.

It is not possible, however, to aeeount for the operations that go on in the human machine on the supposition that man is a thermodynamic engine. 
The unit by whieh work is measured is the kilogramme-metre (kgm.). This is the foree necessary to raise a kilogramme vertically through 1 metre from the earth's surface.*

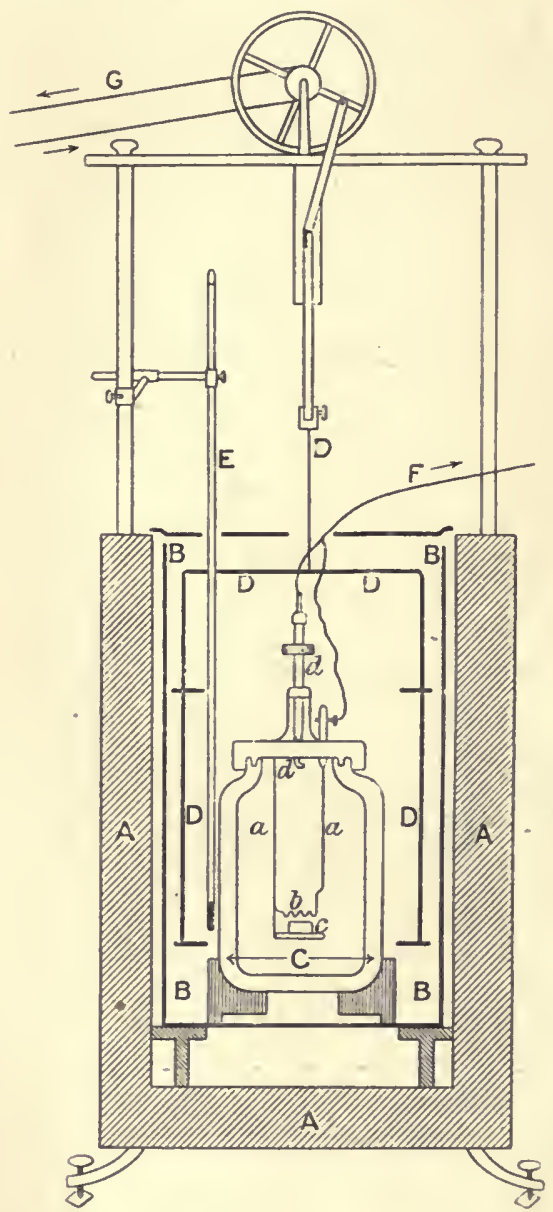

Fiv. 185.-Bomb Calorimeter. (Berthelot.)

.. Water jacket; $B$, water ealorimeter; $C$, bomb; $D$, stirrer worked by motor $G$; $E$, thermometer; $F$, eable earrying wires to $a$ and $d$.

The unit by which heat is measured is the Calorie. This is the heat required to raise 1 kilogramme of water through $1^{\circ} \mathrm{C}$. (preferably from $20^{\circ} \mathrm{C}$. to $21^{\circ}$. C.). For smaller measurements the small calorie

* As this force varies, owing to the shape of the earth being greater at the poles than at the equator, the unit known as the "erg" is now emploved in exaet work. This is the force which will impart to a resting gramme-mass a veloeity of 1 centimetre per second. One kilogramme-metre equals 980,000 ergs. 
( $\frac{1}{1000}$ Calorie), or gramme-calorie, is employed; while for the finest work the micro calorie, or milligramme-calorie, is used.

In order to measure the amount of heat retained or given out by a inan, it is necessary to know the specific heat of his tissues. This has been determined as 0.8. A hibernating dormouse weighing 10 grammes, and with a body temperature of, say, $4^{\circ} \mathrm{C}$., when placed in 100 c.c. of water at $0^{\circ} \mathrm{C}$. until cooled to $3^{\circ} \mathrm{C}$., does not yield 10 , but only 8 , calories to the water. Consequently, if a $70 \mathrm{kgm}$. man has his temperature raised $1^{\circ} \mathrm{C}$., he stores up $70 \times 0 \cdot 8=56$ calories of heat.

The Intake of Energy.- The combustion of each of the foodstuffs liberates a definite amount of hcat, be it burnt inside or outside the animal body. Exact measurements of the heat of combustion of the different constituents of the body are obtained by means of an instrument known as the bonb calorimeter. The substance to be burnt is dried, weighed-end placed in a strong stcel bomb, the inside wall of which is protected cither by thick enamel or platinum. The bomb is then filled with oxygen under pressure (20 to 25 atmospheres), and placed in a vessel (Fig. 185) containing a weighed quantity of water. This water vessel contains a delicate thermometer and a stirrer, $D$, which can be driven by a motor. It is also carefully protected by a jacket $(A)$-a. vacuum jacket is best-from alcerations in temperature of the surrounding atmosphere. The temperature of the water is carefully noted, and then the substance is burnt in the oxygen by causing a wire with which it is in contact to glow. This is effected by passing an clectric current through wires led into the bomb. Combustion is rapidly completed; the tcmperature of the water is raised thereby, and the risc noted. From this by means of appropriate calculations allowing for the caloric capacity of the apparatus, etc., the heat liberated by the combusted substance is ascertained.

In the calorimeter all the carbon combined in the molecule of foodstuff is converted to carbon dioxide, the hydrogen to water, and the nitrogen is freed as nitrogen gas. In the body the carbon mostly is excreted as $\mathrm{CO}_{2}$, and the hydrogen as water; but the whole of the nitrogen and a small part of the carbon and hydrogen are excreted combined in urea, uric acid, creatinin, etc. Thesc bodies have a considerable specific heat of combustion; thereforc, in cstimating the heat value of the protein in the diet, it is necessary to subtract the heat value of the nitrogenous excrcta from the total value, obtaincd on burning the protein in the bomb calorimeter.

The table on p. 328 gives the combustion value of some of the chicf substances met with in the body, cxpresscd in several terms.

The Indirect Method.-The food given is carefully weighed, and its content in protein, fat, and carbohydrate, calculated from tables giving the analytical composition of the various foodstuffs.

In morc accuratc work the amount of protein in the diet may be estimated by detcrmining, when the diet contains no other nitro- 
genous bodies, the total nitrogen excreted in the urinc, and multiplying this by $6 \cdot 25$-the average ratio of nitrogen ( 16 per cent.) to the total weight of protcin $\left(\frac{100}{16}=6 \cdot 25\right)$.

\begin{tabular}{|c|c|c|c|c|c|c|}
\hline , & & & $\begin{array}{l}\text { Per Gramme of } \\
\text { Substance } \\
\text { (g. cal.). }\end{array}$ & $\begin{array}{c}\text { Per Cramme } \\
\text { Molecult.r } \\
\text { Weight of } \\
\text { Substance } \\
\text { (kg. cal.). }\end{array}$ & $\begin{array}{c}\text { Per Gramme } \\
\mathrm{O}_{2} \text { used } \\
\text { (g. cal.). }\end{array}$ & $\begin{array}{c}\text { Per Gramme } \\
\mathrm{CO}_{2} \text { formed } \\
\text { (g. cal.). }\end{array}$ \\
\hline Starch & . & $\cdots$ & 4190 & $678 \cdot 8$ & 3536 & 2572 \\
\hline Dextrose & .. & .. & 3743 & 673.7 & 3509 & 25.2 \\
\hline Cane-sugar & & .. & 39.5.5 & $1353 \cdot 6$ & $352 \div 2$ & 2562 \\
\hline Lactose (wate & $\left.r-f_{1} c c\right)$ & .. & 3952 & $1351 \cdot 6$ & 3520 & 2560 \\
\hline Fat (human) & .. & .. & 9540 & - & 3353 & 470.2 \\
\hline Butter .. & .. & .. & 9230 & - & - & - \\
\hline Caseinogen & .. & $\ldots$ & $5850(4350)^{*}$ & - & 3291 & 2947 \\
\hline Musclc proteir & & .. & $5650(4150)^{*}$ & - & $3: 23$ & $296^{\circ}$ \\
\hline Legumin & . & .. & $5793(4: 93)^{*}$ & - & 3291 & 2969 \\
\hline Urea .. & .. & .. & 2542 & $152 \cdot 5$ & 3177 & 3466 \\
\hline Uric acid & .. & . & 2750 & $462 \cdot 0$ & 3208 & 2100 \\
\hline Hippuric acid & $\ldots$ & .. & 5668 & $1014 \cdot 6$ & 3252 & 1281 \\
\hline Alcohol & .. & .. & 7080 & $325 \cdot 7$ & 3392 & 3701 \\
\hline Butyric acid & .. & .. & 5940 & $52 \cdot 2 \cdot 7$ & 3267 & 2970 \\
\hline
\end{tabular}

* The first is bomb value; the second is value for body after subtracting value for urea formed, etc.

Note that column 2 is kilogramme-calories, the other columns gramme-calories.

Let us suppose, for example, that the dict is calculated to contain (dry weight) 125 grammes of protein, 500 grammes of carbohydrate, and 50 grammes of fat.

From the chemical composition of cach of thesc foodstuffs the amount of carkon and nitrogen is calculated-

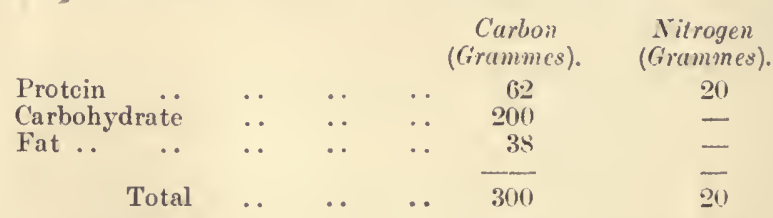

The energy value of such a diet in terms of heat is- :

$$
\begin{aligned}
& \text { Calorics. }
\end{aligned}
$$

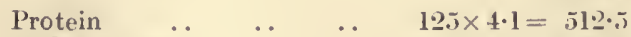

$$
\begin{aligned}
& \text { Carbohydrate } \quad \ldots \quad \ldots \quad 500 \times 4.1=2050 . \cdot 1 \\
& \text { Fat } \quad . \quad \ldots \quad \ldots \quad \ldots 50 \times 9 \cdot 3=465 \cdot 0 \\
& 30 \cdot 2 \pi \cdot 5
\end{aligned}
$$

The Output.- Since protein is the only body in the alove diet which contains nitrogen and sulphur, the amount of protein katabolism of the body can be arrived at by estimating earefully the amount. of nitrogen or sulphur combined in the excreta. The nitrogen is most.

* For the food digested ard utilized the values can be taken as protein 4 , fat 9 , en rbohydrate 4 . 
usually chosen. This occurs mainly in the urine, to a small extent in the fres and sweat. The total nitrogen of the urine is usually determined by Kjeldahl's process (see p. 455), and to this 1 gramme of nitrogen is added-that is, the average amount excreted in the fæces. The nitrogen of the fæces is derived in part from unabsorbed food, and in part from the various secretions of the alimentary tract. The above average has been ascertained by experiments upon animals placed on a nitrogen-free diet. It has to be borne in mind that several days are required for the elimination of all the nitrogen taken in in the case of some proteins. The nitrogen is eliminated at varying rates when different types of proteins are ingested.

The proportion of sulphur in urine to nitrogen is $1: 5 \cdot 2$-about the same as in protein. The determination of the sulphur excretion is therefore a guide as to the breaking down of protein and a control of the nitrogen determinations. The determination of the protein metabolized from the sulphur excretion has the advantage that in general the sulphur of the protein is more quickly excreted than the nitrogen, but has the disadvantage that, being small in amount, the experimental error is likely to be greater.

Protein yiclds a certain amount of carbon combined with the nitrogen of the urinary excreta. It has been determined that for every gramme of nitrogen excreted 0.67 gramme of carbon is excreted. This ratio is constant, so that it is not necessary to estimate the proportion of carbon in the nitrogenous bodies of the urine.

Protein on its oxidation also yields $\mathrm{CO}_{2}$ and water. The $\mathrm{CO}_{2}$ output is more easy to estimate than the water output of the body.

Of the carbon dioxide excreted a small part comes from protein, the remainder from fat and carbohydrate. The amount of carbon coming from protein is found by multiplying the amount of nitrogen excreted by $3 \cdot 3$, since the proportion of carbon to nitrogen in protcin is $3 \cdot 3: 1$. Since the tissues contain far more fat than carbohydrate, any carbon retained in the body is usually reckoned as fat. Each gramme of carbon represents 1.3 grammes of fat, the proportion of carbon to the total weight of fat. A small amount of carbon is lost as fat in the frecs.

Let us suppose that with the above intake the output was-

\begin{tabular}{|c|c|c|c|c|c|}
\hline \multirow{4}{*}{$\begin{array}{l}\text { In urine } \\
\text { In freces } \\
\text { In breath }\end{array}$} & & \multicolumn{3}{|r|}{ Carbon. } & Nitrogen. \\
\hline & .. & .. & .. & $11(16.5 \times 0.67)$ & $16 \cdot 5$ \\
\hline & .. & .. & .. & 5 & $1 \cdot 0$ \\
\hline & . & . & . & 254 & - \\
\hline & & & & 270 & $17 \cdot 5$ \\
\hline
\end{tabular}

There is a retention in the body of 30 grammes of carbon and 2.5 grammes of nitrogen. This nitrogen $=2.5 \times 6.25=15.625$ grammes of protein. In this protein there is $2.5 \times 3 \cdot 3=8.25$ grammes of carbon; so that $30-8 \cdot 25=21 \cdot 75$ grammes of carbon is represented as fat. To estimate this as fat we must multiply the carbon by 1.3 (fat contains 76 per cent. of carbon), $21.75 \times 1 \cdot 3=28.275$. Therefore on 
the above diet $15 \cdot 625$ grammes of protein and 28.275 grammes of fat were retained per day in the organism. The energy exchange can be obtained by deducting from the energy value of the food eatcn the amount of heat represented by these.

\begin{tabular}{|c|c|c|c|c|c|}
\hline \multirow{2}{*}{$\begin{array}{l}\text { Protein } \\
\text { Fat }\end{array}$} & \multirow{2}{*}{$\ddot{\therefore}$} & \multirow{2}{*}{. } & $\ldots$ & \multicolumn{2}{|c|}{ Calories. } \\
\hline & & & . & $28 \cdot 275 \times 9 \cdot 3=263$ & , \\
\hline & & & & 327 & ", \\
\hline
\end{tabular}

Since $3,027.5$ were supplied, the amount of energy liberated is, therefore, $3,027 \cdot 5-327=2,700 \cdot 5$ ealories.

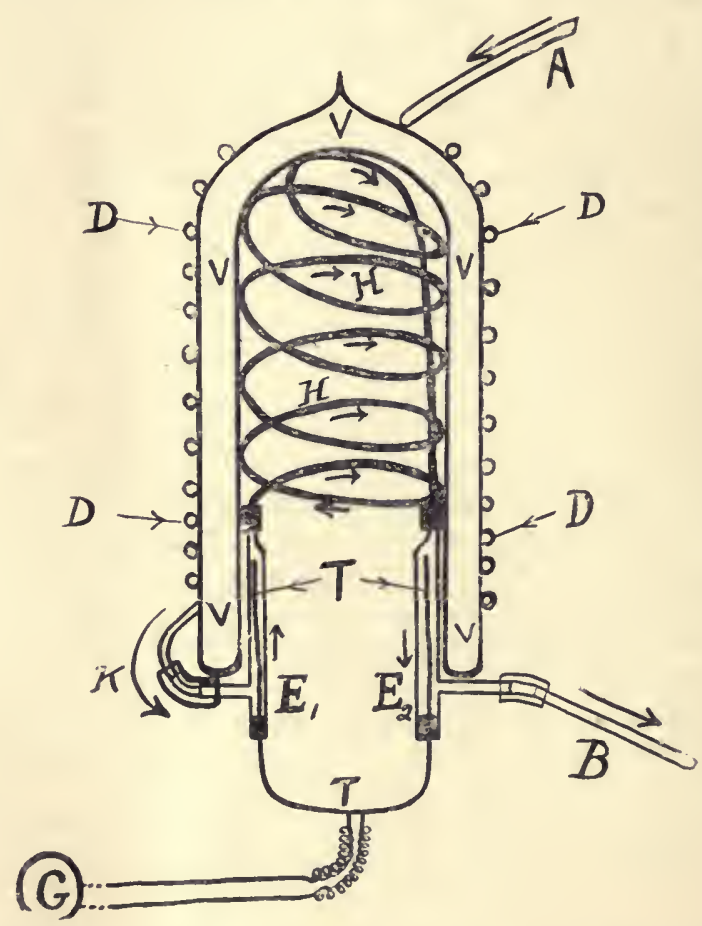

Fiu. 186.-Horizontal Section of Self-Registerixg Calorimeter for Experi. Mexts With Silal Aximals. (A, V. Hill and A. M. Hill.)

$V, V, V, V$, Vacuum between walls of a cylindrical Dewar's flask; $A$, incoming water from tank; $D, D, D, D$, scction of lead tubing around outside of flask; $K$, junction between outer lead tubing and $T$-piece $E_{1} ; E_{1}$ and $E_{2}$, inlet and exit T-pieces containing the thermopilc $T ; H, H$, eoil of lead tubing inside flask; $B$, exit pipo for water; $G$, self-registering galvanometer.

Another indirect guide to the energy liberated by the tissues under varying conditions is the amount of oxygen absorbed by them. This is a good guide in successive comparative experiments, sinee, provided the quality and relative proportion of the foodstuffs burnt are 
approximately the same, it is fair to assume that any change in the oxygen intake, and also in the $\mathrm{CO}_{2}$ output, are due to the conditions of experiment, such as exposure to cold, warmth, wind, etc. The respiratory exchange is therefore often used to cstimate the amount of energy liberated in the tissues.

It is necessary for very accurate work to remember that different foodstuffs liberate different amounts of energy for the same amount of oxygen absorbed. Thus, 100 grammes of oxygen will burn-

35 grammes of fat, giving energy equal to 325 calories.

84.4 grammes of carbohydrate, giving energy equal to 346 calories.

$\mathbf{7 4 \cdot 4}$ grammes of protein, giving energy equal to 362 calories.

Given the respiratory quotient and total encrgy output of the body, calculations can be made of the relative use of glycogen and fat for each litre of oxygen consumed (see Respiratory Quotient, p. 319).

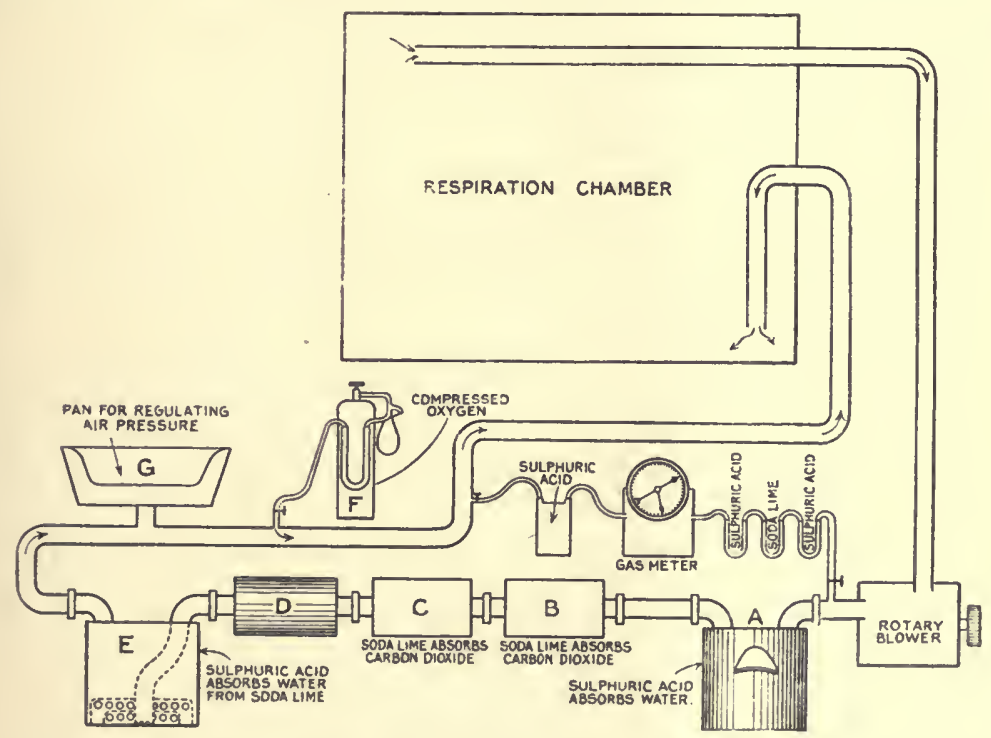

Fig. 187.-Figure of Respiration Cianber for Mlas.

The sir is drawn from the ehamber by the rotary blower and pibsed over vessels A- $E$ back to the chamber. Oxygen may be added as required from $F$.

The Direct Method.-This is done by placing the man or animal in a respiration calorimeter. In the case of an animal it is difficult to estimate the exact amount of encrgy lost as muscular work; the animal is therefore in these direct observations kept as quiet as possible. 'The forms of water calorimeter which were first used have been given up, on account of large experimental error, and replaced by some 
form of air calorimctcr. In Fig. 186 is shown a self-registering apparatus, suitable for the study of small animals. It consists of a Dewar's flask, with the thermo-electric junctions upon the inlet and exit water tubes. These junctions are connected with a galvanometer, the deflection of which can be registered.

The direct method is especially applicable to man, since the amount of work done can be measured, and the amount of heat lost and the respiratory exchange calculated, at the same time. Special doublewalled calorimeters adequately furnished with bed, chairs, ctc., and devices for performing mechanical work, have been built in some laboratories. Within the calorimeter is a coil of water-pipes, fitted with special metal discs, which quickly takes up any heat liberated in the chamber. Cool water is made to flow through this coil and the volume and temperature of the water entcring and leaving it is accurately measured, and thus the heat output is calculated. Almost the whole of the heat given off by the body is taken up by the circulating water, for any loss of heat to the outside air is checked by maintaining equality of temperature between the inner and outer walls. This is insured by means of (1) thcrmo-electric couples connected with a galvanometer which detects any inequality; (2) electric furnaces; (3) water coils placed between the outer and inner walls, by means of which any difference in temperature is compensated. Adequate ventilation is maintained by some form of pump, and the carbon dioxide output and oxygen intake obtained after the fashion already described for determining the respiratory exchange; precautions have to be taken to secure the measurement of heat giren off in the ventilation air (Fig. 187).

For the performance of mechanical work a bicycle is used; the hind-wheel is replaced by a metal dise which rerolres against a strap, the tension of which is measured by a spring balance. By means of friction the work done is thus converted into heat. The revolutions of the bicycle and the force required to turn the bicyclc can be measured, and the work calculated from these data.

How accurately such appliances can work is shown by the following: In several series of experiments extending over forty-five days, the measurement of the amount of heat produced by the animal in the calorineter equalled 99.53 per cent. of the heat calculated to have arisen from the combustion of food and body tissues.

The following is an examplc of a five-day cxperiment on a fasting dog of 4.5 kilos weight:

Calculated indirectly from the nitrogen and carbon cxcreted $=\mathbf{2 5 9 \cdot 3}$.

Calculated dircetly by the calorimeter method $=261 \cdot 0$. 


\section{CHAPTER XXXVIII}

\section{METABOLISM DURING STARVATION}

StaRvatiox may be brought about by withholding all foodstuffs from the body, or by withholding separately either proteins, water, or mineral salts. When all foodstuffs are withheld from an animal, and only water given, the body begins to live at its own expense, loss of weight ensues, and finally the animal dies. The time of death depends largely upon the state of nutrition at the start. The process of starvation is only painful in the last stages. Professional fasters appear in public from time to time, going without food for as long as forty days, with apparently but little inconvenience to themselves. From observations upon such, it appears that the ratio of metabolism to actual body weight alters but little during starvation; in other words, the loss of weight and the lessening of the metabolic processes of the body proceed together. At the beginning of the starvation period, the nitrogen elimination in the urine quickly drops to a fairly constant level. The drop is quicker the greater the amount of nitrogen in the food eaten beforehand. For example, a dog receiving 2,500 grammes of meat daily excreted on the first day of starvation $60 \cdot 1$ grammes of urea; on the fifth day, 12.3 grammes. With a moderate nitrogenous diet-1,500 grammes of meat-the excretion on these days was $\mathbf{2 6 . 5}$ and 14.8 grammes; with a diet poor in nitrogen, $13 \cdot 8$ and $12 \cdot 1$ grammes.

$\begin{array}{cccc}\begin{array}{c}\text { Day of } \\ \text { Starvation. }\end{array} & \begin{array}{c}\text { Much } N \\ \text { in Food. }\end{array} & \begin{array}{c}\text { Moderate } N \\ \text { in Food. }\end{array} & \begin{array}{c}\text { Little } \\ \text { in Food. }\end{array} \\ 1 & 69 \cdot 1 & 26 \cdot 5 & 13 \cdot 5 \\ 2 & 24 \cdot 9 & 18 \cdot 6 & 11 \cdot 5 \\ 5 & 12 \cdot 3 & 14 \cdot 8 & 12 \cdot 1 \\ 8 & 10 \cdot 1 & 12 \cdot 1 & 10 \cdot 7\end{array}$

From this day onward the nitrogen excretion remains more or less constant until just before death, when there occurs a sudden rise. The explanation is that the animal is living on a minimum amount of its own protein, and getting nearly all its energy for the first day or so from its store of earbohydrate, and subsequently from its body fat. This conclusion is reached by measuring the heat loss and by ascertaining the respiratory quotient, and calculating from this how much carbohydrate and how much fat are being metabolized. It is possible, since starving animals and man give a low respiratory quotient, that some of this fat may first be changed to carbohydrate and metabolized in this fashion. It is difficult, however, to say exactly 
what is causing the low respiratory quotient of the starving animal. It may be partly accounted for by the elimination of acetone bodies in the urine (see p. 468). When the store of fat is exhausted, the protein consumption and the urea output goes up and the end is then near.

During starvation, the urine becomes considerably lessened in amount. Salts continue to be excreted, the amount of sodium chloride being markedly decreased, but that of potassium, calcium, magnesium, and phosphates increased. This is due to tissue destruction, especially of the bony tissues. Life persists at the cxpense of what may be termed the less important tissues and organs, as can be seen from the following table:

\section{Male Cat.}

\begin{tabular}{|c|c|c|c|c|c|c|c|}
\hline Adipose $t \mathrm{j}$ & . & . & .. & .. & \multicolumn{3}{|c|}{97 per eent. loss of weight. } \\
\hline Spleen .. & . & .. & .. & .. & 67 & , & , \\
\hline Liver .. & . & .. & .. & .. & 54 & ,. & ," \\
\hline Testicles & .. & .. & .. & .. & 40 & , & , \\
\hline Muscles & . & . & .. & . & 31 & , & ", \\
\hline Kidners & .. & .. & .. & .. & 26 & , & ," \\
\hline Skin .. & . & . & .. & . & 21 & ,. & , \\
\hline Intestine & $\cdots$ & .. & . & .. & 18 & .. & ," \\
\hline Lungs $\ldots$ & . & .. & .. & .. & 18 & , & ," \\
\hline Pancreas & $\because$ & . & .. & .. & 17 & ," & ", \\
\hline Bones .. & .. & .. & . & . & 1.1 & .. & ," \\
\hline Heart .. & .. & .. & .. & .. & 8 & .. & ," \\
\hline Brain & .. & .. & .. & .. & 3 & ,, & ," \\
\hline
\end{tabular}

An outstanding feature in starvation is the manner in which the blood, although somewhat decreased in amount, is kept more or less constant in composition.

A similar principle applies to those animals which undergo periods of voluntary abstention from food. Previous to such periods they make special provision by storing up large supplies. One particularly interesting example is the salmon. While living in the sea, the foodsupplies are taken in and stored as protein and fat chicfly in the tail muscles and the fat depots of the body. During the migration up-river to the "spawning-ground," which lasts scveral months, no food is taken in, and the whole of the energy, spent in swimming and in the development of the scx organs, takes place at the expense of these food-supplies.

Animals which hibernate also lay up a storc of food previous to and live at the expense of this during the period of hibernation (see pp. 43!. 440).

Lack of Water.-The living processes of protoplasm are dependent on its water content. Water has been found to form 66 per cent. of the entirc body of a well-fed ox, 57.9 per cent. of a well-fed pig, and 63.2 per cent. of a well-fed sheep. Since it is continuously lcaving the body in the urine, breath, sweat, and other secretions, it must ke replaced. The amount of water lost under average conditions of temperature and humidity is about 1.25 per cent. of body weight during rest and hunger, 1.32 per cent. during rest and average diet, and 2.91 per cent. during hard work and average 
diet. Depriving an animal of water will kill it more quickly than depriving it of the dry proximate principles of the food.

Water is taken in as such and in combination with the food. Fresh fruit and vegetables have a large water content. This water may be contained in the system of water-tubes of a plant, when it is more or less pure water, or it may be in the form of "sap," when it is more concentrated and contains mineral salts and organic bodies in addition. Lean meat contains about 80 per cent. of water, so a carnivore almost gets enough water in its food.

The proportion of water in various vegetables can be seen in the table on p. 349 .

Lack of Mineral Salts.-The withholding of mineral salts from the diet also brings about death more quickly than the withholding of the proximate principles. The salts of the body are partly in solution and partly combined with the organic substances. Those in solution are of the greatest importance in providing the proper medium for the living tissues. When salts are withheld, those cambined with the organic substances of the body become free to replace the salts in solution, which are lost in the urinc.

The ions of sodium, potassium, and calcium, must be continually taken in with the food, to keep the proper relationship between these bases in the blood, so that the action of the ion of no one base prcdominates. We know that certain enzymic processes, such as the clotting of blood and milk, depend on the presence of calcium ions, and that muscular contraction is affected by the concentration of calcium, sodium, and potassium ions present in the blood. When calcium is withheld from the diet, the bones are gradually decomposed to replace the loss.

Different results follow the withholding of one or other groups of salts. Thus, deprivation of chlorides is followed by marked symptoms of inanition.. This is due partly to gastric disturbance, and partly to the ascendancy obtained by the potassium ion, which works deleteriously upon the bodily functions. When therc is a lack of sodium salts as compared with potassium salts, or an abundance of potassium salts relative to sodium salts, such as occurs with a vegetable diet, the potassium of the salts ingested is in part replaced by sodium from the body, and some of the sodium salt so formed is excreted in the urine. This causes a loss of $\mathrm{NaCl}$ from the body, and a supply of $\mathrm{NaCl}$ becomes imperative. For this reason many vegetarian animals wander miles to visit "salt-licks"-lumps of crude rock salt. On an animal diet sufficient salts are introduced with the food itsclf. The desire for salt by the various human races varies with the preponderance of vegetable food in their diet. The peasants in France eat four times as much salt as the town dwellers; the carnivorous tribes of men do not know or do not value salt. Rice-eaters are an exception. Rice contains six times less potassium than wheat, ten to twenty times less than peas, twenty to thirty times less than potatoes. Riceeaters, like flesh-eaters, do not require much common salt. In the Soudan the negroes burn a plant which yields an ash rich in sodium, 
and use this for salt. During salt starvation the amount of chlorine in the urine constantly decreases, so that eventually the excretion of cllorine may stop.

Lack of Alkali Carbonates.-If the alkaline bases be withheld, there ensues an acid intoxication of the body, and life thus endangered.

Lack of Phosphates.-Lack of phosphates may seriously impair the bodily functions. The bony tissues are particularly affected. It is a question as to how far lack of phosphates affects the formation within the body of phosphorized compounds such as phosphoprotein, and of phosphorized fats such as lecithin. The available evidence seems to show that these bodies can be synthesized from organic bodies poor in phosphorus and inorganic phosphates.

Lack of Iron.-Iron is of great importance to the organism, since it is contained in the blood-pigment, hæmoglobin, and also in the nuclei of cells. It is necessary, too, for the oxidative processes initiated by oxidases. Lack of iron leads to anæmia, insufficient nutrition, and eventually to death.

Although debated, it seems probable that iron may be utilized when ingested in either organic or inorganic form. Iron is introduced into the body by various foodstuffs. This can be seen from the following table, which shows the amount of iron in milligrammes in 100 grammes of dried substance:

\begin{tabular}{|c|c|c|c|c|c|c|c|c|c|}
\hline White of egg & . & $\cdots$ & . & traee & Carrots & $\cdots$ & & & $8 \cdot 6$ \\
\hline Rice .. & .. & .. & .. & $1 \cdot 2$ & Apples & .. & $\ldots$ & .. & 13 \\
\hline Wheat flour & .. & .. & . & $1 \cdot 6$ & Cábbage & . & .. & 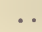 & 17 \\
\hline Milk .. & .. & .. & .. & $2 \cdot 3$ & Beef & .. & $\ldots$ & .. & 17 \\
\hline Peas .. & . & $\cdots$ & .. & $6 \cdot 2$ & Yolk of egs & & .. & .. & $10-24$ \\
\hline Potatoes & .. & .. & . . & $6 \cdot 4$ & Spinaeh & & .. & $\ldots$ & $33-39$ \\
\hline
\end{tabular}

Lack of Carbohydrates and Fats.-The result of withdrawing fats and carbohydrates from the diet depends on the class of animal. Carnirora can live for a long time on a diet consisting, as nearly as possible, of protein only, viz., lean meat freed from as much fat as possible. Omnivora or herbivora do not appear to be able to live on such a dict. The replaccment of fat by excess of carbohydrate leads to the retention of water in the body. Fat starvation causes a form of dropsy. The food eaten per dicm should contain at least 60 grms. of fat.

Lack of Lipoids. - There is some evidence that these may be synthesized in the body out of protein and carbohydrate. They are essential, and it is advisable that they should be in the diet.

Lack of Vitamines.-The fresh foods contain certain active principles necessary for nutrition and growth, which may be remored by the modern processes of milling or canning food. If these are insufficient nutrition is gravely affected.

The first knowledge of the effect of a deficit of these bodies was afforded by the study of the disease known as beri-beri. It is now conclusively shown that this disease is due to feeding (as the almost sole article of dict) on " polished" rice-that is to say, rice from which 
the outer husks have been removed. Under these eonditions pains and weakness of the muscles in the limbs develop, with a lowering or complete loss of sensibility; often œdema also supervenes, and in some eases death rapidly ensues. If instead of polished riee the whole riee be eaten, sueh symptoms do not develop. The addition of the "polishings" to polished rice also prevents the onset of symptoms. The proportion of eases of beri-beri in the Java prisons was redueed from 1 in 39 to 1 in 10,000 when unshelled riee was substituted

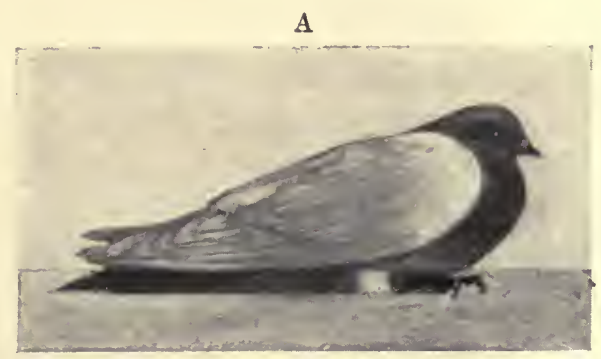

$\mathrm{C}$
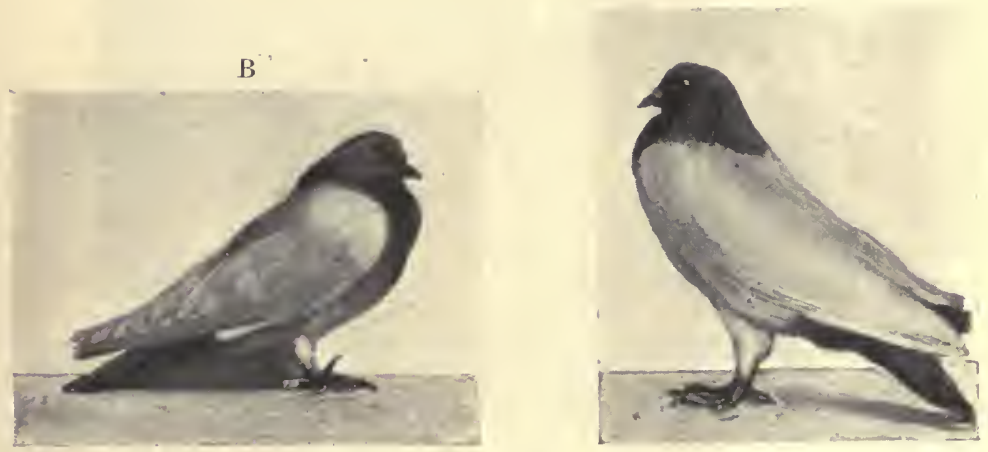

Fig. 183.-To show Effect of Vitamise on Nutrition. (Sehaumann.)

$A$, Pigeon fed on food eontaining no vitamine, unable to stand up; $B$, after adding vitamine to food the first day; $C$, the second day.

for shelled riee. In some distriets of the East the disease has completely disappeared sinee this substitution has been made. The necessary substance is contained in the subpericarpal tissue of the riee; its nature has not yet been doternined. The phosphorized organie bodies which are abundant in the husk may be of considerable importance to the organism.

Symptoms similar to beri-beri may be indueed in animals by feeding them on polished riee; these symptoms are almost immediately relieved when an acid extract of the "polishings" is added, after neutralization, to the riee. 
Animals-e.g., pigeons-fed upon polished rice gradually lose weight, develop nervous symptoms akin to beri-beri, and die. Post mortem extcnsive changes are found in the cells of the central nervous system, and inflammatory changes in the nerve trunks.

A similar substance is included in the husks and germ of the wheat berry. White flour made from the wheat berry from which the bran (the outer husk), the sharps (the under husk), and the germ have been removed, will not support life by itself. Neither will bread made from it; while wholemeal bread will.

The possession of this substance accounts for the superiority of "standard" and particularly of wholemeal bread over "white" bread. By the children of the very poor, who live mainly on bread and nargarinc, it is imperative that wholemeal bread should be caten.

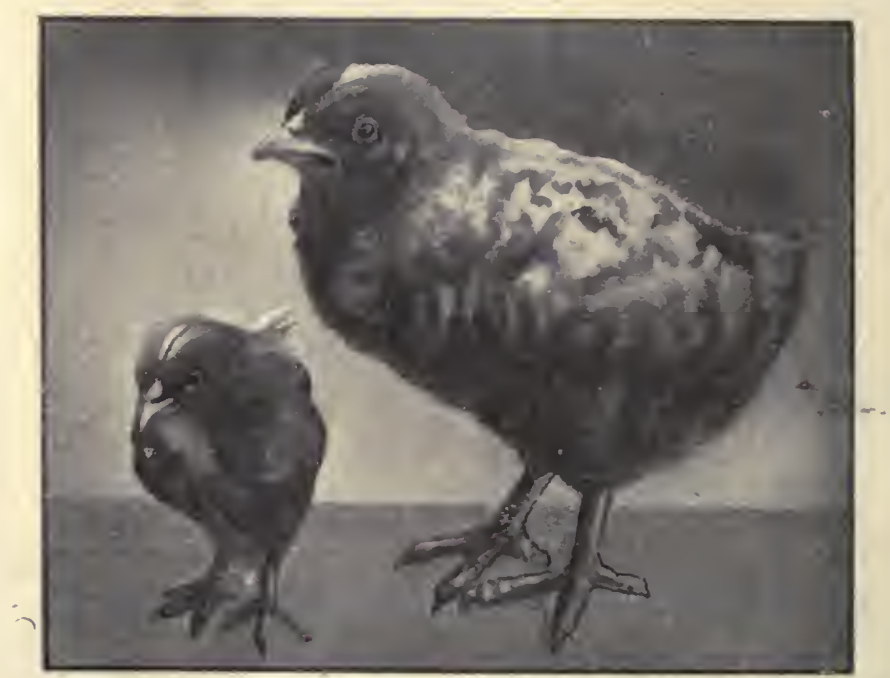

Fig. 189.-To show Effect of Vitamines on Growti. (After C. Funk.)

These chicks are of the same age, the smaller fed on a diet deficient in vitamines.

The anti beri-beri vitamines have becn found to occur in yeast, in various vegetables, and in milk; they are not destroyed by heating to $100^{\circ} \mathrm{C}$., but are destroyed at $120^{\circ} \mathrm{C}$.

There are also anti-scorbutic vitamines, the lack of which cause scurvy. These arc destroyed easily by cooking or preserving, hence the advantage of raw fruit or salads in the diet. Potatoes, fresh vegctables, oranges, and fruit not too ripe are rich in these vitamines. The introduction of the potato has expelled scurvy from the towns. In addition to the above there is a fat-soluble vitamine essential to growth present in lutter and animal fat margarine, but not in vegetablc oil margarine or lard, present also in $g_{i}$ een regetables which form the complete food of an herbirorous animal. 
Metabolism with Excess of Protein.-When an animal excretes in the urine daily the same amount of nitrogen as it is receiving in the diet, it is said to be in a state of nitrogenous equilibrium. If the amount of the nitrogen taken in be suddenly increased (for example, an animal is put on to a lean meat diet), the nitrogen output goes up; but at first the amount of nitrogen excreted lags behind that ingested,

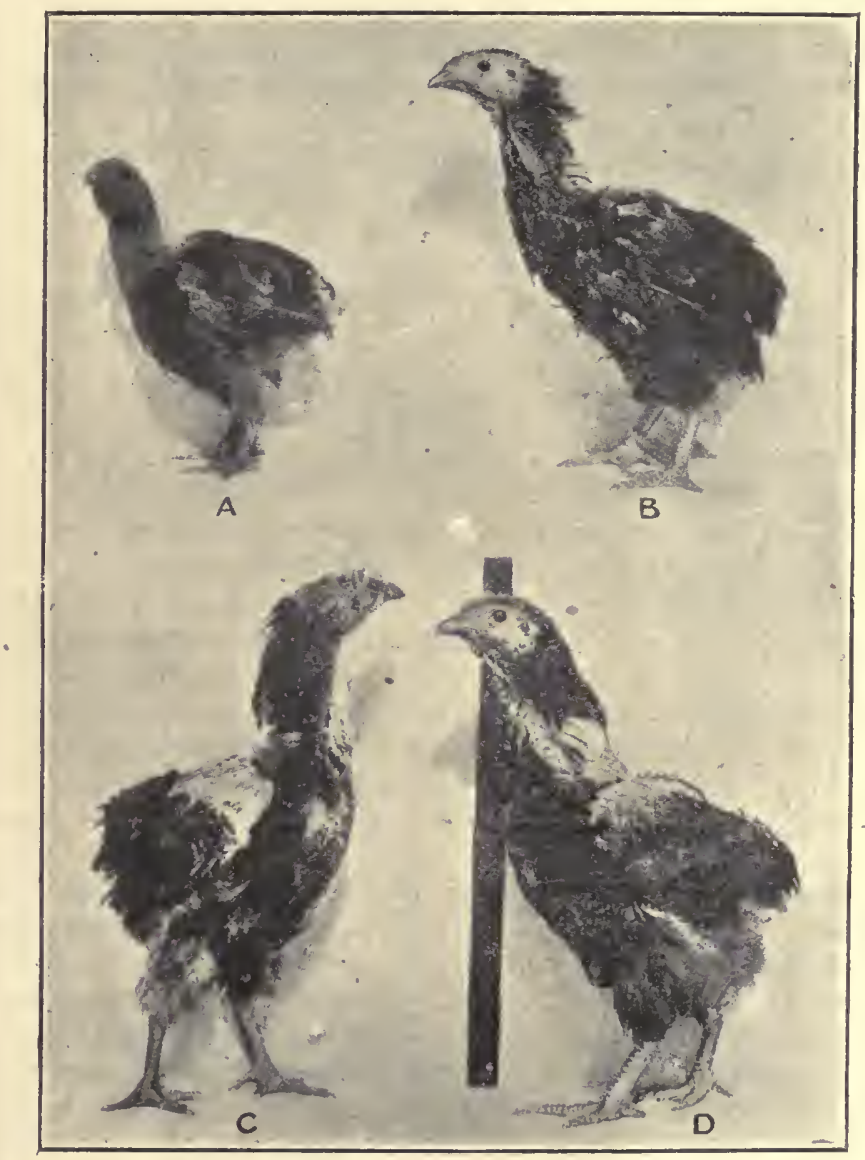

FIG. 189 A.

Chiek $A$, weight $162 \mathrm{gms}$; Chick $B, 342 \mathrm{gms}$., are birds of same age (81 days). $A$ received corn gluten food, $B$ received lactalbumin in addition. Chicks $C$ and $D$ also (81 days old) reeeived corn gluten and cottonsced flour. A gained 52 gmis. in 55 days; $B, 283 \mathrm{gms}$, in 55 days; $C, 284 \mathrm{gms}$. in 53 days; $D, 322$ gms. in 53 days. (Osborne and Mendel.)

so that nitrogen equilibrium is not attained for several daysgenerally three to five, the time varying according to the nature of the protein fed. During these days the animal is storing up nitrogen 
in the body, and this store is not again lost until the amount of protein in the diet is reduced.

When there is a large amount of protein in a mixed diet, the fat katabolism in the body is reduced, so that some of the fats, or carbohydrates, in the diet are not used, and may be stored up as fat. The proteins are not all of equal value, for some do not contain essential " building stones." Thus, gelatin does not suffice as a tissueformer, but can act as a source of energy. When fed with an adequate protein diet, galatin acts as a protein-sparer. Fed during starvation, galatin spares protein to the extent of about 35 per cent. Generally speaking, about one-fifth of the true protein nitrogen can be replaced by gelatin nitrogen. Gelatin also exerts a sparing action on fat katabolism. Gelatin, therefore, although insufficient for bodybuilding, from the point of view of energy is quite a useful article of diet. Gelatin can be made a much more sufficient tissue-builder by feeding with it those important amino-acids, tyrosin and tryptophane. which are lacking in its constitution. The same holds good for zein, a protein obtained from maize. The amino-acid content of a dict is important in regard to growth (see Fig. 189, A).

The Effect of Fat.-Fat, when added to the diet, exerts a sparing effect upon the katabolism of protein. Thus, when a dog was fed with 1,500 grammes of protein, its nitrogen excretion was equivalent to the katabolism of 1,512 grammes. On the addition of 150 grammes of fat, the nitrogen excretion equalled 1,474 grammes of protein. Carbohydrates exert a like or even greater sparing effect on proteins. The addition of fats or carbohydrates to a diet of protein, insufficient by itself, will enable an animal to attain nitrogenous equilibrium and even to store protein in the body. But the protein-supply cannot be taken below a certain minimum, a minimum which seems to vary with different foodstuffs. Thus $30 \mathrm{grms}$. of protein suffice on a diet of potatoes, and 80 grms. on a diet of bread. On a diet Jargely consisting of potatoes the body can be run on a very low plane both of energy and protein value. For times of scarcity, then, the potato is invaluable. The most virile races of the world occupy cool climates and eat foodstuffs yielding high energy, protein, and fat values-e.g., meat and cereals. Few people requiring a diet of 3,500 colories can digest witl comfort more than 500 grms. of carbohydrates, while the use of more than $120 \mathrm{grms}$. of piotein is wasteful. About 1,000 calories have then to be made up from fat, and this means eating a little over $100 \mathrm{grms}$. Fat is easily digested, and does not cause the rise in heat production which protein, and to a lesser degree sugar, does. 


\section{CHAPTER XXXIX}

\section{METABOLISM UNDER VARYING CONDITIONS}

THe body requires a certain amount of energy for the performance of its functions during rest. This is known as the basal requirement, and is best ascertained by determining the respiratory exchange of a person in a state of complete rest twelve hours after the last meal, which should not have been rich in earbohydrate. Such a state is best obtained in bed, before rising, in the early morning, when the surrounding medium is uniform in temperature, the muscles are well rested, and other systems of the body, such as the alimentary system, are more or less inactive.
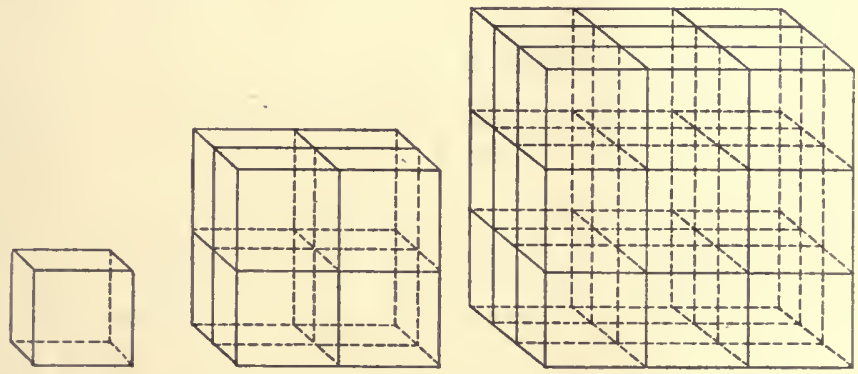

Fig. 190. - Diagram to illustrate the Relation between Volume or Weight AND SuRface. (Waller.)

The volumes are $1,8,27 \mathrm{c.cm}$; the weights are 1, 8, 27 grammes; the surfaces are $6,24,54$ square $\mathrm{cm}$; the ratio of increase is $1,4,9$.

Of this basal requirement it is calculated that 10 to 20 per cent. of the total energy is required for the maintenance of the work of circulation and respiration.

The Weight of the Body and the Surface Area.-The larger the mass of an animal, the greater its absolute encrgy requirements, and the greater its absolute consumption of material. While this is true for the absolute, it is not true for the relative amounts. The smaller the animal, the relatively greater is its energy output. This is because, calculated per kilo body weight, small warm-blooded animals have a proportionately greater surface area. They have therefore need of a greater heat production, involving an increased metabolism. 
This is seen in the following table from experiments on animals during a period of twenty-four hours' hunger:

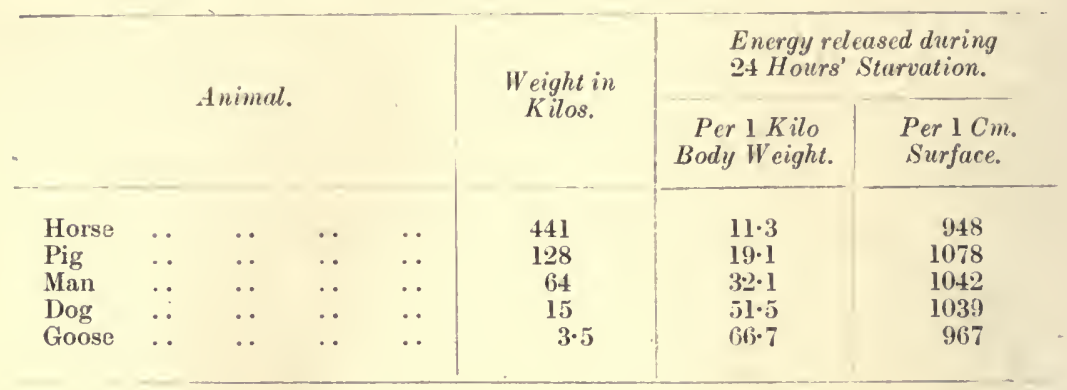

This rule holds for larger and smaller animals of the same speeics, as may be seen from the following figure.

The aceompanying table shows the oxygen use per minuta in man in the first few years of life, and again at the age of puberty.

\begin{tabular}{|c|c|c|c|c|c|}
\hline \multirow{2}{*}{$\begin{array}{c}\text { Age, } \\
\text { Yeurs. }\end{array}$} & \multirow{2}{*}{$\begin{array}{l}\text { Weight } \\
\text { in Kilos. }\end{array}$} & \multirow{2}{*}{$\begin{array}{l}\mathrm{O}_{2} \text { consumed } \\
\text { per.Min., } \\
\text { C.C. }\end{array}$} & \multirow{2}{*}{$\begin{array}{c}0, \text { Use per } \\
\text { Kilo of } \\
\text { Body Weight. }\end{array}$} & \multicolumn{2}{|c|}{$\begin{array}{l}\text { Relative Consumption } \\
\text { of Oxygen to Adult } \\
\text { (Standard }=100) .\end{array}$} \\
\hline & & & & $\begin{array}{c}\text { Per Kilo of } \\
\text { Body Weight. }\end{array}$ & $\begin{array}{l}\text { Per Sq. } M . \\
\text { of Surface. }\end{array}$ \\
\hline $2 \frac{1}{2}$ & $11 \cdot 5$ & $112 \cdot 2$ & $9 \cdot 76$ & 285 & 160 \\
\hline $6^{2}$ & $18 \cdot 4$ & $139 \cdot 9$ & $7 \cdot 61$ & 223 & 145 \\
\hline 9 & $21 \cdot 8$ & $148 \cdot 0$ & 6.79 & 199 & 137 \\
\hline 14 & $36 \cdot 1$ & $188 \cdot 1$ & $5 \cdot 21$ & 152 & 125 \\
\hline 17 & $44 \cdot 3$ & $212 \cdot 7$ & $4 \cdot 80$ & 140 & 123 \\
\hline $\begin{array}{l}\text { Adults } \\
(22-43)\end{array}$ & $66 \cdot 7$ & $227 \cdot 9$ & $3 \cdot 41$ & 100 & 100 \\
\hline
\end{tabular}

The basal metabolism of man, measured under conditions of fasting and rest in bed, is 40 ealories per hour per sq. metre of skin surfaee, 37 for woman, 50 for boys of $12-13$ years. The formula used for measuring the surface is $\mathrm{A}=\mathrm{W}^{0} 0^{\circ} 25 \times \mathrm{H}^{0} 0^{\circ} 25 \times 71.84 . \quad \mathrm{A}=$ sq. metres; $\mathrm{W}=$ weight in kilogrammes; $\mathrm{H}=$ height in eentimetres.

In young animals the increased metabolism may be due in part to the actual processes of metabolism being more active in the growing than in the adult animal. During the early months of their life infants appear to be an exeeption to the rule; their metabolisin is much lower than it should be as ealculated from the body surface. The infant is kept warm, and sleeps quietly most of its time in eradle or pram. This very likely is not the ease with the infant of the native Australim or Terra del Fuegian. Infants are generally over-coddled, and are made more virile by some exposure to eold and exercise. In old age the metabolism is redueed.

It is doubtful whether sex influences the metabolism in any degree. 
Work.-During work the metabolism is inereased. This is due to the inereased aetivity of the museles. Investigation shows that this is mainly at the expense of the fats and carbohydrate, and but little at the expense of the proteins, unless there be a defieit of the two first. The respiratory exehange is greatly increased by museular work (sce p. 319).

A subjeet pedalled a $b^{\circ}$ cyele sixteen hours out of twenty-four. The whole energy expended $=9,981$ calories. The energy of the food taken $=5,138$ calories. The energy taken out of the body substanee $=4,843$ calories. The energy derived from tissue protein only $=478$ ealories. As the man was an athlete in training, his museles were not overdone, and thus the protein metabolism was seareely inereased. The experiment shows how body fat may be taken off by hard exercise.

When no museular work is done, as during the first hours of sound sleep, the metabolism of the body markedly deereases; during the waking hours it again increases. But if thə individual keeps at rest and proteeted from eold, there is no inereased metabolism during these hours.

External Temperature.-A lowering of the external temperature excites to more museular movement, voluntary and involuntary, and thereby increases metabolism. Shivering helps to keep up the temperature. Exposure to eold wind may double the respiratory exchange, even if the individual sits quiet in a ehair and does not shiver.

There is a relation between the cooling power of the atmosphere. the skin temperature, and the rate of metabolism. Thus the appetite is increased at a braeing place.

The raising of the body temperature increases the metabolism.

Feeding.-The taking in of food raises the metabolism, partly owing to the meehanical work involved in digestive processes, partly owing. to the ehemieal proeesses. With some foods this may be very greatas mueh as 50 per cent. of the encrgy value of the food taken in. For instance, with a horse ehewing hay, 48 per eent. of the energy value is used up in the work of mastieation and digestion, whereas but 19.7 per eent. is so used in the case of oats. It has been ealeulated, for the ealorie value of the food taken there is expended in heat production during digestion and assimilation-

\begin{tabular}{|c|c|c|c|c|c|c|}
\hline Fats & $\ldots$ & & & & .. & about $2 \frac{1}{2}$ per cent. \\
\hline Starches & .. & .. & .. & .. & .. &, 9 \\
\hline Proteins & .. & .. & .. & .. & .. &, 17 \\
\hline
\end{tabular}

Proteins, having so high " a specific dynamie energy," are heating, thus more protein is consumed by man in cold, and less in tropical climates. In the adaptation of an Englishman to a tropieal elimate dict is of great importánee. On a diet of rice and bananas monkeys successfully withstand exposure for hours to the tropieal sun. 


\section{CHAPTER NL}

\section{DIETETICS}

BRIEFLY stated, we take in food-

1. To rebuild the living tissues.

2. To obtain energy for the biological processes.

3. To preserve the proper medium in which these processes can be carried out.

The Selection of Foodstuffs.-Hitherto we have spoken of proteins, fats, and carbohydrates, somewhat as if they were usually fornd separately, as such, in the food materials in common use. This is not. the case in regard to the majority of the commoner natural food materials. These are mixtures of all three classes of nutrients, as can be seen from the following tables. Nevertheless, the food materials. can be grouped, according to their constitution, into those which are mostly protein, mostly fat, mostly carbohydrate, or mostly water. Some prepared foodstuffs, such as sugars and starches, or butter and oils, are almost exclusively one class.

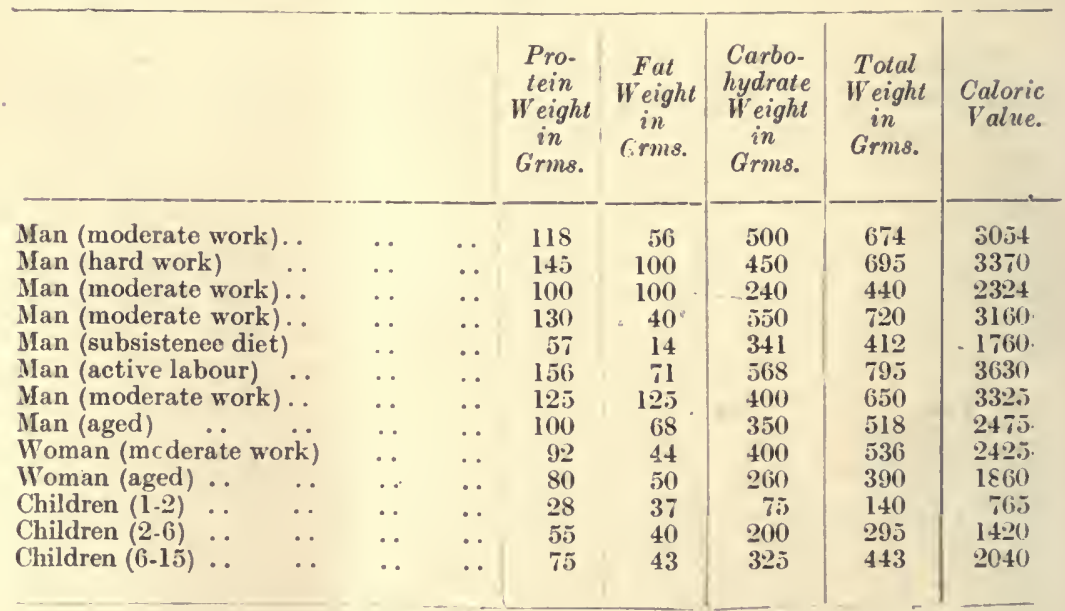

In regard to practical dietetics, several important points have ton be considered:

1. The amount and proportion of the rarious foods which are necessary to meet the physiological needs of the body at different ages in the different sexes, and under various conditions of activity and environment. 
2. The proper selection of food materials to supply such an adequate diet, including the economic purchase of the same.

3. The various methods of preparing food for consumption.

4. Food hygiene.

Much study has been expended upon the question of the adequate dietary. There is a general consensus of expert opinion that all three classes of foodstuffs should enter into the dietary of man, the amount and proportion of these being regulated according to conditions of age, sex, activity, and environment. In the table on p. 343 are shown a few of the diets suggested by various authorities, the weights being given in the dry condition of the foodstuffs:

The chief point of interest in the above is the amount of protein required in the adequate diet. It is generally conceded that the a mount of protein required is from 100 to 120 grammes. The following. diets have been suggested for temperate climates as the result of recent. work. The values are given for food as purchased.

\begin{tabular}{|c|c|c|c|c|c|c|}
\hline & & & Protein. & Fat. & $\begin{array}{l}\text { Carbo- } \\
\text { nydrate. }\end{array}$ & Calories. \\
\hline Sedentary & . & 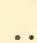 & 88 & 108 & 345 & 2501 \\
\hline M Ioderate hard work & & & $\int 125$ & 137 & 476 & 3364 \\
\hline & ・. & . & $\{116$ & 158 & 538 & 3762 \\
\hline Very hard work & • & 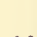 & $\int 145$ & 195 & 557 & 4223 \\
\hline 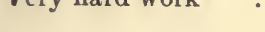 & $\cdots$ & . & 145 & 235 & 666 & 4954 \\
\hline
\end{tabular}

The work done by an ordinary labourer is estimated to be 100,000 $\mathrm{kg}$. metres, 2000 calories can be taken as the maintenance requirement of the resting man. The micchanical equivalent of heat $-4.23 \mathrm{~kg} . \mathrm{m} .=$ 1 calorie. The efficiency of a man as machine is taken as 20 per cent. The fuel value of the food spent on work is then about 1200 calories.

The peace dietary provided to the British Army is supplemented by food bought for supper, and the pay is now sufficient to enable this to be done without hardship. Experience seems to show that the plan of letting the men buy their own supper works smoothly, and is preferred; it gives elasticity to the diet, and allows each man to select the quality and amount of food which suits him. The recruit. - a growing lad-requires more food, and the Army Council have wisely granted him a messing allowance. H.s ususlly buys considerable quantities of cakes. The war rations of the British Army in South Africa may be contrasted with that of Japan and Russia in Manchuria:

\begin{tabular}{|c|c|c|c|c|c|c|c|c|}
\hline & & . & & & Protein. & Fat. & $\begin{array}{l}\text { Carbo- } \\
\text { hydrate. }\end{array}$ & Calories. \\
\hline $\begin{array}{l}\text { British } \\
\text { Japanese } \\
\text { Russian }\end{array}$ & $\begin{array}{l}\cdots \\
\cdots\end{array}$ & $\begin{array}{l}\cdots \\
\cdots\end{array}$ & $\begin{array}{l}\cdots \\
\cdots\end{array}$ & $\begin{array}{l}\cdots \\
\ldots \\
\ldots\end{array}$ & $\begin{array}{l}138 \\
158 \\
187\end{array}$ & $\begin{array}{r}105 \\
27 \\
27\end{array}$ & $\begin{array}{l}528 \\
840 \\
775\end{array}$ & $\begin{array}{l}3903 \\
4313 \\
4891\end{array}$ \\
\hline
\end{tabular}


A little one, 4,000 calories, is now the amount of the field scrvice ration of the British Army.

A study of the different dietaries of the world, selected by the people themselves, shows that the agc and occupation markedly influence the actual consumption of food, but that economic and other conditions largely influence the diet chosen by men doing the same type of work in different countries. In the following table (Langworthy) the physiological availability of food ingested is taken into account :

\begin{tabular}{|c|c|c|c|c|c|c|}
\hline & & & $\begin{array}{l}\text { Protein } \\
\text { erten. }\end{array}$ & $\begin{array}{l}\text { Calories of } \\
\text { Total Diet. }\end{array}$ & $\begin{array}{l}\text { Protein } \\
\text { digested. }\end{array}$ & $\begin{array}{l}\text { Energy } \\
\text { utilized. }\end{array}$ \\
\hline \multicolumn{3}{|c|}{$\begin{array}{l}\text { United States (labourer, moderate mus- } \\
\text { cular work) } \\
\text { United States (labourer, hard muscular }\end{array}$} & 100 & 3,655 & 92 & 3,425 \\
\hline work) . . . & . . . . & ... & 177 & 6,485 & 162 & 6,000 \\
\hline Ireland (working man) & $\ldots$ & .. & 98 & - & 90 & 3,107 \\
\hline England (working man) & & .. & 89 & - & 82 & 2,685 \\
\hline Scotland (working man) & . & .. & 108 & - & 93 & 3,228 \\
\hline Sweden (working man) & & .. & 134 & - & $1 \cdot 23$ & 3,281 \\
\hline Sweden (working man, ha & ard work) & .. & 189 & - & 174 & 4,557 \\
\hline Finland (working man) & & .. & 114 & - & 105 & 3,011 \\
\hline Finland (working man, $h$ & lard work) & .. & 167 & - & 150 & 4,378 \\
\hline Northern Italy (labourer: & .. & .. & 125 & - & 115 & 3,655 \\
\hline Southern Italy (labourers & s) & .. & 148 & - & 136 & 4,400 \\
\hline Japan (labourers) .. & . & .. & 118 & - & 103 & 4,415 \\
\hline China (labourers) ... & $\ldots$ & $\therefore$ & 91 & - & 83 & $3,400^{\prime}$ \\
\hline Congo (labourers) . . & .. & .. & 108 & - & 90 & 2,812 \\
\hline United States (students) & .. & .. & 106 & 3,560 & 98 & 3,285 \\
\hline Scotland (students) & $\ldots$ & .. & 143 & - & 132 & 3,979 \\
\hline Sweden (students) & .. & $\ldots$ & 127 & - & 117 & 3,032 \\
\hline Finland (students) & .. & . & 157 & - & 144 & 3,984 \\
\hline Japan (students) . . & .. & .. & 98 & - & 88 & 2,800 \\
\hline
\end{tabular}

These confirm the results of research as to the amount of protein required in a diet. It is apparent that, allowing for individual tastes and characteristics, 100 to 120 grammes of protein should be contained in the diet of an average individual. Allowance also must be made for the fact that all proteins are not of equal nutritive value. Reference has already been made to the great value of protein bodies, like caseinogen, containing aromatic groupings such as tyrosin and tryptophan, and to the inefficiency to support life of bodies like gelatin, zein, hordein, which contain none or little of such groupings.

Recently it has becn suggested that a diet containing a minimum of protein (about 40 to 50 grammcs) daily is better. It is certain that an cxcessive ingestion of protein is harmful, especially when taken with lack of exercise, but the evidence adduced in favour of such a small amount when the individual is healthy and encrgetic is by no means convincing. It does not follow that a minimum diet is an optimum diet, and since we must assume that the present races are the survivors of the fittest, there is no reason to believe that the ingestion of 100 to 120 grammes of protein daily, as is common to all virile races of the 
world, is in any way harmful, provided the other ordinary rules of health are attended to at the same time.

It has also been shown by investigations carried out in Indian prisons that the more virile races of India oxt animal food in which protein figures largely; the less virile races, on the other hand, exist mainly on a vegetarian and small protein diet. By transferring members of the less virile tribes to a diet containing a larger amount of protein, a great improvement in physique was observed. It is noticeable, also, that the children of parents who have visited Europe are often of better physique than their parents. This is probably because, during the visit to Europe, their parents acquires the habit of taking more protein in the diet, and, consequently, the growing children have received more protein, especially animal protein, than did their parents when young. It is quite possible that the small physique of some races is due in part to a lack of protein in the diet of their ancestors. The fat in animal food may be of no less importance. The mighty Norsemen were great flesh-eaters.

In regard to the selection of foodstuffs, the tables on pp. 347-350 give the analyses of the most important groups of foodstuffs, with their approximate cost.* Certain valuable facts can be gleaned from them for the recommendation of dietaries, especially to the less well-to-do classes. Thus, it will be seen that the chief protein-containing foods are lean meat, fish, eggs, cheese, milk, legumes (peas and beans), certain nuts (almond, brazil, walnut), and the cereals. The chief fat-containing foods are butter, margarine, fat pork, various vegetable oils (olive), and nuts (almond, brazil, cocoanut, and walnut). The chief carbohydrate-containing foods are the cereal grains (wheat, barley, rye, oats, etc.), with certain fruits (banana, grape, cherry, etc.), and the chestnut. As watery foods may be classed milk, fresh vegetables and fruits, fresh meat, fish, and shellfish. As relatively dry foods may be grouped flours and meals, bread, biscuits, dried fruits, nuts, cured meats and fish, cheese, butter, sugar. It is obvious that the food value of a substance is to be gauged largely by the amount and nature of the dry matter it contains.

Certain foodstuffs, chiefly natural, can in themselves supply all the necessary proximate principles of food: grains, meat, eggs, milk, cheese, nuts. Other foodstuffs, chiefly manufactured, supply but one kind of nutrient - e.g., starches (sago, tapioca), sugar, butter, lard. Vegetable foodstuffs (flours, meals, oats, sugar) are relatively cheap, animal foodstuffs (beef, mutton, etc.) relatively dear. In supplying extra calories it is to be noted also that carbohydrates are relatively cheap, fats relatively dear. The tables show, for cxample, that one shilling may purchase as flour, 11,646 calories; as meat, 2,490 calories; as fish (large amount of waste), 495 calorics.

In regard to cost, it is a great waste of money on the part of the public to buy many articles already packed for them. What they

* These prices are the average priees whieh were in operation in 1913-14, and were obtained by visiting markets and shopping quarters, especially those where the poorer elasses shop. Th's prizes of food hive duubled during the war (see also graph. p. 361). 
gain in some eases in cleanness they lose in all eases in the cost of the packing.

Man's vagaries in appetite are no guide to the nutritive value of food.' Expensive foodstuft's are not necessarily more nutritiouse.g., rib of beef and brisket, butter and margarine, salmon and herring.

Table showng Conposition, Food Value, axd Cost of Proteix Foods.

\begin{tabular}{|c|c|c|c|c|c|c|c|c|c|}
\hline & 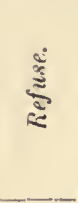 & है & 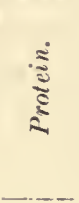 & 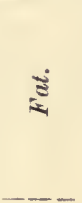 & हूँ & के & 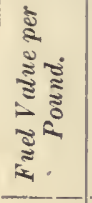 & 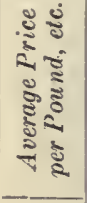 & 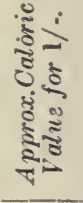 \\
\hline Fresh Beef: & & & & & & & & & \\
\hline $\begin{array}{c}\text { Brisket, edible ... } \\
\text { as bought }\end{array}$ & $\overline{23 \cdot 3}$ & $\begin{array}{l}54 \cdot 6 \\
41 \cdot 6\end{array}$ & $\begin{array}{l}15 \cdot 8 \\
12 \cdot 0\end{array}$ & $\begin{array}{l}28 \cdot 5 \\
22 \cdot 3\end{array}$ & - & $\begin{array}{l}0 \cdot 9 \\
0 \cdot 6\end{array}$ & $\begin{array}{l}1,495 \\
1,165\end{array}$ & $\overline{6 \mathrm{~d}}$ & $\overline{330}$ \\
\hline Flank, edible .. & - & $59 \cdot 3$ & $19 \cdot 6$ & $21 \cdot 1$ & - & 0.9 & 1,255 & - & 2,330 \\
\hline as bought & $5 \cdot 5$ & $56 \cdot 1$ & $18 \cdot 6$ & $19 \cdot 9$ & - & $0 \cdot 8$ & 1,185 & $5 \frac{1}{2} \mathrm{~d}$. & 2,400 \\
\hline Ribs, edible & - & $57 \cdot 0$ & $17 \cdot 8$ & $24 \cdot 6$ & - & $0 \cdot 9$ & 1,370 & - & - \\
\hline as bought & $2(1 \cdot 1$ & $45 \cdot 3$ & $14 \cdot 4$ & $20 \cdot 0$ & - & 0.7 & 1,110 & $1 /$. & 1,110 \\
\hline $\begin{array}{l}\text { Veal (average) .. } \\
\text { Mutton: }\end{array}$ & - & $70 \cdot 0$ & $20 \cdot 2$ & $9 \cdot 0$ & - & $1 \cdot 2$ & 755 & - & - \\
\hline Neck, edible .. & - & $56 \cdot 6$ & $16 \cdot 7$ & $26 \cdot 3$ & - & $1 \cdot 0$ & 1,420 & - & - \\
\hline as bought $\ldots$ & $26 \cdot 4$ & $41 \cdot 5$ & $12 \cdot 2$ & $19 \cdot 6$ & - & $0 \cdot 7$ & 1,055 & $6 d$. & 2,110 \\
\hline Leg, edible & $=$ & $63 \cdot 2$ & $18 \cdot 7$ & $17 \cdot 5$ & - & $1 \cdot 0$ & 1,085 & $\overline{1+1}$ & - \\
\hline $\begin{array}{l}\text { as bought } \\
\text { Pork: }\end{array}$ & $17 \cdot 7$ & $51 \cdot 9$ & $15 \cdot 4$ & $14 \cdot 5$ & - & $0 \cdot 8$ & 900 & $11 \mathrm{~d}$. & 982 \\
\hline Flank, edible & - & $59 \cdot 0$ & $18 \cdot \overline{5}$ & $2 \cdot 2 \cdot 2$ & - & $1 \cdot 0$ & 1,280 & - & 一 \\
\hline as bought & $18 \cdot 0$ & $48 \cdot \overline{5}$ & $15 \cdot 1$ & $18 \cdot 6$ & - & $0 \cdot 7$ & 1,065 & $9 \mathrm{~d}$ & 1,420 \\
\hline Loin, edible & - & $48 \cdot 2$ & $15 \cdot 7$ & $36 \cdot 3$ & - & $0 \cdot 7$ & 1,825 & $\overline{11}$ & - \\
\hline Middle, as bought & $19 \cdot 7$ & $38 \cdot 6$ & $12 \cdot 7$ & $28 \cdot 9$ & - & $0 \cdot 7$ & 1,455 & $1 /$. & 1,455 \\
\hline $\begin{array}{l}\text { Fowls: } \\
\text { edible }\end{array}$ & - & $63 \cdot 7$ & $19 \cdot 3$ & $16 \cdot 3$ & - & $1 \cdot 0$ & 1,045 & - & - \\
\hline as purchased & $25 \cdot 4$ & $47 \cdot 1$ & $13 \cdot 7$ & $12 \cdot 3$ & - & $0 \cdot 7$ & 775 & $\begin{array}{c}3 / 6 \\
\text { each. }\end{array}$ & - \\
\hline Fish : & & & & & & & & & \\
\hline Cod (whole Jedible & - & $82 \cdot 6$ & 16.5 & $0 \cdot 4$ & - & $1 \cdot 2$ & 325 & - & - \\
\hline $\begin{array}{c}\text { as purchased } \\
\text { Salmon (wholc), }\end{array}$ & $5 \cdot 2 \cdot 5$ & $38 \cdot 7$ & $8 \cdot 4$ & $0 \cdot 2$ & - & $0 \cdot 6$ & 165 & $4 \mathrm{~d}$. & 495 \\
\hline edible & - & $64 \cdot 6$ & $2 \cdot 2 \cdot 0$ & $12 \cdot 8$ & - & $1 \cdot 4$ & 950 & - & 一 \\
\hline rchased. & $34 \cdot 9$ & $40 \cdot 9$ & $15 \cdot 3$ & $8 \cdot 9$ & - & $0 \cdot 9$ & 660 & $2 !-$ & 330 \\
\hline Turbot ediblc & - & $71 \cdot 4$ & $14 \cdot 8$ & $14 \cdot 4$ & - & $1 \cdot 3$ & 885 & - & - \\
\hline as purchased & $47 \cdot 7$ & $57 \cdot 3$ & $6 \cdot S$ & $7 \cdot 5$ & - & $0 \cdot 7$ & 460 & $1 / 3$ & - \\
\hline $\begin{array}{rr}\begin{array}{r}\text { Herring, } \\
\text { edible }\end{array} & \text { fresh, }\end{array}$ & - & $72 \cdot \overline{5}$ & $19 \cdot 5$ & $7 \cdot 1$ & - & $1 \cdot 5$ & 660 & - & - \\
\hline as purchased & $42 \cdot 6$ & $41 \cdot 7$ & $11 \cdot 2$ & $3 \cdot 9$ & - & $0 \cdot 9$ & 375 & ld.ea. & - \\
\hline $\begin{array}{c}\text { Herring, smoked, } \\
\text { edible }\end{array}$ & - & $34 \cdot 6$ & $36 \cdot 9$ & $15 \cdot 8$ & - & $13 \cdot 2$ & 1,355 & - & - \\
\hline urchased.. & $44 \cdot 4$ & $19 \cdot 2$ & $20 \cdot 5$ & $8 \cdot 8$ & - & $7 \cdot 4$ & 750 & 1d.ea. & - \\
\hline Shellfish: & & & & & & & & & \\
\hline $\begin{array}{l}\text { Oysters, edible } \\
\text { in shell, as pur }\end{array}$ & - & $86 \cdot 9$ & $6 \cdot 2$ & $1 \cdot 2$ & $3 \cdot 7$ & $2 \cdot 1$ & 235 & - & 一 \\
\hline chased & $81 \cdot 4$ & $16 \cdot 1$ & $1 \cdot 2$ & 0.2 & 0.7 & $0 \cdot 1$ & 45 & - & - \\
\hline Lobster, edible.. & & $79 \cdot 2$ & $16 \cdot 4$ & $1 \cdot 8$ & $0 \cdot 4$ & $2 \cdot 2$ & 390 & - & - \\
\hline as purchased.. & $61 \cdot 7$ & $30 \cdot 7$ & $5 \cdot 9$ & $0 \cdot 7$ & $0 \cdot 2$ & $0 \cdot 8$ & 140 & 一 & 一 \\
\hline $\begin{array}{l}\text { Eggs: } \\
\text { edible (cookcd). }\end{array}$ & - & $73 \cdot 2$ & 14 & $12 \cdot 0$ & - & $0 \cdot 8$ & 765 & - & - \\
\hline in shell, as bought & $11 \cdot 2$ & $65 \cdot 0$ & $12 \cdot 4$ & $10 \cdot 7$ & - & 0.7 & 680 & $1 /-$ & 850 \\
\hline
\end{tabular}


Table Showisg Composition, Food Value, axd Cost of Protein Foods (Continued).

\begin{tabular}{|c|c|c|c|c|c|c|c|c|c|}
\hline & & $\stackrel{\text { डे }}{=}$ & : & $\Xi$ & 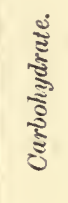 & $\stackrel{3}{\frac{3}{4}}$ & 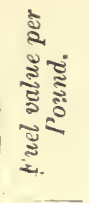 & 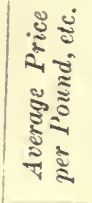 & 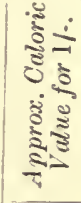 \\
\hline $\begin{array}{l}\text { Choese: } \\
\text { American red, as }\end{array}$ & & & & & & & & & \\
\hline & - & $28 \cdot 6$ & $29 \cdot 6$ & $38 \cdot 3$ & - & $3 \cdot 5$ & 2,165 & $7 d$. & 3,711 \\
\hline $\begin{array}{c}\text { chased } \\
\text { Dutch, as pur- }\end{array}$ & - & $27 \cdot 4$ & $27 \cdot 7$ & $36 \cdot 8$ & $4 \cdot 1$ & $4 \cdot 0$ & 2,145 & $7 \frac{1}{2} \mathrm{~d}$. & 3,432 \\
\hline $\begin{array}{c}\text { chased } \\
\text { Roquefort, as }\end{array}$ & - & $35 \cdot 2$ & $37 \cdot 1$ & $17 \cdot 7$ & - & $10 \cdot 0$ & 1,435 & $7 \frac{1}{2} \mathrm{~d}$ & 2,296 \\
\hline $\begin{array}{l}\text { purchased } . \\
\text { Milk: }\end{array}$ & - & $39 \cdot 3$ & $22 \cdot 6$ & $29 \cdot 5$ & $1 \cdot 8$ & $6 \cdot 8$ & 1,700 & $1 / 3$ & 1,360 \\
\hline $\begin{array}{c}\text { Whole, as pur- } \\
\text { chased }\end{array}$ & 一 & $87 \cdot 0$ & $3 \cdot 3$ & $4 \cdot 0$ & $5 \cdot 0$ & 0.7 & 325 & $\begin{array}{l}2 d . \\
\text { p. pt. }\end{array}$ & 2,440 \\
\hline Skimmed & - & $90 \cdot 5$ & $3 \cdot 4$ & $0 \cdot 3$ & $5 \cdot 1$ & $0 \cdot 7$ & 170 & $\begin{array}{l}\text { ld. } \\
\text { p. pt. }\end{array}$ & - \\
\hline $\begin{array}{l}\text { Condensed, } \\
\text { swcetened }\end{array}$ & - & $26 \cdot 9$ & $8 \cdot 8$ & $8 \cdot 3$ & $54 \cdot 1$ & $1 \cdot 3$ & 1,520 & $4 \frac{1}{2} \mathrm{~d}$ & - \\
\hline $\begin{array}{l}\text { Beans: dried } \\
\text { Peas: dried }\end{array}$ & $\begin{array}{l}(4 \cdot 4) \\
(4 \cdot 5)\end{array}$ & $\begin{array}{r}12 \cdot 6 \\
9 \cdot 5\end{array}$ & $22 \cdot 5$ & $1 \cdot 8$ & $59 \cdot 6$ & $3 \cdot 5$ & & $2 d$. & 9,630 \\
\hline Peas: dried & $(4 \cdot 5)$ & 9.5 & $24 \cdot 6$ & $1 \cdot 0$ & $62 \cdot 0$ & $2 \cdot 9$ & 1,65.5 & $2 d$. & 9,930 \\
\hline
\end{tabular}

Table showing Composition, Food Value, axd Cost of Fat Foods.

Salt Pork:

\begin{tabular}{|c|c|c|c|c|c|c|c|c|c|}
\hline $\begin{array}{l}\text { Edible .. } \\
\text { Belly as pur. }\end{array}$ & - & $17 \cdot 7$ & $8 \cdot 4$ & $72 \cdot 2$ & - & $3 \cdot 4$ & 3,200 & $6 \mathrm{~d}$. & 6,400 \\
\hline $\begin{array}{c}\text { Belly, as pur- } \\
\text { chased }\end{array}$ & $8 \cdot 2$ & $16 \cdot 2$ & $7 \cdot 7$ & $66 \cdot 2$ & 一 & $3 \cdot 2$ & 2,935 & - & \\
\hline atter .. & 一 & $11 \cdot 0$ & $1 \cdot 0$ & $85 \cdot 0$ & 一 & $3 \cdot 0$ & 3,605 & $1 / 4$ & 2,704 \\
\hline rgarine .. & 一 & $9 \cdot 5$ & $1 \cdot 2$ & $83 \cdot 0$ & 一 & $6 \cdot 3$ & $3,52.5$ & $6 \mathrm{dl}$ & 7,050 \\
\hline $\begin{array}{l}\text { am, as pur- } \\
\text { chased }\end{array}$ & & $7 \pm \cdot 0$ & $2 \cdot 5$ & $18 \cdot 5$ & $4 \cdot 5$ & $0 \cdot 5$ & 910 & $1 / 6$ & \\
\hline $\begin{array}{l}\text { rl, refined } \\
\text { t3: }\end{array}$ & 一 & - & - & 1000 & - & - & 4,220 & $8 d$. & 6,330 \\
\hline Almond, cdible & $(2 \cdot 0)$ & $4 \cdot 8$ & $21 \cdot 0$ & $54 \cdot 9$ & $17 \cdot 3$ & $2 \cdot 0$ & 3,030 & $3 \mathrm{~d}$ & - \\
\hline $\begin{array}{l}\text { as purchased } \\
\text { razil ediblc }\end{array}$ & $45 \cdot 0$ & $\frac{2 \cdot 7}{5 \cdot 3}$ & 1 & $30 \cdot 2$ & $9 \cdot$ & & 1,6 & 6d. & 3,320 \\
\hline $\begin{array}{l}\text { 3razil, edible } \\
\text { as purchased }\end{array}$ & $4 \overline{49 \cdot 6}$ & $\begin{array}{l}2 \cdot 3 \\
2 \cdot 6\end{array}$ & $\begin{array}{r}17 \cdot 0 \\
8 \cdot 6\end{array}$ & $\begin{array}{l}66 \cdot 8 \\
33 \cdot 7\end{array}$ & $\begin{array}{l}7 \cdot 0 \\
3 \cdot 5\end{array}$ & $\begin{array}{l}3 \cdot 9 \\
2 \cdot 0\end{array}$ & 16 & $8 d$ & - \\
\hline $\begin{array}{r}\text { ocoanut, pre- } \\
\text { pared }\end{array}$ & & & & & & & & & - \\
\hline $\begin{array}{l}\text { pared } \\
\text { Walnut, edible }\end{array}$ & $(1.7)$ & 3.5 & $\cdot 3$ & $57 \cdot 4$ & $31 \cdot 5$ & $1 \cdot 3$ & 3,125 & 一 & 一 \\
\hline as purchased.. & $74 \cdot 1$ & $\begin{array}{l}2 \cdot 5 \\
0 \cdot 6\end{array}$ & $\begin{array}{r}27 \cdot 6 \\
7 \cdot 2\end{array}$ & $\begin{array}{l}56 \cdot 3 \\
14 \cdot 6\end{array}$ & $\begin{array}{r}11 \cdot 7 \\
3 \cdot 0\end{array}$ & $0 \cdot 5$ & $\begin{array}{r}3,105 \\
: 05\end{array}$ & id. & إ \\
\hline $\begin{array}{l}\text { n: } \\
\text { moked, medium }\end{array}$ & & & & & & & & & 1,810 \\
\hline cdible & - & $40 \cdot 3$ & 16 & $38 \cdot 8$ & - & $4 \cdot 8$ & 1,940 & - & - \\
\hline as purchased.. & $13 \cdot 6$ & 3 & & 33 & - & 4 & 1,675 & $1 /$. & 1,675 \\
\hline sage, pork & - & $46 \cdot 2$ & 17 & $32 \cdot \overline{0}$ & - & 3 & 1,695 & 10d. & - \\
\hline ble. . & - & 7 & 2 & $4 \cdot 5$ & $1 \cdot 5$ & 1. & 605 & -- & - \\
\hline is purchased .. & $7 \cdot 3$ & $65 \cdot 6$ & $20 \cdot 2$ & $3 \cdot 1$ & $2 \cdot 5$ & $1 \cdot 3$ & $55 \tilde{5}$ & $6 d$. & 1,110 \\
\hline $\begin{array}{ll}\text { rectbreads, } & \text { as } \\
\text { as purchased } & \text {.. }\end{array}$ & - & 70.9 & 16 & $12 \cdot 1$ & - & 1 & 82 & - & - \\
\hline ripe & - & $86 \cdot 5$ & $11 \cdot 7$ & 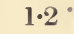 & $0 \cdot 2$ & $0 \cdot 3$ & 270 & $6 d$. & 550 \\
\hline
\end{tabular}


Table showing Composition, Food Valoe, axd Cost of Carbohydrate foons.

Wheat flour:

Patent roller,

$\begin{array}{lllll}\text { family grade } & (0.6) & 12.8 & 10.8\end{array}$

\begin{tabular}{l|lll} 
Self-raising & $(0.4)$ & 10.8 & 10.2
\end{tabular}

\begin{tabular}{l|l|l|} 
Wheat bread, white $(0 \cdot 5)$ & $35 \cdot 6$ & $9 \cdot 3$
\end{tabular}

\begin{tabular}{l|l|l|} 
Wheat rolls, white $(0 \cdot 6) \quad 29 \cdot 2$ &
\end{tabular}

\begin{tabular}{l|l|l|} 
Wheat bread,brown & - & $\mathbf{4 3} \cdot 6$
\end{tabular}

$\begin{array}{llll}\text { Rye bread } & \ldots(0 \cdot 5) & \mathbf{3 5} \cdot \mathbf{7}\end{array}$

Biseuits: Cream

$\begin{array}{llll}\text { eraekers } & \ldots & (0 \cdot 6) & 6.8\end{array}$

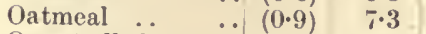

$\begin{array}{lll}\text { Oats (rolled) } & \cdots(1 \cdot 3) & 7.7 \\ \text { Riee } & \cdots(0.2) & 1 \cdot 2.3\end{array}$

$\begin{array}{llll}\text { Riee } & \ldots & (0 \cdot 2) & 12 \cdot 3 \\ \text { Stareh (tapioea) } & \ldots & (0 \cdot 1) & 11 \cdot 4\end{array}$

$\begin{array}{llll}\text { Stareh (sago) } & \ldots & (0 \cdot 3) & 12 \cdot 2\end{array}$

Sugar brown
Sugar (granulated)

Honey..$\quad$.. -18.2

Apples (dried) .. - 28

Currants (dried) .. - 17

Raisins, as pur$\begin{array}{llll}\text { ehased .. } & \text {.. } & 10 \cdot 0 & 13 \cdot 1\end{array}$

Figs (dried) $\quad \ldots \quad-18$

Prunes, as pur\begin{tabular}{lrr|r|r} 
ehased & $\ldots$ & $15 \cdot 0$ & $19 \cdot 0$
\end{tabular}

Chestnuts (dried):

edible $\quad \ldots(2 \cdot 7)$

as purchased $\ldots 24 \cdot 0$

\begin{tabular}{l|l}
$7 \cdot 2$ & $1 \cdot 6$ \\
\hline
\end{tabular}

हैं
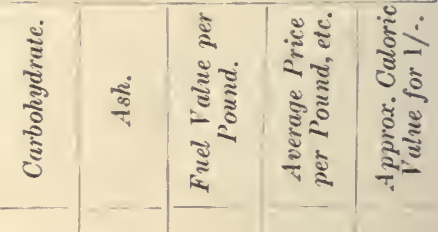

$8 \cdot 9$

$5 \cdot 4$
$9 \cdot 0$

$9 \cdot 7$

$16 \cdot 1$

$16 \cdot 7$

$0 \cdot 4$

$9 \cdot 0$

-
-
$0 \cdot 4$
$1 \cdot 6$
$2 \cdot 4$

$1 \cdot 1$
$1 \cdot 2$

$74 \cdot 8$

$0 \cdot 5$

1,640

$1 \frac{3}{4}$ d. $\quad 11,646$

\begin{tabular}{ll|l|l|l|l}
$73 \cdot 0$ & $4 \cdot 8$ & 1,600 & $2 d$. & 9,600
\end{tabular}

$4 \cdot 1+56 \cdot 7$

$1.8 \quad 47 \cdot 1$

\begin{tabular}{l}
$0 \cdot 6$ \\
\hline
\end{tabular}

\begin{tabular}{l|l}
$12 \cdot 1$ & $69 \cdot 7$
\end{tabular}

$1 \cdot 2 \quad 1,205$

$1 \cdot 1 \quad 1,395$

$2 \cdot 1 \quad 1,050$

$1.5 \quad 1,180$

-

-

$\begin{array}{ll}7 \cdot 2 & 67.5\end{array}$

\begin{tabular}{l|l|l|}
$7 \cdot 3$ & $66 \cdot 2$
\end{tabular}

\begin{tabular}{l|l|l}
$0 \cdot 3$ & $79 \cdot 0$
\end{tabular}

\begin{tabular}{l|l}
$1 \cdot 7$ & 1,990
\end{tabular}

$7 \mathrm{~d}$.

\begin{tabular}{l|l}
$1 \cdot 9$ & 1,860
\end{tabular}

$2 \cdot 1 \quad 1,850$

$0 \cdot 4 \quad 1,630$

\begin{tabular}{l|l|l|}
$0 \cdot 1$ & $88 \cdot 0$
\end{tabular}

$0 \cdot 1 \quad 1,650$

$0 \cdot 4 \quad 78 \cdot 1$

$0 \cdot 3$

1,635

95.0
$-\quad 100.0$

-

1,765

$\begin{array}{ll}- & 81.2 \\ 2 \cdot 2 & 66.1\end{array}$

$0 \cdot 2$

1,860

$2 \frac{1}{2} \mathrm{~d}$
21
2
2

$2 \frac{1}{2} \mathrm{~d}$.

$4 d . \quad 4,950$

3d. $\quad 6,540$

$2 \frac{1}{2} \mathrm{~d}$. $\quad-$

\begin{tabular}{l|l|}
\hline $2 \cdot 2$ & $66 \cdot 1$ \\
$1 \cdot 7$ & $74 \cdot 2$
\end{tabular}

1,350

$21 \mathrm{~d}, \quad 11,320$

$4 \cdot 5 \quad 1,495$

$\overline{5 d}$.

-

\begin{tabular}{l|l|l|}
$2 \cdot 3$ & $3 \cdot 0$ & $68 \cdot 5$ \\
\hline
\end{tabular}

$3 \cdot 1 \quad 1,445$

$7 d$.

3,588

\begin{tabular}{|l|l|l|l|}
\hline $8 \cdot 8$ & $4 \cdot 3$ & $0 \cdot 3$ & $74 \cdot 2$ \\
\hline
\end{tabular}

\begin{tabular}{l|l}
$2 \cdot 4$ & 1,475
\end{tabular}

6d.

2,477

$2 \cdot 0 \quad 1,190$

$5 d$.

2,856

$\begin{array}{lllll}5.9 & 10 \cdot 7 & 7 \cdot 0 & 74.2\end{array}$

$2 \cdot 2 \quad 1,875 \quad 3 d$.

$5 \cdot 3 \quad 56 \cdot 4$

$1 \cdot 7 \quad 1,425$

Table showlig Composition, food Value, axd Cost of Watery foods.

Vegetables:

\begin{tabular}{|c|c|c|}
\hline $\begin{array}{cc}\text { Artichokes, } \\
\text { pureliased }\end{array}$ & $(0 \cdot 8)$ & $79 \cdot$ \\
\hline $\begin{array}{cc}\text { Asparagus, } & \text { as } \\
\text { purchased } & \text {.. }\end{array}$ & $(0 \cdot 8)$ & $94 \cdot 0$ \\
\hline $\begin{array}{l}\text { Beans, edible } . . \\
\text { Fresh string, }\end{array}$ & $(1 \cdot 9)$ & $89 \cdot 2$ \\
\hline as purchased & $(1 \cdot 8)$ & $83 \cdot 0$ \\
\hline $\begin{array}{l}\text { Beetroot, edible } \\
\text { as purehased }\end{array}$ & $\begin{array}{l}(1 \cdot 1) \\
20 \cdot 0\end{array}$ & $\begin{array}{l}87 \cdot 5 \\
70 \cdot 0\end{array}$ \\
\hline Cabbagre, edible & $(1 \cdot 1)$ & $91 \cdot 5$ \\
\hline as purchased & $15 \cdot 0$ & $77 \cdot 7$ \\
\hline $\begin{array}{l}\text { Carrots, edible } \\
\text { as purehased }\end{array}$ & $\begin{array}{l}(1 \cdot 1) \\
20 \cdot 0\end{array}$ & $\begin{array}{l}88 \cdot 2 \\
70 \cdot 6\end{array}$ \\
\hline Cauliflower & $(1 \cdot 0)$ & $92 \cdot 3$ \\
\hline Celery, edible & & $94 \cdot 5$ \\
\hline eliased & $20 \cdot 0$ & $75 \cdot 6$ \\
\hline Cueumber, edible & $(0 \cdot 7)$ & $95 \cdot 4$ \\
\hline as purchased & & $81^{\circ}$ \\
\hline $\begin{array}{l}\text { cttuee, edible. } \\
\text { as purehased }\end{array}$ & $(0 \cdot 7)$ & $94 \cdot 7$ \\
\hline $\begin{array}{l}\text { as purelias } \\
\text { Mushrooms }\end{array}$ & $\begin{array}{l}10 \cdot 0 \\
(0 \cdot 8)\end{array}$ & $\begin{array}{l}80 \cdot 5 \\
88 \cdot 1\end{array}$ \\
\hline
\end{tabular}

\begin{tabular}{|c|c|c|c|c|c|c|}
\hline $2 \cdot 6$ & $0 \cdot 2$ & $16 \cdot 7$ & $1 \cdot 0$ & 365 & $1 d$. & 4,380 \\
\hline $\begin{array}{l}1.8 \\
2.3\end{array}$ & $0 \cdot 2$ & $3 \cdot 3$ & 0.7 & 105 & $10 \mathrm{~d}$. & 126 \\
\hline $2 \cdot 3$ & $0 \cdot 3$ & $7 \cdot 4$ & $0 \cdot 8$ & 195 & - & 4,160 \\
\hline $2 \cdot 1$ & $0 \cdot 3$ & $6 \cdot 9$ & $0 \cdot 7$ & 180 & ld. & - \\
\hline $1 \cdot 6$ & $0 \cdot 1$ & $9 \cdot 7$ & $1 \cdot 1$ & 215 & & \\
\hline $1 \cdot 3$ & $0 \cdot 1$ & $7 \cdot 7$ & 0.9 & 170 & $\frac{1}{2} \mathrm{~d}$. & 2,260 \\
\hline $1 \cdot 6$ & $0 \cdot 3$ & $5 \cdot 6$ & $1 \cdot 0$ & 145 & & 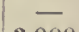 \\
\hline $1 \cdot 4$ & $0 \cdot 2$ & $4 \cdot 8$ & $0 \cdot 9$ & 125 & $\frac{1}{2} \mathrm{~d}$. & 3,000 \\
\hline $1 \cdot 1$ & $0 \cdot 4$ & $9 \cdot 3$ & $1 \cdot 0$ & 210 & $\overline{3}$ & 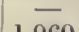 \\
\hline 0.9 & 0.2 & $7 \cdot 4$ & $0 \cdot 9$ & 160 & $\frac{3}{4} \mathrm{~d}$. & 1,960 \\
\hline 1.8 & 0.5 & $4 \cdot 7$ & 0.7 & 140 & ld. & 1,680 \\
\hline $1 \cdot 1$ & 0.1 & $3 \cdot 3$ & $1 \cdot 0$ & 85 & d] & 840 \\
\hline $\begin{array}{l}0.9 \\
0.8\end{array}$ & $\begin{array}{l}0.1 \\
0.2\end{array}$ & $\begin{array}{l}2 \cdot 6 \\
3 \cdot 1\end{array}$ & $\begin{array}{l}0.8 \\
0.5\end{array}$ & 80 & 10. & $8+0$ \\
\hline 0.7 & 0.2 & $2 \cdot 6$ & 0.4 & 70 & $2 \mathrm{~d}$. & 420 \\
\hline $1 \cdot 2$ & $0 \cdot 3$ & $2 \cdot 9$ & $0 \cdot 9$ & 90 & - & - \\
\hline $1 \cdot 0$ & $0 \cdot 2$ & $2 \cdot 5$ & $0 \cdot 8$ & 75 & 1d. & 900 \\
\hline & $0 \cdot 4$ & $6 \cdot 4$ & $1 \cdot 2$ & 210 & $8 d$. & 315 \\
\hline
\end{tabular}


Table showisg Composition, Food Value, and Cost of Watery Fonds (Continued)

\begin{tabular}{|c|c|c|c|c|c|c|c|c|c|}
\hline & 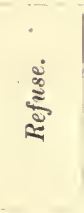 & $\stackrel{\Xi}{\Xi}$ & 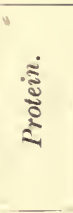 & है & 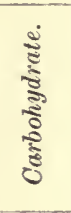 & 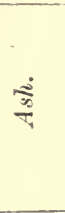 & 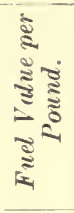 & 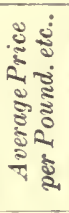 & 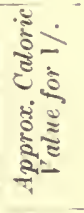 \\
\hline getables (cont.) : & & & & & & & & & \\
\hline Oni & $(0 \cdot 8)$ & $87 \cdot 6$ & $1 \cdot 6$ & $0 \cdot 3$ & $9 \cdot 9$ & $0 \cdot 6$ & 225 & & \\
\hline $\begin{array}{l}\text { ased } \\
\text { (fresh) }\end{array}$ & $10 \cdot 0$ & $78 \cdot 9$ & $1 \cdot 4$ & $0 \cdot 3$ & $8 \cdot 9$ & $0 \cdot \tilde{z}$ & 205 & ld. & 460 \\
\hline $\begin{array}{l}\text { Pcas, green(fresh) } \\
\text { cdible }\end{array}$ & $(1 \cdot 7)$ & $74 \cdot 6$ & $7 \cdot 0$ & 0.5 & $16 \cdot 9$ & $1 \cdot 0$ & 465 & & \\
\hline rchased.. & $45 \cdot 0$ & $40 \cdot 8$ & $3 \cdot 6$ & $0 \cdot 2$ & $9 \cdot 8$ & $0 \cdot 6$ & 255 & $1 \frac{1}{2} \mathrm{~d}$. & 040 \\
\hline Potatoes (raw) & & & & & & & & & \\
\hline hased.. & $\begin{array}{l}(0 \cdot 4) \\
20 \cdot 0\end{array}$ & $\begin{array}{l}78 \cdot 3 \\
62 \cdot 6\end{array}$ & $\begin{array}{l}2 \cdot 2 \\
1 \cdot 8\end{array}$ & $\begin{array}{l}0 \cdot 1 \\
0 \cdot 1\end{array}$ & $\begin{array}{l}18 \cdot 4 \\
14 \cdot 7\end{array}$ & $\begin{array}{l}\mathbf{l} \cdot 0 \\
0 \cdot 8\end{array}$ & $\begin{array}{l}385 \\
310\end{array}$ & $\frac{3}{4} \mathrm{~d}$. & 960 \\
\hline edible & $(1 \cdot 1)$ & $94 \cdot 4$ & $0 \cdot 6$ & $0 \cdot 7$ & $3 \cdot 6$ & 0.7 & 105 & & \\
\hline as 1 & $40 \cdot 0$ & $56 \cdot 6$ & $0 \cdot 4$ & $0 \cdot 4$ & $2 \cdot 2$ & $0 \cdot 4$ & 65 & $\frac{1}{2} \mathrm{~d}$ & 520 \\
\hline $\begin{array}{r}\text { Spinach (fresh), } \\
\text { as purchased.. }\end{array}$ & & $92 \cdot 3$ & $2 \cdot 1$ & 0.3 & $3 \cdot 2$ & $2 \cdot 1$ & 110 & 128 & \\
\hline taste. & $(0 \cdot 6)$ & $94 \cdot 3$ & $0 \cdot 9$ & o & $3 \cdot 9$ & $0 \cdot 5$ & 105 & 4 d. & 315 \\
\hline Turr & $(1 \cdot 3)$ & $89 \cdot 6$ & 1 . & $0 \cdot 2$ & $8 \cdot 1$ & $0 \cdot 8$ & 185 & & \\
\hline & $30 \cdot 0$ & $62 \cdot 7$ & 0.9 & $0 \cdot 1$ & $5 \cdot 7$ & $0 \cdot 6$ & 125 & $\frac{1}{2} \mathrm{~d}$ &, 000 \\
\hline Fruits & & & & & & & & & \\
\hline $\begin{array}{l}\text { Apples, } \\
\text { as pur }\end{array}$ & $\begin{array}{l}(1 \cdot 2) \\
25 \cdot 0\end{array}$ & $84 \cdot 6$ & $0 \cdot 4$ & $0 \cdot$ & $14 \cdot 2$ & 0 & 290 & & \\
\hline Jased.. & $25 \cdot 0$ & $63 \cdot 3$ & $0 \cdot 3$ & $0 \cdot 3$ & $10 \cdot 8$ & $0 \cdot 3$ & 220 & d. & 0 \\
\hline & $(1 \cdot 0)$ & $75 \cdot 3$ & $1 \cdot 3$ & $0 \cdot \hat{t}$ & $22 \cdot 0$ & .8 & 460 & - & - \\
\hline as & $35 \cdot 0$ & $48 \cdot 9$ & 0 . & & $14 \cdot 3$ & & 00 & $6 d$. & 80 \\
\hline Cherries & $(0 \cdot 2)$ & $80 \cdot 9$ & 1. & 0 . & $16^{\circ} 7$ & & 36 & - & - \\
\hline & $15 \cdot 0$ & $76 \cdot 8$ & 0 & 0 - & $15 \cdot 9$ & $0 \cdot$ & 345 & $4 d$. & 5 \\
\hline Grape & $(4 \cdot 3)$ & $77 \cdot 4$ & $1 \cdot$ & & $19 \cdot 2$ & & 0 & $\overline{-1}$ & $=$ \\
\hline as & $25 \cdot 0$ & $\begin{array}{l}58 \cdot 0 \\
86.0\end{array}$ & 1 & $1 \cdot$ & $4 \cdot 4$ & 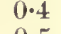 & 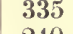 & 6d. & 30 \\
\hline $\begin{array}{l}\text { Oranges, cdible } \\
\text { as purchased }\end{array}$ & $2 \overline{27 \cdot 0}$ & $\begin{array}{l}86 \cdot 9 \\
63 \cdot 4\end{array}$ & $\begin{array}{l}0 \\
0\end{array}$ & $\begin{array}{l}0 \cdot 5 \\
0 \cdot 1\end{array}$ & $\begin{array}{r}11 \cdot 6 \\
8 \cdot 5\end{array}$ & ). & ) & $\overline{18 d}$ & 360 \\
\hline Pears, & $(2 \cdot 7)$ & $84 \cdot 4$ & 0 & $0 \cdot$ & $14 \cdot 1$ & & 295 & & \\
\hline & $10 \cdot 0$ & $76 \cdot 0$ & 0 . & 0 . & $12 \cdot 7$ & & 2 & $3 \mathrm{~d}$. & $1.0 .+40$ \\
\hline Plums, & - & $78 \cdot 4$ & 1 . & - & $20 \cdot 1$ & $0 \cdot$ & 3 & - & \\
\hline a & $5 \cdot 0$ & $74 \cdot 5$ & $0 \cdot 5$ & - & $19 \cdot 1$ & $0 \cdot$ & 37 & $2 \mathrm{~d}$. & 2,220 \\
\hline Raspberries .. & $(2 \cdot 9)$ & $85 \cdot 8$ & $1 \cdot 0$ & - & $12 \cdot 6$ & $0 \cdot 6$ & 255 & 5d. & 612 \\
\hline $\begin{array}{l}\text { Strawberries: } \\
\text { edible }\end{array}$ & $(1 \cdot 4)$ & $90 \cdot 4$ & 1 . & 0 . & $7 \cdot 4$ & $0 \cdot$ & 18 & - & - \\
\hline chased.. & $5 \cdot 0$ & $85 \cdot 9$ & $0 \cdot 7$ & $0 \cdot \mathrm{c}$ & $7 \cdot 0$ & $0 \cdot 6$ & 175 & $4 d$. & 525 \\
\hline Water-melon: & & & & & & & & & \\
\hline & & $92 \cdot 4$ & 0 & $\begin{array}{l}0 . \\
0 .\end{array}$ & $6 \cdot 7$ & $0 \cdot 3$ & 140 & $\overline{1 d}$ & $\overline{1}+10$ \\
\hline $\begin{array}{l}\text { as purchased.. } \\
\text { nimal: }\end{array}$ & $59 \cdot 4$ & 37. & 0 & & $2 \cdot$ & $0 \cdot 1$ & 60 & $\frac{1}{2} \mathrm{~d}$. & $4+0$ \\
\hline & - & 87 . & 3 . & 4. & $5 \cdot($ & $0 \cdot$ & 32 & - & -- \\
\hline Oysters & 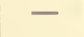 & $86 \cdot 9$ & $6 \cdot$ & $1 \cdot 2$ & $3 \cdot 7$ & $2 \cdot 0$ & 235 & - & - \\
\hline
\end{tabular}


Food Values in Housenold Meastres.

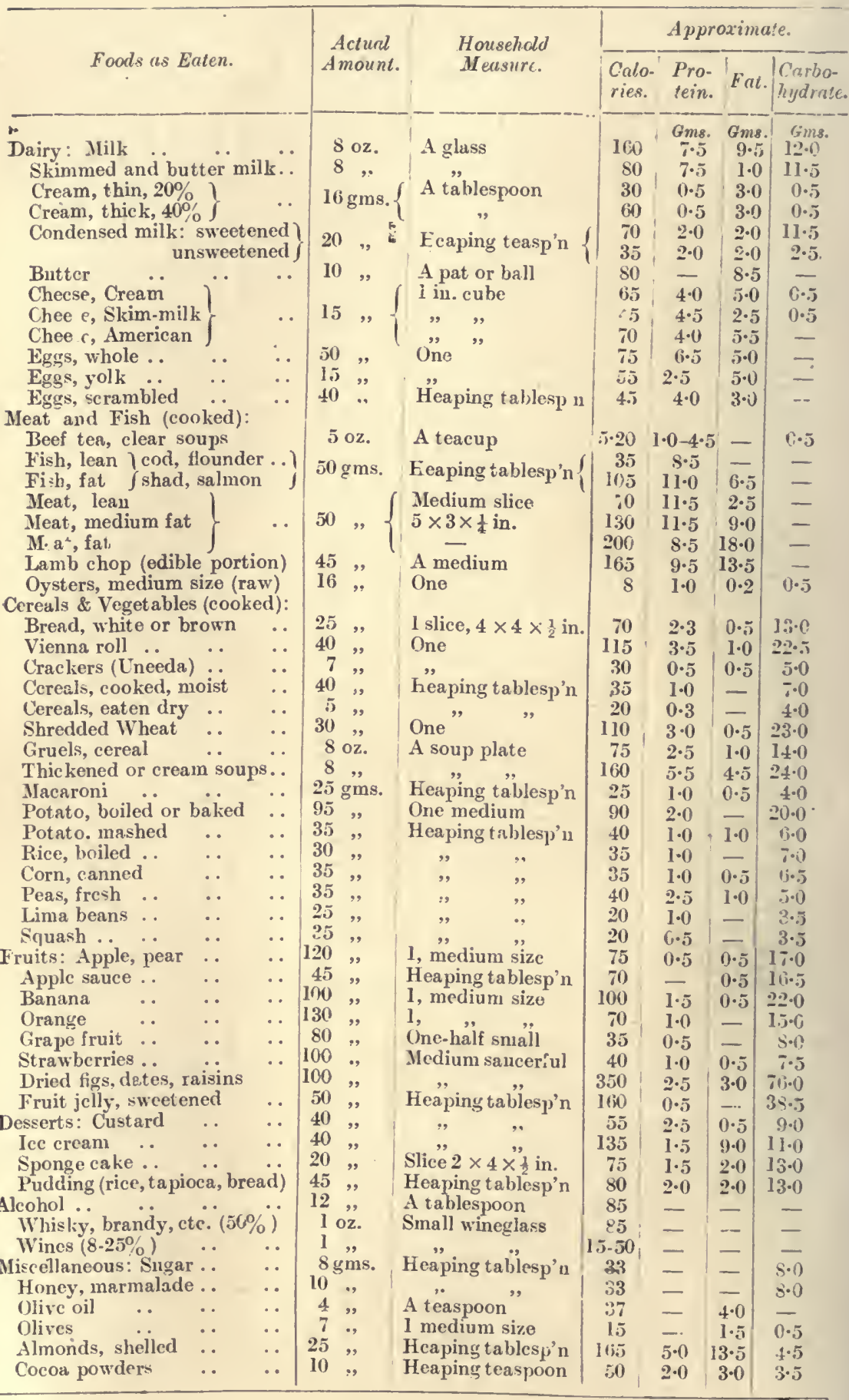




\section{CHAPTER XLI}

\section{THE CHIEF FOODSTUFFS}

IT is necessary to consider a few of the commoner foodstuffs in more detail.

Milk.-Cow's milk is a staple article of diet for persons of all ages. It is to be noted that milk is relatively a watery, and therefore not a cheap, food. Fresh cow's milk is amphoteric in reaction, with a specific gravity of 1028 to 1034 . When skimmed, the specific gravity rises to 1033 to 1037. A little water added will again reduce the specific gravity, and a little colouring matter will help to cover up the fraud. Milk contains all the necessary foodstuffs-proteins, fat, lipoids, carbohydrate, water, and salts. The chief protein is case ${ }^{\circ}$ ogen, a phospho-protein, notable for its high content in the ringed amino acids-tyrosin and tryptophane. A certain amount of coagulable protein-lactalbumin-is also present. Caseinogen is clotted by rennet. When this takes place outside the body, "junket" is formed.

Caseinogen is easily precipitated from solution by acid. When milk goes sour on standing, lactic acid is formed as the result of the action of a bacillus-B. lactis-upon the sugar contained in milk. The lactic acid so formed precipitates the caseinogen as the "curds," lcaving a clear fluid-the "whey." The term "whey" is often given to what is left after caseinogen has been removed by any means. When milk is clotted, a clear fluid exudes after a time-- "rennet whey." If caseinogen be precipitated by acid, neutral salts or alcohol, "acid," "salt," or " alcoholic " whey is obtained. Some wheys - e.g., rennet, acid-contain lactalbumin; others do not, the albumin being removed with the caseinogen-e.g., alcoholic whev.

The fats of milk are carried down with the caseinogen. Olein forms the chief fat (43 per cent.); palmitin (33 per cent.) and stearin ( 17 per cent.) are also present, togather with 7 per cent. of fats of the volatile fatty acids-butyrin, caproin, and caprylin. It is this content of volatile fatty acids which aids to distinguish butter from margarine. The fats occur in the form of fine droplets, each drop of the emulsion bzing surrounded with a fine film of caseinogen.

In the whey are contained the sugar lactose and the salts. The chief salt is calcium phosphate; the phosphate of magnesium and the chlorides of sodium and potassium are also present. Milk contains but little iron. The milk of different animals varies in the content of the chief constituents. The differences between cow's and human milk are discussed elsewhere (see p.53i). The composition 
of the milk of various animals can be seen in the following table (König) stated in parts per 1,000 of milk:

\begin{tabular}{|c|c|c|c|c|c|c|c|c|}
\hline & & & Water. & Solids. & Proteins. & Fut. & Sugar. & Salts. \\
\hline Cow & .. & .. & $871 \cdot 7$ & $128 \cdot 3$ & $3.5 \cdot 5$ & $36 \cdot 9$ & $48 \cdot 8$ & $7 \cdot 1$ \\
\hline Horse & . & $\because$ & $900 \cdot 6$ & 93.4 & 18.9 & $10 \cdot 9$ & 66.5 & $3 \cdot 1$ \\
\hline Ass .. & .. & .. & $900 \cdot 0$ & $100 \cdot 0$ & $21 \cdot 0$ & $13 \cdot 0$ & 63.0 & $3 \cdot 0$ \\
\hline Goat & .. & .. & $869 \cdot 1$ & $130 \cdot 9$ & $36 \cdot 9$ & $40 \cdot 9$ & $44 \cdot 5$ & $8 \cdot 6$ \\
\hline Sheep & .. & .. & $835 \cdot 0$ & 165.0 & $57 \cdot 4$ & $61 \cdot 4$ & $39 \cdot 6$ & $6 \cdot 6$ \\
\hline Pig .. & .. & . & $823 \cdot 7$ & $167 \cdot 3$ & $60 \cdot 9$ & $64 \cdot 4$ & $40 \cdot 4$ & $10 \cdot 6$ \\
\hline Dog .. & . & .. & $754 \cdot 4$ & $245 \cdot 6$ & $99 \cdot 1$ & $95 \cdot 7$ & $31 \cdot 9$ & $7 \cdot 3$ \\
\hline Cat .. & . & $\ldots$ & $816 \cdot 3$ & $183 \cdot 7$ & $90 \cdot 8$ & $33 \cdot 3$ & $49 \cdot 1$ & 5.3 \\
\hline Elephant & .. & . & $678 \cdot 5$ & $321 \cdot 5$ & $30 \cdot 9$ & 195.7 & $88 \cdot 5$ & $6 \cdot 5$ \\
\hline
\end{tabular}

The walıus's milk contains as mueh as 43 per eent. of fat. By the action of a special fungus--the kephir fungus-the lactose of milk, which does not normally undergo alcoholic fermentation, ferments. to alcohol ( 1 to 3 per cent.), giving with eow's milk the drink known as kephir, with mare's milk koumiss. It is a general drink in Bulgaria and the Steppes of Russia.

Meat consists of the muscle of animals and fat, with a eertain amount of eonnective tissue. Besides the visible fat in prime meat, there is a considerable amount of masked fat also in the fibres. Themuscle also eontains various extraetives and other bodies.

Eggs are an exceedingly valuable article of diet by virtue of their great digestibility. The white of the egg consists chiefly of egg albumin, with a small amount of egg globulin, and a mucus-like bedy-ovo-mucoid. A small amount of sugar $(0.5$ per eent.), and traees of fats, lipoids, and salts $(0.6$ per cent.), are present. In the yolk there is present also the phospho-protein vitellin, fat, and the eolouring matter lipochrome.

The Cereals - wheat, barley, oats, rye, rice-are the most widely used artieles of diet. They contain much stareh, and have the groat advantage of being cheap. In their husks are contained valuable salts and vitamines. Their proteins, besides not being so well absorbed as animal proteins, do not contain sueh an appropriate assortment of "bricks" for building animal tissues as do the animal foodstuffs. Some of the "bricks" - e.g., glutamic acid --are present in large quantity, and if used for body-building, must be broken down previous to resynthesis. It has been shown that proteins, sueh as zcin (from maize) and hordein (from barley), do not by themselves suffice to give the appropriate nitrogen to the body. Oatmeal with $7 \mathrm{pcr}$ cent. of fat, against 1 per cent. in wheat, is a very valuable article of diet, and should figure largely in the diet of all peoples inhabiting temperate zones.

Flour is made from the endosperm of wheat. Generally the outer husk (bran), inner husk (sharps), and the germ, are removed during. 
tho milling process, and white flour is obtained. Further, it is frequently bleached with acids, and white calcium salts added to give extra whiteness. There is economic loss in such bleaching processes, which are, if anything, injurious to the consumer. When milled whole, whole-meal is obtained; when only the bran is removed, "standard" flour results. The chief protein, gluten, globulin-like in nature, when mixed with water, becomes viscid, forming a dough. Gluten consists of two portions-gliadin, soluble in alcohol; and glutinin, soluble in alkali. The viscidity is due to the gliadin. Grains poor in gliadin-e.g., rice, oats-do not form a dough when mixed with water.

Bread.-The dough formed from flour is not a suitable food, owing to its imperviousness to the digestive juices. When made pervious by aeration, and baked, it becomes bread. 'This aeration is performed by carbonic acid gas generated by the action of the yeast which is mixed with the dough, and of a diastase already present in the flour.

The Pulses. - This group of dry foodstuffs contain in the dry state a large amount of protein and carbohydrate, and, being cheap, are valuable as articles of diet. They have the disadvantage, however, that their physiological arailability - the amount absorbed during digestion-is considerably lower than with the animal foodstuffs. They cannot be eaten dry, and when mixed with water and cooked they become very bulky foods. The proteins of pulses and cereals do not seem to be composed of such suitable "bricks" for building animal tissues as are the proteins of animal foodstuffs.

The Fruits are of value by reason of the anti-scorbutic principles, the organic acids, salts and water they contain. Certain fruits also contain appreciably large quantities of sugar. The banana, often classed as a fruit, contains a relatively large amount of nutriment.

Green Vegetables are of value as introducing a small percentage of food, with salts, vitamines, and a certain amount of cellulose, which stimulates the peristaltic action of the intestines. The salts of the vegetable acids are converted into alkaline carbonates, and are of importance in regulating the acidity of the blood. The green foodstuffs, particularly spinach, also introduce iron into the body. Chlorophyll is possibly a precursor of hæmoglobin.

Potatoes contain carbohydrate and a small amount of protein, but this is in a most arailable form. They also contain vitamines, and thus are of great importance to town populations. 


\section{CHAPTER XLII}

\section{DIET UNDER VARIOUS CONDITIONS}

If man had to take his nutriment as one article of diet, to get the neccssary protein-15 grammes of nitrogen-he would require: $1 \frac{1}{2}$ pounds of beef, or 8 pints of milk, or 3 pounds of bread, or 13 pounds of potatoes, * or 60 pounds of apples. A diet consisting of 125 grammes of protein, 50 grammes of fat, and 500 grammes of carbohydrate, is contained in approximately $\frac{1}{2}$ pound prime lean meat, $1 \frac{1}{2}$ pounds bread, 2 ounces butter, $\frac{1}{2}$ pint milk, 1 pound potatoes, and $\frac{1}{4}$ pound oatmeal. The fat is raised to 100 grammes in the army service ration-i.e., for hard work in the open air of this climatc.

Sex and Age.-Since man is gencrally bigger than woman and does more muscular work, he requircs the bigger intake of energy. Men and women of equal surface arca, and performing equal work, require the same energy intake. A family of father, mother, and four children $(13,11,9$, and 7 years $)$ is estimated to requirc the food of 4.5 men. Boys over 13 require a full "man value" - viz.., 3,400 calories - food as purchased, the loss in cooling and absorption is estimated to be 10 per cent. A woman or girl over 13 requires $\cdot 8$ man value. In old age there is a marked decrease in vitality and bodily activity. Old people therefore need not, and do not, take in the supply of cnergy required in the prime of lifc. Old bedridden people live on a diet which probably does not yicld more than 1,000 calories.

Work.-It has already been mentioned how the oxygen consumption and $\mathrm{CO}_{2}$ output are increased by muscular work. Not only do the inuscles perform more mechanical work, but the body generally is called upon to do more "physiological" work to meet their nceds. Either protein, fat, or carbohydrate, can yield the energy required for muscular work, but since sueh work can be done most economically at the cxpense of the last, a diet for hard muscular work should eontain an ample supply of carbohydrate with encugh fat to sustain the work between meals. Carbohydrate is used first, while fat, more slowly digestcd and absorbed, is used later.

Temperament.-Some people are by temperament vivacious and active, others are more phlegmatic and quiet. The latter will expend less energy as muscular work than the former, and thercfore requirc

* Three to four grammes of nitrogen seem to suffice on a potato diet. 
a correspondingly less intake of energy as food. If they take as much, they grow fat.

Climate.-Cold incrcases the activity-i.e., the amount of muscular work pcrformed-heat diminishes it. In cold climates there should therefore be an increase in the energy intake, particularly in the form of fat, which, owing to its high caloric value, is very heat-giving. In the tropics, on the other hand, food must be cut down, particularly protein owing to its high specific dynamic energy. The diet of natives in Singapore a verages $60 \mathrm{grms}$. protein, $35 \mathrm{fat}$, and 250 carbohydrate, with an energy value of about 1,600 calories.

The Nutrition of the Fœtus.-During pregnancy, the embryo is nourished at the expense of the mother through the placenta. It is during the last three months of pregnancy that the great increase in weight of the foetus occurs; at the same time, the mother's oxygen use increases about 25 per cent. above the normal. Calculation shows, however, that not more than 10 grammes of dry matter per day are required for adequate growth of the foetus. Analysis of the full-time fœetus shows that an average child of 7 pounds contains nearly 400 grammes of protein, 300 grammes of fat, and 83 grammes of mineral ash, chiefly calcium and phosphoric acid. In regard to the question of the diet of the mother, therefore, it is obvious that no excessive demands are made upon her in the matter of food intake. Special diets are not required by the pregnant woman. All that is required is a slightly increased intake of simple protein and lime-giving foods, such as meat, milk, eggs, cereals, fruits, and vegetables. The more nearly a mother lives a normal healthy life, the better it is for the foetus.

The Nutrition of the New-born Infant.-The new-born infant should be fed, if possible, by its mother. Every mother should do, and should be encouraged to do, all in her power to suckle her own infant. The mother's milk is best adapted to the needs of the growing child. It is sterile; it contains the right kinds and proportions of protein, lecithin, and salt3. It has been shown that there is a proportion between the composition of the mother's milk and the rate at which the young grow. This is especially marked in quickly growing animals. Thus, a puppy doubles its weight in eight days; its mother's milk contains $7 \cdot 1$ per cent. of protein and 1.3 per cent. of ash. A child takes six months to double its weight; human milk contains but 1.5 pcr cent. of protein and 0.2 per cent. of ash. The lecithin-content of the mother's milk varies somewhat with the relative weight of the brain to the body weight. Relatively, the larger the brain the bigger the lecithin-content of the mother's milk. In the calf the brain weight to body weight is $1: 370$; in the puppy, $1: 30$; in the new-born child, $1: 7$. In proportion, the milk of the different mothers contains lecithin in percentage of the total protein $1 \cdot 4,2 \cdot 11$, and 3.05 respectively. It is well adapted to the child's digestive powers, and, what is also important, it contains bodies capable of increasing the child's immunity to any ailments which may befall it in early life. This last point was proved by the following ingenious "changeling" experi- 
ment: A male and a female mouse were rendered immune to a poison (abrin). Each was then mated to a non-immunc companion. It was found that the offspring of the immune male and non-immune female possessed no immunity against the poison. On the other hand, the offspring of the non-immune male and of the immune femalc possessed such an immunity, which gradually increased after birth, and was therefore not derived solely from the placenta. The offspring were then changed. The inmune female suckled the non-immunc young, the non-immune female suckled the immune young. It was found that the former soon acquired an immunity, the latter quickly lost their immunity to the poison.

Of the infant mortality under one year, and particularly under eight months, the great proportion of deaths-in somc cities as large as 170 per 1,000 , over 300 in Russia-is among artificially fed babies. It must be borne in mind that such deaths are largely among the very poor, and the artificial food in such cases is often inadequate, and certainly not kept sterile and clean. The case against artificial feeding is largely a case against careless or ignorant artificial fceding. With a properly prepared clean food, such as the child can digest, and containing the "building stones" suitable for its adequate growth, there is every reason to believe that the child develops, in most cases, into just as healthy a babe as does the breast-fed infant. The introduction of dricd milk has proved of the greatest importance in lessening infant mortality.

The mother should bc urged to suckle the child during the first months as much for her own sake as for the child's. The act of suckling exerts a tonic effect upon the utcrus. It assists in stopping hæmorrhage from the placental site, and helps to securc the proper involution of the uterus.

The Secretion of Milk-The Mechanism of Secretion.-During pregnancy, preparation is made for the feeding of the young. The mammary glands begin to increase in size-the engorged veins testify to the activity taking place; there is great proliferation of the alveolar cells and duct epithelium. This takes place under the influence of a hormone produced by the corpus luteum of the mother, and possibly by the foetus itself. Nervous connections of the gland are not essential. The gland may be transplanted in the pregnant animal, and will continue to proliferate. After birth, the proliferated resting glands enter into a state of great secretory activity, possibly owing to the removal of an inhibitory influence from the foetus. The first secreted fluid is known as "colostrum." This is secreted for the first few days, and is then followed by the supply of the milk proper. The secretion is under both nervous and chemical agencies. The sucking efforts of the offspring are a great factor in producing a good supply of milk. For this reason, the new-born child should be frequently put to the breast, even though the supply of food be scanty. It has been shown in animals that various chcmical bodies, such as pituitary extract (see p. 523), and extract of the involuting uterus, when injected, cause an increased flow of milk. It is stated, also, that in woman the injection 
of some of the mother's own milk or of a sterile solution of caseinogen into the buttock will cause an increased supply of milk. In medical practice, various lactagogues are employed to increase the flow of milk, such as extract of cotton-seed. It is doubtful if the supply of milk thus stimulated is adequate to the needs of the child. It is probably better to supplement a deficient supply by careful artificial feeding.

Milk is a true secretion. It contains proteins and carbohydrate not found in the blood-plasma. It contains, also, a proportion of salts quite different to those found in the blood-plasma, the proportion of some salts, such as that of calcium, being so great that they could not be derived from the blood by such processes as filtration, diffusion, or osmosis. The phospho-protein caseinogen probably originates from the cell protoplasm of the mammary gland itself, possibly by a hydrolysis of the nucleo-protein of the gland, and subsequent synthesis to caseinogen. The milk fat comes partly from the fat of the food. An ingested fat, such as sesame-oil, may be traced into the milk, but only in very small quantities. Most of the fat is probably formed in the gland by synthesis from the components of the mammary gland, probably the proteins. It is possible, also, that some is formed from the carbohydrate brought in the blood to the gland.

The origin of the mi.k-sugar is not we'l known: possibly it is formed by a rearrangement of the dextrose brought in the blood to the gland. Certain drugs are secreted in the milk-a fact of importance to nursing mothers. Compounds of morphine, iodine, arsenic, mercury, and iron, are among such.

The Composition of Human Milk.-Colostrum, the first secreted milk, has a high specific gravity-1040 to 1060. It is richer than ordinary human milk in coagulable protein (albumin), and is yellower in colour. It is rich in special cellular elements, known as " colostrum corpuscles."

Human Milk is whitish-blue in colour, with a specific gravity of 1026 to 1036. It is amphoteric in reaction, but has a lower absolute alkalinity and acidity than cow's milk. The caseinogen of human milk has a slightly different chemical constitution to that of cow's milk. It is said by some authorities to have a carbohydrate moiety attached to it. With rennet, it yields a far less dense and uniform clot. The precipitate with weak acid is more easily soluble in exccss. This accounts for the greater digestibility of human milk. The proportion of caseinogen to lactalbumin is smaller in human than in cow's milk, being in human milk $2: 1$, in cow's milk nearly $6: 1$. The fat of human milk is stated to be poorer in the volatile fatty acids than cow's milk. The composition of human milk varies greatly. Its average composition is probably respresented by the following figures, those of cow's milk being given for comparison:

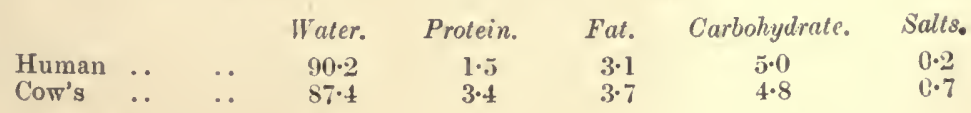


It will be secn that, in addition to the qualitative differences mentioned above, the quantitative composition of human milk is markedly different from that of cow's milk. Woman's milk is poorer in proteins, richer in sugar, poorer in salts. Human milk is also richer in lecithin. In regard to the salts, it is to be noted also that they are present in quitc different proportions to those of cow's milk. The following figures represent the content in 1,000 parts of mi k:

$\begin{array}{llllllllc} & & \mathrm{K}_{2} \mathrm{O} . & \mathrm{Na} \mathrm{O} . & \mathrm{CaO} . & \mathrm{MgO} . & \mathrm{Fe}_{-} \mathrm{O}_{3} . & \mathrm{P}_{2} \mathrm{O}_{5} & \mathrm{Cl} . \\ \text { Human } & \ldots & 0.884 & 0.35 \mathrm{j} & 0.378 & 0.053 & 0.002 & 0.310 & 0.591 \\ \text { Cow's } & \ldots & 1.72 & 0.51 & 1.98 & 0.20 & 0.0035 & 1.82 & 0.98\end{array}$

It will be secn that human milk is much poorer (six times) in calcium salts and in inorganic phosphorus, as well as being gencrally poorer in all salts. It is obvious, therefore, that, besides being impossible to make cow's milk qualitatively like human milk, is: is quite out of the question to make it quantitatively the same. In the past, much has been written about humanizing cow's milk. To effect such is out of the question. If the old rule bc followed, by which it was sought to bring about a correct human proportion of proteins, fats, and carbohydrates, in cow's milk-namely, to dilute with water and then add cream and sugar-it is obvious that the proportion of salts is disregarded. "Humanizing" is thereforc a very rough process at the best, and it is never worth while putting a patient to expense to buy so-called humanized milk.

Artificial Feeding.-Artificial feeding is sometimes necessary, and the question then arises as to what food an infant should be given. The principles to be borne in mind in artificial feeding are that the food and receptacles shall be clean, and not teeming with microorganisms; and that the food shall be easily digestible by the child, and contain the essential "bricks" necessary for its growth. Cow's milk is obviously the most handy substitute; as shown above, it is not possible to humanize it; but it must be acknowledged that some of these attempts at humanizing have succeeded in rendering the cow's milk more easily digestible by the child. Some authoritics recommend the addition of barley-water, others of sodium citrate. In the table (p. 359) is set forth a method of feeding proved successful. It should be noticed that there is no necd to use expensive lactose, and if the parent be too poor to purchase cream, a regetable oil may ke used. The large quantity of fat serves a double purpose: it nourishes the child, and at the same time ensures that the infant. is not constipated. The addition of the lime-water insures that the clot of casein is light and easily digestible.

Generally speaking, the patent infant foods by no means approximate to the correct proportions of the constitu onts of human milk; many contain starch, wh ch a very young child cannot digest. The proteins are not readily soluble in water, and there is also a deficiency in fats. If milk is boiled, the anti-scurvy vitamines require to be replaced by the giving of orange or swede juice. 


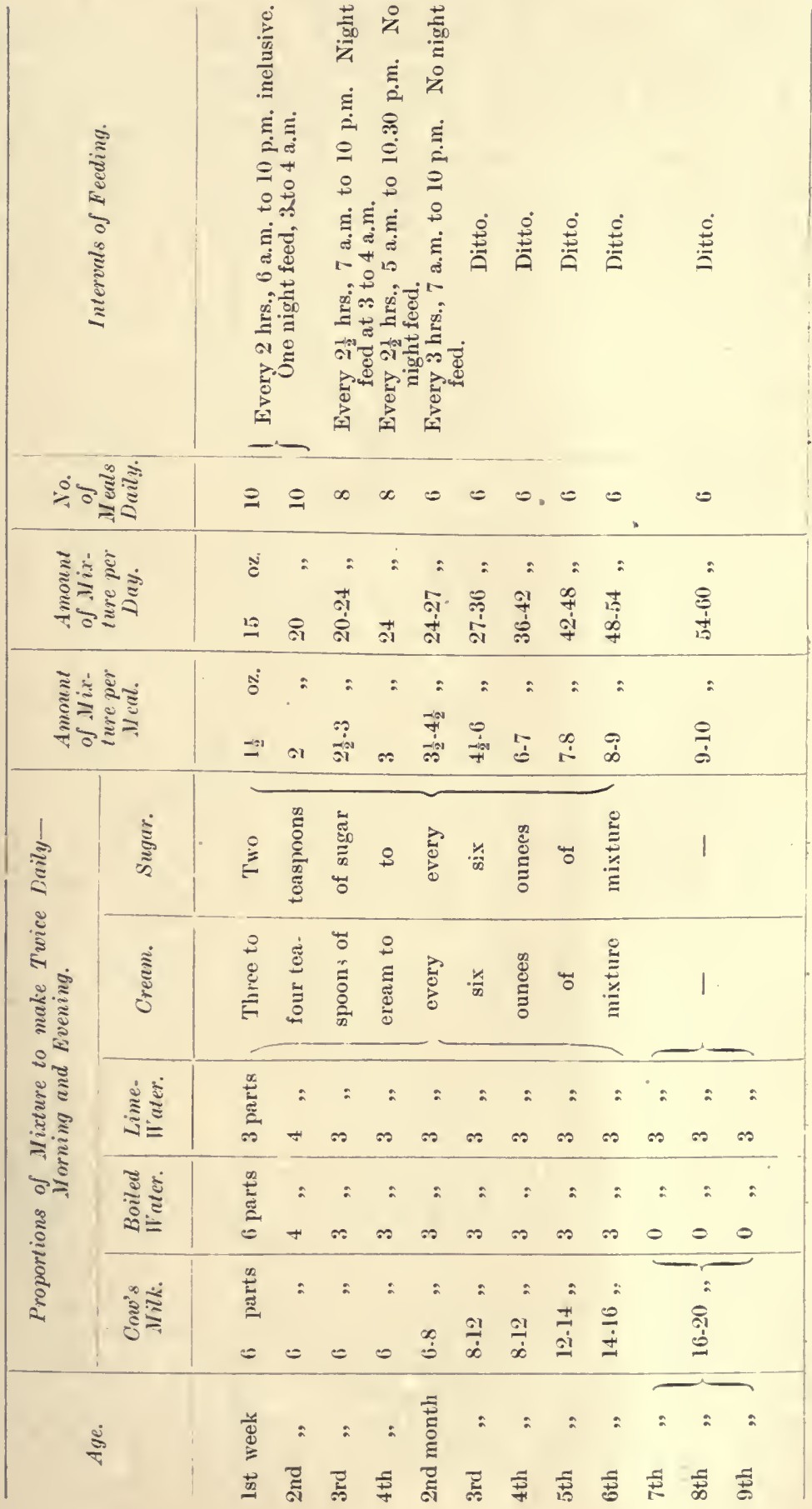


Weaning.-The milk of a mothcr begins to decrease in quantity at the end of the sixth or seventh month. It is therefore desirable that the child should be partially weaned at this time. A further reason is that the mother's milk is deficient in iron, and this deficiency begins to be felt about this time. It has been shown that the young embryo has stored within it sufficient iron to last it until it can begin to take other food. Thus, in the case of the rabbit, the embryo has enough iron stored until the young animal begins to run about and take grecn food.

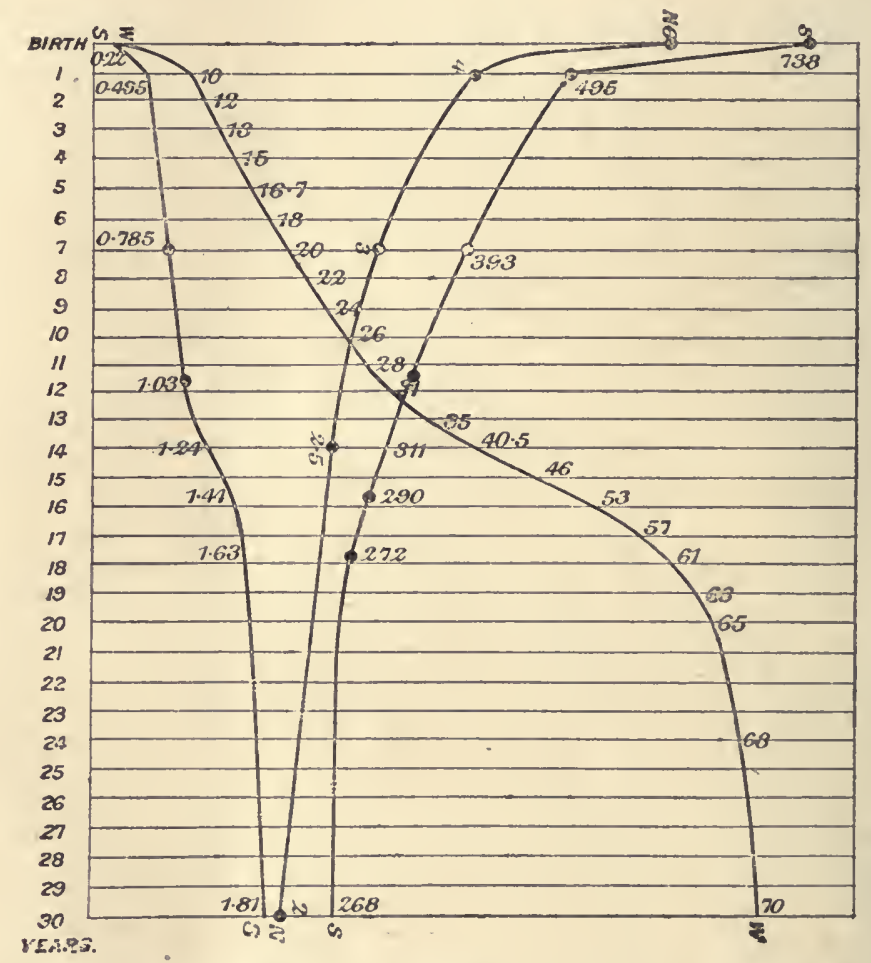

Fig. 191.-Protein required for Weight axd Surface at Differext Ages. (Waller.)

$W, W=$ Body weight in kilos $(1 \mathrm{~mm} .=1$ kilo); $S, S=$ body surface in square metres

( $1 \mathrm{~cm} .=1$ square metre); $s, s=$ body surface per 1 kilo body weight in square cms. $(1 \mathrm{~cm} .=1$ gramme $) ; N, N=$ protein per kilo body weight in grammes $(1 \mathrm{em} .=1 \mathrm{gramme})$.

During the period of lactation, the mother's dietary must be liberal in the more nutritious foodstuffs. It must be remembered that she is called upon to supply amounts varying from 20 grammes on the first day up to about 1,000 grammes at the end of the sixth or seventh month. As far as possible, also, she must be spared from grief or anxiety, which seriously affect the milk, causing digestive 
disturbances and loss of weight. Since certein drugs are secreted in the milk, only such medicines as are prescribed by a medical man should be taken by her. The progress of an infant is best judged by a gain in weight, which should be steady-from 4 to 16 ounces per weck, excepting during the first week of life

Childhood.- It is obviously important that the growing child should have all abundant supply of food material, especially protein and such inaterial as is necessary for the growth of the developing organism. Further, it is to be bornc in mind that the child is not only growing, but also that it is a small animal, and therefore has a relatively

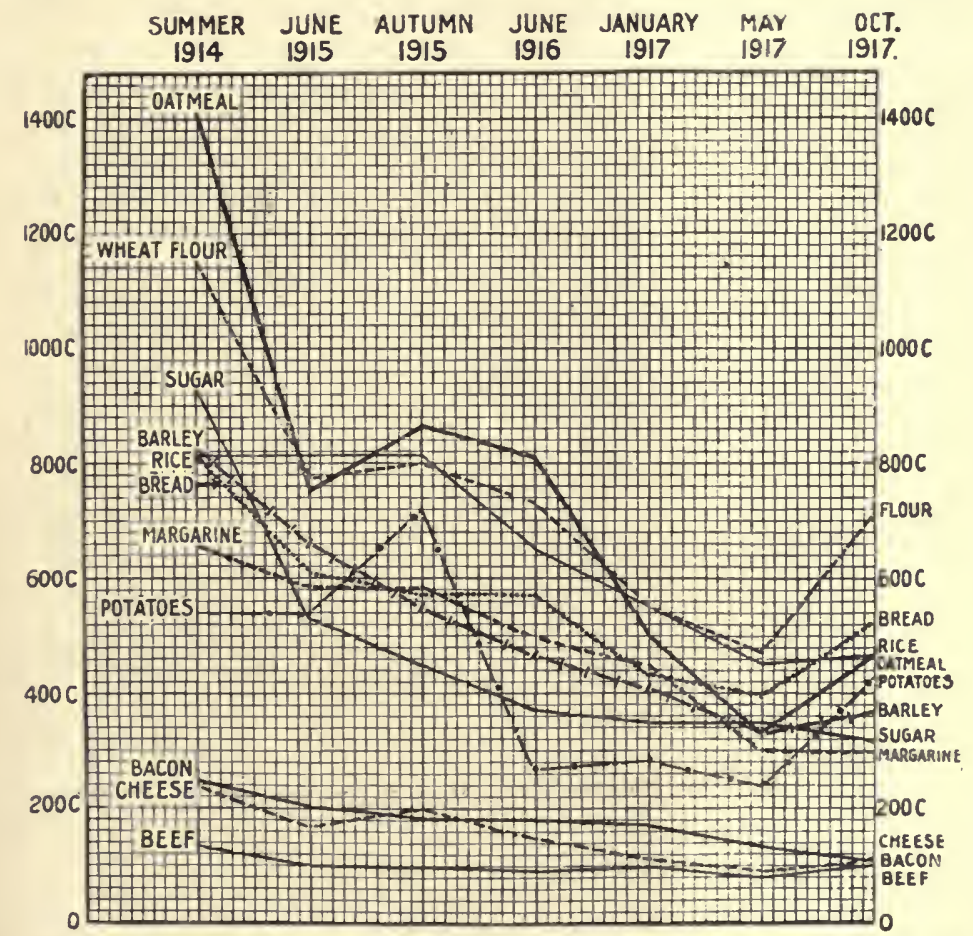

Fig. 191a.- Table of food Values showisg Calories perchashie per Penvy. (Nuel Paton.)

greater surface area and a corresponding greater respiratory cxchange (Fig. 190). Further, the child, when healthy, is always active while awake. From Fig. 191, it is obvious that in the first few years of life, and again at the age of pubcrty, the food-supply should be particularly liberal.

In the diet of a growing child, the cereals and potatoes should figure largely. At first ground oats, later oatmeal or rolled oats, are of particular value, by virtue of the large amount of proximate principles, as well as the large salt content. Milk in various forms, eggs, mcat, fresh fruit, should also be incorporated in the dictary. 


\section{CHAPTER XLIII}

\section{SPECIAL DIETETIC METHODS, ALCOHOL, COOKING, ETC.}

Special Dietetic Methods.-Of these the best known is regetarianism, either "true " or "falsc." In "true " vegetarianism, no animal food whatsoever is eaten; in "false" vegetarianism, such animal foods as milk, cheese, and eggs, are frcely consumed. There is little to be said against false vegetarianism, provided that sufficient of these animal foodstuffs are eaten, insuring a good supply of protein and not too much vegetable fibre. The proteins, too, are such in kind and amount that putrefaction in the large intestine is not great. 'To this "false" vegetarianism owes its popularity.

In regard to "truc" vegetarianism, there is very little evidence in support of the main contentions of its devotees. It is said that, on anatomical grounds, man is not a carnivorous animal; that meat is therefore an unnatural food, dangcrous to health. Man's alimentary canal is very different from that of a rabbit, with its enormous cæcum; and the monkey, his near relation, eats animal food, eggs, insects, etc. as well as nuts and fruits. Granted that excessive ingestion of animal protein induces unwholesome putrefaction in the large intestine, so that toxins are formed deleterious to health, this was no case against a moderate intake of meat. The most virile tribes of the world, past or present, were or are great meat-eaters. Trouble arises from over-indulgence; some meat-eaters, owing to lack of exercise, do not keep themselves fit, and therefore do not eompare favourably with vegetarians, who keep themselves fit. The evidence shows that a "fit" meat-eater is of better physique and mental capacity than a "fit" vegetarian. True vegetarianism has the disadvantage of introducing too much ballast, just as pure meat-eating introduces too little. Further, the physiological availability of such foodstuffs is considerably less, and the proteins are of less value for tissue-forming.

Various other speeial dietetic methods - "raw food," "purinfree," "low protein"-have their adherents. In these days of adulteration and separation of natural foods it is quite possible that errors may arise in man's diet, but it is safe to conclude that if the general public devoted as much attention to keeping itself fit by proper muscular exercise in the open air, as it does to the question of diet, the latter would cease to be of such importance.

Alcohol.-When taken in small quantities, alcohol is burnt in the human body, serving as a source of energy. Thus, it has been shown 
in an experiment on man in the respiration calorimeter that the addition of 72 grammes of alcohol (500 calories) to a fixed diet exerted a greater sparing effect on the protein of the diet than did 130 grammes of sugar (515 calories). It is probable that alcohol in such small non-toxic amounts acts as a carbohydrate-sparer. It is possible, also, that a small amount of alcohol facilitates digestion. While there is no basis of fact for the assertion that dire effects are produced by the taking of a small amount of alcohol into the human system, there is great economic waste of food in their preparation. Energy is dissipated by the process of fermentation. There is in a gallon of beer only one-tenth of the energy of the barley used in its preparation, and, even allowing for the food value of the waste products used for feeding cattle, there is still a considerable loss of valuable energy.

By virtue of its quick absorption from the stomach, and the ease by which it is combusted, alcohol is of great service in medicinal doses in treatment of cardiac failure. The feeling of warmth promoted by alcohol is due to an increased blood-flow in the cataneous vessels, so that alcohol, instead of keeping out the cold, may tend to make the body lose more heat. "Wine is a mocker," and he who is exalted by it is a lenient critic; hence its reputation for promoting sociability. It removes the consciousness of fatigue and the feeling of care, and makes facile the play of thought and speech by weakening the higher function of brain-inhibition. The subjective impression of mental capacity, exalted under the influence of alcohol, is unconfirmed by test. Small doses have no effect, larger ones diminish the fineness of control and skill in handiwork. A man under the influence of alcohol will make more mistakes in type-writing and in casting columns of figures. Habitual indulgence in alcohol, by banishing the pressing sense of duty, makes a man indifferent to the obligations of family and national life. It is the monotonous, confined existence in modern cities which impels him to such indulgence. He who lives a hygienic life, oxygenates his tissues by outdoor exercise, and thus keeps a cheerful, active mind, will need not the "wine which maketh glad the heart of man," but the "bread which strengtheneth man's heart."

Table showixg Percentage of Alcohol in the Commoxer Spirits, Wines, and Beers (Pre-War Times).

\begin{tabular}{|c|c|c|c|c|c|}
\hline Spirits. & $\begin{array}{l}\text { Alcohol } \\
\text { per Cent. }\end{array}$ & Wines. & $\begin{array}{l}\text { Alcohol } \\
\text { per Cent. }\end{array}$ & Beers. & $\begin{array}{l}\text { Alcohol } \\
\text { per C'ent. }\end{array}$ \\
\hline Ruy & .. 43-45 & Por & 25 & English alc & .. $5-7$ \\
\hline & . . 43-45 & Sherry & .. 21 & Stout & $4-7$ \\
\hline zy & . 40 & Champagne & .. 10-15 & English & $4-5$ \\
\hline Gin $\quad \cdots$ & . $\quad 35-37$ & $\begin{array}{l}\text { Hock } \\
\text { Claret }\end{array}$ & $\begin{array}{rr}\ldots & 10 \\
\ldots & 9\end{array}$ & German lager & $3-4$ \\
\hline
\end{tabular}

Tea and coffee owe their popularity partly to the alkaloid caffeine -a methyl-purin-partly to the aromatic principles contained in them. In small dozes caffeine is stimulating; in large doses it is 
poisonous. When prepared properly-that is, when infused for only a few minutes and then poured off-tea is frec from injurious effects, but the habit of taking strong tea every two or three hours of the day is to be condemned no less strongly than the taking of alcohol.

Cocoa is more of a foodstuff, particularly if made with milk. It contains fat and a certain amount of theobromine-an alkaloid closely related to caffeine.

Cooking of Food.-This is accomplished by means of heat, either moist or dry. Cooking has certain advantages and certain disadvantages, the former outweighing the latter. The chief disadrantage in cooking is that coagulable proteins are possibly rendered more insoluble in the digestive juices, so that their digestion takes longer, although eventually it is just as complete. On the other hand, cooking kills bacteria and other parasites such as trichinæ and tape-worms, which may be present in the food. The connective tissue of meats is rendered more soluble, the fibres disintegrated and made easier for mastication, especially by moist heat. In the cereals, the starch granules swell up and rupture the cellulosc envelope, rendering the cell-content more accessible to the digestive juices. In vegetables, the woody fibre is also more or less disintegrated, the tissue rendered more tender, and the cell-contents more or less liberated. Dry heat also converts a certain amount of starch into dextrin-e.g., as in the crust of bread.

The chief forms of cooking are boiling, broiling, and roasting. The main loss in cooking is water-the loss increases with the length of time of cooking-in roasting a considerable quantity of fat (the dripping) is lost from the joint. When boiling is employed, the liquor should be used to prepare soup, otherwise a considerable proportion of proteins, extractives, vitamine, and salts, is lost. This is true both for meat and regetables. The peeling of regetables greatly increases such loss. The most economical forms of cooking are broiling and by casserole.

In the preparation of food, various flavours and condiments are often added. When used in moderate quantitics, these, by rendering the food "toothsome," have the effect of causing a "psychic" flow of gastric juice, and thereby promoting digestion. On the other hand, the excessive use of condiments tends to upset the digestive apparatus. The appetizing effects of cooking enhance the pleasures of the table, but often lead to overeating, and so to nutritive disorders of sedentary workers. A certain amount of uncooked natural food should be eaten, such as fruits and salads.

Meals should be restricted to three a day, and no food should be taken between meals. For the preservation of the teeth, it is necessary that the mouth be kept free from food for most hours of the day. 


\section{BOOK VI}

\section{THE PROCESSES OF DIGESTION}

\section{CHAPTER XLIV}

\section{THE MECHANISM OF THE SECRETION AND ACTIVATION OF THE DIGESTIVE FLUIDS}

For the proper digestion of the food, digestive juices are necessary. These are provided either by large compound glands which lie wholly outside the alimentary canal, and are connected to it by ducts, such as the salivary glands, liver, and pancreas; or by glands which oceur in the lining membrane of the alimentary tract itself. Thesc are eomparatively simple gland tubes, and line the whole of the stomach, small and large intestine. The lining cells of the alimentary canal also contribute to the secretion of mucus, which acts as a lubricant, protects the mucous membrane from too high a concentration of ingested material, and furthers the passage of contents down the gut.

To understand rightly the processes concerned in the digestion of food, it is necessary that we study-(1) the mechanisms by which the digestive fluids are provided; (2) the means by which the enzymes they contain are activated or otherwise rendered efficient digestive agents.

The proper preparation of foodstuffs for digestion, and their adequate digestion, are matters of first importance to the general well-being of the body. Discomfort and loeal pain occur when these funetions are temporarily deranged; malnutrition, anæmia, depression of spirits, and general ill-health, follow chronic indigestion.

Digestion of the food is necessary, in the first place, in order to convert the complex, colloidal, non-diffusible, and insoluble protein, stareh, and the fat, into simpler soluble, diffusible, and non-colloidal compounds, which are absorbed by the eells lining the alimentary tract. Secondly, it is necessary because some of the component parts of the food material introdueed into the body are of little or no value to the body; others are of intermediate value; others, again, are so precious that without them the body cannot live. In order, therefore, that these eomponents may be sorted according to their true value, it is necessary that they be separated from each other by the hydrolyzing action of the digestive enzymes. 
Generally, throughout both the vegetable and animal world, we find foodstuffs are taken into the living cells in a state of simple solution, either already dissolved in water, or brought into solution by enzymes and watcr secreted by the cells. From the protozoon which engulfs its food up to the mammal is this true. True also is it of the insectivorous plants, such as the sundew and pitcher-plant (the former entraps insects with nets, or the latter with lethal wells of water); of the yeast or bacterium; and of plants generally.

The Mechanism of Secretion.-Two methods of calling forth secretion are employed: (1) The nervous reflex; (2) the chemical reflex, or "hormone" mechanism.

One or both of these mechanisms may be used to provide a juice. More exact details are given when each juice is considered separately. Nervous tissue has been elaborated for the especial purpose of quick transfercnce of messages from one part of the body to another. The nervous mechanism is called into play when rapid secretion is wanted. The nervous mechanism is therefore used for the supply of the saliva and for the first flow of the gastric juice. While enough fluid for the immediate demands of the body is provided by the nervous mechanism, the chemical mechanism is present to insure the presence of an adequate amount of digestive juices for the thorough preparation of food and its complete digestion.

For the liberation of the "hormone reflex," either (1) the products of the digestion brought about by " nervous " flow, or (2) some constituent of the juices so secreted, is concerned in calling forth this "chemical" flow of juice. For example, in the stomach we find that the presence of dextrin and peptones-that is, the products of a salivary and gastric digestion respectively-liberate from the pyloric mucous membrane a body-" gastrin "-which is absorbed into the blood, and, reaching the gastric glands, excites a further flow of gastric juice. It may be also that there is something in the saliva able to bring this mechanism into action, for it has been noticed that swallowed saliva appears to have the power of evoking a flow of gastric juice.

The flow of pancreatic juice is also brought about by a "chemical " reflex-namely, by the liberation from the duodenal mucous membrane of a body termed "secretin," which passes in the blood to the pancreas, and stimulates that organ to activity. There is evidence that the pancreas may also be excited to secrete by impulses reaching it through its nerves. This, however, does not appear to be the normal mechanism. In the case of secretion excited by nervous mechanisms, it is probable that the nervous excitation of the gland evokes a " hormone " in the gland itself, which excites the secretion. For example, an extract of resting salivary gland has no effect when injected into the blood, but an extract of the same gland, after stimulation of the chorda tympani nerve, is said to provoke secretion of saliva when injected.

The exact nature of the substance provoking the flow of succus entericus is not well known. Undoubtedly, the acidity of the chyme entering the duodenum plays a most important part as regards the 
provision of this juice in the duodenum. It is suggested that, for the other parts of the small intestine, the absorption of the products of the digestion in the parts above evokes a messenger which, absorbed into the blood, calls forth a flow of appropriate juice in the regions lower down the tract.

The bile takes an important share in the preparation of the food for intestinal digestion-for example, in the emulsification of fats and the precipitation of protein from acid solution. A quick flow of bile is therefore required. In animals where a gall-bladder exists, the first flow of bile is probably provided by the contraction of the gall-bladder, which is excited by a nervous reflex. The reflex arises from the stimulus of food passing the pylorus. A further supply of bile is provided from the liver by the action of "secretin." This insures its presence in the intestine in amounts adequate to the food which is arriving there to be digested. Possibly, too, the products of digestion reaching the liver cause a further flow of bile. The reabsorption of bile salts from the intestine stimulates the liver to secretion, but this is usually after the period of active digestion, and the bile secreted by this mechanism is generally stored in the gall-bladder, there being a correspondingly active secretion to replenish the depleted store. The following chart shows how different juices are provided:

Juice

Saliva $\quad \ldots \quad \ldots \quad \ldots$ Nervous reflex.

Gastric juice $\quad \ldots \quad$. $\quad$ (1) Nervous reflex.

Bile

Pancreatic juice . .

Succus entericus ..

(1) By secretin.

\section{Mechanism.}

(2) Liberation of gastrin (chemical reflex).

(1) Probably nervous reflcx contraction of gall-bladder.

(2) By secretin (chemical reflex).

(3) By products of digcstion reaching liver.

(4) By absorption of bile salts.

(2) Probably also by nervous reflex.

(1) By acid chyme.

(2) By absorption of products of digestion.

We have, therefore, to bear these mechanisms in mind when thinking of the digestive disorders which may possibly arise. It may well be that in some conditions the flow of one or other of these juices is not evoked adequately, owing to a failure of the proper stimulus for its secretion.

The Activation of the Juices.-In most of the juices the digesting agent, or enzyme, is in the form of a precursor, or zymogen. This zymogen must be converted into the enzyme, or "activated," as it is termed, before it becomes potent. The enzyme of the saliva"ptyalin"-is probably activated by the bactcria of the mouth, or some other body present in the mouth, since in the horse it has been found that if the saliva be collected ascptically it manifests no digestive action. It is only when bacteria are allowed to enter the saliva that the cnzyme attains its digestive power. Bacteria probably play a similar and important part in other parts of the alimentary tract, ercn when specific activators of the zymogens arc scereted there. 
The normal activator of the gastric zymogens-pepsinogen and prorennin-is the hydrochloric acid $(\mathrm{HCl})$ of the gastric juice. It has been found, however, that these two zymogens may become converted into the active enzymes in conditions where hit'? or no $\mathrm{HCl}$ is keing secreted. In such cases, the exact activator is not known; it is quite probable that bacteria play a part. Similarly, the normal activator of the trypsinogen of the fancreatic juice is a substance known as "enterokinase," which is secreted in the succus entericus. But it is protable that an enzyme- - deuterase" - and calcium salts also possess the fower of converting this zymogen. The other enzymes found in pancreatic juice are fossibly secretad as zymogens, but the exact nature of their activating agent is not known. The same must be said in regard to the enzymes of the succus entericus. The steapsin of the pancreas requires the presence of bile salts to act as co-enzyme. The enzyme loses its digestive fower if these be dialyzed away. It is quite rossible that in some conditions of digestive disturbance there is an inadequate liberation of the enzymes from the zymogens, in others an inadequate secretion of the zymogens. At present, our knowledge on these points is fragmentary.

$\begin{array}{lllll}\begin{array}{c}\text { Juice. } \\ \text { Saliva }\end{array} & \ldots & \begin{array}{c}\text { Proenzyme. } \\ \text { Ptyalin }\end{array} & & \begin{array}{c}\text { Activator. } \\ \text { Gastric }\end{array} \\ \text { Pancreati : } & \ldots & \begin{array}{l}\text { Pepsinogen } \\ \text { Prorennin }\end{array} & \ldots & \text { Hydrochloric acid. } \\ & & \text { Trypsinogen } & \ldots & \begin{array}{l}\text { Enterokinase. } \\ \text { Calcium salts. } \\ \end{array} \\ & & & \begin{array}{l}\text { DeLterase. } \\ \text { Bacteria (?). }\end{array}\end{array}$

In regard to other enzrmes, the present state of knowledge is insufficient for trem to be tabulated. 


\section{CHAPTER XLV}

\section{DIGESTION IN THE MOUTH}

The Saliva.-The saliva is secreted from three pairs of glands in the region of the mouth. These are the parotid, the submaxillary, and the sublingual. It is also secreted by other minute glands contained in the buccal mucous membrane. The character of the saliva varies in the different glands.

The parotid of man and most animals yields a thin serous (albuminous) saliva, while from the submaxillary gland " mixed " saliva, partly serous or watery, partly mucous or viscid, is usually obtained; in the rabbit, however, the secretion of the submaxillary glands is wholly serous. Saliva is a mixture of the secretions of all these glands. The parotid saliva of man is a thin, faintly alkaline fluid, containing but little protein and no mucus. Its specific gravity varies from 1003 to 1012. It contains a starch-splitting enzyme-ptyalin-and in most cases a small amount of potassium sulphocyanide, with a variable small amount of salts $(0.5$ to $\mathbf{l} \cdot 6$ per cent.) and gases in solution (oxygen, nitrogen, and carbon dioxide). The oxygen in the saliv a is greater in amount than that which is dissolved in water when exposed to the atinosphere. The excess must be secreted in the saliva.

Submaxillary saliva varies according to the exciting conditions. In man, the submaxillary saliva is ordinarily a clear, viscid, alkaline secretion, with a specific gravity of 1002 to 1005 , and about 0.3 to 0.5 per cent. of solids. It contains much mucin, traces of protein and the ferment ptyalin, potassium sulphocyanide, and inorganic salts, the chief of which are the chlorides of sodium and potassium, the phosphates of calcium and magnesium, and the bicarbonate of calcium and sodium. Traces of sulphates are also present. In the dog two kinds of submaxillary saliva are recognized: that produced by stimulation of the chorda tympani nerve, known as chorda saliva, and that produced by stimulation of the sympathetic nerve, known as svmpathetic saliva. Chorda saliva is the abundant secretion of the gland, having a specific gravity of 1003 to 1005, and containing about 1.2 to 1.4 per cent. of solids. Sympathetic saliva is very much smaller in amount, and considerably richer in solids (1.6 to 2.8 per cent.). Its specific gravity is 1007 to 1018 .

Sublingual saliva, the most alkaline of the salivas, is transparent, viscid saliva, comparatively rich in mucin and solids. It also contains ptyalin and potassium sulphocyanide. 
The secretion of the buccal glands consists chiefly of thick mucus.

The mixed saliva obtained from the mouth has therefore a combination of the properties of the secretions forming it. Its quantitative composition may be seen by the following analysis:

$\begin{array}{lcccccc} & & & & & \text { Per Cent. } & \text { Per Cent. } \\ \text { Water } & \ldots & \ldots & \ldots & \ldots & 995 \cdot 16 & 994 \cdot 10 \\ \text { Solids } & \ldots & \ldots & \ldots & \ldots & 4 \cdot 84 & 5 \cdot 90 \\ \text { Mucin } & \text { M } & \ldots & \ldots & \ldots & 1 \cdot 62 & 2 \cdot 13 \\ \text { Soluble organic bodies } & \ldots & \ldots & 1 \cdot 34 & 1 \cdot 42 \\ \text { Sulphocyanide } & \ldots & \ldots & \ldots & 0 \cdot 06 & 0 \cdot 10 \\ \text { Salts } & \ldots & \ldots & \ldots & \ldots & 1.82 & 2 \cdot 19\end{array}$

It is usually somewhat turbid, owing to the presence of epithelial cells and of food particles. Upon standing, it becomes more so, owing to the deposition of calcium carbonate and organic matter, which forms the tartar deposited on teeth.

In some animals, saliva contains an oxidase and maltase. The exact significance of the potassium sulphocyanide is not known. Smokers are said to have more than non-smokers. This is very doubtful. Its presence can readily be detected by the red colour obtained upon adding a little $\mathrm{HCl}$ and some ferric chloride to the saliva.

The functions of the saliva are-

1. To act as a solvent by virtue of the large amount of water it containis, and also in part as a solvent for the digested soluble nutritive substances. Probably, saliva plays a larger part in this way than is usually believed.

2. To act as a lubricant by virtue of its mucus content, and thus facilitate the act of swallowing.

3. To act upon boiled starch as a digestive agent.

4. To aid taste-dry substances cannot be tasted-and indirectly, through tastc, to stimulate the flow of saliva and gastric juice.

5. To moisten the mouth, and thereby aid articulation; to wash out the mouth, and thereby get rid of noxious, evil-tasting, or poisonous substances; to clean and protect the teeth from decay.

6. Possibly, when swallowed, to act as an cxcitant to the flow of gastric juice.

The manifold nature of its functions accounts for the variation found in the composition of saliva. The nature of the saliva secreted is adapted in the main to that function which is in most demand. This adaptation depends upon three factors-chemical, physical, and psychic. Acids and evil-smelling substances cause a grcat flow of thin parotid saliva; dry bread, cooked potatoes, hard-boiled eggs, causc a flow of saliva rich in ptyalin, the mucus and water contentvarying according to the dryness; sugar evokes a saliva poor in mucin; a pcbble put in the mouth crokes no secretion, while sand calls forth a large flow.

The movements of chewing and spcaking cxcite the flow; the holding of food in the mouth erokes little or no secretion. The sight of food makes an animal's mouth "water"; the sight of a colour associated with a given food may do this also. A stone painted like a 
piece of meat will at first evoke secretion in a dog until the animal realizes it is a fraud; then it ceases to do so.

The smell of food causes a flow of saliva, varying according to the appetite. It is particularly copious when the animal is hungry. Hearing a noise associated with food--e.g., the rattle of the food-plato -also induces a salivary flow.

The amount of saliva secreted while eating depends-

1. Upon the dryness of the food.

2. Upon its chemical properties.

3. Upon the length and thoroughness of the act of chewing.

4. Upon the water intake.

5. Whether accessory stimulants be present, such as mustard or pepper.

6. Upon the excitability of the nervous mechanism of the salivary glands themselves.

The quantity of saliva generally varies from 500 to 1,500 c.c. per day. Experiments showed that a girl secreted while chewing-

\begin{tabular}{|c|c|c|c|c|c|c|c|c|c|c|}
\hline 150 & & of sugar & .. & . & .. & . & $\therefore$ & 200 & c. & aliva. \\
\hline 200 & ", & of milk.. & .. & .. & .. & .. & .. & 200 & ," & , \\
\hline 200 & , & of bread & .. & .. & .. & $\ldots$ & $\ldots$ & 126 & ," & ", \\
\hline 700 & ," & of mixed diet & meat, soup & potatoe & & .. & .. & 300 &. & ", \\
\hline 10 & ," & of thin bread & and butter & .. & .. & .. & .. & 2 & ," & ", \\
\hline 10 & ", & of dry bread & . & .. & .. & .. & $\ldots$ & 15 & ," & ", \\
\hline
\end{tabular}

The Mechanism of Secretion.-During the process of secretion there occur certain well-marked changes in the gland cells. In a serous gland, prior to secretion, the cclls are filled with granules which stain readily, the nuclei of the cells being almost obscured or appearing at one side as more or less irregular masses. During secretion, these granules become discharged from the ccll, the nuclei become more prominent, while the cells markedly shrink in size.

In the mucous gland the process is comparable. The resting cell, with its large refractile granules and nuclei flattened towards the base of the cell, is replaced after secretion by the smaller "exhausted" ccll, devoid of mucigen granules, with well-marked spherical nucleus placed in the middle of the cell. During the period of rest, the cells again elaborate new granular material, and pass into the "resting state."

The salivary secretion takes place under nervous influence, the whole process being presided over by a centre in the medulla oblongata (c) in the region of the glosso-pharyngeal nucleus. To this centre come impulses directly by various sensory nerves, and also indirectly via the higher centres $(c)$ of the brain (Fig. 192). Thus it is that contact of food with the buccal mucous membrane or stimulation of the central end of the lingual or glosso-pharyngeal nerve gives rise to a flow of saliva. Exactly how the sensory discrimination and adaptation of the flow of saliva are brought about is not known. The results show that such discrimination is a function of the lower subconscious centres. Sight and hearing act reflexly through the higher centres; so do past 
impressions, such as are aroused by thinking of a favourite meal. This may make the mouth water, especially in a state of hunger.

The efferent nerves from the centre are the auriculo-temporal nerve to the parotid gland, the chorda tympani nerve to the submaxillary and the sublingual glands. The sympathetic system also gives a weak effector nerve to the submaxillary gland and sublingual gland.

The course of the effector nerves is somewhat complicated. While stimulation of the fifth nerve above the otic ganglion is without effect upon the secretion of the parotid gland, stimulation of the ninth nerve as it leaves the brain causes a flow of saliva. The effector fibres therefore pass from the ninth nerve to the fifth. They follow the path of Jacobson's nerve, and the small superficial petrosal, to the otic ganglion, which is the cell-station of this nerve.

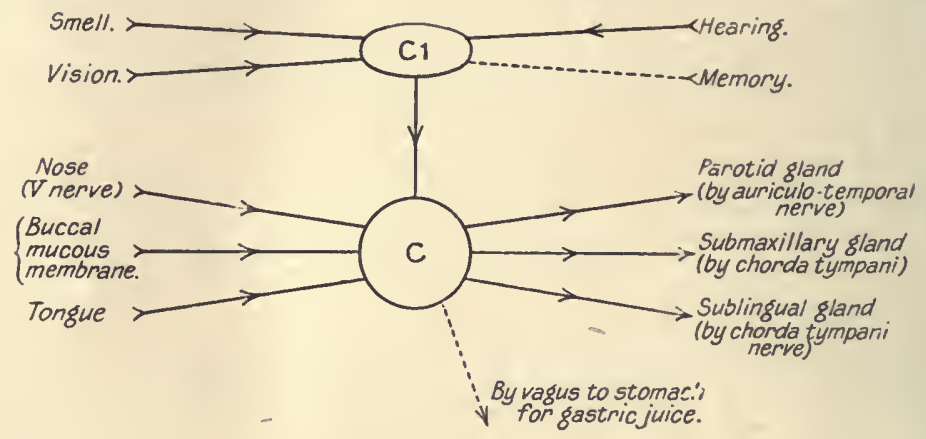

Fig. 192.-Diagray to show Connections of the Nervots Centre concerned in the Secretion of Saliva and Gastric Joice.

The stimulation of the sympathetic nerve to the parotid does not effect a flow of saliva. It is stated, however, that if the nerve be stimulated at the same time as Jacobson's nerve, or the glosso-pharyngeal, the solid content of the saliva, particularly the organic, is considerably raised.

In regard to the submaxillary and sublingual glands, it has been proved experimentally that if the lingual nerve be cut high up, reflex secretion of saliva still occurs. Similarly, stimulation of the peripheral end of this nerve, and after it has been cut high up, has no effect upon secretion. On the other hand, if the chorda tympani ncrve be cut, reflex sccretion is abolished; while stimulation of the peripheral end causes a copious flow of watery saliva. This nerve issues from the seventh nerve as a small branch, and, joining the lingual in the lower part of its course, runs with it for a short way, and then passes to the glands. The coursc of the fibres, however, is interrupted by the interposition of ganglia. The fibres to the sublingual gland end in a small ganglion, known as the "submaxillary ganglion" (it ought to be termed "sublingual"); the fibres to the submaxillary gland end in a minute ganglion situated in the hilus of the gland. The cell 
stations are shown by painting the ganglia with nicotine; this paralyzes the synapses or end terminations of the preganglionic fibres with the ganglion calls.

There is some discussion as to the manner in which the effector nerve acts. According to one view, there are two kinds of fibres in the nerve-trophic fibres, which cause changes in the granular material, preparing it fo: its dissharge from the cell; and the secretory fibres, which bring aboat this discharge. Upon this view, the sympathetic nerve is mainly trophic, the cranial (chorda) nerve is mainly secretory.

It is more generally held, however, that one kind of fibre causes all the changes attendant on secretion, the differense between chorda and sympathetic saliva being due to the difference in blood-supply. With the chorda stimulation there is a great vaso-dilatation, with sympathetic stimulation there is marked constriction of the small arteries supplying the gland. Vaso-dilatation is probably also produced locally by the products of matabolism of the gland.

The action of the nervous mschanism appears to be more marked at som 3 tims3 than others. It is more marked in a state of hunger than in a state of satiety. It may possib:y be that the product s of digestion or the saliva itself bəcoms absorbed, and affect the excitability of the norvous machanism or the cells of the gland.

A day or two after the chorda tympani nerve has bəan divided there begins a slow continuo:us seeretion of saliva, known as paralytic sicretion which lasts from five to six weeks. As the nerve itself degenerates in thres to five dxys, the sesretion is obviously due to soms losal apparatus in the gland. If the sympathetic nerve bs cut at the sams tims, the sesretion is diminished or stopped. No paralycic serretion follows sesretion of the sympathetic norve by itself; this produces little or no observable effest. The sams is true in regard to excision of the supərior cervical ganglion.

The characteristic saliva of any one gland may be obtained by placing a small glass cannula in the main duct, and stimulating the effestor nerve. The submaxillary gland is the one which lends itself most rexdily to this experiment. By sush means the true secretory nature of the saliva can bo demonstrated. If the cannula placed in the submaxillary duct be connected to a manometer, and the pressure which is produced in the duct during stimulation of the chorda tympani be measured, it may be found to rise to twice the height of the pressure of the arterial blood supplying the gland (Fig. 193). The salivary secretion is therefore a true secretion. It is not merely a passage through into the salivary ducts as the result of pure mechanical prozesises, such as filtration, diffusion, or osmosis. Even with so great a pressure, the blood still flows through the salivary glands. This is because the blood-capillaries of the gland are protected from ozclusion by the basement membranes which cnclose the alveoli of the gland. Tnese membranes, strengthened by connective tissue, limit the expansion of the alveoli, just as the leather case of a football limits the cxpansion of the bladder within. A certain amount of expansion is allowed, however-enough to narrow the veins within the gland, and convert the 
bloodvessels, arteries, capillaries, and veins, into a more rigid system, through which a very rapid flow of blood takes place. Thus, the whole gland swclls under these conditions, and feels very tensc to the touch. If the blood-supply to the gland be lessened by a moderate compression of its arterial supply, the rate of secretion remains unchanged. Considerable compression decreases the amount. A salivary gland will
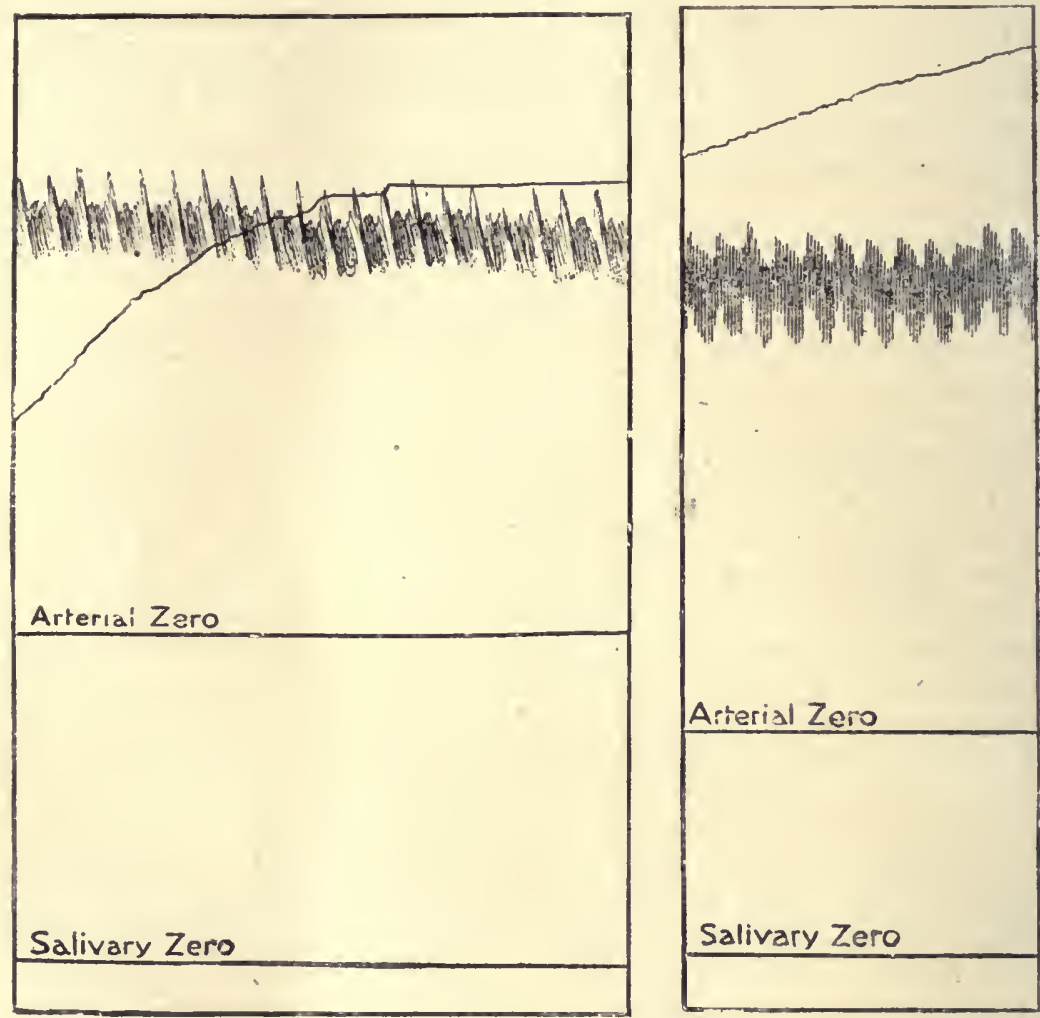

Fig. 193. -Tracisgs fron Two Differext Dogs, ax.esthetizid by Morphixe and Chloroform, showixg the Arterial (Carotid) Presseires axd the Secretory Pressures of Saliva during Excitation of the Chohd Trupaxi Nerve. (From Proceedings Rcyal Scciely.)

With a salivary pressure of $240 \mathrm{~mm}$. $\mathrm{Hg}$ and \&n arterial pressure of $1 \Sigma 0 \mathrm{~mm}$. Hg., blood still flowed through the gland.

even secrete a few drops when its blood-supply is cut off-e.g., after eutting off the head. Certain drugs, such as atropine, paralyze the secretory fibres of the gland, but not the fibres producing vaso-dilatation. Thus, when the chorda tympani nerve is stimulated after injeetion of atropine, a rapid blood flow and increased pressure is obtained in the gland, but no secretion. An injection of quinine hydrochloride produced vaso-dilatation in the gland, but no secretion. 
The total osmotic pressure of the blood is $4,500 \mathrm{~mm} . \mathrm{Hg}$, whereas that of the saliva is but $3,000 \mathrm{~mm} . \mathrm{Hg}$.

During the process of secretion there is a greatly increased tissue respiration within the gland, the amount of oxygen used up and the amount of carbon dioxide given out being markedly increased.

Gaseous Exchange.

$\begin{array}{lllll} & & & \mathrm{O}_{2} \text { taken up. } & \mathrm{CO}_{2} \text { Output. } \\ \text { Resting gland } & \ldots & \ldots & 0 \cdot 25 \text { c.c per minute. } & 0 \cdot 17 \text { c.c. per minute. } \\ \text { Active gland } & \ldots & \ldots & 0.86, ", \quad, & 0.39, ",\end{array}$

The blood-flow may be increased seven to ten times during secretion, and the amount of lymph formed goes up markedly.

From these considerations, the conclusion is reached that the saliva is not a filtrate or transudate, but a product of the activity of the gland cells, separated by forces which cannot at present be grouped under the physico-chemical processes which have been worked out in the laboratory.

Certain diffusible substances in the blood-sugar, for examplenever appear in the saliva, whereas certain salts, if taken into the body, are picked out by the salivary glands and secreted in the saliva. This is the case with iodides and mercury. This fact must be borne in mind in prescribing these drugs.

The secretion of iodides is sometimes made use of to test the absorbing power or motility of the stomach. Potassium iodide is given by the mouth, and the time taken for the appearance of iodides (tested for by starch solution and chloroform) in the saliva noted. The rate of appearance varies with the absorptive power of the stomach for iodides. It is questioned whether this gives any guide for the ordinary absorptive power. To test the motility, the iodide is given in a capsule, which is not digested by the gastric, but by the pancreatic fluid, and the time taken until the iodide appears in the saliva.. The test cannot be regarded as by any means accurate, since its passage out of the stomach is rather a haphazard matter; but should the iodides appear within two to three hours, the motility of the stomach is regarded as normal.

Heat is produced in the gland, as is shown by the oxygen use and production of carbon dioxide, but, owing to the velocity of the circulation, it is not possible to observe the difference in tempcrature. It has been claimed that the saliva is one or two degrees warmer than the blood; but if the bulb of a very delicate thermometer be introduced into the aorta through the femoral artery, and the bulb of another thermometer is placed in the cannula attached to the salivary duct, and this cannula be filled with water of the same temperature as the blood, then on stimulating the secret:on no change in temperature is observed. Electrical changes (see later, p. 566) are also observed in the gland. The current of rest gives place to a current of action, but the direction of the current is different according as the chorda tympani or cervical sympathetic is excited. 
The Action of the Ptyalin.- The enzyme ptyalin, when present in the saliva of an animal, acts upon boiled starch, and converts it through the stages of erythrodextrin and achroödextrin to maltose. 'The stages can well be demonstrated by taking a series of test-tubes containing iodine solution, and a test-tube containing some Fehling's solution. Another tube containing some starch solution, preferably at about $37^{\circ} \mathrm{C}$., is taken, and some saliva placed in it. A drop of this mixturc, added at once, gives with the iodine a blue colour; after a short time, the addition of a drop to another tube gives a red colour (erythrodextrin); later, no colour is obtained when a drop of the solution is added to the iodine. A little later, some of the solution boiled with the Fehling solution will give the reduction due to the presence of sugar (maltose). With very active saliva, sugar may appear in half to one minute.

The rate of action of ptyalin depcnds upon the kind of starch; also the reaction in which it is acting. It acts best in neutral or very weak acid- 0.003 per cent. $\mathrm{HCl}$. It is inhibited by stronger acid, such, for example, as $0 \cdot 3$ per cent. $\mathrm{HCl}$. Organic acids do not stop the action of ptyalin until they reach a strength abont ten times that of inorganic acids.

Common salt greatly favours the action of ptyalin, making it about ten times as active. Other chlorides have a similar but less marked action. Alkaline carbonates hinder the action.

The action of ptyalin continues in the stomach, digestion of polysaccharides proceeding until inhibited by acid. This may be as long as forty-five minutes. The saliva has an immunizing effect, protecting the teeth from decay. Mouth-breathing and the habit of eating too often and too much soft and sticky food, whereby chronic slight derangement of the alimentary canal is induced, together contribute to the decay of teeth. The decay is the result of bacterial action, favoured by acid fermentation of food allowed to stick betwecn the teeth. 


\section{CHAPTER XLVI \\ DIGESTION IN THE STOMACH}

Or anatomical and physiological grounds this organ is divided into three divisions-namely:

1. The fundus, or the reservoir.

2. The cardia or body, or the digestive chamber.

3. The pylorus, or the churn or mill.

A schematic outline of the organ is shown in Fig. 194. The normal position in man in the vertical position is seen in Fig. 195. It is to be noted that it reaches to the umbilicus $(C)$.

The fundus may be regarded in animals as being separated from the cardia by an imaginary line passing from the cardiac orifice to the opposite point on the greater curvature; in man, by the part lying above the horizontal plane of the cardiac orifice.

The incisura angularis, $I . A$., denotes the point of demarcation between the body or cardia and the pyloric portion. This portion itself is divisible into two parts-the pyloric vestibule and the pyloric canal. The vestibule lies between the incisura angularis and the pyloric canal. The canal is the tube-like portion of the pylorus which leads from the vestibule to the pyloris sphin ster. The stomach wall consists of three muscular coats, arranged from outside inwards in longitudinal, circular, and oblique fashion. The longitudinal are continuous with those of the œsophagus, and radiate over the stomach, to end at the pylorus. The circular fibres completely invest

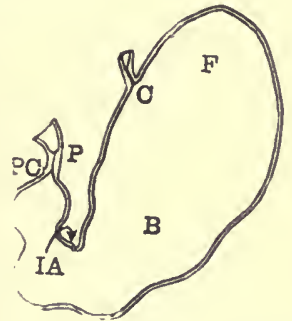

Fig. 194. - Schematic OUTLINE OF THE STिMACH. (Cannon.)

$C$, Cardia; $F$, fundus; $B$, body; $P$, pylorus; I.t, incisura angularis; $P C$, pyloric canal. the whole stomach, being particularly well marked in the pyloric portion, especially at the pyloric sphineter. They also form a well-marked thickening at the incisura angularis, termed the "transverse band." The oblique fibres, starting as two strong bands from the left of the cardiac orifice, pass along the anterior part of the dorsal and ventral surfaces towards the pylorus, grartually disappearing as they go.

The structure of the glands varies in the different portions of the 
stomach. The glands of the fundus are simple tubules lined with one layer of cells, somewhat similar to the crypts of Licbcrkühn of the smaller intestine. The glands of the cardia or body have short ducts with long, straight tubules. In thesc tubules arc two sets of cells. The central or chicf cells are cubical in shape, and contain coarse granules, which arc usually in greater profusion nearer the lumen. Lying in between the central cells, and to their outer side, are a number of large spheroidal cells, known as the "par:etal" or "oxyntic" (acid-forming) cells. Each of these cells appears to be connected to the lumen of the gland by a number of small channels which pass betwcen the central cells.

In the pylorus the glands have long ducts, and the secreting tubules are long and much branched, being often continucd into the submucous

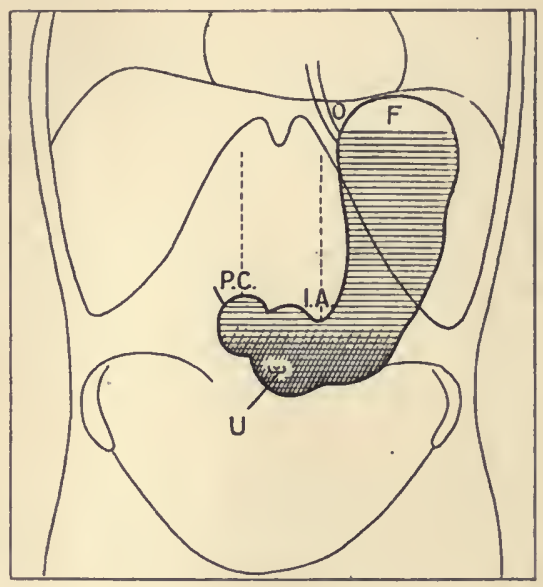

Fig. 195.-Diagray showing the Positiox of the Stomach. (Hurst.)

$$
F=\text { Fundus ; } P . C .=\text { pyloric canal; } U=\text { umbilicus. }
$$

tissue. Here, again, there is only one form of cell lining the gland, corresponding to the central cells, but distinctly less granular in nature.

Corresponding to these different sets of glands we have, also, three distinct kinds of sccretion or juices. The sccretion of the cardia is neutral or faintly alkaline in reaction, poor in salts, rich in mucin, and containing in some animals (the pig) an amylolytic and probably a maltose-splitting enzyme (maltase). The juice of the fundus is characteristic in being acid in reaction. It contains peptic, rennet, and lipolytic enzymes. The secretion of the pylorus is alkaline in reaction, and contains a small quantity of proteolytic enzyme, no. lipase, and much mucin.

Gastric Juice.-The term "gastric juice" is now usually applied to the fundal secretion, which, in fact, must be regarded as the 
characteristic secretion of the stomach. It is a matter of some difficulty to obtain it pure; indeed, there is only one methodnamely, that of making a gastric fistula.

The older methods include--(1) the giving of perforated hollow balls of lead which contain food to birds of prey (the balls are subsequently romited up); (2) the swallowing of a sponge to which a string is fastened, whereby it is subsequently withdrawn and squeezed; (3) killing of an animal after giving some indigestible material to eat, and collecting the juice; (4) the withdrawal of the stomach-contents by the passage of an oesophageal tube three-quarters of an hour after a test-meal has been eaten. These methods give only gastric contents, the mixed secretions plus the ingested food and fluid, and we gain thereby no idea of what constitutes the true gastric juice.

The first gastric fistula studied was one accidentally made by a gunshot wound upon a Canadian, Alexis St. Martin. Beaumont took
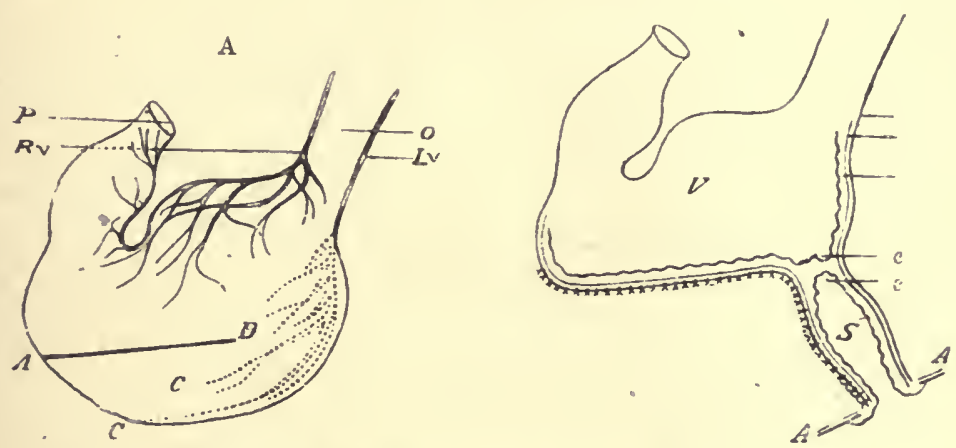

Fia. 196.-Pawlow's Method of establishixg a Gastric Fistula.

$A, B$, Incision; $S$, segment of stomaeh separated off; $A$, abdominal wall; $e$, mucous membrane; $P$, pylorus; $O$, nsophagus; $R v$, right vigus nerve; $L v$, left vagus nerve.

the man into his service, and published a small book. the result of patient years of observation. A fistula has been establishéd in dogs, and observations made by several workers. A technique which leaves intact the blood and nerve supply has been recently perfected (see Fig. 196).

In order that no food or saliva shall reach the stomach. an œesophageal fistula is made by bringing the oesophagus out to the side of the neck, dividing it, and stitching both the upper and the lower end into the wound, so as to leave the orifice of each patent. Any food or saliva passing down the œesophagus falls out from the upper end, and does not reach the stomach (sham feeding). Through the lower opening substances can be introduced directly into the stomach. The gastric juice obtained in this manner is a clean watery liquid; its percentage composition varies in different animals. 


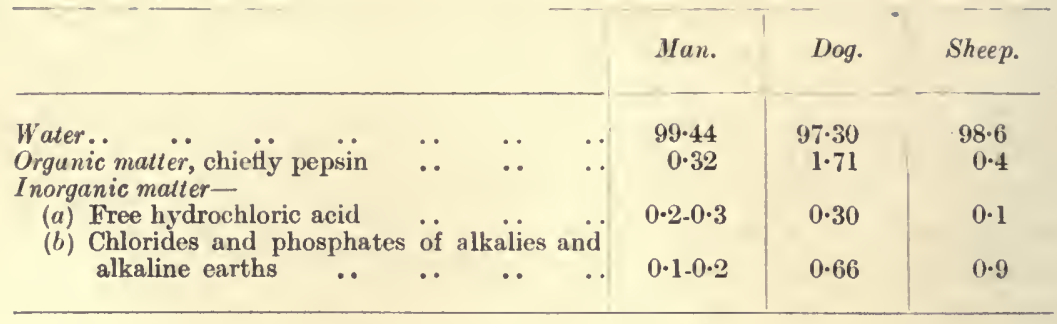

The specific gravity is 0.001 to 0.010 .

The special characteristic of this juice is its acidity. This has four main functions:

1. To kill ingested bacteria in the stomach, and thus $(a)$ inhibit the entry of pathogenic organisms into the body, and $(b)$ prevent the early putrefaction of the ingested food.

2. To facilitate protein digestion.

3. To liberate the hormone secretin from its precursor in the duodenal mucous membrane, and thus excite the flow of juices from the pancreas and liver.

4. To induce a flow of intestinal juice in the duodenum.

In regard to the first function, it has been shown that the acidity of the juice in guinea-pigs is sufficient to kill the cholera fibrio or bacillus. If, however, the gastric juice were first neutralized, the introduction of the bacilli killed the animals.

Apart from pathogenic bacteria, it is important that bacteria which split proteins and carbohydrates be kept in check; otherwise a large part of the ingested food would be wasted.

Meat mixed with gastric juice, or a dead frog in a snake's stomach, will keep sweet and free from putrefaction for days.

A considerable amount of controversy has taken place in regard to the nature of this acidity. It was at first believed to be due to lactic acid. That it is due to hydrochloric acid is shown conclusively by the fact that in an analysis of the juice there are more chlorine atoms found than can combine with all the bases. How far the acid is combined or free in the secreted juice is a matter of doubt. Most of it is probably not free in the chemical sense, but so loosely combined that it is able to effect its physiological function. The difference is shown thus: (1) A solution of pure hydrochloric acid of the same degree of acidity, when heated quickly, gives off acid fumes; gastric juice does not until a syrupy consistency of concentration is reached; (2) hydrochloric acid of the same acidity will transform starch into dextrins, gastric juice will not; (3) the inverting power of gastric juice upon disaccharides is not so powerful as an equivalent strength of hydrochloric acid. Nevertheless the acid in the pure juice certainly reacts acid to such indicators as congo-red, dimethylaminoazobenzol, and therefore may be termed "physiologically" active. $\mathrm{HCl}$ is freely dissociated into $\mathrm{H}$ and $\mathrm{Cl}$ ions in such dilutions as are found in the stomach. Weak organic acids, such as lactic and butyric, are 
but slightly dissociated. Hydrochloric acid readily combines with proteins, and this is known as "combined acid," for it dissociates very slightly. Under these circumstances, it will not give the reactions of free acid. Considerable importance is attached clinically to the proportion of the free acid to the combined. A small,amount of acidity may also be due to the presence of acid salts.

The Mechanism of Secretion. - After a period of secretion, the granules of the chief cells have greatly decreased in number, and the colls have become shrunken. These granules have given rise to the peptic ferment of the juice, for less ferment can be obtained from cells poor in granules than from those rich in granules.

The granules arc the precursor or zymogen. This can be shown as follows: Sodium carbonate destroys the active enzyme pepsin. Nevertheless, a sodium carbonate extract of the fundus, when rendered faintly acid with hydrochloric acid, manifests all the digestive actions of pepsin. The precursor is not destroyed by sodium carbonate, and the extract of zymogen, when rendered acid by $\mathrm{HCl}$, is converted into the enzyme. If the fundus is first treated with hydrochloric acid, and then with sodium carbonate, no active enzyme is obtained, for the zymogen is converted by the acid and the enzyme destroyed by the sodium carbonate.

The parietal or oxyntic cells secrete the hydrochloric acid, since the acidity only appears in the juice of that portion of the stomach where they occur. ' This is not the only example of free mineral acid being excreted by glands. In a giant mollusc, Dolium, the salivary glands secrete $\mathrm{H}_{2} \mathrm{SO}_{4}$ (about 2 per cent. solution). This juice effervesces when it falls on a marble floor. It is strange that living cells should secrete so potent an acid, which is destructive to life. The hydrochloric acid is probably secreted in a combined state, which becomes active after secretion.

The gastric juice is liberated by a double mechanism-nervous and chemical.

The Nervous Mechanism.-The gastric glands have a double nervesupply from the autonomic system: (1) the vagus, (2) the sympathetic. It is not easy to excite directly the secretory fibres to the stomach and produce secretion, as can be done in the case of the salivary gland. On the other hand, the secretion can be excited reflexly, the afferent paths being the same as those which excite the secretion of saliva. The effect of psychic and other stimuli has been fully studied by means of sham feeding on the dog, in which oesophageal and gastric fistulæ have been established. Secretion results from-(1) the psychic element, (2) contact with buccal mucous membrane and the act of mastication, (3) the taste of food (see Fig. 192). The sight of food causes a secretion; in a hungry dog this continues for as long as one and a half hours. If the animal is then given a sham meal, it is found that the amount of secretion obtained by the psychical stimulation is rather greatcr than that obtained by the introduction of the food into the mouth. 
The psychical secretion, or "appetite juice," may be proroked by seeing, hearing, by smelling food, and in human bcings by memory alone. The thought of food makes the mouth of a hungry person "water," and the gastric juice flow. "Digestion waits on appetite" is a sound proverb. It is a disputed point as to whether food, by its presence in the stomach, nervously excites.a flow of juice. It is now gencrally held that such is not the case, for introduction of food through an œesophageal fistula into a dog's stomach while it is sleeping excites no flow of juice. The same is true in the case of man. The secretion, excited either by the psychical reflex or by the reflex from the mouth, is abolished by cutting the vagi; this points to these nerves as containing the efferent secretory nerves to the stomach. Division of both vagi may give rise to absence of gastric movement and disorder of digestion; it has been performed below the diaphragm with little ill effect. The existence of tho second mechanism of providing juice complicates matters. It is difficult to produce a secretion of gastric juice by stimulating the peripheral end of the vagus nerve, owing to the disturbing action of the nerve upon the heart. About four days after section of the nerve, when the cardio-inhibitory fibres have degenerated, stimulation of the peripheral end of the divided ragus excites, after a latent period of three to five minutes, a marked flow of gastric juice. It is difficult, however, to explain the long latent period.

The Chemical Mechanism. - Secretion is called forth by the liberation of a hormone - "gastrin" - and its absorption into the blood-stream. The "gastrin" is stored in the pyloric mucous membrane, and is liberated by such bodies as dextrins, maltosc, dextrose, peptones; in fact, the products of digestion of a part of the alimentary tract at higher level than the pylorus. The products, when injected into the blood by themselves, excite. little or no secretion. The gastrin is not destroyed by boiling.

Variation of Composition. - It is held by some authorities that the juice obtained by nervous excitation does not vary in quality, whercas that secreted by the chemical mechanism (local changes in the stomach) shows marked variation in the quantity and nature of the juice. Thus, the secretion is said to be greatest in amount with meat, the digestive power greatest with bread.

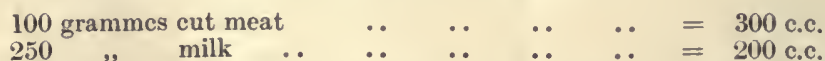

Fats are said to increase the amount of pepsin, starch to lessen it. Others doubt this adaptation of the juice to the food eaten. The amount of juice may also vary with the amount and character of the salts in the food, its alkalinity or acidity. Thirst, muscular exercise, and a condition of plethora, markedly influcnce the quantity of juice sccreted. The introduction of food into the ileum and into the rectum excites a flow of juice; at present, it is difficult to say whether by the nervous or chemical mechanism. The effect of food on the juice is given in the following order: 
Degree of
Acidity.

Meat

Milk

Bread

$\begin{array}{cc} & \text { Degree of } \\ & \text { Digestive Activity. } \\ \ldots & \text { Bread } \\ \ldots & \text { Meat } \\ . & \text { Milk }\end{array}$

Duration of Secretion of Juice.

$\begin{array}{llll} & & \ldots & \text { Bread. } \\ \cdots & & \ldots & \text { Meat } \\ \text { Milk }\end{array}$

The Digestive Processes in the Stomach-Peptic Digestion.-The peptic enzyme is proteolytic in nature, and acts only in acid medium (HCl 0.1 to 0.5 per cent.); in fact, it is probable that the true digestive principle is a combination-pepsin-hydrochloric acid. The protein is first swollen and partially disintegrated by the hydrochloric acid, and then acted upon by the pepsin-hydrochloric acid. This can be shown by the following experiments: (1) Coagulated egg-albumin soaked in $0.3 \mathrm{HCl}$, and then washed and added to neutral pepsin, is not digested; (2) if the swelling of protein be stopped by the presence of bile, digestion is stopped or greatly hindered.

The peptic ezyme digests all proteins except keratin. Elastin is but little attacked. The other proteins, including gelatin, are easily digested, passing through the preliminary stages of conversion into proteoses, primary and secondary, to peptones and peptides (abiuretic bodies not giving the biuret test). The change is by no means so complete as in the case of the pancreatic enzyme, trypsin. It may be represented as follows:

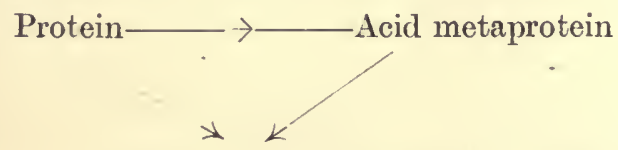

Primary proteoses (proto and hetero)

Secondary proteoses $(\mathrm{A}, \mathrm{B}, \mathrm{C})$

Peptones (A, B)

Peptides (giving no biuret test).

The methods by which the presence of these bodies can be shown in the digest can be gathered from the table on p. 386, which embodies the chief facts ascertained by recent research. It will be seen that the chief differences between them are brought out by their relative solubility on addition of a saturated solution of ammonium sulphate, salicylsulphonic acid, or alcohol.

It has been found that only a small percentage of protein is converted into acid metaprotein (formerly called "syntonin"). Some of the primary proteoses are split off earlier than the others; the same remark applies to the secondary proteoses and peptones. Thercfore, quite early-in the digestive process, peptones and peptides nake their appearance. This is to be explained by the fact that these bodies are not of the same chemical composition. For example, heteroproteose yields, on decomposition, chiefly leucin and glycin, whilst proto proteose yields much tyrosin and indol. Similarly, with the secondary proteoses, one was found to contain much sulphur, another 
but little; one much earbohydrate, another but little. Their ehemical nature in part determines the rate at which these bodies are split off from the protein ingested. Therefore, early in digestion there is a beginning of the sorting out of the speeial constituents of the different proteins-a sorting out to enable the body to choose the portions of the ingested protein requisite for the building of its own special proteins. In digests made in the test-tube, the maximum of hetero- and proto-proteose occurs in half an hour, and then rapidly diminishes. One form of secondary proteose (B) showed similar variations, A gave its maximum in five to eight hours, $\mathrm{C}$ after two or three days, peptone in one to two months. Of the contents of a dog's stomaeh, after half to six hours' digestion of cooked meat, 90 per cent. consisted of proteoses, aeid metaprotein accounting for the other 10 per cent. The peptones and peptides are absorbed as soon as they are formed in the stomach. Normally, this absorption is from 20 to 30 per eent. of the protein eaten. The toxin of protein-like bodies-for example, of tetanus. and of snake renomis rendered innocuous by gastric digestion.

\begin{tabular}{|c|c|c|c|c|c|}
\hline Protcin. & $\begin{array}{c}\text { Precipitation } \\
\text { with } \\
A m_{-} S O_{-}\end{array}$ & $\begin{array}{l}\text { Solubility } \\
\text { in Alcohol. }\end{array}$ & $\begin{array}{l}\text { Salicylsul- } \\
\text { phonic Acid } \\
\text { and } \\
\mathrm{HNO}_{3} \text { Tests. }\end{array}$ & Biuret Test. & $\begin{array}{c}\text { Millon's } \\
\text { Reaction. }\end{array}$ \\
\hline Native & $\begin{array}{l}\text { Globulins(half } \\
\text { saturation) } \\
\text { Albumins (full } \\
\text { sctirutiun) }\end{array}$ & Insoluble & $\begin{array}{l}\text { Prec pitate } \\
\text { coagulated } \\
\text { on boiling }\end{array}$ & Violet & + \\
\hline $\begin{array}{l}\text { Acid meta } \\
\text { protein }\end{array}$ & $\begin{array}{c}\text { Half } \\
\text { saturation }\end{array}$ & - & Do. & Do. & Do. \\
\hline $\begin{array}{l}\text { Primary } \\
\text { proteose } \\
\text { (lhetero and } \\
\text { proto) }\end{array}$ & $\begin{array}{c}\text { Half } \\
\text { saturation }\end{array}$ & $\begin{array}{c}\text { Hetero in- } \\
\text { soluble in } \\
32 \% \text {; proto- } \\
\text { soluble in } \\
80 \%\end{array}$ & $\begin{array}{l}\text { Precipitate } \\
\text { soluble on } \\
\text { boiling, } \\
\text { reappearing } \\
\text { on cooling }\end{array}$ & Rose pink & $\begin{array}{l}\text { Hetero,feeble; } \\
\text { proto, strong }\end{array}$ \\
\hline $\begin{array}{l}\text { S'ccondary } \\
\text { proteose }\end{array}$ & $\begin{array}{l}\text { Two-thirds } \\
\text { saturation }\end{array}$ & $\begin{array}{l}\text { Partly in. } \\
\text { soluble in } \\
70 \%\end{array}$ & Do. & Do. & + \\
\hline $\begin{array}{c}\text { Secondary } \\
\text { proteose B } \\
\text { (several } \\
\text { varieties) }\end{array}$ & $\begin{array}{c}\text { Full satura- } \\
\text { tionl }\end{array}$ & $\begin{array}{l}\text { Partly insol- } \\
\text { uble in } 35 \% \\
\text { partly solu- } \\
\text { ble in } 80 \%\end{array}$ & Do. & Do. & $\begin{array}{c}\text { One variety } \\
\text { Others }\end{array}$ \\
\hline $\begin{array}{l}\text { Secondary } \\
\text { proteose C }\end{array}$ & $\begin{array}{l}\text { Full satura. } \\
\text { tion plus acid } \\
\left(\mathrm{H} \mathrm{SO}_{4}\right)\end{array}$ & $\begin{array}{l}\text { Solublc in } \\
68-80 \%\end{array}$ & Do. & Do. & - \\
\hline \multirow[t]{2}{*}{ Peptones } & $\begin{array}{l}\text { Not pre- } \\
\text { cipitated }\end{array}$ & $\begin{array}{c}\text { A insoluble } \\
\text { in } 96 \%\end{array}$ & $\begin{array}{l}\text { Not pre- } \\
\text { cipitated }\end{array}$ & & - \\
\hline & & $\begin{array}{c}\text { B soluble in } \\
96 \%\end{array}$ & $\begin{array}{l}\text { Not pre- } \\
\text { cipitated }\end{array}$ & Do. & + \\
\hline
\end{tabular}

Peptic digestion in the same period does not break down the protein so far as tryptic digestion. The faet that with prolonged gastric digestion in vitro all the end produets of tryptic digestion are formed, exeept the hexone bases, would seem to afford support to the 
view that these bodies form the central nucleus round which the rest of the protein molecule is built.

The Action of Rennet.-The rennet enzyme runs parallel in secretion to pepsin. There is a prorennin in the mucous membrane, like pepsinogen, which is not destroyed by a weak sodium hydrate solution, and is converted by hydrochloric acid; but rennin, unlike pepsin, can act also in neutral and faintly alkaline media. The action of rennin is upon the caseinogen of milk. The molecule of this soluble protein is rearranged by the action of the rennin, so that a body called "soluble casein" is formed. Here the action of the rennin ceases. This soluble casein, in the presence of calcium salts, forms insoluble casein, or the clot of milk.

(1) Caseinogen + Rennin $=$ Soluble casein.

(2) Soluble casein + Ca salts = Insoluble casein, or clot.

Thus, if in a test-tube experiment rennin be added to some milk, from which the calcium salts have been removed by the addition of a soluble oxalate, its action proceeds to stage (1), and no clot forms. If after, say, fifteen minutes the milk be heated to $100^{\circ} \mathrm{C}$, , the rennet enzyme is destroyed. The addition of calcium salts now causes the clot to form, thus showing that the rennet enzyme is merely concerned in the rearrangement of the molecule, and not in the formation of the insoluble clot.

Why a rennet enzyme should be provided to clot milk is somewhat a mystery, since unclotted milk is digcsted by pepsin and trypsin. It is noteworthy that in plants, as well as animals, a rennet enzyme is found running parallel in secretion with proteolytic enzymes. The clotting may be merely a result of the action of the proteolytic enzyme on the protein caseinogen.

The Lipase of the Gastric Juice.-The presence of a gastric lipase has been established; at one time it was held to be due to a reflux of pancreatic juice through the pylorus. It exerts its maximum action in neutral or faintly acid medium. Therefore, normally its action in the stomach is not at all potent. Nevertheless, it is probably important, inasmuch as by its action neutral fats will be rendered slightly rancid, and these fats, on entering the small intestine, owing to this rancidity, will bc far more easily and more finely emulsificd than would otherwise be the case, and their digestion thereby greatly facilitated (see later, p. 395).

The Action of Gastric Juice upon Starches and Sugars.-In some animals-e.g., the, pig-the starches will be digested by the amylopsin of the cardiac juice. By the stomach of man and the dog there is probably no amylopsin secreted. Nevertheless, the fact must not be overlooked that in the cardiac reservoir salivary digestion normally proceeds for thirty to forty minutes.

The hydrochloric acid of the gastric juice exerts but little or no hydrolyzing effect upon starches, dextrins, and the disaccharides. 
In man, but not in the dog, there is probably an invertase present which converts cane-sugar into dextrose and levulose.

Why does the Stomach not Digest itself ?-It may be asked: "Why does the stomach not digest itself ?" There are probably scveral conditions contributing to this; among the chief reasons assigned are the following:

1. The large amount of mucin secreted is protective against the secreted juice.

2. The circulation of a large amount of alkaline blood keeps the cells of the wall alkaline in reaction.

The cells of the wall are living, and living substance can, by its reactions, resist attack, neutralize acid, secrete antiferment, etc. Any part of the stomach wall from which the blood-supply is cut off-e.g., by thrombosis-is attacked. Gastric ulcers result from lessened powers of resistance. The injection of gastric mucous membrane of guinea-pig into rabbit may cause a specific cytolysin to form in the rabbit's serum. Injection of this serum into the guinea-pig may cause gastric ulcer. It has been shown that if the hind-leg of a living frog is introduced into the stomach it is digested by the gastric juice. Probably, acid first kills the tissue and then digestion takes place. On the other hand, the alkali of the pancreatic juice is not sufficiently strong to alter the structure, and so no digestion takes place.

Absorption in the Stomach.-The absorption of water from the stomach is very small in amount. This has been shown to be the case by injecting a measured quantity through the pyloric orifice, keeping this orifice closed, and drawing the water off again after a given time. There is a small but definite absorption of salts and sugar, while the absorption of protein in the form of peptides (abiuretic bodies) amounts to 20 to 30 per cent. The absorption of alcohol is rapid, and bodies soluble in it are therefore well absorbed, such as strychnine and other drugs.

The Examination of Gastric Contents.-Much importance is attached by some clinicians to the examination of the gastric contents after a test-meal, which is given in the morning after fasting twelve hours. The meal usually consists of 50 grammes bread and a little tea without milk; it is important that it should be withdrawn by the stomach-tube at a definite time (three-quarters of an hour) after the meal. It should be noted that the contents consist of-

1. The remnants of the test-meal.

2. The mixed secretions of the stomach.

3. The swallowed saliva.

It must be remembered that the amount of secretion may vary, as may also the rate of emptying of the stomach and the rate of absorption. For this reason it is difficult from a test-meal alone to say definitely what is-(1) the secretory power, (2) the motor power, (3) the absorptive power of the stomach. The chief points to ascertain about gastric contents are the total amount of the acidity of its contents; its nature, 
whether hydrochloric or some abnormal organic acid, such as lactic, is present; the total acidity; whether the acid is free or combined; and how much in each state. Many methods have been devised for this purpose. Opinion varies as to whether it is important for the hydroehloric aeid to be free. Apparently it matters little, from the digestive point of view, whether it is free or combined; but in the combined state the proteetive power of the free acid against bacteria is lacking. The amount of free to combined acid will depend upon-

1. The amount of secretion.

2. The amount of protein in the stomach.

3. The rate of emptying.

4. The rate of absorption.

5. The amount of mixing of the contents.

For testing the total acidity, the best indicators are probably phenolphthalein (which gives a slightly high reading) and rosolic acid. The amount of free acid is obtained by the use of such indicators as congo-red (turned blue by free acid), Günzburg's reagent, dimethylaminoazobenzol (Töpfer's reagent), tropæolin OO. The amount of the combined acid is obtained by deducting the free from the total acidity. An excellent method is that known as the method of deficit and excess.

Method of Excess.-Ten c.e. of the contents are taken. If free acid is present, this is estimated by running in $\frac{\mathrm{N}}{\mathrm{i} \sigma} \mathrm{NaOH}$ until neutralized, and testing from time to time by removing a small drop to eongo-red paper, which is no longer turned blue when the neutralization point is reached. A few drops of phenolphthalein are then added, and the acidity to this indicator measured. This amount gives the eombined acidity, that with congo-red the free acidity, and the two together give the total acidity.

The Method of Deficit.- If by testing with congo-red it is found that free acid is absent, 10 c.c. of the contents are taken, and $\frac{\mathrm{N}}{10} \mathrm{HCl}$ added until free acid makes its appearance to congo-red. The amount added is noted, and this gives the deficit. The sample is then exactly neutralized by a corresponding amount of $\frac{\mathrm{N}}{10} \mathrm{NaOH}$, phenolphthalein added, and the acidity to this indicator measured, this giving the amount of the combined and also the total acidity.

Physiologically, active $\mathrm{HCl}$ may also be determined (A) by mixing the filtcred gastric contents with excess of sodium bicarbonate, drying, incinerating, and determining the total chlorides in the ash by Volhard's method (see Urine, p. 462). The process is now repeated without the addition of sodium bicarbonate (B). In this case only the mincral chlorides are retained in the ash. $\mathrm{A}-\mathrm{B}$ gives the physiologically active $\mathrm{HCl}$.

The amount of enzyme may be estimated roughly by determining the action of the rennin present. The rennin is assumed to run parallel with the pepsin. In several tubes 5 e.e. of milk and 2.5 e.c. of 1 per cent. calcium chloride are takcn. To these are added 5 c.c. of the gastrie 
contents diluted respectively $10,20,40,80,160$, and 320 . With normal juice, a solid clot is obtained with dilutions of 10, 20,40; a dilution of 80 gives a cheesy clot, and of 160 a flaky clot. This method is of value for clinical purposes.

The amount of pepsin present is most quickly and convenicntly estimated by the use of carminc-stained fibrin. It is only an approximate method. It depends upon the fact that, as the fibrin becomes digested, the liberated carmine stains the solution. Therefore, the deeper the tint, the greater the amount of the enzyme. The exact amount of carmine set free is gauged by comparison with an artificial scale of solution of carmine of known strength, and thus the activity of the enzyme is estimated.

Another method consists in the digestion of coagulated eggalbumin in narrow tubes of known dimensions; it is only accurate for very weak pepsin solutions, since after a certain amount of digestion stagnation ensues. Recently, several accurate methods have bcen introduced. One depends upon the fact that a suspension of coagulated egg-white becomes quite clear under the influence of pepsin. Various quantities $(0 \cdot 2$ to 1 c.c.) of the enzyme are added to 5 c.c. of this suspension and 1 c.c. of 0.4 per cent. $\mathrm{HCl}$, and the time at which clearing occurs noted. The egg-white suspension is prepared by rubbing up egg-white in a basin until it is of uniform consistence. This is then slowly mixed and rubbed with water until it is diluted five times. After straining through gauze, the solution is heated at $60^{\circ} \mathrm{C}$. for twenty minutes, and again strained. For use this is again diluted nine times.

The description of the anatomy and digestive processes already given above applies to man and the carnivora. In many other animals, the lower end of the osophagus is dilated to form a crop, or proventriculus, which functionates as a rescrvoir. In the horse and pig, this passes into the stomach without any marked constriction; food therefore passes easily from one part to the other. In ruminants, the crop is modified into a large rumen, or paunch, and a small honeycombed reticulum. The rumen acts as a reservoir for the swallowed food. The function of the reticulum is apparently to hold fluid and moisten the foodstuffs in the rumen preparatory to the "chewing of the cud." From the rumen, the food is returned again to the mouth, the cud is chewed, and again swallowed. This time it is passed through the rumen into the omasum by means of the unfolding of a double fold in the roof of the rumen. The omasum, sometimes termed by butchers "the Bible," is an organ containing many strong muscular leaves. These leaves are covered with coarse epithelium, and the organ, by its movements, churns the food into a proper consistency for entering the rest of the alimentary tract. It yields no digestive secretion. The true stomach, with its digestive fluid, is the next chamber, and is known as the "abomasum." Here digestion proceeds, as already described. 


\section{CHAPTER XLVII}

\section{DIGESTION IN THE SMALL INTESTINE}

AFTER being ehurned to a proper fluid consistency in the pyloric mill, and having attained to a certain degree of acidity, the gastric contents little by little are passed through the pylorie aperture, and enter as a ehyme the first part of the small intestine. This is the short, horseshoe-shaped duodenum. It is the acidity of the ehyme in the pylorus which excites the relaxation of the pyloric aperture. On reaehing the duodenum, the acidity of the chyme causes the door behind it to shut, and prevents regurgitation into the stomach. The chyme eontains-

1. Such sugars, starches, and proteins as have not been aeted upon by the salivary or peptie ferments.

2. Acid, free and eombined.

3. Proteoses and peptones.

4. Rancid fat.

On its entrance into the duodenum, a number of important events are brought to pass:

1. A flow of bile is provoked from the gall-bladder.

2. The acid eontained in the chyme liberates from the duodenal mucous membrane the hormone "secretin," which, circulating in the blood, calls forth a flow of digestive juice from the pancreas and a further flow of bile from the liver.

3. The presence of the chyme in the intestines, probably owing to its aeidity and the nature of its contents, exuses a flow of succus entericus-the digestive fluid of the small intestine.

On these three fluids - the bilc, pancreat c juice, and succus entericus-depends the proper digestion of the entering foodstuffs.

THE BILE.-This varies in appearance and composition according to its source. Bile from the gall-bladder is a ropy, viscid substance, bittcr to taste, faintly alkaline in reaction, with a specific gravity from 1015 to 1040 . Its eolour in man varies from yellow to green. Bile obtained from the liver before entering the gall-bladder is a clear, limpid fluid of low specific gravity (1010), pale yellow in colour. In the gall-bladder, water is absorbed varying in amount according to the time of stay, and a mucous secretion is added. The protcin in this secretion in most animals mainly consists of phospho-protein. In man, however, it is stated to be true glyco-protein. The difference between the two kinds of bile is shown in the following analysis: 
I., obtained from gall-bladder of pcrsons accidentally killed while in good health; II., obtained from a fistula cluring life:

Is 100 PARTS OF BILE.

\begin{tabular}{|c|c|c|c|c|c|c|}
\hline & & & & & 1. & 11.* \\
\hline Water & $\cdots$ & .. & . & . & 86 & 97 \\
\hline Solids & .. & .. & .. & .. & 14 & 3 \\
\hline Organic salts & .. & .. & .. & .. & 9 & 0.9 to 1.8 \\
\hline Mucin and pigment & & $\ldots$ & $\cdots$ & .. & 3 & 0.5 \\
\hline Cholesterol .. & .. & .. & .. & $\ldots$ & $0 \cdot 2$ & $0 \cdot 06$ to $0 \cdot 16$ \\
\hline Lecithin and fat & . & .. & $\therefore$ & $\therefore$ & $0 \cdot \bar{i}$ to 1.0 & 0.02 to 0.09 \\
\hline Inorganic salts & . & .. & .. & .. & $0 \cdot 8$ & 0.7 to 0.8 \\
\hline
\end{tabular}

The Organic Salts.-The organic salts are the sodium salts of the bile acids. These acids are known as glycocholic $\left(\mathrm{C}_{26} \mathrm{H}_{43} \mathrm{NO}_{6}\right)$ and taurocholic $\left(\mathrm{C}_{26} \mathrm{H}_{45} \mathrm{NSO}_{7}\right)$. The former is more abundant in herbivora, the latter in carnivora. The bile acids are formed in the liver, and are compounds of cholic or cholalic acid with the amino-acids glycin and taurin respectively. Cholalic acid is probably related to cholesterol; it contains two primary and one secondary alcoholic groupings. It is probable, also, that there are several varieties of it, and therefore several varieties of glycocholic and taurocholic acids. Glycin is mon-amino-acetic acid, $\mathrm{CH}_{2} \mathrm{NH}_{2} \mathrm{COOH}$ (see p. 40). Taurin is amino-ethyl-sulphonic acid, $\mathrm{CH}_{2}-\mathrm{NH}_{2}-\mathrm{CH}_{2} \cdot \mathrm{SO}_{2} \cdot \mathrm{OH}$, and is derived from cystin, $\mathrm{COOH} \cdot \mathrm{CHNH}_{2} \cdot \mathrm{CH}_{2} \cdot \mathrm{S}-\mathrm{SCH}_{2} \cdot \mathrm{CHNH}_{2} \mathrm{COOH}$.

This is converted by reducticn into cystein, and this by oxidation to cysteinic acid, $\mathrm{COOH} \cdot \mathrm{CHNH}_{2} \cdot \mathrm{CH}_{2} \mathrm{SO}_{2} \mathrm{OH}$, which, by the loss of a molecule of $\mathrm{CO}_{2}$, yields taurin.

The salts of the bile acids are dextro-rotatory, and crystallize in fine needles or prisms. It is due to their presence that lecithin and cholesterol are soluble in the bile. In the intestine, they are decomposed by bacterial aetion into their constituent parts, and mostly reabsorbed, only a small amount of cholalic acid being found in the fæces. The exact fate of the taurin is not known.

Sodium glycocholate (holding cholesterin in Sodium taurocholate

Glycocholic acid

Glycin

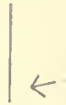

Reabsorbed solution)

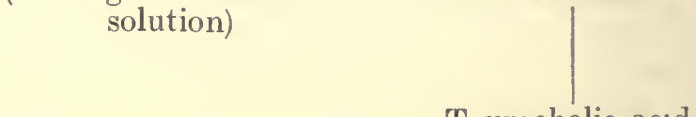

Taurocholic acid

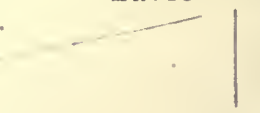

Taurin

Tho bile salts can be recognized by the fact that, when added to

* The average quantity secreted in twenty-four hours varies from 500 to 1,000 c.c. ; on an average about 750 c.c. 
canc-sugar and strong sulphuric acid, they give a purple colour (Pettenkofer's test). This is due to the reaction of cholalic acid with the furfurol formed by the interaction of the cane-sugar and sulphuric acid. An even more delicate test depends upon the fact that the bile salts so lower the surface-tension of any fluid containing them that flowers of sulphur will no longer float when sprinkled on the top, but immediately sinks to the bottom. The test is a useful one for showing the presence of bile in the urine. It is sometimes known as Hay's test.

The bile salts endow the bile with its powers of solution of fatty acids, and of aiding the digestion and absorption of protein. The property of bile salts of precipitating protein from acid solution may be used as a test for bile salts. If a solution of bile salts be added to a 1 per cent. solution of Witte's peptone acidified with acetic acid, a white precipitate or milkiness, due to the precipitated protein, is produced.

In the shark and allied fishes there exists a third group of bile acids, rich in sulphur, and akin to ethereal sulphuric acid. These bile acids yield sulphuric acid on boiling with hydrochloric acid.

The Bile Pigments.-There are several bile pigments. The chief pigments of normal bile are bilirubin and biliverdin. By oxidation, derivatives of these pigments are formed, some of which have been isolated from gall-stones-bilifuscin, biliprasin, bilicyanin, choleprasin, and choletelin. Bilirubin occurs most abundantly in carnivora, biliverdin in herbivora. The pigments, however, are readily interchangeable, bilirubin being found in gall-stones of cattle, and biliverdin in the placenta of the bitch. Their presence can be detected by the addition of fuming nitric acid (that is, nitric acid containing nitrous acid); there occurs a play of colours due to oxidation derivatives-green, blue, purple, yellow.

Bilirubin may be isolated as a reddish powder or as rhombic plates. It combines readily with calcium to form an insoluble salt, and upon standing in contact with air becomes oxidized to biliverdin. It is soluble in chloroform, and in solution exhibits no absorption bands in the spectrum.

Biliverdin is an amorphous substance, insoluble in chloroform, and therefore easily separated from bilirubin. Bilirubin appears to be derived from the disintegration of hæmoglobin in the liver, the iron portion of the blood-pigment being split off and retained in the liver. Its empirical formula is $\mathrm{C}_{32} \mathrm{H}_{36} \mathrm{~N}_{4} \mathrm{O}_{6}$, that of hæmatin is $\mathrm{C}_{2} \mathrm{H}_{32} \mathrm{~N}_{4} \mathrm{O}_{4}$ Fe. Bilirubin has the same empirical formula as hæmatoidin, which occurs in old blood-clots, and hrematoporphyrin, which is sometimes found in urine. Neither of the latter, however, give Gmelin's test. When reduced by sodium amalgam, in alcoholic solution, both it and bilirubin are converted into hydrobilirubin. Hydrobilirubin can also be formed from hæmatin or hæmatoporphyrin by the action of nore powerful reducing agents.

By still further oxidation, hæmatinic acid $\left(\mathrm{C}_{8} \mathrm{H}_{8} \mathrm{O}_{5}\right)$ is formed from bile pigments, hæmatin, and hæmatoporphyrin. These facts indicate the close relationship between hrematin and bile pigments. 
It is from the pigment of effete corpuscles that the bile pigments are formed in the liver. In the intestine, the bile pigments are converted by bacteria into the pigment stercobilin (similar to hydrobilirubin). Most of this is excreted with the fæces, but some is absorbed into the portal blood, in part to be excreted again in the bile, in part to give rise to a urinary pigment-urobilin.

Lecithin and cholesterol have already been dealt with (Chapter VI.). These substances are widely distributed in the tissues, and are of great value to the organism. They are probably to be regarded both as secretory and excretory products in the bile. It has been found that the bile of animals which normally ingest much fat-e.g., the polar bear-contains relatively more lecithin (and probably other phosphorus-containing bodies) than does the bile of other animals. Lecithin and cholesterol play a part in the digestion of fat, helping the bile salts in the solution of fatty acids and absorption of fat.

The Inorganic Salts are chiefly sodium chloride, sodium carbonate, and disodium hydrogen phosphate. There are also salts of iron (iron phosphate), calcium, and magnesium. Manganese is also present in minute quantity.

The Mechanism of Secretion.-While the secretion of the bile from the liver is continuous, periods of greater and less activity oecur. Its entrance into the intestine is intermittent. The first increase in flow is brought about directly the food begins to enter the duodenum; a second maximum is reached about six hours later. The bile secreted in the periods between digestion is stored in the gall-bladder. Some animals, however, such as the horse, elephant, donkey, mouse, have no gall-bladder. The stimuli to the continuous secretion of bile arc at least three in number-viz.:

1. The hormone "secretin."

2. The products of digestion.

3. The reabsorbed bile salts.

The flow in response to secretin is by no means so marked as that of the pancreatic juice. It is stated that the products of digestion modify the amount of bile excreted considerably, proteins exciting the biggest flow, fats somewhat less, and carbohydrates little, if any, flow. Injected bile salts are known to act as cholagogues. The constituents of the bile salts reabsorbed from the intestine probably play a similar part, and stimulate an adequate secretion of bile to fill the gall-bladder in the periods between active digestion. The gall-bladder and the excretory passages receive nerve fibres from the vagus and sympathetic nerves. The sympathetic are stated to be inhibitory, the vagus to be motor, in nature. It is probably in virtue of these latter fibres that bile is ejected from the gall-bladder in response to passage of food through the pylorie orifice.

The Functions of Bile.- That the secretion of bile is continuous, even during starvation, points to the fact that it is an excretion; that bile is poured into the beginning of the digestive tract, and not into 
the end, points to the fact that it is a secretion which plays an important part in the digestive proeesses. Bile is not an aetual digesting agent, for by itself it has little or no digestive power. It is true in some eases it eontains an amylopsin, but the action of this enzyme is negligible. Bile plays an important part in the preparatory digestive and absorptive proeesses of the small intestine. As its early presenee in the duodenum would suggest, bile is essentially "the preparer for digestion." The funetions of the bile may be summarized as follows:

1. The raneid fats in the ehyme are far more effieiently emulsified in the presenee of bile than in the presenee of the alkaline juiees alone.

2. The undigested proteins and proteoses are precipitated by the bile from their aeid solution, and thus delayed in the digestive area of the duodenum; if they remained in solution, they might be passed on too quiekly; in this state, too, they are more easily assailable by the digesting enzymes, since food in a partieulate form is more easily attaeked.

3. The digestive proeesses are helped-(1) by the neutralization of the aeid in the ehyme; (2) by activation of the lipolytie (fatsplitting) enzymes of the panereatic juice; (3) by all the digestive enzymes working with greater rapidity in the presenee of bile.

4. In the absorptive proeesses, bile is especially helpful in promoting the absorption of fat. When bile is withheld from the intestine, much of the fat eaten eseapes digestion and absorption, and appears in the fæees. Bile aids this absorption by dissolving fatty aeids and taking into solution insoluble soaps of ealeium and magnesium formed in the eourse of digestion.

5. By its property of lowering surfaee tension, bile enables the substanees to be absorbed to eome into more intimate contaet with the absorbing surfaee.

6." Bile has been eredited with antiseptic properties. There is nothing in support of this view; in faet, speeial media for the growth of baeteria are sometimes prepared eontaining it. The truth of the matter is this: Owing to the presenee of bile, all digestive, and therefore absorptive, proeesses are quiekened, so that the baeteria of the intestine have little ehance to earry putrefactive and fermentative processes beyond normal limits. It is the digestion and absorption of fats wh:ch is of partieular importanee, for, when fats are not well digested, protein digestion is hindered by their presenee, and putrefaetive ehanges then take plaee.

7. The chief exeretory funetion of the bile would seem to be to rid the organism of the dissolved eholesterin, some of the cholalie acid, and the bile pigment.

THE PANCREAS AND ITS SECRETION.-The panereas is a long, narrow gland of the aeino-tubular type. In man, its main duet (the duet of Wirsung) opens into the duodenum, together with the eommon bile duet, about 8 to 10 eentimetres beyond the pylorie orifiee. The point and mode of entry, however, varies in other animals. In the dog, there are two duets-the one opening with the bile duet, the other 3 to 5 eentimetres lower down. The latter is usually the 
bigger. In the rabbit, the orifice of the pancreatic duct is considerably below that of the bile (35 centimetres). The structure of the living gland can be particularly well studied in this animal, since the gland is spread in the mesentery in a thin, transparent layer which can be examined under the microscope. The cells are seen to resemble closely those of the parotid gland. Befcre secretion, they have been observed to be swollen and distended with granules; after secretion, the cells become shrunken, most of the granules have disappeared, and are only seen near the lumen.

In this gland, also, are certain little aggregations of tissue known as the "islets of Langerhans." The exact significance of these has been much debated. Some hold that they are the secrcting alvcoli in an exhausted condition. It is now, however, generally conceded that they represent the inclusion of another gland within the pancreasa gland which is formed separate in certain fishes. The function of these islets is discussed in the chapter on internal secretions (p. 511).

The Pancreatic Juice can be obtained by the insertion of a cannula into the duct, and making a temporary or permanent fistula. It is a clear, slightly viscid, strongly alkaline fluid. The composition of the juice varies, that secreted upon the establishment of a fistula bcing as a rule considerably richer in solids than that secreted somo days later.

$\begin{array}{ccccccc} & & & & & \begin{array}{c}\text { Directly after } \\ \text { Operation. }\end{array} & \begin{array}{c}\text { Pancreatic } \\ \text { Fistula. }\end{array} \\ \text { Water } & & & & & 90 \cdot 08 & 97 \cdot 68 \\ \text { Total solids } & \ldots & \ldots & \ldots & \ldots & 9.98 & 9.92 \\ \text { Organic } & \ldots & \ldots & \ldots & \ldots & 9.04 & 1 \cdot 64 \\ \text { Inorganic } & \ldots & \ldots & \ldots & \ldots & 0.88 & 0.68\end{array}$

In cases where a pancreatic fistula has resulted from an opcration in man, the amount of the sccretion has been found to vary from 600 to 800 c.c. per diem, and to have a specific gravity of 1007 .

The organic constituents are due to the enzymes containcd in it, together with some heat-coagulable protcin. There are also traces of leucin, tyrosin, xanthin, and soaps. The inorganic salts are mostly the chloride, carbonate, and phosphate of sodium. The alkalinity of the juice is due to the two latter. In addition, there is present potassium chloride and the phosphates of calcium and magnesium.

This juice is the most powerful digestive fluid of the alimentary canal. It contains several enzymes, the best known being the proteinsplitting (trypsin), fat-splitting (steapsin or lipase), starch-splitting (amylopsin), and the rennet cnzyme. It is probable that rennin and trypsin are to be regarded as side-chains of the same body. The other enzymes can apparently be scparated from cach other, and are stated to vary in amount in the juice according to the naturc of the food. Thus, when the sccretion on a milk diet is compared with that on a bread diet, it is found to contain half the tryptic, onequarter the amylolytic, and six times the fat-splitting potency. Further evidence of the independence of the enzymes is- 
1. The diastase does not appear in the juice until a month after birth, trypsin being present from the start.

2. Trypsin can be precipitated and separated from the other enzymes by addition of collodion.

It was at one time stated that the enzymic content of the juice was not only modified to meet the nature of the food, but, if necessary, new enzymes were manufactured to digest fresh articles of food in the diet. For example, on a mixed diet, the pancreatic juice contains no lactose-splitting enzyme (lactase). It was said that, with the introduction of a milk diet, a lactase became secreted in the pancreatic juice. The experimental evidence is now against this view, and by some workers the adaptation to the diet of the enzymic content of the juice is seriously called in question.

The juice is said by some to contain several other enzymes, in particular a nuclease (nucleic-acid-splitting enzyme). Traces of erepsin, maltase, and lactase have been found.

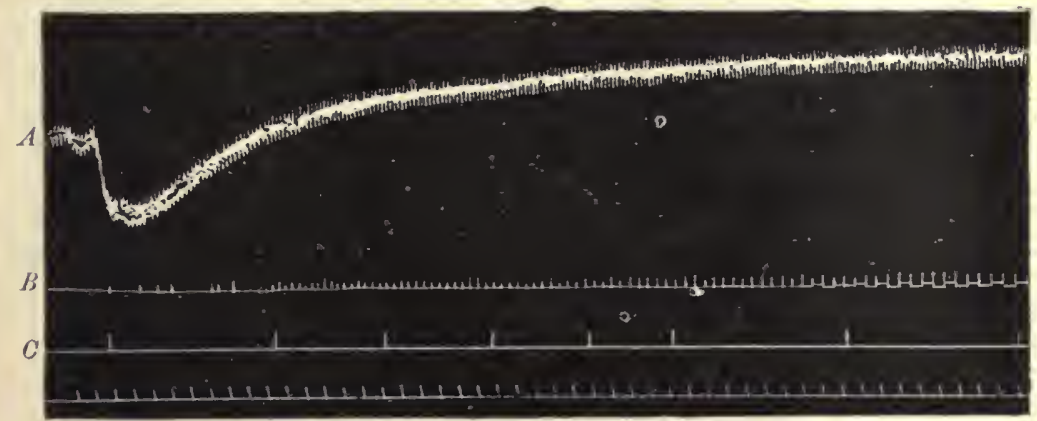

Fia. 197.-To show EfFect of Ixjection of Secretix. (Bayliss and Starling.)

$A$, Blood-pressure; $B$, drops of pancreatic juicc; $C$, drops of bilc.

The Mechanism of Secretion.-Reference has been made to the "hormone," or chemical mechanism of secretion. "Secretin" is stored as pro-secretin, especially in the duodenal mucous membrane, and in less amount in the jejunum. In the ileum there is none.

To prepare it the mucous membrane is scraped from a piece of small intestine, thoroughly minced, and ground up with sand in a montar. The whole is then treated with $0 \cdot 3$ per cent. hydrochloric acid, and boiled. This coagulates the proteins and cxtracts the secretin, which is not destroyed by boiling. The clear fluid is filte:ed off, carefully neutralized, and used for intravenous injection to provoke pancreatic secretion (Figs. 197, 198). Secretin is soluble in alcohol and ether.

Not only acid, but water and oil call forth, by their presence in the intestine, a flow of pancreatic juice. So do such bodies as pepper, mustard, and alcohol. Soaps have a particularly potent 
effect, and it is quite possible that the products of digestion may in some way modify -the enzymic content, soaps calling forth steapsin, dextrins amylopsin, peptones trypsin, and so on.

It is a question whether the secretion of the pancreatic juicc may be reflexly excited by a nervous mechanism. Stimulation of the vagus causes a flow of juice after a long latent period, probably by increasing the movements of the stomach and the flow of acid chyme into the duodenum. However, a secretion has been obtained when the outflow of chyme from the stomach was prevented, and the chemical mechanism thus excluded. In favour of the nervous mechanism is the fact that, in the dog, pancreatic juice kegins to flow one to one and a half minutes after the ingestion of food, and before the entrance of the gastric contents into the dundenum.

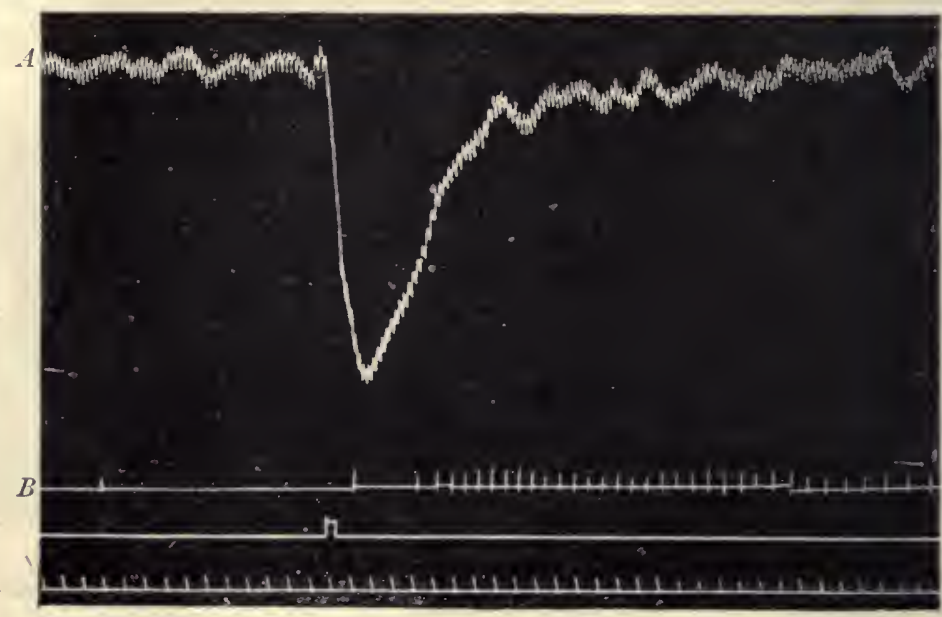

Fig. 198. - Tu shull Action of Acid Extract of Mecous Membrane of Duodexum (SEcretix) DEHYdRATEd BY AlCOHOL. (Bayliss and Starling.)

$A$, Blood-pressure; $B$, drops of pancreatic juice.

The quantity of juice secreted varies in amount with the nature of the nourishment. The period at which the maximum secretion occurs alco varies, as the following figures show: meat, 2 hours; bread, a little later: milk, 3 to 4 hours. These figures apply to the dog. In man, after a carbohydrate meal, the maximum is reached between 3 to 4 hours; after meat and fat, 4 to 5 hours. Carbohydrates produce most secretion, proteins somewhat less, and fat least of all.

The Activation of the Pancreatic Enzymes.-Opinion seems to vary considerably about the state in which the steapsin and amylopsin of the juice are secreted. Some hold that they arc secreted in the active state, others that the pancreas elaborates and secretes their zymogens.

There is no doubt about trypsin: this is secreted as trypsinogen. 
It seems probable the other two are also secreted as zymogens. The potency of freshly secreted juice or of a glycerine extract of fresh pancreas is feeble. Treatment with dilute acetic acid greatly increases it. A glycerine extract increases in potency with keeping, and its fower is accelerated by dilution with a weak solution of salts, and especially by the addition of another potent extract. The transformation of the zymogens of steapsin and amylopsin (if transformation there be) must be rapid, that of trypsinogen is slow. The activation of trypsinogen does not normally take place until the small intestine is reached. If trypsin were active in the juice, it would destroy steapsin and amylopsin. In the intestine, these enzymes are protected by the presence of the bile and the proteins of the chyme. How the activation of trypsinogen is brought about by enterokinase, calcium salts, and probably bacteria, has been already mentioned (p. 370).

The Digestive Action of the Pancreatic Juice-Trypsin.-Most proteins are readily hydrolyzed by this enzyme acting in an alkaline medium. Trypsin, unlike pepsin, does not attack collagen and gelatin. Like pepsin, it digests elastin but little, and keratin not at all. Nucleo-protein is split into nucleic acid and a protein. In the digestion of other proteins, little alkali metaprotein is formed, and digestion proceeds so quickly that primary proteose is not as a rule found; the peptone stage is quickly reached. The peptones are hydrolyzed to polypeptides, and these in turn to amino-acids, ammonia, pyrimidin, and pyrollidin bases. The following table shows this:

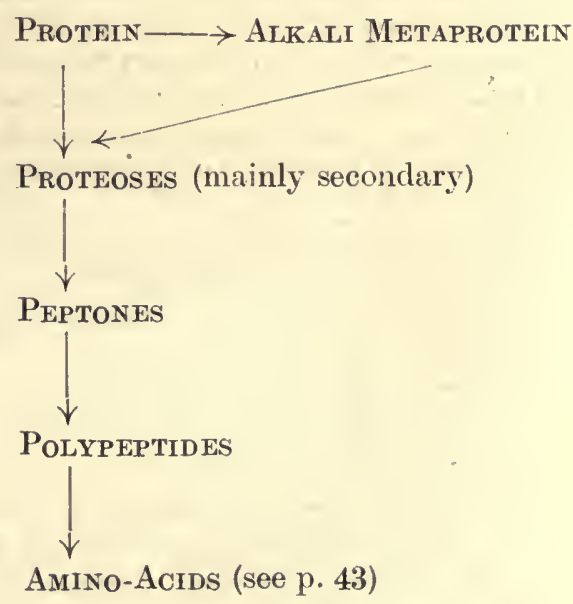

This digestion takes place in stages. Some amino-acids, such as tyrosin, are split off earlier than others.

Starch is digested by amylopsin, passing to maltose through the same stages as in the case of digestion by ptyalin. The pancreatic diastase, however, exerts a considerable action upon unboiled starch. This is not the case with ptyalin (see p. 71). 
Steapsin, in the presence of bile, acts upon the finely emulsified fats, and converts them into glycerine and fatty acid (see p. 71).

Lecithin is hydrolyzed to glycerine, fatty acid, and choline. It is not clear what part rennin can play, as all ingested milk is curdled in the stomach.

The nuclease present splits nucleic acid into purin bodies. In cases of pancreatic disease, it is stated that, owing to the absence of trypsin and nuclease, the cell-nuclei in the food are not disintegrated, and therefore pancreatic disorder can be traced by examining the fæeces after a meal rich in cell nuclei, such as sweetbreads.

THE SUCCUS ENTERICUS.-This is secreted by the tubular glands lining the small intestines, and also by the glands of Brumer. To obtain the juice, a piece of the intestine is isolated with the mesentery intact, and the two open ends are sewn into the abdominal walls-the severed ends of the intestine are reunited (Vella's method), or one end only of the isolated piece of the intestine is sewn into the abdominal wall, the other being sutured (Thiry's method). Such fistulæ have been established in man by operations undertaken to relieve strangulated hernia, etc. In either case, the juice can be removed from the loop and tested in vitro, or food can be introduced into the loop, and afterwards removed and examined.

Obtained in this way, the succus entericus is a yellowish, turbid, viscid fluid, alkaline in reaction, with a specific gravity of 1007 to 1010 , and a solid content of about 1.5 per cent. The viscidity is probably due to a body of the nucleo-protein type, rather than to a true mucin (gluco-protein). It plays an important part in protecting the intestine and facilitating the movements of the intestinal contents. The juice also contains a small amount of serum albumin and globulin, and certain enzymes-erepsin, invertase, maltase, and a feeble lipase. In animals taking milk, a lactase is also present. In addition, it contains enterokinase. The chief salts are sodium chloride and carbonate. The glands of Brunner in the duodenum secrete a pepsinlike enzyme; also in herbivora a diastatic enzyme.

The intestinal secretion reaches its maximum about three hours after food, continuing for six to eight hours. It is greater in the upper than in the lower part of the intestine. It is stated to average in the dog about 100 c.c. daily, in man from 150 to 300 c.c., but it is very difficult to give accurate figures.

The Mechanism of the Secretion.-The mucus comes mainly from the goblet cells, the rest of the secretion from the other cells of the glands. The granules of these increase during rest, and diminisl during activity. The juice is secreted in the upper part of the intestine in response to the presence of hydrochloric acid in the gut, but whether it is due to the direct excitation of the cells or to a "hormone" mechanism is not definitely decided. In regard to the secretion in the lower part, it seems probable that this is determined by the absorption of the products of digestion higher up, and it may be that it varies in composition and amount according to the nature of the food absorber. 
It is claimed that the absorption of intestinal juice itself may also play a part in excicing further secretion.

As regards nervous influence upon secretion, the evidence that such exists is inconclusive. The result which follows division of the nerves supplying an isolated portion of intestine is untrustworthy, since the large amount of fluid then secreted but little resembles the true juice, and is more akin to lymph. It is a result of the vasodilatation and congestion of the loop.

The Uses of the Juice.-By virtue of its mucus, it is protective and lubricatory. The enterokinase plays an important part in the activation of trypsinogen. Invertase inverts cane-sugar to dextrose and levulose; maltase converts maltose into two molecules of dextrose; lactase converts lactose into dextrose and galactose. The action of the lipase and diastase are similar to those of pancreatic juice. As extracts of the intestinal mucous membrane are distinctly more active than the juice itself, it has been suggested that the enzymes are present as such in the mucous membrane, and. may exert most of their action intracellularly during absorption. This applies particularly to erepsin, an enzyme which acts upon proteoses and peptones, and converts them into amino-acids and ammonia, Since this enzyme occurs-in all animal tissues, it may be inferred that its action is mainly intracellular. It occurs in greatest amount in the intestinal mucous membranc, next in the kidney, and then in decreasing amount in the pancreas, spleen, liver, heart muscle, skeletal muscle, and brain. The large amount in the intestinal mucous meinbrane indicates its important function there. Perhaps, by the reversible action of which enzymes are capable, it brings about the synthesis of the products of protein digestion during their absorption through the intestinal mucous membrane (see later, p. 424).

Functions of the Small Intestine.-The functions of the small intestine may be briefly reviewed as follows: In the upper part of the intestine, into which the digestive fluids are poured, the function is essentially digestive; in the middle and lower parts, the function is in the main absorptive. By the time the contents of the small pass into the large intestine, practically all the foodstuffs have been absorbed that are going to be absorbed. Little or no absorption of foodstuffs takes place in the large intestine.

A certain amount of fermentation of carbohydrate, as the result of bacterial activity, may occur under normal conditions in the small intestine, but as a rule there is no putrefaction of proteins. 


\section{CHAPTER XLVIII}

\section{THE LARGE INTESTINE}

The Function of the Large Intestine.-Recently there has been some discussion as to whether the large intestine performs a useful function. By some surgeons it is regarded merely as a scwer-pipe, in which, as the result of bacterial action, the fermentation of carbohydrate and the putrefaction of protein proceed apace, so that he is to be considered a happy man who has rid himself of such an encumbrance (!). Such an opinion flies in the face of Nature and the laws of evolution. The trouble would appear to be that people, while clamouring loudly for modern sanitation, do not trouble to keep this "sewer-pipe" in a wholesome condition. In the large intestine, the greater part of the ingested water is absorbed into the body. This is curious, considering the disgust such feculent water would give us. It is very doubtful whether any products of digestion are absorbed in the large intestine. It was formerly believed that protein digestion was continued in the large intestine, and that an appreciable absorption of the products was absorbed into the system. Recent researches cast doubt upon this point. It may be that a small absorption of the products of protein digestion takes place.

In rectal fecding, the nutriment so given is passed back by reversed peristaltic movements into the small intestine, and there digested and absorbed. Within a few minutes of giving an egg enema, the yellow fluid has been seen pouring from a duodenal fistula.

The absorption of water is of considerable importance to the body It is also of great convenience, since it conduces to the proper formation of freces and greatly reduces their bulk. As the result of extirpation of the whole large intestine in a dog, it was found that the fæces passed each day were greatly increased in weight, and contained five times the normal amount of water. The absorption of protein was slightly diminished, but not that of carbohydrates and fats. In some way not at present adequately understood, the calcium and phosphatic metabolism is influenced by the large intestine. On a herbivorous diet, the amount of calcium excreted by the large intestine and passed in the fæces is considerably greater than on an omnivorous diet. On this latter diet, the proportion of calcium passed in the frces compared to the urine is $75: 25$; on a herbivorous dict, the proportion may be 95 to 5 .

The large intestine is the playground of bacteria. The contents afford an ideal culture medium. Its glands secrete an alkaline 
mucus, and little or no oxygen is present. The conditions thus favour the growth of anaerobic organisms, and their action consists of oxidations and reductions, rather than of hydrolytic changes, such as are occasioned by enzymes. Proteins and carbohydrates are chiefly acted upon, fats but little. The action upon carbohydrates is often referred to as fermentation, that upon proteins as putrefaction. The same bacteria do not act upon both kinds of foodstuffs; indeed, they are antagonistic to each other to a certain extent. The protein-decomposing bacteria are of many kinds, the chief of which is Bacillus putrificus. They are anaerobes, working in the absence of oxygen. The bacteria which act upon carbohydrates, on the other hand, are aerobes, the chief being $B$. coli and B. lactis aerogenes.

Protein decomposition leads to the formation of such bodies as sulphuretted hydrogen, methyl-mercaptan, marsh gas, ammonia, carbon dioxide, lower fatty acids, phenyl-acetic and phenyl-propionic acids, phenol, cresol, indol, skatol. The first-named bodies are generally passed per rectum; the last four bodies are absorbed into the system, and are harmful. If only absorbed in small amounts, they are arrested in the liver, combined with sulphuric acid, and converted into the ethereal sulphates which are excreted in the urine. If absorbed in larger amounts, they escape this action of the liver, and there then follows a general feeling of unfitness and depression, headache, and various other nervous symptoms, due to alimentary toxæmia.

Normally, there is no formation in the large gut of putrescin and cadaverin, bodies which result from protein decomposition outside the body. These are only found in special conditions, such as dysentery and cystinuria. The difference between enzymic and bacterial action upon protein can be appreciated by placing in an incubator at $37^{\circ} \mathrm{C}$. two flasks containing minced meat in alkaline fluid. The meat in one flask is acted upon by trypsin, bacterial action being stopped by some toluol; the meat in the other is acted upon by any bacteria which happen to be present. After two or three days, the flask containing the enzymic digest has a peculiarly faint, but not repulsive, smell; the flask containing the products of bacterial action stinks.

Carbohydrate fermentation leads to the formation of carbon dioxide, hydrogen, butyric, lactic, and acetic acids. The two processes proceed simultaneously in different parts of the intestine. Generally speaking, carbohydrate fermentation leads to the formation of a greater bulk of gas of a less unpleasant nature than the smaller amount of gas derived from protein decomposition.

Under normal healthy conditions, protein decomposition does not proceed to the same extent as outside the body. There is considerablc discussion as to the reason of this. It has already been mentioned that there is an antagonism between the different kinds of bacteria, and the presence of carbohydrate may be partly responsible for this limited action. Milk in the diet, and especially milk-sugar-lactoseare said to be particularly efficient in limiting the putrefaction of 
protein, and this is believed to be due to the fact that they give play to the growth of antagonistic lactic acid bacilli. Quite recently it became fashionable to take lactic acid bacilli by the mouth. This eannot be said to have been very effective as a cure, partly, perhaps, because many of the preparations sold were sterile. At the best it substituted the lesser evil-fermentation of carbohydrate for the putrefaction of protein.

The bacteria are killed off by the action of the healthy intestinal wall; while the contents swarm with bacteria, the mucous membrane and blood circulating within it are sterile. Foreign bacteria, such as vibrios, appear to be killed if introduced into the large intestine.

As the result of bacterial action, the pigment of the fæces-stercobilin-and one of the pigments of the urine-urobilin-together with its precursor urobilinogen, are formed from the bile pigments. Bile salts are also decomposed into cholalic acid, and either taurin or glycin. Cholesterin becomes converted into an allied body-coprosterin.

The fact that extensive bacterial action takes place in the intestine does not mean that it is necessarily harmful; indeed, when kept within limits, it is, if anything, helpful to the body. A certain amount of gas promotes the movements of the large bowel, and assists the removal of the waste material. Experiments have been made to test the value of the intestinal flora to the animal. Guinea-pigs delivered by Cæsarian section, breathing sterile air, and fed on sterile food, progressed as well as the controls kept non-sterile. Sterile chicks, on the other hand, did badly on sterile food. Some died in eighteen days, while, in about the same time as a starving control, others recovered when the bacteria of chicken fæces were added to their food. The guts of Arctic animals, such as the polar bear, are said to be almost sterile. Herbivorous animals obtain a great deal of the nitrogenous foodstuffs from non-protein compounds, especially asparagin. It is suggested that the intestinal bacteria of herbivora build up proteins which are utilized out of these amides. Asparagin cannot - be utilized by carnivora. By the bacteria in the capacious cæcum of herbivora cellulosé is split into glucose, lactic, butyric acids, etc. These are absorbed and utilized, and thus cellulose, which forms so large a bulk of the food, becomes a chief source of energy. Hydrogen and methane are also produced by the bacterial fermentation of cellulose, and constitute a small part of the flatus passed from the bowel. A certain amount of oxygen is set free and utilized. In balancing up the metabolism of cattle, these gaseous excretions, which leave the body both by way of bowel and lung, have to be taken into account.

Protein putrefaction is always going on in the large bowel, even when no food is being taken. The proteins of the secreted juices are then decomposed. It is only when bacterial action is allowed to get keyond proper limits that it becomes harmful. Excess of food and a sluggish large intestine favour the condition. It is obvious that no more food, especially proteins, should bc taken in than can be digested 
and absorbed by the small intestine. No large excess of digestible foodstuffs should be passed, with the juices capable of digesting them, into the large intestine, for the products of digestion cannot be, or are not readily, absorbed there. More important still, the movements of the large intestine must be aided by the massage obtained by exercise of the abdominal muscles, by hard physical work, and deep breathing. The great prevalence of trouble in the large intestine is due to loading it with excess food, and to the development of a sluggish colon by lack of exercise. Plain living and exercise, not the quack's pill or the surgeon's knife, are the cure for the troubles which arise in this region of the gut. The fortunes of pill-vendors are an index of the gluttony and sloth of man.

Fæces.-The freces consist of-

1. Indigestible material, such as keratin and cellulose.

2. Material digested with difficulty - elastin, cartilage.

3. Superfluous and non-absorbed products of digestion-fatty acids, insoluble soaps, amino-acids, purin bodies from nucleo-protein, hæmatin from hæmoglobin, toxic bodies with an aromatic nucleus.

4. Products of bacterial activity-indol, skatol. These are absorbed and excreted in the urine as non-toxic compounds of sulphuric and glycuronic acids.

5. Components of digestive juices secreted by the alimentary tract -trypsin, diastase, cholalic acid, bile salts, lecithin, stercobilin from bile pigments, coprosterin from cholesterin.

- 6. Excretion of the intestinal wall-calcium and iron salts, epithelial cells, leucocytes.

7. Bacteria, forming a large part of the fæces, even half the weight.

The fæces are as a rule alkaline or neutral in reaction. The bulk varies with the kind of food and kind of animal. In man, on a mixed diet, the daily amount evacuated is about 120 to 150 grains, containing 30 to 37 grains of solids; on a vegetable diet, 333 grains, and 75 grains of solids. The offensive smell is mostly due to skatol. The colour varies according to the food. Meat gives a dark, almost black, stool; large amounts of fat make the fæces clay-coloured; much bread imparts a light colour. The breast-fed infant passes motions of the colour and consistency of mustard, acid in reaction, and inoffensive in smell. Meconium, the dark-greenish fæces passed by the newly-born child, are similarly acid in reaction, and inoffensive. It consists of cells, and remains of bile and digestive fluids. There is no sign of any bacterial action.

The chemical analysis of the frees is not often undertaken in clinical laboratories. It affords valuable information in certain conditions. 


\section{CHAPTER XLIX}

\section{THE MECHANICAL FACTORS OF DIGESTION}

THE mechanical factor plays an important part in the processes of digestion, and is intimately related with the chemical factors. The mechanical factor insures the proper subdivision and mixing of the food with the digestive secretions, exposes the products of digestion to the absorptive surfaces, propcls them from one region of the gut to another, and finally discharges the waste material from the body. It is obvious that these processes must be conducted in an orderly fashion, otherwise the food might either be inadequately digested or

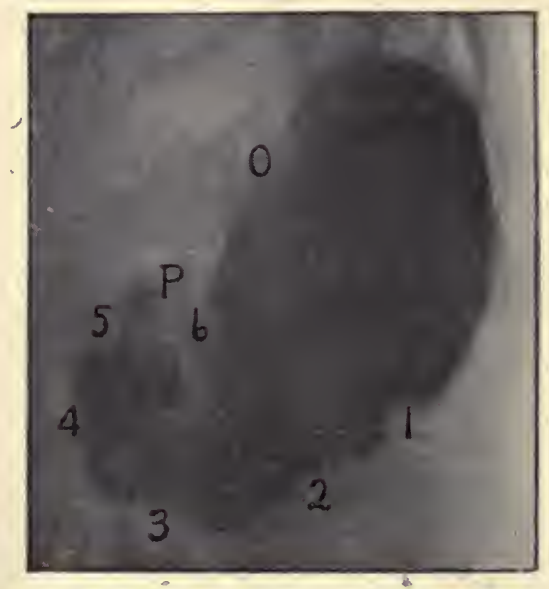

Fig. 199.-Outlines of à Almost Instantaneous Radiograph of the Stomach of a Cat during Digestion. (Cannon.)

$O$, Cardia; $P$, pylorus; at $1,2,3,4,5$, arc indentations due to peristaltic waves passing towards the pylorus.

inadequately absorbed. The kind and rate of movement in the different parts of the alimentary tract varies, therefore, according to the special digestive actions which are being effected in those parts.

The muscles at the beginning and at the end of the alimentary tract are under voluntary control; the rest of the musculature of the tract, however, is of the smooth varicty, automatic in action. The automaticity is dependent, for the most part, upon the primitive nerve plexus (Auerbach's) in the wall of the gut; it is influenced by 
impulses from the central nervous system. Some of the movements may be purely muscular in origin.

To study the movements, animals or men are given food mixed with bismuth subnitrate, or, better, with bismuth oxychloride. The position and movements of the food is observed, by means of the $X$ rays and the fluorescent screen, or by almost instantaneous radiographs (Fig. 199) at various intervals after the taking in of the food. Tracings may be taken upon tissue paper laid upon a piece of lead glass* placed over the screen (Fig. 200). The great advantage of this method is that the normal passage of food through the alimentary tract can be observed over a long period of time, and the characteristic movements of cach part, their normal rate and frequency, be
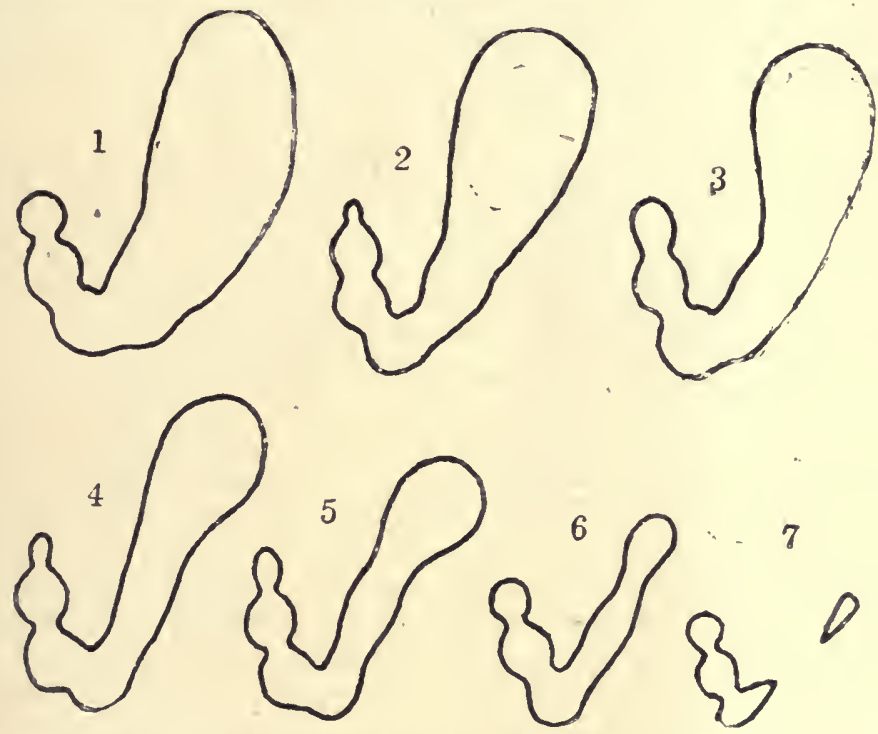

Fig. 200.-Tracixgs of the Shadow cast by the Stomach (Cat), showixg Changes ix the Shape of the Orgax at Ixtervals of ax Hodr durisg the Digestion of A MEaL. (Cannon.)

accurately studied. The disadvantage of viewing the guts directly after operative procedures is that the normal movements are greatly interfered with thereby, or even abolished. Nevertheless, they can to a certain extent be studied by immersing the anæsthetized animal in a bath of warm Ringer's solution, before opening the abdominal wall.

Movements of Mastication.-By an up-and-down movement of the lower jaw, the food is seized by the front teeth; by a side-to-side morement, it is chewed by the back teeth. The tonguc and cheeks assist in this latter process by forcing the food between the grinding

* The lead glass is used to protect the observer from the ill effects of prolonged exposure to $\mathrm{Y}$ rays. 
surfaces until it is thoroughly chewed. In man, the duration of the process of chewing varies with the nature of the food and the tempera: ment of the individual. Some people, generally young, chew their food much less than others. Great value is attached to thorough mastication by some, but many continue to bolt their food, as does a dog, often apparently without harm.

The degree of chewing varies with the nature of the food, a hard, dry food requiring considerably more chewing than a soft, pappy food. Generally speaking, the food is chewed for twenty to thirty seconds, and in this time about 1 to $1 \frac{1}{2}$ grammes of saliva may be added to a mass which generally varies from 3 to 6 grammes. The pressure exerted during chewing may be as great as 270 pounds as measured by a spring dynamometer. Such great pressures are, however, not usually employed, since a side-to-side grind is more effective than the direct thrust. Thus, the crushing-point of cooked meat to

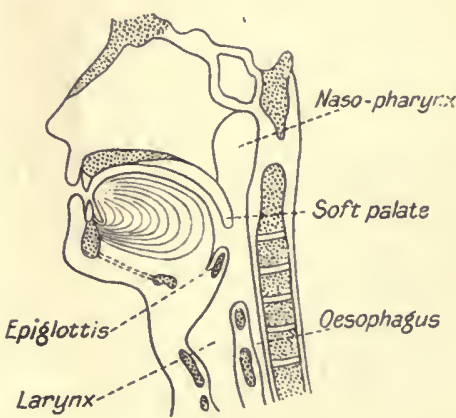

A

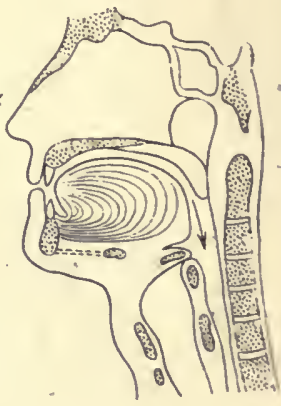

B

Fro. 201.-To show the Mechanisa of the First Stage of Swallowing.

$A$, at rest; $B$, swallowing.

a direct thrust varies from 15 to 80 pounds, with a grinding movement but 1 to 2 pounds pressure is required for cooked tongue, and but 40 pounds pressure for tough beef. The softening effect of saliva upon the pressure required in chewing is also very marked. Soft crumb bread, for example, requires more than 60 pounds direct pressure, but when softened with a little saliva it can be masticated with a pressure of 3 pounds. The chewing of agreeable foodstuffs is of value in reflcxly promoting a flow of gastric juice, and perhaps causing a tonic contraction of the circular muscles of the stomach, thus regulating the stomach movements.

The Mechanism of Swallowing.-After a proper degree of mastication, the food is gathered as a bolus at the back of the tongue. Then follows the complex sequence of events which constitute the act of swallowing. Forward movement of the bolus is prevented by the pressure of the tip and sides of the tongue against the hard palate and the teeth. It is impossible to swallow with the tongue relaxed. 
Then, breathing being inhibited, there follows a short, sharp contraction of the mylohyoid and hyoglossus muscles. The action of the mylohyoid is to press the tongue upwards against the hard palate, that of the hyoglossus to pull it backwards. The result of the combined action is a piston-like thrust, which propels the bolus into the pharynx. Its entrance into the naso-pharynx is prevented by the contraction at the same time of the palato-pharyngeus and levator palati muscles. The levator palati pulls the soft palate down against the posterior pillars of the fauces, which are approximated by the contraction of the palato-pharnygeus muscles. The bolus first strikes the soft palate, then the back wall of the pharynx; it next passes between the pharyngeal wall and the epiglottis, the oesophagus in the meantime being kept closed by the pressure of the larynx; the hyoid bone and the larynx are now raised, the glottis approximated to the epiglottis, the respiratory tract thus shut off, and the gullet opened; so that the bolus, propelled by the mylohyoid, glides into the open œsophagus (Fig. 201).

This is the end of the first stage of deglutition - the stage voluntarily initiated. Then follows the second stage-the involuntary stagenamely, the passage of food down the oesophagus proper to the cardiac orifice of the stomach. In time past, conflicting opinions were held as to the relative importance of the initial impulse imparted in the first voluntary stage and of the peristaltic action of the oesophagus itself. From recent experiment by means of $\mathrm{X}$ rays, it would appear that this depends largely upon the nature of the food, solids and pappy foods being passed down by the peristaltic action of the osophagus itself-liquids, on the other hand, passing quickly down by the impetus given by the piston action of the mylohyoid. The rato of the transmission in the different parts of the ossophagus is variable. It depends upon the nature of the muscle. Thus, in the goose, where the muscle is smooth, a uniform slow peristalsis takes place. It takes twelve seconds for a solid bolus to traverse 15 centimetres of gullet. In the cat, the peristalsis is rapid as far as the heart level (4 seconds), and slow (6 or 7 seconds) for the remainder-less than a third of the whole distance. It is at the heart level that the muscle changes from striated to smooth. In the dog, the peristalsis is quick throughout, the time taken for a solid bolus being 4 or 5 seconds from larynx to cardia. In the dog, the whole osophagus is composed of striated muscle. In both the cat and dog, liquids travel much more quickly than the solid or semi-solid bolus.

In man, the lower end of the œsophagus is composed of smooth muscle, and a slower rate of peristalsis is observed in this region. $\mathrm{X}$-ray observations upon man show that solids and semi-solids are moved down the oesophagus by peristaltic action, irrespective of the position of the body, and owe practically nothing to the preliminary impetus, the time required for a well-lubricated bolus being from 8 to 18 seconds, for a dry bolus several minutes. Liquids, on the other hand-e.g., milk containing bismuth-are shot rapidly through the greater part of the esophagus. In the head-down position, they 
ascend the gullet in one-third of the time occupied by solids in the normal position of the body.

The Nervous Mechanism of Swallowing.- Swallowing is a reflex act, the nervous centre controlling it being situated in the floor of the fourth ventricle in the spinal bulb. The afferent impulses which provoke the reflex arise in the neighbourhood of the pharynx; in the dog and cat, chiefly from the posterior wall of the pharynx, opposite the opening from the mouth-an area supplied by the glossopharyngeal nerve. Impulses also arise from the upper part of the soft palate, supplied by the ninth and the second part of the fifth nerves, and from the base of the epiglottis, supplied by the superior laryngeal division of the tenth nerve.
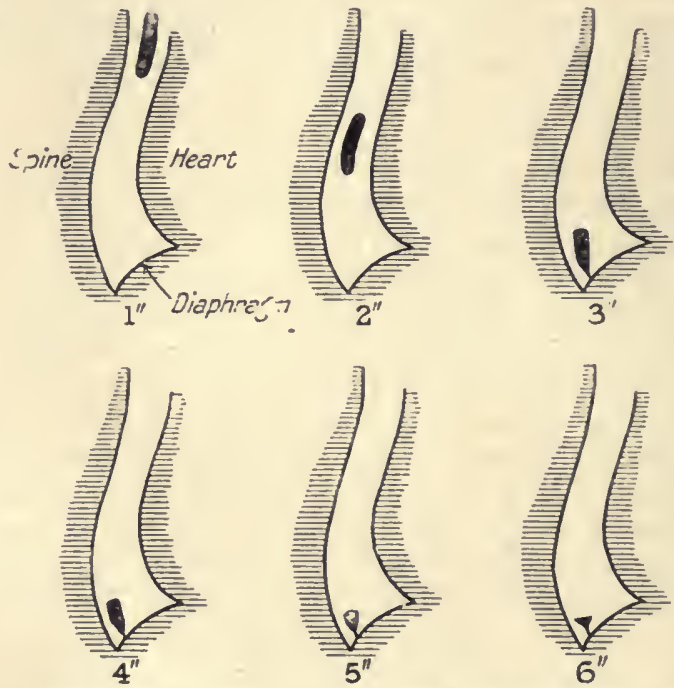

Fig. 202.-Diagraus of Position of Shadow in Esophagus at Ixtervals of a Second after Swallowing. (Hurst.)

In monkeys, the swallowing reflex is most easily evoked in the region of the tonsils; in man, from the back wall of the pharynx and round about the base of the tongue. The ability to swallow depends upon the presence of these special sensitive spots, as is shown by the fact that if a sponge moistened with cocaine be swallowed, and then pulled back by means of an attached thread, the power to swallow is lost for a time. Whenever a bolus of food or saliva is made to stimulate one of these sensitive spots, swallowing involuntarily occurs.

The chief efferent or effector paths are fibres running in the hypoglossus to the hyoglossus, in the third branch of the fifth to the mylohyoid, in the glosso-pharyngeal and the pharyngeal branches of the vagus to the muscles of the palate and pharynx, and in the vagus to the œsophagus itself. Stimulation of these fibres causes strong contraction of the esophagus; section of both vagus nerves produces 
paralysis. The paralysis, however, passes off after a time in the nonstriated part of the œsophagus, which is endowed with the property of performing peristaltic movements by virtue of its intrinsic nervous mechanism: a secondary "lower" reflex mechanism, dependent upon the nerve plexuses in the wall of the œesophagus. By this mechanism, the presence of the bolus in the oesophagus itself causes contractions, which push it onward towards the stomach. Norinally this mechanism probably plays little or no part, the peristaltic movements being controlled reflexly through the vagus nerve. After the œsophagus has been divided in an animal under moderate or light anæsthesia, a swallowing movement initiated in the upper segment is followed by a movement in the lower segment. The peristaltic wave of the latter must in this case be excited and co-ordinated reflexly through the central nervous system. In deep anæsthesia, however, this reflex propagation of the peristaltic wave may be abolished, and a wave of peristalsis initiated in the upper segment of a divided
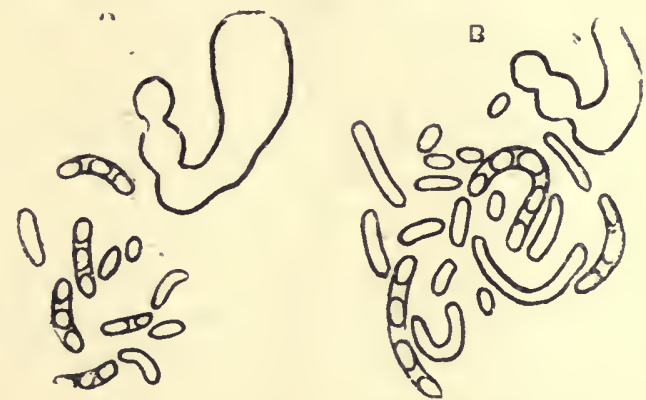

Fig. 203.-Tracings of the Shadows of the Costents of the Stomach axd Intestines (Cat's) made Two Hours after Feedixg $(A)$ with Botled Lean Beef, $(B)$ With Bolled Rice. (Cannon.)

or ligated oesophagus is not passed beyond the point of interruption. We conclude, then, that normally the contraction of the osophagus is a part of the series of reflex nervous discharges initiated in the "swallowing centre" by the stimulation of the afferent fibres.

The Movements of the Stomach.-The movements of the stomach are adapted to the functions of its different parts. By the X-ray method it is seen that the fundus, or reservoir, is practically devoid of movement. It exerts a tonic grasp on its contents, which tend to press them onwards whenever opportunity arises. Peristaltic waves arise from the middle of the stomach (1 to 6, Fig. 199), and pass in succession towards the pylorus. As food becomes discharged into the intestine, the circular muscle becomes tonically contracted so as to give a tubular form to the middle region, along which the peristaltic waves continue to pass. The contents of the fundus are thus gradually passed into the pylorus, and eventually the shadow of the fundus disappears $(5,6,7$, Fig. 200). The regular, wave-like contractions which pass over the pyloric end deepen as they go, and 
churn up the food when the pyloric orifice is closed, and pass it on to the duodenum when the orifice is open.

These churning movements are the first movements noticed when an animal is examined under $\mathbf{X}$ rays after receiving a good

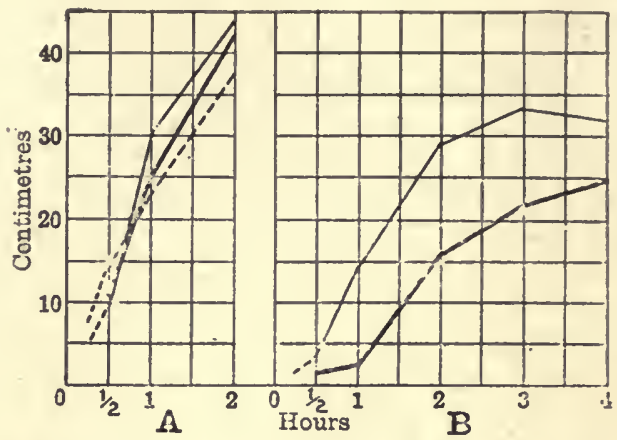

Fig. 204.-To show Effect of Consistexcy of Food opon the Rate of Leaving THE Stonach. (Cannon.)

$A$, Light continuous line = potato of standard consistency; heavy continuous line $=$ potato of thick doughy consistency; dash line=thin gruelly consistency. $B$, heavy line=lean beef of standard consistency; light line=lean beef of thin gruelly consistency.

meal. After a short time, an annular constriction appears at the vestibule, and passes slowly over the rest of the pylorus, being followed by regular waves arising in the same rcgion. Then a little later (two

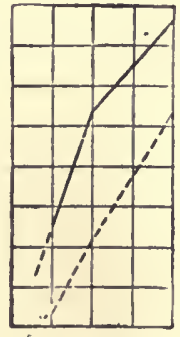

Fig. 205.

The continuous line shows the rate of disappearance from the stomach of a carbohydrate meal (biscuits, rice, potatoes) moistened with water; the dotted line of a similar meal moistened with 1 per cent. $\mathrm{NaHCO}_{3}$. There is marked retardation of the latter. (Cannon.)

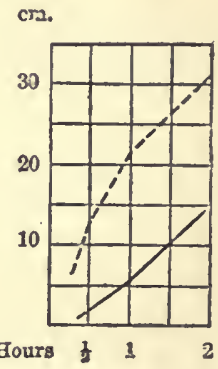

FIG. 206.

The continuous line shows the rate of disappearance of a meal of protein (fibrin, fowl, lean beef); the dotted lino that of same meal fed as acid protein. (Cannon.)

to three minutes) the contractions which arise from the middle of the body make their appearance, the amount of contraction becoming much more marked when the vestibule is passed. These peristaltic 
waves do not pass into the duodenum, the muscular continuity between the parts being interrupted by a ring of fibrous tissue. The time of recurrence of the waves varies in different animals; and also with the nature of the food. In cats, there are generally four to six per minute; in dogs, about four; in man, three. Fat diminishes the number per minute, carbohydrate increases them.

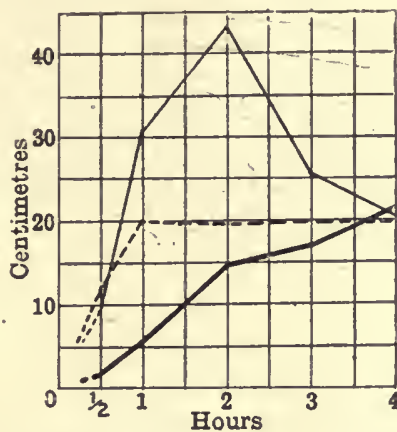

Fig. 207.-To show Retardina Effects of Fats upon food leaving StomaCh. (Cannon.)

Light line =eurve of mashed potato; heavy line=eurve of mutton fat; dash line= curve of potato and mutton fat mixed.

The opening of the pyloric orifice is co-ordinated with the acidity and the consistency and nature (Fig. 204) of the gastric contents. Generally speaking, carbohydrates leave first, proteins next, and fats last (Fig. 205). Carbohydrates as a rule leave the stomach quickly, but if fed with alkali their exit is retarded (Fig. 205). Feeding proteins with acid, on the other hand, hastens their normally slow exit (Fig. 206). Fats retard the exit of other foods (Fig. 207). When the acid contents of the stomach reach the duodenum, the pyloric

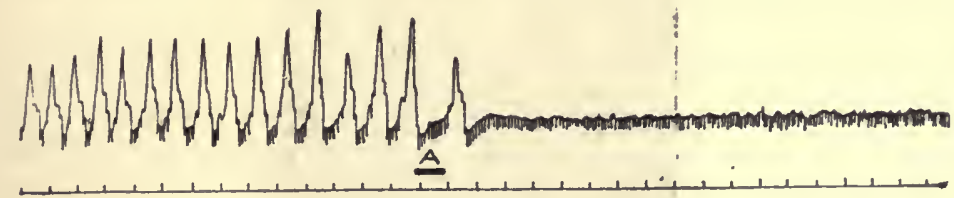

Fig. 208.-Record showing Cessation of Rhythmic Regurgitations of Fluid fron Stovach into Esophagus after acidifying Gastric Contents at $A$. (Cannon.)

Upstroke=outflow, small oscillations due to respiration. Time in half-minutes.

aperture closes. Thus, acid on the pyloric side opens, on the duodenal side shuts the pyloric orifice, the regulation probably depending on a local reflex mechanism.

The cardiac orifice is normally kept shut. In the resting condition of the stomach the sphincter resists a tension of about $25 \mathrm{~cm}$. of $\mathrm{H}_{2} \mathrm{O}$. We are, therefore, not conscious of the rancid contents of the stomach. 
During digestion, the acidity of the contents causes the closure of the sphincter to become firmer. When the stomach is very full, and there is no acidity of the reservoir contents, rhythmic relaxation and contraction of the cardiac orifice may occur, with the result that the stomach contents are regurgitated into the œsophagus. This has been experimentally demonstrated on cats both by the $\mathrm{X}$-ray method and

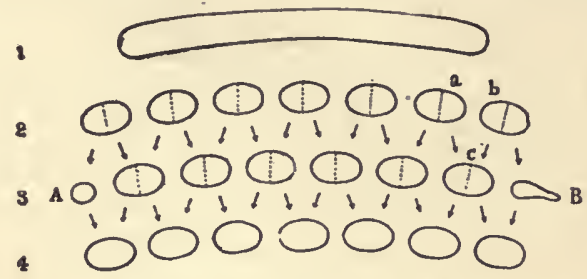

Fig. 209.-Diagram represexting the Process of Rhythilc Segmestation. (Cannon.)

Lines 1, 2, 3, 4, indicate the sequence of appearance in a single loop. The dotted lines represent the regions of division. The arrows show the relation of the particles to the segments they subeequently form.

by direct registration by means of a tambour placed in the œesophagus. The addition of acid immediately caused a cessation of such movements (Fig. 208).

That such a regurgitation occurs in man has been proved by the fact that lycopodium srores swallowed overnight in a gelatin capsule

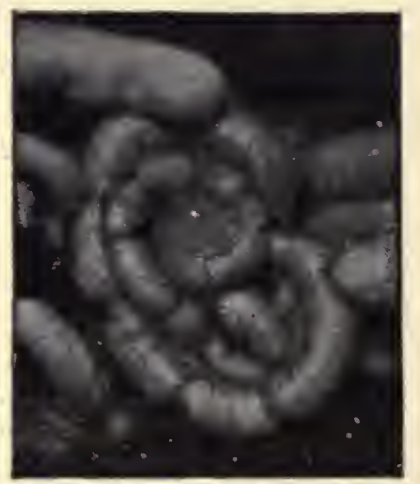

I'ig. 210.-P'Hotograph of the Syall Ixtestine segmenting its Contents.

(Cannon.)

have been found in the mouths of persons next morning, although there was no trace of them in the mouth one to two hours after swallowing. It is suggested that the disagreeable taste in the mouth and the coated tongue of the dyspeptic may be due in part to particles of food regurgitated from the stomach, especially when there is a deficiency of hydrochloric acid in that organ. 
The movements of the stomach and its sphincters may be modified by the action of the vagus nerve. Stimulation of the peripheral end of the vagus nerve causes contraction of the cardiac sphincter, but after the intravenous administration of atropine the action of the same nerve on this sphincter becomes inhibitory. On vagal stimulation, the tone of the stomach increases, and the peristaltic waves augment. In some cases there may be a preliminary transitory inhibitory effect. The effect on the pyloric sphincter is uncertain. It is probably dependent upon the condition, at the moment of stimulation, of the local nervous mechanism which controls that orifice. Sometimes it opens, and sometimes it closes. The sympathetic nerve is generally believed to be inhibitory to the stomach, but this action is open to question.

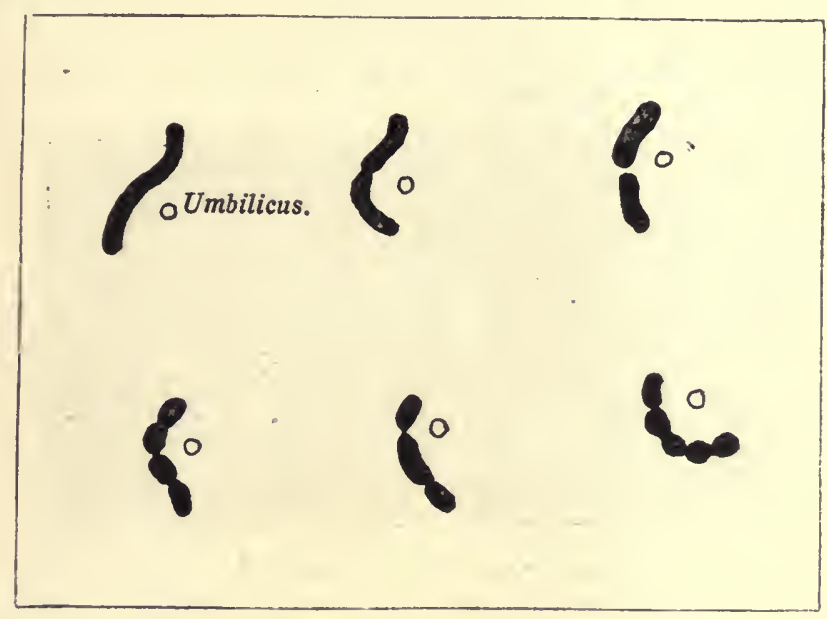

Fig. 211:-Segmextation of the Small Ixtestine in Max. (Hurst.)

Vomiting is controlled by a nervous reflex, and can be induced either centrally or peripherally. Tickling the throat between the pharynx and top of the œesophagus will often induce it. The effector fibres run in the vagus nerve. The cardiac orifice is relaxed, the body of the stomach rendered flaccid and dilated, and the tone of the pylorus increased. A strong contraction occurs at the incisura angularis, dividing the stomach into two separate portions. The stomach contents are then voided by a simultaneous contraction of the diaphragm and the muscles of the belly wall. As vomiting proceeds, the stomach wall contracts down on the remaining contents; otherwise the stomach is essentially passive during the act of vomiting.

The Movements of the Small Intestine.-On observing by the $\mathrm{X}$-ray method a length of small intestine, it is noticed that the first movement, after food enters it, is the sudden division of the length into a number of small ovoid segments of almost equal size (Fig. 209). A moment later, these small segments themselves divide into two, the 
neighbouring halves uniting to form new segments. A moment later, the process is repeated, and this "rhythmic segmentation" of the intestinal contents proceeds incessantly for about half an. hour at a rate of about twenty-eight to thirty a minute. During this period, the position of the food within the gut is but slightly changed. Rhythmic segmentation has been observed in the cat, white rat, dog, and man. In the rabbit, a rhythmic shifting of the food to and fro has been observed (Fig. 210). Segmentation of the small intestine in man is shown in Fig. 211.

The effect of rhythmic scgmentation is to mix the food in the gut thoroughly, bring it into intimate contact with the mucous membrane, and to pump on the contents of the capillaries and lacteals carrying the absorbed foodstuffs. These movements probably correspond to the gentle, swaying, "pendulum" movements which have been observed by the method of direct observation. The pendular movements arc accompanied by rhythmical contractions at a rate of twelve

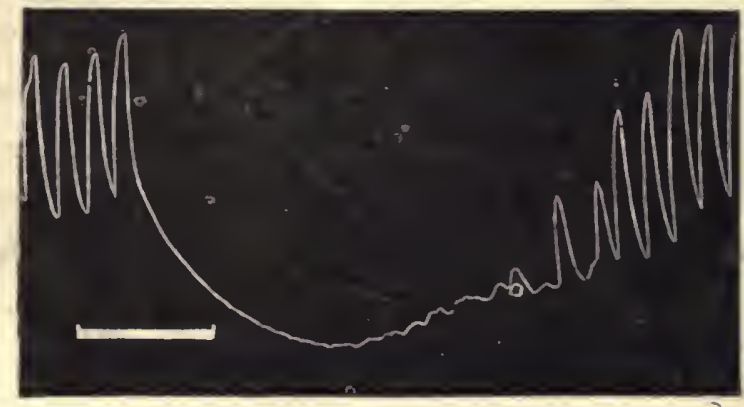

Fig. 212.-Pexdulum Movemexts of the Ixtestixè ixhibited by Excitation

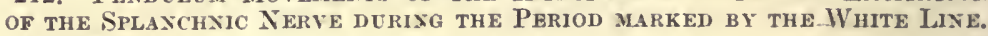
(Starling.)

to thirteen per minute. These movements are not affected by the application of nicotine or cocaine. They appear, however, to be depcndent upon the integrity both of the inuscle and the nervous plexus, since strips of the intestinal longitudinal muscle devoid of any nervous plexus do not perform these movements. They are inhibited by excitation of the splanchnic nerve (Fig. 212). The separated muscle has no refractory period, gives summated contractions, can be tetanized, and gives no rhythmic responsc to continued stimulation. Preparations of muscle with Auerbach's plexus attached possess a refractory period to weak stimulation, cannot be summated or tetanized, and exhibit rhythmic contractions to continucd stimulation.

The food is moved onward in the intestine by means of a peristaltic wave, which may be observed in two forms-(1) a slowly advancing contraction ( 2 to 3 centimetres per minutc), which moves the nutriment but a slight distance (" true peristalsis "); and (2) a swift move- 
ment, passing over the entire length of intestine in about a minute, and tending to void it of its contents (so-called "rushing peristalsis").

"True peristalsis" involves a contraction of the gut above the contents, and a relaxation below them (Fig. 213). To study this, a small balloon may be introduced into the gut, and connected with a recording tambour. The animal is immersed in a bath of warm Ringer's solution before exposure of the gut. A stimulus applied locally above a bolus introduced into the gut will cause relaxation of the wall in the region of the bolus, whereas pinching below the bolus induces a strong contraction of the gut upon the bolus itself. Peristalsis is dependent upon the local nervous mechanism of the small intestine, and is abolished by painting the wall with cocaine or nicotine. It continues, however, when all connections with the central nervous system are destroyed (Fig. 214).

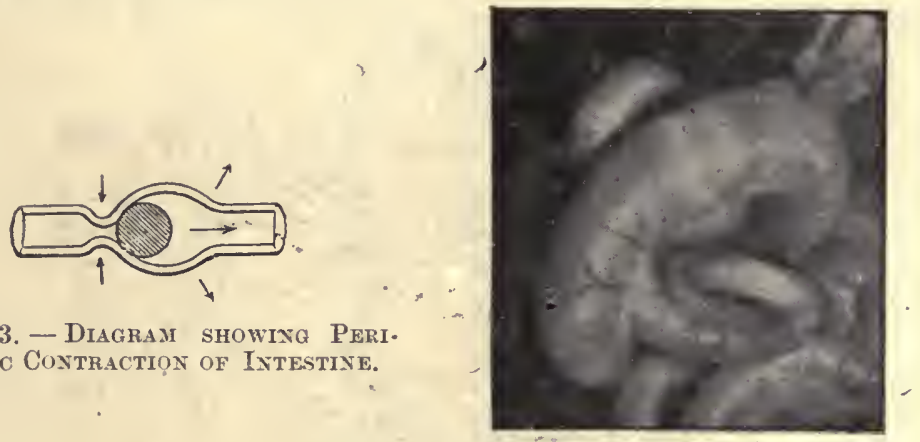

Fig. 213. - Diagray showixg Peri. staltic Contraction of Intestine.

Fiv. 214.-Photograph of a PeriStaltic Wave of SMall INTestine pushing Material into the Colon. (Cannon.)

* Peristaltic rush" is probably of the nature of true peristalsis, and occurs particularly when it is necessary to rid the gut of irritating substances. It is usually stated that antiperistalsis does not occur in the small intestine, and, so far, has not been obscrved, but clinical evidence points to the fact that it occurs. For instance, nutrient enemata containing egg administered per rectum have been observed shortly afterwards flowing from a duodenal fistula. In cases of intestinal obstruction, also, the vomit may become of a fæeal nature -so-called "freal vomiting."

The movements of the small intestine are affested by the vagus and sympathetic nerves. Peripheral stimulation of the vagus causes an initial inhibition of the whole small gut, followed by increased contractions. Stimulation of the splanchnic nerves causes inhibition of the movements, with relaxation of both muscular coats. The splanchnics probably excrt a tonic inhibitory influence, which may become excessive in abdominal and nervous disorders. The time usually occupied by the food in traversing the $22 \frac{1}{2}$ feet of small intestine is about six hours. 
The ilco-colic sphincter is normally closed, but relaxes before an advancing peristaltic wave, and admits the food into the large intes. tine. Stimulation of the splanchnic nerve produces a strong contraction of this sphincter. Vagal stimulation has no effect on it.

The Movements of the Large Intestine.-The ileo-colic sphincter opens before the wave of peristalsis when this reaches the terminal part of the ileum, and the ileal contents are then passed on into the large intestine. The first effect of their advent, observed by the skiagraph method, is to bring about antiperistaltic movements of the ascending colon. These start from the junction of the ascending and transverse colon, and force the food down into the cæecum, the ileo-colic sphincter being now closed. The waves of antiperistalsis occur at about the same rate as those of the stomach (five to six a

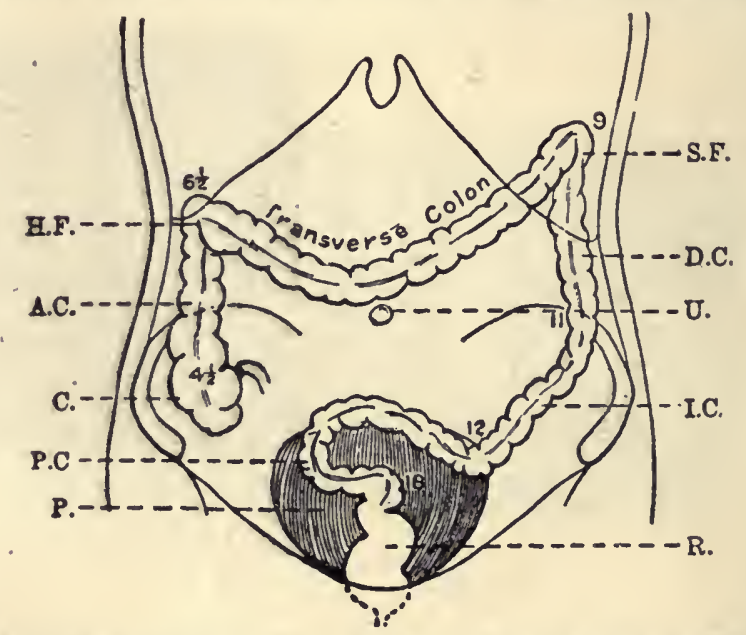

Fig. 215.-Diagam to show the Hours which elapse after a Bismoth Meal before the Differest Parts of the Colon are reached, (Hurst.)

minute), and the period of antiperistalsis lasts on an average about four to five minutes, and recurs after varying lengths of time, generally from ten to fifteen minutes. Antiperistalsis is the predominating movement of the first part of the colon. As a result, the contents are retained there for a considerable time, generally about two hours, and the absorption of water is greatly facilitated. It is probable that the arrival of new material in the large intestine pushes on the contents beyond the antiperistaltic area, but it is possible that from time to time a wave of true peristalsis helps to push on the contents into the transverse colon.

Thus far, true waves of antiperistalsis have not been observed in man, but there is reason to think that such take place in him no less than in animals. It is known that nutrient enemata are quickly passed back into the ascending colon, and, when large, may pass thence into the small intestine. 
As the contents pass along the large intestine, they become separated into semi-solid globular masses. In the transverse and descending colon, antiperistalsis is very slight, and the predominating movement is a slow true peristalsis.

The pelvic colon down to the acute flexure (P.R.F., Fig. 216) just above the rectum is the storehouse of fæces. Occasional longcontinued waves of contraction force the contents well down into the pelvic colon, and eventually, by rendering the angle of flexure less acute, force some of the contents into the rectum. This leads to a desire to defæcate. - These long-drawn movements are subject to the control of a centre in the lumbar spinal cord. They are probably evoked by distension of the gut stimulating the afferent nerveendings in the pelvic nerve. The times taken for the passage of food through the large intestine in man are marked in hours in Fig. 215.

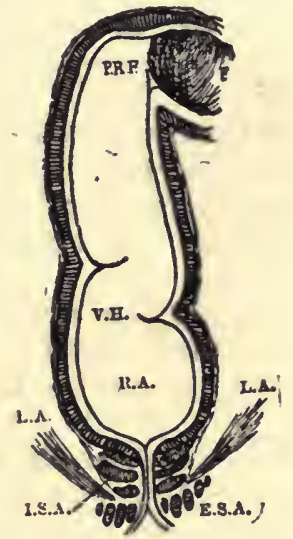

Fig. 216.-Dlagram of Rectum (Hurzt), showing Pelvi-Rectal Flexure (P.R.F.); F eces in Colon (F.); Houstox's Valve (V.H.); Rectal Ampolla (R.A.); Levator Ani (L.A.); Internat Sphincter (I.S.A.); External Sphincter (E.S.A.).

Defæcation.-To stimulate the desire to defæcate, the distension of the empty rectum by a small amount of fæces is sufficient (Fig. 216). Such an amount is normally passed into the rectum from the pelvic colon as the result of peristaltic action reflexly induced by the taking of food on an empty stomach. Hence the desire to: defæcate after breakfast. The result may also be brought about by physical exercises and a cold bath, or even by the muscular exencise involved in dressing.

That it is the distension of the rectum, and not the actual contact of the fæces with the rectal mucous membrane, which leads to the desire to defæcate has been shown by inflating the rectum with a balloon. If the desire be not obeyed, the wall of the rectum relaxes, the intrarectal pressure falls, and the desire passes away, only to recur when the intrarectal pressure is again raised by the advent of fæces. Defæcation may sometimes be started by voluntary effort. 
The glottis is closed after an inspiration, and the action of the diaphragm and the abdominal muscles forces fæces past the pelvi-rectal flexure.

When the desire to defæcate is obeyed, the rectum is further distended by fæces by raising the intra-abdominal pressure in the abovementioned fashion. The contraction of the diaphragm after inspiration is the most effective agent in raising the abdominal pressure. This is aided by the crouching posture assumed. The contraction of the abdominal muscles, the flexion of the spine, the pressure of the thighs against the belly wall, and the contraction of the muscles of the pelvic floor, serve to sustain the increased abdominal pressure. .

When the rectum is sufficiently distended, there ensue strong peristaltic contractions of the whole colon, which, in conjunction with continued contraction of the abdominal muscles and the relaxation of the anal sphincters, force the fæces out, the final expulsion being aided by the contraction of the levator ani muscles, which draw the anal canal upwards, and also constrict the lowest part of the rectum.

Although normally a voluntary process, defæcation may take place in involuntary fashion when the rectum becomes sufficiently distended with fæces. The frees may become hard and dry when the voluntary aids to defæcation are lacking, and it may be difficult to expel the hardened masses.

Defæcation is stated to be under the control of a centre in the lumbo-sacral region. The effector nerves run to the rectum in the sympathetic system by way of the inferior mesenteric ganglion and the hypogastric nerves, and in the pelvic nerves (nervi erigentes) from the third sacral nerve to the inferior hæmorrhoidal plexus. Stimulation of both sets of nerves leads to contraction of the rectum. It is probable, however, that the pelvic nerves are the more effective, and that the hæmorrhoidal plexus may be regarded as a subordinate centre for defæcation, since a somewhat incomplete reflex act of defæcation can occur in the dog even when the lumbo-sacral cord is destroyed. The levator ani and the extcrnal sphincter muscles are supplied by the fourth sacral nerve. The action of these muscles, controlled from the spinal centre, is essential for the complete reflex. The lumbo-sacral centre is under eontrol of excitatory or inhibitory impulses from the cerebrum, and when this control is withdrawn, as after division of the spinal cord, incontinence of frees results. 


\section{BOOK VII}

\section{CHAPTER L}

\section{SPECIAL METABOLISMS}

Absorption.- The absorption of the foodstuffs takes place chiefly in the small intestine, and particularly in the middle and lower portions. Considerable discussion has taken place as to the mechanism of this absorption, and at first, when physiological science was young, such comparatively simple processes as filtration, diffusion, and osmosis, were evoked to explain it. It is now generally conceded that it is controlled by unknown forces of the living cells lining this part of the alimentary canal. The chief cvidence upon which this conclusion is based may be summarized as follows:

1. If the mucous membrane be removed from a picce of intestine, the absorptive power is abolished.

2. Poisoning the cells by washing the mucous membrane with a dilute solution of sodium fluoride, or scalding them, destroys the absorptive process.

3. The absorption of water from the intestine takes place much more quickly than does diffusion through a dead membrane.

4. The rate of absorption of the products of digestion is too rapid to be explained by simpler physical processes. Peptone is absorbed from the intestine more readily than dextrose; on the other hand, dextrose diffuses through parchment quicker than peptone. Sodium sulphate is not readily absorbed from the intestine, yet it readily diffuses through parchment.

5. The absorption of water, saline and other salts (magnesium sulphate) is attended by a greatly increased consumption of oxygen by the intestinal cells, showing that absorption, even of water, is an active process (see p. 321).

6. The animal's own serum, identical in composition and isotonic with the blood, is completely absorbed if introduced within a loop of intestine.

7. Certain products of digestion, such as those of fat, and probably of protein, are altered during their passage through the cells of the mucous membrane.

The Metabolism of Protein.-In the intestine the protein is broken down into protcoses, peptones, polypeptides, and amino-acids. There 
is eonsiderable difference of opinion as to how far it is necessary for protein to be broken down before it can be absorbed. It depends to a certain extent upon the nature of the protein. Thus, casein, edestin, acid metaprotein, introduced directly into the small intestine, are not absorbed at all; egg-albumin, serum-albumin, are absorbed slightly (about 20 per cent.); and alkali metaprotein considerably (70 per cent.). Undoubtedly, these proteins are considerably modified, but to what degree is uncertain, before reaching the blood. Proteoses and peptones appear to be readily absorbed from the small intestine, but it is doubtful whether they reach the blood as such. When they do, it is only in such minute quantities, difficult of detection, and out of all proportion with the amount actually absorbed. It is probable that the absorbed proteoses and peptones are converted into aminoacids by the cells of the wall of the intestine. It is known that the cells of the mucous membrane are very rich in erepsin. It has bcen shown that proteoses and peptones disappear from the lumen of an isolated loop of intestine which is perfused with defibrinated blood, and that no peptones can be detected in the blood. The amino-acids formed as the result of digestive processes within the lumen are also absorbed. In this process it is suggested the leucocytes present in the mucous membrane in some way play an important part.

The question now arises, What becomes of these amino-acids, which either pass into or are formed within the intestinal wall ? It is a very complex one, and at present by no means fully elucidated.

Before attempting to consider the two main hypotheses, it is well to grasp the general idea underlying the processes of protein metabolism. The proteins of the food are necessary to the life of the animal. Without a certain amount of protein in the diet, the animal slowly but surely dies. This protein is necessary for the repair and growth of tissue proteins. Two points are to be observed in this connection: first, that the animal's own proteins, which require building afresh, differ in constitution-the protein of the muscles, for instance, differs from the protein of the kidney substance; secondly, the ingested proteins, from which these different proteins are to be replaced, differ even more widely in constitution. This is especially the case when the ingested protein is of vegetable origin. It is easily understood that only a portion of such ingested proteins may be of service to the animal in rebuilding its particular proteins. Sueh portion may be considerable or inconsiderable, according to the nature of the protein taken in. The process of protein digestion may be compared to house-breaking, the process of protein anabolism to the reconstruction of a number of new houses from the bricks of the demolished houses. Certain of the building-stones are of great value in rebuilding the new houses, others are of partial value, others are of little or no value at all. In protein anabolism, the amino-acids are such building-stones. Some are of great valueprecious-others appear to be of lesser value.

It has been shown by experiment that an animal can live when 
fed on the amino-acid products of a meat digest. If, however, it be fed on selected amino-acids, it is found that on some it can still live, on others it gradually starves. For example, the monamino-acids by themselves do not support life, neither do the diamino-acids. On the other hand, the addition of ringed amino-acids, such as phenylalanin, tyrosin, and tryptophan, has been found to support life. So, too, proteins which do not contain these last amino-acids, such as gelatin and zein, fail to keep an animal alive. The addition of ringed amino-acids to such proteins renders them more life-supporting. From this point of view, it is interesting to note that Nature provides the young growing animal with a protein-caseinogen-especially rich in both tyrosin and tryptophan.

The two hypotheses held in regard to the metabolism of protein differ (1) as to the place of selection of the building-stones-the amino-acids; $(2)$ as to the form in which the material for reconstruction is presented to the tissues.

According to one view, the amino-acids pass as such into the portal blood. It is claimed that their presence there can be demonstrated by special indicators, such as $\beta$-naphtha-sulphonic acid. The gut of the octopus is naturally suspended in a bath of blood, and aminoacids are said to appear in this blood when protein is digested in the gut. The absorbed amino-acids are then taken in the portal blood to the liver, which controls their passage into the general circulation according to the needs of the body. Each amino-acid has its own special metabolism.

It has been shown that, if such bodies as glycin, alanin, arginin, be perfused through the isolated liver, the urea content of the blood leaving the liver is increased. These amino-acids are only of partial value to the body. The nitrogenous moiety contained in them may perhaps be regarded as valueless, for it is rapidly excreted. These amino-acids are first deaminized, the ammonia split off being converted into urea, while the non-nitrogenous inoiety remains. There is reason to suppose that this is first converted into a lower fatty acid, which then becomes converted into dextrose, a conversion of great importance in carbohydrate metabolism. In the case of alanin, for example, the process may be represented as follows:

$$
\begin{aligned}
& \mathrm{CH}_{3} \mathrm{CH} \cdot \mathrm{NH}_{2} \mathrm{COOH}+\mathrm{H}_{2} \mathrm{O}=\mathrm{CH}_{3} \mathrm{CHOH} \cdot \mathrm{COOH}+\mathrm{NH}_{3} \\
& \text { Alanin } \\
& \text { Lactic acid } \\
& 2 \mathrm{CH}_{3} \mathrm{CHOH} . \mathrm{COOH} \\
& \left(\mathrm{C}_{3} \mathrm{H}_{6} \mathrm{O}_{3}\right) \\
& =\mathrm{C}_{6} \mathrm{H}_{12} \mathrm{O}_{6} \\
& \text { Dextrose }
\end{aligned}
$$

The fate of the monamino-dicarboxylic acids, such as aspartic and glutamic acids, is probably the same. The diamino-acids, such as arginin and lysin, together with the closely allied histidin, are probably also broken down into nitrogenous and non-nitrogenous moieties, the nitrogenous being mainly excreted from the body in the form of urea, the non-nitrogenous part being possibly converted into dextrose.

It is not yet known sufficiently well what exactly happens to 
tyrosin and tryptophan. These are of great value to the body, and in the liver they are probably modified into a form available for the tissucs. It is certain that they are not rapidly destroyed, and their nitrogenous moiety excreted from the body in the form of urea. If a non-nitrogenous moiety be split off, it may give rise to dextrose.

Cystin (diamino-di-thio-lactic acid) is broken down in the liver, the sulphur moiety giving rise in part to taurin and in part to inorganio sulphates. It is possible that the carbon-containing lactic acid portion may give rise to dextrose.

The fate of the other bodies is not sufficiently elucidated to be mentioned here, but, according to this hypothesis, they also each undergo their own special metabolism in the ljver. The fact that there occur certain inherited but very rare errors of metabolism, such as alkaptonuria and cystinuria, is held to lend support to the hypothesis, which may be represented diagrammatically as follows:

\section{Products of Protein Digestion.}

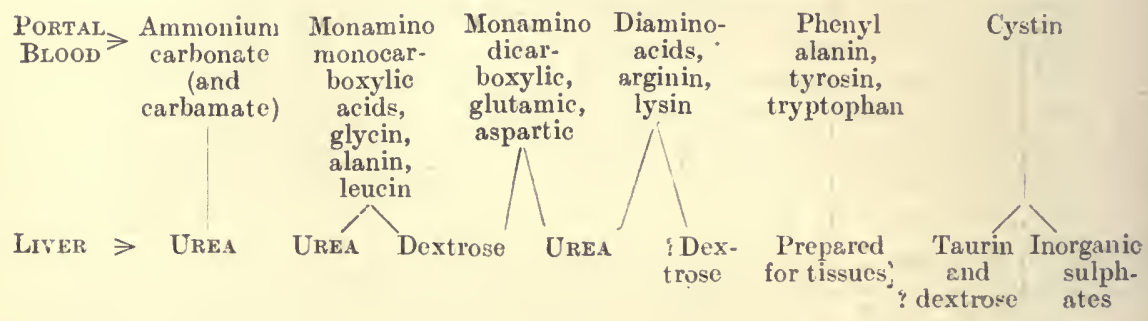

An objection to this hypothesis is that it is not quite clear from what source the body derives all the bricks nccessary for the rebuilding of its proteins. In these proteins, amino-acids, such as alanin and glycin, are incorporated, and it is by no means clcar from what scurce such amino-acids come.

According to the second hypothesis, the amino-acids do not pass from the intestine into the blood. It is said-(l) that their presence therc has never been conelusively demonstrated; (2) that if the circulation be confined to the intestinal wall and pancreas, heart, lungs, and muscles of respiration, the blood contains no proteoses, peptones, or amino-acids. It is therefore held that the amino-acids, during their passage, are-(1) either synthesized into protein, so-called "plasma protein"; or (2) deaminized, with the formation of ammonia.

The "plasma protein" is held to be a protein so built that all the cells of the body can abstract from it just the bricks they desire to rebuild their own particular protein. In building up this plasma. protein, all the amino-acids of digestion are not used. Many are in excess-such, for example, as glutamic and aspartic acids, when plant proteins have been ingested. These are deaminized in the intestinal wall, and the ammonia thus formed passes to the liver as ammonium carbonate or carbamate, there becoming converted 
into urea. It may be assumed in this case that the non-nitrogenous moiety formed as the result of deaminization is taken to the liver, being there converted into dextrose and, finally, in part to glycogen (see next page).

In support of this view, it has been shown that a dog may be fed on digested protein (amino-acids), and kept in nitrogen equilibrium, even when its portal blood is short-circuited from the liver by an Eck's fistula (see p.448). The blood coming from the intestine during periods of digestion is stated to be demonstrably richer in protein of a globulin nature.

This view may be regarded as a modification of older ones concerning protein metabolism. According to these, serum albumin and serum globulin were formed in the intestinal wall, and passed into the portal blood. The views differed as to the subsequent fate of these proteins. According to one view, all protein was subsequently built up into living protoplasm before it was destroyed; according to the other, some of the protein, called "tissue protein," was built up into protoplasm; the remainder was not so built up, but served as a source of energy - the so-called " circulating protein." The speed with which an increased intake of nitrogen appears in the urine as urea is against the view that such nitrogen has been built up into protoplasm. On the other hand, when we consider the rapidity with which protoplasm grows-e.g., yeast multiplying-we cannot put such a possibility out of court. As to whether any of the protein formed in the intestinal mucous membrane acts solely as circulating protein, there is at present no evidence.

Much more work is required upon this intricate and difficult subject. Up till now, there can be said to be no established theory of protein metabolism, only two tentative hypotheses, of which the sccond, given above, appears the more probable-namely, that a special plasma protein is synthesized in the intestinal mucous membranc, containing all the necessary bricks for the rebuilding of the tissue proteins. Excess of digested protein is deaminized in the intestinal mucous membrane, and the ammonia thus formed is short-circuited from the body as urea.

Protein, or the amino-acids split from it, increases the rate of metaholism and heat-production stimulating the cells of the body to activity, having a specific dynamic action greater than carbohydrate and much greater than fat. This stimulating action is traced to oxyor keto-ncids, the non-nitrogenous moiety of protein metabolism. 


\section{CHAPTER LI}

\section{THE METABOLISM OF CARBOHYDRATE}

THE digestive processes reduce the carbohydrates to the monosaccharides-dextrose, levulose, and galactose-the chief of which is dextrose, since cane-sugar and lactose normally form but an insignificant part of the diet. Dextrose is absorbed unchanged into the portal blood by the activity of the intestinal cells. The portal blood therefore becomes charged with sugar above the content normally present in blood. The excess of sugar acts as a stimulus to the liver, which abstracts the excess, so that the blood leaves that organ supplied with about 0.01 per cent. of sugar-the normal content. The diffusible sugar retained by the liver is elaborated into the non-diffusible colloid glycogen, and stored as such. There has been much controversy as to the ultimate fate of the glycogen. The generally accepted view is that there is a reversible ferment action in the liver. The ferment converts sugar into glycogen when the portal blood comes laden with sugar, and glycogen into sugar when the blood comes to the liver impoverished in sugar.
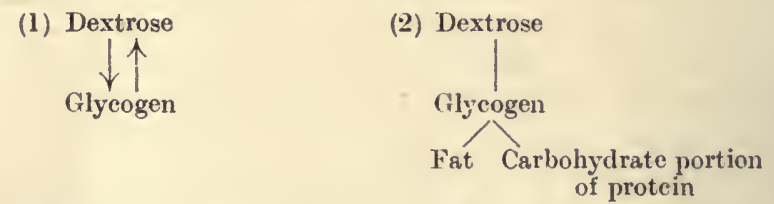

Another view is that glycogen is never again converted to dextrose in life, but is elaborated into fat, or it may possibly be combined to the proteins as a carbohydrate moiety. The balance of evidence is in favour of the first view.

The glycogen quickly disappears from the liver after death, and dextrose is formed. It is also probable that this process takes place in life, and not only post-mortem. There seems to be good evidence, too, that when blood, with a low dextrose content, is perfused through the liver, it acquires dextrose. It is true that glycogen may give rise to fat under certain conditions, but the available evidence indicates that such fat, when metabolized within the body, is again broken down to glycogen and dextrose (see p. 440). Leaving the liver, the dextrose passes in the blood to the heart, and thence to the system generally, to be katabolized.

The Katabolism of Dextrose.-Three views are held as to the manner in which dextrose is normally broken down within the body. Accord- 
ing to one view - the least accepted-sugar is broken down by the body in the same way as it is by the yeast cell-that is, through intermediary stages to alcohol, and then to carbon dioxide and water. There is some proof of this taking place in plants, but the evidence for such a katabolism in the animal tissues is scanty.

According to a second view, dextrose breaks down to glycuronic acid, and then to carbon dioxide and water. Until recently, this view has received wide acceptance. Glycuronic acid is closely related to dextrose, and is found in the blood and in the urine.

All the recent evidence, however, tends to show that dextrose is normally broken down to lactic acid, and then to carbon dioxide and water. The muscles are the chief seat of dextrose katabolism. In the absence of oxygen, lactic acid is not broken down, and may be detected in the urine and in the sweat-e.g., after hard muscular exercise, or when an excised muscle is tetanized in the absence of oxygen.
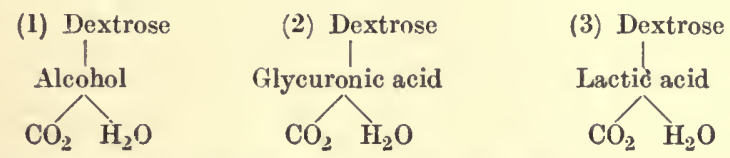

We must now inquire with a little more detail into-(1) the glycogenic function of the liver; (2) the conditions necessary for the breaking down of sugar in the body.

The Glycogenic Function.-By this function, the supply of dextrose in the blood is regulated, and kept at a constant amount $(0.01$ per cent.) adequate to the needs of the body. When the supply of sugar in the blood is large, as at the height of digestion, the dextrose is abstracted and stored as glycogen; when the supply of sugar in the blood is poor, then glycogen is converted into dextrose, and passes into the blood. Normally, the liver restrains any surplus supply of dextrose from reaching the systemic blood, and causing what is termed a hyperglycamia. When hyperglycæmia results, the kidneys immediately eliminate the excess sugar, and dextrose appears in the urine, forming the condition known as glycosuria. The efficiency with which the liver performs this function is judged by the sugar content of the blood and urine.

As a general rule, the urine only is tested, but in special conditions the sugar content of the blood is also tested, for a small excess of sugar may exist in the blood without causing glycosuria. Moreover, all glycosurias are not due to inefficiency of the liver and hyperglycæmia. To estimate the amount of dextrose, the blood is laked and diluted, shaken with colloidal ferric hydroxide (dialyzed iron), and then a small amount of sodium sulphate added. By this means the bloodprotcins are precipitated. The sugar in the filtrate may then be estimated by Bertrand's process (see p. 468).

The Sources of Glycogen-Carbohydrate.-That glycogen is largely formed from dextrose may be experimentally proved by starving a rabbit, and subsequently feeding it with carrots - a diet rich in 
carbohydrates. During starvation, the glycogen content of the liver falls very low; during feeding with abundant carbohydrate, the liver content becomes very high-e.g., 18 per cent. of the weight may be glycogen. As already stated, at the height of digestion the blood leaving the liver is poorer in dextrose than the blood reaching it. Perfusion cxperiments also show that dextrose is abstracted by the liver from defibrinated blood containing an excess of this sugar. Levulose also gives rise to glycogen; galactose gives but little. Pentoses do not appear to be direct glycogen-formers.

Protein.-Opinions differ widely as to whether glycogen arises from proteins. As the result of direct feeding experiments, many obscrvers claim that feeding with proteins incrcases the amount of glycogen in the liver, even when proteins are fed which yield no carbohydrate group, such as caseinogen and gelatin. Other observers contend that proteins arc glycogen-sparers rather than glycogenformers; that, under such feeding conditions, the glycogen content of the liver is increased, because dextrose is spared in the body when there is an abundance of protein fed. The fact that glycogen does not disappear entirely from the body even during long-continued starvation would appear to indicate that proteins may serve as a source of glycogen. The conversion of protein into glycogen probably takes place by the deaminization of amino-acids, the non-nitrogenous moiety of such acids becoming converted into dextrose, and thence to glycogen. Perfusion experiments have shown that glycin, alanin, asparagin, act as precursors of glycogen. It seems probablc that more sugar and glycogen arise from protcin than is generally rccognized.

Fat.-In regard to the products of the digestion of fat, there is no evidence to show that glycogen arises from the fatty acids. On the other hand, there is evidence to show that glycerine gives rise to dextrose, and may possibly give rise to a small amount of glycogen.

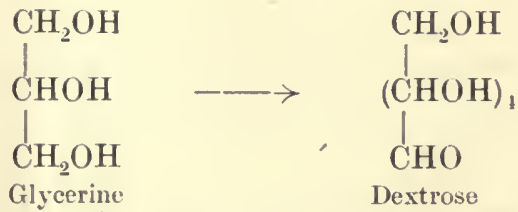

It is possible, also, that under certain conditions fat stored in the liver bccomes broken down to form glycogen. Such fat, however, has been previously built up in the organism from dextrose and glycogen (see p. 440).

The glycogenic function of the liver is very easily disturbed, and its continual disorder results in the disease diabetes.

The Influences affecting the Glycogenic Function-(1) The Nervous Influence.-First and foremost come nervous influences. Puncture of the floor of the fourth ventricle in the middle line in the region between the origin of the eighth and tenth nerves causes hyperglycæmia, the disappearance of glycogen from the liver, and the appearance for 
the time being of much dextrose in the urine. If the animal has bcen starved previous to the puncture, no such result follows. There is therefore, supposed to be a "centre" in this region of the medulla through which the glycogenic function of the liver is controlled. The result has been attributed by some authorities to the disturbance of the circulatory conditions of the liver, owing to interference with the vaso-motor centre. Such circulatory disturbance possibly does play

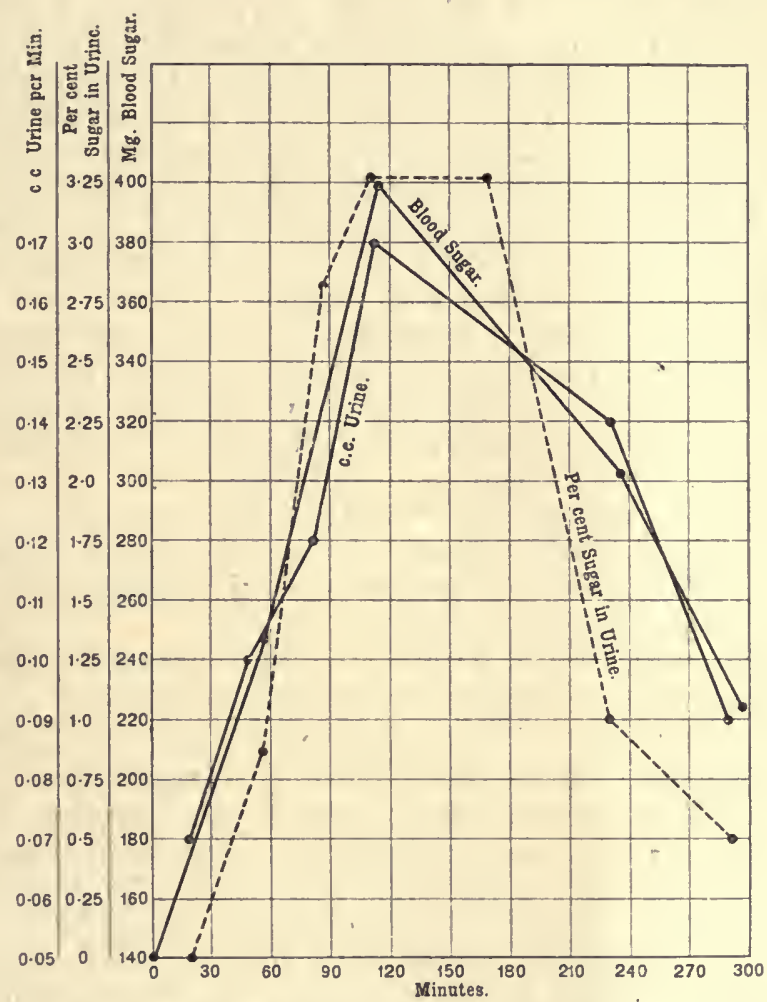

Fig. 217. - Curves showlyg the Relationship between the Concentration of Sugar in Arterial Blood, the Concentration of the Urine, aNd tile Rate of Urine Formation, following Stimulation of the Splanchic Nerve. (MacLeod.)

a part, but it is more generally held that there exists a true glycogenic centre apart from the vaso-motor centre. To this centre run affercnt, and from it efferent paths. The afferent paths are not fully elucidated. Interference with other parts of the brain and nervous system may induce glycosuria. Fright causes glycosuria in a cat. If the vagus nerve be cut in the neck, stimulation of the central end produces glycosuria. This experiment has been interpreted as showing that the vagus contains afferent fibres to the glycogenic centre. It seems morc probable that the glycosuria results from the asphyxial 
condition which results from the spasm of respiration induced by the vagus stimulation. The chief efferent fibres ultimately reach the splanchnic nerve. When the splanchnics are cut, puncture of the medulla induces no glycosuria. Stimulation of the uncut splanchnic nerves brings about glycosuria (Fig. 217).

To sum up, in the medulla is situated a centre which regulates the glycogen metabolism of the liver. The vagus nerve possibly contains afferent fibre:; to this centre; the splanchnic nerve conveys efferent fibres from it to the liver. It is possible that this centre is directly affected by the sugar content of the blood supplied to it, and that some drugs which induce glycosuria act directly upon the centre, exciting in much the same manner as a puncture does.

(2) The Chemical Influence.-Adrenalin plays a part in the regulation of the glycogenic function. It has been known for a considerable time that injection of adrenalin into the blood-stream causes glycosuria. This is now attributed to the action of adrenalin upon the endings of the splanchnic nerves in the liver. Adrenalin has the property of stimulating in the body all the functions which the sympathetic nerves cxcite. It acts upon the so-called "receptive substance," which occurs between the sympathetic nerve fibre and the effector tissue.

We may provisionally conclude that the liver performs its glycogenic function-(1) under the influence of nervous impulses brought from the glycogenic centre by the splanchnic nerves; (2) under the influence of adrenalin brought by the blood.

By some authorities it is held that the internal secretion of the pancreas also plays a part in regulating the glycogenic function of the liver. The evidence on this point is contradictory in nature.

The Influences under which Sugar is Broken Down. - Various agencies have been or are held to influcnce the splitting of dextrose in the body. At one time, considerable weight was attached to the supposed presence of a glycolytic ferment in the blood. Recent evidence indicates that the presence of such an enzyme in the blood is more than doubtful. At the present time, great importance is given by many authorities to the action of an internal secretion from the pancreas. This internal secretion is believed to be derived from the "islets of Langerhans" in the pancreas. Circulating in the blood, it enables the tissues, particularly the muscles, to break down dextrose. The tissuc fluid obtained from a mixture of pancreas and muscle can break down dextrose; extract of pancreas by itself has no such action; that of muscle but slight action on dextrose. The active substance obtained from the pancreas is not an enzyme. It is soluble in water and alcohol, not destroyed by heat, and is believed to activate the zymogen of a glycolytic enzyme present in muscle, or possibly in the leucocytes.

The above statement has not been accepted by all workers.

Pancreatic glycosuria is discussed more fully elsewhere. From the evidence, we tentatively conclude that in the normal body an internal secretion derived from the pancreas plays a part in the 
breaking down of dextrose by the muscles. The parts possibly played by the secretions of the suprarenal and pancreas are shown diagrammatically in Fig. 218.

Glycosuria.-Dextrose may appear in the urine under any of the following conditions:

1. The liver, supplied with too much dextrose, is unable to deal with it all, so that an excess of sugar passes into the blood and is excreted by the kidneys.

2. The liver, over-stimulated, suddenly turns a large amount of glycogen into dextrose, floods the blood with sugar, and thus induces glycosuria.

3. The glycogenic function of the liver remains normal, but the power of the body to break down dextrose is diminished, so that the sugar accumulates in the blood, and this leads to glycosuria.

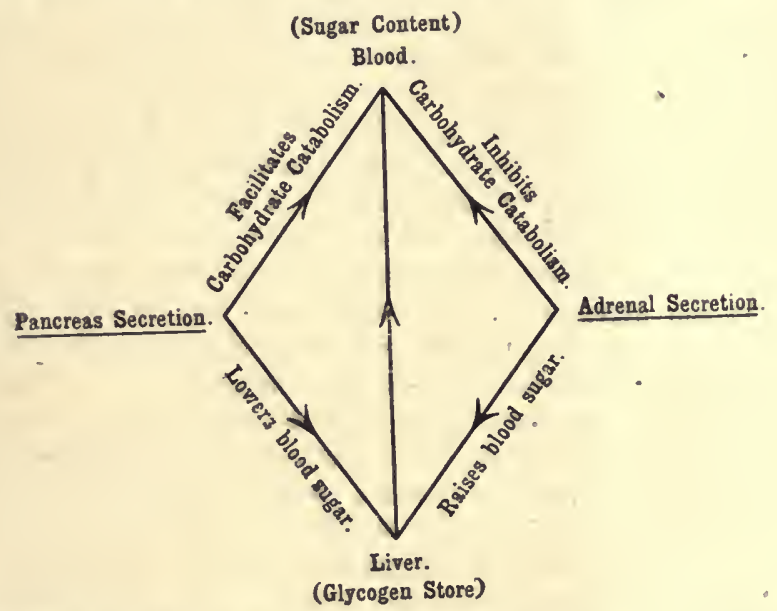

Fig. 218. - Diagram indicativg Influence of Paxcreas and Suprarenals on Carbohydrate Metabolism. (After Underhill and Fine.)

4. There is no excess of dextrose in the blood, but sugar forms within the kidney substance itself, and is excreted in the urine.

5. The amount of dextrose in the blood remains normal, but the kidneys become more "permeable" to sugar. Thus sugar, which is normally retained in the body, passes into the urine.

When glycosuria occurs, it may be due to one or other or a combination of these conditions. Glycosuria may be experimentally induced in various ways, the chief of which are the following:

1. Alimentary Glycosuria.-This follows the ingestion of too much sugar - for example, 150 to 200 grammes of dextrose, and considerably less lactose, levulose, and galactose. Children sometimes eat $\frac{1}{4}$ pound or even $\frac{1}{2}$ pound of sweets. Alimentary glycosuria is due to the "flooding" of the liver with too much sugar. It is sometimes termed "glycosuria e saccharo." It may also be produced, but more rarely, 
by the ingestion of too much starch ("glycosuria e amylo"). Many healthy members of a German garrison were found to have sugar in the urine because too much starch was included in their dietary. Alimentary glycosuria occurs more readily in some individuals than others. Clinicians differ as to whether people in whom this glycosuria occurs easily are to be regarded as physiological or pathological.

2. Puncture (Neurogenous) Glyccsuria has been already mentioned. It results from the disturbance of the glycogenic centre in the inedulla oblongata which controls the conversion of hepatic glycogen into sugar. Clinical experience shows that a similar condition arises from meningitis (inflammation of the coverings of the brain), injuries to the brain and upper part of spinal cord, tumours of the brain, especially of the fourth ventricle, cerebellar hæmorrhage, and possibly from psychic shock, mental worry, and overwork. The increased mobilization of sugar in the blood may be secondary to the passage of adrenalin into the blood, and possibly the internal secretion of the pituitary gland. It has been shown that fright increases the output of adrenalin.

It is possible that some of the drugs, such as caffein and strychnine, which cause glycosuria, act on the glycogenic centre. Injection of piperine and the giving of anæsthetics cause glycosuria, apparently due to the dyspnoea thereby produced, for it is abolished if oxygen be given simultaneously. The same holds true of the glycosuria induced by the stimulation of the central end of the vagus nerve. The results may be due to the effect partly upon the centre, and partly upon the peripheral nervous mechanism.

3. Pancreatic Glycosuria.-The remarkable discovery was made at the end of last century that total extirpation of the pancreas results in a fatal glycosuria, while if a small piece of gland (one-fifth) be left in situ, or transplanted, no glycosuria results. The glycosuria has 110 relation, therefore, to the digestive secretory function of the pancreas. Considerable discussion has taken place as to the cause of this glycosuria. Some have contended that it results from opcrative damage done to the splanchnic nerves and sympathetic ganglia in the neighbourhood of the pancreas. This view now finds little acceptance.

It has been suggested by others that after the extirpation of the pancreas the liver more actively produces sugar. In an ordinary fasting animal, the liver loses more weight than the rest of the body, whereas in a depancreatized animal starving from glycosuria (the gland was removed in part at first, followed by subsequent destruction of the remainder) the liver does not lose weight, although the total weight of the animal diminishes rapidly.

The view most generally accepted, however, in regard to pancreatic gdycosuria is that there results a diminished utilization of sugar by the tissues. Possibly the hepatic control of sugar is also affected. As the simultaneous injection of a pancreatic extract prevents that glycosuria which follows injection of adrenalin, it has been suggested that the internal secretions of the suprarenals and 
pancreas together control the sugar content of the blood. There is also evidence of a mutual retardation of action effected between the thyroids and the pancreas. Thus, when the pancreas is removed, there oscurs an increased metabolism of protein and fat, which is attributed to the unrestrained activity of the thyroid and suprarenal glands. These conclusions, if substantiated, afford a striking example of the mutual interdependence of the various internal secretions of the body (see later, p. 503).

The fasting depancreatized animal continues to excrete sugar. As regards the source of this sugar, it has been shown experimentally that injection of such amino-acids increased its formation. The sugar may therefore be derived from protein decomposition.

The question of the formation of sugar from tissue protein has also been investigated by comparing the amount of dextrose (D) secreted in the urine with the amount of nitrogen $(\mathrm{N})$ secreted as urea, giving the so-called $\underset{\mathrm{N}}{\mathrm{D}}$ ratio. When a depancreatized animal is fed on protein freed from all traces of carbohydrate, both dextrose and nitrogen are increased in the urine, but the ratio is not altered from what it was during fasting, which shows that the dextrose and the nitrogen of the urine have a common source. If all the non-nitrogenous moiety of protein were used to form sugar, the $\frac{\mathrm{D}}{\mathrm{v}}$ ratio would be about 7. This can be seen from the following calculation: Protein contains on an average $\mathbf{5 2}$ per cent. of carbon and 17 per cent. of nitrogen; urea, $\mathrm{CON}_{2} \mathrm{H}_{4}$, contains 20 per cent. of carbon and 51 per cent. nitrogen. If 17 grammes of nitrogen derived from 100 grammes of protein are excreted as urea, the latter accounts for $6 \frac{2}{3}$ grammes of carbon. This leaves $52-6 \frac{2}{3}=45 \frac{1}{3}$ grammes of carbon to be accounted for. In the gramme-molecular weight of sugar, $\mathrm{C}_{6} \mathrm{H}_{12} \mathrm{O}_{6}-$ 180 -there are 72 grammes of carbon. Therefore, if 72 grammes of carbon go to form 180 grammes of sugar, $45 \frac{1}{3}$ grammes of carbon will form $180 \times 45$ ?

$$
\begin{aligned}
& =\frac{180 \times 136}{3 \times 72} \\
& =113.3 \text { grammes of sugar } \\
\therefore \mathrm{D} & =\frac{113.3}{17}=7 \text { nearly. }
\end{aligned}
$$

In an animal suffering from pancreatic glycosuria, however, all the carbon is not converted, a D : N of about 3 to 4 being maintained.

Dextrose may also be formed from the glycerine moiety of fats. It has been shown that in the condition of pancreatic glycosuria glycerine yiclds an increase of sugar in the urine. It is to be concluded, then, that after extirpation or in certain diseased states of the pancreas dextrose may appcar in the urine, and this sugar may be derived from carbohydrates, proteins, and fats.

4. Phloridzin Glycosuria-Phloridzin is a glucoside obtained from the root bark of cherry and apple trees. If it be injected into an animal glycosuria results. If it be injected into one renal artery, sugar 
appears in the urine secreted by that kidney before it appears in the urine secreted by the other kidney. If it ke mixed with defibrinated blood and perfused through an excised kidney, sugar is excreted. No hyperglycæmia is induced, and no store of glycogen in the liver is requisite. The sugar is formed in the kidney under the influence of the drug. The sugar does not come from the drug itself, since phloretin, the portion of the alkaloid which is free from dextrose, also causes glycosuria. Two sources of the sugar have been suggested: (1) Glucosa mine, the carkohydrate-holding group attached to the blood-proteins; (2) amino-acids formed within the kidne $y$ itself.

The amount of sugar is often too large to be accounted for wholly

by the first view. The administration, together with the drug, of alanin and other allied amino-acids causes an increased sugar excretion. The nitrogen excretion of the urine is also increased by phloridzin, the $\frac{\mathrm{D}}{\mathrm{N}}$ ratio bcing 3.6 after all the hepatic glycogen has been got rid of by fasting.

5. Adrenalin Glycosuria.-The fact that injection of adrenalin causes glycosuria has already been mentioned. It is believed that adrenalin normally aids the liver in the performance of its glycogenic function (see p. 42\&). Injection of adrenalin apparently increases the conversion of glycogen into dextrose, and thus floods the blood with sugar-a condition allied to puncture diabetes. Adrenalin causes glycosuria in starved animals, and also in animals which have teen subnitted to the administration of phloridzin. It is stated that the administration of adrenalin in increasing doses causes a deposition of glycogen in the liver, but not in the muscles, in rabbits from whom all traces of glycogen had been removed both by starvation and doses of strychnine. The convulsions produced by strychnine expend the last of the glycogen. This internal secretion therefore plays an important part in the production of glycogen from sugar, of sugar from glycogen, and of sugar from protems.

6. Thyroid and Parathyroid Glycosuria.-After removal of both the thyroid and parathyroid glands, the organism is said to show a diminished tolerance to dextrose. When the thyroids alone are reimoved (see p.515 for a discussion of the relationship of these glands to each other), there is no evidence of such diminished tolerance. It is necessary that the parathyroids be also removed. The parathyroids apparently influence carbohydrate metabolism in such \& way as to prevent the accumulation of excessive sugar within the organism. The thyroids probably have a function which is supplcmentary to the action of adrenalin. Taking away the thyroids has been shown to lessen the glycosuria induced by a given dose of adrenalin. Excess of thyroid, on the other hand, possibly causes glycosuria by bringing about a more marked action of adrenalin (see p. 505).

7. Pituitary Glycosuria.-It is claimed that intravenous or subcutaneous injection of extracts of the posterior lobe of the pituitary gland causes a glycosuria in animals fed on an ordinary diet, and that this is due to an internal secretion which lowers the utilization of 
dextrose in the organism. Conversely, removal of the posterior lobe is said to endow animals with an increased tolerance to excessive amounts of dextrose (see later, p. 522).

The interrelation and exact mode of action of all these glands requires far more work before any clear and dogmatic statements can be made in regard to their control of carbohydratc metabolism.

8. "Salt" Glycosuria.-Glycosuria follows the injection of 1 per cent. solution of sodium chloride into the blood of an animal. It has been suggested that the salt renders the kidney cells more permeable to sugar. On the other hand, it is quite possible that the glycogenic centre in the medulla is affected. Injection of a soluble calcium salt (ionized calcium) abolishes the glycosuria induced by the sodium ion.

Diabetes Mellitus. - In this disease, or rather in the collection of pathological conditions grouped under this name, the patient generally passes much sugar in the urine. Cases may be described as mild and severe. In the mild cases, the glycosuria disappears when carbohydrate is removed from the diet, the trouble being due only to defective storage or oxidation of sugar. In the severe cases, the sugar cannot be thus removed from the urine. It is probable that the less severe of such cases derive sugar from protein only, whercas the more severe and rapidly fatal cases derive it from fats also. The acetone bodies which often occur in the urine of diabetics are discussed elsewhere (Urine,p. 468). Under the name diabetes are classed glycosurias of various origin-neurogenous, hepatogenous, pancreatic, etc.- - a great number of such, but by no means all, being due to some defect in the pancreatic control of carbohydrate metabolism. For a full discussion, textbooks of pathology and medicine should be consulted. The tests for sugar in urine arc dealt with under Urine (p. 467). 


\section{CHAPTER LII}

\section{THE METABOLISM OF FAT}

The Absorption of Fat. - Fat is digested into fatty acids and glycerine, and brought into solution. The preliminary emulsification of the fat facilitates its digestion, not its absorption. The view once put forward, and now abandoned, was that emulsified neutral fat is absorbed in the particulate form without being split into fatty acid and glycerine. The absorption of fats from the intestine depends upon the solubility of free fatty acids and soaps in the bile. The bile salts increase the solubility of soaps in water; they also prevent its gelatinization, and thereby greatly aid absorption. The lecithin of the bile also plays an important part in the solution of fatty acids and soaps. Fats of high melting-points are not absorbed so well as fats with low melting-points; free fats are better absorbed than those enclosed in cell membranes.

During absorption the dissolved fatty acids and soaps pass into the intestinal mucous membrane. Here, by the activity of the cells, they are again synthesized with glycerine into particles of ncutral fat, and these pass into the lacteals, which fill with a milky whitc lymph known as chyle. The lacteals derive their name from this milky fluid, and were discovered through it.

Leucocytes aid the passage of the synthesized neutral fat into the lacteals. They are to be seen in sections of the villi stained with osmic acid, crowded with particles of fat. How the particles are handed on from the columnar cells to the leucocytes is unknown. Not all the fat eaten finds its way into the lacteals. The fate of the remainder is unknown. It probably passes into the blood, forming some linkage with the protoplasm of the plasma and corpuscles. The lacteals, then, act as an overflow, and protect the liver from being flooded with fat. Our methods of analysis do not allow us to detect any increase of fat in the portal blood, but neither do they permit us to be sure of an increase therein of sugar or amino-acids during digestion. The circulation is so rapid that an immeasurably small increase of any of these substances must suffice to carry them away. About 60 per cent. of the ingested fat is found in the chyle as neutral fat, and a small quantity ( 4 to 5 per cent.) as soaps.

Anabolism of Fat.-From the lacteals the chyle passes to the receptaculum chyli, and thence by the thoracic duct into the venous blood. During this passage the neutral fat is again broken down into soluble. soaps, passing as such into the blood, so that there is no danger of the 
fat plugging the small bloodvessels, as would be the case if it were in a state of fine emulsion. It is also better available for storage in the various fat depots of the body.

The fat depots of the body are situated in the subcutaneous tissue, in the subperitoneal tissue, between the muscles, and around various organs of the body, such as the kidney and the eyeball. The depots of fat act primarily as the storehouses of a food possessed of great energy value. They also protect the body from heat loss, and act as cushions, giving form and beauty to the body, preventing jarring, and giving support to the various organs. The haggard face, the chilly temperament, and the falling down of the viscera, alike result from want of fat. Fat is also stored intracellularly in other cells-e.g., muscle fibres and the liver cells-beside those of the true adipose tissue, much of it in a masked form, probably combined with protein or other bodies, so that it does not react with fat stains.

The fat in the various depots is not always of the same character. It is more fluid in some parts than others. Chemically, also, the same difference is found.

This is shown in the following table:

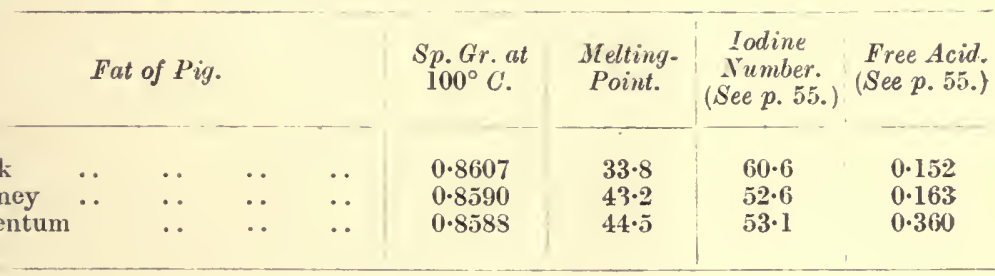

The fats of the subcutaneous tissue are chiefly compounds of oleic, stearic, and palmitic acids. From the fats of the liver, kidney, heart muscle, however, acids are found more unsaturated than oleic, belonging to the linoleic and linolenic series.

The fat of milk is also characterized by the presence, in addition to the ordinary fats, of butyric and other volatile fatty acids. The lower melting-point of the fat of the pig's back may allow mobility of the tissues there, exposed as they are to the cool atmosphere. The melting-point may be adapted to keep the fat of any part soft, but not fluid. The melting-point of the subcutaneous fat is altered by covering the pig's back with a sheep's pelt. The fat stored within the body may arise from three sources: (1) Ingested fat, (2) carbohydrate, (3) proteins.

Fat from Fat.- That fat arises from ingested fat is easily capable of demonstration. Nature makes experiment for us. It can be shown that the fat of the sea-dolphin has a high iodine value when the fish it feeds on have fats of a high iodine value. When the fish eaten have fats of a low iodine value, the iodine value of the fat of the dolphin falls. The fat of the fish-eating ducks has a high iodine value (84.8), that of farm duck a lower value (58.5). Horses fed orr oats have an oily fat of a high iodine number similar to that of the 
oil contained in oats. The wild-boar, when feeding on acorns and beech-nuts, acquires a fat with properties akin to those of the beech and acorn oils. Many exact experiments have also been made to prove this point. An animal is starved to reduce its fat as much as possible, and it is then fed with a fat the properties of which, such as melting-point, iodine number, etc., arc known. In addition, the fatty acid contained in the fat often has its own characteristic properties. Such fats are rapeseed oil, linseed oil, sesame oil, cocobutter, etc. After feeding a starved dog or goose with sesame oil, it was found that the fat was more oily, and the presence of the sesame oil could be demonstrated in the fat by shaking it with an equal volume of strong hydrochloric acid and a trace of a 2 per cent. alcoholic solution of furfurol. A purple-red colour developed when sesame oil was present. The following figures show the effect of feeding mutton - fat and of feeding coco-butter on dogs:

\begin{tabular}{|c|c|c|c|c|c|c|c|}
\hline & & & & $\begin{array}{l}\text { Melting- } \\
\text { Point of Fat } \\
\text { fed. }\end{array}$ & $\begin{array}{l}\text { Melting: } \\
\text { Point of } \\
\text { Animal's } \\
\text { Fat. }\end{array}$ & $\begin{array}{l}\text { Iodine } \\
\text { Number. } \\
\text { (See p. 55.) }\end{array}$ & $\begin{array}{c}\text { Fatty } \\
\text { Acid } \\
\text { Number. } \\
\text { (See p. 55.) }\end{array}$ \\
\hline $\begin{array}{l}\text { Mutton . } \\
\text { Coco-butter } \\
\text { Carbohydrate }\end{array}$ & $\begin{array}{l}\cdots \\
\cdots \\
\cdots\end{array}$ & $\begin{array}{l}. . \\
\cdots \\
. .\end{array}$ & $\begin{array}{l}. \\
\cdots \\
. .\end{array}$ & $\begin{array}{c}46-51 \\
23-28 \\
-\end{array}$ & $\begin{array}{c}46-48 \\
27 \cdot 5-29 \cdot 5 \\
35-36\end{array}$ & $\begin{array}{l}34-46 \\
8 \cdot 6 \\
-\end{array}$ & $\begin{array}{c}47 \\
27 \cdot 70 \\
63-66\end{array}$ \\
\hline
\end{tabular}

The fed fat also goes in part into the milk, so that the iodine number and other properties of the cream are altered. The characteristic test for sesame oil is given by the cream yielded by a cow fed with sesame oil. It is probably of considerable importance that the right fat should be stored in order that the body may be kept hard and in good condition. The soft townsman may owe his softness to the quality of his fat as well as to lack of muscular development.

Fat from Carbohydrate.-Fat may also arise from the carbohydrate taken in as food. This is obvious to those engaged in fattcning pigs or geese for market. Carbohydrate is the chief food given. It has been proved scientifically by giving animals, after preliminary starvation, a diet containing a minimum of protein and much carbohydrate. By comparing these with controls-e.g., animals taken from the same litter-it can be shown that the experimental animals put on so much fat that even if it be supposed that all the non-nitrogenous moiety of the protein eaten were converted into fat, yet there is more fat to be accounted for; this must have come from the carbo. hydrate fed.

Evidence in favour of the formation of fat from carbohydrate is also obtained from the respiratory quotient (1) of hibernating animals which are storing fat preparatory to their winter sleep, (2) of animals which are being fattened by forced feeding with large amounts of carbohydrate-for example, of geese stuffed to make fat livers for the preparation of paté de foie gras. Under these circumstances, 
the respiratory quotient, which for carbohydrate is 1 , and under 1 for proteins and fats, rises well above $1-2 . g$., to 1.3 or 1.4 . At first the discrepancy was attributed to experimental error, but the explanation now generally accepted is that carbohydrate is being turned into fat, and that in the process carbon dioxide is liberated, so that the respiratory quotient is raised above 1. The following formula summarizes the series of chemical changes which bring about this result:

$$
13 \mathrm{C}_{6} \mathrm{H}_{12} \mathrm{O}_{6}=\mathrm{C}_{55} \mathrm{H}_{104} \mathrm{O}_{6}+23 \mathrm{CO}_{2}+26 \mathrm{H}_{2} \mathrm{O}
$$

Fat from Protein.-The question as to the formation of fat from protein is a vexed one. It cannot be denied that such a formation is possible within the organism. From the amino-acids arising from autolyzed body protein or from digested protein the formation of carbohydrate may take place, and from this carbohydrate fat may well be formed. From the available evidence it would appear that, although such a formation is possible, the animal body under normal conditions doas not make use of this power.

Under certain conditions, however, such as the development of larvæ, the formation after death of a waxy body known as adiposere, and possibly in some cases of so-called fatty degeneration during life, such a transformation of amino-acids into fat doэs take place. It has been shown, for example, that some of the higher non-volatile fatty acids are formed when the larvæ of the blowfly, Calliphora, are rubbed with Witte's peptone into a homogeneous mass. So, too, it has been shown that fly-maggots, estimated from controls to contain a known quantity of fat, when allowed to feed on blood of a known fat content, develop after a time much more fat than existed in themselves and the blood together at the start of the experiment. Such experiments have not been accepted, owing to the fact that fat may result in the blood from bacterial decomposition. Rscent researches, however, tend to confirm rather than discount these results.

In regard to the formation of adiposere, this is a wax-like mixture of insoluble soaps, fatty acids, and ammonia, which is found in corpses exposed to water. It is quite possible that lower organisms may also play a part here, and its development from the body proteins is by no means proved. Positive results have been claimed from feəding experiments, but it has been pointed out that the calculations giving these were based upon a wrong assumption of the proportion which nitrogen bears to carbon in the meat fed. When the calculations are corrected, the formation of fat from protein is found to be unproven. The evidence of the most recent feeding experiments is contradictory, some observers claiming that a formation of fat from protein can be shown, others denying this.

From what has been said above, we may conclude that there exists in omnivora no fat rigidly characteristic of each type of animal, for foreign fats may be stored as such. Recent work, however, is tending to show that an animal's own characteristic fat is formed from carbohydrate just the same as a plant's characteristic fat or oil is formed from these bodies. Different species of animals form a different fat 
when fed with the same carbohydrate. The figures given in the table (p.458) show that the fat deposited from the carbohydrate in the diet differs considerably from that of the same animal when fed on other fats, and probably represents the animal's own characteristic fat. It is this fat which makes for a hard body and physical fitness.

The Katabolism of Fat.-In regard to the katabolism of fat, evidence is. scanty. It is quite probable that there exists two different forms of katabolism-(1) of the ingested fat taken; (2) of the fat formed within the animal's own body from other todies. The fat of the food may be regarded as a wanderer. It is formed, in the first place, within some plant or animal from lower bodies, and, unless used up again within the parent organism, it passes from plant to animal, and from animal to animal, until burnt up and used in the processes of metabolism. Such foreign fat is eventually burnt to carbon dioxide and water. The fatty acids, if saturated, are probably first broken down to the higher unsaturated fatty acids, and then to the lower unsaturated fatty acids, such as $\beta$-oxybutyric acid and aceto-acetic acid, and finally to $\mathrm{CO}_{2}$ and water.

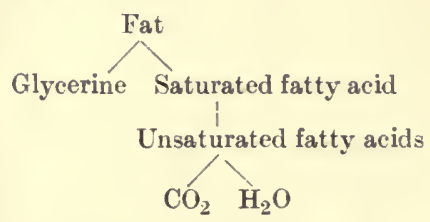

If, however, the fat formed within the organism-for example, from carbohydrate in the time preparatory to hibernation-be katabolized-e.g., during hikernation-there is good evidence to show that such fat is broken down by way of carbohydrate again.

$$
\begin{gathered}
\text { Fat } \\
\mathrm{CO}_{2}
\end{gathered} \mathrm{H}_{2} \mathrm{O}
$$

The best evidence in favour of this view has been obtained from the observation of the respiratory quotient of hibernating animals. Normally, fat gives a respiratory quotient of 0.7 (see p. 319). This is the lowest of the figures given by the three classes of foodstuffs. In hikernating animals, however, much lower figures have been obtained-e.g., 0.23 for the dormouse, 0.5 for the hedgehog. The explanation given for these low figures is that the stored fat is being converted into carbohydrate; and since carbohydrate contains more oxygen in its molecule, oxygen is used up in the process, and the respiratory quotient of the animal correspondingly reduced. The process may be summarized by the following formula:

$$
\begin{aligned}
& 2 \mathrm{C}_{2} \mathrm{H}_{5}\left(\mathrm{C}_{18} \mathrm{H}_{33} \mathrm{O}_{2}\right)_{3}+64 \mathrm{O}_{2}=16 \mathrm{C}_{6} \mathrm{H}_{12} \mathrm{O}_{6}+18 \mathrm{CO}_{2}+8 \mathrm{H}_{2} \mathrm{O} \\
& \text { Olein } \\
& \text { Dextrose } \\
& \therefore \frac{\mathrm{CO}_{2}}{\mathrm{O}_{2}}=\frac{18}{64}=0.281
\end{aligned}
$$


In man, during starvation, respiratory quotients below 0.7 have also been observed, and it is quite possible that, under these circumstances, some fat is being converted into carbohydrates, and inetabolized in that manner.

The Metabolism of Lecithin.-Lecithins are found in all the tissues of the body, partly free, partly combined with protein. Entering largely into the composition of the cell membrane, they are supposed to control the passage of bodies into the cell, in addition to playing an important part in the chemical processes of the cell. The amount of lccithin is diminished in the body by starvation, and also by wasting diseases and phosphorus-poisoning.

Anabolism:-The various lecithins are probably continuously being formed in the organism. From experiments made by feeding with foreign fats, it is found that such-e.g., linseed oil-are not bnilt.up into the lecithins of the body. That lecithin is formed in the organism is shown by the fact that mice fed on a lecithin-free. diet grew well, and brought forth young. It is possible that each animal has its own characteristic lecithin, and that the fatty acid molccules of these are developed from the carbohydrate of the diet, and not from the fat. Lecithin is formed in green leaves exposed to light.

Katabolism.-When lecithin breaks down, it forms first of all glycerophosphoric acid and cholin, and subsequently glycerine, phosphoric acid, and fatty acid. The phosphoric acid is probably excreted in the urine as phosphates, and the other bodies burnt up in the organism. Under certain circumstances, the lecithin and its derivatives may be deposited in the cell as oily droplets, giving a condition similar to that known as "fatty degeneration."

Fatty Degeneration.-In certain diseases, and after the application of experimental methods, such as phosphorus-poisoning, the cells of certain organs show on microscopic examination the presence of fatty droplets within the cell. The nucleus of the cell may or may not be fragmented. Such a condition has been termed "fatty degeneration." Much experimental work has been done to prove the origin of this fat, and also the circumstances which bring about the condition. In regard to the latter point, one of the chief causes is a diminished alkalinity of the cell fluid. Fatty degeneration takes placo in dying colls.

In regard to the source of the fatty droplets, the chief views held are these:

1. That the fat is cssentially an infiltration into the cells from the fat depots of the body.

2. That the fat is the "masked" fat of the cell which has become " revealed" in droplet form-e.g., that the fat is fat which was linked to protein, and has become dissociated and visible.

3. That the fat has been formed from carbohydrates of the cell, or from amino-acids produced as the result of the autolysis of the cell proteins. 
4. That the fatty substance is derived from the lecithin of the cell.

5. That the fatty substance is a compound of cholesterincholesteryl oleate, possibly derived from lecithin.

It is quite possible that there are various chemical bodies which give rise to the microscopical appearance known as fatty degeneration. It seems very likely, also, that "fatty degeneration" varics in nature according to the tissue in which it is taking place.

Obesity is usually the outcome of excessive feeding and lack of muscular exercise, particularly the latter. But this is not the only cause, for some people never become fat, however much they eat or however little exercise they take; others, while eating little and taking much exercise, show a tendency to fatness. The obesity of some may be associated with a greater absorption of foodstuffs from the alimentary tract rather than a greater intake of food; that of others is associated with an inadequate oxidation of the foodstuffs, a peculiarity of their metabolism due, perhaps, to a deficiency of oxidases. An hereditary tendency to fatness is often seen in families. It is well known that different breeds of cattle vary in the readiness with which they can be fattened. The amount of the internal secretions of the sexual glands, and possibly also of the thyroid, may play some part in this tendency to fatness. Castrated animals and eunuchs become fat. This may only be due to laziness developed as a result of the loss of their sexual instincts, but is probably also due to the removal of some direct effect upon metabolism. At the menopause, many women tend to put on flesh.

We know that the secretion of the thyroid promotes the metabolism of protein and fat, so that a deficiency of thyroid secretion may be a cause of obesity. Thyroid extract is frequently given with success in obesity, but its effects have to be carefully watched. For most cases, a restricted diet, mainly of protein, which of all the foodstuffs most promotes metabolism, and much exercise, is the best treatment. Fresh fruit and green vegetables are bulky, and satisfy the desire for a full stomach. They contain some 90 per cent. of water. The obese should eat these and avoid concentrated foods, such as sugar, fat, meat cooked with fat.

The truly obese man is an unfortunate. Owing to the large amount of fat, he has much weight to carry, he cannot easily lose heat, his breathing movements are impaired, so that he readily becomes fatigued, quickly gets out of breath, and sweats profusely. The duration of life in the obese is shortened. By giving a few minutes daily to physical exercise of all parts of the body, with bathing, massage, and skin friction, by active exercise on holiday, and a wisely restricted diet at all times, the body can be kept fit and the protuberant belly of the middle-aged citizen aroided. 


\section{CHAPTER LIII}

\section{- THE METABOLISM OF NUCLEIN}

NUCLEIN linked on to protein forms the compound body nucleoprotein, the chief protein constituent of the cell nucleus. Little or nothing is known as to the building up of nuclein or of nucleo-protein within the body. Such a synthesis is undoubtedly always taking place, but the exact nature of the precursors employed in the process is not known. In the adult body there is no evidence to show that the purin bodies of the food are used in the process. In the young, in the early months of growth, there takes place an abundant formation of nuclein, and upon a food (milk) which contains practically no nuclein. During the incubation of the hen's egg, nucleo-protein is formed within the cells of the embryo at the expense of the food yolk, which contains almost no nuclein or its derivatives,

Nuclein breaks down as follows:

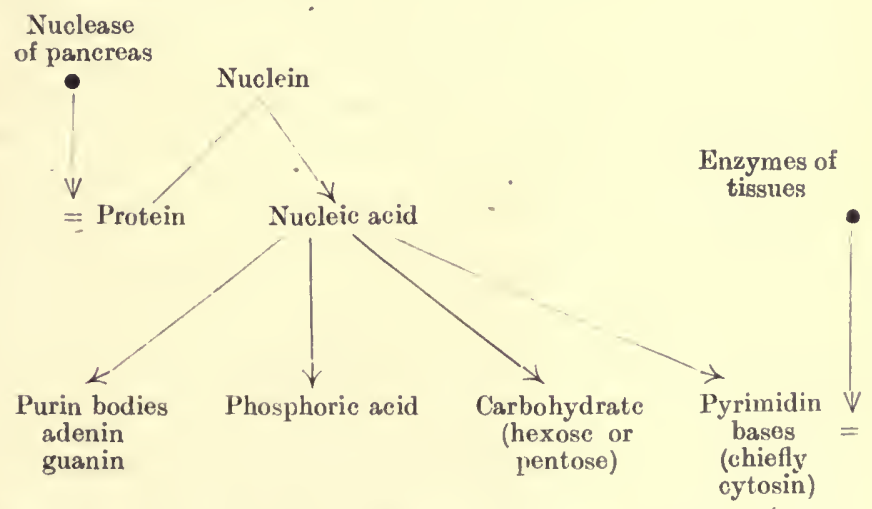

Adenin and guanin are amino-purins, being respectively aminopurin and amino-oxypurin (cf. p. 50). In some cases, guanin alone is formed. Probably the ingested nuclein is broken down by the nuclease of the pancreatic juice to nucleic acid and protein. The nucleic acid thus formed is absorbed into the blood, perhaps by the action of the pale corpuscles, and taken to tissues, where it is further acted upon, particularly in tissues such as the spleen, liver, and thymus, which contain enzymes eapable of breaking it down into the purin bodies adenin and guanin, phosphoric acid, carbohydrate and pyrimidin bases. The adenin and guanin thus formed are, by the 
action of the enzymes adenase and guanase present in these tissues, converted by deaminization into hypoxanthin and xanthin respectively (cf. p. 50):

$$
\begin{gathered}
\mathrm{C}_{5} \mathrm{H}_{3} \mathrm{~N}_{4} \cdot \mathrm{NH}_{2}+\mathrm{H}_{2} \mathrm{O}=\underset{\text { Adenin }}{\mathrm{C}_{5} \mathrm{H}_{4} \mathrm{~N}_{4} \mathrm{O}+\mathrm{NH}_{3}} \\
\begin{array}{c}
\text { Hypoxanthin } \\
\mathrm{C}_{5} \mathrm{H}_{3} \mathrm{~N}_{4} \mathrm{O} . \mathrm{NH}_{2}
\end{array}+\mathrm{H}_{2} \mathrm{O}=\underset{\text { Guanin }}{\mathrm{C}_{5} \mathrm{H}_{4} \mathrm{~N}_{4} \mathrm{O}_{2}}+\mathrm{NH}_{3} \\
\text { Xanthin }
\end{gathered}
$$

By the action of oxidases also present in the tissues the hypoxanthin and xanthin are converted into uric acid (tri-oxy-purin).

The whole process may be graphically represented as follows:

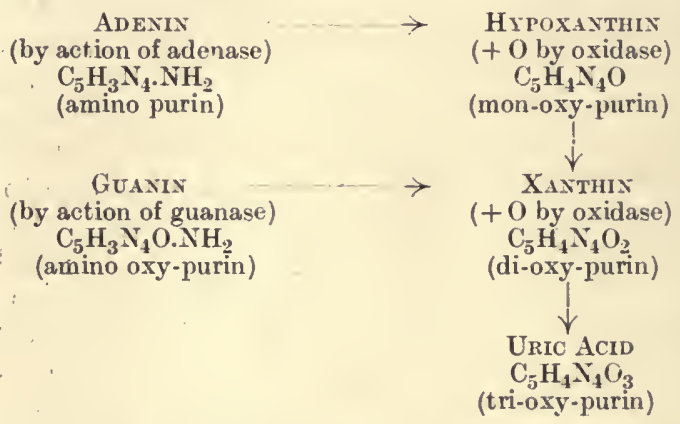

Some of the uric acid thus formed may further be converted into urea by the presence of a uricolytic enzyme. This enzyme occurs in the liver, muscles, and kidneys, and probably destroys a considerable amount of the uric acid formed in the body. Indeed, uric acid, even when given in the food, owing to the presence of this enzyme, causes no increase in the uric acid output of the body.

Uric acid is, however, regarded as the chief end product of nuclein and purin metabolism. The uric acid thus formed is taken to the kidneys for excretion, but in what form is not exactly known. Uric acid is about forty times more soluble in blood than in distilled water. This is not attributable to the alkalinity of the blood (which is in reality neutral), since uric acid is also much more soluble in acidified blood-serum than in distilled water. Probably uric acid is carried in the blood in combination with some other organic body, and not, as was once generally supposed, with sodium salts (sodium urate and sodium acid urate). The nature of the organic complex is not known. It is by some supposed to be thyminic acid, but no such compound has yet been isolated from the blood.

Experiment shows that the uric acid which occurs in the urine has two sources-an exogenous, from the purins of the food; an endogenous, from the purins liberated by the breaking down of the cell nuclei, and possibly also from other bodies. The presence in the urine of uric acid of endogenous origin is shown by the fact that upon a purin-free diot uric acid is excreted in the urine. The amount then excreted is fairly constant for each individual. This excretion reaches 
its maximum during the early hours of the morning, and subsides to a minimum towards evening. It is apparently unaffected by the periods of digestive and metabolic activity following each meal, but more uric acid is excreted after a rich than after a poor, nitrogenous, purin-free meal. The amount of uric acid is therefore in some way associated with the degree of nitrogenous metabolism of the body. The excess of uric acid may be ascribed-in part, at least-to the increased functional activity of the bodycells. Thus, severe muscular exercise is followed after several hours by a rise in the amount of endogenous uric acid excreted. Also, in diseases where a large amount of cell disintegration is taking place (e.g., leukæmias, fevers), the output of endogenous uric acid is increased. It is not affected by the giving of diuretics. While endogenous uric acid undoubtedly arises from the destruction of the cell nucleins, the question remains as to whether any can come from other sources. It is known that there is a large hypoxanthin content in muscle, and it may possibly be that some uric acid, especially the increase after muscular exercise, comes from this source. The amount of endogenous uric acid is more than can come from nuclear destruction in the body.

It has been demonstrated on birds that perfusion of the liver with ammonia and lactic acid leads to a formation of uric acid. There is no evidence that any such synthesis of uric acid takes place in the mammal. In birds, such a synthesis is homologous to the formation of urea in the liver of a mammal, and therefore it is not to be expected in the latter. It must be concluded that the exact source of all the cndogenous purin is not known. The exogenous origin of uric acid is proved by the fact that it is greatly increased in the urine by the giving of foods containing nuclein or purin, especially foods rich in nucleo-protein, such as sweetbreads, and those containing much hypoxanthin, such as meat extracts. All the purins administered in the food are not, however, excreted in the urine as uric acid; some are excreted as purins. The amount of uric acid formed in the organism varies with the kind of purin fed and the species of the animal which eats it. For example, in man, only one-half of the hypoxanthin administered as such appears as uric acid in the urine, and but onefourth of the purin in nuclein when that is fed. In the dog, compared with man, about ten times as much purin disappears in its passagc through the organism; in the rabbit, about three times.

There is doubt as to whether the methyl purins (caffeine, theobromine) lead to a formation of uric acid in the organism, or whether they are secreted as purins in the urine.

One of the symptoms of gout is a permanent increase in the amount of uric acid in the blood-a " uricæmia." Various reasons have becn ascribed as the cause of this. At one time it was believed to be due to defective excretion of uric acid by the kidney. Rescarch does not lend much support to this view, although it is quite possible that the kidney changes which occur late in the disease may to some extent affect the elimination of uric acid by the organ. 
It is suggested by some that the chief factor in gout is a defect in the transport of uric acid; by others it is belioved to be duc to a deficient enzymic activity, particularly of the urieolytic enzyme of the body. Others believe that gout is due to a toxin of intestinal origin; yet again others deem it to be secondary to abnormal carbohydrate or fat metabolism. The whole question is sub judice. 


\section{CHAPTER LIV}

\section{THE FUNCTIONS OF THE LIVER AND SPLEEN}

THE liver is developed as a tubular outgrowth from the duodenum. The ultimate endings of this tube break up into numerous fine ducts lined by epithelial cells of large size-the liver cells. The whole makes a lobulated gland, the lobule belonging to each branching duct being separated from its neighbour by connective tissue (Glisson's capsule). In this interlobular conncctive tissue run(1) bile ducts, (2) branches of the portal vein (interlobular), (3) branches of the hepatic artery, (4) lymphatic vessels. In (1) bile, in (4) lymph flows from the lobules, in (2) and (3) blood flows to the lobules. The liver lobule has a large blood-supply. The hepatic artery brings oxygenated blood, and the portal vein blood containing foodstuffs which have been absorbed from the alimentary canal. The capillaries arising from the artery and portal vcin anastomose as they radiate through the lobule, forming a network of fine branching vessels (interlobular branches). These unite in the centre of the lobule to form an intralobular vessel, which joins with others to make a sublobular vein, the fusion of sublobular veins finally forming the hepatic vein. The large branches of this gape open when the liver is cut. The bile canaliculi, the first comemncement of the bile ducts, are channels between the liver cells, and can be demonstrated by giving such a dye as sulph indigotate of soda. This is secreted with the bile, and distends and stains the canaliculi. They can also be steined by Golgi's method.

The liver is an organ of manifold functions, some of which have already been mentioned or lealt with. We propose in this section to group together the various functions of the organ in order that the scope of its activities may be appreciated.

1. The Formation and Excretion of Bile.-Within the liver the bile salts are synthesized, and the bile pigments are derived from the hæmoglobin of effete blood-corpuscles. These, together with the other constituents of the bile, are secreted into the bile canaliculi, and pass thence into the intestine, there to fulfil the various functions alrcady indicated (see p. 391).

2. The Glycogenic Function.-The liver acts as the storehouse of the colloid glycogen. This it forms from the dextrose brought by the portal vein, and under appropriate circumstances reconverts it into dextrose for use in other parts of the body, particularly in the 
muscles (see p. 42i). The liver probably also forms glycogen from other bodies, including the non-nitrogenous moiety left over when certain amino-acids are deaminized, either in the intestinal mucous membrane or in the liver itself ( $c f . p .424)$.

3. Storage of Fat.--Although the liver contains a certain percentage of "masked" fat-that is, fat which is not visible to staining processes-under certain circumstances, such as during pregnancy and lactation, the liver contains large amounts of visible fat, the exact significance of which is not known. Thus visible fat in the liver, which occurs in "fatty degeneration," is not always a pathological phenomenon.

4. The Formation of Uric Acid.-The liver possesses deaminizing enzymes which are capable of converting purin bodies, such as adenin and guanin, into the oxypurins hypoxanthin and xanthin, and also oxidizing enzymes capable of converting these bodies to uric acid. It also in the mammal contains a uricolytic enzyme which turns uric acid into urea.

5. The Formation of Urea.-The liver plays an important part in the metabolism of protein, particularly in the end processes of this metabolism which result in the formation of urea.

The fact that urea is formed in the liver can be demonstrated in various ways:

(1) Extirpation of the liver in the frog leads to a diminution in the amount of urea excreted, and an increase of ammonia bodies in the excreta.

(2) In birds, such as the goose, there is a connecting vein between the portal vein and the inferior vena cava. Ligature of the portal vein on the liver side of this connection diverts the contents of the portal system into the inferior cava. Under these circumstances, there occurs in birds a marked diminution in the excreta of the amount of uric acid, the homologue of urea in the mammal, and a corresponding increase in the amount of ammonium compounds.

(3) In mammals, a similar condition of affairs may be brought about by the operation devised by Eck, and known as Eck's fistula. The operation consists in making a communication between the portal vein and the inferior vena cava. As before, the portal vein is ligated as it enters the liver, and the portal circulation is thereby deviated from the liver. Under these circumstances, the amount of urea is greatly decreased in the urine, the ammonia content being greatly increased. It is generally stated that animals upon which this experiment has been performed show marked symptoms of metabolic disturbance, accompanied by signs of ferocity and bad temper. This apparently depends upon the nature of the diet given after the operation. Dogs which have had such an experiment performed upon them, with the hepatic artery and rein ligated in addition, remain for many days after the operation quite happy and docile so long as they were fed on bread and milk. During this time they were becoming progressively thinner. Any form of meat in the diet, however, 
immediately brought on signs of surliness, and eventually induced convulsions.

(4) In certain forms of liver disease the amount of urea passed in the urine is markedly diminished, the amount of ammonia bodies being correspondingly increased.

(5) Pcrfusion of blood-containing ammonium carbonate through the liver of a mammal leads to a marked increase in the urea content of the blood. This experiment was done originally upon the liver of a dog, but it holds true for all mammals. According to some authorities, amino-acids, such as glycin, alanin, arginin, also lead to the formation of urea when perfused through the isolated liver. This, however, is not accepted by all-at any rate, as a normal process.

Urea, therefore, is undoubtedly formed in the liver, the main precursor being compounds of ammonia. These compounds are particularly the carbonate, which may be graphically represented as

$$
\mathrm{CO}: \mathrm{ONH}_{4}
$$

and the carbamate, which may be figured as

$$
\mathrm{CO}<\underset{\mathrm{NH}_{2}}{\mathrm{ONH}_{4}}
$$

The change to urea may probably, therefore, be represented as follows:
$\mathrm{CO} \mathrm{ONH}_{4}$
$\mathrm{CO}$
$\mathrm{ONH}_{4}$
$\mathrm{CO}<\mathrm{NH}_{2}$
A mmonium carbonate
Ammonium carbamate
Ures

Some of the urea formed in the liver may be derived from the conversion of uric acid to urea. It has been shown in the laboratory that creatin may give rise to urea. There is, however, no good evidence to show that such is the case inside the body.

Most of the urca formed in the liver is derived from the nitrogenous part of the food taken in-that is to say, it is exogenous in origin. Alterations in the amount of nitrogenous food cause similar Huctuations in the amount of urea in the urine (see p. 455). The view held as to the form in which the precursor of urea reaches the liver depends naturally upon which hypothesis of protein metabolism is put forward. According to , the first view (p. 424), urea would be derived mainly from the amino-acids brought to the liver by the portal blood, particularly from such amino-asids as glycin, alanin, leucin, and arginin. According to the other view, no such acids exist in the portal blood. The precursor of most of the urea formed in the liver would in this case be the ammonia which has been broken off from the excess amino-acids during the prosess of their deaminization in the intestinal mucons membrane. This is transported to the liver in the form of the carbonate and carbamate, and converted into urea. Some urea might also be formed from excess amino-acids left over in the bloodstream after a tissue has 
taken from the plasma protein the particular amino-acids of which it has need. Another part of the urea might also be endogenous in origin, being formed in the liver from the amino-acids resulting from the katabolism of protein in various parts of the body.

The question as to whether urea is formed solely in the liver should probably, despite views to the contrary, be answercd in the negative. There is apparently a small formation of urea from endogenous precursors in other parts of the body, particularly the muscles. Perfusion of the hind-limbs of an animal with defibrinated blood leads to an increase of the urea content in the venous over the arterial blood. It is correct, however, to say that the "main mass of urea execreted from the body is formed in the liver from the nitrogenous moiety of the protein food taken in.

6. Protective Function.-Another important function of the l ver is its protective function. This is manifested in rarious ways:

(1) The nocuous products of protein putrefaction in the large intestine, such as indol, skatol, phenol, cresol, are combined in the liver with sulphuric acid to form the innocuous potassium salt of the acid.

$$
\begin{aligned}
& \mathrm{NH}: \mathrm{C}_{8} \mathrm{H}_{6}+\mathrm{O}=\mathrm{NH}: \mathrm{C}_{8} \mathrm{H}_{5} \mathrm{OH} \\
& \text { Indol Indoxyl } \\
& \mathrm{NH}: \mathrm{C}_{8} \mathrm{H}_{5} \mathrm{OH}+\mathrm{SO}_{2}<\mathrm{OK}=\mathrm{OH}: \mathrm{C}_{8} \mathrm{H}_{5} \cdot \mathrm{O} \cdot \mathrm{SO}_{3} \mathrm{~K}+\mathrm{H}_{2} \mathrm{O} \\
& \begin{array}{cl}
\text { Potassium } & \text { Potassium indoxyl } \\
\text { anid sulphate } & \text { Sulphurie acid (indican) }
\end{array} \\
& \mathrm{C}_{6} \mathrm{H}_{5} \mathrm{OH}+\mathrm{SO}_{2}<\mathrm{OK}=\mathrm{C}_{6} \mathrm{H}_{5} \cdot \mathrm{O} \cdot \mathrm{SO}_{3} \mathrm{~K}+\mathrm{H}_{2} \mathrm{O} \\
& \text { Phenol Potassium phenol } \\
& \text { Sulphuric acid }
\end{aligned}
$$

In cases of excessive formation these bodies are combined vith glycuronic acid also.

(2) Drugs, such as chloral, camphor, etc., are combined with glycuronic acid in the liver, and rendered harmless or less harmful.

(3) When acid formation is going on within the body-for example, the formation of aceto-acetic acid and $d$-oxy-butyric acid during starvation, or in pathological conditions such as diabetes mellitusthe liver to a certain extent negatives the ill effects of such acids by combining them with ammonia, thereby markedly inereasing the ammonia content of the urine.

(4) The liver possesses the property of retaining- within its cells poisonous minerals, such as phosphorus, arsenic, mercury, antimony. But little is known as to the exact manner in which this is accomplished.

7. Fibrinogen Formation, - The liver is possibly the organ in which the fibrinogen of the blood arises, also antithrombin when peptone is injected into the blood; this, according to the generally accepted view of blood-coagulation, renders the blood and lymph incoagulable - the result of such an injection. 
8. Heat Formation.- - The liver, by virtue of its manifold chemical activities, produces heat.

9. Venous Reservoir.-Lastly, the liver acts as a venous reservoir interposed in the portal circulation, and by virtue of this property prevents overdistension of the right side of the heart. The blood within it is expressed into the heart by the action of the diaphragm, and the vigour of the hepatic circulation therefore depends very much on the vigour of respiration that is on muscular exercise. In cases of failure of the right side of the hcart the liver becomes greatly engorged with blood, and is felt pulsating below the margin of the ribs..

The Spleen.-The exact nature of the main function of the spleen is a matter of surmise. The gland can be extirpated from man and animals without ill effects. It is stated to have been removed from athletes in classical times, to prevent "stitch." It appears probable that, after the operation, there is a compensatory overgrowth or hypertrophy of lymphatic tissue. It has been shown recently that after extirpation of the spleen more iron is lost than formerly in the urine; the spleen may therefore be the regulator of the iron metabolism of the body. There is some evidence that in the spleen the effete red blood-corpuscles of the body are destroyed. It is questionable whether in adult life the spleen plays any part in the formation of red corpuscles, although it certainly does so in the foetus. By virtue of its lymphatic tissue, the spleen gives origin to some of the lymphocytes of the blood, and plays a considerable part in the purin metabolism of the body. During the first hours following digestion the spleen is swollen in size, acting like the liver as a blood-reservoir in the portal circulation. The spleen rhythmically contracts. The enlargement of the spleen in certain fevers-e.g., malaria, typhoidshows that it, like the lymph gland, is engaged in protecting the body against bacterial invasion. 



\section{BOOK VIII \\ THE FUNCTIONS OF THE KIDNEY}

\section{CHAPTER LV}

\section{THE URINE}

THE urine, continuously secreted by the kidneys, averages about 1,500 c.c. (50 ounces) in twenty-four hours. The larger part of this amount is passed during the day, but in certain diseased conditions more may be passed during the night. For this reason, some clinicians have the urine passed during the twenty-four hours collected in two portions. The day urine is taken, say, from 8.30 a.m. to 8.30 p.m., the bladder being emptied at both these times. The remainder is the " night urine." Children pass considerably less urine than an adult. At five years the daily amount is about 390 c.c., at twelve years about 830 c.c., about fifteen the amount begins to approximate to that of the adult.

As the urine passed at different times during the day varies considerably in composition, it is usual to take the total urine of twentyfour hours for purposes of clinical analysis. Various factors modify the amount passed. An increased secretion follows a large consumption of food or drink, and exposure to cold. On the other hand, ingestion of little food or drink, exposure to heat, great muscular work, the conditions which produce sweating, lead to a diminished secretion.

Normal urine is a transparent, limpid, watcry fluid, yellow in colour. When shaken in a test-tube, there is a little froth, which does not last long. When eertain pathological bodies are present, particularly bile and protein, the urine is less mobile, and the froth much more marked. Thus, the presence of albumin may be indicated by the froth on shaking.

The odour of healthy urine is described as aromatic. After standing for some time, this changes to an "ammoniacal "smell, owing to the action of organisms (Micrococcus urece) which fall into it, and by their growth break down the urea present, with the liberation of ammonia.

The specific gravity of urine, as tested by the instrument known as the urinometer, is on an average 1015 to 1025 . These figures apply to the twenty-four-hour sample; for samples casually taken 
it may vary greatly. A urine may have a speeifie gravity below 1010 after much drinking, or as high as 1035 after much sweating. An abundant urine of low speeifie gravity is suggestive of some pathologieal condition, such as diabetes insipidus or chronie renal disease, while the passage of large quantities of pale urine of high specific gravity suggests the presence of sugar in the urine. If, on the other hand, the colour be high, some condition eausing loss of water from the body, sueh as diarrhœea or fever, may be present. The quantity of the solids in the urine per litre may be roughly estimated by taking the specific gravity of the urine at $15^{\circ} \mathrm{C}$, and multiplying it by $2 \cdot 33$.

The osmotic pressure, measured by depression of freezing-point, varies from $-0 \cdot 8^{\circ}$ to $-2 \cdot 7^{\circ} \mathrm{C}$.

The reaction of the urine, as tested by chemical indieators, is generally acid. To the physical test the urine, like the blood, is neutral (see p. 76). The asidity to litmus is due mainly to the aeid phosphate of sodium $\left(\mathrm{NaH}_{2} \mathrm{PO}_{4}\right)$. When, however, urine is passed during the digestion of a meal, it is often amphoteric or alkaline in reaetion. This is beeause the acid phosphate in the blood is converted into disodium phosphate $\left(\mathrm{Na}_{2} \mathrm{HPO}_{4}\right)$, owing to the formation of the $\mathrm{HCl}$ of the gastrie juice. The reaction of urine may also be alkaline after eating fruits and vagetables containing organie acids (eitrie, malic, etc.). These are converted in the body into alkaline earbonates, which are excreted in the urine. It is believed by some authorities that the acidity of the urine is in part due to the presenee of volatile organic acids in the urine. It is stated that, if urine be distilled, the part which distils off is acid, owing to the presence of sueh volatile aeids.

For clinical purposes, the total aeidity, and indireetly the ammonia, of the urine may be determined by a method in which the aeidity is first estimated by titrating with iv NaHO. Neutralized formalin is then added. The ammonia of the urine combines with this to form the neutral compound urotropine, setting free the acids to whieh the ammonia is combined. A second estimation with $\frac{\mathrm{N}}{10} \mathrm{NaHO}$ gives this acidity, and from it the amount of nitrogen present as ammonia may be calculated by multiplying by 0.0014 .

The Transparency and Colour of the Urine.-Freshly voided normal urine is transparent, and possesses a yellowish colour, the exaet tint of which fluctuates widely even in health aecording to the degree of dilution and the reaction of the urine. This colour is due chiefly to the piginent urochrome. Other pigments-urobilin, uroerythrin, urorosein-also occur in normal urine under various conditions.

Urochrome.-The origin of this pigment is not known. It is probably derived from protein, as it contains nitrogen and sulphur in its moleeule. It yields no absorption bands when examined speetroscopically.

Urobilin is not present in freshly roided urine, but its chromogen is-urobilinogen. The darkening of urine on standing is due to the conversion of urobilinogen into urobilin. Urobilin, when present, 
gives one broad absorption band in the green between $b$ and $\mathbf{F}$. The urine containing it is generally dichroic, appearing red by transmitted, and green by reflected, light. If urobilinogen be in cxcess, it is found thet an acid solution of dimethylparaminobenzaldehyde ( 2 grammes in 100 c.c. 5 per cent. $\mathrm{HCl}$ ), when added to the urinc, turns red in the cold. With normal urine, such a red colour is only developed on heating.

Uroerythrin confers a dark pink colour on concentrated urine. Spectroscopically, it yields two bands, one at E, the other at F. They are not well defined. Urorosein is an indol derivative.

Composition.-Normal urine contains about 96 per cent. of water and 4 per cent. of solids. The chief organic bodies are-Urea, uric acid, purin bodies, creatinin, cthereal sulphates, neutral sulphur compounds, oxalic acid, hippuric acid, enzymes, pigments.

The inorganic solids are-Chloride solids of sodium and potassium, sulphates, phosphates, carbonates.

The Nitrogenous Constituents.-The chief of these are urea, ammonia, uric acid, creatinin, hippuric acid. There sare various other substances in small quantities, including the purin bases. These vary in percentage according to the intake of nitrogenous food in the diet. With the exception of creatinin, the amount of these bodies excreted falls as the amount of the nitrogen in the diet is decreased.

According to the diet the percentage of urea varies in relation to the percentage of other bodies, particularly to the percentage of ammonia.

This is shown by the following analyses of such urincs:

\begin{tabular}{|c|c|c|c|c|c|}
\hline & & & & Nitrogen-Rich Diet. & Nitrojen-Poor Diet. \\
\hline Total nitrogen exc & reted & & & $\begin{array}{c}\text { Grms. } \\
16 \cdot 8\end{array}$ & $\begin{array}{l}\text { Grms. } \\
3 \cdot 60\end{array}$ \\
\hline Urea $\mathrm{N}$ & .. & $\because$. & .. & $14.7(87.5$ per cent. $)$ & 2.20 (61.7 per cent.) \\
\hline Ammonia $\mathrm{N}$ & .. & .. & .. & $0.49(3.0)$ & $0.42(11.3$ \\
\hline Uric acid N .. & $\ldots$ & .. & $\ldots$ & $0 \cdot 18(1 \cdot 1$ & $0.09(2 \cdot 5$ \\
\hline Creatinin $\mathrm{N}$.. & .. & $\ldots$ & .. & $0.58(3.6$ & $0 \cdot 60(17 \cdot 2$ \\
\hline Undetermined $\mathrm{N}$ & .. & .. & .. & $0.85(4.9$ & $0 \cdot 27(7 \cdot 3$ \\
\hline
\end{tabular}

Almost the whole of the nitrogen taken in the food is excreted in the urine. Protein contains about 15 per cent. of nitrogen, and if 100 grammes are consumed, about 1 gramme nitrogen will be passed in the fæccs, a trace in the sweat, and the rest in the urine. By estimating the total nitrogen of the twenty-four hours' urine the intake of protein can be calculated.

The Total Nitrogen of the Urine is estimated by means of Kjcldahl's method, or one of its modifications. The process is carricd out in three stages: (1) The oxidation of the nitrogen present in the urine to ammonia; (2) the distillation and collection of this ammonia in a standard acid solution; (3) the ascertaining by titration of the amount of this ammonia. 
In the first part of the process, a known quantity of the urine is heated in a long-necked, hard glass flask with strong sulphuric acid, and a little of the sulphates of potassium and copper are added tofacilitate oxidation by raising the boiling-point of the acid. The ammonia formed is combined with the sulphuric acid to form ammonimm sulphate. The heating is continued until the fluid becomes. almost colourless.

In the second part of the process, the excess of acid is neutralized by strong alkali (40 per cent. $\mathrm{NaHO}$ ), an excess of alkali being added. Then the ammonia is distilled over into a standard acid solution $\left(\frac{\mathrm{N}}{10} \mathrm{H}_{2} \mathrm{SO}_{4}\right)$ containing an indicator such as methyl orange. The indicator is required to show that there is sufficient acid present to trap all the ammonia driven over.

In the third part of the process, the excess of acid in the receiving flask is ascertained by titrating with standard alkali $\left(\frac{\mathrm{N}}{10} \mathrm{NaHO}\right)$. By subtracting this excess from the amount of standard acid originally taken, the amount of acid combined with ammonia is found. Multiplying this amount by 0.0014 , we arrive at the amount of nitrogen in the sample of urine.

Urea is the chief nitrogenous waste substance of the mammal. Its formula is

$$
\mathrm{CO}\left\langle\frac{\mathrm{NH}_{2}}{\mathrm{NH}_{2}}\right.
$$

and it may be regarded as carbonic acid $\left(\mathrm{H}_{2} \mathrm{CO}_{3}\right)$, or

$$
\mathrm{CO}<\mathrm{OH}
$$

in which the two hydroxyl groups $(\mathrm{OH})$ have been replaced by two amine $\left(\mathrm{NH}_{2}\right)$ groups. It has the same empirical formula as ammonium cyanate, from which body it was first prepared by Wöhler in 1828-

$$
\mathrm{CONNH}_{4} \longrightarrow \mathrm{CO} / \frac{\mathrm{NH}_{2}}{\mathrm{NH}_{2}}
$$

- the first synthesis of an organic substance out of inorganic material. Carbamic acid

$$
\mathrm{CO}<\mathrm{OH}_{2}^{\mathrm{NH}_{2}}
$$

may be present in the urine as a salt, for example after experimentally excluding the liver from the circulation. It is apparently a precursor in the synthesis of urea (see p. 449).

Pure urea consists of colourless elongated crystals. It is extremely soluble in water, alcohol, and acetone, but insoluble in ether and chloroform. It possesses the property of dissolving connective tissue, and may be used in making teased preparations-e.g., to isolate muscle fibres. It is also a good solvent for uric acid. It combines with acids to form salts, such as urea nitrate and urea oxalate (Figs. 219, 220). 
When solid urea is heated in a dry test-tube, it first melts and then goes solid again. During the process ammonia gas is given off, and the body known as biuret is formed, which, with a little copper sulphate and some caustic potash, gives a pink colour.

$$
2 \mathrm{CO}<\mathrm{NH}_{2}^{\mathrm{NH}_{2}}=\mathrm{NH}_{3}+\underset{\mathrm{CO}}{\mathrm{CO}} \underset{\substack{\mathrm{NH}_{2} \\ \text { Biuret }}}{\mathrm{NH}_{2}}
$$

If still further heated, a body known as eyanuric acid $\left(\mathrm{C}_{3} \mathrm{~N}_{3} \mathrm{H}_{3} \mathrm{O}_{3}\right)$ is formed, which does not give the biuret test.

- Urea is precipitated from solution as a dense white precipitate by the addition of mercuric chloride.

The presence of urea in urine may be shown by concentrating the urine by evaporation over a water-bath, and adding concentrated nitric or oxalic acid, when crystals of urea nitrate or oxalate will be

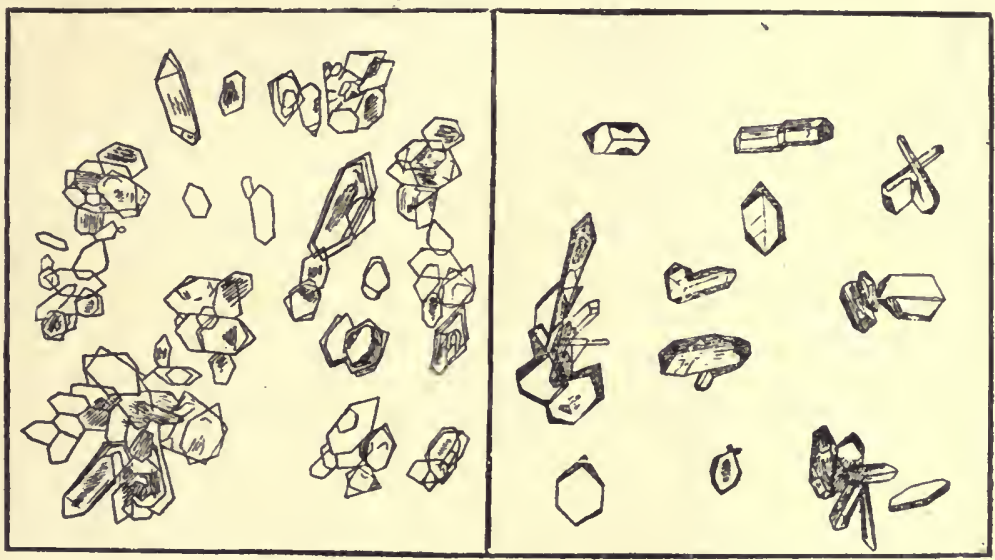

Frł. 219.-Urea Nitrate.

Frg. 220.-Urfa Oxalate.

deposited. Crystals of urea may be obtained by rubbing the urea nitrate into a paste with barium carbonate-as a result, barium nitrate and urea are formed, with the evolution of carbon dioxide, and then extracting with alcohol, and allowing the alcohol to evaporate. Crystals of urea may also be obtaincd directly from concentrated urine by extracting with acetone, and allowing the acetone to evaporate. On heating with acids under pressure, urea is decomposed into ammonia and carbon dioxide. It is also split thus by the ferment urease present in certain bacteria and in the soya bean. When fuming nitric acid is added to urine, an evolution of carbon dioxide and nitrogen takes place, owing to a decomposition of the urea, as expressed by the equation

$$
\mathrm{CO}<\mathrm{NH}_{2}+2 \mathrm{HNO}_{2}=\mathrm{CO}_{2}+2 \mathrm{~N}_{2}+3 \mathrm{H}_{2} \mathrm{O}
$$


A similar reaction takes place when sodium hypobromite is added to urine, but nitrogen alone is evolved, the $\mathrm{CO}_{2}$ remaining combined to the alkali present in the solution.

$$
\mathrm{CO}<\mathrm{NH}_{2}+3 \mathrm{NaBrO}+2 \mathrm{NaHO}=3 \mathrm{NaBr}+\mathrm{N}_{2}+3 \mathrm{H}_{2} \mathrm{O}+\mathrm{Na}_{2} \mathrm{CO}_{3} .
$$

Advantage is taken of this reaction for estimating the daily output of urea. The method is not very cxact, since nitrogen is also evolved from uric acid and other bodies present in the urine. A known amount of urine is mixed with an excess of the hypobromite solution, and the evolved nitrogen collected. The apparatus employed, such as Dupré's, is generally graduated in percentages of urea. With Southall's ureometer (Fig. 221) one c.c. of urine from a special pipette is carefully injected below the bend of the tube which is filled with hypobromite.

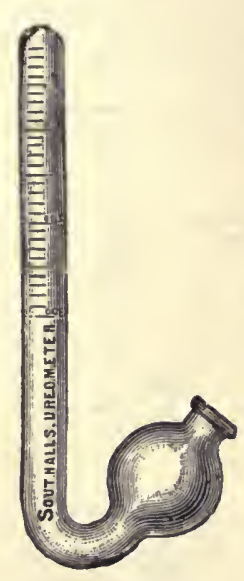

Fig. 221.

UREOMETER.

If no such apparatus be available, the gas may be collected over water in a burette, and the amount of urea calculated from the fact that 0.1 gramme of urea yields $35 \cdot 4$ c.c. of nitrogen.

A more exact method of estimating urea in urine is to heat some of the urine witl magnesium chloride and hydrochloric acid. The urea under these circumstances is broken down to ammonia, which combines with the acid present to form ammonium chloride. The other nitrogenous constituents of the urine are not affected in the process. The amount of ammonia in the ammonium chloride thus formed is then determined by Kjeldahl's process.

There is little information of clinical value to be gained from an estimation of the urea output alone. What is required is a knowledge of the amount of nitrogen taken in the diet, and the relative values of the urea, creatinine, ammonia, etc., excreted in pathological conditions. Clinical information of this character has yet to be collected.

The precursors of urea and the site of its formation in the body have already been discussed. About 25 to 40 grammes of urea are excreted dai-y, the amount varying according to the diet.

Uric Acid is the chief nitrogenous waste product of birds and reptiles. It occurs also in mammalian urine combined with alkalies. The empirical formula of uric acid is $\mathrm{C}_{5} \mathrm{H}_{4} \mathrm{~N}_{4} \mathrm{O}_{3}$; it is tri-oxy-purin, and the formula may be graphically represented thus:

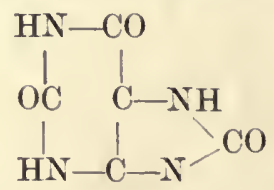

(see p. 50). About 0.4 to 0.7 gramme of uric acid is excreted in the human urine daily. It is a dibasic acid, and therefore forms two 
classes of salts-the normal urates $\left(\mathrm{Na}_{2} \overline{\mathrm{U}}\right)$ and the acid urates ( $\left.\mathrm{NaH} \overline{\mathrm{U}}\right)$. The chief urates present in the urine are acid sodium urate $\left(\mathrm{C}_{5} \mathrm{H}_{3} \mathrm{NaN}_{4} \mathrm{O}\right)$ and normal sodium urate $\left(\mathrm{C}_{5} \mathrm{H}_{2} \mathrm{Na}_{2} \mathrm{~N}_{4} \mathrm{O}_{3}\right)$. Sometimes ammonium urate also occurs. Urates are frequently deposited from concentrated urine as a pinkish deposit coloured by uroerythrin. Such a deposit is soluble on heating or addition of alkali. Urates are sometimes amorphous, sometimes crystalline, as " thorn apples," fan-shaped clusters of prisrnatic needles (Fig. 222). To obtain uric acid quickly, a considerable quantity of urine (about 100 c.c.) is taken, ammonia added till the reaction is alkaline, and then the urine saturated with ammonium chloride. Ammonium urate is precipitated, and from this precipitate uric acid may be obtained by the addition of acid. If hydrochloric

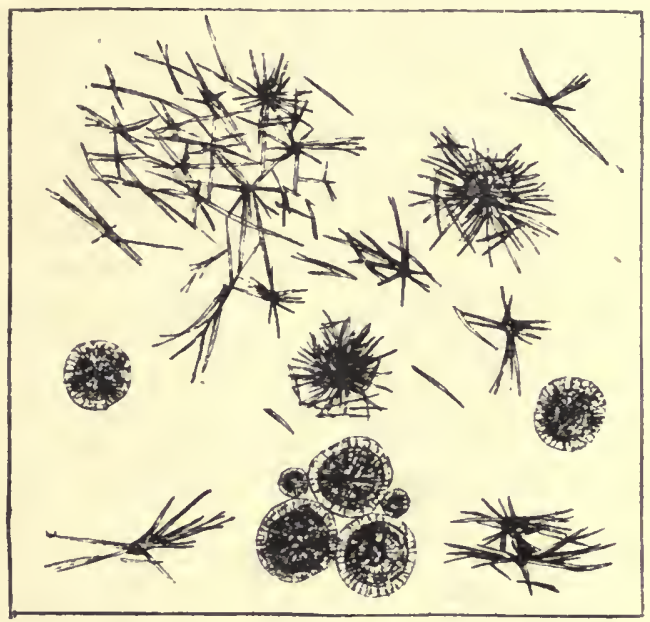

Fig. 222.-Sjoivi Urate. $\times 350$.

acid be added to urine, and the urine be left to stand for twenty-four hours, crystals of uric acid fall out, usually highly pigmented with urorosein, and known as the brick-dust or cayenne-pepper deposit. Under the microscope, the crystals appear shaped like whetstones, bariels, wedges, rosettes, and coloured reddish-yellow (Fig. 223). Uric acid is sometimes passed in acid urines, and known as gravel. Stones forming in the bladder and kidney are often found to be composed of uric acid or urates.

Uric acid is almost insoluble in water. It is held in solution in the urine partly by the alkaline phosphates, and partly by the urea prescnt. It is readily soluble in alkalics. When craporated with nitric acid, it leaves a yellowish residuc, which turns purple on adding anmonia, and blue with caustic potash (the murexide test). Urates also give this murexide test, which depends upon the fact that a substance-alloxantin-is formed from uric acid, and combines with ammonia to form ammonium purpurate. 
A strong solution of uric acid in alkali reduces Fehling's solution on heating, but not Nylander's solution (see p. 61). It will also reduce silver nitrate in the cold. If a drop of an alkaline uric acid solution be placed on a filter-paper, and a drop of silver nitratc solution be added, a blackened area of reduced silver results (Schiff's test).

Uric acid is estimated quantitatively by precipitating it as ammonium urate, as described above, washing the precipitate carefully to remove all traces of chlorides, setting free the uric acid by the addition of sulphuric acid, and titrating with a standard solution of potassium permanganate until the rose colour, which at first disappears, just persists.

Uric acid is both exogenous and endogenous in origin (see p. 444). It is increased by ingestion of bodies rich in nuclei (sweetbreads, etc.). In disease, it is increased when tissue destruction is going on, as in

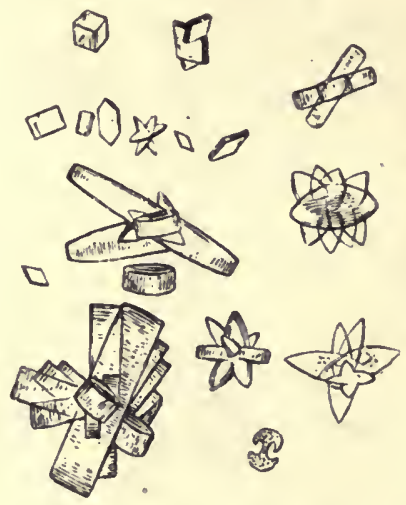

Fig. 223.-Uric Acid Crystals. (Savill.)

leukæmia and acute fevers. Much has been made of uric acid as a cause of gout. There is no evidence to show that its formation is increased in gout. "It has no toxic properties, and there is nothing to justify its ill reputation, or the advertisements of the quack medicine vendors. The precursors of uric acid and the site of formation have already been discussed (p. 444).

Purin Bodies.-Hypoxanthin, adenin, and xanthin, are present in normal urine in small amounts. These are supposed to be derived from the decomposition of nucleic acid. Methylxanthin results from the taking of coffee and tea which contain caffeine (tri-methylxanthin), and of cocoa which contains theobromine (di-methylxanthin). Guanin is present in the urine of several of the invertebrata.

Allantoin is the chief end-product of the metabolism of nuclein in some animals, and occurs in human urine in traces and in allantoic 
fluid. It is obtained on oxidation of uric acid by a ferment-uricase —or by oxidising agents (ozone, permanganate of potash).

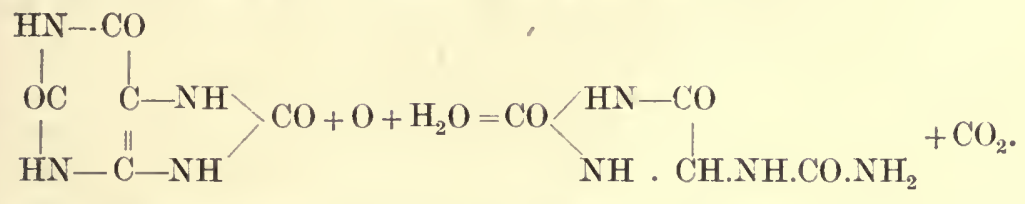

It can be synthesized out of glyoxylic acid (COOH.CHO) and urea, and is a diureid of glyoxylic acid.

Creatinin $\left(\mathrm{C}_{4} \mathrm{H}_{7} \mathrm{~N}_{3} \mathrm{O}\right)$ is excreted in the urine in sucli a very constant amount-about 1 gramme in twenty-four hours-that some have regarded it as a measure of the nitrogenous metabclism of the tissues (endogenous metabolism). Creatin, or methylguanidin-acetic acid is found in the muscles, and therefore in meat extracts. On heating with dilute $\mathrm{H}_{2} \mathrm{SO}_{4}$, it passes into its anhydride, creatinin. Creatin is excreted when the protein substance of the body is being broken down, and occurs in the urine during starvation and fevers, also during lactation. The creatin which is eaten in meat is probably decomposed by the intestinal bacteria.

The relationship of the creatin to the creatinin of the body is a matter of considerable complexity. Contrary to what was once believed, it is probable that creatinin is the mother-substance of creatin, and not creatin of creatinin. It is possible that creatinin is formed in the liver from some product of protein digestion, and that the creatin of the muscles is built up from the creatinin thus formed.

The presence of creatinin in the urine is shown by adding a few drops of a saturated solution of picric acid and a little 20 per cent. solution of caustic potash. A transparent red colour is produced (Jaffe's test). Sugar in the urine gives the samc colour, but deeper and opaque. Thus, there is no difficulty in distinguishing between the two.

Another test for creatinin is to add a few drops of a freslily prepared solution of sodium nitroprusside and 20 per cent. solution of caustic potash to the urine. A red colour is produced, which disappears on heating or on the addition of acetic acid.

Oxalates occur in the urine combined with calcium, and the salt is 'normally kept in solution by the acid solium phosphate prezent. When precipitated, it occurs as envelope or dumb-bell shaped crystals insoluble in acetic and easily soluble in hydrochloric acid (Fig 224). About 0.017 gramme of oxalic is excreted daily. This is mainly derived from the food, and is

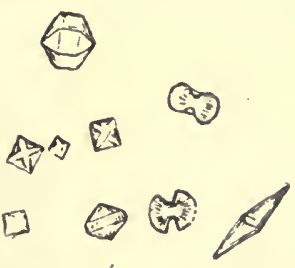

F1G. 224, CaLcIU M ()XALATE CRYSTALS. (Savill.) increased by the ingestion of fruits and vegetables, such as rhubarb; strawberries, tomatoes, spinach, cabbage. There are cases of "oxa- 
luria" where the oxalates are precipitated, but as a rule are not increased, in the urine. Such patients generally suffer from an acid dyspepsia, and have less acid sodium phosphate than usual in the urine; hence the oxalates fall out of solution.

Hippuric Acid $\left(\mathrm{C}_{9} \mathrm{H}_{9} \mathrm{~N}_{4} \mathrm{O}_{3}\right)$ occurs in human urine in small quantities as sodium hippurate ( $\frac{1}{4}$ to $\frac{1}{2}$ gramme daily). It is much more plentiful in the urine of herbivorous animals, such as the horse. It is increased in man by the ingestion of fruits, such as mulberries and cranberrics, which contain aromatic acids which are oxidized to benzoic acid in the body, and also by taking benzoic acid as a drug. Hippuric acid is of interest, since its sinthesis from benzoic acid and glycin takes place by enzymic action in the kidney itself. If the kidney be perfused with defibrinated blood containing these two bodies, hippuric acid is formed.

$$
\mathrm{C}_{6} \mathrm{H}_{5} \mathrm{COOH}+\mathrm{CH}_{2} \mathrm{NH}_{2} \mathrm{COOH}=\mathrm{CH}_{2} \mathrm{NH} \cdot \mathrm{COC}_{6} \mathrm{H}_{5} \cdot \mathrm{COOH}+\mathrm{H}_{2} \mathrm{O} .
$$

Hippuric acid separates as crystals from the urine of the cow or horse on standing after the addition of 125 grammes of ammonium sulphate and 7.5 c.c. of concentrated sulphuric acid to 500 c.c. of urine. The crystals, on evaporation with strong nitric acid, form nitrobenzene, with the odour of oil of bitter almonds.

Ammonia generally, appears in small quantities in normal urine, its amount varying according to the diet. When acids are introduced into the body, or acid formation takes place in the organism, the amount of ammonia in the urine is increased. The ammonia provided by the liver neutralizes the acids. This is sometimes the case in diabetes mellitus and in eclampsia of pregnancy.

Again, ammonia ma be increased in the urine when the liver, the chief seat of urea formation, is diseased. Normally, about 0.7 gramme of ammonia escapes conversion into urea.

Chlorides.-The chief chloride is that of sodium ( 1 gramme por 100 c.c. urine). It is derived chiefly from the "salt" of the food. The presence of chlorides in urine may be shown by addition of silver nitrate and nitric acid to the urine, when a white precipitate is obtained which is soluble in ammonia. Without the addition of nitric acid, the phosphates of the urine are also precipitated.

To estimate the chlorides in the urine, they are precipitated by excess of standard silver nitrate in presence of nitric acid. The excess of silver nitrate is then found by titrating with a standard solution of potassium or ammonium thiocyanate, using iron alum as the indicator (Volhard's method).

Chlorides are diminished in amount in the urine in many febrile affections, particularly pneumonia.

Sulphates and Neutral Sulphur.--Sulphur occurs in the urine in three forms: (1) The inorganic sulphates; (2) the organic or ethereal sulphates; (3) neutral sulphur.

Inorganic Sulphates occur as the compounds of sodium and potassium. They are readily detected by adding a solution of barium 
chloride and a little hydrochloric acid to the urine. A white precipitate of barium sulphate results. The acid prevents the precipitation of phosphates.

Organic or Ethercal Sulphates are compounds of sulphuric acid with such bodies as indol, skatol, phenol, cresol. Their presence may be shown by precipitating the inorganic sulphates and phosphates with alkaline barium chloride, filtering, and hcating the filtrate almost to boiling with strong $\mathrm{HCl}$. By this means the organic sulphates are decomposed, and form a faint white cloud of barium sulphate. If they are in excess, a white precipate forms.

"Neutral Sulphur" is the sulphur present in urine, not in the form of sulphate, but as an integral part of the molecule of the organic substance-e.g., cystin.

About $2 \frac{1}{2}$ grammes of sulphuric acid $\left(\mathrm{SO}_{3}\right)$ are excreted daily. The inorganic sulphates are derived mainly from the protein katabolism of the food. Inorganic sulphates-e.g., Epsom salts-arc not ingested as such, owing to their unpleasant bitter taste.

The ethereal sulphates are conjugates of sulphurie acid with toxic bodies formed by putrefaction of protein in the intestine, especially of the tyrosin and tryptophan portions of the molecule. The phenol, cresol, indol, and skatol, there formed are absorbed into the portal eirculation, and combined in the liver with sulphuric acid, and so rendered harmless.

Normally, the inorganic sulphates are about ten to twenty times more abundant than the organic. The relative proportion, however, is not, as has been supposed, a direct measure of the putrefactive processes in the intestine. It has been found that this proportion, and that of the neutral sulphur, varies with the amount of nitrogen in the diet, as shown in the following table:

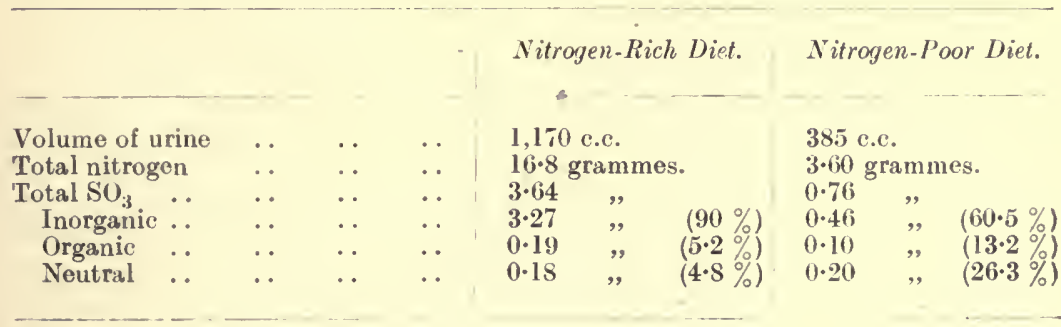

The best guide to the extent of the intestinal putrefactive processes is now believed to be given by the amount of indican present in the urine. Indican is the indoxyl-sulphate of potassium formed from the indoxyl brought to the liver in the portal blood (see p. 450).

$$
\begin{aligned}
& \text { NH. } \mathrm{C}_{8} \mathrm{H}_{5} \mathrm{OH}+\mathrm{SO}_{2}<_{\mathrm{OK}}=\mathrm{SO}_{2}<{ }_{\mathrm{OK}} \mathrm{O}_{3} \mathrm{C}_{6} \mathrm{H}_{6} \mathrm{~N}+\mathrm{H}_{2} \mathrm{O} \text {. } \\
& \text { Indoxyl } \\
& \text { Acid Ind:can } \\
& \text { potassium } \\
& \text { sulphate }
\end{aligned}
$$


Indoxyl is formed from indol $\left(\mathrm{C}_{8} \mathrm{H}_{7} \mathrm{~N}\right)$ and probably in the intestinal wall during absorption. Indol is formed as the result of bacterial action upon tryptophane.

The best test for indican is to add to the urine some concentrated $\mathrm{HCl}$ containing a trace of ferric chloride. Upon shaking with a little chloroform, indigo blue, or occasionally indigo red, is formed. Normal urine gives but a trace of colour, if any; with excess of indican the colour is deep.

Phosphates. - These are grouped as-(1) alkaline phosphates of potassium, sodium, and ammonium; (2) earthy phosphates of calcium and magnesium. The two groups occur in about the ratio of $3: 1$. Phosphoric acid forms three series of salts: Normal phosphate, $\mathrm{Na}_{3} \mathrm{PO}_{4}, \mathrm{Ca}_{3}\left(\mathrm{PO}_{4}\right)_{2}$; mono-hydrogen phosphate, $\mathrm{Na}_{2} \mathrm{HPO}_{4}, \mathrm{Ca}_{2} \mathrm{H}\left(\mathrm{PO}_{4}\right)$; di-hydrogen phosphate, $\mathrm{NaH}_{2} \mathrm{PO}_{4}, \mathrm{CaH}_{2}\left(\mathrm{PO}_{4}\right)_{2}$. The normal and

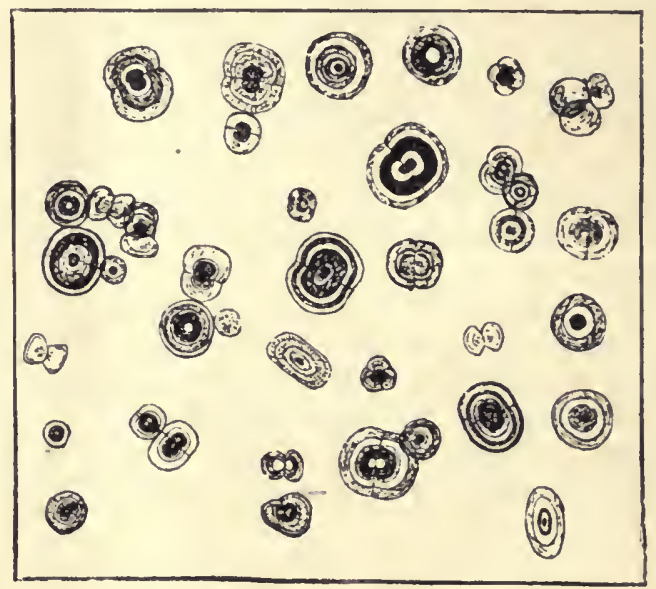

Fig. 225.-Calcium Carbongte (From Humax Urine). $\quad \times 400$.

mono-hydrogen phosphates are alkaline to litmus, the di-hydrogen to acid. The three sodium phosphates and the di-hydrogen calcium phosphate are soluble in water, the other two calcium salts are insolublc. The deposit of phosphates which sometimes occurs is due to the earthy phosphates being precipitated when the urine loses its acid reaction. When $\mathrm{CO}_{2}$ is driven from urine by heating, such a deposit of phosphates sometimes occurs. It is distinguished from a coagulum of protein by the fact that it is readily soluble in acetic acid.

The earthy phosphates yield a white crystalline precipitate on the addition of ammonia. The presence of phosphates generally may be shown by adding nitric acid and ammonium molybdate to urinc. Upon heating this, a yellow precipitate is obtained.

To estimate phosphates in the urine, some acid sodium acetate is first added to the urine to prevent the formation of free nitric acid 
from the uranium nitrate employed in the titration. The urine is heated to $80^{\circ} \mathrm{C}$., and the phosphates are then precipitated by a standard solution of uranium nitrate. A little powdered solid potassium ferrocyanide may be added as indicator. This turns brown when the end-point is reached. One c.c. of the standard solution equals 0.005 gramme of phosphoric acid.

Normally, about 2 to 3 grammes of the phosphoric ion $\left(\mathrm{P}_{2} \mathrm{O}_{5}\right)$ are excreted daily. This is chiefly derived from the phosphorus compounds of the food, inorganic phosphates, and organic phosphorus compounds, such as phospho-protein, nucleo-protein, and lecithin. A considerable proportion of the phosphates is excreted by the large bowel, particularly the earthy phosphates. The deposit of phosphates which sometimes occurs in the urine of children is probably due to an excessive amount of calcium in the urine arising from defective excretion by the large intestine.

Carbonates.-These occur as the carbonate and bicarbonate, particularly of sodium, after the ingestion of organic acids in vegetables and fruits. A crystalline deposit of calcium carbonate may be found (Fig. 225). On addition of acid, the urine efferresces from the evolution of carbon dioxide. The urine of the horse or cow is normally alkaline, and cloudy with phosphates and carbonates.

Abnormal Constituents of the Urine.-The chief abnormal constituents met with in urine are protein, sugar, blood, and bile.

Proteins.-Various proteins may be passed in the urine. In the condition known clinically as albuminuria the serum albumin and serum globulin of the blood pass through the kidneys into the urine. The former is usually in larger amount. Such a urine always gives an abundant froth on shaking. "Albumin" in the urine is detected by the following tests, which must be applied to clear urine-i.e., filtered or centrifuged - if necessary: (1) The urine boiled after being faintly acidified with acetic acid. Albuminous urine gives a coagulum. (2) On the careful addition of nitric acid a white ring (precipitate) appcars at the junction of the fluids. This ring does not disappear on heating.

Other tests mentioned in the section on the proteins

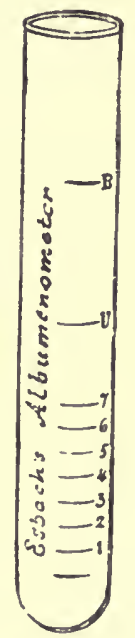

VIG. 226. E S.BACH's AlbominoMETER. (p. 46) may also be used. It must be remembered, however, that normal urine contains a trace of protein, and the tests employed should be such as will reveal only an increase beyond the normal amount.

For quantitative clinical purposes, a special form of test-tube is used (Fig. 226). This tube is filled with clear urine up to the mark $U$, and a mixture of picric and cit ic acids up to the mark $R$. If albumin be present, a whitish-ycllow precipitate forms. On leaving 
this to stand for twenty-four hours, the amount may be read off on the graduations of the tube. The figures correspond to the number of grammes of albumin present per litre.

Normal urine yields a "mucus" on standing, which appears to be a mixture of nucleo-protein and gluco-protein. This is derived from the urinary tract. In catarrhal conditions of this, the amount of mucus may be so much increascd that a condition known as "mucinuria" is met with. A white precipitatc, insoluble in excess, and increased on boiling, is indicative of "mucin." The test often succeeds better when the urine is previously diluted to half its strength with water.

Another abnormal condition of the urine sometimes met with is due to the presence of proteoses in the urine. These appear in the urine when disintegration of tissue is going on during an infective disease-e.g., in pneumonia, when an abscess known as empyema is forming. A spccial form of proteosuria, known as myelopathic or Bence-Jones proteosuria, occurs with a condition of diffuse malignant tumour (sarcoma) of the bone-marrow.

Proteoses may be distinguished from albumin by the fact that the precipitate with nitric or salicylsulphonic acid disappears on heating, and reappears on cooling. The Bence-Jones proteose is further characterized by the fact that urine containing it becomes opaque at a comparatively low temperature $\left(60^{\circ} \mathrm{C}\right.$.), with the formation of a sticky coagulum. If the reaction be acid, this coagulum disappears on further heating, and reappears on cooling. With strong hydrochloric acid this proteose gives a sharp ring, which also disappears on heating and reappears on cooling.

Blood.-The red corpuscles or the blood-pigment may pass into the urine. The former condition is known as "hæmaturia," the latter as "hæmoglobinuria." When the urine contains but little blood, it presents a peculiar "smoky" appearance; with larger quantities, the urine appears red or reddish-brown, according to the varicty of blood-pigment present. The presence of blood is detected clinically by making some of the urine strongly alkaline with caustic soda, and boiling. Should blood be present, a reddish-brown deposit is formed, with greenish fluid above. Various drugs taken by the patient, such as senna, rhubarb, may yield a similar result. The "guaiac test" (see p. 112) also serves to identify blood. There are certain fallacies in this test. Iodides in the urine may give it; also the presence of saliva, through spitting into the pot, and pus. In hæmaturia, blood-corpuscles may be detected in the sediment after centrifuging or allowing the urine to stand. The spectra of oxyhæmoglobin or methremoglobin may be obtained; more often the latter.

Occasionally, alkaline hæmatoporphyrin is inet with in considerable quantities in the urine, giving it a dark, port-winc colour. This is generally due to poisoning by drugs, such as sulphonal. Such a urine will not give the guaiac test, owing to the absence of iron in hæmatoporphyrim. To identify it, the pigment should bc converted into the acid variety by the addition of hydrochloric acid, and, if 
necessary, extracted with amyl alcohol. The spectrum of acid hæmatoporphyrin can then be identified.

Sugars in the Urine.-The sugar which, under certain conditions, appears in the urine is dextrose or glucose. Rarely levulose, lactose, or pentose, may be excreted.

Glycosuria is a symptom of the disease known as diabetes mellitus. It does not follow, however, that every person who is found to have dextrose in the urine has diabetes, although it is probable. Traces of dextrose occur in normal urine, but not in sufficient amount to give the tests for sugar as generally applied. Various other substances in the urine, such as glycuronic acid, uric acid, creatinin, phosphates, may give a positive reaction with Fehling's solution, which is the test most frequently employed for the detection of dextrose. This is a matter of considerable importance, for the presence of one or other of these substances may lead to a false diagnosis of sugar in the urine, a serious error, and one which falls particularly hard on candidates for life insurance. Therefore, the tests for sugar in urine should always be carefully applied.

Trommer's test is not to be recommended, owing to the haphazard proportions of the testing solutions-copper sulphate and potash.

Fehling's test is best applied by boiling the Fehling's solution and the urine in separate tubes, and then mixing the two. If reduction occurs without further heating, it is almost certainly due to the presence of dextrose in the urine. Glycuronic acid and compound glycuronates, uric acid, creatinin, phosphates, do not cause reduction under these conditions.

A positive reaction obtained with Nylander's test is strongly confirmatory, for, besides sugar, only glycuronic acid and its componnds will reduce the bismuth salt.

The phenyl-hydrazine test helps to differentiate sugar, but the most certain test of all is fermentation with yeast. This should always be applied.

An approximate estimate of the amount of sugar present in the urine may be made by taking the specific gravity of the urinc before and after it has been fermented with yeast for twenty-four hours. Each degree of specific gravity lost equals 1 grain of sugar per ounce of urine. The quantity of sugar in the urine may be cstimated in various other ways. The methods given here arc not very exact, but suffice for clinical work. The standard solution of Fehling is generally userl. A measured quantity of the solution is taken, and kept boiling in an open dish, while the urine, suitably diluted, is run in from a burette until the blue cupric solution is entirely rednced and decolorized. Ten c.c. of Fehling's solution are reduccd by 0.05 gramme of dextrose. The unmodified Fehling's method is not to be recommended, owing to the difficulty of recognizing the end-point. The use of an indicator, such as fcrrous thiocyanate, is helpful. The end-point is reached when a drop of the solution no longer turns a drop of the indicator red. This shows that there is 
no cupric salt left, for a cupric salt, when brought into contact with the ferrous thiocyanate, oxidizes it to ferric thiocyanate, which is red in colour. A modified Fehling's solution (Pavy's solution) has strong ammonia added to it. As this keeps the red precipitate of cuprous oxide in solution, the disappearance of the blue colour is evident. The end-point is reached when the solution becomes colourless. Pavy's solution is ten times less strong than Fehling, 1 c.c. being reduced by 0.005 gramme of dextrose. The urine should therefore be diluted more before carrying out the test.

In another modification of the test (Gerrard's), the red deposit of the Fehling's solution is held in solution by the double cyanide of potassium and copper. Gerrard's solution is mixed and boiled with Fehling's solution. In Bertrand's modification, the cuprous oxide precipitate produced by the presence of the sugar is dissolved in a solution of ferric sulphate in sulphuric acid. During the process of solution, an amount of terrous salt becomes produced, which is equivalent to the amount of cuprous oxide. The ferrous salt is then measured by titrating with a standardized solution of potassium permanganate. It is the most reliable method for estimating sugar in simple solutions.

The polarimeter may also be employed to estimate the amount of sugar in urine, but it is necessary that the urine be absolutely clear, and not high-coloured. Protein, if present, and any other leiorotatory substances, must be removed before the measurement is made.

In diabetic urine, various volatile acids, such as $\beta$-oxybutyric acid and aceto-acetic acid, are wont to occur in conjunction with acetone. The acetone bodies are also excreted in starvation or on a diet of fat with a limited amount of protein, in certain fevers, severe anæmias, and phosphorus-poisoning-conditions in which the tissues are unable to use glucose. These bodies are closely related, as their formulæ show, the bodies with the smaller molecule being derived from those with the larger:

\section{$\beta$-oxybutyric acid, $\mathrm{CH}_{3}$. $\mathrm{CHOH} . \mathrm{CH}_{2} . \mathrm{COOH}$. Aceto-acetic acid, $\mathrm{CH}_{3} \cdot \mathrm{CO} \cdot \mathrm{CH}_{2} \cdot \mathrm{COOH}$. Acetone, $\mathrm{CH}_{3}$. $\mathrm{CO} . \mathrm{CH}_{3}$.}

They are most probably derived from an incomplete breaking down of amino-acids, particularly in the liver, and are therefore indirectly derived from protein (see p. 423). In starvation and in the last stages of diabetes, in diabetic coma, they are probably also derived from the higher fatty acids of the body fat.

$\beta$-Oxybutyric Acid, a volatile acid, is levo-rotatory, and does not ferment with yeast. No satisfactory simple test has been devised for its detection in urine. It generally occurs combined with ammonia, and an idea of the amount of the volatile acids of the urine can be obtained by the method already given (p. 454).

Aceto-acetic Acid may be tested for by adding ferric chloride to the urine. If present, a red colour is obtained; if small in amount, it may be first extracted with ether, to which a little sulphuric acid is added. 
Acetone gives a peculiar fruity odour to the urine. It is best detected by Rothera's test. Ten c.c. of urine are saturated with ammonium sulphate by adding the solid salt, and a few drops of a solution of sodium nitro-prusside and 2 to 3 c.c. of strong ammonia added. On allowing to stand, a colour appears like that of permanganate of potash. Urine containing acetone will also yield the characteristic odour of iodoform when an alcoholic solution of iodine and a little strong ammonia are added to it.

Levulose.-Levulosuria by itself is a rare condition, but levulose occurs in the urine with dextrose in cases of "mixed mellitu' ia." The polarimeter and the resorcin test are used for its detection.

Lactose.- "Lactosuria" occurs sometimes in mothers who are suckling their children. The sugar may occur in quite appreciable amount in the urine. The chief points which aid in its detection are these : it reduces Fehling's solution; it does not ferment with yeast; it yields characteristic small rosettes with the phenyl-hydrazine test (see p. 65).

Pentose.- "Pentosuria" is a rare condition. It may occur temporarily as the result of large ingestion of fruit; such as cherries, grapes, and plums. Occasionally, a pentose occurs in conjunction with dextrose in cases of glycosuria. There is a rare anomaly of metabolism in which pentose occurs regularly in the urine. Such a pentosuria is accompanied by no morbid symptoms, is probably harmless, and needs no treatment. The pentose in question is usually arabinose. The low melting-point of the osazone $\left(160^{\circ} \mathrm{C}\right.$.), the nonfermentation with yeast, and Bial's orcin test, serve to indicate the presence of a pentose in the urine.

Bile in the Urine.-In the condition known as "jaundice," bile appears in the urine. As the result of obstruction of the bile-passages, bile enters the blood, and so reaches the urine. The bile pigments generally confer a greenish or brownish colour on the urine. They may be detected by the play of colours formed when fuming nitric acid is added (Gmelin's test). The presence of bile salts in the urine may be best shown by Hay's sulphur test. If "flowers" of sulphur are sprinkled on the surface of urine containing bile, the sulphur sinks readily.

Alkaptonuria is due to an inborn anomaly affecting protein metabolism. It is of interest as throwing light on the halfway stages of protein decomposition, for it seems probable that the breaking down of the tyrosin group is not carried so far as usual, rather than that an abnormal body is formed. In the urine, homogentisic acid. (dihydroxyphenylacetic acid) is secreted.

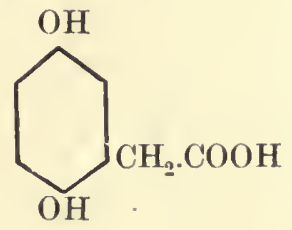


The urine is natural in appearance when passed, but on exposure to air gradually darkens from the surface downwards, until it ultimately becomes a deep brown-black colour. Such a urine reduces Fehling's solution, but does not give Nylander's test. With Millon's reagent it gives a yellow precipitate; the addition of ferric chloride drop by drop causes a passing blue colour. It does not ferment with yeast, nor rotate the plane of polarized light. After poisoning with carbolic acid, the urine may contain a similar body. Alkaptonuric urine may be distinguished from one containing the pigment melanin by the fact that the latter does not reduce Fehling's solution.

Cystinuria.-Cystin, di-amino-di-thiolactic acid is the sulphurholding product of protein decomposition. It is a condensation derivative of molecules of cystein - thio-amino-propionic acid. Taurin (of the bile acid-taurocholic acid) yields cystein on oxidation. It does not normally occur in the urine. It is a rare anomaly, the

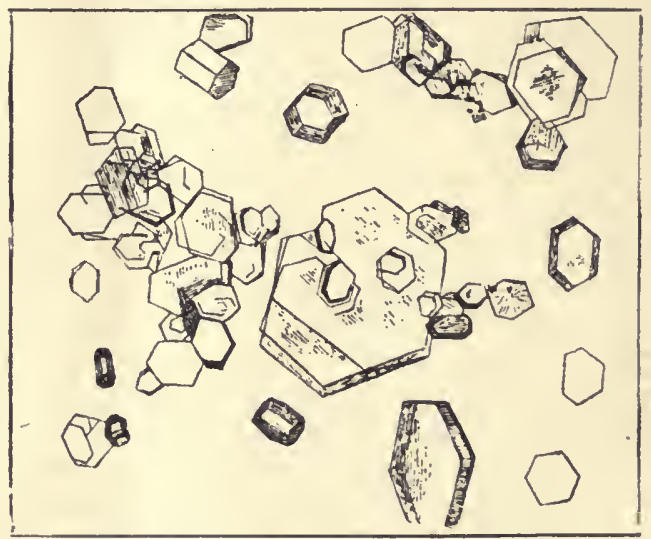

Fig. 227.-Crstin Crystals. $\times 350$.

result of an inborn error of metabolism. It affects particularly the male issue of the marriage of near relations, such as first cousins.

Cystin only occurs in acid urine. Six-sided crystals of cystin (Fig. 227) may form from the urine on the addition of acetic acid, but usually the urine yields a deposit of these crystals. They are soluble in alkali. If some of the deposit be placed under a coverglass, and strong hydrochloric acid added, delicate prisms are formed as the acid reaches the crystals. These disappear if water be added. Dissolved in caustic potash, cystin gives a violet colour when fresh sodium nitroprusside is added and the solution warmed. An alkaline solution of cystin gives a black precipitate of lead sulphide when boiled with lead acetate solution. Stones composed of cystin have rarely been found in the bladder.

Urinary Deposits.-The deposits of normal urine vary in character, according as they are deposited from acid or alkaline urinc. The following occur in acid urine: 
1. Uric Acid.--These appear as a "cayenne-pepper" deposit at the bottom of the specimen, the crystals being pigmented with uroerythrin. In shape, the crystals resemble whetstones, dumb-bells, orange pips, etc., and are often grouped together in rosettes (Fig. 22:3)

2. Amorphous Urates occur as a brickdust or pinkish deposit. They consist of masses of amorphons granules tinted with urinary pigment. They easily pass into solution when the urine is warmed or rendered alkaline.

3. Sodium Urate.-This occurs but seldom in adults; frequently, however, in the urine of the newly-born. In appearance, the crystals resemble the thorn-apple, little spheres with numerous spines radiating from them (Fig. 222).

4. Calcium Oxalate occurs as characteristic colourless, shining, "envelope" crystals (Fig. 224). In reality, they are small octahedra. In some cases, calcium oxalate occurs also in dumb-bells forms. They are insoluble in acetic acid and ammonia, but soluble in hydro chloric acid.

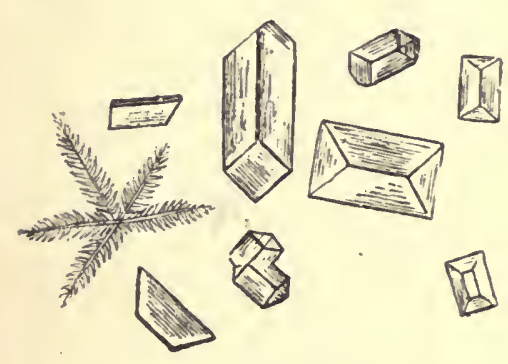

Fig. 228.-Triple Phosphate Crystals.
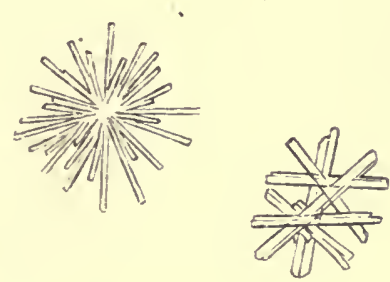

Fig. 229.-Stellar Phosphate Crystals. (Savill.)

Rarely, deposits may occur in acid urine of-(a) acid calcium phosphate $\left(\mathrm{CaHPO}_{4}\right)$-rosettes of prisms or dumb-bells; (b) hippuric acid, especially after the administration of benzoic acid-colourless four-sided prisms, insoluble in hydrochloric acid, soluble in ammonia; (c) cystin-colourless hexagonal crystals, often thrown out of solution by the addition of acetic acid, soluble in ammonia; $(d)$ cones of leucin and white sheaves of tyrosin.

In alkaline urine, the chief salts to be deposited are the phosphates. They are all soluble in acetic acid, and the amount of deposit is increased by boiling. There occur-

1. (a) Most commonly the Phosphate of Calcium, "Earthy" Phosphate, $\mathrm{Ca}_{3}\left(\mathrm{PO}_{4}\right)_{2}$, generally as white amorphous granules, more rarely as colourless prismatic crystals radiating in clusters.

(b) Ammonium Magnesium Phosphate, $\mathrm{IgNH}_{4} \mathrm{PO}_{4}$, or Triple Phosphate, especially in 'nrine which has undergone ammoniacal fermentation. In appearance, they resemble coffin-lids or feathery stars-" fcathery phosphates" (Fig. 223).

2. Ammonium Urate, especially in cases of inflammation of the bladder-"cystitis." Small spherical crystals resembling sodium 
urate, usually associated with triple phosphate crystals and bacteria

3. Calcium Carbonate,-Occasionally in human urine, but commonly in the urine of herbivora. In human urine, generally as amorphous granules; more rarely, as in horse's urine, as dumb-bells - or spheres (Fig. 225). They are easily soluble, with effervescence, in acetic acid.

In the urine there may also occur epithelium from the kidney, bladder, and urinary passages, and in women from the ragina. In pathological urine there may occur-

1. Red blood corpuscles, either normal, swollen, or crenated.

2. White corpuscles, or "pus" corpuscles.

3. Fatty globules in "lipuria."

4. Various forms of "casts" of the kidney tubules. 


\section{CHAPTER LVI \\ THE SECRETION OF URINE}

Is unicellular organisms of low activity there is no special structure for the excretion of the waste products of metabolism; the general surface of the cell serves as a medium for their discharge. In one-

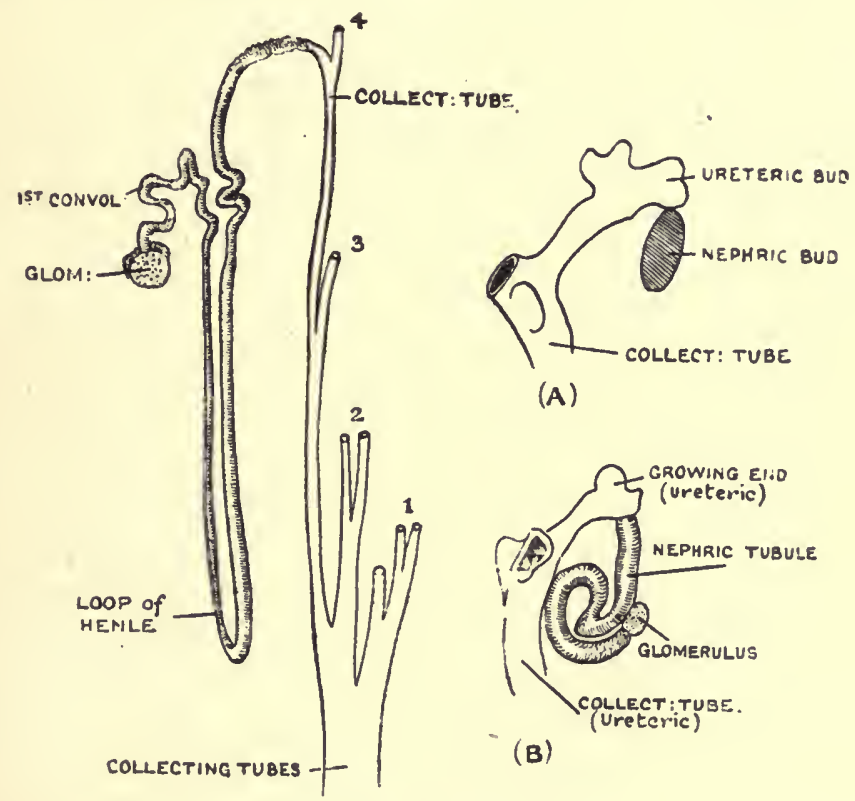

(c)

íg. 230.-Illustratixg the Developiext of the Rexal Tubule. (Keith. after G. C. Huber.)

$A$, Growing end of colleeting tubule with nephrie bud attached to it. $B$, First stage of development of nephrie bud into nephric tubule. $C$, Fully developed r:nal tubule. The part formed from the ureteric bud is represented in outline; the part from nephrie tubule is shaded.

celled organisms of greater activity there exist special contractilo vacuoles, which from time to time expel from the cell waste fluid, which may contain solid particles. In such a fluid the presence of uric acid has been demonstrated. 
In the mctazoa, the taking up of waste products is done by specialized organs - the nephridia-which are bathed by the body fluid.

In the vertebrates there are three stages of renal development. First, the pronephros which represents a collection of primitive nephridia and excretes the waste products into the cœlom. The pronephros is represented by the kidney of fishes. Secondly, the mesonephros appears; thirdly, the metanephros. The mesonephros is represented by the kidney of the amphibia, the mctanephros by the kidney of birds and mammals. In the development of the human embryo, all three stages are represented, a transitory pronephros at the third week, then the mesonephros, from which the genital organs are developed, and lastly, the metanephros or permanent kidney. The last is formed by the combination of two elements: a nephric or secretory part, a duct or excretory part (Fig. 230). The kidney is a collection of these elements, the whole being held together by connective tissue, and compactly bound up in a covering capsule.

The Minute Structure of the Kidney Tubule.-Each tubule starts in the cortex of the kidney as an expansion - the capsule of Bowmaninto which dips a tuft of capillaries-the glomerulus. The wall of the capsule is formed of flattened endothelium, and is involuted by the tuft of the capillaries. The cells covering the glomerulus form a syncytium. The glomerulus itself is a lobulated structure. The endothelium of the capsule and other parts of the renal tubule rests upon a homogeneous basement membrane. The capsule narrows to a neck, also lined by flattened epithelium, and this passes into the first convoluted tubule. Here the epithelium consists of cubical grannlar cells, called, on account of the rod-like disposition of the granules, " rodded epithelium." Leaving this convoluted portion, the tubule narrows and passes down into the medulla as a long, straight limb, lined with flattened epithelium-the descending loop of Henle. Turning suddenly upwards, it again passes into the cortex as the ascending loop of Henle. Here the epithelium is cubical and grannlar. In the cortex the tubule again expands as the distal convoluted tubule, where the epithelium once more becomes "rodded." Finally, the tubule opens into a collecting tubule lined with a more flattened epithelium. This conveys the urine to the pelvis of the kidney (Fig. 231 A).

The Arrangement of the Blood-Supply. - In the manmalian kidney the renal artery, after entering the substance of the kidney at the hilum, breaks up in the boundary zone between cortex and mednlla into a number of small ressels, which anastomose with each other, and give off branches both to the cortex and to the medulla. Of these, the arteriæ rectæ pass downwards into the medulla, and form capillaries around the descending and ascending loops of Henle. The main blood-supply, however, passes by straight (interlobular) branches into the cortical zone. These give off on all sides small branches, which pass to the glomeruli. From the glomeruli pass efferent reins, which are of smaller calibre than the afferent arteries. These veins partake of the nature of a "portal circulation," since from the glomeruli 
they pass among the tubules of the cortcx, and there again form a second capillary system which anastomoses with the capillary system
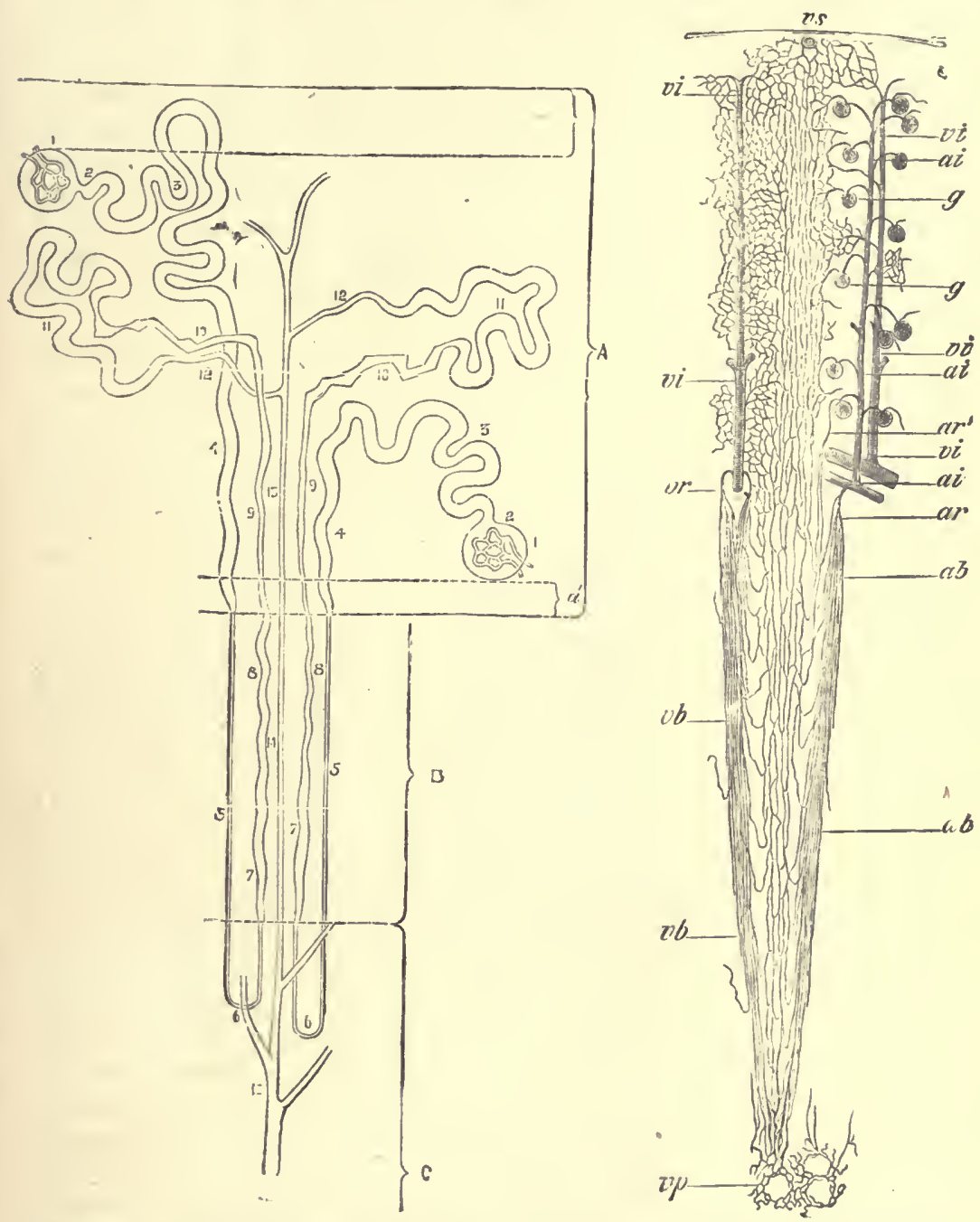

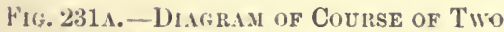
Uniniferous Tubules. (Klein.)

$A$, cortex ; $B$, boundary zone ; $C$, papillary zone of medulla; $a c^{\prime}$, superficial and deep layers of cortex free from glome. ruli.

of the medulla. Both systems then join to form the efferent veins,
which anastomose in the boundary zone, whense larger veins run

of the medulla. Both systems then join to form the efferent veins,
which anastomose in the boundary zone, whense larger veins run

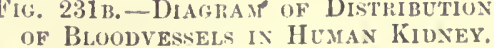
(Ludwig.)

$a i$, Interlobular arteries; $v i$, interlobular reius; $g$, glomerulus; $c s$, stellate vein ; $\mathrm{rer}, v r$, arterix and vene recte forming bundles; $a b, v b ; v p$, venous plexus in the papille. 
to the hilum of the kidney, and together form the renal rein (Fig. 231B).

Such an anatomical arrangement of tubules and blood-supply suggested to Bowman, who first described it, in 1840, that the urine had a double source of origin-glomerular and tubular. $\mathrm{He}$ suggested that the water and salts of the urine werc filtered from the blood in the glomeruli, while the organic constituents of the urine were secreted by the tubules, especially by the convoluted portions. Ludwig laid stress on the vas efferens leaving the glomerulus being narrower than the vas afferens, and put forward the view about the same time (1844) that water and crystalloids of the blood filtered through the glomeruli, and the urine was concentrated from this by resorption in the tubules.

A controversy arose around these two views, which resolved itself into a question of principle. The Ludwig view was the more mechanical one. It sought to minimize the unknown forces of the living cells, and to make the excretion of urine a question of filtration through the glomeruli and concentration by physical means in the tubules. The adherents of the Bowman view attributed special selective activity to the glomerular and tubular cells. The secretion of urine, to them, was a vital function, and not to be explained by known physical processes, such as filtration and osmosis. The glomerular epitheliun secreted water and salts ( $\mathrm{NaCl}$, etc.), the tubules the specific urinary substances (urea, etc.) and some water. The activity of the kidncy was regulated by the amount of water and urinary substances in the blood, and the velocity of flow of the blood through the kidney. This is the view which has steadily gained support.

In the course of the controversy two salient facts have emerged: (1) That a concentration by resorption of dilute urine in the tubules cannot be brought about by such physical forces as osmosis; (2) that in the secretion of urine the kidney cells are performing work.

In regard to the first point, it soon became clear that those physical forces which had been evoked by the Ludwig school, such as diffusion and osmosis, could not concentrate the weak urine supposedly filtered through the glomerulus. When blood and urine are placed on either side of a parchment membrane, water passes by dialysis from the blood to urine. The clectrolytes in normal urine are more concentrated than in the blood. In the case of the urine passed after drinking a quart or two of water the opposite condition pertains. The kidney works either way against osmotic force. It may secrete a urine with far more salt than in the blood, or a urine with almost no salt in it at all.

In regard to the second point, it has been demonstrated that during the process of active secretion the amount of oxygen taken 11 p by the kidney from, and the amount of $\mathrm{CO}_{2}$ given up to, the blood is greatly incrcased. This is seen from the following figures:

\begin{tabular}{|c|c|c|c|}
\hline $\begin{array}{l}\mathrm{O}_{2} \text { per minute } \\
\mathrm{CO}_{2} \text { per minute } \\
\text { Urine per minute } \\
\text { Work per minute }\end{array}$ & $\begin{array}{l}\cdots \\
\cdots \\
\cdots\end{array}$ & $\begin{array}{l}\ldots \quad 4.35 \text { c.c. } \\
\ldots \quad 1.88 \text { c.c. } \\
\ldots \quad 0.05 \text { c.c. } \\
\ldots \quad 327.0 \text { g.cms. }\end{array}$ & $\begin{array}{c}5.58 \text { c.c. } \\
3.93 \text { c.c. } \\
1 \cdot 53 \text { c.c. } \\
\text { 1 } 5 \mathrm{~s} \cdot 0 \text { g.cms. }\end{array}$ \\
\hline
\end{tabular}


The work may be performed in an excretory direction or in an absorptive direction. For instance, to concentrate through a semipermeable membrane the urine from the chloride content of the blood $(0.38$ per cent.) to that of normal urine $(0.8$ per cent.) requires the expenditure of a large amount of work on the part of the kidney cells. It would also require a large expenditure of work to separate, as after large libations, a urine consisting of little more than water.

The questions in dispute, then, at the present time are these: (1) Is the work of the kidney performed in actively secreting substances in the glomerulus and in the tubules? or (2) is it secreting in the tubules only? or (3) is the work performed in concentrating urine in the tubules? or (4) is it concerned in all these processes?

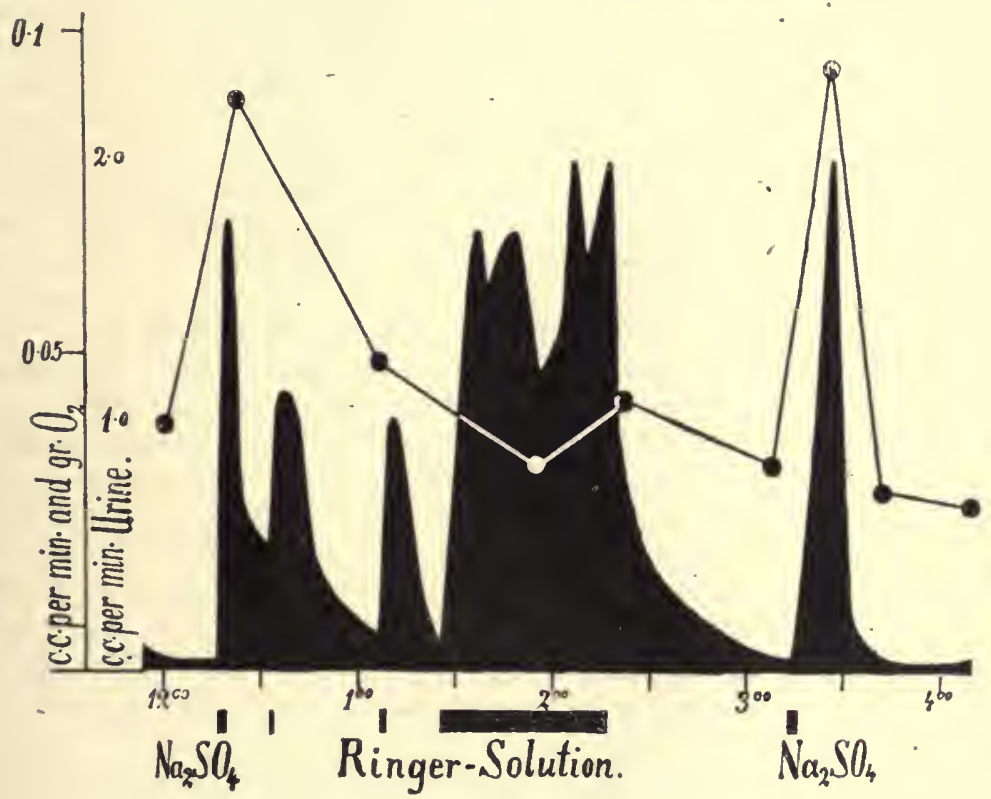

FIG, 232 .

Line $=$ oxygen consumption; black arca $=$ urine exereted. (Barcroft and straul.)

Valuable evidence has been adduced by the study of the action, upon the internal respiration of the kidney, of various substances, such as sodium chloride, Ringer's solution, urea, caffcine, and sodium sulphate-substances which stimulate the flow of urine, and act as diuretics. The last three substances, when injected into the blood, cause a diuresis which is attended by a markedly increased absorption of oxygen; 5 per cent. sodium chloride and Ringer's solution, on the other hand, cause a diuresis which is unattended by any such increased oxygen absorption (Fig. 232). When the kidney cells have been poisoned by mercaric chloride, the oxygen consumption of the kidney almost stops. Sodium sulphate is then practically without action in 
causing diuresis; sodium chloride still continues to do so. Also it is found, under these circumstances, that if the blood be much diluted with Ringer's solution, the chlorine content of the urine closely approximates to that of the blood.

From these experiments it would seem that the excretion of such bodies as urca and sodium sulphate call forth the cell activity of the kidney, while chlorides do not. Such experiments, however, do not negative the view that work may also be spent in actively concentrating the urine in the tubules.

The theories of Bowman and Ludwig have becn variously modified as the result of the ever-extending researches into the nature of the renal functions. The following are the chief modifications:

1. A modification of the original view of Ludwig. A dilute urine containing all the urinary constituents is filtered through the glomerulus, and becomes concentrated by cell activity during its passage through the urinary tubules.

2. Modifications of the original view of Bowman. (a) Water and salts are filtered through the glomerulus, and the organic constituents are actively added by the tubules. (b) The water and salts are actively secreted by the glomerular cells, and the organic substances by the cells of the tubules.

3. A combination of the above views-namely, that water and salts are either filtered or secreted from the blood in the glomeruli, and that the tubules have a double function- $-(a)$ to add the organic constituents of the urine by cell activity in one part of their course; and $(b)$ to concentrate the urine by a similar agency in another part.

It will be seen at once that research resolves itself into an inquiry into-

1. The function of the glomerulus and its mode of action.

2. The functions of the tubules.

The Function of the Glomerulus.-Three points have to be settled: (1) Is a dilute urine filtcred through the glomerulus? or (2) are only the water and salts of the urine isolated in the glomerulus? and (3) if so, is it by a simple physical process, such as filtration, or by an active process of cell secretion?

Those who uphold the filtration hypothesis base it, in the first place, upon the arrangement of the bloodvessels of the glomerulus. As measured in histological preparations of injected kidney, the afferent artery appears to be of greater bore than the efferent vein. It is suggested that this develops a high filtration pressure in the capillaries of the glomerulus. It is claimed that evidence of this is afforded by the results of various experiments which are directed towards the increase of the arterial pressure within the kidney, either by producing a general rise of arterial pressure or a local rise by causing vaso-dilatation within the organ. Whenever the pressure is thus raised-as, for example, by stimulation of the spinal cord after section of the renal nerves, or during the injection of large amounts of fluid, which temporarily leads to a condition of plethora-there is an increased flow of urine. When, however, tho arterial pressure is lowered, 
either locally, as by ligature of the renal artery, or generally by division of the spinal cord in the neck, then the secretion ceases. When the arterial pressure in the renal artery is diminished, as by stimulation of the spinal cord without previous section of the renal nerves, or of the splanchnic lerve, or by hrmorrhage, then the flow of urine is diminished.

Such experiments undoubtedly show that, the flow of urine is increased, when the renal arterial pressure is high, and diminished when it is low. The results may, however, be correlated with the flow of blood through the kidney. When the flow of blood is increased or diminished, so also is the secretion of urine. Against the filtration hypothesis is the fact that ligature of the renal vein, which certainly raises the pressure in the renal capillaries to the full arterial pressure, not only causes no increased flow of urine, but stops it altogether. Again, when the renal artery is ligated for a few minutes, and the liga ture then removed, the flow of urine does not immediately begin again for an hour or so, and, when it does, the character of the urine is pathological-it contains albumin.

On the filtration hypothesis, it is assumed that $\mathrm{F}$ (the filtration pressure) $=\mathrm{P}$ (the kidney arterial pressure) $-p$ (the glomerular pressure). $\mathrm{F}=\mathrm{P}-p$.

This being the case, then, in the condition of $\mathrm{P}-\left(p+p^{\prime}\right)$-where $p^{\prime}$ indicates a slight obstruction to the flow in the ureter, and therefore a rise of glomerular pressure, and a consequent diminution of the filtration pressure-there should be a diminished flow of urine. This, however, has been shown experimentally not to be the case. Indeed, under these conditions, there is an increased flow of urine, and if phloridzin is administered to the animal, there is an increased excretion of sugar as the result of this obstruction. The obstruction stimulates the kidney to secrete.

Further, it may be pointed out that, according to the views expressed in the section on capillary pressure, it does not seem possible for a high filtration pressure to exist within the glomeruli. The pulsatile force is transmitted to, and expands, all parts of the kidney.

The histological examination of the kidney shows no evidence of membranes so arranged as to allow filtration from the capillaries into the capsules. There is nothing to keep the membrane separating blood and urine open and rigid as a filtration membrane. The capsule and tubules are surrounded by a membrane, but this is so arranged as to limit their expansion and allow the passage from capillary to lumen of tubule by osmotic or other forces set up within the tubule by the active secretion of the renal cells. The structural arrangements point to a pull of fluid from capillary to tubule, not to a mechanical push produced by blood-pressure.

The process of secretion at the glomerulus must be just as much an act of cell activity as is the formation of the corresponding waste fluid in unicellular organisms, or in worms which have their nephridia bathed in blood-sinuses-conditions which clearly negative the filtration hypothesis. 
Whatever the nature of the mechanism may be, the passage of water seems to be carried out with a minimum amount of work on the part of the kidney, as is shown by the fact that an intravenous injection of 5 per cent. sodium chloride solution causes a diuresis unattended by any increased oxygen absorption. The total osmotic pressure of the blood is equal to seven atmospheres, and if water were separated from the blood through a semi-permeable membrane, work would have to be done to overcome this pressure. If the water and salts of the blood, and not the urea, sugar, etc., were separated, the osmotic pressure overcome would be considerably higher than the bloodpressure. After dilution of the blood with 0.9 per cent. $\mathrm{NaCl}$ solution to provoke diuresis, it was found that the kidney secreted urine when the blood-pressure was lowered even to $18 \mathrm{~mm}$. $\mathrm{Hg}$.

Water flows from the ureter when circulated through the bloodvessels of the dead kidney. In contiguity lie the renal vessels, glomeruli, and the tubules, and it is probable that the membranes which separate these allow leakage in the poisoned or dead kidney. It becomes then an indifferent matter whether the water takes the channel of the tubules or venules. The kidney substance imbibes the water, becoming converted, so to speak, into a bog or morass. When a 0.75 per cent. solution of $\mathrm{NaCl}$ is perfused through the excised kidney of the ox, the filtrate varies very slightly from the perfused fluid, and stoppage of the renal vein increases its amount. In the living kidney, the stoppage of the renal vein arrests the secretion of urine.

It has been suggested that one function of the glomerulus is to act as a pulsating mechanism placed at the commencement of the tubule. Undoubtedly, with each heart-beat the urine is driven forward out of the tubules into the pelvis of the kidney. The whole kidney expands with systole and shrinks on diastole, and not only blood is expressed from the renal veins, but urine from the collecting tubules by each systolic expansion. The pulsatile cxpansion of the kidney is necessary for the normal secretion of urine.

The Nature of the Glomerular Secretion.--At the present time it is impossible to say what is the exact nature of the secretion of the glomerulus. Probably the mechanism is such that water and salts, especially chlorides, pass through with great ease. In cases where by injury or operation the tubules in the medulla have been largely destroyed, and the glomeruli in the cortex left intact, a much more watery urine is secreted.

The proteins and the sugar of the blood are held back, by the glomerular membranes, since normal urine contains only traces of these bodies. When the glomeruli are damaged, these bodies may pass through into the urine, especially the blood-proteins. Direct leakage then takes place. It is a matter of doubt whether any of the nitrogenous constituents pass into the urine at the glomerulus. It may be concluded that its main function is the separation of water and salts.

In the frog, the renal portal vein is the main blood-supply of the 
urinary tubules, and ligation of this vein affects but little the amount of urine secreted. On the other hand, ligation of the renal arteries which supply the glomeruli causes a cessation of the urinary flow. As a small amount of secretion may then be excited by the injection of a diuretic, it is concluded that the tubules can secrete some water.

The Secretory Function of the Tubule.-If the kidney tubules are damaged by a poison, and a solution of sodium chloride added to the blood, the excess of chloride quickly passes into the urine. On the other hand, if urea is added to the blood, it is not excreted.

This experiment indicates that the chief secretory function of the tubules is to add the waste nitrogenous products to the fluid separated from the glomerulus. Confirmatory evidence has been obtained by injesting into the blood of an animal an organic dye, such as indigo-carmine, which is serreted in the urine. The site of secretion can only be ascertained after stopping the glomerular secretion of water. This is effected by the fall of blood-pressure which follows a section of the spinal cord. Under these circumstanses, the convoluted portions of the tubules of the kidney are found filled with pigment granulez. In the bird, after ligation of the ureter, there follows a deposition of urates (which correspond to the urea of the mammal) within the cells of the tubules. Uric acid and its salts can be stained with silver nitrate, and demonstrated within the cells of the tubules, the stain being developed by a solution of hydroquinone.

Vacuoles akin to excretory vacuoles have been described in the cells of the convoluted tubules. These gradually grow in size, and eventually void their watery and granular contents into the lumen of the tubule. In thirsty animals fed on dry food the cells fill up most of the lumen, and are full of granules. After diuresis, the cell are shrunken and the lumen is wide.

Resorption by the Renal Tubules. - The evidence so far adduced in favour of resorption is far from conclusive. It is claimed that, after removal of the medulla of the kidney, there tends to be secreted a urine which is much more watery. It is also claimed that such a function is indicated by notable differences in the rate of secretion of two salts when injected into the blood in equal amounts of their equivalent solutions--e.g., of $\mathrm{NaCl}$ and $\mathrm{Na}_{2} \mathrm{SO}_{4}$. The difference is equally well explained by a selestive secretory activity. The kidney has the special function of turning out from the blood foreign salts, and of keeping constant the concentration of normal salts in the blood.

"Pigment casts" have been found in the collecting tubules after the injection of carmine into the circulation, and this may point to a coneentration of the urine, possibly in the sccond convoluted tubules. Only a little carmine is to be found in the first convoluted tubules, for the glomerular secretion of water washes it on as it is secreted there. This is the best evidence so far adduced in favour of resorption within the urinary tubule.

The concentration of urea in the blood is 0.5 to 0.6 per mille, 
and 30 grammes of urea may be secreted per diem. To effect this by resorption, 60 litres would have to be concentrated to 2 litres. Such an active resorption is pcssible for the amount of blood flowing through the kidneys is very large. It has been estimated at 300 to 600 litres, and even at 1,800 litres, per diem-an amount ample cnough to allow resorption to play an active part.

Intravenous injection of concentrated salt or sugar solution produces diuresis both by exciting the renal cells and by making the blood more watery. The water is drawn into the blood from the tissues, and the concentration of the blood thus rapidly brought back to normal. The diuresis is not large because the body holds to its water. The intravenous injection of isotonic and hypotonic solutions both excites the renal cells and accelerates the blood-flow through the kidney; the water thus introduced produces much diuresis. Urea acts as a powerful diuretic, and causes vaso-dilatation of the kidney. Caffeine likewise, but this acts when the renal vaso-motor nerves are destroyed. Caffeine causes little diuresis in thirsty animals.

To sum up, the balance of evidence at present available seems to indicate that the water and salt content (particularly chloride) of the urine are secreted by the action of the glomerular cells, and that the organic constituents of the urine are added by the cell activity of the tubules. The evidence in favour of a concentrating mechanism in the tubules is slight, but it is most probable that the urine is the product of the give and take of the renal cells, bathed as they are by the contents of the tubule on one side, and by the lymph which percolates from the capillaries on the other. There are diuretic substances in the blood which stimulate the kidney to secrete, e.g., urea; and the secretory activity depends on the amount of these substances - that is, on their concentration and on the volume of the blood passing through the kidneys per diem. The above view is strengthened by the fact that developmentally the kidney has a (touble organ-a secretory and an excretory part.

The Passage of Urine along the Ureters. - The urine collects in the pelvis of the kidney, and passes thence down the ureters to the bladder. The ureters are smooth-muscle tubes lined by transitional epithelium. The muscle is arranged in a circular outer and a longitudinal inner layer. It is probable that ganglion cells are present between the muscular layers throughout the entire length, but they are particularly abundant in the upper and lower thirds.

Under the influence of the secretory pressure, and in the erect man under the influence of gravity, the urine passes into the beginnings of the ureter, which then by peristaltic movements passes the urine down into the bladder. These peristaltic movements occur regularly about every ten to twenty seconds, being more frequent the greater the amount of urine, but the presence of urine in the ureter does not seem to be necessary to evoke them. They proceed over the ureter at a rate of about 20 to 30 millimetres per second.

There is some doubt as to the exact nature of these movements. It was held that they were myogenic in origin, because the middle 
third of the ureter was believed to be devoid of a local ganglionated nervous mechanism. Such, however, is now known to exist, and it is h:ghly probable that the smooth muscle of the ureter executes these rhythmic peristaltic movements by virtue of a local nervous mechanism.

Although the ureters are supplied by extrinsic nerves, the exact action of these is somewhat doubtful. It is stated that stimulation. of the splanchnic fibres, which reach the ureter through the renal plexus, produce acceleration of the upper end of the ureter, while stimulation of the hypogastric nerves has a similar acceleratory effect upon the lower end of the ureter.

The ureters enter the bladder obliquely at the upper corners of the trigone of the bladder. This oblique course prevents a regurgitation of urine. The orifice of the urethra is closed by the thickened circular fibres at the base of the bladder-the internal sphincterand by the voluntary muscle-the compressor urethræ-outside the bladder. The urine, therefore, gradually accumulates in the bladder, and this gradually relaxes to accommodate its load. The incoming urine raises the pressure within the bladder up to about 15 to $20 \mathrm{c.m}$. of $\mathrm{H}_{2} \mathrm{O}$. At this point the desire to micturate usually manifests itself, and the urine is voided. If, however, this be not done, the bladder further relaxes, and the desire passes away for the time being.

The Act of Micturition.-During the time that urine is accumulating within the bladder the organ performs rhythmic movements. As the organ fills, these gradually increase in force, until some urine is forced past the internal sphincter, and then micturition may reflexly take place. This is the case in the decerebrate or spinal animal, or in the involuntary micturition of children with weak control. Normally, however, the reflex is curbed, and when there is desire to micturate, the passage of urine into the first part of the urethra is aided by the voluntary efforts of the individual. The intra-abdominal pressure is raised by closing the glctlis, so holding the diaphragm in the inspiratory position, and by contracting the muscles of the abdominal wall. The passage of a few drops of urine through the internal sphincter stimulates the sensory nerve-endings of the pelvic nerve. As a result of this, the sphincter of the bladder is reflexly inhibited, while the body of the bladder contracts down and voids its contents.

Micturition is therefore a reflex act, the centre for which is situated in the lumbar spinal cord. This centre is, in the adult, under the control of the will, but in the new-born this is not the case. A baby, for the first few months of its lifc, passes urine in response to the demands of the lower, and not of the higher, reflex arc. It has to be taught control. In some, the nervous mechanism concerned in this reflex is overexcitable, so that even in adult life, when the cerebral control is cut off, either by sleep or excitement, urine is reflexly voided.

The efferent nerves concerned in the reflex are chicfly the pelvic nerves. In some animals the hypogastric ${ }^{\circ}$ nerves are also con- 
cerned. As indicated, the action of these nerves varies in different animals. It is possible that both are usually concerned in the act of micturition, particularly in raising the tension for the initial process. The pelvic nerves, when stimulated peripherally, usually cause a marked contraction of the body of the bladder, and an inhibition of the sphineter of the trigone, while the hypogastrics cause an inhibition of the wall of the bladder. The latter are therefore mainly in action during the accumulation of urine within the bladder; the pelvic, on the other hand, during the voiding of the viscus.

The hypogastric supply of the bladder affords an example of what is known as an "axon-reflex." If all the nerves connected with the inferior mesenteric ganglion be divided with the exception of the right hypogastric nerve to the bladder, then stimulation of the central end of the left hypogastric nerve will cause a contraction of the right half of the bladder. The explanation is that the preganglionic fibre branches in the ganglion, one branch forming a cell station with the right nerve, another branch continuing in the left nerve to the bladder. Stimulation of the left nerve therefore can influence the bladder through the cell station in the ganglion.

The last drops of urine are expelled from the urethra by the contractions of the bulbo-cavernosus (accelerator urinæ) muscles. The act of micturition can be stopped by the contraction of the compressor urethræ, but it is difficult to do this when the reflex is in full action. 


\section{BOOK IX \\ THE FUNCTIONS OF THE SKIN AND BODY TEMPERATURE}

\section{CHAPTER LVII \\ THE FUNCTIONS OF THE SKIN}

ONe function of the skin is to confine and support the soft parts with a strong, pliable, elastic cover, and protect them from harm. Its structure is adapted to these functions. The skin, by virtue of its blood-supply and sweat glands, also plays a great part in regulating the temperature of the organism, and by virtuc of special nervous structures affords information of the nature of the surroundings in which the organism finds itself.

The skin, in addition, acts as an organ of excretion, and to a certain extent as an organ of absorption. In some animals, the skin serves a respiratory function.

The skin consists of two parts - the epidermis, or outer skin, and the cutis vera (true skin), or corium. The epidermis consists of stratified squamous epithelium, and has no bloodvessels. The most external layer is known as the stratum corneum, or "horny layer." Its cells are largely composed of keratin, and are of a scaly nature. This layer is particularly thick in the palms of the hand and soles of the feet. The next layer inwards is known as the stratum lucidum. Its cells appear clear and free from granules. Within this layer is another, known as the stratum granulosum. Its cells are characterized by the presence of granules of eleidin, a substance which stains deeply with hæmatoxylin. Beneath this comes the deepest layer of the epidermis - the rete mucosum, or stratum Malpighii (the Malpighian layer), the cells of which are not horny, but protoplasmio in nature. It is in this layer that there is deposited the pigment melanin, which gives a characteristic black colour to the skin of the dark races. The cells are in more than one layer, those in the deepest are columnar, those above polyhedral in shape. They multiply in the deepest layer, and are gradually pushed out, and undergo the change into horny matter as the older layers are worn off. Tissue lymph soaks between the cells, and keeps up the transpiration of 
water from the surface. The lymph affords material whereby the chemical change into keratin is effected.

The true skin-dermis, or corium-consists chiefly of connective tissue. The outermost layer is a dense fibrous tissue, which is thrown into multitudes of papilla or ridges. Corresponding to these are the patterns, seen on the surface of the epidermis, which corer the ridges. The patterns on the finger tips are peculiar to each individual, and afford finger prints for identification. This layer is well supplied with plexuses of capillary vessels, and also contains some of the organs of sensation, such as Meissner's corpuscles, etc. The deepest layer of true skin consists of fatty or adipose tissue. Besides serving as a fat depot, it is of importance in keeping the heat within the

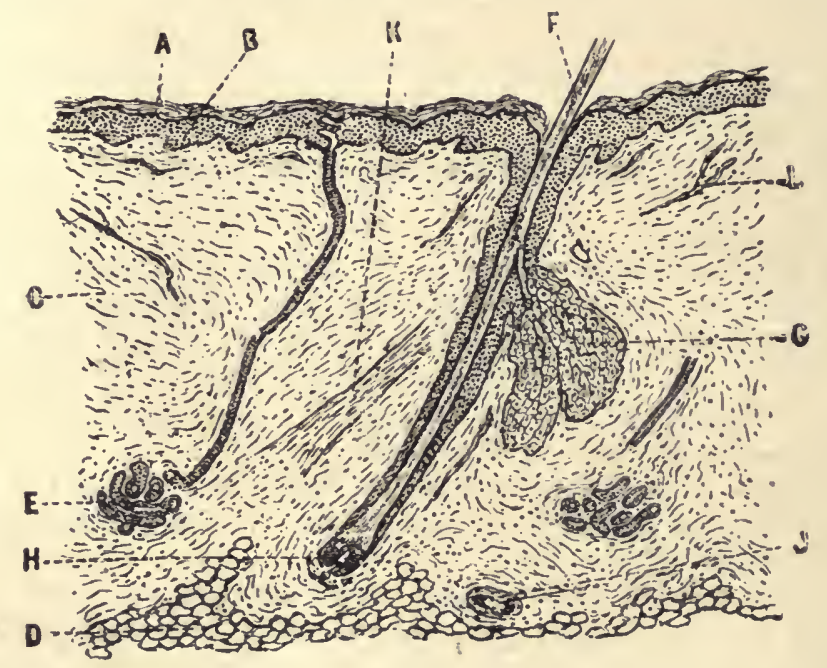

Fig. 233.-Microscope, Low Power. Section throvgh the SkiN,

$A$, Horny layer of cells; $B$, layers of soft growing_cells; $C$, thick connective-tissue coat; $D$, fat layer; $E$, sweat-gland and duct; $F$, hair; $G$, sebaceous gland; $H$, papilla of hair; $J$, small artery; $K$, muscle of hair; $L$, capillaries.

body. Arctic mammals are protected by thick layers of blubber. It also acts as a cushion, and gives softness of contour and beauty of form to the body. In some positions-e.g., neck, scrotumplain muscles fibres are found in the corium. Connecting the two layers of the corium is a loose fibrous-tissue layer.

Hair follicles are found in all parts of the skin of man, except in that of the palms of the hand and of the soles of the feet. They are developed from the Malpighian layer, which grows downwards into the corium. They consist of various layers corresponding to the epidermis and cermis, the hairs growing up from a layer of cells known as the hair bulb. Smooth muscle fibres, forming the pilo-motor nerves, are attached to each hair follicle, and cause it to stand erect 
when in action. Nerves end in plexuses within the outer layers of the follicle. The mouths of sebaceous glands also open into the upper part of the hair follicles. These glands are situated in the Malpighian layer, and are of a compound saccular form, and lined by cubical cells.

The thick epidermis protects the underlying structures from the ceaseless frictional contact with the external world, and wards off wounds and invasion by pathogenic organisms.

The. nails were originally weapons of offence, as well as of defence.

The hairs shoot off the rain, and keep the body dry. They also, when touched, stimulate organs of sensation. The fur of animals prevents loss of heat by convection. Man developed as a tropical animal, with scanty hair, and endures the cold of the temperate and Arctic climates by fashioning clothes of the hair of animals or fibrez of plants.

The fat of the deep layers protects against heat loss, and also serves as fat depots for the body against times.of stress (starvation).

The ceruminous glands of the ear, by the odour and bitter taste of their sycretion, are said to prevent insects entering the external ear.

The sebaceous glands, by their secretion-the sebum-keep the skin supple, and protect it from the drying effects of the atmosphere, and from the ill-effects of immersion in water. Moreover, pathogenic organisms cannot grow through this secretion.

The sebum is of a fatty or waxy nature, containing fatty acids, which render it acid, and iso-cholesterin. It is continuously secreted by the sebaceous glands, which occur mainly in the regions supplied with hair, the mouths of the glands opening into the hair follicles. 'The secretion is squeezed out of the gland by the contractile action of the smooth muscle supplying the base of the hair follicle.

Sweat Glands.-From the stratum Malpighii are developed sweat glands. These lie in the deeper layer of the corium, and are particularly abundant in the palms, soles, forehead, and axillæ. There are estimated to be per square inch of skin:

$\begin{array}{lcccr}\text { Forehead .. } & \ldots & \ldots & \ldots & 1,258 \\ \text { Cheeks . } & \ldots & \ldots & \ldots & 548 \\ \text { Hand, palm } & \ldots & \ldots & \ldots & 2,736 \\ \text { Hand, back } & \ldots & \ldots & \ldots & 1,490 \\ \text { Font, scle } & \ldots & \ldots & \ldots & 2,638 \\ \text { Foot, back } & \text { Neck, front and sides } & \ldots & \ldots & 924 \\ \text { Neck } & \ldots & & 1,303\end{array}$

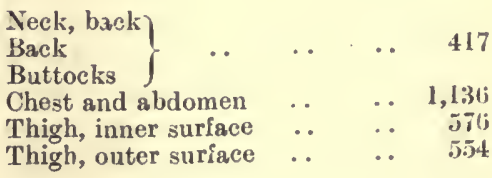

The gland proper is situated in the dermis. It consists of a coiled tube, lined with a-single layer of secreting cells, arranged upon a basement membrane, on the inner side of which lie some smooth muscle fibres. The dusts are lined with cells in the corium, and form 
a spiral passage through the epidermis, and so reach the surfacc of the skin.

The perspiration, or sweat, is a watery fluid (99 per cent. is water), generally neutral or faintly alkaline in reaction. The 1 per cent. of solids is chicfly sodium chloride and fatty bodies, as is seen from the following table:

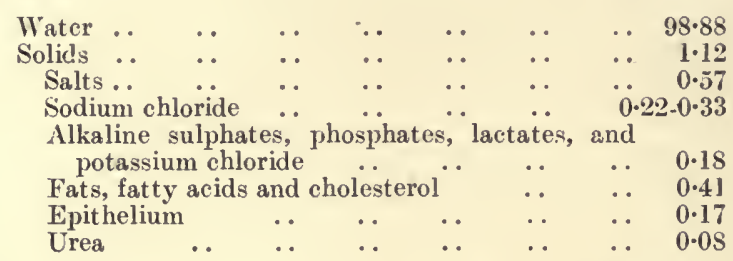

Usually the excretion of urea by the skin is negligiblc, but during a day's march on a very hot day as much as 12 per cent. of the total nitrogen output may be excreted in the sweat. Sometimes a pink sweat. is secreted in the axillæ, coloured, it is said, by products of putrefaction absorbed from the large intestine.

The amount of sweat varies largely with the temperature of the surroundings and the heating of the body by muscular work-e.g., 600 grammes on an ordinary, and 3,000 grammes on a warm day in which considerable exercise is taken.

The function of the sweat is to moisten the skin and to cool the body by evaporation. As the evaporation of 1 granme of water requires 540 calories, we see the cooling efficiency of the sweating mechanism. A man without sweat glands was only able to work in the hot sun by wetting his shirt frequently, and so artificially making good the absence of sweat. In a hot chamber his body temperature quickly became febrile. The importance of the swcat as an excretion of material is little or nil.

Sweating is under tle control of the central nervous system; the ceritre is stated to be situated in the floor of the fourth ventricle, and is proroked by a rise of temperature of the blood which circulates through it. Such a rise is generally produced by muscular work. Experimentally it can ke shown that the warming of the carotid blood induces sweating. It may also be stimulated by increased concentration of $\mathrm{CO}_{2}$ in the blood, as in asphyxia, and by certain drugs known as diaphoretics-e.g., morphire.

The centre is also affected by afferent nerrous impulses. Stimulation of the central $\epsilon$ nd of the sciatic nerve causes sweating reflexly. Such sweating is associated with a vaso-constriction in the limb, showing that the raso-dilatation of the skin, which generally accompanies sweating, is not a necessary, although a farourable, condition.

The efferent channels for the sweat nerves run in the sympathetic system, arising from the thoracic region of the spinal cord (see p. $7 \leftleftarrows 0$ ). Communication is established with the sympathetic ganglia by the white rami communicantes of the various nerres. Leaving the ganglia, 
the grey rami communicantes establish connection with the nerves supplying the skin of the various parts of the body (se3 p. 750). After the spinal cord has been divided, sweating docs not takc place in the parts below the lesion.

Sweating is provoked in the pads of a cat's foot on stimulating the peripheral end of the sciatic nerve. A few beads of sweat will appear if the nerve be stimulated just after amputation of the foot, but its amount is very scanty in thэ absence of blood-flow. The secretory pressure of the sweat, when this is obstructed, rises higher than the blood-pressure. Sweating, therefore, is the result of an active secretion, and not a mere mechanical transudation of fluid from the blood. 'It is accompanied by an electrical variation in the skin current, as may be demonstrated in the pad of the excised cat's foot, if this be led off to the galvanometer, and the sciatic nerve excited. The nerve-endings in the sweat glands may be paralyzed by atropine, and stimulated by pilocarpine and physostigmine applied locally.

Transpiration of water from the bloodvessels through the skin is continually taking place. The skin is thus kept supple and moist. The loss of water by transpiration is insensible perspiration, and it increases with the temperature of the skin. Sensible perspiration is produced by the action of the sweat glands.

Absorption by the Skin.-For a body to be absorbed by the unbroken skin, it is necessary for it either to be of a fatty nature or to bo administered in fat. 'Thus, it is stated that cod-liver oil rubbed into a weakly child serves as a source of nutriment. Mercury has been administered in the form of an ointment.

Watery fluids are not absorbed. For such a fluid to pass into the tissue lymph, it is necessary to abrade the skin, as in vaccination. A foreign protein injected subcutaneously sensitizes the body, so that a subsequent injection of a trace of the same protein made a few weeks later may produce shock, or death, the phenomena of anaphylaxis (see p. 111). The mere washing of the uninjured skin by the solution of foreign protein has no such effect, showing that none is absorbed.

The Respiratory Function of the Skin.-The amount of $\mathrm{CO}_{2}$ given off by the skin of man is very small. It increases markedly during sweating, and may become two to four times as great as before. This is seen in the following figures obtained from a naked man:

\begin{tabular}{|c|c|c|}
\hline Temp. of Air. & Wuter per Hour. & $\mathrm{CO}_{2}$ per Hour. \\
\hline $\begin{array}{l}29 \cdot 8^{\circ} \mathrm{C} . \\
31 \cdot 9^{\circ} \mathrm{C} \\
35 \cdot 4^{\circ} \mathrm{C} \\
38.4^{\circ} \mathrm{C}\end{array}$ & $\begin{array}{c}22 \cdot 2 \text { grammes } \\
50 \cdot 3 \quad, \\
106 \cdot 8 \quad, \\
158 \cdot 3 \quad,\end{array}$ & $\begin{array}{l}0 \cdot 37 \text { gramme } \\
0 \cdot 35, ", \\
1.04 \text { grammes } \\
1.23 \quad,\end{array}$ \\
\hline
\end{tabular}


When clothing is worn, the increased $\mathrm{CO}_{2}$ and water output occurs at a lower temperature:

\begin{tabular}{|c|c|c|}
\hline Temp. of Air. & Hater per Hour. & $\mathrm{CO}_{2}$ per Hour. \\
\hline $\begin{array}{l}28 \cdot 9^{\circ} \mathrm{C} . \\
31 \cdot 8^{\circ} \mathrm{C} . \\
32 \cdot 7^{\circ} \mathrm{C} . \\
33 \cdot 4^{\circ} \mathrm{C} .\end{array}$ & $\begin{array}{l}50 \cdot 9 \text { grammes } \\
110 \cdot 1 \quad ", \\
119 \cdot 1 \quad ", \\
122 \cdot 3 \quad "\end{array}$ & $\begin{array}{l}0.33 \text { gramme } \\
0.30 \quad " \\
0.37 \quad " \\
0.80 \quad "\end{array}$ \\
\hline
\end{tabular}

These observations were carried out in still air in a respiratory chamber.

In frogs and kindred animals, the exchange is great enough to enable the animal to live without lungs. There is a special pulmocutaneous circulation for this purpose.

The Function of Pigment. - The value of pigment in the Malpighian layers of the skin of man is to protect against the lcthal effect of intense sunlight. Rays are absorbed by the pigment of the skin, and converted into heat-rays, which in their turn increase the transpiration of water from the cutaneous capillaries, and stimulate the cutaneous nerve-endings, and provoke sweating. Thus, the energy of the sun is sweated off the body of the black man. On the other hand, rays penetrate to the blood of the white man, and are absorbed by the hæmoglobin, and there converted into heat-rays. Moreover, the rays produce sunburn in the skin of the white man, resulting in pigmentation. The white man, therefore, to kcep whitr; has to wear clothes and to shelter himself from the sun, while the black man is happy naked. The white man wears white clothes in the tropics to reflect and scatter the sun's rays; also these, by entangling air, lessen the loss of heat by convection and evaporation. Thus, the clothed white man cannot do field labour and be comfortable in the tropics, and fans are of the utmost necessity for securing his comfort and efficiency indoors. The naked black man is physiologically efficient for life in the tropics.

The absorption of rays by the skin of the negro is probably the reason why the photograph of the naked negro is less distinct than that of the white man, from whose skin more rays are reflected. The pigment is not derived from blood-pigment, but belongs to a group of bodies known as melanins. The pigment of the hair and skin of the negro has been found to contain about 15.5 per cent. of nitrogen, 3.6 per cent. of sulphur, and a trace of iron, the pigment of the hair containing less nitrogen than that of the skin. The pigment is probably derived from tyrosin by the action of an oxidase.

In addition to the function of protection against the sun's rays, pigment is used among animals for various other purposes. Animals, such as the Arctic fox and hare, may undergo seasonal change of colour for protective purposes, changing a brown, soil-colour summer coat to a white, snow-colour winter coat. The change seems to be 
mole than one of colour, for a white rabbit, or an Arctic hare in its winter coat of white, is immune to an intravenous injection of nucleo-protein, which produces in the pigmented animal coagulation of the blood.

Pigment is used for purposes of offence as well as of defenze. It is particularly marked in reptiles, amphibia, and fishes. Pigmentation also plays a marked part in the sexual relationships of some animals, particularly of birds, The male bird is decked in vivid colours, especially in the springtime of active courtship. True albinos are devoid of pigment, and their irises are pink owing to the reflexion of light from the blood circulating therein. 


\section{CHAPTER LVIII}

\section{THE TEMPERATURE OF THE BODY}

MAN, in common with other mammals, belongs to the group of warm-blooded or homothermic animals. In this group the internal temperature of the body, under normal circumstances of life, is kept approximately constant.

During the katabolic processes of the body heat is constantly evolved, chiefly in the muscles and the glands. It is estimated that, of the 1,700 calories of heat produced per diem by a man of 11 stone when fasting and resting quietly in bed, about 1,200 calories are proproduced in the muscles, and 500 in the glands. On the other hand, loss of heat is constantly occurring from the surface of the body by radiation and convection, and by the evaporation of sweat. A certain amount of heat is also lost through the lungs. It has been calculated that an adult man in a still atmosphere of medium temperature loses 43.7 per cent. of his heat by radiation, 31 per cent. by convection, 20.6 per cent. by evaporation of sweat, 1.2 per cent. in warming inspired air, 1.5 per cent. in warming the food and drink, 1.8 per cent. in performance of external work. These proportions vary with the temperature, as is shown by the following table:

\begin{tabular}{c|c|c|c}
$\begin{array}{c}\text { External } \\
\text { Temperaturc. }\end{array}$ & $\begin{array}{c}\text { Total Heut } \\
\text { produced. }\end{array}$ & $\begin{array}{c}\text { Loss by Con- } \\
\text { vection and } \\
\text { Radiation. }\end{array}$ & $\begin{array}{c}\text { Loss by } \\
\text { Evaporation. }\end{array}$ \\
\hline Deg. C. & Cal. per Kg. & Cal. & Cal. \\
$7 \cdot 6$ & $83 \cdot 5$ & $71 \cdot 7$ & $11 \cdot 8$ \\
$15 \cdot 0$ & $63 \cdot 0$ & $49 \cdot 0$ & $14 \cdot 0$ \\
$20 \cdot 0$ & $53 \cdot 5$ & $37 \cdot 3$ & $16 \cdot 2$ \\
$25 \cdot 0$ & $54 \cdot 2$ & $37 \cdot 3$ & $16 \cdot 9$ \\
$30 \cdot 0$ & $56 \cdot 2$ & $30 \cdot 0$ & 26.2 \\
\hline
\end{tabular}

As the temperature rises the loss by convection and radiation decreases, and that by evaporation rises.

The Normal Temperature.-The normal temperature of man is usually stated to be $98.4^{\circ} \mathbf{F}$. This is the temperature as ascertained by taking it in the mouth or axilla. This method is liable to considerable error. A more correct idea of the true internal temperature may be obtained by taking the temperature in the rectum, or by passing water and holding the bulb of the thermometer in the stream of urine. 
The rectal temperature is normally about $99 \cdot 6^{\circ} \mathrm{F}$., the " urine " temperature about $99^{\circ} \mathrm{F}$.

Owing to the loss of heat from the surface, the temperature of the skin is not so constant as the internal temperature of the body; in fact, it shows considerable variation according to the surrounding conditions. For example:

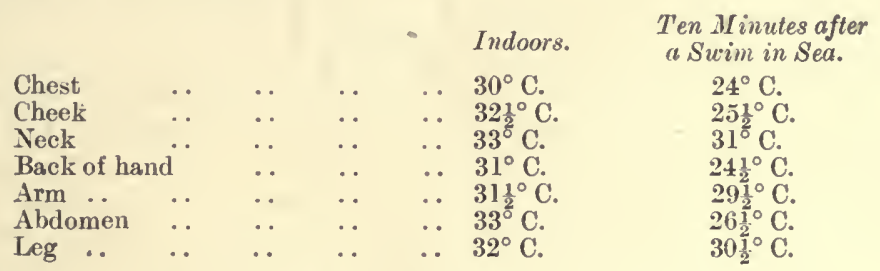

In a cold wind the cheek temperature nay be as low as $15^{\circ} \mathrm{C}$. In hot, moist atmospheres the skin temperature rises up to the internal temperature of the body. Too much uniformity of skin temperature is undesirable.

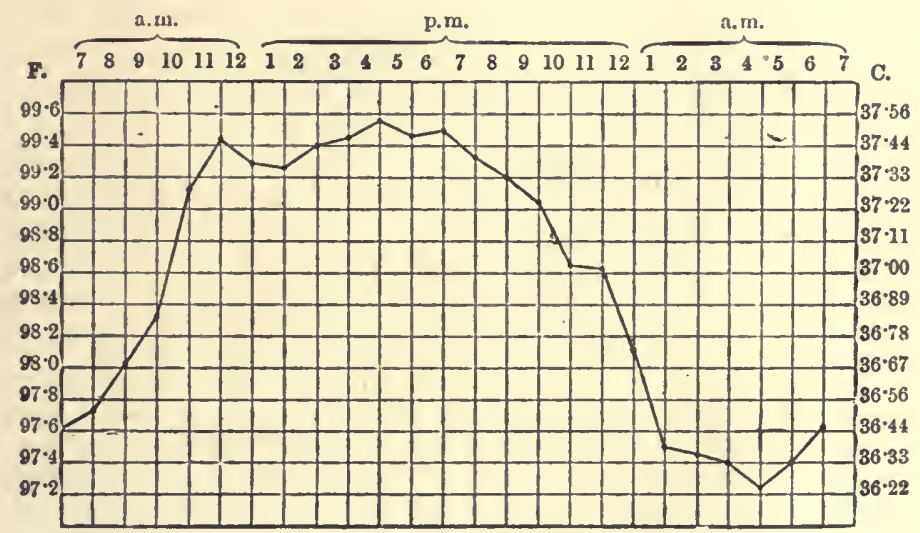

Fig. 234.-Daily Variation of Temperature of Max. (M. S. Pembrey.)

While the rectal temperature represents the body temperature, that of the mouth rises and falls with the cooling power of the atmosphere. It is therefore illusory to fix the mouth temperature at any given figure. In the Arctic region, when the outside temperature ranged from $12^{\circ}$ to $30^{\circ} \mathrm{C}$. below zero, and that of the engine-room of the ship was $37^{\circ} \mathrm{C}$., the mouth temperature varied from $34.58^{\circ} \mathrm{C}$. to $37 \cdot 45^{\circ}$ C.-i.e., $5 \cdot 17^{\circ} \mathrm{F}$. The mouth is cooled through the floor of the mouth rather than through the inspired air. After drinking hot fluid, the mouth will give too high a reading.

The temperature of man shows a daily variation dependent for the most part upon muscular activity. It rises during the day to a maximum about 6 p.m., and falls during the night to a minimum about 2.30 to 3 a.m. Night work, depending largely upon its severity, 
reverses or tends to reverse this curve. In nocturnal birds the temperature rises during the night, and falls during the day. On travelling from Australia the curve adjusts itself as night becomes day. The clergyman, the navvy, and the sailor, show temperature curves which vary with the occupations and mode of life of each.

A man resting in ked shows the same variation, but not to so marked an extent. The diurnal variation is accounted for by the "restlessness" during the day as compared with the deep rest of sleep during the early night hours. It is more difficult to get absolute rest in the light and noise of daytime. Infants, in the first fow wecks of life, show no marked variation.

The taking of food, especially if it be warm or involve much work on the part of the glands and muscles cf mastication, may raise the general temperature of the body slightly. It plays no part, howcver, in the production of the daily variation, which is approximately the same whether a man be taking food or starving.

Muscular activity raises the body temperature. After a threemile race the rectal temperature in a man not in good training was as high as $105^{\circ} \mathrm{F}$., and did not reach normal again until the sixth hour after the race. After a strenuous game of football, rectal temperatures of $102^{\circ}$ to $103^{\circ} \mathrm{F}$. are the rule. This is owing to the large amount of heat liberated by the muscles during muscular work (see p. 5̃52).

If the subject be unsuitably clothed, and do hard muscular work in a warm, windless atmosphere, there may result "heat-stroke." Such a danger arises in the marches of soldiers in close formation on warm, windless days. This is because the loss of heat from the body cannot, under these conditions, keep pace with the heat production. The subject, owing to his clothing and the high external temperature, cannot lose heat rapidly enough by convection and sweating. The clothes entangle air, and keep it stationary. This air is warmed and moistened by the skin, and thus the body is enclosed in a layer of stagnant humid air. In a crowd, too, the air is confined between the bodies of the people. Wind sweeps the stagnant air out of the clothes, and by throwing off the coat and opening the shirt we gain relief. The clothing should be adapted to the requirements of climate and occupation, not to fashion.

The highcst temperature recorded with recovery is in a case of malaria $\left(45^{\circ} \mathrm{C}\right.$.) or $113^{\circ} \mathrm{F}$; ; the lowest temperature with recovery, $22.5^{\circ} \mathrm{C}$. It has been shown that rabbits lowered to $31^{\circ}$ to $34^{\circ} \mathrm{C}$. breathed more slowly, and could not raise their temperature by shivering. At $26^{\circ}$ to $29^{\circ} \mathrm{C}$. their nervous co-ordination was damaged, and they were easily hypnotized. At $26^{\circ}$ to $22^{\circ} \mathrm{C}$. the arterial pressure began to fall; stimulation of the skin provoked twitches. At $19^{\circ} \mathrm{C}$. the vital centres became paralyzed, and death ensued. The temperature in local peripheral parts may be lowered far more, and these parts recover from the temporary "numbness." Prolonged and excessive cold leads to local death and gangrene (frost-bite).

Generally speaking, the internal temperature of birds is warmer 
than mammals, and the temperature of small warm-blooded animals is in most cases higher than that of large ones. This can be seen from the following table:

\begin{tabular}{|c|c|c|c|c|}
\hline Hedgehog & & .. $34 \cdot 8^{\circ}-35 \cdot 5^{\circ} \mathrm{C}$. & Man, rectum & $37 \cdot 2^{\circ}\left(95 \cdot 96^{\circ} \mathrm{F}.\right)$ \\
\hline Dog & .. & $37 \cdot 5^{\circ}-39 \cdot 5^{\circ} \mathrm{C}$ &, axilla & .. $36.9^{\circ}\left(98.45^{\circ} \mathrm{F}.\right)$ \\
\hline Rabbit & . & . $\quad 38 \cdot 3^{\circ}-39 \cdot 9^{\circ} \mathrm{C}$. & mouth & . $36.87^{\circ}\left(98 \cdot 36^{\circ}\right.$ F. $)$ \\
\hline Guinea-pig & .. & .. $37 \cdot 3^{\circ}-39 \cdot 5^{\circ} \mathrm{C}$. & Infants & . $37 \cdot 6^{\circ}$ \\
\hline Pigeon & .. & $41 \cdot 0^{\circ}-42 \cdot 5^{\circ} \mathrm{C}$ & & \\
\hline
\end{tabular}

The lower vertebrata, such as reptiles, fish, amphibia, are coldblooded-that is to say, they maintain their body temperature scarcely above that of the surrounding air or water. Fish may be frozen, and recover if carefully thawed. A frog in winter becomes cooled down, and hibernates; in summer it is warmed up, and becomes active. The mammal, by maintaining a uniform body temperature, is active in all the seasons. A hibernating mammal changes from warm- to cold-blooded when food becomes scarce in the winter. A hibernating animal will not allow itself to be frozen. It wakes up, and in a short while becomes warm-blooded.

In between these two classes-warm- and cold-blooded-come the rarer egg-laying marsupials of Australia, such as Echidna and Ornithorhynchus. The power of these animals to regulate their body temperature at a constant level is less well developed than in mammals, but their temperature in a cold atmosphere is always many degrees above the surrounding medium. For example, the normal temperature of Echidna is-

\begin{tabular}{|c|c|c|c|c|c|c|}
\hline At $4^{\circ} \mathrm{C}$. & . & & & • & . & .. \\
\hline At $20^{\circ} \mathrm{C}$. & $\cdot$ & . & • & - & $\cdots$ & .. \\
\hline At $30^{\circ} \mathrm{C}$. & . & . & .. & . & $\ldots$ & .. \\
\hline At $35^{\circ} \mathrm{C}$. & .. & .. & .. & .. & 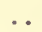 & .. \\
\hline
\end{tabular}

The Regulation of the Body Temperature depends upon nervous control. In young birds just before hatching, and in prematurely born mammals, this mechanism is not working, they have to be kept warm. A child born at the seventh month has to be carefully wrapped in cotton-wool, or even placed in an incubator. At birth at full time, on the other hand, the heat-regulating mechanism is working in man, and for this reason so much care need not be taken to prevent heat loss. Some mammals, such as the rabbit, which is born naked, do not acquire the power of regulation until a considerable time after birth. The newly-born guinea-pig, on the other hand, is born covered with hair, and can regulate its temperature. The newly hatched chick can regulate its temperature; the naked young of many birds, on the other hand, are not able to do so.

The evidence as to the existence of a centre regulating the temperature of the body is conflicting. It is known that lesions of the central nervous system in certain regions-e.g., the optic thalamus and corpus striatum, pons, and medulla-produce an upset of the power of heat regulation, but it would not be exact to describe any one of these sites as the "heat-regulating centre" of the body. 
The nervons system regulates the body temperature in two ways: (1) By the control of the sites of production-the muscles and the large glands: (2) by the control of the structures concemed in heat loss- the cutancous bloodressels, the sweat glands, etc. That heat is developed in the muscles has been demonstrated (see p. 552). It has not bcen shown in other organs, but the respiratory exchange in the glands proves that heat is developed therein. The circulation through a gland is so rapid that the heat formed therein is at once distributed through the body; thus cren the most delicate thermometcrs fail to show that the gland is hotter than the blood.

The Regulation of Heat Production is controlled reflexly through the sensitivity of the skin to changes of temperature. The sensation of cold increases the tone and activity of the muscles; shivering increases muscular activity without displacing the layer of air which is in contact with, and warmed by, the body. It may increase the heat production of a man at rest from 50 to 90 per cent. The cooling of one leg in a bath of cold water may provoke local shivering in that leg. Exposure to cold leads us voluntarily to increase our muscular movements. We move about, stamp our feet, and beat our arms, in order to keep warm.

A certain degree of exposure to cold is therefore valuable. It stimulates the tone, metabolism, and activity, of the body, and in this lies the healthiness of open-air life. The activity of the body provoked by cold leads to an ampler ventilation of the lungs and a more vigorous circulation of the blood. By raising the metabolism, it increases the appetite and better digestion of food, thus lessening the bacterial decomposition of food in the large bowel, and preventing the absorption of toxic products therefrom. The cooling effect of the wind is far more powerful than that of the surrounding temperature, and is the most important quality of open fresh air. It not only cools, but by its varying stimulation of the skin prevents monotony of sensation and invigorates. Ideal outdoor conditions are the radiant heat of the sum warming the ground and thereby the feet and those parts of the body turned towards it, together with a cooling wind blowing on the face.

On the other hand, the sensation of heat produces relaxation of the muscles, a lessened tone and activity, and diminished metabolism. Too warm an atmosphere-in particular, one that is windless and monotonous-is therefore disadvantageous, on account of its relaxing effect.

The Regulation of Heat Loss is accomplished by the nervous control of the loss of heat from the skin by radiation, convection, and evaporation. This regulation is brought about through the vaso-motor centre and the centre controlling sweating. The afferent channels concerned in the regulation of the cutane 'is bood-supply are chiefly those from the skin. The sensation of cold causes a constriction of the cutaneous bloodvessels, and thus diminishes the loss of heat. On the other hand, a sensation of warmth induces a flushing of the 
eutaneous vessels, which greatly facilitates heat loss by convection and radiation. Sweating is controlled by a centre in the medulla which is stimulated reflexly, or directly by the temperature of the blood passing through it. When this temperature is raised by warming the carotid arteries, visible beads or drops of sweat are secreted by the sweat glands, and these, by the cooling produced by their evaporation, greatly aid in the cooling of the surface of the body. The effect of raising the external temperature upon the water output, the heat production, and the carbon dioxide output of the body is seen in the accompanying charts (Figs. 235, 236).

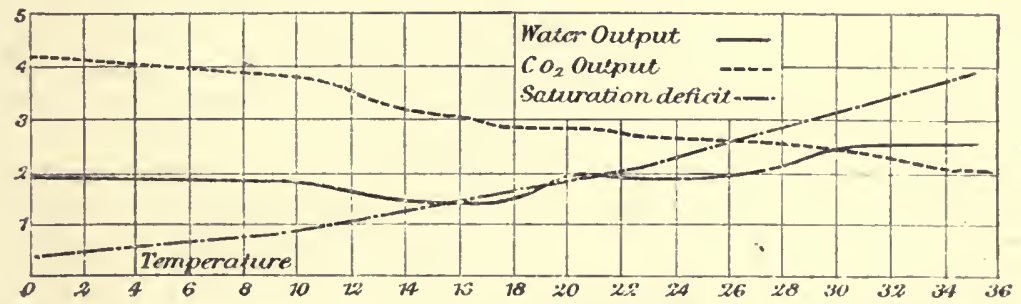

Fig. 235.-The Effect of raisixa the Exterxil TeMperature ox the Water Odtput axd Heat Productiox. Saturation Deficlt ixdicates Regitive Saturation of Air with Molsture. (Rubner.)

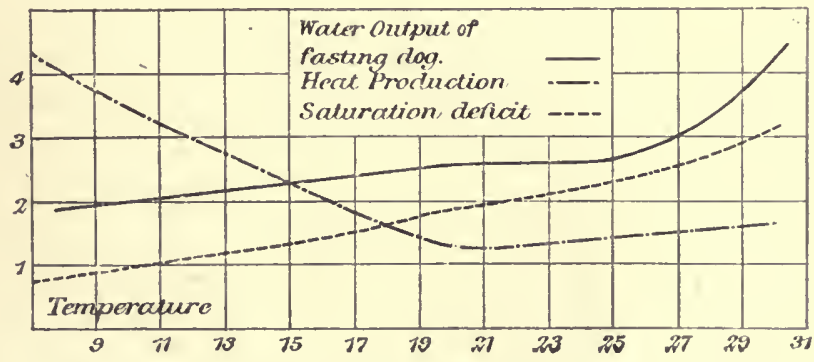

Wig. 236. - The Effect of raising External Temperature on Water axo Carbon Dioxide OUtput. (Rubner.)

The amount of heat lost in the expired air may also be regulated. Warming the carotid artery leads to increased breathing, and this increases the evaporation of watcr and heat loss. The loss of heat by evaporation demands further considcration.

The rate of evaporation from a wet surface at body temperature in still air depends directly upon the vapour pressure of the surround. ing atmosphere, and is independent of either the temperature or barometric pressure of the atmosphere. The skin may be regarded as a porous wall backed by capillary vessels, by means of which moisturc is supplied. The capillaries are profoundly affected by physical conditions without-e.g., constricted by cold-and by physiological conditions within-e.g., flushed with wine.

Simple diffusion of aqueous vapour away from the body would be 
relatively a very slow process; but as aqueous rapour has a density of only 0.62 , air being taken as unity, and as the cooler air of the atmosphere is warmed and expanded by the body heat, the body itself sets up convectional currents which greatly accelerate the loss of vapour. At $32^{\circ} \mathrm{F}$. saturated air holds $\frac{1}{160}$ th of its weight of water vapour, at $59^{\circ} \mathrm{F} \cdot \frac{1}{80}$ th, and at $86^{\circ} \mathrm{F} \cdot-_{4}^{1} \mathrm{th}$. The body warms up the air in contact with it, and saturates it at skin temperature. The air entangled in the clothes thus warmed and saturated camnot escape easily if the atmosphere is still. Wind carries away the air as fast as, or much faster than, the skin warms and saturates it. Thus, wind enormously increases the cooling of the body surface both by convection and evaporation. The skin responds to a cold dry wind by vaso-constriction and diminished transpiration of water. The skin becomes pale and dry, and the heat loss is thus cut down. We seek shelter, and put on more clothes. On warm, close days the skin becomes flushed and moist, we throw off clothes, and make use of fans.

Water rapour is a far better conductor than dry air, and this damp cold air feels raw and chill, while dry cold air is pleasant. Water has 240 times the ther mal conductivity and 3,000 times the heat capacity of air. The particles of cold or even freezing water in a winter fog strike the cold nerve-endings, and by cooling these give us an unpleasant chilly sensation. The fog, by penetrating into our clothes, robs these of their protecting value. The intensity of the temperature sense depends on the difference between the blood-temperature within the cutaneous capillaries and the surface temperature of the skin without. The fog gives us a shower of cold particles of water, while a cold dry wind constricts the bloodvessels of the skin, and, whilc having a far greater cooling effect, dces not give us the same sensation of chill.

Water vapcur, like glass, is almost opaque for the least refrangible rays-the infra-red-and transparent for the middle luminous and ealorific radiations. Thus, on a cloudy day the water vapour both scatters and absorbs the dark heat rays, and less heat reaches the earth. On the other hand, clouds after a sunny day, just as a glass-house, prevent the escape of the dark heat rays from the earth, and cause a warm night. On a clear night these rays radiate into space, and the earth cools. The transparency and diathermancy of the air are properties of the greatest importance, since living energy is derived from the sun's light and heat. Water vapour and dust in the atmosphere serve both to soften the scorching power of the sun and to prevent the rapid scattering into space of the heat gained by the earth.

The motive-powers of the atmosphere are convection and evaporation produced by the sun's heat. The winds arise from the displacement of the warm moist and therefore lighter air by cold heavier air, and the rain falls as the moist air becomes condensed in higher altitudes or against cold land surfaces. The beauty of earth and sky, the glories of sunrise and sunset, depend upon the particles of dust and vapour in the atmosphere. The particles reflect and scatter the shorter rays and transmit the longer. At sunrise and sunset the oblique rays pass 
through a much greater depth of atmosphere; hence the greatcr splendour of the colours.

As the temperature of the air and surrounding objects is made to approach that of the body, loss by radiation and convection becomes small, then nil. Finally, as the air temperature comes to exceed that of the body, heat passes from the air to the body. The body, however, does not become heated so long as the air is dry. The swcat glands come into action, and the body heat continues to be lost by conversion of water into aqueous vapour. The difficulty of maintaining the thermostatic equilibrium of the body increases when the conditions become such that the whole elimination of heat is by evaporation.

A man can stay in a dry atmosphere at a temperature sufficient to cook his dinner. He can keep cool by sweating. He cannot stand a water or steam bath above body temperature without becoming overheated. Immersion for a few minutes in a bath at $110^{\circ} \mathrm{F}$. raises the rectal temperature to $103^{\circ} \mathrm{F}$., greatly accelerates the breathing and pulse, lowers the arterial pressure, and flushes the skin. On standing up suddenly, a sense of faintness ensues. A cold showerbath taken now at once constricts the skin, slows the pulse, raises the blood-pressure, and removes all sense of faintness, while the rectal temperature still remains at $103^{\circ} \mathrm{F}$.

Baths cold and hot are a most potent means of altering the inetabolism both of the skin and of the whole body.

The amount of heat lost by evaporation is very great under conditions of hot dry atmosphere. Thus, it was estimated that 10 litres of water were lost from the body during a ride at a temperature of $45^{\circ} \mathrm{C}$. in South California.

In a dry hot atmosphere, such as the stokehole of a steamer in the tropics, the men are kept cool by sweating, the forced draught of air to the furnace insuring this. The amount of drink required may be enormous - e.g., 15 pints of water a day. In certain factories, mines, etc., where the air is warm and moist, it is of great economic importance to keep the air in movement, or the vapour pressure down to a level commensurate with the performance of efficient work, and maintenance of comfort and health. A regulation made for weavingsheds and spinning-mills is that the wet-bulb thermometer should not he allowed to rise above $75^{\circ} \mathrm{F}$.

The amount of water lost from the body during a march may be calculated by weighing the.body before and after the march, supposing no food or drink is taken, and no fæces or urine passed during the march. The weight of oxygen taken in balances approximately the weight of carbonic acid given out. The water retained in the clothes may be estimated by weighing the clothes before and after the inarch. Such estimations, coupled with those of pulse-rate and body temperature, have shown the value to soldiers of opening or taking off their tunics in hot weather. If the evaporation of sweat and convection is made easy, fatigue and danger of heat-stroke are prevented. It has been calculated that a resting soldier weighing 70 kilogrammes, 
while marching with a load of 31 kilogrammes, produces 7.73 calories per minute, or enough heat to raise his body by $1^{\circ} \mathrm{C}$. in 8.7 minutes. This shows the importance, then, of properly clothing the soldier for marching in hot weather.

The thermometer gives the average temperature of the surroundings; it tells nothing as to the rate of cooling - the matter of greatest importance to the body. The katathermometer has been introduced to measure this. This is a large-bulbed spirit thermometer which is warmed above body temperature. The rate of cooling is determined as the meniscus falls from $100^{\circ}$ to $95^{\circ} \mathrm{F}$. with a stop-

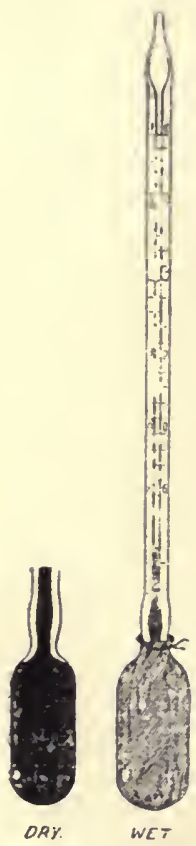
watch (Fig. 237). A factor is determined for each instrument, by means of which is reckoned the rate of cooling per sq. cm. of surface per second at body temperature. The dry-bulb katathermometer indicates the rate of heat loss by radiation and convection, the wet-bulb by radiation, convection, and evaporation. The difference between the two gives the rate of cooling by evaporation. The instrument shows the great cooling effect of wind, and is of value in investigating the conditions of the open air and of ventilation in buildings (see p. 316).

Clothes.-The cutaneons fat is the natural garment of the body. The warming value of fat may be gathered from the fact that with a temperature difference of $18 \cdot 2^{\circ} \mathrm{C}$. a layer of skin, 2 millimetres thick, lets through 0.00248 calory per minute, whereas 2 millimetres of skin plus 2 millimetres of fat lets through only 0.00123 calory. Anointing the skin with grease wards off "frost-bite" in those exposed to cold and wet. The grease prevents the maceration of the skin by water. If water soaks into the skin its non-conducting power is greatly reduced. Exposure to sea water can be borne much better than fresh water because salt water, owing to its Fig. 237. - THE isotonic properties, does not macerate the skin. Kata THermo- Channel swimmers thickly cover their bodies with
METER. (Reiluced from Phit. Trans. Soc.) grease, and are noted for the thickness of their cutaneous fat. The remix caseosa of the new-born, washed off by the midwife, is designed to protect it from wet and cold after birth.

Clothes increase evaporation and lessen loss of heat by convection and radiation, in still air io an extent of 47 per cent. At $18^{\circ} \mathrm{C}$. a clothed man of 74 kilos lost 79 calories per hour clothed, and 124 calories per hour naked. The clothes cntangle and render stationary the air within their cellular structure and between their layers. The nore garments we put on over one another, the more layers of entangled air. To keep us warm, the clothes must prevent the wind sweeping away the entangled air; to keep cool, the wind must have free play. When dry, cellular, wool, or cotton 
elothes are equally good-e.g., flannel or flannelette of the same thiekness; but flannel prevents heat loss mueh better than cotton when wet. The wet cotton touches the skin while the wet elastie hair fibres stand off and keep air entangled. Silk or eotton is the coolest garb for summer, and flannel the best for damp, cold weather. Overclothing throws out of use and weakens the natural defensive meehanisms of the body against cold. Man has immense innate powers of withstanding cold, evolved in his long struggle with Nature. Exeessive exposure to eold produces loeal death, or death of the whole body; but if a man survive exposure-e.g., after a shipwreek-he recovers, and does not 'suffer from such ills as are commonly attributed to chill. Darwin describes the inhabitants, ineluding mother and baby, of Tierra del Fuego standing in the cold sleet naked, but greased with fish oil, and they have to keep down the population to the food supply by infanticide. Babies, especially among the poorer classes, are generally overelothed and kept in too warm and stagnant atmospheres to the detriment of their vitality. This is a cause of the high mortality of infants in industrial towns. The amount of elothes worn by individuals depends much on habit. We can accustom ourselves to few or many clothes. The young and vigorous want few clothes, while the old, in whom the fires of life are weakening, want many. 



\section{$-x^{2}$}

\section{BOOK X}

\section{THE FUNCTIONS OF THE DUCTLESS GLANDS}

\section{CHAPTER LIX}

\section{INTERNAL SECRETIONS}

THE metabolism is greatly affected by what are known as the "internal secretions." In certain glands there is elaborated material which, instead of being discharged from the glands by a system of ducts as an "external" secretion, passes from the gland cells into the blood or lymph as an " internal secretion." Such may come from glands which have no system of ducts-e.g., the thyroid, suprarenal-or they may come from glands which are also provided with a system of ducts-e.g., pancreas, testes-and have therefore both an "cxternal " and an "internal" secretion.

Of late, researches have been extremely piolifie in this branch of physiology. So much is controversial that it is only possible to indicate what appear to be the characteristic functions of each glantl even these cannot be stated in a dogmatic manner.

With the evolution of the multicellular organism there takes place a differentiation of organs corresponding to a division of labour, and an interworking of these organs is established. It is hard to say, then, what are all the functions of any one organ, since an organ, in performing these, not only fulfils its own life, but aids the functions, growth, and nutrition of the other organs of the body. Thus, the blood carries the heat developed in one part from that part to another, and thereby affects the working of the body; it carries the hormones "gastrin" and "secretin," which provoke secretion of digestive juices; it carries urea from the liver, where it is formed, to the kidney, where it excites that organ to secretion. The musclez yield carbonic acid and other acids, which, going to the respiratory centre, control the respiration. The action of the secretions we are considering form part of this interworking system, and the keynote of their action is their interdependence on one another.

The whole body is bathed internally with tissue fluid or lymph, and it is necessary that this fluid colloidal complex contain $0^{\circ}$ have linked to it various salts in proper proportions, also a number of intemal secretions. The diminution or excess of any 
one of these secretions will alter the metabolic conditions of the body, sometimes in an anatolic, sometimes in a katabolic direction.
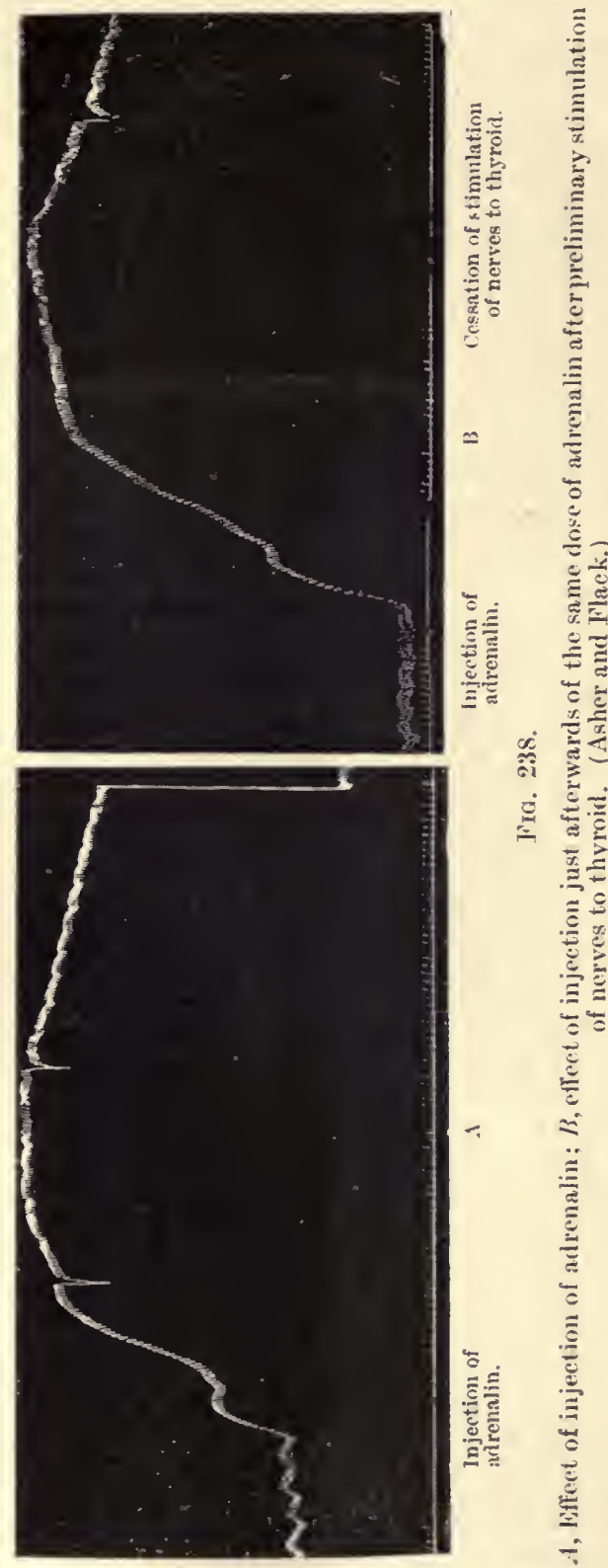

A possible example of this interdependence has already been referred to nunder carbohydrate metabolism. It is suggested that normally internal secretions from the pancreas, suprarenal, thyroid, and possibly other glands, help to regulate carbohydrato metabolism. When all these are present in correct amounts, the metabolism proceeds in orderly fashion. If, however, the balance be upset-for example, by too little of the pancreatic secretion being present-then the katabolism of sugar is deranged. Too much sugar therefore accumulates in the blood, and the condition of glycosuria results.

In the development of sexual characteristics a balance between various internal secretions is concerned-for example, the testes or ovary, and the suprarenal, thymus, and in the female possibly the thyroid gland. The action of these internal secretions has been investigated by rarious methods, chief of which are the extirpation, transplantation of tho gland, and the injection of gland extracts. Clinical cxperience has yielded raluable information.

Although the exact extent of the dependence of the action of the various internal secretions one on another is to a large extent conjcctural, the fact that such an interworking does take place has been experi- 
mentally demonstrated. The active principle of the suprarenal gland - adrenalin-produces certain well-known effects; for instance, it produces a rise of blood-pressure.

'From Fig. 238 it will be seen that, after the nerves to the thyroid gland have been stimulated, the injection of the same amount of adrenalin in the same time gives a greater rise of blood-pressure than it did before the stimulation of these nerves. This is the more remarkable, since a second injection of adrenalin, without stimulation of the thyroid nerves, normally gives a smaller rise of blood-pressure than before. This increased action of adrenalin is abolished if the thyroid be excised before its nerves are stimulated, but is obtained when extracts of the thyroid gland are injected into the animal just previously to the dose of adrenalin.

These experiments, then, give definite evidence of the interworking of the secretions named, and it is probable that the other secretions also interact, some in an anabolic and some in a katabolic direction.

The Organs of Generation-Testes.-The testis is generally regarderl as a "double" gland, consisting (1) of germinal cells, which form the external secretion or elements concerned in reproduction; (2) of interstitial cells, which form an internal secretion intimately connected with the general metabolism of the body and the acquisition of secondary male characteristics. The view that the interstitial cells act as a separate gland is not accepted by all authorities, but the following facts go to support the view. It is stated that, when the vasa deferent'a are tied, the germinal cells atrophy, but the interstitial cells persist. Exposure to $\mathbf{X}$ rays is known to render animals impotent, but does not change their secondary sexual characteristics. Histological examination in such cases shows that the generative cells are destroyed, but the interstitial cells are not damaged.

The effects of castration have long been known. As a direct local result the animal is rendered impotent, and the accessory sexual apparatus atrophies. Generally, the sexual development of the animal is arrested; the so-called secondary sexual characteristics are not acquired (Figs. 239, 240); the general metabolism is so affected that the animals tend to laziness and fatness. An excessive growth of bone is also frequently brought about. These results are due to the cutting off from the body of the internal secretions of the glands. It makes no difference whether the seminal vesicles be left or removed.

The results of transplantation experiments show that the secondary male characteristics may be developed by this means-e.g., the spurs and comb of the cock, or the large thumb of the male frog. If the testicle be transplanted in infancy, no spermatozoa develop, but the gland becomes composed of large quantities of interstitial cells, and tho sccondary male characteristics are acquired. It is stated that a testicle so transplanted into a female tends to give her body male characteristics.

The internal secretion of the testes has been held to exert marked influence upon the general health and mental and muscular activity of the individual. It is claimed that a substance-spermin $\left(\mathrm{C}_{5} \mathrm{H}_{11} \mathrm{~N}_{2}\right)$ 
-isolated from testicular extracts, may be used to increase neuromuscular activity and lessen fatigue, and thus be of service in old age, when the testes are failing to act. Some advertised patent medicines on the market claim on untrustworthy cvidence to give wonderful rejuvenating effects. They contain a certain amount of extract of boar's testicles.

Whether the general effect of excision or transplantation upon metabolism be so great as is supposed by some, it is obvious that upon the growing animal the effects are far-reaching. For instance, in man, not only are the secondary male characteristics called forth - e.g., the beard, the large larynx, etc.-but the growth of the skeleton is affected, so that it is possible to differentiate between the malc and female skeleton. It is probable that such secretions may be held partly responsible for the different outlook of man and of

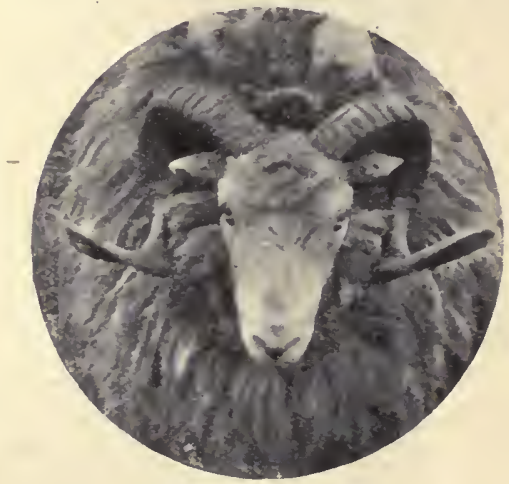

FiG. 239.-HERDWICK R.A. (NoRMaL).

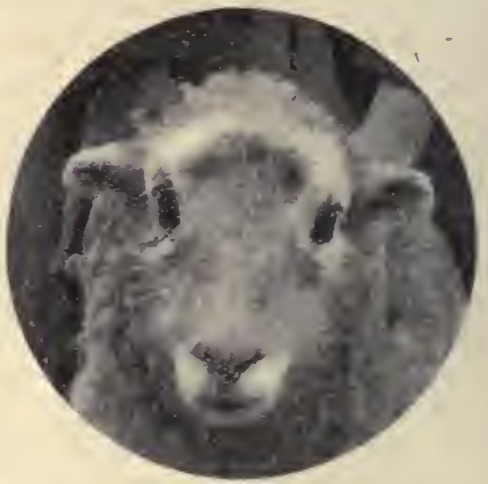

Fia. 240. HERDWICK WETHER without HoRss Visible.

The effect of castration on horn-growtl is well seen. (Marshall.)

woman upon life, the cerebral processes differing according as the nervous system is bathed with testicular internal secretion or with orarian internal secretion.

The Prostate Gland.-It is believed by some that an internal secretion of the prostate gland has an important action on the formation and ejaculation of spermatozoa. There is, however, little evidence for this riew. It is generally believed that the prostatic secretion aids the movements of the spermatozoa.

The Ovary.-The interstitial cells of the ovary play much the same part in the female as the interstitial testicular cells in the male. Extirpation of both ovaries in young girls prevents the onset of menstruation, and brings about notable alterations in their appearance. When the ovaries are removed after puberty, menstruation ceases and pregnancy is prevented. There follow some atrophy of the breasts, uterus, and vagina, and a tendency to obesity.

That these effects are not nerrous in origin, as was once believed, is shown by the fact that transplantation of the orary induces once 
more heat, or "vestrus," in spayed animals. Further, the injection of extracts of ovaries in an œestrus state, or the grafting of such into these animals, produces the signs of heat in them. It is also stated that as the result of transplantation of an ovary into the growing male the teats and breasts becomc enlarged, and may even form milk.

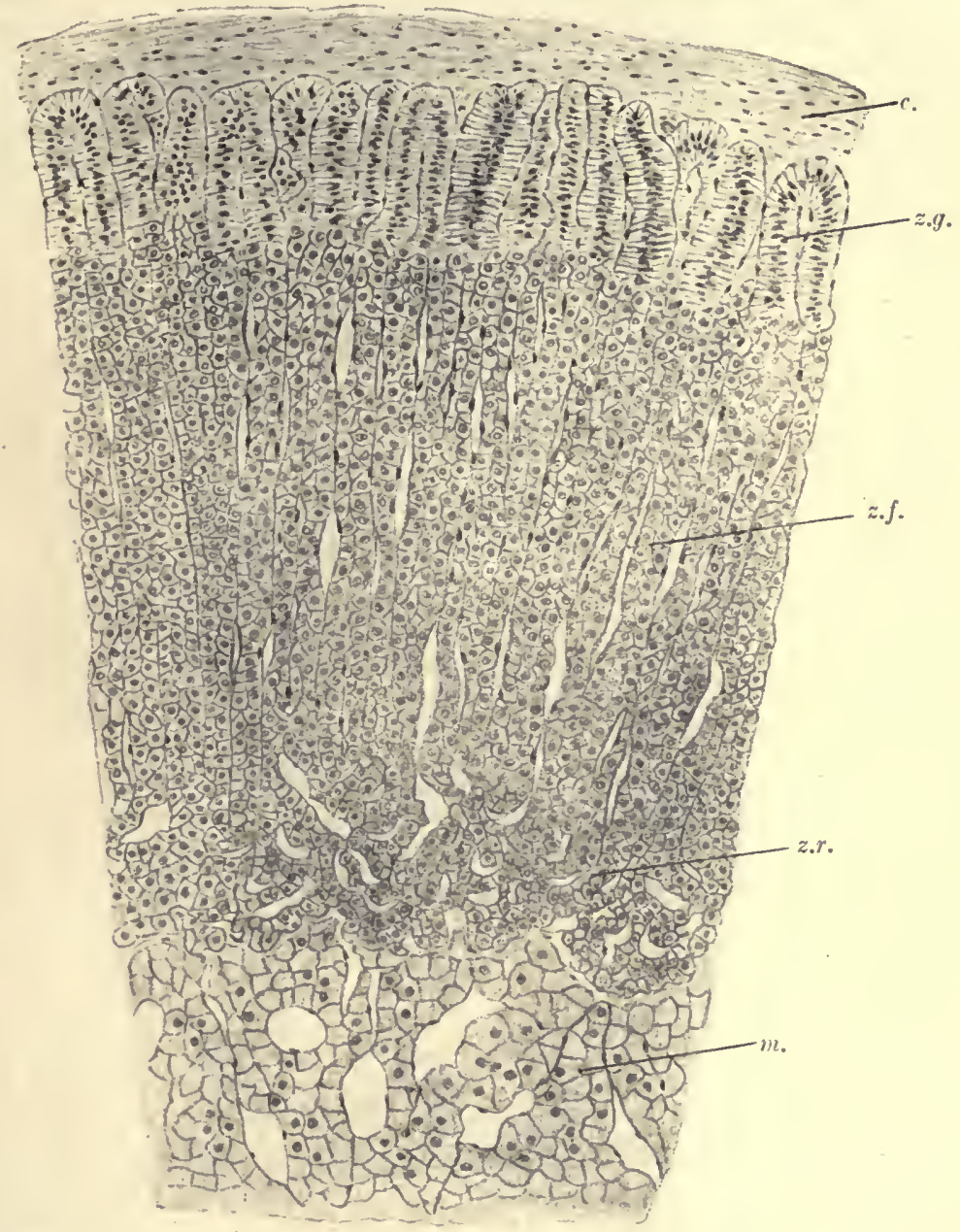

Fig. 241.-Sectiox through Supraresal Body of Dog showisg Zoxes of Cortex AxD Medulla. (Swale Vincent, drawn by Mrs. Thompson.)

$c$, Capsule; m., incdulla; z.f., zona fasciculata; z.g., zona glomerulosa; z.r., zona reticularis.

The corpus luteum, into which a Graafian follicle develops after discharge of the ovum, is believed to exert considerable influence by yielding an internal secretion. This controls the fixation of the orum 
within the uterus, probably by maintaining an increased metabolism of the uterus during the early stages of pregnancy. The corpus luteum also furnishes, in the initial stages of pregnancy, an internal secretion which stimulates development of the mammary gland.

The Suprarenal Bodies.-Each suprarenal gland consist of a cortex and a medulla. The cortex, the cclls of which are arranged in characteristic columnar fashion, is derived from the mesoblast associated with the urogenital system, the Wolffian ridge. The medulla is of nervous origin, and its cells are arranged in strands which cnmesh lacunar veins. Many of these cells are characterized by their affinity for chromium salts, and are therefore known as chromophil cells. Such chromophil cells are also found in the ganglia of the sympathetic

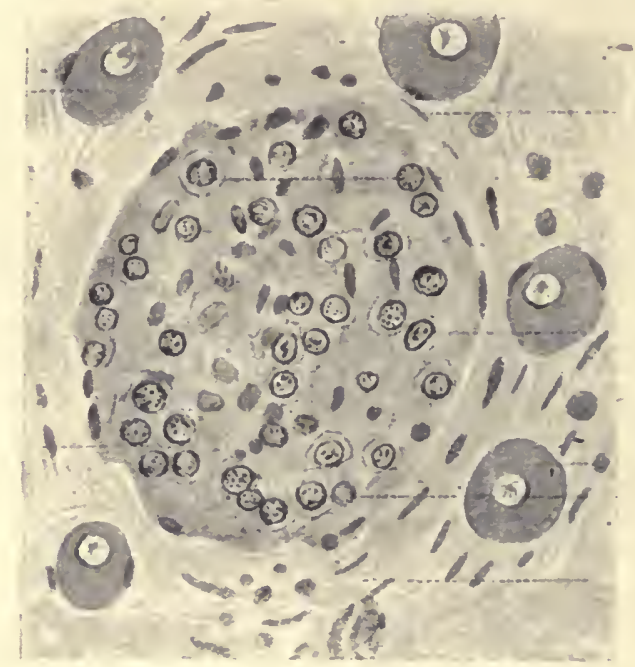

lig. 242.-Section throvgh a Group of Chronophil Cells is Ixferiur Cervical Gixaliox of a Dog. (Swale Vincent.)

nervous system, and in accessory suprarenal masses which are often found connected with the abdominal ganglia of this system (cf. Fig. 242).

Little is known concerning the function of the cortex of the suprarenal glands, but it has been suggested that it interacts with the sexual glands influencing the acquirement of sex characters. In many cases of sexual precocity an abnormal development of the cortex of the suprarenal has been found.

Far more evidence has been obtained as to the function of the medulla of the suprarenal, which appears to be of great importance to the organism. Addison long ago pointed out that the fatal disease known by his name was always attended by, and therefore probably due to, disease of the suprarenial glands. The disease is characterized by these symptoms: a gradual increasing muscular weakness, bronzing of the skin, and romiting. 
It has:been shown that extirpation of the suprarenal glands almost invariably causes death. The fatal resilt was at one time attributed to an accumulation of toxic bodies within the organism. Such toxic

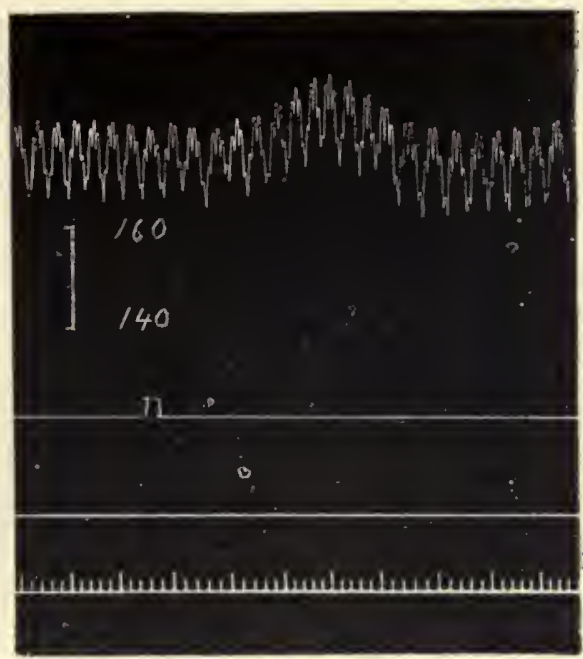

Fig. 243. - Showing Rise of Blood-pressure due to Release ue Pressule ux Suprarenal Veis. (From "Internal Seeretions," Swale Vincent.) (Gardner and Gunn.)

The vein has been compressed for some time and was released at point signalled.

bodies were believed to be destroyed by the glands. It is now known that the chief function of the suprarenal medulla is to furnish as an internal secretion an active principle-adrenalin. Adrenalin, as its structural formula shows-

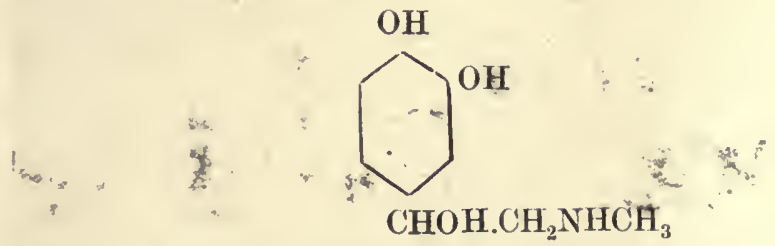

-is an aromatic body nearly allied to tyrosin, and is probably derived from tyrosin.

The best-known function of adrenalin is its power to induce constriction of the smooth muscle of the arterioles, and thereby cause a rise of arterial pressure (Fig. 238, A, B). The supply of adrenalin to the blood is under the control of the splanchnic nerves. If these be stimulated the arterial pressure is raised, but not after extirpation of the suprarenals (Fig. 245).

This is only one of the functions of adrenalin, for an intravenous injection of adrenalin acts upon all smooth muscle supplied by the 
sympathetic system, and in every case produces the same effects as does excitation of the sympathetic nerves (see Figs. 246, 247). It is probable that this action is manifested through the "receptive substance"

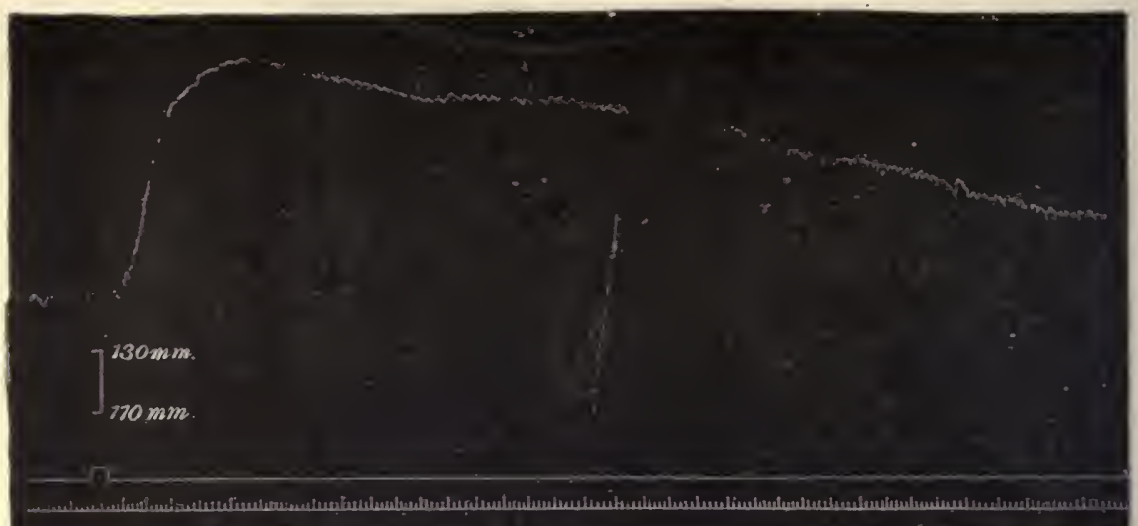

Fig. 244.-Tracisg showixg Effect on Carotid Pressure of Axesthetized Dog by INTrayenous Injection at Sigxal of ax Extract from the ChromoPHIL Bodifs of Three DOGs.

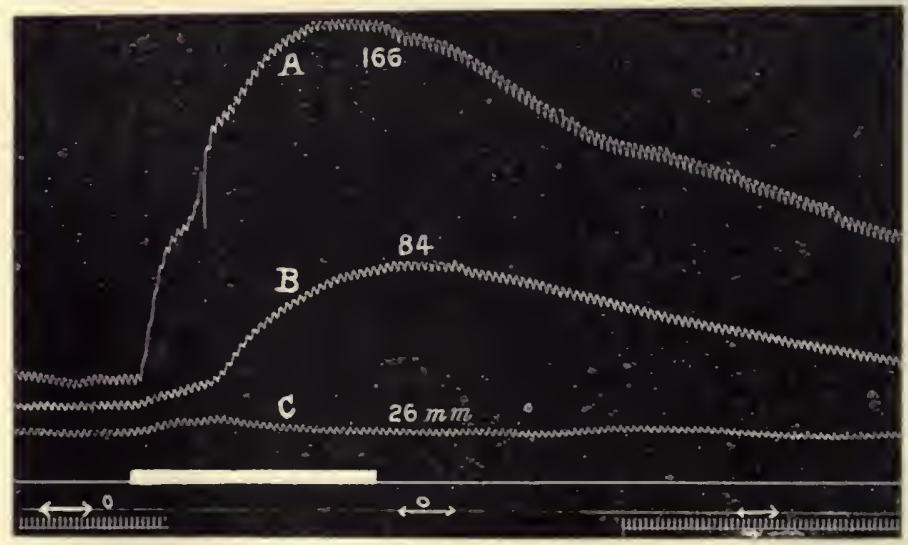

Fig. 245.-Pithed Aximal. (T. R, Elliott.)

A Effect of stimulation of both splanchnic nerves; $118 \mathrm{~nm} . \mathrm{Hg}$ rice of pressurc. $B$, Ditto, after removal of intestines; $48 \mathrm{~mm}$. risc of pressurc. $C$, Ditto, after removal of suprarenals; no risc of pressure.

which effects the union between the sympathetic nerve fibre and the smooth muscle. This receptive substance depends for its action upon the integrity of the muscle rather than upon the integrity of the nervo 
fibre, as is shown by the fact that, after the sympathetic nerves have been cut and allowed to degenerate, the receptive substance is still capable of responding to adrenalin. There is evidence that adrenalin acts in conjunction with the internal secretion of the thyroid; also with that of the pancreas, and possibly other internal secretions.

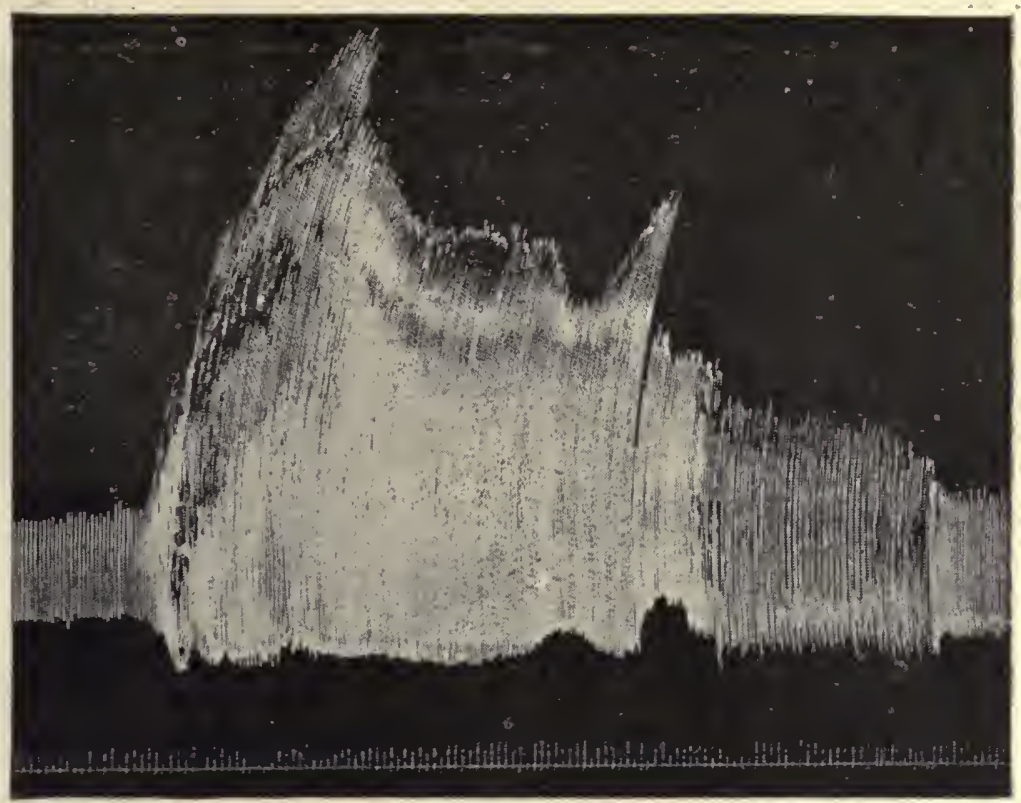

Fig. 246.-Record of Movemext of Isolated Rabit's Heart during Perfusiox With Rixger's Solutiox, Showixg EfFect of ixtroducing Adrenalin (1 ix 100,000 ) ixto Circulating Fluid for a Period of Thirty Seconds. (Dixon.).

The heart is greatly accelerated and the force of beat increased, corresponding to a. stimulation of the sympathetic nerves to the heart.

The Pancreas. - The pancreas is an example of a gland which affords both an external and an internal secretion. The internal secretion of the pancreas is believed to play a part in the regulation of carbohydrate metabolism, to be necessary for the primary stage in the oxidation of sugar within the body (p. 430). Possibly it also plays a part in regulating the glycogenic function of the liver.

It is believed by many that this internal secretion is afforded by the islets of Langerhans (Fig. 248); which may be looked upon as a separate gland included within the pancreas. The islets vary in size in different animals. In certain teleostean fishes the islct matcrial is largely separate from the gland which forms the external digestive secretion. Some have regarded the islets as the exhausted acini of the pancreas. It has, however, been recently shown that the 
exhausted acini stain quite differently from islet tissue. By other authorities the islets are looked upon as rudimentary pancreatic cells, but the evidence for this cannot be considered satisfactory.

The Function of the Thyroid and Parathyroids.-The thyroid gland lies in front of the trachea, and consists of two lobes, each about 2 inches long and 1 inch wide, joined by an isthmus. The para-

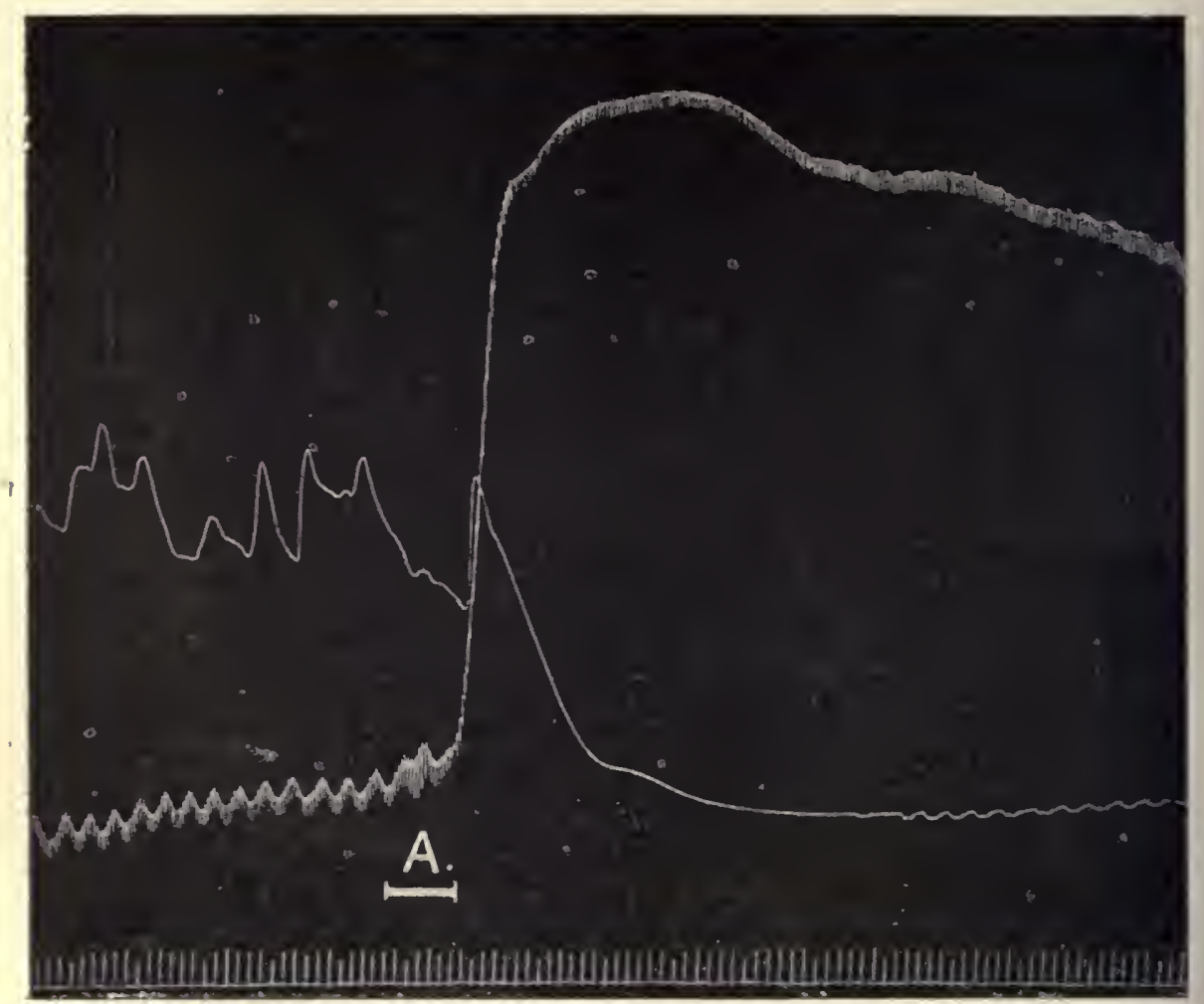

Fig. 247.-Record of Arterial Pressurf axd Ixtestixal Movemexts ix Cat. (Dixon.)

At A, 1 c.c. of 1 in 20,660 edrenalin was injected into a vein. The arterial pressure rises, the intestinal movements are inhibited, both effects corresponding to stimulation of the sympathetic nerves.

thyroids in mammals are small oval bodies 6 to 7 millimetres in length, . 3 to 4 millimetres in breadth, 1.5 to 2 millimetres in thickness. They are usually stated to be four in number, and varying in position in different species of animals.

The thyroid develops as a median endodermal downgrowth from the tongue; to this the lateral lobes from the fourth cleft are added. A considerable portion of the adult lateral lobes are derired, however, 


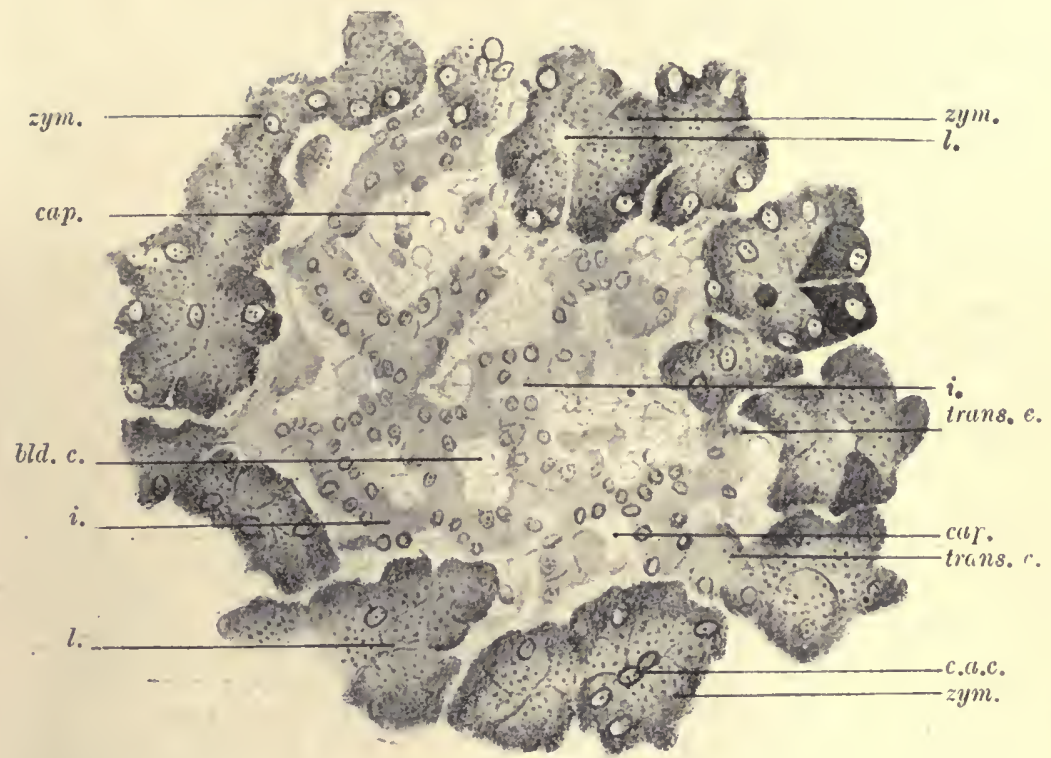

Fig. 243.-Isegi of Lixaerhanj from Splenic Exd of Paxcreas of Dog.

(Vincent and Thompson, drawn by Mrs. F. D. Thompson.)

bld. c., Red blood-corpassles; c.a.c., central acinar cells of pancreas proper; cap., blood eapillaries; $i$., islet of Langerhan ; $l$., lumen; trans. $c$., transitional cells; zym., zymogenous tissue.

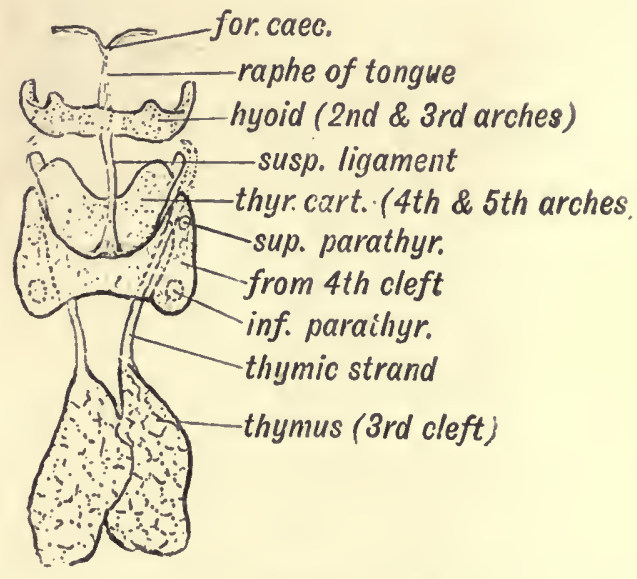

Fig. 249.-Diagran showixg Developmest of the Thyrom and Thymos. (Keith.) Tho three parts of the thyroid body are indicated by a stippled lis e; tho position. of the parathyroids on the posterior aspect of the lateral parts is indicated. 
from the median portion (Fig. 249). The cells first form networks of solid cords. These separate into solid masses, within which lumina may appear. The mature gland consists of rounded closed spaces or vesicles filicd with a colloid material, and by a single layer of low

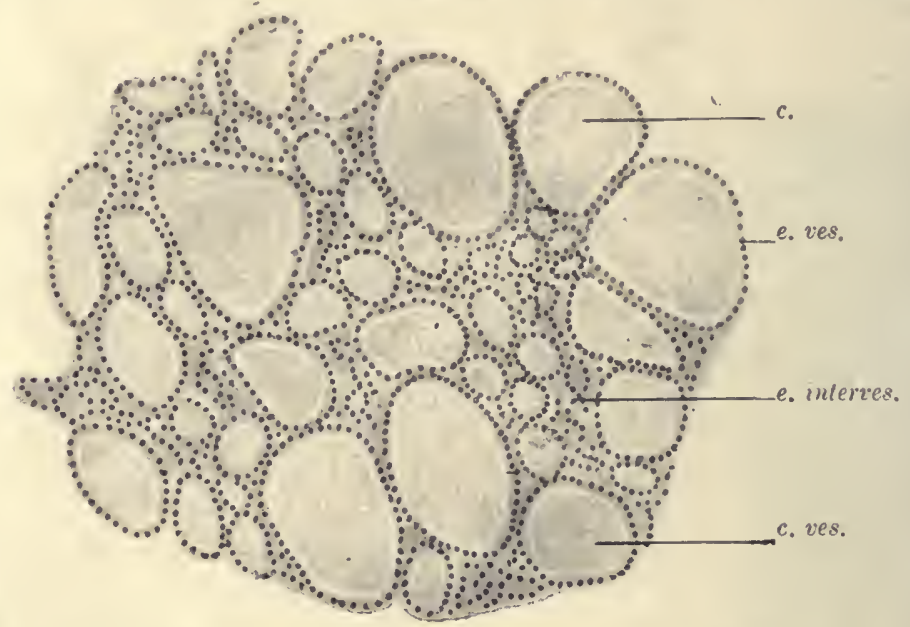

Fig. 250.-Thyroid of Normal Dog. $\times 120$. (Swale Vincent.)

c., Colloid; e. ves., epithelium lining vesicles; e. interves., epithelial intervesicular tissue; $c$. ves., colloid vesicle.

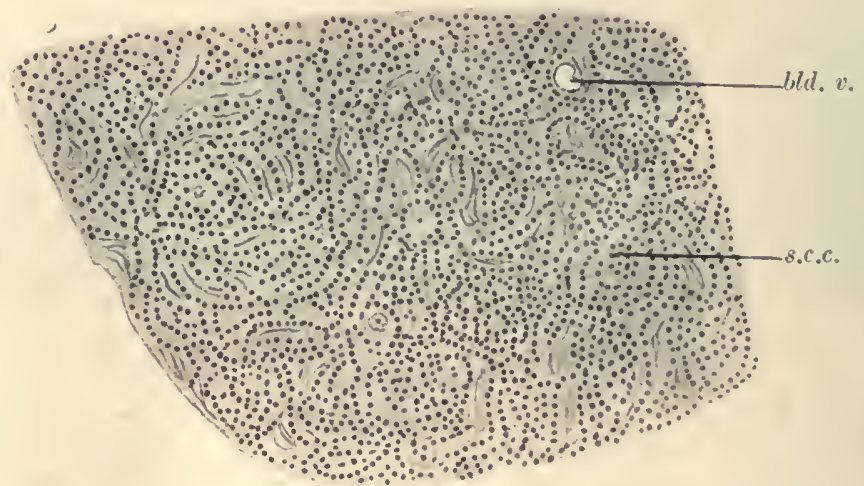

Fio, 2jl.-Parathrom of Normal Dog. $\times$ 120. (Swale Vincent.) s.c.c., solid columns of cells; bl.v., blood vessel.

columuar cells (Fig. 250). The vesicles are separated by connective tissue. which carries the bloodvessels and nerves, with which the gland is most plenteously supplied. The parathyroids are built up of closely packed polygonal cells divided up by connective-tissue septa into areas of rarious shapes (Fig. 251). 
There is a considerable divergence of opinion as to whether the thyroids and parathyroids are one and the same tissue, or whether they are quite distinct glands with markedly different functions. According to the first view, the two tissues are cssentially the same, and all grades from normal thyroid to normal parathyroid tissue may be found when the glands of a scries of different animals are studied. The difference in appearance is to be attributed to the presence of colloid. After excision of the thyroid colloid appears in the parathyroid (Fig. 252).

Devclopmentally, the parathyroids arise from the third and fourth gill clefts. the thyroid from a median remnant in the ventral wall of the embryonic pharynx. These glands arise at different times, and come therefore only secondarily into relation with each other.

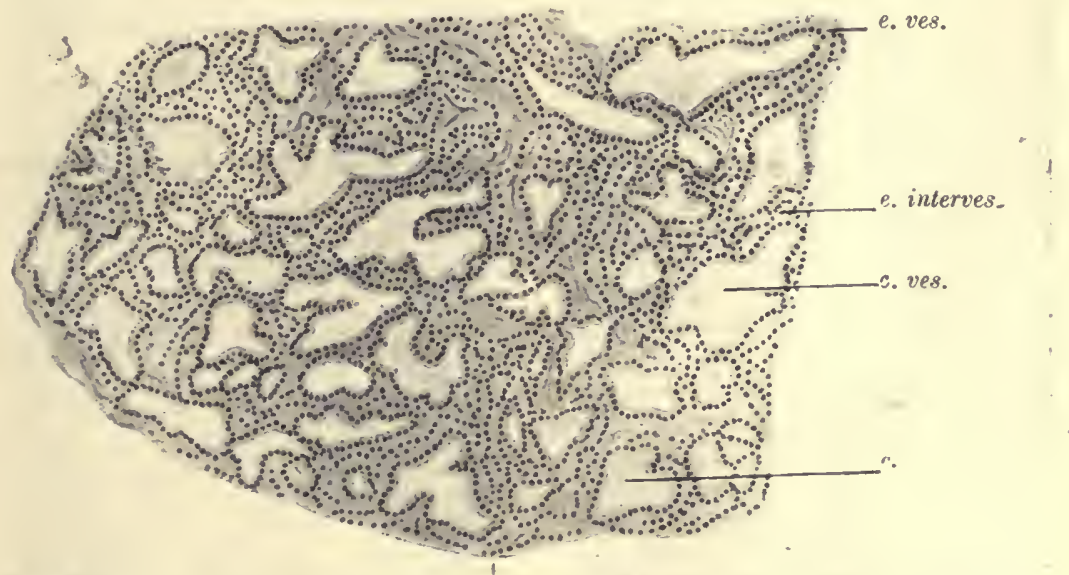

Fig. 252.- Parathyoid of a Dog EightY-Three Dals after Thyolinectoms. showise Vesicles, Some of Which contais Colloid. (Swale Vincent.)

c. res., Colloid vesicle; e. ves., epithclium of colloid vesicles; e. interces., intervesicular epithelial cells.

Attention was first drawn to the function of the thyroid (including the parathiroid) by clinical observations. In certain districts the gland enlarges in adults, forming what is known as a "goitre." This appears to be due to an infection through the drinking-water of the district of the alimentary tract by a living organism. Goitre has been experimentally produced by drinking the residue filtcred from such water, and cured by the taking of thymol. Goitre is very localized, hence the name "Derbyshire neck." "The thrroid cnlargement is. pathological in nature, and often entails a deficiency of thyroid function. The children of mothers suffering from such a deficicncy of thyroid function suffer from a condition known as "cretinism." Such endemic cretinism is common in Switzerland, and in the central and Gilgit valleys of India. It varies with the prevalence of the "endemic goitre." The "cretinism" is cluc to toxic agencies acting upon the thyroid and parathyroids of the nuborn. 
There are in general two types of cretins, the myxœdematous and the nervous. The nervous type, met with chiefly in India, are generally deaf and dumb. The upper limbs often assume a position of right-angled flexion, with the thumb drawn into the palm and the fingers elosed over it. The lower limbs exhibit a "knoek-kneed" spasticity. These cretins suffer from convulsive movements of the head, nystagmus, internal squint, and idioey.

The myxoedematous type shows marked interferenee with the growth of the skeleton, leading to a stunted, pot-bellied appearance. There is usually a marked lack of mental efficiency, a ehild of twelve

$\Lambda$

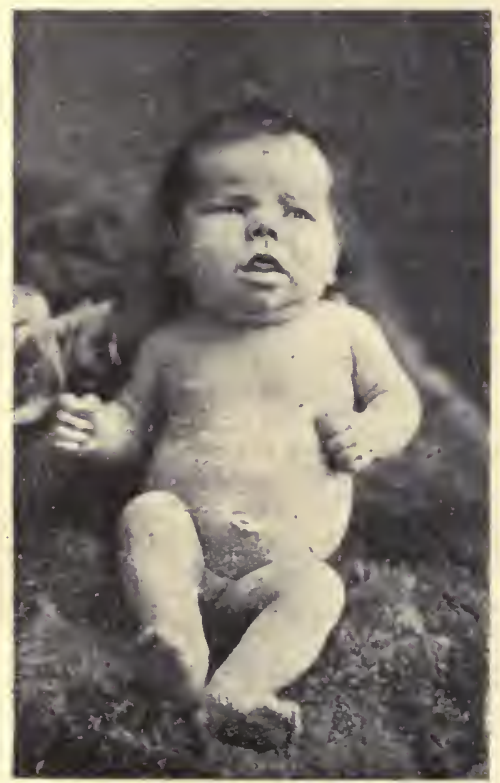

I

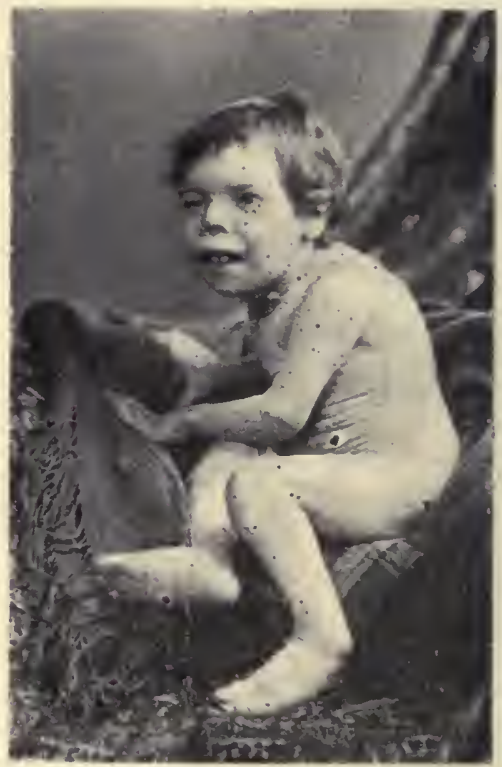

Fia. 253.-Nun-Gortrous Cretins. (Photographs kinäly lent by I). Robert Hutchison.)

to sixteen having the intelligence of a child of two or three. The appearance remains childish throughout life. Often fatty tumours make their appearanee in the region of the eollar-bone.

When thyroid deficiency first manifests itself in the adult, the effeets upon growth are naturally absent. A gradual swelling of the skin sets in, frequently aceompanied by nervous disorders, sueh as headaehe, languor, eonvulsions, mental disturbances, dulness, drowsiness, or even hallucinations. Tho skin beeomes wrinkled, dry and rough, swollen generally, but with a " solid œdema,". henee the name "myxoedema" (mueous cedema). The swelling is at first most noticeable on the face (see Fig. 254). The hair beeomes scanty, the scaly, dry and scaly. The teeth often beeome carious. 
Cretins and cases of myxœdema show marked improvement when fed upon thyroid gland. It was noticed that a condition- " cachexia thyreopriva"-similar to myxœdema was induced when the goitrous thyroid was removed by operation; hence it became customary always to leave a piece of thyroid tissue.

In contrast to the condition due to lack of thyroid activity is that known as "exophthalmic goitre," or "Graves' disease" (Fig. 255). In this disease the thyroid is generally enlarged and overactive. This "overaction" manifests itself in "nervous" symptoms-exophthalmos and tachycardia. On account of the nervous symptoms,

B
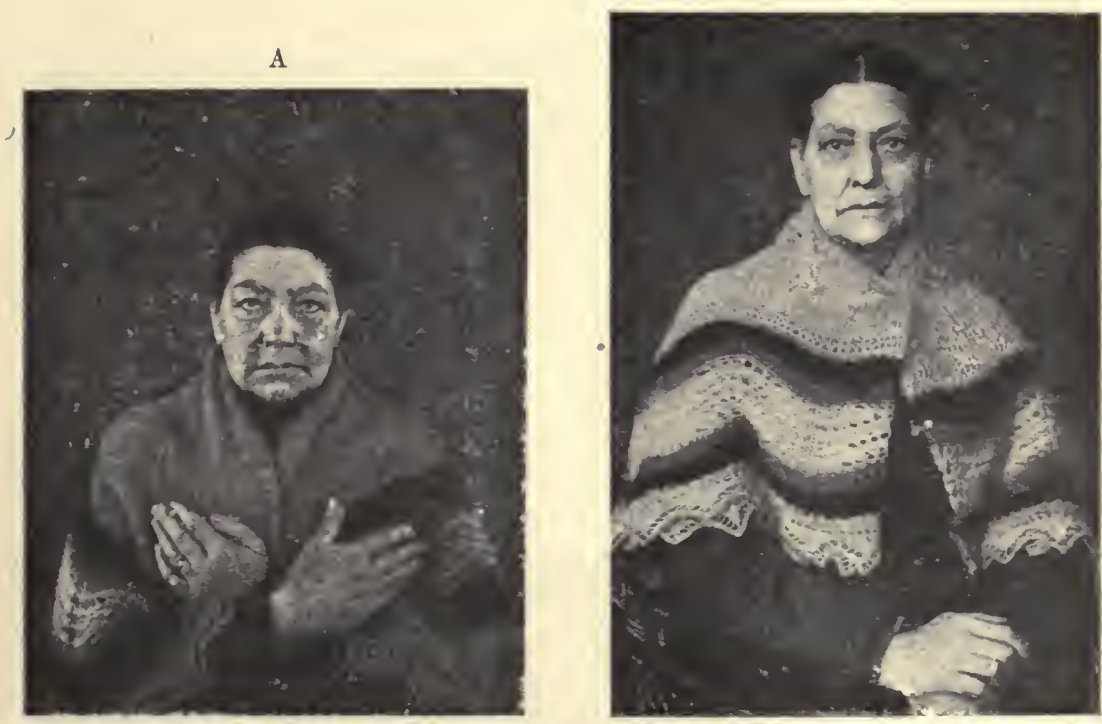

Fig. 254.-Typical Case of Mrxeedema. (Photographs kindly lent by Dr. Robert Hutchison.)

$A$, Before treatment; $B$, after treatment.

the disease has been regarded by some as primarily a lesion of the sympathetic nervous system, and not of the thyroid gland. A possible explanation of this may be that many of the symptoms are due to the increased action of adrenalin upon sympathetic nerve endings, this increase being due to the exccssive thyroid sccretion (cf. p. 519).

The results of extirpation expcriments, on the whole, support clinical observation. There is, however, much contradiction in the cridence, owing to the fact that extirpation of the thyroid and of the parathyroids produces different effects in different species of animal. It is difficult to produce all the symptoms of myxœedema as a result of thyroid deficiency; possibly, therefore, some othcr factors come into 
this disease. By those who believe that thyroid and parathyroid are glands with different functions it is claimed that extirpation of the thyroid produces symptoms akin to myxœdema, with sometimes a

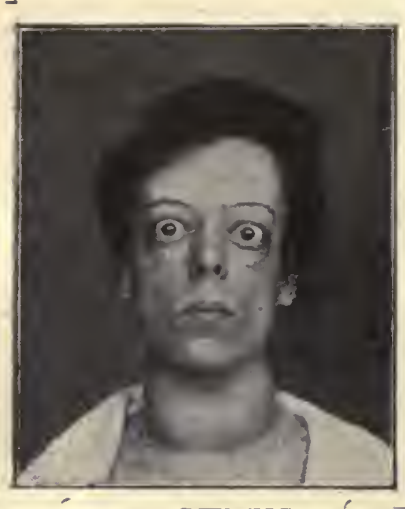

Fig. 25J.-A Trpical Case of ExophthaLMic GoITRE Ix A Youxg Womax.

(From "Index of Differential Diagnosis," J. Wright and Sons,'Ltd.) to show that this is not the case. The true secretion passes into the blood when the"nerves (the superior laryngeal) [to the 'gland are

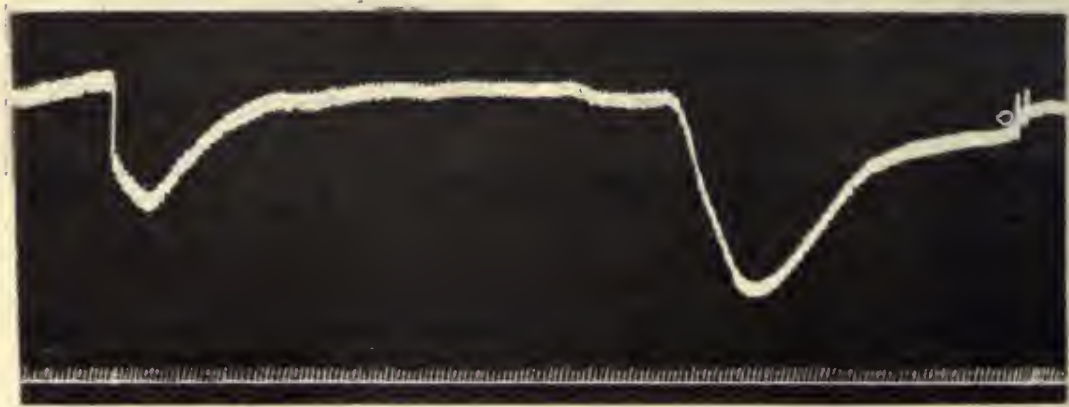
" slow death; while extirpation of the parathyroids produces the nervous symptoms of tetany - convulsions and a quick death.

The evidence in favour of and against these views is very conflicting. Undoubtedly, in some cascs the removal of the thyroid produces the "myxodematous," and of the parathyroids the ". nerrous" syndrome; but in some cases thyroid icmoval produces in addition the nervous symptoms, or these alone; while extirpation of the parathyroid, instead of producing the nervous symptoms of tetany, calls forth " cachexia," or deficient metabolism of myxœedema.

A substance rich in iodine has been isolated from the thyroid, called iodothyrin or thyreo-iodine. The active part of the colloidal protein secretion of the thyroid is often stated to be this substance. Recent evidence, however, tends (the superior laryngeal)'Tto the gland are
(the suto 
thyroid extract. For example, if the depressor nerve be stimulated before and after excitation of the thyroid nerves (or injestion of thyroid extract), the fall of blood-pressure is greater in the second case (Fig. 256). Likewise, if adrenalin be injected, the rise of bloodpressure is greater in the second case (Fig. 238).

The injection of any of the commercial preparations of thyroid extract produces these effects, but not the separated product, "iodothyrin." As to the exact chemical nature of the active body, nothing definite is known. Its iodine content, no doubt, is of great importance, but is not the sole factor.

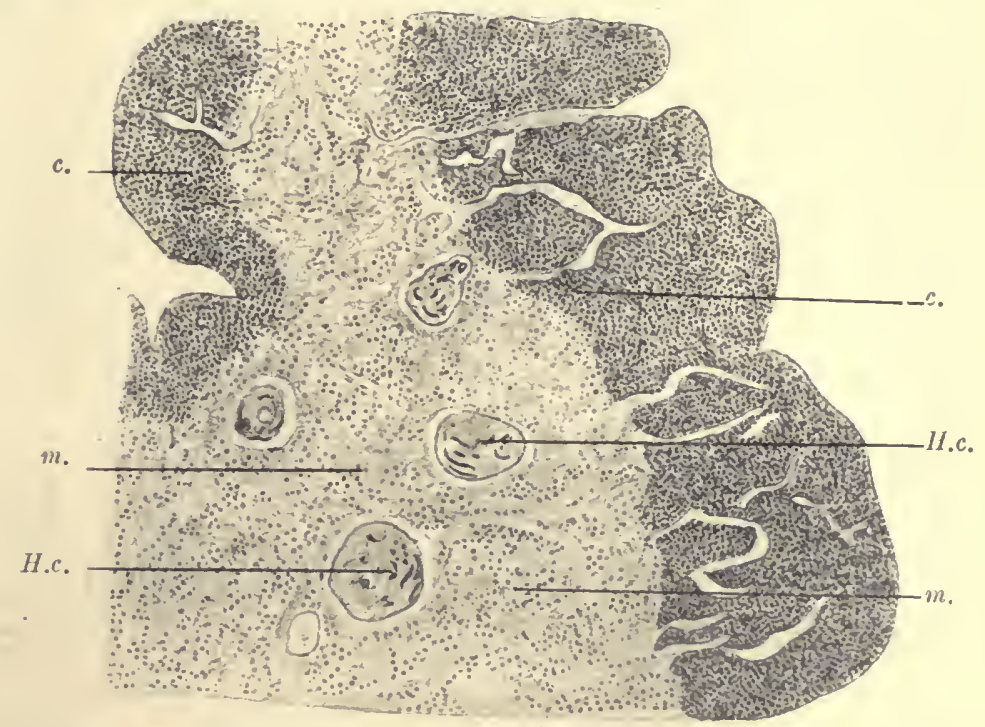

Fig. 257.-Portiox of Thymus Gland of a Monkey. Low Power. (From Swale Vincent, drawn by Mrs. Thompson.)

c., Cortex; H.c., Hassal's concentric corpuseles; m., medulla.

The Carotid Body is a minute structure situated at the bifurcation of the common carotid artery. It is richly supplied with nerrous elements, and probably belongs to the group of chromophil tissues, with a function akin to that of the medulla of the suprarenal gland.

The Thymus Gland.--In its development, the thymus gland arises from the gill-clefts, and may be apparently entodermal or ectodermal in origin, or both (Fig. 257). In man and the rabbit it is entodermal, in the mole it is ectodermal, in the guinea-pig and pig it has a dual origin. At birth it weighs about $\frac{1}{2}$ onnce, and is relatively a large organ. It increases in size and weight for some years after birth, probably until puberty, and then atrophies slowly.

It is subdivided by connective tissue into lobes, and each of these is made up of several lobules, which are dirided into a darker cortex 
and a pale medulla. All the lobules in each half of the thymus are attached to a cord of medullary substance, as may be seen if the organ is pulled apart. The thymus resembles in structure a lymphatic gland, but germinal centres are absent, and there is nothing to correspond with a lymph sinus. The cortex is crowded with lymphocytes, and is very vascular. The medulla is more open in texture, and is characterized by the presence of the concentric corpuscles of Hassall.
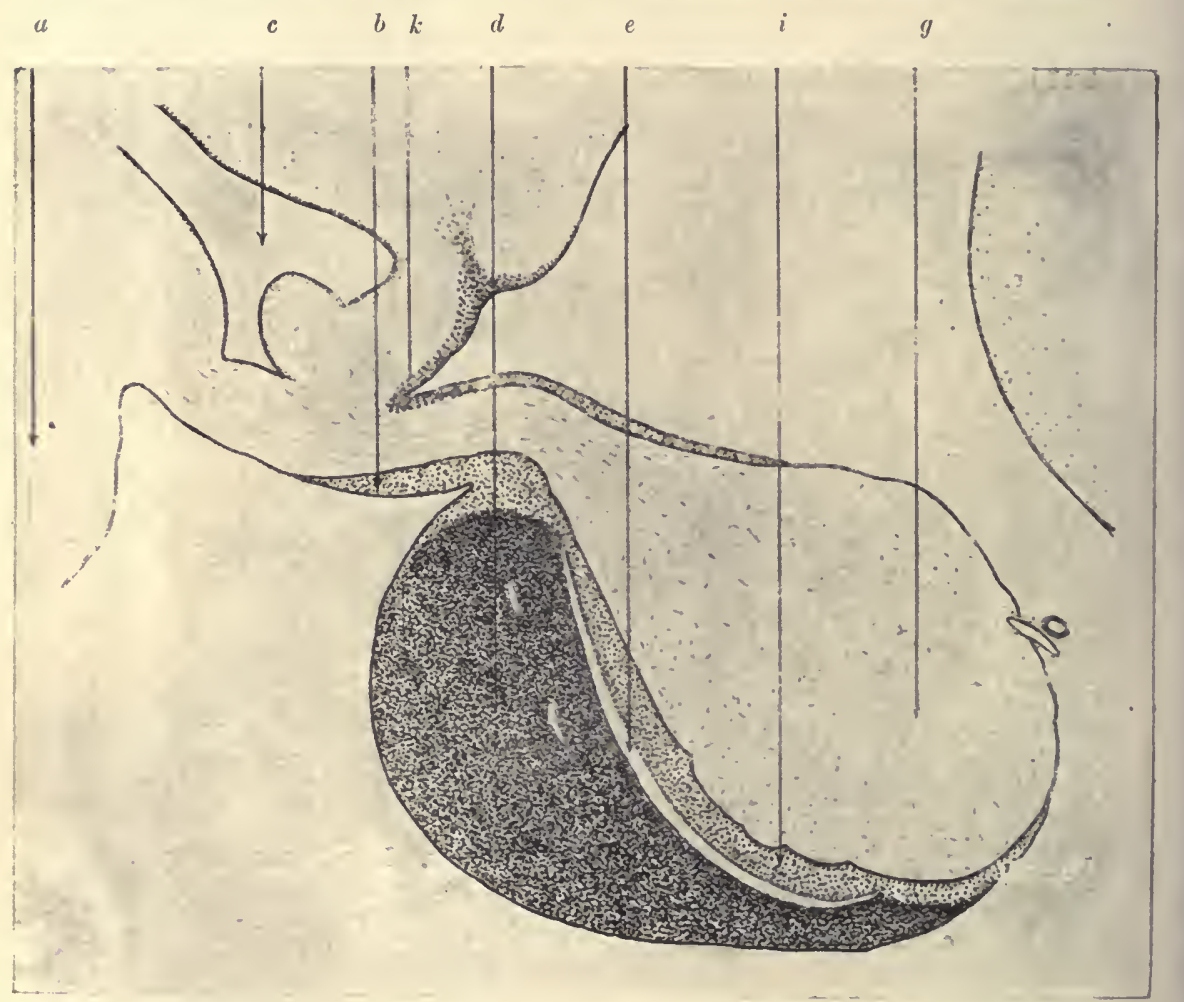

Fig. 258.-Mesial Sagital Sectiox throvgh the Pituitary Body of ax Adult MONKEY. (Herring, from Quarterly Journal of Experimental Physiology.)

$a$, Optic chiasma; $b$, tongne-like process of pars intermedia ; $c$, third ventricle; $d$, anterior lobe ; $e$, epithelial cleft of posterior lobe; $k$, epithelium of pars intermedia extending over and into adjacent brain substance. The dark shading indicates anterior lobe proper; the lighter shading shows the position of the epithelium of pars intermedia ; $g$, nerrons substance of posterior lobe; $i$, epithelial investment.

These are generally regarded as degenerated products of entodermal epithelium. Some anthorities maintain that the thymic cells are not true lymphocytes, but are of entodermal origin.

The Function of the Thymus.-By virtue of its lymphatic tissue, the thymus gives origin to the lymphocytes of the blood, and possibly 
also plays some part in the purin metabolism of the body. In some hibernating animals it also acts as a storehouse of fat. It has long been known to butchers and others that the thymus persists in castrated animals, and atrophies with the onset of puberty in the intact animal. It has been shown, also, that the atrophy is accelerated should the bull be used for breeding purposes or the unspayed heifer become pregnant. It is also suggested that the extirpation of the thymus interferes with the growth of the skeleton. Rickets has been attri-
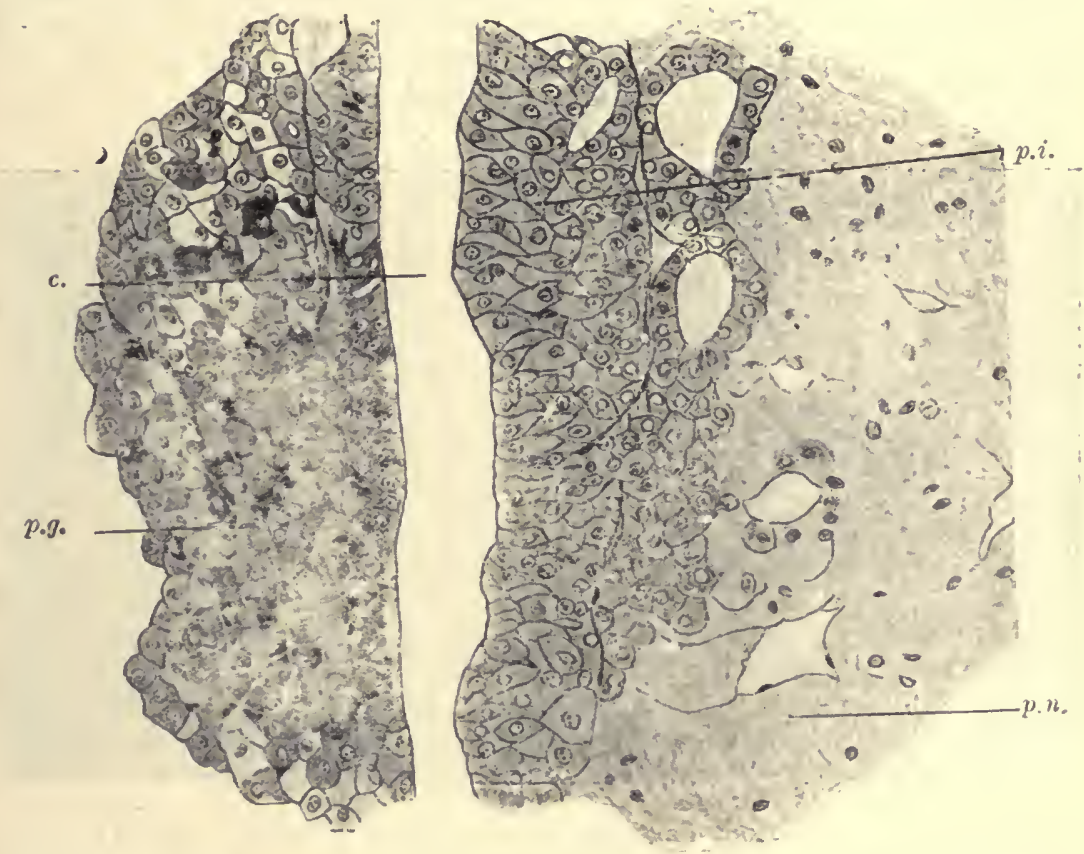

Fig. 259.-Section through Portions of Pituitary Bodr of Dog, showing Glandular and Nervous Portions axd the Pars Ixternedia. (Swale Vineent, drawn by Mrs. Thompson.)

$c$, Cleft in glandular portion between glandular portion proper and pars intermedia; p.g., glandular portion showing three kinds of eells; $p . i$. , pars intermedia; $p . n$. , nervous portion.

buted to disease of this organ. The evidence in favour of such views is not conclusive. It has recently been stated that tadpoles fed on thyroid became diminutive frogs, while those fed on thymus became giants.

The Pituitary Body.-The pituitary body consists of three portions: (1) The anterior, (2) the intermediary, (3) the posterior lobes. The anterior and intermediary lobes have a common origin from a portion of the glandular epithelium of the stomodæum, known as Rathke's pouch. Quite early a differentiation between the two portions takes 
place. The intermediate part is closely adhercnt to the wall of the posterior lobe; its cells are clear, and tend to form colloid; the anterior portion is formed of columns of granular cells separated by bloodchannels (Fig. 258).

The posterior lobe, or infundibulum, is nervous in origin. It is an invagination of the portion of the developing brain known as the thalamencephalon. In some animals, such as the cat, it retains its central cavity; in others this becomes entirely obliterated. Early in development it becomes closely associated with cells of the pars intermedia, so that eventually the posterior lobe becomes a composite structure of intermediary and nervous epithelia-a mass of gland cells, neuroglial cells, and nerve fibres (Fig. 259).

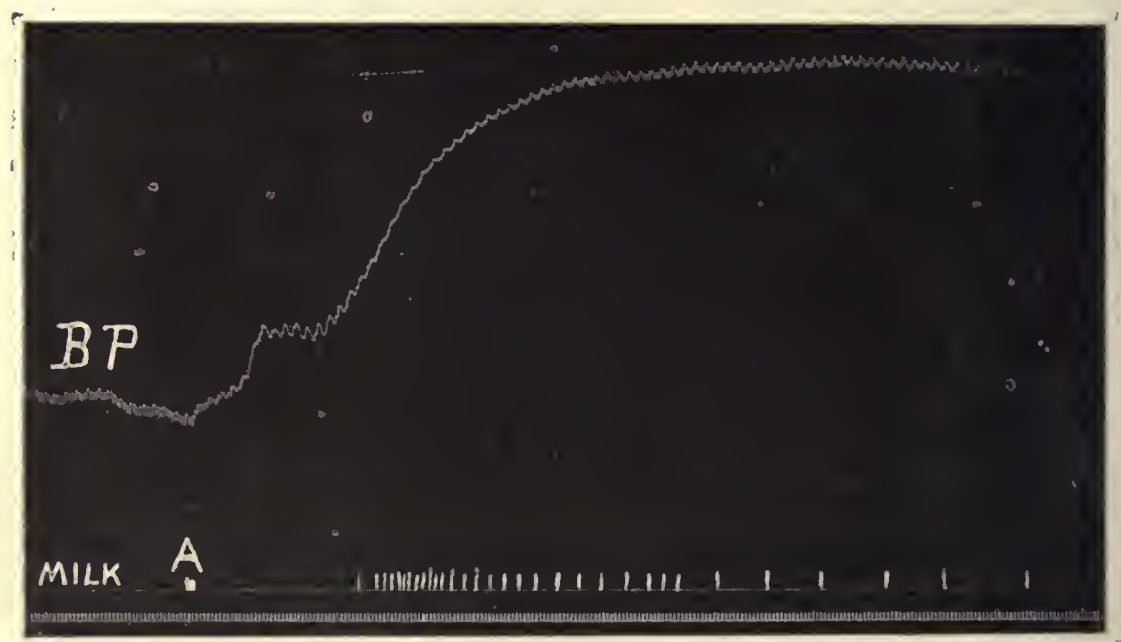

Fig. 260.-Record of Blood-Pressure and Milk-Flow in Drops from Oxe Nipple of a Lactativg Cat. (Dixon.)

At $A$ pituitary extract was injected.

The Functions of the Pituitary Body. - The chief evidence of the physiological action of the pituitary gland is obtained from clinical experience and pathological findings, and from observations upon the effects which follow injection or feeding extracts of the gland. Owing to its anatomical position, it is difficult to obtain satisfactory evidence by means of extirpation. It has been claimed that the removal of the gland invariably causes death, often in thirty-six hours. Many such deaths are undoubtedly due to post-operative shock. Recently, skilled experimenters have succeeded in keeping animals alive several months after removal of the pituitary. The effects claimed to result from its removal are thus contradictory.

The injection of extract of the anterior lobe is without physiological action. Injection of extract of the intermediary and posterior lobe 
causes a rise of blood-pressure, accompanied by marked diuresis. A second injection generally does not affect the arterial pressurè, but the diuretic action is still marked-in fact, the active substance may be regarded as the most potent diuretic known. The smooth muscle of the pupil and uterus is also affected by pituitary extract, and it is used by clinicians to promote contractions of the uteris.

The contractions of the bladder are also increased in the dog and rabbit by the injection of pituitary extract. The excitability of the pelvic nerve supplying this viscus is increased, while that of the

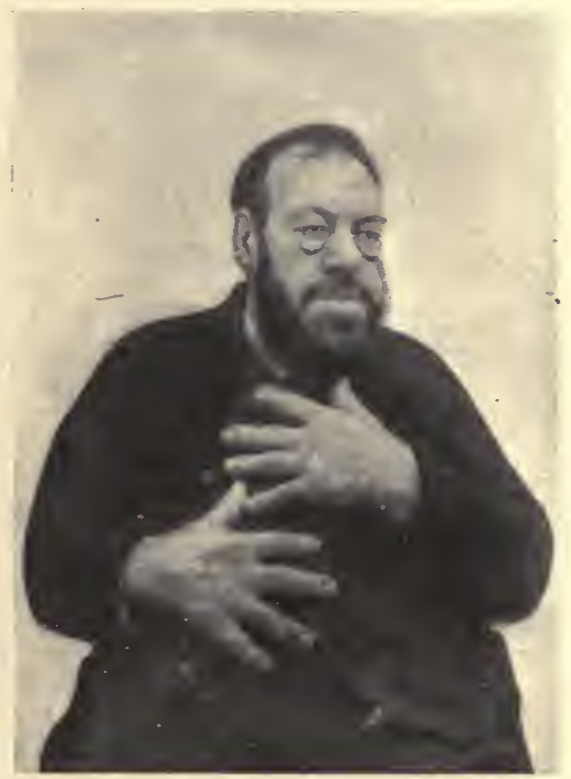

F1G. 261.-A Case of Acromegaly. (Photograph kindly lent by Dr. T. Reuell Atkinson.)

The head measurements are-Circumference, $25 \frac{1}{2}$ inches; from forehead to chin, 11 inches; from nape of neck to chin, over nose, 25 inches. The lower jaw protrudes $1 \frac{1}{2}$ inches in front of the upper. The two hands measure 6 inches across the root of the thumb and 5 inches across the root of the fingers. When closed the hand measures 151 inches round.

hypogastric nerves is unaltered. Pituitary extract has no action upon other organs supplied by the autonomic system, such as the heart and the salivary glands; an action upon the intestine is doubtful The extract of the infundibulum is also a powerful galactagogue. and the active substance can be obtained from both the intermediary and posterior lobes (Fig. 260). The active substance is probably derived from both lobes, but chiefly from the intermediary lobes. Its exact nature is unknown, but its action is closely allied to bodies of the digitalis series, and it apparently acts dircetly upon muscle rather than upon the nerve or nervous connections. 
The function of the anterior lobe is suggested by clinical records of the results which accompany its disease; thus the affection known as "acromegaly" is associated with a hypertrophy of the anterior lobe. This affection begins about puberty, and is characterized by progressive increase in the size of the face and limbs (Fig. 261). The disease runs a slow course to a fatal issue. Some attribute the development of giants to hypertrophy of this organ. Excessive growth is also found associated with hypertrophy of the cortex of the suprarenal gland, and there may be some internal secretion common to the two glands which stimulates growth.

It has been suggested that the pituitary gland plays a part in regulating the calcium metabolism of the body. The evidence of this is inconclusive. It is also claimed that the posterior lobe helps to regulate carbohydrate metabolism, and that after its removal an increased tolerance to carbohydrate is induced.

There is some evidence that the pituitary interacts with the thyroid and sexual glands, especially the ovary. Thus, after extirpation of the thyroid the pituitary is said to show an increase of colloid material, while during pregnancy, it is stated that the pituitary increases in size - an effect also produced by removal of the ovaries in women and in animals.

The Pineal Body is a small pinkish body situated on the dorsal aspect of the brain, underneath the posterior region of the corpus callosum. It consists chiefly of neuroglial and secretory cells, made up into a number of follicles often resembling. adenoid tissue. There is little physiological evidence of any internal secretion of this body. Clinically, it is suggested that disease of the gland is associated in some cases with obesity, in others with abnormal sexual development and gigantism. 


\section{BOOK XI}

\section{THE TISSUE (OF MOTION}

\section{CHAPTER LX \\ THE MECHANISM OF MOVEMENT}

A UNICELlular organism, such as the amceba, moves by the flowing of its protoplasm in one or other direetion, the rest of the cell flowing after the protrusion or pseudopodium. In other unicellular forms, the development of one or more cilia or flagella enables the organism to move, often with a relatively high rate of speed. In the multicellular organizations this function of motion has been assigned to special cells. Such cells are termed the musele cells. The fully specialized muscle eell eontracts with a force, rapidity, and frequency, far beyond the power of less specialized protoplasm. Its greater power and efficiency have been acquired by the development within the protoplasm of long, and exceedingly slender, contraetile structuresthe muscle fibrils-lying parallel to the long axis of the cell and in the direction of motion. Fibrils vary in the degree of differentiation. Some exhibit a marked cross-striation, and are termed striated; others are unstriated. The fibril affords the essential mechanism of rapid motion.

In the higher animals the prineiple of loeomotion is that the moving part first becomes angular in shape, and then straightens itself out against some resisting substance; the prineiple being the same whether the organ of loeomotion be fin, wing, or leg. Force exerted against resisting water, air, or earth, and reaeting in proportion to the resistance, imparts movement to the body of the animal.

The principle of the lever is applied in the various movements of the body. There are three kinds or orders of levers (see Fig. 262). (1) The first order, in which the fulcrum $(F)$ lies between the force applied $(P)$ and the resistance overcome $(W)$, as exemplified in a pair of scissors; $(2)$ the second order, in which resistance $(W)$ lies between the fulcrum $(F)$ and the foree applied $(P)-e . g$. , in nuterackers; $(3)$ the third order, in whieh the force $(P)$ lies between the fulcrum $(F)$ and the resistance $(W)$, as, for example, in a pair of sugar-tongs. By means of levers the power applied may be augmented or the range and rapidity of movement increased. In the body the power is usually 
applied to the bones in such a way that the latter is the case. In order that the muscles may be packed within the skin and the body made as compact as possible, the.power is applied at the insertion of the muscles close to the joints or fulcra. All three orders of levers are exemplified in the body. Belonging to the first order is the movement by which the head, jointed to the top of the spine, is nodded backwards and forwards by the neck muscles (Fig. 262, I.). Another example is the straightening movement of the forearm by the action of the triceps muscle. The power is applied at the insertion of the muscle into the ulna just above the clbow-joint, which is the fulcrum, and the resistance (the weight of the forearm) lies beyond. Range and rapidity of movement of the hand are here gained at the expense of power.

The second order of lever is seen in the movement by which the calf muscles raise the body on tiptoe (Fig. 262, II.). The power is applied at the back of the heel, the fulcrum is at the toes, and the weight of the body falls on the foot at the ankle-joint. Here power is gained at the expense of range of movement.

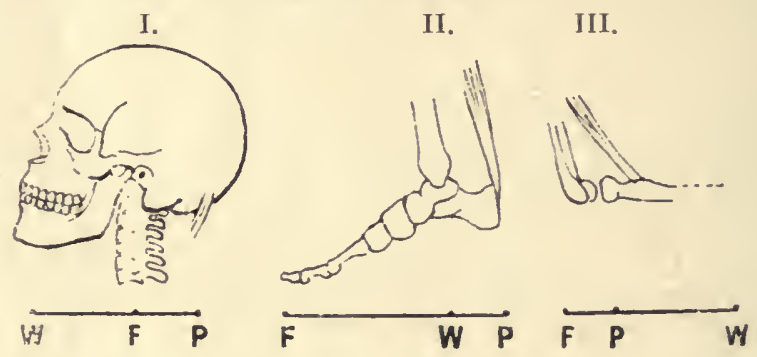

I'i 2 . 262.-Diagray of Three Kinds of Lever Actios.

$F$, Fulcrum; $P$, power; $W$, weight.

I. The head is tilted back by neck muscles.

II. The toes rest on the ground, and the body is raised by the calf muscles. III. The forearm is bent up by the biceps muscle.

Examples of the third order of lever are numcrous. In the bending of the forearm on the upper arm (Fig. 262, III.), the power is applied by the biceps musclc to the radius just below the clbow-joint, the fulcrum is at the elbow, and the resistance is the weight of the forearm and hand. The bending and the straightening of the leg at the knec-joint are other examples. In all these movements rapidity and range of movement are obtained at the expense of power.

We usually employ that combination of levers which require the least muscular effort. It is easier to carry a wcight with the arm hanging fully extended, when it is slung to the shoulder by the bones and tendons, and the muscles have only to maintain the grip of the fingers, than it is to carry it with the arm bent, and much greater muscular effort. Man is constantly devising methods to sare the cxpenditure of muscular effort. Thus a drayman pulls a beer-barrel up an inclined plane, which bcars a large part of the weight. 
The muscular work done by a man is calculated by multiplying the weight lifted by the height of the lift. Thus 2 kilogrammes lifted through 2 metres gives 4 kilogramme-metres of work. When a. man runs upstairs very fast he may, in lifting his body, do seventy times more work in a minute than a narvy does in the same time who is steadily shovelling up earth. The man, however, is spent at the end of such an effort; the navry can continue to shovel leisurelyfor hours.

Excess either of rate of work or of load will lessen efficiency and diminish output. Scientific management determines the suitable rate and load for each kind of labour.

The Erect Posture.-With the assumption of the erect posture one of the chief functions of the system of levers of the human body. became that of maintaining the centre of gravity of the body within: the body. Since the centre of gravity of a body always tends to take up the lowest possible position, it must lie over the base of support, otherwise the body will topple over.

A dead man cannot, without support, be made to stand in the erect posture. If a man standing erect faints, the head tends to fall forward on the chest, the trunk forwards at the hip-joints, and the whole body forwards over the ankle-joints. Although the body is balanced by muscular action, the weight of the body is borne by the bones and ligaments, and thus fatigue is avoided. In the stork the bones of the leg can be so locked together to balance the body that the bird can sleep restfully standing on one leg. In man the maintenance of the erect posture is more of an effort, so that for this, as well as other reasons, he seeks rest in the recumbent posture.

The body is maintained erect by the following means:

The head is balanced by the muscles so as to rest on the top of the vertebral column. As the ecntre of gravity lies in front of the joint, the head tends to fall forwards in a sleepy man; the neck muscles must act to keep it from doing so. The vertebral column forms an elastic rod supporting the head and trunk; below it is fixed immovably to the broad pelvic basin, into which presses the weight of the abdominal organs. The centre of gravity of the body is situated near the front of the last lumbar vertebra. If a plummet-line could be dropped from the centre of gravity, the line would pass a little bchind the line which joins the two hip-joints. The trunk thus tends to fall backwards at the hip-joints; this is prevented by the strong ligament which passes from the pelvis to the femur across the front of each joint. Thus the joint is locked and the muscles passing from, the trunk to the thighs have simply to balance the body upon the heads of the thigh-bones. To do this but little effort is required. At the knee the plummet-line dropped from the centre of gravity would pass through a line joining the posterior parts of both joints. The weight of the upper part of the body thus presses upon the flat articular surfaces of the tibix. The great extensor muscles in front of the thigh prevent the knees from bending, and the body from falling backwards whenerer balance is disturbed. Owing to the check liga- 
ments which lock together the femur and the tibia, the knee can neither be overextended nor bent to one side. In a man standing at attention the plummet-line drawn from the centre of gravity passes in front of the line joining the two ankle-joints; the body is prevented from falling forwards by the action of the calf muscles. The weight of the body thus transmitted is borne by the spring of the arch of the foot; the balls of the toes and the heel rest upon the ground.

The centre of gravity of the body is always kept over the base of support by varying the attitude of the body. Thus a man stoops when carrying a child on his back, but walks erect if it be on his shoulders. If the child be on his arm he leans back, and to the other side. In most of the Herculean feats of strength exhibited on the stage, the strong man supports enormous weights, not by muscular effort, but by so placing his body that the bones form pillars of support on which the weight rests.

In young children the centre of gravity is high, for the head is large and the small feet form but a narrow base. A slight push from behind brings the centre of gravity outside the base, and the child must move its feet quickly forward or fall. Thus the tiny child has many tumbles, for the brain has to learn by experience how to carry out rapidly the appropriate movements. The younger a child the more he tends to stand with his feet wide apart. The tottering old man also widens his base of support by using a staff.

The body is equilibrated by means of the proprioceptive mechanism of the body (see p. 654) and the co-ordinating influence of the cerebellum and the cerebrum.

Walking.-On standing on one foot the body is inclined to that side, so that the other leg is left free to move. In walking, one leg, say the right, is slightly bent at the knee and planted down in front of the other. The weight of the body is thrown on this leg, while the left leg, raised on the toes by the action of the calf muscles, forms a straight stiff rod. The left leg, by giving a push to the ground, next throws the body forwards. Thereupon the right leg strightens up, while the left, slightly bent at the knee, swings forward as a pendulum and comes down in front of the right. It is now the turn of the right leg to push off, and of the left leg to bear the weight of the body. The length and rapidity of the step in walking naturally depend on the length of leg. A duck waddles, a hen ruus. The longer a pendulum the slower it swings. Thus it is difficult for a long and a short man to kecp pace, and a regiment camnot maintain a regular march when the men are fatigued, for each soldier then falls into his own natural swing.

Running.-In rmming, both legs momentarily leave the ground. The muscles act far more powerfully than in walking. The body is raised and thrust forward, not only by the contraction of the calf muscles of the hind-leg, but by the powerful action of the extensors of the thigh, which straighten the bent knee of the forward leg. The body thus propelled forwards leaves the ground, while the hind-leg 
swings forward as a pendulum for the next thrust. The exact changes which take place during rapid movement have been analyzed by taking a succession of instantaneous photographs on a film. Such a film passed at a correct speed through the cinematograph lantern faithfully reproduces the movement; the different photographs succeed each other so rapidly that they fuse together and give the sensation of a moving object. In real life we only get a fused impression of the position of a moving animal. If an artist drew a horse in some of the attitudes revealed by instantaneous photography it would be deemed unnatural.

The position of the feet in walking and rumning can be well seen in the footprints made in the firm, wet sand left by the receding tide. 


\section{CHAPTER LXI}

\section{THE STRUCTURE AND PHYSICAL PROPERTIES OF MUSCLE .}

The Structure of Muscle.-In the vertebrate animals, the muscles derelop from cells which line the primitive colom or body cavity. These cells become invaginated as buds from the coelomic surface, to form a row of myomeres along exch side of the animal. These flatten, so as to form two plates, the inner of which gives rise to con nective tissue, the outer to the striated muscle of the body. The cells which are about to become inuscle (the sarcoblasts) undergo a great lengthening, and show signs of nuclear activity. The division of the nucleus is amitotic-there is no division of the cell body-and many nuclei are formed in one cell.

At this stage fibrils, or, as they are sometimes termed; sarcostyles, gradually appear in the sarcoplasm of the sarcoblast, faint at first, but gradually becoming more distinct. They first appear on the inner side of the cell, gradually pushing the nuclei to the outer side. The formation of fibrils goes on until each cell appears a mass of fibrils, with but little interibrillar sarcoplasm. Each fibril is composed of two kinds of substance, differentiated by staining and refractive power. One substance-the isotropic-does not stain readily and is singly refractile: the other-the anisotropic substance-stains readily and is doubly refractile. Each substance is deposited alternately with the other at regular intervals in the fibril. Thus, after suitable treatment the fibril may be broken up into sarcomeres, or sarcous elements. The lines of cleavage takc place in the isotropic substance; each sarcomere consists of a portion of anisotropic substance, with half a portion of isotropic substance on either side of it. As all the sarcous elements of the neighbouring fibrils are in perfect alignment-isotropic with isotropic, anisotropic with anisotropic-the general effect is to give the fibres that cross-striped appearance from which cross-striated muscle gets its name.

The difference in the degree of differentiation of muscle is well seen in the human body. The musculature of the trunk and limbs (the skelctal muscles) differs from that of such internal organs as the hladder, intestines, uterus (smooth or non-striated muscle), and also from that of the heart (cardiac muscle).

Voluntary or striated muscle is composed of a number of separate fibres joined together to form the muscle. The character and number of these fibres varies considerably with different muscles. In some thev are palc and delicate-so-called pale or white muscle: in others 
they are coarser and coloured red by the presence of a pigment-ired muscle. In general, it is found that this difference corresponds to a difference in function. The white muscles are those which are called upon to perform quick movements over short periods, whereas red inuscles are those which perform less quick movements, but for longer periods of time, and often without any marked intervals of rest. Thus, the leg muscles of the chicken are red, the breast muscles white; on the other hand, the breast (flying) muscles of the wild-goose are red.

The length of the fibres also varies greatly with different muscles; from some muscles fibres 12 centimetres long have been obtained.
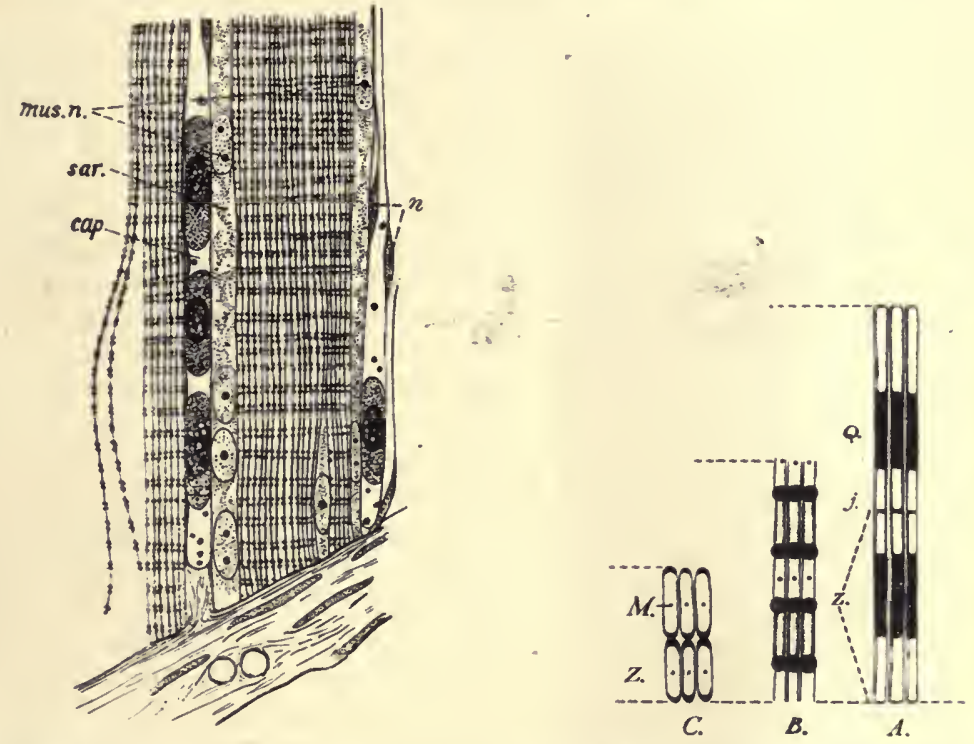

Fig. 263.-Longitudinal Section of a Piece of Muscle from the Sucker Cata. stonius. $\times 1000$. The Relations of the Dark and Light Elements during Contraction of the Fibril are shown is $A, B, C$. (After Dahlgren and Kepner.)

cap., Capillaries; sar., sarcoplasm; mus. $n_{.}$, muscle nuclei; $n_{.}$, connective tissue nuclei: $Q$, anisotropic material; $j$., non-staining isotropic material.

Each muscle fibre shows under the microscope longitudinal and transverse striations. The fibres are composed of groups of fibrils (sarcostyles), between which is a varying amount of clear, finely granulated protoplasm - the sarcoplasm. Some are rich in sarcostyles and poor in sarcoplasm; others are rich in sarcoplasm, and eontain relatively few sarcostyles. In this lies the difference between pale and red muscles. For example, the red soleus muscle of the rabbit contains much sarcoplasm; the pale gastrocnemius is composed mainly of sarcostyles. The sarcoplasm evidently affords material for sustained action to the sarcostyles, which are the contracting elements. 
1 Smooth Muscle.-A smooth muscle fibre develops from a single cell with a single nucleus. Such cells specialize in the embryo out of the mesenchyme. Fibrils are deposited within the cell, sometimes around the nucleus, sometimes to one side of it. In the latter case, the nucleus may appear on the side of the cell. The fibrils are homogeneous, and vary in number. There is a considerable amount of sarcoplasm in the smooth muscle fibres, which generally take the form of elongated spindles with thin tapering ends. Occasionally, as in the aorta of young mammals, the ends may be branched.

Cardiac Muscle.-The structure of cardiac muscle has been dealt with in the section on the circulatory system (1).122).

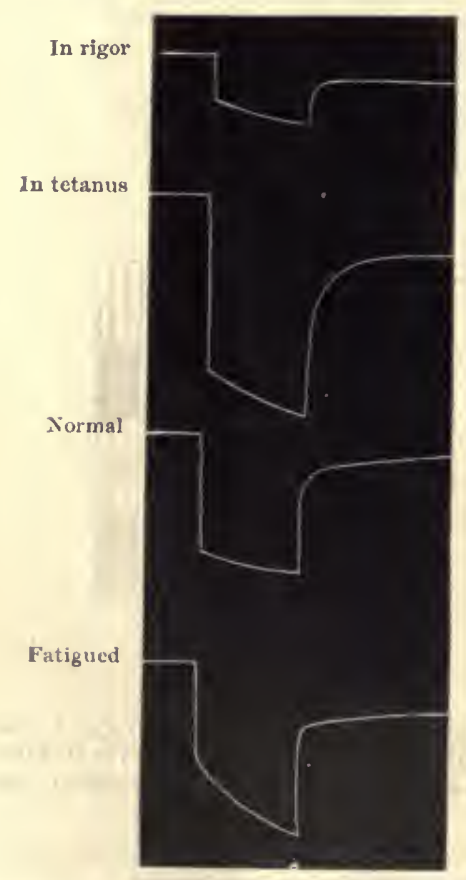

Fili. 264.-EXTENSIBILTT OF MUSCLE in Variods States. (Waller.)

Tested by 50 grammes applied for short periods.

The Physical Properties of Muscle. -In speaking of muscle, we generally mean striated muscle, since this is the kind of muscle which forms the flesh and has been most investigated. The living muscle fibre is semi-fluid and translucent. Its fluid nature has been shown by the fact that a nematode, worm has been observed to traverse it; and after the passage of the invader, the muscle substance to return to its previous ordered structure.

Muscle is very extensile and elastic. The former property is shown by the fact that but a small stretching force is requircd to change its shape, the latter by the fact that when this stretching force is taken off the muscle resumes its previous form. Living inuscle has a wide range of this elastic property; it requires a rery considerable force to overstep its limits. If a stretching force be applied suddenly and increased by equal increments, a living muscle extends most at first and then by less amounts till the limit of its extension withont rupture is reached. Conversely, on removing the extending force, the muscle returns at first quickly and then more slowly to its original form. Rubber and most inorganic bodies, such as metal rods, on the other hand, extend almost equally for each increment of the extending force, and return almost equally as the stretching force is removed. Dead muscle is less extensible and less elastic than living muscle (Fig. 264).

A contracted muscle is more extensible than a resting one. This gives us the paradox that, if - a muscle were loaded by a weight. 
greater than it could lift, it would actually lengthen during its stimulation.

The above properties are of great importance in the body. If a muscle were not readily extensible, the sudden contraction of one set of muscles would tend to rupture those muscles (the antagonizers) which perform the opposite action. Morcover, the contraction of a muscle acting through an elastic medium is more efficient than through a rigid medium. It is far less jerky in its effects. The simooth working of the various body movements and of the circulation depends greatly upon this elastic property. The muscles are kept in a slight state of tension, so that no time is lost in "hauling in the slack." The elastic property of the muscle insures its return to the normal state after any contraction has been performed. Again, if the contracting inuscle were not more extensible, there would always be the risk, when trying to lift a heavy weight, that the muscle would rupture either itself, or its tendon, or the bones to which it is attached. Of these three structures, the muscle is least often ruptured.

Muscle is also excitable or irritable - that is to say, it responds with a contraction to different forms of stimulation. A muscle may be stimulated directly or indirectly through its nerve. An excised muscle may be directly stimulated by any sudden change in its physical state-by mechanical, chemical, thermal, or electrical stimuli. Striking a muscle or pricking it causes its contraction; sudden heating or cooling of a muscle may cause it to contract. Among chemical excitants, we find that the application of such substances as ammonia, dilute acids, strong saline solutions, induce muscular contraction. Excitation follows any sudden alteration in the concentration of electrolytes in the fluid bathing the muscle fibrer.

In experimental work, the electrical method is most generally employed for purposes of stimulation, since it is convenient, easily graduated and less injurious to the tissues.* The source of the electroinotive force may be a Daniell or a Leclanchć cell. To make and break the current, a mercury or a spring key is used, preferably the latter. To protect the preparation from the current, a shortcircuiting key is used (the Du Bois-Reymond key). When shut, the current is short-circuited through the metal blocks, which are attached to a wooden or vulcanite base; when open, the current flows to the preparation to be excited.

Sometimes it is desired to reverse the direction of the current, or to shunt it into another preparation. For this purpose, special forms of keys are used. For making the actual stimulation of the preparation, electrodes are used. These may be made of needles insulated by a small piece of cork, and soldered to pieces of fine insulated conducting wire. Such ordinary metal electrodes tend to polarize, owing to the electrolysis which takes place in the tissue fluids at the point of application. For accurate work, thercfore, nonpolarizable electrodes arc required. A form commonly employed

* The stident is advicet to consult a practical manial for details of apparatus. 
consists of a smooth amalgamated zine rod dipping into a saturated solution of zinc sulphate contained in a U-tube. Into the other limb of the tube is inserted a glass flange carrying a plug of kaolin paste made up with physiological saline solution. The kaolin plug is pulled out to a point which serves as the electrode, or pieces of lamp-wick soaked in the paste may be employed to make the contact.

Electrical stimulation may bo made either with a constant current or with an induced current. With the former, the current from the cell or battery is led by a make-and-break key direct to the muscle preparation (Fig. 265). Stimulation is effected at the moment when the current is caused to flow (at make) (Fig. 266), or stopped from

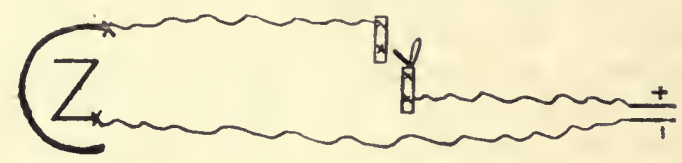

Fig. 265.-_Plax of the Úse of a Constant Currext to Stmulate.

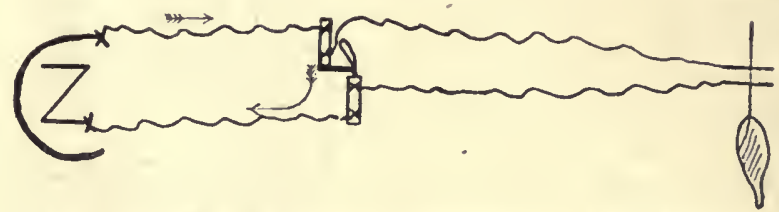

Fig. 266.--Circuit arraxged with Short-Circuiting Key: Key Shut. Openive KEY $=$ MaKE SHOCK.

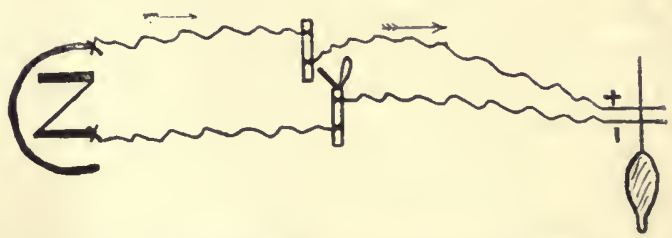

Fig. 267.-Circuit arranged with Short-Circuitixg Key: Kex Open. Closing KEY = BREAK SHOCK.

flowing through the preparation (at break) (Fig. 26\%). There is no sign of stimulation while the current is actually passing through the muscle, provided the current be not too strong. If the current be strong or the muscle injured, a long-continued contraction may take place both in frog and human muscle. When muscles are degenerating, it is found that the passage of even a relatively weak current may cause this prolonged contraction, sometimes termed "galvano-tonus."

The contraction which occurs at the make is stronger than the contraction at the break of the constant current. The make contraction starts from the kathode, the point where the electric current leaves the muscle; the break contraction starts from the anode, the 
point where the current enters the muscle. The alteration of concentration of electrolytes under the kathode heightens, while that under the anode depresses, excitability during the passage of the current. When the current is broken, the efferts are reversed (see p. 553).

To alter the strength of a constant curent, a piece of apparatus known as the rheocord is used. In its simplest form this consists of a wire wound to and fro across a board, with a terminal at either

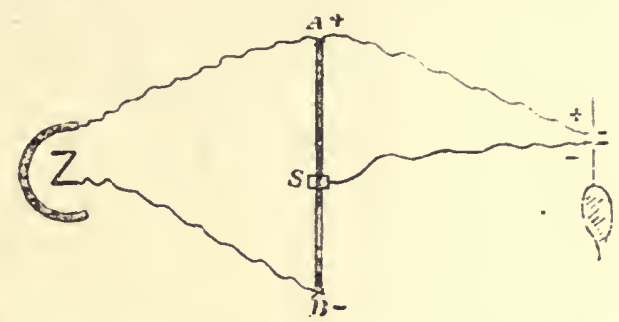

Fig. 268.-To illustrate the Prixciple of the Rheocord.

end and a movable contact or slider between them (Fig. 268). In use, the cell is connected to the two terminals $A, B$, and the preparation connected to the end $A$, at which the current enters, and to the slider $S$. The current from the cell can now pass either through the preparation or back along the wire of the rheocord. The amount which will pass in either direction is determined by the position of $S$. The fall of potential in the rheocord is from $A$ to $B$; therefore, when

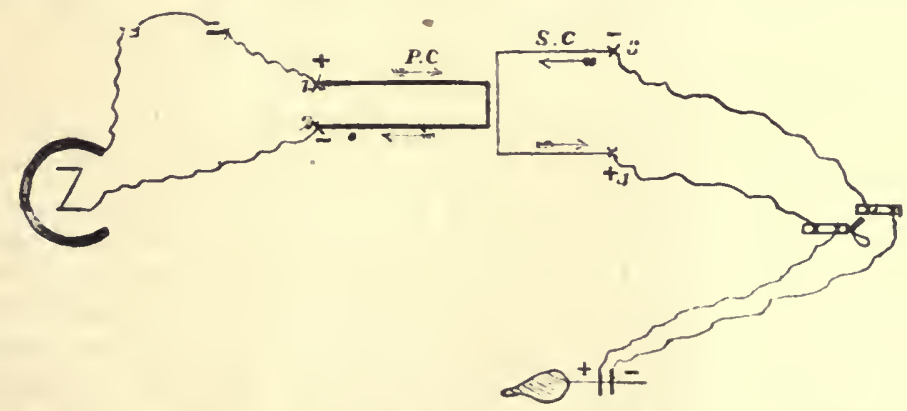

Fig. 269.-Diaghay of ax Indectios Coll axd its Coxiections.

$S$ is near to $A$, the fall of potential from $A$ to $S$ is small, and but little of the current will pass to the preparation. The amount of current, therefore, going to the preparation is directly proportional to the fall of potential between $A$ and $S$. It is also inversely proportiona! to the resistance of the circuit through the nerve. This resistance, howerer, need not be considered, since the resistance in the nervo is so many times greater than that caused by any change in the position of $S$. 
The constant current is not often employed, since it is of low electromotive force (E.M.F.), and, owing to its comparatively long duration, it tends to cause polarization of the tissues, due to the dissociation of electrolytes from the colloid of the muscle substance. The induced current is thercfore more convenient, since it has, as compared with the constant current, a comparatively high E.M.F., and, being of very short duration, does not induce so much polarization of the tissues for ordinary experiments it is practically nil.

The induction coil comprises two co:ls-the primary and the secondary. The primary coil is made up of a few turns of thick copper wire wound around an iron core. The secondary coil consists of a large number of turns of insulated fine copper wire. Each turn of wire in the primary coil induces an effect in every tum of the wire of the secondary coil. By this means, thereforc, the low E.M.F. of the current in the primary circuit is transformed into a current of high E.M.F. in the secondary circuit, the intensity of the current leing proportional to the number of turns of wire in each coil. It has been found that the E.M.F. of this current var:es-

1. Directly with the intensity of the change of current in the primary circuit. The greater the change, the greater the induction.

2. Directly as the rate of change. The more rapid the change, the greater the induction.

3. With the angle between the coils. When the secondary coil is at right angles, there is no induction. It is greatest when the wires are parallel to each other-i.e., in the ordinary position.

4. Inversely as the distance between the coils, being grcatest. when the secondary is completely over the primary coil.

The induced current is in the oppositc direction to that of the primary circuit at make, in the same direction at break.

When the induced current is employed for purposes of stimulation by means of single shocks, the current from the battery is led into the primary coil of the "induction coil" by means of the two. top binding screws. There is no direct connection of the muscle with the battery, this being placed in connection with the secondary coil of the apparatus, and protected from stimulation, except when wanted, by a short-circuiting key. A make-and-break key is placed in the rrimary circuit, and the current in the primary coil made to. induce an exciting current in the secondary coil of the apparatus, ther by closing the key (the make induced current) or by opening - The break induced current). An induction shock is produced cnly at make or brcak not while the current is flowing. The strength of the induced current may be adjusted by varying the distancebetween the primary and secondary coils. Gencrally speaking, an experiment is begun with the coils far apart, and the secondary coil then advanced until the stimulus kecomes effective (Fig. 269).

The ccntraction obtained from a muscle at the break of an induced current is strcnger than that caused by the make of the current. This is because there is at make a momentary self-induced current in the rrimary coil which is opposite in direction to that of the battery- 
current. At the break of the current, an extra current is also produced in the primary coil in the same direction as the battery current; but the primary circuit being broken, it cannot delay the rapidity of the fall of the battery current.

When rapidly induced shocks (50 to 100 per second) are required (the so-called faradic or tetanizing current), the primary circuit is rapidly made and broken by means of Wagner's hammer. The wires from the battery are connected to the two bottom screws of the primary coil (Fig. 270). It will be seen that the current passes, via the pillar $A$ and spring $H$, through the primary coil to the electro-magnet $E$. This becomes an electro-magnet, and pulls down the piece of steel on the spring $H$, and thus breaks the circuit. $E$ then, being no longer a magnet, releases the spring hammer, which flies back, and again completes the circuit; and so the process is repeated. Every time the hammer is attracted to the magnet the current is broken, and a break

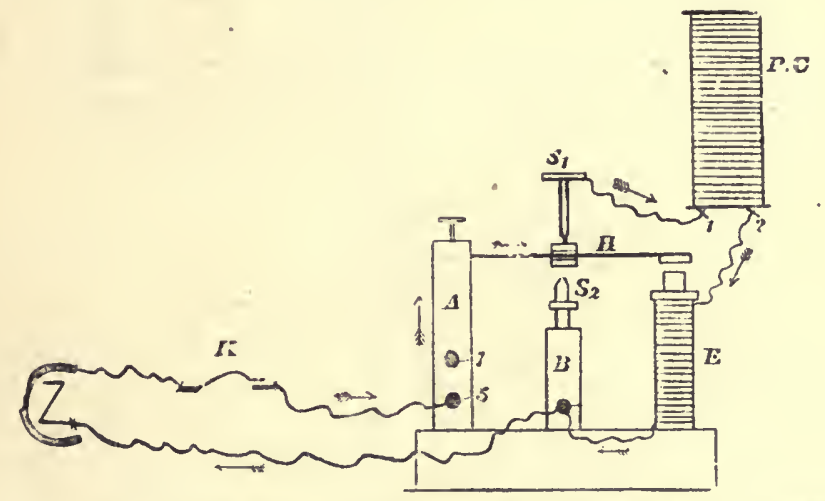

Fig. 270.-Diagam to show the Action of Wagner's Hammer.

shock induced; every time it flics back a make shock is induced Hcre again the make is less in intensity than the break shock. The make-and-break shocks can be equalized by placing a wire from the binding screw (7) to the top binding screw (1) of the primary coil, and screwing up the top screw $S_{1}$ out of the way, and at the same time screwing up screw $S_{2}$. The current now passes into the primary coil by this wire. $L$, as before, becomes a magnet, and pulls down the armature. This short-circuits the current back to the battery. There is still left, however, a circuit for the extra break current (7, $W, 1, P C, E, H, A, 7$ ), and this reduces the strength of the break current in the secondary coil, thereby equalizing the make and break currents (Fig. 27l).

Proof is required to show that a muscle is really stimulated dircetly, and not indircetly, through the nerve-fibres and nerve-endings in the muscle? The direct excitability of muscle is shown by the following experiments: (1) Parts of muscles which contain no nervefibres-for example, the end of the frog's sartorius-respond to direct 
stimulation. (2) Muscle will contract in response to certain chemical stimuli-e.g., ammonia-which do not excite nerve. (3) The South American arrow-poison curare abolishes the action of nerve by paralyzing the nerve-endings in the muscles; yet, under these conditions, the muscle is directly excitable. The experiment is generally made as follows: Both the sciatic nerves are dissected out in the thighs of a frog in which the cerebral hemispheres have been destroyed.

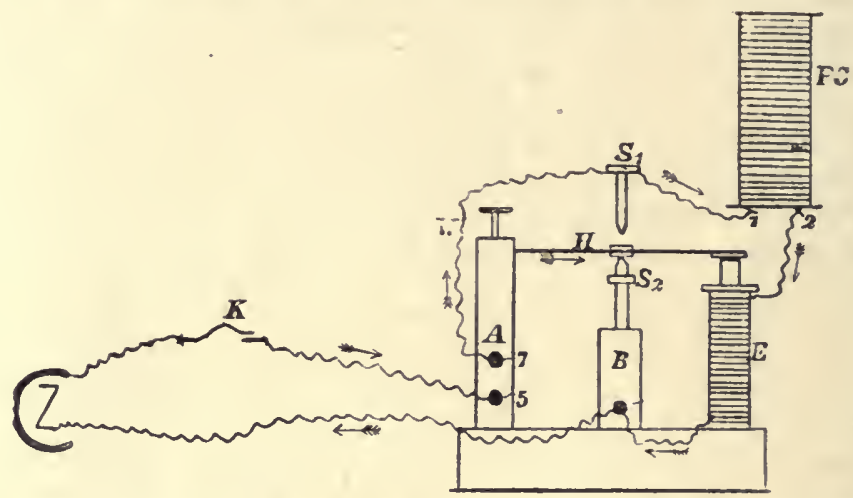

Fig. 271.-Diagran to show the Actiox of the Heliholtz Side-Wire.

Round one thigh, but not including the nerve, a ligature is tied. Curare is injected into the dorsal lymph sac, and circulates everywhere but in the ligated thigh. The upper ends of both sciatic nerves are certainly exposed to the action of the drug. It is found that stimulation of the nerve-supply to the ligated side produces a contraction of that leg, whereas stimulation of the nerve to the other leg does not. Direct excitation of the muscles, howerer, causes a response in both legs. The block is therefore in the nerve-endings. 


\section{CHAPTER LXII}

\section{THE CONTRACTION OF MUSCLE}

THE great property of muscle is its power of contractility. When a muscle contracts-

1. It undergoes a change in shape, becoming shorter, tenser, and thicker.

2. It becomes, as we have seen, more elastic and more extensile.

3. It develops heat.

4. It undergoes an alteration in its electrical condition.

5. It suffers metabolic changes, which alter its chemical condition.

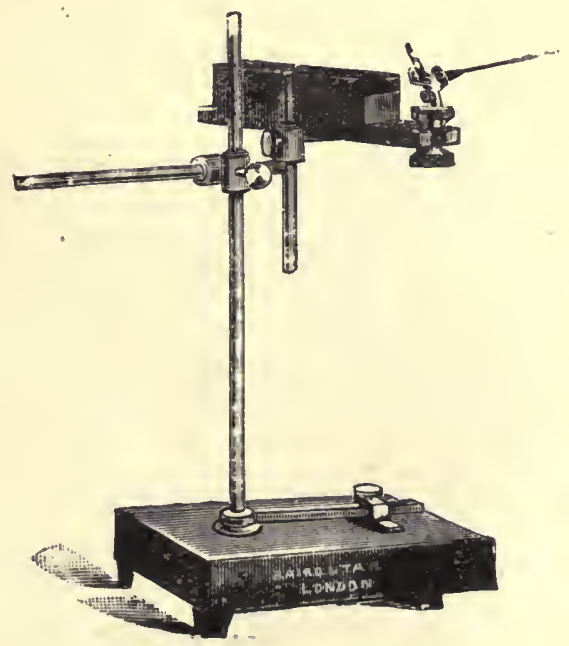

Fig. 272.-The Craxk Lever, Muscle Board, axd Stand.

The Change in Form. - The change in form of a muscle, when it contracts, is usually registered by means of the graphic method. The muscle most frequently omployed for this purpose is the gastrocnemius muscle of the frog. The muscle is connected to a magnifying lever, or myograph. It may either bo pinned out on a board in a form of apparatus resembling Fig. 272, or it may be clamped in the apparatus shown in Fig. 273. The writing lever, which should be as light as possible, is then made to write upon a smoked drum, or kymograph. In order to study the time occupied by the contraction, a 
time tracing is simultaneously recorded on the drum. This may be done either with a tuning-fork or, better, with an electro-magnet chronograph.

When working with single induction shocks, the exact point at which the stimulus is thrown into the muscle is obtained by placing

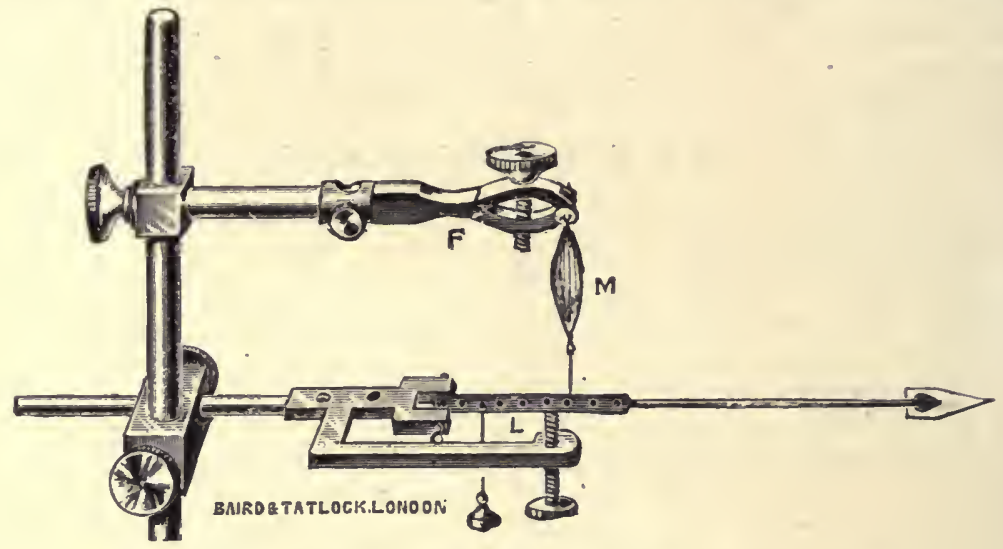

Fig. 273.-The Simple Lever with After-Londivg Screw.

$F$, Clamp; $L$, lever; $M$, muscle.

the kymograph in the primary circuit. The drum carries a metal striker, which, as the drum revolves, strikes against a piece of metal mounted on the stand of the drum but insulated from it. One wire is attached to the metal stand of the drum, the other to the insulated metal. The current in the primary eircuit is therefore

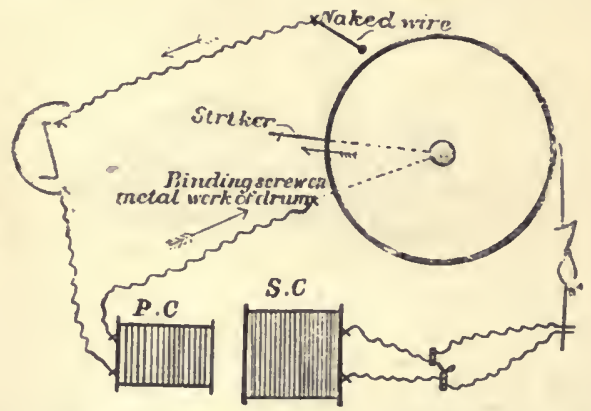

Fig. 274.-Dlagran of the Apparates for Pecording a Sixgle Muscular Coxtractiox.

rapidly made and broken when the striker hits and passes the insulated metal (Fig. 274).

In recording a muscle curve, the muscle may have a weight dircetly pulling on it. The muscle is then said to be "loaderl." If, however, 
the weight be so arranged that the muscle only raises it during its contraction, it is then said to be "after-loaded." When the resistance is slight, so that the muscle can change its shape during contraction,

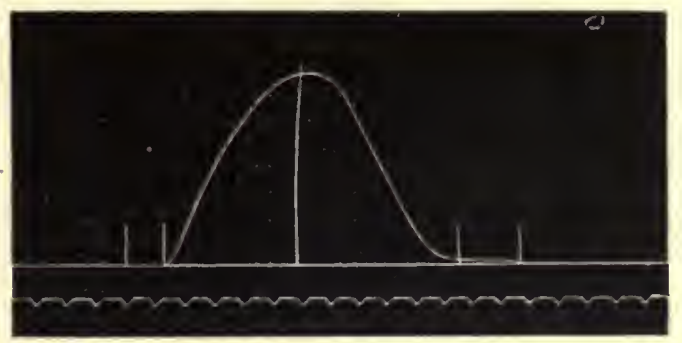

Fig. 275. - A Sixgle Muscular Contraction (Frog's Gastrocxemius).

From 1 to 2 is the latent period; from 2 to 3 , the period of shortening; from 3 to $t$, the period of relaxation. Time in $1 \frac{1}{10}$ seeonds.

the curve yielded is said to be "isotonic." Its length alters, but the tension remains equal throughout the contraction. This is the case when the contraction is registered by such forms of apparatus as

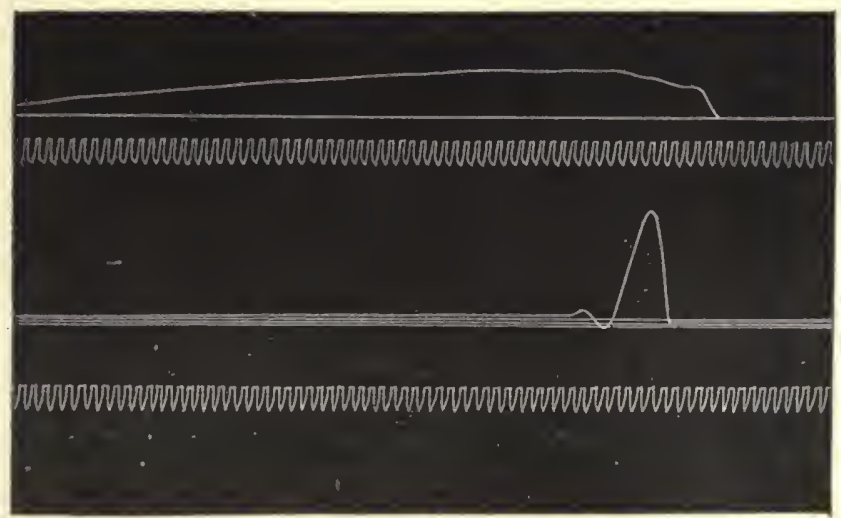

Fig. 276.-Comparison of Cuxtractions of Red axp White Muscle of Rabbit, stimulated indirectly. (M. S. Pembrey.)

Upper eurve is response of the red soleus, and lower eurve that of the white gastrocnemius. Time marker, 50 per second. The traeing to be read from right to left.

are shown in Figs. 272, 273. When the muscle contracts against a large resistance, so that it can shorten but little, the recording lever gives an "isometric" curve. The muscle in these conditions remains of approximately the same length, but alters in tension. 
The length of time taken by a single contraction or twitch varies greatly with the kind of muscle employed. In general, the response of the gastrocnemius of the frog occupies about one-tenth of a second (Fig. 275). The following table gives examples of the time of various muscles:

\begin{tabular}{|c|c|c|c|c|c|}
\hline $\begin{array}{c}\text { Tortoise: Peetoralis major } \\
\text { Semi-membranosus }\end{array}$ & & $\ddot{\cdots}$ & $\ddot{*}$ & $\because$ & $\begin{array}{l}\text { Seconds. } \\
1 \cdot 8 \\
0 \cdot 6\end{array}$ \\
\hline $\begin{array}{c}\text { Frog } \\
\begin{array}{c}\text { Hyogtossus (tongue) } \\
\text { Reetus abdominis }\end{array}\end{array}$ & $\begin{array}{l}\ddot{*} \\
\cdots\end{array}$ & $\begin{array}{l}\cdots \\
\cdots\end{array}$ & $\begin{array}{l}\ddot{*} \\
\cdots\end{array}$ & $\begin{array}{l}\cdots \\
\cdots\end{array}$ & $\begin{array}{l}0 \cdot 12 \\
0 \cdot 25 \\
0 \cdot 17\end{array}$ \\
\hline $\begin{array}{l}\text { Wing muscle of unsp } \\
\text { Wing muscle of honey-bee } \\
\text { Wing muscle of bumble-bee }\end{array}$ & $\begin{array}{l}\cdots \\
\cdots\end{array}$ & $\begin{array}{l}\cdots \\
\cdots\end{array}$ & $\begin{array}{l}\because \\
\therefore\end{array}$ & $\begin{array}{l}\because \\
\because\end{array}$ & $\begin{array}{l}0 \cdot 009 \\
C \cdot 005 \\
0 \cdot(10) 4\end{array}$ \\
\hline
\end{tabular}

The muscle curve may bè divided into three periods-the latent period, the period of contraction, and the period of relaxation. In the ordinary graphic curve of the frog's gastrocnemius these periods occupy approximately $\frac{\frac{1}{10}}{100}, \frac{4}{10 \overline{0}}$, and $\frac{5}{100}$ of a second respectively. In such a curve, the length of the latent period does not represent the true latent period of the muscle. It is, in reality, much too long, and is due largely to the inertia of the apparatus. This may be shown by contrasting the graphic curve, in which the muscle pulls upon the writing lever, which is made to record upon a smoked surface, with the curve obtained when a muscele is excited, and its, change of shape recorded photographically. Under thesc latter conditions, the latent period is but 0.001 to 0.005 of a second. This latent period is probably due to the time taken by the impulse to reach sufficient muscle fibres to bring about a change in the shape of the muscle.

Although in the graphic curve the length of the latent period is mainly due to the inertia of the apparatus, it is partly due to another factor-namely, that the contracting muscle is more extensile. With delicate recording apparatus it can be shown that the latent period, represented by a straight line in the ordinary muscle curve,

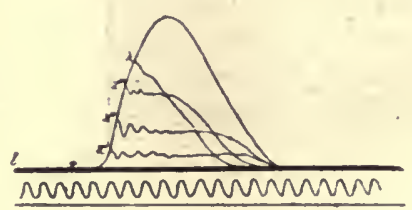

Fig. 277.-Curves of Arrested Contractions of UNLOADED Muscle. (Kaiser.) - the time taken for the impulse to pass down the nerve through the nerve-endings to stimulate sufficient fibres to induce contraction adds considerably to the latent period of contraction. For this reason, the latent period of direct stimulation of a muscle is shorter than that for indirect stimulation of the same muscle. In general, it may 
be stated that the shorter the whole period of the muscle twitch, the shorter the latent period, and vice versa.

The Period of Contraction is the period during which the muscle shortens until the maximum shortening is reached. It is the period

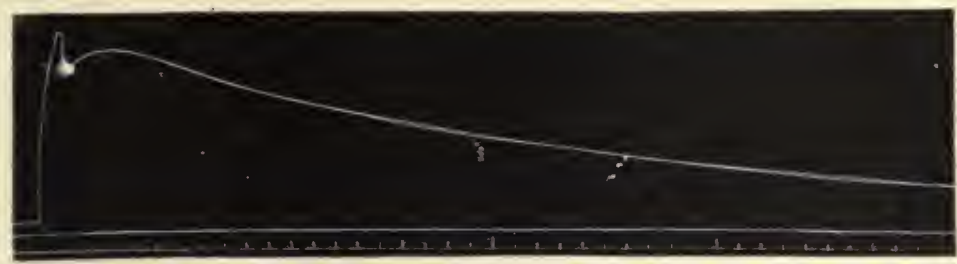

Fig. 278.-Veratrin Curve. (Waller.)

of rising energy. In graphic curves, this is represented as too long, since the recording lever owing to inertia tends to rise too high. This can be demonstrated by arresting the lever at different heights during the process of contraction. At a certain point before the

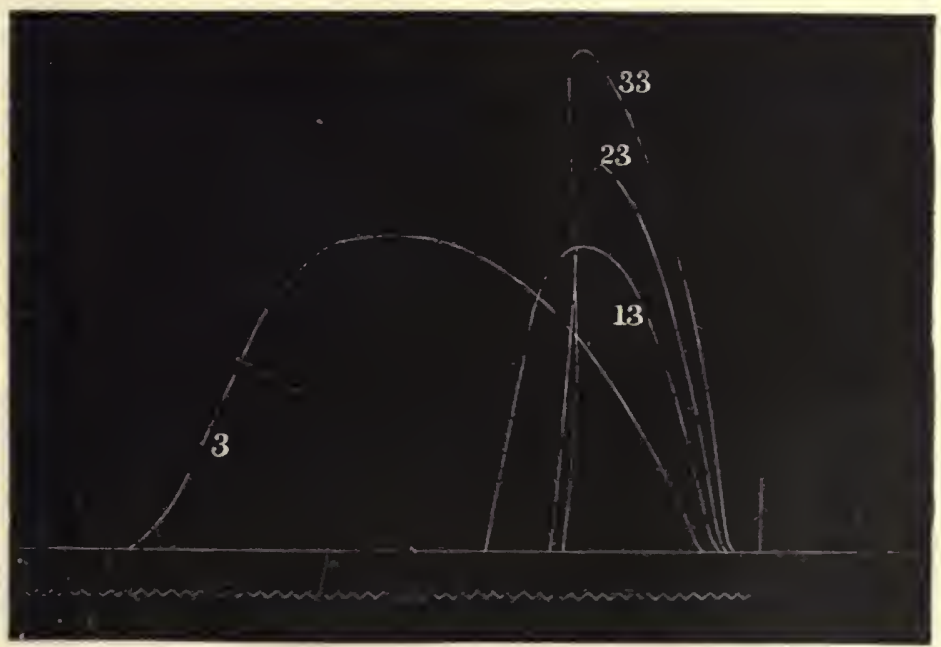

Fig. 279. -The Effect of Temperature upon the Contraction of the Gastrocnemius Muscle. (Pembrey and Phillips.)

The time is marked in róv second. The tracing should be read from right to lift. Figures on curve are the temperatures of the salt solution.

summit of the eurve is reached it will be found that the lever as soon as it touchez the arresting body, immediately starts to fall. That point marks the true height of the contraction (Fig. 27i).

Tne differense in the contraction time of different muscles is mainly due to differense in anatomical structurc. The quickly con- 
tracting muscles are those rich in sareostyles, the slowly contracting muscles those containing abundant sarcoplasm; many muscles are mixed. It has been suggested that, when the number of sarcostyles

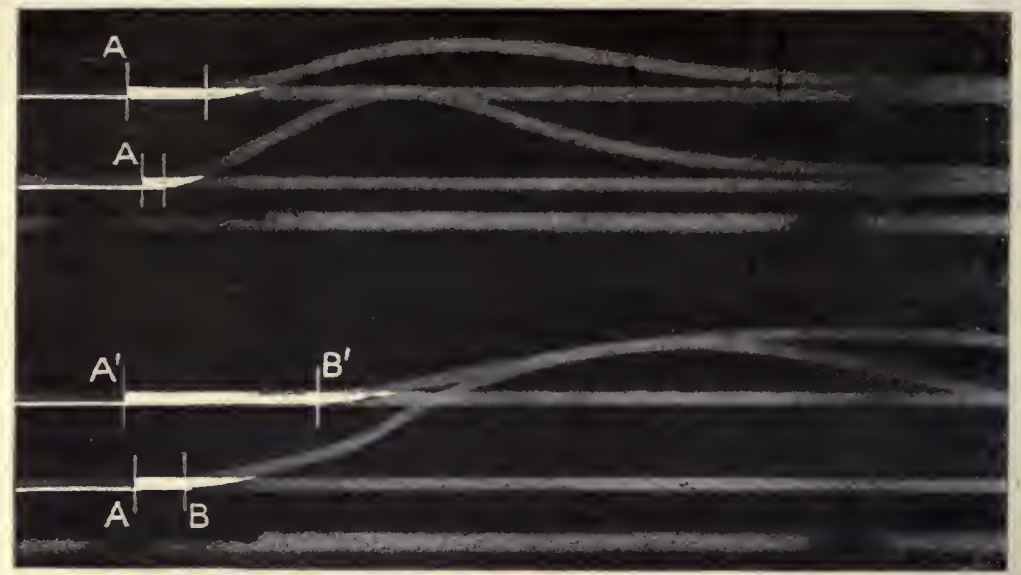

FIG. 280.

The upper curves show the latent period and movements of two levers on muscle at $15^{\circ} \mathrm{C}$., the lower curves at $5^{\circ} \mathrm{C}$. It will be seen that the latent period is shorter at $15^{\circ} \mathrm{C}$. than at $5^{\circ} \mathrm{C}$, , also that the rate of conduction given by the difference in the latent periods is quicker at $15^{\circ} \mathrm{C}$. than at $5^{\circ} \mathrm{C}$. (V.J. Woolley.)

are not greatly in excess of the amount of sarcoplasm, the muscle curve may show two summits-the first due to contraction of the sarcostyles, the second due to contraction of the sarcoplasm. This is

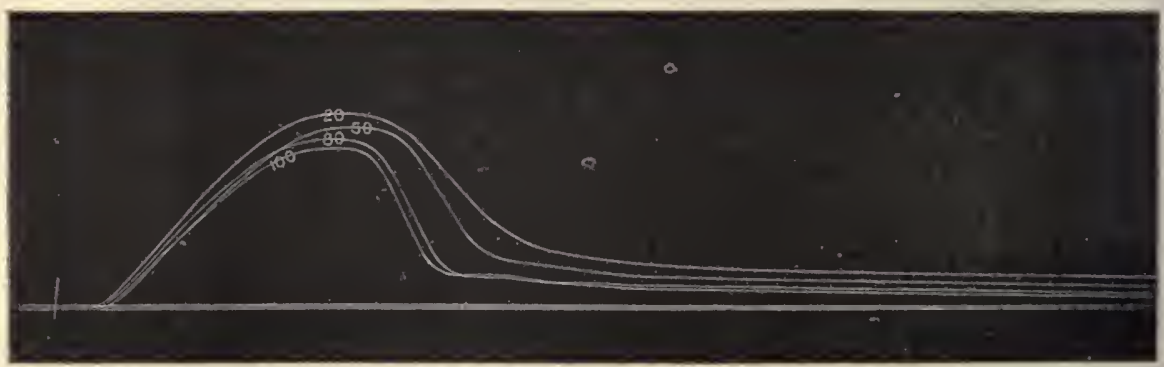

Fig. 281.-Tíe LfFict of Load upon the Contractiox of the Gastrocxemius Mescle. (A. P. Beddard.)

the explanation sometimes afforded of the curve given by the reratrinized muscle (Fig. 27i). It is also suggested that the slow response of a fatigued muscle may be a response of the sarcoplasm after the yuickly responding sarcostyles have ceased to respond. For example, 
in a fresh state, the triceps femoris of the rabbit gives a quick response; when fatigued, it yields a long-drawn-out curve.

The Period of Relaxation is from the maximum shortening of the muscle to the position of rest. The relaxation has been thought to be due to an active process, but there is little evidence of this beyond the fact that there ars special changes going on during it (see p. 554).

The Conditions which affect Muscular Contraction.-Beside the constitution of the muscle and the effect of drugs, such as veratrine, the muscle response is affected by other conditions, such as the strength of stimulus, the temperature, the amount of load, and previous activity.

The Strength of Stimulus.-Striated nusclc gives a graduated rosponse according to the strength of stimulus. With a weak (minimal) stimulus, it just contracts. The contraction then increases in amount with the strength of stimulus until a maximal contraction is obtained, after which no increased contraction is obtained; however much the current be strengthened. The minimal contraction is duc to the

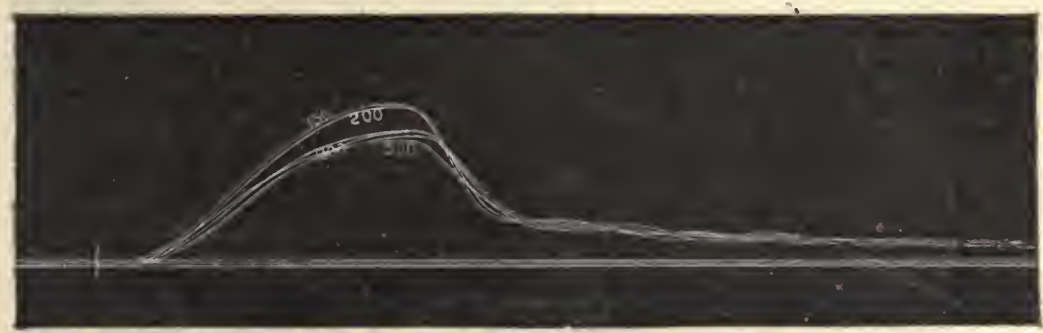

Fis. 282.-Continuation of the Experiment in Pis. 231. Sinzle Contríctions of the Gastrocnemius with Differext Loads. (A. P. Beildard.)

The figures on the curves represent the weights in grammes hung at the axis of tive lever; aetual load on musele was in each ease one-fifth. Magnifieation, 5. Temperature, $12^{\circ} \mathrm{C}$.

wcak stimulus only spreadirg to a few fibres. Probably any stimulus which is effecturl makes the fibres rffected contract maximally.

Temperature.-Cold $\left(0^{\circ}\right.$ to $3^{\circ} \mathrm{C}$.) lengthens the whole curve, especially the latent period and the period of contraction. The rate of condiction is also lessened by cold (Fig. 280). Frequently the relaxation is incomplete, showing a "contraction remainder." At first the height of the contraction is increased, then diminished. Gentle warmth $\left(25^{\circ}\right.$ to $35^{\circ} \mathrm{C}$.) incrases the rate of all stages of the curve, and greatly increases its height, partly duc to an incrtia sffect of the lever (Fig. 279). Heat $\left(42^{\circ} \mathrm{C}\right.$. in the frog) coagulates the muscle proteins, and brings about a condition of "heat rigor."

Load.-An increase in load is found generally to (lecrease the amount of contraction, and lengthen the latent period (Figs. 281, 282). When, however, a muscle is fresh and in good condition, the first few increments of load may give an increased height to the contraction. When the work done by the muscle is calculated-

Work done $=$ load lifted $\times$ lheight 
- it will bo found that the amount of work done at first increases with the load, and then diminishes, giving a "curve of load." The act ual height through which the weight is lifted is obtained by dividing

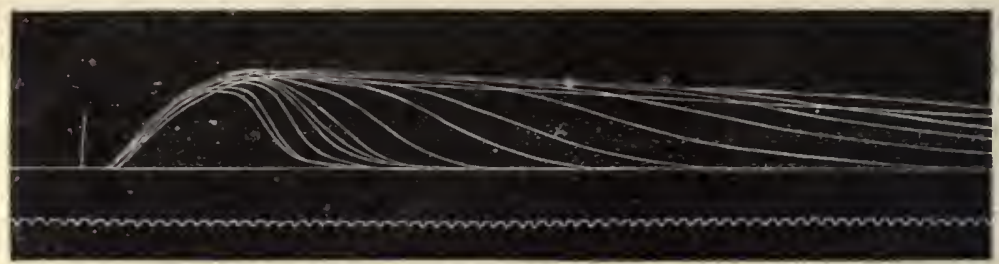

Fig. 283.-Fatigue: Frog's Gastrociemes. (Waller.)

J)irect excitation; 125 successire maximal contractions at intervals of $1 \frac{1}{2}$ seconds, showing at the outset increase of height and of duration, later decreasing height . The exhaustion has not bcen pushed to the end.

the height of the curve by the magnification due to the recording lever. For purposes of "load" experiment, it is better to use the form of apparatus shown in Fig. 273 , since the load can then ke applied directly below the muscle.
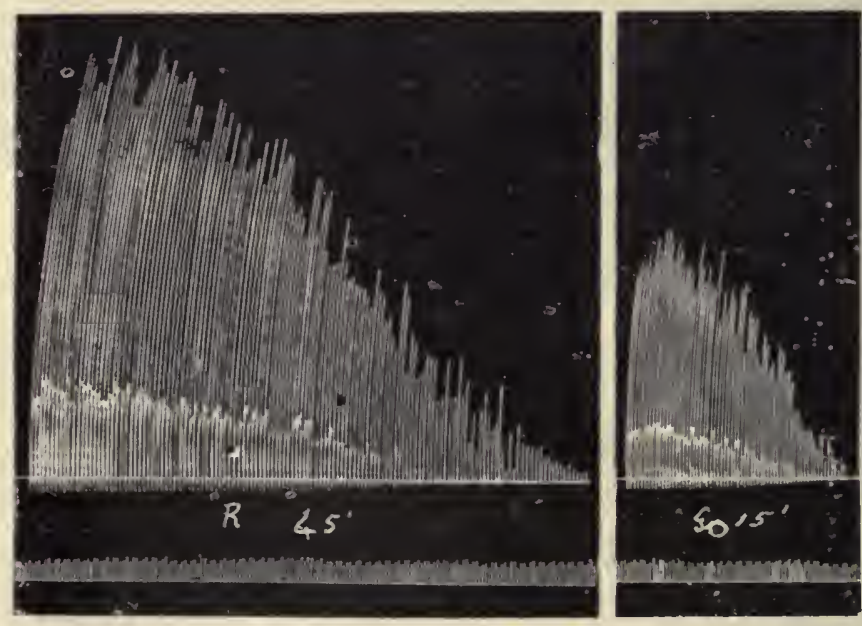

lia. 284.-Fatigue Curves of $k$, sartorios Mtscle in Ringer's Solutiun; $G$, sirtorius after Fifresx-Minute Inuersius in Guanidix 0.1 per Cent. Solttios. (Camis.)

Time in seconds. The staircase effect is seen and also the depressant effect of guanidin in high concentrations.

Previous Activity.-When curres are taken from a perfectly fresh muscle preparation, the first few may show an improvement in the degree of contraction. This is known as the "staircase effect," and 
it is suggested that it is due to the beneficial action of the metabolites formed in the previous contractions. When the contractions are made to follow each other without any pause they finally become less and less, and the relaxations become more and more drawn out, a well-marked "contraction remainder" usually. appearing, until eventually the muscle gives no contraction at all; the muscle is "fatigued" (Figs. 28:3, 284).

"Fatigue" is due mainly to the accumulation of the products of activity within the muscle-in part, however, to the using up of food material. The fatigue products are acid in nature-chiefly lactic acid. Fatigued muscles placed in oxygen recover more quickly (Fig. 285). If the muscles be made to contract in an atmosphere of oxygen, lactic acid does not appear, and the onset of fatigue is much delayed or postponed altogether. Recent evidence tends to show that

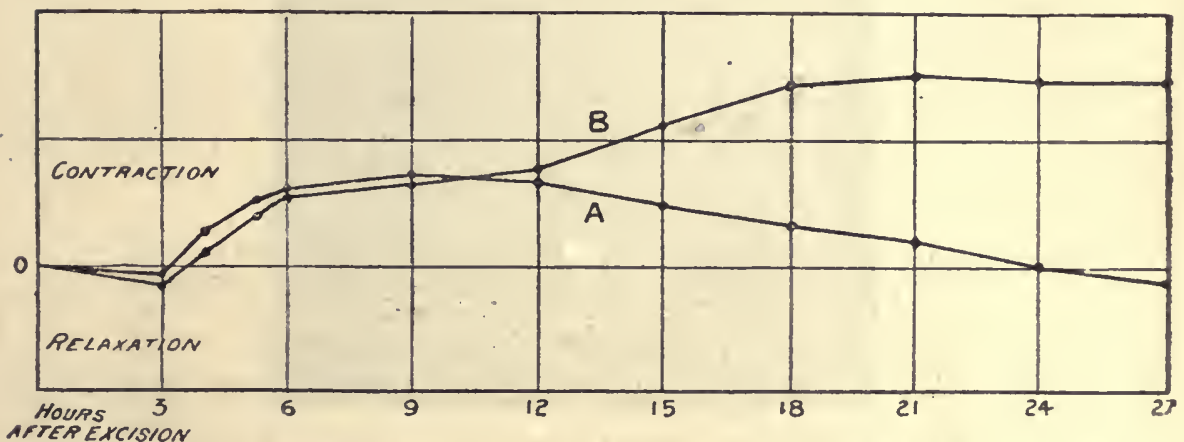

Fig. 285. - Chaseas is Lexgth of a Pair of Excised Gastiocsemin after Fatigte. (W. M. Fleteher.)

A. Exposed to oxygen; B. exposed to air. Load 3 grammes, temperature $16^{\circ} \mathrm{C}$. The ordinates are measured direetly from the reeord; levers magnified six and a half times.

lactic acid is not normally a wastè product, but a stage in the metabolic changes of the muscle. A muscle through which the blood is circulating is fatigued only when either the load, or the frequency of contraction is made too great. Thus the muscles of the skilled workman perform thousands of contractions without fatigue. So with the respiratory muscles and the heart. To secure the maximum output of athletes or workers, load and frequency must be carefully adjusted to prevent overstrain.

Summation.-If a muscle be given two stimuli in quick succession, the effects of the two are added together-" summated "-and a bigger curve is obtained than either of the single curves would lrave beon if recorded separately (Fig. 286). If, however, the interval between the stimuli be very' short, so that the second stimulus falls within the latent period of the first stimulus, then, if this be maximal, no summation is obtained, the curve is unaffected by the second 
stimulus. If, however, the first stimulus is not producing a maximal contraction, then the second stimulus will add itself to the first, and again a greater effest is obtained than would have obtained by either separately.

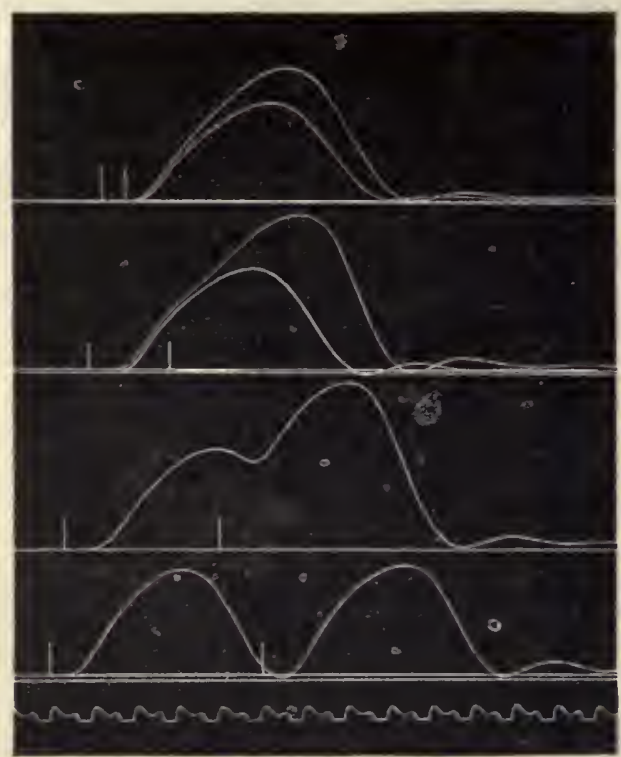

Fivi, 286. - Superposition of Two Sixgle Contractions.

Each contraction is recorded alone by a break shock caused by opening a fixed key; both keys are then set, and the recording plate striking them open successively, causes two stimuli and a summation of the two contractions.

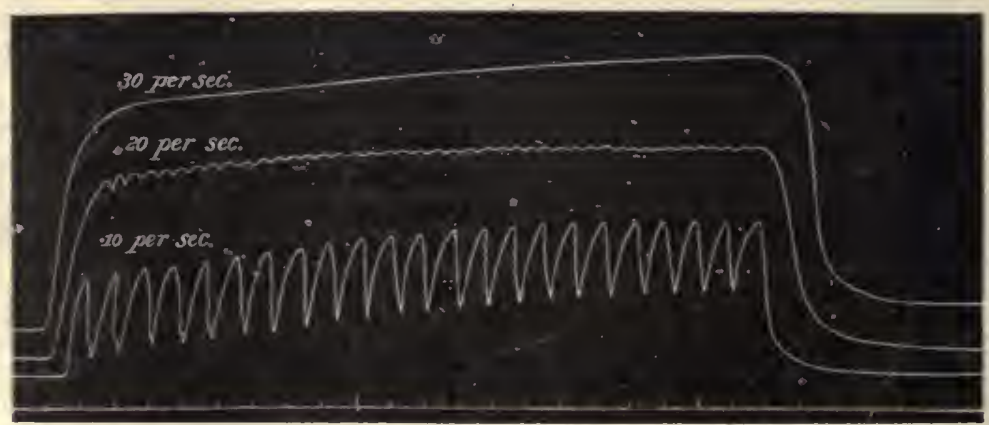

Fig. 287.-Conposition of Tetaxus, (Waller.)

stimuli caused by a spring interrupting a primary circuit by vibrating in and out of a mercury cup; the vibration frequency is increased by shortening the spring. 


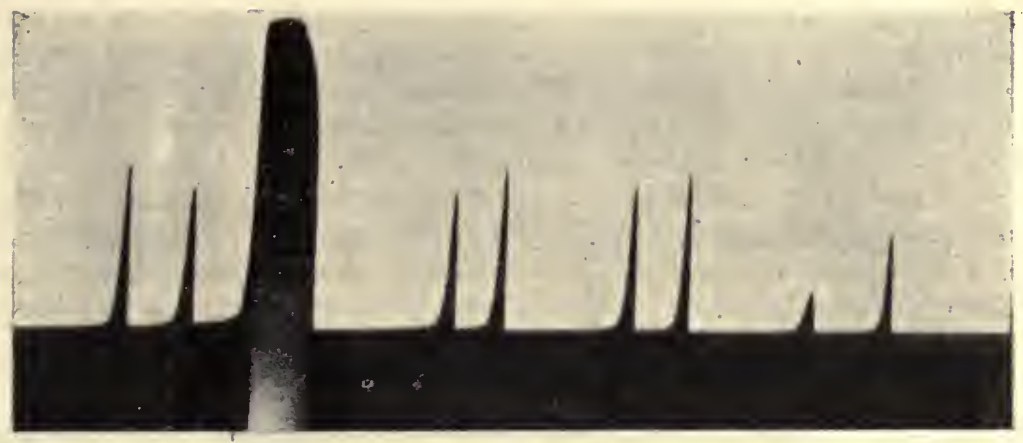

FrG. 288.

To be read from right to left. Photographie eurve of sartorius muscle by isometric method. At first two submaximal stimuli, followed by two pairs of maximal stimuli, then by a tetanus, followed by another pair of single responses. The tension set up in the musele during tetrnts is greater then the maximal tension of a single twitch. (G. R. Mines.)

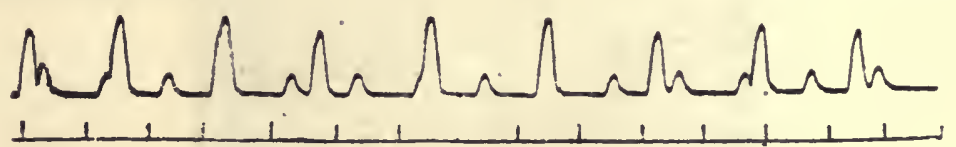

Fif. 289. - Spontaneous Movements in Toad's Sartories ix 7 per CeNt. Sodium Chloride. (G. R. Mines.)

Temperature $8^{\circ} \mathrm{C}$. Time in seeonds.

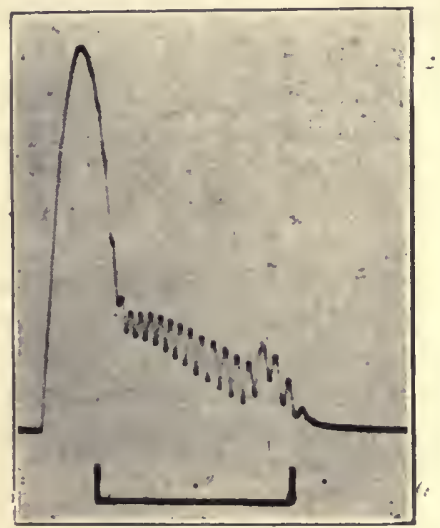

Fig. 290.-Biceps Crurls of Frog in Sodium Chloride 0 65 per Cent., Potassium Chloride C.05 per Cext. (G. R. Mines.)

A pariod of one second is marked below. 
Owing to this property of summation, a number of successive stimuli may cause a number of contractions between which the muscle does not properly relax. The greater the frequency of the stimuli, the less the relaxation between each contraction, until at last a long, fused, compound curve is obtained, known as the "complete tetanic curve." Tetanus is produced by about 30 to 50 stimuli per second in the case of frog's striated muscle." The number varies with the temperature and the state of the muscle. When warmed, more stimuli are required; when cooled, less are needed. If the muscle be fatigued, fewer stimuli are required to induce the complete tetanic contraction.

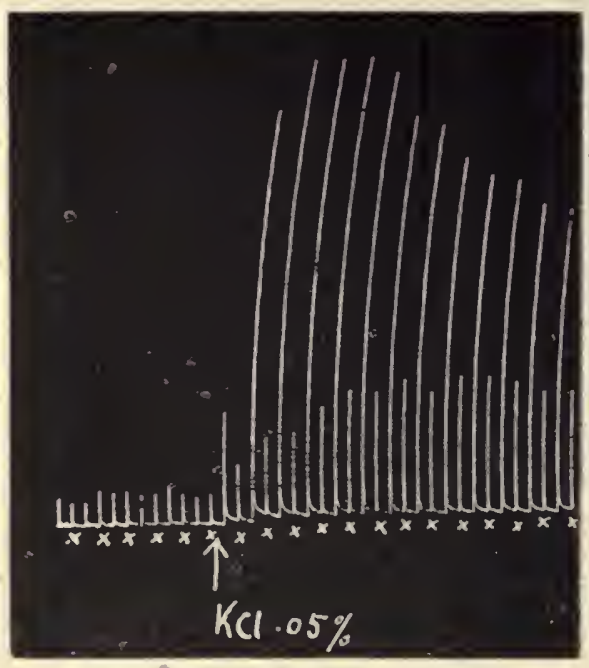

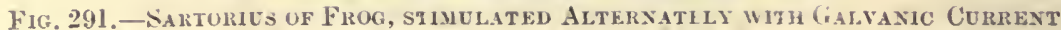
Axd Ixductiox Shock at Thirty-Second Istervals. (G. R. Mines.)

Each response to an induction shock is marked with a cross. At the beginning of tracing the muscle was in $\mathrm{NaCl} 0.7$ per cent.; at arrow Huid was changed to $\mathrm{NaCl} 0 \cdot 65$ per cent, $\mathrm{KCl} 0.05$ per cent.

The genesis of tetants is studied by employing the vibrating reed. By, varying the length of the reed, the number of stimuli per second is easily regulated, and all forms of incomplete to complete tetanus may be obtained (Fig. 237). Incomplcte tetanus is sometimes termed "clonus." Ankle clonus may be clicited in certain nerrous conditions when the foot is suddenly bent up.

Powerful alternating currents, vibrating frequently to and fro in jopposite directions-e.g., 1,000,000 per second-may be passed through muscle without producing excitation, and with suitable apparatus, such a current may be sent through several people and electric lamps. The former feel nothing, while the lamps glow. 
Muscular "Tone."-During life, the muscles, never fully relaxed, are kept in a state of incipient contraction, or "tonus "- a condition dependent upon their connection with the central nervous system. "The muscles are ceaselessly influenced by their nervous centres, which in turn are excited by messages reaching them from all parts of the body, particularly the skin, joints, and the muscles themselves.

This tonus makes for a general "wakefulness"-a readiness to contract-on the part of the muscle. It also plays a considerable part in the production of heat within the body, being reflexly increased by sensations. of cold, and relaxed by sensations of warmth. It is also affected by mental states, such as excitement, anger, fear.

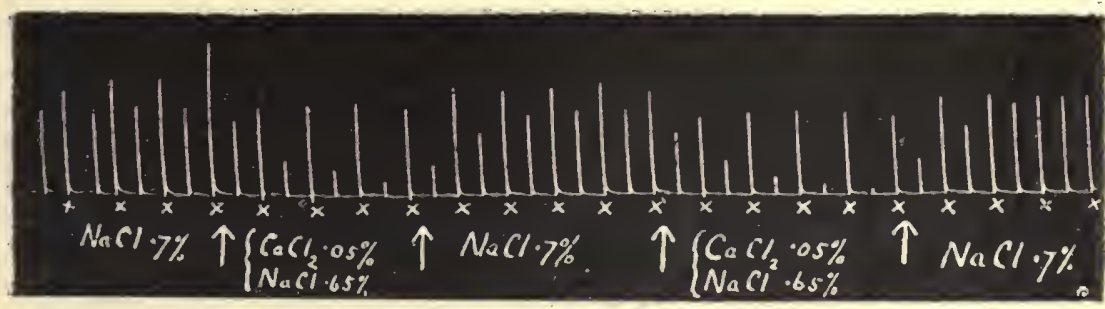

Fig. 292.-Sartorius of Frog, 'stimulated at Ixtervals of Thirty Seconds Altersately with Galvaxic Currext axd Ixduction Shocks at $\times$. (G. R. Mines.) :

Spontaneous Movements.-Amphibian muscles in saline solutions exhibit spontaneous movements (Fig. 289). These movements will continue in concentrated curare solution, indicating that the source of the movements lies in the contractile substance of the muscle fibres. This is also proved by expcriments on muscle containing no nerve endings, e.g., the non-neural regions of the sartorius muscle. Potassium chloride at first increases the movements, often causing a very rapid rhythm (Fig. 290), and then stops them entirely. Its effect on the excitability of the muscle towards galvanic currents of long duration, which is increased in this condition of the muscle, is a further exaltation and then depression (Fig. 29I). The addition of calciun chloride leads to an immediate diminution or cessation of the movements and a fall in the excitability towards galvanic currents (Fig 292). 


\section{CHAFTER LAIII}

\section{THE PRODUCTION OF THERMAL AND CHEMICAL CHANGES IN MUSCLE}

Tнат muscular exercise produces warmth is a familiar observation. For this reason, hard muscular exercise is uncongenial on a very hot day, but is resorted to when the temperature is low, since, under these conditions, even the habitual loafer is often constrained to beat his arms across his chest or stamp violently to keep his feet. warm. It is somewhat difficult to show by means of the mercurial thermometer the development of heat during the contraction of the excised muscle, even when a rery sensitive thermometer is inserted between the muscles of the thigh, and the sciatic plexus stimulated. It has been,calculated that during a tetanus of two to three minutes? duration the tcmperature of a frog's muscle rises on an average about $016^{\circ} \mathrm{C}$.

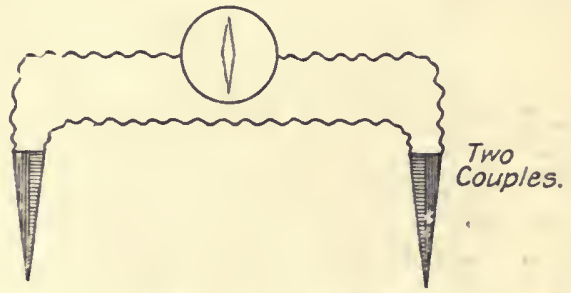

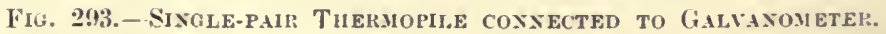

The production of heat can not only be shown but mensured by sueans of a thermopile. If a thermopilc (Fig. 293) be placed between the calf muscles of a resting limb of a frog, and another between the calf muscles of a limb which is made to contraet, and the two thermopiles be then connected with a galvanometer, it will be found that contraction liberates sufficient heat to cause a deflection of the galvanometer needle. When both sets of muscles are at rest, no dcflection takes place. For accurate work, special forms of apparatus. are used (Fig. 294).

The muscle fibre has been regarded as a heat engine. It has been suggested that the contraction is produced by the production of heat in the locality of the fibril, which contracts under the influence of heat. Such a conception is erroneous. The muscle is rather to be regarded as a chemical machine working at constant temperature. It has been calculated that to behave as a heat machine it would be neccssary to keep up a temperature difference of $100^{\circ} \mathrm{C}$. at two points not more 
than a fow $\mu$ apart. This would mean an almost infinite loss of heat by conduction between the two points. It is inconceivable that such differences of temperature exist. It has been shown, moreover, that the heat is not formed solely during the period of contraction of the muscle. It is formed both during the contraction and during the relaxation (Fig. 295). There is, moreover, no constant ratio between the amount of work done and the amount of heat evolved. High initial tension and strong excitation favour the production of heat.

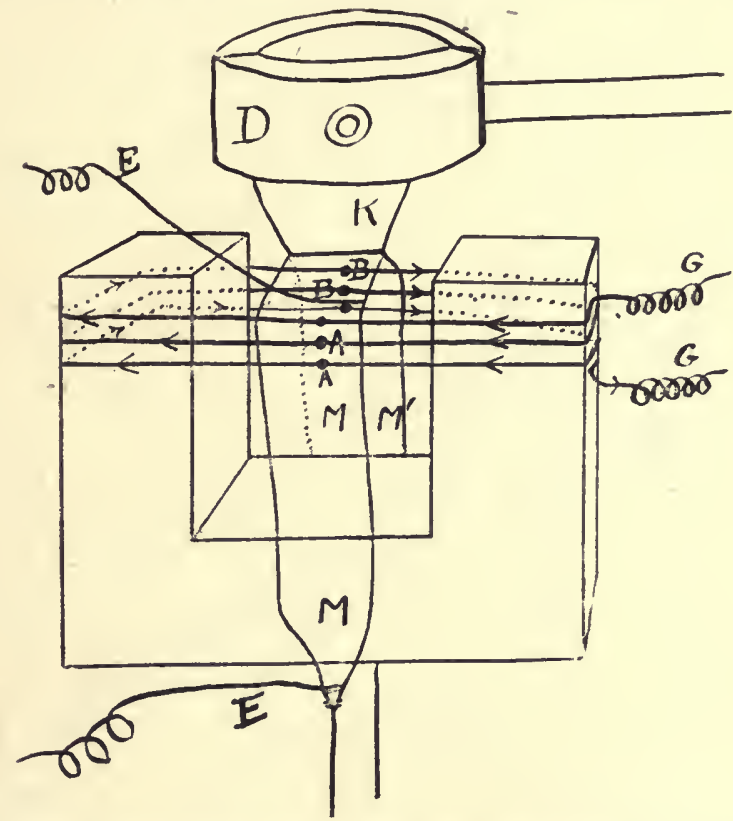

Fre. 294.-Dodble Thermopile, Each of a Pair of Sartorit being in Coxtact with Oxe Set of Junctions. (A. V. Hill.)

$A, A$, Junctions of iron and constantan in contact with front sartorius, $M ; B, B$, junctions in contact with rear sartorius, $M^{\prime} ; K$ is bone of pelvis held by clamp, $D ; G$, copper leads to galvanometer; $E$, electrodes-only two out of four shown. Arrow shows direction of eurrent. Only six instead of twenty-four to thirty junctions shown.

An isolated frog's muscle at $15 \cdot 5^{\circ} \mathrm{C}$. continues for about five hours to carry on the normal oxidative processes of life, but at a declining rate. This is due to the gradual exhaustion of the oxygen supply, and to the gradual accumulation of waste products other than $\mathrm{CO}_{2}$. Possibly, also, the supply of oxidizable material becomes exhausted.

The initial process of contraction consists largely', if not entirely, of the liberation of potential energy, which is manifested as "tension energy" in the cxcited muscle. This potential energy is capable of being used indifferently for the accomplishment of work or the production of heat. The efficiency of the whole of the processes, including those of recovery, is sometimes as high as 50 per cent.- that 
is to say, 50 per cent. of the energy of the foodstuffs katabolized may appear as work, an efficiency much greater than that of a steam engine (10 per cent.), and greater even than the best petrol engine (30 per cent.).* In the muscle machine, the "free energy" which is to become mechanical or thermal energy is stored in certain unstable chemical compounds, one of which is possibly the lactic acid precursor.

During the preliminary stage of the contractile process, certain molecules are liberated in the muscle under the influence of oxygen

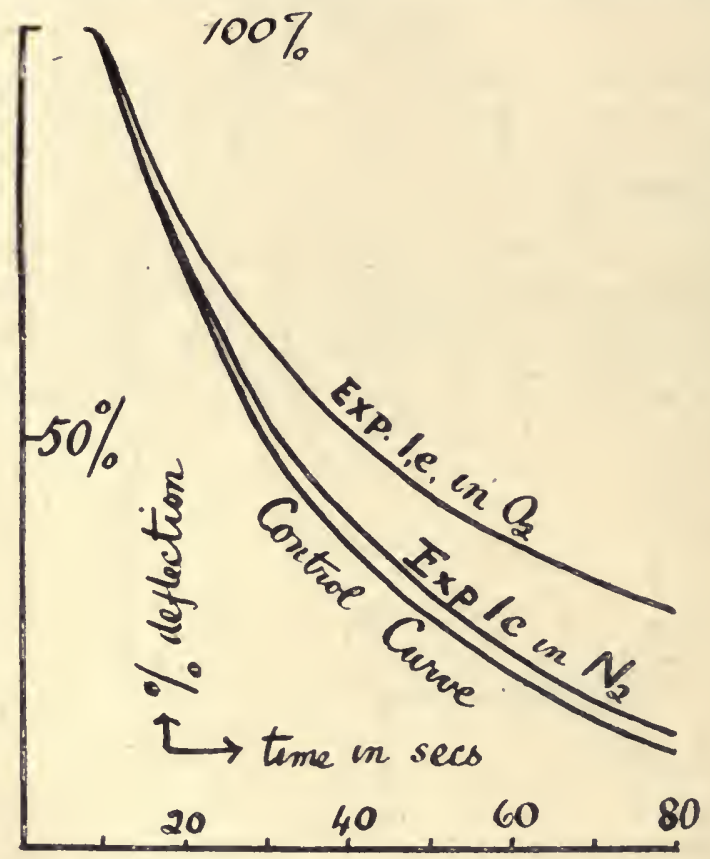

Fig. 295.-Galvaxometer Deflectiox showivg Fall os Temperature of Musce after Excitation in Nitroges, in Oxygen, axd Warmed WheN Dead as Control. (A. V. Hill.)

The curve for living muscle in nitrogen nearly coincides with control curve, but the curve for living muscle in oxygen after nitrogen is very considerably displaced to the right, showing continued heat production during relaxation of the muscle.

and with the production of heat-for example, lactic acid from its unstable precursor. These produce "tension energy," occasion the contraction, and are then, under the further action of oxygen during the relaxation, removed or replaced in the muscle substance complex with the evolution of heat. It is conceived, therefore, that heat is developed in three stages: (1) During process preliminary to contraction; (2) during contraction; (3) during relaxation.

The Mechanism of Muscular Activity is by no means clear. As we have seen, the application of the laws of the thermodynamies to

\footnotetext{
* The efficiency of a labourer scems to he 20.25 per cent.
} 
muscular contraction has afforded valuable information. The phenomenon of contraction has also been studied from the point of view of the osmotic properties of the muscle.

It has been suggested, after due consideration of the time relations of the contraction and the distance in the fibril through which osmotic force has to act, that muscular contraction may be brought about by this force. Provisionally, we may suppose that lactic acid is set free, and that combines with protein to form a salt, with a consequent rise of osmotic pressure in the dim-bands of the muscle fibrils, which therefore swell at the expense of the water in the light bands. Granting that this may be so, we do not know how the osmotic equilibrium is upset by the stimulus or restored during relaxation.

The Changes in the Chemistry of Muscle-1. The Chemical Constitution of Muscle.-If muscle be taken from an animal and minced, and then squeezed, a plasma can be expressed from it. This, like blood, possesses the property of coagulating at body temperature under suitable conditions.

Upon analysis, it contains from 75 to 78 per cent. of water, 20 to 24 per cent. of organic and about 1 to 2 per cent. of inorganic bodies. The chief organic bodies are the proteins, of which there are from 18 to 20 per cent. Various classifications and names have been given to these proteins, which apparently vary in their properties according to their method of preparation, the species of animal used (mammals, birds, reptilia, etc.), the condition of the muscle at the time of death, and the degree of post-mortem changes. To illustrate the chaos which pervades the nomenclature of these proteins, it may be mentioned that the name "myosin" has been given by different investigators to at least three different bodies.

The most generally accepted classification of these proteins is into-(1) Myosin, or paramyosinogen, which forms about one-fifth; . and (2) myogen, or myosinogen, which forms the other four-fifths Traces of albumin and globulin are also present, but these probably come from the blood and lymph, and not from the muscle proper.

In the plasma of " red "muscles the colouring matter is also present. This consists of hæmoglobin or a closely allied compound proteinmyohæmatin.

Myosin, or paramyosinogen, is a globulin soluble in dilute salt solutions which coagulates on heating a about $45^{\circ}$ to $50^{\circ} \mathrm{C}$. It is precipitated by weak acids, dialysis, half-saturation with ammonium sulphate, etc., and gives the other reactions characteristic of globulins (see p. 5l). It is characterized by its power of passing at body temperature-probably under the influence of an enzyme derived from the muscle-directly into an insoluble modification known as myosin fibrin.

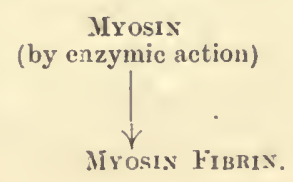


Myogen, or myosinogen; on the other hand, is an albumin. It gives the characteristic reactions for such, and is therefore not precipitated by dialysis, and only by complete saturation with ammonium sulphate. Its heat coagulation temperature is frem $55^{\circ}$ to $60^{\circ} \mathrm{C}$. Unlike myosin. it is apparently not coagulated at body temperature by an enzyme, but passes without such assistance somewhat slowlyinto a variety known as soluble myogen fibrin, which is coagulated by heating to hody temperature $\left(37^{\circ}\right.$ to $40^{\circ} \mathrm{C}$.) into insoluble myogen fibrin.

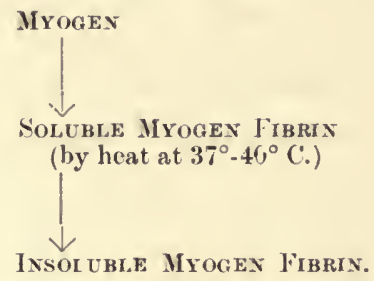

In the residue left after the expression of muscle plasina there is a protein which has been termed myostromin. This is of the nature of a nuclein. This, together with some sclero-protein, the collagen of the fibrous tissue, probably forms the framework of the fibres. The sclero-protein collagen yields gelatin on boiling. Nucleo-protein is also present in the nuclei. A certain amount of fat is present, either in the fibre itself or in the interstices of the framework.

Other bodies separable from the plasma comprise-

Fats in small amounts.

Glycogen in variable amounts, varying with the "freshness" of the muscle, its state of "activity" or "rest." Generally, it is from 0.5 to 1 per cent. It is present also in larger amounts in embryonic than in adult muscles.

Dextrose in traces only if the muscle be absolutcly fresh.

Inosit, $\mathrm{C}_{6} \mathrm{H}_{6}(\mathrm{OH})_{6}+\mathrm{H}_{2} \mathrm{O}$, a kenzene compound having approximately the same formula as dextrose, and sometimes termed muscle sugar. It does not give the ordinary tests for sugar, is not fermented by yeast, and is without action upon polarized light.

Sarcolactic Acid, $\mathrm{C}_{3} \mathrm{H}_{6} \mathrm{O}_{3}$, an isomer of the lactic acid formed by the fermentation of the lactose of milk. It is present only in fatigued or dying muscle.

Nitrogenous Extractives, the chief of which are creatin (sec p. 46I), hypoxanthin. and xanthin (sce p. 444).

It is claimed that there is also present a complicated nitrogenous body known as Phosphocarnic Acid. It yields as cleavage products succinic acid. lactic acid, phosphoric acid, $\mathrm{CO}_{2}$, a carbohydrate body, and a body known as carnic acid.

Inorganic Salts.-The chief of these is the potassium phosphates. Traces only of chlorides and sulphates are found. In addition, salts of sodium, unagnesium, calcium, and iron, are found, their relativo amounts corresponding to the order given. 
2. The Chemical Changes induced by Activity.-The methods used for investigating tissue respiration show that an increased amount of oxygen is used up, and more $\mathrm{CO}_{2}$ formed, when muscle is contracting than when at rest. If the hind-limb of a frog be tetanized, it will be found the plasma expressed from the muscles gives the colour reactions for lactic acid. The muscles of the resting limb give no such reactions. If the limb be made to contract in an atmosphere of oxygen, no lactic acid is formed, for it is only when the muscle is made to contract with an insufficient supply of oxygen that this acid is formed. Such is the case in man during excessive muscular exercise. The lactic acid then formed can be shown in the urine and in the sweat. In the blood it plays an important pari in the production of the dyspncea attendant upon such exercise.

It has been suggested that lactic acid might come from muscle protein or from the complicated body known as " phosphocarnic acid." However, researches into the amount of nitrogen and sulphur excreted in the urine at rest and after muscular exerise tend to show that the protein metabolism is not greatly affected by muscular exercisecertainly not in sufficient amount to account for the lactic acid formation.

Dextrose is apparently the chief source of the lactic arid.

$$
\underset{\text { Dextrose }}{\mathrm{C}_{6} \mathrm{H}_{12} \mathrm{O}_{6}}=\underset{\text { Lactic acid }}{2 \mathrm{C}_{3} \mathrm{H}_{6} \mathrm{O}_{3}}
$$

When ample oxygen is present, $\mathrm{CO}_{2}$ and water are formed as the waste products of contraction and any lactic acid that appears in the process is rebuilt into the muscle substance.

$$
\mathrm{C}_{6} \mathrm{H}_{12} \mathrm{O}_{6}+6 \mathrm{O}_{2}=6 \mathrm{CO}_{2}+6 \mathrm{H}_{2} \mathrm{O} \text {. }
$$

The exact significance of the crextin and hypoxanthin present in muscle is not known. They do not appear to be waste products. It is possible that the muscle may perform some of its work at the expense of these bodies, especially the hypoxanthin, since muscular exercise after a delay is followed by an increased excretion of uric acid in the unino. Further, meat extiacts have a restorative offect upon musele tonc.

3. Rigor Mortis.-When a muscle dies, either as a result of its removal from the body or by reason of general bodily death, it (1) loses its transparency, and becomes opaque; (2) shortens; (3) revelops an acid reaction, and evolves carbon dioxide; (4) passes from a semitluid to a firm, solid state, or rigor.

After death, this rigor supervenes in a more or less detinite orderfirst the jaws, then neck, trunk, upper and lower limbs. The rate of onset varies. Generally, several hours elapse; but if just previous to death the muscles have been greatly fatigued, particularly in the absence of oxygen, the changes may set in at once. Soldieris are said to have been found standing dead in the trenches, with the rifle held to the shonlder, probably due to shell-burst and oxygen deprivation by carbon monoxide. After a time-gencrally two to six days-this 
rigidity passes off. In wasting diseases, rigor may not appcar at all, or appear early and pass off quickly.

Rigor is mainly due to the formation of lactic acid in the absence of oxygen. The lactic acid thus formed alters the normal reaction of the muscle, and brings about coagulation of the muscle proteins. If the accumulation of lactic acid be prevented, either by the presenco of oxygen or by perfusion of the muscle with saline, rigor does not supervene.

Rigor may also be induced in muscles by plunging into boiling water. In this case, "heat rigor" takes place. The proteins of the muscles are coagulated without any attendant chemical changes, such as acid formation. Similarly, soaking in distilled water brings about a "water rigor." A water pressure of 400 atmospheres produces rigor of the muscles of terrestrial and shallow-water animals.

Smooth Muscle.-Although smooth muscle is generally found in organs which perform slow movements, in some animals noted for quickness and grace, such as the squid, there exists nothing but smooth muscle. In the higher animals it gives motility to organs over which there is no voluntary control; hence the name "involuntary" muscle.

In addition to a slow rate of contraction, with a long latent period, smooth muscle is characterized by the fact that it cannot be thrown into complete tetanus. Its contraction is of the nature of a single twitch.

Smooth muscle, like striated muscle, responds to a gradation of stimuli, and shows thermal, chemical, and electrical changes. In chemical composition it is probably much the same as striated muscle. It undergoes both chemical and heat rigor.

Smooth inuscle possesses the property of tonus-a condition of sustained muscular contraction, which is influenced in the direction of further contraction or relaxation by the nerve-supply. Augmentor or accelerator nerves increase tonus, inhibitory nerves relax. This double nerve-supply is a characteristic of smooth muscle.

Smooth muscle is also characterized by the property of rhythmicity-periods of contraction alternate with periods of rest. This seems to be a function of the muscle itself. Such is obserred in the stomach, intestine, bladder, spleen, and other organs.

Associated with smooth muscle are local nervous networks or plexuses, such as Auerbach's and Meissner's plexuses in the intestine. These endow the muscle with the property of peristalsis-co-ordinate and recurring waves of contraction, preceded by waves of relaxation which together force the contents along the muscular tube 


\section{CHAPTER LXIY}

\section{"ANIMAL ELECTRICITY"}

VARIous tissues of the body display electrical currents when in action or when injured. Such currents are sometimes referred to as "animal electricity." If a nerve-nuscle preparation be placed upon a glass plate, and by means of a glass rod the free end of the nerve be allowed to touch the muscle, a contraction occurs (Fig. 226). This is an experiment contrived by Galvani to prove the existence of animal electricity. In his first experiment, Galvani used metals. He found that if the hind-limbs with the skin removed be suspended from an iron stand by a copper hook passed through the lower part of the vertebral column, contraction of a leg occurs every time it is made to touch the iron stand. He supposed that this contraction was due to animal electricity. Volta insisted that it was due to the completion of the circuit between the two metals by the wet tissue of the frog. From the controrersy between Galvani and Volta came about the invention of the galvanic battery, and the development of electrical science. The discovery of the electric fishes gave the crowning proof of animal electricity. The Malapterurus was known

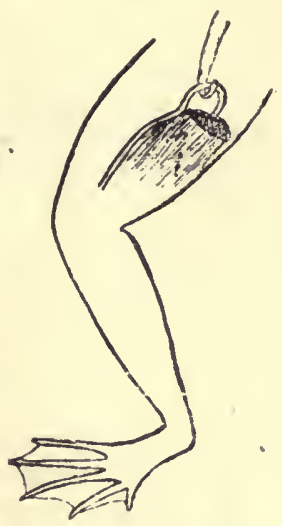

Fig. 296. - Diagray of Galvasi's ExPERIMEXT. CONTRACTION WITHOUT METALS. to the ancient Egyptians, and figured in their monuments. The electric eel of South América gives a most powerful shock. The natives used to exhaust wild-horses by driving them into a marsh infested with these eels, and so capture them.

Animal currents now play an important part in the study of abnormal conditions of the heart. It was at first believed that natural currents pre-exist in normal resting tissues, but it is now known that these currents only occur when the chemico-physiological condition of the tissue is altered by activity or injury.

The Electromotive Properties of Muscle and Nerve.-If a normal muscle or nerve be connected by a pair of non-polarizable electrodes to a galvanometer, no deflection of this instrument takes place, showing that normal muscle or nerve is isoelectric: Perfectly" "normal" muscle is difficult to obtain, since it is necessarily injured in the pre- 
paration. A muscle which has been soaked in normal saline sereral hours after its preparation is isoelectric.

If a muscle which is at rest in such an isoelectric condition be damaged-e.g., by heating-it is found that there is now an electric current flowing through the galvanometer. In such an injured muscle

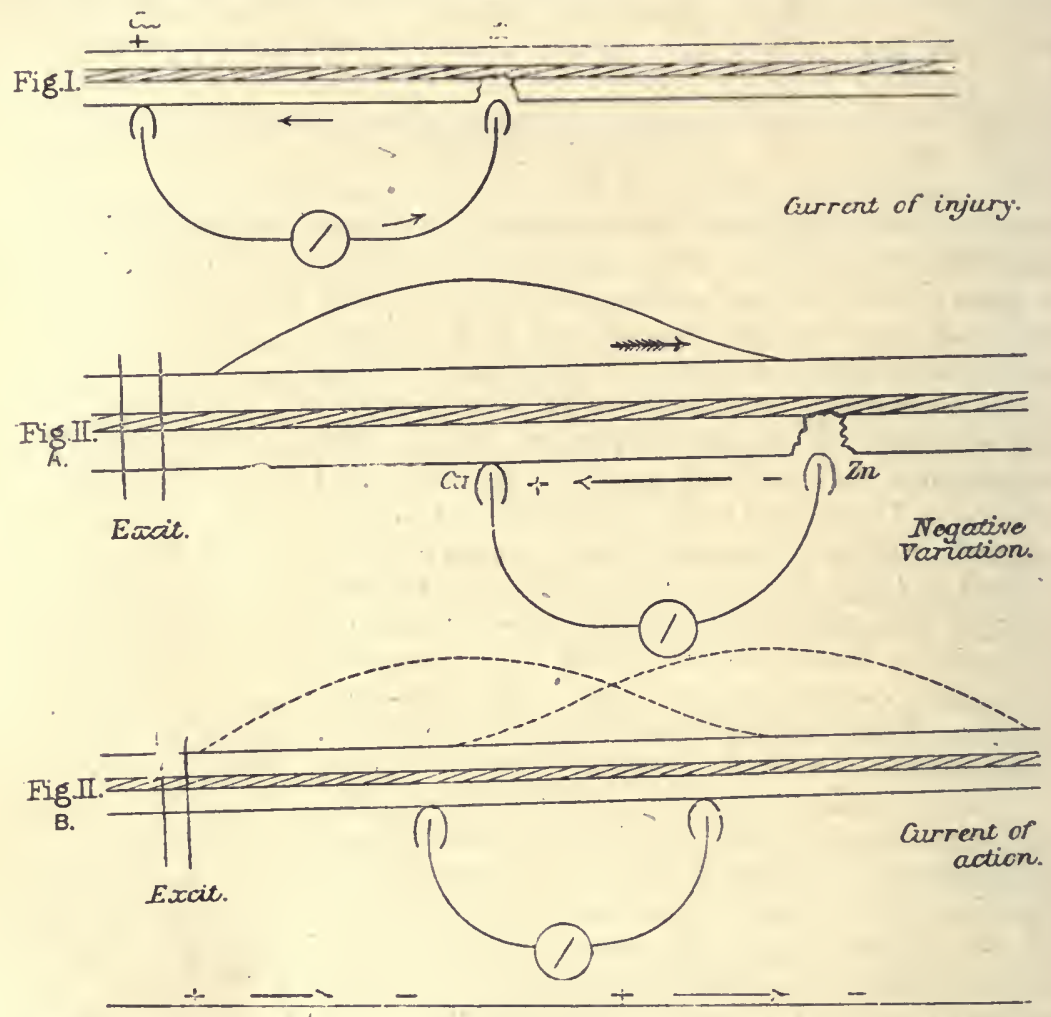

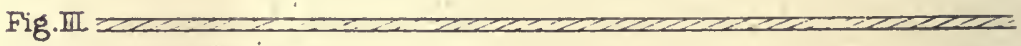
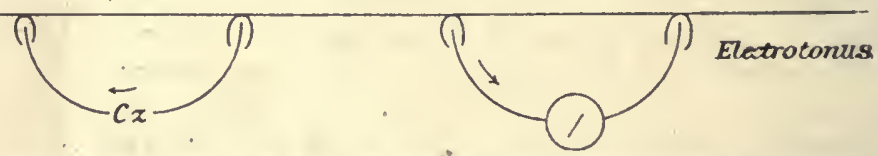

Fig. 297. Diagrais to Illustrate Currext of Injury, Negative Variatiox, Currext of Actiox, Flectrotonus.

the injured part corresponds to the positive element of a galvanic battery. The current therefore flows in the muscle from the injured part to the normal part; outside the muscle it flows through the galvanometer from the normal $t$ ) the injured part. The "current of injury" is usually described in terms of the direction of the current through the galvanometer; therefore, the site of injury is said to be negative (or zincative, like the zinc of the battery) to the normal 
tissue (Fig. 297). The current of injury can be simply demonstrated by Galvani's experiment already quoted. It may also be shown in nerve by placing the cut surface of the nerve on one plug of kaolin and the uninjured part on another. Then, if the attached muscles be sufficiently excitable, on bringing the kaolin plugs into contact with strong saline, which is a good conductor of electricity, the muscles contract (Fig. 298).

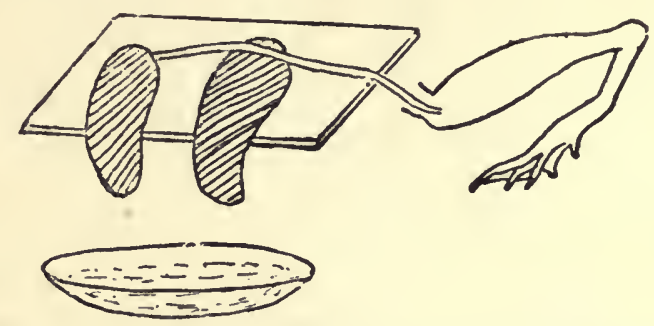

Fig. 298. -Diagram of the Experiment to show the Stimelation of a Nerie BY ITS OWN "CURRENT OF INJURY."

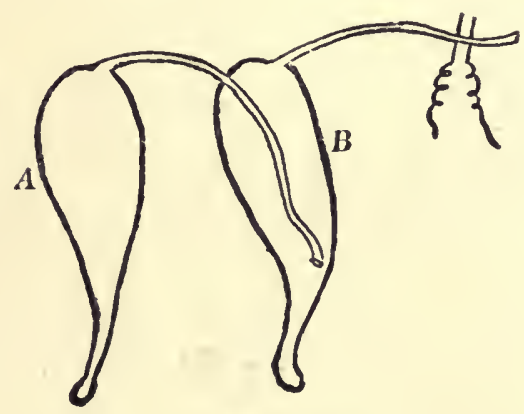

Fig. 299.-Diagan of the EXPerimest ox Secostary Twith.

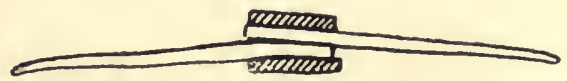

Fia. 300.-Diagram of the Experimext to show the Stindelatiox of a Mescle bY THE "CuRrext of ACtiox" OF Axother MUSCLE.

A similar condition pertains when any part of a muscle or nerve is more active than the rest. The active part in reference to the current through the galvanometer is negative to the resting part. Such a current is termed the "current of action." It may be simply shown by laying two nerve-muscle preparations, A and B, upon a glass plate, and placing the nerve of one muscle (A) along the other muscle (B). Upon exciting the nerve of $B$, the muscle contracts, followed immediately by a contraction of "A. Similarly, if B bo 
tetanized through its nerve muscle, A also passes into the tctanic state. The muscle $\mathrm{A}$ is stimulated to contraction by the current of action in $\mathrm{A}$, and not by any spread of the exciting electric current. This is shown by using the reating heart and a nerve muscle pre-

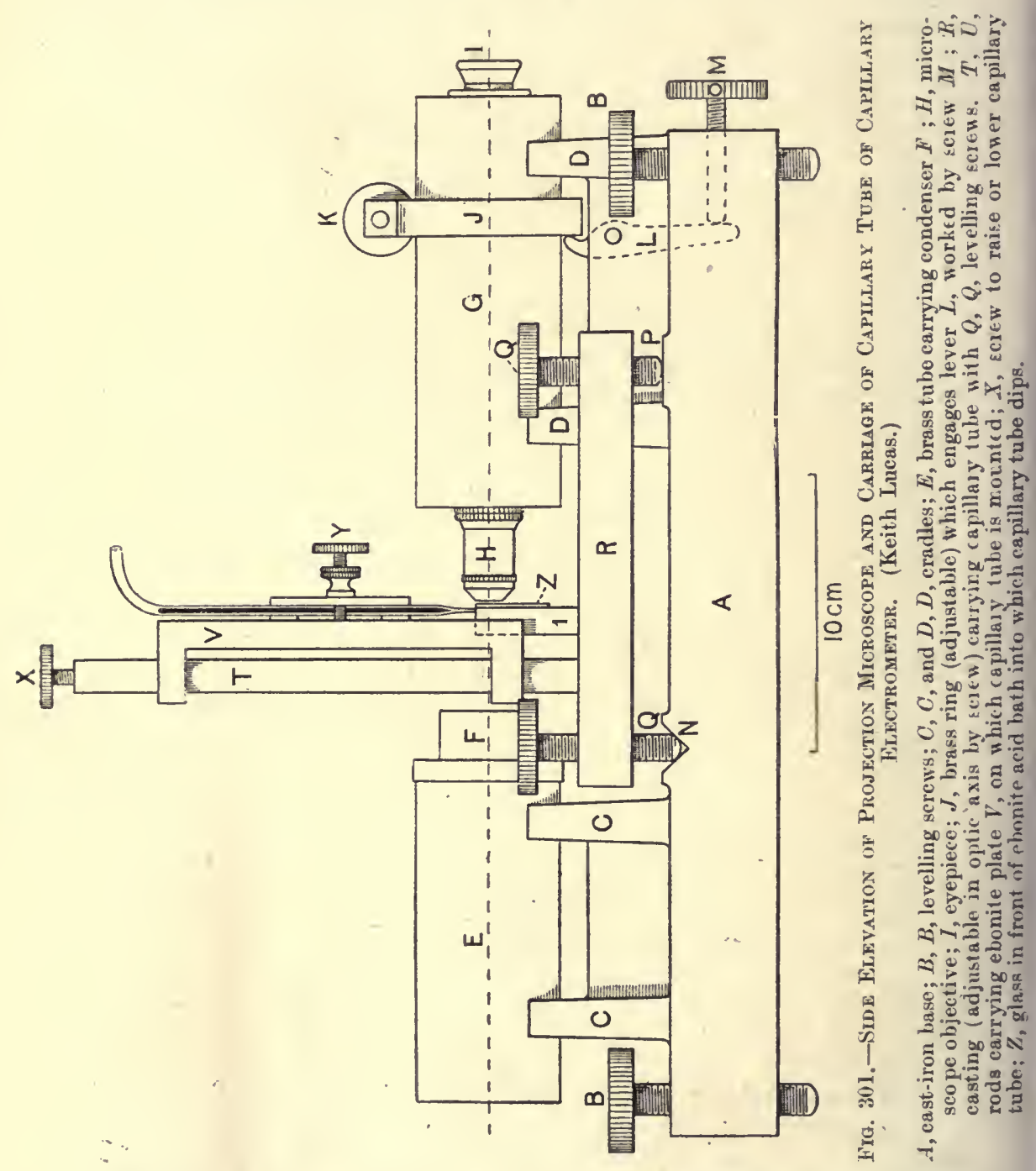

paration. If the nerve be placed upon the leating lieart, the musclo contracts with each beat of the heart. Occasionally, if the nerve be very excitable, the muscle contracts at the end as well as at the - keginning of the heart's contraction.

If two muscles be pressed togetrer, excitation of either causes 
contraction of both. In this case, the current of action in one muscle excites the other directly (Fig. 300).

Normally, the presence of such currents is shown by the use of the galvanometer and special apparatus (Fig. 301).

If an injured muscle be led off to the galvanometer and stimulated, it is found that on each single contraction, or, better still, on tetanus, the current of injury is diminished or may be overbalanced, since

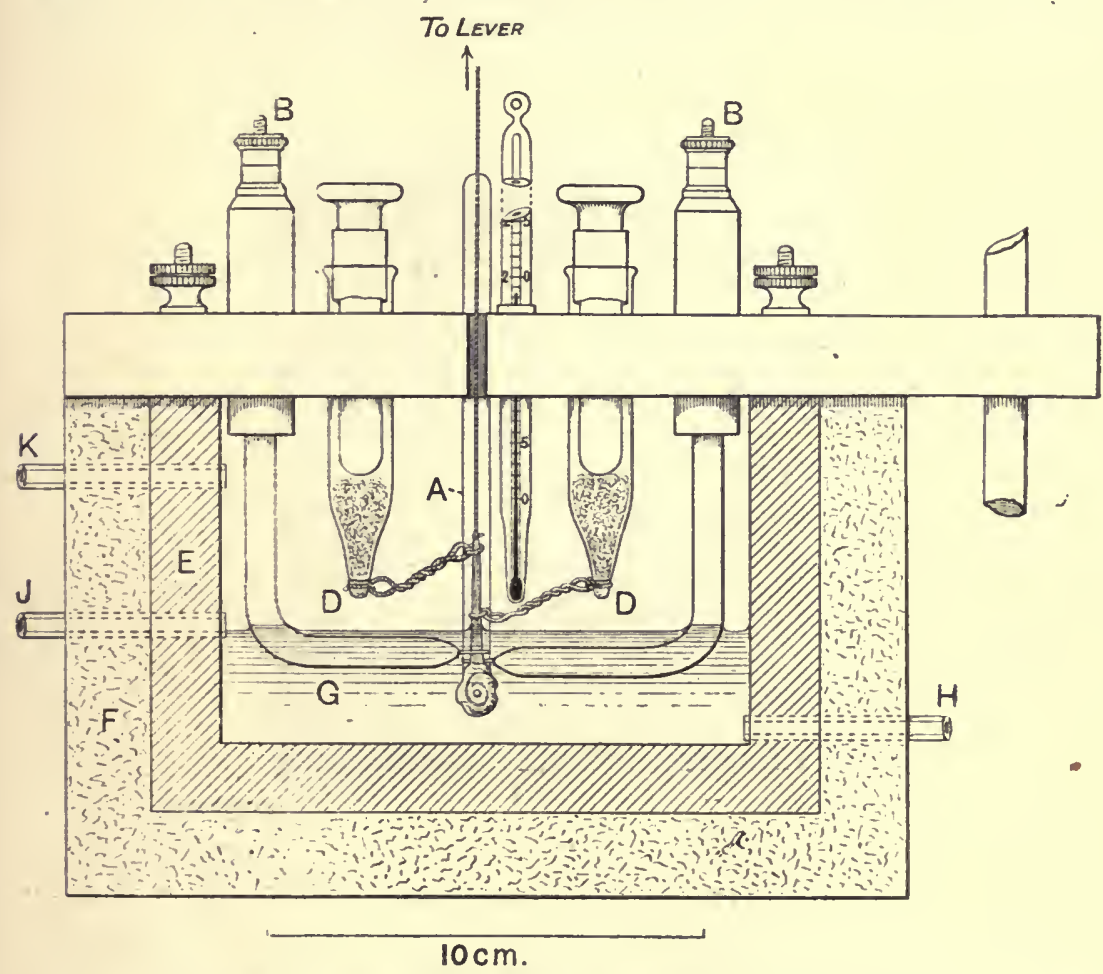

Fie. 302.- Keith lucas Moist Chajber and Electrodes.

$A$, Glass rod; $B, B$, tubes containing platinum eleetrodes; the leading off eleetrodes are glass tubes filled with Ringer's solution plugged by filter candles containing zinc sulphate and below by cotton-wool wads $D, D$, conneetcd to musele; $E$, ebonite trough with glass sides enclosed in felt $F: G$, Ringer's solution immersing lower part of muscle; $H$, inlet, $J$, outlet for fluid: $K$, aeeessory outlet for totally immersing muscle when $J$ is elosed. ?

the change from rest to action is greater in the uninjured part than in the injured part. This diminution of the injury current is termed "negative variation" (Fig. 297).

When uninjured tissue passes into action, there is what is termed a "diphasic variation." This is because first the part proximal to the stimulus is active, then the distal part; the action is not simultaneous throughout the whole of the muscle. When $\mathrm{A}$ is active 
and $B$ at rest, there is a current of action through the galvanometer from $B$ to $A$; when both $A$ and $B$ are active, there is no deflection. When $B$ is active and $A$ at rest, there is a current through the galvanometer from $A$ to $B$.

If the transmission of the active state from $A$ to $B$ is quick, the isoelectric interval is naturally short; if it be long, the interval is correspondingly increased. Thus, the rate of transmission of the wave of activity may be measured. In the nerve trunk of a frog it is about 30 metres per second; in striated muscle about 1 metre per second; in the frog's ventricle about $\frac{1}{10}$ metre per second.

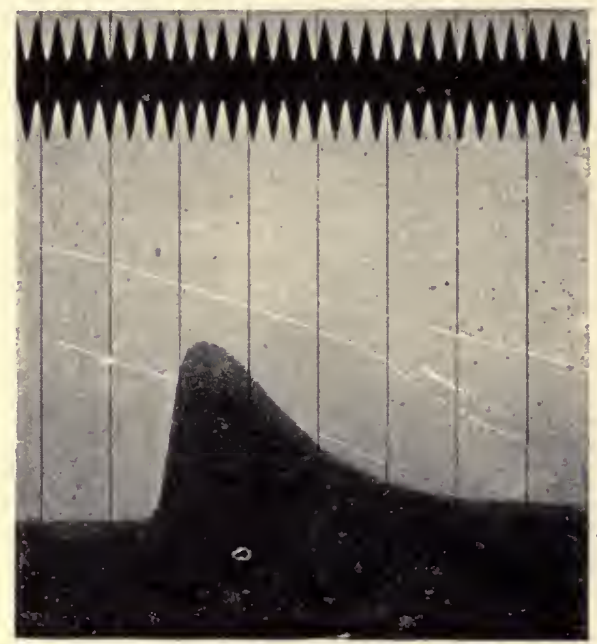

Fio. 303.-Typical Excursion of Sartorius Muscle to Single Induction Twitch. (Keith Lucas.)

Read right to left.

In the heart, the current of action induces a triphasic variation. This can probably be explained as follows: Suppose one non-polarizable electrode $(B)$ is placed on the base of the ventricle, another $(A)$ on the apex. The excitatory wave enters the base of the ventricle by the A.-V. bundle. $B$ is now negative to $A$. It passes then to the apex. $A$ is now negative to $B$. The ventricles contract in such a manner that the apex finishes contracting before the base. The blood is wrung out from the ventricle, and the muscle round the arterial orifices is the last to contract; $\mathrm{B}$ finally, therefore, becomes negative to $\mathrm{A}$. The response of the heart in terms of negativity is therefore $B, A, B$ (base, apex, base).

Cutaneous Currents.-Normally, the skin of all vertebrate animals is traverzed by an electric current from without inwards (Fig. 305). This current appears to be caused mainly by the action of the cutaneous glands, or of active secreting single cells in the skin. When the parl 
of a cat's foot is made to sweat by stimulation of the sciatic nerve, the pouring out of the sweat is accompanied by an increase (a positive variation) of the ingoing current. If, however, the effect of the nerve be abolished by atropine, such a result is no longer obtained. The normal current of the skin is found to be increased by direct excitation, this increase or positive variation being reduced or abolished by the local application of atropine, chloroform, or carbon dioxide.

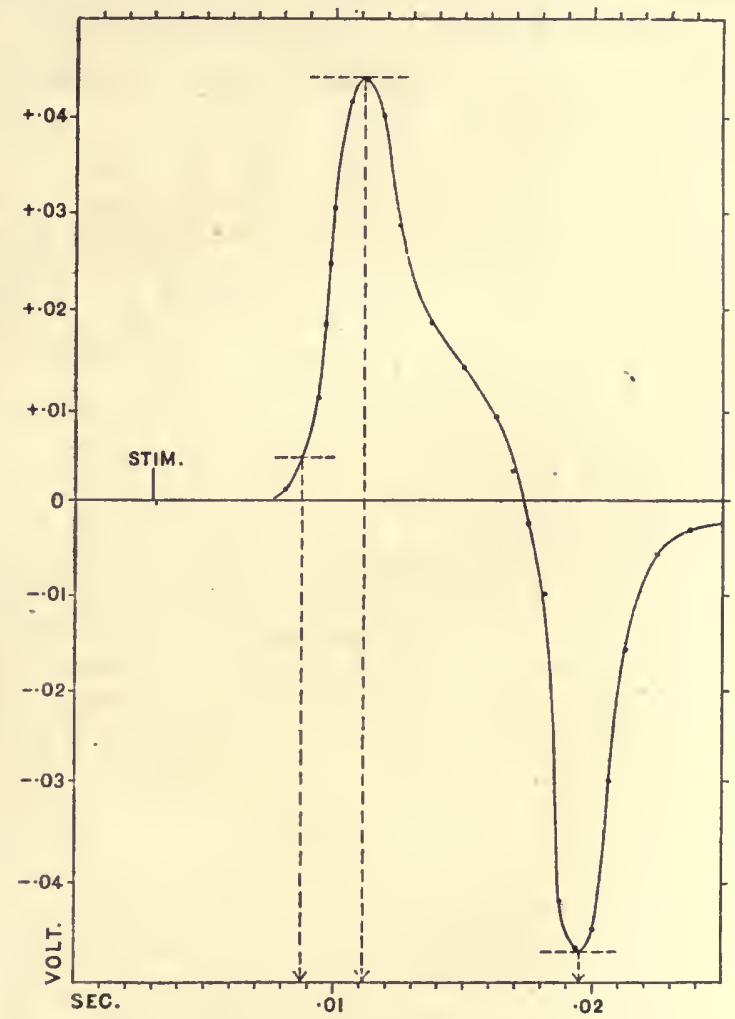

Fig. 304.-Analyzed Diphasic Response of Sartorius at $18^{\circ} \mathrm{C}$. (Keith Lucas.)

Salivary Glands.-In the submaxillary gland, which has been especially studied, the resting current flows through the gland from the surface to the hilus, and therefore from the hilus through the galvanometer to the surface (Fig. 306). When the gland is made to secrete by stimulation of the chorda tympani nerve, the hilus becomes still more galvanometrically positive-an effect abolished by atropine. Stimulation of the cervical sympathetic nerve has the opposite effect.

Retinal Currents.- If the eyeball and the retina be connected to a galvanometer, $a$ " current of rest" is observed, the direction of which depends on whether the outer or inner surface of the retina 
be used (Fig. 307). When light falls upon the retina, a complex variation ensues, depending upon the strength and duration of the stimulus, upon the condition of the eye, whether adapted to light or dark, fresh or fatigued, and upon the nature of the light, whether white or coloured. In the isolated retina there is first a positive and then a negative variation when light falls on it. When the light is cut off, a positive variation is produced. As the result of a momentary flash there is a short latent period- 0.01 second-followed by a short negative variation, followed by a large positive variation, quickly

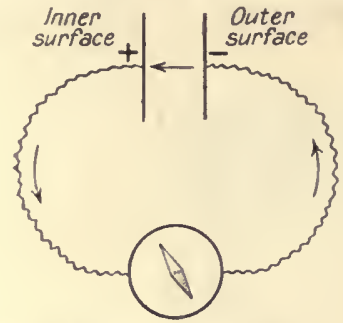

Fig. 305.-Skin Current.

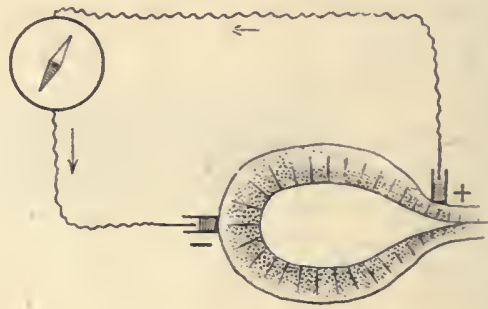

Fig. 306.-Gland Current.

followed by another diminution of the positive variation, and then by a long-drawn-out increase of the positive variation.

Electric Tissues.- In some fishes there is developed a tissue capable of producing electricity. These fishes are either elasmobranchs, such as the rays (Raia ocellata, $R$. lævis, etc.) and the torpedo fish (Tetronarce), or teleosts, such as the electric eel (Gymnotus), the somewhat similar elongated fish (Mormyrus), the star-gazer (Astroscopus), and the electric catfish (Malapterurus). The electric tissue consists of
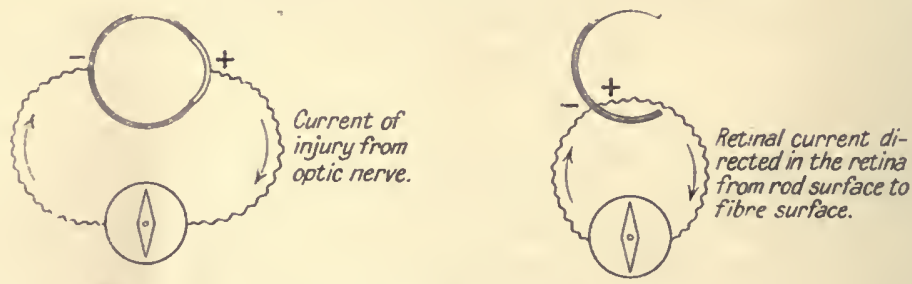

FIG. 307.

a series of plate-like units known as electroplaxes (Fig. 308). The electroplax lies in a compartment of connective tissue embedded in a jelly-like mass, through which the nerve and blood-supply pass to it. In some cases it is to be considered as a single cell with many nuclei, in others a fusion of cells-a syncytium. The discharge is composed of about 200 shocks per second, and the E.M.F. may be sufficient to kill other fish in the neighbourhood. In the discharge of the organ the current flows through the organ from the ventral to the dorsal surface, and through the galvanometer from the dorsal 
to the ventral surface. In Gymnotus the shocks are from tail to head, in Malapterurus from head to tail, the direction depending upon the point of entrance of the nerves to the organ. A giant ganglion cell and its nerve fibre, branching multitudinously, supplies the whole of each electric organ in this fish.

Blaze Currents,-After any living tissue has been strongly tetanized for a short space of time, a "blaze" current follows in the same direstion as the tetanizing current. This is a sign of life; dead tissue does not give it. Seeds hare been tested by this means, and their germinating power thus demonstrated.

Electrotherapy.-Elestricity is largely employed in the treatment of disease. It may act by producing either chemical or thermal effects. In the first case, the galvanic electric current is used, since it causes a steady migration of positive ions to the negative pole, and of negative ions to the positive pole. It may be employed therapeutically for three purposes: (1) To produce an alteration in the ionic

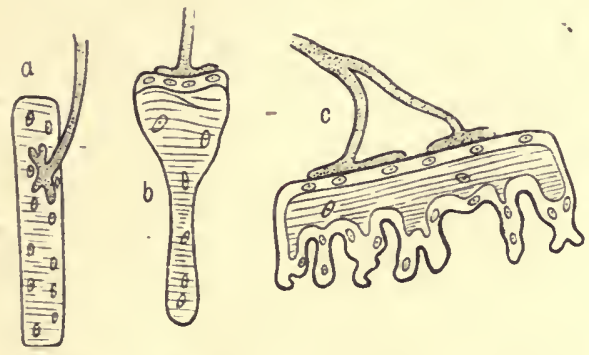

Fig. 308.-Nervous Structures Stippled, Striated Structures ixdicated by LINES. (Redrawn from Dahlgren and Kepner.)

$a$, Diagram of muscle fibrc; $b$, of electroplax of Raja batis; $c$, diagram of electroplax of Raja lavis.

content of a region, as is probably the case when used for piomoting the absorption of fluid effusions. (2) To causc a formation and accumulation of new chemical bodies at the poles. Such bodies may have a caustic action, and be used for the destruction of hair follicles (superifuous hairs), nævi, etc. (3) By moxns of the current to introduce curative ions through the skin-the "ionic method of medication."

The faradic current cannot be used for the above purposes, since the current is frequently made and broken. The ions then migrate in sudden movements or jer'ss, and act as a stimulus to excitablc tissue, such as muscle. The faradic current is of great value in the treatment of paralysis.

If an interrupted current be made to oscillate with extreme rapidity across the body, the ions do not have sufficient time to act as a stimulus, and remain more or less stationary. Under these conditions, a powerful current (3 ampìres), six times stronge: than a current 
necessary to kill if passed in one direction only, may be oscillated without any contraction being produced, provided it be oscillated frequently enough. The result of such a current is an agreeable sensation of heat. This forms the basis of "high-frequency" treatment, or "diathermy." When these high-frequency" currents are passed through the body, part of the electrical energy is transformed into heat, which is produced in all parts, both superficial and deep, in which the current flows. The effects of diathermy, so far as can be seen, are produced through their thermal action, and the same results can be obtained by the simple use of hot baths. 


\title{
BOOK XII \\ 'THE NERVOUS SYSTEM
}

\author{
CHAPTER LXV
}

THE NEURON

THE nervous mechanism was evolved to correlate the inulticellular organism with its surroundings and facilitate the proper interaction of the various organs. We have seen in previous chapters how the heart, the vaso-motor mechanism, the respiratory and digestive mechanisms, are all correlated to the body needs by the aid of the nervous system. We have now to consider how, by the aid of the nervous system, the animal adjusts itself to its environment.

The unit structure of the nervous system is the neuron. It consists of a nerve cell, with its processes. The neuron may have a variety of forms, according to the function it subserves (Fig. 309). Those engaged in the perception of the outside stimulus are small, with short processes-as, for example, the receptor cells, concerned in olfactory and visual sensations. On the other hand, neurons which conduct impulses to distant parts are supplied with one or more long and a number of short processes. The cells of the anterior horn of the-spinal cord are an example of this type of neuron. They have several processes, and are termed multipolar. In the living cell body there may be seen a large, well-defined nucleus, and numerous granules floating in a homogeneous fluid. On treatment with alcolol, the cell contents are precipitated as Nissl's granules-discrete masses which stain with methylene blue. These are not found in exhausted cells, and disappear from those cells whose axons are divided and functional activity arrested. Of the processes, all but one are short, and branch like the roots of a tree, till they end in small, bud-like expansions, known as gemmules. These processes are known as dendrons. The long process, known as the axis cylinder, or axon, comes away from a part of the cell in which there are no Nissl's granules-a part known as the axon hillock. The axon is characterized by its length and by the fact that it does not divide until near its final terminations.

The axon, or axis, cylinder is the essential conducting part of the nerve-fibre. Many such fibres go to make up the anatomical " nerve." Such fibres may be either medullated or non-medullated. 
Medullated nerves are so called because in them the axon is surrounded by a cylinder of fatty material, forming the medullary sheatl. This sheath is interrupted at regular intervals. Such points are known as the nodes of Ranvier. The neurilemma is a nucleated sheath of fibrous tissue, and is continuous over the nodes of Ranvier.

A non-medullated nerve, sometimes called a grey fibre, in contradistinction to the white medullated nerve, consists merely of an axon surrounded by the nucleated neurilemmal sheath.

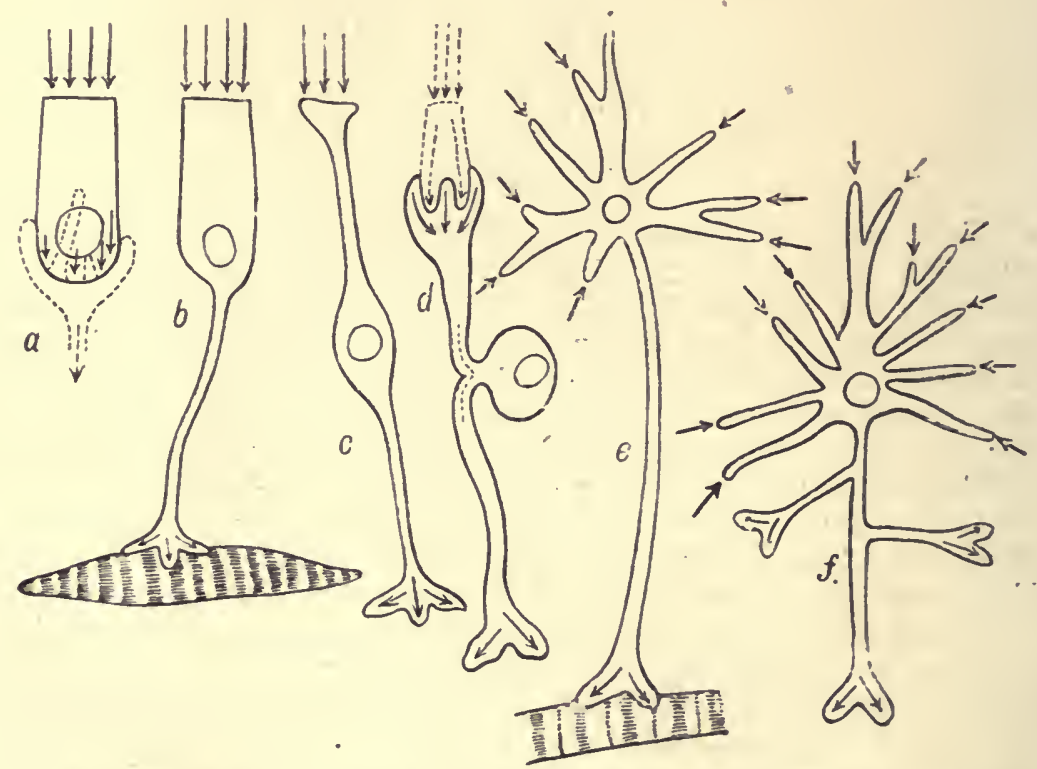

Fig. 309.-Diagrays of Different Kinds of Nerte Cells. External Arrows at Perceptory (Receptor) Surface; Ixternal Arrows at Discharging (EFfector) Surface of Cell. (Redrawn from Dahlgren and Kepner.)

$a$, Nerve cell with no process; $b$, nerve cell with one process at effector end organ attached to muscle fibre; $c$, nerve ccll with end organs on two processes; $d$, nerve cell with impulse path independent of cell; $e$, nerve cell with multiple perceptory end organs; $f$, nerve cell with multiple perceptory and discharging end organs.

Medullated fibres are those of the brain and spinal cord, and the cerebro-spinal nerves; the non-medullated are the post-ganglionic fibres of the sympathetic nervous system.

Speculations, based on the concentration of ions in the various parts of the nerie fibre, have been put forward concerning the transmission of the nervous impulse. Histological means (staining with solutions of silver nitrate containing a little nitric acid) seem to show that chlorides occur in abundance along the course of the axon. Salts of potassium appear mainly at the nódes of Ranvier, and just outside the axon in the medullary sheath. They are demonstrated by treat- 
ing the nerve with cobalt sodium hexanitrite, and after washing differentiating as a black precipitate by adding ammonium sulphide. Such mothods destroy the integrity of the nerve, and set free the salts from their combination with the colloidal living substance.

It is claimed that there is laid down in the cytoplasm of the cell for the purposes of conduction a system of neuro-fibrils, which run
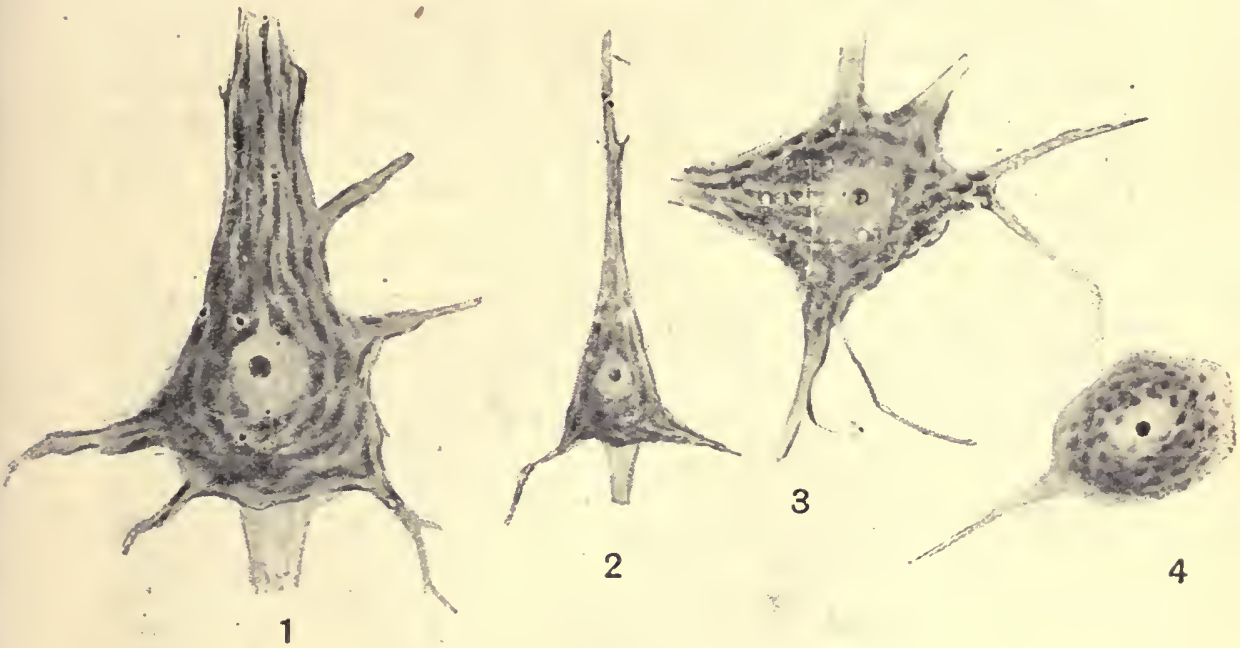

FIG. 310.

1, Large Betz cell from human cerebral cortex, showing Nissl's granules and cone of origin of axon at the base. 2, Medium-sized pyramidal associntion cell. 3, Anterior cornual cell. 4, Posterior root ganglion cell. (Mott.)

from end to end of the cell processes. Aceording to some authorities, the neurofibrils are not confined to one nerve unit, but freely leave one neuron and pass into another, thus forming a netion throughout the whole nervous system. The study of the living nerve cell does not reveal these fibrils; they are artefacts produced by the method of preparation.

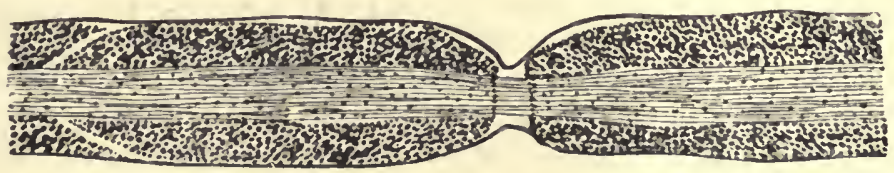

Fig. 311.-Portiox or a Medullated Nerve-Fibre from a Mamadi.

Another type of neuron is the bipolar nerve cell (Fig. 303). In mammals, these occur only in the ganglia in connection with the eighth nerve; in fishes, they are found in the spinal ganglia also. The cell body is elliptical in shape, with two processes given off from the two ends of the ellipse. Such a cell is the parent cell of the unipolar 
spherical cell found in the spinal ganglia of mammals. The two processes of the bipolar cell gradually approach each other during development until they combine to form a $\mathrm{T}$-shaped junction.

In the cortex of the great brain are other characteristic neurons; the cells are pyramidal in shape; branching dendrons arise from each angle of the pyramid, and an axon from the middle of the base (Fig. 310).

In the cerebellum are found neurons with large, pear-shaped cclls, with a single axon at the base, and a wonderfully branched dendritic process at the stalk end. Throughout the grey matter of the brain and spinal cord there are small association cells, known as the Golgi cells, characterized by the fact that their axons, after a short course, divide into many terminal branches.

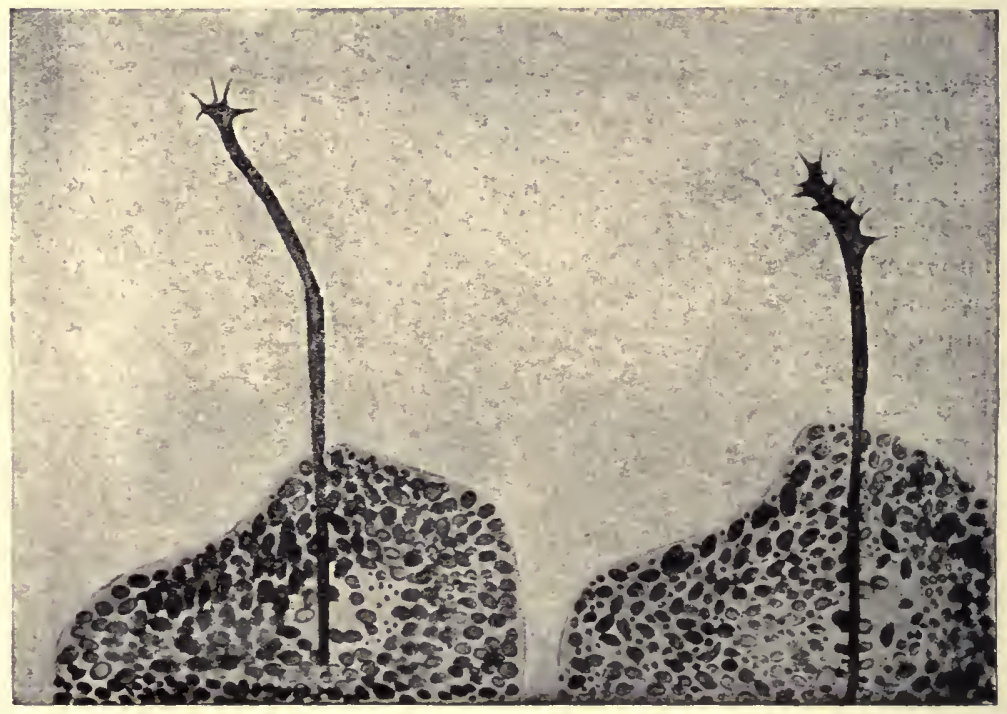

Fig. 312.-Two Views, taken at Twentr-flve Mixutes' Interval, of the Same Nerve-Fibre growixg from a Group of Eybryonic Spinal Cord Cells ixto THE LYMPH. (Ross Harrison.)

Microscopical preparations of the central nervous system are identified largely by the type and arrangement of nerve cells.

The neurons are held together by a supporting tissue, known as neuroglia. They are brought into relationship with one another through their end terminations-the dendrons and the axon. These processes do not fuse together; they are in contiguity, not in continuity. The intertwining branches form a synapse; one neuron, conducting an impulse, induces an impulse in another through the synapse. The synapses only allow conduction in a forward, not in a backward, direction. For example, a stimulus can pass up a motor nerve-fibre as far as the anterior horn cell but not beyond it into 
the spinal cord. It has been suggested that the gemmules at the end of the dendrons are amœboid in nature, so that this contiguity may be rendered more complete at some times than at others-for example, that they may be separated during sleep. There is no evidence in favour of this view.

The above statement embodies what is known as the neuron theory. Of recent years, the theory has come in for a considerable amount of criticism. Some have affirmed that neuro-fibrillæ pass from one neuron into another. Doubt has also been expressed as to whether the neurons are genetically single cells, and whether regcnerated nerve-fibres are to be regarded as parts of a single cell. It is obvious that, should either of the above contentions be true, the neuron theory, as originally enunciated, is no longer valid. On the whole, recent evidence tends rather to conform the theory than otherwise. The development of the nerve cell has been watched in living preparations made from the embryo, and the outgrowth of the axon observed (Fig. 312).

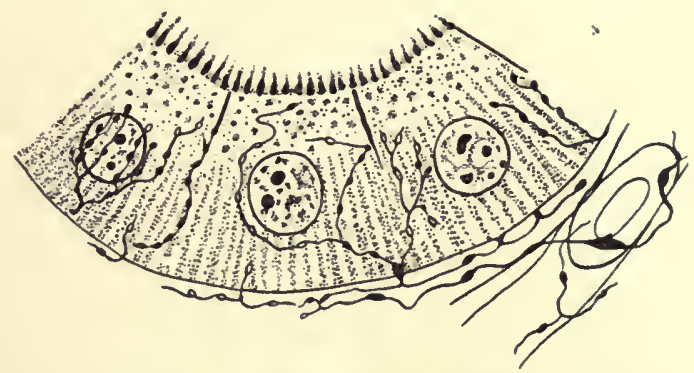

Fig. 313.-Portion of Rexal Epithelium of Frog, showisg Effector (Motor) Nerve Evdings ix Cells. (Redrawn after Smirnow, from Dahlgren and Kepner.)

Those nerve-fibres which conduct inwards towards the nervous system are termed ingoing, or afferent; those which conduct outwards, the outgoing, or efferent. The nature of a nerve may be ascertained-(1) by observing the results of its sestion; (2) liy studying the effects produced when the cut ends of the nerve are stimulated. If an afferent nerve be divided, there results a loss of sensation in the area supplied by the nerve. Stimulation of its peripheral end yields no result; stimulation of its central end, on the other hand, calls forth some. If it be sensation, the nerve is termed sensory; if some form of movement, excito-motor ; if inhibition, excito-inhibitory ; if a secretion, excito-secretory.

Section of an efferent nerve paralyzes some function, the movement of muscle, striped or smooth, secretion of a gland, etc. Stimulation of the central end of such a nerve is without result; and stimulation of the peripheral end produces the action which it normally excites. This action may -either be in a direction of increased activityaugmentor - or of decreased activity-inhibitory. If it excites a muscle, it is termed motor; if the bloodvessels, vaso-constrictor; if it 
cause the secretion of a gland, secretory. Similarly, it may be músculo-inhibitory, vaso-inihibitory, secreto-inhibitory, etc.

Most nerves of the body are mixed nerves, containing both afferent and efferent fibres.

The Reflex Arc.-The sensory neuron, when stimulated through its nerve-ending, transmits its impulse inwards, passes it on to the efferent neuron, which transmits it outwards, and effects some action or other. This chain-scnsory surface (receptor), afferent conductor (the joining synapse), the efferent conductor, the reacting organ, or effector-forms what is known as the reflex arc. In any reflex arc at least two neurons arc essential. Generally, a third neuron connects the afferent and efferent neurons, and in many reflex arcs several connecting neurons are interposed in the reflex path.

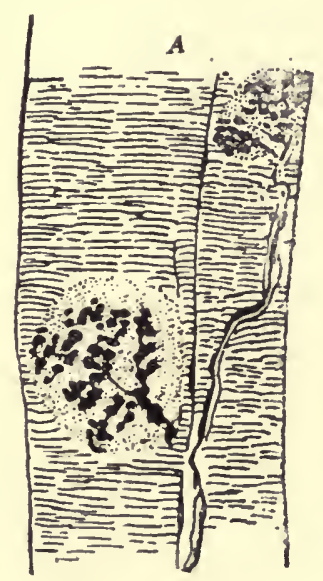

Hig. 31\%,-EFFector NERVE ExDINGS IN MUSCLes OF LizAFid. (Redrawn after Kühre.)

The receptors are classified according as they respond to stimuli from-(1) without the body (extero-ceptive); (2) from the animal's own tissues-e.g., the muscles, tendons, joints, ol the labyrinth of the ear (proprio-ceptive); (3) from the viscera (entero-ceptive).

The Conductors consist of the axons of afferent and efferent neurons, and the synapse between these. The code of interaction between the afferent and efferent conductors of the spinal cord has been studied in what is known as the "spinal animal "- that is, an animal in which a division of the cord has been made in the lower cervical region. Such an animal can be kept in health with careful attention, and studied months after the initial effects of the lesion have subsided (see p. 674). The conduction of the nervous impulse in a reflex arc differs materially from conduction in the nerve-fibre only. This is mainly owing to the interposition of the symapses.

Conduction across a synapse is much slower than along a nervefibre, and is easily fatigned. Want of oxygen particularly causes failure of conduction at this point, and drugs such as nicotine painted on ganglia paralyze the synapses in them. The synapse interposes a valve-like action in the chain of conductors, permitting conduction of the impulse in one direction only-namely, from the receiving afferent to the effecting efferent neurons.

The Effector Organs form the colmection between the efferent nerve and the cells of the tissuc affected. In some cases they have a definite structure-for example, the motor end-plate in muscle. In other cases there is merely a "receptive substance," dependent for its nutrition rather on the cells of the tissue than on the nervefibre with which it is in connection. It therefore does not degencrate 
when the nerve is serered. Such receptive substance may be acted upon by chemical substances, and a "chemical reflex" thereby evoked. For example, adrenalin acts upon the effector organs in connection with the sympathetic system, and evokes actions identical with those obtained by stimulation of the various sympathetic nerves.

The effectors are concerned-(1) in effecting the movements of voluntary muscle; (2) in regulating the action of smooth and cardiac muscle; (3) in evoking the secretion of glands. The functions of these effectors have already been dealt with in their various sections, and are also considered in connection with the central nervous system (cf. cranial nerves) and the autonomic system (p. 748).

A knowledge of the functions of the nervous system is best acquired by a study of two units: (1) The neuron; (2) the reflex are.

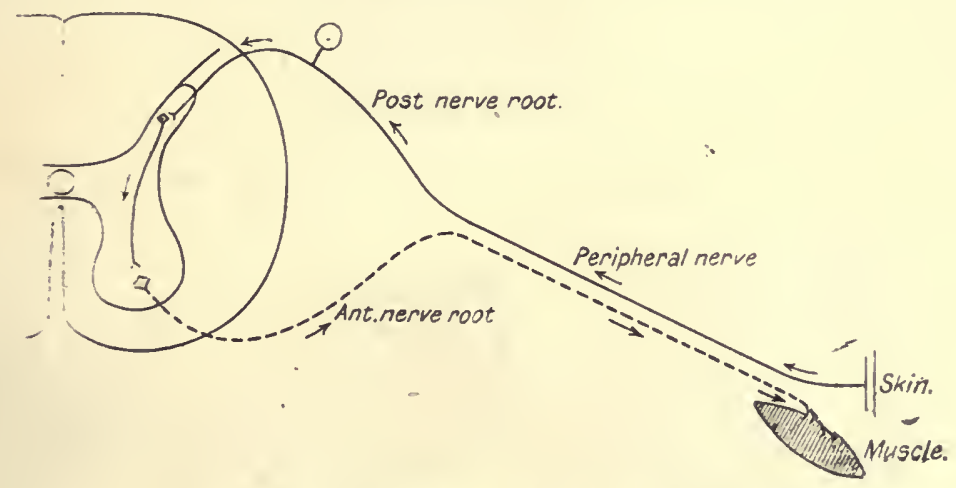

Fig. 315.-Diagram of Simple Reflex Arc.

The Function of the Neuron.-The cell body governs the nutrition of the whole neuron. Its power of nutrition probably depends upon the nucleus and the protoplasm which, when precipitated by reagents, form. Nissl's granules. The exact chemical nature of these granules is not known. 'They may' be of the nature of nucleo-protein, for they have great affinity for basic aniline dyes, such as methylene and toluidin blue. When a nerve cell has had a long spell of continuous activity, these granules become diminishod- "chromatolysis," as it is termed, occurs (Fig. 316). Such, for example, is the case in the nerve cells of the swallow after a day's flight.

It was found that if one eye of a dog be bandaged, and the other eye kept active by leading the animal about for twenty-four hours, that in the part of the brain concerned with the vision of the active oye chromatolysis had occurred, but not in the part of the brain connected with the rest:ng eye.

Chromatolysis takes place during asphyxia and in certain fevers. It also occurs in the nerve cell when the axon is cut. In this case, further changes occur, the cell body becomes swollen, the nucleus goes to one side of the cell. By observing in which cells this secondary 
retrograde degeneration occurs, the nerve cells connected with particular nerve-fibres can be traced. It has been shown, moreover, that such a degeneration may occur in other cells closely connected with the severed neuron; for example, cutting the posterior roots of a nerve causes chromatolysis in the closely connected cells of the anterior horn of the spinal cord.

The nutritive function of the nerve cell is most clearly seen in the axon after its section. When an axon is cut, the part of the axon cut off from the nerve cell undergoes Wallerian or primary degeneration.

The Effects of Section of the Axon.-In the first place, the conduction of impulses is interrupted. A current of injury is set up in the nerve which soon subsides, and is followed by a gradual loss of excitability and conductivity; the loss begins in the most central part of the cut peripheral end, and gradually passes towards the periphery.

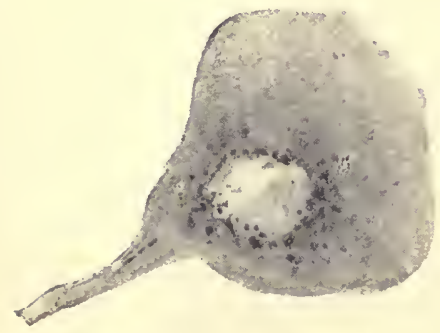

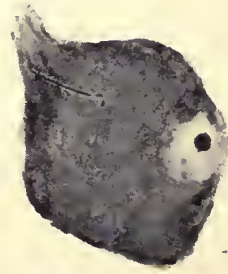

$B$

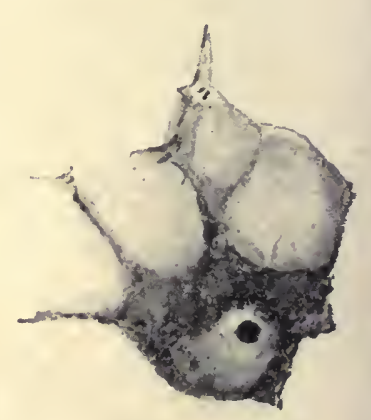

$C$

Fig, 316 .

$A$ shows pericellular chromatolysis of anterior horn cell; $B$ shows perinuelear chromatolysis; $C$ shows degeneration with vacuolation of the cytoplasm. (Mott.)

Following upon this, Wallerian degeneration occurs. The complex lipoid material of the medullated coat splits up, and the lecithin it contains breaks down, yielding cholin and fatty acid. The staining properties of the myelin change, owing to the setting free of oleic acid, and thus the degeneratc fibres, two or three weeks after their section, stain black with Marchi's fluid. Normal fibres do not stain so. By this staining reaction it is possible to trace the course of degenerating fibres in, and so unravel the structure of, the central nervous system. The myelin breaks up into droplets, and finally is absorbed. The nuclei multiply in the fibre, and finally the axon goes and the nucleated sheath is alone left. Old degenerated fibres are marked by their failure to stain with the Weigert-Pal method.

Regeneration of Nerve.-Even during the degeneration of the axon the first regenerative change begins to take place. This consists of 
the proliferation of the neurilemmal cells of the isolated part, to form a large number of spindle cells. At the same time, the products of

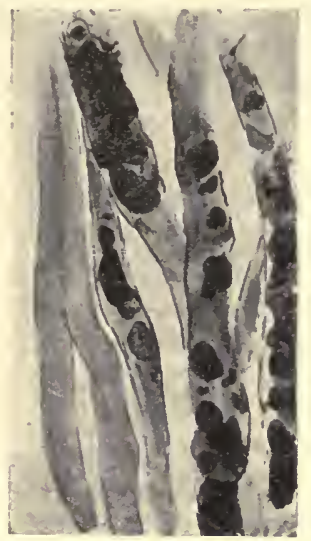

Fiù. 317. - Wallerian Degexeratiox is a Cat. Mlarchi Method of staising. $\times 600$. (Mott, from Allbutt's "System of Medicine.")

degeneration are remored by. invading leucocytes, possibly also through the agency of these spindle cells themselves, so that, when

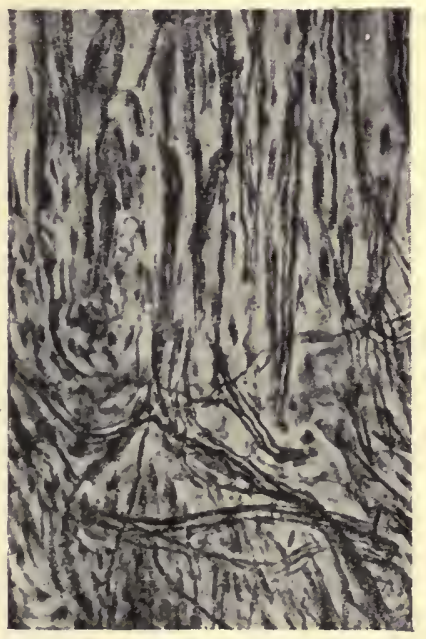

A

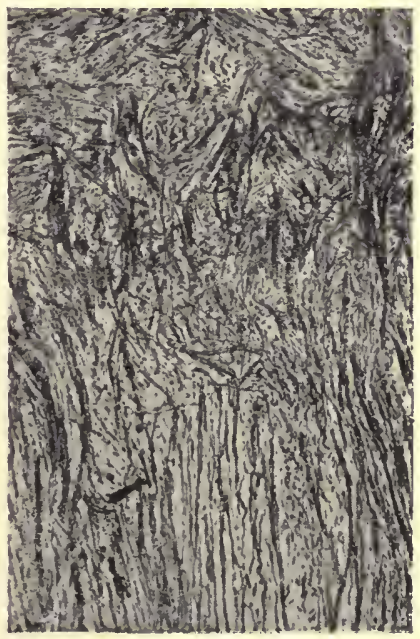

$B$

Fig. 318.-A, Section uxder High Pow his showixg Regexeration after Sirctiox of Sciatic Nerve of Kitten, Ose Mosth after Operatios. Active RegeNeration has OCCURRED, AS SHOWX by OUTGROWTH OF NEUROFIHIILS ACROSS the Seat of Legrox. $\times 300 . \quad B$, the same $\times 80$. (Mott.)

all signs of degeneration are removed, the isolated part of the nervefibre consists of these proliferated spindle cells. 
Under suitable conditions, the nerve-fibre may become regenerated, with the formation of a new axon, medullary sheath, and neurilemma (Fig. 318). There is considerable difference of opinion as to what exactly are the suitable conditions, and also as to what is the exact part played by the spindle cells in this regeneration. It is held by some authorities that "peripheral regeneration " or "autogenetic regeneration" may take place - that is to say, that full regeneration of the peripheral part may occur without any connection being made with its original nerve cell or some other nerve cell. Such a view cannot be accepted, for it has been shown that in all experiments favouring this view the possibility of the central influence of a nerve cell has by no means been excluded. When procautions are taken-as, for example, enclosing the nerve in a sterilized rubber cap, or transplanting to regions, such as tho peritoneal surface of the stomach, where no invasion of nerve-fibres occurs-then no regeneration takes place. The central influence of a nerve cell is necessary for the true regeneration of nerve. If no central connection is made, the regenerative changes will not pass beyond the stage of the formation of spindle cells. The question then arises as to what is the function of these spindle cells. According to the view of central regeneration, they serve merely as a scaffolding down which the new axon grows from the central end of the nerve. According to another view, the spindle cells, under the influence of the central nerre cell, develop into the new peripheral nerve-fibre, some spindle cells dereloping into axon, some into medullary sheath, and some into the new neurilemma. The former view is generally accepted. 


\section{CHAPTER LXVI}

\section{THE PHYSIOLOGY OF THE NERVE-FIBRE}

Nerve may be stimulated by natural or artificial stimuli. Natural stimuli are applied to the "receptor" mechanisms of the body, such as the nervous elements concerned in sight, smell, taste, hearing, touch, temperature. These are dealt with later.

A nerve may be artificially stimulated in various ways: mechanically, by pinching; thermally, by a hot wire; chemically, by placing on the nerre a few grammes of sodium chloride, or some glycerine; electrically, the induced current is commonly employed in experimental work upon nerve.

As judged by the effects of its stimulation on a muscle, nerve responds to minimal, submaximal, and maximal stimulation. The response, if any, is probably always maximal, but as by a weak stimulus only a few nerve-fibres are stimulated, the number of muscles-fibres which contract are correspondingly few; hence the minimal contraction evidenced by the lift of the muscle lever. In a mixed nerve, all the fibres are not equally excitable. For example, on gradually increasing the stimulation of the sciatic nerve of a frog, first the flexor muscles, and then the extensor muscles, are excited to contraction. Similarly, in a mixed nerve, the vaso-constrictor fibres respond to a stimulation weaker than that which affects the vaso-dilator fibres. The nerve of a nerve-muscle preparation is not equally excitable in all parts of its course.

Immediately after making the preparation, the nerve is most. oxcitable at its upper end. After a time this passes off, and the most excitable part progressively descends towards the muscle. A nervefibre is also more excitable in the neighbourhood of the main branches severed during its preparation. The increased excitability is probably due to changes in the nerve provoked by injury.

The excitability of nerve is modified by various factors. It is increased by slight cooling below room temperature, and decreased by greater cold. It is increased by gentle warmth. Loss of water at first increases and then abolishes excitability. Chemical substances affect nerve in various ways. Carbon dioxide, chloroform, and ethor depress the excitability.

If a constant (polarizing) electric current be passed through a nerve, it increases the excitability around the negative pole-the kathodeand depresses it around the positive pole-the anode.

The rate of conduction of the nerve-impulse is computed to be 
from 33 to 100 metres per second. It may be estimated as iollows, using the sciatic-gastrocnemius preparation of the frog: The recording drum is arranged at a fast rate, with a "striker" for completing the circuit of the primary current of the induction coil. To the secondary coil are attached two Du Bois keys in the manner shown in the diagram (Fig. 319). From these pass two pairs of electrodes, one of which will be applied to the upper portion of the nerve, the other to the lower portion. The latent period of the muscular contraction is determined, first for stimulation by the upper pair of electrodes, the lower pair being short-circuited by closure of its Du Bois key; then for stimulation by the lower pair of electrodes, the upper pair being short-circuited. The difference in time of the latent periods is determined by recording underneath the curves the vibrations of a tuning-fork oscillating 100 times per second. This difference represents the time taken for the nervous impulse to pass along the length of nerve between the two pairs of recording electrodes (Fig. 320). The length is measured in millimetres, and the volocity of the

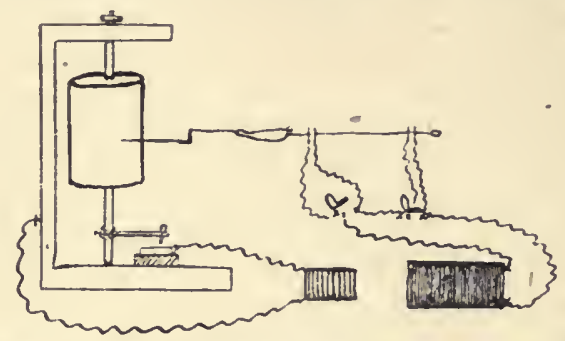

Fig. 319.-Diagram of the Experinext ox the Rate of Traxsmissiox of a Nervous IMPULSE.

transmission of the nervous impulse thus calculated. The rate of conduction may be measured more accurately by means of an electrometer and determining how long it takes for the "current of action" to pass between two points of a nerve. The velocity may be ascertained in man by estimating the time taken for the impulse to pass along the length of nerve from the clavicle to elbow, by stimulating first at one point, then at the other, and recording the contraction of the thumb muscles by means of tambours.

The impulse is conducted along a nerve in both directions. This can be shown by the following experiments: The iliac end of a dissected sartorius muscle is divided into two portions (Fig. 321). Stimulation with a weak induction shock at $a$ or $a^{\prime}$, where there are no nerve-fibres, produces a contraction of the one half of the muscle; excitation at $b$ or $b^{\prime}$, where there are nerves, evokes contraction of both halves. Again, the gracilis muscle of the frog is completely separated into two portions by a tendinous intersection (Fig. 322). Both halves of the muscle are supplied by a single nerve, the individual fibres of which divide and supply both halves of the muscle. Stimulation at $a$ or $a^{\prime}$, where there are no nerve-fibres, causes only the 
corresponding half of the muscle to contract; but excitation at $b$ or $b^{\prime}$, where the nerves lie, will cause both halves to contract. The "action current" spreads along a nerve in both dircetions.

The rate of conduction in nerve is modified by various factors. Cooling decreases, gentle warmth raises, the rate. Exact measurements of the relation of temperature to conductivity do not afford proof that the transmission of nervous energy is a chemical rather than

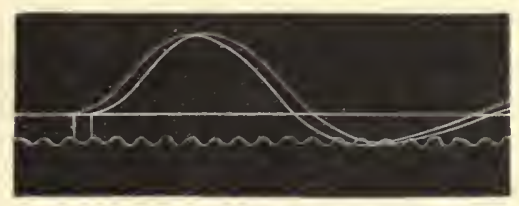

Fig. 320.-Velocity of Motor Impule ix Humax Nerve. (Waller.)

a physical process. Its nature is unknown. Chloroform and many other poisons diminish and then abolish the conductivity.

Unlike muscle, the excised nerve, as the result of activity, shows no measurable mechanical, thermal, or chemical changes. Like muscle, it shows electrical phenomena-the current of injury, the current of action (negative variation), and electrotonic currents (see below).

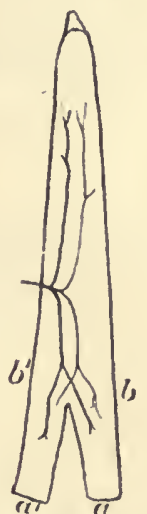

Fig. 321. - Diagray of the SARTORIUS EXPERIMENT TO SHOW the Transmission of a Nervous IMPULSE in BOTH DiRections.

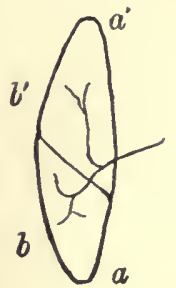

Fig. 322. - Diagram of the Gracilis Experiment to show the Transmission of a Nervous IMPOLSE IN BOTH DIRECTIONS.

The Effects of a Constant Current.-To study these effects, a sciaticgastroznemius preparation and non-polarizable electrodes are used. Both make and break of a constant current excite the nerve, and cause a contraction of the muscle; no excitation occurs while the current is flowing. The effect of the make and break stimuli vary according to the strength of the current, and according to its direction. If it. be 
flowing in the nerve from the muscle, it is said to be ascending; if towards the muscle, descending (Fig. 323). In other words, it depends upon the position of the point of entry of the current (the anode), and the point of exit (the kathode). When a current begins to flow at make, excitability and conductivity is diminished in the region of tho anodo and increased in the neighbourhood of the kathode; when the current

$-4$

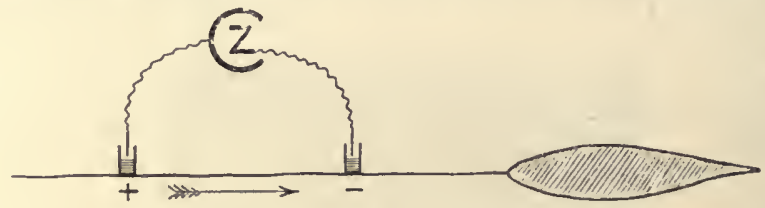

$B$

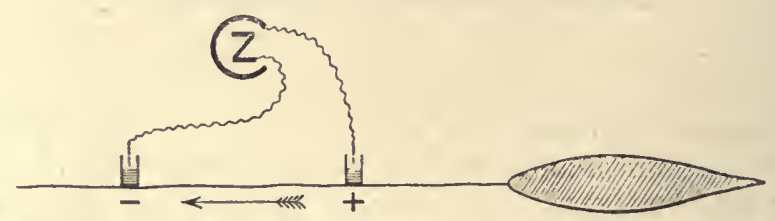

Fig. 323.-A, An "Ascending" Currext. B, A "Descendine" Current.

ceases to flow, the condition of depressed excitability and conductivity at the anode gives way, swings back, it may be said, to a condition of raised excitability and conductivity, thus affording a stimulus. Similarly, at the kathode the condition of raised excitability and conductivity swings back to a condition of lowered excitability and conductivity. At make, therefore, the kathode is the, exciting electrode; at break, the anode.

With weak currents, only the more efficient stimuli excite. The sudden increase when the current is made is more effective than the sudden "swing-back" at the anode when the current is broken; thercfore, with weak currents in either directicn, contractions occur only at make :

\begin{tabular}{cccc}
\multicolumn{2}{c}{ Ascending. } & \multicolumn{2}{c}{ Descending. } \\
Make. & Break. & Make. & Break. \\
C. & O. & C. & O.
\end{tabular}

With medium currents in both directions, there occur contractions at make from the kathode and at break from the swing-back at the anode :

\begin{tabular}{cccc}
\multicolumn{2}{c}{ Ascending. } & \multicolumn{2}{c}{ Descending. } \\
Make. & Break. & Make. & Break. \\
C. & C. & C. & C.
\end{tabular}

With "strong" currents, the effect is mcdified according to the direction of the current. When the current is ascending, the anode lies between the exciting kathode and the muscle. Around the anode the excitability and conductivity are so depressed that no impulse gets through to the inuscle, which is therefore only stimulated from the anode at break. This stimulation sometimesind uces a tetanus, known as "Ritter"s tetanus."

With a strong descending current, the kathode being next the muscle, the impulse generated at the kathode at make is not blocked in any way, and causes a contraction. At break, however, the depressed excitability and conductivity which supervenes in the kathodic region is sufficient to block the impulse arising -from the anode at break. We have, therefore : 


\begin{tabular}{cccc}
\multicolumn{2}{c}{ Ascending. } & \multicolumn{2}{c}{ Descending. } \\
Make. Brcak. & Make. & Break. \\
O. & C. & C. & O.
\end{tabular}

This regular order of contractions for currents of different intensities is known as "Pflüger's law of contractions."

The altered conditions at the anode and at the kathode can be proved by stimulation in these regions by single induction shocks, using ordinary electrodes. Fig. 324 shows the result of such an experiment.

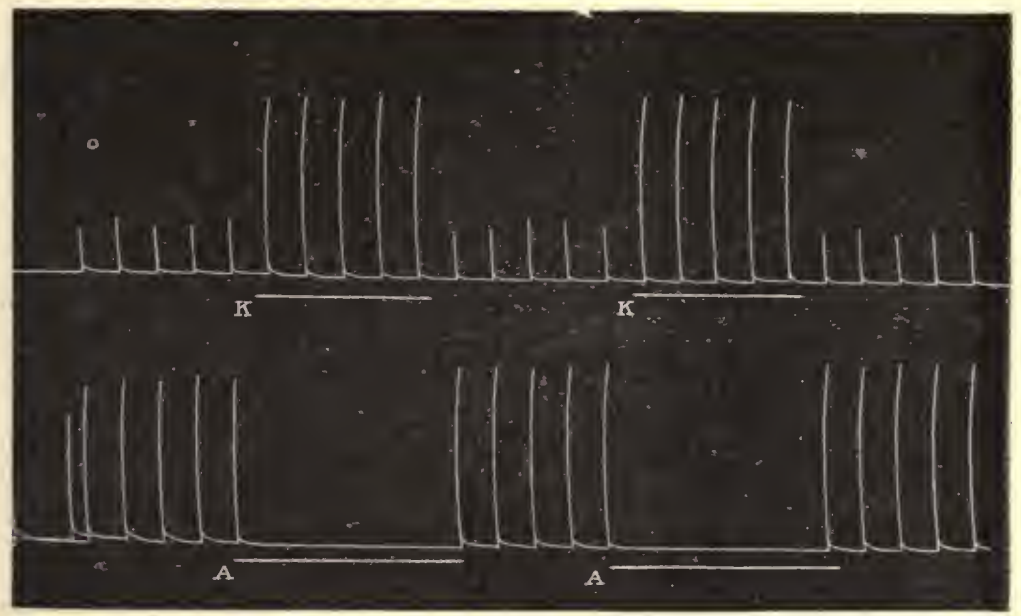

Fig. 324.-Showing Effect of Stimulation in Regions of Kathode and Anode.

The above alterations of excitability are sometimes referred to as "electrotonus"; they are better described as "elcetrotonic alterations of excitability." The term "electrotonus " is best employed for the electrical currents which occur in the nerve itself in the parts outside that throligh which the constant current passes. The current which

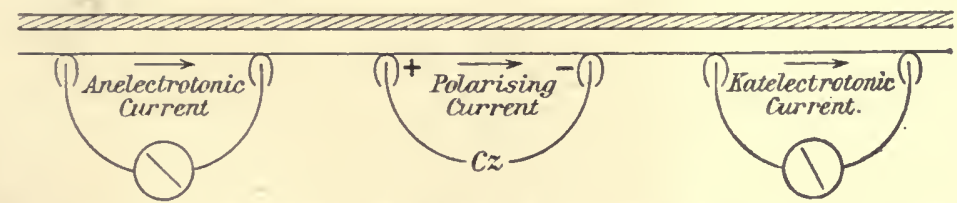

Fis. 325.-Showivg Directiox of Avelectrotoxic axd Katelectrotonid CURRENTs.

is found in the neighbournood of the anode is termed the anclectrotonic surrent, that in neighbourhood of the kathode the katelectrotonic. Galvanometric observations show that the anelectrotonic current flows towards, and the katelectrotonic current away from, the polarized regiorr (Fig 32:5). 
When the polarizing current is broken, there occur " after-elec tro. tonic currents." In the intrapolar region it is in the opposite direction (umless the current has been strong and of short duration, when it is in the same direction); outside the kathode it is, as before, away from the polarized area; outside the anode it is at first towards, and afterwards away from, the polarized area.
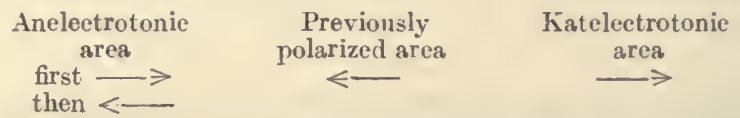

If the nerve be excited by a tetanic current, the electrotonic currents are weakened and the polarizing current strengthened by the " current of action."

The "paradoxical contraction" of muscle takes place when the branch of a divided nerre is stimulated with a constant current, and is due to the electrotonic current spreading along the branch towards the point where the nerve-branches come together, and thus exciting the fibres of the nerve which supplies the muscle. 


\section{CHAPTER LXVII}

\section{THE RECEPTOR MECHANISMS - CUTANEOUS SENSATIONS}

THE Receptors are classified as Extero-ceptive: Non-Distance: 'Touch, heat, cold, pain, taste; and Distance: Smell, sight, hearing. Proprio-ceptive: labryinthine (semicircular canals), and kinæsthetic (muscles, tendons, and joints). Entero-ceptive: those of common sensibility (thirst, hunger, and pain).

In regard to the extero-ceptive mechanism, certain general formulæ or laws have been formulated to describe the relations between external stimuli and conscious reactions. The most important of these is known as the "law of specific sense energy," or "Müller's law." It states that - ( 1 ) different stimuli acting upon the same sense mechanism produce the same kind of sensation; (2) the same stimulus acting upon different sense mechanisms calls forth different sensations. For example, stimulation of the optic nerve, whether by the normal means of stimulation (the so-called "adequate" stimulus), the vibrations of the ether, or by abnormal mechanical means, such as a blow on the eye (a so-called "inadequate" stimulus), evokes the sensation of light.

Another important law, known as Weber's law, states that "the just noticeable increase of a stimulus bears a constant ratio to the original stimulus," or "two stimuli, in order to be discriminated, must be in a constant ratio, the latter being independent of the absolute magnitudes of the stimuli." The actual value of this ratio, although constant for any one sense mechanism, varies from organ to organ. For example, if one candle added to ten just perceptibly increased the illumination, ten candles would have to be added to a hundred to do so, and one hundred to a thousand. The validity of this law has been hotly contested, since the experimental methods employed to establish it have yielded very inconstant results. Undoubtedly, some relation of the kind enunciated by Weber's law does exist, since all judgments involve comparison.

Touch, Heat, Cold, Pain.-With the exception of taste, the nondistance receptor mechanisms mainly come under the class of "cutaneous sensations," and are located in the skin.

The Structure of the Receptors of Cutaneous Sensation.-There is a dearth of knowledge as to the structure of the receptor mechanism concerned in the sensations of touch, heat, cold, and pain. In the skin various nerve-endings have been described: 
1. Several forms of eud-organs or terminal corpuseles, such as Meissner's corpuscles, Krause's end-bulbs, Ruffini's organs, and the corpuscles of Pacini or Vater. Such terminal corpuscles consist of a coarse nerve-fibre or knot of branches surrolinded by a semifluid intercellular substance enclosed in a capsule.

Meissner's Corpuscles are oval bodies about $\frac{1}{62,5}$ to $\frac{1}{12}$. inch in length. Each corpuscle consists of flattened cells surrounded by a capsule, around which one or two medullated nerve-fibres wind, to enter at the upper pole. The medullated coat is lost at the point of entrance. These corpuscles occur particularly in the papillæ of the true skin, especially in the palms of the hands and in the soles of the feet.

Krause's End-bulbs have the form of an encapsulated bulb, the axon of the medullated nerve entering its lower extromity to ramify

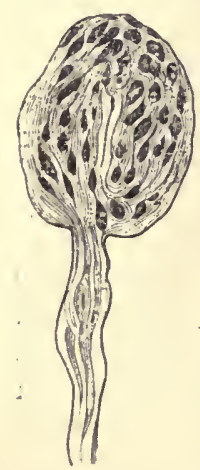
among the ovoid cells contained within the capsule. They oceur particularly in the conjunetiva, the mucous membrane of the mouth, the glans penis and clitoris, and the ligaments of joints. They also occur on the under-surface of the toes of guinea-pigs and in the wing of the bat.

Ruffini's Organs are found in the subcutaneous tissue near the sweat glands, and in the corium of the fingers and toes; they lack distinct eapsules.

The Pacinian Corpuscle (Fig. 328) occurs in the subcutaneous tissues of the palm, fingers, sole; in the sexual organs; in the deep layers of conncctive tissue near joints; and in the mesentery. Each corpuscle is of oval shape, and consists of forty to fifty lamellæ FIG. 326. - ExD concentrically arranged. The lamellæ are formed BULB of THE of connective tissue, and covered with endothelium. HuMax Cox- A lymph space exists between each lamella and its
JuNCTIVa. (Krause.) neighbour. A medullated nerve-fibre enters at one pole. Its axon passes through all the lamellæ to the central core of the corpusele, ramifies therein, and ends in small terminal buds near the distal pole of the eorpuscle.

2. Nerve-endings in connection with tactile hairs. Fine medullated nerve-fibres form a network in the outer coat of the hair follicle, and, losing their medullary sheath, run parallel to the hair, and finally penetrate and end in the inner layer of the hair sheath (Fig. 329).

3 . Single nerve-fibres pass to the under-surface of the epidermis, lose their medullary sheath, and divide into fine filaments, which end among the cells of the epidermis (Fig. 330).

Various other special forms of nerve-endings have been described in different animals-for example, in the bill of the duck, the skin of the whale, etc.

Methods of Investigation.-The sensation of touch or pressure is investigated by a series of hairs of different thicknesses attached at right angles to wooden rods. The hair is applied perpendicularly to the skin, and the amount of pressure required to bend visibly any 


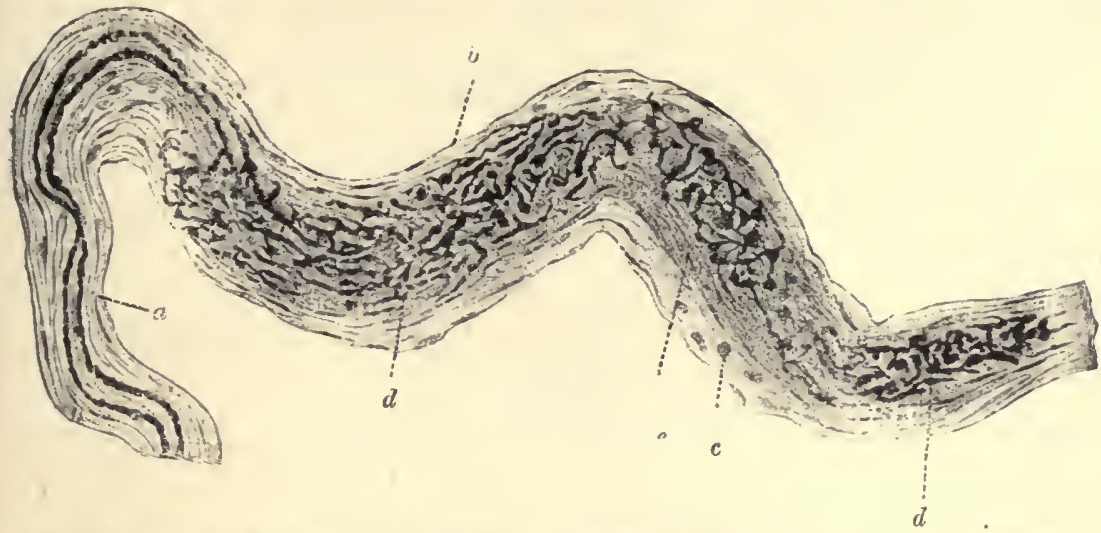

Fr7. 327.-Nerve Endive is a Special Cosnective Tissue Organ ix the Deeper Part of the Cutis. $\times 320$. (Ruffini, from "Quain's Anatony.")

$a$, Sheath of entering nerre; $b$, sheath of terminal organ; $c$, blood capillaries; $d, d$, terminations of axons; $e$, spindle-shaped connective tissue core in which these terminations ranify.

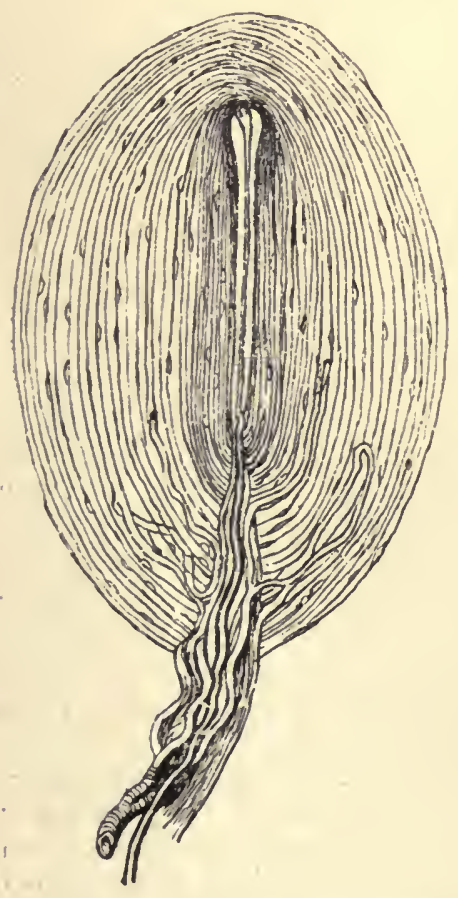

Fig. 3:9.-Pacisiay Corpescle.

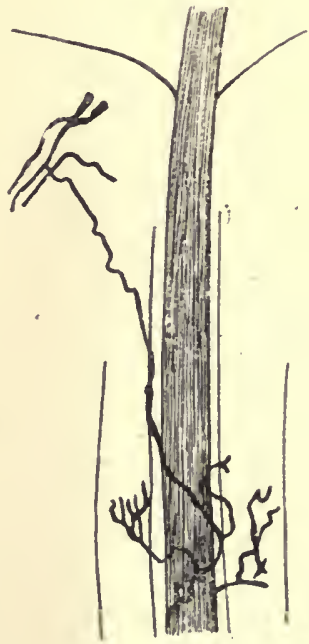

Fig. 329. - Showisg Sensori Nerve ENDixgs at THE BASE OF a HAIR. (Redrawn after van Geluchten, from Dahlgren and Kepner.) 
lair being known, the threshold value of the sensation of pressure can be accurately determined. For ordinary clinical purposes, the presence or absence of sensation to the touch of cotton-wool is usually employed. To test relative sensitiveness or the power to discriminate the part touched in various parts of the skin, the distance between the points of a pair of compasses is measured when the points are just sensed as touching two places. Temperature sensations may be tested with a hollow pencil-shaped rod in which water of various temperatures is circulated. A more common method is to use the bottom of test-tubes containing water at various temperatures. Pain may be tested with the prick of a needle-point.

The Sensations of Touch or Pressure.-Pressure-point $\mathrm{S}$ are closely related to the distribution of hairs, each hair having a pressure-point

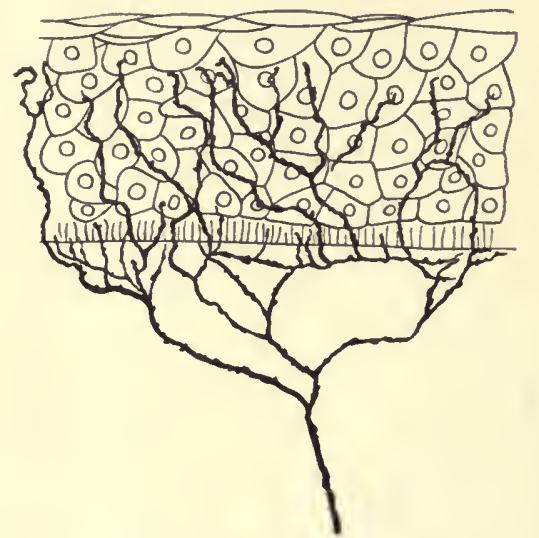

Hig. 330.-Sensury Nerve Exd-Organ in Extersal Epitheliun of Pig's Sxout. (Redrawn after Retzius, from Dahlgren and Kepner.)

on the surface corresponding to the situation of the hair follicle. Some pressure-points have no such relation to the hair follicle. In hairless parts it is suggested that pressure is associated with the corpuscles of Meissner and of Pacini. These pressure organs are not directly stimulated, since they do not reach the exposed surface of the skin. The cxcitation is produced by the variation in pressure in the neighbourhood of the end-organ, as can be shown by the fact that they are stimulated either by pushing against or pulling on a hair.

The extent of the surface to which the stimulus is applied is an important factor. For example, a greater pressure per unit is required for an area of 0.25 square millimetre than one of 0.5 square millimetre. The optimum surface is about 0.5 square millimetre. Above or below this area the amount of pressure required is increased. It has been found that the hairy parts are more excitable and more easily fatigued than the smooth areas of the skin.

In estimating weights, it is easier to compare them applied successively than simultaneously. Further, the rapidity with which the 
stimuli are successively applied influences the judgment. Generally speaking, the slower the rate of change, the higher must be the stimulus value. It is also easier to judge of a difference in weight than to say whether such a weight is heavier or lighter than another. It is easier to detect an increase in weight than a decrease. The experimental results are so variable that it cannot be said that Weber's law has been proved to hold good for tactile impressions.

The most sensitive parts are those which we use habitually as organs of touch. Thus, the under-surfaces of the tips of the fingers and the palms of the hand are far more sensitive than the skin of the gluteal region. Sensitiveness is also marked in the parts of the body habitually moved, and increases from the joints towards the extremities. It is also greater along the transverse axis of a limb than in the same distance along the long axis.

The following table shows in millimetres the distance in various parts of the body at which the points of a compass are appreciated as separate:

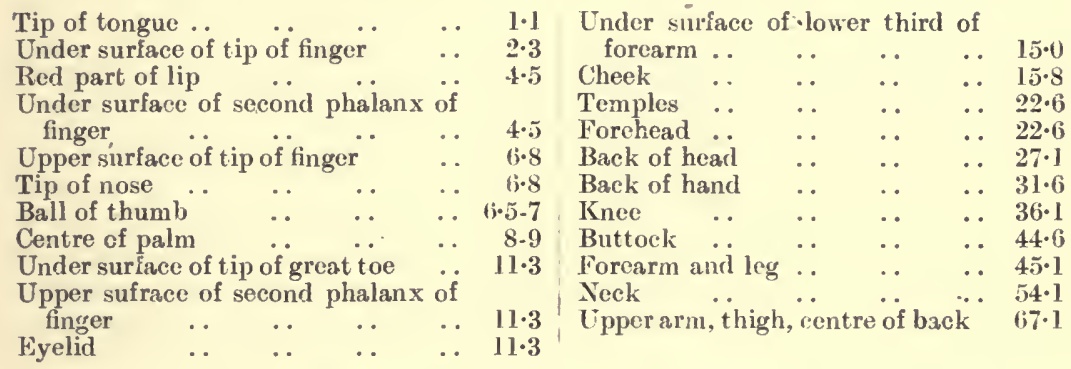

According to these degrees of sensitiveness, it is possible to locate with precision the exact spot touched. Most people are unable to localize a touch on the sccond, third or fourth toc to the exact toe touched. By education the local sign is developed.

The sensitiveness of the skin is increased after massage or salt baths, blunted by cold, anæmia, venous congestion, or after the appli cation of solutions of certain drugs, such as atropinc, chloral, etc. In regard to absolute sensitiveness, the most sensitive parts of the body are the forehead, temples, back of hand, and forearm. These are said to be able to detect a pressure of 0.002 gramme. Many ex. periments have been made to determine the frequency with which pressure stimuli must follow each other to produce a fused sensation, but the results are discordant. The length of time a sensation persists after removal of the stimulus varies greatly in different parts. In the finger it vanishes almost at once, on the forehead it porsists for some little time, after a modcrately strong stimulus.

The Information derived from Tactile Sensations.-From the tactile sensations, associated with the kinæsthetic sensations, which occur when the object presses heavily or is moved, we derive information as to form, size, and nature, of the body touched. It may be small or big, smooth or rough, ete. When a large area of the 
skin is uniformly pressed upon, the sensation of pressure soon disappears; when a finger is immersed in a bath of mercury, the sensation of pressure is limited to the area dividing the regions of different pressure.

Judgments are formed from the sensations receired on the supposition that there is no displacement of the body from the normal position. Such a displacement may lead to an erroneous judgment, as exemplified by the experiment of Aristotle. A pea or marble placed between the first and second fingers, held in the normal position, feels one body. If the fingers be crossed, and the pea be so placed as to touch the outer side of both fingers, two peas are felt. So, too, the tip of the nose, touched by the fingers in this position, gives the sensation of two noses, particularly if the eyes be closed at the time.

The local sign attached to the sensations, when received in the brain, is definite and precise. It is for this reason that a patient's nose shared in a headache after a surgeon had transplanted a piece of skin from his forehead to his nose!

The Sensations of Temperature.-Sensations of temperature can be eroked from the whole of the skin; the fiont part of the nares; from the mucous lining of the beginning (mouth, pharynx, œsophagus) and end of the alimentary tract (the region of the anus); from the cornea, conjunctiva, and penis. The spots stimulated by heat and cold are different. Cold spots are more numerous than hot spots, especially orer the extremities. They are generally arranged in curved lines. The curves of the hot and cold spots do not, however, coincide. It has been suggested, but the evidence is very slight, that Krause's end-bulbs and Ruffini's organs are respectirely the special structures associated with the appreciation of cold and warmith.

Two views are held as to what constitutes the adequate stimulus of these sensations. According to one view, the chief factor is the alteration of the end-organ temperature, whatever that may be, a rise of temperature in the end-organ creating a sensation of warmth, a fall in temperature producing the sensation of cold. Upon this view, it is somewhat difficult to account for the sensation of cold which persists after removal of a cold body. During this time the temperature in the end-organ is rising. For example, after a cold penny $\left(2^{\circ}\right.$ C.) has been applied to the forehead for thirty seconds, the sensation of cold may persist for twenty seconds after its removal.

According to the second view, a skin area gives no temperature sensation when it is at the so-called physiological zero of temperature. This point shifts with the conditions to which the part is exposed. Any alteration of temperature will give rise to a sensation the intensity and character of which depend upon the difference from this point of reference. Thus, if one hand is put into hot and another into cold water, and then both into tepid water, the "hot" hand feels it cold and the "cold" hand warm. Probably it is the difference between the surface and deep skin temperature (surface and deep sense organs) which gives the intensity 
of sensation; the surface and deep sense organs may be compared to a pair of thermo-electric junctions. The adequate stimulus depends not only on the intensity of the stimulus, but upon the actual size of the region stimulated. It is probably for this reason that water at $37^{\circ} \mathrm{C}$. feels warmer to the whole hand immersed in it than does water at $40^{\circ} \mathrm{C}$. to one finger only. The degree of sensation evoked also depends upon the thermal capacity and conductivity of the body applied to the skin.

The parts of the body in which the thermal sense is most acute are the tip of the tongue, the eyelids, cheeks, lips, and belly. The laundress tests the warmth of her iron with her cheek, and not with her hand, and the bared elbow is used by a good nurse to test the temperature of a hot bath. The temperature sensations regulate to a large extent the tone of the skeletal muscles, the vaso-motor tone, the activity and metabolism of the body. The play of wind, sunlight and shadow stimulate the nervous system and prevent monotony.

The Sensation of Pain.-It seems probable that special "pain spots " exist for the appreciation of pain. They have a long latent period when subjected to weak stimulation, and do not react easily to rapidly alternating or oscillating stimuli. They do not coincide with pressure-points, and are about four times as numerous as these. It has been suggested that the free nerve-endings in the skin are the special organs excited. In support of this viow, it has been shown-

1. That diminution of the surface area stimulated does not diminish the effectiveness of the stimulus. form.

2. That the electrical stimulus is more effective than any other

3. That the first sensation produced by the application of a corrosive is one of pain.

It is stated also that from the cornea only sensations of pain arise, and that here the only receptive elements are the intra-epithelial nerve-endings.

It is probable, however, that pain may arise from excessive stimulation of the organs connected with the other sensations of the skin. Excessive heat or cold produces the same kind of sensation of pain.

Protopathic and Epicritic Sensibility.-A careful study of the sensory changes associated with the experimental division and regeneration of cutaneons nerves in trained observers, has led to a new classification of the sensibilities of the skin. In the area supplied by the severed nerves the sensations of heat, pain, and cold, were lost, also sensa. tion of touch to cotton-wool, and to the pulling of the skin outwards. Pressure inwards was appreciated and well localized-that is, deep pressure-due to sensation in the underlying muscles. After seven weeks, sensibility to pin-prick returned, but it required a higher minimal stimulus than the normal parts, and produced a peculiar unpleasant sensation which radiated and tended to be localized in rcmote parts. Water of $38^{\circ}$ to $50^{\circ} \mathrm{C}$. was recognized as hot, and 
of $0^{\circ}$ to $24^{\circ} \mathrm{C}$. as cold; but no sensations of warmth or coolness were experienced from water at intermediate temperatures. The areas where these sensations were experienced corresponded to hot and cold spots previously marked out.

This kind of sensibility to pain and temperature is termed protopathic. Its chief characteristics are its high threshold stimulation value and the fact that it depends upon the existence of specific ondorgans. It probably represents a more primitive type of nervous organization.

After a variable time the skin again became sensitive to light touch, compass-points were discriminated, and varying degrees of temperature appreciated. This more delicate organization is termed the epicritic system. Epicritic sensibility is characterized by low threshold stimulation value. Its re-establishment may depend on the completion of a single regenerative process, rather than on the regeneration of a special system of epicritic nerves.

The central connections of the conductors associated with these various sensations are dealt with later. 


\section{CHA P T E R L VIII}

\section{TASTE AND SMELL}

Taste-The Receptor Mechanism.-The taste buds probably form the receptor mechanism for the sensation of taste, for the sense of taste is absent from those parts of the tongue where these organs do not exist, and is most acute in the regions where they are most abundant. Further, section of the glosso-pharyngeal nerve, the nerve of taste, leads to a degeneration of the sensory cells in these buds.

The taste buds are found in many of the fungiform and in all the circumvallate papillæe of the tongue; to a certain extent also on the

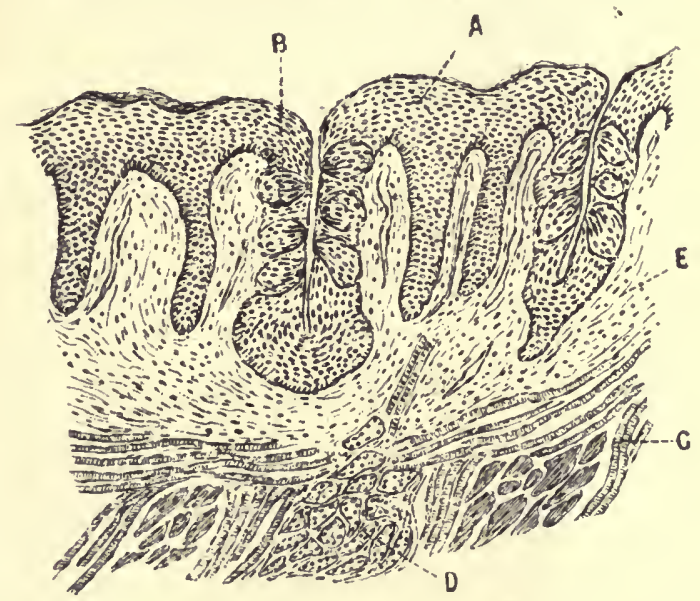

fig. 331.-Mlicroscopic View of Sectiox throdgh Circunvaliate Papili.e.

$A$, epithelial layer; $B$, taste buds; $D$, gland; $E$, subepithelial layer; $G$, musele.

soft palate and the surface of the epiglottis. They are best seen in the circumvallate papillæ. These are eight to fifteen in number, and form at the base of the tongue a $\mathbf{V}$, with the apex backwards: it is calculated that there are more than 30,000 taste buds in th:s region in the ox. They are far more numerous in the embryo at the sixth to the scventh month than in the adult. Many of them subsequently become infiltrated with leucocytes and destroyed. The fungiform (fungus-like) and filiform (rod-like) papillæ of the tongue are concerned in the sensations of touch, tempcrature, and pain.

The tastc buds are minute oval bodies embedded in the epithelial lay'er, and communicating with the surface by a funncl-shaped opening 
- the taste pore. Into this pore the hair-like processes of the true gustatory cells projeet. These eells are delieate rod-like eells, with a eentral nueleus surrounded by granular protoplasm. Around the tapered base of the eell are the fine ramifieations of the nerve of taste. The taste eells are supported externally on either side by eolumnar eells-the sustentacular eells. These form no conneetion with the gustatory nerve (Fig. 332).

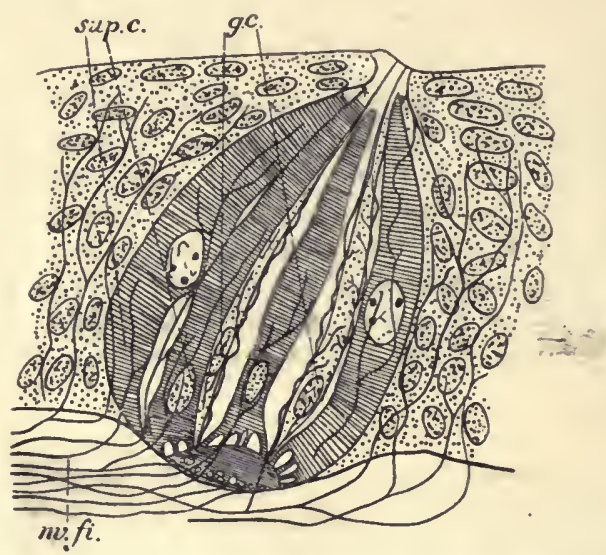

Fig. 332.-Taste Bud in Tongue of Max. (Redrawn after Hermann, from Dahlgren and Kepner.)

g. c., Gustatory or taste eells; sup. $c$., supporting cells; $n v$. fi., nerve fibrils.

There are four sensation qualities of taste, swcet, salt, acid, and bitter. They may be investigated by applying to the tongue test solutions of various strengths at body temperature with a fine camel'shair brush, or by placing a measured volume of the, solution on the tongue. For exaet loealizing work, a form of instrument such as shown in Fig. 333 may be used. It is usual to employ ether and ehloroform vapour with this instrument, sinee it has been found that ether vapour blown on the tongue produees the sensation of bitterness, and ehloroform vapour a sensation of sweetness.

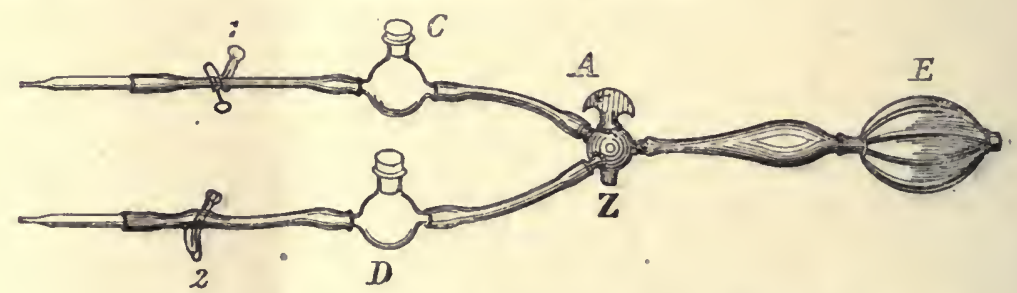

Fig. 333.-Apparates for testixg Taste Sexsations.

$A, Z$, two-way tap; $E$, insufflating bulb; $C, D$, odour chambers; 1,2 , clips.

The nature of the stimulus for taste is chemical. It is neeessary for a body to be in solution for the sensation to be eroked. A dry 
substance-e.g., solid quinine-applied to the dry tongue evokes no sensation of taste. Again, a crystal of quartz gives the sensation of touch and cold, but not of taste. A crystal of common salt of the same size gives not only these sensations, but that of saline taste. There is no evidence to show that the sensations of taste can be elicited. by mechanical stimulation of the tongue. It is probable that the sensations evoked by electrical stimulation are due to the electrolytic decomposition of the saliva. The various taste sensations are grouped in different areas of the tongue.

The responsiveness to bitter substances is confined mainly to the back and edges of the tongue. Acid is tasted all over the dorsum, except a small anterior part just behind the tip. Salt and sweet are likewisc appreciated all over the dorsum, except for an antero-median area of the dorsum, a little posterior to the insensitive area for acid. "Sweet" is, however, in most people best appreciated at the tip of the tongue.

It has been argued that this distribution points to special receptors for each form of taste, and in support of this it is stated that saccharine is sweet to the tip and bitter to the back of the tongue. In like manner, sulphate of magnesia is bitter at the base and sweet or acid in the region of the tip. Further, the drug Gymnema sylvestre affects the sensation of sweetness. After chewing the leaves of this plant, sugar no longer tastes sweet nor quinine bitter. The sensations of acid and salt are unaffected.

There is apparently no relation between the chemical structure and taste of substances. For example, sugar, lead acetate, and chloroform, all taste sweet; magnesium sulphate, and various alkaloids, like quinine and strychnine, evoke bitter sensations.

The application of sugar and salt at the same time to opposite sides of the tongue increases the effectiveness of both stimuli ( $c f$. simultaneous contrast in vision, p. 634). Again, after tasting weak sulphuric acid, distilled water has a sweetish taste ( $c f$. successive contrast, p. 634).

It is to be noted that flavours are either smells or combinations of taste and smell. Thus, a man with cold in the head cannot appreciate the fine flavour of wine. If the nose be held, an onion, when bitten, is indistinguishable from an apple. The smell of a strong cheese will destroy the appreciation of the taste of fruit.

The nerve distribution for taste is associated in the posterior third with the glosso-pharyngeal nerve, and in the anterior two-thirds with the lingual branch of the fifth. The course of the taste fibres is complicated and still in doubt. The fibres from the anterior twothirds leave the lingual nerve and pass backward along the chorda tympani nerve to join the seventh nerve in the Fallopian aqueduct. They pass in the seventh nerve as far as the geniculate ganglion, where some join the nerve of Wrisberg and pass to the nuclcus of the ninth nerve; others are said to pass along the great superficial petrosal nerve to Meckel's ganglion and to rejoin the fifth nerve. The fibres from the posterior third of the tongue pass to the brain by: way of the glosso-pharyngeal nerve. 
Smell.-The Receptor Mechanism is formed by the olfactory cells situated in the mucous membrane of the upper meatus of the nose, and covering the upper part of the superior turbinate bone and nasal septum. The middle and inferior meatus constitute part of the respiratory tract.

The nasal mucous membrane, or Schneiderian membrane, is thick and of a yellowish hue, in marked contrast to the reddish tint of the respiratory portion of the nose. In section it is seen to consist of an epithelial layer-the olfactory epithelium-which rests upon at basement membrane, and separates it from the deeper mucous layer or corium (Fig. 334).

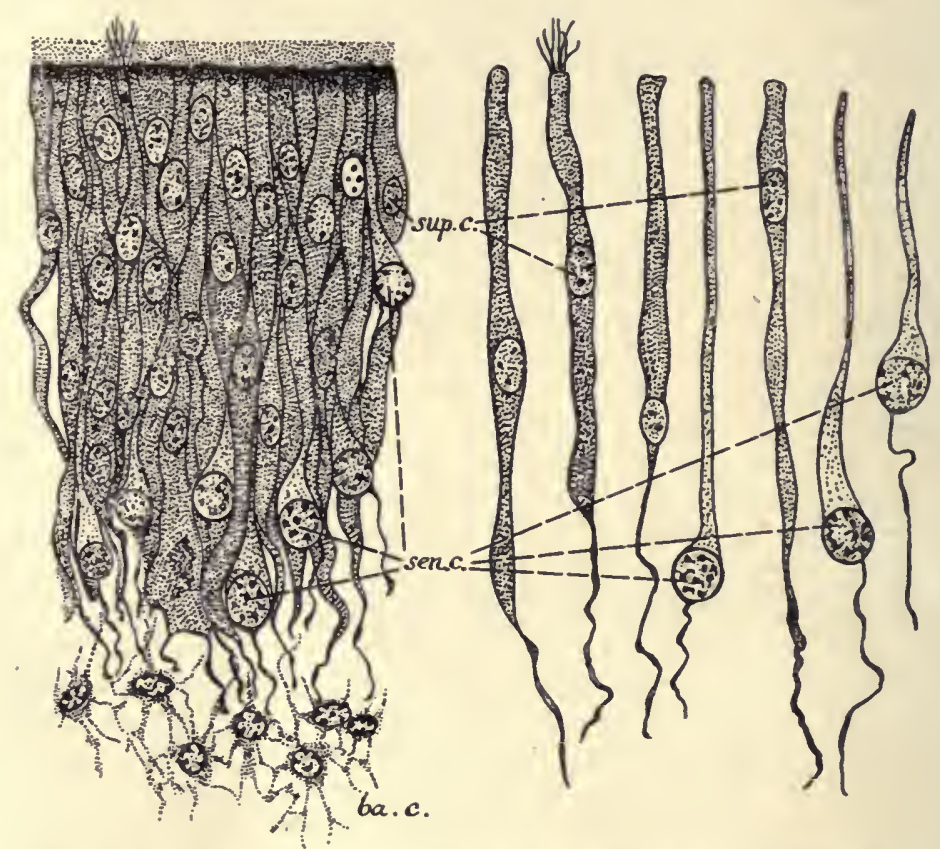

Fig. 334.-Section of Olfactory Epithelium of the Fowl, showing sup. c., Supportixg Cells; sen. c., Sexsory Celus; and ba.c., Basal Cells. (Redrawn from Dahlgren and Kepner.)

The receptor olfactory cells lie in the epithelial layer. They possess a central nucleus surrounded by a small quantity of protoplasm, from which there passes towards the surface a narrow round filament with a cilium attached. A smaller similar process, arising from the base of the cells, arborizes with the terminal ramifications of the olfactory nerve. Supporting these cells are other "sustentacular cells." These have a knife-handle-like shape, the upper half being cylindrical in shape, and often provided with stiff cilia attached to the free border. The lower half is narrow, and ends in a long process which joins with the neighbouring cells. At the boundary of the 
epithelial layer with the loose underlying connective tissue there are found supporting "basal cells." These are irregularly cubical, being broadest at the base and tapering towards the surface.

The Mode of Excitation.-Smells are not destroyed by passing the air containing them through a long tube packed with cotton-wool. It is estimated that such a tube removes particles $\frac{1}{50000}$ cubic millimetre in size. It is known that a gramme of musk will give off its odour for years, and not weigh appreciably less at the end of the time; 0.01 milligramme of mercaptan diffused in 230 centimetres of air is perceptible to the sense of smell-i.e., 0.00000004 milligramme per litre, or a dilution of 1 in $50,000,000$. A hound will follow every zigzag that a fox takes across country.

It is obvious, therefore, that the mode of excitation is as subtle as that of the retina by light. Substances of low molecular woight either have no odour or tend to irritate the nose rather than evoke the true sense of smell. Increase in molecular weight often increases the property of smell-for example, of the paraffins. In the series of alcohols also there is an increase in:the intensity of odour as the molecular weight increases.

The Investigation of the Sense of Smell.--Keenness of smell may be investigated roughly by preparing a series of solutions of camphor from 1 in 1,000 to 1 in $1,000,000$, and placing them in flasks holding 10 to 15 c.c., and having an opening of 17 millimetres diameter. For

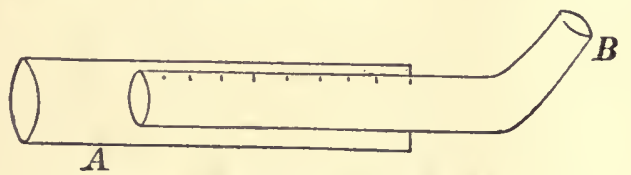

Fig. 335.-The Olfactometer.

inore accurate work, the instrument known as the olfactometer is used (Fig. 335). This consists of two concentric cylinders, the inner one of which ends in a nose-piece. The outer cylinder $(A)$ is lined with an odorous substance. It will be seen that, when the inner cylinder $(B)$ is pushed in level with the outer one, air inhaled through the instrument does not pass over this substance; but the more the cylinder is drawn out, the greater the area of the odorous substance exposed to the indrawn air. The extent to which it is necessary to draw out the inner cylinder to recognize the odour is the measure of the responsiveness of the nose to that particular stimulus.

A classification of different smells is very difficult, almost impracticable. Such classifications have been made, but they cannot be regarded as satisfactory. There is an antagonism between certain odours-e.g., iodoform is masked by balsam of Peru, musk by bitter almonds, ammonia by acetic acid.

The sense of smell may be fatigued. After smelling tincture of iodine, alcohol and copaiba balsam are odourless. Some people do 
not appreciate certain smells-e.g., mignonette. Such "anosmia" is probably congenital, but temporary anosmia may occur in disease of the nose and in nervous conditions. It may be induced by the application of drugs, such as cocaine. Parosmia (perverted sense of smell) and hyperosmia (increased sensibility to smells) may also occur in nervous conditions (hysteria, etc.).

Tastc and smell, as we have secn, are intimately related. It is possible for them to be antagonistic. This fact is made use of by the physician. Thus, "tinct. aurantii," by its odour, counteracts the bitter taste of quinine, and effervescing saline drinks (taste) mask the flavour (odour) of castor oil.

The central connections for smell are made by means of the olfactory lobes of the brain (see p. 715). 


\section{CHAPTER LXIX}

\section{THE SENSE OF VISION}

\section{Section I}

The Receptor Mechanism.-The perception of the rapid undulations of the ether is usually confined to specialized nerve cells, the visual cells. Some low forms of life have a rudimentary eye or eyespot (Fig. 336,e). The visual cells may be scattered over the body

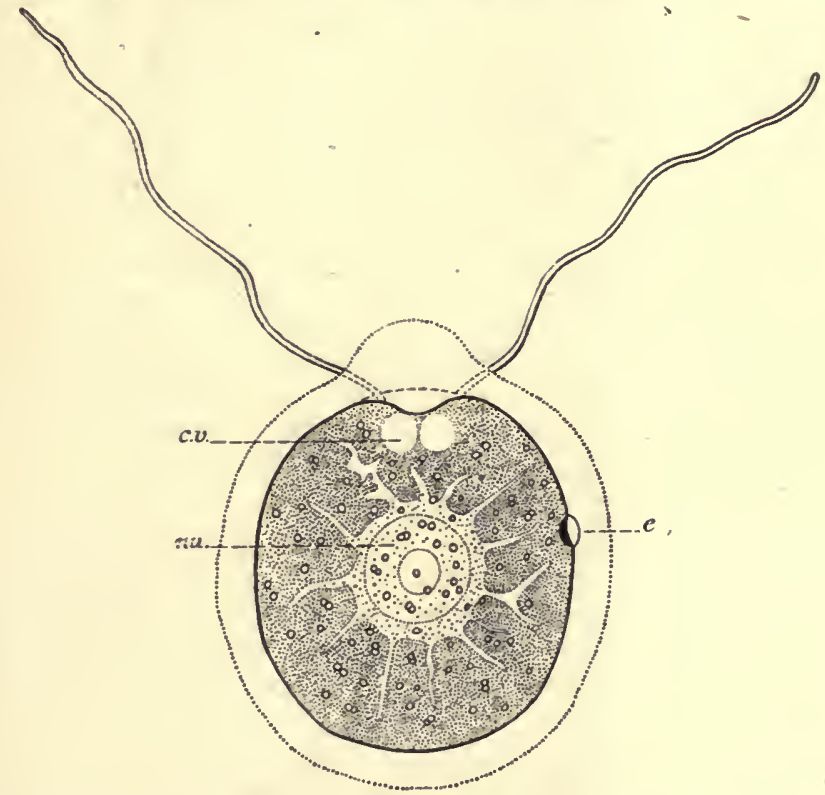

Fig. 335.--Isdividual flagellate Chlamidononas Reticulata. (Redrawn from Dahlgren and Kepner.)

e, Eyespot with pigment and lens; nu., nucleus; $c . v$., contractile vacuole. $\times 1,000$.

surface, but usually are aggregated together with accessory tissues to form a specialized organ of vision, the eyc. Various complicated forms of eyes are described among the invertebrates. In the higher animals the receptor mechanism for vision is contained in the retina, the delicate nervous layer lining the posterior portion 
of the eycball. The rest of the eycball is an accessory mechanism for focussing the vibrations of the ether upon the retina, in order that light may not only be appreciated, but vision rendered distinct. It is convenient, therefore, first to study the structurc of this apparatus, and also the physical laws which apply in connection with vision.

The Anatomy of the Eye.-The eye may be compared to a camera, with its framework, its system of lenses, its diaphragm, and its sensitive plate. The framework of the eyeball consists of an outer tough, opaque, fibrous coat-the sclera, or sclerotic. In front, this becomes transparent, and forms one of the system of lenses-the cornea. At the back, the sclerotic is pierced by the optic ncrve, which then spreads out over the posterior two-thirds of the eyeball to form the sensitive plate - the retina. Between the sclerotic and retina lies the black pigmented and vascular coat, the choroid. Within the eye is suspended the lens and its supports, dividing the eyeball into two chambers: (1) That between the cornea and the front of the lensthe "aqueous chamber" - containing a watery fluid (the "aqueous "); (2) that between the posterior surface of the lens and the retinathe vitreous chamber-containing a glassy, jelly-like mass (the "vitreous humour"). The aqueous chamber is incompletely divided into two by the diaphragm, ol iris. To understand the mechanism by which rays of light are rendered-distinct upon the sensitive retina, it is necessary for us to study in detail these accessory parts.

\section{Accessory Parts and their Functions.}

The Conjunctiva covers the anterior part of the sclera, and is reflected over the inner aspects of the upper and lower eyelids. It consists of several layers of stratificd epithelium. The anterior surface of the cornea is covered by a similar epithelium continuous with that of the conjunctiva. The conjunctiva is kept moistened by the secietion of the lachrymal glands-the tears.

The Lachrymal Glands.-The lachrymal glands closely resemble in structure a serous gland. They are situated in the upper outer angle of the orbit, and pour out their secretion by several ducts situated on the inner surface of the upper lid. Normally, the amount of secretion is just sufficient to keep the conjunctiva moist, and enable the eyelids to work smoothly. It is drained away by a small orificeplaced at the imner anglc of the eye, and thence into the lachrymal sac and to the nasal duct which opens into the inferior meatus of the nose. Excessive secretion is induced by foreign bodies acting on the conjunctiva, irritating vapours in the nose, and by painful emotion, leading to the formation of tears. The eyelids, besides moistening the conjunctiva during the process of winking, protect the eyeball, and, by means of the eyelashes, shade the eyes. They consist of folds of skin and areolar tissue, kept in shape by a plate of fibrous tissue - the tarsus. In the skin are contained sweat glands, sebaceous (Meibomian) glands, and the eyelashes. Beneath the skin are fibres of the muscle which closes the lids-the orbicularis palpebrarum. 
Inserted into the middle portion of the tarsus of the upper lid are fibres of the muscle which open the eye-the levator palpebræ superioris.

The Cornea is the transparent layer in the front of the eyeball. In the adult human being it is about 1 millimetre thick. It is the first of the system of lenses of the eye-camera. It is continuous at its edges with the sclerotic, forming the corneo-sclerotic or sclero-corneal junction. The angle at which the cornea joins the iris within the eyeball is known as the corneo-iridic or filtration angle.

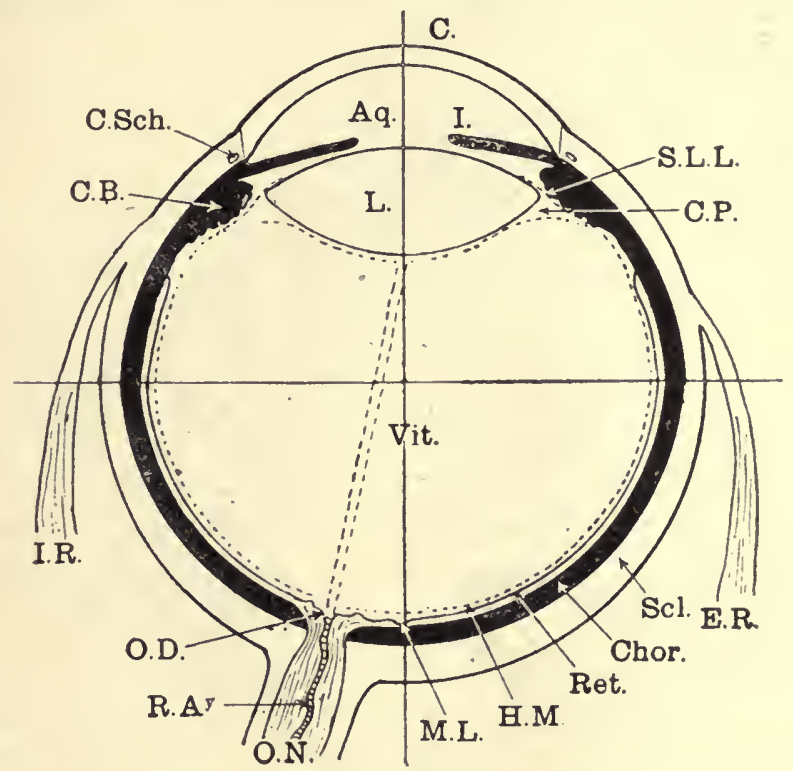

Fir. 337.-Horizontal Section of Exeball. (Parsons and Wright.)

C., Cornea; Aq., aqueous humour; I., iris; S.L.L., suspensory ligament of lens; C.P., canal of Petit; E.R., external rectus; $\mathrm{Scl}$., sclerotic; Chor., choroid; Ret.; retina; H.M., hyaloid membrane; M.L., macula lutea; O.N., optic nerve; R.Av, retinal artery; O.D., optic disc; I.R., internal rectus; Vit., vitreous humour; $C . B$., ciliary body; C.Sch., canal of Schlemm; $L$., lens.

Microscopically, the cornea consists of a layer of stratified epithclium, in which ramify numerous delicate nerves, resting upon a homogeneous layer (the anterior homogeneous layer of Bowman). Beneath this layer the transparent fibres of the cornea proper are arranged in layers, each successive layer being at right angles to the next. Lying in minute tissue-fluid spaces between the fibres are connective-tissue cells, known as the corneal corpuscles. In the proper substance of the cornea there run delicate plexuses of ncrvefibres derived from the ciliary nerves. Posterior to the cornea propcr comes a transparent elastic membrane (Descemet's), on the inner surface of which is the single layer of flattened epithelial cells lining 
the aqueous chamber. These, at the corneo-iridic angle, become reflected on to the iris, the membrane stopping short at the angle. The inner fibres of the cornea in the neighbourhood of the conseo-iridic angle continue on as longitudinal fibres-cribriform ligament. This ligament is also composed of circular fibres, which are continuous with those surrounding the venous canal of Schlemm (Fig. 338).

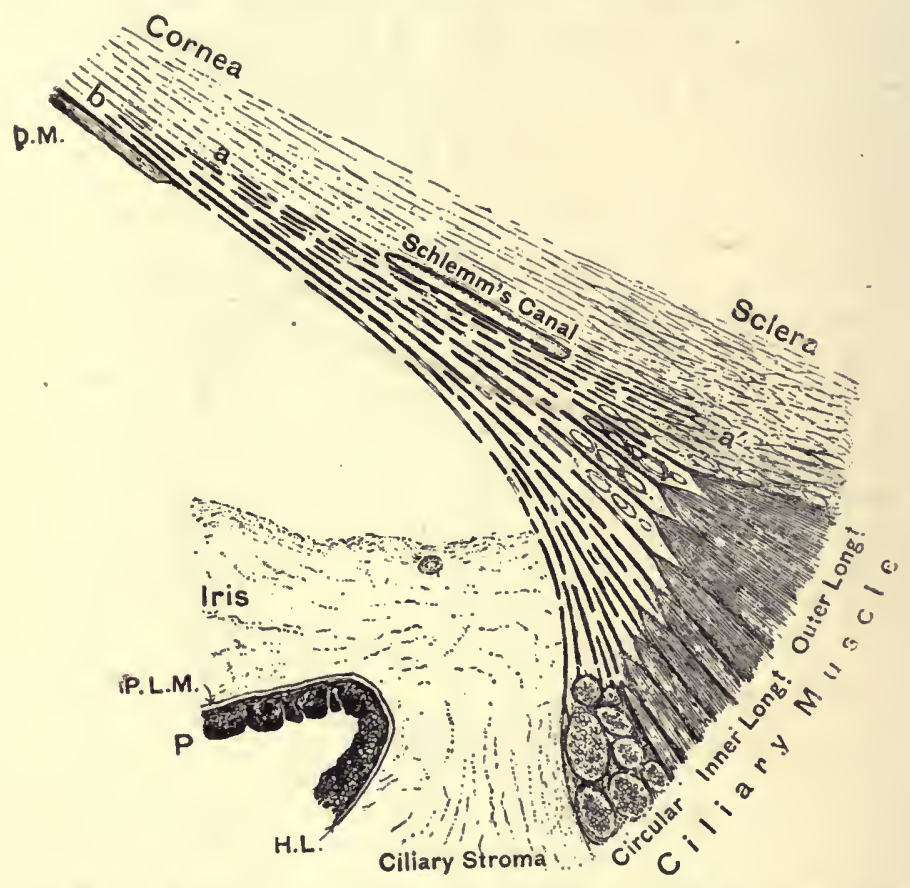

Fig. 338. - To show Details of the Cribriform Liganext, Ciliari Muscle, and CORNEO-IRIDIC JUNCTIOx. (Thomson.Henderson.)

The outer fibres of cribriform ligament start at $a$ and end at $a^{\prime}$. The inner fibres start at $b$ and spread out to act as fibrils of origin to the longitudinal fibres of the ciliary muscle. P, pigment epithelium of iris; P.L.M., posterior limiting mem. brane of iris continuous with hyaline layers $(H . L$.$) of ciliary body; D . M$., Descemet's membrane.

By its inner longitudinal fibres it serves as a point of attachment for the ciliary muscle and the dilator pupillæ; by its outer longitudinal fibres it is connected to the sclera, the fibres passing backwards internal to the canal of Schlemm. The circular fibres help to keep the ciliary muscle in position.

The Sclerotic Coat (Sclera) is extremely tough, being made up of white fibrous tissue with a small amount of yellow elastic tissue. It is pierced at the back by the optic nerve, and at various parts by the veins bringing blood from the eyeball (the venæ vorticosæ). The muscles moving the eyeball are inserted into the sclera just behind 
the cornea. On its inner surface there is a layer of brown-black pigment cells (the lamina fusca). The sclera is connected by loose connective tissue to the structures internal to it-the ciliary body and the choroid-the space thus formed being known as the suprachoroidal space (Fig. 345).

The Choroid is the vascular coat for the posterior part of the eye. It is connected with the ciliary body and the iris, and, together with them, constitutes the vascular tract, or uvea, of the eve. Lying between the sclera and the retina, the function of the choroid is to nourish these structures, particularly the retina. Its pigment also absorbs the light which passes through the retina. The choroid consists mainly of networks of bloodvessels held together by a stroma containing branched pigment cells. There is an outer layer of larger bloodvessels, and an inner close network of wide capillaries. Next to the retina is a homogeneous elastic membrane, which may be $2 \mu$ thick. A similar elastic membrane lies at the back of the cornea, and covers the iris and ciliary processes. The fluid within the eyeball is contained by this membrane, and it is probably of great importance in the maintenance of the intra-ocular pressure.

The Ciliary Body lies just behind the corneo-scleral junction, being continuous with the choroid behind and with the iris in front, and consists of two portions - an outer muscular portion, the ciliary muscle, and an inner non-muscular portion. The latter is divided into two parts-the pars plana and the pars plicata.

The Ciliary Muscle is composed of smooth muscle, and also consists of an outer portion and an inner portion. The fibres of the outer portion (Brücke's muscle) run in a meridional and radial direction. They arise from the portion of the cribriform ligament derived from the cornea, and pass backwards to be inserted in part into the choroid, in part into the suspensory ligament of the.lens.

The inner portion consists of circular fibres (Müllẹr's muscle). It arises indirectly by interstitial tissue from the internal fibres of the cribriform ligament, and forms a sphincter round the margin of the lens.

The Pars Plana is the posterior smooth portion of the ciliary body.

The Pars Plicata is the anterior inner portion of the ciliary body, so called because it is thrown into many folds - the ciliary processes, about seventy in number. Lying in the connective tissue of these processes are networks of wide capillary tufts. Each process arises from a base of connective tissue continuous with the stroma of the iris, and each is covered by columnar epithelium, within which is a set of pigment cells. Between the processes lie the interciliary grooves, lined by pigmented cubical cells, and continuous with the radial furrows on the back of the iris. The sensory nerve supply of the ciliary body comes from the ophthalmic division of the fifth nerve. The ciliary muscle is supplied by the inferior division of the third nerve. The long posterior ciliary arteries supply the ciliary body with blood. 
Functions of the Ciliary Body.-The ciliary muscle effects the accommodation of the cye (see later, p. 614); the ciliary processes secrete the aqueous humour, the pigment in the ciliary bodies assists the iris in preventing light passing through the periphery of the lens.

The Iris is the pigmented curtain or diophragm which lies in the aqueous chamber, dividing it into an anterior chamber in front and a posterior chamber behind. The aperture in the centre forms the pupil of the eye. At its base, where it is thinnest, the iris is continuous with the anterior part of the ciliary body, both as regards stroma and the pigmented and epithelial cells, which lie on its posterior surface. The epithelial cells on the front of the iris are reflected at the corneo-iridic angle on to the back of the cornea. Both sets of epithelial cells, anterior and posterior, lie on basement membranes, in between which there is a delicate network of connective tissue containing the pigment cells which give the iris its characteristic colour. This connective tissue contains a network of capillaries which run into a large vein at the base-the circulus iridis major. It also forms lymph spaces, which connect by minute crypts at the base of the iris with the aqueous fluid in the anterior chamber. By these crypts, therefore, aqueous fluid can pass into the lymph spaces of the iris, and thence into the iris veins.

In this connective tissue, also, lie the muscle fibres of the iris. These arc of the smooth variety, and consist of two sets: (1) Circular fibres, developed mostly near the free pupillary margin, and sphincter in action-the sphincter pupillæ; (2) meridional fibres arranged about the radial furrows of the iris. These fibres arise from the innermost strands of the cribriform ligament, and terminate in the connective tissue of the sphincter pupillæ.

The sensory nerve of the iris is the nasal branch of the ophthalmic division of the fifth nerve. The motor ncrve to the sphincter muscle is the inferior division of the third nerve. This has its cell-station in the ciliary ganglion, and passes to the iris as the short ciliary nerves. The nerve to the dilator pupillæ is the cervical sympathetic. Its cell-station is in the superior cervical ganglion, and the fibres reach the eye through the ophthalmic division of the fifth and the long ciliary nerves.

The Function of the Iris.-The function of the iris is to regulate the amount of light admitted to the eye, and to diminish spherical and chromatic aberration (see later, p. 609). Its action is reflex. It contracts when strong light falls on the retina (the light reflex). When light falls on one eye, the pupil of the other eye also contracts (the consensual light reflex). The iris also contracts during accommodation of the eye for a near object, during sleep, and under the action of certain drugs known as myotics-e.g., morphia, which acts centrally, and pilocarpine, eserine, etc., which act locally. Besides stimulation of the third nerve, section or paralysis of the cervical sympathetic nerve will cause contraction of the pupil. Dilatation of 
the bloodvessels of the iris will help to bring about its expansion, and constrietion its eontraction.

The iris dilates normally in weak light or in the dark, and when the eyes are at rest. It also dilates under the influenee of strong emotion and of pain, particularly if the pain is in the region of the neek. Certain drugs, known as mydriaties, produce dilatation of the pupil. Sueh are atropine, homatropine, which aet loeally, paralyzing the terminations of the third nerve; eocaine, whieh acts locally, stimulating the endings of the sympathetic nerve; curare, whieh acts eentrally.

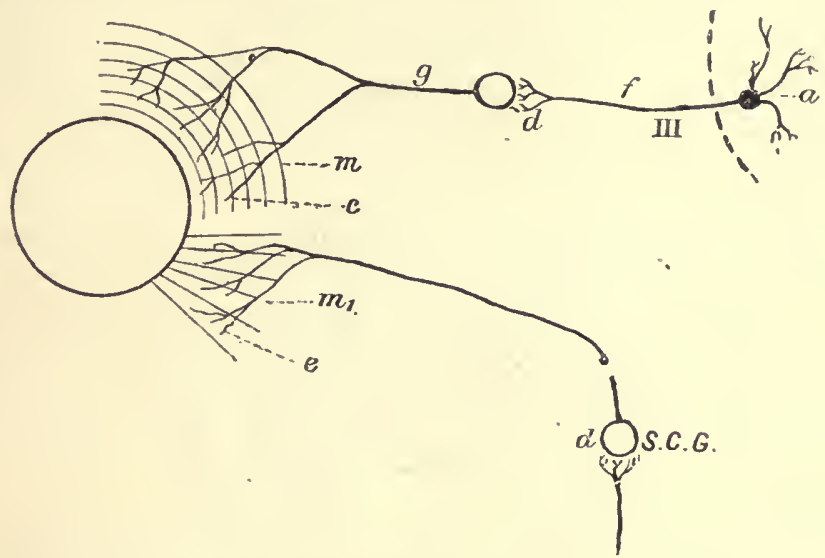

Fig. 339.-Diagray showing Nerve Supply of the Iris. (Dixon.)

III., Third nerve; $f$, preganglionic fibre to ciliary ganglion; $g$, postganglionic fibres to circular muscle $(m)$. S.C.G., superior cervical ganglion giving fibres which ard in radiating fibres, $m$, of the iris. Drugs may act upon the pupil at nerveendings $d$ and $e$, or centrally at $a$.

In eertain nervous diseases, such as locomotor ataxia, the pupil does not react to light, although it still responds when looking at a near objeet (aeeommodation). This eondition is known as the ArgyllRobertson pupil, and is probably due to degeneration of the eells of the ciliary ganglion.

The Lens eonsists of a semi-solid core - the nucleus - with somewhat more fluid edges. Its main eonstituent is crystallin, a protein of the globulin type. It is held in position by a fine membrane - the eapsule-to whieh is attaehed the suspensory ligament, or zonule of Zinn. Strueturally, the lens eonsists of a number of "lens fibres with serrated edges." These are formed by a process ef elongation from the layer of cubieal cells from whieh the lens is originally derived.

The Suspensory Ligament, or zonule of Ziun, is derived from the hyaloid membrane, whieh eneloses the vitreous humour (see Fig. 337). The canal of Petit is a spaee enelosed in this ligament in whieh the 
aqueous humour passes. The fibres of the ciliary inuscle are partly attached to this ligament.

The Retina is a delicate nerve-film covering the posterior two-thirds of the eye. It ends in front in a notched edge-the ora serrata. In the centre of the retina is a round yellowish spot, 1 millimetre in diameter, known as the macula lutea. When viewed in the living eye, however, it is of a deep red colour. It is depressed in the centre, forming the fovea centralis. Just to the nasal side of the yellow spot is the point where the optic nerre leaves the eyeball. It is known as the optic disc, or, since there is no sensation of vision there, the blind spot. Here the retinal artery enters the eyeball, and the retinal vein leaves it. The clinician particularly studies the condition of the optic disc with the ophthalmoscope. Normally, it appears as a circular pink disc, from which the artery and vein radiate out on to a red background.

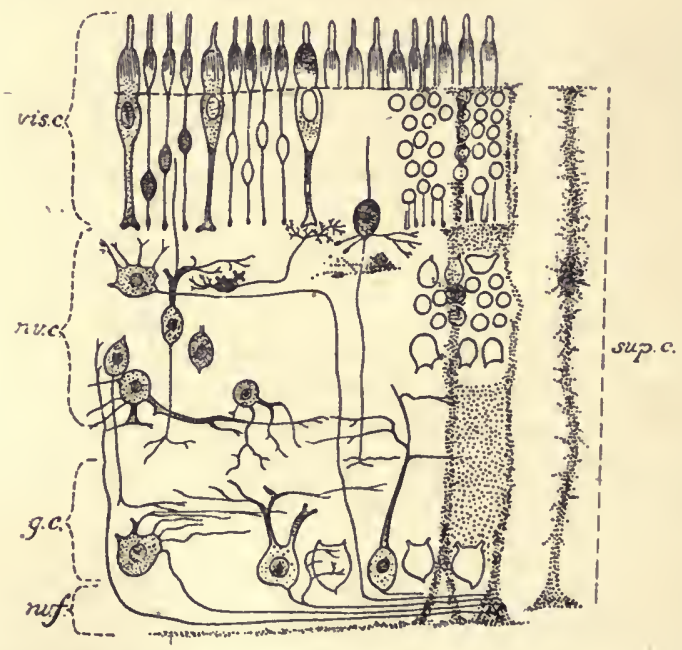

Fig. 340.-Digram of the Regina in Max. (Redrawn after Lewes-Stöhr, from Dahlgren and Kepner.)

vis. c., Laying of visual cells (rods and cones), the nuelei and processes forming the outer nuclear layer; $n v$. $c$., layer of bipolar eells, the inner nuclei of which form the inner nuelear layer; $g_{0} c_{.}$, ganglion eells, forming the ganglion cell laver; $n v . f .$, nerve fibre layer; sup. c., supporting or neuroglia cells.

Structuraily, the retina is cxceedingly complicated (Fig. 340). It contains-(1) the receptor mechanism (the rods and cones); (2) the second (conductor) neuron; (3) the third (conductor) neuron, the elongated processes of which go to form the optic nerve. The cells of these neurons, the interdigitation of their synapses, and the supporting cells, form the many layers of the retina. These are usually, enumerated as follows: 
1. Adjacent to the choroid is a single layer of polygonal pigment cells, from which elongated processes containing fine pigment (fuscin) granules pass into the next layer, and end between the rods.

2. The receptor mechanism of the eye, the layer of rods and cones A rod consists of an outer elongated part, about $30 \mu$ long and $2 \mu$ broad. It is transparent, transversely striated, and in it are to be found the minute pigment granules which form the "visual purple." The inner part of the rod spreads out somewhat in the shape of a carrot, the upper part being longitudinally and the lower part transversely striated. From the tip arises a rod-fibre, which pierces the external limiting membrane, and swells out as the rod granule or nucleus, finally passing on to form a varicose synapse (see Fig. 340).

A cone also consists of an inner and outer portion. The outer portion is tapering and pointing, about one-third the length of the corresponding portion of the rod. It is transversely striated, and contains no pigment. The inner part of the cone is broad, and ends in a cone-fibre. This is somewhat thicker than that of the rod, but, like it, pierces the external limiting membrane, contains a nucleus or granule, and ends as an arborizing synapse.

3. The external limiting membrane is a well-defined membrane formed by the outer processes of the sustentacular fibres. The sustentacular fibres of Müller reach from this layer to the internal limiting membrane. This membrane serves to support the rods and cones.

4. The external nuclear layer is made up of the rod and cone granules (the nuclei of the rod and cone fibres), and also of fine fibres belonging to the supporting cells of the internal limiting membrane (Fig. 340).

5. The outer molecular layer is really a synapse layer, consisting of the ramifying interdigitations of the rod and cone fibres and the synapses of the cells in the next layer-the, bipolar cells (Fig. 340). It also contains a few supporting cells, probably of a neuroglial nature.

6. The inner nuclear layer consists chiefly of the bipolar cells which form the first neuron (Fig. 340). One process, as we have seen, arborizes in the preceding layer; the other passes into the inner molecular layer of synapses, to end around the terminations of the dendrites of the ganglion cells of the optic nerve. In this layer are also oval cells, termed spongioblasts, which send a single process into the inner molecular layer, and other small cells, termed amacrine cells; which send a short process into the outer molecular layer. There are also a fow bipolar cells. The large oval nuclei of the supporting fibres of Müller are found in this layer.

7. The inner molecular layer is a synaptic layer containing the synapses of the bipolar cells, and of the ganglion cells. It also contains neuroglial cells.

8. The layer of ganglion cells consists of the large flask-shaped ganglion cells which constitute the second set of neurons (Fig. 340). 
Their dendrites pass outwards to arborize in the inner molecular layer; their axons pass in towards the optic nerve, forming

9. The layer of non-medullated nerve-fibres (Fig. 340).

10. The internal limiting membrane is formed by the expanded bases of the supporting fibres of Müller.

\section{Section II}

\section{LAWS OF DIOPTRICS}

The generally accepted hypothesis of the phenomena of light is that first enunciated by Thomas Young-namely, that light is a mode of motion of the ether which pervades space. By the molecular movements of luminous bodies the ether is caused to vibrate in a series of waves, forming a ray of light. The component particles of the ray move at right angles to the direction in which the ray is travelling, just as do the particles of water in the waves caused by disturbing the smooth surface of a pool.

Waves of big amplitude give rise to a sensation of bright light, small waves to one of dim light. All the waves are of very rapid rate of vibration- $-435,000,000$ to $764,000,000$ per second. Outside these limits the eye is not stimulated, although there are present both infra-red and ultra-violet rays. Beyond the ultra-violet rays comc the Röntgen rays, and below the infra-red the electrical waves in unbroken sequence. The light rays, with the low rate of vibration, give rise to the sensation of $\mathrm{rcd}$, those with the high rate to that of violet. In between we have the colours orange, green, blue, indigo, gradually merging into one another. Ordinary sunlight, as Isaac Newton showed, is composed of this series of colours blended together.

Light travels through the ether at about 190,000 miles per sccond. A ray, falling upon a polished surface, is reflected, the angle with the perpendicular of the reflected ray being equal to that which the incident ray makes with the same perpendicular.

When a ray passing through one transparent medium, such as air, meets perpendicularly another medium, such as water, part of it passes into the new inedium, and part is reflected upon itself. If, however, the ray meets the new inedium obliquely, the part which passes into the incdium is bent out of its course, or refracted. This refracted ray is in the same plane as before, and in the case of a ray passing from a rarer to a dellser medium the deflection is toward the perpendicular. The law for single refraction is that, whatever the obliquity of the incident ray, the ratio of the sine of the incident angle to the sine of the angle of refraction is constant for the same two media, but varies with differcnt inedia. This ratio of the angles is known as the index of refraction, and, knowing this index for any two media, the direction which will be taken by a ray of light can 
be calculated. Water refracts the ray more than air, and glass more than water.

When a ray meets obliquely a piece of glass with parallel surfaces, part of the light is reflected and part is refracted-bent towards the perpendicular to the surface. On again emerging at the other surface, it is bent back again to its former direction, and therefore passes on not in the same line as that in which it struck the glass, but in one parallel to it. So, when light falls obliquely on the sides of a prism, it is doubly bent, the amount of deflection depending upon the shape and material of the prism.

A similar effect is caused by lenses, both biconvex and biconcave. A biconvex lens will bring to a focus all rays parallel to its principal axis - that is to.say, parallel to the line which passes through the centres of curvature of its two surfaces. Such a point is termed the principal focus of the lens. Conversely, rays starting from the principal focus will energe from the lens in a parallel direction.

Spherical Aberration.-It has been stated that parallel rays falling upon a biconvex lens meet at the focus. In practice, however, this is not the case, as may be seen by trying to focus the sum's rays on a piece of paper with a burning-glass. The image of the sun can not be reduced to an absolute point, because the rays which meet the circumference of the lens are more refracted than those which fall nearer the middle of the lens. This is known as the spherical aberration of the lens. If the outer rays be cut off by interposing a diaphragm, it is found that the image is made sharper. The iris acts as a diaphragm and sharpens the image in the eye. If the central part of the lens were made more refrangible than the outer parts, then the rays nearer the centre would be more refracted than the outer rays, and a similar result obtained. Such is the case with the lens of the eye.

Chromatic Aberration,-It is found that, as is the case with a prism, owing to the different degrees of refrangibility of the various rays constituting white light, the latter is split up or dispersed into its component colours in passing through a lens. The violet rays aro bent most, the red ray's least. Therefore, if a scresn be interposed before the focus, there will be an image with a violet centre and a red edge; after the focus there will be an image with a red centre and a violet margin. This is known as chromatic aberration. Opticians remedy this by combining lenses of different powers of dispersion, forming thereby the so-called compound achromatic lens.

In a system of lenses there exist six cardinal points. If tho position of these be known, then the direction of all rays through the system can easily be traced. These six cardinal points are the first and second focal, the first and second principal, and the first and second nodal points:

The first focal point is the point so placed that all rays from it, after passing through the system, emerge parallel to the axis of tho 
system. The second focal point is the point to which parallel rays are gathered after passing through the system.

The principal point is situated on the principal axis at the point where the vertex of the spherical surface and the plane perpendicular to the axis meet. Ray's which pass through the first principal point after refraction pass through the second principal point.

The nodal point corresponds to the centre of eurvature of the lens. It is the point where a ray, falling perpendicularly on the surface, and therefore passing through without refraction, cuts the axis. Rays which pass through the first nodal point after refraction seem to emerge from the second nodal point in a direction parallel to that of the incident ray.
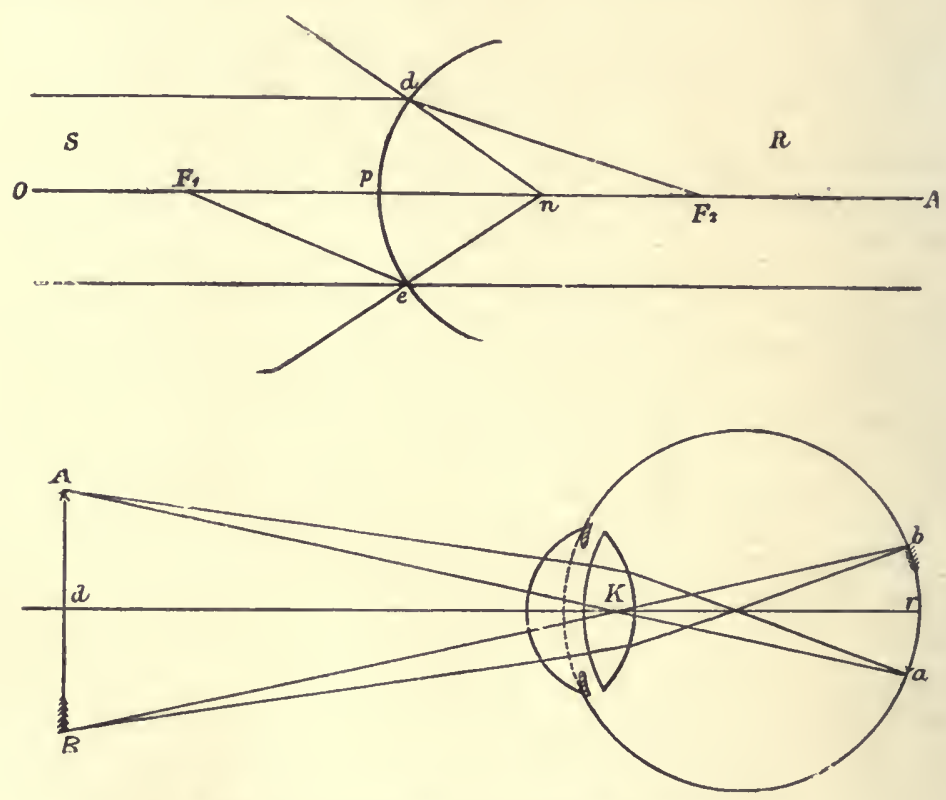

Fig. 341.-Diagrans to.illustrate Refractiox.

In the simplest form of optieal system, where there are only two media separated from each other by a spherical surface ( $d, p, e$, Fig. 341), $n$, the eentre of curvature of the surface, is known as the nodal point. A line drawn from $a$ through the vertex of the spherical surface $(p)$ gives the optic axis $(O A)$. Rays parallel to $O A$ in the less refractive medium $(S)$ will be brought to a point $\left(F_{2}\right)$ on the optic axis in the more refractive medium $(R)$-the posterior principal focus. Rayss parallel to $O A$, proceeding from $R$, will be brought to a point $\left(F_{1}\right)$ on the optic axis-the anterior principal focus. The principal point is at $p$.

In the eye, there are several surfaces between the various media, but since the refractive indices of some are approximately the same- 
e.g., those of the aqueous humour and the cornea-the refracting surfaces may be regarded as three in number: anterior surface of the cornea, the anterior and posterior surfaces of the lens. Thero are three refractive media-the aqueous humour, the lens, and the vitreous humour. These surfaces and media are arranged in such a manner that rays of light travelling from a distance-i.e., parallel rays-are brought to a focus upon the retina at the point known as the yellow spot, the principal focus of the eye. The line drawn through the centres of curvature of the cornea and lens to this spot is known as the optical axis of the eyeball (dr, Fig. 341).

Many careful measurements have been made to determine the cardinal points of the normal eye. The following measurements have been deduced:

First (anterior) principal focus of eye Second (posterior) principal focus .. First principal point . second principal point First nodal point .. Second nodal point ..

\begin{tabular}{|c|c|c|c|c|c|}
\hline$\cdots$ & . & $12 \cdot 8326$ & $\mathrm{~mm}$. & in fron & t of cornea. \\
\hline . & . & $22 \cdot 647$ & mn:. & behind & cornca. \\
\hline & . & $1 \cdot 7532$ & ," & ", & ", \\
\hline & . & $2 \cdot 1101$ & ," & , & ," \\
\hline & - & 6.9685 & , . & ", & , \\
\hline & . & $7 \cdot 3254$ & ", & , & , \\
\hline
\end{tabular}

The principal points and nodal points are so close together that they may be combined, giving what is known as the schematic or reduced eye. In such a schematic eye, the path of the rays leading to the formation of the image upon the retina can be mapped out. The rays of light travelling from $A$ and $B$, the extreme point of the image, and falling parallel upon the surface, are not refracted, but pass straight through the nodal point $(K)$ to the retina. The angle formed by these lines is known as the visual angle. The rays parallel to the axis from $A$ and $B$ are refracted through the principal focus, and cut, on the retina, the first rays passing through the nodal point at $a^{\prime}$ and $b^{\prime}$ respectively: Hence an inverted object $\left(a^{\prime} b^{\prime}\right)$ is produced upon the retina.

The eye, however, is not a mathematically correct instrument. The various refractive surfaces are not usually so centred that the optic axis coincides with the line drawn from the point viewed to the fovea centralis of the retina-the visual axis. The angle of one axis to the other, where they meet at the nodal point, is usually about 5 degrees, but may be as great as 12 degrees. Moreover, since the centre about which the eye rotates is in the optical and not in the visual axis, the line of regard (the line joining the point-view to the centrc of rotation of the eye) does not coincide with the line of vision.

There is a certain amount of spherical aberration in the normal eye. This is not of much consequence, since it is corrected by the action of the iris. There is also some chromatic aberration, which is not, however, generally appreciated psychologically. It can be demonstrated by looking at the sky through the upper part of a window, and holding the edge of a card parallel to the upper side of the window-frame, passing it from below upwards and from above downwards. When the card covers half the pupil, the window-framo: 
during the upward movement, will be seen to have a border of blue, while during the downward movement it has a reddish-yellow one.

The refracting surfaces of the eye are not strictly spherical, but of the forms known as ellipsoids of rotation-surfaces formed by the rotation of an ellipse upon one of its axes. The result of this is that their eurvatures vary in different planes. Usually, in most eyes, the curve is more convex in the vertieal meridian than in the horizontal. Vertical rays are therefore, after passing through the eye, brought to a focus nearer than horizontal rays. For this reason, stars are seen "star-shaped." Werc the eye absolutely correct, stars would be luminous points. This defect is known as astigmatism. When, however, the defect of vision is so great that, owing to differences in refraction in different meridians, the subject is incommoded seriously, there is present some greatcr irregularity of the cornea or lens. It is necessary to correct the defect by reinforcing the curvature of the weaker meridians by means of cylindrical lens.

\section{SECTION III}

\section{THE ADJUSTMENT OF THE EYE FOR DIFFERENT DISTANCES}

WHEN at rest, the eye is normally adjusted to focus parallel rays upon the retina. For practical purposes, rays coming from a distance greater than 6 metres may be regarded as parallel. Inside this distance, the rays to the normal eye become divergent, and for a clear image to be formed on the retina it is necessary for them to be more refracted, otherwise a blurred image is formed, and the objeet is not distinctly seen. Thus, while standing 20 feet from a window, a needle held 2 feet from the eye is blurred when the window-sashes are distinct. Conversely, when the needle is seen clearly, the windowsashes are blurred. In looking at the needle under these conditions, we are conscious of the effort of accommodating the eye for near vision. Normally, although we are not eonscious of it, the effort required helps us to form our judgment of the distance of objects. The nearer the object, the greater the effort required to accommodate, and the sooner fatigue is experienced. Accommodation is brought about, not, as in the camera, by altering the position of the sensitive plate, but by altering the refractive power of the lens. When we accommodate for near vision, the anterior surface of the lens becomes more eonvex. This can be shown by viewing in a darkened room the images of a candle-flame reflected from the eye of a subject. When the light is properly adjusted, three images are seenone from the cornea, bright and erect; one from the anterior surface of the lens, apparently coming from near the centre of the pupil, feebler than the first, but erect; and a third, more deep-seated, generally a 
mere spot, and inverted, from the posterior surface of the lens. When the subject accommodates for near vision, the middle image alone moves. It advances and grows smaller, showing that in the process the anterior surface of the lens moves forward and becomes more

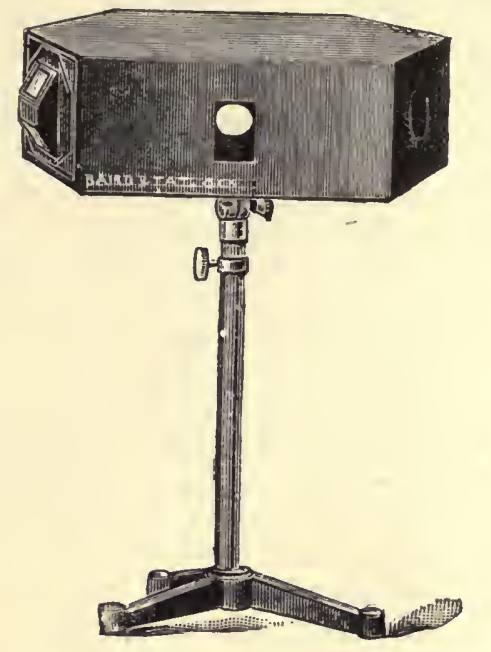

Fig. 342.-The Phakoscope.

convex. This phenomenon can also be demonstrated in daylight by means of the instrument known as the phakoscope (Fig. 342). It consists of a dark box, roughly triangular in shape, with the angles of the triangle bevelled off, and at $S$ and $O$ fitted with windows (Fig. 343).

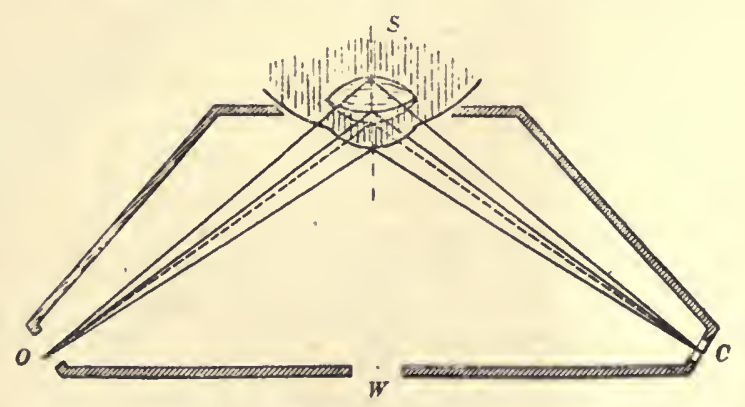

Fig. 343.-Diagray of the Course of the Rays of Light in the Phakoscope.

The observer's eye is at $O$, the subject's at $S$. At $C$ two prisms are arranged vertically, and these are illuminated by a lamp, so as to allow two illuminated squares to fall upon the eye placed at $S$. The eye at $S$ can either be focussed for the vertical needle placed at the opening $W$, or for a distant object beyond the opening. With 
the alteration of the lens corresponding to the change of accommodation, the images from the anterior surface of the lens are seen to vary, as described above.

The Mechanism of Accommodation.-According to the received hypothesis, the meridional and radial fibres of the ciliary muscle

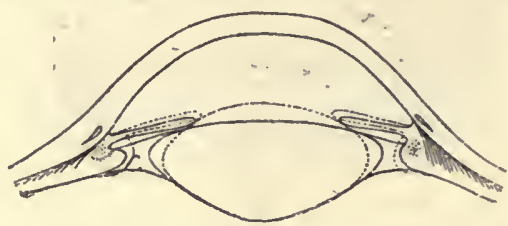

Fig. 344.-Diagray to show how Anterior Surface of the Lexs becoyes More Convex dURING AcCominodion for Near Vision.

contract and pull forward the posterior part of the ciliary body and the anterior part of the choroid, with the hyaloid membrane. This slackens the suspensory ligament and diminishes its pull upon the capsule of the lens, and the lens then, by its own elasticity, is free to assume a more convex shape. It is further suggested that the

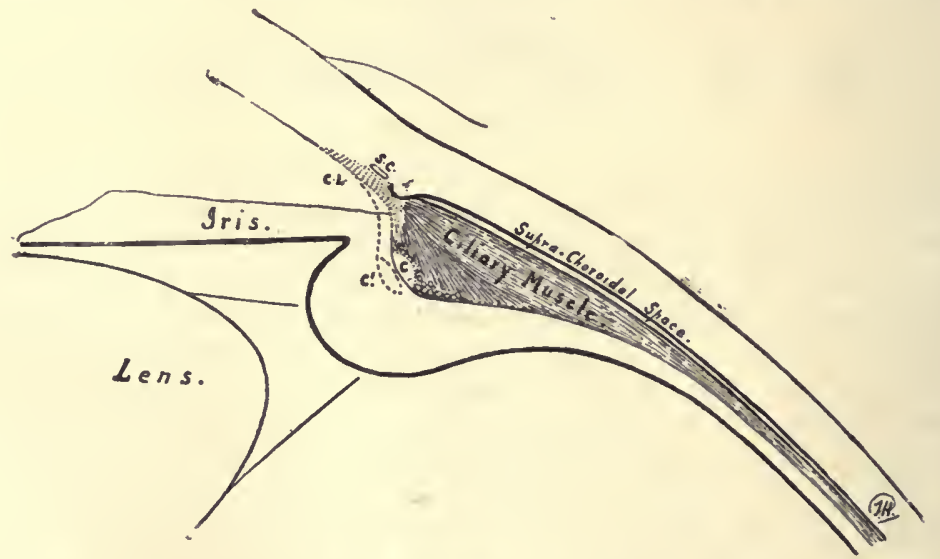

Fig. 345.-To illustrate the Movenext of the Corneo-Iridic: Axgle ix Accommodatiox. (Thomson Henderson.)

The eiliary sphineter moves from $c$ to $c^{\prime}$, the eribriform ligament is pulled taut, affording ready passage of aqueous into the supraehoroidal space. The angle of the anterior ehamber is not deepened in an anatomical sense.

circular fibres of the ciliary muscle, by their contraction, squeeze the free edges of the lens in a sphincter-like manner, thereby helping to squeeze the anterior surface forwards. The circular fibres are especially well developed in long-sighted people, who accommodate with special effort. It is said that the lens becomes more movable in the accommodated eye, as it can then be made to shake by sudden movements of the head. The essential part of the act of accommo- 
dation is the translation of aqueous fluid from the front to the cireumferential edge of the lens. The exeised lens, in itself, does not possess elastieity. It is a jelly-like mass. The whole eyeball is distended with fluid-aqueous, vitreous, and blood in the bloodvesseis - at a pressure of about $30 \mathrm{~mm}$. $\mathrm{Hg}$. The fluid is seereted by the cells whieh line the eiliary processes, and the intra-oeular pressure is regulated by their sesretory power. The pressure of this fluid keeps the eyeball distended, and maintains its shape eonstant in aecordanee with the requirements of an optical instrument. It keeps the suspensory ligament taut and the lens flattened. Aeeepting the importanee of the fluid, we must suppose that the eireular fibres of the eiliary musele and the radial fibres-taking the attachment of these to the suspensory ligament as the fixed point-by their eontraetion, pull open the meshes of the cribriform ligament, and allow aqueous fluid to pass therein. The eiliary body, in its outer part, is thus distended with fluid, and its inner part approximated to the circumferenee of the lens, and the suspensory ligament relaxed. The lens then takes on a more globular shape, and beeomes more mobile in its watery bed. By the passage of more, or less, fluid from the aqueous chamber in front into the meshes of the cribriform ligament at the cireumferenee, the eurvature of the lens is controlled with the greatest nieety. As the fluid is distributed all round the eireumferenee of the eyeball, the aetual expansion of the spaees in the cribriform ligament requires to be rery small in order to contain the fluid whieh is translated and determine the neeessary ehange in the convexity of the lens. If the meridional fibres of the eiliary musele relax when the radial and cireular fibres eontraet, they will be bowed inwards. If they eontraet when the other fibres

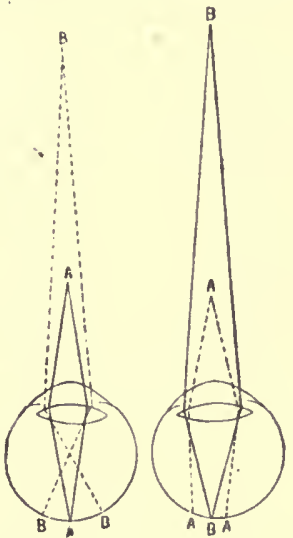

Fig. 346.-Diagram tu SHOW HOW THE [MAGES OF NeAR AND Far Piys fall on Retixa.

$A$, Near pin; $B$, far pin. relax, they will restore the aceommodated eye to its resting eondition. It is eoneeivable, and probable, that these fibres aet as antagonists to the eireular and radial fibres, and that aecommodation is brought about by the balaneed action of antagonist muscles. During the aet of aceommodation, the pupil contraets and the eyeballs are rotated inwards. All the museles concerned in the aet of accommodation are supplied by the third nerve.

The Near Point of Vision.-The range of aeeommodation in the adult is sueh as to allow elear vision of objeets held up to, and slighitly within 6 inehes of, the eye. This ean be demonstrated by making in a pieee of eardboard two holes separated by less than the diameter of the pupil. Holding these elose to the eye, a needle held inside 5 inehes is seen as two, but as it is gradually moved farther away the images fuse, and one needle only is seen (Fig. 346). 
Children possess a greater power of accommodation than adults. The near point of vision gradually increases with advancing age, so that at about the age of forty it is outside the normal reading distance of 10 inches, and print has to be held farther away in order to be read. This is the condition known as presbyopia, and is attributed to a diminished elasticity of the lens and atonicity of the ciliary muscle. It is remedied by biconvex glasses, which help to focus the rays correctly on the retina.

In the condition known as hypermetropia, or long sight, tlie parallel rays are not brought to a focus, becausc the eyeball is shorter than normal in its antero-posterior axis (Fig. $247, \mathrm{~A}$ ). To see even

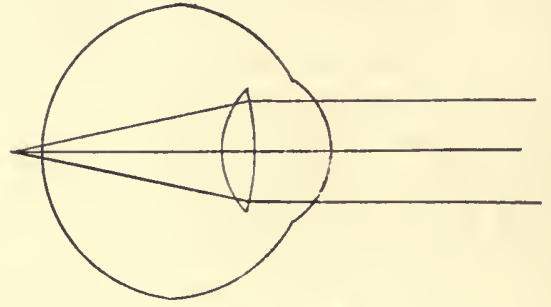

$A$

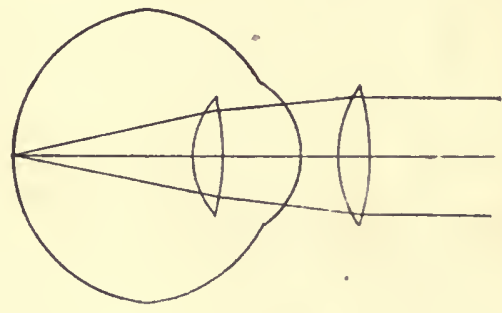

$B$

Fig. 347.-Digram showixg $A$, Codrse of Parallel Rays ix the Hrpermetropic Eye ; $B$, Patch of Parallel Rays ix Hypernetropic Eye after Correction by Means of a Convex Lexs.

distant objects well, the subject has to accommodate slightly, and this throws a strain upon the eye. The condition is corrected by a convex lens (Fig. 347, B).

The opposite condition is known as myopia. In this condition a person is short-sighted, and cannot see distant objects at all. The defect is due to an increased antero-posterior axis of the eye, the eyeball being longer than normal (Fig. 348, A). This being the case, parallel rays from a distance are brought to a focus in front of the retina. The defect is often associated with some degree of astigmatism, and is corrected by the use of biconcave lenses of suitable strengths (Fig. 348, B).

The standard lens for ophthalmic purposes is one which has a focal length of 1 metre; its refractive power is then said to be 1 diopter, or 1 D. A 2-diopter (2 D.) lens has therefore a focal length of $\frac{1}{2}$ 
metre, a 3-diopter ( 3 D.) lens one of $\frac{1}{3}$ metre, and so on. Biconvex lenses are called +, biconcave - , lenses.

Retinoscopy, or Skiascopy affords an accurate method of testing the refraction of the eye. The direction is observed in which the "shadow" in the eye moves when a light is reflected into it from a mirror. The "shadow" is seen against the illuminated background of the eye, which appears a brilliant red-choroidal reflex, as it is called. The operation takes place in a darkened room, preferably on an eye with the pupil dilated by a drug, such as homatropine. From a metre distance the eye is observed through a small plane or concave mirror with a hole in the centre-the retinoscope. The

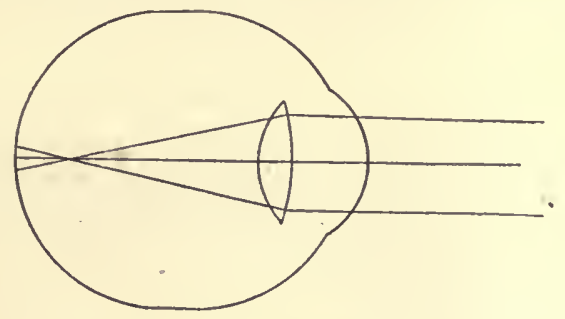

$-1$

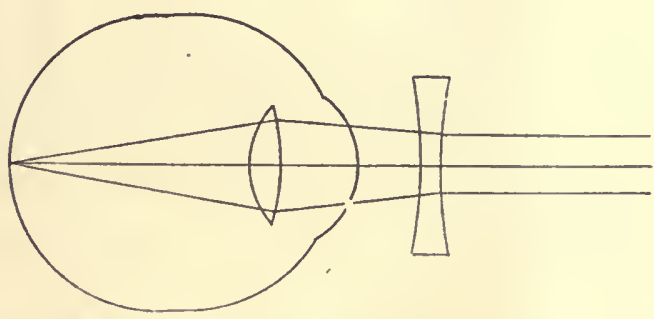

$B$

Fig. 348.-Digram showivg $A$, Course of Parallel Rays in Myopic Eye; $B$, Path of Parallel Rays is a Myopic Eye after Correction by Mleans of a Biconcave LeNs.

mirror is then slowly tilted from side to side. When a plane mirror is used, the shadow moves in the same direction as the mirror is tilted in the normal and in the hypermetropic eye, in the opposite direction in the myopic eye.

If the eye be normal, a lens of $1 \mathrm{D}$. will bring about a reversal of the direction. In the case of hypcrmetropic and myopic eyes, the reversal of the image is ascertained by introducing respectively biconvex and biconcave lenses; $-1 \mathrm{D}$. is added to the lens, which complately neutralizes the shadow: in other words, is subtracted from the strength of the + lens used in the case of hypermetropia, and added to the strength of the - lens cmployed in myopia. If a concave mirror be used as the retinoscope, the shadow moves against the direction in the normal eye in hypermetropia, and in the same direction in myopia. 


\section{SECTION IV}

\section{THE EFFECTS OF LIGHT FALLING ON THE RETINA}

Wrex those vibrations of the ether which eroke the scnsation of light fall upon the retina, certain marked changes occur. In the first place, there is a variation of the resting electrical current. In the resting eye, the current is normally ingoing; when the eye is stimulated by light, the current becomes outgoing (Figs. 349, 350).

Secondly, there is a movement of the granules in the pigment cells from the centre of the cells into the processes between the rods. In a frog's eye which has been kept in the dark, the pigment layer
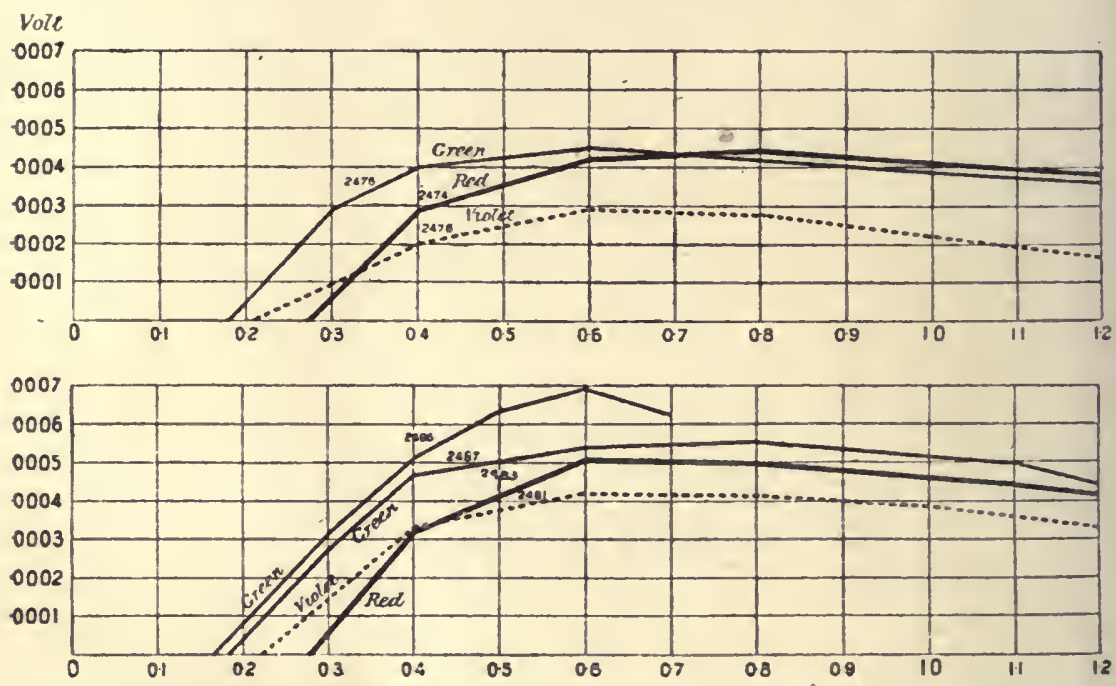

Fig. 349.-Plotted Curves constrdcted from Electroneter Records of Eyeball Responses to the Light froy the Red, GReex, aNd VIOLET RegioNs of the Spectrum. (Gotch.)

The upper records are fairly typical, the lower show the most pronounced resronses.

is easily separated from the rods and cones. After exposure to light, these layers are difficult to separate; the pigment is much more abundant between the outer limbs of the rods, and passes as far as the external limiting membrane between the inner limbs (Fig. 351).

Thirdly, the visual purple present in the outer limbs of the rods is bleached in the parts upon which the light falls. By this means, therefore, a negative image, or optagram, is obtained in the retina of an object, such as a window at which the eye may have been looking (cf. Fig. 352). When light ceases to fall, the visual purple is again regenerated at the expense of the pigment cells. For this purpose, it is necessary for them to be in contact with the rods. If they be in any way detached, regeneration does not take place. 
Fourthly, there is a contraction of the inner limbs of the cones.

The Functions of the Retina.-The retina is able to reccive and transform the ether vibrations into nervous impulses, so that the brain perceives. Not only is light perceived, but at the same time is appreciated the colour and also the form of external bodies. The function of the retina may therefore be said to be to transform light into nervous energy so that luminosity, form, and colour may be perceived by the brain.

The question arises as to which part of the retina is conccrned in the reception of the stimulus of the ether vibrations. The effects (described above) which light produces on the layer of rods and cones and pigment layer indicate that the transformation of energy takes place here. This is confirmed by the following considerations:

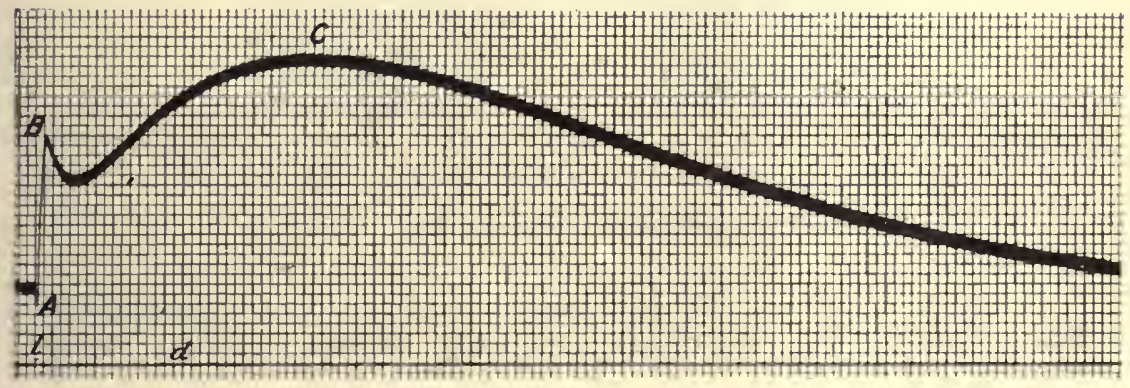

Fig, 350.-Conbined Action of Three Substances, A, B, C, on Dark Eye. (Einthoven and Jolly.)

Absc., $1 \mathrm{~mm} .=0.5$ second; ordin., $1 \mathrm{~mm} .=10$ microvolts.

1. The bloodvessels supplying the retina are distributed to the anterior portion of the retina in the nerve-fibre and ganglionic laycers, the main vessel entering the eyeball at the spot where the optic nerve passes in. Under certain circumstances, these ressels may be seen as a shadow. This being the case, they must be perceived by the parts of the retina lying behind them-namely, the layer of rods and cones.

If a subject turn one eye inwards, and look towards a dark wall, and with a lens a good light is focussed upon the cxposed sclerotic, so as to make a small but strongly illuminated area, then on giving the lens a gentle rocking or circular movement, the field will appear to the subject as reddish-yellow, and dark figures will be seen appearing in the field, which branch and have the character of the retinal bloodvessels, of which they are really the shadows. In the direct line of vision a small area will be seen free from these branching shadows. This is the yellow spot. So, too, if a white cloud be viewad through a pinhole in a card held close to the eye and the card be given an up-and-down movement, a number of vessels will 
be seen, generally running horizontally; if a side to side, vertically running vessels will be apparent; if a cireular movement, the general distribution of the vessels will be visible. In the direet line of vision there is a small area in which no vessels are seen-the macula lutea, or yellow spot.

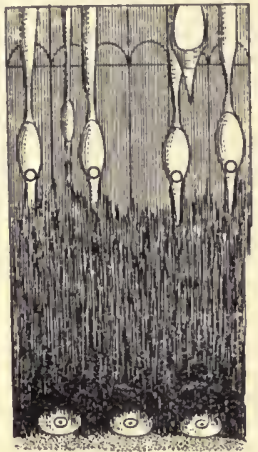

A

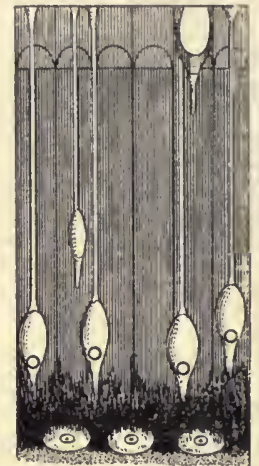

Is

Fig. 351.-Secriox_of Frog's Retixa. (After Englemann.)

$A$, After exposure to light; $B$, when kept in the dark.

In these experiments the movement of the light or the illuminated field is important. The retina appreciates shifting shadows better than fixed ones.

2. At the point where the optie nerve leaves the eye there are no rods or eones, and this spot is insensitive to light. This blind

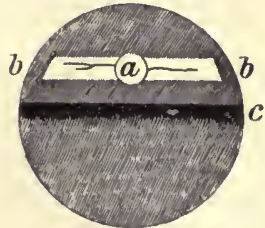

A.

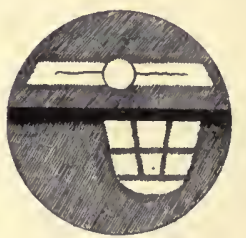

B.

Fic. 352. - A, The Normal Appearaxce of the Retixa in the Rabit's Eye before Exposure to Light; $a$, the Extrance of the Optic Nerve; $b, b, a$ Colourless layer of Medullated Nerve Fibres; $c$, a Layer of Deeper Colour separativg the Lighter Upper from the More Heavily Pigmented Lower Portion. B, Optogray of a Window after Exposure of Eye. (Kihne.)

spot is readily demonstrated by Fig. 353. If the left eye be closed, and the right eye gazes at the dot from the distanee of.a foot, the line will appear continuous. Normally, we do not notice the blind spot, but fill in the gap with sensations similar to those falling on the neighbouring areas of the retina. The blind spot can be mapped out as follows: Let the head rest in a fixed position, 
as by placing the chin in a tin mug, and place a sheet of white paper vertically in front of it at a distance of 18 inches. Draw a dot in the centre of the paper. Close one eye, and with the other regard the dot. Take a thin strip of white cardboard, and blacken about 2 millimetres of the end. Move the blackened end over the region of the field of vision corresponding to the blind spot, and note the points where the black area disappears, marking them on the white paper. A sufficient number of these points can be taken, and a curve drawn through them will indicate the margin of the field of the blind spot.

3. At the fovea centralis there are chiefly cones; the other layers of the retina are thinned out. This is the spot of acute vision.

Fig. 353.-To demonstrate the Bhind Spot.

When held about 12 inches away, with left eyo closed, the line on the left appears continuous.

The Perception of Light, and the Relation of the Sensation to the Stimulus.-We have seen that the sensation of light is due to the stimulation of the recptor mechanism of the eye by means of the vibrations of the ether. According to the amplitude of these vibrations, so the sensation of light varies in intensity. According to the length of time the waves fall upon the retina, so the sensation varies in duration. The sensation evoked lasts much longer than the stimulus. The sensation of a flash of lightning or of an electric spark, for example, is much longer than the time during which vibrations are actually falling on the retina. When the stimuli fall in sufficiently quick succession, the sensations become fused, so that a lamp swung quickly in a circle gives the sensation of a ring of light. In moving pictures such a fusion of sensation takes place. For such a fusion to take place, it is necessary for the stimuli to be about ten a second for weak light, and forty a sccond for strong light. The length of interval varies with different colours, being long sst with blue, shortest with yellow, and intermediate with red.

From the consideration of an electric light and a candle it is obvious that the intensity of the sensation varies with the luminous intensity of the object. Following Weber's law, it is found that it is easier to distinguish a slight difference in brightness between two feeble lights than the same difference in brightness between two bright lights. The smallest difference which can be apprcciated in the case of the eye moderately stimulated by light is about $\frac{1}{100}$ of the total luminosity. The total sensation is greater in amount when light falls on a large area of the retina than when it falls on a small area.

The effect of a stimulus also varies according as it falls upon an eye accustomed to the daylight (the light-adapted eyc) or an eye which has bcen attuned to the dark (the dark-adapted eye). Upon going from the light into the dark, it is impossible at first to see anything; but after a time the eye becomes adapted to the darkness, 
and surrounding objects are localized and identified. The sensitiveness of the retina has increased many times. Conversely, on emerging from darkness to light, one is "dazzled," owing to this extremo sensitiveness. This soon passes off, and the eye becomes "lightadapted."

Experiment seems to indicate that the different regions of the retina have different functions. The peripheral regions are found to be relatively more sensitive than the fovea to feeble stimuli-that is, to light of moderate or short wave-lengths. On the other hand, the central portion of the retina responds particularly to bright light -light of long wave-lengths. When the eye becomes adapted to the dark- "dark-adapted "-the increased responsiveness of the retina under these circumstances is in the regions outside the forea. It is much easier to perceive stars of small magnitude when looking sideways than when looking directly at them. It is for this reason, also, that a star may be suddenly observed in the heavens during a movement of the head, and yet, when that part of the heavens is scanned directly, it cannot be seen.

On the other hand, as already stated, it is known that it is in the fovea centralis that vision, especially form sensation, is most acute. We always look directly at a thing when we want to appreciate its shape. At the same time, the pupil is contracted to shut out peripheral rays. In order to differentiate similar objects grouped closely together, it is necessary that these should subtend an angle of a certain magnitude at the nodal point with respect to the eye. Further, in order that objects may be differentiated, it is necessary that their contiguous margins and the space between should form an image on the retina, which should not be less than a certain length. It has been found that a subtended angle of 63.75 seconds, equivalent to a retinal distance of 0.00463 millimetre, is necessary for discrimination. Double stars, which subtend an angle less than this, appear to the naked eye as single stars.

The acutenesis of vision at the fovea is ordinarily tested by noting the distance at which letters, which at a given distance subtend an angle of 5 minutes at the eye, can be read. This method may be applied either to ascertain what error of refraction may exist in the eye, or, if this be absent or corrected, what the acuteness of vision in the particular eye is. We shall see later that it is also in the region of the fovea that the different colours are best appreciated.

The so-called duplicity theory supposes that there are two distinct risual mechanisms in the retina-one that of the rods and visua! purple, upon which depends achromatic reactions, especially under conditions of darkness adaptation; secondly, that of the cones, which serves achromatic responsiveness in bright light, and also chromatic responsiveness. This riew is not altogether accepted, but it is supported by the fact that a great abundance of rods and visual purple is found in animals which see badly in broad daylight, but which have good " twilight vision." Such animals are the bat, owl, and hedgehog. Cones, on the other hand, predominate in the retinæ of 
animals which have acute daylight vision-e.g., birds, such as the pigeon and chicken-but which see imperfectly in feeble or artificial light.

Further, ín cases of total colour-blindness (achromatopsia), the spectrum is seen merely as a band of light of varying intensity, the greatest brightness being in the regions outside the fovea, while in many cases a blind spot (scotoma) is found in a position corresponding to the fovea. In such cases there is good vision in twilight, but in daylight a marked diminution in the acuity of vision, a fear of strong light (photophobia), bad fixation leading to nystagmus (quick sideto-side movements of the eyes).

In cases of nicotine-poisoning, with visual trouble (tobacco amblyopia), there is a loss of acuity of vision and deranged colour sensation. It is the region of the fovea which is affected.

In cases of "night-blindness" (hemeralopia or nyctalopia) there is, in comparison with the normal colour sense, a shortening of the violet end of the spectrum, and an impaired responsiveness to light or short wave-lengths. For this reason, a person suffering from this condition is unable to see well in twilight or artificial light, and is said to be night-blind. This condition is inherited, transmitted by the females, but present only in the males of a family.

The Perception of Colour. - When white light is passed through a prism, it is broken up into a number of colours, owing to the greater

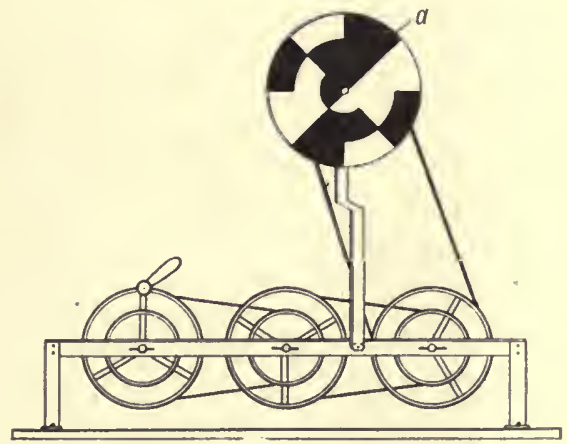

Fig. 354.-WheEl For Mixine Colours.

refrangibility of some rays than others. To most people, the spectrum is madc up of six distinct colours: Red, orange, yellow, green, blue, violet. Normal individuals may therefore be said to be " hexachromic." A few people, however, can, like Newton, see a seventh colour-indigo -bctween the blue and the violet. "They are "heptachromic." White light is therefore made up of a fusion of these colours. This can be shown by passing the colours through 'a sccond prism, when they are recombined to form "white" light.

It is not neccssary, however, that all the colours be fuscd to give 
a sensation of white. It has been shown that various pairs of colours, when mixcd, will give the sensation of "white." The mixing can be done by placing the colours upon a wheel or top which is quickly rotated (Fig. 354). It is better, however, to superimpose on a white surface the different colours from two spectra. The chief pairs of colours which give white are red-green, blue-yellow. Such colours are termed "complementary." If in a good light one of these colours in the form of a disc or letter be viewed steadily for a time on a white surface, and the gaze then turned to another white surface, the disc or letter will appear after a time in the complementary colour. This is known as the negative after-image. After beholding a red letter, a green letter will appear as the after-image, and so on.

The different colours of the spectrum vary in lummosity. Normally, the yellow is the brightest part of a spectrum. But the luminosity of a colour may vary. Thus, any of the colours of one spectrum may be made of equal luminosity with the yellow of another spectrum by increasing the intensity of the white light used to form the spectrum. With feeble light, the maximum luminosity shifts to the green, and the colours of the red end of the spectrum become less easily perceived than those of the blue end. This accounts for the order of the changing colours of a sunset or the change of colours in a flower garden as twilight passes into night.

Saturation.-Besides luminosity, a colour possesses a degree of saturation. By this is meant the extent to which it is mixed with white light. A fully saturated colour is entirely free from white light, such as the sodium flame in a dark room.

When colours are mixed which are not complementary, we get "shades." As many as 160 shades have been observed in the spectrum; some shades, such as purple, are not prescnt in the spectrum. When two colours are mixed which are nearer in the spectrum than the complementary colours, a colour is obtained of the part of the spectrum between the two. If the colours are farther apart in the spectrum than the complementary colours, then a colour mixed with white light is obtained-an unsaturated colour. By taking the three colours red, green, violet, or, r, according to other authorities, four colours-red, yellow, green, blue-all the colours of the spectrum may be obtained by mixing in varying proportions. These are known as the fundamental colours.

In the mixing of pigments, the nature of the pigment substance has to be taken into account. A blue and a yellow pigment, when mixed, give green, not white. This is because the blue pigment absorbs the red and ycllow rays from white light, and reflects the blue and green rays. The yellow pigment reflects red, yellow, and green, and retains the blue. When the pigments are mixed, the green rays are the only ones not absorbed. By examination of the light reflected from any pigment with the pocket spectroscope, it can be seen what rays are reflected and what are absorbed. 
Colour Vision.-Numerous theories have been advanced to explain the phenomena of colour vision. The two classical views are those of Young-Helmholtz and of Hering.

The Young-Helmholtz Theory.-This theory assumes that there are three separate substances in the retina stimulated by the wave-lengths of the three fundamental colours-red, green, and violet. Simultaneous excitation of all three gives the sensation of white, while absence of stimuli gives that of black. The colour sensations depend upon different degrees of stimulation of these three substances (see Fig. 355). From the diagram, it will be seen that orange is due to a large stimulation of the red, and lesser stimulation of the green and violet substances. In the sensation of yellow, the red and green elements are almost equally excited, and the violet but little, and so on according to the manner indicated in the diagram.

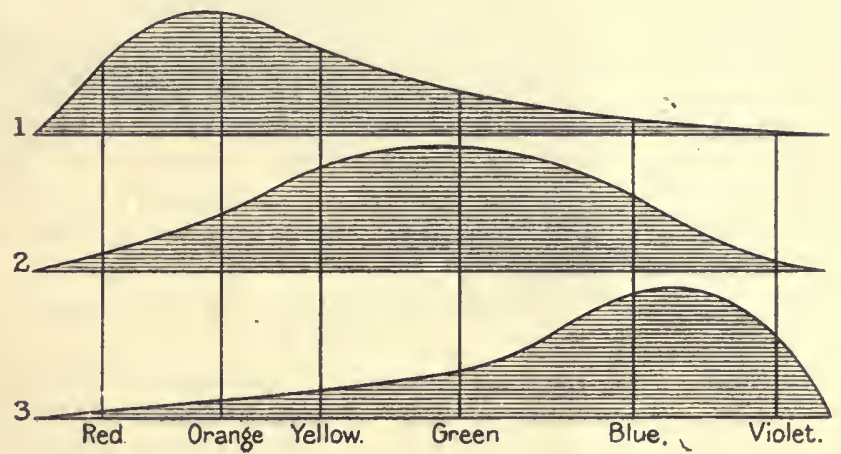

Fig. 355.-Schema to illustrate the Young-Helmholtz Theory of Colour Vision. (Helmholtz.)

The curves represent the intensity of stimulation of the three colour substances: 1 , The red-percei ving substance; 2 , the green-perceiving; 3 , the violet-perceiving. Vertical lines drawn at any point of the spectrum indicate the relative amount of stimulation of the three substances for that wave length of the spectrum.

The Hering Theory.-According to this view, the fundamental colour sensations are red, yellow, green, and blue. These are grouped together in pairs - red-green, blue-yellow, and in addition black and white (black-white). In the retina are three corresponding substances-the green-red, blue-yellow, and black-white. These substances may be stimulated either in an anabolic (a building-up) direction or in a katabolic (a breaking-down) direction. Thus, if one or other of the substances be broken down, the receptors of the retina are stimulated in such a manner that red, yellow, and white, are respectively appreciated by the brain. If the changes be in an anabolic direction, then the conscious sensation is respectively green, blue, or black.

$\begin{array}{cc}\text { Anabolism. } & \text { Katabolism. } \\ \text { Grecn. } & \text { Red. } \\ \text { Blué. } & \text { Yellow. } \\ \text { Black. } & \text { Whitc. }\end{array}$


The black-white substance is stimulated also by the sensations of luminosity. If, therefore, red and green sensations of equal intensity are thrown on the retina, they negative one another, and the result is a sensation of luminosity.

Against this view is the experimental fact that stimulation of the retina $b_{y}$ the different colour pairs does not produce electrical variations. in opposite directions, as they should do if the substance were affected in one case in an anabolic and in the other case in a katabolic direction. As the result of the exposure of the retina to coloured lights, the current of action is in the same direction, but with different latent. periods (Fig. 349).

Many experiments have been performed to support one or other of these views. Considerable importance has been attached to the evidence afforded by the condition of "colour-blindness." It would appear that the varying conditions met with in colour-blindness are not satisfactorily explained by either hypothesis.

Colour-Blindness. - Certain peoplc are said to be colour-blind. They are unablc to distinguish certain colours or shades which are easily appreciated by the normal eye. The defect is generally due to one of two conditions, or a combination of them: (1) The person is unable to perceive all the six colours normally seen in the spectrum; (2) the person is unable to appreciate the full extent of the spcctrum, especially of the red end.

In the first group, all degrces of colour-blindness may be found. Instead of perceiving six colours, an individual may only be able to see two colours; he is therefore termed a dichromic. If he see three colours, he is a trichromic; if four, a tetrachromic; if five, a pentachromic - as compared with the normal person, who sees six colours, and is hexachromic. A certain number of people perceive scren colours, and are heptachromic.

The commonest colours which arc confused are red and green, two forms of colour-blindness being distinguished-the " red-blind" and the " green-blind."

The " red-blind" is a dichromic, with a shortening of the red end of the spectrum. He cannot see the extremc red rays. From the nearer red rays, orange, and yellow, the red clement is lacking, and it appears as some shade of green. Green, violet, and blue, are normal.

The "green-blind" is also a dichromic. The middle of the spectrum appears to him grey, with a patch of strong red gradually fading into the grey on one side, and the violet merging into the grey on the other. Such a person can sce red well, and sees also a variety of shades. of rose. Greys and greens are confused, both being mistaken for red. The case of a small boy is quoted who wanted to paint a picture with the dust from his boots, because it was such a pretty" rose" colour.

Such persons get greatly muddled as the result of correction. Thus, the boy referred to above, having been told that a green was green, judged a donkey also to be green in colour. So confusion arises to the red-blind. Having been told that yellow, which appears to him green, is yellow, he confuses it with orange and red, which also 
appear green. Yot it is astonishing with what accuracy such a person can learn to name and match colours. He does not see the lips and cheeks as red, but learns to call them so. One case of colour-blindness

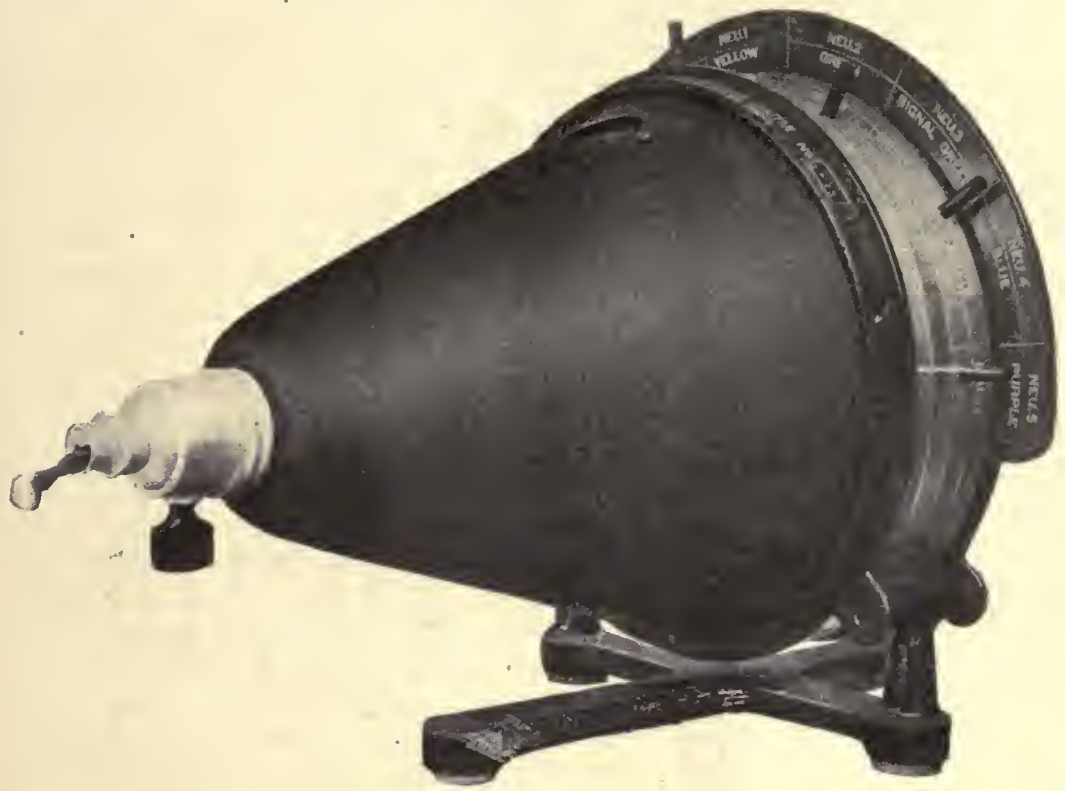

Fig. 356.-The Edridge-Greex Colodr Perception Lanters.

The lantern consists of four dises: threc carrying seren coloured glasses-Clear, red A, red B, yellow, green, signal green, blue, purplc-and one carrying seven modifying glasses-Clear, ground glass, ribbed glass, and five noutral glasses. Fach disc has a clear aperture. The diaphragm is graduated in respect to three apertures to represent a $5 \frac{1}{2}$-inch railway signal bull's-eye at 600,800 , and 1,000 yards respectivcly when the test is nade at 20 feet. The colours are brought successivcly into view by moving one or more of the handles to position, denoting the colour or unodifier in use, on the scale at the top of the lantern. The classification of colour perception is as follows:

Heptachromic appreciating in

the spectrum $\because . \quad$ Pied Orange Yellow Green Blue Indigo Violet

Hexachromic appreciating in

the spectrum $\ldots \quad \because$ Red Orangis Yellow Green Blu? - Violet

Pentachromic appreciating in the spectrum _. $\quad$.. Fed - Yellow Green Blue -.. Violet

Tetrachromic apjreciating in the spcctrum $\quad \because$ Red _ Ycllow Green - $\quad$ Violet

Trichromic appreciating in the spectrum $\quad . \quad$. Ped $\quad-\quad$ P Green -. $\quad$ - Violet

Dichromic appreciating in the spectrum ... .. . Red

Totally colour-blind appreciating Iight and Shade only.

explained that all colours appeared modifications of blue and yellow. The brightest and purest yellow he called yellow; a slightly darker and not so pure a yellow was green to him. A darker yellow still 


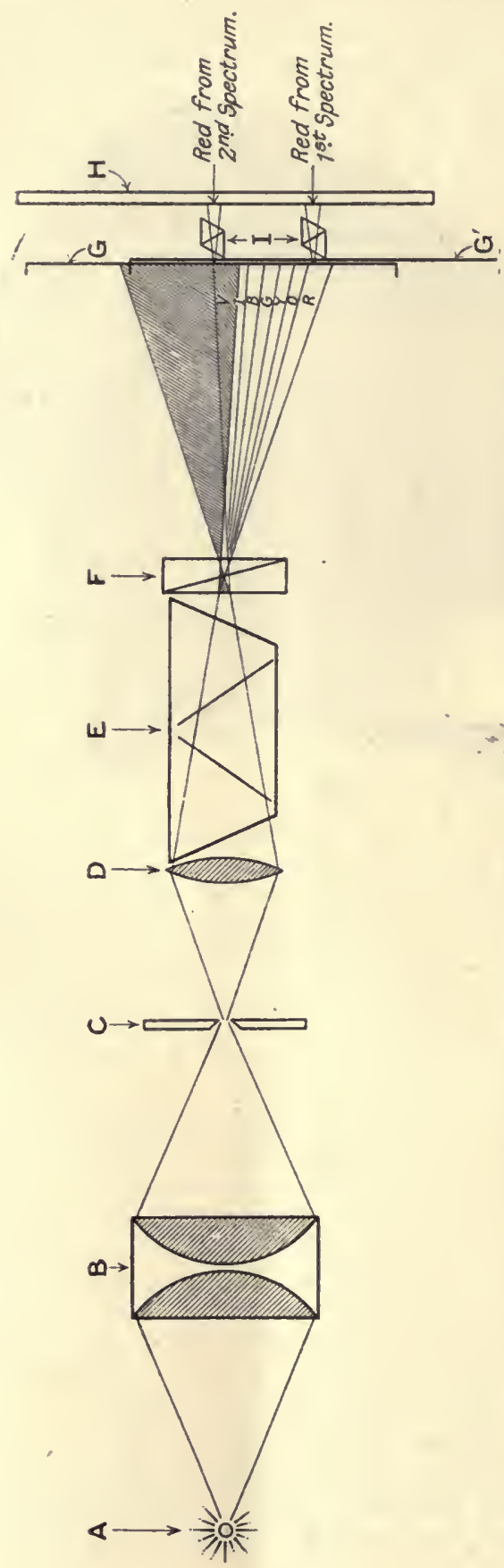


was red: The brightest blue was violet; a less bright, blue; a dirty bluc, purple; and a very impure blue, cerise.

The trichromic sees red, green, and violct. Cases with a shortening of the red end of the spectrum are unable to see red unless mixed with some degree of orange. Such a casc sees shades minus the red rays; therefore, a rose colour, which is a mixture of red and violet, appears violet to him, and more akin to blue than to red.

Since a system of colour signals is in vogue on sea and land, it is very necessary that persons employed in the marine and railway services should be able to recognize the standard red, grcen, and white lights under all conditions in which they are likely to be placed. For this reason, it is necessary to have an efficient mearis of testing colour vision, so that persons whose vision is not satisfactory may be excluded from such services. Generally speaking, such persons are: (1) Those who see three colours or less in the spectrum. (2) Those who have such a degree of shortening of the red end of the spectrum that they are unable to see distant red lights. This is of the greatest importance when it is remembered that in foggy weather the extreme red rays are the most penetrating. (3) Those who, although their vision is normal when close, are unable through insensitiveness of the central part of the retinal apparatus to perceive them at a distance.

The test most often einployed up till now has been the Holmgren wool test. The test colours used are a light green and a light shade of rose, which the candidate is asked to match without naming the colours. A red is also used as a confirmatory test.

It must be acknowledged that the test is more theoretical than practical. Wool is not a suitable material, and if the dyes used be different, the colours will be different in composition. The colours are also liable to fade, some colours more quickly than others. They also become dirty, particularly the greens, which enables the colour. blind to pick them out. Again, the different colours may have a different feel. The degree of luminosity also varies-an excellent aid to the proper identification for passing the test.

Persons suffering from insensitiveness of the retina will easily pass the test, and others who should not pass for marine and railway work will frequently do so with a little practice with the wools.

The best test is one where the spectral colours are used, where the luminosity of the light can be varied to approximate the various conditions met with on land and sea, and the subject names the colours which he sees. Such are the lantern and the spectrum apparatus shown in Figs. 356, 357.

By such means the three groups of cases mentioned above are detected with the greatest ease, while those may be discriminated who would be rejected by the wool test, and yet make useful servants. In testing for colour vision, it must be borne in mind that considerable colour ignorance exists among the suneducated, especially in regard to shades. 


\section{SECTION V}

\section{BINOCULAR VISION-VISUAL JUDGMENT}

THE formation of visual judgments depends largely upon the eyes acting together, the increased visual field and the combinations of eye movements greatly aiding in the formation of such judgments.

Ocular Movements.- The ocular movements depend upon the action of six muscles. Of these, four arise from the back of the eyeball, and are termed the superior, inferior, internal, and external rectus, according to the site of their insertion into the side of the eyeball. Contraction of the internal muscle turns the eye directly inwards, of the external muscle directly outwards. The superior and inferior muscles pass somewhat obliquely to their insertion. On this account, during their action they pull the eyeball somewhat inwards as well as upwards in the case of the superior, and downwards in the case of the inferior muscle. This inward deviation is corrected by the action of two oblique muscles. The superior oblique passes along the inner wall of the orbit, and, after passing through a fibrous ring, passes pulley-fashion backwards and outwards, to be inserted into the upper surface of the eyeball. Acting alone, this muscle rotates the eyeball downwards and outwards. The inferior oblique takes origin from the front part of the inner wall of the orbit, and passes beneath the eyeball backwards and outwards, to be inserted into its outer part. By its action, the eyeball is turned upwards and outwards. For direct upward movement, the superior rectus and inferior oblique act together; for direct downward move. ment, the inferior rectus and superior oblique. For oblique movements, two recti and one oblique act together, according to the direction of the movement. Thus, in looking obliquely downwards and outwards, the external and inferior recti and the superior oblique are employed. When two eyes are used, the same muscles are employed in both eyes for upward and downward movements; but for looking sideways, the outer rectus of one orbit acts in conjunction with the inner set of the other. When converging the eyes upon a near object, or when intentionally turning both eyes-inwards, the inner muscles act together.

All eye movements are normally so dirceted that the image of the object looked at falls upon the yellow spot of both eyes; indeed, it is impossible voluntarily to turn the eyes so that this is not the case. It is not possible to turn one cyc up and the other down, or both eyes outwards. It is stated that the "seeing double" of intoxication is due to the fact that, under this condition, the muscles of the eyeballs are relaxed, the eyeballs diverge slightly. If we intentionally diverge the eyeballs, as by pressing on the outer side of one, objects are seen double. By shutting one eye, it will be found that the left image belongs to the right eye, and the right image to the left eye. In death the eyeballs diverge slightly. Such a divergence may be due to the 
fact that in the passive position the eyeballs coincide with the axes of the eye-sockets, which are somewhat divergent.

Normally, double vision, or diplopia, is prevented by the balanced action of the ocular muscles; when these muscles are relaxed, except for their normal tone, the visual axes of the two eyes are parallel. It sometimes happens that the balance is not perfect, and that a constant action of one or more. muscles is necessary to keep the visual axes parallel for distant vision-a condition known as heterophoria. If in the relaxed condition of the eye muscles the eye

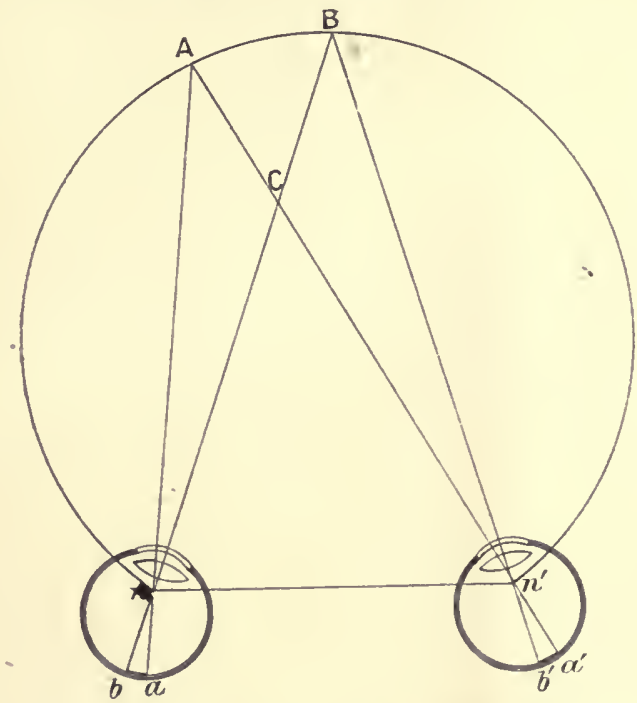

Fia. 358.-To illostrate tile Horopter.

$A$ is the point of regard; its retinal images are formed on the yellow spots at $a, a^{\prime}$. $b, b^{\prime}$ are colresponding points of the two retinæ, therefore the distance $a b=$ the distance $a^{\prime} b^{\prime} . \quad n, n^{\prime}$ are the nodal points of the two eyes.. The angles $a n b$, $a^{\prime} n^{\prime} b^{\prime}$, are equal to each other and to the opposite angles, $A n B, A n^{\prime} B$; and in the triangles $B C n, A C n^{\prime}$, the opposite angles at $C$ are equal; therefore, in these triangles the remaining angles at $A$ and $B$ are equal. Therefore the point $B$ by which the corresponding images $b, b^{\prime}$ are formed must lie in the arc of a circle passing through the points $B$. $n$, and $n^{\prime}$. Similarly, it may be shown that any other point forming corresponding images on the two retina will lie in the circular arc $n .4 n^{\prime}$.

turns outwards, the condition is known as exophoria; if inwards, esophoria; if upwards or downwards, hyperphoria. Such a condition throws a strain upon the eye muscles, and entails considerable ocular distress. The trouble is corrected by the prescription of prisms, or by operation. When the defect is so marked that it cannot be corrected by muscular action, we have the condition of strabismus, or squint. This results either from the overaction of one or more of the muscles, or from a deficient action or paralysis of one or more muscles. In the former case, it may be cured by surgical operation. 
Normally, when we look at a distant object, the eyes are parallel, so that the image falls upon the same point in both eyeballs-the yellow spot. When looking at a close object, owing to the position of the yellow spot, the eyeballs converge slightly, so that the image still falls on this point of distinet vision in both eyeballs. Thus, a sensation of oneness is obtained, due to the fact that the same point is regarded by the yellow spots of both eyes at the same time, and the attention is directed to the object looked at, and not to other objects. also in the field of vision. That this is the case may be proved by holding vertically at different distances from, and in the middle line of, the body two small rods or pencils. When we concentrate attention on one, the other becomes blurred or double. This is owing to the fact that, when the eyes are directed so that the rays from one fall on the yellow spots of the retine, the rays from the other fall on different parts of the retinæ which do not habitually work together (cf. Fig. 346). Thus, when the near object appears as one, the rays from the farther one fall on the inner side of each yellow spot and the result is two images are seen. These appear the same distance away as the near object, and when one eye is closed, the image on the same side disappears, and is ealled homonomous. When the distant object is seen singly, the rays from the nearer object fall on the outer side of each yellow spot. The result is that two objeets are seen, but in this case, when one eye is closed, the image of the opposite side disappears, and is known as heteronomous.

It requires special attention to see such double images, and as a rule we are not conscious of them, since attention is paid only to the object looked at, and we do not at the same time try to view carefully objects at two markedly different distances from the eyes. If such images are formed, they are cerebrally suppressed, and not secn. This is particularly the case in persons suffering from squint. Generally speaking, right-handed people appreciate the right image and suppress the left. The tendency to do this is illustrated by asking a person having both eyes open to point carefully in the middle line of the body at a distant object, either hand being used. On elosing first one eye and then the other, it is found that, viewed with one eye the finger is still pointing correctly, while with the otker eye the image of the finger has mored to one side, and the finger is not pointing at the object.

Each person has a eertain visual field. This depends to a certain extent upon the setting of the eyes, whether deep or protruding, and also for each eye upon the shape of the brow, bridge of nose, and chcek-bones. A certain part of the field of vision is common to both cyes. On closing the eyes alternately, it is seen that part of the visual field is common to both eyes, but that the brows and nose cut off part of the field visible to the other eye. There is therefore narked advantage in a binocular visual field. From every point in this field the rays of light in a fixed position of the eyes fall upon corresponding points of the two retinæ. Each point in the field has 
a corresponding point in each retina, so that the yellow spots correspond, and also the inner and outer, upper and lower, parts of each retina. For this reason, the projections of the objects by the cerebral apparatus upon the visual field correspond in position, and are seen single. This is facilitated by the fact that the fibres from the retinæ have a special arrangement; and connect with definite brain areas (see p. 712).

A line joining all the points which appear single in the field of vision isknown as the horopter. It assumes various forms for different positions of the eyes. When the visual lines are parallel, as in the case of very distant objects, the horopter is a plane at infinite distance coinciding with the ground. When a near object is being looked at, and the visual lines converge-as, for example, in looking at points A and B (Fig. 358)-then the horopter takes the form of a circle.

Visual Judgments-The Perception of Distance, Size, and Solidity."Judgments" are performed in the brain, and are in some ways more correctly dealt with when considering the cerebral functions. Of all judgments, the visual are perhaps the most easy of analysis. If we were born blind, and suddenly acquired the power of vision, we should not immediately recognize everything. In our first application of the sense of sight, we make great use of touch to ascertain the detailed outline of objects. By this means we arrive at a correct understanding of these objects, and remember them later. This is well illustrated by cases of congenital blindness in which vision has been restored by operation after as long as twenty-eight y'ears. In one such case, aged eighteen, when the bandage was first removed after the operation, the patient, in reply to the question as to whether the surgeon had a beard, asked to be allowed to feel it, and only on touching it replied unhesitatingly, "Yes." On being shown a chair, he said he saw it, but could not tell what it was without touching it. He made many wild guesses as to what an apple was, but on touching it said immediately: "Just fancy, an apple!"

Recognition of colours is soon learnt. The appreciation of space, size, and distance, comes but slowly. Such patients at first walk warily, with hands extended, like a blind man. One paticnt of twentyeight years, in taking his walks by moonlight, kept jumping every now and again over objects lying in his path. These were shadows which he was doing his best to avoid, and he would not believe that there were no obstacles in his way until he had satisfied himself by touch that the ground was in reality quite flat.

A patient of eight years, when taken on a moonlight night to the veranda illuminated by three low-hanging are lamps, thought the vcranda was covered with snow, and thought the moon to be an arc lamp quite near him.

Such cases also show the interesting fact that objects are seen at once in their proper position, and not upside down. The first two patients mentioned wcre each taught the colour of two strips of paper -red and green. They were then placed one above the other, and 
a quick and correct answer was immediately given to the question as to which colour was uppermost.

A white object seeu on a dark background appears larger than a black object of equal size on a white background. This is known as

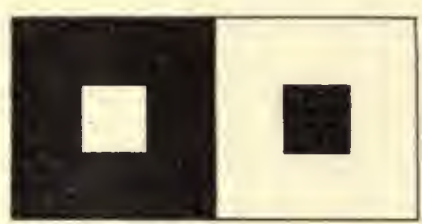

FIG. 359.-TO DEMOXSTRATE IRRADIATIOX.

The white spaces appear larger than the black. They are the same size. irradiation (Fig. 359). When a white strip is placed between two black strips, the edges of the white strip near the black appear whiter than the middle portion; the centre of a white cross placed on a black background appears shaded.'A white dog may appear clean indoors, but very dirty when out on newly fallen snow. The phenomenon is known as simultaneous contrast. This contrast is also experienced with colours. A neutral grey strip surrounded by green seems to acquire a pinkish hue, the tint of the complementary colour to green (red). If surrounded by blue the acquired hue of the neutral grey object is yellow. If a grey strip surrounded by green be viewed intently for some time and the gaze then transferred to a sheet of white paper of other white surface, the after-image of the strip will then appear greenish surrounded by red. This is known as successive contrast. Various speculations are put forward to account for the phenomena. According to the Helmholtz view of colour-vision such contrast effects are cerebral in origin, and in reality are errors of

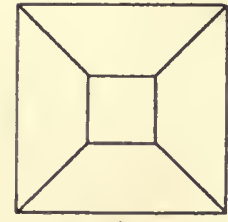

B.

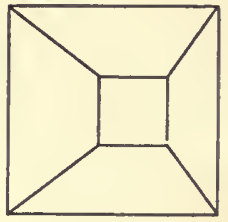

L.

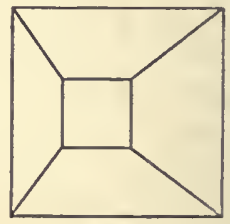

R.

Fig. 360.-Right- and Left-Eyed Images of Truncated Pyramid.

$B$, Truncated cone; $L, R$, right- and left-handed images. By fixing the vision beyond the book, $L$ and $R$ may be made to combine and give $B$.

judgment. According to the Hering view they are retinal in origin due to modified metabolic effects of the visual substances.

If a solid object be viewed fixedly by either eye separately, and then by both eyes, it is easily appreciated that separately the eyes view the object from a different standpoint. Together they view the object from the combined standpoint, and we have in addition an increased sensation of solidity and perspective. This is well seen by looking vertically downwards at the truncated pyramid. With both eyes it has the appearance of $B$, with the left only it is seen as $L$, and with the right eye only as $R$ (Fig. 360). 
The effect of combining the pictures of the lcft and right eye is well seen in the stereoscopc. In the more commonly used form, the Brewster stereoscope, the corresponding picture for each eye is viewed through a curved prism, so placed with its base outwards that the rays from the pictures impinge on the retina in lines of convergence which meet at points behind the plane of the pictures (see Fig. 351). A partition cuts off the sight of the opposite picture, so that each eyc sees only its own picture, usually slightly magnified by the prism. Owing to differing distances between the corresponding points in the two individual pictures, the effect of apparently differing distances is obtained in the combined picture. The nearest points-that is, those which require the greatest convergenee of the optic axes-stand out in most marked relief, the most distant points, which require less convergence, in least relief. It is not necessary to have a stereoscope to get this combined effect. With practice, it is aceomplished by merely fixing the eyes on the pictures, and adjusting the eyes for distant vision. The two pictures then gradually merge together, and the whole effect of solidity is suddenly perceived. This is known as haploscopic vision (Fig. 362).

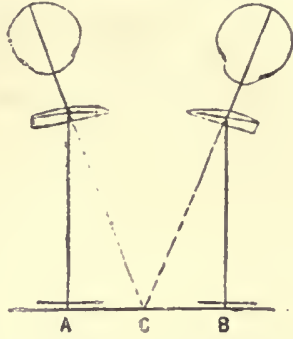

Fig. 361.-Diagram of A STEREOSCOPE.

Two photographs, $A$ and $B$, are seen at $C$. The rays of light from $A$ and $B$ are refracted by the prisms into the eyes so that they appear to come from $C$.

Stereoseopic pietures are obtained by drawing or photographing the same scene from slightly different points of view. The perception of solidity is due in the main to a mental process fusing slightly
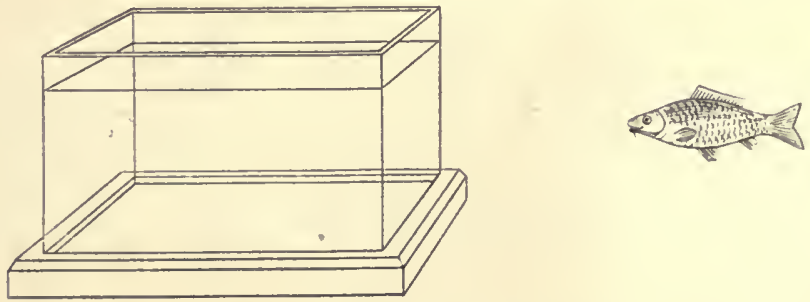

Fig. 362.-To illustrate Haploscopio Visiox.

The distance between the fish and tank is here given as rather less than the distance between the two pupils, so that the haploscopic combination can bo effected easily, with the visual axez somewhat convergent. The illusion is facilitated by holding a card vertically between the eyes, so as to hide the fish from tha left eye and the tank from the right eye.

different images from the two retinæ, the amount of activity of the eye museles in converging the optic axes being also an important factor.

Judgment of size and distance also depends largely upon the degree of muscular effort put forth in the convergenee of the eyes 
and in the mechanism of accommodation. Objects at the near point are seen clearly, and are judged to be near; those farther off less and less distinetly, and are judged to be correspondingly distant.

Judgment of size is the resultant of two factors-the actual size of the retinal image of the object, and the known or apparent distance from the eye. Similarly, we estimate distance by the size of the retinal image, and the known or presumed size of the object. An object seen through field-glasses appears near at hand, but seen through the wrong end appears far away. The after-image of an object appears large or small, according as the surface on which it is seen is near or far away.

The relative transparency of the air also plays a part in such judgments. A hazy atmosphere turns a small hill into a large mountain, a very clear atmosphere makes objects appear much nearer than usual. In addition to the size of familiar objects, judgment is also aided by the disposition of lights and shades, according to the position of the objects in relation to each other.

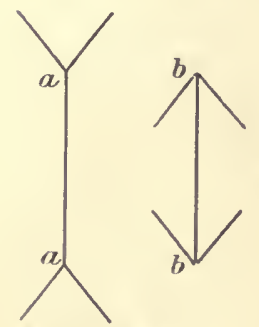

Fio. 363.

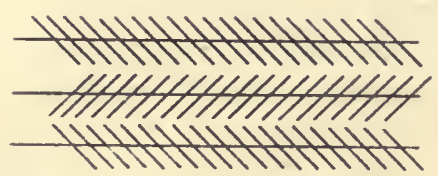

F'IG. 364.-ZöLLxeR's Jises.

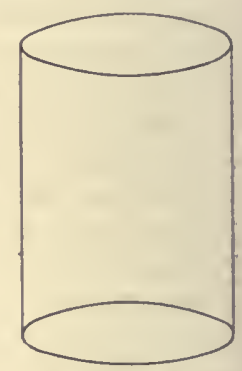

Fio. 36i.

The horizontal lines are parallel.

Mathematical perspective also plays a part. Parallel lines, like those of a railway-track, converge more and more in proportion to the distance away. We learn accurately to appreciate this perspective, but many optical illusions are associated with uncommon combinations of lines. One of the best known is that shown in Fig. 363. The lines of $a a, b b$, are of equal length. In Fig. 364, the horizontal lines are parallel.

To sum up, the visual judgment depends upon both monocular and binocular elements. The chief monocular elements are musclo sense, aerial perspective, mathematical perspective, the size of familiar objects, and the disposition of lights and shades. Superimposed on this is the binocular clement, due to the fact that external objects, particularly those close at hand, are not seen exactly the same in both eyes. This adds greatly to our judgment of depth and solidity. Visual judgments are made in the brain. We have no exact knowledge of the seat of such inferences. The judgment may be influenced quite independent of any outside cause. Thus, in Fig. 365, the vessel may be imagined to be with its open 
end either towards or from the observer; especially if one eye be closed an actual vessel can equally be "seen" in either position.

\section{Apparatus used in Clinical Investigation of the Eye.}

For acuity of vision, Snellen's test-types are generally used (Fig.366). The size of the letters is so arranged that a person with average acuity is able to read the top letter at a distance of 60 metres, the second
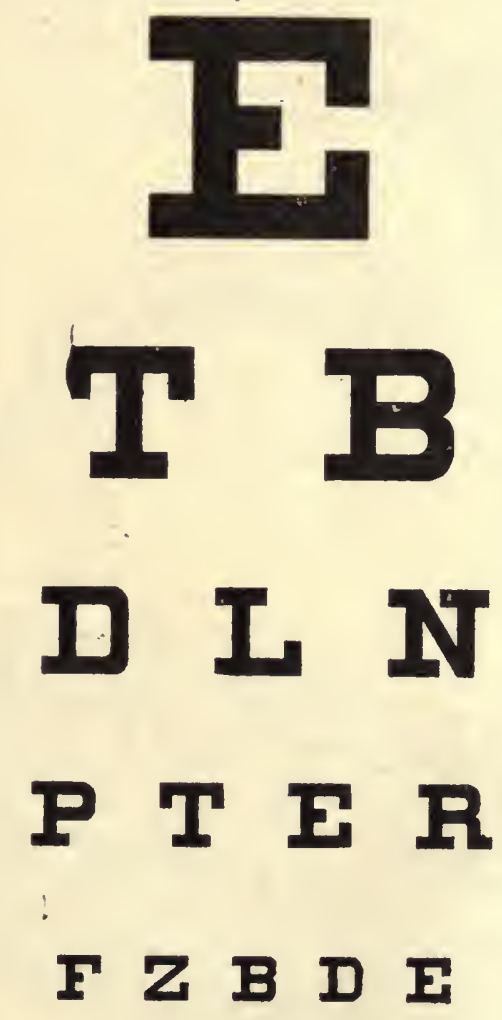

\section{O E I Z T G}

\section{P O R $\mathbf{F} \mathbf{Z}$}

Fia. 366.-SNelten's Test-Types Redtced in Size.

line at 36 inetres, the third at 24 metres, the fourth at 18 metres, the smallest at 6 metres. In testing the acuity, the subject stands 
about 6 metres away, and endeavours to read the types. Defective vision is usually recorded by stating the distance from the type as numerator, and the distance at which the last line read by the subject should normally be read as the denominator. Normal rision (V)

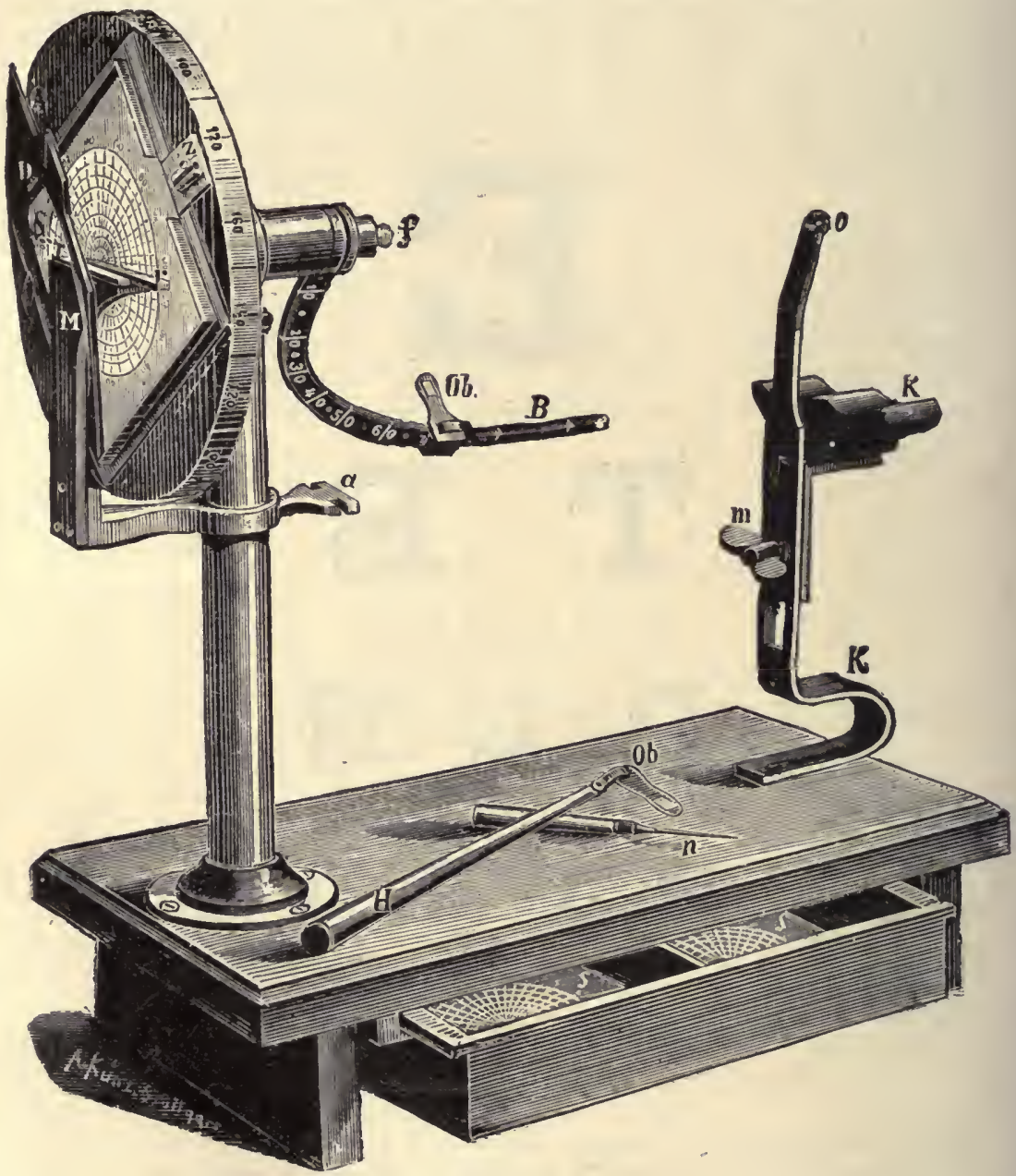

Fig. 367.-THE PerIMeTH.

is $\frac{63}{6}$ - that is, the 6-metre type can be read at 6 metres. $V=\frac{6}{36}$ signifies that at 6 metres' distance the subject only succeeded in rearling type which should normally be read at 36 metres.

It is customary to employ an instrument called a perimeter to obtain accurate details of the extent of the field of vision. The 
perimeter (see Fig. 367) consists of a quadrant upon which a white spot can be moved, and this quadrant can be revolved about a line continuous with the optic axis. At $K$ is the chin-rest, double, so as to enable either eye to be adjusted against $O$. The subject, having taken his position, covers one eye, and fixes the eye that is to be examiner on the mark at $f$. The quadrant is then placed, say, in the vertical meridian, and at the back of the wheel which rerolves with the quadrant is inserted in the frame a special chart adapted for recording perimetric observations. Starting at the extreme distance, the mark $O b$ is gradually moved along the quadrant, and at a certain angle the white spot will be just visible. The angle indicates the limit of vision in this meridian, and can be recorded on the chart. Similar observations are made in other meridia. In this manuer the limits

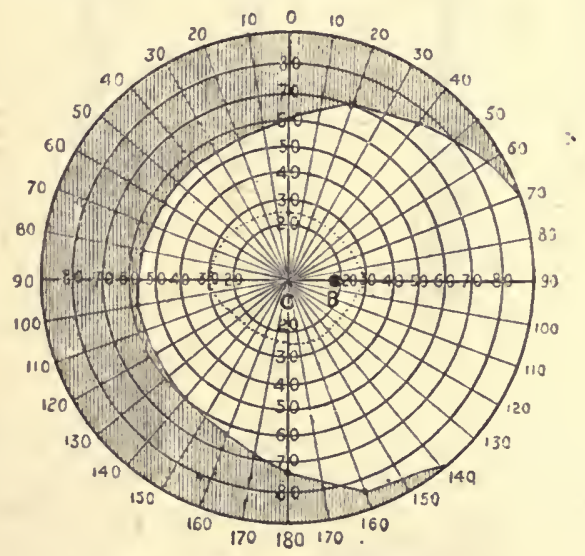

Fia. 368.-Perimetric Chart of the Riaht Ere.

The thick line surrounds the area within which white is visible, tho point $C$ being fixed by the eye-(right); the fine dotted line surrounds the area within which green is visible. "The area of red would be somewhat larger, that of blue larger still, thnugh not so large as that of white. $B=$ the situation of the blind spot.

of vision in the different meridia of the field of vision can be recorded. It is essential that the subject keep his eye fixed on $f$ the whole time the spot is being moved (Fig. 368).

The area bounded by a line drawn through the limiting points in the different meridia is properly the area of the field of vision. If the meridia be inverted, the figure traced corresponds to the sensitive portion of the retina. Perimeters are generally so constructed that the limiting marks in the different meridia are inverted on the chart, so that the latter becomes a chart of the extent of the sensitiveness of the retina. This is indicated in the figure above.

The Ophthalmoscope.-The ophthalmoscope (Fig. 369) is an apparatus to enable an observer to direct his vision along the axis of the pencil of light illuminating the subject's ey'e, thereby enabling 
him to receive light reflected from the retina of the subject, and thus actually to see the illuminated retina. The instrument consists of
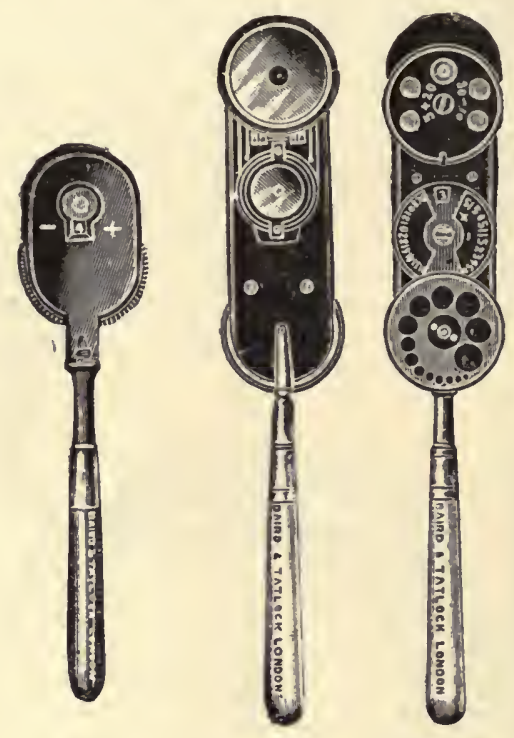

Fif. 369.-OPhthalaoscopes.

a mirror with a central aperture so arranged as to reflect light from some source through the pupil into the interior of the eye. The

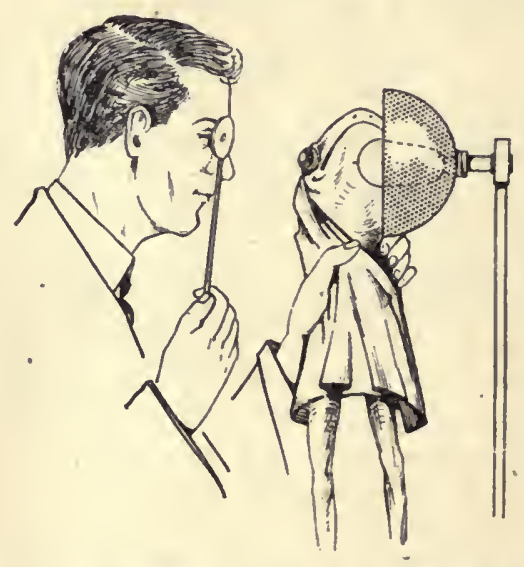

Fig, 370.-Examixation of thw Eye of a Frog by Meaxs of Orhtialmosculis Mirror (Direct Mfthod).

observer, looking through the central aperture, is able to view the illuminated posterior wall of the eye. 
Two methods are usually adopted of using the ophthalmoscope, one being known as the direct, the other as the indirect. In the first case, there is obtained an erect view of a small area of the retina, magnified about thirteen times; in the second case, a less magnificd and inverted view is obtained of a larger area of the retina.

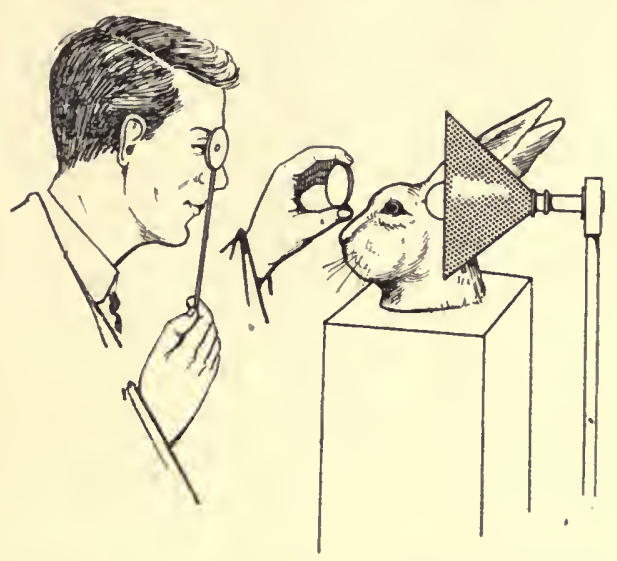

Fro. 371.-Exanisation of the Ere of a Ribbit after Atropise by the INDIRECT METHOD.

In the direct method, the source of light is placed at the side of the head of the subject, so that no light falls directly on the cornea. The mirror, which is somewhat strongly concave, is held a few inches from the subject's eye, and is so tilted that light is directed into the pupil. The observer uses his left eye to examine the subject's left eye, and similarly his right eye for the subject's right ey'e.

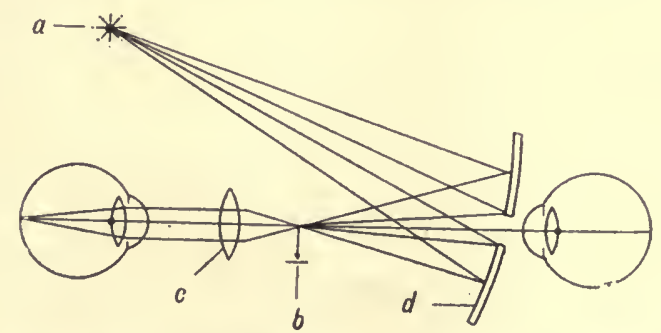

Fig. 372.-To Show the Course of the RaYs of Light fRoM the laMp to the OBSERVER's Eye by The Isdrec't Mnthod.

$a$, Lamp; $b$, the fold of lens; $c$, lens; $d$, mirror of ophthalmoscope.

In the indirect method, a somewhat larger but less concave or a plane mirror is used. The mirror is held at a distance of about 18 inches, and if the accommodating power of the subject is intact. 
his eye will accommodate for the source of light or its image forme: by the mirror. An inverted image of the illuminated area of the retina will be formed at a certain distance behind the mirror. The rays issuing from the eye are intercepted by a rather strong convex lens held close to the cornea, so that the observer, looking through the aperture of the mirror, obtains a clear view of a considerable portion of the illuminated retina.

Ophthalmoscopes are generally supplied with a revolving disc of lenses of different strengths. These are used to correct any error of refraction in the subject's or observer's eyes.

It is frequently a matter of difficulty to obtain a clear view of the back of the eye, or fundus, unless atropine has been applied previously which causes dilation of the pupil. For practice in the use of the ophthalmoscope, the eye of an albino rabbit which has been treated with atropine can be advantageously substituted for the human subject. 


\section{CHAPTER LXX}

\section{HEARING}

The Receptor Mechanism. -The receptor mechanism for hearing in mammals consists of a specialized nerve-epithelium, contained deep in the skull within the cochlea of the internal ear, in what is known as the organ of Corti. To this the vibrations of the air are conducted by means of the elaborate accessory apparatus of the external, middle, and internal ears. The fully developed spiral sochlea exists only in mammals. In birds its homologue, the lagena, is a simple, slightly curved tube; in reptiles it is rudimentary, and in amphibians and fishes does not exist.

For a long time it was thought that the whole of the apparatus of the ear was connected with the sensation of hearing. This is now known not to be the case, part of the internal apparatus being connected with the sense of position and equilibration. The rudimentary forms of ears described in lower forms, both vertebrate and invertebrate, are connected with this mechanism rather than with hearing (see p. 6.54). It is improbable that molluses, fishes, etc., have any sensation of hearing, although the notion that they have is one which dies hard. Recent experiments have shown that snails are supremely indifferent to sounds of any description, but are exceedingly sensitive to touch. The so-called hearing of fishes is probably due to tactile response to the vibrations of the water surrounding them, rather than to hearing. The fish in a pond which came to be fed when a bell was l'ung did not hear the bell, but felt the vibrations of the water produced by the approaching of the steps of the bell-ringer. The power of hearing in amphibians and in reptiles is also very doubtful, and has been assumed rather than proved. It is more than probable that such apparent hearing is in reality due to the vibrations of the ground on which they lie, or, as in the case of fish, of the surrounding water.

The hearing powers of birds and mammals are undisputed. From the point of view of comparative anatomy, it is interesting that the bird, with its lovely range of sound production, and therefore probable wide range of hearing, has only the simple, slightly curved lagena; whereas the animal with the most complex cochlea, a shy rodent of South America, has a very limited range of sound production with which to charm the five whorls of the cochlea of his fellow-kinsinen. There is therefore reason to suppose that the complexity of the oochlea has to do with sensitivity rather than with the range of 
hearing powers. In cetacea there are $1 \frac{1}{2}$, in man $2 \frac{1}{2}$, and in the rodent Cœlogenys paca 5 whorls to the cochlea.

The External Ear.-In mammals this varies greatly in form, from the rigid, almost immovable structure of man to the easily movable organ of most mammals, which in some may be rigid, in others flapping. The external ear consists essentially of two parts-the auricle, which acts as a sound-catcher and reflector; and the external meatus, by which the sound-waves arc conducted down to the drum-head, or tympanic membrane. The external ear is also protective in function. The bitter waxy secretion, or cerumen, and the outward pointing hairs, deter insects from entering, while the varying curvature makes it difficult for foreign bodies directly to impinge upon the tympanic membrane.

The tympanic membrane separates the external from the middle ear. It is firmly fixed in a bony groove, and lies obliquely to the

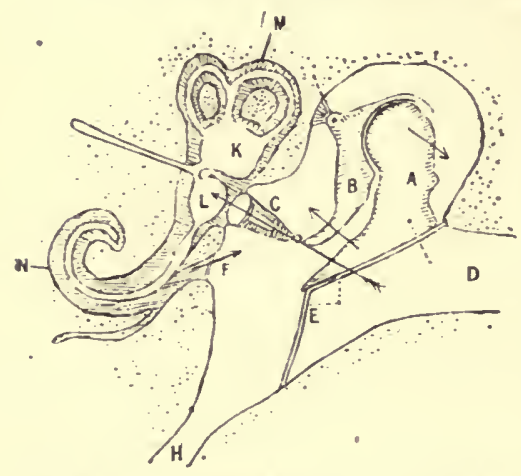

Fig. 373. - DlagraM of Ear, SHowixg OSSICLES,

-1 , Mallous; $B$, incus; $C$, stapes; $D$, external auditory meatus; $E$, tympanic membrane; $F$, foramen rotundum; $H$, Eustachian tube; $K$, utricle; $L$, saccule; $M$, semicircular canals; $N$, cochlea. The shaded part of internal ear, the bony labyrinth, is full of perilymph; the white part, the membranous labyrinth, is full of endolymph.

therefore relatively great effects. lumen of the meatus, the lower margin being farther in than the upper. The membrane consists mainly of connective tissue, together with a little elastic tissue. Some of the fibres radiate to the circumference from the umbo, a point just below the centre of the membrane, the others being arranged circularly about the same point. Into the membrane the first of the three bones of the middle ear is inserted in such a way as to render the membrane conical in shape, with the conrexity towards the meatus. The membrane thus curves slightly outwards, and is not uniformly stretched in all dimensions. The value of this arrangement is that very slight changes of air-pressure produce relatively large movements of the membrane, and to vibrate to a great range of tones.

The condition of the membrane is examined by the use of a speculum and the reflected light from a mirror with a central hole, attached to the forehead of the observer (Fig. 374).

Across the middle ear stretches a chain of three small bones, or ossicles - the malleus, or hammer; the incus, or anvil; and the stapes, or stirrup. The stapes is inserted by ligamentous tissue into the fenestra ovalis.

The function of the ossicles is to interpose a solid element which 
conducts the vibrations of the tympanic membrane to the fluid of the internal ear, which in its turn excites the receptor mechanism. In the frog we find only a single cartilaginous rod-the columella. A chain of bones, however, has considerable mechanical advantages. The handle of the hammer is inserted into the tympanic membrane, and leads upwards to the head, which is placed above the level of the tympanic membrane, and is fixed in position by ligaments which pass to a fissure in the bone, onc from a delicate forward pointing process-the processus gracilis-another from the head of the malleus to the roof. This is one of the fixed points about which the bones rotate. FIG. 374.-VIEW OF The anvil is in such a position that its conical TYMPAXI Mexprocess points downwards. This process ends by

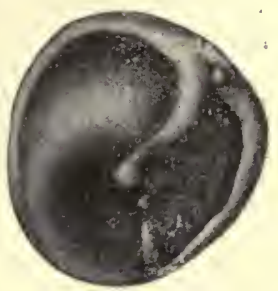
bending inwards to a flattened knob-the lenticular process. From the base of the anvil, ligaments pass to the posterior wall of the cavity, while the head of the anvil articulates with the malleus. The stapes is fixed by the head of the stirrup to the lenticular process of the anvil, and passes horizontally to be inserted by the foot of the stirrup into the oval window.

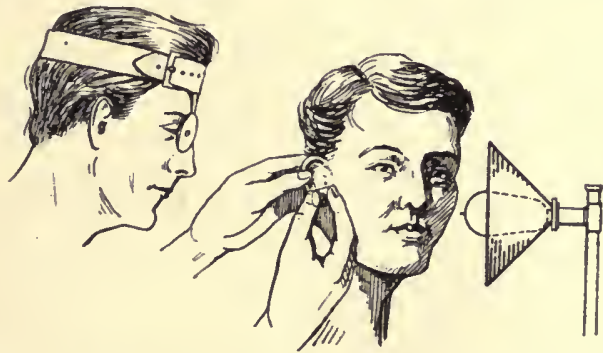

Fig. 375.--Method of Examinatios of the Ear Drdm by Refrected Lteht.

The malleus and incus rotate as one bone round a horizontal axis. When the handle of the malleus is pushed inwards, the head of the bone moves outwards, carrying with it the body of the incus, excessive movement being prevented by the ligaments of the malleus. The descending process of the incus is thereby moved inwards, and pushes the stapes against the fenestra ovalis. The chain acts as a bent lever, so that, when the malleus moves a certain distance, the stapes moves but two-thirds of that distance; the resulting impact, owing to the order of the lever, is increased by half, and since the area of the tympanic membrane is about twenty times as great as that of the base of the stapes, the force falling upon the oval window at the base of the stapes is about thirty times as great as that falling on the tyinpanic membrane at the umbo. For this reason, it is easy to understand that hearing is seriously interfered with when the action of the ossicles is deranged by middle-ear disease. 
On the inner wall of the middle ear there are two apertures: an upper oval one, known as the fenestra ovalis, or the oval window; a lower, smaller, round one-the fenestra rotunda, or round window. Each of these is closed by a membrane. Into that of the oral membrane is inserted the terminal process of the chain of ossicles.

Leading away from the front of the tympanum is a channel divided into two by a ledge of bone. The upper compartment contains a muscle - the tensor tympani-while the lower passage connects with the pharynx, and is known as the Eustachian tube.

The action of two muscles of the middle ear requires consideration -namely, the tensor tympani and the stapedius. The tensor tympani, supplied by the fifth nerve, arises, as we have seen, in the upper compartment of the channel leading from the front of the middle ear, and is inserted by its tendon, which crosses the tympanum, into the inner part of the handle of the malleus. Its action is to maintain by its tone a constant tension on the tympanic membrane. When it contracts, it renders the membrane more taut-an action which is believed to limit the movement of the membrane, and thus dampen the effect of loud notes.

The stapedius lies in a space behind the tympanum, and its tendon passes through a perforation in the bone behind the oval window, to be inserted into the neck of the stapes. Its action is doubtful. It may be that it moderates the force of the stapes against the fenestra ovalis, or it is possible that, by pulling on the stapes, it acts through the chain of ossicles upon the tympanic membrane, and induces relaxation of it - an action antagonistic to that of the tensor tympani. It is supplied by the facial nerve, and when this nerve is paralyzed loud sounds are heard with painful intensity. The muscles may help to tune the tympanic membrane for the reception of sound.

The Eustachian tube serves to keep the pressure equal on the two sides of the tympanic membrane. It is normally kept closed except during the act of swallowing. This has a double usefulness. If the tube were always open, then, in the first place, since all parts of the head are affected by the waves of sound, the tympanic membrane would tend to become pushed upon on both sides at once, and the effect of the vibrations damped. Secondly, were it open, there would be a great reverberation of our own voice in our ears.

The equality of pressure on both sides of the tympanic membrane is of great importance for normal hearing. Deafness from "colds in the head " is due to the occlusion of the passage by the congestion of its mucous membrane. The Eustachian tube allows the escape of mucus from the middle ear. During exposure to increasing or rarefying atmospheric pressure hearing becomes defective, unless the tube be kept open by swallowing or forced expiratory movements with the nose and mouth shut. It is important for the airman to keep the pressure equal on both sides of the tympanic membrane in this manner both for the sake of hearing and for the sake of correct balance.

The Internal Ear consists of a thick-walled cavity in the temporal bone, known as the osseous labyrinth. It is filled with a lymph-like fluid, known as the perilymph. Lying in this perilymph is a smaller 
membranous duplicate of the osseous labyrinth, known as the membranous labyrinth. This contains a fluid, known as the endolymph.

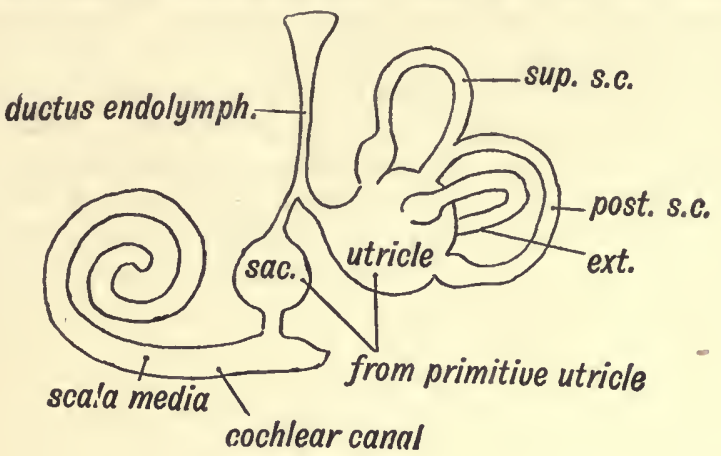

Fira. 376.-Diagram of Membraxious Labyrinth. (Keith.)

Into the central portion of the osseous labyrinth-the vestibulethe fenestra ovalis opens. Anteriorly from this there arises a convoluted tube-the osseous cochlea - which is wrapped around a central

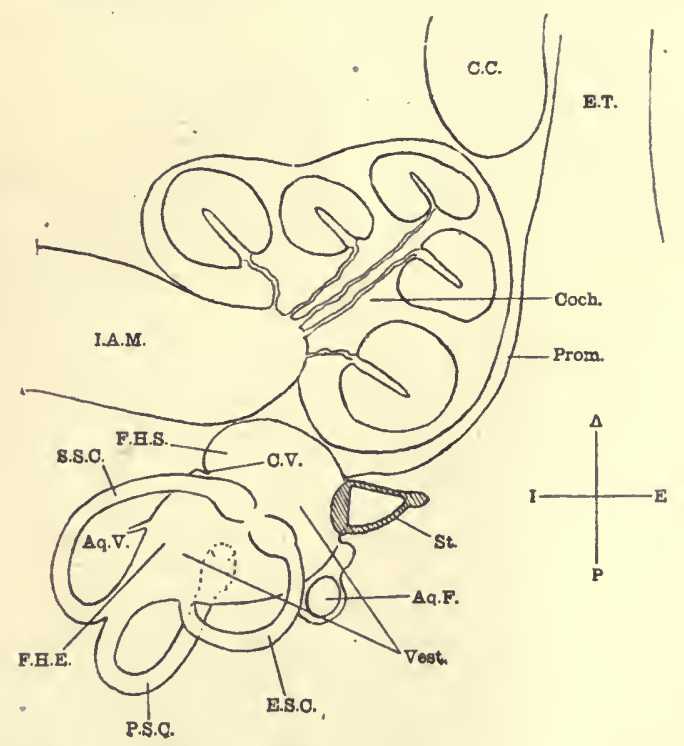

F13. 377.-Dlagram of Riaht Interyal Ear, seen from Above. (From larsons and Wright, "Practical Anatomy.")

Coch., Cochlea; Prom., promontory; C.C., carotid canal; E.T., Eustachian tube; I.A.M., internal auditory meatus; Vest., vestibule; F.H.E., fovea hemielliptica lodging utricle; C.V., crista vestibuli; St., stapes fixed in fenestra walls; $A q . F$., Fallopian aqueduct (for facial nerve); $A q . V$., aqueductus vestibuli; S.S.C., P.S.C., E.S.C., superior, posterior, and external semicircular canals.

pillar-the modiolus. The tube is divided into two by a septum partly bony - the spiral lamina—and partly membranous - the basilar 
membrane. The upper spiral section, or staircase, is called the scala vestibuli, the lower one the scala tympani. The scala vestibuli begins at the fenestra ovalis, and ascends to the top of the whorl. Here it connects by way of an opening in the lamina spiralis - the helicotrema - with the scala tympani, which descends to the fenestra rotunda. A membrane - that of Reissner-cuts off a part of the scala vestibuli, the scala media, membranous cochlea, or cochlear canal. This is bounded by the basilar membrane below, and ends blindly at the top of the cochlea. Like all the inembranous structures, it is filled with endolymph; the other two staircases, being bony, are filled with perilymph. In section, the scala media is triangular.

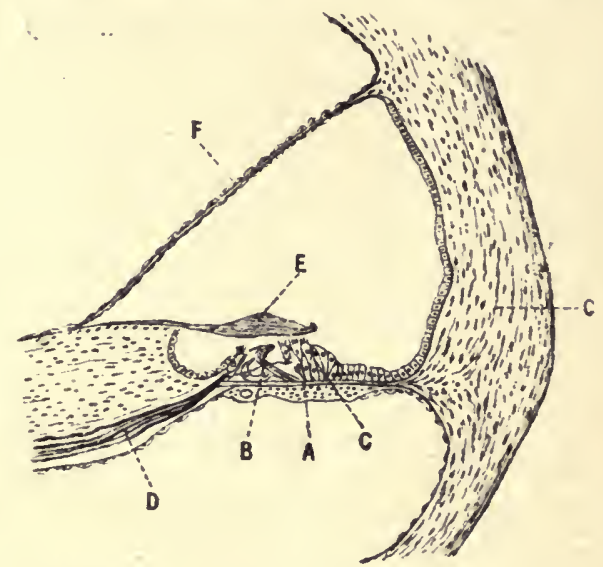

Fig. 37s.-Sectiox (Low PuW en) throvgh Part of Cochlea, showisi MeMbraxous CAxal of the CochIEA. (After Retzius.)

$A$, Basilar membrane; $B$, rods of Corti; $C$, hail cells; $D$, fibres of auditory nerve; $E$, tectorial membrane; $F$, membrane separating off membranous canal of cochlea; $G$, wall of cochlea.

Within this membranous cochlea, or scala media, is contained the organ of Corti, the receptor mechanism for hearing. The organ of Corti is set upon the upper aspect, or in respect to its position in the head, the anterior aspect of the basilar membrane. It runs almost the whole lengtl of the cochlear canal, and consists of a set of elongated, cylindrical, rod-like cells, the outer and inner rods fixed by all expanded base to the basement membrane. These meet at their upper ends like the beams of a sloping roof, the outer cells fitting into a socket in the inner cells. The inner rod may be compared in shape to the ulna, and the outer to a swan's neck, head, and beak. From the head of each rod a flattened process projects, the process of the inner cell overlapping that of the outer, and giving, when seen from above, an appearance like the keyboard of a piano. The inner rods are about half as numerous again as the outer, two outer rods thus fitting into three inner ones. It is conjectured that there are about 6,000 inner and 4,000 outer rods. Intern- 
ally to the inner rods is a layer of columnar cells of the same height as the rods, with about fifteen to twenty short, stiff hair-like processes arising in crescentic manner from the surface. These are known as the inner hair cells.

Externally to the outer rods there are also hair cells-the outer hair cells. There are generally three or four rows of these, each cell being supported outside by a supporting cell, known as Deiters' cell. These cells are broad at their base of attachment to the basilar membrane, and pass as narrow processes to be attached to a fenestrated membrane, or membrana reticularis, which arises as a sort of latticework from the upper portions of the rods, and serves to support the free hairs of the hair cells. A similar membrane supports the inner hair cells. Outside the hair cells are several rows of columnar supporting cells deroid of hairs, which become continuous with a layer of cells lining the whole of the cochlear canal. Rising from a connective-tissue structure on the spiral lamina there arches over the whole organ a homogeneous membrane-the membrane tectoria.

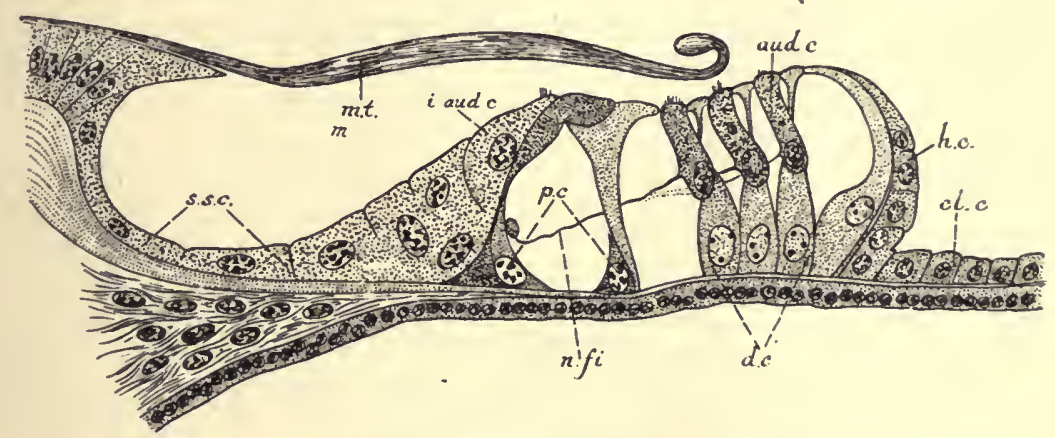

Fig. 379.-Sectiox of Orgax of Corti of a Youxg Guinea-Pic.

(Redrawn from Dahlgien and Kepner.)

cl.c., Cells of Claudius; h.c., Hensen's cclls; d.c., Deiters' cells, or supporting cells; aud.c., auditory cells, or hair cells (outer); p.c., outer and inner pillar cells; i.aud.c., inner auditory cells, or hair cells; $n . f$., nerve-fibres; m.t., membrana tectoria; S.S.C., cells lining sulcus spiralis.

Situated in the spiral lamina is the spiral ganglion, from which the fibres of the nerve of hearing arise. Processes from these nerve cclls pass along to and around the hair cells, the bases of which do not touch the basilar membrane. The central connections of these nerves go to the acoustic nuclei in the pons (see p. 699)).

The part of the membranous labyrinth corresponding to the restibule consists of two membranous sacs-the saccule and the utricle - connected by a small canal. From the saccule arises the cochlear canal. In connection with the utricle are three membranous semicircular canals, which lie within three corresponding bony semicircular canals. These latter open into the posterior and superior aspect of the vestibule. This apparatus probably has no connection with hearing, and is dealt with later (see p. 654). 
Sound.-Sound is the sensation produced through the organ of hearing by the vibrations emanating from vibrating bodies. Such vibrations trarel by the air at the rate of 1,100 feet per second.

Physiologically, sounds may be divided into noises and musical tones, although one may merge imperceptibly into the other-as, for example, the tuning-up of an orchestra. Many so-called noises are in reality more musical than otherwise. Vibrations of the air at regular intervals produce what is termed a musical sound; vibrations at irregular intervals produce an unmusical sound or noise. Sounds may differ in pitch, intensity, and quality or timbre.

The pitch of a note depends upon the frequency of the vibrations in a given time. The more frequent the vibrations, the higher the note; the less frcquent, the lower the note. The range of tones employed in music varies between 30 and 4,000 per second, although it is possible for the ear to perceive notes and vibration-rates as high as 40,000 per second. The relation between frequency of vibration and the pitch of a note is best shown by means of the siren. When the wheel is rotating slowly, nothing is heard but the puffs of air; as the speed increases, the puffs begin to fuse, and then produce a low buzz, rising with increasing speed to such a height that the note finally becomes decidedly unpleasant.

The sensibility to pitch varies in different people, as does the power of distinguishing notes of nearly the same vibration. This latter defect may generally be improved by training, although there are certain people who are "tone-deaf." They can only discriminate a few tones, and find it impossible to recognize a tune or to sing in tune. Such people only recognize the tune of the National Anthem by the fact that others are standing up with their hats off. The extreme range of the human voice is about half the range of the human ear for musical tones.

The intensity or loudness of a note depends upon the amplitude of vibration of the sounding body. This is well seen in the tuningfork. When the fork is vibrating visibly, the note is loud, and as the visible vibrations pass away, so the note diminishes in loudness or intensity, the pitch remaining the same. If the ear be held to a vibrating tuning-fork, it will be found that the note is loudest when the limbs are vibrating in a plane at right angles to the external ear, since in this position the air is most disturbed, causing a greater difference in pressure upon the tympanum.

The quality or timbre of a musical note enables us to tell the instrument by which it is produced. It is easy for most people to distinguish between the human roice, the note of the riolin, and the note of the clarionet. This is due to the characteristic wave-forms which are being produced in each case. Just as no two great waves of the sea are exactly alike, but differ in the shape of the crests and wavelets, so the wave-forms of different musical instruments vary. The tones emitted are really compound tones, and contain numbers of warelets or "overtones." The fundamental tone is due to that 
of the large wave; the quality is determined by that of the large wave and the wavelets.

The simplest musical tone is produced by a body like a tuningfork vibrating in simple harmonic motion-that is to say, in such a manner that the waves are all of equal size. This can be seen by the tracing made, by a vibrating tuning-fork (time-marker) upon a revolving kymograph. Such a sound is uniform, weak, and dull, and quickly becomes monotonous. If two tuning-forks be sounded, one of which vibrates twice as fast as the other, there can be heard the tones of the two forks and a combination of the tones. The

A

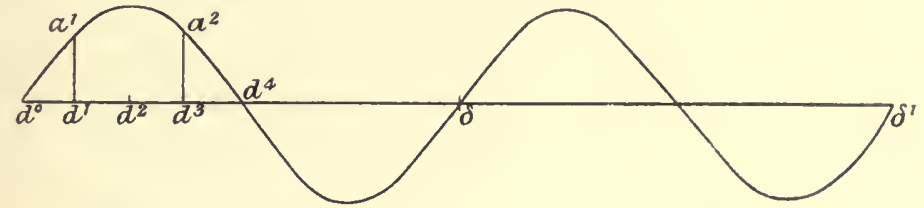

8

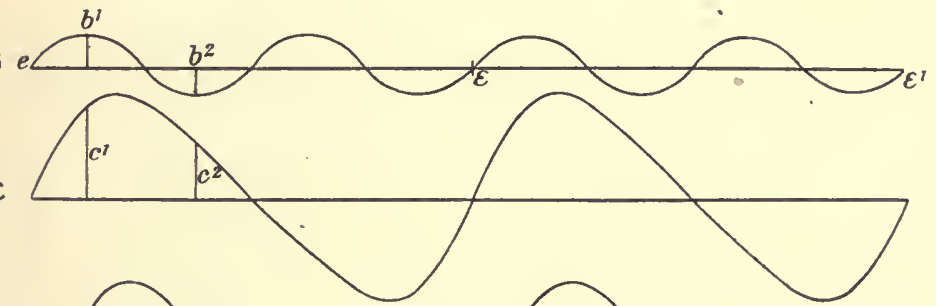

D

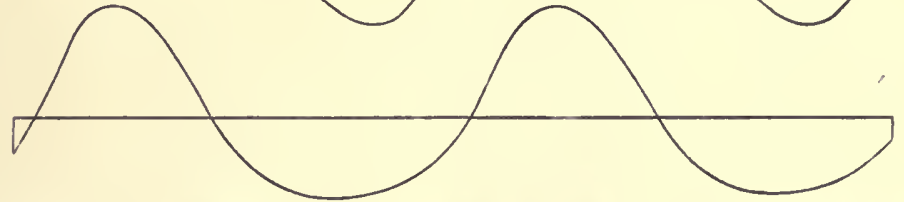

Fig. 380.-To iluustrate the Formation of a Compouno Wave from Two Pexdular Waves. (Helmholtz.)

$A$ and $B$, Pendular vibrations, $B$ being the oetave of $A$. If superposed so that $\epsilon$ coineides with $d^{\circ}$ and the ordinates are added algebraically, the non-pendular eurve $C$ is produeed. If superposed so that $e$ eoincides with ' $l$ ' the non-pendular eurve $D$ is produeed.

form of vibration will vary according as the forks produce at the same time rarefaction or condensation, or one is producing rarefaction while the other is producing condensation of the air (curves $C$ and $D$, Fig. 380). From an indefinite series of such vibrations, of which the period of vibration of the fundamental is always a multiple of the least frequent of the series, an infinite variety of curves may be obtained, yielding musical tones having the same fundamental pitch, but differing in quality according to the character of the wavelets.

The character of the musical notes of different instruments may be analyzed by means of resonators. A note resonates in a cylinder having the same wave-length of vibrations that constitutes the original note, or an exact divisor of the wave-length of that note. If different 
notes be sounded together, a cylinder will resonate with and reinforce the note of corresponding wave-length. So, too, will tense strings. This can be ascertained on the piano. If straws be attached to the wires, it will be: seen that, when one note is struck with the loud pedal raised to remove the action of the damper, other strings than the one struck are vibrating at the same time. This is because their vibration numbers correspond to the overtones. It is the overtones which, when not excessive, give a pleasant fulness to the note. Uneven overtones give a rough, penetrating note.

When two different notes are sounded at the same time, they interfere with each other, alternately strengthening and weakening each other, and giving a succession of phases known as beats. The number of beats per second depends upon, and is equal to, the difference of the rate of vibration of the two partial tones. A difference of one vibration gives one beat per second, of two vibrations two beats per second. When beats come very quickly, the alternate strengthening and weakening is lost, and a whirring, dissonant sound results.

In harmony, or consonance, there is all absence of beats. The greatest consonance is obtained from the same note with the same overtones. After that come the octave notes, corresponding to the note sounded. Then follow various chords, producing varying degrees of consonance.

Theories of Hearing.--In the present state of knowledge it is not possible to give any full and satisfactory explanation of the function of the cochlea. The problem to be solved is whether sound-wares produce movement of the hair cells of the organ of Corti, and, if so, the nature of the movement and the means by which it is produced. It is generally held that some form of mass motion, the exact nature of which is not clear, is normally produced in the perilymph through the to-and-fro action of the footplate of the stapes upon the membrane of the fenestra ovalis. This mass movement of the perilymph causes synchronous movements of the membrane of the fenestra rotunda, and also affects the endolymph, producing therein waves of compression and rarefaction. As the result of these waves, it is believed that either the basilar nembrane or the tectorial membrane is caused to vilbrate, and thus the hair cells are affected. Various considerations arise as to the nature of the vibration of such membranes. Is the vibration throughout the whole length, or only in part, or in some particular part for a particular sound?

According to the view of Helmholtz, each portion of the basilar membrane is set into reciprocal vibration by tones of a different pitch, high tones being produced by vibration at the basal extremity, where the membrane is narrowest, low tones in the apex of the cochlea, where the membrane is widest and most lax. Except for the fact that Helmholtz supposed that only musical tones were perceived by the cochlea, and, that noises were appreciated by the vestibular apparatus, his view still meets with wide acceptance. It 
is now recognized that muscial tones and noises are not fundamentally different, and that both are perceived by the cochlea, the vestibular apparatus having nothing to do with hearing.

i On embryological grounds it does not seem probable that a membrane of mesoblastic origin would stimulate hair cells of epiblastic origin. It has also been pointed out that in some animals-for example, the pig-the basal portion of the organ of Corti rests upon a bony plate which takes the place of the basilar membrane.

To meet these objections the view that the tectorial membrane vibrates has been put forward by several observers. As originally put forward, it assumed that high-pitched tones caxsed a vibration of the basal end of the membrane, and in descending the scale more and more of the membrane was set in vibration, until with the lowest tones the whole membrane vibrated. Such an explanation fails to account for the ability of the musician's ear to perceive separately the different sounds from an orchestra which reach it simultaneously, and, furthermore, does not account for partial defects - "tone-gaps "-in the range of hearing. The view has therefore been modified on the lines of the Helmholtz view, and it is now suggested that the tectorial membrane vibrates to different tones in different parts of the cochlea in the sume manner as suggested for the basilar membrane. It is pointed out that the tectorial membrane gradually increases in breadth from base to apex after the manner of the basilar membrane, and that, by virtue of its elasticity, transverse flexibility, and the fact that it is attached on onc side only, it makes a better and more sensitive vibrator than docs the basilar membrane.

Auditory Judgments.- In arriving at auditory judgments, we are aided by other senses and by knowledge previously acquired. Normally, we refer sounds to the exterior of the body, and from the nature of the sound determine what it is, its direction, distance, and so forth. According to its quality and loudness, we pronounce a sound to be a gunshot fired in a certain direction, close at hand, or far away. The direction of a sound is determined largely by the force with which it strikes the two ears. Judgment of direction is aided by turning the head from side to side, so that first one ear and then the other receives the sound fully. It is easier to judge the distance of noises than of musical sounds. The power to judge the distance of the source of sound depends on previous experience. Therein lies the effect of distance imparted by the operatic chorus, which, on leaving the stage, by singing more and more softly, gives the impression of passing farther and farther into the distance. 


\section{CHAPTER LXXI}

\section{THE PROPRIO-CEPTIVE MECHANISM}

INASMUCH as the force of gravity is continuously acting upon the organism, it is necessary for it to develop some mechanism by which its position in regard to gravity may be appreciated, and also, when moving, its successive positions in space. In the lower organisms, such a mechanism is developed from the epithelium, and is of such a nature that the perceiving tissues are stimulated by the positions of small heavy bodies which press against them by the force of gravity. When the organism moves or changes its position, such bodies will affect the sensitive surface by their inertia, or the latter may be stimulated by the flow of fluid over it. In higher animals, the sensitive receptor

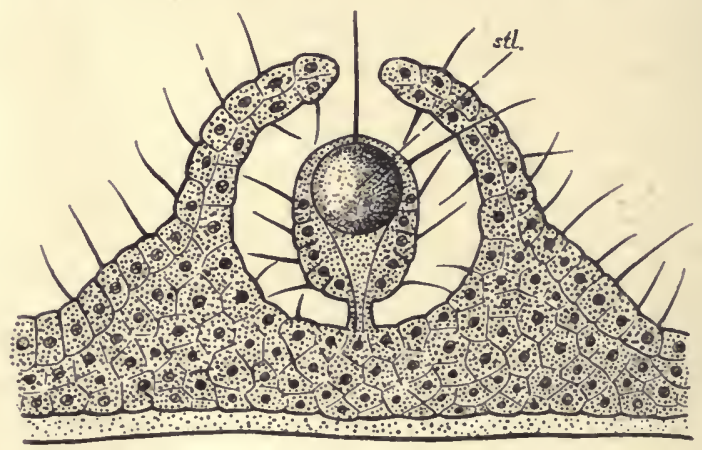

Fig. 381.-'Tentacolocrst (Statocist) of a Medusa. (Redrawn after Hertwig from Dahlgren and Kepner.)

$S t l$. is the statolith cnclosed in a pedicle which sways with the animal's motion and affects the hairs which project from the surface.

mechanism has become removed from the surface of the body, and has come to lie within the head in the vestibular apparatus, and within the body in connection with the muscles, tendons, and joints.

The proprio-ceptive mechanism is the mechanism of sense of position and movement - the mechanism by which we are able to poise our bodies in space, by which, also, we are able to adjust our muscular movements to a great degree of accuracy, especially the movements of the limbs. It is this mechanism which enables a man to shave in the dark or with his eyes shut. By the proprioceptive mechanism of his head he is aware of its position; by tho 
proprio-coptive mechanism of the body he is aware of the position of the razor in his hand, and is ablo to adjust the blade so as to shave without, at any rate, badly cutting himself. In this, of course, he i ; aided by cutaneous tactilc scnsation, but this, as wo shall see later, is not the factor controlling the main movements.

The Proprio-ceptive Mechanism of the Head-The Labyrinthine Sensations play an important part in the equilibration of the body. The receptor mechanism for these is, as the name signifies, contained within the bony labyrinth of the middle ear, the utricle, and the three membranous semicircular canals. The utricle connects with the saccule, and lies in the restibule of the internal ear. From

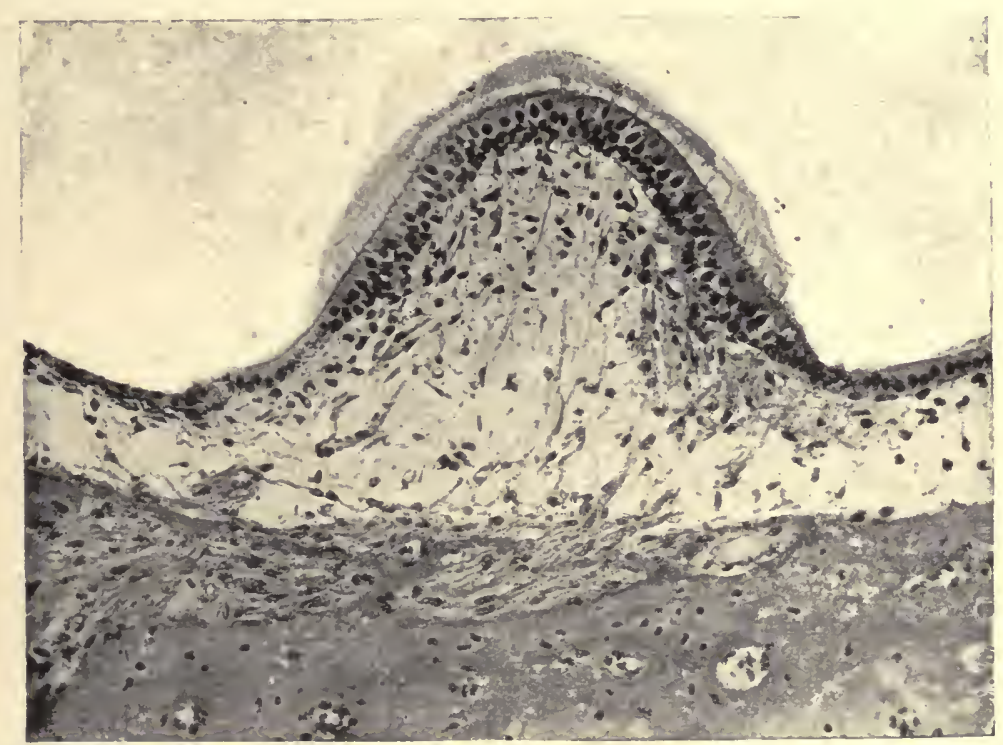

Fig. 382.-Photograph Section through Crista of the Ampulla of the Goinea-Pig. (H. Pringle, from "Quain's Anatomy.")

In lowest part of section nerve-fibres are seen passing through the bone to the loose tissue below the erista. The epithclial cells of the crista are pear-shaped surmounted by hairlets projecting into a mucinous material.

it also arise the three membranous semicircular canals which lie within the bony semicircular canals, and connect with the utricle by five openings. The bony semicircular canals arise from the posterior and superior aspect of the vestibule, each canal having at one end a swelling, or ampulla. They are arranged at right angles to one another, two in a vertical and one in the lorizontal plano. The latter is known as the external canal. It lies horizontally, with its curves outwards and the ampulla in front.

of the vertical canals, one is termed the anterior, or superior, the other the posterior. The horizontal canals occupy approximately the same plane. The superior canal lies in a plane inclined at an 
angle of about 37 degrees to the coronal plane, and the posterior callal at an angle of about 37 degrees to the sagittal plane. The superior canal of one side forms, therefore, an angle of 15 degrees with the posterior canal of the opposite side. There is a considerable space between the bony and the membranous canals. The former are filled with perilymph, the latter with endolymph.

The special receptor mechanisms lie within the utricle and the ampullæ of the semicircular canals. The specialized structures of the ampullæ are known as the cristæ. They consist of specialized nerve-epithelial hair cells and supporting cells, which lie upon a basement membrane, supported upon a hillock of subendothelial tissue, through which pass the nerve-endings of the vestibular part of the eighth nerve, to arborize around the hair cells.

In the utricle and saccule there are somewhat similar structures, known as the maculæ (Fig. 383). These have, in addition, crystals of calcium carbonate (otoliths), which lie among the hair cells.

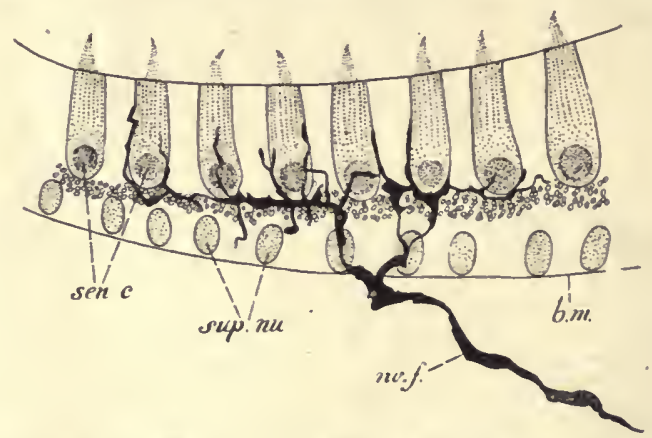

]'ig. 383.-Poktiux of the Macula of a Mouse, treated bi Golgi's Method to show Nerve-Exdisgs in the Sexsory Cells (sen.c.). (Redrawn after $Y$. Lenhossek from Dahlgren and Kepner.)

b.m., Basement membrane; sup.nu., nuclei of supporting cells; $n v . f .$, nerre-fibre.

The vestibular ganglion, or ganglion of Scarpa, lies in the internal auditory meatus, an upper nerve-branch connecting with the utricle and the ampullæ of the superior and external canals, a lower nervebranch with the saccule and the ampullæ of the posterior canals. Centrally the fibres enter the medulla oblongata in the region of the restiform body, and make connections as described later (see p. 699).

The first proof that the semicircular canals are concerned with equilibration was adduced by Flourens in 1828. He showed that injury of one canal produced rotatory movements of the body, the axis of rotation being at right angles to the severed canal. He noticed that the disturbances, like those produced by injury of the cerebellum, were of a co-ordinated nature, due to one set of muscles contracting while another set relaxed. For many years Flourens' work passed unnoticed, but since then it has been many times confirmed.

The extirpation of both labyrinths is attended with most marked upset of equilibration. 
The extirpation of one labysinth in an animal immediately affects the resting attitude of the animal; and also its movements in spase. In the frog, the head is incline 1 to the side of the lesion. In swimming, the operated side is lowor in the water, with an abluction and extension of the limbs of the opposite side, particularly the fore-limb.

In the pigeon, destruction of the membranous labyrinth produces marked disturbances of equilibration. The bird is unable to rest quietly, and is continuously performing inco-ordinate movemonts. After a time these pass off, and it learns to a certain extent to coordinate its movements by means of sight and touch.
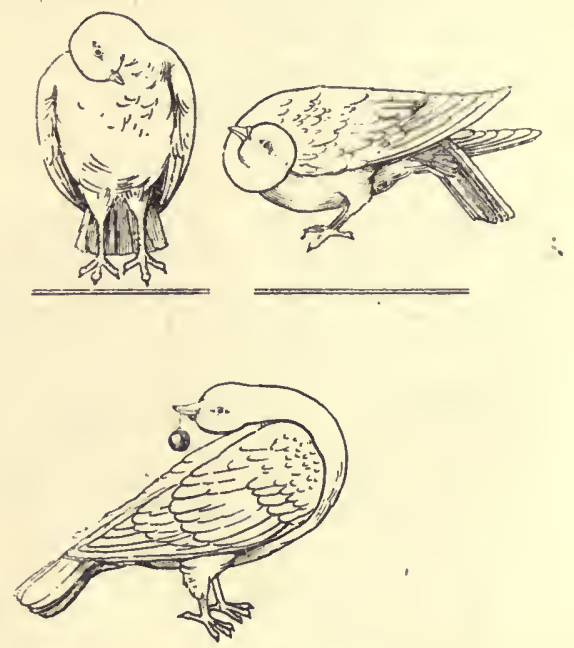

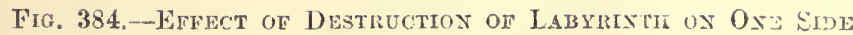
is a Piakox.

Extirpation of one labyrinth produces a loss of tone on the opposits side of the body. When only one canal is put out of action, oscillatory movements of the head are produced in the plane corresponding to the damaged canal (Fig. 384). The same results hold for mammals, but the canals are not so accessible as those of the pigeon.

The canals have been stimulated experimentally, chiefly the external canal, owing to its greater accessibility. By plugging. one end of the canal behind an artificial opening, and introducing into it a syringe, it has boen shown that prossure on the ampulla causes a deviation of the eyes to the opposite side, with nystagmus when the eyes looked to the same side of the body. Rarefaction produced an opposite result-a deviation of the eyes to the same side of the body, and a nystagmus when the eyes turned towards the opposite side of the body

Like results have been obtained upon the human subject in cases of middle-ear disease where suppuration has produced a fistulous opening into the external canals. 
Similar phenomena may be evoked by changes of temperature applied to the outer wall of the labyrinth-as, for example, by irrigation of the middle ear with tepid water. In irrigation experiments upon the superior canal, it has also been shown that reflex forced movements of the head, eyes, and trunk, are produced in the same direction as the wave of increased pressure in the endolymph. Stimulation of the labyrinth by means of the galvanic eurrent has confirmed these results both in animals and in man.

Passive rotation upon a turn-table causes the subject to turn his head in the opposite direction, and on stopping in the direction of rotation, with a sensation of actual rotation in the opposite direction. Cases of vestibular trouble may be investigated by mcans of the turn-table, and their bchaviour compared with that of normal subjects. The giddiness and upset of equilibration produced by

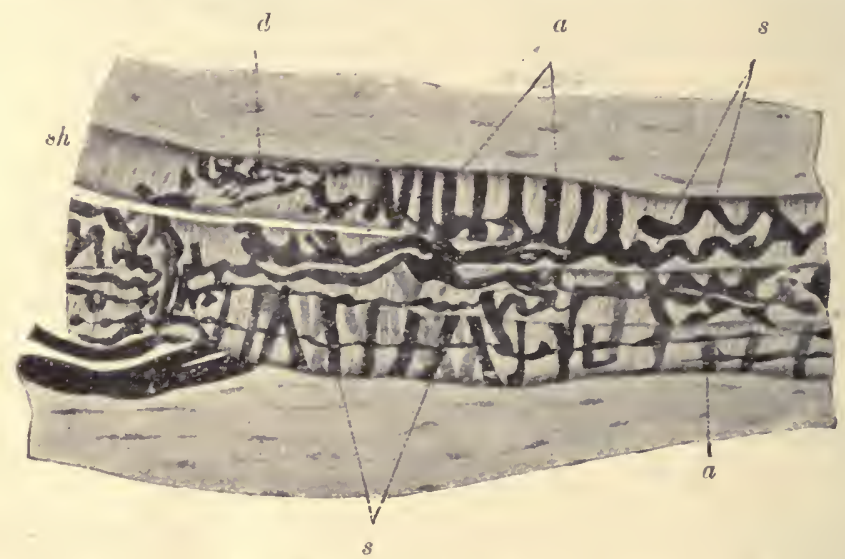

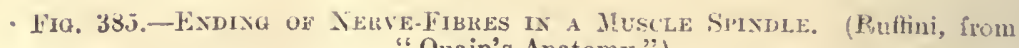
"Quain's Anatomy.")

", Nerve-ribres to spindle; $"$, aunular endings of axon; s, spiral endings: $d$, dendritic endings; $s h$, connective-tissue shoth of spindle.

shifting the head from one plane to another after rotation is familiar in the children's game, where, after turning round quickly with the forehead resting on the poker, the subject stands up and tries to. walk straight out of the door or to touch a certain person.

Comparative anatomy also supports these results. It has been shown that Japanese waltzing mice and tumbler pigeons have abnormal semicireular canals.

The mode of excitation of the receptor mechanism is generally belicved to be due to the inertia of the fluid within the canals. Rotation of the head causes a lag of fluid and pressure in the opposite direction, which acts upon the hair cells of the ampulla. Owing to the small size of the canals, there is probably no actual movement of the fluid, but merely positive and negative alterations of the fluidpressure within the canals. 
It is possible that sense of movement is referable to the semicircular canals, and sense of position to the end-organ of the utricle. Here the solid particles - the otoliths-play a part by acting upon the hair cells with varying pressures, according to the position of the head.

The Proprio-ceptive Mechanism of the Body.-The sensations concerned in "kinæsthetic sense," or the "muscular sense," as it is sometimes called. arise from the muscles themselves, the joints, and the tendons. As the receptor mechanism special sensory nerve terminations have been described in muscle, the neuro-muscular spindles. These are long, fusiform structures in connection with the muscle fibres. Into them passes a medullated nerve, which finally breaks up into a non-medullated plexus surrounding the modified muscle fibre (Fig. 386).

In connection with the tendons are found the organs of Golgi-sinall fibrous capsules containing a plexus of non-medullated nervefibres derived from a branch of medullated nerve. Somewhat similar varicose nerve terminations are also found in the synovial membranes and ligaments of joints.

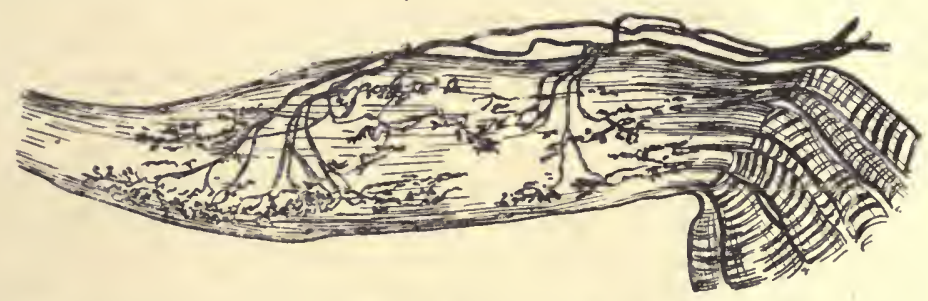

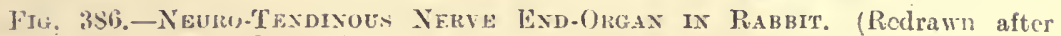
Hüber and De Witt from Dahlgren and Kepner.)

The nerve-supply to these structures is large. It is computed that two-thirds of the fibres of the mixed sciatic ncrve are connected with the proprio-ceptive systen, and sensory in function. By means of these terminations, information is conveyed to the central nervous system as to the degree of contraction or relaxation of a muscle or sets of muscle, and also as to the degrce of extension or flexion of a joint. The position of a limb may therefore be fairly well localized, even with the eyes shut. Such information is of great importance in guiding and co-ordinating the movements of a limb. Such impulses do not necessarily affect the consciousness, but they are of value in aiding the extero-ceptive mechanism in determining the size and shape of bodies-as, for example, the amount and nature of muscular movement necessary to feel completely over the surface. This sense is of particular value in determining the size of a body in the dark. The weight of a body is also gauged by determining the amount of muscular contraction necessary to prevent it falling or to raise it. The condition of this mechanism may be investigated by testing the judgment of the individual in regard to moderate weights, and also in regard to "deep pressure." Deep pressure sensation-e.g., the pressure of a 
pencil-point-is eonneeted with this mechanism, and persists when the cutaneous nerves have been eut. The nerves conneeted with this sense pass into the eord by the posterior roots, and have their cell-stations in the posterior root ganglion. The distribution of the fibres is referred to later (see p. 673).

The sense of "balance" is due to a eo-ordination of impulses received from the eyes, the semieireular eanals, and the organs of eutaneous and kinæsthetie sensibility. 'The airman is particularly dependent upon his sense of vision. He also derives much information as to the position of his machine by eutaneous sensaticns frcm his seat and from the play of the wind on his eheeks. The "feel" of the joystiek in which kinæsthetic sensations play a part is also important, as well as the impulses reeeived from his vestibular apparatus.

The Entero-ceptive Mechanism.-The entero-eeptive meehanism is assoeiated with the sensations arising from the alimentary traet from the beginning of the gullet down to the reetum. Various forms of reeeptor mechanisms have been deseribed, varying in nature from free expansions of dendritie nerve-endings to the elaborate Paeinian corpuscle. The total number of afferent fibres to the viseera is small - not more than those eontained in a single posterior root. By means of this meehanism, the orderly sequence of the movements of the digestive tract is insured, usually without involving conseiousness of the proeess.

The different parts of the tract vary to different formis of stimulation in their power to provoke eonscious sensitivity. From the beginning of the cesophagus to the junetion of the rcetum the alimentary traet is insensitive to taetile stimuli. Heat and eold clo not exeite the mueous membrane of the stomaeh; the colon is almost insensitive; the gullet and anal eanal, on the other hand, are sensitive to thermal stimulation.

Chemieal stimuli also vary in effect. Alcohol produees a feeling of warmth in all parts, whereas glycerine has a loealized stimulatory effect upon the anal eanal. The mucous membrane of the cesophagus and stomaeh is insensitive to stimulation with weak hydrochlorie acid.

The sensation of thirst is due to changes in the mouth, throat, and stomach. It is generally brought about by a drying of the mueous membrane of the throat after the inhalation of dry or dusty air, or the ingestion of salt or dry food. When water is long withheld, it is possible the terrible sensation of thirst also arises from an altered eondition of the blood.

The sensation of hunger is evoked by the contractions of the eontraeted empty stomaeh. It may be satisfied to a eertain extent by swallowing the saliva to induce relaxation, hence the efficacy of chewing tobaceo. Normally, food induces such a relaxation. It may, however, be induced by swallowing any solid material. Thus. the natives on the Orinoco appeased their hunger in the time of need by eating baked earth. The distension of the stomach thus induced satisfies hunger by stopping its movements. The sensation of fulness after a large meal is due to dilatation of the stomaeh. 
The eall to defreation is due to distension of the reetum, and may be evoked artificially, e.g., by the introduetion of fluid, or of a balloon and its distension to a pressure of about $50 \mathrm{~mm} . \mathrm{Hg}$ (see p. 419).

Pain is due to the stretehing of the alimentary tract by obstruction or overdistension. Colic is due to a tonic contraction of the gut, whieh prevents peristalsis from forcing on the contents of the gut. Vague sensations, such as uneasiness, tingling, tickling, are due to some form of abnormal stimulation As a rule, pain in the alimentary tract is not well localized, but is more acenrately localized in the fixed than in the movable viseera. The nerves subserving the, pain sensation are the sympathetie, and the pain is referred to the superficial eutaneous areas supplied by those nerves which are in connection with the same segment of the eord as that from which the sympathetic supply of the viscus is derived. The stimulation of the sympathetic nerves produces an irritable foens in the eord, and this gives rise to hypersensitivity and so to pain felt in the peripheral tissues conneeted with that scgment of the cord. In the ease of the stomach, the hypersensitivity affeets the seventh, eighth, and ninth thoracic nerves; of the intestine, the tenth and eleventh thoraeic; of the reetum, the first, second, and third

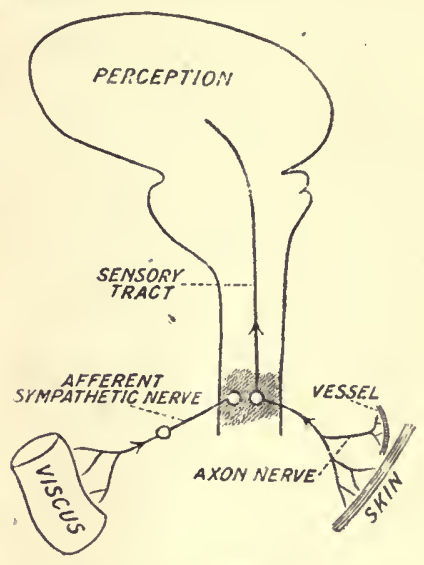

Fig. 387.-Diagram to expeais Referred PaIN and CodNTERIrritatrox. (Dixon, after Mackenzie.)

The diagram shows, also, how irritants to the skin may eause local dilatation of the ressels by an axon reflex. saeral. An irritant applied to the skin in the area where the pain is fclt may take possession of the sensory nerve and the attention of the patient so that those from the viscus have no effeet. 


\section{CHAPTER LXXII}

\section{THE SPINAL CORD}

THE nerve-fibres act as conductors connecting the receptor and effector mechanisms. The conductors form the nerve trunks of the: body-the cranial and the spinal nerves-and the tracts within the central nervous system. The conductors are the processes of the nerve cells, or neurons; these interlace and form synapses, through which the nervous energy is transinitted from one neuron to another.

We have to consider the ingoing neuron, which connects the sensory nerve-ending, or receptor, to the central system, and the efferent neuron - the final common path - which connects the central system to the effector organ. The axons, or conductors, of these two sets of neurons form the mixed nerve trunks of the body. The arrangement of each spinal nerve is as follows: On the postero-lateral aspect of the spinal cord there enters the posterior root, which has a ganglionic swelling upon it-the posterior root ganglion. From the antero-lateral aspect of the cord emerges the anterior root. The two roots combinc to form the spinal nerve. In all the thoracic nerves, and some of the sacral, there are not only large fibres, which pass to the body-wall structures, and are known as somatic fibres, but also small fibres which supply the viscera and the involuntary muscle of the body, and are known as splanchnic fibres. The course of these latter fibres is dealt with when the autonomic system is considered (see p. 748).

The fibres of the posterior root form the great afferent system, the fibres of the anterior root the great efferent system. Section of a postcrior root leads, therefore, to a cutting-off of the impulses which come both from the extero-ceptive and proprio-ceptive mechanismsthat is, the sense organs which receive impulses from the outside world, and those which initiate the impulses which arise in the inner world of the body itself. In the case of the spinal nerve, the former impulses include those of touch, temperature, pain, and the latter those of the kinæsthetic sense. Section of an anterior root causes a paralysis of the muscles and any other effector organ supplied by the nerve. Wallerian degeneration affects the axons, which arc cut off from the cell bodies of the ncurons.

The cells which give origin to the fibres of the posterior root are situated in the posterior root ganglion; those of the anterior ront fibres in the anterior horn cells of the spinal cord. As a consequence of section of an anterior root, the nerve-fibre degenerates towarls 
the periphery. The path of degeneration which follows seetion of the posterior root depends upon the site of section. If it be between the ganglion and the cord, then, since the nerve cells are in the ganglion, degeneration will take place in the parts of the fibres which enter the spinal cord; if, on the other hand, it be peripheral to the ganglion, then the nerve-fibres will degenerate towards the periphery, where they form connections with the various rezeptor mechanisms. The

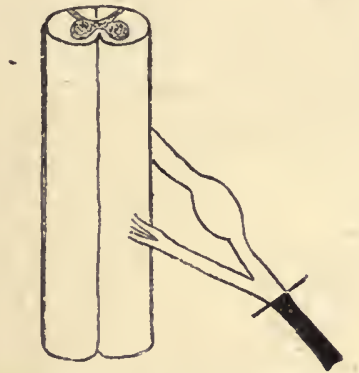

Degeneration of efferent and of afferent fibres balow a section of entire nerve.

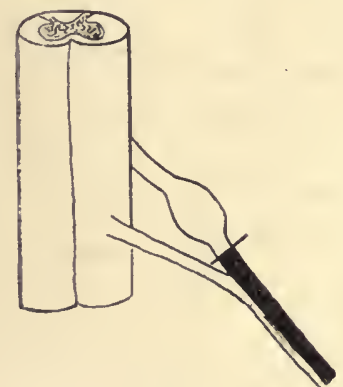

Degencration of afferent fibres below a section of posterior root beyond the ganglion.

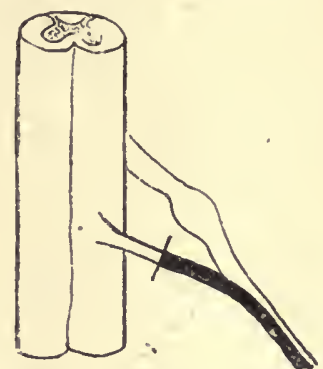

Degeneration of efferent fibres below a section of anterior ront.

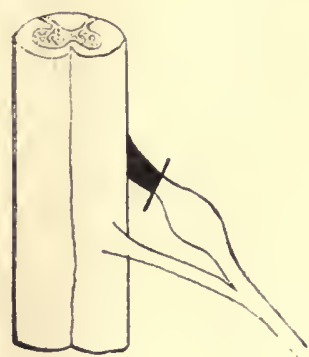

Degeneration of afierent fibres above a section of posterior root above the ganglion.

Fig. 388.-Diagrams to iflestrate Wallferax Degexeration of Nerve-Roots. (Waller.)

ingoing afferent fibre from the posterior root ganglion makes a variety of connections. These are best considered after the structure of the spinal cord has been described.

The Structure of the Spinal Cord.-The spinal sord is the long strand of nervous tissue which passes down the rertebral canal from the base of the brain to the level of the first lumbar vertebra - a length of about 18 inches. It derelops in three zones from the neural tube (Figs. 389, 390). From it are given off the anterior and posterior roots of the spinal nerves. In the cervical and again in the lumbar region there is an enlargement from which arise respectively the nerves 
of the brachial and lumbar plexuses. In these enlargements the cord is more or less oval in section; in other parts it is nearly round. Down the centre there runs a fine canal lined by ciliated epithelium, while

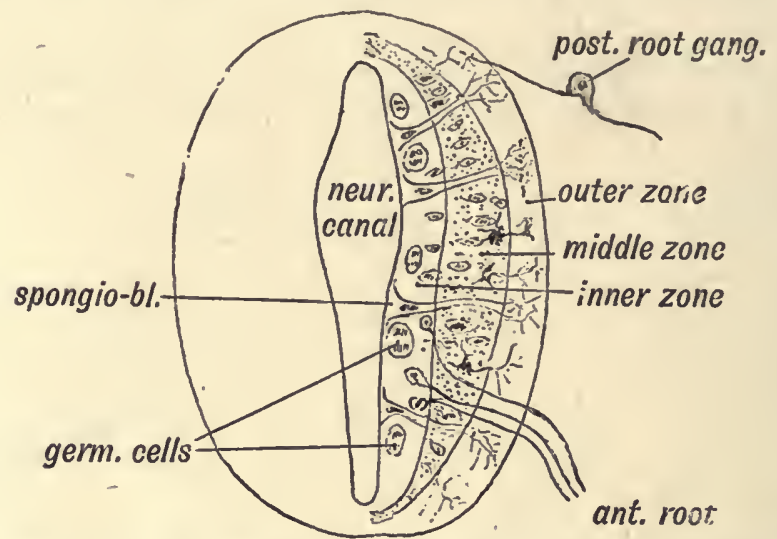

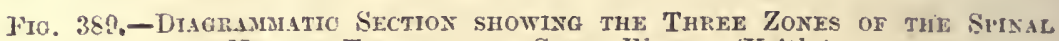
Necral Tebe at the Sixti WeEk. (Keith.)

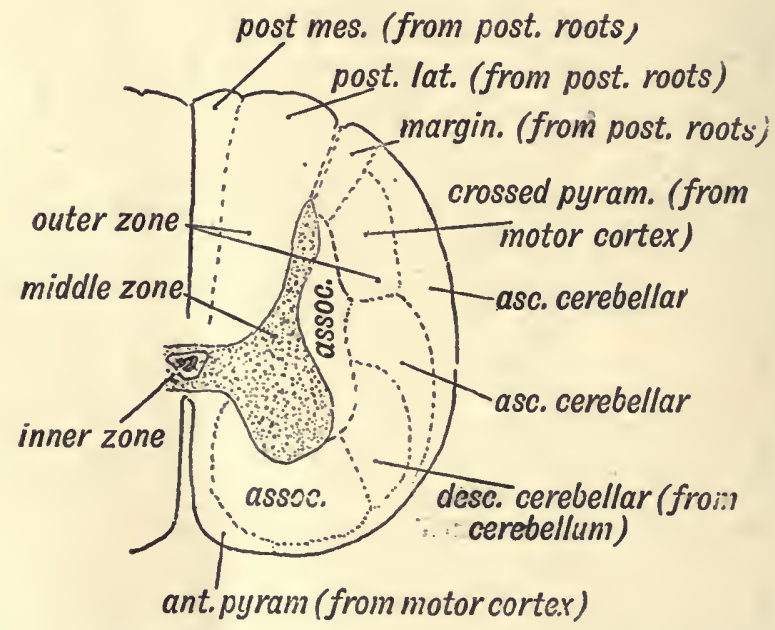

Fig. 390.-Didcramuate Sectios of SPINal Cord to SHow the Palits formed ix the Thret Zoxes of the Eybuyonic Spixal Cord. (Keith.)

two fissures in the middle line dip into the cord anteriorly and posteriorly. The anterior fissure is more or less open-a kind of furrow - the posterior fissure is practically elosed, being formed mainly of supporting neuroglial tissue.

On section, the spinal cord is seen to be composed of white and grey matter. The latter is centrally plaeed in the shape of an $H$. The joining limb of the $H$ passes on either side of the central canal 
The grey matter consists mainly of nerve cells and their nonmedullated processes; the white matter of the axons, or medullated nerve processes. The nerve-fibres in the spinal cord are devoid of neurilemmal sheath. The neuroglia, the supporting tissue of the cord, is intimately woven into the structure of the cord, particularly of the grey matter. Round the central canal it forms the substantia gelatinosa centralis, and around the head of each posterior horn of grey matter is another collection of neuroglia, the substantia. gelatinosa Rolandi.

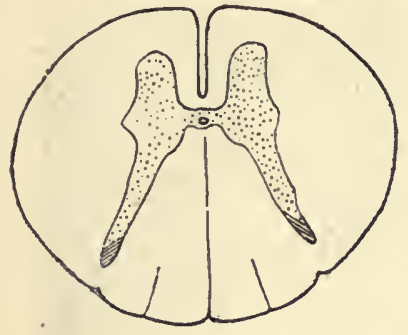

Fig. 39L. - Dragrammitic Section tirrovgh SPINAL CoRd IN THokacio Rngrox, (Parsons and Wright.)

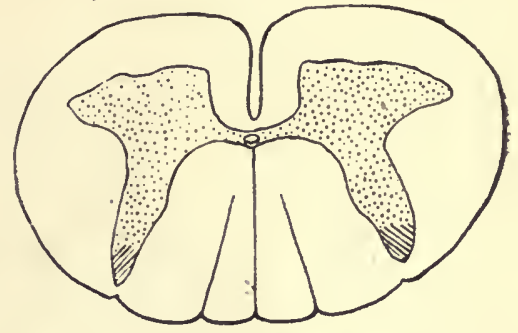

Fig. 392.-Diagramatic Section of Sprival Cord throveh Cervical Enlargement, (Parsons and Wright).

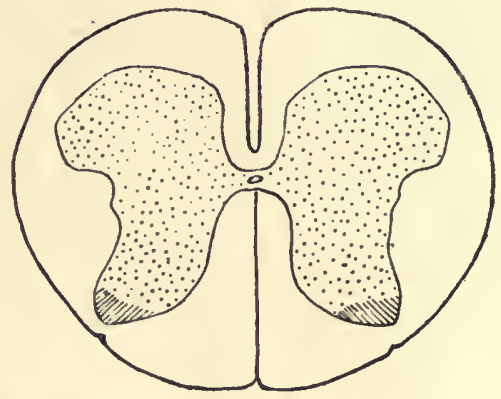

Fig. 393.-Diagamantic Section of Spinal Cord through the Luabae Eviargement. . (Parsons and Wright.)

The grey matter in each half of the cord is divided into a posterior horn, a lateral horn, and an anterior horn. In it are various groups. of cells, the chief of which may be classified as-

1. Posterior horn cells. These are small multipolar cells, chiefly of commissural function.

2. Clarke's column of cells-cells, more or less bipolar in form, situated on the inner aspect of the posterior limb of grey matter, near its junction with the connecting limb. From it axons pass into the cerebellar tracts.

3. Intermedio-lateral group-a group of cells situated chiefly in the lateral horn. From it axons pass out into the sympathetic system. 
4. Anterior horn group-groups of large multipolar cells from which the efferent fibres of the anterior root arise.

The white matter of the spinal cord consists of tracts of fibres which run mainly up and down. There are fibres-(1) from the posterior root ganglia of the spinal nerves, which ascend or dessend in the spinal cord; (2) from the grey matter of the spinal cord, which ascend to the brain; (3) from the grey matter of the brain, which descend to the spinal cord; (4) commissural fibres which conncet various parts of the spinal cord. The corresponding tracts are-

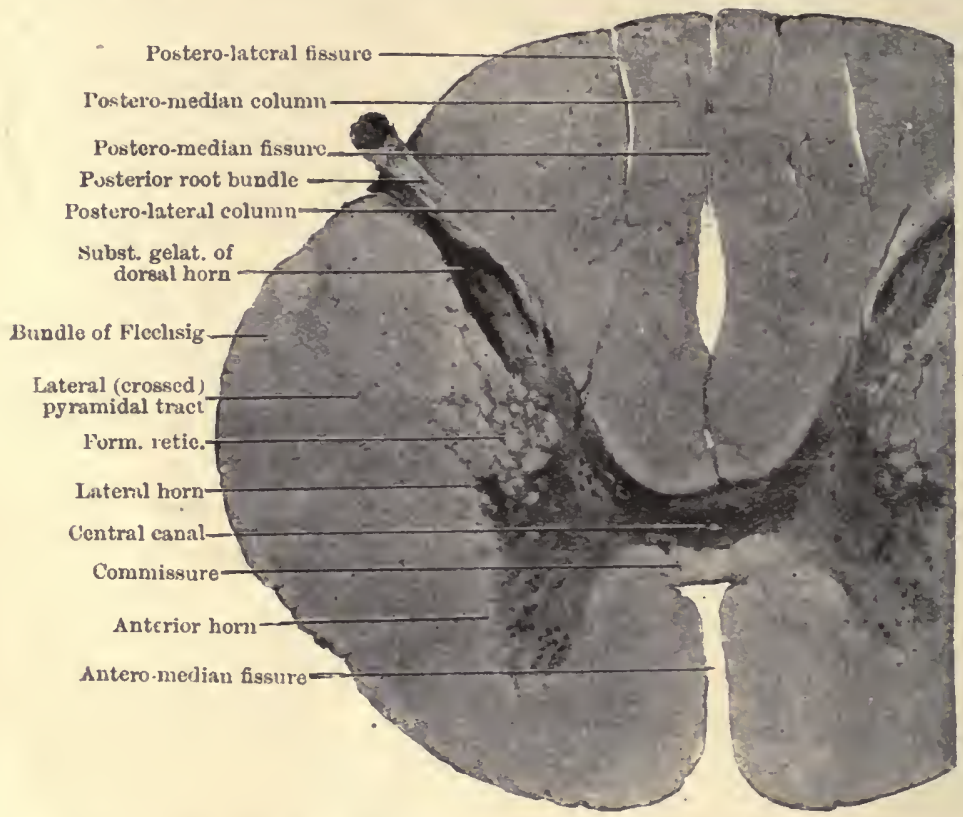

Fig. 394.-Sectiox of Hunax Spixal Cord from Upper Cervical Rheiox. Photografil Magnified abovt 8 Dihneters. (F. A. Schäfer, from "Quain's Anatomy.")

1. Ascending.-The postero-median tract (of Goll): the posterolateral tract (of Burdach); the marginal tract (of Lissaner).

Descending.-The comma tract.

2. Ascending.-The dorsal spino-cerebellar (or the direct or posterior cerebellar tract of Flechsig); the ventral spino-cerebellar (or ascending antero-lateral or ventral cerebellar tract of Gowers); the spino-thalamic.

3. Descending. - The cortico-spinal or pyramidal tract (crossed, uncrossed, or direct); the rubro-spinal tract (prepyramidal of Monakow); the vestibulo-spinal tract (antero-lateral descending of Loewenthal); the olivo-spinal tract, the thalamo-spinal tract (of Helweg).

4. Ascending and Descending.-The septo-marginal tract; fibres of the basis bundles. 

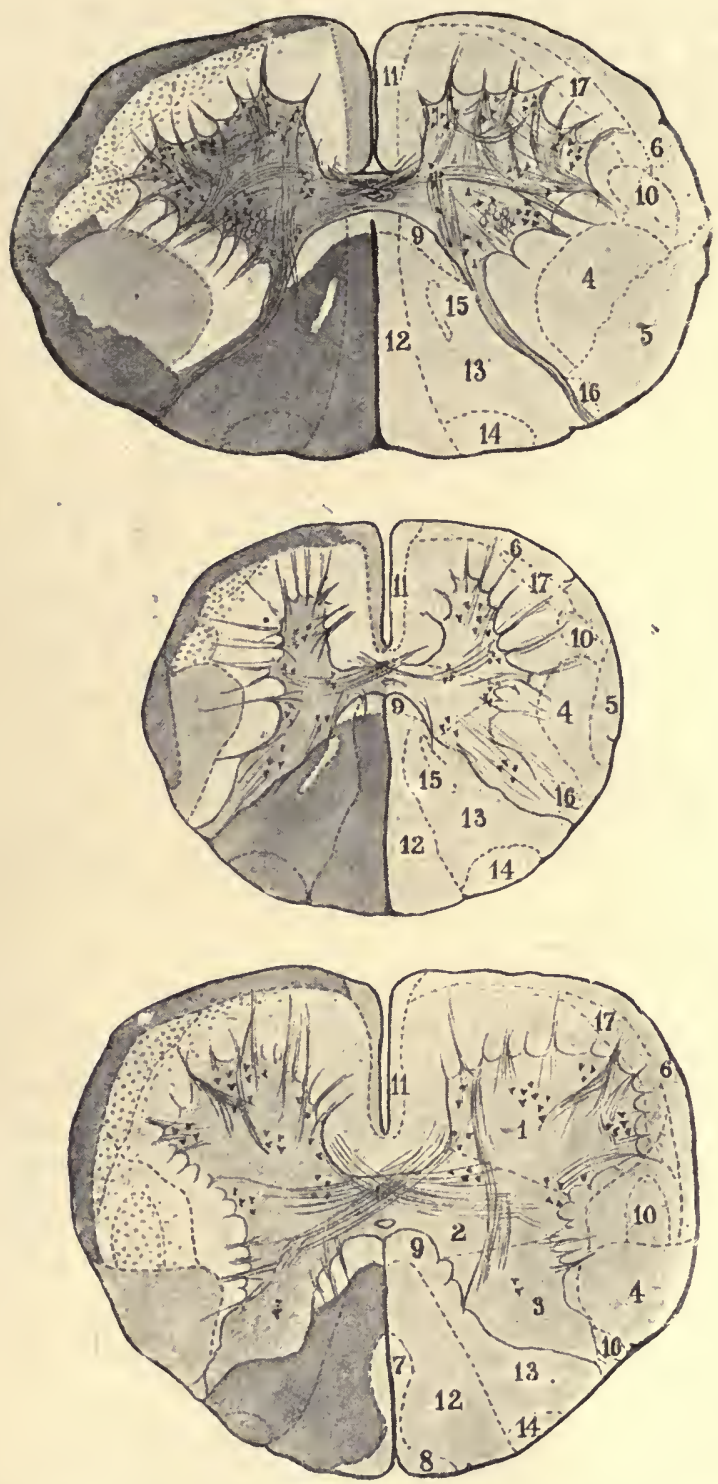

Fig. 395.-Diagram to show the Various Exdogexous axd Exogenous Tracts uf SPINal, Cord. (Mott.)

1, Anterior horn; 2, commissural fbros: 3 , posterior hor'n; 4, crossed pyranidal tracts; 5 , direct cercbellar tract; 6 , antero-lateral ascending tract; 7 , endogenous (oval area of Flechsig); 8, endogenous tract (Gombault and Philippe's traet); 9, endogenous cornu commissural tract; 10, rubro-spinal and spino-thalamic tract; 11, direct pyramidal tract; 12, postero-median column (of Goll); 13, postcroexternal column (of Burdach); 14, pjstero-internal triangle (cndogenous); $1 \bar{i}$, comma tract (endogenous); 16, Lissauer's tract; 17, teeto-spinal, spino-tectal, vestibulo-spinal, and cercbro-spinal filsres. 
The Tracts arising from the Posterior Root Ganglia, and passing into the Cord (Posterior Columns)-The Postero-Median T'ract (of Goll).-The cell-stations are in the posterior root ganglia, especially the sacral and lumbar. The fibres first enter the postero-lateral column, and then pass into the postero-median, lying dorsally close against the postero-median fissure (12, Fig. 395). They pass up to the gracile nucleus situated at the junction of the cord with the spinal bulb, giving off many eollaterals on the way.

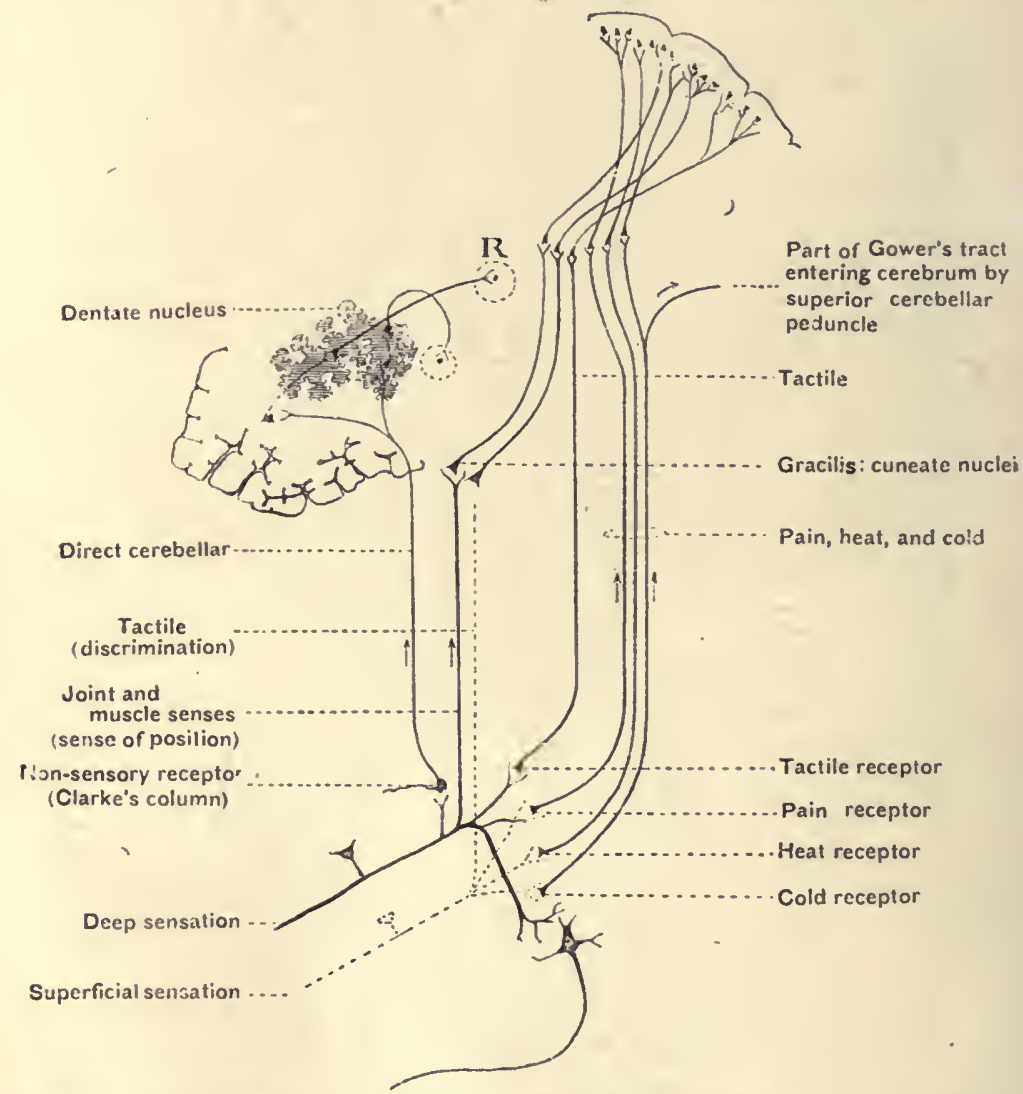

Fi3. 396.-Dingham to ilgujtrate the Afferhix Systems to Cerebrem and Cerebetrum. (Mott.)

The Postero-Laleral Tract (of Burdach).-The fibres arise like the preceding and pass in a more external position, to end around the cells of the cuneate nucleus at the base of the spinal bulb (13, Fig. 395).

The Marginal Trast (of Lissauer) lies just external to the posterior horn of grey matter. The fibres arise from cells in the posterior root ganglia. They are very fine assending fibres, which gradually form 
synapses with the posterior horn cells. Possibly they are connected. also with the sympathetic system.

The Comma Tract (Descending) intermingles with the tracts of the postero-median and postero-lateral columns. It consists of the descending processes of the afferent fibres of posterior root ganglion cells, which branch when they reach the spinal cord. Possibly somc fibres of this tract arise in the spinal cord itself.

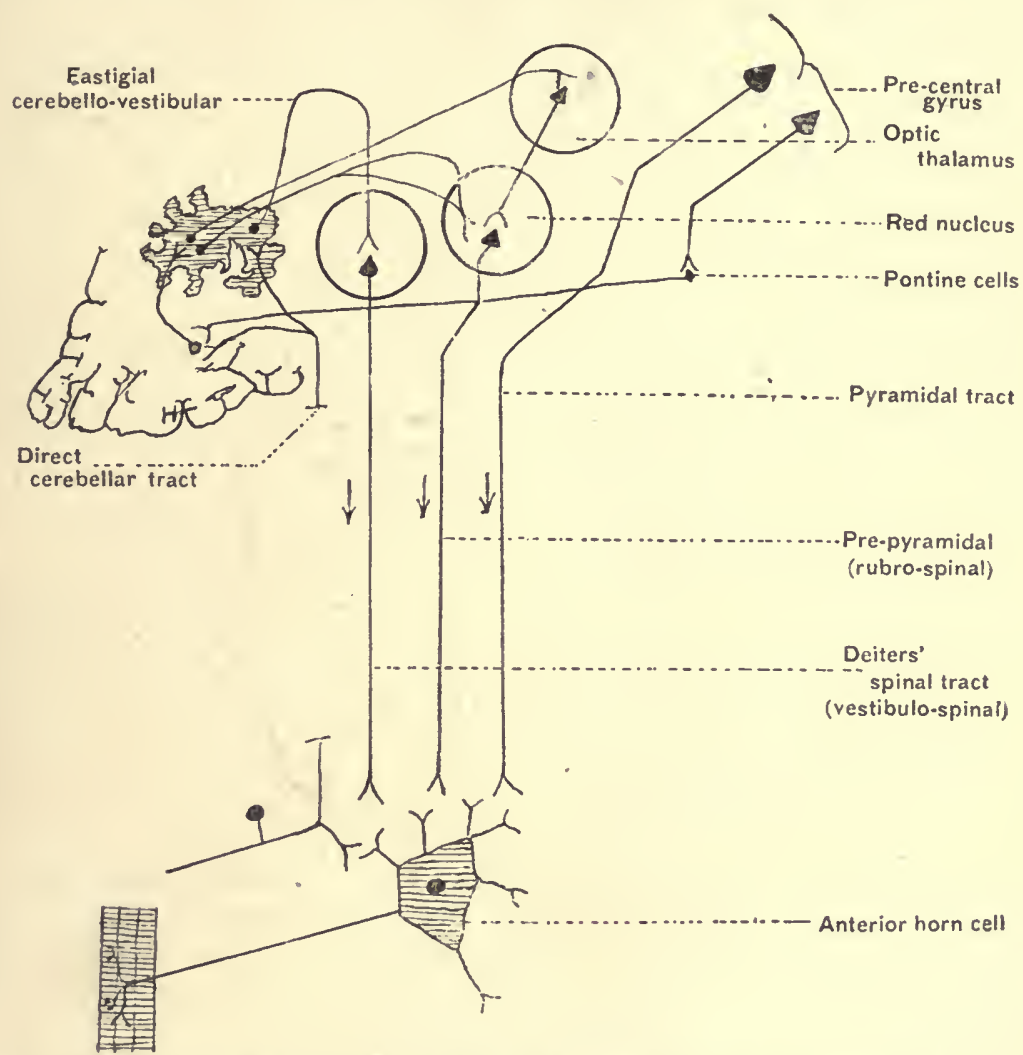

Fig. 397.-Diagray to illustrate the Various Patis of Transilssion froy Braix to Sinal Motor Neurons. (Mott.)

Tracts which pass from the Cord to the Brain (Lateral Columns)-The Dorsal Spino-Cerebellar (the direct or posterior cerebellar tract of Flechsig). - The large fibres of this tract are derived from cells in Clarke's column of the same side, and pass in a postero-lateral marginal position (5, Fig. 395) into the spinal bulb, and thence by the restif :rm body to the anterior portion of the supcrior vermis of the cerebellum.

The Ventral Spino-Cerebellar Tract (or ascending antero-lateral or ventral cerebellar tract of Gowers) arises on the opposite side from 
scattered posterior horn cells, and possibly from cells of Clarke's column. It passes up in the antero-lateral marginal position of the spinal cord, and passes through the bulb and pons, to enter the supcrior vermis of the cerebellum by the superior peduncle.

The Spinu-Thalamic Tract consists of a scattered group of fibres lying just internally to the ventral spino-cerebellar tract. Its fibres pass upwards, to end mainly on the same side in the optic thalamus. Some, however. end on both sides in the anterior corpora quadrigemina (10, Fig. 395).

Tracts which pass from the Brain to the Spinal Cord-The Cortico. Spinal or Pyramidal Tract.-This tract, consisting of the axons of the large pyramidal cells which exist in the motor region of the cerebral cortex (see p. 7 . 3 ) passes down through the brain stem in a ventral position to the base of the bulb, where most of the fibres cross to the other side, forming the motor decussation. These crosised fibres come to occupy within the spinal cord a postero-lateral position (Fig. 397). They gradually terminate during their passage down the cord around the cells at the base of the posterior horn (some say round the cells of the anterior horn). The few uncrossed or direct fibres pass down on the margin of the anterior fissure of the spinal cord; some end around the cells of the same side, some pass across the anterior commissure, and end around the cells of the opposite side.

The Rubro-Spinal Tract (or prepyramidal tract of Monakow).The fibres of this tract arise from the cells of the opposite red nucleus of the mesencephalon, and, crossing in the mid-brain (Forel's decussation), pass through the pons and bulb to the spinal cord, occupying therein a somewhat triangular space just anterior to the crossed pyramidal tract (Fig. 397). The fibres terminate around or approximate to the anterior horn cells.

The Vestibulo-Spinal Tract (antero-lateral descending tract of Loewenthal). - This consists of fibres which arise from Deiters' nucleus, situated in the upper part of the medulla and lower parts of the pons varolii, and pass down into the spinal cord in an anterolateral position, mingling to a certain extent with the fibres of the ventral spino-cerebellar tract. It constitutes a pathway for impulses which pass from the cerebellum to the spinal cord; its fibres end by arborizing in the proximity of the anterior horn cells.

The Olivo-Spinal and Thalamo-Spinal Tracts (tract of Helweg) occupy an antero-lateral position opposite the anterior horn. The fibres pass from the thalamus by way of the inferior olive of the bulb into the cervical region of the spinal cord, where they gradually disappear. Their destination is not certainly known.

Fibres which pass from one Part of the Spinal Cord to Another (Commissural Fibres). - These fibres, of which there are many, are not grouped into very definite bundles. Many pass up in the lateral columns, other in the so-called anterior basis bundle, and form connections with the posterior longitudinal bundle of the brain stem; others lie posteriorly near the postero-median fissure, and form whet is known as the septo-marginal tract. 
The pusition of the various groups of cells and of the above tracts have been traced by various means:

1. Wallerian degeneration ( $c f$. p. 663): If a nervous lesion be made, such as hemisection of the cord, and the animal kept alive a sufficient time for the nerve-fibre to degenerate, the path of the degenerated fibres is then easily traced by certain methods of staining. Thus, two or three weeks after such a lesion, degenerated fibres stain black with Marchi's fluid, owing to degradation of the myeline and setting free of oleic acid. At a much later stage the degenerated fibres do not take the Weigert-Pal stain, while normal fibres stain deeply. The pathological investigation of clinical cases by this method affords valuable evidence, especially in the case of the sensory tracts, where the feelings, etc., of the patient have been carefully investigated.

2. Method of retrograde degeneration: The position is traced of the cells which show chromatolysis as the result of a nervous lesione.g., section of an anterior root about three weeks before death. The degeneration of different groups of cells which follows amputa. tion of the leg at different levels points to a definite connection of certain groups of anterior horn cells with definite muscles.

3. Histological methods-such as the silver chromate method of Golgi,* or intravitam staining with methylene bluc. Certain neurons, with their processes, are picked out in their entirety.

4. The myelination method: The Weigert-Pal method differentiates the myelinated fibres from those which are not yet myelinated. The development in the foetus of the medullary sheath of medullated nerves takes place at different times in the various tracts. It occurs first in the fibres which enter the cord from the spinal nerves; next in the commissural fibres between different parts of the spinal cord; then in fibres which pass from the spinal cord to the cerebellum; and last in the tracts which pass from the great brain to the spinal cord (the pyramids). The last become myelinated after birth.

Tise Neural Ares.- We are now in a position to consider the chief neural ares through which sensory impulses are received, transmitted, co-ordinated, and made effective: the spinal, cerebellar, and cerebral arcs.

The ingoing fibres, whose end processes make connection witll the receptors at the periphery, pass in by the posterior root, in the ganglion of which their cells are situated, to form various connections in the spinal cord. The chief of these are illustrated in Fig. 397, and may be summarized as-

1. With the posterior horn calls of the same side.

2. With the anterior horn cells of the same side.

3. With the posterior horn of the oppositc side.

4. With Clarke's column of the same side.

J. With the lateral horn of the same side.

6. With segments of the cord higher up, and with the gracile

* 'This method consists in hardening the ncrvous tissue in potassium chromate, and soaking it in silver nitrate, thereby causing a deposition of silver chromate in the nervo cell and its processes. 
and cuncate nuclei of the medulla through the postero-median and postero-lateral columns.

7. With other segments of the eord lower down by the comma tract.

The Spinal Arc. - This are, in its simplest plan, may be regarded as being made up of the ingoing afferent fibre, which ends around the anterior horn cell of the same side, and the efferent fibre from this cell. It is probable that the ingoing neuron ends around the posterior horn cells of the same side, and a connecting neuron joins up these cclls to the anterior horn cells.

The Cerebellar Arc-To the Cerebellum.-- Impulses from the posterior root neurons reach the cerebellum by several ways: (1) On the same side by processes which end in Clarke's column, and then by the ncurons of this column, the axons of which form the dorsal spino-cerebellar tract, which goes to the superior vermis by way of the inferior peduncle. (2) On the opposite side by means of neurons of posterior horn cells, axons of which form the ventral spino-cerebellar tract. This passes to the superior vermis by the superior pedunclc. (3) By the postero-median and postero-lateral columns to the gracile and cuneate nuclei in the spinal bulb, and thence by neurons the axons of which pass to the cerebellum by the inferior peduncle (the arcuate fibres, see pp. 689, 680).

From the Cerebellum axons pass to Deiters' nucleus, which lies in the npper part of the bulb, and is connected with the vestibular branch of the auditory nerve (see p. 698); thence by the vestibulospinal tract to the spinal cord. Connection with the spinal cord is also made by way of the posterior longitudinal bundle.

The Cerebral Arc-To the Cerebrum.-(1) The axons of the posterior root neurons pass up to the gracile and cuneate nuclei of the bulb by the postero-median and postero-lateral columns; (2) the axons of the neurons (the intermediate neuron) of these nuclei pass to the thalamus by a tract known as the mesial fillet; (3) the axons of the third relay of neurons (the upper neuron) pass from the thalamus to the cortex.

From the Cerebrum by the cortico-spinal (pyramidal) fibres, crossed and direct, to the anterior horn cells.

Since the cerebellum is also connected with the cerebrum, it is possible for impulses from the spinal cord to reach the cortex via the cerebellum, and also to pass to the spinal cord from the cortex through this organ.

The Functions of the Spinal Cord.-The chief functions of the spinal cord are to act-(1) as a reflex centre; (2) as a conductor of impulses to and from the brain.

The Spinal Cord as a Conductor.-This function has becn dealt with in the description already given of the position of the various tracts. It remains only to indicate that the impulses coming into the spinal cord from the extero-ceptive and proprio-ceptive mechanisms undergo a redistribution according to their function and destina- 
tion. This has been worked out largely from eareful clinieal observa . tions made upon patients who are suffering from definite cord lesions, the nature of the lesion in each case being determined subsequently by post-mortem examination. The impulses conneeted with pain cross at once to the opposite side, and aseend in the spino-thalamic tract. Thermal impulses do not cross quite so soon, but take a very similar course. Tactile impulses pass up on the same side for four or five segments of the eord, and then eross, to aseend in the anterior region of the eord. Kinæsthetie impulses, concerned with

Hoinolater.s impulses uncerlving musculur sensibility (passive position and of movement), also of touch and pressurc for a few segments

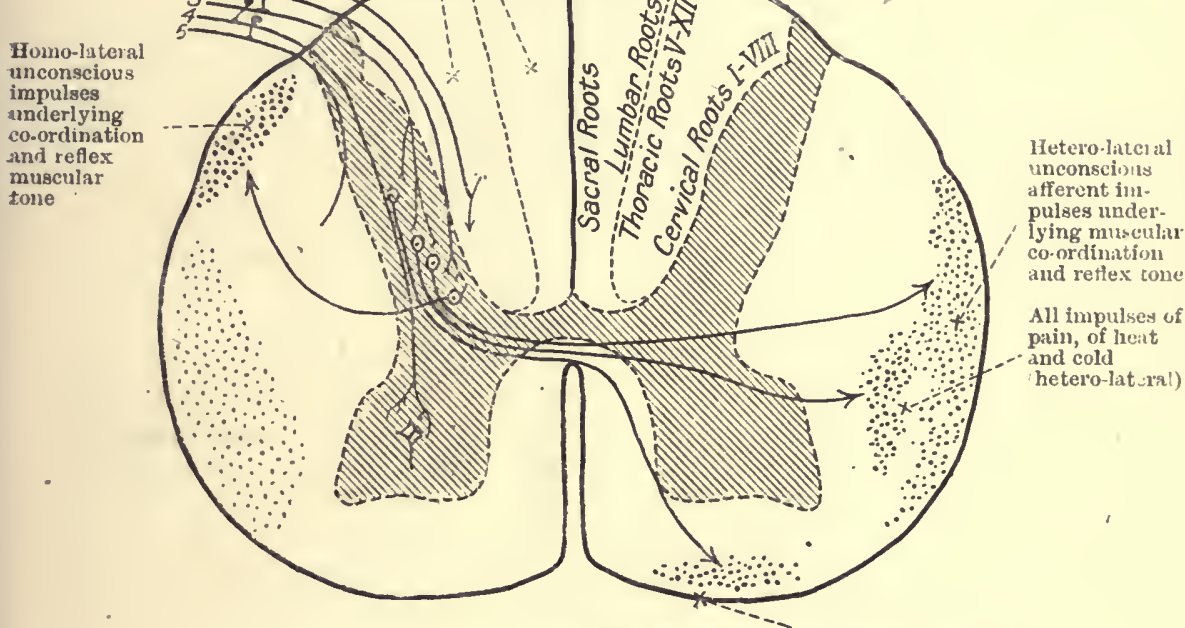

Impulses of touch and pressure (hctero-lateral)

FIG. 398.

1, Fibres in posterior columin; 2, fibres in Clarke's column; 3 , fibres to cells of postorior horn; 4, fibres to cells of anterior horn; 5 , fibres to cells of lateral column: 6, dorsal cerebellar tract; 7, ventral ccrebellar tract; 8, spino-thalamic and tectal tracts; 9, ascending fibres in anterior colununs. (IV. Page May, by permission of the editor of Brain.)

the scuse of passive position and movement, pass up in the posteromedian and postero-lateral columns of the same side. Impulses concerned in eo-ordination and reflex museular tone which do not enter into eonsciousness, pass up on the same side in the dorsal spinocerebellar, and on the opposite side in the ventral spino-eerebellar tract (Fig. 398).

The Fffect of Transterse Section.-The effect of transverse seetion depends aecording as it is partial or eomplete. Section of one half (hemi-section) leads to a loss of movement on the same side as the lesion in the parts supplied by nerves ar sing below the site of injury. It also leads to a partial loss of sensation in the same arca. The kinæ:- 
thetic and tactile sensations are markedly impa.red, while those of pain and temperature, which cross soon after entering the cord, are but little affected (Fig. 396). Degeneration takes place on the side of the lesion in the motor traets-e.g., the pyramidal, rubro-spinal.

In complete section-for example, in the thoracic area-there is jaralysis below the site of the lesion of sensation and of all the volunitary muscles, and of some of the involuntary, on both sides of the body. This leads to a total loss of movement, a lowering of the hlood-pressure, and loss of control of the various sphineters. If the section ho made high up in the cervieal region, the muscles of

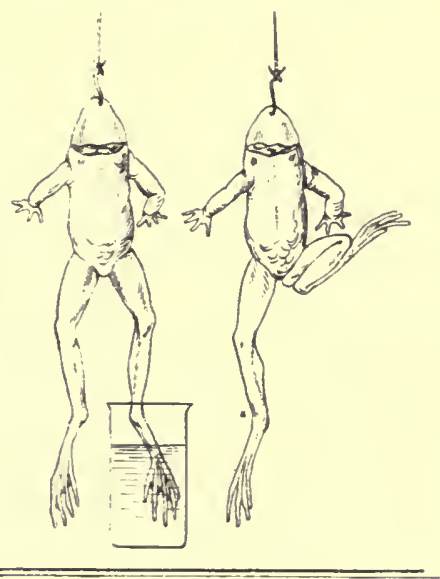

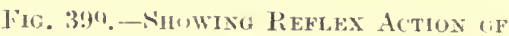
('ORD AFTEF REMOVA, OF E.XTIR: Jis.11x.

The beak.or eontains weak sulphuric aeid. respiration, including the diaphragm, are paralyzed, and death results.

In the spinal cord there takes place an upward degencration in the ascending tracts, and a downward degeneration in the descending tracts.

\section{The Cord as a Reflex Centre.-} In addition to conducting impulses to and from the higher parts of the central nervous system, the spinal eord acts as a reflex centre. Afferent messages entering the cord are received, and diverted into appropriate efferent channels. Such reflexes are regulated by a certain code, which is applieable to all the reflex reactions carried out by means of the central nervous system. The system has been most conveniently worked out in the vare of the "spinal animal" - that is to say, an animal in which the spinal cord is separated from the higher parts of the central nervous system, which may. or may not, be destroyed.

Such in operation at first results in "spinal shock." After the familiar "peration of pithing a frog without destroying the spinal cord, the animal lies in a state of flaecidity. irresponsive to any form of stimulus. After a time it recovers movement of the limbs, and assumes a nearly hormal sitting position. In response to a pinch, the hind-limb is drawn away: if a piece of paper moistened with acid be placed on the side of the belly, the animal attempts to sweep away the irritant by movements of the hind-limb of the same side (Fig. 399), or', if the stimulation be sufticiently intense, by movements of the limbs of both sides. Placed in water, the animal will perform swimming movements, swimming, however, somewhat more deeply than usual; swing to the head being held in a lower position than normal.

IVith bigher animals-e.g., the dog-the effects of sucl an opcration 


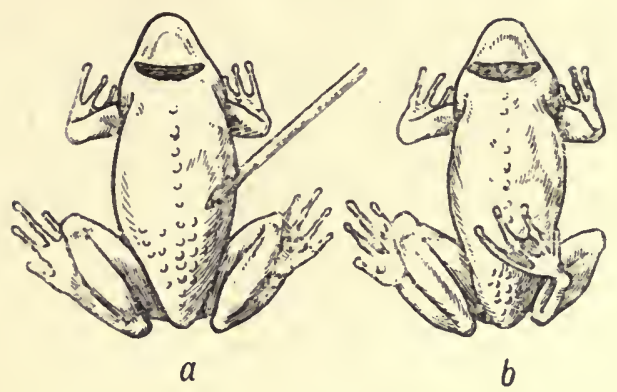

Fig. 400.--Showisg Reflex Action after Removal of Brain.

In $a$ weak acid is applied; $b$ shows reflex efforts at removal of the stimulus
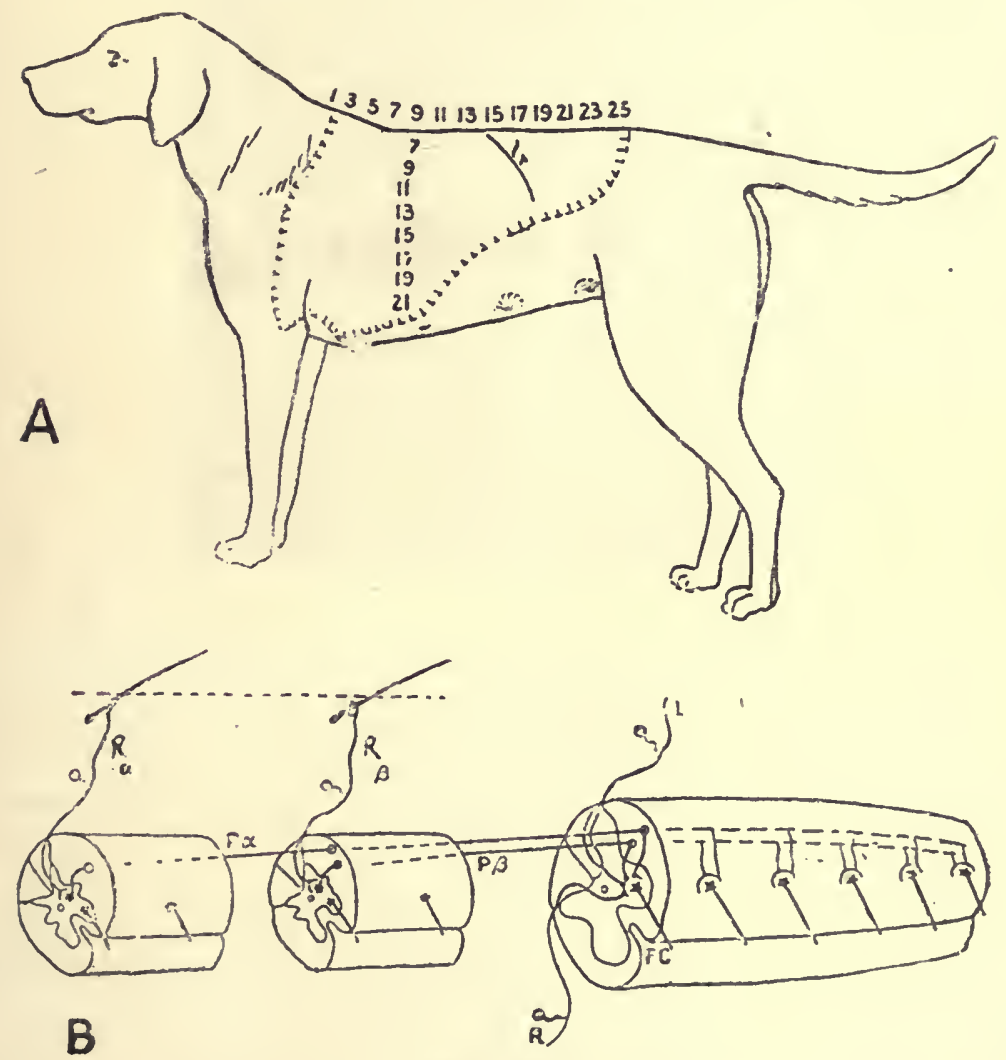

H1a. 401.

$A$, The receptive field for the scratch reflex as revealed after low cervical transaction. Ir marks position of last rib.

B, Diagram of spinal arcs involved. $L$, receptive or afferent nerve-path from left foot; $R$, receptive nerve-path from opposite foot; $R a, R \beta$, recoptive nerve-paths from dorsal skin of left side; $F C$, the final common path, in this case to a flexor muselc of the hip; $P a, P \beta$, proprio-spinal neurons. (From Sherrington's "Integrative Action of the Nervous System," by permission of Yale University Press and Messrs. Constable and Co., Ltd.) 
arc eonsiderably more lasting and more complex. Bclow the site of the lesion there is total loss of sensation in the skin, the skeletal muscles are inert and flabby, the sphincters are toneless, there is increased loss of heat, and the arterial pressure of the animal falls from 40 to $50 \mathrm{~mm}$. Hg. After a few days many of these symptoms pass away. The arterial pressure rises to normal; the sphincters again act, so that urine and fæces are passed in a normal manner; the skeletal muscles recover their tone; and sensory stimuli applied to the skin evoke reflex muscular responses. It is upon such an animal that the code of reflex actions has been worked out. A second section of the cord at a lower level does not renew the shock. The

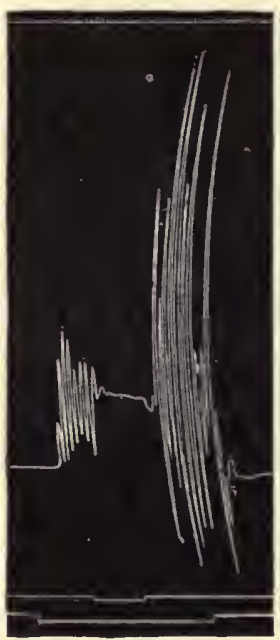

A

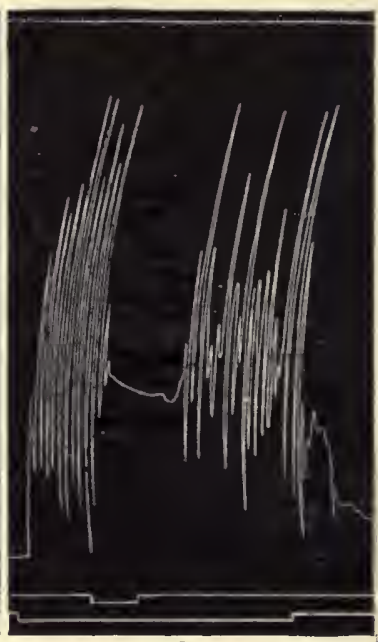

B

FIG. 402 .

A, Seratch reflex interrupted by a brief flexion-reflex. The time of application of the stimulus evoking scratch reflex is shown by the lowest signal line; that for flexion-rcflex by line immediately above. Time in fifths. The scratch reflex returns with increased intensity after the interruption.

$B$, Similar to $A$, but the scratch reflex is interrupted later and returns more slowly and with marked irregularity in its beat. (From Sherrington's "Integrative Action of the Nervous System," by pernission of Yale University Prcss and Messrs. Constablo and Co., Ltd.)

shock is caused, then, by cutting off the spinal from the higher centres, not by the lesion of the spinal cord itself. The chief reflexes studied have been-

1. The flexion reflex. A harmful stimulus applied to the hind-foot causes the withdrawal of the foot from the site of injury-an action often accompanied by extension of the opposite hind-limb.

2. The extension reflex. The application of gentle pressure to the pad of the flexed limb induces the movements of extension of that limb, and of flexions of the opposite limb-i.e., the movements of walking in the normal animal. 
3. The scratch reflex. Light stimulation of the "saddle" area calls forth movements corresponding to the familiar scratching movements indulged in by dogs removing a flea or other irritant from this area.

The first point to be observed in regard to such reflexes is that a given stimulus always evokes the same response. Thus, a pin-prick applied to the foot alway's evokes the flexor and not the extensor response. The reflex is localized.

Another important point is that only one reflex can have charge of the final effector path at once. Just as it would be very embarrassing if the telephone exchange permitted several callers to speak at once down the same final transmitting. wire, so would it be if various afferent calls had possession of the final effector path at the same time. All kinds of inco-ordinate movements would be evoked. Any such incoordination is therefore prevented by the law that only one reflex at a time can have charge of the final common path. This is exemplified as follows: If the stimuli inducing the flexor and extensor reflexes be applied to the foot at the same time, one or other reflex is evoked, and not a combination of the reflexes. The same final common path is used in both reflexes, and is taken possession of by the stronger stimulus. If the stimuli be of equal intensity, but entering different levels of the cord, then there is a further code of rules. For instance, if, while the animal is performing the scratch reflex as the result of a stimulus applied to the saddle area $(R a)$, a stimulus of equal intensity be applied to the scratching foot $(L)$, the scratching ceases, and the foot is withdrawn from the harmful stimulus applied to the foot (Fiz. 402). Or, again, if, during the performance of the scratch reflex, a stimulus be applied to the hindlimb of the opposite side $(R)$, the scratching ceases, and the opposite hind-limb is with-

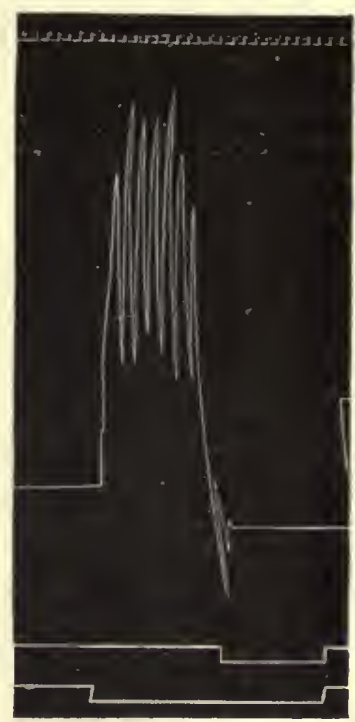

Fig. 403,-Scratch ReFLEX CUT SHORT BY Excitatios of the SKin of A Digit of OpPosith Hixd Font.

Below upper signal mark marks period of application of stimulus to opposite hind foot; lower signal marks application of stimulus exciting scrateh reflex. Time in tifths of second. (From Sherrington's "Integrative Action of the Nervous System," by permission of Yale University Press and Messrs. Constable and Co., Ltd.) drawn out of harm's way (Fig. 403). It will be seen, therefore, that an impulse entering the same seginent of the cord, whether from the same or the opposite side, has priority over an impuls entering the cord in a more remote segment.

So, also, can it be shown that for the same level of the cord an impulse entering the same side has priority over an impulse enterin's at the same level on the opposite side. 
In regard to the nature of the stimuli, it has been found that the stronger the stimulus the quicker the response (Fig. 404). This can be tested upon the pithed frog by various strengths of acid, as shown in Fig. 405. The stronger impulse obtains possession of the final common path, and that painful stimuli (nociceptive) and those evoking sexual feelings are more potent than other forms. The strength of the stimulus required varies according to the length of time of application. Fatjgue takes place in the nerve-endings; therefore, after a time, a stimulus applied to another reflex arc may eapture the final common path.

c

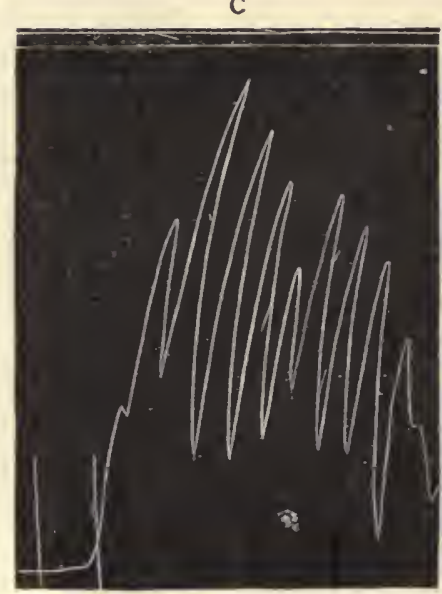

Fig. 404.-Fffect of Ixtexsity of Stimelus ox Scratch Rerlex.

$A$, Stimulus is very weak; one small beat of characteristic slowness is eroked after long latent period. $B$, increase in intensity of shocks with resulting shorter latent time and a reflex movement of two fecble beats. $C$, further increase of intensity of stimulus; latent period shorter and a reflex of ten fairly quick and ample beats ensues. The stimulus lasted less than a half-second; the reflex is not completed for more than two scconds after cessation of stimulus. (From Sherrington's "Integrative Action of the Nervous System," by permission of Yale University Fress and Messrs. Constable and Co., Ltd.)

There is one exception, however, to the above rules. This is when the stimuli are of the same character and in adjacent areas. It may be exemplified as follows: If, as the result of a stimulus in one part of the saddle, the animal be set scratching, then a similar stimulus applied in an adjacent area of the saddle will cause an increased sweep in the scratching movements, so that both irritants will be dealt with and remored at the same time. Similar stimuli in adjacent areas reinforce one another, and increase the general reaction.

Another important point to be noticed in such reflex responses is that there is reciprocal excitation and inhibition of muscles (Fig. 407). 'The response to a stimulus is not simply the contraction of a uuscle or 
group of muscles; at the same time, the antagonistic muscle or group of muscles is relaxed. Thus, when the flexors contract and draw up the leg, the extensors are relaxed (Fig. 407); and when the extensor's extend the leg, the flexors are rclaxed. Each movement is brought about by co-ordinate contraction of one group of muscles and relaxation of the antagonists. On this depends the perfect balance of the movements of a technician or musician.

In the body, it is difficult to get a reflex which does not either antagonize or reinforce other reflexes. This is well illustrated by Fig. 409. Here the final motor nəuron is that to the vasto-crurcus of the dog. It is excited by stimulation of the ear, fore-foot, tail, and pressure on the pad of the foot of the same side, and by stimulation of the shoulder and nocuous stimuli to the hind-foot of the opposite
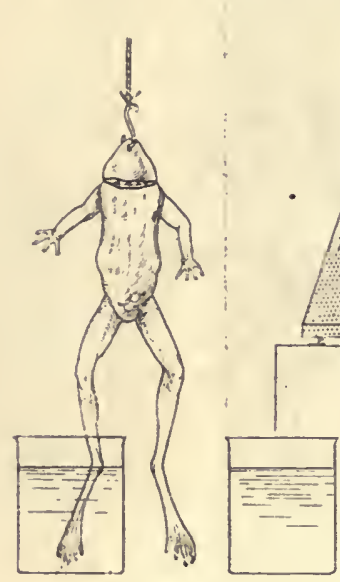
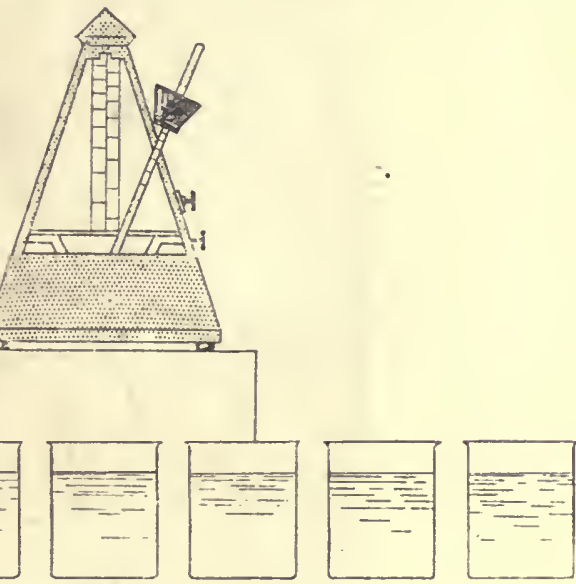

FIG. 405 .

To show that as the strength of acid is inereased the reflex is more quickly performed.

The beakers contain respectively, from left to right, $0 \cdot 1,0 \cdot 2,0 \cdot 3,0 \cdot 4,0 \cdot 5$, and

1 per cent. sulphuric aeid.

side. It is inhibited by stimulation of the shoulder of the same side (the scratch reflex), and by nocuous stimuli of the hind-foot of the same side.

Not only do sensory stimuli (the extero-ceptive mechanism) react apon the reflexes of the body, but the impulses which arise from the muscles themselves and from the joints and tendons (the proprioceptive mechanism), and from the viscera (the entero-ceptive mechanism), also play a part in determining the effector nature of reflexes.

The chief points in connection with spinal reflex action may be summarized as follows:

1. Peflexes are lozal:zed, definite, and purposive.

2. Owing to the interposition of synapses in the course of the reflex arcs, there is marked delay in the rate of conduction therein, as compared with the rate of conduction in nerve. The synapses also 
evert a valve-like action, so that conduction manifests it self in one direction only. The symapses also offer a varying degree of resistance to the impulse, so that, generally, a reflex is localized; but under the influence of certain poisons, such as strychnine, a slight stimulus will evoke tonic muscular spasms over the whole body.

3. In the reflex arc there is a summation of stimuli; a succession of stimuli, each of an intensity insufficient to evoke a response when applied alone, will eventually provoke a response.

4. Excessive stimulation leads to a fatigue in the synapses, which occurs principally in the connection between the nerve and the effector organ.

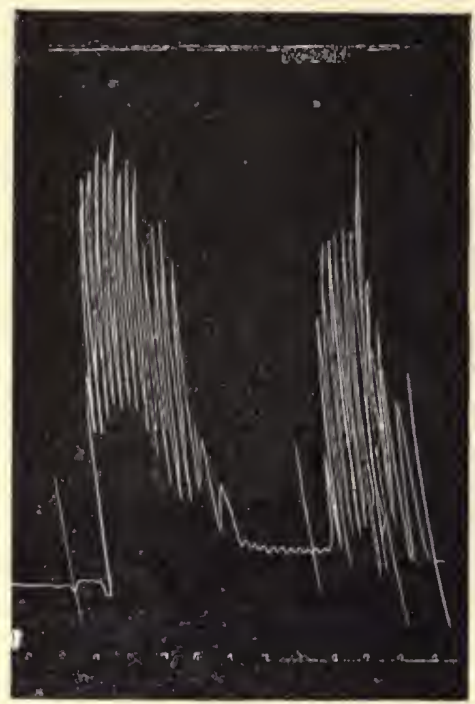

Fis. 406,--Schatcil Reflex evoken br a Relatively Feeble Stimulatiox axd DISAPPEARING UNDER THAT STIMLATLOX.

Ou inereasing the intensity of the stimulus the reflex reappears. It does not rappear on revelting to the original intensity of stimulation. Time in seconds. (From Sherrington's "Integrative Action of the Nervous System," by permission of Yale University Press and Messrs. Constable and Co., Itt.)

5. When fatigue is not evoked by too frequent transmission of an impulse, it is found that subsequent impulses call forth a reaction more easily. This "facilitation," as it is termed, is really the basis of habit. By facilitation, good habits, if sufficiently repeated, obtain preference over bad ones, if these sre not often repeated. Training consists largely in the proper adjustment of the necessary reflexes, and in this the law of facilitation takes a great part. The whole of ochucation consists in the obtaining of facilitation for fit paths, and in the inhibition of unfit ones.

(i. Such inhibition is a l:aw of reflex action. Only one impulso can have possession of the final common path at the same time, unless 
it be of a similar nature. Stimuli of a harmful or sexual nature arethe most potent in obtaining command of the final comınon path.

The spinal cord has already been referred to as the reflex centre concerned in micturition and movements of the large intestine. In.

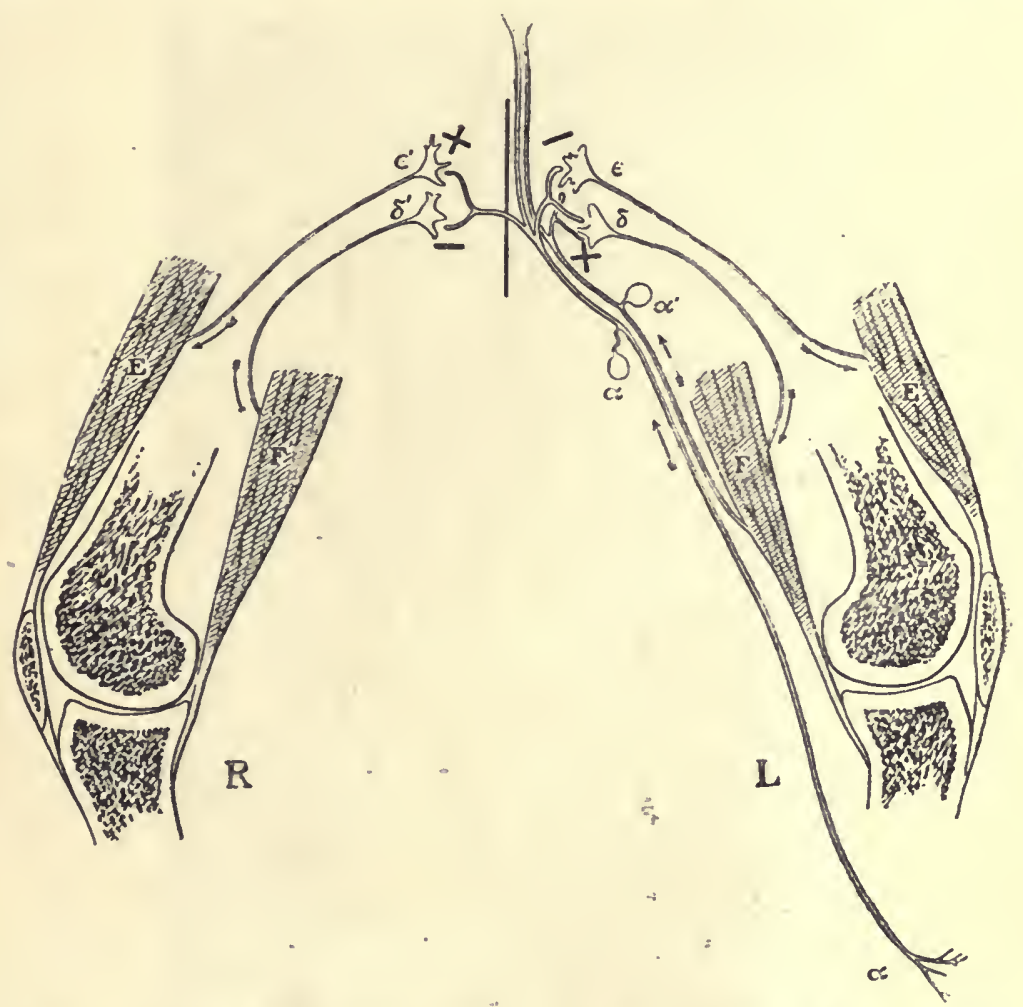

Fig. 407.-Dharam ixdicatisg Coxpretions and Actrons of Two AfFerent Spinal Root Cells ( $\alpha$ and $c^{\prime}$ ) IN Regaid to thetr Reflex Ixfluexce on the Extensor axd flexor Mescles of the Two Krees.

$\alpha$, Afferent fibre from skin below knee; $\alpha^{\prime}$, afferent from flexor musele of knee-i.e., in hamstring nerve; $\epsilon$ and $\epsilon^{\prime}$, efferent neurous to extensor museles of the knee, left and right; $\delta$ and $\delta^{\prime}$, efferent neurons to flexor museles; $\mathrm{E}$ and $\mathrm{E}^{\prime}$, extensor museles; $F$ and $F^{\prime}$, flexor museles. The sign + indieates that at the synapse which it marks the afferent fibre $a$ (and $\alpha^{\prime}$ ) excites the motor neuron to discharging aetivity, the sign - indieates that at that synapse the afferent fibre $\alpha$ (and $\alpha^{\prime}$ ) inhibits the diseharging activity of the motor neurons. The effect of strychnine and tetanus toxin is to eonvert - into +. (From Sherriugton's "Integrative Action of the Nerrous System," by permission of Yale University Press and Messrs. Constable and Co., Ltd.)

diseases of the spinal cord affecting these centres, these processes will be impaired. It also contains the centres controlling the erection of the penis and the ejaculation of the seminal fluid. The. spinal: cord is also normally concerned in the process of parturition. It is 
possible, however, for this to take place when the influence of the cord is removed.

The condition of the spinal cord is investigated in mau by the study of certain superficial or true reflexes, and of certain tendon or

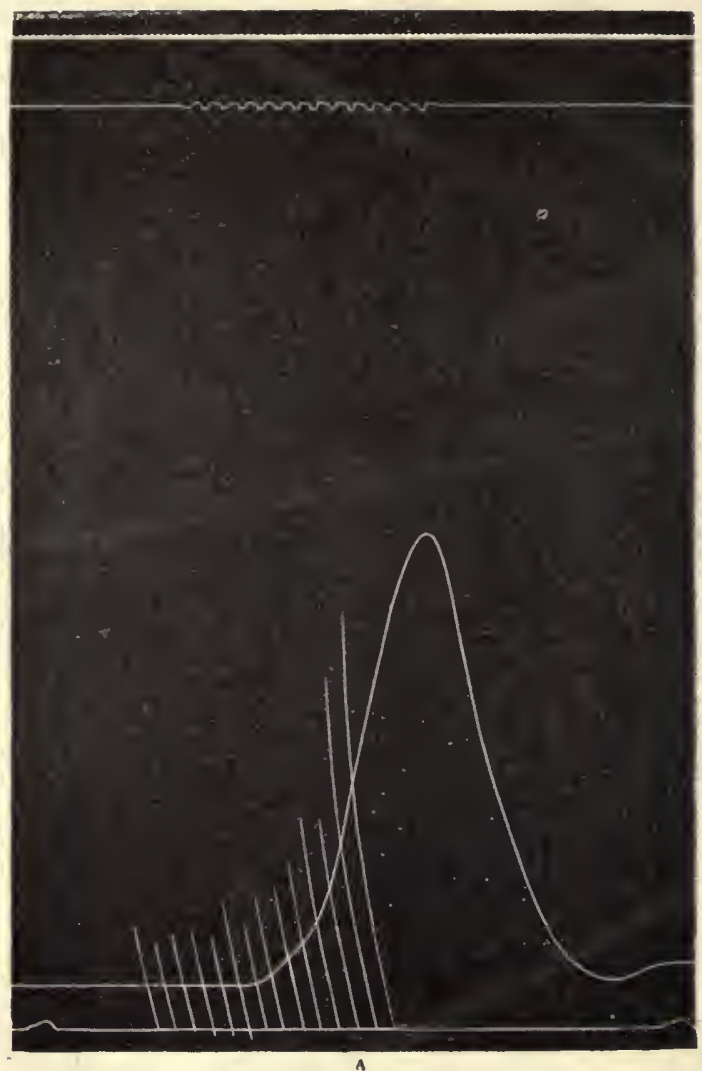

Fig. $40 \overline{8}$.

$A$ and $B$, The flexion-reflex observed as a reflex eontraction $(A)$ of the licxor muscli of the knee and as a reflex relaxation $(B)$ of the extensor musele of the knee. The intensity of the stimulating shoeks was feeble, hence the relatively long latent period. Time in $\frac{1}{10}$ second above and in seconds below. (From Sherrington's "Integrative Action of the Nervous System," by permission of Yale University Press and Messrs. Constable and Co., Itd.)

deep reflexes. An example of the true reflex is the plantar reflex. If the finger be drawn along the sole of the foot of a normal individual, the foot is drawn away; if the stimulation be gentle, the big toc in the adult is turned downwards. In certain cases of organic nervous disease the big toe is turned upwards (the extensor response). This is known as Babinski's sign.

Other superficial reflexes are-(I) The conjunctival, closing the eye, 
evoked by touching the conjunctiva; (2) the pupil reflexes, by throwing light on the eye, or getting the subject to accommodate by looking at a near object.

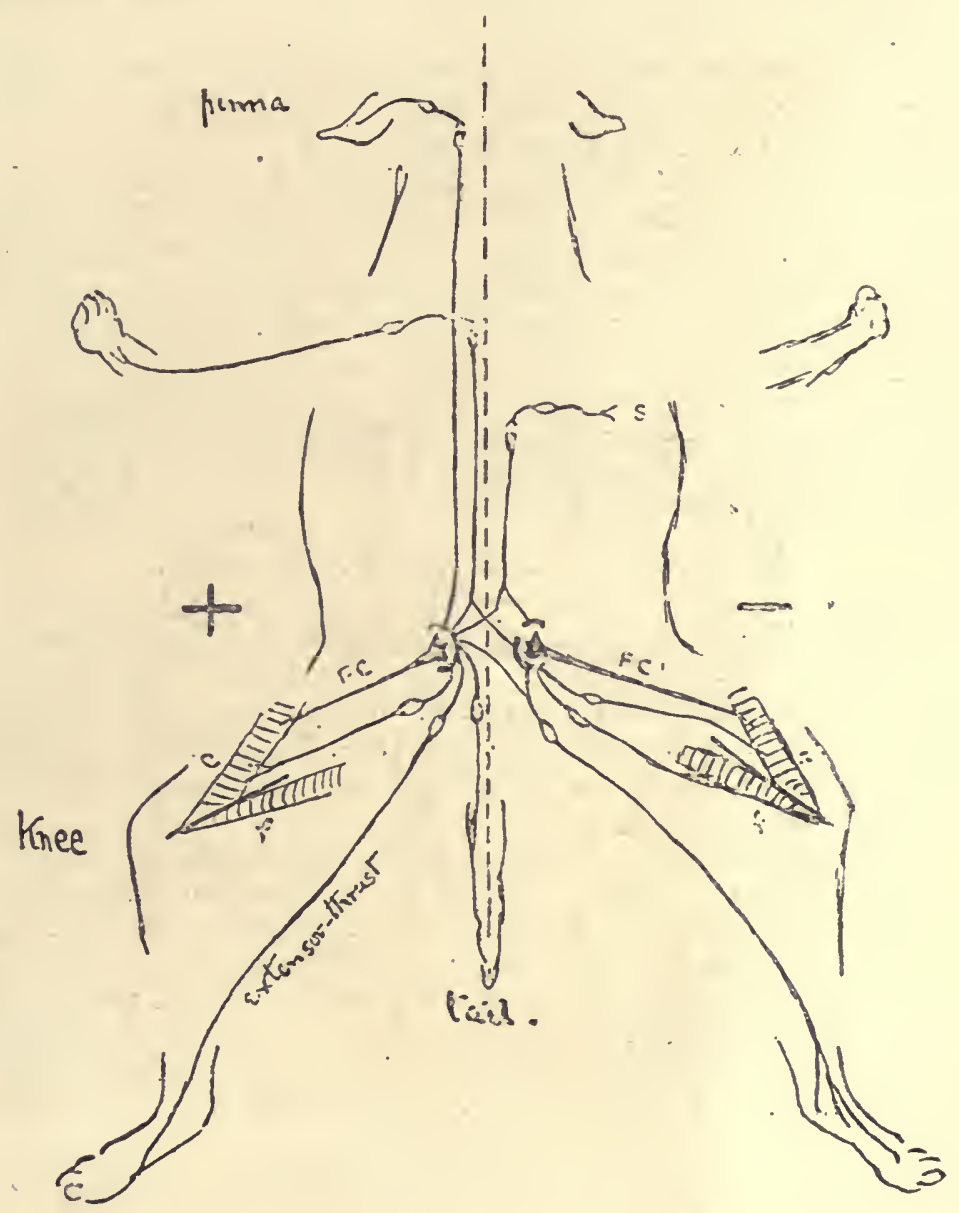

Fig. 409. - To show Ixteraction of Certain Groups of Reflex Paths upon the Fival Common Pitit $(F C)$.

$S$, Scratch receptor; $e$ and $f$ are extensor and flexor muscles of knee respectively. Reflexes that act as allied reflexes on $F C$ are rapresented as having their terminals joined together. Reflexes with excitatory effect $(+)$ are brought together on the left, those with inhibitory (-) on the right. (From Sherrington's "Integrative Action of the Nervous System," hy permission of Yale University Press and Messrs. Constable and Co., Ltd.)

Various other reflexes may also be evoked. Such reflexes show that the reflex are concerned is intact. If there be no response, then there is damage to the are in some part of its course. 
Tendon reflexes, of which the knee-jerk is an example, are not usually regarded as true reflcxes. They are elicited by placing a muscle on the stretch, and sharply striking the tendon. As a result, the muscle contracts. In the knce-jerk, the quadriccps extensor is stretched by placing one knee over the other. The patellar tendon of the upper knee is then sharply struck, preferably when the subject's attention is diverted. As a result, the foot is jerked up by the sudden contraction of the quadriceps muscle.

The value of this "reflex" is that it shows the condition of the reflex are which supplies the quadriceps extensor. If it be not intact, the muscle is toneless, and there is no response. An excessive response indicates that the cerebral control of the reflex is missing. The knee-jerk is, therefore, of great clinical value. It has been taught

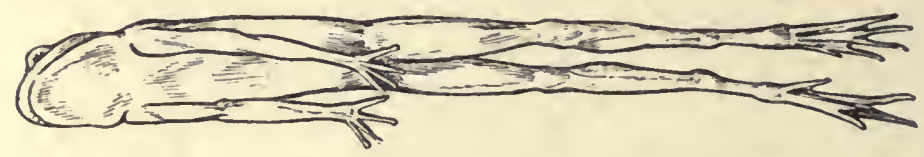

Fig. 410.- Prog with Struchene Coxvulsioxs.

that it camnot be a true reflex, on the grounds that the time occupied betwcen the striking of the blow and the muscular response is too short for an impulse to have travelled into the cord and out again to the quadriceps muscle. Reflexes as short are, however, now considered possible, and the knee-jerk may be regarded as an example of a true reflex.

Another tendon reflex which is often investigated is that known as "ankle clonus." This is evoked by bending the subject's knee slightly while supporting it with one hand. With the other hand the fore-part of the foot is suddenly " dorsiflexed," and the pressure maintained. As a result of the sudden strain, the calf muscles may contract and then relax; but as the result of the continued pressuro contract again, and so on, the result being that a series of contractions, or "clonus," results. Ankle clonus is nearly always a sign of disease. 


\section{CHAPTER LXXIII}

\section{THE BRAIN}

THE central nervous system is formed in the fotus by an infolding of the epiblastic layers. At the anterior end of the nervous tube thus formed the brain becomes developed. This is the end of the animal which normally progresses forwards, and it is here, thercfore, that develop the special sense mechanisms which serve to protect the animal. This end of the neural tube becomes thickened, and

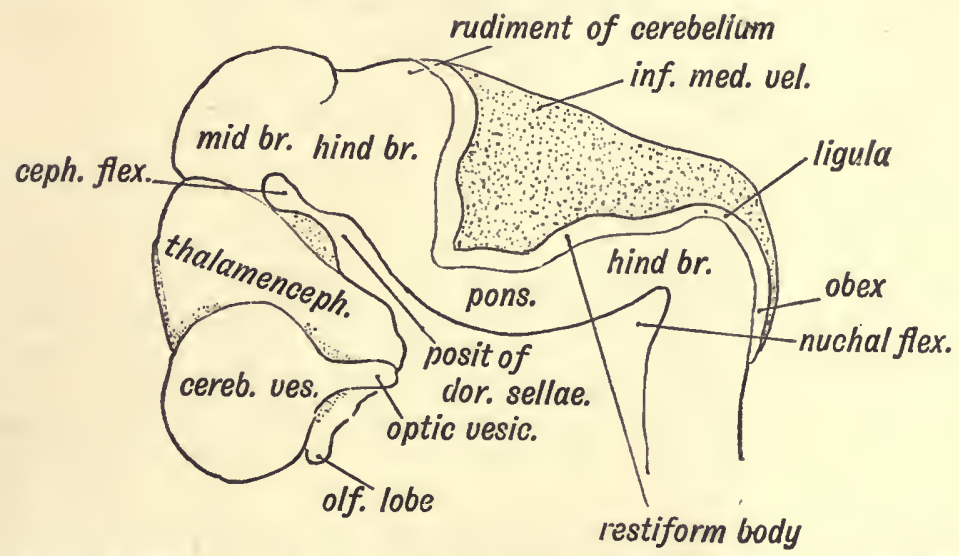

Fig. 411.-Lateral View of Cephalic Part of Neural Tube in a Fifti-l'eek Humax HMBryo. (Keith, after His.)

enlarges to form three primary cercbral vesicles-the prosencephalon, mesencephalon, and rhombencephalon. The first and third of these again divide, so that we have eventually five primary parts:

First primary vesicle: The pros-encephalon (fore-brain). The di-encephalon, or thalamencephalon (between-brain).

Second primary vesicle: The mes-encephalon (mid-brain). Third primary vesicle: The met-encephalon (hind-brain). The myel-encephalon (after-brain). H

The myelencephalon becomes developed, to form the spinal bulb. The bulb connects the spinal cord with the rest of the brain.

From the metencephalon develops the little brain, or cerebellum, 
and the pons. The cerebellum lies dorsally to the pons, which bridges its two hemispheres, covering the brain-stem as it ascends from the

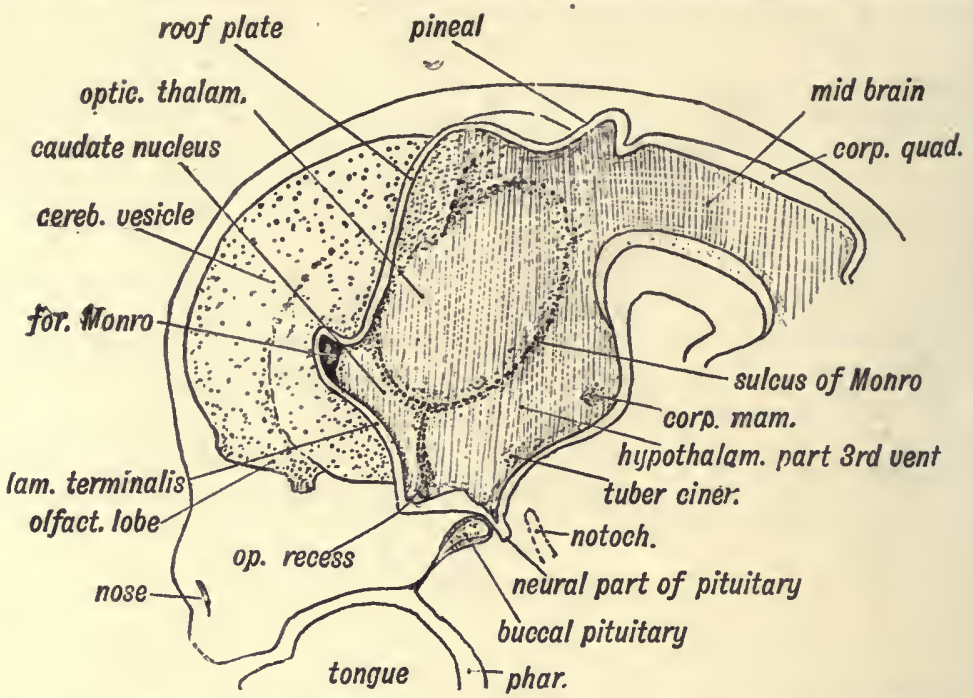

Fig. 412.- Schematic Figure to show the Parts deriven from the Walls of THE Forw-Brats. (Keith, after His.)

bulb to mid-brain. In the region of the bulb ard pons, the central canal of the spinal cord opens out, to form the-lozenge-shaped fourth

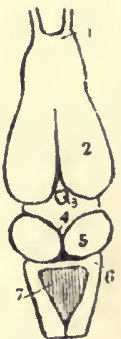

Fig. 413.-DIAGRAM OF THE Frod's BRAIN.

1, Olfactory Lobs; 2. cerebrum ; 3 , pineal gland; 4, thalamencephalon; 5 , optic lobe; 6, cerebellun; 7, fourth ventricle and medulla oblongata.

(a) ventricle of the brain.

The mesencephalon consists, in the adult brain, mainly of the limbs (crura) of the grcat brain, and the four bodies known as the corpora quadrigemina. Through it runs the central canal, here knowi as the aqueduct of Sylvius. The optic lobes of the lower animals are associated with this part of the brain.

The diencephalon, or thalamencephalon, develops into the optic thalami and the parts enclosing the third ventricle of the brain. From the primary vesicle, of which this is the hinder part, there arise lateral expansions-the optic vesicies, which go to form the retinx and optic tract of the adult animal. These form close connections with the optic thalami and with the corpora quadrigemina of the mid-brain.

The prosencephalon expands forwards and downwards at first, and then from the lateral aspects large hollow outgrowths arise-the cerebral hemispheres. The dorsal and lateral walls of these hemispheres become greatly thickened internally with white matter, and externally with a grey cortex, and thus the great brain 
is formed. This, in man, is greater than all the rest of the brain. They eneluse the expansions of the eentral neural canal, known as the lateral ventrieles. The olfaetory bulbs are outgrowths from this part of the brain.
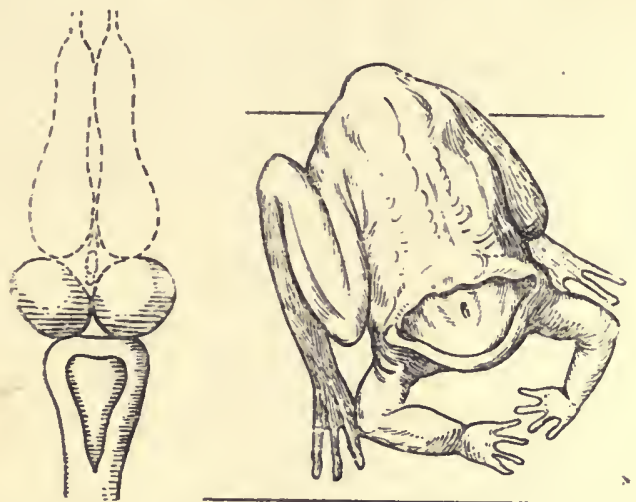

Fig. 414.-Showlyg the Position assumed by Frog after Removal of Cerebial LOBES.

Voluntary movement is lost. When the mid-brain is romovel the frog eannot control its movements.

The cerebral hemispheres are the latest outgrowths to be developed, and are especially marked in the primates and man. In the lower animals, on the other hand, the thalamencephalon and meseneephalon are more developed, parts which are connected with primitive sensations and emotions rather than judgments.

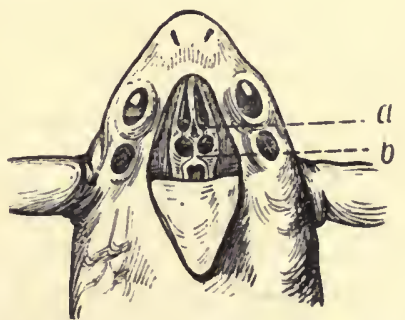

Fig. 415.-To show the Dissectiox for Rlugoval in the Frog of the Fore-Brain (a) AND THE OPTIC LoBes (b).

After removal of these the flap of skin may be stitched in pasition again.

In the lower vertebrates, the brain is formed by the enlargement of the anterior end of the spinal eord, and by the widening and division of the central canal to form ventricles. Upon this primitive brainstem are devoloped swellings in eonncetion with the senses of most importance to these lower forms-namely, the sense of smell and the sense of sight. Usually, one or other of these is predominantly 
developed. The brain of the frog is seen in Fig. 413. In reptilia, the brain is long and narrow, much increased in size. It begins to show marked differentiation with the appearance of the neopalliumthe higher cortex, or brain proper.

In birds, the brain is broad and highly developed, the greatest - development being in the size of the striate bodies (corpora striata). The thalamns and optic lobes are also highly organized.

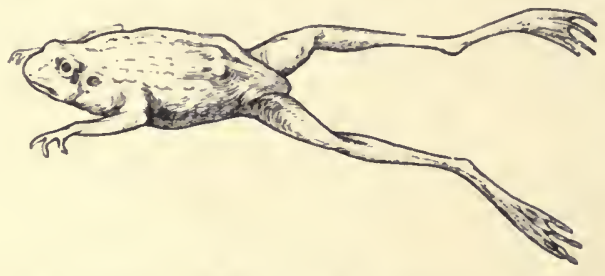

Fig. 416.-Position assumed by frog after Ruyoval of the Extre Braix: It hes Limp and Flaccid.

The function of the brain may be studied on the frog. If the cerebral hemispheres be destroyed, preferably by forceps by dissection, and the bleeding stopped by wax (Fig. 414), the frog, when the shock has passed off, will exhibit spontaneous movements such as swimming when placed in water, and turning over if placed on its back. If the corpora striata and optic thalami be destroyed, the shock is greater, but the animal on recovery can still jump, swim, climb an inclined board, and maintain its equilibrium. If the cerebellum and medulla oblongata are destroyed, the power to maintain equilibrium vanishes, and the respiratory movements of the nares and of the floor of the mouth cease. The animal lies in a listless condition (Fig. 416), but still shows co-ordinated movements when stimulated, since the spinal cord is still intact.

\section{Section I}

\section{THE MEDULLA OBLONGATA AND PONS VAROLII}

The Medulla Oblongata.-The mednlla oblongata may be regarded as the expanded upper end of the spinal cord; indeed, it is sometimes termed she spinal bulb. In this region, the central canal gradually becomes more superficial, and eventually opens out, to form part of the fourth ventricle. On either side of the middle line posteriorly there are seen, at the lower end of the mednlla, prominences which represent the terminations of the posterior columns of the cord. Each postero-median column ends in a prominence on either side of the middle line, known as funiculus gracilis, each postero-lateral in a more laterally piaced funiculus cuneatus. Promincnt in the mid-line anteriorly are the pyramids, which are composed of the pyramidal fibres coming from the cortex, and have not yet crossed. The decussation of these fibres takes place at the lower end of the medulla. 
The lateral columns of the spinal cord pass outwards to the cercbellum, forming its inferior peduneles, or, as they are also callad, the restiform bodies. Between the lateral and anterior columns there is, on either side, an oval swelling, known as the olive.

Sections of various levels of the medulla reveal important changes, as compared with the cord. It is seen that, as the result of two decussations, the central canal is set baekwards and gradually opens out into the fourth ventriele, and that the grey matter of the cord becomes broken up and scattered. New groups of grey matter also make their appearancc. The chief groups of grey matter are(1) The nuclei of the posterior columns-the nucleus gracilis and cuneatus, on cither side, at the lower level of the medulla (Fig. 41S);

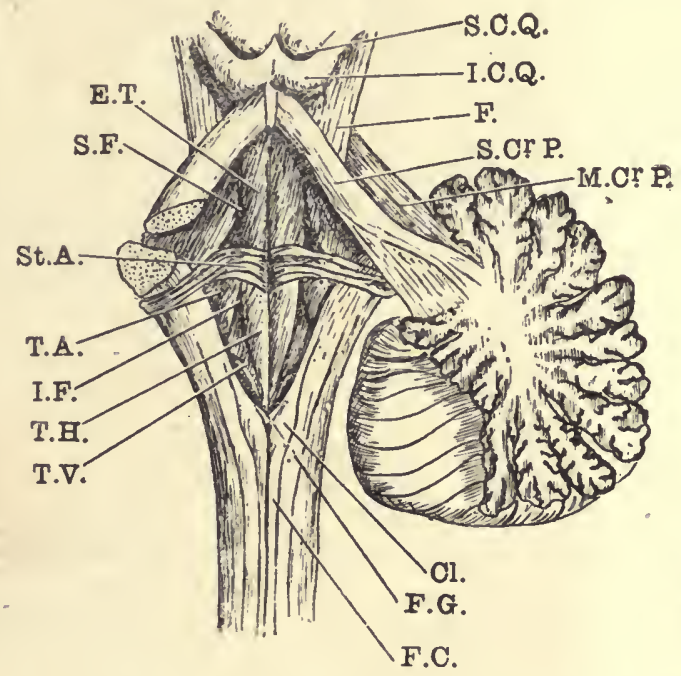

Fig. 417.-The Founth Vestricle. (Parsons and Wright.)

S.C.Q., Superior cor pora quadrigcmina; I.C.Q., inferior corpora quadrigemina: $F$, fillet; S.Cr.P., superior cerebellar peduncle; $M . C r . P^{2}$, middle ccrcbellar peduncle; Cl., Clava; F.C., funiculus cuncatus; F.G., funiculus gracilis; E.T., Eminenti: teres; S.F., superior fovea; St.A., stria acustica; T.A., trigonum acustici; $I . F$., inferior fovca; $T . H$., trigonum hypoglossi; $T$.V., trigonum vagi.

(2) the inferior olivary nucleus, which makes its appearanee in the mid-level (Fig. 419); (3) the nuclei of the cranial nerves, the twelfth to the ninth appearing from below upwards at various levels.

The Nuclei of the Posterior Columns.-Around the cclls of the gracile mucleus end the fibres which ascend in the postero-modian column of the cord (Goll); around those of the euneate nucleus those of the postero-lateral column (Burdach). From the eells of these nuclei arise fibres which-(1) pass inwards and eross the middle line, to ascend as the mesial fillet (Fig. 419); (2) pass inwards and upward:; .on the same side to the cerebellum by the restiform body - the internil 
arcuate fibres (Fig. 418); (3) deeply inwards across the median raphe, to become external on the ventral aspect of the medulla, pass thence superficially around the medulla, to enter the cerebellum by the inferior peduncle-the external arcuatefibres (Fig. 418).

The inferior olive is a characteristically shaped mass of grey matter. From its cells fibres pass to the cerebellum by the infer:or peduncle of the same side, but chiefly by that of the opposite side-the olivocerebellar fibres.

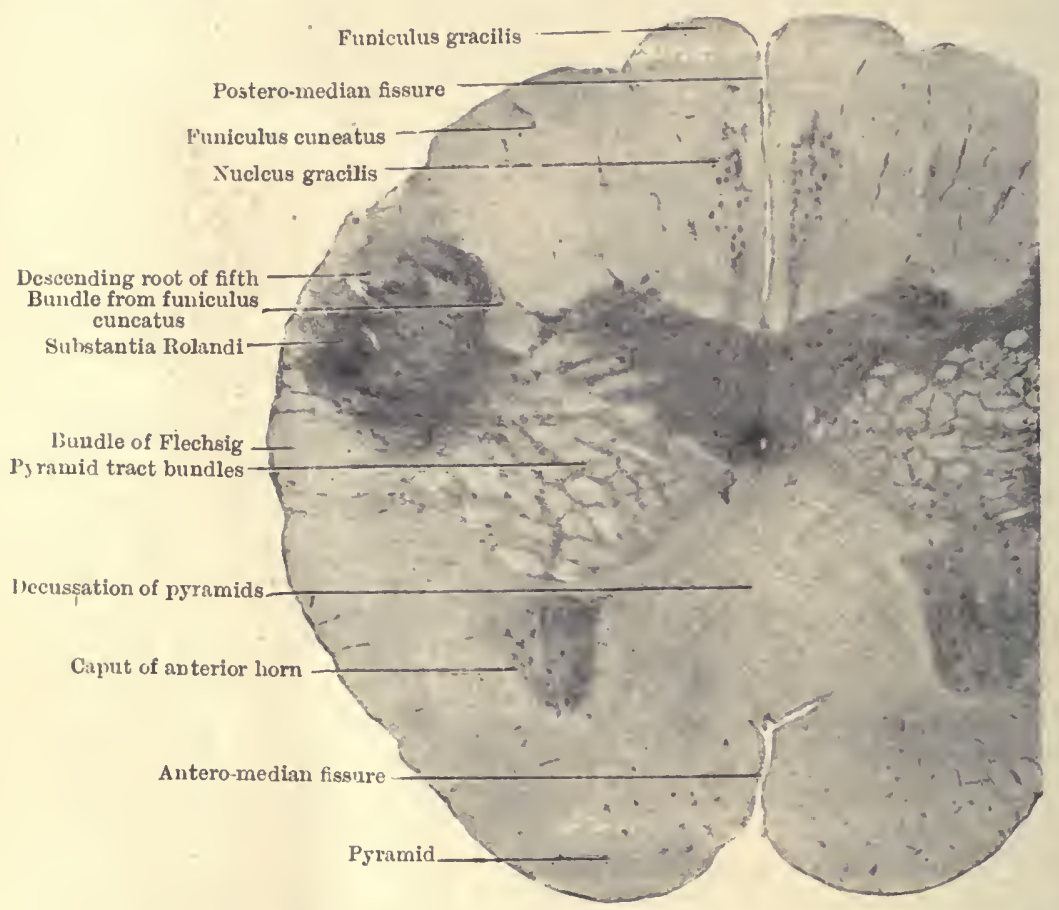

Fia. 4i8.- Section across the Loiver Patt of the Metolla Oblovgata ix the Midde of the Decussatiox of tue Priamids. Magnified aboet 6 Dia. METERS. (E. A. Schäfer, from "Quain's Anetomy.")

Cranial Nerves.-The cranial nerves do not conform to the spinal arrangement of an anterior and posterior root, the two forming a "mixed" nerve. Some of the cranial nerves consist almost wholly of motor or effector fibres. In most of the nerves the fibres are somatic; in ecrtain nerves there are splanchnic fibres also.

The cell-stations of afferent nerves are situated in ganglia, corresponding to posterior root ganglia, on the course of the nerre outside the central nervous system. The effector fibres arise from groups of eells or "nuclei" corresponding, in the case of somatic fibres, to the anterior horn cells, and of splanchnic fibres to the lateral horn cells of the spinal cord. 
The Twelfth Nerve, or Hypoglossal.-This is a purely motor nerve supplying the muscles of the tongue. It arises from a nucleus of grey matter situated dorsally close to the middle line (Fig. 419). The nerve passes ventrally outwards.

The Eleventh Nerve.-Anatomically, this nerve consists of two parts - the spinal and the accessory portions. The accessory portion arises from the medulla, and is, in reality, a part of the tenth nerve. It arises from the same nucleus as part of the tenth nerve (Fig. 419), and supplies splanchnic fibres, which run eventually in the tenth

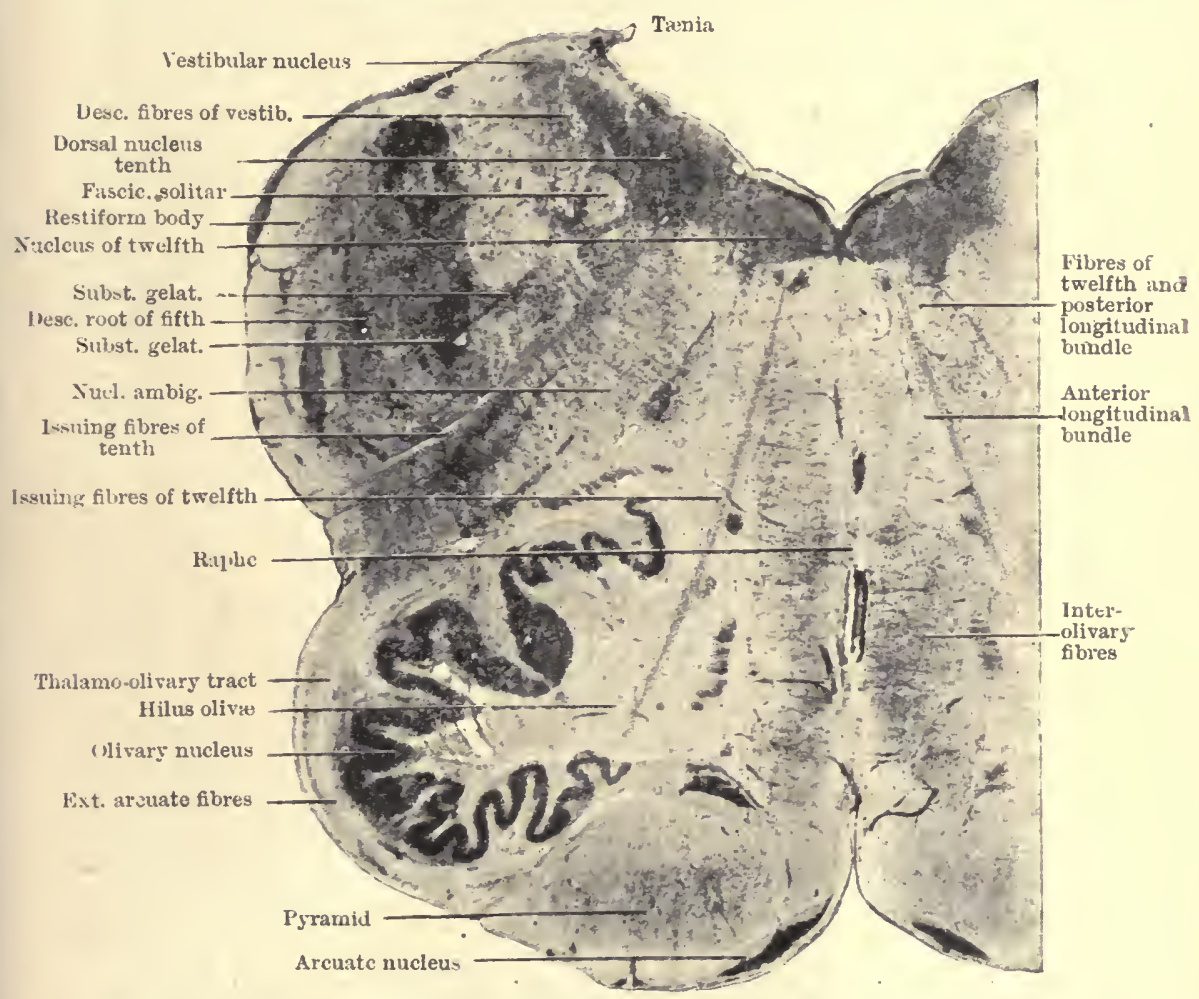

Fig. 419.-Siection across the Medulla Oblongata at abodt the Mindle of the Orivary Body. Magnified 6 Diameters. (E. A. Schä 'er, from "Quain'= Anatomy.")

nerve. These fibres are chiefly cardio-inhibitory and viscero-motor. The spinal fibres supply two muscles--the trapezius and the sternomastoid.

The Tenth Nerve (the Vagus, or Pneumogastric).-This is, composed of afferent and efferent fibres-somatic and splanchnic. The afferent fibres have their cell-stations in the ganglia of the trunk and root. The ingoing fibres from these bifurcate after the manncr of posterior root fibres. The upgoing branches are short, and end around cells 
known as the principal nucleus (Fig. 419). The descending fibres (corresponding to the comma tract of the cord) are longer, and pass into a tract of fibres known as the funiculus solitarius (Fig. 419). In this tract also rum corresponding fibres from the ninth nerve, and the intermediate nerve of Wrisberg.

The efferent fibres arise chiefly from the so-called nucleus ambiguus (Fig. 419), and also from the upper part of the same nucleus as the eleventh nerve. The afferent sensations broight up by the tenth nerve are eoncerned with the respiratory and cirenlatory systems. Impulses from the superior laryngeal nerve inhibit inspiration, and bring about expiration and coughing. Those from the lung alveoli

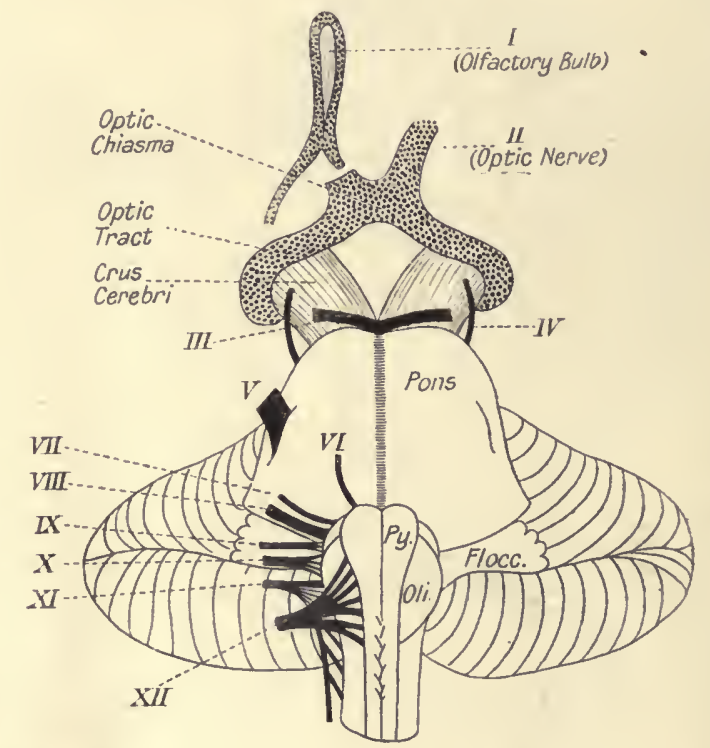

jig. 420.--Anteru-Ixferior Vifw of the Cruka, Pons, and Bulb (Diagranaatig), to illestrate tile Seperficial. Origin of the Cranlat Nenves.

segulate the depth and frequency of inspiration, and possibly also of expiration (see p. 296). Those from the heart (depressor nerve), which generally run in the vagus, go to the vaso-motor eentre, and reflexly bring about a fall of arterial pressure, owing to vaso-dilatation especially in the splanchnic area. Other fibres of the vagus have a pressor effect, and cause a rise of arterial pressure. Central stimulation of this nerve also brings abont reflex inhibition of the heart.

The effector functions of the vagus nerve may be summarized as motor to the levator palati, 'the eonstrietors of the pharynx, the muscles of the larynx, and to the smooth muscle of the bronchi and bronchioles, to the muscles of the walls of the œsophagns, stomach, 
and small intestine. It is inhibitory to the heart, and secretory to the glands of the stomach, and possibly of the pancreas.

The Ninth Nerve, or Glosso-Pharyngeal Nerve, is essentially an afferent nerve, the cell-stations of its fibres being the jugular and petrosal ganglia. The ingoing branches from the ganglia branch, on entering the medulla, passing slightly upwards to the cells constituting the ninth uncleus, and downwards in the fasciculus
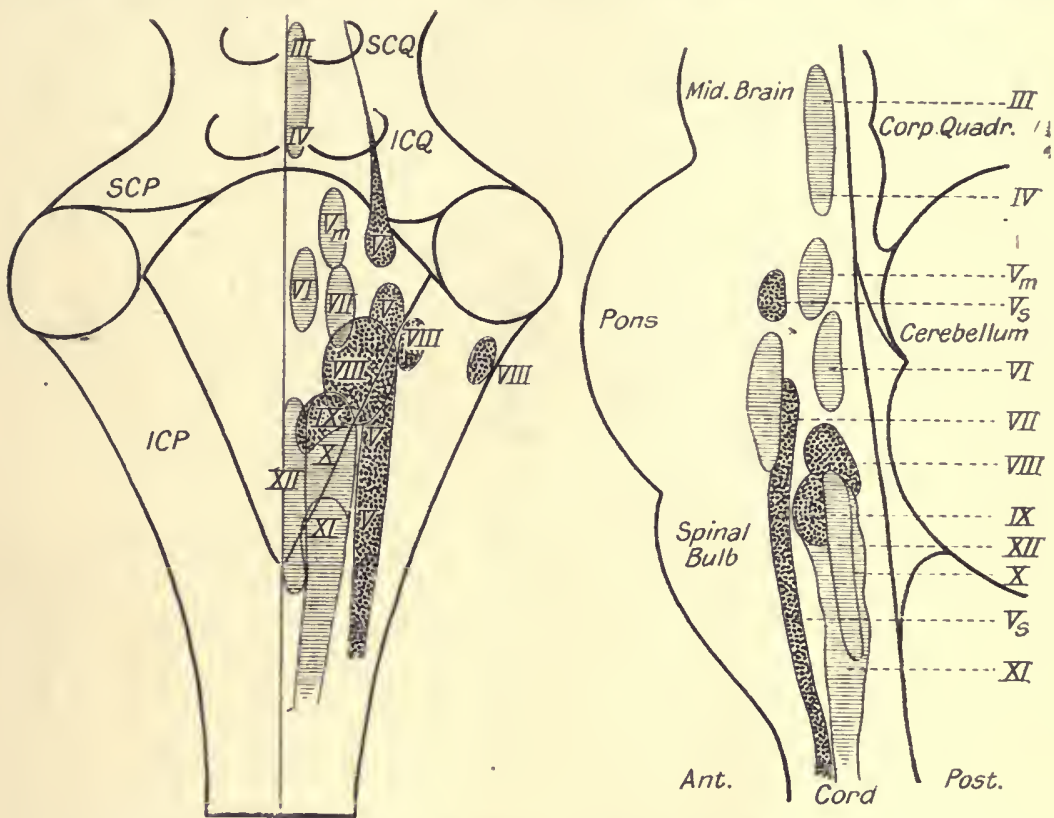

Fig. 421.-DiagraM To ILLUSThate THE Position of the Bulbar Teclei of the Cranial Nurves.

Posterior aspect of the fourth ventricle exposed by removal of the pons and cerebellum. Motor nuclei indieated by horizontal lines, sensory nuclei by dots. Median group of motor nuclei, $I I I, I V, V I, X I I$. Lateral group of motor nuclei, $V m, V I I, X, X I$. Sensory nuclei, $V s, V I I I, I X$.
Fig. 422.-Lateral VIEW of the Right HaLF of THE BuLb aNd PoNs Exposed BY a Vertical Section, AND IMaGixed as Tinassearext. (After Ero.)

In this ricw the lateral group of motor nuclei. Vm, VII, $\mathrm{X}, \mathrm{XI}$, lio fartlicr from the surface of section. and aro indieated by lighter lines than the median group of motor muclei, $I I I$, $I V, I I, X I I$.

solitarius. The afferent fibres are concerned with the sensation of taste in the posterior third of the tongue, and with common sensation of this region and of the upper part of the pharyux. In the nerve also run some effector fibres. These arise mainly from the upwarl continuation of the nucleus ambiguus, and supply the constrictor muscles of the pharynx, the stylo-pharyngeus, and levator palati muscles. The nerve also contains effector secretory fibres to the parotid gland, the cell-stations of which are not exactly known. These pursue a somewhat devious course to reach the gland (see p.374). 
The white matter of the spinal bulb consists of eonducting traets, both ingoing and outgoing. The ehief ingoing afferent paths are-

1. The mesial fillet. The fibres of this tract arise from the gracile and cuneate nuelei, immediately eross the middle lime and pass up in elose proximity to and on either side of it (Fig. 396). This crossing forms the sensory decussation; the fibres of the fillet eventually reaeh the optic thalami (Fig. 434).

2. The ccrebellar tracts of the eord pass up through the medulla to reaeh the cerebcllum (Fig. 4.31). They oceupy part of the area known as the retieular formation (formatio retieularis).

3. The spino-thalamic tract passes through, and joins with, the mesial fillet to reach the thalamus.

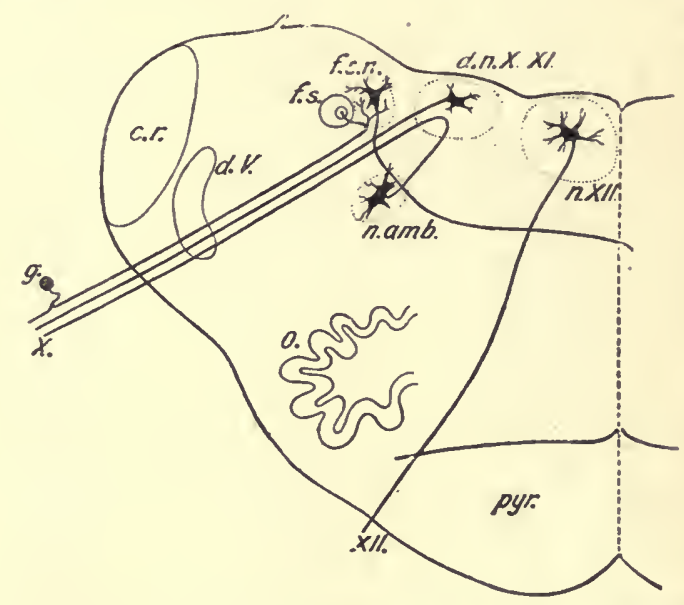

Fif. 423.-Plax of the Oriais of tue Twentrii and Tenth Nerves.

(A. E. Schäfer.)

pyr., Pyramid; n.XII., nucleus of hypoglessal; XII., hypoglossal nerve; d.n.X.XI., dorsal nuclcus of vagus and accessory; n.amb., nuclcus ambiguus; $f . s$. , fasciculus solitarius (desecnding root of vagus and glosso-pharyngeal; $f$.s.n., its nucleus; $X$., issuing fibres of vagus; $\%$, ganglion cell in ragus giving origin to a sensory fibre; $d . P$., descending root of fifth; c.r., corpus restiforme.

4. The cxternal and internal areuate fibres, whieh arise from the graeile and euneate nuclei, and pass to the cerebellum either by an external course from the opposite side or by an internal eourse from the same side.

The outgoing fibres take part in the formation of the chief reflex ares (Fig. 397):

1. The restibulo-spinal, which arises in the upper part of the medulla in Deiters' nucleus.

2. The rubro-spinal, eoming from the red nucleus of the midbrain.

3. The pyramidal traets from the eerebral cortex. These lie anteriorly throughout the great part of the medulla, but in its lower 
part most of the fibres cross the middle line, to become the crossed pyramidal tracts of the cord, thus forming the motor decussation.

Tracts which may perhaps be grouped as conducting in both directions are-

1. The olivo-cerebellar fibres, which connect the inferior olive to the cerebellum.

2. The posterior dorsal longitudinal bundle fibres, in which run fibres in both directions botween the medulla and the anterior basis bundle of the cord, and the pons and mid-brain. This tract lies dorsally to the mesial fillet, just below the central canal and fourth rentricle. The chief fibres of this tract come -(1) from the nuclei of the third and sixth nerves, being concerned in the regulation of eye movements, and by way of the seventh nerve in the movements of the accessory apparatus, such as the eyelids and eyebrows; (2) from Deiters' nucleus to the cord in connection with the equilibration of the body; (3) from the twelfth nucleus by way of the seventh nerve to the orbicularis muscle of the mouth.

In close association ventrally with the posterior longitudinal bundle (sometimes classed as part of it) is the anterior longitudinal bundle, or tecto-spinal tract. In it run fibres from the roof of the mid-brain to the cord.

The Functions of the Medulla Oblongata. - The medulla, like the spinal cord, acts as a conductor and as a reflex centre. The centres are those associated with the functions of the nerves arising from it, of which the vagus nerve is the chief. Here, therefore, are situated the centres concerned in

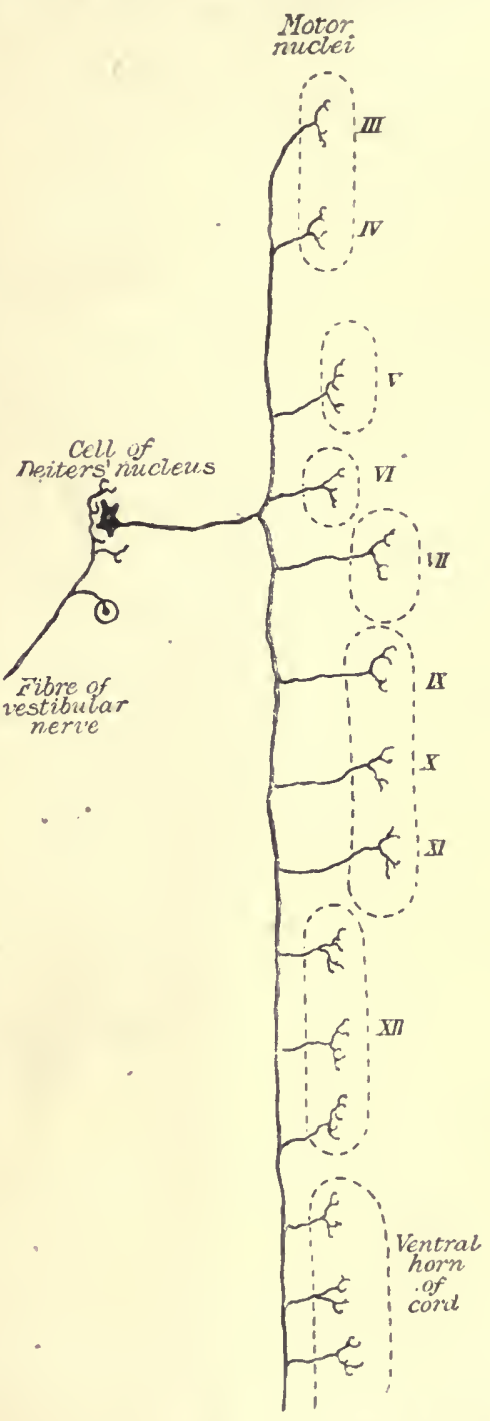

Fig. 424.-Diagrail of a Fibre of the Posterior Loseitudival Bondiz: ARISING FroN a Cell OF DeIters' NuCleUs. (E. A. Schäfer, from "Quain's Anatomy.") . the regulation of the heart-beat (the cardio-motor centre), the regulation of the peripheral resistance (the raso-motor centre), the 
centre for respiration, and other centres already referred to, such as those for the provision of saliva and gastric juice for mastication, swallowing, phonation, and romiting.

The destruetion of the medulla brings about death, owing to respiratory failure. The body of a pithed mammal may be kept alive for some hours by artificial respiration. The blood-pressure, however, is low, owing to the destruction of the chief raso-motor centre.

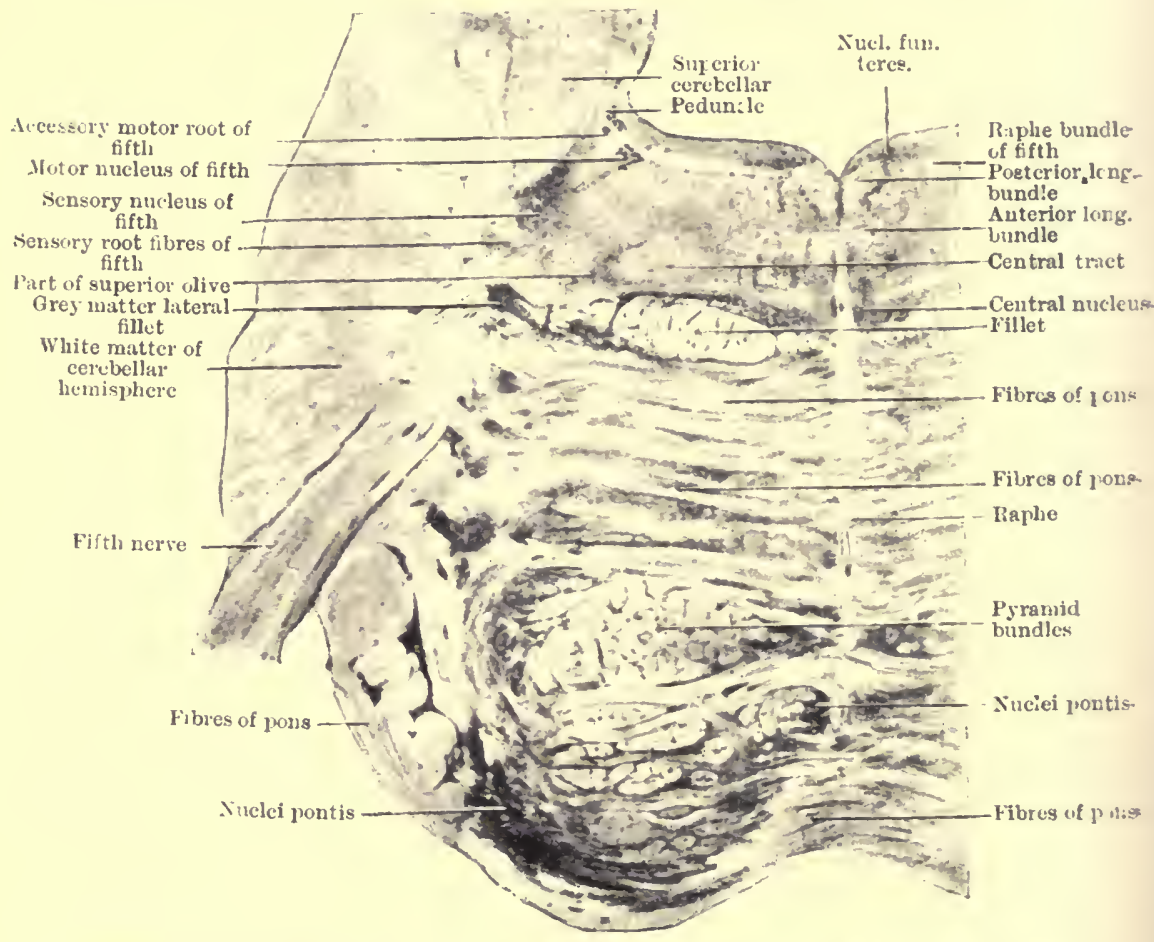

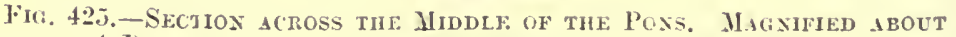
4 limmters. (F. A. Schäfr, from "Quain's Anatomy.")

The Pons Varolii is : continustion of tl:a medulla oblongeta, surrounded by transverse fibres, which form the middle or transverse peduncles of the cerebellum; a large part of tlac anterior portion of the pons is made up of these transverse fibres passing from one side of the ecrebellum to the other (Fig. 42.5). It aets ass a conductor to ingoing and outgoing fibres. and in it are sitnated the nuclei of the eighth to the fifth cranial nerves. Passing 11 , through the pons sre the fibres of the ventrel spino-cerebeller trect and of the mesial fillet. Passing downwards through the pons are the fibres of the pyramidal tract from the cortex, which in this region lic ventrally somewhat scattered among the transverse fitres. The rubro-spinal fibres alsopass downwards. In this region they lie in the reticular formation 


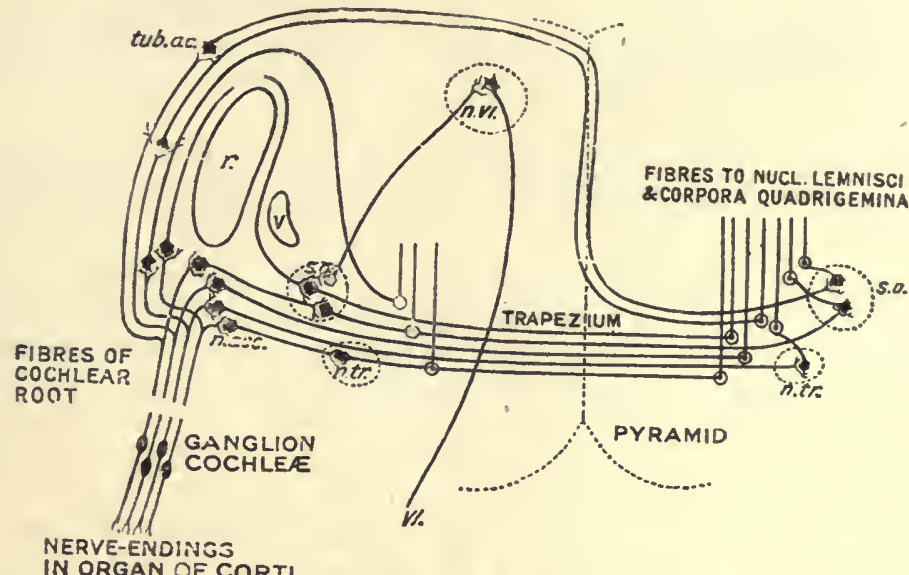

Fig. 426.--Plax of Course axd Consections of the Fibies fornixg the Cochle.ir Root ot Aunitori Nerve. (E. A. Schäfer.)

$r$.",Restiform body; $v$.s descending root of fifth nerve; $t u b$.ac., tuberculum acusticum; n.acc., acessoly nucleus; s.o., superios olive; n.tr., nucleus of trapezium; n.t $i$, nueleus of sixth nerve; $V I$., issuing root-fibre of sixth nerve.

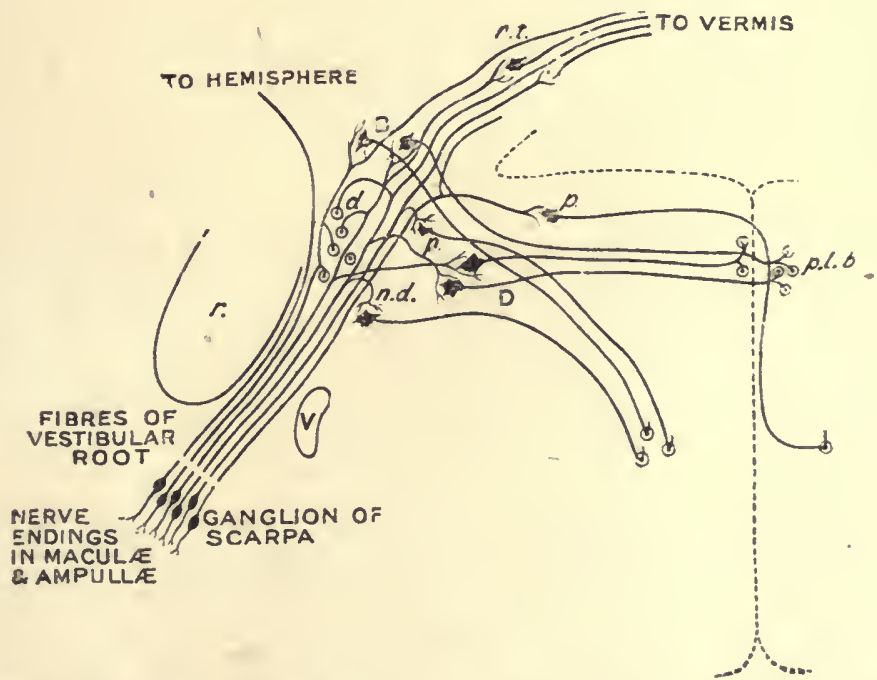

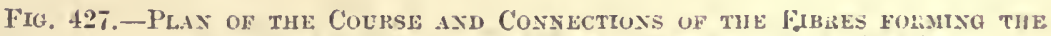
Vestiblak Root of the Eichur Nerve. (E. A. Sehäfer.)

$r$., Restiform broly: $V$, descending root of fifth norve; $p$. principal nucleus of vestibular root; $n . d$., cell of the descending vestibular nueleus; $D$, nuclens of Deiters; $B$, nueleus of Bechtcrew: n.t., nucleus teeti (fastigii) of the eerebellum; p.l.b., posterior longitudinal bundle. 
dorsally to the mesial fillet (Fig. 425). More dorsal still, in a position corresponding to that in the medulla oblongata, lies the postcrior longitudinal bundle, its fibres making connections both upwards and downwards.

The chief masses of grey matter are-1. Deiters' nucleus. 2. The nucleus pontis. 3. The superior olive. 4 4 . The nuclei of the eighth to the fifth cranial nerves.

The Nucleus of Deiters is an important mass of grey matter lying at the lower end of the pons, and partly in the upper part of the spinal bulb. Around the large cells constituting the nucleus end fibres from the vestibular nerve and the dentate nucleus of the cerebellum.

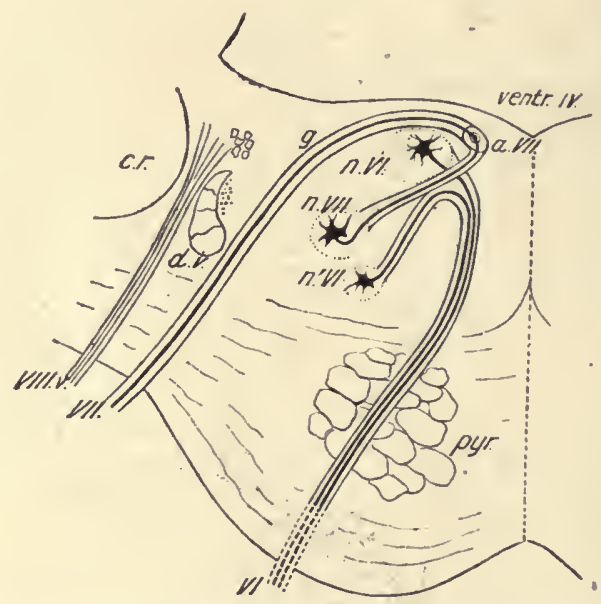

Fig. 428.-Plan (Transverse) of the Origrn of the Sisth and of the Motor Part of the Seventh Nerve. (E. A. Schäier, from "Quain's Anatomy.")

$V I .$, Sixth nerve; VII., seventh nerve; $a . V I I$, ascending part of root of seventh, shown cut across near the floor of the fourth ventricle; $g$, genu of sevanth nerveroot; $n . V I$., chief nucleus of the sixth nerve; $n . ' V I$., accessory nucleus of sixth; $n . V I I .$, nucleus of scventh; $d . V$. , descending root of fifth; pyr., pyramid bundles; VIII.v., vestibular root of eighth nerve.

From the cells of the nucleus arise fibres which pass downwards through the medulla oblongata, into the antero-lateral position of the cord-the vestibulo-spinal tract. Other fibres pass inwards to the middle line, to ascend and descend in the posterior longitudinal bundle (Fig. 427). The ascending fibres go chiefly to the sixth and third nuclei, the descending to the anterior horn cells of the cord. In close proximity to this nucleus, forming in reality its upper part towards the cerebellum, is the nucleus of Bechterew.

The Nucleus Pontis is the name given to the grey matter lying between the crossing fibres of the pons, around the cells of which end fibres from the frontal and occipital cortex-the fronto-pontine 
and cortico-pontine fibres. From the eells arise the transverse fibres, whieh cross the middle line, and pass by the middle peduncle to the vermis of the cerebellum.

The Superior Olive is a small mass of grey matter closely associated with the co-ordination of the movements of the eyes with the mechanism of equilibration.

The Nuclei of the Cranial Nerves.--The eighth nerve is a wholly afferent nerve. It eonsists of two portions-the cochlear and the vestibular. The cochlear portion is concerned with hearing. Its cell-station is in the spiral ganglion of the eochlea. Peripherally, the nerve processes arborize around the hair cells of the organ of Corti. Centrally, the axons pass into the uppermost part of the medulla oblongata. They braneh on entering; one set of branehes ends in a nucleus-the accessory nucleus-just anterior to the restiform body (Fig. 426); the other around cells in what is known as the tuberculum acusticum, or acoustic tubercle, a mass of grey matter resting upon the outer aspect of the restiform body. From the cells of these nuclei arise fibres which go to form the lateral fillet (Fig. 426). The fibres from the accessory nucleus pass transversely across in the tract known as the trapezium, making in their eourse connection with the superior olive and trapezoid nucleus of the same and opposite sides, and then turning upwards in the lateral fillet to reach the nucleus of the lateral fillet and the inferior corpus quadrigeminum. The fibres from the tuberculum acusticum eross the floor of the fourth ventricle superfieially as the striæ acusticæ, and, dipping inwards at the middle, pass with those of the trapezium to the superior olive of the opposite side, and thenee to the lateral fillet and inferior corpus quadrigeminum.

The vestibular portion of the eighth nerve is concerned with tha mechanism of equilibration. It arises from the cells of Scarpa's ganglion in the vestibular portion of the internal ear. The ingoing fibres divide into ascending and descending branches. The ascending branches connect with the principal vestibular nucleus (Fig. 427), a mass of grey matter situated just external to the nucleus of Deiters, with whieh it makes intimate connection by means of collaterals. The descending fibres end in the descending vestibular nucleus, which lies below the prineipal nucleus. Many fibres of the vestibular. nerve pass directly by way of the restiform body to the roof nuclei of the cerebellum.

The seventh nerve is mainly motor in function. It arises from a group of eells - the seventh nucleus-whieh lies in the reeticular formation just below and somewhat external to the nucleus of the sixth nerve. The fibres pursue a somewhat devious course inside the pons. At first they pass inwards towards the middle line; then dorsally towards the floor, and upwards to a slightly higher level of the pons; then, encircling the sixth nucleus, they turn outwards, and emerge from the lateral margin of the pons (Fig. 428). The fibres supply 
the museles of expression of the face. Paralysis of the nerve learls to a charaeteristic "facies"-an expressionless, vacant look. In addition, the stapedius musele of the ear and certain muscles of the scalp are also supplied.

Certain afferent fibres belonging to the nerve of Wrisberg also run in the seventh nerve. Their eell-station is in the genieulate ganglion. The fibres passing inwards from the ganglion divide into ascending and descending branehes, the latter eonnecting with the ninth nucleus. Peripherally, the fibres pass into the large superfieial petrosal nerve and the elorda tympani nerve, and thence to the fifth nerve, furnishing the sensation of taste to the anterior two-thirds of the tongue. From the nerve of Wrisberg also eome secretory fibres which go to supply the submaxillary and sublingual glands through the chorda tympani nerve.

The sixth nerve arises from a group of eells situated on either side of the middle line just below the floor of the upper part of the fourth ventricle (Fig. 428). The fibres form the motor nerve to the external rectus muscle of the eyeball. From the sixth nueleus other fibres aseend in the posterior longitudinal bundle, to emerge with the third nerve and supply the internal rectus muscle. The oculo-motor nerres, sixth, fourth, and third, contain musels-sense fibres, the ganglion eclls of whieh are to be found in the nerve trunks.

The fifth or trigeminal nerve has three nuelei in the medulla: one connected with the central eonneetions of the sensory cells of the Gasserian ganglion-the prineipal sensory nueleus of the fifth; and two eonnected with the motor functions of the nerve-the ehief and the accessory motor nuclei (Fig. 429). The afferent fibres of the nerve enter the pons, and bifurcate into asecnding and descending branehes, The aseending pass to the prineipal sensory nueleus, whieh lies just laterally to the principal motor nucleus. The eells of this nuclens give rise to fibres nost of whieh eross the middle line and pass in the mesial fillet, to end in the optie thalamus. Some fibres ascend in the mesial fillet of the same side. The deseending fibres form a wellmarked tract, which deseend in the reticular formation (the descending branch of the fifth) into the eervical part of the spinal eord. In its eourse it forms conneetions with the motor nuclei of the pons and medulla. It lies in elose association with the substantia gelatinosa Rolandi.

The nerve aets as the nerve of eommon sensation to the face, eyeball, nose, and mouth. The fibres eomected with the gustatory nerve-endings: in the anterior two-thirds of the tongue rum in this nerve.

The motor fibres, whieh form but a small part of the nerve, arise chiefly from the principal motor nueleus, whieh is situated laterally below the floor of the fourth ventriele (Fig. 429). Some arise from the aecessory nucleus, whieh is situated higher in the pons, and in part in the mid-brain (see Fig. 429). The fibres are motor to the muscles of mastication, the tensor palati, the tensor tympani, and the anterior belly of the digastrie museles. 


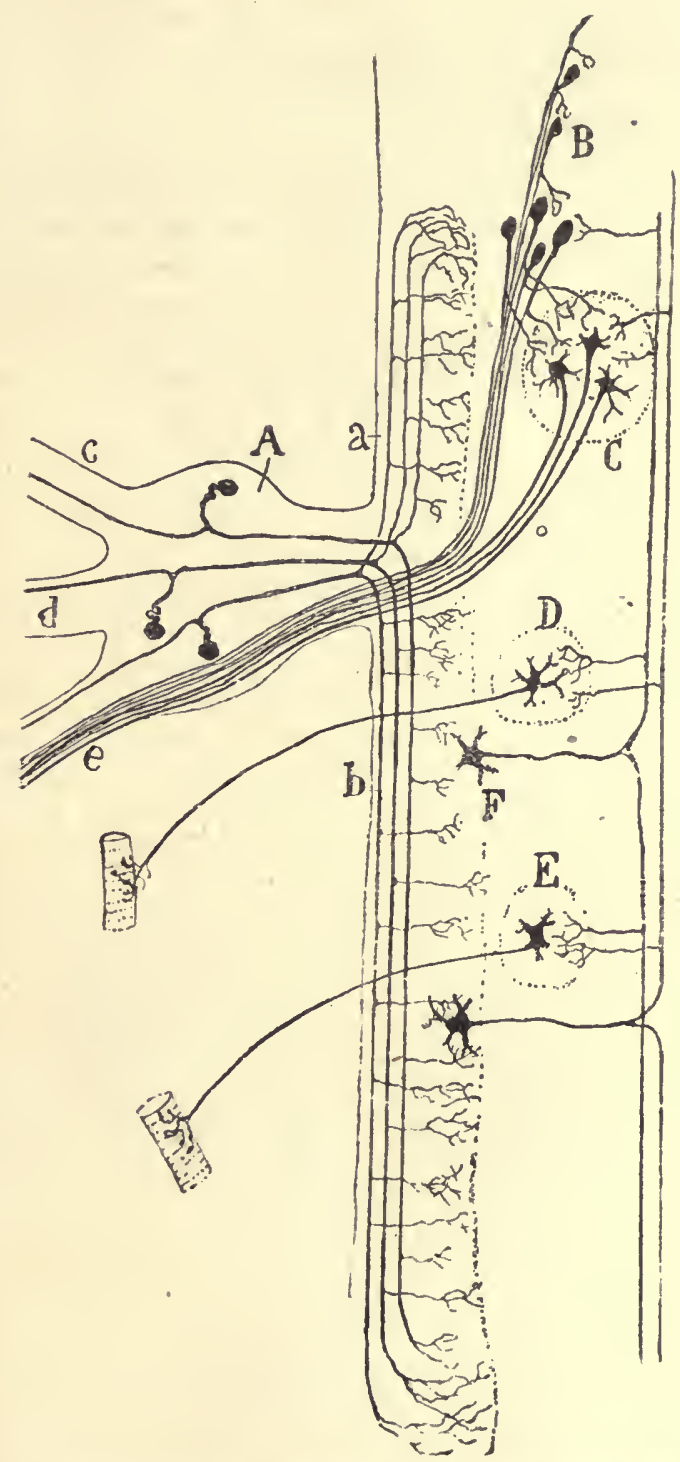

Fio. 429.-Plan of the Ohigr axd Relatioss of tife hifru Nekve. (Cajal, from "Quain's Anatomy.")

$A$, Gasserian ganglion; $B$, accessory motor nucleus; $C$, main nucleus; $D$, screnth nucleus; $E$, twelfth nucleus; $F$. sensory nucleus of fifth; $G$, cerebral trace of fifth; $a$, ascending branches; $b$, descending branches of sensory root-fibres; $c, d, e$, ophthalmic, maxillary, and mandibular branches of fifth. 


\section{SECTION II}

\section{THE CEREBELLUM}

The Structure of the Cerebellum.-The little brain, or cerebellum, consists of a middle lobe, or vermis, and two lateral hemispheres. Its surface is thrown into many folds, which in section give it a treelike appearance - the arbor vitæ. The organ consists of a grey cortex, and white matter within. In the latter, near the middle line, are

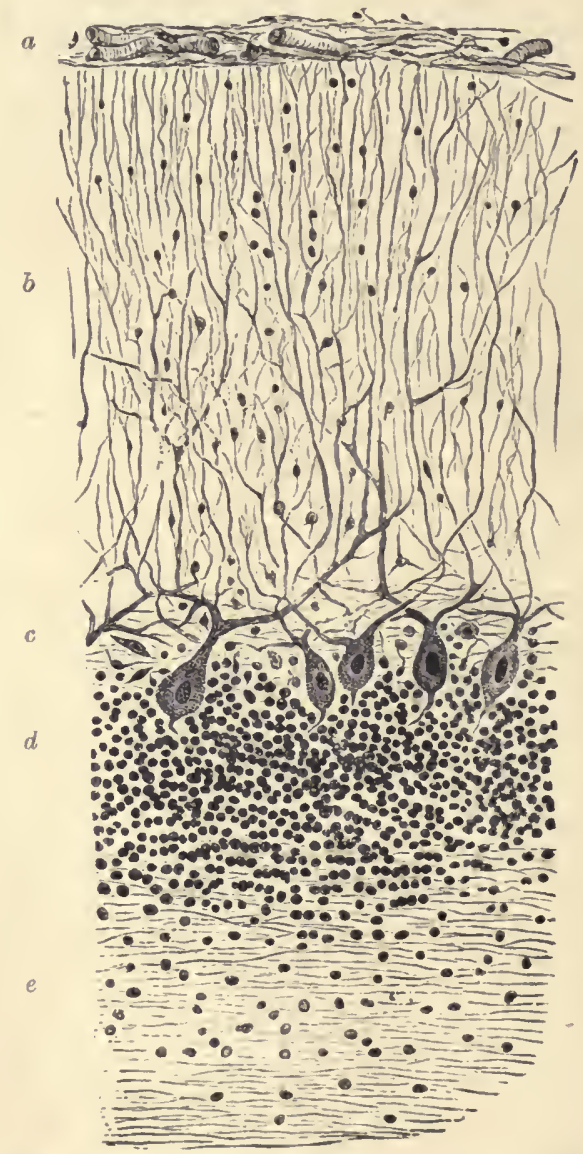

Fia. 430.-Sectiox of Cerebelati Cortex. (Sankey, from "Quain's Anatomy.")

$a$, Pia mater; $b$, molecular layer; $c$, cells of Pur'inje; $d$, granule layer; $e$, white eentre.

ganglia of grey matter-the roof nuclei-and in the middle of each lateral lobe the dentate nuclei. It is from these nuclei that the axons which leave the cerebellum arise 
In a section of the cerebellar cortex three layers are to be distinguished, the most characteristic of which is the one in the middle, in which occur the flask-shaped cells of Purkinje (see Fig. 430).

The apical dendrites of these cells ramify in the external layer, while the efferent axon passes down internally into the central layer of white matter. Afferent tendril fibres aborize round these cells.

External to the Purkinje cell layer is the outer molecular layer, which consists of irregular star-shaped cells, neuroglial cells, and the dendrites of the Purkinje cells. The axon of the star-shaped cell runs parallel to the layer for a certain distance, and then turns down to arborize around the Purkinje cells.

Internal to the Purkinje cell layer is the nuclear layer, or inner molecular layer, therein afferent fibres-the so-called moss fibresarborize, forming curious mossy-like figures. In this layer are small star-shaped cells, irregular cells of Golgi, and neuroglial cells.

The underlying white matter is composed of the afferent axons of the tendril and moss fibres, and the efferent processes of the Purkinje cells.

The cerebellum is connected to the brain-stem by three pairs of peduncles: The inferior, or restiform body, to the medulla; the middle to the pons; the superior to the mid-brain. It is by these thrce sets of channels that it receives messages from, and sends messages to, the other parts of the central nervous system. The conneetions of the cerebellum may be tabulated as follows:

Afferent Fibres to the Cerebellum.-From spinal cord-(1) By the dorsal spino-cerebellar tract (direct cerebellar tract of Flechsig) to the lower part of the vermis; (2) by the ventral spino-cerebellar tract (antero-lateral ascending of Gowers) to the upper part of the vermis by the superior peduncle.

From the medulla by the inferior peduncle-(1) To the vermis by the internal arcuate fibres of the gracile and cuneate nuclei of the same side;.(2) to the vermis by the external arcuate fibres from the gracile and cuneate nuclei of the opposite side; $(3)$ to the vermis from the inferior olive, chiefly of the opposite side; $(4)$ to the vermis by fibres from Deiters' nucleus, and directly from ganglia of the vestibular nerve.

From the pons to the lateral hemisphere by the terminal neurons in the connection between cerebrum and cerebellum. These arise from the nucleus pont is of the opposite side, around which the corticopontine fibres terminate, and pass by way of the middle peduncle.

From the mid-brain, optic thalamus, and cerebral cortex, on the opposite side by way of the superior peduncle.

Efferent Fibres from the Cerebellum.-Fibres gather from all parts of the cerebellum to the roof and dentate nuclei and pass thence(1) In the inferior peduncle to Deiters' nucleus, and thence to the cord by the vestibulo-spinal tract; also upwards to the sixth and third nerves, and downwards to the cord in the posterior longi- 


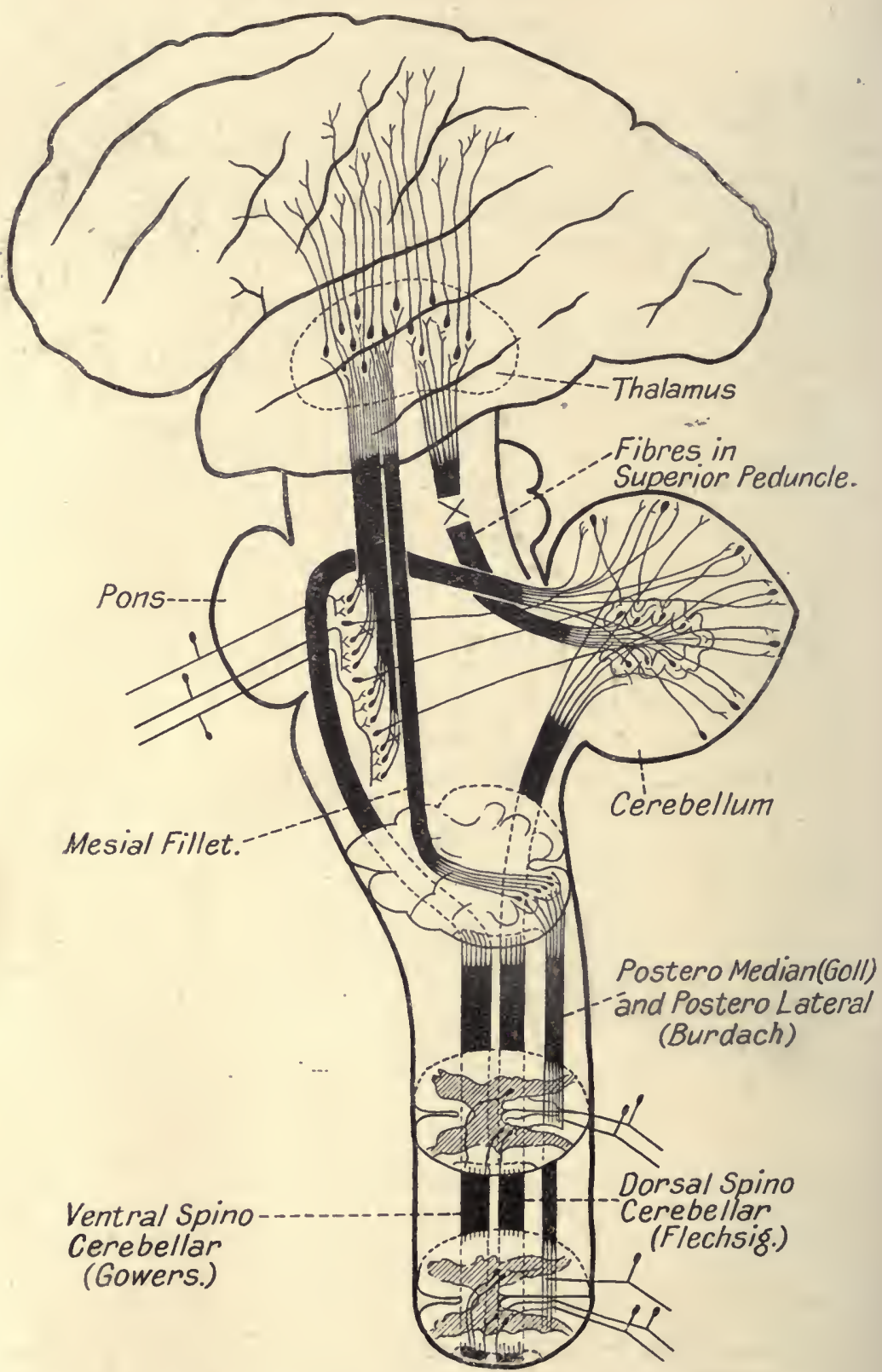

Fig. 431.-Diagram of the Spino-Cermbellar, Olivo-Tiegmental, Cfirlibilo. Tegmental, Ponto-Tfgmental, axd Ponto-Cerenellal Tracts. (Redrain after Van Gehuchten.) 
tudinal bundle; (2) in the middle peduncle to the nucleus pontis of the opposite side; (3) in the superior peduncle to the red nucleus, superior corpus quadrigeminum, and third nucleus and optic thalamus of the opposite side (the first neuron of the cerebello-cerebral path).

The Functions of the Cerebellum.-The cerebellum was credited by Gall, the founder of phrenology, with the control of the organs of generation. To this day the bump of philoprogenitiveness is placed in the skull above the cerebellum. We now know that the cerebellum has nothing whatever to do with this function.

Comparative anatomy indicates the chief function of the cerebellum. In a variety of skate which lies at the bottom of the sea, and practically does not move, the cerebellum is almost absent; in the common variety, which swims about in search of food, it is well marked. All strong-swimming fish and hard-flying birds have a welldeveloped ccrebellum. The cerebellum is therefore indicated as the coordinating cantre for muscular movements, especiatly for those of equilibration. When half the cerebellum is cut away, the animal is at first quite unable to stand, any attempt to do so causing it to fall to the side of the lesion. There is only slight loss of power of the muscles (asthenia), but marked loss of tone (atonia). After a week or two it recovers the power to stand, although the limbs droop owing to the loss of power and tone; but its power of equilibration is so imperfect that-in walking the limbs have to be widely abducted in order to correct the tendency to fall to the side of the lesion. The contractions of the muscles during such a purposive movement are attended by tremors (astasia). If such an animal be excited, it will fall toward the side of the lesion, and turn completely over. This is particularly well seen in monkeys. After some weeks the symptoms disappear. This is due to a cerebral compensation. Destruction of the cerebral cortex of the opposite side leads to a reappearance of the symptoms. It takes a much longer time to recover from extirpation of the whole cerebellum, and even then the mode of progression is not normal. Owing to the fear of falling during diagonal movements, the animal performs galloping movements with the limbs wide apart. This ataxia presents marked difference from the high-stepping ataxia due to overaction of the muscles in spinal lesions.

In man, lesions of the cerebellum may, or may not, show symptoms according to the rapidity of onset. When symptoms are present, there is the staggering ataxia, the marked tremors, and, if placed on all fours, the tendency to turn over on the side of the lesion. In many cases, however, where a ccrebellar tumour has bcen found after death, there have been no marked symptoms, owing probably to the concomitant acquirement of cercbral control.

Stimulation experiments have also been conducted upon the cerebellar cortex. This is difficult to excite, but thus far the experiments indicate that the roof nuclei are particularly concerned in the novements of the eyes and head, the lateral nuclei with the movements of the trunk and limbs. 
The eerebellum is therefore to be regarded as the ehicf centre for the museular eo-ordination and adjustment neeessary for the equilibration of the body. It receives its ehief impressions from the proprio-ceptive mechanisms of the head and body, the receptor meehanisms, the semieireular eanals, and the museles, joints, and tendons, and also from the retinæ. Normally, these are in aeeord with the impulses from the eye. If, however, they are not, then giddiness results, as illustrated by the ehildren's game already mentioned, in whieh tle subject, after walking round several times with the forehead on a poker, stands upright and attempts to walk straight. The resultant loss of balanee is due to the eonfliet between the semieireular canals, which give a sense of rotation in the opposite direetion, and the eyes, whieh afford no evidenee of any sueh rotation. The giddiness experienced in looking down from great heights is also well known. The importanee of the eyes is also seen in the ataxia whieh results from lesions of the posterior eolumns of the eord affecting the kinæsthetic mechanisms of the limbs. A patient suffering from sueh ataxia balances well so long as his eyes are open. If these be elosed the power to equilibrate ceases. Should sueh a person elose his eyes while bending over a basin of water to wash his faee, he will fall forward into the basin. Such an incident is in some cases the first sign of the spinal lesions.

The cerebellum effects its eontrol over the museles coneerned in equilibration through the eerebrum of the opposite side, and through the eranial nuclei and anterior horn cells of the cord.

\section{Section III}

\section{THE MESENCEPHALON, OR MID-BRAIN}

THE mid-brain may be looked upon as being chiefly made up of four perluncles-the two cerebral and the two superior cerebellar peduncles. Superimposed upon the two latter are the anterior and posterior quadrigeminal bodies, two on either side. Through the mid-brain runs the aqueduet of Sylvius, conneeting the fourth ventricle to the third rentricle of the great brain.

In seetion, a blaek pigmented zone on either side-the substantia nigra-divides off an anterior part, or crusta, from a posterior part, or tegmentum. The erusta eonsists principally of efferent fibres from the eerebral cortex. In the eentre are sitnated the pyramicial fibres, on either side the fibres passing from the cortex to the nuelei pontis and eerebellum-the fronto-pontine and oeeipito-pontine fibres.

In the tegmentum run the afferent traets, the mesial fillet to the optic thalamus, the lateral fillet to the inferior eorpora quadrigemina, and the fibres whieh pass to and from the eerebellum by means of the superior peduncles. In it are also situated masses of grey matter - (1) the red nuclei; (2) the nuclei of the fourth and third eranial nerves. 
The red nuclei are so called on account of the colour they present to the naked eye on section of the mid-brain. They are situated centrally, just on either side of the middle linc. The nuclei form intimate eonnection with the fibres of the superior cerebellar peduncles, and with fibres from the optic thalamus and cerebral cortex. Its cells give origin to the rubro-spinal tract (Monakow's bundle, or the prepsramidal tract). The fibros of this tract almost immediately

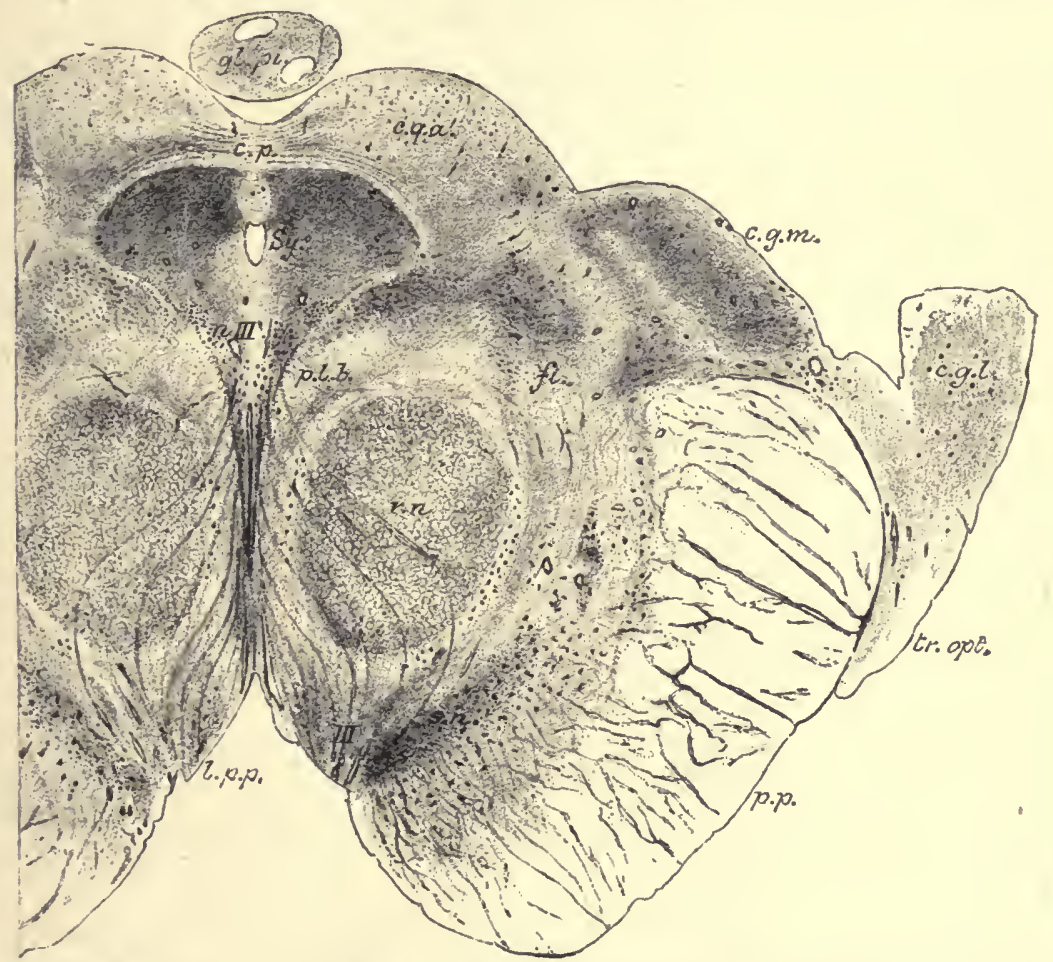

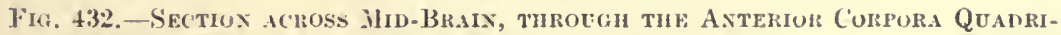
araina. Photograph magnififd abott 31 Diameters. (1\%. A. Schäf $x$, from "Quain's Anatolly.")

sy., Aqueluct of Sylvius; c.p., josterior commissure; gl.pi., pineal gland; c.q.a., an. terior corpus quadrige.ninum; c.g.m., interaal geniculato body; c.g.l., lateral geniculatc body: tr.opt., optic tract; p.p.., pes; p.l.b., posterior longitudinal bundle; fi., upjer fille; $r . n$., ret nucleus; $n . I I I$., nucle ss of third narve; $I I I$., issuing fibre; of third nerve; l.p.p., locus perfora us posticus.

cross, forming what is known as Forel's decussation, and pass down through the pons and medulla to occupy a position in the cord just anterior (prepyramidal) to the crossed pyramidal tract. Eventually, they terminate around the cells of the anterior horn. From cells in the roof of the mid-brain arise the fibres of the tecto-spinal tract, which cross the mid-line forming the fountain decussation of Meynert, and then pass into the anterior longitudinal bundle. 
The Cranial Nuclei. - The nucleus of the fourth nerve lies close to the middle line in the lower part of the mid-brain. The fibres arising from it pass dorsally outwards, decussating in their course just above the aqueduct of Sylvius. The fourth nerve is effector in function, supplying motor fibres to the-superior oblique muscle of the eye. This muscle, acting in conjunction with the inferior rectus, enables the eye to look directly downwards. It is to be noted that the left muscle is supplied by fibres from the right side of the mid-brain.

The nucleus of the third nerve lies in the upper part of the mid-brain in a central position just ventrally on either side to the aqueduct of Sylvius. Its fibres pass ventrally outwards, and go to supply all the muscles of the eyeball except the superior oblique and the external rectus. An intimate communication is established with the fourth and sixth cranial nuclei by means of the posterior longitudinal bundle. It is suggested that some fibres from the sixth nuclei run in this bundle to the third nuclei, and enter into the formation of the third nerves. This is particularly suggested for the fibres supplying the internal recti-the antagonizers of the external recti muscles supplied by the sixth nerve.

The Inferior Corpora Quadrigemina are masses of white matter, in the centre of which are contained nerve-cells, around which end fibres of the lateral fillet. These fibres are connected with the auditory nuclei; the inferior corpora quadrigemina are to be regarded as cellstations in connection with hearing.

The Superior Corpora Quadrigemina are likewise made up of white matter and groups of nerve-cells. They are to be regarded as important cell-stations in connection with vision, in particular in connection with the regulation of eye movements. Around the cells end fibres from the optic tract, and also from the lateral fillet. From its cells arise fibres which pass to the nuclei of the third nerve, and downwards in the posterior longitudinal bundle-probably to the sixth and serenth nerve.

The Geniculate Bodies.-In close association with the quadrigeminal bodies are the geniculate bodies, of which there are two pairs - the external and internal. They are small, elevated masses of nerve-fibres and nerve-cells. Around the cells of the external bodies end fibres from the optic tract, while from its cells arise fibres which pass as the optic radiation to the occipital part of the cerebral cortex concerned in vision. The external bodies are therefore important cell-stations in connection with sight.

The internal bodies are concerncd with hcaring. Around the cells terminate the fibres of the lateral fillet from the auditory nuclei. The cells give rise to the auditory radiations, which pass to the temporal region of the cortex. The two internal geniculate bodies are connccted with each other by v. Gudden's commissure, which runs in the posterior part of the optic tract.

Passing upwards, the brain-stem enters into association on either side with three masses of grey matter-the optic thalamus and the 
caudate and lenticular nuclei. The thalamus is the representative of the thalamencephalon of the primitive brain; the caudate and lenticular nuclei, of the old brain, or archipallium. Alternating with these nuclei of grey matter are strands of white matter; hence the name of corpus striatum given to the whole. The relationship of these structures is seen in Fig. 433.

Of importance are the fibres which constitute the internal capsule the tract of white fibres running anteriorly between the caudate and

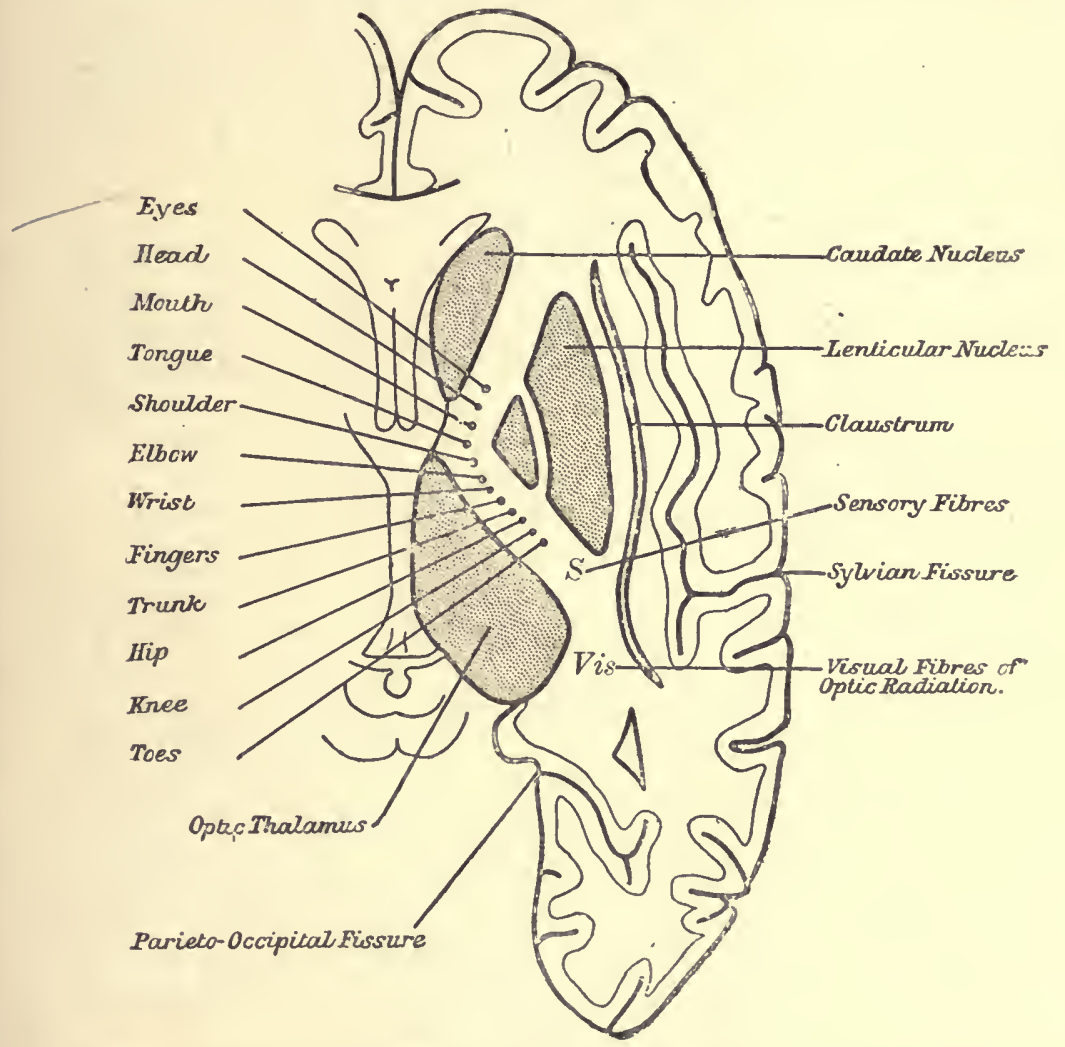

Fig. 433.-Horizoytat. Section throdgit Right Cerebral Hemispherf, showixg Position of 'she Various Strands ix the Internal. Ca psule. (l'urves Stewart, after Beevor and Horslcy.)

lenticular nuclei, and posteriorly between the thalamus and the lenticular nucleus. Through this capsule swcep the fibres to and from the various regions of the cerebral cortex. In the front part of the anterior limb run fibres connceting the frontal cortex with the pons and cercbellum (the fronto-pontine fibres), and fibres from the thalamus to the frontal cortex (the thalamo-frontal fibres). In the neighbourhood of the knce, or genu, of the capsule, run efferent motor fibres from the cortcx. In the posterior part of the anterior 
limb run fibres eonnected with movements of the head and eyes; in the genu with the movements of the tongue and mouth; in the anterior two-thirds of the posterior limb the fibres whieh go to form the pyramidal tract in the following order from before backwards: shoulder, elbow, wrist, fingers, trunk, knee, toes (Fig. 433).

In the posterior part of the posterior limb of the cepsule rum fibres from the occipital cortex to the pons and cercbellum (the occipito-pontine fibres), and in front of and behind these other fibres, known respectively as the auditory and optic radiations, connceted with the sensory cortical areas for hearing and sight. The fibres of the auditory radiation pass from the inferior corpus quadrigeminum and internal geniculate body to the temporo-sphenoidal lobe of the brain; those of the occipital radiation from the optic thalamus and external geniculate body to the occipital cortex.

The Optic Thalamus consists of a mass of white and grey matter situated to the inner side and below the floor of the third ventricle of the brain. It receives fibres from-(1) the cuneate and gracilc nuclei of the opposite side by the mesial fillet; (2) the opposite dentate nuclei of the cerebellum by the superior cerebellar peduncles; (3) the retina by the optic tract; (4) the cortex of the same side. Its cells give rise to fibres which pass-(1) to the cortex as the last link of the great sensory chain to the motor area of the cerebral cortex; (2) to the part of the cortex concerned in vision; (3) to fibres which run in the rubro-spinal tract to the cord.

The Function of the Thalamus. - The nature of the function of the thalamus has been adduced chiefly as the result of the clinical evidence obtained from diseases of this part of the brain. In a lesion of the thalamus there is persistent loss of superficial sensation, touch, pain, and tempcrature of half the body. There is also marked loss of deep sensation and acute pains on the affected side. There may be more or less eomplete want of knowledge of structure and form in the sense of touch (astereognosis). There is but little affection of the motor system. There may be slight ataxy on the affected side, or a partial hemiplegia, which quickly passes off. There may be "choreic" and "athetotic" (twirling) movements of the affected side. These, lowever, are not due to the thalamus: only sensory affections are caused by thalamic lesions.

From the clinical evidence which has accumulated, it seems fairly ccrtain that the impulses which pass up the posterior columns of the cord to the gracile and cuneate uuclei are so rearranged during their passage up the mesial fillet to the thalamus that the fibres eonnceted with each kind of cutaneous sensation arborize round definite groups of cells within the thalamus, whence other axons arising in these groups convey the impulses to cortical areas. The thalamus is therefore a great scnsory centrc. It responds to all stimuli capable of evoking either pleasure and pain (fceling tone) or eonseiousness of a change in state. The feeling tonc of somatic or visceral sensation is the product of thalamic activity, and the fact that a sensation is devoid of feeling tone shows that the impulses which underlie its 


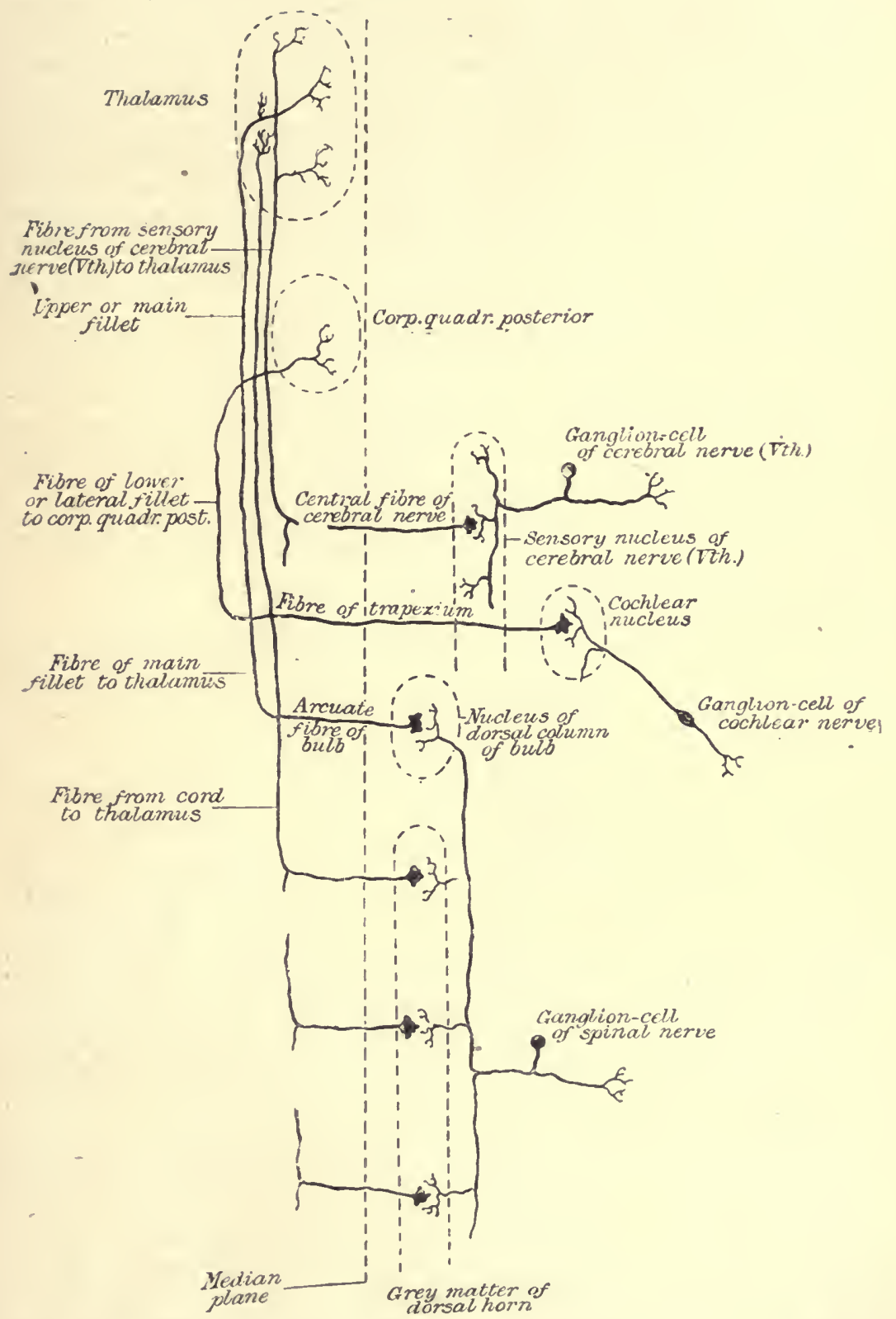

Fig, 434.-Diagran of Sexsory Path from Peripherai Nerve to Corpora Quadricemixa axd Thalauds. (E. A. Sehäfer, from "Quain's Anatomy.") 
production make no thalamic appeal. Most sensations in patients. with a thalamic lesion are of painful quality. One patient, for instance, could not bear the singing of hymns. It produced unpleasant sensations on his affected side, "and during the singing he rubbed his affected hand." Another patient, during the scraping of his palm on the affected side, said: "It is a horrid sensation. It feels as if my hand were covered with spikes, and you were running them in. It is not painful, but very unpleasant." Another highly educated patient said: "I crave to place my right hand [the affected one] on the soft skin of a woman. It's my right hand that wants the consolation. I seem to crave for sympathy on my right side. My right. hand seems to be more artistic."

Thalamic stimulations have a high threshold value. Stimuli of low intensity arouse the sensory cortex, which is quick in reaction and controls the thalamic centre. The aim of evolution is the domination of feeling and instinct by discriminating mental activities. The

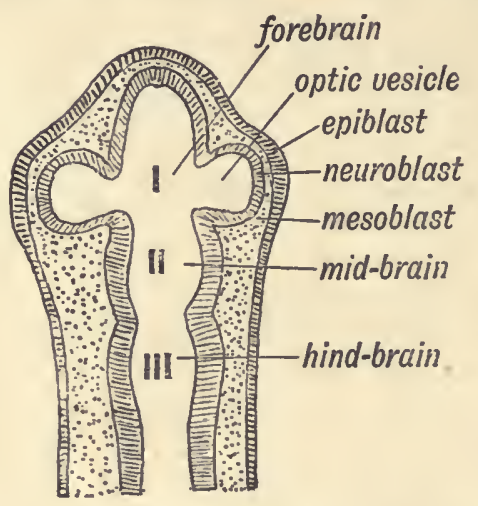

Fio. 435.-Diagray of the Llffyexts Which form the Evebald. (Kíeith.)

sensory cortex cerebri is an organ by which attention can be concentrated on any part of the body that is stimulated. The focus of attention being arrested, the stimuli from this part are sorted out in the cortex, and brought into relation with their sensory processes, past or present. The thalamus is aroused by impulses of affective activity. It refuses to react to those which underlie the purely discriminative aspects of sensation. Long latency, persistent character, and freedom from control mark the thalamus sensations when acting by themselves.

The Paths concerned in Vision-The Visual Tract.-The optic nerve is an outgrowth of the brain (Fig. 436). It consists in the main of afferent fibres coming from the retina. The study of the degenerations which follow its section shows that there are also some fibres running in the nerve from the brain to the eye. Degenerative changes are found in the other optic nerve, indicating that fibres pass from one retina to the other through the optic chiasma, where the two optic nerves 
meet. From the optic chiasma the optic tracts pass backwards to form connections on either side with the external geniculate body, the optic thalamus, and the superior corpus quadrigeminum. A band of fibres, known as v. Gudden's commissure, passes posteriorly in the chiasma, connecting the two internal geniculate bodies. These fibres are not connected with vision, but are probably concerned in some way with the process of hearing.

The inner fibres of each optic nerve decussate in the chiasma in such a way that the fibres of the nasal half of each retina pass to the tract of the opposite side, while the fibres of the temporal part of each

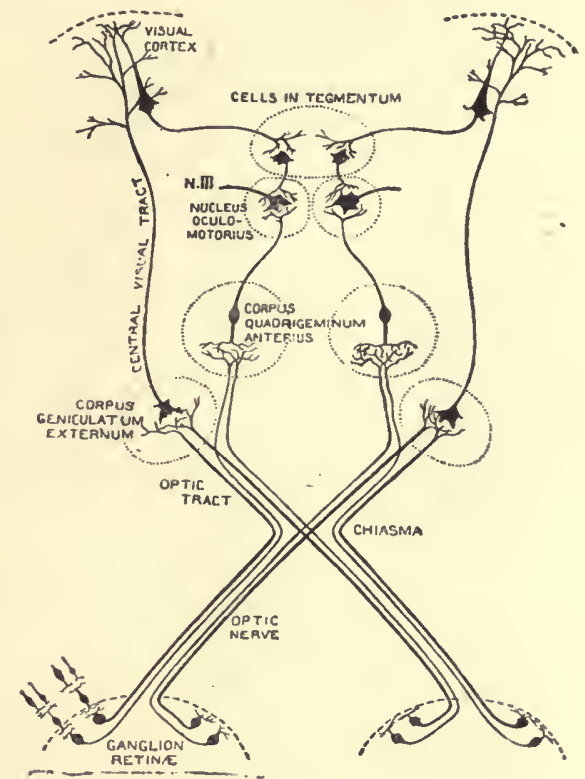

Fig. 436.-Diagran to show the Probarle Course and Refations of the Optic F18Res. (From "Quain's Anatomy.")

To simplify the diagram, only single neurons are represented as enntinuing the two nourons from the reinre in the geniculate and quadrigeminal bodies of exch side with the visual cortex. This must not be taken to imply that the retinal impressions from the two retinæ are fused in these intermedinte nuclei.

retina pass to the same side of the brain. It is stated that in man the fibres coming from the macular region of the retina bifurcate, and pass to the external geniculate bodies of both sides of the brain.

From the cells of the thalamus and external geniculato body arises the optic radiation, which passes through the posterior portion of the internal capsule to the occipital cortex, to end in the neighbourhood of the calcarine fissure. This is the tract concerned in vision.

From the superior corpus quadrigeminum connection is made with the nuclei of the muscles concerned in the movements of the eyes. Fibres pass in the posterior longitudinal bundle to the third, 
fourth, and sixth nuclei. The superior corpus quadrigeminum is to be regarded as the co-ordinating centre for eye movements. It is intimately related with the chicf centre of co-ordination-the crebellum.

In mammals, the development of the optic connections is measured by the importance of vision to the animal. The squirrel requires accurate vision, and has large optic nerves and well-developed anterior corpora quadrigemina. In the rabbit and the hare, a wide panoramic vision, together with an acute sense of hearing, is necessary to escape capture. The eyes are placed laterally, and the fibres of the optic nerve cross almost completely.

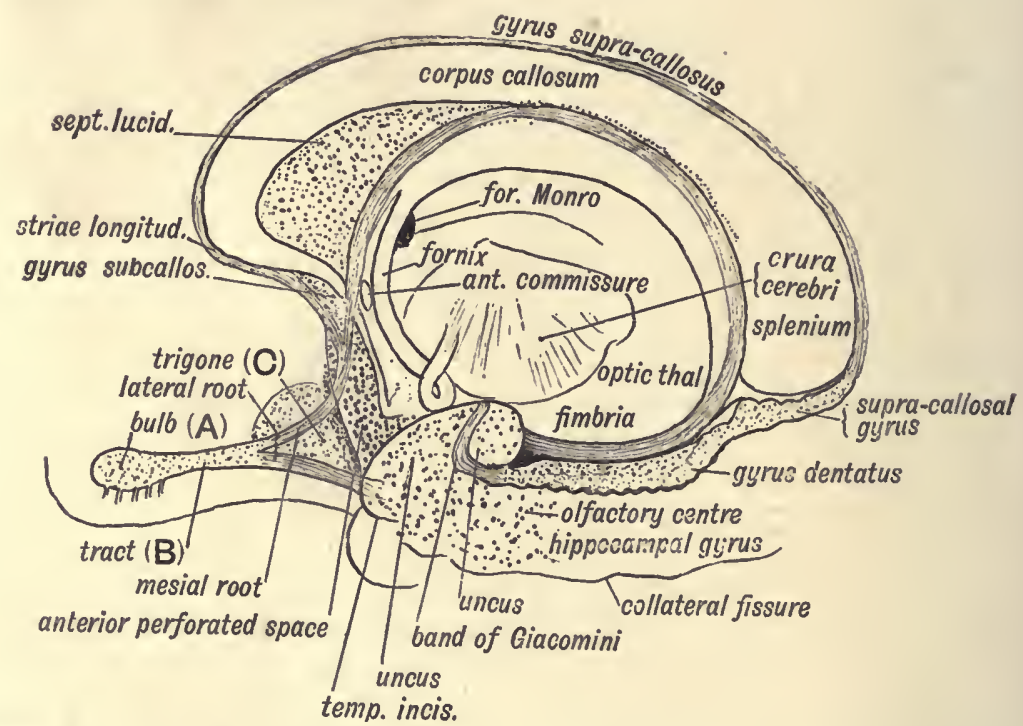

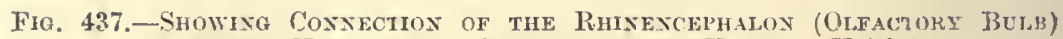
With the Hippocanpat Gyrus axd the Uxces. (Keith.)

In birds, the optic chiasma is single and complete. The fibres from each nerve interlace and alternate, but eventually all pass to the opposite side around the optic thalami to well-developed geniculate bodies. The optic lobes are well marked in birds of prey. Vision is as a rule panoramic, one cye for each side. In owls and hawks, which possess a considerable amount of binocular vision, it is probable that all the fibres decussate, so that the vision, although being binocular, is not stereoscopic. In fishes, the optic nerves cross completcly, and pass to the opposite optic lobe.

The effect of injury to the visual tract in man differs according to the site of the lesion. Section of the optic nerve causes total blindness in the corresponding eye. A median section of the optic chiasma brings about blindness in the nasal halves of both retinæ, inducing a hemianopia in the outer ficlds of vision of both eyes. Section of the optic 
tract eauses blinduess in the temporal half of the retina of the same side, and of the nasal half of the retina of the opposite side, resulting in blindness in the field of vision of the opposite side to the lesion.

A lesion of the optic radiation in the internal capsule results in a corresponding loss of vision - a hemianopia of the opposite side. It can be diagnosed from a lesion of the tract by the fact that rays of light thrown upon that part of the retina in which vision is lost, cause a reaction of the pupils to light, since the reflex arc is intact. When the tract is damaged, this reflex is abolished. as the reflex are for light is broken. Moreover, a lesion of the optic radiation is also associated with the effects due to damage of other tracts of the internal capsule, such as loss of sensation and movement in the opposite half of the body.

A lesion of the carebral cortex in the occipital region also induces a hemianopia of the opposite side, in which the light reflex is preserved, but it is not associated with hemianæsthesia or hemiplegia. In this case, the psychical processes in connection with vision are interfered with.

The Caudate and Lenticular Nuclei.-The functions of these nuclei are not yet well ascertained. Being parts of the archipallium, or old brain, they are possibly associated with "instinctive" mental processes.

The Paths in Connection with the Sense of Smell.-In many of the lower animals the sense of smell is of great importance, and the part of the brain concerned in the sensation of smell is highly developed, and known as the rhinencephalon. While the forebrain owes its evolution to this sense, in higher animals it becomes of less importance. The non-medullated processes of the receptor olfactory cells pass through the cribriform plate of the skull, to end in the olfactory lobe. Each process forms an olfactory glomerulus by interlacing with an arborizing dendritc coming from one of the "mitral" cells of the olfactory lobe. The axons of the initral cells pass backwards in the olfactory tract. This divides the mesial root, passing inwards to end around the part of the brain known as the callosal gyrus, and also to make connection with the uncus of the opposite side. The exact connections of the lateral root are difficult to follow, but it makes connections eventually with the uncus of the hippocampal gyrus of the cortex (see Fig. 437) and with the thalamus. Fibres conecrned in the sense of smell pass in the anterior commissure of the brain, comnecting the region of the uncus of the two sides. The fornix is a commissure connecting the hippocampal gyrus and the thalamus. 


\section{Section IV \\ THE FUNCTIONS OF THE CEREBRUM}

The Cerebral Hemispheres.-The cerebral hemispheres are the latest outgrowths of the brain to be developed, and are particularly well developed in the higher apes and man. Particularly is, this the case in man, where the cerebral hemispheres reach a large size and become much convoluted. The convolutions are marked off by fissures and sulci.

The great development of the brain of man is seen from the following figures:

\section{\begin{tabular}{c|c} 
Brain Weight. $\quad$ Body Weight. & Ratio of Brain to \\
Body Weight.
\end{tabular}}

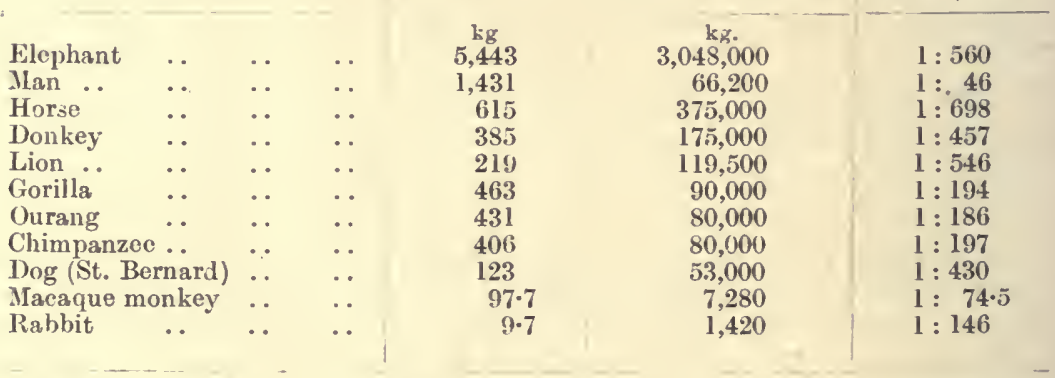

Man's brain is only surpassed in weight by that of the whale and the elephant. It is markedly heavier than that of the primates. Although this indicates man's great intellectual development, mere weight of brain is not in itself everything. One of the heaviest brains on record belonged to a bricklayer. But many great men have had brains decidedly above the average in weight. Byron's brain weighed 2,238 grammes, Cromwell's 2,233 grammes, Cuvier's 1,830 grammes. Many eminent men, however, have not had such exceptionally' heavy brains. Helmholtz's brain weighed 1,430 grammes, Gauss's brain 1,492 grammes. The depths of the convolutions rather than the absolute weight appears to be of importance.

The Functions of the Cerebrum.-The functions of the cerebrum have been elucidated by studying the effect of its removal or partial removal. This varies with the status of the animal in the evolutionary scale. Thus, in the early experiments on this point it was found that in a bony or teleostean fish the effect of removal of the forebrain was scarcely apparent; such a fish immediately seized and swallowed a worm when thrown near it. The fish either did not touch or, if seized, did not swallow a skein of thread of about the dimensions of the worm. When thrown one red and four white. wafers, the red was regularly devoured first. The fish would follow a worm held in the forceps, but would not attempt to swallow it. 
When the worm was attaehed to a thread, and the observer retired from view, the fish swallowed both worm and thread. The fish also apparently "played" in normal fashion with fish whieh had not been operated upon. These fish depend mainly upon vision for their aetivities, and in the operation the optie lobes are not destroyed,

In selachean or eartilaginous fishes, sueh as the shark, the result. was different. These fish depend largely upon the sense of smell, and in them the proseneephalon is represented almost entirely by the primitive rhinencephalon, or smell-brain. Thus, when sardines were thrown into an aquarium, the teleostea immediately seized their booty, the selaehea gradually approached in circles. When, in selachea, the olfaetory lobes, the representatives of the cerebrum, were taken away, the fish was redueed from a state of activity to one of eomplete quiescenee.

In the frog, after removal of the cerebral hemispheres, the animal appears at first sight quite normal. It sits in normal fashion, jumps when pinehed, and starts swimming after stimulation just as quickly as the normal animal. It will catch its food as normally, but shows no power of differentiating between what is food and what is not: It will snap at anything moving like a fly.

In lizards, the loss of spontaneity is marked; the animals lie about as if sleeping. When roused, they just move away. The movements are normal, obstaeles are avoided, but the animal does not feed spontaneously, and exhibits no fear, as does the normal animal.

In birds, sueh as pigeons, the results are somewhat similar to those on reptiles. The bird ean balanee itself, and, when thrown in the air, can fly, avoiding obstacles. When undisturbed, it remains still, sleepy and motionless. It does not feed of itself, and manifests no feelings of any sort. It was observed that a brainless female pigeon responded in no way to the wooing of a male, nor showed any affection or interest in the young which followed her, crying aloud for food. It would push another pigeon out of the way, as if it were a stone, or climb over it. It had no fear of anything-e.g., cat or dog; it knew neither friend nor foe. The eerebral proeesses of birds are loealized chiefly in a great development of the eorpus striatum; in mammals, on the other hand, they are more particularly dependent on the great development of the eerebral hemispheres.

In mammals, the operation of removal of the cerebrum is one of considerable diffieulty, and has only bcen suceessfully performed by removing the brain pieeemeal in sueeessive opcrations. It has been done by several observers, ehiefly upon dogs, but also upon apes. In the ease of a dog whieh remained healthy after the final operation, and was killed at the end of eighteen months, it was found post mortem that, of the eerobral hemispheres, only such traces had becn left as were necessary to preserve the optic nerves from injury by tho operation. This, however, was sueeessful only on the right side; on the left side the nerve had atrophied. The optie thalami were not injured by the operation, although the grey matter of the anterior part was found to be atrophied. 
After recovering from the operation, the animal snapped at food and licked milk when it was bronght right against its mouth. It took no notice of another dog or of a "strong-smelling " cat held in front of its nose. Taste was preserved; meat soaked in quinine was rejected with signs of anger. Tasty morsels, however, were eagerly devoured. After a good meal it curled up and slept like an ordinary dog, but never showed any signs of dreaming. Sleep generally was of shorter duration than normal. It could only be awakened by very loud noises, such as the notes of a fog-horn; it then moved its ears and made pawing morements at them. The animal could also be awakened by blowing tobacco-smoke into its nose-an act which sometimes caused sneezing. A strong light on the eyes sometimes cansed it to turn the head away, but men and animals were not reeognized. The pupils reacted to light normally". Threatening noises had no effect. Co-ordination of muscles was retained, and, when one foot was injured, it could walk on three legs. There was always, however, some muscular weakness, especially of the hind-quarters. The animal never showed any signs of joy or pleasure, but signs of rage when the cage was touched. It showed no signs of purposive movement, and was always but " a child of the moment." Its tone feeling was due to the preservation of the thalamus. After ligation of all four cerebral arteries, a dog may be in a similar condition for a day or two, and then recover, as a collateral circulation becomes established by way of the superior intercostal, anterior spinal, and basilar arteries. Corresponding to the "idiot" stage, the cortical cells are found to have swollen nuclei and loss of Nissl granules.

In marked contrast is the effect of remoral of one cerebral hemisphere only. A dog from which the left ccrebral hemisphere had been removed tifteen months bcfore appeared quite a "hcalthy, wellbehaved animal." When greeted, it came wagging its tail to bestrokerl: It wonld follow anyone, moving quickly by ruming or even springing. He greeted a new-comer with a joyful bark, but snarled at strang? dogs if he did not like the look of them. He held a bone with his fore-paws, but did not use the right foot so purposefully as the left. He could turu round both ways, but preferred to go round to the left. Sensation was diminished over the right side of the body, but was nowhere absent. When irritated, he would at first move away, then yelp, and finally bite. Diminished sensation was well showi by the dog's failure to respond to a jet of air blown hy a bellows among its hair. When this was done on the left side, the dog turned round to see what was happening, and moved away from the stimulus; when done on the right side in an identical spot, the animal took no notice at all. "He would also stand in cold water with the right paw, but immediately took the left out. Whilc rmmning and jumping, all obstacles were avoided. Interference of vision was shown by the swinging of a club in the fields of vision. In the right. field this caused no response. The left eyeball could be touched without evoking a wink. Touching an eyelash immediately eroked a wink. Hearing was somewhat interfered with, but there was apparently no 
disturbance of smell or taste. The animal was more docile than before the operation, and showed no longer any inclination to play with its companions. To a stranger, however, it appcared no less intelligent than a normal dog.

In apes (Maeacus rhesus), the effects of total extirpation of both hemispheres are exceedingly severe. In a series of experiments recently reported, only one animal out of seventeen lived any length of time (twenty-six days). In this case, an interval of forty-four days elapsed between the removal of the first and second hemispheres. As a result of the operation, the movements of the head and eyes were in many animals apparently unaffected; the movements of the extremities, on the other hand, were severely impaired, in some cases there was marked tonic contraction. Tactile stimulation, such as stroking or blowing, produced raising of the head, opening of the eyelicls, widening of the pupils, and some movement of the limbs. Stimulation by light, even intense, produced but a slight reaction of the pupils. Noises induced movement of the ears and eyelids, and caused the body to be drawn up together. The animals inade noises, but showed no signs of mimicry. They exhibited periods of sleep and wakefulness. When asleep, they had their eyelids firmly closed, marde no spontaneous movement or sound, and did not respond to stimulation such as would arouse a normal animal. In one case only were swallowing movements observed when liquid nourishment was given.

The removal of one hemisphere, on the other hand, had surprisingly little effect. A few hours after the operation the animal sat up, seized food, ate, and climbed, although there was marked paresis of the limbs of the oppositc side. Then followed a pcriod of drowsiness, but after three or four weeks it was difficult by supcrficial observation to tell such an animal from a sound one. Upon examination, the limbs of the opposite side showed a certain degree of paresis, more marked in the upper than in the lower limb, hand and finger movements being more affectert than elbow or shoulder movements. Head movements, hardly disturbed by the operation, soon became perfectly normal. In regard to sensation, there was at first, at any rate in some of the animals, a hyperzesthesia of the opposite side. Eventually, all animals showed some degree of diminished sensibility, but reacted to strong stimuli. All the animals showed a marked, lasting disturbance of vision (hemianopia). The pupil light reflex remained normal, and the eyo movements undisturbed. No disturbance of hearing could be demonstrated. It made no difference which hemisphere was extirpated, but in two cases, after extirpation of the left hemisphere, an impression was obtainer that the left hand was not so skilled as the right had been. In all cases the completeness of the remoral was proved post mortem. The caurlate and lenticular nuclei and the optic thalamus were for the greater part destroyed.

Recently there has been described the case of a child which lived three and three-quarter years without cerebral hemispheres. These had been reduced to thin-walled cysts. No trace of nerve-fibres was found in the part of the brain eorresponding to the nco-encephalon. 
The palæo-encephalon was normal, as well as the rest of the brain, except for the lack of fibres arising from the neo-encophalon, such as the fibres to the red nucleus, to the pons, and to the spinal cord. Till the day of its death the child scarcely altered its behaviour, and presented a marked contrast to a brainless dog. It had never made any attempt to raise itself up, or to take anything in its hands and hold it. The only movements were those of the face, which sometimes took on an expression of pain. The lips and tongue were used in sucking and taking food from a spoon. After two years it uttered a dull cry, which could be soothed by pressing its head. Urine and fæees were passed in any position, and it did not display any discomfort at being wet. The child appears not to have shown periods of wakefulness and sleep, but to have always slept. The light reflex was present, the eyes being shut tightly when light was thrown on them. It was impossible to elicit any sign of psychic reaction, to train or teach the child in any way. Without the mother's help, the child would certainly have perished. New-born babies behave in much the same way, because in them the connection between the new brain and the old brain is not yet developed. The same is true for all mammals. These, unlike fish, amphibia, and reptiles, are almost wholly paralyzed without the new brain. The importance of the new brain gradually increases as we ascend the scale, until in man it becomes paramount.

There has also been reported the case of a man from whom it was found post mortem that a cerebral hemisphere had been missing. Although hemiplegia and hemianæsthesia were present, the intelligence of this individual was normal. So in many cases of injury in man large masses of brain tissue have been lost which, while involving loss of sensation or of movement, have apparently scarcely affected the intelligence.

From such evidence, then, it is clear that brainless animals are incapable of perceiving certain stimuli, that they possess no assiociative memory, are incapable of psychic processes, and are not able to initiate any of the movements which normally result from such processes. The functions of the great brain may therefore be grouped as--(1) The reception of impulses (a receiving sensory mechanism); (2) the storing of the effects of such impulses, and the association of present with stored impressions (a storing and associating mechanism), resulting in the highest processes of the brain-discrimination, inhibition of emotion, judgment; (3) the production of actions as the result of these (a motor or discharging mechanism).

It has been found that the receptor and effector mechanismis of the cortex cerebri are more or less localized in special parts. Such localization has been effected by five methods: (1) The effects of removal of parts of the cortex; (2) the effects of stimulation of parts of the cortex; (3) by clinical observations in cases of brain disease, followed by an investigation of the central nervous system after death; (4) by a histological cxamination of the cerebral cortex; (5) by a study of the nerve tracts during their development. 
The localization of parts of the brain which govern particular movements was first established by Hughlings Jackson's investigation of those cases of epilepsy in which the spasm begins in some particular part, and spreads in a definite order to the other parts of the body. The fits are generally preceded by a sensation in the part where the spasm begins-the aura. Many such cases have been operated on, the motor centres localized by electric excitation and the offending centre removed. The results thus obtained in man confirm the observations made on the chimpanzee and gorilla. The motor area of the chimpanzee is shown in the accompanying figures. On the outer side it occupies chiefly the precentral

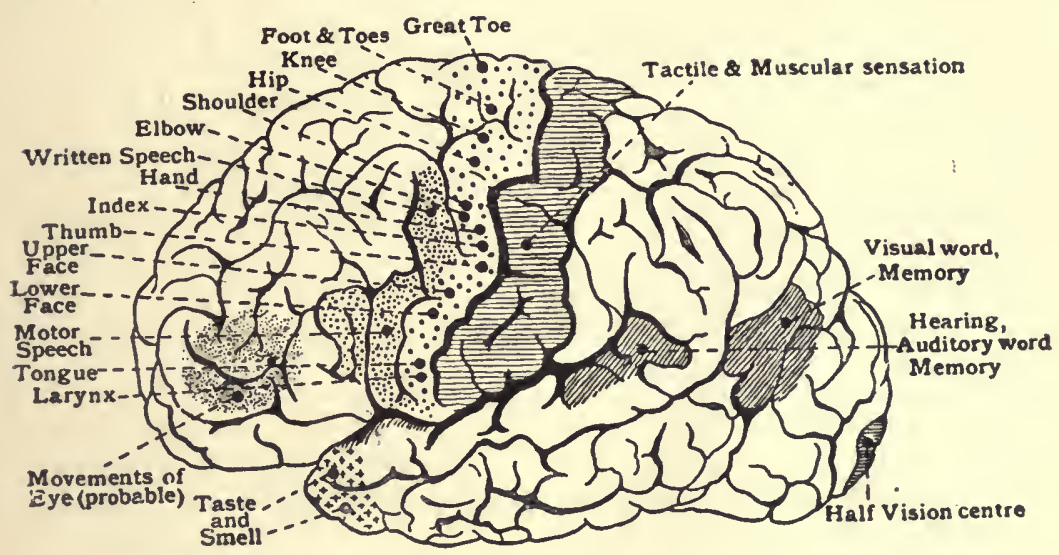

Fig. 438.-Left Heirisphere, showing Situation of the Human Cortical Projection Centres. (Mott.)

convolution in front of the fissure of Rolando; it overlaps slightly on the inner side of the hemisphere. The localization corresponds in a reverse order to the distribution of the spinal nerves. The order is perineum; up the leg-toes, ankle, knee, hip; trunk; down the armshoulder, elbow, wrist, fingers; neck; movements of mouth, tongue, etc. Eye movements are situated farther forward in the frontal region.

The Effects of Ablation of the Motor Area.-If one of the motor areas be removed, there results a paralysis of voluntary movements in the corresponding part of the body on the opposite side. In the dog this paralysis almost wholly passes off; in the ape to a less degree; while in man the degree of recovery is very limited. So much is this the case that the site of a brain lesion can be diagnosed during life, and verified after death. Even in man there is a certain amount of recovery, especiall! of limb movements made in association with the other limbs. Accompanying the loss of movement is a diminution in the sensibility, particularly in regard to the position of the part. For example, a man whose arm centre has been excised does not know the position of the limb, or how much it has been passively 
moved, when his eyes are shut. Ablation of other regions of the cortex have no effect upon the motor mechanism.

The Results of Stimulation.-If the brain be stimulated with an adequate stimulus in the regions shown in Fig. 438, co-ordinated movements of the corresponding parts are evoked on the opposite

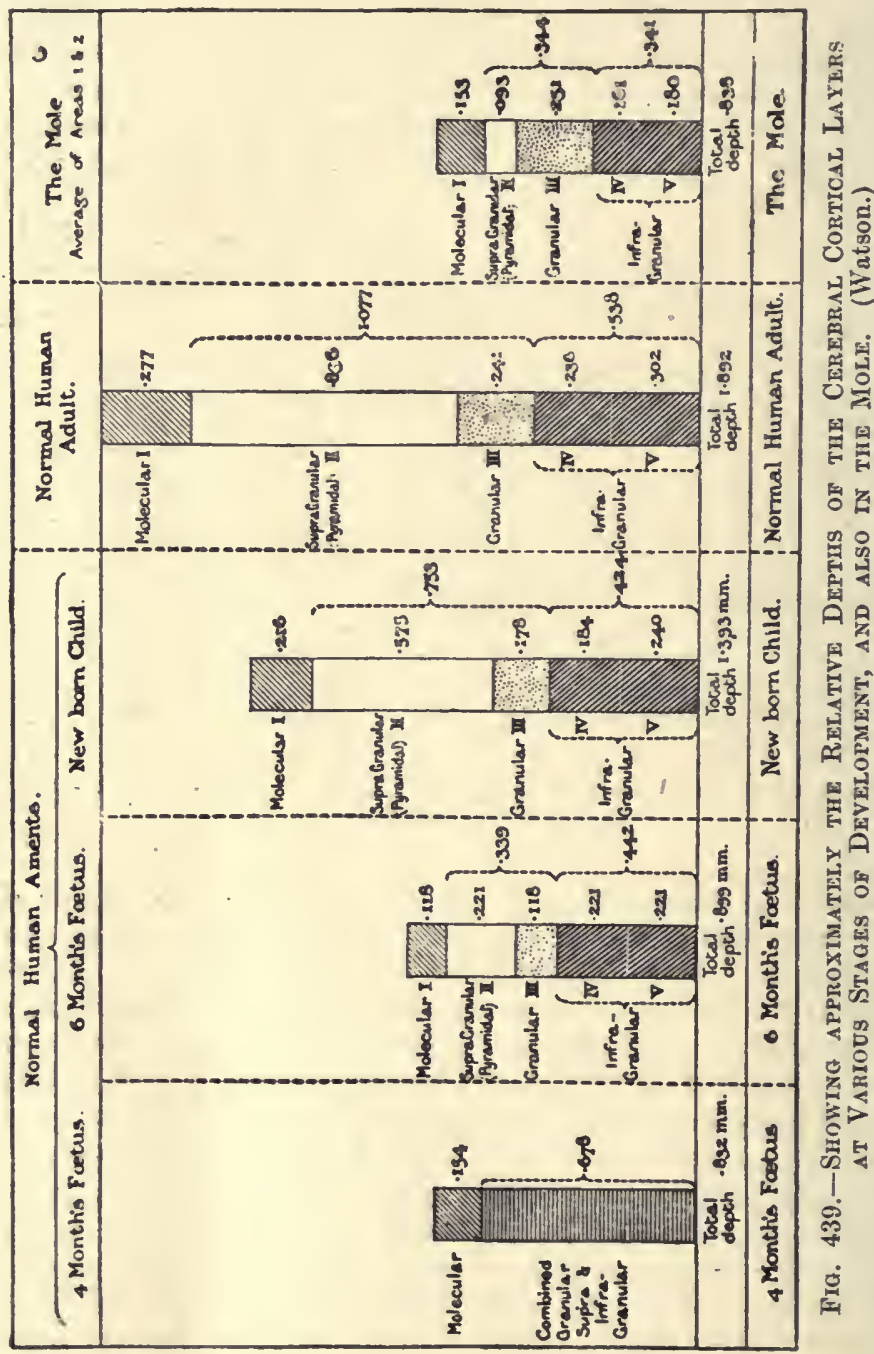

side of the body. Too strong a stimulus leads to a spread in orderly sequence to the neighbouring areas. At first the contractions are tonic in character, but later these are superseded by contractions of a clonic nature. This is what takes place in cortical epilepsy, the convulsive symptoms of which proceed in 
a definite order. Administration of tetanus toxin or strychnine abolishes the co-ordinated nature of the response. The injection of absinthe into the vein of an animal causes epileptic convulsions of a universal nature, which stop when the carotid arteries are clamped, to begin again when the blood carrying the poison flows through the cortex.

The Evidence from Structure.-The structure of the cortex is complicated, and varies in details in different parts. There are five layers, or laminæ : (1) The outer fibre lamina. (2) The outer cell lamina. (3) The middle cell lamina. (4) The inner fibre lamina. (5) The inner cell lamina.

The outer fibre lamina consists principally of medullated fibres from the underlying layers. It contains also cells which give rise to processes running parallel to the brain surface.

The outer cell lamina consists of pyramidal cells, the outermost being small, the middle ones medium-sized, and the most internal large in size. Running among the outer cells is a strand of fibres known as the outer line of Baillarger.

The middle cell lamina consists of a layer of small stellar cells.

The inner fibre lamina consists chiefly of an inner strand of fibres known as the inner line of Baillarger. In this lamina are also large pyramidal cells. These occur particularly in the motor area of the brain, and are there known as the cells of Betz.

The inner cell lamina consists of various types of cells-Golgi, stellate, pyramidal, spindle-shaped, ovoid, etc. Characteristic are pyramidal cells, with the axon passing towards the surface of the brain-the cells of Martinotti.

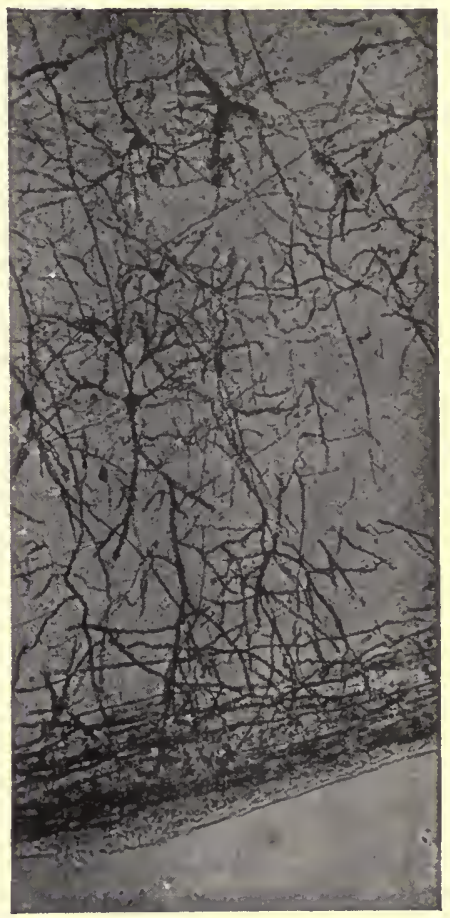

Fig. 440.-Section of Cruciat SUrcus of the Brain of a Dol: stained By Golgi's Method, showing a Large Pyramidal Cell givisg off a Large: Branching Apical Dendron. Gemmeles can be seren on the Procrsses. $\times 80$. (Mott.)

These layers vary in structure and in thickness in the different parts of the cortex. They also develop in the embryo at different times. The inner cell lamina is the first layer to be developed, and is well marked in the lower mammals. This layer and the inner fibre layer is held to be concerned in the lower instinctive and voluntary activities of the animal, such as feeding, excretion. In man, these layers are developed during the fourth month of fœtal life. 


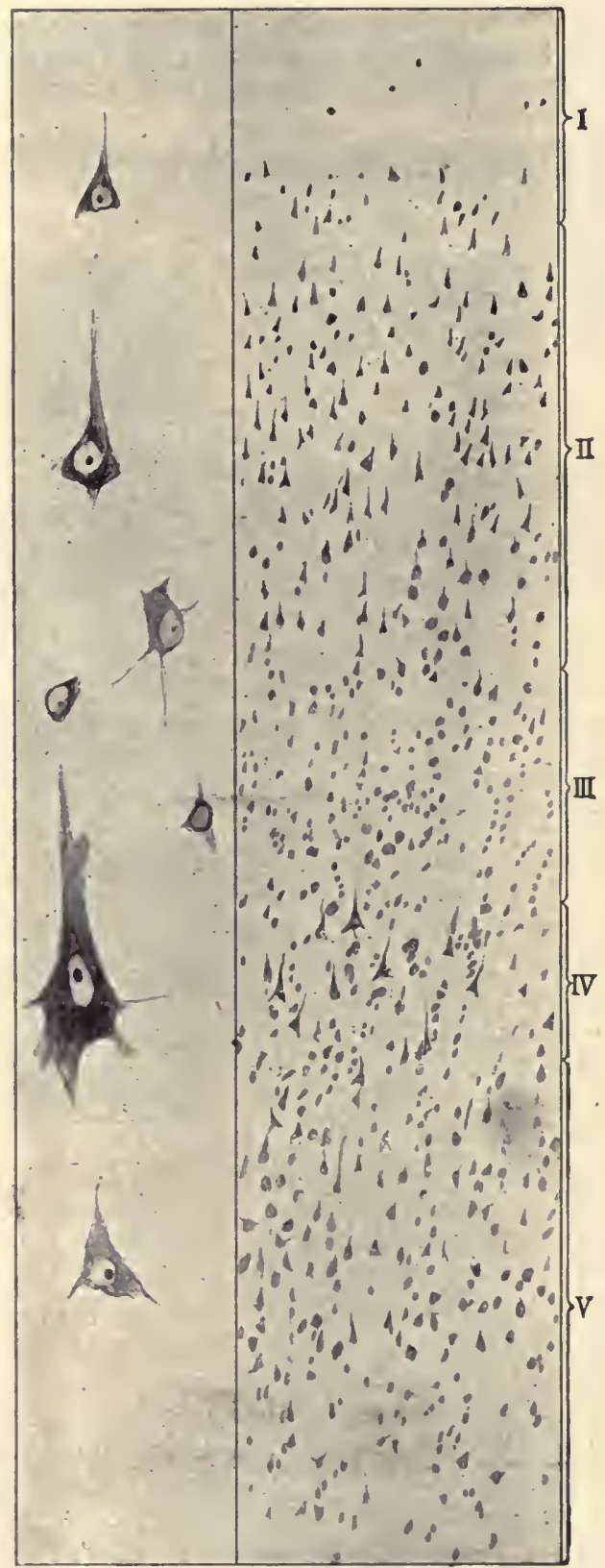

Fig. 441.-Cell Lamination of the Grrus Post-Centray.is. 3 (Mott.) 


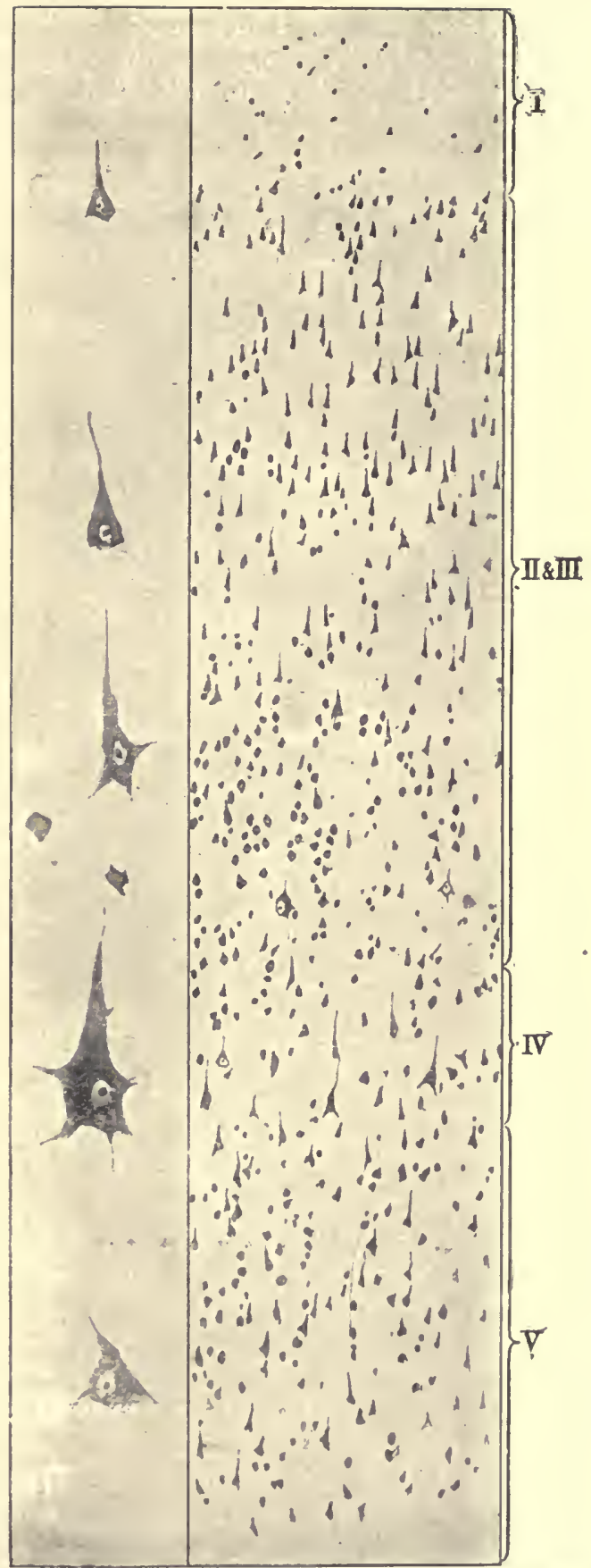

Fig. 442. - Fibre Arrasaemest and Cell lamination ix qhe Motor Area. (Mott.) 
The middle cell lamina is next developed, and is believed to be concerned in the reception of sensory stimuli. It is most marked in the sensory regions of the cortex. In man, it develops in the sixth month of fœtal life.

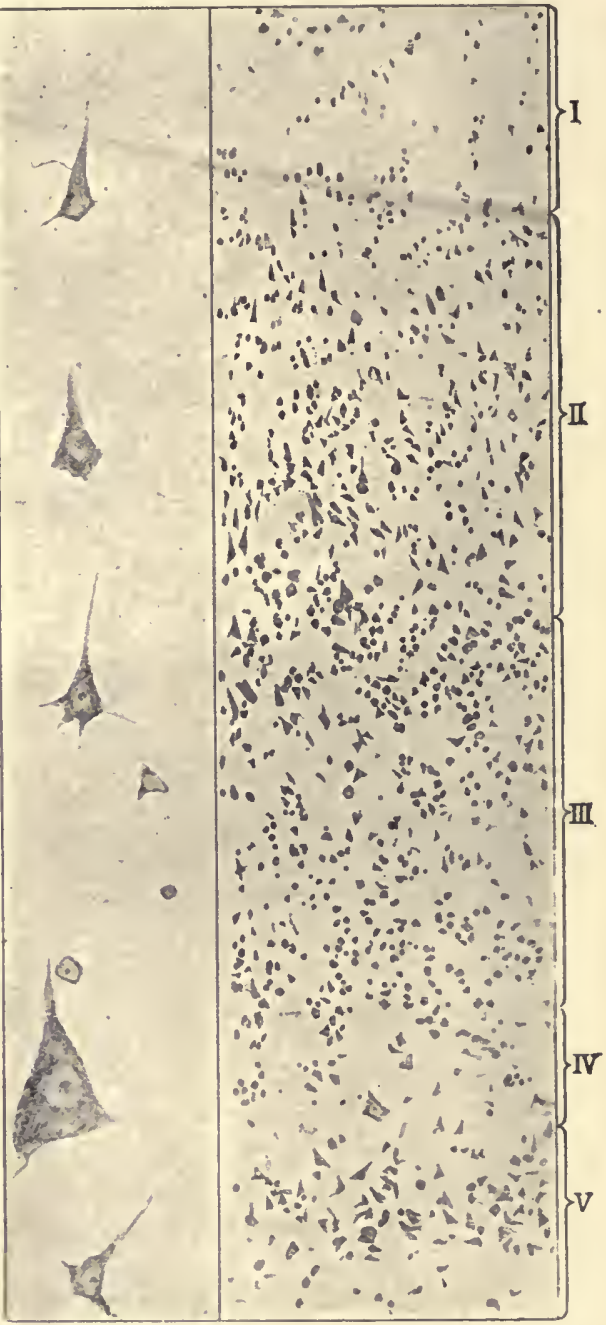

Fig. 443. -Fibre Arrangement and Cell Lamination of Visual Area. (Mott.)

Last to be developed is the outer cell lamina. It is suggested that this is concerned in pyschic processes, and is particularly marked in regions concerned in these processes, especially in the frontal area of the brain. 
The differences in thickness and structure are well seen in Figs. 441-443. In the motor area the second lamina is thick, the third lamina is thin, and the fourth lamina contains the characteristic large pyramidal cells of Betz.

In the "visuo-sensory" area the third lamina is thick, and is divided into two by a strand of fibres-the line of Gennari.

The "visuo-psychic" area, except for the absence of the large Betz cells, resembles more the motor than the sensory area. It is obvious that from a study of the histological structure of areas of which the function is known valuable indications may be obtained as to the function of the parts of the cortex of which the function has not been clearly ascertained.

The Evidence from Myelination.-It has been found that groups of fibres going to certain regions of the cortex in the embryo acquire their medullary sheaths earlier than other groups. These regions of the cortex have been shown to correspond closely with the "sensory areas" of the cortex.

The Localization of the Receiving Sensory Mechanism. - The receiving station for cutaneous and kinæsthetic impulses has been localized in the ascending parietal convolution, which lies just behind the fissure of Rolando (Fig. 411). Cutaneous sensations have also a receiving station in the callozal gyras on the mesial aspect of the brain (Fig. 444). It is probable that the various sensations are represented in special parts of these regions. It is known that during their passage from the cord to the thalamus the various sensations become grouped, and it is probable that the final neurons from the thalamus to the cortex establish communications with definite areas.

The motor and sensory areas around the Rolandic area are in close connection. It is for this reason that epilepsy is preceded by the sensory "aura," and stimulation of the sensory area leads to movements which, with weak stimluation, are localized in that area of the motor cortex which is in most intimate communication.

The receptive arza for vision is situated in the occipital regions on both the outer and inner aspect of the brain (Fig. 444). The area varies considerably in extent, being larger in the dog than in man. In man, the main centre is around the calcarine fissure on the mesial aspe $3 t$. The occipital part of the brain is connected with the thalamus, external geniculate body, and superior corpora quadrigemina, by means of the optic radiations. For instance, stimulation of the upper. surface of the right occipital lobe causes eye movements downwards and to the left; of the posterior part, eye movements upwards and to the left; of the mesial surface, a turning of the eyes laterally to the left. Extirpation of both occipital lobes induces complete blindness; ablation of one occipital lobe causes a crossed hemianopia. The vision of the fovea is not impaired, since it is represented on both sides of the brain.

In man, the visuo-sensory region is confined to the mesial aspect of the brain. A lesion of the whole of the left cuneate lobe causes 
right hemianopia-blindness in the right half of each visual field. A lesion of the region above the calcarine fissure causes hemianopia in the right lower part of the visual fields of both eyes; of the region below the calcarine fissure, in the right upper part of both visual fields. The external surface of the occipital lobe is probably concerned in psychic processes connected with the recognition of the things seen.
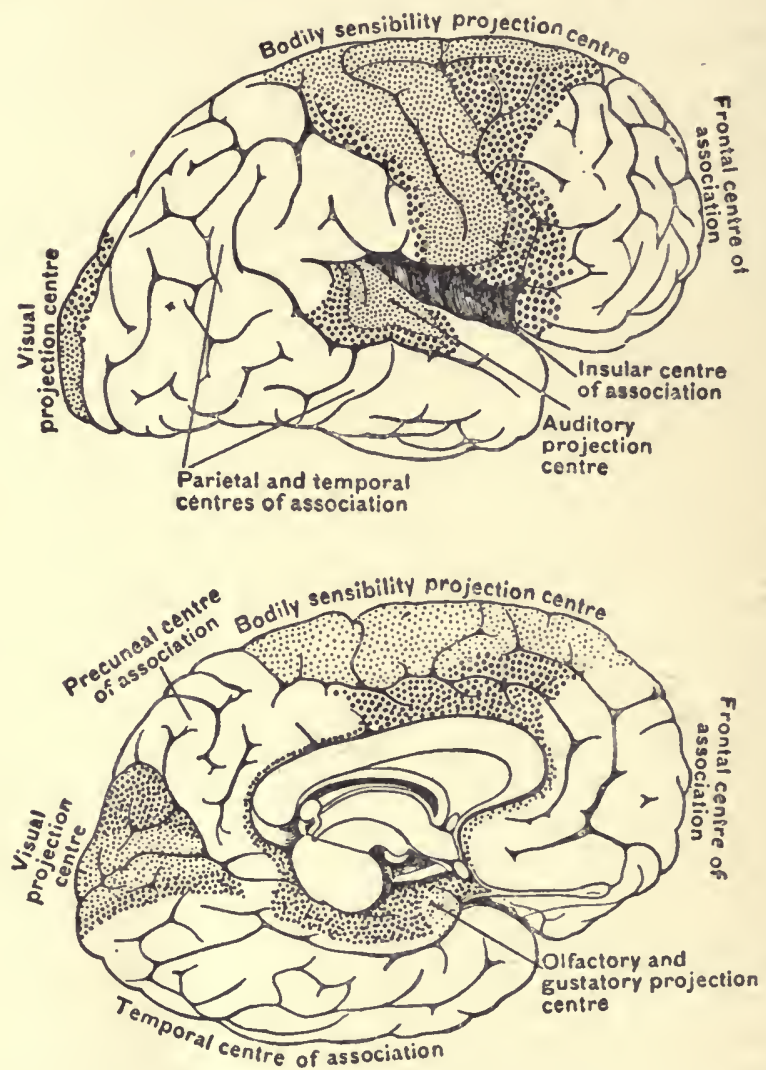

Fig. 144.-Dingrasis of the "Centrfos of Projfction" and "Centres of Assocratiox." (Bolton, after Flechsig.)

The small dots are placed in the chief focus of each centre of projection; around these chief foci are regions (larger; dots) to which a smaller number of projection-fibres pass.

The receptive area for hearing is situated in the superior temporal lobes (Fig. 444). It is connected with the inferior corpora quadrigemina by the auditory radiations, which pass through the most posterior part of the internal capsule. The effect of stimulation points to this region of the brain as being concerned in hearing. In 
the monkey, it induces a pricking of the opposite ear, with a rotation of the head to the opposite side. Ablation effects are not so conclusive, as it is difficult to tell whether an animal, like a monkey, is deaf or not. Clinical evidence points to the central part of the lobe as the true receiving station - the audito-sensory area-and to the area just behind this as the part concerned in the psychic processes-the appreciation of the s:gnificance of the sound heard.

The receiving stations for taste and smell are probably present in the anterior part of the temporal lobe, particularly in the deeper aspects. Electrical stimulation of the hippocampal region causes movement of the nostril and lip of the same side., The evidence of the effects of ablation and of clinical observation are by no means: conclusive. It has been suggested that sensations of hunger and thirst are received in the cortex of the anterior part of the temporal lobe in its outer part.

The Association Areas.-The cortex as a whole is to be regarded as one great association centre concerned in the storing of sensations. as memories, and the association of present with past impressions, resulting in the power of discrimination, inhibition of emotion, and judgment. There is evidence that there is some localization of these functions. It has already been pointed out that the external aspect of the occipital lobe in man is concerned with the appreciation of the significance of things seen. Further, in the angular gyrus of the brain, on the left side in right-handed people, there is thought to be the "visual word area," by means of which the meaning of written words is appreciated. So, in regard to hearing, it has been pointed out that the posterior part of the temporal lobe is probably concerned in the appreciation of the meaning of the sound heard, and in this region is also situated the auditory word centre, which enables the appreciation of the word heard.

These centres belong to one of the three great areas which have been designated as association areas. These areas are the posterior -in the parieto-temporal region-chiefly concerned in sensorial function; the middle-in the island of Reil; and the anterior-in the prefrontal region. All these regions are intimately connected by association fibres. The exact function of the island of Reil is not known. In regard to the frontal region, it is suggested that this is the centre concerned in voluntary attention, memory, and thought. Dementia is associated with the disorder of this region, the degree of permanency varying according to the degree of dissolution of the area. If this region be not developed, then the subject is generally permanently imbecile (amentia), temporarily insane, or liable to the onset of insanity. In the frontal region the outer cell lamina is particularly well marked. It is the last to develop, the first to regress.

Speech.-The functions of the cerebral cortex are well illustrated in the power of speech. To give an answer to a question directed to him, a man must- 
1. Hear the noise-The receiving mechanism.

2. Appreciate the meaning of the noise (the words)

3. Associate it with former stored impressions

4. By judgment formulate the answer

5. Clothe the answer in words

6. Associate this answer with the motor centres concerned in the activation of the muscles taking part in the production of speech movements-lips, tongue, larynx, etc.

7. Send impulses down the efferent tracts to the nerves to these parts, and cause the muscles to functionate-The discharging mechanism.

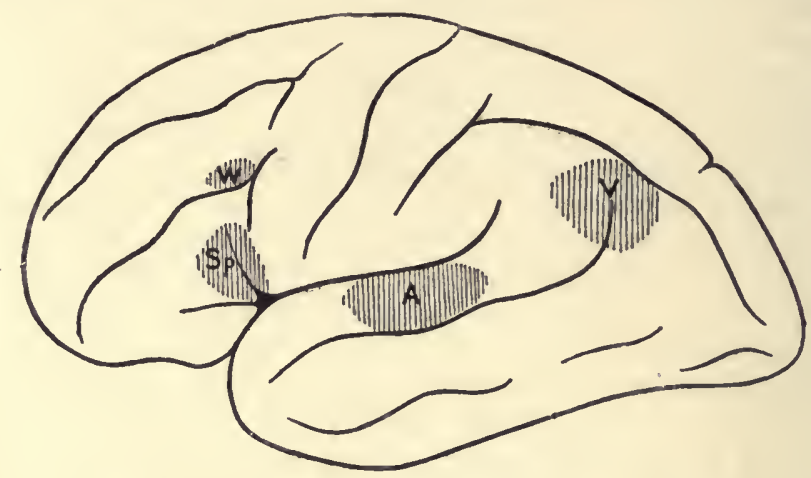

Fig. 445.-Diagram of Left Cerebral Hemisphere, showing Approximate Posimions of the Centres concerned in Speech. (From Purves Stewart's "Diagnosis of Nervous Diseases.")

Similarly, a great number of processes are concerned in the appreciation of written words and in the power to express the answer in writing. It was at one time believed that a certain part of the brain, known as Broca's area, was especially concerned, as the special coordinating centre, in speech. This area is unilateral, and is situated in a right-handed person in the left inferior frontal convolution. It is undoubtedly in intimate connection with the neighbouring motor areas concerned in the movements of the tongue, lips, and larynx, but it has been shown that it may be diseased without any disorder of speech (aphasia) resulting. The cases of "motor" aphasia, which were said to be the result of a lesion of Broca's area, are now said to be due to a lesion of the lenticular nucleus, and to a varying extent of an area known as Wernicko's area. The former lesion involves the external capsule, and possibly the anterior part of the internal capsule, and causes an inability to articulate (anarthria).

Wernicke's area is situated in the supramarginal and angular gyri, comprising the "visual word centre," and in the posterior part of the superior temporal sphenoidal lobe, comprising the "auditory word centre." A lesion of the area results in "sensory aphasia," 
varying according to the extent of the lesion. Sometimes the impairment of intelligence is very marked; in other cases, as in the so-called cases of "motor" aphasia, it is but little affected. If the auditory area be destroyed, there results a loss of spoken word appreciation (sensory aphasia), with great diminution of mental powers. If the occipital lobe be affected, there will result alexia, or word blindnessan inability to appreciate the meaning of written words.

It will be seen that it is improbable that there is any localized speech centre, as suggested by Broca. Disorders of speech are due to local lesions, bringing about a loss of continuity between the cortical centres concerned in the power of speech. "Motor" aphasia, therefore, is probably not due to a lesion of Broca's area, but principally to a lesion of the lenticular nucleus, causing an inability to articulate, often combined with a lesion of the sensory area of Wernicke.

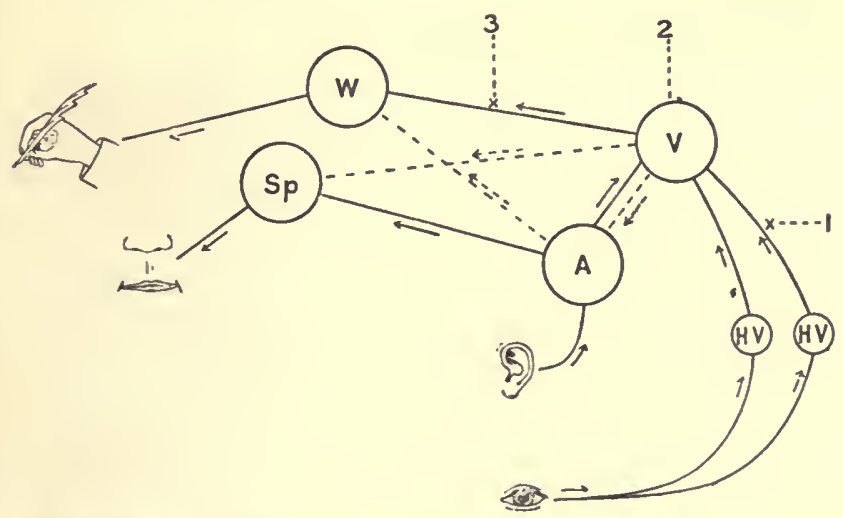

Fig. 446.-Diagram of Speech Centres. (After Bramwell, from Purves Stewart's "Diagnosis of Nervous Diseases.")

Similarly, in the power to read and to clothe thoughts in writing there is involved a number of centres connected by association fibres (see Fig. 446).

Reaction Time.-Various methods have been devised for measuring the "reflex time," or, as it is usually termed, the "reaction time," of conscious processes, such as sight, hearing, the response being by movement or speech, etc. The subject is usually told to perform some movement, recorded on a drum, such as to open an elcctric key or to depress a lever, directly he rcceives the stimulus, which is also recorded-e.g., the ringing of a bell, the appearance of a coloured disc. The "reaction time" is made up of the time taken in the conduction of the impulse to and from the brain, and of the processes in the brain. From the knowledge of nerve conduction and of the reflex times of simple arcs we can measure the reaction time of more complicated cerebral processes. The more complicatcd the process, the longor the time. Thus, if a man has to move his right hand when a red disc 
is shown, and his left hand when a green one is shown, the time is considerably longer than if he has to make a simple motor response with one hand to any kind of disc. Still more complex is the process when the subject has to speak different words in response to different forms of stimulation.

Mind and Consciousness.--Extero-, proprio-, and entero-ceptive impulses stream into the central nervous system from the time of its embryonic development until death, ceasclessly modify the pattern 'of its structure, lay down the pathways of reflex actions, and establish habits. A very large proportion of these impulses, and particularly the proprio- and entero-ceptive, never enter into consciousness, and yet occasion actions which are perfectly adapted to the end in view.

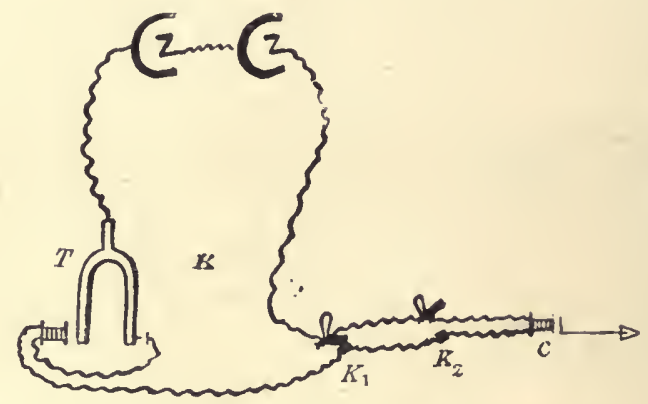

Frg. 447.-Diaray of the Apparatus for the Determination of Reaction Trme. (W. G. Smith.)

The electro-magnatic tuning-fork $T$, with 100 vibrations per second, is connected with two Daniell cells and with the chronograph $C$. By means of either of the two Du Bois keys, $K_{1}$ and $K_{2}$, the chronograph can be short-circuited. The kcy $K_{1}$ is closed and $K_{2}$ is open; the tuning-fork is set vibrating, but does not affect the chronograph. The subject, whose reaction time is to be determined, is told to listen for the sound of the opening of the key $K_{1}$, and to close the key $K_{2}$ directly he hears the sound. When the key $K_{1}$ is opened the chronograph vibrates in unison with the tuning-fork and the vibrations are recorded upon a revolving drum; the closure of the key $K_{2}$ by the suhject of the cxperiment brings the chronograph to rest. The number of vibrations recorded upon the drum gives the reaction time for sound in $\frac{1}{100}$ ths of a second.

For example, the character $c f$ the saliva secreted is adapted according as sand or bread is put into the mouth. In the one case a watery saliva is secreted, in the other a saliva containing the ferment ptyalin. It might be argued that the salivary centre felt, judged, and willed an appropriate action, and yet none of these processes enter into consciousness. We each have from moment to moment of our waking life a general consciousness of well-being or the reverse, maintained by proprio- and entero-ceptive impulses arising in the organs and tissues of the body, coupled with a tone of feeling evoked by extero-ccptive sensations. These arouse in us from time to time emotions of indifference, pleasure, pain, affection, hate, sex, etc. The more powerful extero-ceptive sensations not only enter into consciousness, but so alter the pattern of the brain structure as to store memories-in what 
manner we have no knowledge. The sensations of the present moment may arouse one or other of these memories to which it is attuned. Our actions are controlled from moment to moment by the sensations which stream in at the present time, and the memories of past sensations which are aroused by these.

Our knowledge, opinions, and beliefs are, then, the result of the supply of sensations furnished by impulses acting on the brain structure. Without such sensations, no mind or consciousness would be manifest. The extero-ceptive mechanism plays an all-important part. This is well seen in the case of Helen Keller, who, deaf and dumb, and uneducated, when her eyes werêt closed, fell asleep.

Memory forms the basis of our experience and knowledge, and our so-called voluntary actions, initiated by the cerebrum, result as inevitably as a spinal reflex action from the synthesis of present and

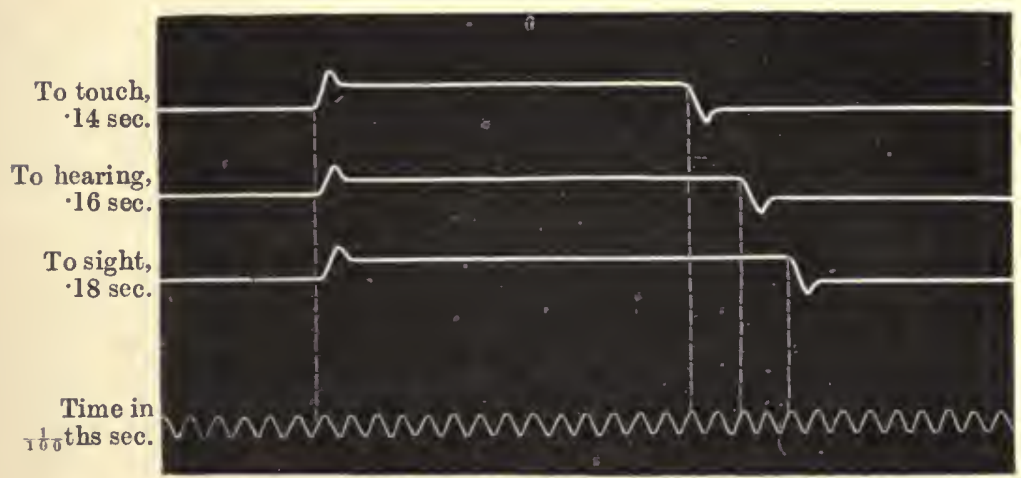

Fig. 448.-Reaction Times to Touch, Hearing, Sigut. (Waller.)

memorized sensations, some of which inhibit, and others facilitatc, motor response. Education thus becomes of supreme power in moulding the actions of a man's life.

As the pattern of the brain is ceaselessly altered by instreaming sensations and metabolic processes, the personality of a man alters from moment to moment. The babe develops into the man of genius, and he, if he lives long enough, bccomes a dotard in his old age. By the time he is in his second childhood the personality of his prime manhood has left him, for this depends on charactcristic responses to sensations, and these can no longer be aroused in a brain the structure of which has deteriorated with age, and from which the store of memories has largely vanished. We must remember that the work of a genius is the accumulated result of successive and innumcrable moments of interaction of sensations, present and memorized. His output results from the inborn qualities of the sense organs and brain structure on the one hand, and education on the other-the storage of his experience-and that of humanity handed on by oral or writton 
tradition. At one moment the man of genius may be conscious of nothing but the desire to visit the privy, and at another moment he may be conscious of the word which makes perfect a line of poetry.

Consciousness leaves us when the brain is suddenly rendered anæmic by closure of the carotid arteries. It leaves us in sleep, and when a chemical agent, such as nitrous oxide or other anæsthetic, interferes with the play of chemical and physical forces in the nervous tissue. The nervous tissue acts as a transformer of energy, and when it becomes inactive or is destroyed, that form of energy which we call consciousness ceases. 


\section{CHAPTER LXXIV}

\section{SLEEP}

SLEeP is to be regarded as the period of rest of the great brain, and to a certain extent of the central nervous system and of the body generally. It is probable that absolute lack of sleep would kill a man even more speedily than absolute lack of water, and certainly more quickly and painfully than the withdrawal of food. Young puppies three to four months old, deprived of sleep for four to five days, died either at once or, if then allowed to sleep, after a few days. The younger the animal, the more speedy its death. The body temperature began to fall on the second day, until just before death the temperature was about $5^{\circ} \mathrm{C}$. below normal. The number of blood-corpuscles became greatly diminished, and after death many capillary hæmorrhages were found in the brain.

It is probable that the greater the animal's need of sleep, the quicker its death from sleeplessness. Dogs sleep, probably, on an average twice as long as man, who normally sleeps about one-third of his life. Some men require considerably less sleep than others; why, it is difficult to say. Children require, according to age, from twelve to ten hours' sleep, women and men from eight to five hours'. Birds apparently require less sleep than mammals. Some mammals require considerably more sleep than others. This is partly due to the character of the sleep, a short profound sleep being as efficacious as a longer less deep sleep. Man is a deep sleeper; the dog is a light sleeper. The companionship of the dog has helped man to attain to his supremacy. But for the companionship and guardianship of the light sleeper, the deep sleeper would have been destroyed by night-prowling, maneating enemies.

Many observations have been made upon man to determine the physiological conditions during sleep. Most marked is the loss of consciousness. It is stated that sleep is more profound in the half of the brain which has been active during the day, so that righthanded people when asleep flick away a fly with the left hand, while true left-handed people perform such an act with the right hand. The depth of the loss of consciousness may be gauged by stimuli, such as the ringing of a bell at half-hour intervals during the sleep, the dropping of a lead ball from a given height on to a lead plate, or the application of electrical stimuli of known intensity. By such means it has been determined that the greatest intensity of sleep oocurs after about an hour to an hour and a half from the onset of 
sleep. From the third hour onwards the sleep in many cases is of a light type. In some cases there is a second rise in the intensity of the depth of sleep in the fourth to fifth hours after onset. This form has been said to occur particularly in persons of a nervous temperament. Although the greatest refreshment from sleep occurs during the first hours, it has been shown that the subsequent hours are also effectual. It is easier to do complicated mental work after several hours' sleep than after only a few hours' sleep, although simple mental acts can be performed equally well after but a few hours' sleep.

It is in the waking hours that dreams occur, and they are generally of short duration. The dreams of healthy sleep are frequently of the past or of a fantastic nature. Only in broken sleep is the day's work continued or present-day affairs worried over. In healthy sleep the parts of the brain most active during the day should rest most profoundly during the night. The parts of the brain do not fall asleep or wake at the same instant. Response to sound sensations are the last to go and the first to return.

In addition to the great brain, the other parts of the central nervous system are also resting. The respiratory centre is affected. Respiration is slowed and deepened, and frequently becomes somewhat periodic (Cheyne-Stokes) in type. The reflexes are depressed, the knee-jerk is scarcely present or absent altogether.

The rate of heart-beat is slowed, the heart beats less forcibly, and the arterial pressure falls, during sleep.

Owing to the relaxation of the muscles and of the bloodvessels in the warm, quiet state of the body, the blood stagnates in the peripheral capillaries and veins, and the circulation is much less rapid. Less oxygen is required, and the blood moving slowly through the capillaries fulfils the metabolic needs of the resting tissues. It furnishes a reserve supply of "munitions" for active service during the waking period.

In the brain, also, the venous side of the circulation is more congested and the blood-flow sluggish. When the sleeper is aroused, the tone of the muscles, skeletal and vascular, at once increases; the blood is sent from the periphery to the viscera, and the velocity of the blood-flow is increased through the brain. The general metabolism is lessened during sleep. The carbon dioxide output and the oxygen intake show a marked decrease. The bodily temperature also falls to its lowest point during the night. In the early morning hours the bodily metabolism is at its lowest ebb.

The bodily secretions are diminished during sleep. The "night" urine in healthy persons is less in quantity and more concentrated than the day urine. The amount of saliva is also decreased, and possibly, also, the alimentary juices.

The onset of sleep is flavoured by muscular and mental fatigue and by the withdrawal of all stimuli of the extero-ceptive nervous mechanism, especially light and sound.

Fatigue produces a metabolic condition of the nervous tissue which tends to put in abeyance the power of response to stimulation; 
with the weakening or withdrawal of the stimuli the abeyance becomes complete. The over-fatigued soldier falls asleep in a dug-out in spite of the enemy's shells bursting around him. We ordinarily favour the onset of sleep by seeking the warm, quiet, and dark atmosphere of our beds, where the excitements of the outside world are at a minimum.

Sleep has been attributed to a lessened circulation of blood through the brain, caused by the dilatation of the vessels of the skin and of the splanchnic area. Rest in an armchair in a warm room after a heary meal conduces to sleep. Exposure to cold wind repels it.

The periodicity of sleep has been attributed to a gradual loss of tone of the vaso-motor centres. When awake the vessels of the body are so regulated that the blood-supply of the brain is ample, but as fatigue of the vaso-motor mechanism ensues the blood-supply to the brain gradually lessens, and the increasing anæmia induces the onset of sleep.
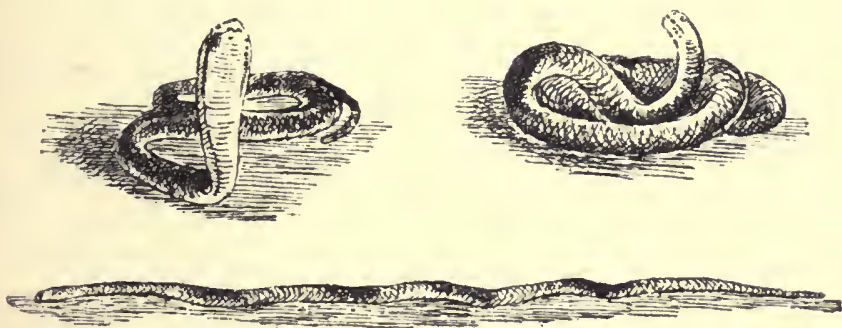

Fig. 449.-Cobra Hypyotized by Stroking, and made Stiff and Strainht.

Another view of sleep is that it is due to the accumulation of waste products or fatigue toxins within the body. It has also been suggested that the synapses of the neurons are interrupted in sleep by an amoboid retraction which blocks the conduction of impulses. There is no evidence of this.

There is no single theory which satisfactorily explains the phenomena of sleep.

Narcosis.-The unconsciousness induced by volatile anæsthetics is due to chemical change of the nerve cells. As the result of prolonged anæsthesia, degenerative changes are induced in the nerve cells and elsewhere. The volatile anæsthetics easily permeate the cell protoplasm. There is no need to evoke the lipoid nature of the cell membrane as an explanation. When administration of the anæs thetic ceases, the volatile anæsthetic diffuses again from the cell into the blood, and the state of anæsthesia gradually passes off as the drug is breathed out.

Hypnosis. - The condition of hypmosis superficially resembles that of normal sleep. It may be induced in many animals merely by holding them in a strange posture, as in the well-known "experimentum mirabile," which consists in placing a fowl on its back with its beak to a line chalked upon the ground. In man it is produced 
by suggestion, generally, but not necessarily, verbal in nature. It is essential that the subject have the idea of sleep and be prepared to surrender himself to the treatment of the operator.

Experiment shows that the condition differs in several respects from normal sleep. The bloodvessels of the skin are constricted, the volume of the limbs is diminished, the blood-volume of the face, and probably the circulation through the brain, is increased. The pulse and respirations are usually quickened. The individual becomes an automaton. The judgment powers of the higher centres are in abeyance, but the receptive centres are alert. Thus, the subject may unhesitatingly peirform an order if not too extravagant or believe a fact suggested to him. If told to perform a certain act at a certain hour, the act may be done; if told that he is paralyzed, the subject may act as if such were indeed the case.

Hypnosis has been practised in medicine, but is of doubtful value, except, perhaps, for certain nervous disorders. Operations can be performed in the hypnotic state, but such operations are better performed under ordinary narcosis. The whole subject is surrounded by quackery and liss.

Hibernation.-Certain animals retire at times to fheir shelters and pass into a torpid state known as "hibernation.". Such animals include insects, amphibians, reptiles, and mammails such as the dormouse, squirrel, hedgehog, marmot, bat, beaver, and bear. As the name implias, hibernation generally occurs with the approach of cold weather, but this is not necessarily the case. Some animals begin to hibernate in summer, or will hibernate when kept in a warm room away from cold. Cold is not the cause of hibernation; in fact, intense cold stops it. It is a device for securing the continuance of life during a period when food is lacking. Before hibernating the animal puts on fat. It has been suggested that the state is a narcosis induced by the accumulation of $\mathrm{CO}_{2}$ within the body. The body temperature falls, the excitability of the nervous system is depressed, the frequency of respiration is slowed, and the heart force and frequency are much reduced.

The awakening from hibernation is characterized, in warm-blooded animals, by a sudden rapid rise of body temperature, accompanied by a greatly increased discharge of carbon dioxide from the body. 


\section{CHAPTER LXXV}

\section{SOUND PRODUCTION AND SPEECH}

THE power of speech is indicative of the high cerebral development of man. Animals possess the power of sound production, but not of speech. Among the insects sound is produced chiefly by a rapid rhythmic movement of one hard part against another, such as the chirping of crickets and grasshoppers. The groan of the death'shead moth is possibly produced by the moth drawing air through its tracheæ, but more probably by a rapid movement of the palps against the proboscis. Among the animals higher in the scale of evolution sound is produced by a blast of air upon elastic membranes. The voice of amphibians is due to the driving of air past the tightly stretched membranes of the larynx; the same is true of the song of the bird and of the voice of mammals and man.

The speech organs are-(1) The wind chest (the lungs) with the wind tubes (the bronchi and trachea); (2) the sound-producer (the larynx); (3) the sound modifier (the cavities of the mouth, nose, and throat).

The wind chest drives the air through the reed instrument (the larynx); the vibration of the reeds (the vocal cords) produces the pitch of the sound, and the mouth and nose cavity, resonating like the tube of a trumpet, amplifies certain overtones and gives the quality which determines speech.

The proper management of the breath is most important. We have seen that the breathing is regulated by the partial pressure of $\mathrm{CO}_{2}$ in the alveolar air, or, rather, by the concentration of acid $\left(\mathrm{H}^{+}\right)$ions in the blood. We can alter the breathing by means of the will only within narrow limits. A shortage of air and a rise of the partial pressure of $\mathrm{CO}_{2}$ will inevitably cut short the most eloquent periods, and give the speaker a catch in his breath. We must learn to speak with a full lung, on the complemental and not on the tidal air-supply. The contraction of the belly muscles must balance the positive pressure in the thorax during the singing of a sustained note, so that the circulation may continue unimpaired. The stammerer fails to use his diaphragm properly; the bellows of his wind chest is at fault, or, more correctly, the nerve centre which plays upon the bellows. The vocal cords vibrate in much the. same way as do the lips in blowing a trumpet. In a reed pipe the air is stopped intermittently for a moment, and then let pass by the vibrating tonguc or reed, so that a set of pulses 
is given to the air, which is alternately rarefied and condensed; the number of these pulses is determined by the length of the "tongue (pendulum). The audible sound is produced, not by the "tongue itself, but by the pulses of the air. By placing the middle and fore finger lightly on either side of the thyroid cartilage and singing a sustained note, one can feel the cords vibrate. A blast of air blown through a sheep's trachea and larynx will give forth a sound when the cords of the larynx are tightened (Fig. 450). The blast forces the cords towards the mouth, and they swing back owing to their elasticity.

The larynx consists of a stiff-walled cartilaginous box divided by the membranous vocal cords into two chambers of unequal size, one above the other. The cords, placed one on either side and opposite each other, can be tightened or slackened, thickened or thinned, shortened or lengthened, moved towards or away from each other, so as to leave either a wide or narrow slit - the rima glottidis - through which the air blast passes.

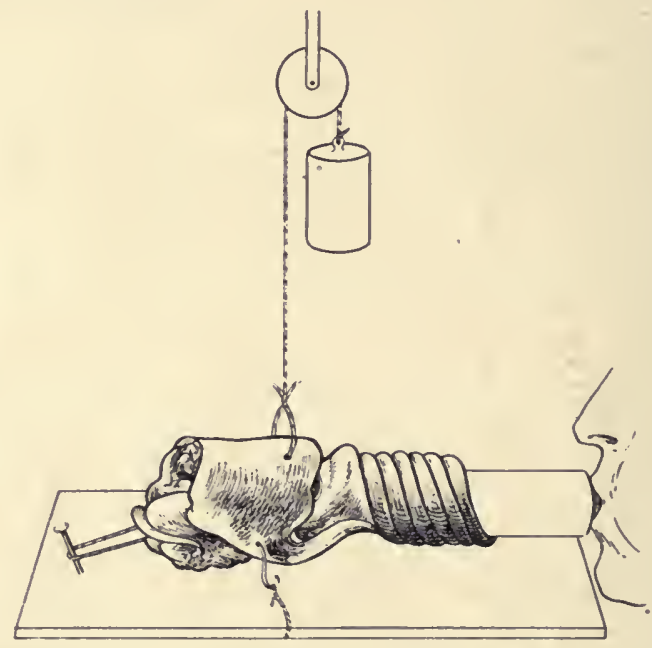

Fig. 450.-Experimental Sounds Produced bY Blowing througif Sheep's Trachea.

The vibration of the cords can be discerned in man by means of the laryngoscope. A small flat mirror (Fig. 451) is attached at an angle to a long handle, so that the mirror can be passed to the back of the throat and the reflection of the rima glottidis seen, when a light is cast upon it from another mirror. This second mirror, a concave one, is fastened to the forehead, and has a central hole in it for the eye, and is placed so as to reflect the light of a lamp on to the small mirror (Fig. 452). If an intermittent source of illumination is used, and the number of intermissions is the same as the number of vibrations of the rocal cords, these appear as if stationary; but if the intermissions are not quite at the same rate, then the cords appear to be slowly moving. 
This optical method employed for determining the rate of vibration is that of the stroboscope. Lesions of the vocal cords or of the neuromuscular mechanism which prevent their vibration causc loss of voice.

The height of a tone in such a two-lipped reed pipe as the larynx depends on the length, thickness, and tension, of the cords, and to a certain degree on the strength of the air-blast.

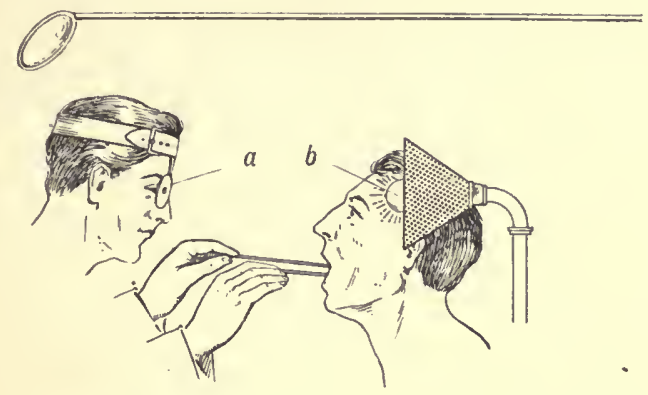

Fig. 451.- Examination of the Iarinx by the LaRgNgoscope.

The shorter and more strongly stretched the membrane, the higher is the tone; women and children have a smaller larynx and shorter cords, and hence high-pitched voices. At puberty there is a rapid increase in growth, and the breaking of the voice is due to the want

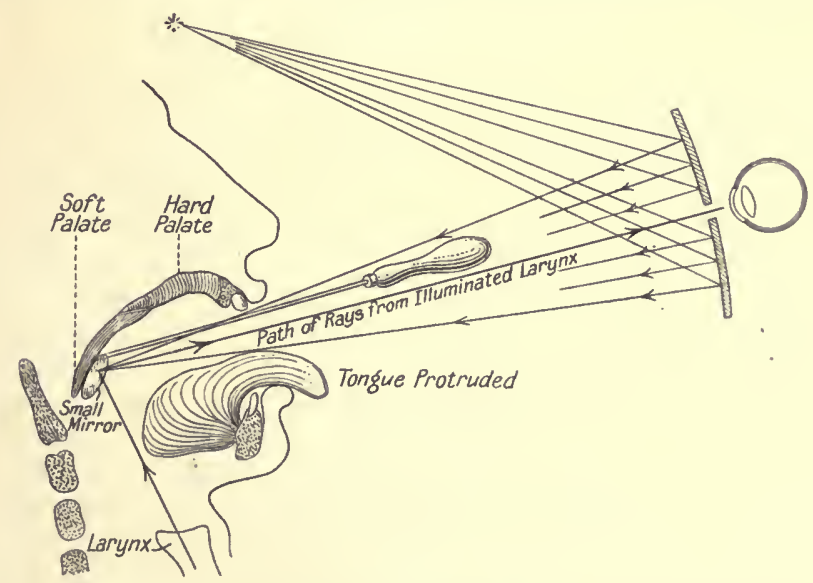

Iito. 452.-To illustrate the Manner in which a View of the Interior of the IAARYNX IS OBTAINED.

of co-ordination between the innervation and the muscular mechanism which has so rapidly increased in strength. The new apparatus has to be practised by the growing lad.

The structure of the larynx has becn evolved to allow the ready alteration of the length and tension of the cords. Four cartilages- 
the cricoid, the thyroid, and two arytenoids-are articulated and knit. together by ligaments.

The cricoid, shaped like a signet ring, articulates with the inferior horns of the thyroid, and can rotate round an axis which passes through these joints. Each arytenoid is jointed to the ring plate of the cricoid behind by a triangular surface. This joint allows movements in three planes.

The cartilages can glide outwards and separate from each other. They can turn round a vertical axis (i.e., an axis in the direction of the trachca), whereby their vocal processes which project forwards are turned outwards or inwards. They can move round an axis which passes inwards and upwards from below and outwards, whereby the vocal processes glide forwards and outwards, or backwards and inwards. These movements are limited by a strong band-the crico-arytenoid ligament.

The mucous membrane of the larynx is raised into folds which run from before backwards. The false vocal cords do not reach so far

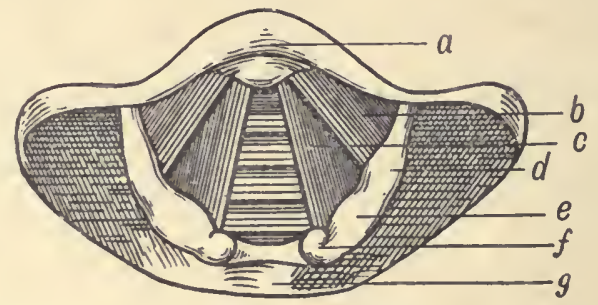

Fig. 453.-VIEW of Larynx obtained by thf. Iaryagoscope.

$a$, Epiglottis; $b$, thyroid; $c$, vocal cord; $d$, aryepiglottidean fold; $e$, cartilage ot II risberg; $f$, cartilage of Santorini; $g$, pharynx.

middlewards as the true. The true cords in section have the shape of a three-sided prism. The upper side of each is vertical to the longitudinal direction of the windpipc, the under surface slopes up to meet this, and the edges so formed become sharp during vocalization: The cords run from the vocal processes of the arytenoids to about the middle of the angle formed by the two wings of the thyroid cartilage. The cords contain much elastic tissue and the fibres of the thyro-arytenoideus muscle. The part of the rima between the cords is called pars vocalis, and the part between the arytenoid cartilages pars respiratoria. The muscular mechanism for changing tension, length, and thickness, in addition to the laryngeal muscles, includes the sterno-thyroid, hyo-thyroid, and laryngo-pharyngeal muscles. These act indirectly, fixing the larynx and steadying it for the direct action of the laryngeal muscles.

The Posterior Crico-Arytenoid Muscles.-Each arises from the posterior surface of the ring plate of the criso: $\mathrm{d}$, and is inserted into the muscular process of an arytenoid. They pull these processes inwards, and so turn the vocal process outwards. Their antagonists 
are the lateral crico-arytenoid muscles; each arises from the

- inner surface of the ring of the cricoid, and is inserted on the muscular processes of an arytenoid. They close the chink of the glottis.

The arytenoid muscles, transverse and oblique, bring the two arytenoid cartilages together. If these muscles are slack, the lateral and posterior crico-arytenoids, acting together, widen the chink.

The crico-thyroids are the chief tighteners of the cords. The fibres arise from the outer surface of the ring on either side, and run upwards and backwards to the thyroid. They pull the front part of the ring up to the thyroid and depress the ring-plate; and this movement, carrying the arytenoids with it, lengthens the distance between

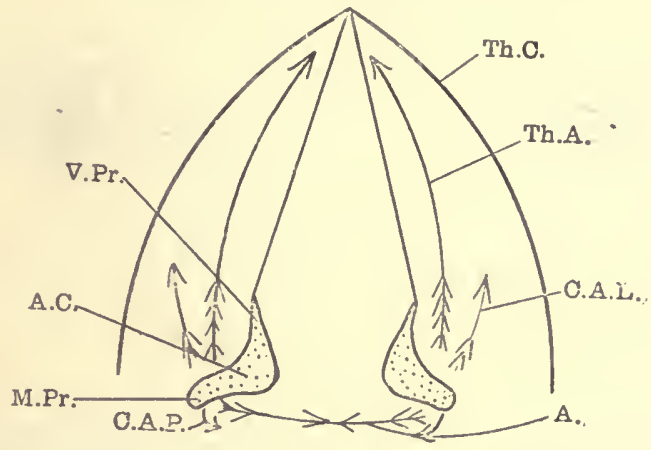

Fig. 454.-Scheme of Larvyeeal Muscles, (Parsons and Wright.)

Th.C., Thyroid eartilage; A.C., arytenoid cartilage; Th.A., thyro-arytenoideus; C.A.L., crico-arytenoideus lateralis; C.A.P., crico-arytenoideus posticus; $A$,, arytenoidcus; V.Pr., vocal process of arytenoid; M.Pr., muscular process of arytenoid.

the rocal processes and the thyroid. The antagonists are the thyroarytenoids, which run from the anterior angle of the thyroid to the vocal process, some of the fibres beginning and ending in the elastic tissue of the cords. These muscles can thicken the cord and press its edge towards the middle line. Acting with the crico-thyroid, they increase the tension of the cords.

The tension of the cords has beell measured by passing the blades of a scissor-like spring gauge between them. The greatest tension is produced by the combined action of the crico-thyroid, posterior crico-arytenoid, and thyro-arytenoid-i.e., the pull is said to be equal to that of a kilogramme. The thyro-arytenoids also can vary the tension of different parts of the cords.

The whole length of the cords, including the vocal processes, vibrates in deep notes, and the tension is raised as the pitch rises. For the higher notes, the vocal processes are pressed together and the shortened cords alone used.

In using the chest or normal register, the chink is narrow and long, 
the cords vibrate in their whole length, the pressure of the air is relatively large, the volume of air used small, and the strain of production not great. In using the head register, the chink is wider and shorter, the hind part closed, the pressure of the air smaller, but more air is used, and so the strain is greater.

The internal fibres of the thyro-arytenoids may contract alone, so that the inner edges of the cords are rendered tense, while the outcr thicker parts are slack. In whispering the air rustles past the opened cords.

While the pitch of the voice is given by the number of vibrations of the cords per second, the changing quality depends on the resonation of certain of the overtones in the resonating cavities formed by mouth, nose, and throat. The mouth can be shut up almost by
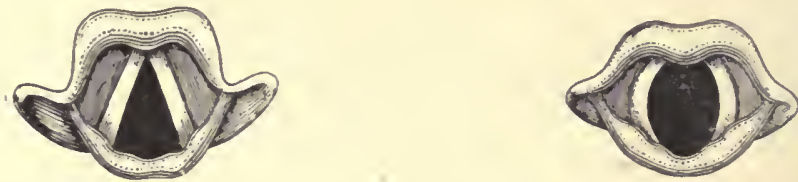

Position of rest. (The vocal cords are Position during forced inspiration. (The midway bitiven abduction and ad- $\{i$ vocal cords are in extreme abducduction )

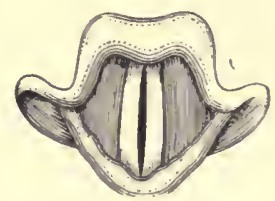

Position during rocalization. ("Chest voice.") The vocal cords are adducted and vibrating in their entire length.

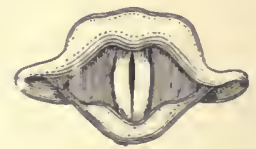

Pcsition during vocalization. (Falsetto voice.) The voca! cords are adducted and vibrating in their anterior portions only.

Fig. 45: - I ilgrams to illustrate the Positiox of the Vocal Cords exder Variods Cif.cumstaxces.

raising up the tongue and drawing in the cheeks, or it can be opened so as to form a wide cavity. The pillars of the fauces are flexible, and can be brought forwards against the tongue, or pulled widely apart. The soft palate, by sinking, can throw the nose into the resonating cavity and cut off the mouth, or, by rising, cut off the nose. By a mean position both cavities may come into play. The tongue can widen or narrow the mouth cavity, divide it into sections and connect these by slits, or cut them off from onc another. In the chest register the passage for the voice is wide and the chest cavity amplifies the resonance. In the head register the passage is narrow and the resonance is confined to the cavities of the head. While in singing and vocalization the rocal cords twang, in whispered speech the rcsonating cavities alone suffice for the production of speech. 
Vowels. - The vowels are tones produced in the larynx, and modified by the form of the resonating eavity. The eonsonants are in the main noises produced by alterations in the resonating eavity, alterations which momentarily eheek the air blast, and so lead to an explosive sound, or lead to the vibration of lips or tongue, as the air rushes through orifiees whieh are of changing form.

A $(a h)$ : The mouth is opened funnel-shaped from behind forwards, the tongue lies flat on the floor.

O $(g o)$ : The mouth opens by a narrow slit, the jaws and lips being approximated; the tongue is drawn back so that the mouth beeomes a long oval eavity.

U $(t o o)$ : The lips are still more approximated and are protraeted, the tongue pulled back and arched still more. The eavity is like a round flask with two orifices-a wider inlet and a narrow outlet.
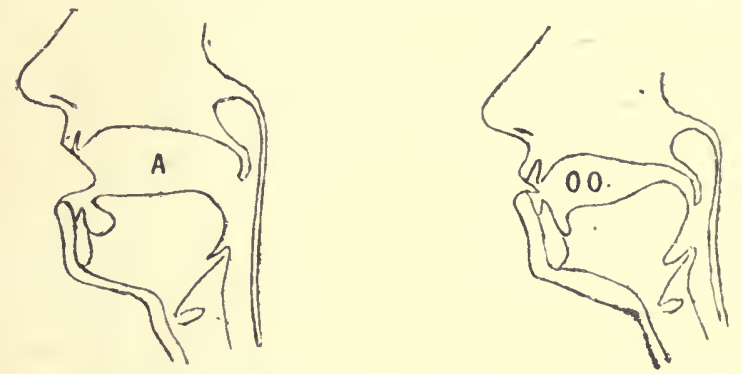

Fic. 456.-Shape of Mouth in Soundiyg Differest Vowers.

A (pay): The point of the tongue approximates to the hard palate, leaving a slit-like canal; the root of the tongue sinks. The mouth cavity takes the shape of a small-bellied flask with a short and somewhat narrow neck.

E $(m e)$ : The point of the tongue comes still nearcr to the hard palate, while the root of the tongue is still further pulled down. The mouth is thus made a larger cavity, but with a longer and narrower neck.

The diphthongs are produeed by the passage from one vowel sound to another, and cannot therefore be sustained on one note.

Sound is refleeted when it strikes against a smooth surface, sueh as a wall. From the walls of an enelosure sound may be refleeted to and fro, and the series of eehoes will produee a musical note, the pitch of whieh will not ehange at the moment when that of the musical note is ehanged, for it is produeed by the number of echoes per minute.

By taking a number of jugs and vases and sounding a musieal note into eaeh, one ean reeognize each vase by the eharaeteristie sound it produces. So are the vowels recognizable, produeed as they aro by the varying-shaped eavity of the mouth. 


\section{The Exglish Vowel Sounds.}

$\mathrm{A}_{1}$ as in father.
$\mathrm{A}_{2}$, ball.
$\mathrm{A}_{3}$, hat.
$\mathrm{A}_{4}$, gate.
$\mathrm{E}_{1}$, me.
$\mathrm{E}_{2}$, men.
$\mathrm{OO} "$ too.
$\mathrm{O}_{1} "$ not.
$\mathrm{O}_{2}$, no.

$I_{1}$ as in girl.

$\mathbf{I}_{2}$, it.

$\mathrm{U}_{1}$, fur.

$\mathrm{U}_{2}$, , hut.

$\mathrm{U}_{3}$, , book.

$\mathrm{E}_{2}$, men

00 , too. $\mathrm{Ai}$, hair.

$\mathrm{O}_{2}$, no. Ou ", how.

Consonants may be classified as follows:-To note the difference between voiced and voiceless, say "wonderful," and note the break in the voice at $f$.

Consonants.

\begin{tabular}{|c|c|c|c|c|c|c|c|}
\hline \multirow[b]{2}{*}{ Labials } & \multirow[b]{2}{*}{. } & \multirow[b]{2}{*}{$\cdots$} & \multirow[b]{2}{*}{$\cdots$} & \multirow[b]{2}{*}{$\cdots$} & \multirow{2}{*}{$\begin{array}{c}\begin{array}{c}\text { Voiceless } \\
\text { Oral. }\end{array} \\
\mathbf{P}\end{array}$} & \multirow{2}{*}{ Voiced Oral. } & \multirow{2}{*}{$\begin{array}{c}\text { Voiced } \\
\text { Nasal. } \\
\\
\text { II }\end{array}$} \\
\hline & & & & & & & \\
\hline $\begin{array}{l}\text { Labio-dentals } \\
\text { Linguo-dentals }\end{array}$ & $\cdots$ & $\begin{array}{l}\cdots \\
\cdots\end{array}$ & $\begin{array}{l}\cdots \\
\cdots\end{array}$ & $\begin{array}{l}\cdots \\
\cdots\end{array}$ & $\begin{array}{l}\text { F } \\
\text { Th } \\
\text { S }\end{array}$ & $\begin{array}{l}\text { V } \\
\text { Th } \\
\text { Z }\end{array}$ & \\
\hline \multicolumn{3}{|c|}{ Anterior linguo-palatals } & . & .. & $\begin{array}{l}\text { Sh } \\
\text { T }\end{array}$ & $\begin{array}{c}\mathrm{Zh} \\
\mathrm{D} \\
\mathrm{L} \\
\mathrm{R} \text { (trilled) }\end{array}$ & $\mathrm{N}$ \\
\hline \multicolumn{3}{|c|}{ Josterior linguo-palatals } & .. & .. & $\stackrel{\mathrm{K}}{\mathrm{H} \text { or } \mathrm{Ch}}$ & 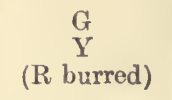 & $\mathrm{Ng}$ \\
\hline
\end{tabular}

Explosives.-B : Vocalized, lips shut and burst open.

P: The same, only not vocalized.

D: Tongue applied to upper teeth, vocalization, and tongue withdrawn suddenly so that blast explodes out.

$\mathbf{T}$ : The same, only silent.

$\mathrm{G}$ : Breath stopped by tongue against palate.

K: The same, silent.

Qu: Soft palate and back of tongue act as stop.

Vibratives.-S: Tip of tongue close to front teeth, and air hisses out between.

Z: A vocalised hiss.

Sh: Tongue close to hard palate in front.

$\mathbf{R}$ burred: Tip of tongue drawn as far back as possible and close to palate.

$\mathbf{R}$ trilled: Vibration of front of tongue against front teeth. 
F : Lower lip against edge of upper teeth and air blown through.

V: The same plus vocalization.

W: Mouth not quite closed by lips and a blast of air.

Th: Small passage between tongue and middle incisors and air blown through.

M: Uvula down, way into nose open, equals a nasal B.

$\mathbf{N}$ : Equals a nasal L.

$\mathrm{Ng}$ : Equals a nasal $\mathbf{G}$.

H: Blast of air through passage formed by parts about the root of tongue.

Man's power of speech depends, not on any great alteration of the sound-producing mechanism, but on the perfection of the nervous control over, and co-ordination of, this niechanism. The stammerer lacks the power of co-ordination, and is made worse by hurry, ill-health, and nervous excitement, better by slow and deliberate efforts at speech. Certain initial consonants are his stumbling-block.

In lisping one consonant is used for another- $t$ for $k$; th for $s$; $f$ for $t h$; $w$ for $r$. In the "Bread and Cheesc Riots" of Richard II.'s time the London mob put to death all foreign workmen from Hanse towns who pronounced " br ead and cheese" with an accent. "Shibboleth" was a test word used by Gilead to identify the Ephraimites who pronounced it "Sibboleth." A foreigner, particularly a German, can usually be detected by the difficulty he experiences in pronouncing th in the English language. 


\section{CHAPTER LXXVI}

\section{THE AUTONOMIC NERVOUS SYSTEM}

THIS system supplies the viscera, vascular system, sweat glands, erector muscles of the hairs, and intrinsic muscles of the cye-in fact,

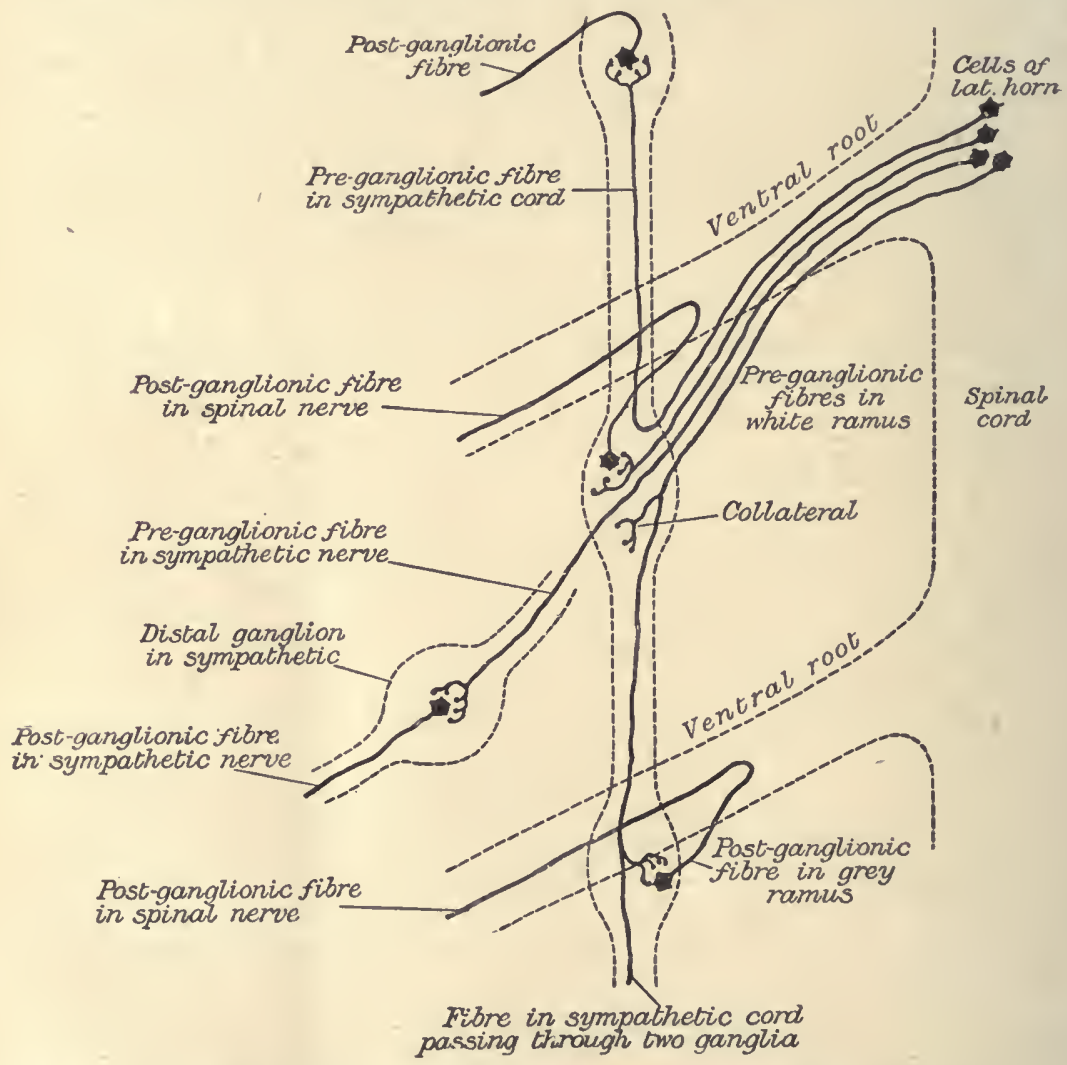

Fig. 457.-Diagram of The Arraygemext of Fibres in the Sympatietic Nervous SYsTfM. (From "Quain's Anatomy.")

all secreting glands and muscles apart from the voluntary muscles. It consists of groups of nerve fibres of the splanchnic type and the ganglia with which they make connection. It is so called because it 
is apparently self-governing and independent of cerebral control. The systcm comprises the sympathetic nerves and their associated ganglia, the sympathetic nervous system, and certain cranial and sacral nerves and ganglia, the cranial and sacral autonomic systems. The fibres are both efferent and afferent.

The Sympathetic Nervous System.-The ganglia connected with this system form a well-marked chain, the lateral chain, lying on either side of the vertebral column, and extending from the neck to the . coccygeal region. In addition there are accessory ganglia (collateral

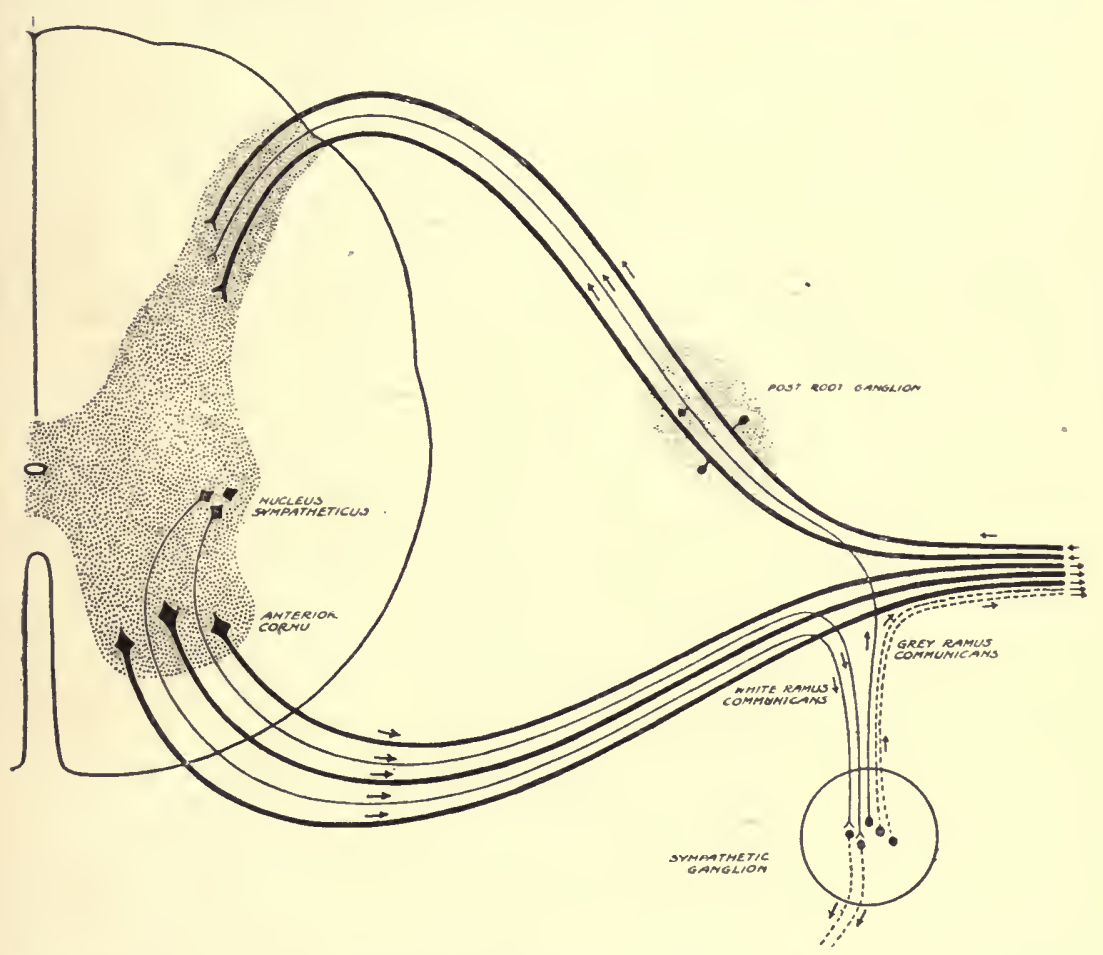

Fig. 458.-Diagray of the Arrangement of Fibres in a Mixed Syinal Nerve. (From Purves Stewart's "Diagnosis of Nervous Diseases.")

ganglia), lying in the abdomen in close connection with the aorta and the large branches arising from it-the semilunar or solar, the superior mesenteric and inferior mesenteric ganglia.

These ganglia are connected with the spinal cord by means of small efferent medullated fibres (the white rami) which pass out by the anterior roots. Each fibre ends by arborizing round the cells of a ganglion. These are the preganglionic fibres. From the cells of the ganglia arise the terminal fibres which go to the various effector organs, smooth muscle, cardiac muscle, or glands. These are known as the 
postganglionic fibres, and are non-medullated. Those that pass back to the spinal nerves form the grey rami communicantes (Fig. 459). The cell-stations of the preganglionic fibres are traced by the nicotine method. It is found that when a ganglion is painted with nicotine

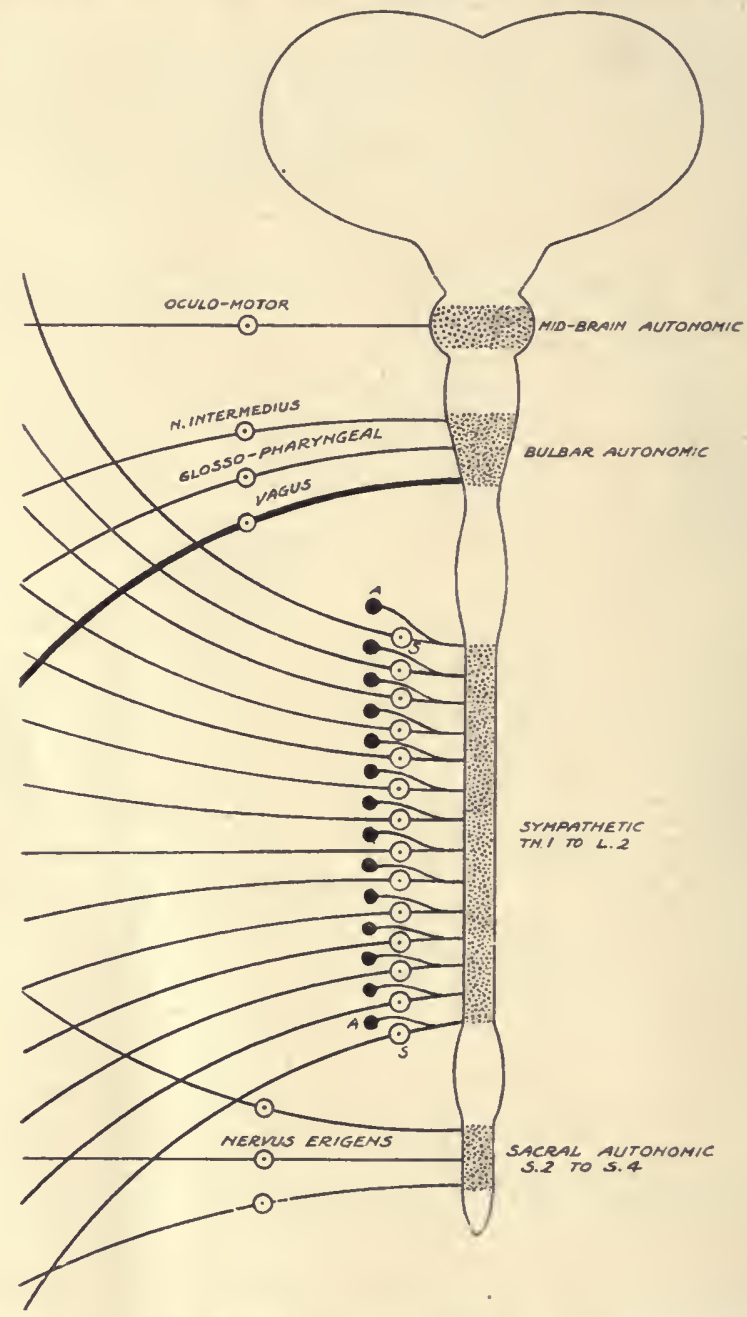

Fig. 459.-The Adtoxomic Nervous Srstem (After Purves Stewart.)

A, Chromaffinic tissue yielding adrenalin; S, sympathetic ganglion.

the preganglionic nerve endings are first stimulated and then paralyzed; when the effect of stimulation of the preganglionic nerve is abolished, stimulation of the postganglionic fibres arising from the ganglion still has its effect. By observing the effects of stimulation of the pre- 
ganglionic fibres before and after painting a ganglion with nicotine, it is possible to determine which set of preganglionic fibres makes connection with the cells of the painted ganglion.

By this means it has been found that the preganglionic fibres passing out from the cord in the white ramus may either end at once in the ganglion which they first enter, or pass upwards or downwards to end in neighbouring lateral ganglia in the sympathetic chain, or . pass through to connect with the abdominal group of collateral ganglia. Each fibre has one cell-station in one ganglion, and no more than one. The white rami emerge from the spinal cord by the anterior roots of the second thoracic to the third lumbar nerves. On examining microscopically cross-sections of thesc roots, the sympathetic fibres are distinguished by their small size. The grey rami which arise in the ganglia connected with these fibres do not necessarily pass back to the spinal nerves coming from the same segment of the spinal cord. Thus the white rami for the sympathetic nerves to the fore-limb are the fourth to the tenth thoracic; the grey rami ascend to join the nerves of the cervical nerves forming the brachial plexus.

For this reason it is necessary to distinguish between the effect of stimulation on a spinal nerve when it contains only the white ramus, and the effect on the same nerve when it has received the grey ramus.

The origin of the sympathetic fibres which supply each part has been determined by stimulating the anterior roots of the spinal nerves, These contain only outgoing preganglionic fibres.

The Function of the Ganglia.-The function of the ganglia is that of distributing-stations, whereby the impulses destined for certain parts are collected together into the appropriate efferent postganglionic nerves. The execution of certain so-called reflex actions has been ascribed to the ganglia, but these seem to be of the naturc of the reflexes concerned in paradoxical contraction, and are more correctly termed "axon reflexes." The co-ordinate peristalsis of the intestine is, however, carried out by the ganglionic plexus in its wall, and this proves that this plexus has the power of executing functions of the same order as those of the central nervous system. The destination, origin, cell-station, and effect, of the various efferent preganglionic fibres may be summarized as shown in the first table on p. 752 .

The Cranial and Sacral Autonomic Systems.-These are characterized by the length of their medullated preganglionic fibres, and by the fact that the ganglia for the most part are situated either very close to or actually in the organ supplied. For example, the ganglia for the submaxillary and sublingual glands, are situated close to the glands; the ganglia for the cardiac fibres of the vagus are actually in the heart itself.

The cell-stations of these fibres can be traced by the nicotinc method. For example, painting the sinu-auricular groove of the frog's heart with nicotine abolishes the effect of the vagus nerve, but not the effect of direct stimulation of the groove. On the contrary, 
atropine abolishes both effects. This is because nicotine paralyzes only the preganglionic, atropine paralyzes the postganglionic nerve endings also.

\begin{tabular}{|c|c|c|c|}
\hline Destination. & Origin. & Cell-Station. & Effect. \\
\hline Head and neck & $\begin{array}{l}\text { 1-5 Th., } \\
\text { ehiefly } \\
2 \text { and } 3 \mathrm{Th} \text {. }\end{array}$ & $\begin{array}{l}\text { Superior } \\
\text { cervieal } \\
\text { ganglion }\end{array}$ & $\begin{array}{l}\text { Vaso-constrietor (? brain); dilator } \\
\text { to pupil; secretory (trophic) to } \\
\text { salivary glands and sweat } \\
\text { glands; ? raso-dilator to lower } \\
\text { lip and pharynx. }\end{array}$ \\
\hline Upper limb & 4-10 Th. & Stellate & $\begin{array}{l}\text { Vaso-constrietor; secretory to } \\
\text { sweat glands. }\end{array}$ \\
\hline Thorax & 1.5 Th. & $\begin{array}{l}\text { Inferior } \\
\text { eervical and } \\
\text { stellate }\end{array}$ & $\begin{array}{l}\text { Accelerator to heart; ? vaso-eon- } \\
\text { strictor to heart and lungs. }\end{array}$ \\
\hline Abdomen .. & $\begin{array}{l}\text { 6-12 Th. } \\
\text { 1-3 L. }\end{array}$ & $\begin{array}{l}\text { Chiefly the } \\
\text { collateral } \\
\text { ganglia: solar, } \\
\text { semilunar, } \\
\text { superior } \\
\text { mesenteris }\end{array}$ & $\begin{array}{l}\text { Vaso-constrietor: stomach, small } \\
\text { intestine, kidney, and spleen. } \\
\text { Inhibitory: stomach, small in- } \\
\text { testine. } \\
\text { Motor: ilen-eolie sphineter. } \\
\text { Glyeogenic: liver. }\end{array}$ \\
\hline Pelvis & $\begin{array}{l}12 \mathrm{Th} . \\
1-3 \mathrm{~L} .\end{array}$ & $\begin{array}{l}\text { Inferior } \\
\text { mesenteric }\end{array}$ & $\begin{array}{l}\text { Vaso-constrietor to pelvic viscera; } \\
\text { inhibitory to colon; motor and } \\
\text { inhibitory to bladder; motor } \\
\text { and inhibitory to uterus; motor } \\
\text { to retractor penis (dog). }\end{array}$ \\
\hline Lower $\operatorname{limb}$ & $\begin{array}{l}\text { 11, } 12 \mathrm{Th} . \\
1-3 \mathrm{~L}\end{array}$ & $\begin{array}{c}\text { Lumbar } \\
\text { ganglia }(6,7) ; \\
\text { sacral } \\
\text { ganglion (1) }\end{array}$ & $\begin{array}{l}\text { Vaso - eonstrictor; seeretory to } \\
\text { sweat glands. }\end{array}$ \\
\hline
\end{tabular}

The cranial autonomic fibres may be summarized as follows:

Nerve.

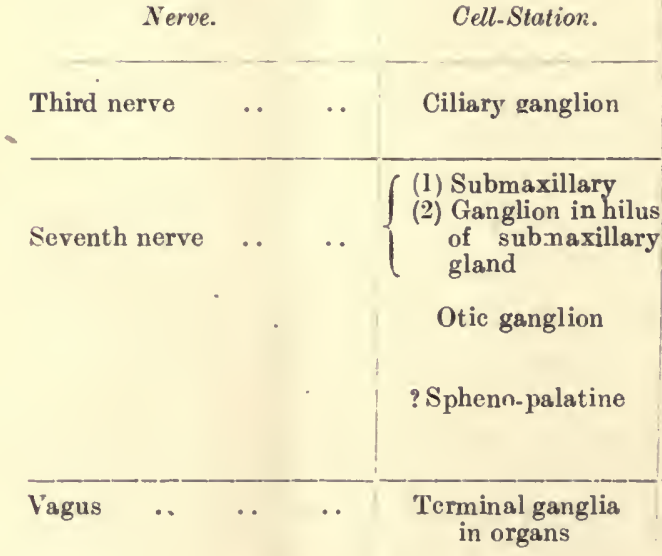

Motor to sphincter pupillæ and ciliary muscles.

(1) Vaso-dilator to tongue; secretory and vaso-dilator to sublingual gland.

(2) Secretory and vaso-dilator to submaxillary.

Secretory and vaso-dilator to parotid, and ? vaso-dilator to back of tongue.

? Secretory and vaso-dilator to mucous membrane of nose, soft palate, and pharynx.

Motor to œesophagus, bronchioles, stoniach, small intestine; inhibitory to heart; secretory to stomach glands. 
The sacral autonomic fibres run in the pelvic viseeral nerve. The cell-station is in the hypogastric plexus at the base of the bladder. The nerve is--vaso-dilator to the penis; motor to bladder, colon, rectum; inhibitory to sphincter of bladder and retractor penis.

Afferent Fibres.-Thus far we have dealt only with the efferent fibres, which form a great preponderance of the fibres of these systems. The afferent fibres make no connections with the cells of the various groups of ganglia, their cells of origin being situated in the posterior root ganglia. Their main function, so far as is known, consists in carrying up impulses which help to regulate blood-pressure. Stimulation of the central end of a white ramus causes a rise in arterial pressure, due to increased vaso-constriction; stimulation of the central end of the afferent nerve from the heart (the depressor) causes a great fall of blood-pressure, due to inhibition of vaso-constriction, especially in the splanchnic area. It is quite possible that the efferent splanchnic fibres to the liver are reflexly affected through afferent fibres of this system; stimulation of the depressor nerve and states of asphyxia bring about a conversion of glycogen to suigar.

The reflexes of these afferent fibres probably play a great part in maintaining the tone of the abdominal viscera. Normally we are not conscious of our viscera, and they are not sensitive to touch or a cutting instrument. Pain is produced, however, by the distension of any hollow viscera, and under certain pathological conditions pain may arise; but the pain is referred to those parts of the body wall which are supplied by the same nerve roots as the diseased viscera (Fig. 387, p. 661). 



\section{BOOK XIII}

\section{REPRODUC'TION}

\section{CHAPTER LXXVII \\ GROWTH AND REPRODUCTION}

LiviNG matter is characterized by the fact that it can grow, and by the fact that it can only be produced by the action of living matter; that nothing but living matter can organize the materials and forms of energy of the non-living into the living world; that each living cell possesses a type of energy which is, so to speak, attuned to the retention of certain attributes of structure and function, and to the capacity of communicating these onward to its offspring-a capacity which is termed heredity; that each living organism dies after a certain period of existence. A unicellular organism placed in a drop of water divides and divides into a multitude, but after a time the generations usually begin to deteriorate, become feebler, and finally die out. If, however, one of the shoal be placed in a vessel with one of another stock of the same species, the two will fuse and become one, with vigour entirely restored.

It has been stated that a single-celled paramœcium by successive division, first of itself and then of its progeny over a period of five years, possesses the power to reproduce to the 3,029th power, or a volume of protoplasm equal to $10^{1000}$ times the volume of the earth.

The higher animals are vast colonies of cells. Most of these eventually become feeble, and die in due season; but the generative cells fuse, reinvigorate each other, and continue the race. Thus does a man live again in his children.

The growth of the tissues depends upon the power of their cells to multiply. The tissues interact upon one another, so as to restrain and confine the growth of any one tissue within its proper boundary. How this restraint is brought about we do not know. Loss of this restraint, or the overpowering energy of growth of any one tissue results in the formation of tumours, benign or cancerous.

It has recently been shown that the growth of human tissues constitutes a type of its own, diffcring markedly from the growth in other mammals, such as the cow, horse, sheep, pig, and other domestic animals. From calculations made upon the animals during the 
period taken to double their -weight at birth, it appears that in all such animals, except man, there is a law of eonstant energy consumption, the total amount of energy neeessary to form 1 kilogramme of animal weight being the same for all animals-4,808 ealories of food. Man requires about six times this amount.

Seeondly, in sueh animals the same fraetional part of the food energy taken in is used for growth-the "growth-quotient" being 34 per cent.-34 calories of each 100 ealories of food being used for growth. In man, the growth quotient is but 5 per cent., being greatest at birth, and sinking slowly to zero at maturity, when food is used only for metabolic, and not for growth purposes.

In regard, also, to the amount of energy for each kilogramme of body weight during the period of life from maturity to death (a period of sixty years-twenty to eighty), a calculation showed that each human kilogramme requires 725,770 calories, the other animals
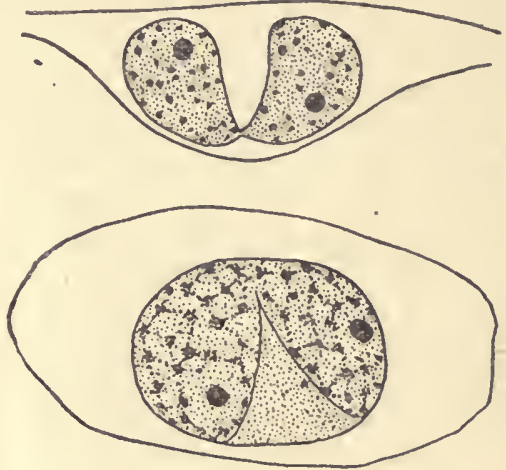

Fij. 460.-Tissues of Flat-Worm, Showixg Amitolic Division cF Nucheds. (After Child, from Dahlgren and Kepner.)

mentioned but 191,600 ealories. What exactly determines this power of assimilation it is difficult to say. If it be, as is suggested, a matter of certain ehemical eomplexes, it is obvious that these complexes in the human cells can perform the transformations and ehanges for a greater number of times than can the cells of other animals ere they expire.

Cell Reproduction.-The division of the nucleus preedes that of the cell. Separated from its nueleus, a eell is unable to grow and divide. The division of the nueleus and of the cell may be relatively simple, known as amitosis, or of complex nature, known as mitosis, or karyokinesis.

In the first proeess, amitosis, the cell divides somewhat in the following manner: At first, the nucleolus clongates at right angles to the plane in whieh division will subsequently take place. It then divides, and the two daughter nueleoli pass apart to what will be the centre of the new daughter cells. Next, the nucleus divides-rarely by a 
gradual constriction, in the same manner as the nucleolus; more often in such a manner that it appears as if it has been clean cut through its centre at the plane of division, leaving the two halves with flat parallel surfaces where the division took place. In some other cases it appears as if the nuclear membrane is the important
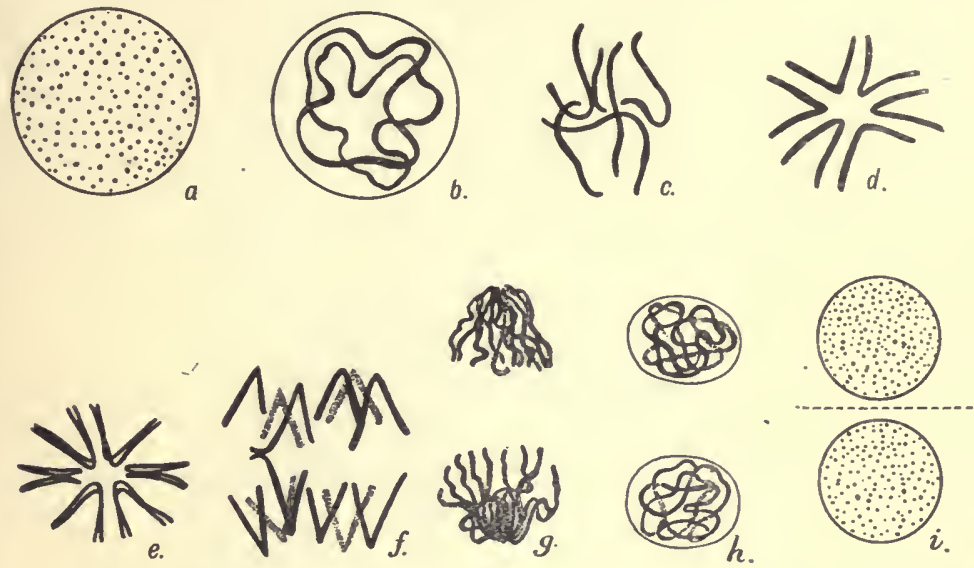

Fig. 461.-Diagrams of Chromatin Changes during she Division of a Cello (Redrawn from Dahlgren and Kepner.)

agent in the division. From the old nuclear membrane an extension passes across the middle of the nucleus, thereby forming two new nuclei with two nuclear membranes. Finally, the cell body may divide; often it does not do so. In such cases, amitosis is apparently a terminal process in the life activities of the cell, and is a method for securing more nuclear surface for the cell's activities, especially in cases of active metabolism. In the stratificd epithelia of vertebrates,
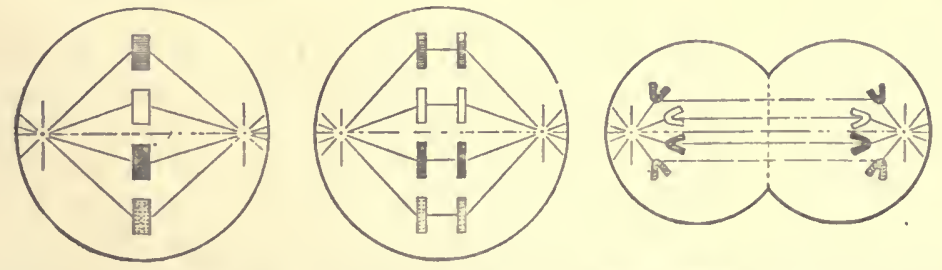

Fig. 462.-Diagray to show Distribution of Chromusomes to Daughter Celes in Ordisary or Somatic Form of Divisiox. (C. F. Walker.)

for example, although at first the cells divide by the process of mitosis, later on, towards the end of the ccll's activities, the process changes to amitosis, the cells remaining undivided (Fig. 460).

Mitosis brings about an equal division of this chromatin matcrial in the mother nucleus, and distributes it equally betwecn the two 
daughter nuclei. The chromatin is the nuclear material, which stains deeply with basic dyes, and is probably nuclein; to nucleic acid is due the affinity for basic dyes.

The series of changes in the chromatin are as follows (Fig. 461): The granules of chromatin of the resting nucleus $(a)$ become assembled to form a skein, or spireme (b). The nucleus now elongates, its membrane generally disappears, and the spireme breaks down into a number of linear fragments, or chromosomes (c), the number of which is constant for the nucleus of any given species. Thus, in Ascaris megalocephala the number is four; in man the number is sixteen. These chromosomes now assemble in the plane through which the cell will divide, forming what is sometimes known as the equatorial plate. The rods become bent in the fashion of a $V$, often

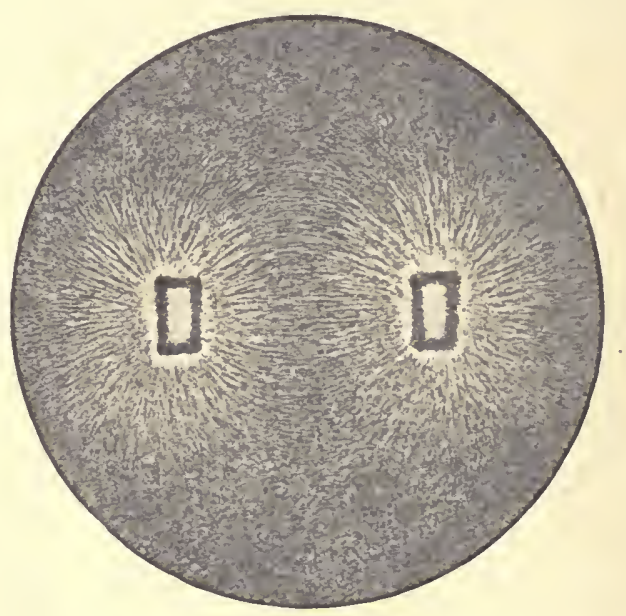

Fig. 463.-Lines of Stress in a Magaetic Field. (Verworn, after Rhumbler.)

with the angles of the $\mathrm{V}$ towards each other, thus forming a radiating figure $(d)$. These progressive changes are known as the prophase. The chromosomes now divide longitudinally to form twice the number of V's, or daughter chromosomes $(e)-$ a change termed the metaphase. These chromosomes become assembled in two sets opposite each other on either side of the plane of division, with the angles of the $\mathrm{V}$ directed away from each other $(f)$. Lastly, these two sets of chromosomes blend again to form a spireme, acquire a nuclear membrane $(g, h)$, and finally break down to form once more the granular inasses of chromatin characteristic of the resting nucleus (i). These final or regressive changes are known as the anaphase.

Frequently, the non-staining portions of the nucleus form what are called the achromatic figures of mitosis. This material forms a spiıdle of delicate fibrils lying at right angles to the plane along which 
the eell will divide. The spindle furnishes the path along which the chromatin filaments move, and probably marks out the lines of ehemieophysieal strain. These lines of stress are very like those assumed by iron particles within a magnetic field (Fig. 463). Mitotie-like figures

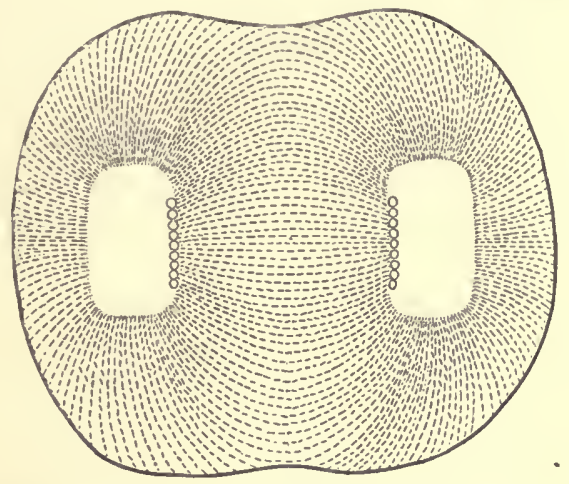

Fig. 464. -Lines of Stress in Living Dividing Ovum of Toxopreustes. (Verworn, after Wilson.)

The circumjacent fluid is of intermediate density.

ean be produced by plaeing droplets of certain solutions coloured with China ink on the surface of other solutions of greater density. Sueh figures may be well seen in many growing plants eells-for example, in those of the root-tip of the hyaeinth.

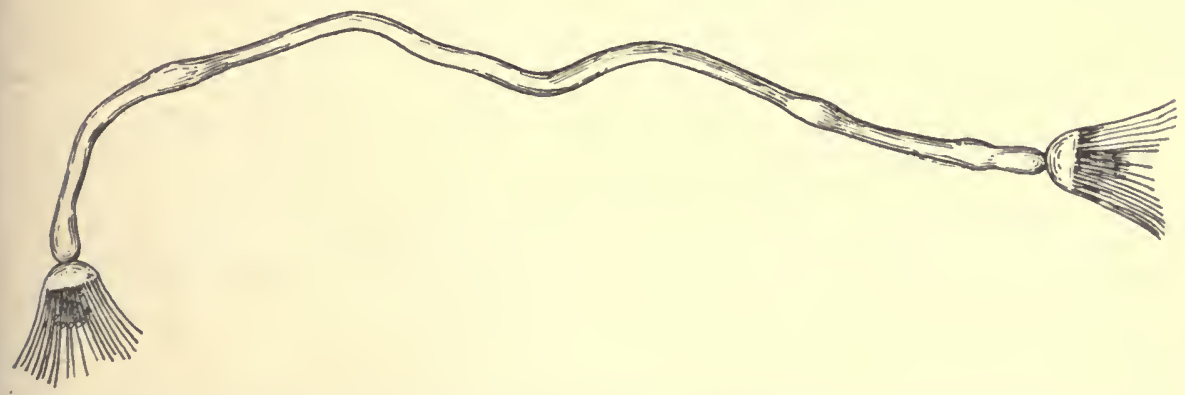

Fig. 465.-Hydrold (Tubularig) Generatisg a Head at Each End of a FragMENT OF THE SteM SUSPENDED IN WaTer. (Redrawn after Loeb, from Wilsoll's "The Coll," etc.)

In many animal eells, espccially ova whieh divide as the result of fertilization, the eentrosome divides into two daughter eentrosomes, whieh move to opposite sides of the nueleus and become surrounded by rays to form an achromatie spindle eonnecting the two daughter ccntrosomes, around the equator of which the ehromosomes arrange themselves (Fig. 467). In the anaphasc stage the divergence 
of the chromosomes seems guided by the spindle, and the new nuclei are attracted to, and formed in, the neighbourhood of the daughter centrosomes. Some authorities hold this to be as constant and permanent a feature as the division of the chromatin, but recent evidence makes this unlikely.

Reproduction.-The ancients believed that many forms of life, even of such a degree of complexity as the insects, generated spontaneously from slime and similar dead matter. In recent times, the belief in the generation of the animate from the inanimate has been confined to the very lowest forms of life. Such a belief is now dead. It has been conclusively shown that if a nutritive solution, such as milk, be

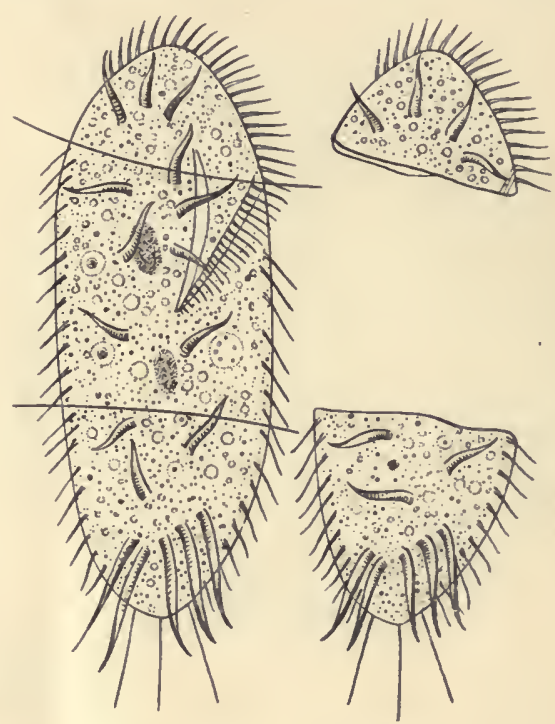

Fia. 466.--Slylunychia, axd Exucleated Fragaexts. (Redrawn after Verworn.)

The lines show the planes of section of the entire animal. The middlo piece, which contains two nuclei, regenerates an entire animal. The enucleated fragments shown on the right swim for a time and then perish.

heated for a suffic:ent time in sealed tubes at a high tempcraturc, such as $200^{\circ} \mathrm{C}$., it remains free for all time from all forms of life, and does not putrefy. Life comes only from the living. The explanation of spontaneous generation, which to many has appeared apparent, is that various forms of life, and particularly the spores of bactcria, can withstand moderatc heating or drying for a great length of time. Although apparently dead, they become revivified when again put in suitable conditions. Leuwenhoek, the famous Dutch scientist of the seventeenth century, kept in a piece of paper the red dust which he found in the gutter of his roof, and saw the little wheel animal, the rotifer, become active when the dust was wet several 
months afterwards. Radiolaria gradually dried have become active after eleven years, anguilulæ after twenty eight years. Corn found in Egyptian mummies is stated to have germinated after thousands of years.
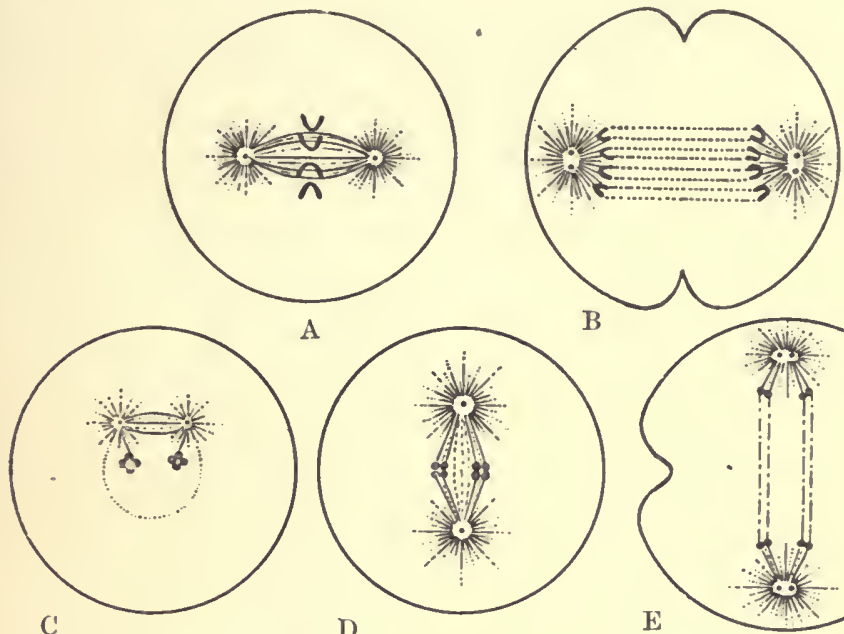

D
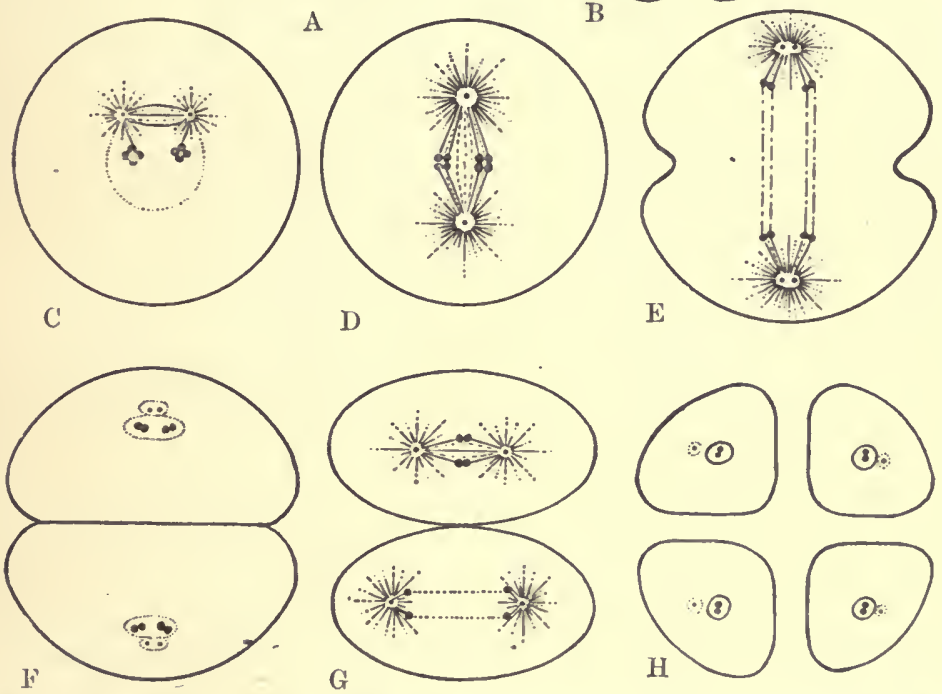

Fig. 467.-Diagrams showing the Essential Facts of Reduction in the Male. The Somatc Number of Chromosomes is supposed to BE Four. (Redrawn from Wilson's "The Cell," etc.)

$A, B$, Division of one of the spermatogonia showing full number of chromosomes (four); $C$, primary spermatocyte preparing for division: the chromatin forms two tetrads; $D, E, \dot{F}$, first division to form two secondary spermatocytes, cach of which receives two dyads; $G, H$, division of the two secondary spermatocytes to form four spermatids. Each of the latter receives two singlo chromosomes and a centrosome which passes into the middle picce of the spermatozoon.

In the development of the multicellular organism on the lines of a division of labour and differentiation of function of the cells, most important was the provision of special cells for the reproduction of the species. Through these cells the organism can, under proper conditions, give rise to new individuals, thus perpetuating the race and winning immortality, the remainder of the individual perishing after an allotted span. 
The reproductive cells may be of two kinds-asexual and sexual. The former occur only in the lower forms of life. The simplest reproduction is by the dividing of the parent organism or cell into two daughter cells. This is accompanied by the changes in the nucleus, either amitotic or mitotic. Sea-stars may shed a whole - finger, which will then develop into a new individual like the parent. A fragment of the stem of a hydroid suspended in water will generate a head at each end (Fig. 465).

Other organisms, such as the polyps, reproduce by a process of budding. From the parent organism a bud springs out, which gradually develops into an adult organism comparable in every way to the parent. Such a new organism may remain attached to the parent, thereby forming a colony of cells, or it may become detached, and lead an altogether independent existence. The nucleated portion (Fig. 466) possesses the property of regenerating an entire individual, but not the non-nucleated portions.

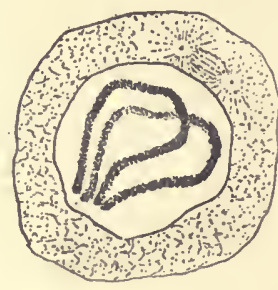

A

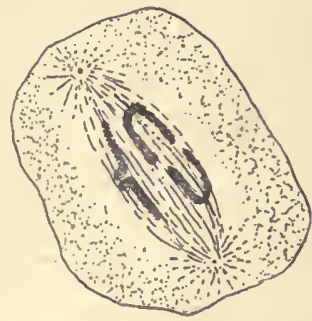

B

Fig. 468.

$A$, Early stage in meiotic division; $B$, the pairs of chromosomes separating in meiotic division. (C. E. Walker.)

But the commonest form of reproduction is that pertaining to the higher organisms-namely, sexual reproduction. In this form of reproduction the essential act consists in the actual union of two different types of cell-the gametes (the male and the female cell)often from two separate individuals. The male cell is termed the spermatozoon. It consists of little else than nuclear material. It varies in shape, and is small in size. It is essentially active, its function being to seek out the female cell and fertilize it. The female element, on the other hand, is cssentially passive. Often it is large in size, containing a large amount of reserve food material, at the expense of which the fertilized cell develops.

These reproductive elements arise from undifferentiated germ epithelium. At first, multiplication of the cells is by means of the karyokinetic division already described, the cells thus formed being termed respectively spermatogonia and oogonia. In the final stages, however, a new form of cell division appears, known as meiotic division, or heterotype mitosis. In this form of division but half the number of chromosomes is formed, as compared with the usual 
form. Further, when division takes place, the chromosomes, instead of dividing lengthwise, divide transversely into halves, one half going into each of the new daughter cells. In this way the daughter cells have but half the number of chromosomes of the parent cell, and it is assumed that the chromatin material may be of different quality in the daughter cells. Thus, supposing there are four chromosomes (see Fig. 469), by this form of division various combinations may occur, and it is suggested that it is in this way that hereditary characters are handed on, and that the offspring may differ among themselves according to the nature of the chromatin material derived from each parent.

In the case of the male gamete, the result of ordinary somatic division yields cells known as spermatogonia. These develop into cells known as primary spermatocytes. By meiotic division, the primary spermatocytes give rise first to seconlary spermatocytes, and then to the spermatids, which develop into the functional spermatozoa. We have thus-(1) a somatic division stage of the primary germ cell; (2) a growth period of the spermatogonia to spermatocytes; (3) a maturation period of the spermatocytes to spermatids.
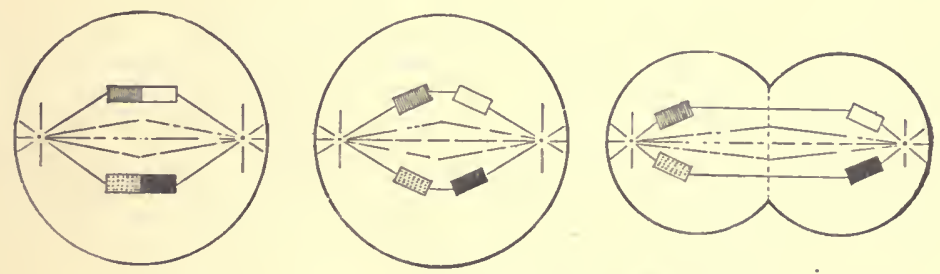

Fig. 469.-Diagram to show the Distribution of Ciromosome3 to the Daughiver Cells is the Meiotic or Redecing Form of Division. (C. F. Walker.)

In the case of the female gamete, we have the corresponding development by the somatic type of division of germ cell to oogonia. Then follows the growth period, with the formation of the primary oocytes from the oogonia. Lastly follows the maturation pcriod, with the meiotic division of the cells. The essential difference between the maturation of the oocyte, as compared with the spermatocyte, is that from the oocytc only one mature ovum, or egg, is formed, whercas each primary spermatocytc yields four mature spcrmatids. In the division of the primary oocyte, the secondary oocytes formed are the large ovum and a first "polar body." The ovum again divides into a mature egg and a small second polar body, while the first polar body also divides. The result, therefore, of the maturation of the oocyte is the formation of one functional mature egg and threc functionless polar bodies (Fig. 470). The result of the maturation of both spermatocyte and oocyte is that the amount of chromatin matcrial is reduced to half, the full complement of chromatin being restored in the fusion .of the inale and female gametes in the process of fertilization. 
The Reproductive Processes in the Male.-The sexual apparatus in the male consists of-(1) the testis, in which the spermatozoa are
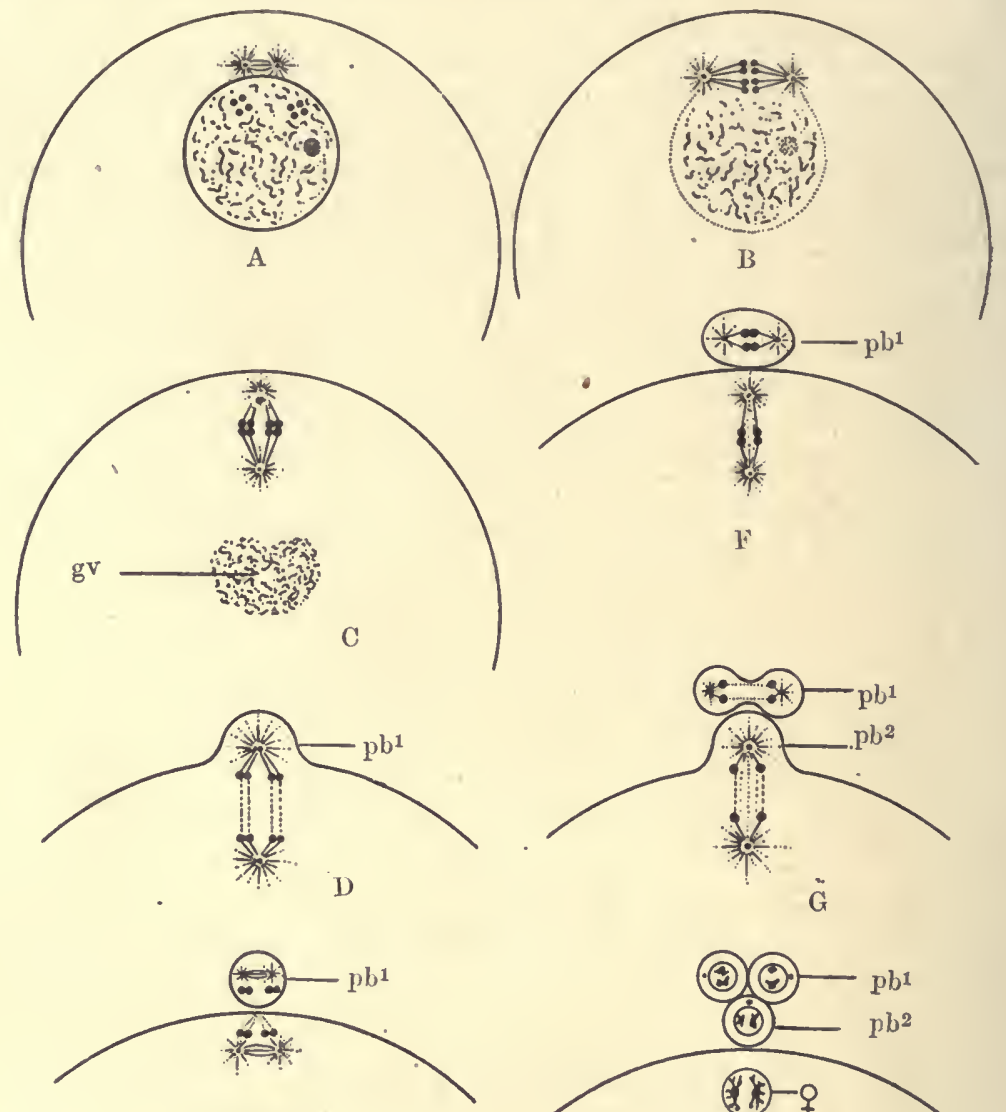

$\mathbf{E}$

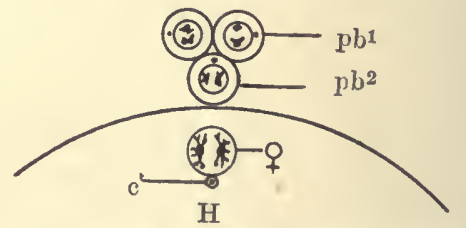

Hig. 470.-Diagraus showing the Essential FaCts in the Maturation of the Ovum. The Somatic Number of Ciromosomes is supposed to be Four. (Rodrawn from Wilson's "The Cell," etc.)

$A$, Initial phase: two tetrads have been formed in tho germinal vesicle; $B$, two tetrads have been drawn up about them to form the equatorial plate of the first mitotic figure; $C$, the mitotio figure has rotated into position, leaving the remains of the germinal vesicle at $g v ; D$, formation of first polar body $\left(p b^{1}\right)$ : each tetrad divides into two dyads; $E$, first polar body formed, two dyads in it and in the egg; $F$, preparation for the sccond division; $G$, second polar body $\left(p l^{2}\right)$ forming and tho first dividing: each dyad divides into two single chromosomes; $H$, final result: thrce polar bodies and the egg nucleus ( $q$ ), oach eontaining two single chromosomes (half the somatic number); $c$, tho egg-centrosome, which now degencrates and is lost.

produced; (2) in higher animals, accessory sexual glands (the prostate, vesiculæ seminales, and glands of Cowper), which aid in the formation 
of the seminal fluid; (3) the intromittent organ, or penis, by means of which the semen is introduced into the female during the act of sexual intercourse, or coitus.

The Testes.-The testes consist essentially of two sets of cells(1) the interstitial cells, which play a part in the acquisition of secondary sexual characteristics; (2) the germinal cells, from which the spermatozoa are developed, and passed by a long system of ducts to the exterior. The testis is enclosed in a thick capsule, known as the tunica albuginea. From this capsule septa pass into the testis, dividing it into a number of compartments. In the compartments are long convoluted seminal tubules, lined by the germinal epithelium. In the different layers of epithelium the various stages of the " maturation of the spermatogonia," spermatogenesis, or may be seen. Most externally, lying upon the basement membrane, are the spermatogonia, supported by elongated "nurse cells," or the "cells of Sertoli." Next comes two layers of spermatocytes-large cells with marked karyokinetic nuclei-and then the layer of spermatids-small cells with a well-marked round nucleus (Fig. 471).
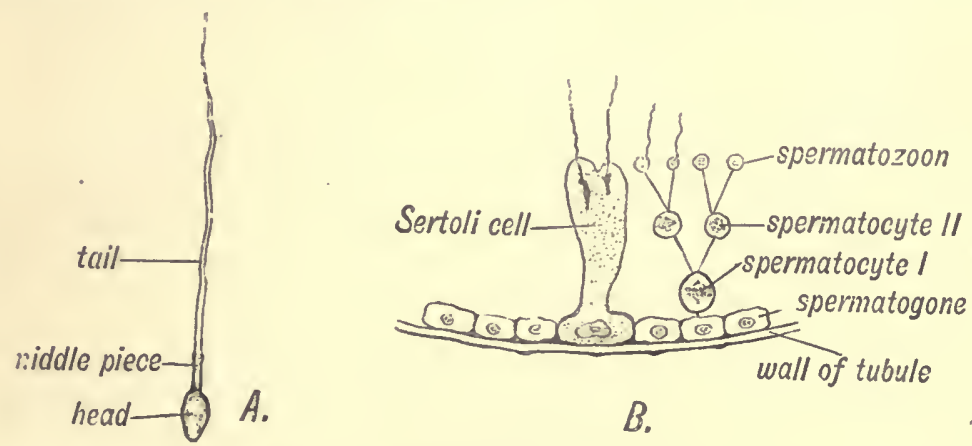

Fig. 471 .

$A$, Diagram of a spermatozoon; $B$, diagram showing the origin of spermatozoa from the living calls (spermatogonia) of the tubules of the testiele. (K ith.)

The spermatids also exhibit various stages of transformation to spermatozoa. In this process the nucleus becomes elongated to form the head of the cell, the main mass of cytoplasm goes to form the middle piece, while a filament of cytoplasm grows out to form the whip-like tail (see Fig. 471). When fully mature, the spermatozoa become detachel, but connect themselves for a time with the free end of the Sertoli cells.

The seminal tubules are supported by a number of fine connectivetissue fibres, in which run the bloodvessels and lymphatics, and in which are also situated the interstitial cells which play so important a part in the acquisition of the secondary male charactcristics (see p. 505). The convoluted seminal tubules of cach compartment pass to join with a few straight tubules (the tubuli recti), to form a network known as the rete testis. From this emerge the vasa efferentia (twelve to fifteen 
in number). These form the epididymis, the tubules gradually uniting to form the vas deferens. The vas deferens is associated with the nerves and bloodvessels of the testis in forming the spcrmatic cord.

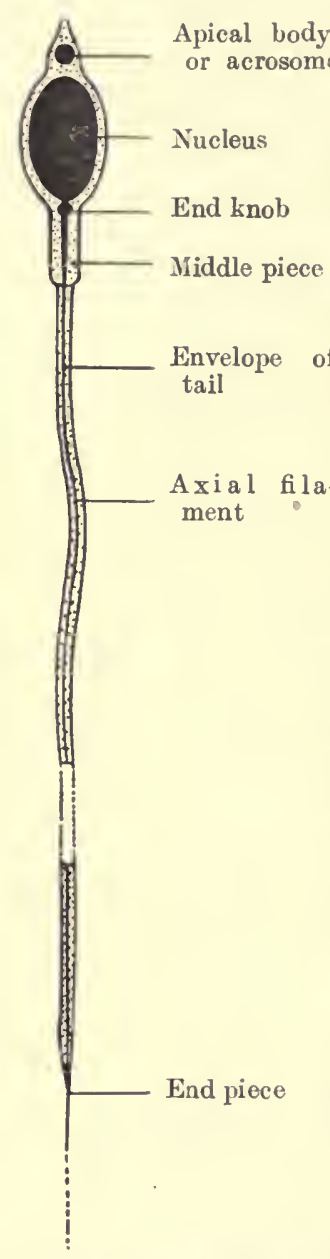

Fig. 472.-Diagrail OF SPERMATOZOOx. (Redrawn from Wilson's "The Cell," etc.)

The Accessory Glands.-The exact function of the accessory glands is not quite clcar. The accessory sccretions, mixed with the testicular secretion, are believed to aid the movements of the spermatozoa, probably owing to their alkalinity. It is stated that extirpation of the prostate causes sterility, owing to the withdrawal of its secretion. The prostatic secretion is serous and milky in appearance, amphoteric in reaction. That the accessory apparatus is of value is shown by the fact that it develops at puberty, and this development is prevented by early castration. Castration after puberty leads to an atrophy of the aparatus.

The Seminal Fluid.-The seminal fluid consists of the external secretion of the testes combined with the secretion of the glands of the vas deferens, of the glands of Cowper, and of the prostate and vesiculæ seminales. It is a whitish viscous fluid, alkaline in reaction, contains about 90 per cent. of water, and is of a specific gravity of about 1034. The inorganic substances $(0.9$ per cent.) consist chiefly of sodium chloride and the phosphates of calcium and magnesium. The organic bodies of the semen consist of nuclein attached to protamine, some albumin and proteose, fats, and the lipoids lecithin and cholesterin.

The spermatozoon is the active agent of reproduction contained in the male ejaculation. It varies in form with different types of animal, but in all higher forms consists essentially of a head piece, a middle piece, and a flagellum-like tail piecc. In man the head is pear-shaped (Fig. 472). Movements are made by the lashings of the flagellumlike tail. The movements are increased by weak alkali, inhibited by acid or distilled water.

The penis serves the purpose of introducing the seminal fluid in the sexual apparatus of the female. It consists largely of erectile 
tissue, which, under the influence of dilator nerves, becomes engorged with blood, leading to the erection of the organ. The urethra passes through the corpus spongiosum of the penis.

The period of sexual life begins in the male with the onset of puberty, and continues more or less throughout life. There is undoubtedly a decline in fertility in the later years of life, but it is not uncommon for men of seventy or even eighty years of age to become the fathers of children.

The Reproductive Processes in the Female.-The sexual apparatus of the female consists of the egg-bearing organ, or ovary, in which the eggs are matured, and the womb, or uterus, in which the fœtus is developed from the fertilized ovum, or oosperm. Accessory to these are the oviducts, or Fallopian tubes, which conduct the egg

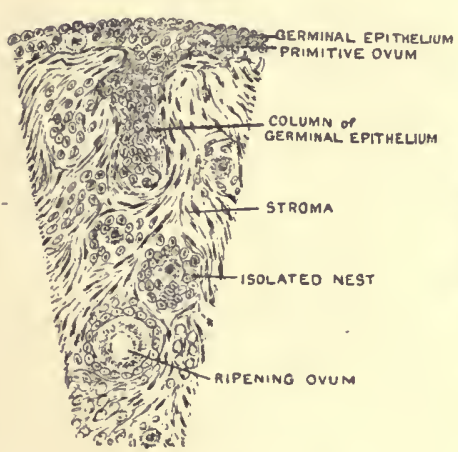

Fig. 473.-Diagrammatic Section of Ovary of Fifth-Month Fetus, SHOWING Nests of Germinal EPIthelium and Unripe Graafian Foldicle. (Keith.)

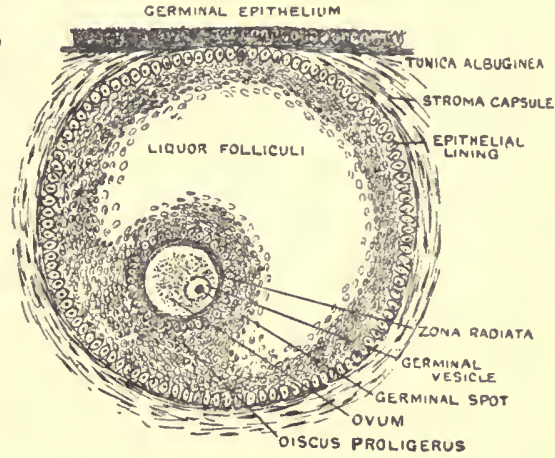

Fig. 474.-Ripe Graafian Follicle at PUberty. (Keith.)

to the uterus, and the vulva and vagina, by means of which the male element is introduced into the female, and through which the fulltime foetus is passed into the world.

The ovary consists of - (1) the germinal cells, which by maturation provide the female gametes, the ova; (2) the interstitial cells, which furnish an internal secretion concerned in the development of the secondary female characteristics (see p. 506). A fibrous stroma carries the bloodvessels, lymphatics, and nerves, which supply the organ, and its cellular elements form the so-called interstitial cells which produce the internal secretion. The cells of the germinal epithelium lie just beneath the external capsule-the tunica albuginea. These divide to produce the oogonea, which, in devcloping into oocytes, gradually sink inwards into the stroma and are surrounded by a layer of stroma cells. Thus is formed an immature Graafian follicle. Eventually the stroma cells divide to form a layer round the oocyte and a layer of cells which surround the follicle. These two laycrs 
multiply, and a fluid becomes secreted between them, so that a mature follicle is formed, the outer layer of cells forming what is known as the membrana granulosa, which is enclosed in a fibrous capsule derived from the stroma, and an inner ovum surrounded by a mass of cells, known as the discus proligerus, the remainder of the follicle being filled with fluid, the liquor folliculi. When fully mature, the follicle is of such a size that it bulges the surface of the ovary, and after a time ruptures, shedding the ovum into the abdominal cavity in the neighbourhood of the Fallopian tube. This process is known as ovulation. The rupture is brought about by cellular activity within the follicle. The external wall of the follicle towards the surface of the ovary is thinned away during the growth, so that it ruptures

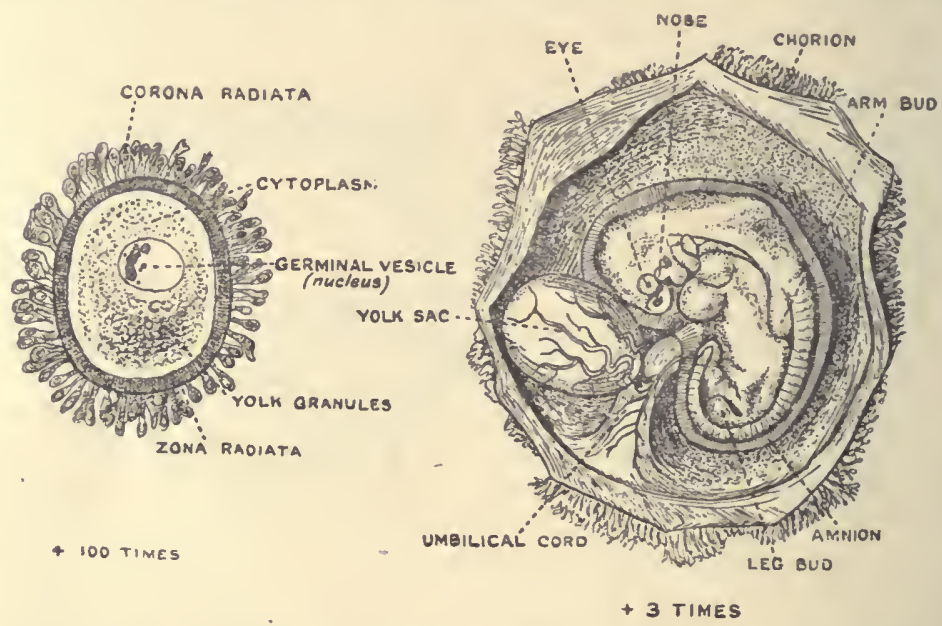

Fig. 475.-The Parts of a Mature Human Ovum. Diameter $\frac{1}{2} \delta$ INCh. (Keith, after Van der Stricht.)

Fig, 476.-Humax Embryo and Its Membranes at ExD OF First Mosth : EMbryo about $\frac{1}{3}$ Ixch, THE ExVElope OF EMBRYoxal MeMBRANES ABOUT AN INCH. (Keith, after Kellmann.)

finally under the strain of the fluid secreted within the follicle. After the rupture, the cells of the membrana granulosa proliferate to form a yellowish tissue, known as the corpus luteum. Connective-tissuc septa carrying bloodvessels bccome developed in the corpus luteum. The corpus luteum is normally about 3 inch in diameter. At the end of three weeks it begins to diminish in size, so that it is a mere scar at the end of two months, and is absent at the end of six months. If, however, impregnation takes place, the corpus luteum grows in size, until at the end of the second month it is $\frac{7}{4}$ inch in diameter. It remains this size until the sixth month of pregnancy, when it gradually decreases in size and becomes converted into scar tissuc. The functions of the corpus luteum have already been mentioned (p. 507). 
The human uterus is a more or less pear-shaped muscular organ about 3 inches long. It c snzists of the main upper part, or body, and of the neck, or cervix. The internal cavity is about $2 \frac{1}{2}$ inches long. It is lined by a mucous membrane consisting of a single layer of epithelium and numerous mucous glands resting upon a fibrous submucous coat. Normally, especially in those who have not had children, the cavity is almost absent, being more or less of the nature of a narrow channel. The oviducts enter into the upper part of the body; the cervix connects with the vagina below.

The vaginal canal is noteworthy for its power of extensibility during parturition. It is lined by a mucous membrame. This is thrown into rugæ, or ridges. The channel is lined by a stratified epithelium. In the mucous membrane are glands which pour out a faintly acid secretion.

The Sexual Life of the Female.-In woman, the period of sexual activity begins about the twelfth to seventeenth year of age, varying with race and climate, being earlier in Southern and later in Northern races. In the temperate zone the age is about thirteen to fifteen. Besides the acquisition of the secondary female characteristics, the beginning of sexual life is betokened by the onset of menstruation, a monthly loss of blood from the uterus - the menses. This lasts from two to six days, and usually from 100 to 200 c.c. of fluid, partly blood, partly mucous uterine secretion, are lost. The mixture is dark in colour, and clots very slowly or not at all.

Just previous to each period of menstruation the whole genital tract becomes more richly supplied with blood, cspecially the uterus. The mucous membrane of this organ becomes swollen, partly by congestion of blood and lymph, and partly by a certain amount of cell proliferation. This, known as the constructive stage, is followed by the destructive stage. The bloodvessels rupture and form hæmatoma below the mucous membrane, the epithelinm of which eventually ruptures, and menstruation proper then ensues. At the cessation of menstruation there is a period of repair (about seven days), in which the uterus returns to its normal state. Then follows a period of rest, or quiescence, generally lasting about twelve or fourteen days.

The exact relationship of menstruation to ovulation is not known. The shedding of the ovum is usually believed to precede menstruation. The two processes are intimately related, and depend upon the presence of the ovary. When these are removed, menstruation ceases. Menstruation also ceases during pregnancy and during the puerperiumthe six weeks after child-birth. During lactation, also, it is usually absent. Women of the poorer classes often suckle their children more than a year, in the hope of deferring its return, and therefore the chance of fertilization. This is not necessarily the case. Pregnancy may take place soon after the birth of a child, cven before the onset of menstruation.

The first stage of menstruation is attended with a certain amount of physical discomfort, amounting in some cases to pain, which 
passes off during menstruation. The emotional nature of women may change at this time.

The period of active sexual life in the female ceascs about fortyfive to fifty years of agc-the climacteric. The menopause is often attended with nervous symptoms, and is the period of life at which certain ailments are more prone to develop.

The Process of Insemination.-The process of insemination varies in different species of animals. In fishes, the sperm is shed into the water in the neighbourhood of the eggs. With frogs, the male clasps the female, and pours the malc secretion over the eggs as they are shed. In birds, the scmen is introduced into the cloaca by the male organ, and incorporated in the egg before it is laid. In mammals, the egg is not shed, and the male secretion is deposited in the female tract by introduction of the penis-the act of coitus. This act is accompanied by erection of the organ. This is brought about by an engorge. ment with blood of the vessels of the penis, so that the organ becomes grcatly increased in volume, its blood-pressure raised, and its temperature increased. The accepted explanation is that, under the influence of the nervi erigentes, the arterioles of the organ become much dilated, while the efferent veins become compressed by the action of such muscles as the ischio-cavernosus, the transversus perinæi profundus, the bulbo-cavernosus.

The erection is controlled by the presence of a centre in the spinal cord. If the centre be destroyed, erection is no longer possible. The afferent stimuli to this centre may come locally from the filling of the testes with semen; from the excitation of the sensory nerves of the penis; from the filling of the bladder (especially noticeable in young children); from the rectum, as when hæmorrhoids (piles) are present. Stimuli may also come from the great brain-the sexual emotions. In animals, the sense of smell plays a considerable part in the process.

Ejaculation of the semen is caused by strong peristaltic contractions of the muscles of the vesiculæ seminales forcing the semen into the urethra. The incoming semen distends the urethra, bringing about a rhythmic contraction of the bulbo-cavernosus muscle, which ejaculates the semen from the urethra. A contraction of the ischiocavernosus and transversus perinæi muscles also occurs at this time, but these probably play but little part in the actual ejaculation of the semen.

Ejaculation is brought about reflexly through a centre in the cord. 'The impulses are brought to the centre by mechanical stimulation of the sensory nerves to the penis. It may, howcver, be caused in sleep as the result of pressure of semen in the vesicles, or by emotional impulses from the great brain (sexual dreams). It is computed that there are about 60,000 spermatozoa in each c.c. of the ejaculation, the volume of which is about 5 c.c.

In the female, a corresponding series of events takes place during scxual intercourse. Reflexly excited, the clitoris becomes engorged and erected, the Fallopian tubes and the uterus perform peristaltic 
contractions, by this means passing down the mucous content of the uterus to the os uteri. The uterus is also said to raise itself, and sink more deeply into the vagina, possibly to facilitate the entrance of the semen into it. Finally, a copious secretion takes place from the uterus and walls of the vagina about the same time as the ejaculations of the semen by the male. The sexual act is usually attended with considerable nervous excitement, and followed by a period of lassitude.

Fertilization.-Fertilization consists in the union of the male and female gametes. In the higher animals, the spermatozoa of the male are deposited by the sexual act in the neighbourhood of the uterine cervix. Stimulated probably by the vaginal and uterine secretions under chemiotactic influence, they seek out the ovum. They ascend the uterus "against the stream." The activity of the cilia of the uterine mucous membrane is such as to impede their

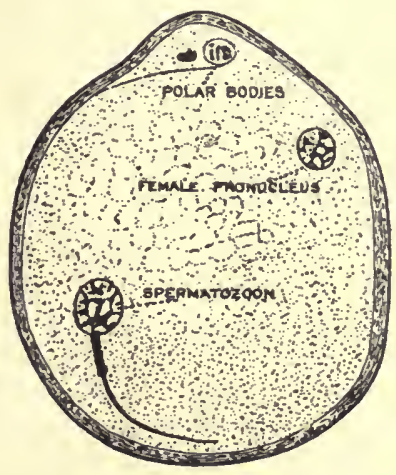

Hig. 477. - Mature Ovum of a Bat, Showtyg the Separated Polar Bodies, the Female Pronucleus and the Formation of the Male Proxucleus from the Head of the Spermatozoon. (Keith, after Van der Stricht.)

In this case the tail-piece has not bcen left behind.

progress. Only one spermatozoon is necessary for fertilization. The race is to the strong, and perhaps to the fleet, since it is calculated that they move from 16 to 20 centimetres in an hour-about the distance from the os uteri to the Fallopian tube. It may be, however, that the winning spermatozoon is deposited within the uterus itself as the result of the relaxation of the cervix uteri which takes place during coitus. This, however, is not necessary, since fertilization may take place when the spermatozoa are deposited only in the entrance to the vagina.

The time taken for fertilization is not known, but it is known that the spermatozoa may remain active in the vagina for a period of three weeks. The actual fertilization is said to take place most commonly in the Fallopian tube, and not within the uterinc cavity. The head and middle picce of the fertilizing spcrmatozoon pass into 
the ovum, the tail, or flagellum, being (generally) left behind. From the head the male pronucleus is formed (Fig. 477); this combines with the female pronucleus to form the oosperm, thus completing the process of fertilization.

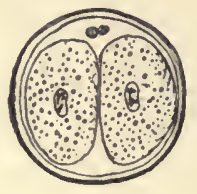

A.

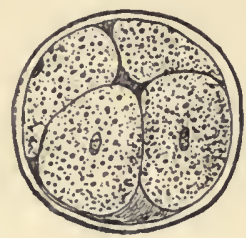

B.

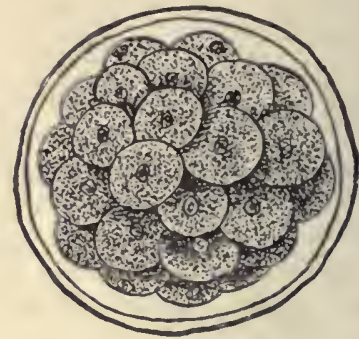

c.

Fig. 478. - Showisg the Production of the Morula from the Ovum. (Keith.) $A$, Ovum after first division; $B$, after second division; $C$, morula stage.

The stimulus supplied by the spermatozoon may be initated by altering the relation of the cell membrane of the ovum to its environment; thus it has been shown that an unfertilized frog's eggs may be made to develop into tadpoles by the prick of a pin.

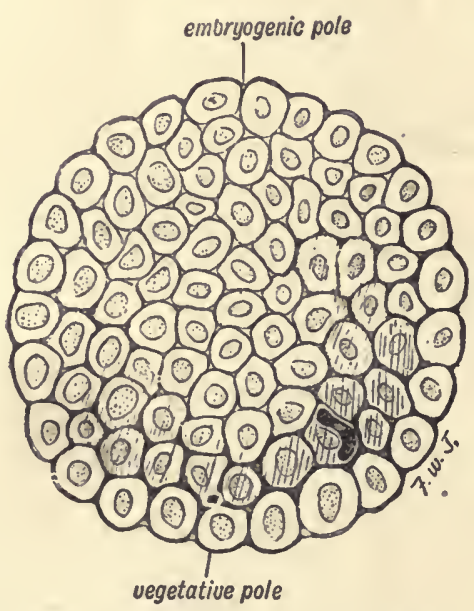

Fig. 479.-The Blastula Stage.
Eribryogenic pole

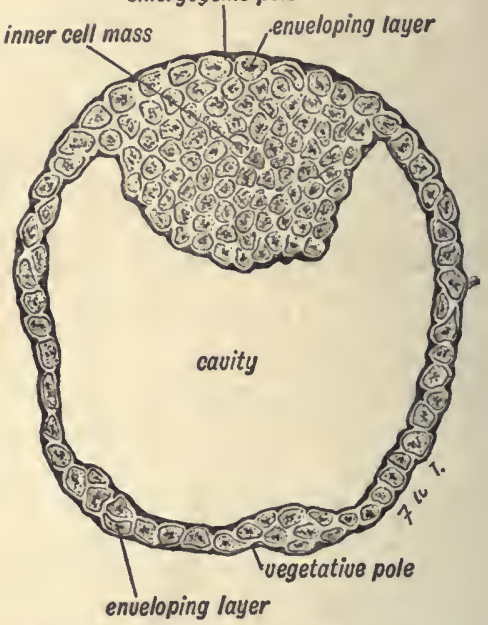

Fig. 480.-The Brastoctst Stage. (Keith, after Van Beneden.)

The tadpoles, however, do not develop into frogs. It has been ascertained that the chromosomes in the parthenogenetic larva of frogs are of the reduced type. This is a matter of interest, and probably explains the failure of the method to produce complete 
frogs. It also sheds light upon the incompleteness and the unlikeness of an embryonal rudiment to a humal fœetus. The organs existing in ovarian dermoids are rarely of the same completeness as those of parasitic foetuses. This indicates the value of the spermatozoon for the production of a complete individual. Similarly, the eggs of the sea-urchin may be made to develop by placing them in sea-water containing a small amount of magnesium chloride. Nevertheless, from the point of view of heredity, the male pronucleus plays an important part.

Segmentation.-After fertilization, the oosperm becomes fixed in position in the uterus, and then undergoes a series of divisions, first into two cells, then into four, until a mulberry-shaped mass of cells, the morula, or, when large, blastula, is formed (Fig. 479). In this morula a cavity then appears, forming a hollow sphere-the blastocyst-which is single-layered except in one part. The inner cells of this part then proliferate, and convert the sphere into a double-layered gastrula with a small pore (the blastopore) connecting the cavity with the exterior. The outer of the cell layers is known as the epiblast, the inner as the hypoblast. Between these two layers a third layer develops, known as the mesoblast (Fig. 481). The developing organism now differentiates the various systems concerned in the division of labour of the body. Different systems become evolved from the three layers:

From the Epiblast.

The epidermis and its derivatives-e.g., hair, nails, glands, and muscle of sweat glands, etc.

The cpithclium of the nose and mouth, and the glands opening into them; the anterior lobe of the pituitary gland.

The central and peripheral nervous systems.
From the Mesoblast.

The supporting tissues of the body: bone, connce. tive tissue.

The muscles except those of the sweat glands and iris.

The blood and lymph systems.

The excretory system except the epithelia of bladder and urethra.

The cortex of the suprarenal gland.

The generative system.
From the Hypoblast.

The epithelia of the alimentary tract, including the glands entering it.

The epithclia of the re. spiratory tract.

The epithelia of the Eustachian tube and tym. panum.

The cpithelium of the thy . roid and of the thymus.

The epithelia of bladder, urethra, and accessory sexual apparatus.

Implantation. - The ovum is usually fertilized in the oviduct, or Fallopian tube. It is then passed by ciliary action into the uterine cavity, where in the morula or blastula stage it embcds itself in the mucous membrane of the uterus by means of a phagocytic action of its outer layer, which is now known as the trophoblast. The corpus luteum is believed to exert considerable influence through its intcrnal secretion upon the process of implantation.

Immediately after fertilization of the ovum, the normal mucous membrane of the uterus, the endometrium, undcrgocs a great increase 
in thickness, forming itself into two layers-a compact supcrficial and a deep spongy layer. It is now known as the decidua, and is divided into three portions - the decidua basalis, or serotina, upon which the ovum rests; the decidua reflexa, or capsularis, which encloses the embedded ovum; and the decidua vera, the rcmaining portion of the mucous membrane not in contact with the ovum (Figs. 482, 483). At first a space-the dccidual space-betwcen the two latter parts represents the remains of the true uterine cavity. These eventually come into contact, and fuse in the human subject in the fourth month of pregnancy.

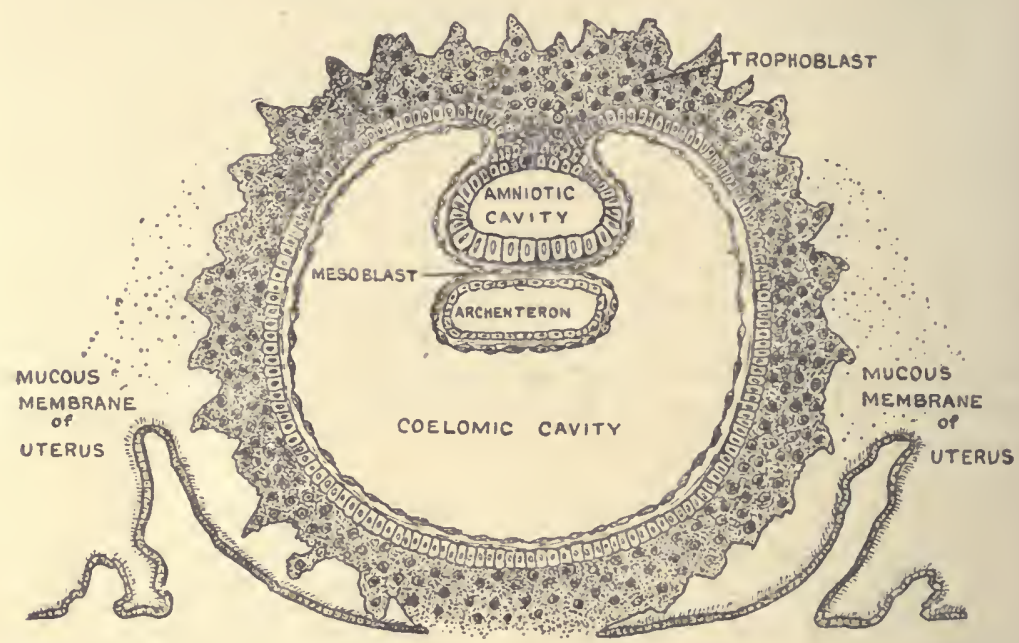

Fig. 481.-Showing Origin of the Primitive Calon, the Mesoblast, and Cavity of the Amion dURing Developmest of the Humas OvUM. (Keith, after I. H. Bryce.)

From the developing embryo, two membranes are formed-the chorion and the amnion (Fig. 482). The chorion is the outer laycr. It early divides into two-an outer fused mass of cells, or syncytium; an inner layer of cells, or Langhans' layer. During the first six weeks the whole chorion becomes covered with vascular villi. These, however, soon disappear except in the region of the decidua basalis, where the ovum is attached. Here is formed the chorion frondosum, its villi and the decidua basalis fuse together, and form the placenta.

Within the chorion is the closed sac-the amnion-filled with fluid, in which the embryo is bathed.

The placenta is formed as a separate organ about the third inonth of pregnancy, gradually increasing in size according to the foetal needs until full term. It is formed by a fusion of the decidua basalis and the chorion frondosum (Fig. 484). Blood-sinuses become developed in both the maternal and fotal portions, so that the maternal and fotal blood 
come into intimate juxtaposition, although, separatcd by eellular membranes, they do not actually mix. Through the action of these membranes oxygen and nutrient material are supplied by the mother to the foetus, and the waste produets of metabolism of the foetus transferred from the foetus to the mother.

Parturition.-After an intra-uterine life of varying duration according to the species, the fœtus is expelled by the proccss of parturition, or labour. In woman, this oceurs at about the end of 280 days. "Labour" is divided into three stages: (1) The first stage, whieh results in the dilatation of the cervix of the uterus as the result of rhythmical contractions whieh become more and more frequent;

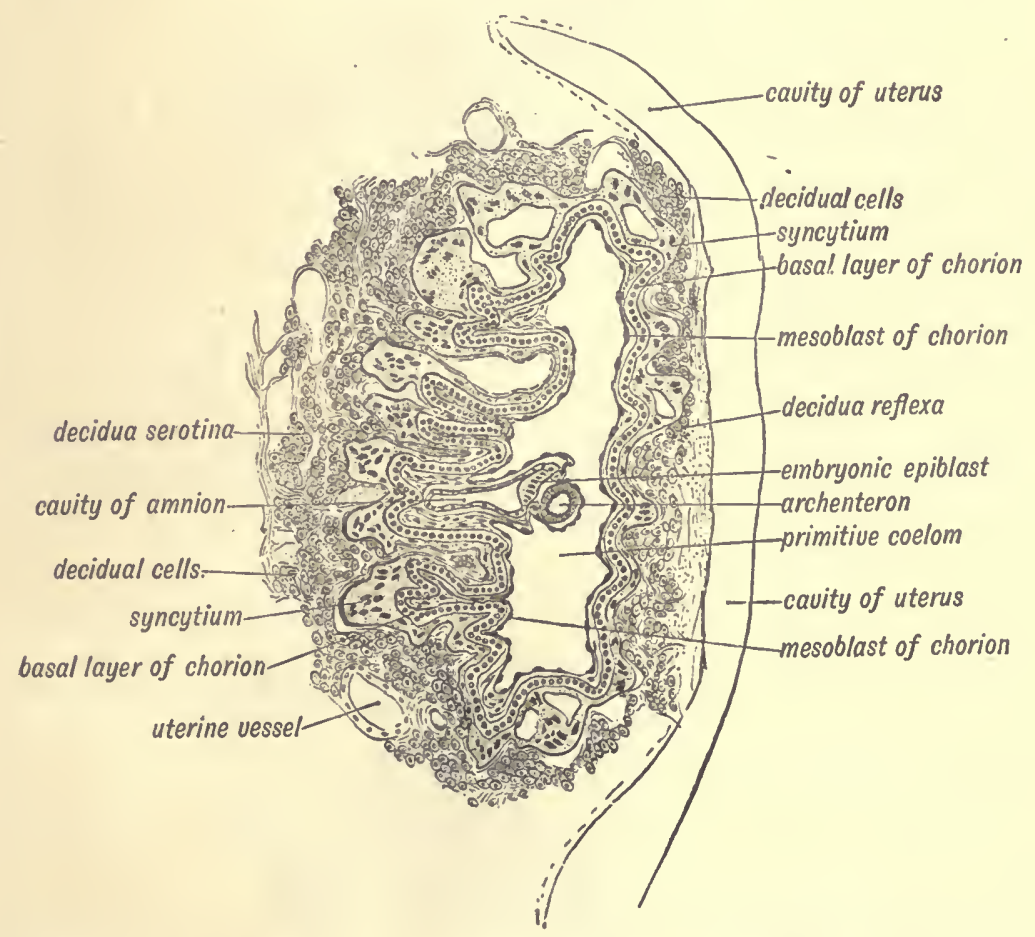

Fig. 432.- Section through Ovum embedded in the Wall of the Uterus (F. W. Jones, after Peters and Silenka, from Keith's "Human Embryology.").

(2) the second stage, in which the foetal membranes are ruptured and the fœtus is expelled, usually hcad first, from the uterus by means of prolonged, sustained eontraetions of the uterus oceurring at freqt cnt intervals; $(3)$ the third stage, in whieh the after-birth is expelled. The whole proeess may take thirty hours or more in a primipara - a woman who is having her first child. In subsequent births, the process is usually considerably shorter. What factor induces the onset of 
labour is not known. The process is normally reflexly controlled through a centre in the lnmbar cord, although the presence of this centre has been shown not to be nccessary. At term the nterus is

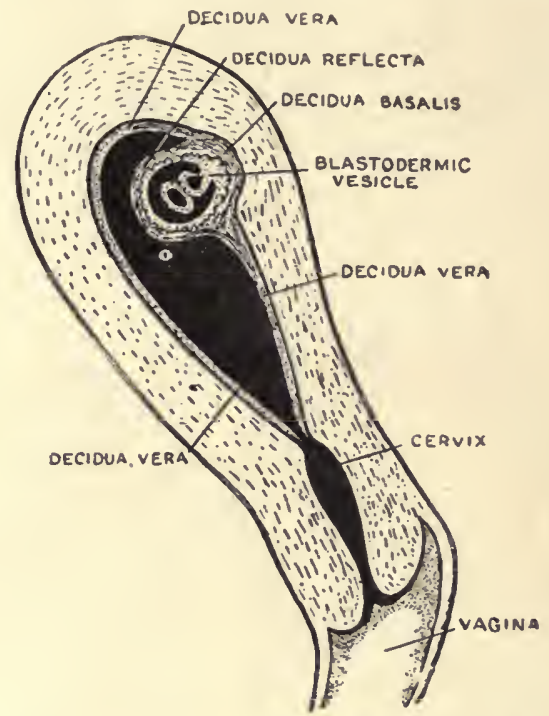

Fig. 483.-Section of Uterus showing is Diagramatic Mañer the emefoded Ovum and tue Eifferentiation of the Decidea isto Three Parts. (Keith.)

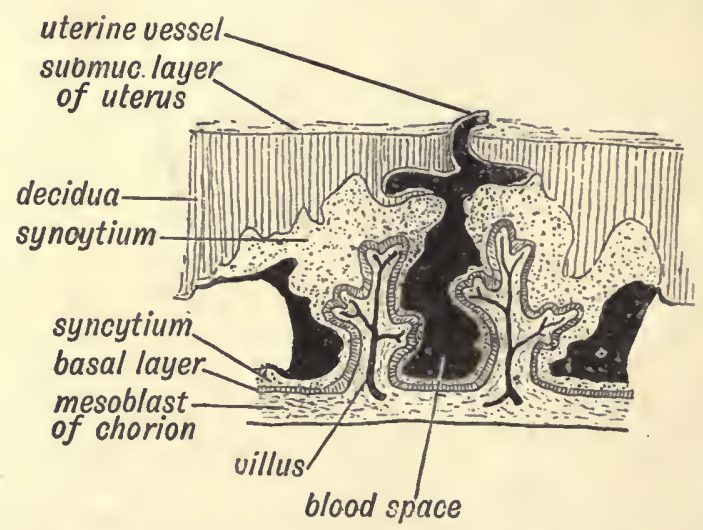

Iig. 484.-Digramatic Section of the Decidta Serotixa (Formed from THE Mucous Membrane of the Uterus) aNd Chorion to show the ManNer ix which the Placental Blood Spaces are formed. (Keith.)

of large size, reaching high up into the abdomen. After delivery by the process of "involution," it returns again within the pelvic cavity. The involution is said to be due to the autolytic action of intracellular 
enzymes within the uterine wall. It is a rapid process, and is complete within three months.

Serum Test for Pregnancy.-Reently therc has been devised a serum test for pregnaney. It is based upon the view that during pregnancy the maternal serum aequires the power of digesting the "speeific" albumin which passes into the eirculation from the plaeenta. In order to test if a subject be pregnant, the blood-serum of the sub-

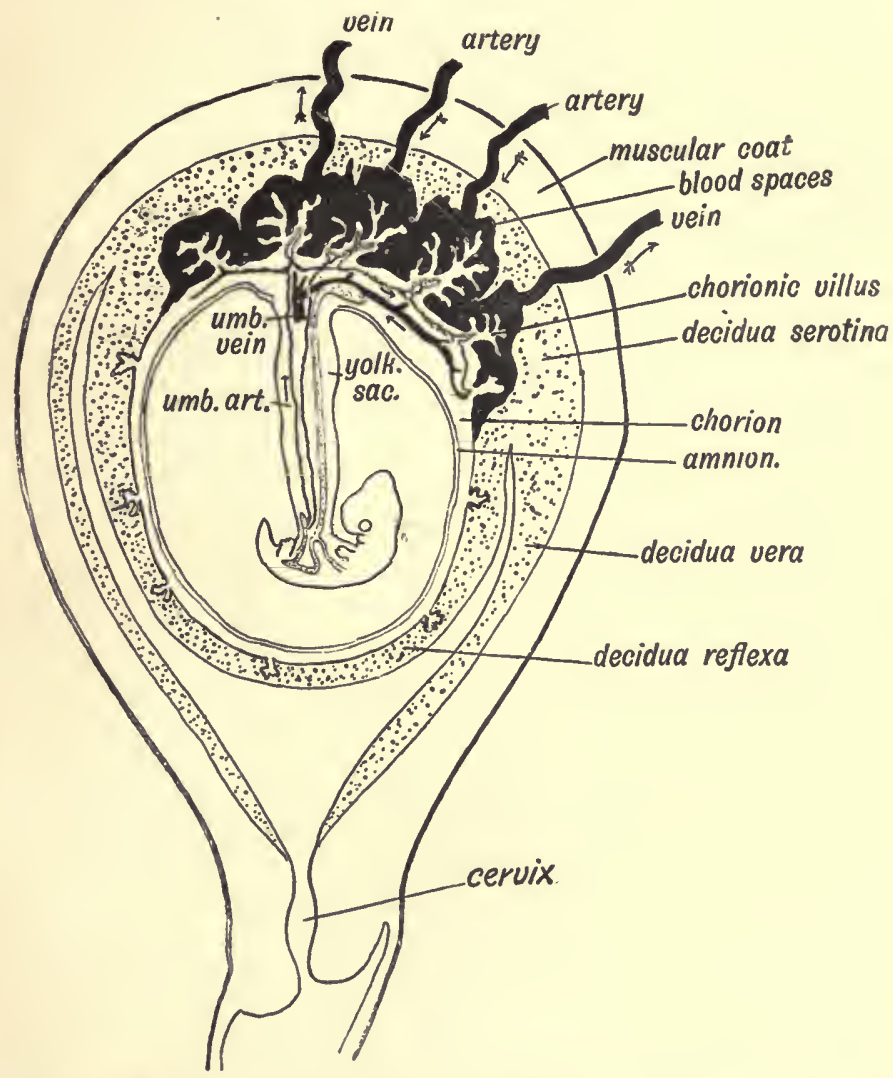

Fig. 485.-Showisg Arrangemeyt of the Amston, Chorloy, and Decidua in . the Third Montr, and the Forvation of the Placenta. (Keith.)

ject is added to specially prepared plaeental tissue placed in a dialyzer. If the tissue is digested and amino-aeids pass through the dialyzer, it is deemed a sign of pregnancy. Normal serum is stated not to have sueh digestive powers. It is true that the test is more often positive in the pregnant than in the non-pregnant, but the test is by no means certain, and it is said that by it even males are oceasionally reported to be pregnant. 
Heredity.-It is a familiar proverb that "like produces like." "Men do not gather grapes of thorns, or figs of thistles." To account for this continuity of species, various hypotheses have from time to time been propounded. It was at onc time beliered that a miniature animal existed preformed either in the spermatozoon or, more probably, in the ovum. Microscopy showed that such was not the casc. The view of "epigenesis" states that in the egg, which is entirely different from the structure of the adult, there is a successive formation of new parts which do not exist as such within the egg. That like should producc like there must, however, be some directing force within the egg. Darwin believed that the parents contributed minute particles of all their own tissues to the reproductive cells, and thus secured physical continuity of species-the theory of pangenesis.

'The most commonly accepted view is that in the simple reproductive cells there exist, probably in the chromatin content of the nucleus, complexes which determine the course of development of the fertilized ovum. These germ cells themselves were produced from the pre-existing germ cells of the fertilized ovum from which each parent developed. The somatic cclls of the developing embryo, and therefore of the adult, are in reality the custodians of the gern cells. They do not form new germ cells; they merely contribute to their growth and development. The germ plasm is continuous from onc generation to another.

Since nuclear material is contributed by both parents, and since in the formation of the germinal elements such material undergocs reduction in amount by a special method of cell division, it affords an adequate explanation of why like should produce like, and yct at the same time why there should be such a marked difference between the offspring and the parents, and also between offspring themsclves. A litter of puppies resembles its parents, but there may be marked variations in colour, temperament, and other characteristics of the puppies.

The question arises as to how these variations are to be accounted for. Are they to be accounted for by heredity or by environment ? It is asserted that heredity plays a large part on th 3 plea that in the case of the new-born puppies the ante-natal environment has to all intents and purposes been the same. But this is not so; the conditions, even in the wounb, will no more be the same for each puppy than they are for each egg in a mass of frog's spawn developing in a pond. The slight variations in chemico-physical conditions may have the profoundest effect on development.

The further question arises as to whether environment after birth can in any way influence hereditary characters. It is not a question of gathering figs of thistles, but whether a bad fig-tree can by environment be made to yield a strain of good figs. This is a question of great importance to the sociologist. Lamarck asserted that "all is preserved in reproduction and transmitted to the offspring, that Nature has made individuals to acquire or to lose by the influence of the 
circumstances to which their race has been for a long time exposed, including the results of excessive use or disuse of an organ."

Of recent years, the action of legislators, sociologists, and others, has been directed to the belief that, by giving a good supply of fresh air, exercise, proper sanitation, better education, the individuals will grow up stronger and healthier, and thus provide a better race. But will such methods convert bad stock into good stock? The test lies in the offspring.

According to one school of thought, such environmental conditions, although making improvement in the individual, will not better the race. The hereditary factor is all-important. Such is the view of Mendelism.

The essence of the Mendelian principle is very easily expressed. It is, first, that in a great measure the characteristics of organisms are due to the presence of distinct, detachable character separately transmitted in heredity; and, secondly, that the parent cannot pass on to offspring a character which it does not itself possess. Each germ cell, ovum, or sperm may contain or be devoid of any of these characters; and since all ordinary animals and plants arise by the union of two germ cells in fertilization, each resulting individual may obviously receive in fertilization similar characters from both parents or from neither. In such cases the offspring is " pure " bred for the presence of the character in question, or for its absence. On the other hand it may be developed from the union of dissimilar germs, one containing a character, the other devoid of it; the individual is then cross-bred, or heterozygous. A population thus consists of threc classes of individuals - those pure-bred for the presence, having received two doses, of a character; those pure-bred for the absence of the character, having received none of it; and the cross-breds, which have received one dose only. A plant, though cross-bred for tallness, may be as tall as one pure-bred for tallness. A dwarf plant, whatever be its parentage, can only produce dwarf offspring. Not having tallness, it cannot transmit that property. A cross-bred tall plant can, by self-fertilization, produce both tall and dwarf offspring. Fowls with silky feathers cannot, if bred together, have offspring with normal feathers, but two birds, normal to all appearance, can, if they be cross-bred in that respect, produce silky offspring.

These results are explained by assuming that a character may be either dominant or recessive. In breeding, the transmission of these characters is said to follow a definite law-Mendel's law. When a dominant and a recessive character are crossed, the first cross-bred generation possesses the dominant character, which may be represented as $\mathrm{D}(\mathrm{R})$ - 2.g., the cross between a tall and dwarf pea possesses the dominant character of tallness. The issue of such cross-breds (impure dominants) in the second generation will be 25 per cent. purc dominant, 50 per cent. mixed (impure dominants), and 25 per cent. recessive. In such a generation interbreeding of the dominants will breed only dominants, of the recessives only recessives, but inter- 
breeding of the mixed impure dominant type again yiclds 25 per cent. D, 50 per cent. $\mathrm{D}(\mathrm{R})$, and 25 per cent. $\mathrm{R}$. This may be tabulated as follows:

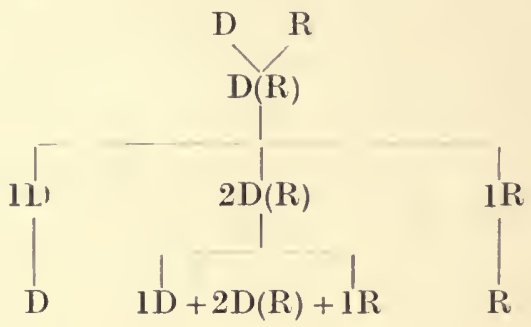

Many experiments to prove this law have been made both upon plants (peas, beans, maize, wheat, stocks, etc.) and animals (mice, rats, poultry, canaries, moths). In peas, for example, it is claimed that tall stems, yellow cotyledons, brown-skinned seeds, and round seeds are dominant characters; while dwarf stems, green cotyledons, white seeds, and wrinkled seeds are recessive characters. Among animals, dominant characters are short hair in rabbits, hornlessness in cattle, crest in poultry, brown eyes in man, etc.; recessive are long hair in rabbits, horns in cattle, absence of crest in poultry, grey and blue eyes in man. The explanation given of this law is that these characters, dominant and recessive, are segregated in two different sets of germ cells.

Although the law derives support from many characters, such as those mentioned above, and from various hereditary diseases and malformations of the human race, such as brachydactyly, it does not explain all hereditary phenomena. The cross-breds of a white and black, when intermarrying, do not produce 25 per cent. pure white, 50 per cent. mixed, 25 per cent. black, but offspring of varying degrees of duskiness.

Following Mendelism, the modern school of eugenists, bent upon the "improvement" of the race, maintain that race improvement is solely a matter of breeding from good stock. This may undoubtedly lead to physical fitness, but it is very questionable as to whether it is the only way. It is also a difficult question to determine at what fitness we are to aim. It is well known that "genius" cannot be made to breed true. A genius in a family is a "spontancous" variation, as much as a child with six fingers. How do such " spontancous" variations arise?

Darwin stated that new varieties of species arose by the cumulative cffect of natural selection upon small fluctuating variations. It is of first-rate importance to ascertain how new varieties, healthy, intelligent, honest, diseased, fceble-minded, and criminal, arise. Can the parents' drunkenness, for exఓmple, affect the germ plasm? At present, "eugenio" principles scem of little hclp. Darwin confessed: "Our ignorance of the laws of variation is profound." It still is.

It has recently been suggested, as the result of observations in the vegetable kingdom, that species arise from one another by dis- 
continuous leaps and bounds-by "mutations." "The new species appears all at once; it originates from the parent species without any visible preparation, and without any obvious series of transitional forms." This is the mutation theory of De Vries.

It would seem, then, that the distinctive characters of a species may arise in two ways: (1) By the accumulation of fluctuations; (2) suddenly by mutation.

The extent to which the acquired conditions of environment are transmitted, if at all, still remains to be settled. 'That such environmental conditions are of great importance is indicated by experiments upon bacteria. It is known that virulent organisms may be attenuated by growths upon special media, and that such diminution of virulence is maintained so long as the environmental conditions remain the same. This would point strongly to the conclusion that the effects of the environment of the race induced by improved conditions may be maintained in the offspring so long as the better environmental conditions are maintained. Herein lies the great hope of the humanitarian.

The Determination of Sex.-The determination of sex has long been a matter of popular speculation, but only recently of scientific inquiry. In consequence, many theories, although of historic interest, are scarcely of scientific value. Such, for example, are the views that sex is determined by parental desire; by the element of the more healthy parent; by the relative age of the parents; by the relation of coitus to menstruation; or whether the ovum comes from the right ovary or the left.

It is generally believed, and to a certain extent it is supported by statistical evidence, that more male babes are born in and after times of stress, such as war and famine. The disproportion between the sexes (women are more numerous) is to some extent accounted for by the more difficult passage of the male babe into the world, owing to his larger head, and to the more precarious occupation of males in the community.

In recent lines of inquiry, efforts have been made to ascertain whether sex is predetermined in the sexual elements, or whether sex is detcrmined by environmental conditions of the ovum after fertilization. Evidence has been accumulated in favour of both views. In support of the environmental view, it is claimed that well-matured frog's spawn develops into an excess of females, and that ill-matured eggs of certain caterpillars yield an excess of males. Differences of temperature, by affecting the nutrition of the mother, have been shown to exert an influence upon the sex of the offspring of the primitive worm Dinophilus. An experiment of great interest is one upon the annclid worm Ophryotrocha puerilis. When a female of this species, with no trace of hermaphroditism,' having ripe ova, was divided into two, the head portion of thirteen segments regenerated seven segments, and, on bcing killed, it was found that the ova and female apparatus had atrophied, and that the animal was now male, with a functional testicular portion 
developed. It is suggested that, owing to the amputation and diminished nutritive conditions, the indifferent germ cells had developed into male cells. On the other hand, experiments in the breeding of mice have shown that nutritive changes and the age of the parents have made but little difference in the proportion of the sexes.

That sex in certain cases is largely determined by the conditions of general metabolism is illustrated by the effects which follow castration, by infection with a parasite, of several varieties of crabs. In all cases the castrated male takes on female characteristics, and even defends the parasite as if he were protecting his eggs. The castrated femalc shows no sign of altered structure or instinct. It has been suggested, in the case of the crab, that the parasite alters the composition of the male's blood, which tends to bring about a female condition, which may be followed by the onset of female characteristics, or even the production of female organs from indifferent germ cells. On the other hand it may be an internal secretion effect from the traces of female tissues present in male.

In support of the view that sex is predetermined in the ovum is the fact that "identical " twins-that is to say, twins arising from the same ovum and included in a single chorion-are always of the same sex. More conclusive is the fact that, in certain mosses, spores of identical appearances, asexually produced, are predetermined as maleor female-producing elements. In the primitive worm Dinophilus, the large fertilized ova develop into females, the small fertilized ova into males. The same is true for the vine pest Phylloxera, and for the rotifer Hydatina. In certain parthenogenetic invertebrates, such as the Hymenoptera, the unfertilized eggs give rise to males, the fertilized eggs to females. Whether fertile queens or infertile worker bees are developed from female larvæ depends on the nature of the food given them.

As to the influence of the male element, it has recently been shown that certain animals, especially insects and arachnids, produce two forms of spermatozoa. Half the spermatozoa have in their nucleus an odd chromosome, or $x$ chromosome; half have not. In the ova the $x$ chromosome is always present. Union of a spermatozoon containing the $x$ chromosome with the ovum produces a female; union of a spermatozoon without the $x$ chromosome produces a male.

By some, maleness and femaleness are regarded as Mendelian characters, like shortness or tallness. If sex be due to some factor, like the $x$ chromosome, it is possible, on the Mendelian interpretation, that males and females may both be cross-breeds (heterozygous), or that the male alone may be heterozygous, the female recessive, or the female heterozygous and the male recessive. Experiments tending to support the last view have been made upon the currant moth.

It is asserted that in vertebrates castration suppresses the maleness, but does not induce any expression of female characteristics. On the other hand, the castrated female, while losing her female. characteristics, tends to develop markedly those of the male. Further proof is needed of such a view. 
It will be seen that we are still far from understanding the circumstances which lead to the determination of sex. In some cases it is apparcntly due to an initial difference in metabolic rhythm, in others to a predetermined morphological difference in the sex units.

Death.-Death is the total cessation of the cell activities of the individual. Cells are always dying and being replaced within the individual. After a time, however, either by the process of decay following a natural adolescence and maturity, or more often as the result of disease or accident, one of the vital functions fails, the general metabolism of the body ceases to be efficient, and death ensues. The custodianship of the genetic by the somatic cells is finished. Yet, if the former have fulfilled their function, the individual does not wholly die; life continues in the offspring. On death, there is a transformation, but no destruction of energy. The disintegrating cells pass into materials of lesser complexity, some or all of which are again worked up into the complex formations of life. Thus continues the ceaseless life and death cycle of the ages. 



\section{INDEX}

AвDоMEN, movements of, in respiration, 306

Aberration, chromatic, 609

- of lens, spherieal, 609

Absorption in the stomach, 388

- of fat, 436

- of food, 421

- power of, 30

Accessory glands, 766

Accommodation, mechanism of, 614

Aceto-acetie acid, 468

Acetone, 469

Aehromatic lens, 609

Achroodcxtrin, 67

Aeid, aspartic, 41

- $\beta$.oxybutyric, 468

- fatty, 53

- glutaminic, 41

- glycuronic, 63

- liematin of blood, 94

- hæmatoporphyrin of blood, 94

- metaprotein, 50

- nonocarboxylic, 36

Aeromegaly, case of, 523

Adenin, 50

Adrenalin, 41

- action of, 505, 509

-- effects of injection of, 504

- glycosuria, 434

-- vaso-constriction caused by, 238

Afferent fibres, 753

- nerves, 245

Age, diet under varions conditions, 356

Agglutinin, 109

Agglutinins, 110

Air, aveolar, 281

- bubbles of, in heart after decompres. sion, 309

- collection of, apparatus for, 281

- composition of, 281

- ehanges by breathing, 293, 312

- complemental, 279

- residual, 280

- supplcmental, 280

- tidal, 278

- volume of, 278

Alanin, 40

Albumino-neter, Esbach's, 465

Albuminoids, 48

Albumins, 48

Albuminuria, 465

Alcohol, 364

- as source of energy, 364

- compounds, 34

— food value of, 352
Alcohol, percentage of, in spirits, wines, and beer, 365

Aldehydes, 35

Alkali carbonates, lack of, 336

- metaprotein, 50

Alkaline hæinatin, reduced, of blood, 94

- hrematine of blood, 94

Alkaptonuria, 469

Allantoin, 460

Allorhythmia, 135, 138

Altitude, high, effeet of on blood, 79

Alveolar air, 281

- - analysis of, 291

- - collection of, apparatus for, 281

- - eomposition of, 281

- - gases in, pressure of, 269

Amblyopia, 623

Amboceptor, 109

Amino-aeids, 44, 422, 423, 424, 425

Amitosis, 756

Ammonia, 462

Ammonium nagnesium phosphate, 471

- urate, 471

Aminion, arrangement of, 777

Amoba, ehanges exhibited by, 2

- protens, 1

Amorphous urates, 471

Amphibians, larval stage of, 276

Ampulla of guinea-pig, erista of, 655

Amylolytie enzymes, 71

Amylopsin, starcli digested by, 399

Anabolism, 441

— of fat, 436

Anacrotie wave, 215

Anæsthetized dog, respiration and bloodpressure of, $290,291,293,294$

Anaphylaxis, 111

Anelectrotonie eurrent, 583

Animal, decerebrate, lung volume and blood-pressure, 278

- eleetricity, 559

- fat, melting-point of, 438

- life, eycle of, 258

Animals, experiments on, during period of hunger, 342

- hæmoglobin in, 90

Aukle elonus, 684

Anode, region of, stimulation in, 583

Antigen, 109

Antitoxins, 108

Aortic blood-pressure, 178, 197, 198; 199

- - excitation of depressor and, 177

Apncea, 299

- forced breathing followed by, 299

Appetite, 384 
Aqueous humowr, 255

Arginin, 42

Army, British, peace diet of, 345

Artcriæ rectæ, 474

Arterial cannula, 186

- pressure, 168, 186

- - circumstances affecting, 192

- - cnrres, relations of, 149

- - measurement of, 186

- - of kidney, 24 $\tau$

- - record of, in cat, 512

- pulse curre, 215

- system, pulse wave in, 217

- wall, deformation of, effect of surrounding tissues upon, 190

Arteries, contracted, elongation of, with rise of internal pressure, 184

- coronary, circulation in, 238

- elasticity of, 184

- relaxed, elongation of, with rise of internal pressure, 184

- structure of, 124

- velocity of flow in, 208

Arteriole muscle, pressor afferent impulses affecting, 231

Arytenoids, 742

AAscending " current, 582

spartic acid, 41

Asphyxin, 306

- effect of, 168

- of rabbit, 304

Association areas, 729

Astigmatism, 612

Atmosphere, effects of, 499

- temperature of, 49 ?

- See also Air

Atmospheric pressure, diminished, effects of, 307

- - increased, 309

Auditory judgments, 653

- nerve, course and connection of fibres, 697

Auricle, right, 119

- - of calf, 121

Auriculo-ventricular bundle, 121

- node, 120

Autolysis, 69

Avogadro's hypothesis, 17

Axis cylinder of nerve-fibre, 569

Axon, 569

- section of, effects, 576

Axon reflex, 484

Bacteria, life cycle of, 258

Bacterial action in intestinal digestion, 404

- hæmolysis, 107

Barcroft's blood-gas apparatus, 262

Barfold's test, 61

Basilar membrane, 648

Bathmotropic fibres, 173

Baths, effect on metabolism, 499

Beckmann's apparatus, 27

Beef, composition and value of, 348

Beer, alcohol percentage of, 365

Biceps, cruris of frog, 549

Bile, 391
Bilc, excretion of, 447

— How of, 369

- formation of, 447

- functions of, 394

- in urine, 469

- mechanism of secretion, 394

- organic salts of, 392

- pigments of, 393

- seeretion of, meelianism, 394

Binocular vision, 630

Biological force, 15

Biotic energy, 15

Bismuth meal, $40 \overline{7}, 418$

Biuret, 46

Blastocyst, 772

Blaze currents, 567

Blind spot, 621

Blood, 75

- absorption coefficients for, 263

- acid hæmatin of, 94

- acid hæmatoporpliyrin of, 94

- alkali of, diffusiblc, 77

- - non-diffusible, 77

- alkaline hrematin of, 94

- - reduced, 94

- amount of, 78

- analysis of, 80

- carbon dioxide of, 290

- clotting of, 101

- coagulation time of, 103

- corpuscles of, 86

- - palc, 97

- - - functions of, 98

- - - origin of, 98

- - red, 86

- - chemistry, 90

- - enumeration of, 87

- - fats of, 90

- - - function, 89

- - origin, 88

- - white, enumeration, 98

- count, differential, 98

- effect of high altitude on, 79

- elcetrical conductivity of, 80

- fixing agent of, 97

- flow of velocity, 203

- gases of, $259,263,275$

- - extraction of by pump, 259

- - pressure of, 269

- hæmoglobin of, estimation, 96

- luman, analysis of, 81

- Haldano's apparatus for determining tension in, 273

- - oxygen curres of, 266 .

- in urine, 466

- osmotic pressure of, 80

- oxygen capacity of, 264

- partial, 269

- platelets of, 99

- pressure of, 186

- - aortic, 178

- - capillary, 221

- - carotid, of pithed cat, 230

- - fall of, 177

- - in nipple of cat, 522

- - in veins, 225 
Blood-pressure, influence of posture on, 198 - - rise of, due to pressure on supra. rewal vein, 509

- reaction of, 76

- specific gravity of, 76

- spectra, 93

- supply of kidney, arrangement of, 474, 475,478

- tests for, 112

- biological, 113

- - chemical, 112

- - guaiacum, 112

- - microscopical, 112

- - spectroscopical, 112

- thrombin of, 102

- velocity of, diagram showing general relations of; 206

- - in veins, 225

- vertebrate, colour of, 76

- viscosity of, 80

- See also Circulation

Blood-gas, analysis of, by Töpler pump, 261

- apparatus, Barcroft's, 262

- pump, Hill's, 260

Bloodvessels, structure of, 124

Body, chemical composition of, 33

- fluids, circulation of, 115

- proprio-ceptive nuechanism, 659

- temperature of, 492

- weight of, and surface area, 341

Bomb calorimeter, 326

$\beta$-oxybutyric acid, 468

Boyle's law, 17, 22

Brain, 685, 716

- afferent systems to, 668

- blood-pressure in, 222, 240

- centres of, 728

- circulation in, 239

- cortcx, 722

- fore part of, 686

- functions of, 716

- liemisplieres, 709,716

- human embryo, 685

- localization of parts of, 721

- of dog, erucial sulcus of, 723

— of frog, 686

- - removal of, 688

- removal of, reflex action of cord after, 675

- results of stimulation, 722

- section througli cerebral hemispliere, 709

- speech centres, 730

- tracts from cord to, 669670

- transmission from, of spilial motor nelurolls, 669

- weight of, 716

- See also Cerebellum

Bread, 355

Breatling, abdominal, influence of, on the pulse, 191

- anatomical considerations of, 281

- effects on blood-pressure, 237

- mechanics of, 284

- regulation of, 289

- types of, 192
Bronchial tubes, 277

Burdach, postero-lateral tract of, 668

Cadaverill, 403

Caisson disease, 309

Calcinm carbonate, 472

- - from human urine, 464

- oxalate, 471

- Crystals, 461

Calories of foodstuffs, 328

Calorinieter, bomb, $320^{\circ}$

- for experiments with small animals, 330

Cane-sugar, 64

Cannula, arrangement of, for recording blood-pressure, 187

- arterial, 186

Capillaries, circulation of, 218

- - in, rate of flow, 221

- velocity of flow in, 208

Capillary blood-pressure, 221

Carbohydrate, 427

- fat from, 438

- foods, composition and value of, 350

- metabolism of, 428

- of plasma, 85

Carbohydrates, 59

- lack of, 336

Carbon, compounds of, 34

- dioxide, deficiency of, effects, 302

- excess of, effects, 302

— - in blood, 263, 275

Carbonal group of organic componuds, 35 Carbonates, 465

Carbonic acid gas, 19

Carboxyhæmoglobin, 91

Carboxyl group of organic compounds, 36

Carchesium, colony of individuals of, 3

Cardiac cycle, 143, 144」

— impulse, 153

- muscle, 532

- nerres, 171

- - of dog, 172

_- of frog, 171

- valves, smrface relatious or, 153

Cardiometer, 166

Carotid artery, velocity of pressurc curves, 207

- blood-pressure of, in pithed cat, 230

— body, 519

- pressure, effect on, of anrsthetized dog 510

Castration, 505

— effect of, on horn-growtl, 506

Cat, blood-pressure, 230

— ovum of, before maturity, 9

- vagus divided in, 300

- vagus intact in, 300

Catalysts, 68

Cataphoresis, 31

Caudate nuclei, 715

Cell, 8

— anterior horn, 576

- division of, chromatin clianges during 757

- lamination in motor area, 725

- - of gyrus post-centralis, $7 \% 4$ 
Cell, lamination of visual area, 726

- meiotic division of, 762,763

- naked, 1

- reproduction, 756

Cells, camera lucida drawing of, 14

- danghter, distribution of chromosomes to, 757,763

- gas-secreting of Paradise fish, 271

- survival of, 13

Celluloses, 65

Cephalin, 58

Cereals, 354

- composition and value of, 352

Cerebellar arc, 672

- cortex, section of, 702

Cerebellum, 702

- afferent fibres to, 703

- afferent systems to, 668

- efferent fibres to, 703

- functions of, 705

- structure of, 702

- tracts of, 704

Cerebral arc, 672

- circulation, 239

- cortex, development of, 722

_ - of mole develojment of, 722

- - structure of, 723

- function, 716

- hemisphere, 709,716

- - positions of centres concerned in speech, 730

- pressire gauge, Hill's, 240

Cerebro-spinal fiuid, 254

C'erebrum. See Brain

Cervical ganglion of dog, section throngh chromophil cells in, 508

- sympathetic nerve, in rabbit, dissection of, 176

Chauveau's hæmodromometer, 204

Cheese, composition and value of, 349

- food value of, 352

Chemical composition of the body, 33

- influence affecting the glycogenic function, 430

Chemiotaxis, negative, 12

- positive, 12

Chemistry of red blood-corpuscles, 90

Chest, influence of, on the pulse, 191

- register of sound, 743

Cheyne-Stokps Breathing, 299, 300

Chicken, hes. of, musoular connection between anrices and ventricles in, 140

Childhood, diet of, 363

Chlorides, 462

- distribution of, 33

Chloroform, effect of, on arterial pressurc of $\log , 201$

- - on heart volnme of $\mathrm{dog}, 201$

Chloropinyll, 257

Cholesterol, 58

Cholin, 57

Choroid, 603

Chorion arrangemcut of, 777

Clirumatic aberration of lens, 609

Chromoproteins, 48

— of limbs, 243
Cliromosomes, 757, 758, 761, 762, 763,764

Chronotropic fibres, 173

Ciliary body, 603

Circulation, artificial schema of, 183

- - to show effect of gravity on, 194, 196

- capillary, 218

- cerebral, 239

- complete, time necessary for, 209

- coronary, 238

- effect of change of postule oll, 194

- examination of microscopical, 219

- foetal, 248

- in generative organs, 248

- in head, 242

- of blood, course of, in mammals, 142

- of limbs, 243

- of nitrogen in Nature, 259

- of salivary glands, 243

- - pliysical factors, 179

- of the body fluids, 115

- - functions of, 604

- unuscle, 602,603

- portal, 246

- pulmonary, 236

- renal, 247

- special, 236

- times, 210

- See also Blood

Circuuvallate papillæ, 593

Climate, diet under varying conditions of, 357

Clothes, 500

Clotting of blood, 101

Coagulation of blood, 101

Coagulative enzymes, 72

Cobra, hypnotized by stroking, 737

Cochlea, niembranous, 648

- section of, 648

Cold, effect of, on sino-auricular node of $\operatorname{dog}, 139$

- exposure to, 499

Cold-blooded anintals, 495

Collagen, 48

Colloids, 29

- surface tension in, 31

Colostrum, 359

Colour-blindnesg, 623, 626

- degrees of, 626

Colour of vertebrate blood, 76

- perception of, 623

- perception lantern, Edridge-Greell, 627

- reactions of proteins, 46

- saturation, 624

- tests for proteins, 52

- vision, 625

- - apparatus, Leonard Hill, 628

- Hering tlicory of, 625

- Young-Helmholtz theory of, 625

Colours, wheel for mixing, 623

Comma tract, 669

Complement, 108, 110

- deviation of, 110

Complemental air, 279

Compounds, inorganic, 33

— organic, 34 
Conductors, nervous, 574

Conjunctiva, 600

- human, end bulb of, 586

Conjunctival reflex, 682

Connective tissue, 5

Consciousness, 732

Consonance, 652

Consonants, sounds of, 746

Cornea, 601

Corneo-iridic angle, movements of, 614

- junction, 602

Coronary circulation, 238

Corpora quadrigemina, 768

Corpus luteum, 507

Corte's organ, 648, 649

- - of guinea-pig, 649

Coughing, mechanism of, 295

Cranial autonomic fibres, summary of, 752

- - system, 751

- nerves, 690

- nuclei of, 699

- - superficial origin of, 692,693

- nuclei, 708

Crank lever for muscle registration, 539

Creatinin, 461

Cretinism, 515

Cretins, non-goitrous, 516

Cribriform ligament, 602

Crico-arytenoid muscles, lateral, 743

- _ - posterior, 742

Crico-thyroids, 743

Cricoid, 742

Cruial nerve, excitation of, 244

Crystalloids, 29

- dialysis of, 29

Cud chewing, 390

Current, constant, effects of, 581

- of action, 561

- of injury, 560

Currents; blaze, 567

- cutaneous, 564

- retinal, 565

Cutaneous currents, 564

- sensation, 585

- - receptor's of, 585

Cybulski's pliotohæmatochometer, 205

Cylindrical tubes, flow of fluid in. 179

Cystin, 43

- crystals, 470

Cystinuria, 470

Cystoplasm, degeneration of, 576

Cytotoxins, 111

De-aminizing enzymes, 72

Deatl, 783

Decidua, formation of, 774

Defrecation, 419

Deglutition, mechanism of, 408

Deiters, nucleus of, 698

Dendrons, 569

Depressor fibres, 177

- nerves, excitation of, aortic pressure and, 177

- - effects of stimulation, 518

- - ill rabbit, dissection of, 170

"Descending" current, 582
Dextrins, 66

Dextrose, 62

- katabolism of, 426

Diabctes mellitus, 435

Diaphragm, action of, 284

- movements of, 284

- spasnı of, expiration, 297

— - inspiration, 297

Diastole, 144

- duration of, table slowing pulsefrequencies, 170

-- - with different pulse frequencies, 168

Diastolic filling of heart, 160

Diathermy, 568

Dicarboxylic acid, 36

Dicrotic ware, 215

Diet, chemical conıposition of, 328

- nitrogen-poor, sulphates in, 463

- nitrogen-rich, sulphates iu, 463

- peace, of British army, 345

- under varying conditions, 356

Dietaries of the world, 346

Dietetic methods, special, 364

Dietetics, 325,344

Diffusion of gas, 17

- - through a liquid film, 20

Digestion in the mouth, 371

— in the small intestine, 391

- in the stomacl, 379

- mechanical factors of, 406

- peptic, 385

- processes of, $36 \%, 385$

Digestive action of pancreatic juice, 399

- fluids, secretion and activation of, 367

Dioptries, laws of, 608

Dipeptide, 45

Diplopia, 631

Disaccharides, 63

Diver's, 311

Dog, sinu-anricular node of, effect of clamping, 139

- - - effect of cold on, 139

Dog's heart, outline of, 13 i

Dorsal spino-cerebellar tract, 669

Dromotropic fibres, 173

Ductless glands, functions of, 503

Dudgeon sphygmograph, suspension method of, 211

Duodenum, mucous membrane of, acid extract of, 398

Dyspncea, 299

Ear, diagram of, showing ossicles, 644

- examination of, method, 645

- external, 644

- internal, 646

- - right, 647

- rabbit's, lesions produced by ultra. violet light on, 13

Edridge-Green colour pereeption lunteru, 627

Effector organs, 574

Eggs, 354

- composition and value of, 348

Eighth nerve, course of, 697

— - vestibular portion of, 699 
Elasticity of arteries, 184

Electric tissues, 566

Electrical change of lieart, 133

- conductivity of blood, 80

Electricity, animal, 559

- constant current of, 534

Electro-cardiogram, 134

- and musical aortic murmur in man, 156

- and rougl aortic murmur in man, 155

- carotid pulse of dog, 155

- heart sounds of dog, 155

- normal, 132

— of complete heart-block, 133

- slowing regularly occurring ventricular extra systoles, 133

- wave of, 214

Electrodes, Keith Litcas moist chamber and, 563

Electrometer, capillary, 562

- records of eyebsll responses to light, 618

Electro-motive force, 536

- properties of niuscle and nerve, 559

Electrotherapy, 567

Elec troton us, 583

Embryo, liuman, 768

- rabbit's, cells from, 14

Endolymph, 647

Endotoxins, 109

Energy, direct method of estimating, 331

- intake of, 327

- output of, 328

English vowel sounds, 746

Entero-ceptive mechanism, 660

Enterokinase, 401

Enzymes, 68, 369

— amylolytic, 71

- coagulative, 72

- de-aminizing, 72

- lipolytic, 71

- pancreatic, activation of, 398

- properties of, 70

- proteolytic, 70

- sucrolytic, 71

Epicritic sensibility, 591, 592

Epithelium, 5

Equilibration, 656

Eicythrodextrin, 67

E'sbach's albumino-meter, 465

Eisophoria, 631

Ether, effect of, on lieart of dog, 201

Eraporation, 497

Exophoria, 631

Eye, accessory parts of, 600

- adjustment of, 612

- anatomy of, 600

- cardinal points of, 611

- examination of, methods, 641

- hypermetropic, rays in, 616

- images of truncated pyramid, 634

- investigation of, apparatus for, 637

- movements of, 630

- myopic, rays in, 617

- of frog, examination of, 640

- of rabbit, examination of, 641

- right, perimetric chart of, 639

- Sce also Vision
Eyeball, formation of, 712

- horizontal section of, 601

- light responses to, electrometer records of, 618

- sclicma of, 223

Frees, 405

Fat, 53, 428, 437

- absorption of, 436

- acid value of, 55

- anabolism of, 436

- effect of, in metabolism, 340

- forms of, 55

- from carbohydrate, 438

- from protein, 439

- iodine value of, 55

- katabolism of, 440

- lack of, 336

- melting point of, 55

- metabolism of, 436

- neutral, 53

— of milk, 437

— of pig, 437

— of red blood-corpuscles, 90

- specific gravity of, 55

- storage of, in liver, 448

- volatile fatty acids in, 55

Fatigue, 546

Fatty acids, charactcristics of, 55

Fatty degeneration, 441

Feeding, artificial, 360

- metabolism raised by, 343

Fehling's solution, 467

- test, 61

- - for sugar in urine, 467

Fenestra oralis, 646

- rotunda, 646

Fermentation test, 62

Fcrments, 68

Fertilization, 771

Fibrinogen, formation of, 450

- of plasma, 84

Fish, composition and value of, 348

- cooked, composition and value of, 352

- swim-bladder of, 271

Fistula, gastric, Pawlow's method of establishing, 381

Flechsig tract, 669

Flour, 354

Fluid, flow of, eflect of introducing resistance, 181

- - - in branching tubes, 180

- - in cylindrical tubes, 179

- - in rigid and elastic tubes, 182

-- - in tube of varying diameter, 180

_ - of velocity and resistance heads, 180

- pericardial, 254

- pleural, 254

Foutus, circulation of, 248

- nutrition of, 357

- ovary of fifth-month, 767

Food, absorption of, 421

- calories table, 328

- composition of, 348

- cooking of, 366

- selection of, 344 
Food, value of, $345,3 \pm 8$

- - table of, showing calories, 363

Foods, carbohydrate, composition and value of, 350

- fat, composition and valuc of, 349

- protein, cost of, 348

- watcry, composition and value of, 350

Foodstuffs, 352

Fourth ventricle, 689

Freezing-point, determination of lowering of, 27

Frog's heart, contraction of, 128

- - diastolic pressure of, 129

- - excitability of, 131

- - lever for recording, 127

Fruits, composition and value of, 351.352, 355

Fundus of eye, 642

Galactosc, 62

Galactosides, 57

Galvani's experiment, $\mathbf{5 5 9}$

Galvanometer, deflection of, temperature of muscle and, 554

- single-pair thermopile connected to, 552

Galvanotaxis, positive, 12

Galvano-tonus, 534

Ganglia, function of, 751

Gas, analysis of, Haldane's apparatus for, 282

- bubbles of, in arteries of intestines, 309

- - in veins of intestines, 309

- diffusion of, 17

- - through a liquid film, 20

Gas laws, 17

Gases, blood, 259

- - extraction of, by pump, 259

- pressurc of, 269,275

- solubility of, in salt solutions, 20

Gastric contents, acidity of, deficit, 389

- - - excess, 389

- - examination of, 388

- juice, 380

- - action of, oll starches, 387

- - on sugar, 387

- - chenical mechanism of, 384

- - composition of, variation, 384

- - lipase of, 387

- - mechanism of secretion, 383

- - nervous mechanism of, 383

- - secretion of, 374

- - variation of composition, 384

Gastrin, 384

Gastrocncmii, exciscd, length of after fatigue, 547 .

Gastrocnemius, contractions of, with different loads, $\mathbf{5 4 5}$

- - effect of temperature upon, 543

- effect of load upon contraction of, 544

— of frog, contraction of, 541

- - fatigue of, $54 \mathrm{~B}$

Gay-Lussac's law, 17, 23

Gelatin, 48

Generation, organs of, 505

- - circulation in, 248
Geniculate bodies, 708

Gland current, 565

Glands, accessory, 760

- salivary, 565

Globulins, 48

Glomerular secretion, nature of, 480

Glomerulus, function of, 478

Glosso-pharyngeal nerve, 693

Glucoproteins, 48

Glucosamine, 63

Glutaminic acid, 41

Glycin, 40

Glycogen, 66

- source of, 427

Glycogenic function, 427

_ - influences a ffecting, 428

- - of liver, 447

Glycosuria, 427, 431, 467

- adrenalin, 434

- alimentary, 431

- pancreatic, 432

- pliloridzin, 433

- pituitary, 434

- puncture (neurogenous), 432

- salt, 435

- thyroid, 434

Glycuronic acid, 63

Goitre, exophthalmic, case of, 518

Goll, posterior-median tract of, 668

Gonium pectorale, 4

Gout, symptoms of, 445

Gowers' tract, 669

Graafian follicle at puberty, 767

Gracilis, nervous impulse in, 581

Graham, gas effusion of, 18

Gravity, centre of, 528

Growtll, 755

- effect of vitamine on, 338

Guaiacum test for blood, 112

Gymnema sylvestre, 595

Gyrus post-centralis, cell lamination of, 724

Hæmachromogen, 94

Hremacytometer, Thoma-Zeiss, 87

Hrematuria, 466

Hæmantogram, 216

Hrmin crystals, 113

- - preparation of, 112

Hrmoblast, 89

Hrimodromometer, Chauveau's, 204

Hænoglobin, animal, 90

— of blood, estimation of, 96

- solution, effect of, on oxygen curve, 267

Hæmoglobinuria, $466^{\circ}$

Hæmolysis, 105

— bacterial, 107

- by for eign sera, 106

- by snake venoms, 107

- chenical, 108

- pliysical, 105

- prorluced by vegetable poisons, 107

Hæmophilia, 104

Hremorrliage, transfusion in, 228

Hair follicles, 486

- nerve endings at base of, 587 
Haldane-Penbrey respiration apparatus, 318

Haldane's apparatus for determining tension in human blood, 273

- gas analysis apparatus, 282

Hammer of Wagner, action of, 537

Haploscopic vision, 635

Haptophors, 108

Harmony, 652

Head, circulation in, 242

- proprio-eeptive meehanism of, 655

- register of sound, 744

Hearing, 643

- reaction time to, 733

- receptive area for, 728

- receptor mechanism for, 643

- theories of, 652

Heart, anatomy of, nicioseopie, 122

- attachment of, arterial and venous, 151

- compensatory panse of, 131

- contractility of, 129

- diagram of, showing course of blood, 142

- diastolic filling of, 160

- electrical change of, 133

- embryonic, divisions of, 117

- examination of, modes, 152

- excitability of, 128

- frog's, contraction of, 169

- - lever for recording, 127

- horse, tracings fron, 145

- human, sinu-anricular junction in, 120

- movements of, 144

- - in situ, 151

- muscle, 127

- musculature of, 152

- nerves of, 171

- nutrition of, 158

- perfused, of frog, 144

- physiology of, 127

- point of primary negativity, 138

- preparation of, diagram of, apparatus for, 164

- pressure eurves of, aortie and intraventricular, 146

- rabbits perfused with Locke's solution, 159

- - perfused with Ringer's solution, 160

-- - record of, movement of, 511

- right side of, diagram of, 150

- sounds of, 154

- Stanniused, tetanizing of, 131

- surface relations of, 153

- systolic output and work of, 163

- tissue of, conduction of excitatory wave, 134

- turtle's, sinu-auricular junction in, 120

- venous cistern of, 147

- vertebratc, nervous elements of, 123

- - type of, 118

- volume of output, tracing showing, 167

Heartblock, complete, electro-cardiagram of, 133

Heat coagulation, 46

- formation of, by lirer, 45i1

- loss of, regulation of, 496

- production of, regulation, 496
Ileat stroke, 494

Helicotrena, 648

Helmholtz side-wire, action of, 538

Helweg tract, 670

Henle loop, 474

Henry's law, 19

Heredity, 778

Hering theory of colour vision, 625

Heteronomous vision, 632

Heterophoria, 631

Heterotyl'e mitosis, 762

Hexoses, 59

Hibernation, 738

Hill's blood-gas punup, 260

- cerebral pressure gauge, 240

- colour vision apparatus, 628

- pocket sphygmometer, 189

Hippuric acid, $₫ 62$

Histidin, 42

Histones, 47

Homonomons vision, 632

Hormone reflex, 368

Hormones, 394, 397, 503

Horns, growth of, effect of castration on, 506

Horopter, 631

- vision, 633

Horse blood, analysis of, 81

- crystals of, oxyhæmogloliu from, 91

Hunger, sensation of, 660

Hürthle's spring manometer, 188

Hydrogen generated from a Kipl's aplaratus, 18

Hyperglycremia, 427

Hypermetropia, 616

Hyperphoria, 631

Hyperpncea, 299

Hypersusceptibility, 111

Hypertonic solution, 24

Hypnosis, 737

Hypoglossal nerve, 691

Hypotonic solution, 24, 26

Hypoxantlin, 50

Imbibition, phenomena of, 31

Immune body, 109

Immunity, 105, 107

Impulse, nerve, 7

Incus, 644

Indican, 463

Induction coil, counections of, 535

Infant feeding, 360

- newboln, nutrition of, 357

Inorganic compounds, 33

Inotropie fibres, 173

Inseminatiou, process of, 770

Internal capsule, 709

- secretions, 503

Intestines, arteries of, gas bublles in, 309

- bacteria of, 403

- large, 402

- function of, 402

- - movements of, 418

- inovements of, record of, in cat, $\$ 12$

- pendulum movements of, 416

- peristaltic contraction of, 417 
Intestines, sniall, digestion in, 391

- - functions of, 401

- movements of, 415

- - segmentation of, 415

- - segmenting its contents, 414

- veins of, gas bubbles in, 309

Iodides, secretion of, 377

Iodine value of fat, 55

Ions, 28

Iris, 604

- function of, 604

- nerve supply of, 605

Iron, lack of, 336

Irradiation, 634

Isocholesterol, 58

Isotonic solution, 24

Jacquet's sphygniograph, pulse tracing by, 215

Jecorin, 58

Jugular bulb, position of, 213

- pulse, waves of, 214

Juices, activation of, 369

- digestive, 369

- pancreatic, 396

Katabolism, 441

— of dextrose, 426

- of fat, 440

- of plasnia, 85

Kata thermometer, 500

Katclectrotonic current, 583

Katlode, region of, stimulation in, 583

Ketones, 35i

Kidncy, arterial pressure of, 247

- blood-supply of, $474,475,478$

- circulation in, 247

- functions of, 453,478

- of cat, decompressed, 310

- schema of, 223

- secretory function of, 481

- tubule of, minute structure of, 474

- - resorption by, 481

- - secretory function of, 481

Kipp's apparatus, hydrogen generated from, 18

Kjeldahl's method of allalysis of urine, 455

- process, 329

Krause's end-bulbs, 586

Krogh's microtollometer, 270

Labyrinth, nienıbranous, 647

- of pigeon, effect of destruction of, 657

Labyrintline sensations, 655

Lachrymal glands, 600

Lactose, 65, 469

Langerhans, islet of, from pancreas of dog, 513

Laryngoscope, 740

Larynx, 277, 740

- examination of, 741

- muscles of, 743

- nerve-supply of, 295

- stimulation of, 295

- view of, 742

- vowels produced by, 745
Lecithins, 56

- metabolism of, 441

Lens, 605

— acliromatic, 609

- cardinal points of, 609

- convexity of, 614

Lenticular nuclei, 715

Leucin, 40

Lellcocytes, 97

- migration of, 99

Lencocytosis, 99

Lever action, kinds of, 526

- simple, witl after-loading serew, 540

Levulose, 62, 469

Liganients, suspensory, 605

Light, effects of, on retina, 618

- perception of, 621

$\rightarrow$ phenomena of, 608

Limbs, circulation of, 243

Lipase of gastric juice, 387

Lipoids, 53,56

- lack of, 336

- of plasma, 84

Lipolytic enzymes, 71

Liquids, diffusion in, 21

Lissauer, marginal tract of, 668

Liver, circulation in, 246

- fat of, storage, 448

- function of, $44 i$

- - protective, 450

- glycogenic function of, 447

- heat formation by, 451

- protective function, 450

- venous reservoir of, 451

Load, effect of, in muscle, 545

Local sign of tonch, 589

Locke's solution, rabbit's heart perfused witl, 159

Locomotion, 525

Loewenthal tract, 670

Lubrication, forms of, 6

Lucas, moist chamber and clectrodes, 563

Lungs, blood-pressure of, 279

- circulation of, 236

- diffusion of gases within, 270

- lobe of, small, volume of, 279

- preparation of, diagram of apparatus for, 164

- right, respiratory movement of root, 287

- surface relations of, 153

- ventilation of, 292

- volume of, 279

Lynıpli, 250

- composition of, 251

- formation of, 252

- movement of, 254

Lymphocytes, 97

Lysin, 42

Mackenzie's polygraph, 212

Macula of mouse, 656

Magnesiuni, sulphate of, injectiou, Traube. Hering curves after, 301

Malleus, 644

Maltose, 65

Mammals, circulation in, course of, 142 
Man, compressiou ellects on, 308

- decompression effects on, 308

Manometer, Hürthle's spring, 188

- mercurial, arrangement of, for recording blood-pressure, 187

Maunbrium sterni, 285

- - respiratory movements of, 286

Marchi method of staining, 577

Marching, 499

Mastication, movements of, 407

Neat, 354

- cooked, composition and value of, 352

Meatus, external auditory, stinulation of, 295

Medulla oblongata, 688

- formation of, 688

- - functions of, 695

- - section of, 690,691

Medullated nerves, 570

Medusa, tentaculocyst of, 654

Meiotic division of cclls, 762

Meissner's corpuscles, 586

Membranes, semi-permeable, 21

- action of, 25

Mesencephalon, 706

Mesonephros, 475

Metabolism, 325

- during starvation, 333

- methods, 325

- of carbohydrate, 426

- of fat, 436

- of lecithin, 441

- of nuclein, 443

- of protein, 421

- protein excess with, 339

- special, 421

- varyiny conditions of, 311

Metanephros, 474

Metaprotein, 43

Mctaproteins, acid and alkali, 50

Methæmoglobin, 93

Microscope, projection, side elevation of, 562

Microtonometer, Krogh's, 270

Micturition, act of, 483

Mid-brain, 706

- red nuclei of, 707

- section of, 707

Milk, 353

- composition and value of, 349,352

- fats of, 353

- flow from nipple of cat, 522

- human, colour of, 359

- - composition of, 359

- secretion of, 358

Mind, 732

Mineral salts, lack of, 335

Mitosis, 757

- heterotype, 762

Molecular complexity, law of, 16

Moliscli's test, 62

Monakow tract, 670

M onocarboxylic acid, 36

M onosaccharides, 59

M oore's test, 60

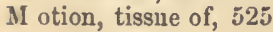

Motor area, effects of ablation of, 721

- - lamination of, 725

- decussation, 670

- impulse, velocity of, 581

Mouth, digestion in, 371

- sliapc of, in sounding vowels, 745

Movement, meclianism of, 525

Movements of body, lever principles, 525

- of heart, 144

- - in situ, 151

Miiller's law, 585

Muscarine, injection of, eflect upon dog's lieart, 175

Muscle, activity of, 546

- arteriole, pressor afferent inpulses affecting, 231

- board, 539

- cardiac, 532

- change in forn of, 539

- chemical changes in, 552

- - induced by activity, 557

- cliemical constitution of, 555

- chemistry of, clianges in, 555

- ciliary, 603

- contraction of, 539

- - apparatus for recording, 540

- conditions affecting, 545

- - Frog's gastrocnemius, 541

- - period, 543

_ - period and movements of levers on 544

- - superposition, 548

- differentiation of, 530

- electromotive properties of, 559

- excitability of, 533

- extcusibility of, 532

- fatigue of, 546

- inhibition of, 678

- injuries of, by electricity, 560

- irritability of, 533

- laryugcal, 743

- lateral erico-arytenoid, 743

- of rabbit, contractions of, 541

- pliysical properties of, 530,532

- posterior crico-arytenoid, 742

- reciprocal excitation, 678

- relation of, 545

- rhythmicity, 558

- section of sucker catastonius, 531

- smooth, 532; 558

- spontalleous movements of, 551

- stimulation of, 561

- stimulus of, 545

- structure of, 530

- thermal changes in, 552

- time of contraction, 542

- tonus, 558

- unloaded, contractions of, 542

Muscular activity, meclianism of, 554

- tissue, 5

- " tone,". 551

Mutton, composition and value of, 348

- fat, melting-point of, 438

Myelination, evidence of, 727

Myogen, 555,556

— fibrin, insoluble, 556 
II yopia, 616

Ilyosin, 555

Myosinogen, 555, 556

II yostronin, 556

Iy xcedema, case of, 517

Narcosis, 737

Nature, nitrogen in, circnlation of, 259

Terve cells, 570

- erural, 244

- eighth, 697, 699

- electromotive properties of, 559

- endings, effector, in muscles of lizard, 574

— fibres in musele spindle, 658

- - medullated, from a mammal, 571 . 572

- - physiology of, 579

- - regeneration of, 578

- impulse, 7

- regeneratiou of, 576,578

- roots, Wallerian degeneration of 663

- stimulation of, $176,561,573,579$

- supply of iris, 605

Nerves, afferent, 245, 573

- cardiac, 171

- - of dog, 172

- - of frog, 171

- cranial, 690

- - nuclei of, 699

-- depressor, effects of stimulation, 518

- efferent, 573

- iris, 605

- laryngeal, 295

- medullated, 570

- non-medullated, 570

- seventh, 698

- sixth, 700

- spinal accessory, 691

- - mixed, 749

- splanchnic, 429, 510

- tenth, origin of, 694

- trigeminal, 700

- twelfth, origin of, 694

- vagus, 173, 241, 298, 691

- vaso-motor, $229,242,246$

Nervous centre, connections of, in secretion of gastric juice, 374

- - - - of saliva, 374

- conduction, 574

- elements of vertebrate heart, 123

- impulse, rate of transmission, 580

- structures, stippled, 567

- system, 569

- - autonomic, 748,750

- - stimulus, 7

- sympathetic, arrangement of, 748

Neural ares, 671

Neurogenous glycosuria, 432 .

Neuroglia, 572

Neuron, 569

\section{- function of, 575}

Nenro-tendinous nerve end-organ in rabbit, 659
Nieotiue, action of, 229

Night-blinduess, 623

Nissl's granules, 569

Nitrogen in blood, 263

- of urine, 455

Nitroxyhæmoglobin, 92

Non-goitrous cretins, 516

Nose, function of, 277

Nuclein, metabolism of, 443

Nucleoproteins, 48

Nucleus of Deiters, 698

- pontis, 698

Nutrition, effect of vitamine on, 337

- of heart, 158

Nuts, composition and value of, 349

Nylander's test, 61

- - for sugar iu urine, 467

Obesity, 442

Odour-producing glands, 6

Olein, 54

Olfactometer, 597

Olfactory epithelium of fowl, 596

Olivo-spinal tract, 670

Ontogeuy, 3

Ophthalmoscopes, 639, 640

Opsonins, 109, 110

Optic fibres, relatious of, 713

- thalamus, 710

Organic compounds, 34

Osmosis, phenomena of, 22

Osmotic pressure, 21, 22

- - of blood, 80

Osseons labyrinth, 646

Ovary, 506, 767

- foetal, 767

Ovum, human, 768

- - development of, 774

- embedded in uterus, 776

- embedded in wall of uterns, 775

- implantation of, 773

- maturation of, 764

- morula from, 772

- of bat, 771

- of cat before maturity, 9

- of toxopreustes, 759

- segmentation of, 773

Oxalates, 461

Oxblood, analysis of, 81

Oxidases, 73

- action of, 444

Oxygen, atmospheres of, lung exudation in, 303

- capacity of blood, 264

- consumption of, relationship of arterial pressure to, 169

-_ - relationship of pulse to, 169

- curves of human blood, 266

- excess of, effects, 303

— in blood, 263, 275

- percentage of, in respiration, 293

- use of, in $\operatorname{man}, 342$

- want of, effects, 304

Oxyhæmoglobin, crystals of, from horse blood, 91

Oxyproline, 42 
Pacinian corpuscle, 586, 587

Pain, 661

- referred, and counter-irritation, 661

- sensation of, 591

Palmitin, 54

Pancreas, 511

- nuclcase of, 443

- secretion of, 395

Pancreatic enzymcs, activation of, 398

- glycosuria, 432

- jnice, 396

- - digestive action of, 399

- - flow of, 368

- - mechanism of secretion, 397

Paradise fish, gas-secreting cells of, $2 \nmid 1$

Paramyosinogen, 555

Parathyroid glycosuria, 434

- of dog, after thyroidectomy, 515

- of normal dog, 514

Parathyroids, function of, 512

Pars plana, 603

- plicata, 603

Parturition, 775

Pawlow's method of establishing a gastric fistula, 381

Pentosans, 63

Pentose, 469

Pentoses, 59, 63

Peptic digestion, 385

Peptoncs, 40, 43, 51

Pericardial fluid, 254

Perilympl, 646

Perimeter, 638

Perimetric chart of right eye, 639

Peristalsis, true, 417

"Peristaltic rush," 417

- wave of small intestine, 417

Perspiration, 488

Phakoscope, 613

- rays of light in, 613

Pharynx, 277

Phenyl alanin, 41

Phenylhydrazine tost, 61

Phloridzin glycosuria, 433

Pliosphate crystals, 471

- of calcium, 471

Phosphates, 464

- distribution of, 33

- lack of, 336

Phosphatides, 56

Phosphoproteins, 48

Photohæmatochonıcter, Cybulski's, 205

Phototaxis, 12

Phylogeny, 2

Physico-chemical pliysiology, 17

Phytocholesterol, 58

Pigments, bile, 393

Pineal body, 524

Pitnitary body, 521

- - functions of, 522

- - of adult monkey, 520

- glycosuria, 434

Placenta, 774

- blood space, formation of, 776

- formation of, 777

Plant life, cycle of, 258
Plasma, 82

- carbohydrate of, $\delta 5$

- fibrinogen of, 84

- katabolism of, 85

- lipoids of, 84

- proteins of, 83,424

- salts of, 85

- serum albumin of, 84

- serum globulin of, 83

Plasmolysis, 24

- effect of, in Tradescantia discolor, 44

Pletlyysmograph and pistou recorder 230

Pletlysmographic method, velocity flow by, 206

Pleura, fluids of, 254

Poisons, vegetable, hæmolysf produced by, 107

Polarimetric test, 62

Polygraph, 213

- Mackenzie's, 212

Polypeptides, 40, 43, 45

Polysaccharides, 65

- reactions of, 66

Pons varolii, 688, 696

- - section of, 696

Pork, composition and value of, 348

Portal circulation, 246

Post-dicrotic wave, 215 ?

Posterior lougitudinal bundlc, 695

Postganglionic fibres, 750

Posture, effect of, on circulation, 194

- erect, 527

Precipitins, 111

Predicrotic wave, 215

Preganglionic fibres, 749

Pregnancy, serum test for, 777

Presbyopia, 616

Pressure, arterial, 186

- bottle, arrangement bf, for recording

blood-pressure, 187

- osmotic, 21,22

- sensations of, 588

Pronephros, 474

Proprio-ceptivc mechanism, 654, 659

Prostate gland, 506

Protamines, 47

Protein decomposition, 403

- digestion of, 385

- - digestion, products of, 424

- foods, cost of, 348

- katabolism, 328

Proteins, 39, 43, 428

- chemical properties of, 45

- classification of, 47

- compound, 48

- constitution of, 39

- derived, 50

- excess of, in metabolism, 339

- fat from, 439

- in urinc, 465

- metabolisnı of, 421

- of plasmia, 83

- physical properties of, 45

- required for weight at different ages, 362

Protcolytic enzymes, 70

Protcoses, 40, 43, 51 
Protopathic sensibility, 591, 592

Protoplasm, 8

- movements of, 11

Ptyalin, action of, 378

Pulmonary circulation, 236

Pulse, 211

- curve, arterial, 215

- frequency of, duration of systole and diastole with, 168

- influence of abdominal breathing on, 191

- - chest on, 191

- investigation of, by spliygmiographs, 212

- ratcs, average of, 216

- tracing of, by Jacquet's spliygmograph, 215

- venous, 213

- wave in the arterial system, 217

Pulses, 355

Purin bases, 49

- bodies, 49, 460

Purkinje, cells of, 703

Putrescin, 403

Pyrimidin bases, 49

Pyrolin, 42

Rabbit, sinu-auricular node of, effect of excision, 140

Rabbit's lieart, a.v. bundle cut, stimulation of right vagus nerve, 156

Reaction time, 731

- apparatus ior determination of, 732

Receptors, 108, 574

- mechanism of, 585

- of chtaneous sensation, structure of, 585

Rectum, showing pelvi-rectal flexure, 419

Reflex arc, 574

- - simple, 575

- centrc, spinal cord as, 674

Reflexes, 674, 676, 678, 680,682, 684

- tendon, 684

Refraction, 610

Regeneration, peripheral, 578

Reval epithelium of frog, 573

- tnbules, development of, 473

- - resorption by, 481

- - secretory functions of, 481

Renuet, action of, 387

Reproduction, 755,760

Reproductive organs, female, 767

- - male, 764

Residual air, 280

Respiration, 192, 257

- air changes in, 293, 312

- apparatus, Haldane-Pembrey, 318.'

— artificial, 323

— - Schäfer's miethod, 322

— - Sylvester's method, 322

- - vivator apparatus for, 324

- chamber for man, 331

- Cheyile-Stokes, 299, 300

- effect of emotion on, 202

- internal, 320

- mechanism of, 276

- record of, in cat, 323

- regulation of, 289

- tissue, 320
Respiration, tracing of, 304

Respiratory centre, 294

- exchange, determination of, 317

- - increase of, by muscular work, 319

- - interual, effect of activity upon, 321

- function of the skin, 489

- quotient, 319

Retina, 606

- effects of light on, 618

- functions of, 619

- human, diagram of, 606

- images on, 615

- of frog, 620

- of rabbit, 620

- structures of, 606

Retinal currents, 565

Retinoscopy, 617

Retz cell from liuman cerebral cortex, $5 i 1$

Rhcocord, principle of, 535

Rhinenceptralon, connection of, 714

Rhythmic automaticity of heart, $12 \%$

Ribs, first pair of, 285

- lower, movement of, 287

- movement of, 285

- respiratory movements of, 286

- upper, movement of, 286

Rice, polished, 336

Rigor mortis, 557

Ringer-solution, 477

- rabbit's heart perfused with, 160

Rubro-spinal tract, 670

Ruffini's organs, 586

Running, 528

Saccharose, 64

Sacral autonomic system, 751

Saliva, 371

- composition of, 372

- paralytic secretion, 375

- quantity of, 373

- secretory pressures of, 376

Salivary glands, 565

- c circulation of, 243

- - schema of, 223

Salkowski's test, 58

"Salt" glycosuria, 435

- solutions of, solubility of gases in, 20

Salts, inorganic, 394

- of plasina, 85

- organic, 392

- proportion of, in blood, 266, 26 '

Saponification of fat, 53

Sartorins muscle, curve of, 549

- - excursion to, 564

- - fatiguc curves of, 546

- nervous impulse in, 581

- - of frog, spontaneous novements in, 549

- - stimulation of, 550

Scala media, 648

Schäfer's method of artificial respiration, 322

Sciatic nerve of kitten, regencration of, 577

Sclera, 602

Seleroproteins, 48 
Scratch reflex, 676, 677, 678, 680

- - receptive field for, 675

Sebaceons glands, 487

Secretion, 368

- meclianism of, 358

Scgmentation of ovum, 773

- rhythmic, 414

Semicircular canals, 655

Seminal fluid, 766

Sensations, cutaneous, 585

Sensory mechanism, localization of, 727

- path from peripheral nerve, 711

Sera, forcign, hæmolysis by, 106

Serin, 40

Serum albumin of plasma, 84

- globulin of plasma, 83

- test for pregnancy, 777

Seventh nerve, function of, 699

- - origin of, 698

Sex, determination of, 781

- diet under various conditions, 356

Sexual characteristics, 504, 505

Sexual life, female, 769

Shellfish, composition and value of, 348

Sighing, 296

Sinu-auricular node, 119 .

Sixth nerve, origin of, 698,700

Skiascopy, 617

Skin, absorption by, 489

- current, 566

- effect of atmosphere upon, 499

- electric currents of, 564

- function of, 485

- - of pigment, 490

- parts of, 485

- respiratory function of, 489

- section of, 486

- sensations, 585

Sleep, 735

Smell, 593

- excitation of, 597

- receiving stations for, 729

- receptor mechanism of, 596

- sense of, investigation of, 597

- - paths in conuection with, 715

Snake venoms, hæmolysis by, 107

Snellen's test-types, 637

Soaps, 55

Sodium urate, 459,471

Solubility of gases, 23

Solutions, hypertonic, 24

- physiological, 26

Sound, 650

- experimeutal production of, in sheep's trachea, 740

- intensity of, 650

- pitch of, 650

- production of, 739

- quality of, 650

- wave, formation of, 651

Sounds of the heart, 154

Spectra, blood, 93

Specch, 729

- centre of, 731

- production of, 739

Spermato $\%$ on, 765,766
Spherical abcrration of lens, 609

Sphingomyclin, 58

Sphygmograph, Dudgcon, suspensior method of using the, 211

- investigation of, pulse by, 212

- Jacquet's, pulse tracing by, 215

Sphygmometer, armlet, 188

- Leonard Hill pocket, 189

Sphygmoscope, 188

Spinal accessory nerve, 691

- are, 672

- bulb, white mattcr of, 694

- cord, 662

- - as reflex centre, 674

- - commissural, fibres of, 670

- - conductor, impulses of, 672

- - effect of, trausverse section through, 673

- - embryonic, 664

- - exogenous tiracts of, 667

- - functions of, 672

- - posterior columns of, necrotic areas in, 311

- - reflex action of, 674

- - sections of, 665,666

- - structure of, 663

- - tracts, 666

- - tracts from brain to, 669,670

- - tracts of from posterior root ganglia 668

- nerve, mixed, arrangement of, 749

Spino-thalamic tract, 670

Spirits, alcohol percentage of, 365

Spirometer, 280

Splanchnic area, 198

- nerves, effect of stimulation of, 429,510

- organs, 246

Spleen, 247

- function of, 447,451

Stapedius, 646

Stapes, 644

Starch, action of gastric juice on, 387

Starches, 65

Starvation, metabolism during, 333

Stearin, 54

Stereoscope, 635

Stimulus of muscle, strength of, 545

- of nervous system, 7

Stomacl, absorption in, 388

- contents, examination of, 388

- digestion in, 379

— digestive processes in, 385

- movenients of, 411

- of cat, changes in shape during digestion, 407

- - digestion in, 406

- - sliadows of contents after feeding, 411

- outline of, 379

- position of, 380

- why not itself digested, 388

Stress, lines of, 758,759

Stromuhr, 203, 204

Strychininc convulsions in frog, 684

Stylonychia, enucleated, fragments of, $; G 0$

Suhlingual gland, 374 
Submaxillary gland, 374

Succus entericus, 400

- mechanism of secretion, 400

- use of, 401

Sucker catastonius, nutusele of, 531

Sucrolytic enzymes, 71

Sugar, action of gastric juice on, 387

- concentration of in arterial blood, 429

- - in urine, 429

- content, in glycosuria, 431

- in urine, 267

- splitting of, 430

Suggestion, effect of, 234

Sulphates, 462

- inorganic, 462

- organic, 463

Sulphur, neutral, 462, 463

Summation of muscle, 547

Superior olive, 699

Suprarenal body, 508

- - of dog, section of, 507

Surface tension in colloids, 31

Suspensory ligament, 605

Swallowing, mechanism of, 408

- nervous mechanism of, 410

- shadow in cesophagus after, 410

Sweat glands, 487

Sylvester's method of artificial respiration, 322

Synapse, 572

Systole, 144

- duration of, table showing pulsefrequencies, 170

- - with different pulse frequencies, 168

Systolic output and work of heart, 163

Tactile sensations, 589

Taste, 593

- bud in tongue of mall, 594

- effect of, 233

- nerve distribution for, 595

- receiving stations for, 729

- receptor mechanism of, 593

- sensations, apparatus for testing, 594

Temperament, diet under various condi. tions, 356

Temperature, body, 492

- effect of, on muscle, 545

- - upon gastrocnemius muscle, 543

- external, effect of raising, 497

- - nietabolism increased by, 343

- normal, 492

- regulation of, 495

- sensations of, 590

- variations of, 493

Tendon reflexes, 684

Tensor tym pani, 646

Testes, 505, 765

Tost-types, Sncllen's, 637

Tetanus, 550

- composition of, 548

Thalamo-spinal tract, 670

Thalamus, function of, 710

Thermonteter, Kata, 500

Thermopile, double, 553
Thermopile, single-pair, connected to galvanometer, 552

Thermotaxis, negative, 12

Thirst, sensation of, 660

Thoma-Zeiss heinacytometer, 87

Thorax, compression of, 163

- movenuents of, in respiration, 306

Thrombin of blood, 102

Th ymus gland, 519

— development of, 513

- function of, 520

- gland of monkey, 519

Thyroid, 742

- development of, 513

- function of, 512

- glycosuria, 434

- of normal dog, 514

Tidal air, 278

Tissnes, combination of, 5

- formation of, 3

- gases in, pressure of, 269

Toad, auricle and ventricle of record of contraction, 128

Tone, muscular, 551

Tonometers, 264

Töpler pump for blood-gas analysis, 261

Torpedo Ocellata, auricle-ventricle of, 130

Touch, reaction time to, 733

- sensation of, 586,588

Toxins, 108

Toxophor, 108

Trachea, 277

Tracts, spinal cord, 666

Transfusion in liæmorrhage, 228

Transport, mechanism of, 115

Traube-Hering curves, 301

Trigeminal nerve, 700,701

Trioses, 59

Tripeptide, 45

Trommer's test, 61

— - for sugar in urine, 467

Trophoblast, $7 \% 3$

Trypsin, 399

Tryptoplian, 42

Tympanic membrane, 644

- - view of, 645

Tyrosin, 41

UItra-violet light, lesions produced on l'abbit's ear by, 13

- - yeast cells photographed by, 10

Unibilical vessels, 248

Ulea, 456

- fornation of, 448

- nitrate, 457

- oxalate, 457

Ureometcr, 458

Ureters, passage of urine along, 482

Uric acid, 444, 458, 471

- - crystals, 460

- - formation of, 448

- - source of, endogenous, 444

- - - exogenous, 444

Urinary deposits, 470

Urine, 453

- abnormal constituents of, 465 
Urine, analyses of, 455

- bile in, 469

- blood ill, 466

- colour of, 454

- composition of, 455

- folmation of, rate, 429

- nitrogen total of, 455

- nitrogenous constituents of, 455

- passage of, through ureters, 482

- proteins in, 465

- secretion of, 473

- sugar in, 431,467

- transparency of, 454

Uriniferous tubules, course of, 475

Urobilin, 454

Urochrome, 454

Uroerythrin, 455

Uterus, ovum embedded in, 776

Vagi, influence of, 296

Vago-sympathetic, excitation of, 170

- stimulation of, contraction of frog's heart showing, 169

Vagus, in cat, 300

- influence of, upon respiratory move. ments, 296

Vagus nerve, 691

- - electrical changes in, 298

- - in rabbit, dissection of, 176

- - inter-auricular septum of, 124

- - periphercal end of, effect of stimu. lating, 241

- - excitation, 173

- stimnlation of, in cat's leart, 175

Valin, 40

Vascular system, changes of pressure in, 227

Vaso-constrictor nerves, $233,238,242$

Vaso-dilator nerves, 242

Vaso-motor centre, reflex action, 233

- mechanisms, 246

- nerves, 229

- - distribution of, 231

Vegetables, composition and value of, 350

- green, 355

Vegetarianism, 364

Veins, blood-flow in, rate of, 226

- blood-pressurc in, 225 .

- blood-velocity in, 225

- structure of, 125

- velocity of flow in, 208

- venous pressure of, 226

Velocity of blood, in veins, 225

- of blood.flow, 203

Venous pulse, 213

Vellous reservoir of liver, 451

Venous system, pressure in, 225

Ventilation, principles of, 312

Ventral spino-cerebellar tract, 669
Ventricle, right, of calf, 121,122

Veratrin curve, 543

Vertebrate heart, type of, 118

Vestibule, 647

Vestibulo-spinal tract, 670

Viscosity of blood, 80

Vision, binoctular, 630

- near point of, 615

- paths concerned in, 712

- reaction time to, 733

- receptor meclianism of, 599

- sense of, 599

Visual angle, 611

- area, cell lamination of, 726

- judgments, 633

- tract, 712

Vital force, 15

Vitamines, effect of, on growth, 338

- - on nutrition, 337

- lack of, 336

Vivator apparatus for artificial respiration, 324

Vocal cords, positious of, 744

Volatilc fatty acids in fat, 55

Volvox globator, colony of cells; 4

Vomiting, 415

Vowels, produced by larynx, 745

- shape of moutl in sounding, 745

Wagner's hammer, action of, 537

Walking, 528

Wallcrian degencration, 576

- - in cat, Narchi method of staining, 577

Warm-blooded animals, 495

Water, 33

- diffusion of gas through, 20

- lack of, 334

- vapour, 498

Weber's law, 585

Weaning, 362

Weight, at different ages, protein for, 362

Wernicke's area, 730

Wheel for mixing colours, 623

Wines, alcohol percentage of, 365

Work, diet under various conditions of, 356

- metabolism increased during, 343

Woulffe's bottle, 18

Xanthin, 50

Yawning, 296

Yeast cells, photogiaphed hy ultraviolet light, 10

Young-Helmholtz theory of colour vision, 625

Zöllner's lincs, 636

Zymogen, 369 




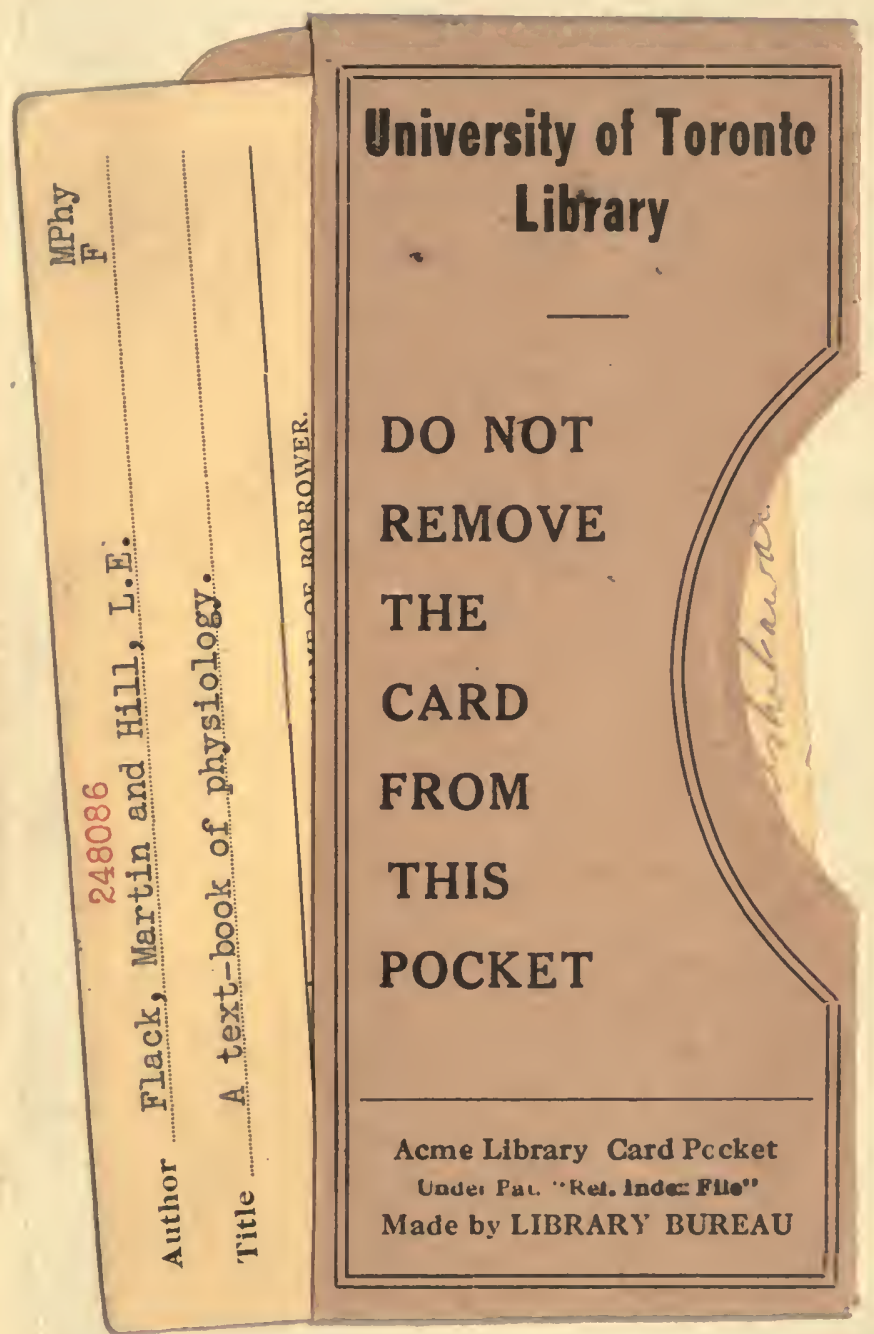



(1) 1
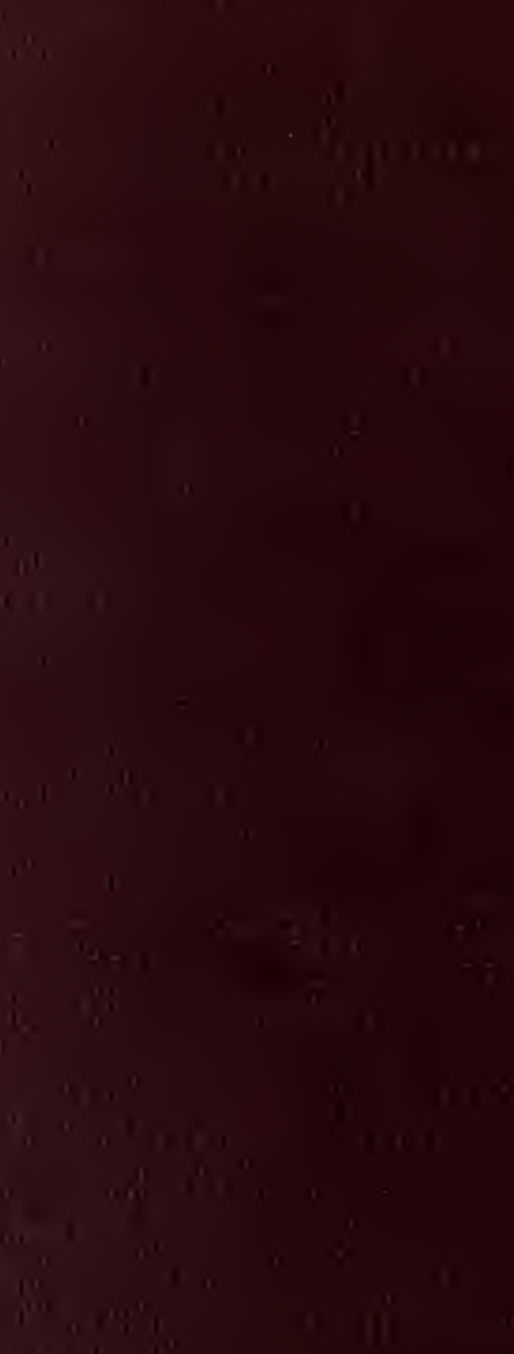